\title{
Photoluminescent Zirconium Complexes for Visible Light Photoredox Catalysis
}

Yu Zhang

West Virginia University, yuzhang1@mix.wvu.edu

Follow this and additional works at: https://researchrepository.wvu.edu/etd

Part of the Inorganic Chemistry Commons, Organic Chemistry Commons, Other Chemistry Commons, and the Physical Chemistry Commons

\section{Recommended Citation}

Zhang, Yu, "Photoluminescent Zirconium Complexes for Visible Light Photoredox Catalysis" (2019). Graduate Theses, Dissertations, and Problem Reports. 4109.

https://researchrepository.wvu.edu/etd/4109 


\title{
Photoluminescent Zirconium Complexes for Visible Light Photoredox Catalysis
}

\author{
Yu Zhang \\ Dissertation submitted to the Eberly College of Arts and Sciences \\ at West Virginia University \\ in partial fulfillment of the requirements \\ for the degree of \\ Doctoral of Philosophy \\ in \\ Chemistry \\ Carsten Milsmann, Ph.D., Chair \\ Jeffrey L. Petersen, Ph.D. \\ Jessica M. Hoover, Ph.D. \\ Brian V. Popp, Ph.D. \\ James P. Lewis, Ph.D. \\ C. Eugene Bennett Department of Chemistry \\ Morgantown, West Virginia \\ 2019
}

Keywords: Solar Energy Conversion, Earth Abundant, Early Transition Metal, Zirconium, Luminescence, Thermally Activated Delayed Fluorescence, Molecular Photosensitizer, Photoredox Catalysis

Copyright 2019 Yu Zhang 


\begin{abstract}
Photoluminescent Zirconium Complexes for Visible Light Photoredox Catalysis
\end{abstract}

Yu Zhang

A zirconium complex carrying two 2,6-bis(pyrrolyl)pyridine ligands has been synthesized and characterized. The neutral complex $\mathrm{Zr}\left({ }^{\mathrm{Me}} \mathrm{PDP}{ }^{\mathrm{Ph}}\right)_{2}\left({ }^{\mathrm{Me}} \mathrm{PDP} \mathrm{Ph}^{\mathrm{Ph}}=2,6-\right.$ bis $(5-$ methyl-3-phenyl-1Hpyrrol-2-yl)pyridine) is photoluminescent upon excitation with visible light and exhibit remarkably long emission lifetimes of $325 \pm 10 \mu$ s in solution at room temperature. Computational studies using time-dependent density functional theory (TD-DFT) were conducted to identify the nature of the luminescent excited state as a mixed triplet intra-ligand/ligand-to-metal chargetransfer $\left({ }^{3} \mathrm{ILCT} /{ }^{3} \mathrm{LMCT}\right)$ state. The electrochemistry studies of the $\mathrm{Zr}\left({ }^{\mathrm{Me}} \mathrm{PDP}{ }^{\mathrm{Ph}}\right)_{2}$ revealed multiple reversible redox events under highly reducing conditions. The excited state of this zirconium compound can be quenched by mild reductants to generate a powerful electron transfer reagent with a ground state potential of $-2.16 \mathrm{~V}$ vs. $\mathrm{Fc}^{+/ 0}$. This reactivity was utilized to facilitate photoredox catalysis.

To gain insight into the zirconium catalyzed photoredox transformations, benzyl coupling reaction was selected as a model reaction. Detailed Stern-Volmer experiments showed a strong dependence of the quenching rate on the redox potential of the quencher indicating photoinduced single-electron transfer (SET) as the quenching pathway. Mechanistic investigations of the photocatalytic homocoupling of benzyl bromide allowed the detection of organic radical 
intermediates during turnover and provided further evidence for SET mediated by $\mathrm{Zr}\left({ }^{\mathrm{Me}} \mathrm{PDP}{ }^{\mathrm{Ph}}\right)_{2}$. Isolation of the one-electron-reduced form of the photosensitizer, $\left[\mathrm{Zr}\left({ }^{\mathrm{Me}} \mathrm{PDP}^{\mathrm{Ph}}\right)_{2}\right]^{-}$, enabled studies of its electronic structure by a combination of experimental and computational techniques and confirmed its role as a strong reductant. Additionally, the role of the benzimidazolium hydride derivatives as two-electron sacrificial reductants during photoredox catalysis was investigated. In combination, the results presented in this report establish a detailed mechanistic picture of a photoredox catalytic reaction promoted by an earth-abundant early transition metal photosensitizer.

Although $\mathrm{Zr}\left({ }^{\mathrm{Me}} \mathrm{PDP}^{\mathrm{Ph}}\right)_{2}$ is a potent photocatalyst in the reductive quenching photocatalysis, the high air/water sensitivity is the major drawback in the application. A new zirconium photosensitizer, $\mathrm{Zr}\left({ }^{\mathrm{Mes}} \mathrm{PDP}^{\mathrm{Ph}}\right)_{2}$, bearing two 2,6-bis(5-mesityl-3-phenyl-1H-pyrrol-2-yl)-pyridine, ${ }^{\mathrm{Mes}} \mathrm{PDP}^{\mathrm{Ph}}$, ligands was synthesized and characterized. This zirconium compound can be easily be handled under regular benchtop conditions with remarkable stability in wet organic solvents and low $\mathrm{pH}$ solutions under air. The space-filling model of the molecule revealed a highly sterically hindering ligand framework with a tightly buried zirconium center, prohibiting any small molecules (i.e. $\mathrm{H}_{2} \mathrm{O}$ ) from approaching. $\mathrm{Zr}\left({ }^{\mathrm{Mes}} \mathrm{PDP}^{\mathrm{Ph}}\right)_{2}$ exhibit two unexpected reversible electrochemical oxidation event, attributed to the highly protected oxidation sites of the molecule: 2,5-positions of the pyrrole moieties. After establishing the optical and electrochemical properties of $\mathrm{Zr}\left({ }^{\mathrm{Mes}} \mathrm{PDP}^{\mathrm{Ph}}\right)_{2}$, we successfully conducted representative organic photocatalysis reactions that undergo oxidative quenching, reductive quenching and energy transfer pathways. 
Optical/electrochemical properties determine the applications of luminescent compounds. Thus, it is critical to understand the structure-photophysical property relationship in order to tune their properties in a predictable manner. A series of luminescent zirconium complexes bearing 2,6bis(3- $\mathrm{R}_{1}-5-\mathrm{R}_{2}-1 \mathrm{H}$-pyrrol-2-yl)pyridine $\left({ }^{\mathrm{R} 2} \mathrm{PDP}^{\mathrm{R} 1} ; \mathrm{R}_{1}=\right.$ pentafluorophenyl $\left(\mathrm{C}_{6} \mathrm{~F}_{5}\right), \mathrm{Ph}, \mathrm{H}, \mathrm{Me} ; \mathrm{R}_{2}=$ $\mathrm{Me}, \mathrm{Ph}, \mathrm{H}$.) ligands were synthesized and characterized. Their reduction potentials, spanning $\sim 0.6$ V, were found highly sensitive to the pyrrole substitution. Through cross comparison of structureproperty relationship between zirconium PDP complexes with different ligand substituents, the radiationless decay of $\mathrm{Zr}\left({ }^{\mathrm{R} 2} \mathrm{PDP}^{\mathrm{R} 1}\right)_{2}$ * seems to be influenced by ligand fluxionality and the number of $\mathrm{C}-\mathrm{H}$ oscillator present in the molecule.

The successful design principle of zirconium PDP photosensitizer can be extended to several other ligand systems:

Luminescent seven-coordinated zirconium and hafnium complexes bearing three monoanionic 2,2'-pyridylpyrrolide ligands and one chloride were synthesized. Solid state structures and the dynamic behaviours in solution were probed by X-ray crystallography and variable temperature ${ }^{1} \mathrm{H}$ NMR experiments, respectively. Absorption spectroscopy and time-dependent density functional theory (TD-DFT) calculations supported a hybrid of ${ }^{1} \mathrm{IL} /{ }^{1} \mathrm{LMCT}$ for the visible light absorption band. The complexes $\left({ }^{\mathrm{Me}} \mathrm{PMP}{ }^{\mathrm{Me}}\right)_{3} \mathrm{MCl}\left(\mathrm{M}=\mathrm{Zr}\right.$, Hf, ${ }^{\mathrm{Me}} \mathrm{PMP}{ }^{\mathrm{Me}}=3,5$-dimethyl-2(2-pyridyl)pyrrolide) are emissive in solution at room temperature upon irradiation with visible light due to a combination of phosphorescence and fluorescence characterized by excited state 
lifetimes in the $\mu$ s and low to sub-ns time-scale, respectively. Electrochemical experiments revealed that the zirconium complex possesses a reversible redox event under highly reducing condition $\left(-2.29 \mathrm{~V} \mathrm{vs} \mathrm{Fc}^{+/ 0}\right)$.

The complexes $\mathrm{Zr}\left({ }^{\mathrm{H}} \mathrm{CNN}\right)_{2}$ and $\mathrm{Zr}\left({ }^{\mathrm{Me}} \mathrm{CNN}\right)_{2}$ were prepared via reaction of the ligand precursors 2-phenyl-6-(5-methyl-3-phenyl-1H-pyrrol-2-yl)pyridine, $\mathrm{H}_{2}{ }^{\mathrm{H}} \mathrm{CNN}, \quad$ and 2-(3,5dimethyl-phenyl)-6-(5-methyl-3-phenyl-1H-pyrrol-2-yl)pyridine, $\mathrm{H}_{2}{ }^{\mathrm{Me}} \mathrm{CNN}$ with tetrabenzyl zirconium. Both complexes are photoluminescent upon excitation with visible light and exhibit remarkably long emission lifetimes in solution at room temperature. The nature of the emissive state was investigated using density functional theory, which allowed the assignment as a mixed ${ }^{3} \mathrm{IL} /{ }^{3} \mathrm{LMCT}$ state. Electrochemical studies revealed two fully reversible one-electron reductions at chemically accessible potentials for each complex and an additional reversible oxidative EC process for the more sterically protected complex $\operatorname{Zr}\left({ }^{\mathrm{Me}} \mathrm{CNN}\right)_{2}$. Based on the optical and electrochemical properties, the utility of the two zirconium complexes as photosensitizers for photoredox catalytic transformations was investigated. While $\operatorname{Zr}\left({ }^{\mathrm{Me}} \mathrm{CNN}\right)_{2}$ readily promotes the photochemical homocoupling of benzyl bromide in the presence of a sacrificial benzimidazolium hydride reductant, $\mathrm{Zr}\left({ }^{\mathrm{H}} \mathrm{CNN}\right)_{2}$ undergoes an intramolecular photochemical reaction with formation of a new carbon-carbon bond between the phenyl units of the two ${ }^{\mathrm{H}} \mathrm{CNN}$ ligands.

An eight-coordinate zirconium photosensitizer, $\operatorname{Zr}(\mathrm{bppda})_{2}$, was prepared in combination of two $N, N^{\prime}$-bis(2-pyrrylmethylidene)-1,2-phenylenediamine $\left(\mathrm{H}_{2}\right.$ bppda) ligands. The high 
coordination number not only significantly increased the rigidity of molecular structure but also lead to a high air/water stability. Investigation into the optical properties suggests the emissive behavior upon visible light irradiation for $\operatorname{Zr}(\text { bppda })_{2}$ arises from a thermally activated delayed fluorescence (TADF) mechanism from ${ }^{1} \mathrm{IL} /{ }^{1} \mathrm{LMCT}$ state. Further computational studies proposed the anti-symmetric stretching mode in the Schiff base moieties is responsible for the excited geometry distortion, which result in vibrationally resolved absorption and emission features. Similar to the PDP system, the $\operatorname{Zr}(\text { bppda })_{2}$ exhibits rich electrochemical redox behavior at highly reducing potential. 
For my parents 


\section{Acknowledgements}

First and foremost, I wish to express my most sincere gratitude to my advisor, Dr. Carsten Milsmann for giving me the opportunity of joining his group in 2014. It is my greatest honor to be his first graduate student. I am grateful for his unconditional support and guidance throughout my whole graduate studies. Not only has he taught me all the techniques and knowledge required for completing this dissertation, but also trained me the thoroughness, critical thinking, and professionalism that are essential for becoming a successful chemist. Without his patience, advice, encouragement, and hard work, earning this degree would not be possible. Although Carsten is my advisor for only five years, I consider him to be my lifelong mentor.

Besides my advisor, I would like to thank other committee members, Dr. Jeffrey L. Petersen, Dr. Jessica M. Hoover, Dr. Brian V. Popp and Dr. James P. Lewis for partaking in every important milestone of obtaining this degree. Their comments and suggestions during my candidacy exams and research are invaluable resources for my learning journey. My special thanks to Dr. Petersen, who has spending enormous amount of time, in conjunction with Carsten, worked on my crystallographic data collection and refinement. He is not only a knowledgeable and experienced crystallographer, but also been straight with me in evaluating my performance. Additionally, I thank Dr. Petersen, Dr. Kung K. Wang, and Carsten for writing recommendation letters. Furthermore, Dr. Novruz Akhmedov's is greatly acknowledged for his incredible effort in helping me with NMR experiments. 
I owe a huge debt of gratitude to all my labmates (Brett, Minh, Dylan, Jordan, Anitha), who have always indulged my childishness. They are always willing to offer genuine help whenever I needed. For this, I will always be grateful. Minh and Dylan, in particular, spent countless amount of their spare time to revise my English writings, conduct meaningful discussions and support many aspects of my research. I also want to thank past undergraduate students (Anne, Dylan, Megan, Rachel) who worked with me as part of my "learning how to teach" experience. Additionally, I would like to thank Dr. Shuangjiang Li and Dr. Aaron Honeycutt for their helpful discussions regarding my research projects. Moreover, I want to thank Dr. Haresh Thakellapalli for teaching me the operating procedures of the UV-Vis and fluorescence instruments.

Most importantly, I would like to express my gratefulness to my mother, Rong Liu, and my father, Xiong Zhang, for their love and sacrifice. It is their continuous support and encouragement that lead to my life-changing study abroad. They have always been a strong pillar on whom I rely in times of difficulties. My heartfelt thanks also go to my maternal and paternal grandfathers, Qian Liu and Quandu Zhang respectively, who offer their love and care in their own, unspoken way. 


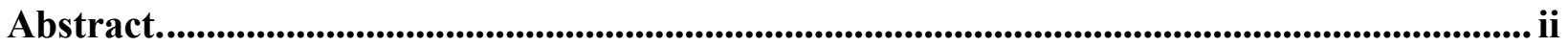

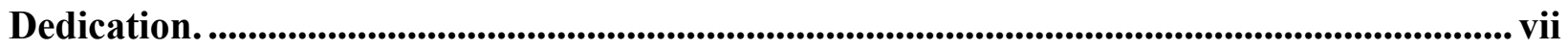

Acknowledgements. ................................................................................................................................... viii

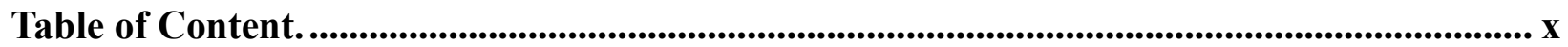

General Introduction............................................................................................................................. xvii

Chapter 1. A Novel Molecular Zirconium Photosensitizer for Visible Light Photoredox

Catalysis......................................................................................................................................................... 1

1.1. Introduction. ................................................................................................................................... 1

1.2. Synthesis and Characterization................................................................................................. 2

1.3. Photophysical Properties. .......................................................................................................... 3

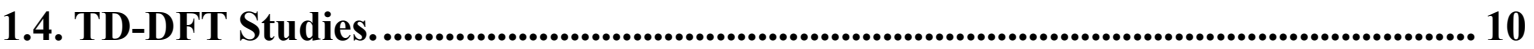

1.5. Electrochemical Properties.................................................................................................. 15

1.6. Estimation of Excited State Potential and Stern-Volmer Analysis. .......................... 16

1.7. Applications as Visible Light Photocatalyst. ...................................................................... 18 
1.8. Summary.

1.9. Experimental Section.

1.10. Reference.

Chapter 2. Mechanistic Insight into Photoinduced Single-Electron Transfer Enabled by Zirconium. 31

2.1. Introduction. 31

2.2. Optimization of Photocatalytic Conditions. 32

2.3. Intermittent Illumination and Quantum Yield of Photocatalysis.

2.4. Stern-Volmer Quenching Experiments........................................................................ 36

2.5. Synthesis, Characterization, and Reactivity of the Reduced Photosensitizer....... 38

2.6. Synthesis, Characterization, and Reactivity of $\left({ }^{\mathrm{R}} \mathrm{BI}\right)_{2}$ Derivatives. 47

2.7. Detection of Radical Intermediates During Photoredox Catalytic Turnover........ 50

2.8. Proposed Photoredox Catalytic Cycle.

2.9. Concluding Remarks. 54

2.11. Experimental Section. 55

2.10. Reference. 64 
Chapter 3. Second-Generation Zirconium Photosensitizers: Oxidative Photoredox Reactions with an Air- and Moisture-Stable Photocatalyst................................................................................. 66

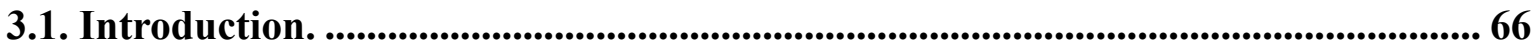

3.2. Synthesis and Characterization................................................................................................ 67

3.3. Photophysical Properties. ......................................................................................................... 71

3.4. Electrochemical Properties..................................................................................................... 79

3.5. Estimation of Excited State Potentials............................................................................... 81

3.6. Photoredox Catalysis Using $\mathrm{Zr}\left({ }^{\mathrm{Mes}} \mathrm{PDP}^{\mathrm{Ph}}\right)_{2}$.................................................................... 82

3.7. Photosensitization Properties. .................................................................................................... 88

3.8. Photostability Investigation................................................................................................ 92

3.9. Summary. ............................................................................................................................... 93

3.10. Experimental Section. .............................................................................................................. 94

3.11. Reference. .......................................................................................................................................114

Chapter 4. Tuning the Optical and Electrochemical Properties of Zirconium Based Molecular Photosensitizer. ...................................................................................................................118

4.1. Introduction. ...............................................................................................................................118 
4.2. Synthesis of Ligands and Zirconium Complexes.

4.3. Crystallographic Characterization.

4.4. Electrochemistry.

4.5. Density Functional Theory (DFT) Studies.

4.6. Electronic transitions and TD-DFT studies.

4.7. Substituent Influence of Excited-State Decay Dynamics. 136

4.8. Photoinduced Electron Transfer. 141

4.9. Catalytic Photoredox Dehalogenation of Aryl Halides. 144

4.10. Summary. 147

4.11. Experimental Section. 148

4.12. Reference. 158

Chapter 5. Photoluminescence of Seven-Coordinate Zirconium and Hafnium Complexes with 2,2'-Pyridylpyrrolide Ligands. 161

5.1. Introduction. 161

5.2. Synthesis and Crystallographic Characterization 162

5.3. Solution Dynamics. 165 
5.4. Computational Studies of Isomerism.

5.5. Photophysical Properties.

5.6. TD-DFT Studies.

5.7. Electrochemical Properties. 182

5.8. Photoredox catalysis. 184

5.9. Conclusion. 185

5.10. Experimental Section. 187

5. 11. Reference. 191

Chapter 6. Photochemical C-C Bond Formation in Luminescent Zirconium Complexes with CNN Pincer Ligands. 194

6.1. Introduction 194

6.2. Synthesis and Characterization. 195

6.3. Electrochemistry. 197

6.4. Optical Properties. 199

6.5. Density Functional Theory. 204

6.6. Photoredox Properties of $\mathrm{Zr}\left({ }^{\mathrm{H}} \mathrm{CNN}\right)_{2}$ and $\mathrm{Zr}\left({ }^{\mathrm{Me}} \mathrm{CNN}\right) 2$. .211 
6.7. Conclusion.

6.8. Experimental Section

6.9. Reference. 225

Chapter 7. A Benchtop-Stable Zirconium Photosensitizer Supported by Pyrrole-Based Schiff Bases.

7.1. Introduction. 227

7.2. Synthesis and Characterization. 228

7.3. Optical Properties. 231

7.4. TD-DFT Studies. 238

7.5. Electrochemical Properties. 244

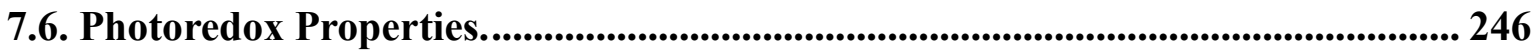

7.7. Summary. .......................................................................................................................... 248

7.8. Experimental Section. 249

7.9. References. 
Chapter 8. Projects in Progress

8.1. Tuning the Physical/Optical/Redox Properties of Pyridine Dipyrrolide Zirconium

Photosensitizer via Distal Control. 253

8.2. Single-Electron-Induced Isomerization of an Octahedral Titanium 2,2'Pyridylpyrrolide Complex. 269

8.3. Synthesis and Characterization of Mix-Ligated Zirconium 2,2'-Pyridylpyrrolide

Complex. 279

8.4. Zirconium Acted Like Nickel with the Help of Light. 288

8.5. Synthesis and Characterization of High Valent Niobium and Tantalum Complexes as Analogues of Pyridine dipyrrolide Zirconium(IV) Photosensitizers. 300

8.6. Reference. 314

Appendix A. Additional Physical Measurement Results 316

Appendix B. NMR Spectrum . 371

Appendix C. X-ray crystallography 410

Appendix D. Additional DFT Calculations 491

Appendix E. Permissions. 548 


\section{General Introduction}

Solar energy delivered by sunlight is the most abundant and green source of energy. The amount of energy the sun delivers to Earth in one hour exceeds the overall human energy consumption per year. ${ }^{1}$ Harvesting this solar power efficiently to produce electricity and synthesize commodity chemicals are two major goals of the chemical community. A key component for every photovoltaic (light-to-electrical energy) or photosynthetic (light-to-chemical energy) system is a light-responsive molecule or material, so-called photosensitizer, that can absorb the energy of photons and produce a chemical change in another molecule in a photochemical process.

Long before humankind, nature already established the utilization of light energy from the sun. Algae, bacteria, and plants harvest solar energy for the fixation of carbon dioxide $\left(\mathrm{CO}_{2}\right)$ and water $\left(\mathrm{H}_{2} \mathrm{O}\right)$ into organic compounds and oxygen. This process, namely photosynthesis, supplies most of the energy necessary for life on Earth. Only until last century, humans have started to rigorously understand how plants function. The most crucial components for photosynthesis are a number of photosensitizers, including chlorophylls, carotenoids, phycoerythrin, and phycocyanin (Figure 1). These pigments absorb sunlight and are promoted into an electronically excited state, which is then converted into electrochemical potential for $\mathrm{CO}_{2}$ reduction and $\mathrm{H}_{2} \mathrm{O}$ oxidation. ${ }^{2}$ One common property observed is that these naturally occurring photosensitizers are typically luminescent (excited state decay via photon emission). In other words, photoluminescence serves 
as a fingerprint for identifying a compound as a photosensitizer. The luminescent/emissive states are usually long-lived ( $\tau_{\mathrm{em}}>1 \mathrm{~ns}$ ) compared to the fast thermal deactivation through molecular vibrations. This long-lived excited state is important since it allows participation in bimolecular photo-induced electron/energy transfer processes because the excited state decays slower than the rate constant of diffusion $\left(\mathrm{k}_{\text {diff }} \sim 1.5 \times 10^{10} \mathrm{~s}^{-1}\right){ }^{3}$

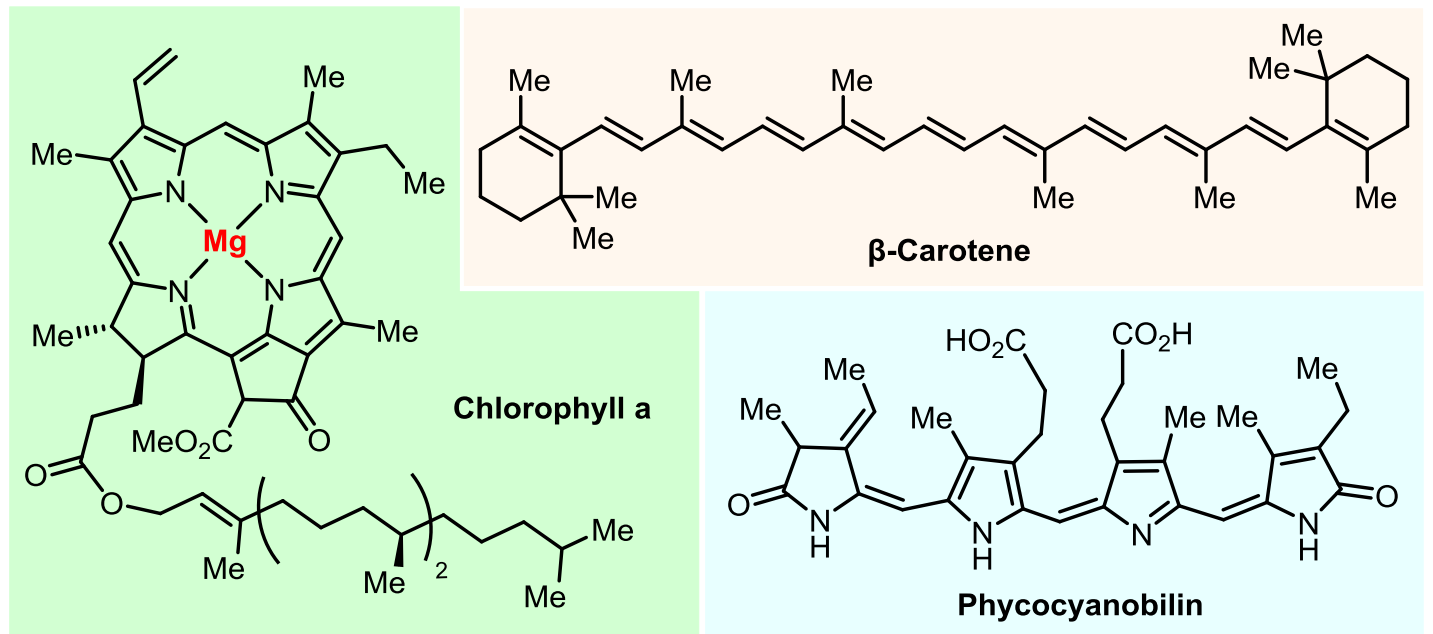

Figure 1. Examples of naturally occurring photosensitizers.

Having understood the physical nature behind these light-harvesting molecules in photosynthetic systems, many molecules with photosensitizer properties have been discovered/developed over the past decades. Not only can these photosensitizers mimic the photosynthetic process in nature, but they also have been widely applied in many aspects of human life, such as: solar cells sensitized with dyes which convert visible light to electricity; ${ }^{4}$ the treatment of human diseases (i.e. cancer) known as photodynamic therapy; ${ }^{5}$ organic light emitting diodes 
(OLEDs) containing a film of a photosensitizer that generates light in response to an electric current; ${ }^{6}$ and in the field of photoredox catalysis, organic chemists use photosensitizers as photocatalysts for promoting challenging organic transformations. ${ }^{3,7,8}$

There are two major types of molecular photosensitizer according to their composition, organic dyes and metal-based (main group metals, transition metals, and lanthanides/actinides). Although organic dyes are widely available and cheap, their photo/thermal-stabilities are unreliable under operating conditions of solar cell, photodynamic therapy and photocatalysis. Contrarily, inorganic photosensitizers are more robust towards applications. Transition metal chromophores, in particular, are most studied, well understood, and widely used.

Among all transition metal photosensitizers, group 6-12 elements are the leading subject of study (Figure 2). As by far the largest class of molecular photosensitizers, these compounds combine electron-deficient ligands (e.g. isocyanide, bipyridine or phenanthroline) with low-valent metal center $\left(\mathrm{d}^{6}, \mathrm{~d}^{8}\right.$, or $\left.\mathrm{d}^{10}\right)$, mostly from the $2^{\text {nd }}$ or $3^{\text {rd }}$ row of the transition metal series. This complementary design enables facile metal-to-ligand charge transfer (MLCT) to generate longlived emissive excited states. Prominent examples for this type of photosensitizer are $\left[\mathrm{Ru}{ }^{\mathrm{II}}(\mathrm{bpy})_{3}\right]^{2+}$ $\left(\mathrm{d}^{6}\right.$, bpy $=2,2^{\prime}$-bipyridine $),{ }^{9,10} \operatorname{Ir}{ }^{\mathrm{III}}(\mathrm{ppy})_{3}\left(\mathrm{~d}^{6}\right.$, ppy= 2,2'-phenylpyridine $),{ }^{11}\left[\mathrm{Cu}^{\mathrm{I}}(\mathrm{dmp})_{2}\right]^{1+}\left(\mathrm{d}^{10}\right.$, $\mathrm{dmp}=2,9$-dimethyl-1,10-phenanthroline $),{ }^{12}\left[\operatorname{Re}{ }^{\mathrm{I}} \mathrm{Cl}(\mathrm{CO}){ }_{3}(\mathrm{bpy})\right]\left(\mathrm{d}^{6}\right),{ }^{13}$ and $\left[\mathrm{Pt}^{\mathrm{II}}(\operatorname{terpy})(\mathrm{C} \equiv \mathrm{CR})\right]^{1+}$ $\left(\mathrm{d}^{8}\right.$, terpy $=2,2^{\prime} ; 6^{\prime}, 2^{\prime}$-terpyridine $) .{ }^{14}$ Recently, much attention in this area has been devoted to $1^{\text {st }}$ row late transition metals ${ }^{12,15-24}$ and low-valent groups 6 and 7 metals ${ }^{12,13,25-29}$ that retains the 
fundamental design principle of photoinduced charge separation via MLCT. In marked contrast, luminescent metal complexes relying on alternative mechanisms such as ligand-to metal charge transfer (LMCT), ${ }^{30-42}$ ligand-to-ligand charge transfer (LLCT), intra-ligand charge transfer $\left(\text { ILCT) }{ }^{43-52} \text { or metal-centered excitations (i.e. } \mathrm{d} \rightarrow \mathrm{d}\right)^{53-56}$ are not as well-studied, but offer the potential to expand the palette of metals suitable for photosensitizer development.
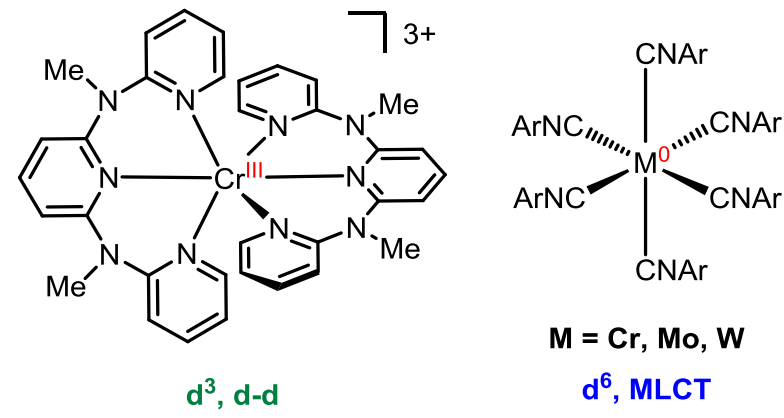

$$
\mathbf{M}=\mathbf{C r}, \mathbf{M o}, \mathbf{W}
$$

$d^{6}$, MLCT

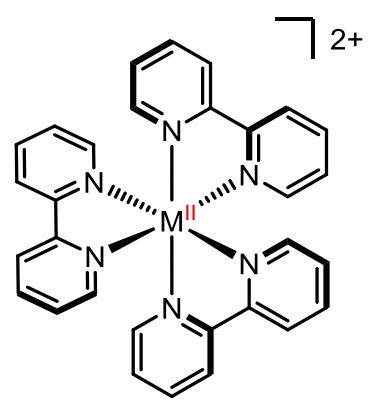

$\mathrm{M}=\mathrm{Ru}$, Os

$d^{6}$, MLCT

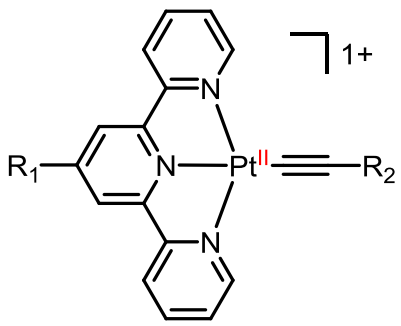

$\mathrm{d}^{8}$, MLCT

$\mathrm{d}^{5}$, LMCT

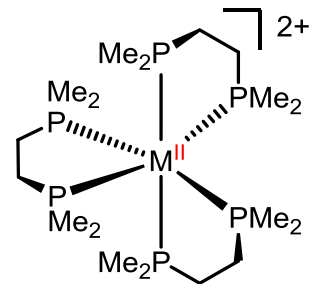

$\mathbf{M}=\mathbf{T c}, \mathbf{R e}$

$\mathrm{d}^{5}$, LMCT
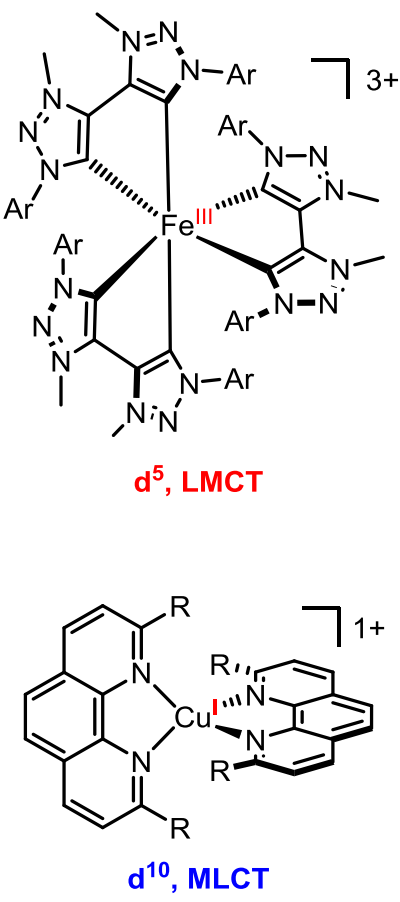

$\mathrm{Cy}_{3} \mathrm{P}-\mathrm{Au}^{\prime}=\mathrm{Ar}$

$\mathrm{d}^{10}$, ILCT

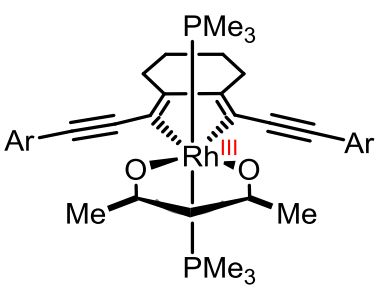

$d^{6}$, ILCT<smiles></smiles>

$d^{6}, M L C T$

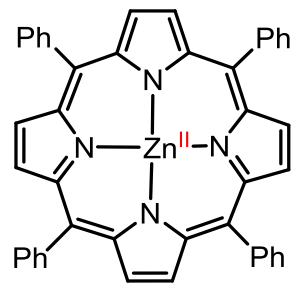

$\mathrm{d}^{10}$, ILCT

Figure 2. Examples of group 6-12 photosensitizers. 
Meanwhile, early transition metal elements (group 3-5) have been overlooked for their potentials in constructing photosensitizer. Molecular photosensitizers on the basis of group 3-5 elements are extremely rare as only few studies are found. As the matter of fact, owing to their generally electron-deficient nature and superior stability in the highest oxidation state $\left(\mathrm{d}^{0}\right)$, group 3-5 metals are ideally suited for generating low-energy LMCT emissive states when combined with electron-rich ligands.

Prompted by the initial discovery of long-lived luminescent LMCT states in cyclopentadienyl $\mathrm{Sc}^{\mathrm{III}}$ complexes ${ }^{30,31}$ several examples of luminescent group 3-5 metal complexes with $\mathrm{d}^{0}$ configuration have been reported. ${ }^{32,33,40-42,57-67}$ From these reports, it seems that those group 3-5 photosensitizers often encounter severe limitations toward applications. Many early transition metal chromophores show emission exclusively in frozen solutions or solid state rather than in fluid solution and often require excitation by UV instead of visible light. However, several examples for early transition metal complexes that luminesce upon visible light excitation in fluid solutions at room temperature have been reported (Figure 3): $\mathrm{Cp} * \mathrm{TaCl}_{3} \mathrm{X}\left(\mathrm{X}=\mathrm{Cl}, \mathrm{RCO}_{2}, \mathrm{CH}_{3} \mathrm{SO}_{3}\right)$ described by Caspar and co-workers exhibited long-lived emission with lifetimes between $900 \mathrm{~ns}$ to $8.2 \mu$ s and quantum yields of 0.5 to $15.7 \%$ in dichloromethane. ${ }^{32}$ The excited states in these systems were assigned as predominantly LMCT in character $\left(\mathrm{Cp}^{*} \rightarrow \mathrm{Ta}^{\mathrm{V}}\right)$. Several group 4 and 5 imido complexes also exhibit emissive states due to LMCT from the electron-rich imido ligand to the $\mathrm{d}^{0}$ metal center $\left(\mathrm{NR}^{2-} \rightarrow \mathrm{M}\right)$. The earliest report by Thorn and Harlow features 
$\left.\left[\left(\mathrm{P}(\mathrm{OSiMe})_{2}\right)_{2}\right)_{2} \mathrm{Ti}=\mathrm{N} t \mathrm{Bu}\right]_{2}$, for which the excited state lifetime was determined at $12.5 \mu \mathrm{s}$ in tetrahydrofuran (THF). ${ }^{40}$ No quantum yield data was reported. More comprehensive experiments were performed for $\mathrm{Nb}$ and $\mathrm{Ta}$ imido complexes. Following the initial work by Hopkins and coworkers ${ }^{33}$ Williams and Korolev demonstrated that lifetime and quantum yield of the complexes $\mathrm{M}(\mathrm{NR}) \mathrm{Cl}_{3} \mathrm{~L}_{2}\left(\mathrm{M}=\mathrm{Nb}, \mathrm{Ta} ; \mathrm{L}_{2}=\mathrm{py}_{2}, \mathrm{dme}\right)$ in dichloroethane is highly sensitive to the nature of the imido substituent. ${ }^{59,61}$ While compounds with aromatic substituents show lifetimes below $200 \mathrm{~ns}$ with quantum yields $<1 \%$, complexes with bulky alkyl substituents ( $\mathrm{R}=$ adamantyl, tert-butyl) exhibit longer-lived emission with lifetimes and quantum yields of up to $15.1 \mu$ s and $20 \%$, respectively. More recently, hydrazone-imidate vanadium(V) oxo complexes with luminescence lifetimes up to $9.9 \mathrm{~ns}$ in acetonitrile have been utilized in photocatalysis. ${ }^{58,60}$ The excited state was assigned as LMCT $\left(\mathrm{O}^{2-} \rightarrow \mathrm{V}^{\mathrm{V}}\right)$ via density functional theory (DFT).
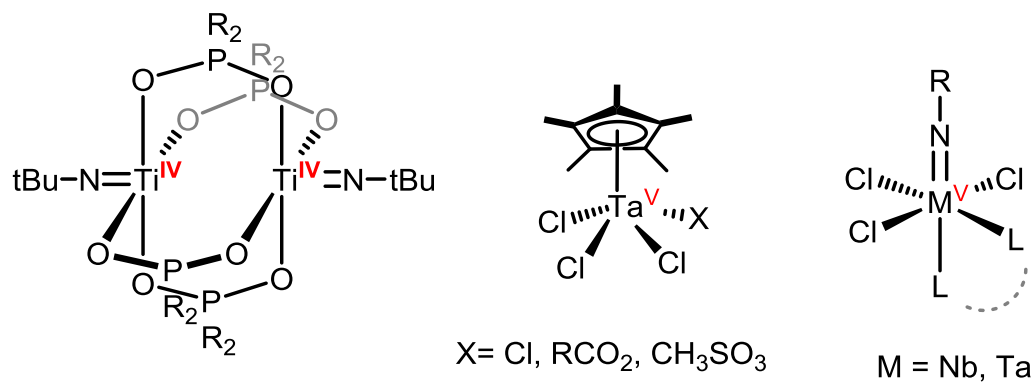

$\mathrm{M}=\mathrm{Nb}, \mathrm{Ta}$

Figure 3. Examples of luminescent early transition metal complexes upon visible light excitation in fluid solutions at room temperature. 
As shown above, within the handful examples of fluid solution emissive group 3-5 complexes, many of them exhibit long-lived excited states with lifetime in the microsecond level. Is it coincident or are early transition metals born to have less non-radiative processes of their excited states? The well-studied excited states behavior for late transition metal phosphors based on $\mathrm{Ru}^{\mathrm{II}}$, Ir ${ }^{\mathrm{III}}, \mathrm{Fe}^{\mathrm{II}}$ or $\mathrm{Cr}^{0}\left(\mathrm{~d}^{6}\right)$, which their excited states decay processes severely suffered from detrimental low-lying metal centered (MC) states deactivation thanks to the various spin multiplicities. ${ }^{25,68-70}$ Although photosensitizer based on $\mathrm{Cu}^{\mathrm{I}}\left(\mathrm{d}^{10}\right)$ ion effectively eliminate $\mathrm{MC}$ deactivation pathway due to its fully filled d orbitals, the excited state radiationless decay is still not ideal and the lifetime of most cuprous complexes are still ns to low- $\mu$ s range. Turns out, nonradiative decay for tetrahedron cuprous complexes encounters large excited state Jahn-Teller distortion following the change of electronic configuration. A formally $\mathrm{Cu}^{\mathrm{II}}\left(\mathrm{d}^{9}\right)$ center in the excited state distorts to pseudo square planar geometry, which lead to exciplex formation with coordinating species and accelerates radiationless decay dynamics. ${ }^{22,71,72}$ Using early transition metal ions for the design of LMCT photosensitizers potentially have two major attractive perspectives: 1) The readily accessible $\mathrm{d}^{0}$ configuration commonly found for group $3-5$ transition metals prevents detrimental metal-centered deactivation pathways and allows for extended luminescence lifetimes. 2) Highly electropositive group 3-5 $\left(\mathrm{d}^{0}\right)$ ions favor high coordination number and the resulting sterically congested environment could limit structural distortion in the excited states and reduce vibrational cooling processes (Figure 4). 

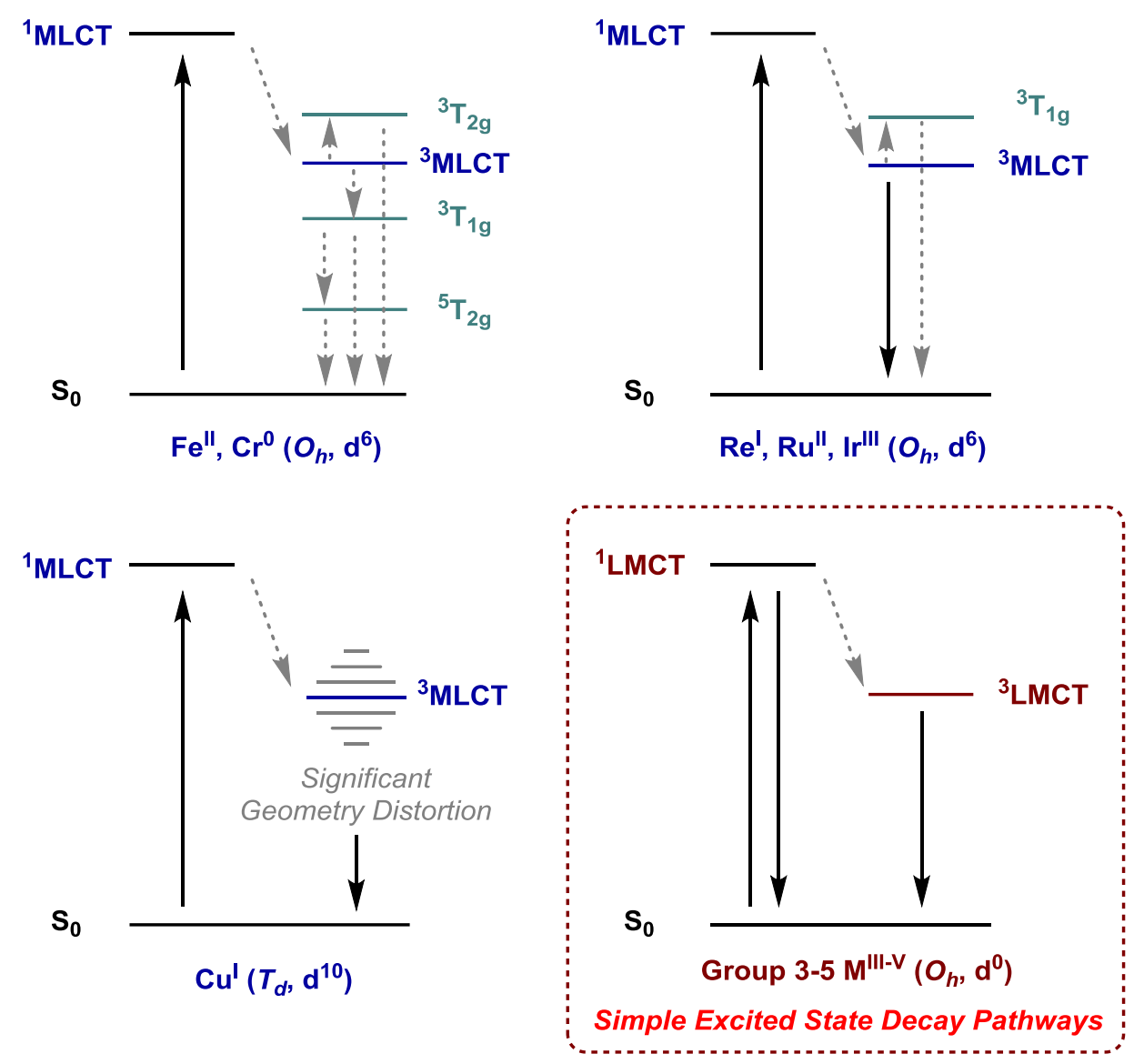

Figure 4. Simplified Jablonski diagram for typical deactivation pathways of excited states of transition metal photosensitizer. Black solid line represents radiative process and gray dotted line stands for non-radiative process.

The most commonly used inorganic photosensitizers are based on precious metals such as ruthenium $(\mathrm{Ru})$ and iridium (Ir). The total amount of available ruthenium on earth are estimated to be 5000 tons, while expected estimations place iridium at an even lower threshold. Their low natural abundance and the resulting high cost limit their application commercially, which has sparked continued interest in the development of photosensitizers based on earth-abundant elements. ${ }^{68,69,73,74}$ Luminescent early transition metal complexes on the basis of group 3-5 
elements are particularly appealing targets also due to their relatively high abundance in the Earth's crust. ${ }^{75,76}$ Especially for group 4 elements, titanium and zirconium are in fact the $2^{\text {nd }}$ and $4^{\text {th }}$ most abundant transition metal, respectively. Zirconium is more than twice as abundant as copper and zinc, with an annual production of more than one million tons (Figure 5). Photosensitizers based on zirconium could allow large-scale applications at more acceptable price. Additionally, zirconium would be a promising replacement for heavy metals because it is generally considered innocuous (no known biological role or toxicity) and environmentally benign.

\begin{tabular}{|c|c|c|c|c|c|c|c|c|c|c|}
\hline 3 & 4 & 5 & 6 & 7 & 8 & 9 & 10 & 11 & 12 & \\
\hline$\underset{\substack{\text { scandium } \\
22}}{\mathbf{S C}}$ & ${ }_{\substack{\text { Titanium } \\
5600}}^{22}$ & ${ }_{\substack{\text { Vanadium } \\
120}}^{\mathbf{V}}$ & ${ }_{\substack{\text { Chromium } \\
102}}^{\mathbf{C r}}$ & $\underset{\substack{\text { Manganese } \\
950}}{\mathbf{M n}}$ & ${ }_{\substack{\text { Iron } \\
56300}}^{26}$ & ${ }^{27} \underset{\substack{\text { Cobaalt } \\
25}}{\mathbf{C o}}$ & ${ }^{28} \underset{\substack{\text { Nickel } \\
84}}{\mathbf{N i}}$ & ${ }^{29} \underset{\substack{\text { Copper } \\
60}}{\mathbf{C u}}$ & ${ }_{\substack{\text { Zinc } \\
70}}^{\mathbf{Z n}}$ & $\begin{array}{c}\text { crustal } \\
\text { Abundance }\end{array}$ \\
\hline${ }_{\substack{\text { Ytrrium } \\
\mathbf{3 3}}}^{\mathbf{Y}}$ & $\underbrace{\mathbf{Z r}}_{\substack{\text { Zirconium } \\
165}}$ & $\underset{\substack{\text { Niobium } \\
\mathbf{2 0}}}{\mathbf{N b}}$ & ${ }_{\substack{\text { Molybdenum } \\
1.2}}^{\text {Mo }}$ & $\underset{\substack{\text { Technetium } \\
\mathbf{0}}}{\mathbf{T C}}$ & ${\substack{\text { Ruthenium } \\
1 \times 10^{-3}}}^{44} \mathbf{u}$ & ${ }_{\substack{\text { Rhodium } \\
1 \times 10^{-3}}}^{\mathrm{Rh}}$ & ${ }_{\substack{\text { Palladium } \\
1.5 \times 10^{-2}}}^{\mathbf{P d}}$ & ${ }_{\substack{47 \\
\text { Silver } \\
7.5 \times 10^{-2}}}^{\mathbf{A g}}$ & ${ }_{\substack{\text { Cadmium } \\
0.2}}^{\mathbf{C d}}$ & $\begin{array}{c}500-100 \\
100-10 \\
10^{-1}-10\end{array}$ \\
\hline${ }_{\substack{\text { Lutetium } \\
0.5}}^{\mathbf{L u}}$ & $\underbrace{\mathbf{H f}}_{\substack{\text { Hafnium } \\
3.0}}$ & ${ }_{\substack{73 \\
\text { Tantalum } \\
\mathbf{2 . 0}}}^{\mathbf{T a}}$ & ${ }_{\substack{\text { Tungsten } \\
1.3}}^{\mathbf{W}}$ & $\underset{\substack{\text { Rhenium } \\
7 \times 10^{-4}}}{\text { Re }}$ & $\mathrm{OS}_{\substack{\mathrm{Osmium} \\
1.5 \times 10^{-3}}}$ & $\underset{\substack{\text { Iridium } \\
1 \times 10^{-3}}}{\text { Ir }}$ & ${ }_{\substack{\text { Platinum } \\
5 \times 10^{-3}}}^{\mathrm{Pt}}$ & ${ }_{\substack{79 \\
\text { Gold } \\
4 \times 10^{-3}}}$ & ${ }_{\substack{\text { Mercury } \\
8.5 \times 10^{-2}}}^{\mathrm{Hg}}$ & $\begin{array}{c}10^{-1}-10^{-2} \\
10^{-2}-10^{-3} \\
<10^{-3}\end{array}$ \\
\hline
\end{tabular}

Figure 5. Abundance of the transition metal elements in earth crust $(\mathrm{g} /$ ton $){ }^{75}$

Having overviewed potential advantages of early transition metal photosensitizers, electron-rich pyrrolide-type ligand frameworks (Figure 6) were identified as promising candidates to support photoluminescence via LMCT. In the remaining sections of this dissertation, detailed studies will be discussed for creating novel photosensitizers in combining different pyrrolide 
ligand scaffold with early transition metal ions (mostly zirconium). We hope that this work will fill the gap of the grand photosensitizer landscape and eventually prosper early transition metal photochemistry.

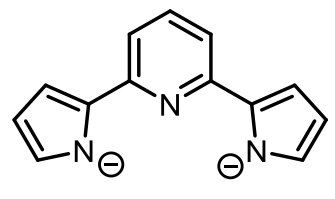

PDP

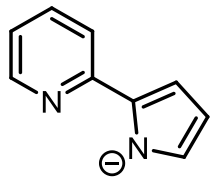

PMP

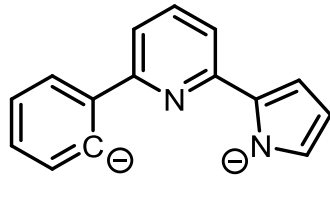

CNN

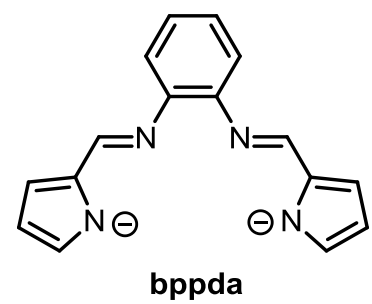

bppda

Figure 6. Examples of pyrrolide-type ligand frameworks.

\section{Reference.}

(1) Lewis, N. S.; Nocera, D. G. Proc. Natl. Acad. Sci. 2006, 103, 15729.

(2) Bertini, I.; Gray, H. B.; Lippard, S. J. and Valentine, J. S. Bioinorganic Chemistry; University Science Books: Mill Valley, CA (USA), 1994.

(3) Romero, N. A.; Nicewicz, D. A. Chem. Rev. 2016, 116, 10075-10166.

(4) Hagfeldt, A.; Boschloo, G.; Sun, L.; Kloo, L.; Pettersson, H. Chem. Rev. 2010, 110, 65956663.

(5) Monro, S.; Colón, K. L.; Yin, H.; John Roque, I.; Konda, P.; Gujar, S.; Thummel, R. P.; 
Lilge, L.; Cameron, C. G.; McFarland, S. A. Chem. Rev. 2018, 119, 797-828.

(6) Xu, H.; Chen, R.; Sun, Q.; Lai, W.; Su, Q.; Huang, W.; Liu, X. Chem. Soc. Rev. 2014, 43, $3259-3302$.

(7) Prier, C. K.; Rankic, D. A.; MacMillan, D. W. C. Chem. Rev. 2013, 113, 5322-5363.

(8) Wang, C. S.; Dixneuf, P. H.; Soulé, J. F. Chem. Rev. 2018, 7532-7585.

(9) Kalyanasundaram, K. Coord. Chem. Rev. 1982, 46, 159.

(10) Durham, B.; Caspar, J. V.; Nagle, J. K.; Meyer, T. J. J. Am. Chem. Soc. 1982, 104, 48034810 .

(11) King, K. A.; Spellane, P. J.; Watts, R. J. J. Am. Chem. Soc. 1985, 107, 1431-1432.

(12) McMillin, D. R.; Buckner, M. T.; Ahn, B. T. Inorg. Chem. 1977, 16, 943-945.

(13) Wrighton, M.; Morse, D. L. J. Am. Chem. Soc. 1974, 96, 998-1003.

(14) Yang, Q.-Z.; Wu, L.-Z.; Wu, Z.-X.; Zhang, L.-P.; Tung, C.-H. Inorg. Chem. 2002, 41, 56535655.

(15) Klemens, F. K.; Fanwick, P. E.; Bibler, J. K.; McMillin, D. R. Inorg. Chem. 1989, 28, 30763079.

(16) Hamze, R.; Peltier, J. L.; Sylvinson, D.; Jung, M.; Cardenas, J.; Haiges, R.; Soleilhavoup, M.; Jazzar, R.; Djurovich, P. I.; Bertrand, G.; Thompson, M. E. Science 2019, 363, 601-606. 
(17) Cunningham, C. T.; Cunningham, K. L. H.; Michalec, J. F.; McMillin, D. R. Inorg. Chem. 1999, 38, 4388-4392.

(18) Eggleston, M. K.; McMillin, D. R.; Koenig, K. S.; Pallenberg, A. J. Inorg. Chem. 1997, 36, $172-176$.

(19) Ruthkosky, M.; Castellano, F. N.; Meyer, G. J. Inorg. Chem. 1996, 35, 6406-6412.

(20) McCusker, C. E.; Castellano, F. N. Inorg. Chem. 2013, 52, 8114-8120.

(21) Hsu, C. W.; Lin, C. C.; Chung, M. W.; Chi, Y.; Lee, G. H.; Chou, P. T.; Chang, C. H.; Chen, P. Y. J. Am. Chem. Soc. 2011, 133, 12085-12099.

(22) Mara, M. W.; Fransted, K. A.; Chen, L. X. Coord. Chem. Rev. 2015, 282-283, 2-18.

(23) Harlang, T. C. B.; Liu, Y.; Styring, S.; Mateos, H.; Ponseca, C. S.; Persson, P.; Uhlig, J.; Wallenberg, R.; Kjaer, K. S.; Gordivska, O.; Chábera, P.; Lomoth, R.; Fredin, L. A.; Huang, P.; Sundström, V.; Wärnmark, K. Nat. Chem. 2015, 7, 883-889.

(24) Büldt, L. A.; Larsen, C. B.; Wenger, O. S. Chem. - A Eur. J. 2017, 23, 8577.

(25) Büldt, L. A.; Guo, X.; Vogel, R.; Prescimone, A.; Wenger, O. S. J. Am. Chem. Soc. 2017, 139, 985-992.

(26) Sattler, W.; Henling, L. M.; Winkler, J. R.; Gray, H. B. J. Am. Chem. Soc. 2015, 137, $1198-$ 1205.

(27) Sattler, W.; Ener, M. E.; Blakemore, J. D.; Rachford, A. A.; LaBeaume, P. J.; Thackeray, J. 
W.; Cameron, J. F.; Winkler, J. R.; Gray, H. B. J. Am. Chem. Soc. 2013, 135, 10614-10617.

(28) Lam, L. S. M.; Chan, W. K. ChemPhysChem 2001, 2, 252-256.

(29) Sacksteder, L.; Zipp, A. P.; Brown, E. A.; Demas, J. N.; Streich, J.; DeGraff, B. A. Inorg. Chem. 1990, 29, 4335-4340.

(30) Pfennig, B. W.; Thompson, M. E.; Bocarsly, A. B. J. Am. Chem. Soc. 1989, 111, 8947-8948.

(31) Pfennig, B. W.; Thompson, M. E.; Bocarsly, A. B. Organometallics 1993, 12, 649-655.

(32) Paulson, S.; Sullivan, B. P.; Caspar, J. V. J. Am. Chem. Soc. 1992, 114, 6905-6906.

(33) Heinselman, K. S.; Hopkins, M. D. J. Am. Chem. Soc. 1995, 117, 12340-12341.

(34) Pal, A. K.; Li, C.; Hanan, G. S.; Zysman-Colman, E. Angew. Chemie - Int. Ed. 2018, 57, 8027-8031.

(35) Bandy, J. A.; Cloke, F. G. N.; Copper, G.; Day, J. P.; Girling, R. B.; Graham, R. G.; Green, J. C.; Grinter, R.; Perutz, R. N. J. Am. Chem. Soc. 1988, 110, 5039-5050.

(36) Lee, Y. F.; Kirchhoff, J. R. J. Am. Chem. Soc. 1994, 116, 3599-3600.

(37) Chatterjee, S.; Del Negro, A. S.; Smith, F. N.; Wang, Z.; Hightower, S. E.; Sullivan, B. P.; Heineman, W. R.; Seliskar, C. J.; Bryan, S. A. J. Phys. Chem. A 2013, 117, 12749-12758.

(38) Chábera, P.; Liu, Y.; Prakash, O.; Morgan, K.; Lidin, S.; Styring, S.; Essén, S.; Honarfar, A.; Uhlig, J.; Ericsson, T.; Bendix, J.; Thyrhaug, E.; Schnadt, J.; Sobkowiak, A.; Nahhas, A. El; Tatsuno, H.; Lomoth, R.; Fredin, L. A.; Ericson, F.; Häggström, L.; Kjær, K. S.; Handrup, 
K.; Huang, P.; Sundström, V.; Harlang, T. C. B.; Persson, P.; Wärnmark, K. Nature 2017, $543,695-699$.

(39) Kjær, K. S.; Kaul, N.; Prakash, O.; Chábera, P.; Rosemann, N. W.; Honarfar, A.; Gordivska, O.; Fredin, L. A.; Bergquist, K.-E.; Häggström, L.; Ericsson, T.; Lindh, L.; Yartsev, A.; Styring, S.; Huang, P.; Uhlig, J.; Bendix, J.; Strand, D.; Sundström, V.; Persson, P.; Lomoth, R.; Wärnmark, K. Science 2018, 363, 249-253.

(40) Thorn, D. L.; Harlow, R. L. Inorg. Chem. 1992, 31, 3917-3923.

(41) Wing-Wah Yam, V.; Qi, G.-Z.; Cheung, K.-K. J. Chem. Soc. Dalt. Trans. 1998, 1819-1824.

(42) Loukova, G. V.; Huhn, W.; Vasiliev, V. P.; Smirnov, V. A. J. Phys. Chem. A 2007, 111, 41174121.

(43) Darwent, J. R.; Douglas, P.; Harriman, A.; Porter, G.; Richoux, M.-C. Coord. Chem. Rev. 1982, 44, 8545 .

(44) Chao, H. Y.; Lu, W.; Li, Y.; Chan, M. C. W.; Che, C. M.; Cheung, K. K.; Zhu, N. J. Am. Chem. Soc. 2002, 124, 14696-14706.

(45) Aoki, K.; Goshima, T.; Kozuka, Y.; Kawamori, Y.; Ono, N.; Hisaeda, Y.; Takagi, H. D.; Inamo, M. Dalton Trans. 2009, 119-125.

(46) Steffen, A.; Costuas, K.; Boucekkine, A.; Thibault, M. H.; Beeby, A.; Batsanov, A. S.; Charaf-Eddin, A.; Jacquemin, D.; Halet, J. F.; Marder, T. B. Inorg. Chem. 2014, 53, 7055- 
7069.

(47) Juliá, F.; Bautista, D.; Fernández-Hernández, J. M.; González-Herrero, P. Chem. Sci. 2014, $5,1875-1880$.

(48) Chow, P.-K.; Cheng, G.; Tong, G. S. M.; To, W.-P.; Kwong, W.-L.; Low, K.-H.; Kwok, C.C.; Ma, C.; Che, C.-M. Angew. Chem. Int. Ed. 2015, 54, 2084-2089.

(49) Sieck, C.; Tay, M. G.; Thibault, M. H.; Edkins, R. M.; Costuas, K.; Halet, J. F.; Batsanov, A. S.; Haehnel, M.; Edkins, K.; Lorbach, A.; Steffen, A.; Marder, T. B. Chem. - A Eur. J. 2016, 22, 10523-10532.

(50) Chan, K. T.; Tong, G. S. M.; To, W. P.; Yang, C.; Du, L.; Phillips, D. L.; Che, C. M. Chem. Sci. 2017, 8, 2352-2364.

(51) Yeung, K. T.; To, W. P.; Sun, C.; Cheng, G.; Ma, C.; Tong, G. S. M.; Yang, C.; Che, C. M. Angew. Chemie - Int. Ed. 2017, 56, 133-137.

(52) Grübel, M.; Bosque, I.; Altmann, P. J.; Bach, T.; Hess, C. R. Chem. Sci. 2018, 9, 3313-3317.

(53) Serpone, N.; Jamieson, M. A.; Henry, M. S.; Hoffman, M. Z.; Bolletta, F.; Maestri, M. J. Am. Chem. Soc. 1979, 101, 2907-2916.

(54) Stevenson, S. M.; Shores, M. P.; Ferreira, E. M. Angew. Chemie - Int. Ed. 2015, 54, 65066510.

(55) Otto, S.; Grabolle, M.; Förster, C.; Kreitner, C.; Resch-Genger, U.; Heinze, K. Angew. Chem. 
Int. Ed. 2015, 54, 11572-11576.

(56) Wang, C.; Otto, S.; Dorn, M.; Kreidt, E.; Lebon, J.; Sršan, L.; Di Martino-Fumo, P.; Gerhards, M.; Resch-Genger, U.; Seitz, M.; Heinze, K. Angew. Chemie - Int. Ed. 2018, 57, $1112-1116$.

(57) Yam, V. W.; Qi, G.; Cheung, K. Organometallics 1998, 17, 5448-5453.

(58) Gazi, S.; Hung Ng, W. K.; Ganguly, R.; Putra Moeljadi, A. M.; Hirao, H.; Soo, H. Sen. Chem. Sci. 2015, 6, 7130-7142.

(59) Williams, D. S.; Thompson, D. W.; Korolev, A. V. J. Am. Chem. Soc. 1996, 118, 6526-6527.

(60) Gazi, S.; Đokić, M.; Moeljadi, A. M. P.; Ganguly, R.; Hirao, H.; Soo, H. Sen. ACS Catal. 2017, 7, 4682-4691.

(61) Williams, D. S.; Korolev, A. V. Inorg. Chem. 1998, 37, 3809-3819.

(62) Tonks, I. A.; Durrell, A. C.; Gray, H. B.; Bercaw, J. E. J. Am. Chem. Soc. 2012, 134, 73017304.

(63) Kuhlmann, L.; Methling, R.; Simon, J.; Neumann, B.; Stammler, H.-G.; Strassert, C. A.; Mitzel, N. W. Dalton Trans. 2018, 47, 11245-11252.

(64) Radivojevic, I.; Bazzan, G.; Burton-Pye, B. P.; Ithisuphalap, K.; Saleh, R.; Durstock, M. F.; Francesconi, L. C.; Drain, C. M. J. Phys. Chem. C 2012, 116, 15867-15877.

(65) Loukova, G. V.; Vasiliev, V. P.; Milov, A. A.; Smirnov, V. A.; Minkin, V. I. J. Photochem. 
Photobiol. A Chem. 2016, 327, 6-14.

(66) Romain, C.; Choua, S.; Collin, J. P.; Heinrich, M.; Bailly, C.; Karmazin-Brelot, L.; Bellemin-Laponnaz, S.; Dagorne, S. Inorg. Chem. 2014, 53, 7371-7376.

(67) Pritchard, V. E.; Thorp-Greenwood, F. L.; Balasingham, R. G.; Williams, C. F.; Kariuki, B. M.; Platts, J. A.; Hallett, A. J.; Coogan, M. P. Organometallics 2013, 32, 3566-3569.

(68) Wenger, O. S. J. Am. Chem. Soc. 2018, 140, 13522-13533.

(69) Wenger, O. S. Chem. - A Eur. J. 2019, Early View, 10.1002/chem.201806148.

(70) Zhou, X.; Burn, P. L.; Powell, B. J. Inorg. Chem. 2016, 55, 5266-5273.

(71) Vorontsov, I. I.; Graber, T.; Kovalevsky, A. Y.; Novozhilova, I. V.; Gembicky, M.; Chen, Y.S.; Coppens, P. J. Am. Chem. Soc. 2009, 131, 6566-6573.

(72) Riesgo, E. C.; Hu, Y. Z.; Bouvier, F.; Thummel, R. P.; Scaltrito, D. V.; Meyer, G. J. Inorg. Chem. 2001, 40, 3413-3422.

(73) Larsen, C. B.; Wenger, O. S. Chem. - A Eur. J. 2018, 24, 2039-2058.

(74) Bryony M. Hockin; Li, C.; Robertson, N.; Zysman-Colman, E. Catal. Sci. Technol. 2019, 9, 889-915.

(75) It's Elemental. https://education.jlab.org/itselemental/index.html.

(76) Odom, A. L.; McDaniel, T. J. Acc. Chem. Res. 2015, 48, 2822-2833. 


\section{Chapter 1.}

\section{A Novel Molecular Zirconium Photosensitizer for Visible Light Photoredox Catalysis}

(The major part of this chapter was published in J. Am. Chem. Soc. 2016, 138, 13115)

\subsection{Introduction.}

Although 2,6-bis-(pyrrolyl)pyridine derivatives have been synthesized and characterized in 90's as novel heterocyclic systems for their potentials of making semi-conducting materials (conducting polymer). ${ }^{1,2}$ Using 2,6-bis-(pyrrolyl)pyridine as a pincer-type ligand framework in the context of transition metal coordination chemistry were only recently reported. ${ }^{3-8}$ This ligand architecture exhibits a number of attractive features for the design of group 4 LMCT photosensitizers: (1) The pincer type backbone provides a rigid framework and its dianionic nature could support high valent metal center, which perfectly suited for synthesizing octahedral neutral group 4 complexes. (2) pyrrolide ligands are $\pi$-donors due to the amide character of the nitrogen atom and the 2,2'-connectivity between the pyrrolide and pyridine rings confers amide character to the pyridine nitrogen via conjugation. (3) the extended $\pi$-system allows for pushing frontier electronic transitions into visible light region. (4) its modular synthesis allows for straightforward tuning of the steric and electronic properties of the ligand. Here, we present a new molecular photosensitizer based on the electron-deficient early transition metal $\operatorname{Zr}(\mathrm{IV})$ and a $\pi$-donating pyridine dipyrrolide, PDP, ligand and its utilization in photoredox catalysis were demonstrated. 


\subsection{Synthesis and Characterization}

Addition of two equivalents of $n$-BuLi to $\mathrm{H}_{2}{ }^{\mathrm{Me}} \mathrm{PDP}^{\mathrm{Ph}}$ resulted in clean deprotonation yielding $\mathrm{Li}_{2}{ }^{\mathrm{Me}} \mathrm{PDP} P^{\mathrm{Ph}}$. Treatment of $\mathrm{ZrCl}_{4}$ with two equivalents of $\mathrm{Li}_{2}{ }^{\mathrm{Me}} \mathrm{PDP}^{\mathrm{Ph}}$ at room temperature provided $\mathrm{Zr}\left({ }^{\mathrm{Me}} \mathrm{PDP}{ }^{\mathrm{Ph}}\right)_{2}$ in over $80 \%$ yield (Scheme 1).

Scheme 1. Synthesis of $\mathrm{Zr}\left({ }^{\mathrm{Me}} \mathrm{PDP}{ }^{\mathrm{Ph}}\right)_{2}$. A representation of the molecular structure of $\mathrm{Zr}\left({ }^{\mathrm{Me}} \mathrm{PDP}{ }^{\mathrm{Ph}}\right)_{2}$ is shown in bottom left with $50 \%$ probability ellipsoids. Hydrogen atoms were omitted for clarity.

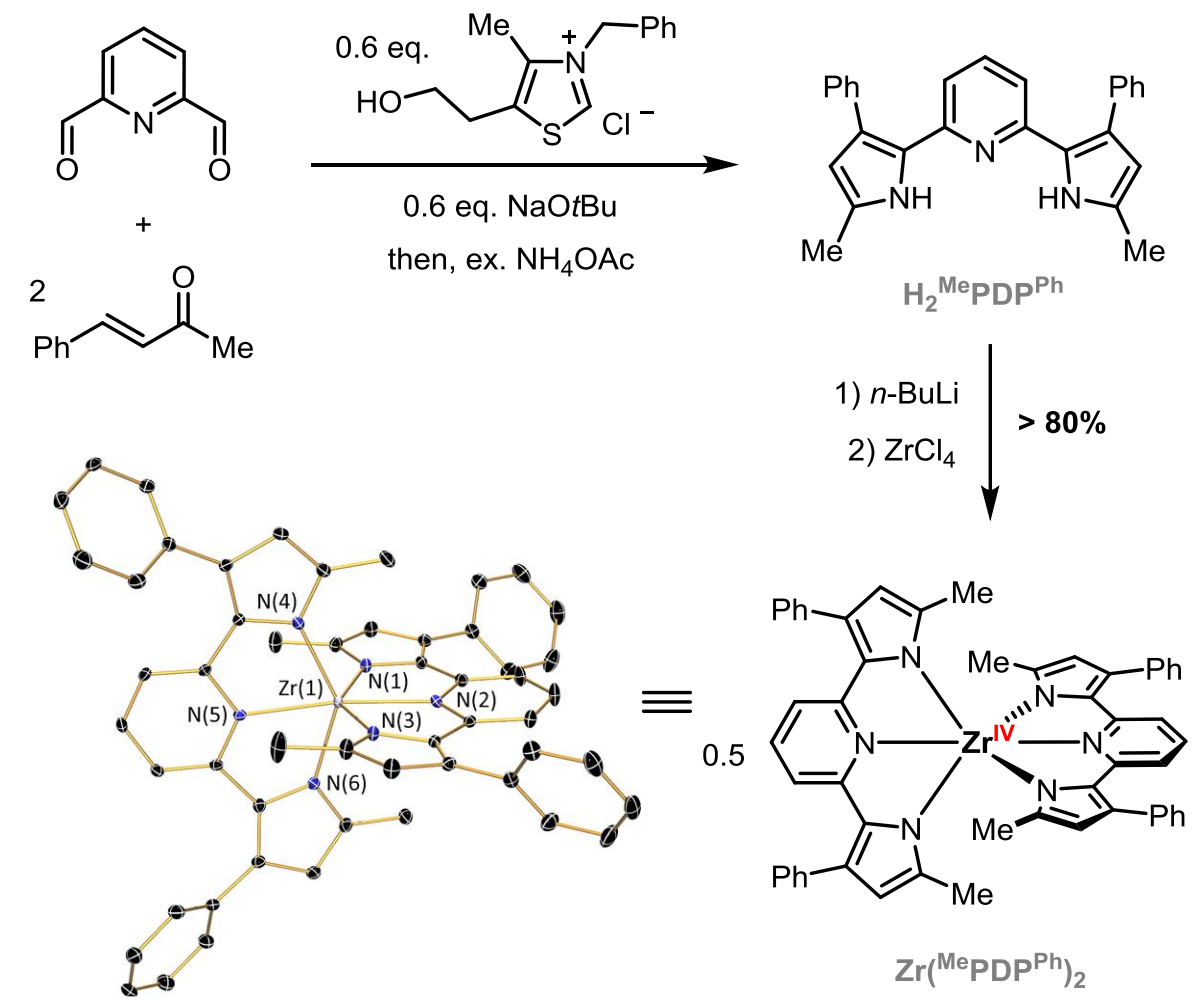

The molecular structures of zirconium complex was established by X-ray diffraction and the structure of $\mathrm{Zr}\left({ }^{\mathrm{Me}} \mathrm{PDP}{ }^{\mathrm{Ph}}\right)_{2}$ is shown in Scheme 1. The coordination environment around the central metal ion is best described as distorted octahedral with two meridionally coordinating 
tridentate $\left[{ }^{\mathrm{Me}} \mathrm{PDP}^{\mathrm{Ph}}\right]^{2-}$ ligands. The geometric constraints enforced by the ligand framework result in reduced average $\mathrm{N}_{\text {pyrrole }}-\mathrm{M}-\mathrm{N}_{\text {pyrrole }}$ angles of $140.00(9)^{\circ}$ for the pincer ligands in $\mathrm{Zr}\left({ }^{\mathrm{Me}} \mathrm{PDP}{ }^{\mathrm{Ph}}\right)_{2}$. The two tridentate ligands exhibit nearly perfect perpendicular orientation as indicated by the dihedral angle of $88.29^{\circ}$ between the $\mathrm{N}(1)-\mathrm{N}(2)-\mathrm{N}(3)$ and the $\mathrm{N}(4)-\mathrm{N}(5)-\mathrm{N}(6)$ planes. The ${ }^{1} \mathrm{H}$ NMR spectroscopy data for diamagnetic $\mathrm{Zr}\left({ }^{\mathrm{Me}} \mathrm{PDP}^{\mathrm{Ph}}\right)_{2}$ is in agreement with $D_{2 d}$ symmetric structures in solution.

\subsection{Photophysical Properties.}

The optical properties of $\mathrm{Zr}\left({ }^{\mathrm{Me}} \mathrm{PDP}{ }^{\mathrm{Ph}}\right)_{2}$ were studied in THF solution at room temperature. The solution of the $\mathrm{Zr}\left({ }^{\mathrm{Me}} \mathrm{PDP}^{\mathrm{Ph}}\right)_{2}$ show an intense pink color and are photoluminescent. Electronic absorption spectra as well as the emission spectrum of $\mathrm{Zr}\left({ }^{\mathrm{Me}} \mathrm{PDP}^{\mathrm{Ph}}\right)_{2}$ upon excitation at $528 \mathrm{~nm}$ are shown in Figure 1. The spectrum of $\mathrm{Zr}\left({ }^{\mathrm{Me}} \mathrm{PDP}^{\mathrm{Ph}}\right)_{2}$ exhibits a single absorption band in the visible region with a maximum at $528 \mathrm{~nm}\left(\varepsilon=27001 \mathrm{M}^{-1} \mathrm{~cm}^{-1}\right)$. Additional bands with maxima at 346 $\mathrm{nm}\left(\varepsilon=40028 \mathrm{M}^{-1} \mathrm{~cm}^{-1}\right)$ and $300 \mathrm{~nm}\left(\varepsilon=61582 \mathrm{M}^{-1} \mathrm{~cm}^{-1}\right)$ are located in the UV part of the spectrum. A weaker absorption band is visible as a shoulder around $395 \mathrm{~nm}$. Excitation at any of these wavelengths resulted in the detection of an emission spectrum with a maximum at $594 \mathrm{~nm}$. A luminescence quantum yield, $\Phi$, of 0.12 was determined via a comparative method using Rhodamine $6 \mathrm{G}$ in ethanol as the reference (Figure 2). ${ }^{9}$ This value is similar to the one reported for $\left[\mathrm{Ru}(\mathrm{bpy})_{3}\right]^{2+}$ in acetonitrile $(\Phi=0.09)$ or water $(\Phi=0.06)$ under oxygen-free conditions. ${ }^{10}$ 


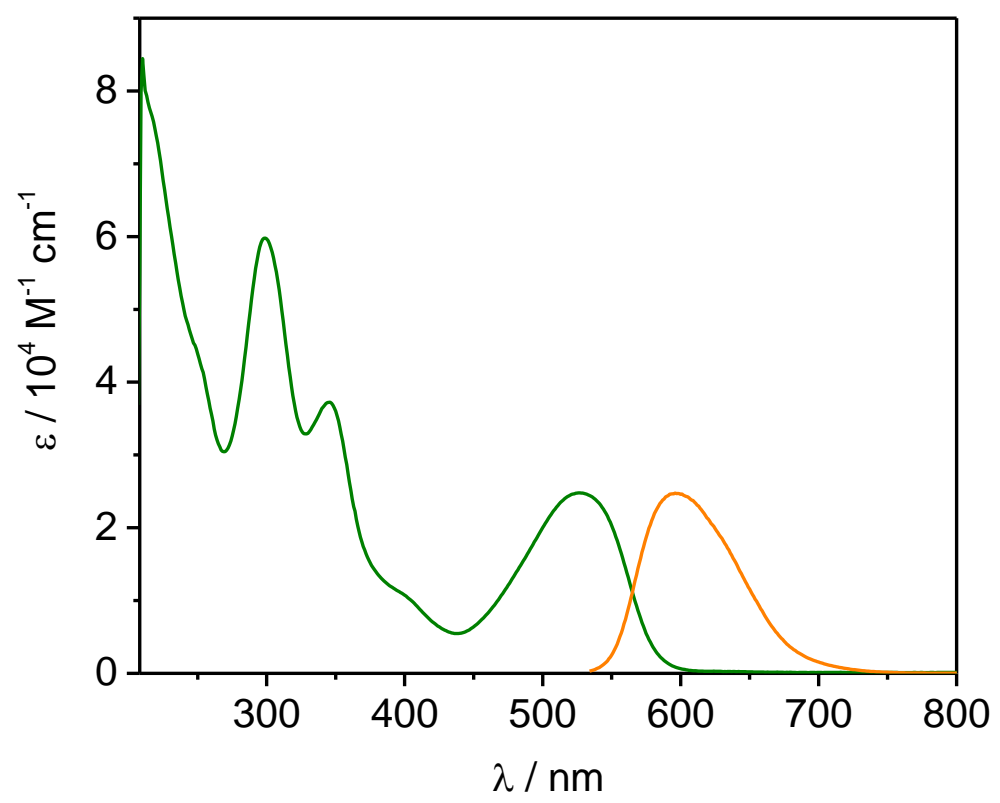

Figure 1. Absorption spectra and emission spectrum of $\mathrm{Zr}\left({ }^{\mathrm{Me}} \mathrm{PDP}^{\mathrm{Ph}}\right)_{2}$ recorded in THF solution at room temperature. Inset: THF solution of $\mathrm{Zr}\left({ }^{\mathrm{Me}} \mathrm{PDP}^{\mathrm{Ph}}\right)_{2}$ under UV irradiation $(365 \mathrm{~nm})$.

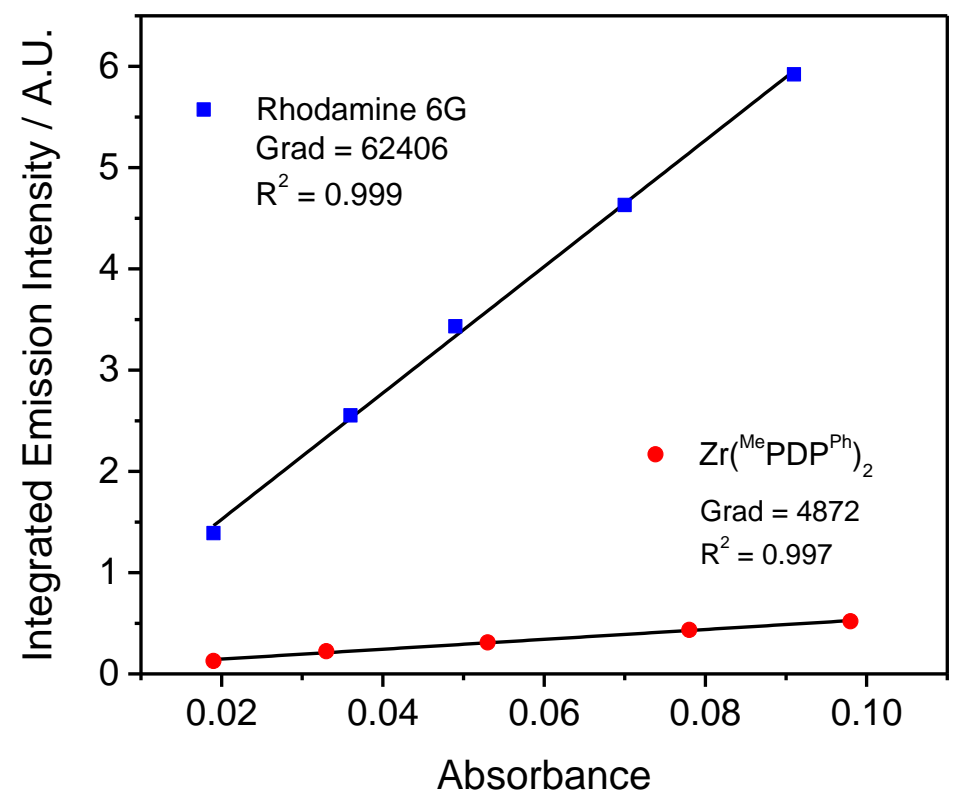

Figure 2. Plot of absorbance at $488 \mathrm{~nm}$ versus integration of the emission spectrum for Rhodamine $6 \mathrm{G}$ in ethanol $(\Phi=0.94)$ and $\mathrm{Zr}\left({ }^{\mathrm{Me}} \mathrm{PDP}^{\mathrm{Ph}}\right)_{2}$ in THF. The black lines represent linear fits of the data and the gradients used for the quantum yield determination is shown next to the corresponding fit. 
Time-resolved emission data for $\mathrm{Zr}\left({ }^{\mathrm{Me}} \mathrm{PDP}^{\mathrm{Ph}}\right)_{2}$ was collected in rigorously deoxygenated and anhydrous THF solution at room temperature and a typical time-resolved emission trace is shown in Figure 3. Excitation of the chromophore was performed at a wavelength of $516 \mathrm{~nm}$, close to the absorption maximum in the visible region of the spectrum, and emission was detected at the maximum of the emission band at $595 \mathrm{~nm}$ for maximum signal intensity. Data collection and fits (single-exponential decay) for multiple independently prepared samples yielded an excited-state lifetime, $\tau_{0}$, of $325 \pm 10 \mu$ s for $\mathrm{Zr}\left({ }^{\mathrm{Me}} \mathrm{PDP}^{\mathrm{Ph}}\right)_{2}$ in THF. The strikingly long lifetime can be attribute to a spin-forbidden $\mathrm{T}_{1} \rightarrow \mathrm{S}_{0}$ transition. This result is also consistent with strong quenching of the emission in the presence of triplet $\mathrm{O}_{2}$ (Figure 4). Emission lifetimes in the hundreds of microsecond range at room temperature are rare for transition metal complexes, but have been reported for $d-d$ excited states $\left({ }^{2} \mathrm{E}_{\mathrm{g}}\right)$ in $\left[\mathrm{Cr}{ }^{\mathrm{III}}(\mathrm{phen})_{3}\right]^{3+}$ derivatives (phen $=1,10$-phenanthroline $)^{11}$ and intraligand charge-transfer states $\left({ }^{3} \mathrm{ILCT}\right)$ in ZnTPP (TPP $=$ tetraphenylporphyrin). ${ }^{12,13}$ For photochemical applications, long-lived excited states are essential for electron transfer process, which usually requires lifetimes in the ns to low $\mu$ s range. 


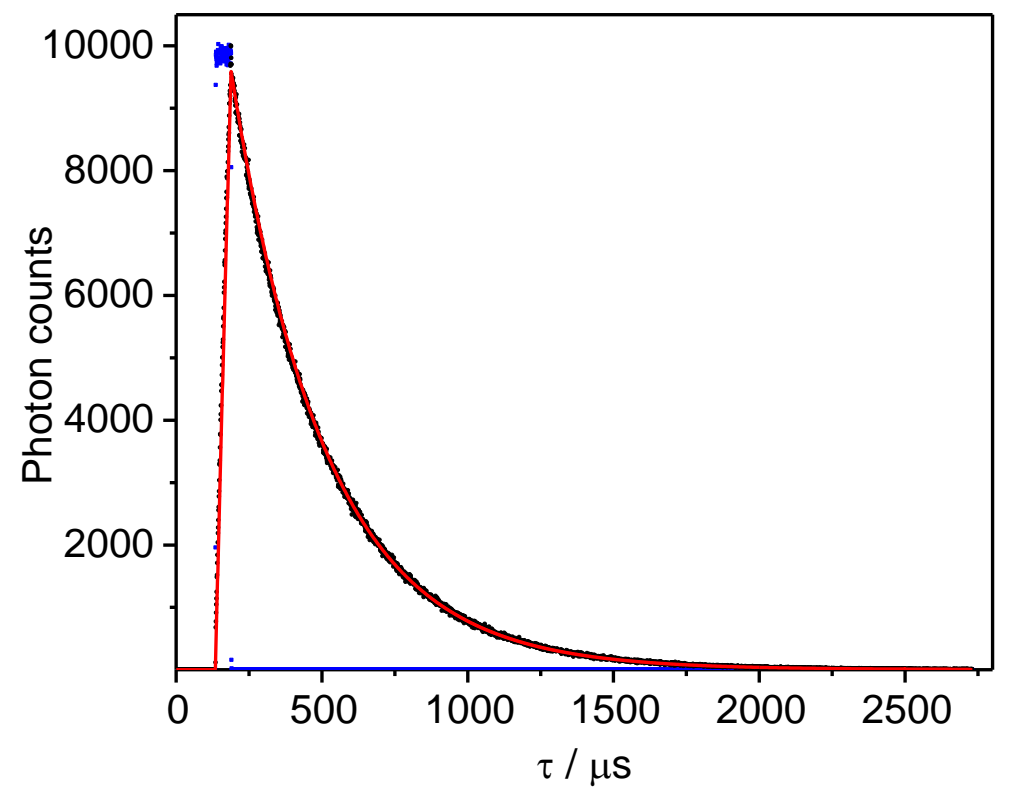

Figure 3. Time-resolved emission data for $\mathrm{Zr}\left({ }^{\mathrm{Me}} \mathrm{PDP}^{\mathrm{Ph}}\right)_{2}$ in $\mathrm{THF}$ at room temperature (black dot) detected at $595 \mathrm{~nm}$ upon excitation at $516 \mathrm{~nm}$. The red line shows the fit to a single exponential decay with $\tau_{0}=325 \mu$ s and the blue dot shows the excitation pulse $(516 \mathrm{~nm})$.

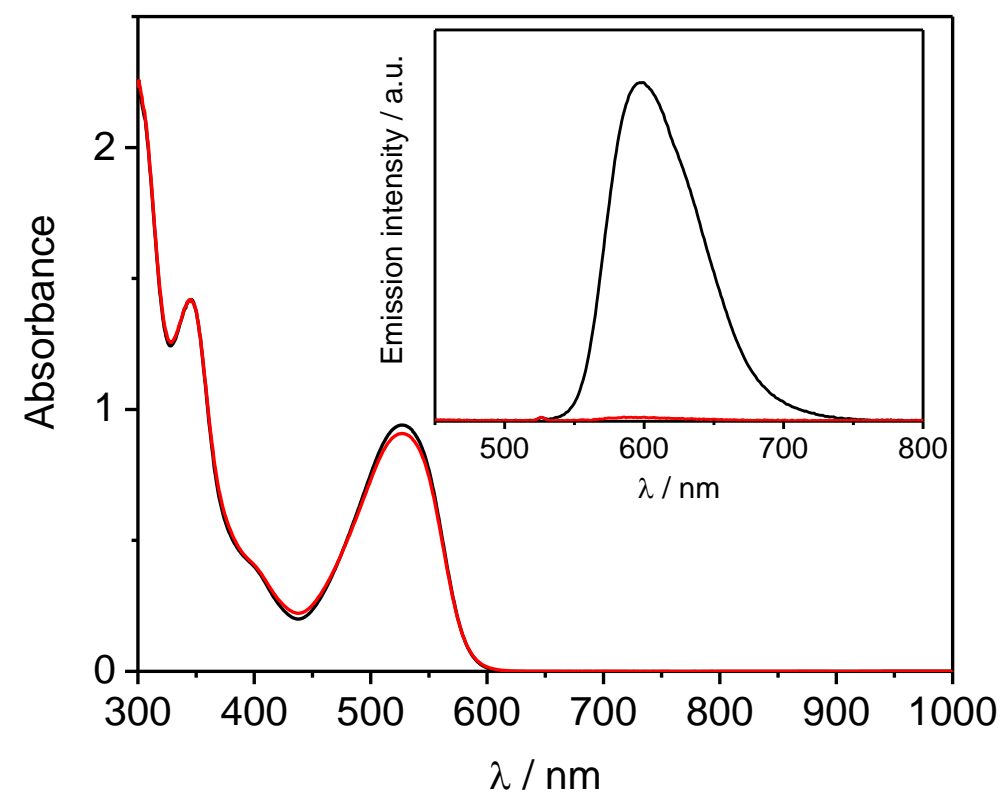

Figure 4. Electronic absorption and emission spectra of $\mathrm{Zr}\left({ }^{\mathrm{Me}} \mathrm{PDP}{ }^{\mathrm{Ph}}\right)_{2}$ upon excitation at $527 \mathrm{~nm}$ in THF under inert atmosphere (black) and upon exposure to air (red). 
For classic transition metal photosensitizers based on precious metals (i.e. Ru, Ir, Re, Pt), the emission behavior with long lifetime at room temperature is typically considered as phosphorescence (Figure 5, left). ${ }^{14-18}$ More recently, some luminescent organic compounds and certain copper photosensitizers were found to emit photon via fluorescence but with lifetime of few to hundreds of microseconds. ${ }^{19-25}$ This phenomenon, so-called, thermally activated delayed fluorescence (TADF) occurs when the energy separation between $S_{1}$ and $T_{1}$ is small enough $(<$ $0.37 \mathrm{eV}),{ }^{25}$ so that the triplet state molecule can thermally populate the singlet state through reverse intersystem crossing process (RISC) at ambient temperature (Figure 5, right). Unfortunately, current experimental data for $\mathrm{Zr}\left({ }^{\mathrm{Me}} \mathrm{PDP}^{\mathrm{Ph}}\right)_{2}$ distinguish neither radiation pathway. In order to further determine the emission mechanism, temperature dependent emission and lifetime studies are required.
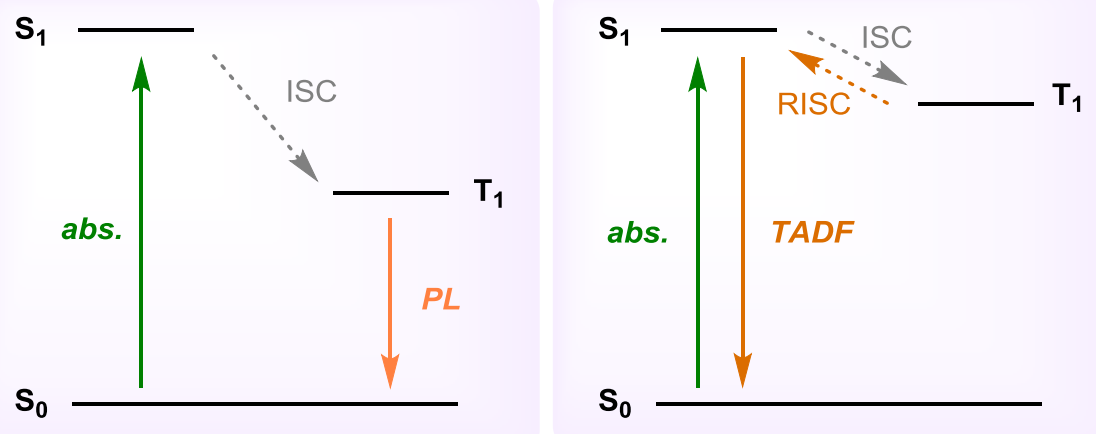

Figure 5. Phosphorescent emission (left) vs. TADF emission (right). 
To gain further insight into the excited-state dynamics of $\mathrm{Zr}\left({ }^{\mathrm{Me}} \mathrm{PDP}^{\mathrm{Ph}}\right)_{2}$, a picosecond ultrafast transient absorption (TA) spectroscopy study was undertaken. The TA contour map for the $\mathrm{Zr}\left({ }^{\mathrm{Me}} \mathrm{PDP}^{\mathrm{Ph}}\right)_{2}$ in benzene at $295 \mathrm{~K}$ is shown in Figure $6 \mathrm{D}$. Spectra at selected delay times are displayed in Figure 6E. Photoexcitation of $\mathrm{Zr}\left({ }^{\mathrm{Me}} \mathrm{PDP}^{\mathrm{Ph}}\right)_{2}$ at $\lambda_{\text {pump }}=480 \mathrm{~nm}$ produced an initial transient spectrum (Figure 6E, orange, $1.5 \mathrm{ps}$ ) that is dominated by excited-state state absorptions (ESA) centered at $575 \mathrm{~nm}$ and $>700 \mathrm{~nm}$ as well as exhibit a clear stimulated emission band between 600 and $700 \mathrm{~nm}$. The ESA can be attributed to the transiently generated radical species of the ${ }^{1} \mathrm{LMCT}$ state. The stimulated emission only occurs for spin-allowed transitions, which offering further support for the ${ }^{1} \mathrm{LMCT}$ assignment of early time excited state. Most of initial features decays within $200 \mathrm{ps}$, converted into a long-lived ground-state bleach (GSB, maxima 550 $\mathrm{nm})$ and new ESA features $(600 \mathrm{~nm}-750 \mathrm{~nm})$ governing the rest of the time (Figure 6E, black). The lifetime of this new excited state was expected way beyond the scale of TA measurement ( 7 ns), which matches a ${ }^{3}$ LMCT state with $325 \mu$ s based on TCSPC. The $100 \%$ intersystem crossing yield from ${ }^{1} \mathrm{LMCT}$ state to ${ }^{3} \mathrm{LMCT}$ state was evident by the isosbestic point observed at $\sim 590 \mathrm{~nm}$ in Figure 6D. To quantitatively evaluate intersystem crossing process, the global analysis at characteristic wavelengths $(576 \mathrm{~nm}$ and $626 \mathrm{~nm}$ ) are performed (Figure 6B). The kinetic traces of ps-TA spectra were fitted with a single exponential decay giving an intersystem crossing rate constants $\left(k_{\mathrm{ISC}}\right)$ of $18 \mathrm{ps}$. This rate is two orders magnitude slower than that of $\mathrm{Ru}(\mathrm{bpy}) 3^{2+}(100$ fs) ${ }^{26}$ which resulted from a smaller spin orbital coupling constant for zirconium. 

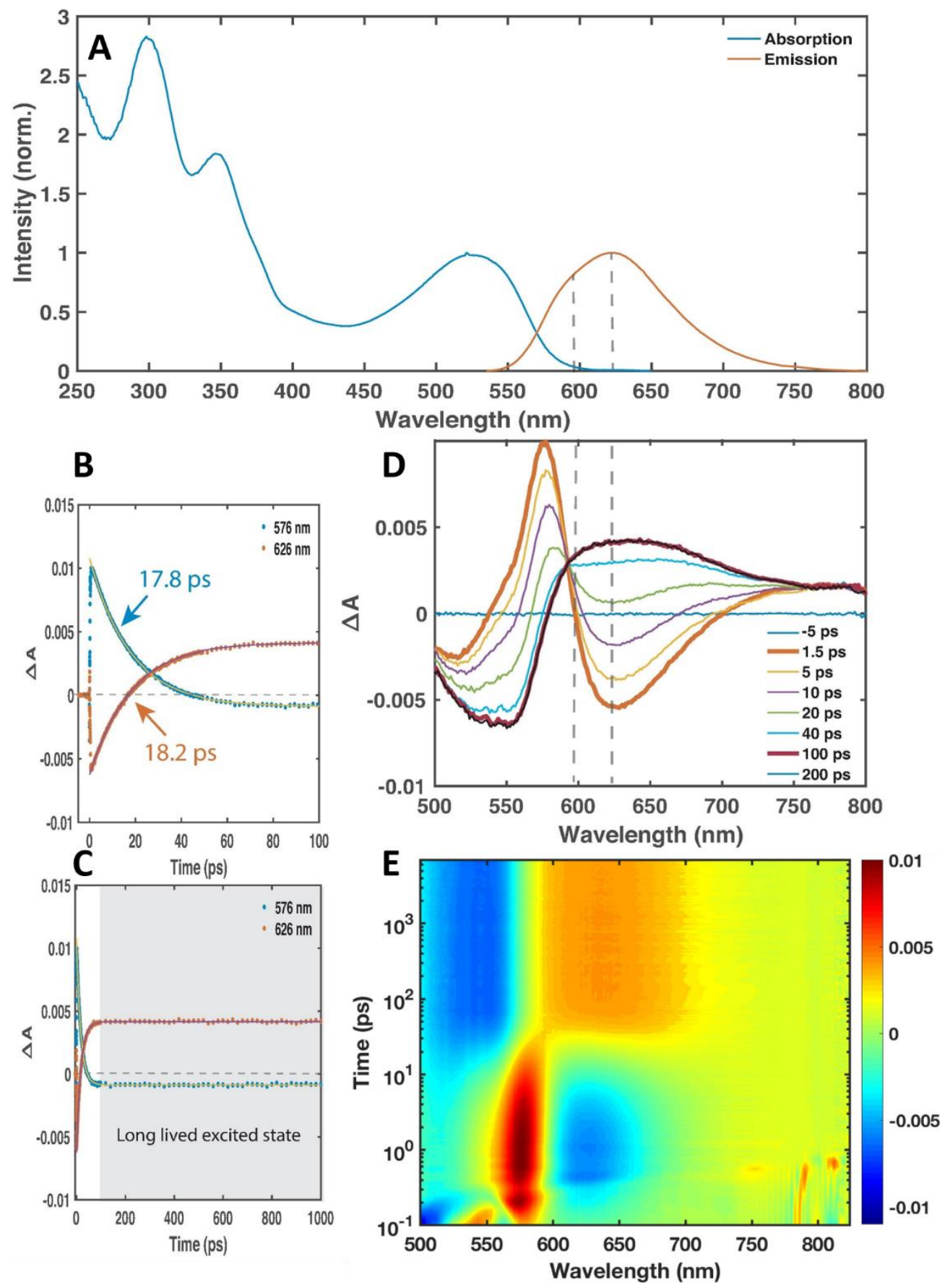

Figure 6. Summary of TA results for $\mathrm{Zr}\left({ }^{\mathrm{Me} P D P^{\mathrm{Ph}}}\right)_{2}$ in benzene at $295 \mathrm{~K}$. (A) Room-temperature absorption and emission spectra of $\mathrm{Zr}\left({ }^{\mathrm{Me}} \mathrm{PDP}^{\mathrm{Ph}}\right)_{2}$ in benzene. (B) and (C) Kinetics and fits monitored at $576 \mathrm{~nm}$ and $626 \mathrm{~nm}$ generated by global analysis. (D) TA spectra at selected delay times ranging from $-5 \mathrm{ps}$ (blue) to $200 \mathrm{ps}$ (black). (E) Contour map of $\mathrm{Zr}\left({ }^{\mathrm{Me} P D P}{ }^{\mathrm{Ph}}\right)_{2} \mathrm{TA}$ at $295 \mathrm{~K}$. 


\subsection{TD-DFT Studies.}

To establish the nature of the electronic transitions, time-dependent density functional theory (TD-DFT) calculations were performed at the B3LYP level of theory. Solvent effects were included using the conductor-like screening model (COSMO). The ground state $\left(\mathrm{S}_{0}\right)$ geometry of $\mathrm{Zr}\left({ }^{\mathrm{Me}} \mathrm{PDP}^{\mathrm{Ph}}\right)_{2}$ was obtained via geometry optimization and is in excellent agreement with the geometric parameters determined by single crystal X-ray diffraction. Even though no symmetry constraints were applied during optimization, the calculated structure exhibits $D_{2 d}$ symmetry with two equivalent ${ }^{\mathrm{Me}} \mathrm{PDP}^{\mathrm{Ph}}$ ligands if the orientation of the phenyl substituents is disregarded. The calculated absorption spectrum obtained via time-dependent density functional theory (TD-DFT) at the computed $\mathrm{S}_{0}$ geometry is shown in Figure 7 . The predicted spectrum is in good agreement with the experimental data showing four major absorption bands in the range of 285-670 nm, which are labeled with Roman numerals in Figure 7. The TD-DFT states (predicted oscillator strength $\mathrm{f}_{\text {osc }}>0.03$ ) contributing to band I are labeled according to their state number. The transition energies and contributing single electron excitations (including their weight) for each TD-DFT state are given in Table 1. 


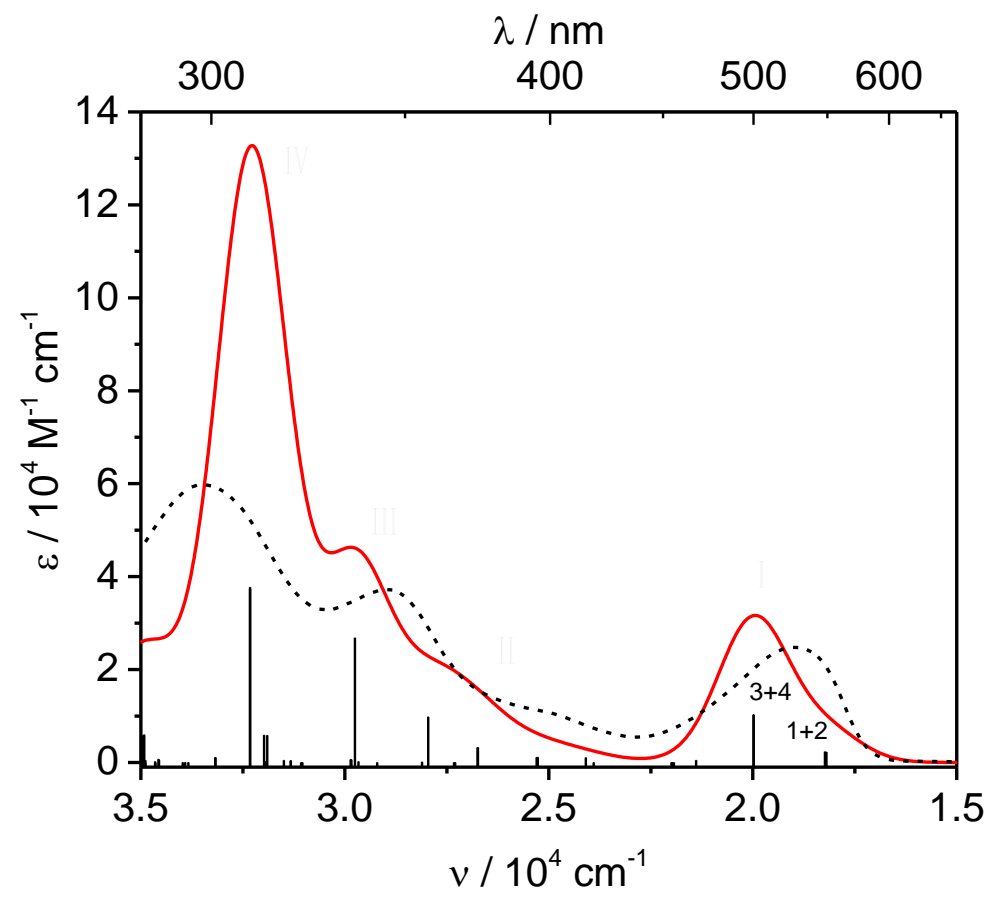

Figure 7. Electronic absorption spectrum of $\mathrm{Zr}\left({ }^{\mathrm{Me}} \mathrm{PDP}^{\mathrm{Ph}}\right)_{2}$ obtained via TD-DFT calculations (red line, fwhm of $2000 \mathrm{~cm}^{-1}$ ). The stick plot indicates the positions and relative intensities of individual transitions. The major contributions to each numbered state are listed in Table 1 . The experimental spectrum is shown as a dotted black line for comparison.

Table 1. Vertical electronic excitation energies and main excitations contributing to the absorption bands of $\mathrm{Zr}\left({ }^{\mathrm{Me}} \mathrm{PDP}^{\mathrm{Ph}}\right)_{2}$ obtained via TD-DFT calculations.

\begin{tabular}{|c|c|c|c|c|c|}
\hline Band & $\begin{array}{l}\text { TD-DFT } \\
\text { State }\end{array}$ & $\begin{array}{c}\text { Energy / } \mathrm{cm}^{-1} \\
(\lambda / \mathrm{nm})\end{array}$ & $\mathrm{f}_{\mathrm{osc}}$ & $\begin{array}{l}\text { Excitations } \\
\text { (weight) })^{\mathrm{a}, \mathrm{b}}\end{array}$ & $\begin{array}{l}\text { Character } \\
\text { (\%LMCT) }\end{array}$ \\
\hline \multirow{4}{*}{ I } & 1 & $\begin{array}{l}18,196 \\
(549.6)\end{array}$ & 0.031 & $223 \rightarrow 224(0.80)$ & $\begin{array}{c}{ }^{1} \mathrm{IL} /{ }^{1} \mathrm{LMCT} \\
(31 \%)\end{array}$ \\
\hline & 2 & $\begin{array}{l}18,230 \\
(548.5)\end{array}$ & 0.032 & $223 \rightarrow 225(0.79)$ & $\begin{array}{c}{ }^{1} \mathrm{IL} /{ }^{1} \mathrm{LMCT} \\
(31 \%)\end{array}$ \\
\hline & 3 & $\begin{array}{l}19,975 \\
(500.6)\end{array}$ & 0.140 & $\begin{array}{l}222 \rightarrow 224(0.71) \\
222 \rightarrow 225(0.15) \\
223 \rightarrow 225(0.10)\end{array}$ & $\begin{array}{c}{ }^{1} \mathrm{IL} /{ }^{1} \mathrm{LMCT} \\
(31 \%)\end{array}$ \\
\hline & 4 & $\begin{array}{l}19,982 \\
(500.4)\end{array}$ & 0.142 & $\begin{array}{l}222 \rightarrow 225(0.71) \\
222 \rightarrow 224(0.15) \\
223 \rightarrow 224(0.10)\end{array}$ & $\begin{array}{c}{ }^{1} \mathrm{IL} /{ }^{1} \mathrm{LMCT} \\
(31 \%)\end{array}$ \\
\hline
\end{tabular}

${ }^{\mathrm{a}}$ only excitations with a weight larger than 0.1 are shown. ${ }^{\mathrm{b}} \mathrm{HOMO} 223$, LUMO 224, 225 (degenerate). 
A qualitative $\mathrm{MO}$ diagram for the $\mathrm{S}_{0}$ state is shown in Figure 8 and allows to characterize the transitions according to the metal and ligand contributions of the donor and acceptor orbitals for each excitation. The lowest energy absorption band (I) observed in the electronic absorption spectrum of $\mathrm{Zr}\left({ }^{\mathrm{Me}} \mathrm{PDP}^{\mathrm{Ph}}\right)_{2}$ is comprised of four TD-DFT states that can formally be described as the result of electronic transitions from HOMO and HOMO-1 (orbitals 223 and 222, respectively) to a set of degenerate LUMOs (orbitals 224 and 225). Due to the $D_{2 d}$ symmetry of the molecule the four transitions can be grouped into two pairs of degenerate excitations with energies of approximately 18,200 $\mathrm{cm}^{-1}(549 \mathrm{~nm})$ and 19,980 $\mathrm{cm}^{-1}$ (500 nm). Minor deviations from perfect degeneracy are due to the absence of $D_{2 d}$ symmetry constraints during geometry optimization. Because the metal character of the LUMOs was calculated to be $31 \%$, these transitions can be classified as mixed ${ }^{1} \mathrm{IL} /{ }^{1} \mathrm{LMCT}$ transitions.

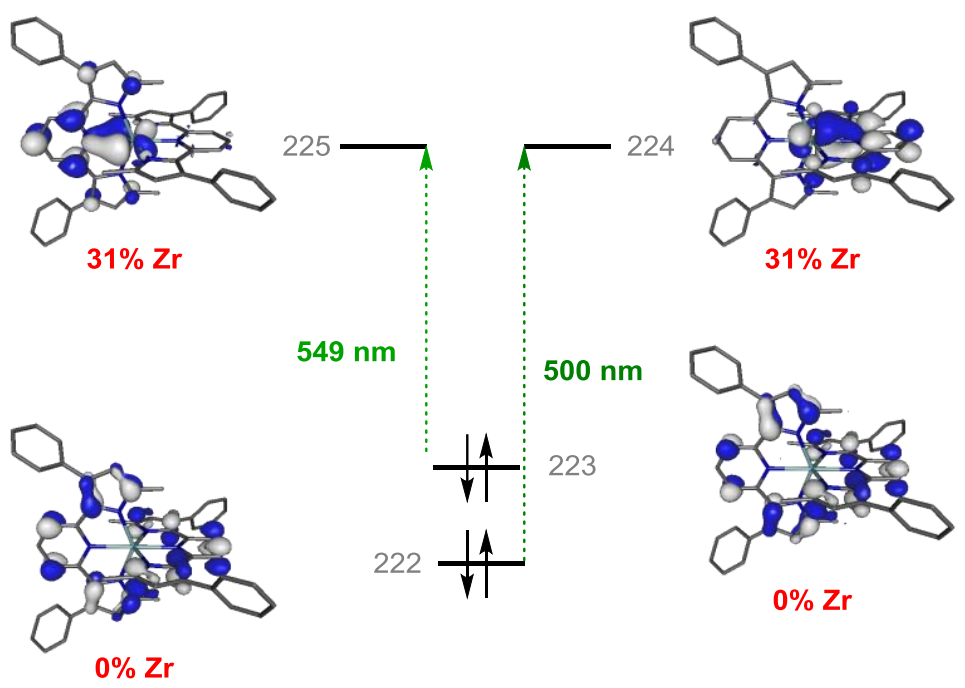

Figure 8. Qualitative MO diagram for $\mathrm{Zr}\left({ }^{\mathrm{Me}} \mathrm{PDP} \mathrm{Ph}_{2}\right)_{2}$ showing the donor and acceptor orbitals for TD-DFT excitations computed for visible absorption band. The gray numbers correspond to the MO number with 223 being the HOMO and 224 and 225 forming a degenerate set of LUMOs. The dotted arrows represent the single electron excitations with the highest weight for the main TD-DFT states of the absorption bands I shown in Figure 7 and Table 1. 
Because the long emission lifetime and quenching by triplet oxygen indicated emission from a triplet excited state, the energies of low-lying triplet states were investigated computationally. Consistent with the long luminescence lifetime, the lowest excited state of the complex is a triplet state composed of two degenerate TD-DFT excitations with a predicted energy of $16,080 \mathrm{~cm}^{-1}(622 \mathrm{~nm})$. This value agrees with the experimental emission maximum at $595 \mathrm{~nm}$. Three additional triplet excited states were predicted within the energy range of the photocatalytically relevant absorption band I.

The structure of the lowest energy triplet state, $T_{1}$, was optimized starting from the $\mathrm{S}_{0}$ geometry using spin-unrestricted DFT methods $(\mathrm{UKS} 3, \mathrm{~S}=1)$. Metal ligand bond distances of the $\mathrm{T}_{1}$ geometry are shown in Table 2 alongside the parameters for $\mathrm{S}_{0}$. Despite the $D_{2 d}$ symmetric starting geometry, the triplet state optimization converges to a lower symmetry structure belonging to the $C_{2 v}$ point group. Most significantly, the $\mathrm{Zr}-\mathrm{N}_{\text {pyridine }}$ bond distance of one of the ${ }^{\mathrm{Me}} \mathrm{PDP}^{\mathrm{Ph}}$ units is contracted by more than $0.08 \AA$ compared to the second ligand resulting in an axial compression along the $C_{2}$ axis of the molecule. This lowering of the molecular symmetry can be understood as a Jahn-Teller distortion. In a simple one-electron picture, excitation of an electron from the HOMO or HOMO-1 to one of the degenerate LUMOs (corresponding to $S_{1}$ and $S_{2}$ ) followed by intersystem crossing results in a $T_{1}$ state with a degenerate electron configuration that undergoes an axial compression lowering the overall energy of the system and reducing the symmetry of the molecule. At the same time, the axial distortion results in an electronic structure in which the spin 
density is localized on zirconium and one of the ${ }^{\mathrm{Me}} \mathrm{PDP}^{\mathrm{Ph}}$ ligands (Figure 9). The spin density of 0.32 on the zirconium center for $\mathrm{T}_{1}$ is consistent with a mixed ${ }^{3} \mathrm{IL} /{ }^{3} \mathrm{LMCT}$ state and mirrors the $31 \%{ }^{1} \mathrm{LMCT}$ character computed for the $\mathrm{S}_{0}$ and $\mathrm{S}_{1}$ states.

Table 2. $\mathrm{Zr}-\mathrm{N}$ bond length for the $\mathrm{S}_{0}$ and $\mathrm{T}_{1}$ geometries of $\mathrm{Zr}\left({ }^{\mathrm{Me}} \mathrm{PDP}^{\mathrm{Ph}}\right)_{2}$ obtained via DFT calculations.

\begin{tabular}{ccccc}
\hline & \multicolumn{2}{c}{ Singlet $(\mathrm{RKS})^{\mathrm{a}}$} & \multicolumn{2}{c}{${\text { Triplet }(\mathrm{UKS} 3)^{\mathrm{a}}}^{\mathrm{a}}$} \\
& Ligand 1 & Ligand 2 & Ligand 1 & Ligand 2 \\
\hline Zr-N(pyrrole1) & 2.195 & 2.195 & 2.221 & 2.234 \\
Zr-N(pyridine) & 2.335 & 2.335 & 2.320 & 2.237 \\
Zr-N(pyrrole2) & 2.194 & 2.194 & 2.225 & 2.237 \\
\hline
\end{tabular}

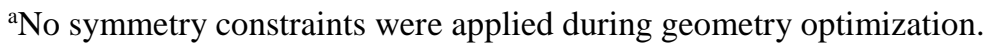

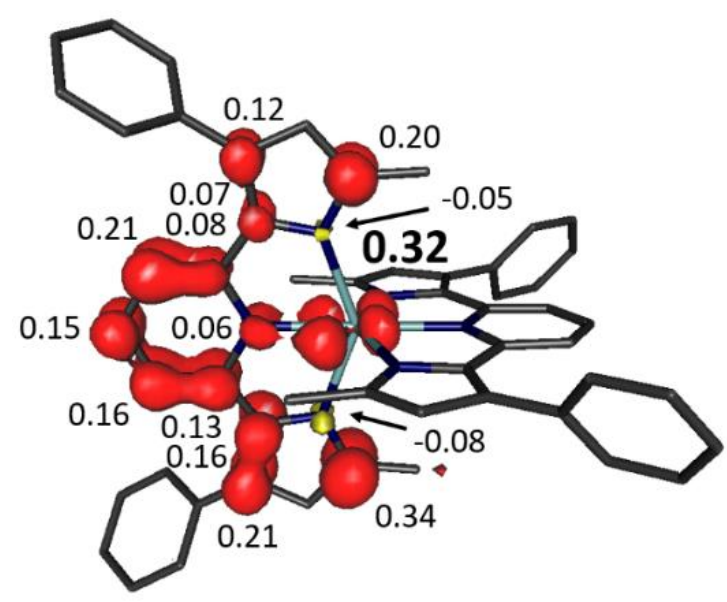

Figure 9. Spin density distribution for the lowest energy triplet state of $\mathrm{Zr}\left({ }^{\mathrm{Me}} \mathrm{PDP}^{\mathrm{Ph}}\right)_{2}$ obtained via Mulliken population analysis. Reprinted with permission from \{ Zhang, Y.; Lee, T. S.; Petersen, J. L.; and Milsmann, C.J. Am. Chem. Soc. 2018, 140, 5934-5947\}. Copyright $\{2018\}$ American Chemical Society. 
Based on our (TD-)DFT studies, we propose the following hypothesis for the generation of a long-lived triplet excited state in $\mathrm{Zr}\left({ }^{\mathrm{Me}} \mathrm{PDP}^{\mathrm{Ph}}\right)_{2}$ during photoredox catalytic turnover. Photoexcitation of the $\mathrm{S}_{0}$ state with visible light (green LED, $\lambda_{\max }=521 \mathrm{~nm}, \mathrm{FWHM}=36 \mathrm{~nm}$ ) generates ${ }^{1} \mathrm{IL} /{ }^{1} \mathrm{LMCT}$ excited states, $\mathrm{S}_{1}$ and $\mathrm{S}_{2}$, with $31 \%{ }^{1} \mathrm{LMCT}$ character. Under Franck-Condon conditions the initial excited state retains $D_{2 d}$ symmetry and the change in charge distribution is delocalized over both ${ }^{\mathrm{Me}} \mathrm{PDP}^{\mathrm{Ph}}$ ligands via the zirconium $\mathrm{d}_{\mathrm{xz}}$ and $\mathrm{d}_{\mathrm{yz}}$ orbitals. The degenerate nature of the $S_{1}$ and $S_{2}$ states allows for strong spin-orbit coupling mediated by the $\mathrm{Zr} \mathrm{d}_{\mathrm{xz}}$ and $\mathrm{d}_{\mathrm{yz}}$ contributions to the degenerate LUMOs and facilitates rapid intersystem crossing to the triplet manifold. Vibrational relaxation results in a localized $\mathrm{T}_{1}$ state with reduced $C_{2 v}$ symmetry. The lowered symmetry lifts the degeneracy of the $\mathrm{d}_{\mathrm{xz}}$ and $\mathrm{d}_{\mathrm{yz}}$ orbitals and reduces spin-orbit coupling resulting in the remarkably long lifetime observed experimentally.

\subsection{Electrochemical Properties.}

To investigate the potential for outer sphere electron transfer, cyclic voltammetry (CV) experiments were performed for $\mathrm{Zr}\left({ }^{\mathrm{Me}} \mathrm{PDP}^{\mathrm{Ph}}\right)_{2}$ in $\mathrm{THF}$ using ferrocene, $\mathrm{Fc}^{+/ 0}$, as an internal standard. Two irreversible oxidation events with a peak potential at $0.05 \mathrm{~V}$ and $0.38 \mathrm{~V}$ were observed. These features are readily assigned as oxidation of the ligand framework followed by rapid decomposition of the oxidized product as metal centered oxidation reactions can be excluded

for $\mathrm{Zr}^{\mathrm{IV}}$ complexes. More interestingly, $\mathrm{Zr}\left({ }^{\mathrm{Me}} \mathrm{PDP}^{\mathrm{Ph}}\right)_{2}$ undergo multiple reductions at very negative 
potentials, where three reversible redox events were observed at $-2.16 \mathrm{~V}$ and $-2.63 \mathrm{~V}$ with a quasireversible feature at $-3.22 \mathrm{~V}$ (Figure 10).

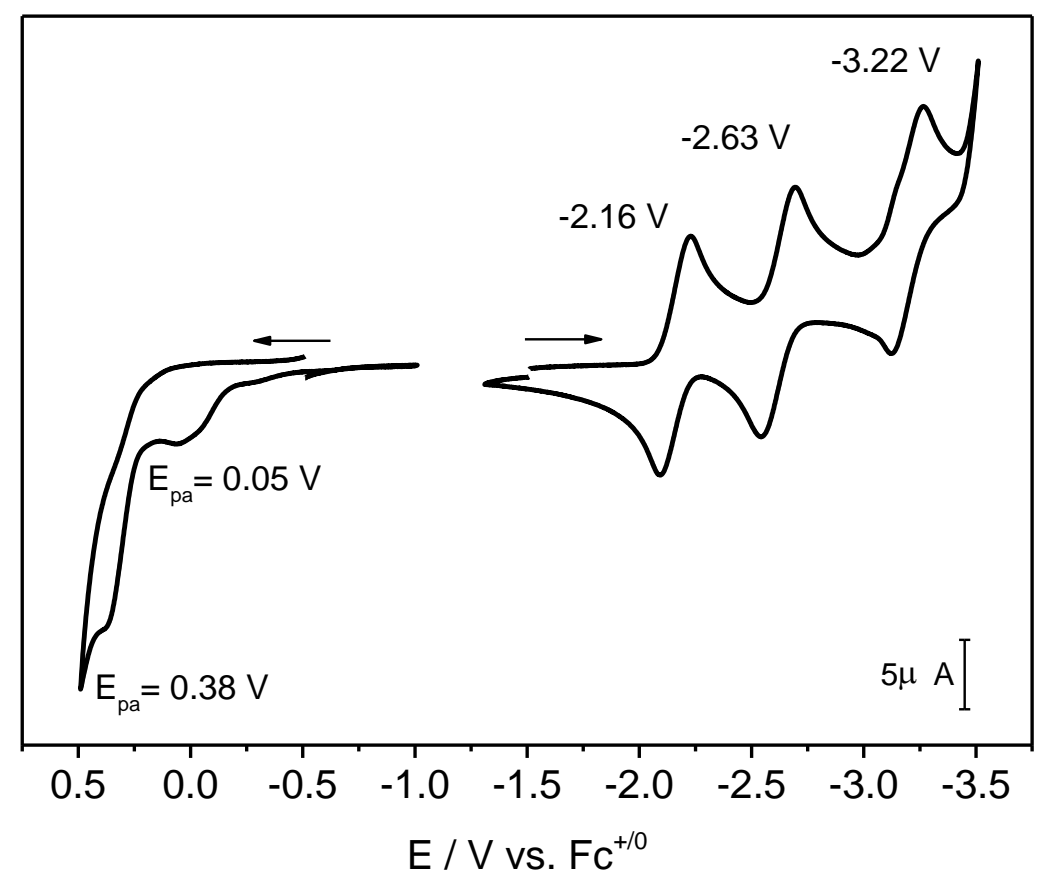

Figure 10. Cyclic voltammogram of $\mathrm{Zr}\left({ }^{\mathrm{Me}} \mathrm{PDP}^{\mathrm{Ph}}\right)_{2}$ in $\mathrm{THF}$ at room temperature (scan rate 200 $\mathrm{mV} / \mathrm{s}, 0.1 \mathrm{M}\left[\mathrm{N}(n-\mathrm{Bu})_{4}\right] \mathrm{PF}_{6}$, glassy carbon working electrode).

\subsection{Estimation of Excited State Potential and Stern-Volmer Analysis.}

Having established the electrochemical properties of the ground state and the emission profile, the excited state potential for the redox-couple $\mathrm{Zr}\left({ }^{\mathrm{Me}} \mathrm{PDP}^{\mathrm{Ph}}\right)_{2} * /\left[\mathrm{Zr}\left({ }^{\mathrm{Me}} \mathrm{PDP}^{\mathrm{Ph}}\right)_{2}\right]^{1-}$ was estimated as $-0.07 \mathrm{~V}$ vs. $\mathrm{Fc}^{+/ 0}$ using the Rehm-Weller formalism (Scheme 2). ${ }^{27}$ Based on this potential, 1,3-dimethyl-2-phenyl-2,3-dihydro-1H-7-methylbenzo-[d]imidazole, $\quad{ }^{\mathrm{Me}} \mathrm{BIH}, \quad$ was identified as a potential reductant for $\mathrm{Zr}\left({ }^{\mathrm{Me}} \mathrm{PDP}^{\mathrm{Ph}}\right)_{2}$. The redox potential for one-electron 
oxidation of ${ }^{\mathrm{Me}} \mathrm{BIH}$ is slightly more negative $\left(-0.16 \mathrm{~V}\right.$ vs. $\mathrm{Fc}^{+/ 0}$ in $\left.\mathrm{MeCN}\right)$ than the one reported for ${ }^{\mathrm{H}} \mathrm{BIH}\left(-0.10 \mathrm{~V}\right.$ vs. $\mathrm{Fc}^{+/ 0}$ in $\left.\mathrm{MeCN}\right),{ }^{28}$ which is frequently used as a terminal reductant in photoredox reductions of organic substrates ${ }^{29}$ and $\mathrm{CO}_{2} \cdot{ }^{30}$

Scheme 2. Estimation of the excited state potential for $\mathrm{Zr}\left({ }^{\mathrm{Me}} \mathrm{PDP}^{\mathrm{Ph}}\right)_{2}$ using Rehm-Weller formalism.

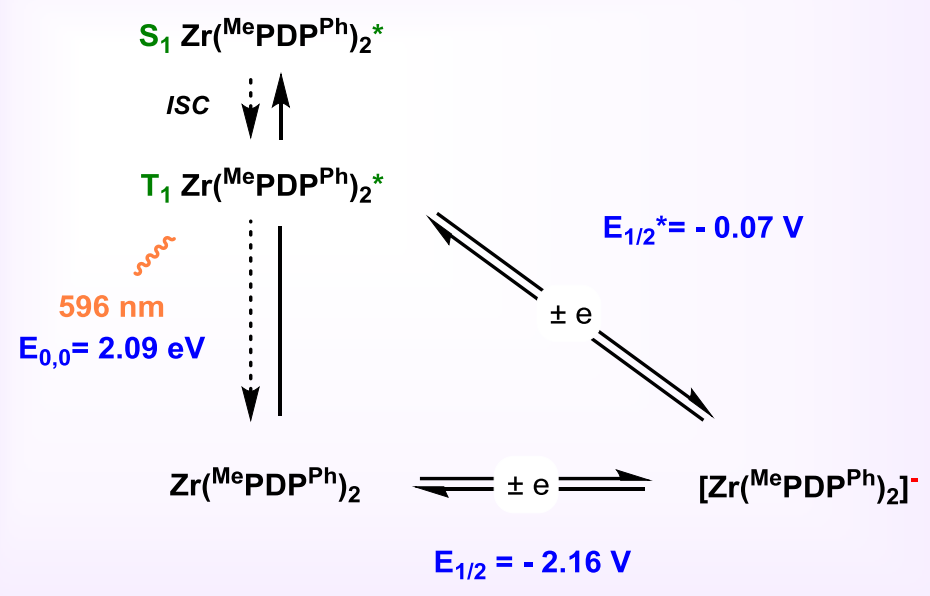

Addition of ${ }^{\mathrm{Me}} \mathrm{BIH}$ to $\mathrm{Zr}\left({ }^{\mathrm{Me}} \mathrm{PDP}^{\mathrm{Ph}}\right)_{2}$ in THF solution lead to a significant reduction of luminescence intensity indicating quenching of the excited state (Figure 11). To quantify the excited state quenching process, Stern-Volmer studies were conducted for ${ }^{\mathrm{Me}} \mathrm{BIH},{ }^{\mathrm{H}} \mathrm{BIH}$ and ${ }^{\mathrm{Cl}} \mathrm{BIH}$ with $\mathrm{Zr}\left({ }^{\mathrm{Me}} \mathrm{PDP}^{\mathrm{Ph}}\right)_{2}{ }^{*}$. The linear dependence of the luminescence intensities on the concentration of the quencher is indicative of diffusion controlled dynamic quenching processes without preassociation of $\mathrm{Zr}\left({ }^{\mathrm{Me}} \mathrm{PDP}^{\mathrm{Ph}}\right)_{2}$ and ${ }^{\mathrm{R}} \mathrm{BIH}$. The quenching rate of the excited state shown a clear 
correlation between quenching efficiency and redox potential (Table 3), which suggesting electron transfer instead of energy transfer processes.

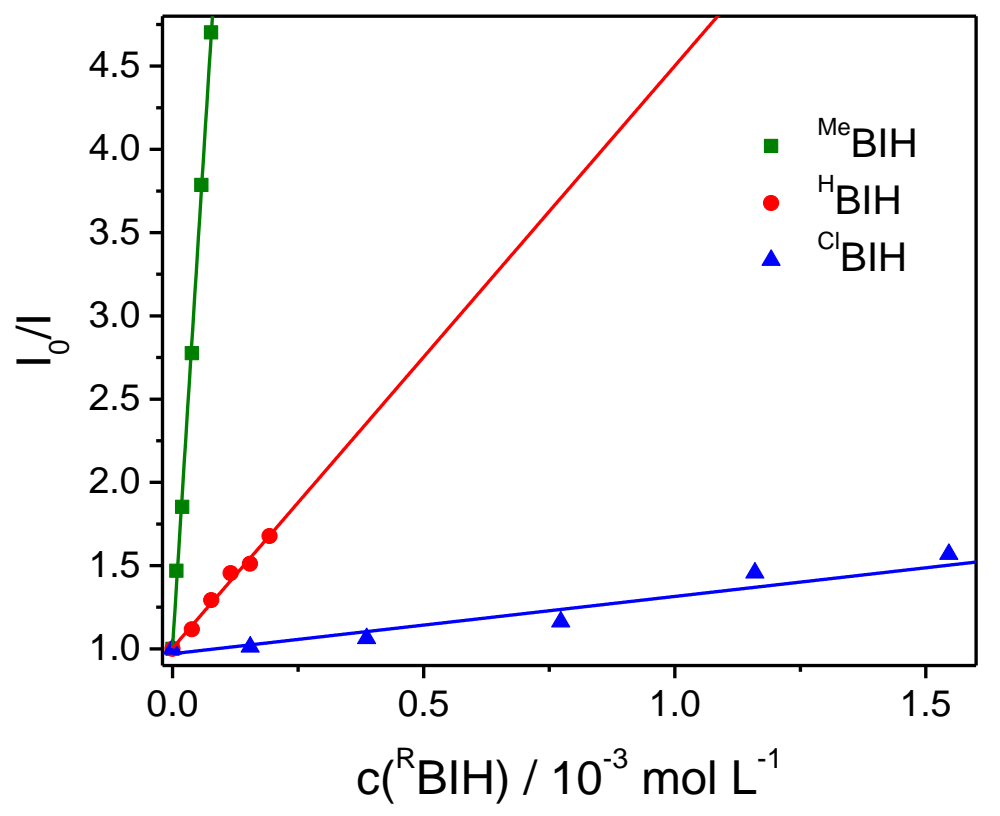

Figure 11. Stern-Volmer plots obtained via steady-state emission spectroscopy.

Table 3. Quenching parameters from Stern-Volmer analysis and redox potentials of ${ }^{\mathrm{R}} \mathrm{BIH}$.

\begin{tabular}{c|ccc}
\hline & $K_{\mathrm{Sv}} / \mathrm{L} \mathrm{mol}^{-1}$ & $k_{\mathrm{q}} / 10^{7} \mathrm{~L} \mathrm{~mol}^{-1} \mathrm{~s}^{-1}$ & $\mathrm{E}_{\text {ox }} / \mathrm{V}$ vs. $\mathrm{Fc}^{+/ 0}$ \\
\hline${ }^{\mathrm{Me}} \mathrm{BIH}$ & $47900 \pm 600$ & 14.74 & -0.16 \\
$\mathrm{BIH}$ & $3500 \pm 100$ & 1.08 & -0.10 \\
${ }^{\mathrm{Cl}} \mathrm{BIH}$ & $340 \pm 50$ & 0.10 & 0.00 \\
\hline
\end{tabular}

\subsection{Applications as Visible Light Photocatalyst.}

Encouraged by these results, the potential for photoredox catalysis using $\mathrm{Zr}\left({ }^{\mathrm{Me}} \mathrm{PDP}^{\mathrm{Ph}}\right)_{2}$ as the photosensitizer was explored (Scheme 3). As a first proof of concept, the dehalogenation of ethyl bromodifluoroacetate was attempted. Photocatalytic dehalogenation reactions with organic 
hydride sources such as 1-benzyl-1,4-dihydronicotinamide (BNAH) or Hantzsch esters were among the earliest examples of photoredox reactions using the reductive quenching cycles of $\left[\mathrm{Ru}(\mathrm{bpy})_{3}\right]^{2+}$ or $\operatorname{Ir}(\mathrm{ppy})_{3} \cdot{ }^{31,32}$ Irradiation of an equimolar mixture of ethyl bromodifluoroacetate and ${ }^{\mathrm{Me}} \mathrm{BIH}$ in benzene- $\mathrm{d}_{6}$ in the presence of catalytic amounts of $\mathrm{Zr}\left({ }^{\mathrm{Me}} \mathrm{PDP}^{\mathrm{Ph}}\right)_{2}$ with green LED light $\left(\lambda_{\max }=520 \mathrm{~nm}\right)$ resulted in clean conversion to ethyl difluoroacetate and precipitation of ${ }^{\mathrm{Me}} \mathrm{BIBr}$ within $2.5 \mathrm{~h}$. No reaction was observed in the absence of either light or $\mathrm{Zr}\left({ }^{\mathrm{Me}} \mathrm{PDP}^{\mathrm{Ph}}\right)_{2}$ (Table 4).

Table 4. Conditions and control experiments for the debromination of ethyl bromodifluoroacetate using photoredox catalysis.

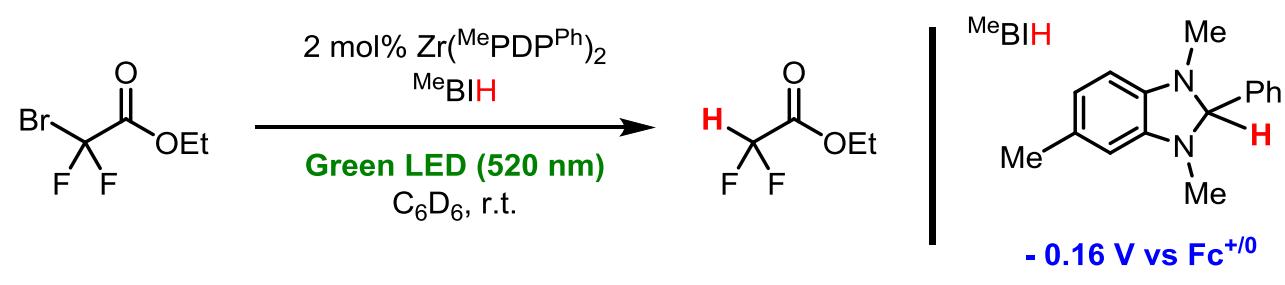

\begin{tabular}{|c|c|c|c|c|}
\hline Entry & Light & $\mathrm{Zr}\left({ }^{\mathrm{Me}} \mathrm{PDP}{ }^{\mathrm{Ph}}\right)_{2}$ & Time (h) & Yield $\%{ }^{a}$ \\
\hline 1 & Yes & Yes & 2.5 & 98 \\
\hline 2 & No & Yes & 12 & 0 \\
\hline 3 & Yes & No & 12 & trace \\
\hline
\end{tabular}

A second reductive transformation that has been well-established for precious metal photosensitizers in combination with $\mathrm{BNAH}$ is the reduction of electron-deficient olefins. ${ }^{33}$ Employing the $\mathrm{Zr}\left({ }^{\mathrm{Me}} \mathrm{PDP}^{\mathrm{Ph}}\right)_{2} /{ }^{\mathrm{Me}} \mathrm{BIH}$ system described herein, the reduction of diethyl maleate to diethyl succinate proceeded readily upon irradiation with green light for $8 \mathrm{~h}$ followed by aqueous 
work up. Again, no reduction was observed in the absence of zirconium catalyst or in the dark (Table 5).

Table 5. Optimization of reaction conditions and control experiments for the reduction of diethyl maleate using photoredox catalysis.

\begin{tabular}{|c|c|c|c|c|c|}
\hline \multirow{2}{*}{$\int_{\mathrm{CO}_{2} \mathrm{Bn}}^{\mathrm{CO}_{2} \mathrm{Bn}}$} & \multirow{2}{*}{\multicolumn{2}{|c|}{$\begin{array}{c}5 \mathrm{~mol} \% \mathrm{Zr}\left({ }^{\mathrm{Me} P D P P h}\right)_{2} \\
\mathrm{Me}_{\mathrm{BIH}} \\
\text { Green LED }(520 \mathrm{~nm}) \\
\mathrm{C}_{6} \mathrm{D}_{6} \text {, r.t. } \\
\text { Then, } \mathrm{H}_{2} \mathrm{O}\end{array}$}} & \multirow{2}{*}{\multicolumn{3}{|c|}{${ }_{-0.16 \mathrm{~V} \text { vs } \mathrm{B}}^{\mathrm{Me}}$}} \\
\hline & & & & & \\
\hline Entry & Light & $\mathrm{Zr}\left({ }^{\mathrm{Me}} \mathrm{PDP}^{\mathrm{Ph}}\right)_{2}$ & ${ }^{\mathrm{Me}} \mathrm{BIH}$ (equiv) & Time (h) & Yield $^{\mathrm{a}}$ \\
\hline 1 & Yes & No & 1.0 & 12 & $0 \%$ \\
\hline 2 & No & Yes & 1.0 & 24 & $0 \%$ \\
\hline 3 & Yes & Yes & 1.0 & 8 & $60 \%$ \\
\hline 4 & Yes & Yes & 0.5 & 8 & $22 \%$ \\
\hline 5 & Yes & Yes & 1.5 & 8 & $84 \%$ \\
\hline 6 & Yes & Yes & 2.0 & 8 & $96 \%$ \\
\hline
\end{tabular}

While the two reactions described above clearly establish the photosensitizer properties of $\mathrm{Zr}\left({ }^{\mathrm{Me}} \mathrm{PDP}{ }^{\mathrm{Ph}}\right)_{2}$, excitation energy transfer to ${ }^{\mathrm{Me}} \mathrm{BIH}$ followed by hydride transfer cannot be ruled out as a mechanistic alternative to the desired single-electron transfer pathway. Therefore, the reductive coupling of benzyl bromide to bibenzyl was investigated as an example for a reduction without net hydride transfer. ${ }^{34-36}$ Initial experiments with $\mathrm{Zr}\left({ }^{\mathrm{Me}} \mathrm{PDP}^{\mathrm{Ph}}\right)_{2} /{ }^{\mathrm{Me}} \mathrm{BIH}$ and benzyl bromide in benzene- $d_{6}$ resulted in poor conversion and decomposition of the zirconium catalyst. However, small amounts of bibenzyl were detected by ${ }^{1} \mathrm{H}$ NMR spectroscopy. The potential formation of $\mathrm{HBr}$ during turnover was identified as a likely reason for the observed catalyst decomposition via 
protonation of the pyrrolide arms of the ligand. In agreement with this hypothesis, addition of pyridine or 2,6-lutidine resulted in full conversion of benzyl bromide and an increased yield of the desired bibenzyl product (40\%) (Table 6). The presence of benzylic C-H bonds in ${ }^{\mathrm{Me}} \mathrm{BIH}$ could result in the formation of unintended by-products. To examine this, we utilized alternative quenchers $\left({ }^{\mathrm{H}} \mathrm{BIH}\right.$ and $\left.{ }^{\mathrm{Cl}} \mathrm{BIH}\right)$ that lack benzylic protons. While the number of by-products was decreased, slow conversion was observed. This can be attributed to the less favorable potentials of ${ }^{\mathrm{H}} \mathrm{BIH}$ and ${ }^{\mathrm{Cl}} \mathrm{BIH}$ for reduction of $\mathrm{Zr}\left({ }^{\mathrm{Me}} \mathrm{PDP}^{\mathrm{Ph}}\right){ }_{2} *{ }^{28}$ which is supported by quenching data.

Table 6. Optimization of reaction conditions and control experiments for the reductive coupling of benzyl bromide via photoredox catalysis.

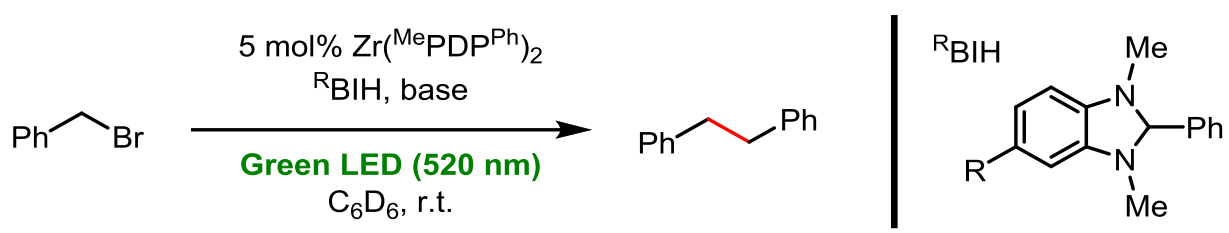

\begin{tabular}{|c|c|c|c|c|c|c|}
\hline Entry & Light & $\mathrm{Zr}\left({ }^{\mathrm{Me}} \mathrm{PDP} \mathrm{Ph}_{2}\right)_{2}$ & $\begin{array}{c}\text { Reductant } \\
\text { (equiv) }\end{array}$ & $\begin{array}{l}\text { Base }^{\mathrm{b}} \\
\text { (equiv) }\end{array}$ & $\begin{array}{l}\text { Time } \\
\text { (h) }\end{array}$ & $\begin{array}{r}\text { Yield \%a } \\
(\text { Conv. \%) }\end{array}$ \\
\hline 1 & Yes & Yes & ${ }^{\mathrm{Me}} \mathrm{BIH}(1.0)$ & No & 16 & $6(47)$ \\
\hline 2 & Yes & No & ${ }^{\mathrm{Me}} \mathrm{BIH}$ (1.0) & No & 16 & N.R. \\
\hline 3 & Yes & Yes & ${ }^{\mathrm{Me}} \mathrm{BIH}$ (1.0) & Py (1.0) & 16 & $15(100)$ \\
\hline 4 & No & Yes & ${ }^{\mathrm{Me}} \mathrm{BIH}$ (1.0) & Py (1.0) & 72 & N.R. \\
\hline 5 & Yes & No & ${ }^{\mathrm{Me}} \mathrm{BIH}(1.0)$ & Py (1.0) & 24 & N.R. \\
\hline 6 & Yes & Yes & ${ }^{\mathrm{Me}} \mathrm{BIH}(0.5)$ & Py (1.0) & 24 & $16(76)$ \\
\hline 7 & Yes & Yes & BIH (1.0) & Py (2.0) & 48 & $35(63)$ \\
\hline 8 & Yes & Yes & ${ }^{\mathrm{Me}} \mathrm{BIH}(0.7)$ & $\mathrm{Lu}(2.0)$ & 24 & 30(99) \\
\hline 9 & Yes & Yes & $\mathrm{BIH}(0.7)$ & $\mathrm{Lu}(2.0)$ & 48 & $20(21)$ \\
\hline 10 & Yes & Yes & ${ }^{\mathrm{Cl}} \mathrm{BIH}(0.7)$ & $\mathrm{Lu}(2.0)$ & 108 & $29(31)$ \\
\hline $11^{\mathrm{c}}$ & Yes & Yes & $\mathrm{BIH}(0.7)$ & $\mathrm{Lu}(2.0)$ & 45 & 40 \\
\hline
\end{tabular}




\subsection{Summary.}

We have developed a photoluminescent zirconium complex supported by 2,6bis(pyrrolyl)pyridine ligands that acts as an earth-abundant metal substitute for precious metal photosensitizers in reductive photoredox catalysis using visible light. The excited state of $\mathrm{Zr}\left({ }^{\mathrm{Me}} \mathrm{PDP}{ }^{\mathrm{Ph}}\right)_{2}$ exhibits a remarkably long lifetime of $325 \mu \mathrm{s}$ that is consistent with spin-forbidden $\mathrm{T}_{1} \rightarrow \mathrm{S}_{0}$ transition. This value is among the longest lifetimes reported for transition metal complexes and exceeds the values found in traditional MLCT photosensitizers. Based on our computational analysis of the absorption spectrum of $\mathrm{Zr}\left({ }^{\mathrm{Me}} \mathrm{PDP}{ }^{\mathrm{Ph}}\right)_{2}$ using TD-DFT and elucidation of the electronic structure of the lowest energy triplet state of $\mathrm{Zr}\left({ }^{\mathrm{Me}} \mathrm{PDP}{ }^{\mathrm{Ph}}\right)_{2}$ by DFT, we propose that the emissive state is best described as a mixed ${ }^{3} \mathrm{IL} /{ }^{3} \mathrm{LMCT}$ state with $31 \% \mathrm{LMCT}$ character due to high covalency between zirconium and the pyridine moieties of the ligand.

\subsection{Experimental Section.}

General experimental considerations for material handling, physical measurements, X-ray crystallography, and DFT Calculations as well as additional experimental information (i.e. NMR spectra, quenching experiments) can be found in the appendices.

Starting Materials. 4-phenyl-3-buten-2-one, 3-benzyl-5-(2-hydroxyethyl)-4-methylthiazolium chloride, sodium tert-butoxide, 1.6 M n-butyllithium solution in hexanes, 1,3,5trimethoxybenzene, diethyl maleate, ethyl bromodifluoroacetate and iodine were purchased from 
commercial source. 2,6-Pyridinedicarboxaldehyde, ${ }^{37}{ }^{\mathrm{Me}} \mathrm{BIH},{ }^{\mathrm{H}} \mathrm{BIH}$ and ${ }^{\mathrm{Cl}} \mathrm{BIH}^{28}$ were prepared following literature procedures.

Preparation of 2,6-bis(5-methyl-3-phenyl-1H-pyrrol-2-yl)pyridine $\quad\left(\mathrm{H}_{2}{ }^{\mathrm{Me}} \mathrm{PDP}^{\mathrm{Ph}}\right)$ : The synthesis was carried out according to a modified literature procedure. ${ }^{1,2,38}$ 2,6Pyridinedicarboxaldehyde (3.50 g, $25.90 \mathrm{mmol}, 1.00$ equiv), 4-phenyl-3-buten-2-one (7.65 g, $52.32 \mathrm{mmol}, 2.02$ equiv), and 3-benzyl-5-(2-hydroxyethyl)-4-methyl-thiazolium chloride (4.19 g, $15.54 \mathrm{mmol}, 0.6$ equiv), were mixed in a $250 \mathrm{~mL}$ Schlenk flask under an argon atmosphere. Absolute ethanol was added, and the mixture was heated to reflux. A solution of sodium tertbutoxide (1.49 g, $15.54 \mathrm{mmol}, 0.6$ equiv) in ethanol was added via syringe and heating was continued for 24 hours. The reaction was cooled to room temperature and ammonium acetate (11.98 g, $155.42 \mathrm{mmol}, 6$ equiv) was added to the mixture. The reaction mixture was heated to reflux open to air for 24 hours. The solid precipitate was collected via filtration, washed with ethanol, and dried under high vacuum to yield the desired product as a pale yellow solid (Yield: $3.14 \mathrm{~g}, 31 \%$, one crop). X-ray quality crystals of $\mathrm{H}_{2}{ }^{\mathrm{Me}} \mathrm{PDP}^{\mathrm{Ph}}$ were grown from DCM and hexane solution cooled to $4{ }^{\circ} \mathrm{C}$. M.p. $210-212{ }^{\circ} \mathrm{C} .{ }^{1} \mathrm{H}$ NMR (600 MHz, $\mathrm{C}_{6} \mathrm{D}_{6} ; \delta$, ppm): 9.59 (s, 2H, NH), $7.43(\mathrm{~d}, J=7.8 \mathrm{~Hz}, 4 \mathrm{H}, \mathrm{Ph} H), 7.37$ (t, $J=7.8 \mathrm{~Hz}, 4 \mathrm{H}, \mathrm{Ph} H), 7.29(\mathrm{tt}, J=7.8,1.8 \mathrm{~Hz}, 2 \mathrm{H}, \mathrm{Ph} H)$, $7.14(\mathrm{t}, J=8.4 \mathrm{~Hz}, 1 \mathrm{H}, \mathrm{Py} H), 6.94(\mathrm{~d}, J=8.4 \mathrm{~Hz}, 2 \mathrm{H}, \mathrm{Py} H), 5.98(\mathrm{~d}, J=3.0 \mathrm{~Hz}, 2 \mathrm{H}$, Pyrrole $H$ ), $2.20\left(\mathrm{~s}, 6 \mathrm{H}, \mathrm{CH}_{3}\right) .{ }^{13} \mathrm{C} \mathrm{NMR}\left(151 \mathrm{MHz}, \mathrm{C}_{6} \mathrm{D}_{6} ; \delta, \mathrm{ppm}\right): 150.51,137.69,136.58,129.62,129.40$, 
128.56, 126.59, 125.99, 125.29, 116.54, 111.03, 12.88. HRMS (ESI) calcd for $\mathrm{C}_{27} \mathrm{H}_{24} \mathrm{~N}_{3}{ }^{+}[\mathrm{M}+\mathrm{H}]^{+}$ m/z 390.19647; Found 390.19704.

Preparation of $\mathbf{Z r}\left({ }^{\mathrm{Me}} \mathbf{P D P}{ }^{\mathrm{Ph}}\right)_{2}: \mathrm{n}$-BuLi (0.972 mL (1.6 M solution in hexanes), $1.56 \mathrm{mmol}, 2.02$ equiv) was added slowly to a $20 \mathrm{~mL}$ vial charged with a solution of $\mathrm{H}_{2}{ }^{\mathrm{Me}} \mathrm{PDP}^{\mathrm{Ph}}(300 \mathrm{mg}, 0.770$ mmol, 1.00 equiv) in $5 \mathrm{~mL}$ of THF. The reaction was stirred for 2 hours at room temperature to generate a luminescent dark green-yellow solution of the deprotonated ligand. A solution of $\mathrm{ZrCl}_{4}$ (99 mg, $0.424 \mathrm{mmol}, 0.55$ equiv) in $3 \mathrm{~mL}$ of THF was added in small portions to the deprotonated ligand over 1 hour. The reaction mixture was allowed to stir at room temperature and the color of the solution slowly changed to fluorescent red. After 2 days, THF was removed in vacuo. The solid residue was washed three times with benzene to remove any unreacted $\mathrm{Li}_{2}{ }^{\mathrm{Me}} \mathrm{PDP}^{\mathrm{Ph}}$ and potential mono-ligated zirconium species. The crude product was redissolved in THF and filtered. Addition of (TMS) $)_{2} \mathrm{O}$ gave the desired product as a red microcrystalline material (Yield: $232 \mathrm{mg}, 69 \%$ ). Anal. Calcd for $\mathrm{C}_{54} \mathrm{H}_{42} \mathrm{~N}_{6} \mathrm{Zr} \cdot{ }^{1 / 2}{ }_{2}$ (TMS) $)_{2} \mathrm{O}: \mathrm{C}, 72.26 ; \mathrm{H}, 5.43 ; \mathrm{N}, 8.87$. Found: $\mathrm{C}, 71.91 ; \mathrm{H}, 5.61 ; \mathrm{N}$, 8.51. ${ }^{1} \mathrm{H}$ NMR (600 MHz, $\left.\mathrm{C}_{6} \mathrm{D}_{6} ; \delta, \mathrm{ppm}\right): 7.45$ - $7.43(\mathrm{~m}, 8 \mathrm{H}, \mathrm{Ph} H), 7.41-7.38(\mathrm{~m}, 8 \mathrm{H}, \mathrm{Ph} H)$, $7.32(\mathrm{tt}, J=7.8,1.8 \mathrm{~Hz}, 4 \mathrm{H}, \mathrm{Ph} H), 7.15(\mathrm{t}, J=8.4 \mathrm{~Hz}, 2 \mathrm{H}, \mathrm{Py} H), 6.81(\mathrm{~d}, J=8.4 \mathrm{~Hz}, 4 \mathrm{H}, \mathrm{Py} H)$, $5.79(\mathrm{~d}, J=0.6 \mathrm{~Hz}, 4 \mathrm{H}$, Pyrrole $H), 2.06\left(\mathrm{~s}, 12 \mathrm{H}, \mathrm{CH}_{3}\right) .{ }^{13} \mathrm{C} \mathrm{NMR}\left(151 \mathrm{MHz}, \mathrm{C}_{6} \mathrm{D}_{6} ; \delta, \mathrm{ppm}\right): 154.68$, $141.77,140.81,136.89,134.85,130.26,129.37,128.57,127.07,113.22,111.89,14.58$. An alternative way of purification could also be employed: After washing with benzene, the crude product was dried in vacuo, redissolved in DCM, and filtered to remove $\mathrm{LiCl}$ and potentially 
unreacted $\mathrm{ZrCl}_{4}$. Removal of the solvent in vacuo provided a red microcrystalline solid (Yield: $263 \mathrm{mg}, 73 \%$, based on $325 \mathrm{mg}$ ligand scale). The compound was pure based on NMR analysis. Single crystals suitable for X-ray crystallographic analysis were grown by slow diffusion of pentane into a saturated solution of $\mathrm{Zr}\left({ }^{\mathrm{Me}} \mathrm{PDP}^{\mathrm{Ph}}\right)_{2}$ in $\mathrm{DCM}$ at $-35^{\circ} \mathrm{C}$.

Photoredox-Catalyzed Debromination of Ethyl Bromodifluoroacetate. In the drybox, a J. Young NMR tube was charged with $\mathrm{Zr}\left({ }^{\mathrm{Me}} \mathrm{PDP}^{\mathrm{Ph}}\right)_{2}\left(1 \mathrm{mg}, 0.001 \mathrm{mmol}, 0.02\right.$ equiv), ${ }^{\mathrm{Me}} \mathrm{BIH}(14 \mathrm{mg}$, $0.059 \mathrm{mmol}, 1.00$ equiv), and ethyl bromodifluoroacetate (12 $\mathrm{mg}, 0.059 \mathrm{mmol}, 1.00$ equiv). 0.6 $\mathrm{mL}$ of $\mathrm{C}_{6} \mathrm{D}_{6}$ was added. 1,3,5-trimethoxybenzene was added as an internal standard. The mixture was placed in a jacketed glass beaker with water cooling and irradiated with green LED light $\left(\lambda_{\max }\right.$ $=520 \mathrm{~nm}$ ). The reaction was complete (as judged by NMR analysis) after 2.5 hours. The products were analyzed by NMR spectroscopy and the yields are based on internal standard.

Reduction of Diethyl Maleate using Photoredox Catalysis. In the drybox, a J. Young NMR tube was charged with $\mathrm{Zr}\left({ }^{\mathrm{Me}} \mathrm{PDP}^{\mathrm{Ph}}\right)_{2}\left(1 \mathrm{mg}, 0.001 \mathrm{mmol}, 0.02\right.$ equiv), ${ }^{\mathrm{Me}} \mathrm{BIH}$ (see Table 5 for amounts), and diethyl maleate ( $4.1 \mathrm{mg}, 0.024 \mathrm{mmol}, 1.00$ equiv). $0.6 \mathrm{~mL}$ of $\mathrm{C}_{6} \mathrm{D}_{6}$ was added. The mixture was placed in a water cooled glass vessel and irradiated with green LED light $\left(\lambda_{\max }=520 \mathrm{~nm}\right)$. Complete conversion of diethyl maleate was observed after 8 hours. The tube was opened to air and $\mathrm{H}_{2} \mathrm{O}(10 \mu \mathrm{L})$ was added to the reaction mixture. The biphasic system was shaken vigorously to ensure complete mixing of the organic and aqueous phases. A small amount of magnesium sulfate was added to absorb excess of water. 1,3,5-trimethoxybenzene was added as an internal 
standard. The products were analyzed by ${ }^{1} \mathrm{H}$ NMR spectroscopy and the yields are based on internal standard. The ${ }^{1} \mathrm{H}$ NMR spectroscopic data of diethyl maleate, diethyl fumarate, and diethyl succinate in $\mathrm{C}_{6} \mathrm{D}_{6}$ and $\mathrm{CDCl}_{3}$ were established from commercially available pure materials.

Reductive Coupling of Benzyl Bromide using Photoredox Catalysis. In the drybox, a J. Young NMR tube was charged with $\mathrm{Zr}\left({ }^{\mathrm{Me}} \mathrm{PDP}^{\mathrm{Ph}}\right)_{2}(1 \mathrm{mg}, 0.001 \mathrm{mmol}, 0.03$ equiv $)$, sacrificial reductant, base and benzyl bromide ( $6.1 \mathrm{mg}, 0.036 \mathrm{mmol}, 1.00$ equiv). $0.6 \mathrm{~mL}$ of $\mathrm{C}_{6} \mathrm{D}_{6}$ was added. The mixture was placed in a jacketed glass beaker with water cooling and irradiated with green LED light $\left(\lambda_{\max }=520 \mathrm{~nm}\right)$. After reaction was complete (as judged by NMR analysis), the products were analyzed by NMR spectroscopy and the yields are based on internal standard. Bibenzyl isolated for characterization was obtained via preparative TLC. ${ }^{1} \mathrm{H}$ NMR $\left(600 \mathrm{MHz}, \mathrm{CDCl}_{3} ; \delta\right.$, ppm): 7.30 - $7.27(\mathrm{~m}, 4 \mathrm{H}, \mathrm{Ph} H), 7.22-7.17(\mathrm{~m}, 6 \mathrm{H}, \mathrm{Ph} H), 2.93\left(\mathrm{~s}, 4 \mathrm{H}, \mathrm{CH}_{2} \mathrm{CH}_{2}\right) .{ }^{13} \mathrm{C}$ NMR $(151$ $\left.\mathrm{MHz}, \mathrm{CDCl}_{3} ; \delta, \mathrm{ppm}\right): 141.93,128.59,128.47,126.05,38.10$. The ${ }^{1} \mathrm{H}$ NMR spectroscopic data of isolated bibenzyl in $\mathrm{C}_{6} \mathrm{D}_{6}$ and $\mathrm{CDCl}_{3}$ matched with commercially available pure material.

\subsection{Reference.}

(1) Alan Jones, R.; Karatza, M.; Voro, T. N.; Civeir, P. U.; Franck, A.; Ozturk, O.; Seaman, J. P.; Whitmore, A. P.; Williamson, D. J. Tetrahedron 1996, 52, 8707.

(2) Jones, R. A.; Civcir, P. U. Tetrahedron 1997, 53, 11529.

(3) Gowda, A. S.; Petersen, J. L.; Milsmann, C. Inorg. Chem. 2018, 57, 1919. 
(4) Searles, K.; Fortier, S.; Khusniyarov, M. M.; Carroll, P. J.; Sutter, J.; Meyer, K.; Mindiola, D. J.; Caulton, K. G. Angew. Chem. Int. Ed. 2014, 53, 14139.

(5) McPherson, J. N.; Das, B.; Colbran, S. B. Coord. Chem. Rev. 2018, 375, 285.

(6) Hakey, B. M.; Darmon, J. M.; Zhang, Y.; Petersen, J. L.; Milsmann, C. Inorg. Chem. 2019, 58, 1252 .

(7) Komine, N.; Buell, R. W.; Chen, C.-H.; Hui, A. K.; Pink, M.; Caulton, K. G. Inorg. Chem. 2014, 53, 1361 .

(8) Yadav, S.; Singh, A.; Rashid, N.; Ghotia, M.; Roy, T. K.; Ingole, P. P.; Ray, S.; Mobin, S. M.; Dash, C. ChemistrySelect 2018, 3, 9469.

(9) Brouwer, A. M. Pure Appl. Chem. 2011, 83, 2213.

(10) Durham, B.; Caspar, J. V.; Nagle, J. K.; Meyer, T. J. J. Am. Chem. Soc. 1982, 104, 4803.

(11) Serpone, N.; Jamieson, M. A.; Henry, M. S.; Hoffman, M. Z.; Bolletta, F.; Maestri, M. J. Am. Chem. Soc. 1979, 101, 2907.

(12) Aoki, K.; Goshima, T.; Kozuka, Y.; Kawamori, Y.; Ono, N.; Hisaeda, Y.; Takagi, H. D.; Inamo, M. Dalton Trans. 2009, 119.

(13) Darwent, J. R.; Douglas, P.; Harriman, A.; Porter, G.; Richoux, M.-C. Coord. Chem. Rev. 1982, 44, 8545 .

(14) Sacksteder, L.; Zipp, A. P.; Brown, E. A.; Demas, J. N.; Streich, J.; DeGraff, B. A. Inorg. 
Chem. 1990, 29, 4335.

(15) King, K. A.; Spellane, P. J.; Watts, R. J. J. Am. Chem. Soc. 1985, 107, 1431.

(16) Caspar, J. V.; Meyer, T. J. J. Am. Chem. Soc. 1983, 105, 5583.

(17) Kozhevnikov, D. N.; Kozhevnikov, V. N.; Shafikov, M. N.; Prokhorov, A. M.; Bruce, D. W.; Gareth Williams, J. A. Inorg. Chem. 2011, 50, 3804.

(18) Vezzu, D. A. K.; Ravindranathan, D.; Garner, A. W.; Bartolotti, L.; Smith, M. E.; Boyle, P. D.; Huo, S. Inorg. Chem. 2011, 50, 8261.

(19) H. Yersin, E. Highly Efficient OLEDs: Materials Based on Thermally Activated Delayed Fluorescence; Wiley-VCH Publishers, 2019.

(20) Penfold, T. J.; Dias, F. B.; Monkman, A. P. Chem. Commun. 2018, 54, 3926.

(21) Di, D.; Romanov, A. S.; Yang, L.; Richter, J. M.; Rivett, J. P. H.; Jones, S.; Thomas, T. H.; Abdi Jalebi, M.; Friend, R. H.; Linnolahti, M.; Bochmann, M.; Credgington, D. Science 2017, 356, 159 .

(22) Goushi, K.; Yoshida, K.; Sato, K.; Adachi, C. Nat. Photonics 2012, 6, 253.

(23) Uoyama, H.; Goushi, K.; Shizu, K.; Nomura, H.; Adachi, C. Nature 2012, 492, 234.

(24) Hamze, R.; Peltier, J. L.; Sylvinson, D.; Jung, M.; Cardenas, J.; Haiges, R.; Soleilhavoup, M.; Jazzar, R.; Djurovich, P. I.; Bertrand, G.; Thompson, M. E. Science 2019, 363, 601.

(25) Leitl, M. J.; Krylova, V. A.; Djurovich, P. I.; Thompson, M. E.; Yersin, H. J. Am. Chem. Soc. 
2014, 136, 16032.

(26) Damrauer, N. H.; Cerullo, G. A.; Yeh, T. R.; Boussie, C. V. S.; J. K. McCusker. Science. $1997,275,54$.

(27) Rehm, D.; Weller, A. Isr. J. Chem. 1970, 8, 259.

(28) Zhu, X.-Q.; Zhang, M.-T.; Yu, A.; Wang, C.-H.; Cheng, J.-P. J. Am. Chem. Soc. 2008, 130, 2501.

(29) Hasegawa, E.; Yoneoka, A.; Suzuki, K.; Kato, T.; Kitazume, T.; Yanagi, K. Tetrahedron 1999, 55, 12957.

(30) Takeda, H.; Ohashi, K.; Sekine, A.; Ishitani, O. J. Am. Chem. Soc. 2016, 138, 4354.

(31) Fukuzumi, S.; Mochizuki, S.; Tanaka, T. J. Phys. Chem. 1990, 94, 722.

(32) Nguyen, J. D.; D’Amato, E. M.; Narayanam, J. M. R.; Stephenson, C. R. J. Nat. Chem. 2012, 4,854 .

(33) Pac, C.; Ihama, M.; Yasuda, M.; Miyauchi, Y.; Sakurai, H. J. Am. Chem. Soc. 1981, 103, 6495.

(34) Kern, J. M.; Sauvage, J. P. J. Chem. Soc., Chem. Commun. 1987, 287, 546.

(35) Hironaka, K.; Fukuzumi, S.; Tanaka, T. J. Chem. Soc., Perkin Trans.2 1984, 1705.

(36) Park, G.; Yi, S. Y.; Jung, J.; Cho, E. J.; You, Y. Chem. - A Eur. J. 2016, 22, 17790. 
(37) Peng, Y.; Li, Z.; Zeng, Y.; Xie, X.; Wang, H.; Li, L.; Liu, X. Microchim. Acta 2010, 170, 17.

(38) Tanaka, K.; Nagata, T. Bull. Chem. Soc. Jpn. 2002, 75, 2469. 


\section{Chapter 2.}

\section{Mechanistic Insight into Photoinduced Single-Electron Transfer Enabled by Zirconium}

(The major part of this chapter was published in J. Am. Chem. Soc. 2018, 140, 5934)

\subsection{Introduction.}

In last chapter, we discovered a novel photocatalyst that based on earth-abundant transition

metal, zirconium. This new zirconium complex, $\mathrm{Zr}\left({ }^{\mathrm{Me}} \mathrm{PDP}^{\mathrm{Ph}}\right)_{2}$, was able to carry out visible light photoredox transformations that had been previously performed using precious metal catalyst. ${ }^{1}$ While the studies provided a proof of concept for photocatalysis by group IV metal complexes, the mechanistic details of the photocatalytic reactions remained unclear. The computational analysis shown the photoluminescence of $\mathrm{Zr}\left({ }^{\mathrm{Me}} \mathrm{PDP}{ }^{\mathrm{Ph}}\right)_{2}$ originate from a mixed ILCT/LMCT states, which was intrinsically different from the emission nature of common late transition metal photocatalyst (MLCT). Such fundamental differences may lead to dramatic change in the reaction pathway. For photocatalytic benzyl coupling reaction, You et al. conducted a thorough study showing the combination of the iridium photocatalyst and Hantzsch ester (HEH) promotes a onephoton-induced two-electron catalytic cycle. ${ }^{2}$ What about our zirconium photocatalyst?

In this chapter, we performed a detailed mechanistic study into photoinduced singleelectron transfer (SET) by $\mathrm{Zr}\left({ }^{\mathrm{Me}} \mathrm{PDP}^{\mathrm{Ph}}\right)_{2}$ that provides further insight into the excited-state properties of the complex. The reductive homocoupling reaction of benzyl bromide to bibenzyl 
was chosen as a mode system to firmly establish SET reactivity rather than energy transfer pathways via in situ trapping and characterization of radical intermediates. Isolation and characterization of the one electron reduced form of the zirconium photosensitizer provide further insight into the electron-transfer characteristics of $\mathrm{Zr}\left({ }^{\mathrm{Me}} \mathrm{PDP}^{\mathrm{Ph}}\right)_{2}$.

\subsection{Optimization of Photocatalytic Conditions.}

To establish a reliable protocol for the mechanistic investigation of photo-induced SET by $\mathrm{Zr}\left({ }^{\mathrm{Me}} \mathrm{PDP}^{\mathrm{Ph}}\right)_{2}$, our study commenced with a re-evaluation of the reaction conditions for the photoredox catalytic reductive homocoupling of benzyl bromide (Table 1). As previously demonstrated, this reaction can be conducted under irradiation with commercially available green LEDs $\left(\lambda_{\max }=520 \mathrm{~nm}\right)$ using $\mathrm{Zr}\left({ }^{\mathrm{Me}} \mathrm{PDP}^{\mathrm{Ph}}\right)_{2}$ as the photosensitizer, 1,3-dimethyl-2-phenyl-2,3dihydro-1H-7-methylbenzo-[d]imidazole, ${ }^{\mathrm{Me}} \mathrm{BIH}$, as the sacrificial reductant, and 2,6-lutidine as the base. Control experiments conducted in the absence of light and/or $\mathrm{Zr}\left({ }^{\mathrm{Me}} \mathrm{PDP}{ }^{\mathrm{Ph}}\right)_{2}$ resulted in quantitative recovery of starting materials. ${ }^{1}$ One potential complication for a thorough mechanistic study under these initial conditions is the presence of benzylic $\mathrm{C}-\mathrm{H}$ bonds in ${ }^{\mathrm{Me}} \mathrm{BIH}$ which can undergo unwanted side reactions with benzyl radical intermediates in the proposed SET mechanism. This hypothesis is supported by the low yield of bibenzyl ( $30 \%$ at $>99 \%$ conversion of benzyl bromide) and concomitant formation of ${ }^{\mathrm{Me}} \mathrm{BIH}$ derived side products during photocatalytic turnover. The benzimidazolium hydride derivatives ${ }^{\mathrm{H}} \mathrm{BIH}$ and ${ }^{\mathrm{Cl}} \mathrm{BIH}$ studied 
previously provide more selective product formation but result in slow photocatalytic reactions which can be attributed to their more positive redox potentials (Table 1, entries 2-4).

Building on these observations, ${ }^{\mathrm{MeO}} \mathrm{BIH}$, a more reducing $\mathrm{BIH}$ derivative without benzylic protons was introduced for the present study to improve the selectivity and rate of the reaction. Despite an improved reaction time (Table 1, entry 5), the yield of bibenzyl was poor (19\%) and a significant amount of toluene (15\%) was observed as a by-product. This competing hydrodehalogenation reaction was proposed to result from facile hydrogen atom abstraction from the oxidized form of the sacrificial reductant, ${ }^{\mathrm{MeO}} \mathrm{BIH}^{*+}$, which exhibits a very weak $\mathrm{C}-\mathrm{H}$ bond $\left(B D F E=29.3 \mathrm{kcal} \mathrm{mol}^{-1}\right)^{3}$ that can easily be attacked by a potential benzyl radical intermediate. This reactivity highlights the complex proton-coupled electron-transfer (PCET) properties of ${ }^{\mathrm{R}} \mathrm{BIH}$ derivatives $^{3}$ and prompted further studies of the influence of the base on the photocatalytic performance.

A significant improvement was achieved by changing the base from 2,6-lutidine to the stronger base triethylamine, $\mathrm{NEt}_{3}$, increasing the yield of bibenzyl (64\%) while simultaneously decreasing the amount of toluene (Table 1, entry 6). This improvement is consistent with more facile deprotonation of ${ }^{\mathrm{MeO}} \mathrm{BIH}^{\cdot+}$ by the stronger base $\mathrm{NEt}_{3}$ resulting in the formation of the strong single electron reductant ${ }^{\mathrm{MeO}} \mathrm{BI}^{\bullet}$ and preventing hydrogen atom transfer (HAT). While the formation of toluene was suppressed, small amounts of the ammonium salt $\left[\mathrm{BnNEt}_{3}\right] \mathrm{Br}$ resulting from nucleophilic attack of $\mathrm{NEt}_{3}$ on benzyl bromide were detected as a new by-product. The use 
of the bulkier trialkylamine base $N, N$-diisopropylethylamine did not alleviate this issue but resulted in slightly lower yields of the desired homocoupling product. Unfortunately, the use of the even stronger base DBU resulted in rapid formation of ammonium salts via nucleophilic substitution and completely shut down the desired photocatalytic pathway.

Table 1. Optimization of the reaction conditions for the photoredox catalytic coupling of benzyl bromide with $\mathrm{Zr}\left({ }^{\mathrm{Me}} \mathrm{PDP}^{\mathrm{Ph}}\right)_{2}$ as the photosensitizer.

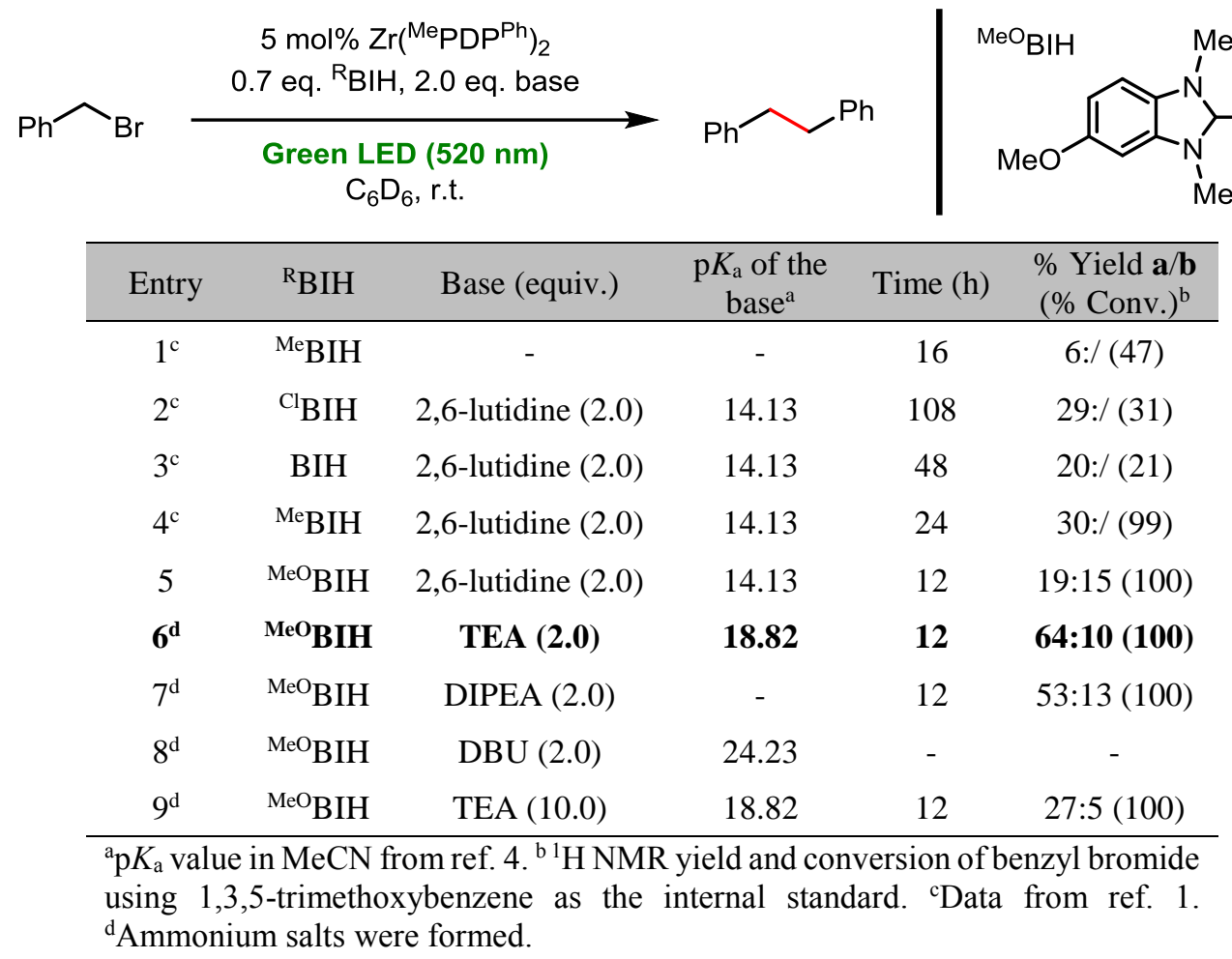

\subsection{Intermittent Illumination and Quantum Yield of Photocatalysis.}

With improved reaction conditions in hand, the photocatalytic nature of the reaction was initially investigated via an intermittent illumination experiment. A correlation of irradiation time 
and bibenzyl yield is shown in Figure 1. No product formation was observed in the absence of light which clearly establishes the light-dependent nature of the reaction. However, this type of experiment is not suitable to rigorously rule out a potential photo-initiated radical chain mechanism. ${ }^{81}$ Even though it is difficult to envision such a pathway for the homocoupling reaction studied herein, the quantum yield of the reaction was determined via actinometry to provide further evidence for a photoredox catalytic mechanism. To establish the photon-flux of the illumination setup, the photodissociation of Reinecke's salt, $\mathrm{K}\left[\mathrm{Cr}\left(\mathrm{NH}_{3}\right)_{2}(\mathrm{NCS})_{4}\right]$, was used as the chemical actinometer due to its well-established quantum yield at $520 \mathrm{~nm} .{ }^{5,6}$ The overall quantum yield of the photo reaction, $\Phi_{\text {cat }}$, was then determined by dividing the number of product molecules formed by the number of photons absorbed over the illumination period (See experimental section for details). The low value of $\Phi_{\text {cat }}=0.004$ obtained in this way for bibenzyl formation clearly favors a photoredox catalytic mechanism over a radical chain process. ${ }^{7}$ The significantly lower reaction quantum yield compared to the luminescence quantum yield of 0.12 is likely due to back electron transfer from the reduced photocatalyst to ${ }^{\mathrm{MeO}} \mathrm{BIH}^{*+}$. This non-productive pathway should be enhanced under the reaction conditions, because the two ionic products of photo-induced SET $\left({ }^{\mathrm{MeO}} \mathrm{BIH}^{\cdot+}\right.$ and $\left.\left[\mathrm{Zr}\left({ }^{\mathrm{Me}} \mathrm{PDP}^{\mathrm{Ph}}\right)_{2}\right]^{1-}\right)$ are likely to remain in close enough proximity for facile outersphere back electron transfer as ion-pair formation is favorable in the non-polar reaction medium benzene. 


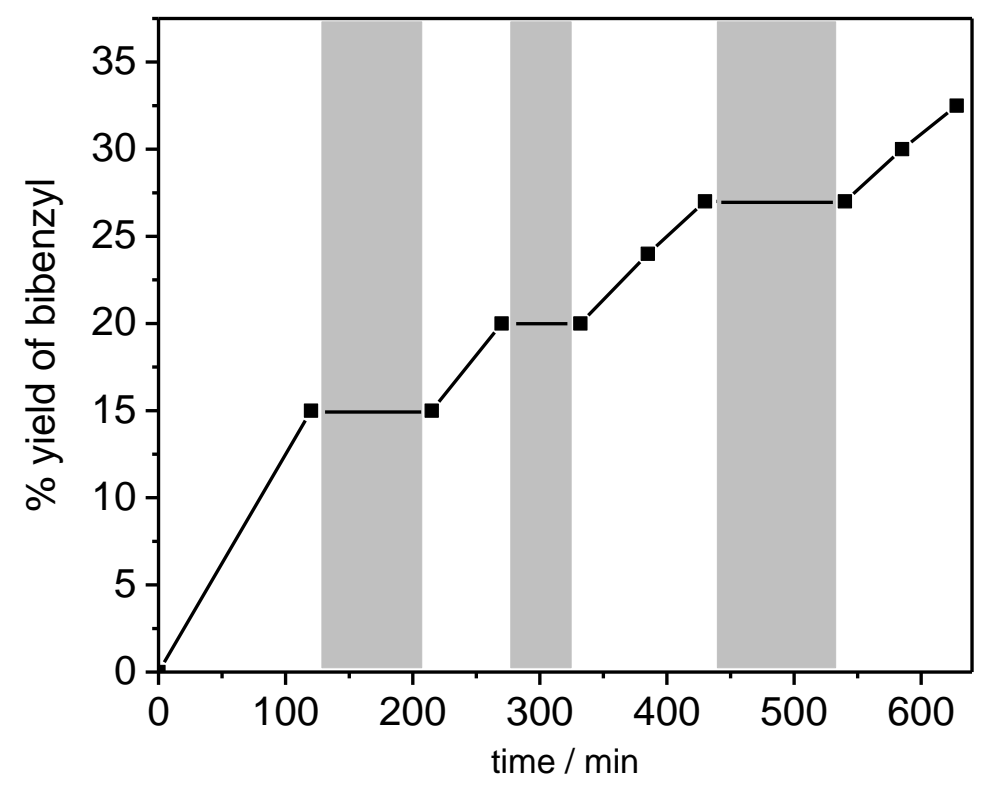

Figure 1. Intermittent illumination experiment for the photoredox catalytic homocoupling of benzyl bromide monitored by ${ }^{1} \mathrm{H}$ NMR in $\mathrm{C}_{6} \mathrm{D}_{6}$. Gray box shown the reaction period under dark.

\subsection{Stern-Volmer Quenching Experiments.}

Having established the emission lifetime and a computational model for the electronic structure of the excited state, we extended our previous Stern-Volmer quenching studies to obtain further insight into the mechanistic steps following photon absorption during bibenzyl formation. A comparison of the Stern-Volmer plots for the three previously reported ${ }^{\mathrm{R}} \mathrm{BIH}$ derivatives and the new sacrificial reductant ${ }^{\mathrm{MeO}} \mathrm{BIH}$ are shown in Figure 2. The strictly linear dependence of the luminescence intensities on the concentration of the quencher is indicative of diffusion-controlled dynamic quenching processes without pre-association of $\operatorname{Zr}\left({ }^{\mathrm{Me}} \mathrm{PDP}^{\mathrm{Ph}}\right)_{2}$ and ${ }^{\mathrm{R}} \mathrm{BIH}$. The obtained Stern-Volmer constants, $K_{\mathrm{Sv}}$, and the corresponding quenching rate constants, $k_{\mathrm{q}}$, are summarized 
in Table 2. The inclusion of ${ }^{\mathrm{MeO}} \mathrm{BIH}$ further establishes the strong correlation between the oxidation potential of the ${ }^{\mathrm{R}} \mathrm{BIH}$ derivative and the quenching rate supporting a photo-induced SET step. Individual quenching experiments for the remaining components of the reaction mixture established that neither benzyl bromide nor $\mathrm{NEt}_{3}$ are suitable quenchers for the excited state of $\mathrm{Zr}\left({ }^{\mathrm{Me} P D P}{ }^{\mathrm{Ph}}\right)_{2}$. The absence of quenching by $\mathrm{NEt}_{3}$ is an important distinction from classic precious metal photoredox catalysts such as $\left[\mathrm{Ru}(\mathrm{bpy})_{3}\right]^{2+}$ and $\operatorname{Ir}(\mathrm{ppy})_{3}$ and highlights the substantially more negative ground and excited state redox potentials of $\mathrm{Zr}\left({ }^{\mathrm{Me}} \mathrm{PDP}^{\mathrm{Ph}}\right)_{2}$, which necessitate more powerful sacrificial reductants. The absence of quenching by benzyl bromide rules out a potential oxidative quenching pathway. As a whole, the Stern-Volmer experiments strongly support reductive quenching by ${ }^{\mathrm{R}} \mathrm{BIH}$ as the first step following photoexcitation.

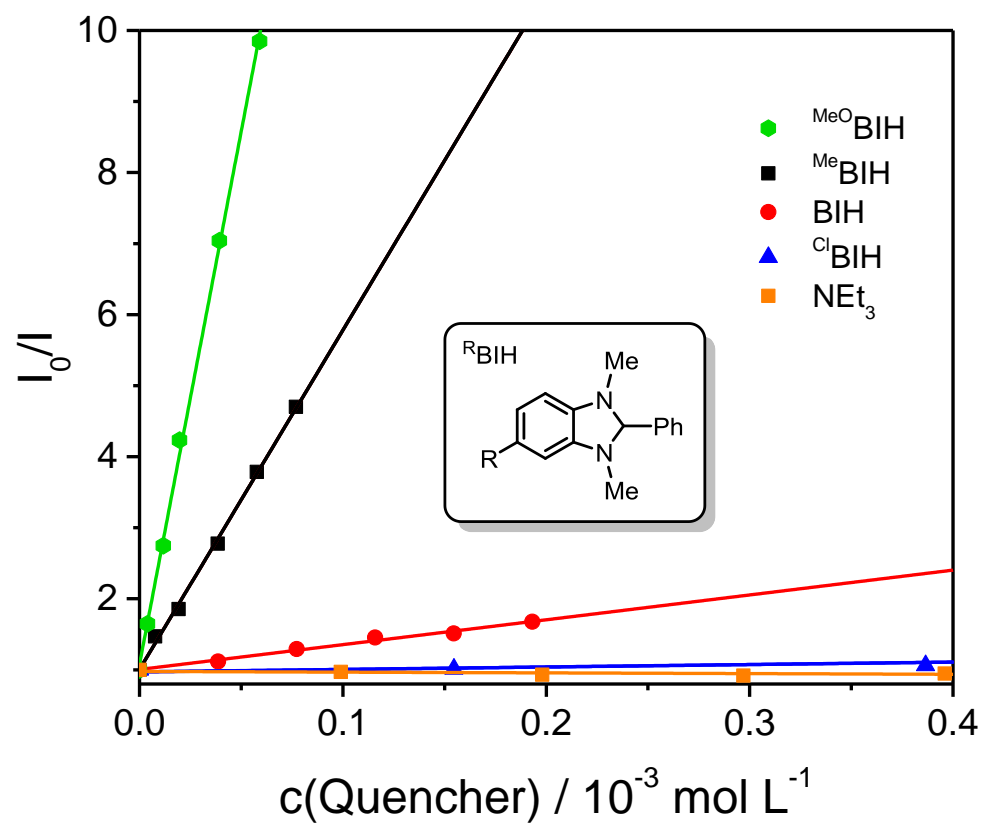

Figure 2. Stern-Volmer plots obtained via steady-state emission spectroscopy. 
Table 2. Quenching parameters from Stern-Volmer analysis and redox potentials.

\begin{tabular}{cccc}
\hline & $K_{\mathrm{SV}} / \mathrm{L} \mathrm{mol}^{-1}$ & $k_{\mathrm{q}} / 10^{7} \mathrm{~L} \mathrm{~mol}^{-1} \mathrm{~s}^{-1}$ & $\mathrm{E}_{\mathrm{ox}} / \mathrm{V}$ vs. $\mathrm{Fc}^{+/ 0}$ \\
\hline${ }^{\mathrm{MeO}} \mathrm{BIH}$ & $150,000 \pm 2000$ & 46.15 & $-0.25^{\mathrm{b}}$ \\
${ }^{\mathrm{Me}} \mathrm{BIH}$ & $47,900 \pm 600^{\mathrm{a}}$ & 14.74 & $-0.16^{\mathrm{b}}$ \\
${ }^{\mathrm{H}} \mathrm{BIH}$ & $3,500 \pm 100^{\mathrm{a}}$ & 1.08 & $-0.10^{\mathrm{b}}$ \\
${ }^{\mathrm{Cl}} \mathrm{BIH}$ & $340 \pm 50$ & 0.10 & $0.00^{\mathrm{b}}$ \\
${ }^{\mathrm{NEt}}{ }_{3}$ & \multicolumn{2}{c}{ no quenching } & $0.47^{\mathrm{c}}$ \\
${ }_{\mathrm{BnBr}}$ & \multicolumn{2}{c}{ no quenching } & n.a. \\
\hline
\end{tabular}

${ }^{\mathrm{a}}$ from reference ${ }^{78}$. ${ }^{\mathrm{b}}$ from reference ${ }^{79}$. ${ }^{\mathrm{c}}$ from reference ${ }^{86}$.

\subsection{Synthesis, Characterization, and Reactivity of the Reduced Photosensitizer.}

The reductive quenching pathway indicated by the Stern-Volmer quenching studies prompted attempts to isolate the one-electron reduced form of the photosensitizer. Addition of one equivalent of a freshly prepared sodium naphthalenide in THF solution to $\mathrm{Zr}\left({ }^{\mathrm{Me}} \mathrm{PDP}^{\mathrm{Ph}}\right)_{2}$ in the presence of 1,4,7,10,13,16-hexaoxacyclooctadecane, 18-crown-6, resulted in an immediate color change from pink to dark purple. Removal of solvent and recrystallization from THF and toluene mixture at $-35^{\circ} \mathrm{C}$ provided a dark purple crystalline solid identified as [Na(18-crown-6)(thf $\left.)_{2}\right][$ $\left.\mathrm{Zr}\left({ }^{\mathrm{Me}} \mathrm{PDP}^{\mathrm{Ph}}\right)_{2}\right]$ in $84 \%$ yield (Scheme 1). The ${ }^{1} \mathrm{H}$ NMR spectrum recorded in THF- $d_{8}$ exhibits several paramagnetically broadened signals consistent with the formation of $D_{2 d}$ symmetric $\left[\mathrm{Zr}\left({ }^{\mathrm{Me}} \mathrm{PDP}^{\mathrm{Ph}}\right)_{2}\right]^{1-}$ in solution. 
Scheme 1. Synthesis of $\left[\mathrm{Zr}\left({ }^{\mathrm{Me}} \mathrm{PDP}{ }^{\mathrm{Ph}}\right)_{2}\right]^{1-}$ via chemical reduction of $\mathrm{Zr}\left({ }^{\mathrm{Me}} \mathrm{PDP}{ }^{\mathrm{Ph}}\right)_{2}$.
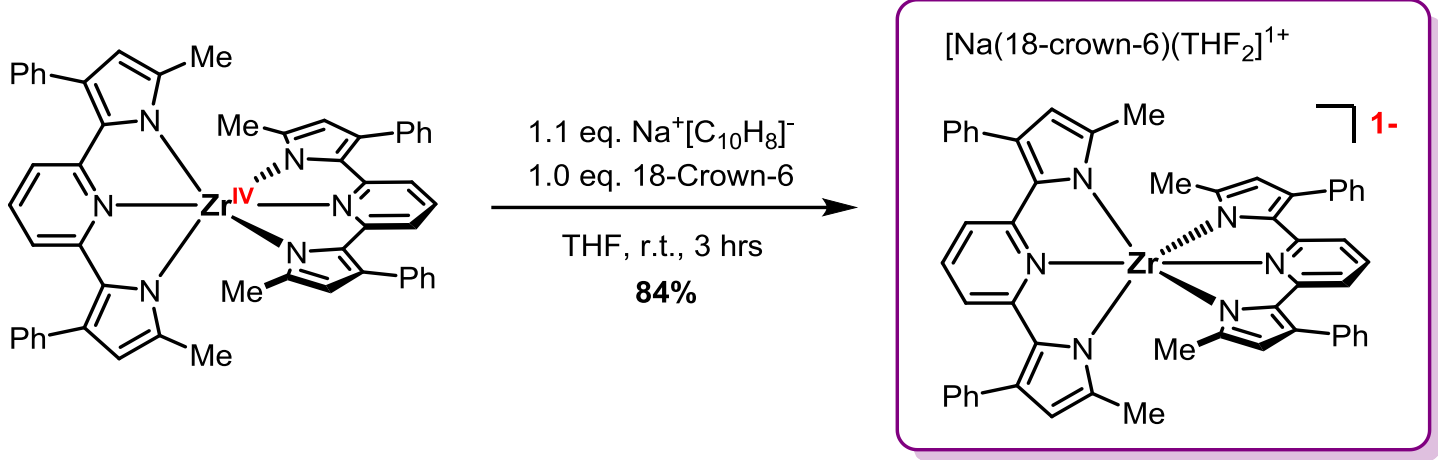

The solid state structure of $\left[\mathrm{Na}(18 \text {-crown-6)(thf })_{2}\right]\left[\mathrm{Zr}\left({ }^{\mathrm{Me}} \mathrm{PDP}^{\mathrm{Ph}}\right)_{2}\right]$ was determined by $\mathrm{X}$ ray diffraction and representations of the molecular structures of the cationic and anionic portions are shown in Figure 3. Comparison of the structural parameters with those obtained previously for the neutral form of the photosensitizer allowed further evaluation of the effects of one-electron reduction on the geometry of the complex and provided insight into the electronic structure of $\left[\mathrm{Zr}\left({ }^{\mathrm{Me}} \mathrm{PDP}{ }^{\mathrm{Ph}}\right)_{2}\right]^{1-}($ Table 3). We have recently shown that the PDP scaffold can act as a redox-active ligand under highly reducing conditions, which raised the question whether reduction in the $\mathrm{Zr}\left({ }^{\mathrm{Me} P D P}{ }^{\mathrm{Ph}}\right)_{2} /\left[\mathrm{Zr}\left({ }^{\mathrm{Me}} \mathrm{PDP}^{\mathrm{Ph}}\right)_{2}\right]^{1-}$ redox couple is metal- or ligand-centered. The overall changes to the molecular structure upon reduction of $\mathrm{Zr}\left({ }^{\mathrm{Me}} \mathrm{PDP}{ }^{\mathrm{Ph}}\right)_{2}$ are remarkably small. For the metal-ligand bond distances a slight decrease by $0.039 \AA$ is observed in the average $\mathrm{Zr}-\mathrm{N}_{\text {py }}$ bond length while an even smaller increase by $0.030 \AA$ can be noted for the average $\mathrm{Zr}-\mathrm{N}_{\text {pyrrole }}$ bond length. The changes in the intra-ligand bond distances are even subtler. Previous studies on the related group VI complexs $\left[\mathrm{M}\left({ }^{\mathrm{Me}} \mathrm{PDP}{ }^{\mathrm{Ph}}\right)_{2}\right]^{\mathrm{z}}(\mathrm{M}=\mathrm{Cr}, \mathrm{Mo} ; \mathrm{z}=1-, 2-)$ established that changes in the pyridine $\mathrm{C}$ - 
$\mathrm{N}_{\mathrm{py}}$ bond lengths are the most reliable reporter of the redox state of the PDP ligand. ${ }^{8}$ While the dianionic form of the ligand typically exhibits $\mathrm{C}-\mathrm{N}_{\mathrm{py}}$ bond lengths of $1.355-1.365 \AA$, as observed for the neutral complex $\mathrm{Zr}^{\mathrm{IV}}\left({ }^{\mathrm{Me}} \mathrm{PDP}^{\mathrm{Ph} 2-}\right)_{2}\left(\right.$ average $\left.\mathrm{C}-\mathrm{N}_{\mathrm{py}}=1.361 \AA\right)$, formation of a metal-bound radical trianion, ${ }^{\mathrm{Me}} \mathrm{PDP}^{\mathrm{Ph} \cdot 3-}$, is associated with $\mathrm{C}-\mathrm{N}_{\mathrm{py}}$ bond elongation to $1.390-1.410 \AA$. The average $\mathrm{C}-\mathrm{N}_{\mathrm{py}}$ bond lengths of $1.380 \AA$ in $\left[\mathrm{Zr}\left({ }^{\mathrm{Me}} \mathrm{PDP}^{\mathrm{Ph}}\right)_{2}\right]^{1-}$ falls in-between these two ranges, while changes in the remaining intra-ligand bond distances are $<0.02 \AA$ and cannot be considered significant within the resolution of the experiment. The experimental data are consistent with two electronic structure descriptions: a) ligand-centered reduction, in which the radical is delocalized over both ligands or b) strong metal-ligand covalency, where the unpaired electron occupies an orbital with significant contributions from both $\mathrm{Zr}$ and the ${ }^{\mathrm{Me}} \mathrm{PDP}{ }^{\mathrm{Ph}}$ ligand. This ambiguity emphasizes the difficulty in unequivocally establishing an electronic structure based on geometric parameters alone and prompted further spectroscopic and computational studies.

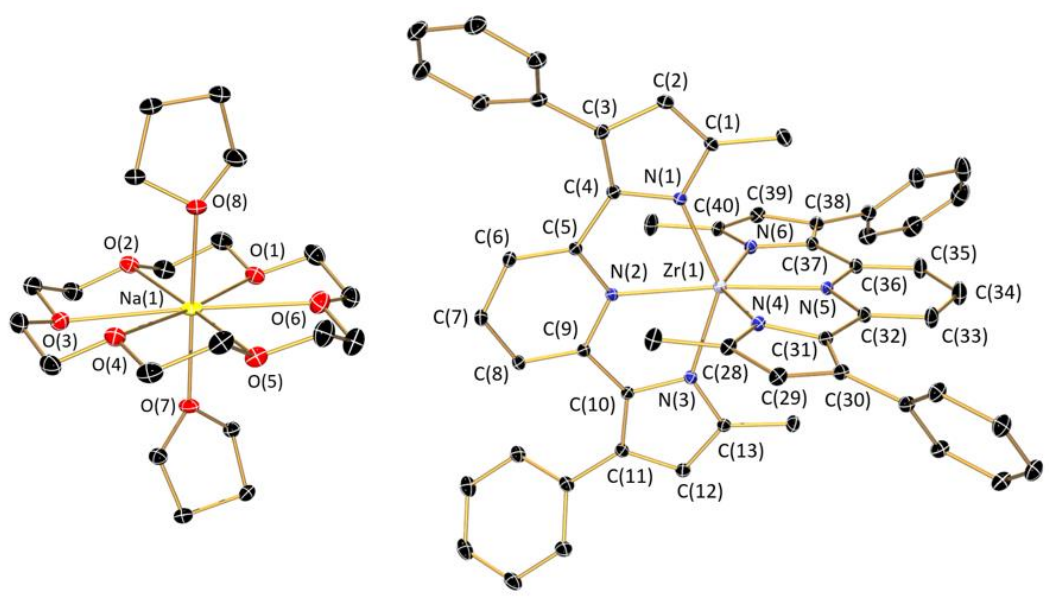

Figure 3. Representation of the molecular structures of $\left[\mathrm{Na}(18 \text {-crown-6)(thf })_{2}\right]^{1+}$ (left) and $\left[\mathrm{Zr}\left({ }^{\mathrm{Me}} \mathrm{PDP}^{\mathrm{Ph}}\right)_{2}\right]^{1-}$ (right) at $30 \%$ probability ellipsoids. Hydrogen atoms were omitted for clarity. Reprinted with permission from \{Zhang, Y.; Lee, T. S.; Petersen, J. L.; and Milsmann, C.J. Am. Chem. Soc. 2018, 140, 5934-5947\}. Copyright $\{2018\}$ American Chemical Society. 
Table 3. Selected bond lengths $(\AA)$ and angles $\left({ }^{\circ}\right)$ for $\left[\operatorname{Zr}\left({ }^{\mathrm{Me}} \mathrm{PDP}^{\mathrm{Ph}}\right)_{2}\right]^{\mathrm{Z}}(\mathrm{z}=0,1-)$.

\begin{tabular}{|c|c|c|}
\hline & $\mathrm{Zr}\left({ }^{\mathrm{Me}} \mathrm{PDP}^{\mathrm{Ph}}\right)_{2}{ }^{\mathrm{a}}$ & {$\left[\mathrm{Zr}\left({ }^{\mathrm{Me}} \mathrm{PDP}^{\mathrm{Ph}}\right)_{2}\right]^{1-\mathrm{b}}$} \\
\hline $\operatorname{Zr}(1)-\mathrm{N}(1)$ & $2.151(3)$ & $2.181(2)$ \\
\hline $\mathrm{Zr}(1)-\mathrm{N}(2)$ & $2.288(3)$ & $2.266(2)$ \\
\hline $\operatorname{Zr}(1)-\mathrm{N}(3)$ & $2.183(3)$ & $2.192(2)$ \\
\hline $\mathrm{Zr}(1)-\mathrm{N}(4)$ & $2.143(3)$ & $2.199(2)$ \\
\hline $\mathrm{Zr}(1)-\mathrm{N}(5)$ & $2.300(3)$ & $2.243(2)$ \\
\hline $\mathrm{Zr}(1)-\mathrm{N}(6)$ & $2.171(3)$ & $2.197(2)$ \\
\hline $\mathrm{N}(2)-\mathrm{C}(5)$ & $1.364(5)$ & $1.375(2)$ \\
\hline$C(5)-C(6)$ & $1.387(5)$ & $1.391(3)$ \\
\hline$C(6)-C(7)$ & $1.376(6)$ & $1.394(3)$ \\
\hline$C(7)-C(8)$ & $1.383(6)$ & $1.393(3)$ \\
\hline $\mathrm{C}(8)-\mathrm{C}(9)$ & $1.383(5)$ & $1.392(3)$ \\
\hline $\mathrm{N}(2)-\mathrm{C}(9)$ & $1.362(5)$ & $1.382(2)$ \\
\hline $\mathrm{N}(5)-\mathrm{C}(32)$ & $1.361(5)$ & $1.389(2)$ \\
\hline$C(32)-C(33)$ & $1.384(5)$ & $1.384(3)$ \\
\hline$C(33)-C(34)$ & $1.381(5)$ & $1.389(3)$ \\
\hline$C(34)-C(35)$ & $1.385(5)$ & $1.405(3)$ \\
\hline$C(35)-C(36)$ & $1.387(5)$ & $1.379(3)$ \\
\hline $\mathrm{N}(5)-\mathrm{C}(36)$ & $1.358(5)$ & $1.372(2)$ \\
\hline Dihedral & 88.30 & 88.81 \\
\hline $\mathrm{N}(2)-\operatorname{Zr}(1)-\mathrm{N}(5)$ & $171.76(8)$ & $174.84(6)$ \\
\hline
\end{tabular}

The X-band EPR spectrum of $\left[\mathrm{Na}(18 \text {-crown-6)(thf })_{2}\right]\left[\mathrm{Zr}\left({ }^{\mathrm{Me}} \mathrm{PDP}^{\mathrm{Ph}}\right)_{2}\right]$ recorded in frozen THF/toluene solution at $80 \mathrm{~K}$ is shown in Figure 4. The observed axial signal clearly establishes the $\mathrm{S}=1 / 2$ ground state of $\left[\mathrm{Zr}\left({ }^{\mathrm{Me}} \mathrm{PDP}^{\mathrm{Ph}}\right)_{2}\right]^{1-}$. The data were simulated using a spin Hamiltonian with $\mathrm{g}$ values of $\mathrm{g} \perp=1.998$ and $\mathrm{g} / /=1.971$. Coupling to ${ }^{91} \mathrm{Zr}(I=5 / 2$, natural abundance $=11.22 \%)$ was taken into account by a hyperfine coupling constant of $\mathrm{A} \perp\left({ }^{91} \mathrm{Zr}\right)=30 \mathrm{MHz}$ and nicely 
reproduces the additional feature in the low field region of the spectrum. No hyperfine splitting was resolved in the high field region of the spectrum. The magnitude of the ${ }^{91} \mathrm{Zr}$ hyperfine coupling and the significant deviation from the $g$ value of the free electron $\left(g_{e}=2.0023\right)$ towards lower $g$ values are consistent with significant $\mathrm{Zr}$ contributions to the $\mathrm{SOMO}$ of $\left[\mathrm{Zr}\left({ }^{\mathrm{Me}} \mathrm{PDP}^{\mathrm{Ph}}\right)_{2}\right]^{1-}$.

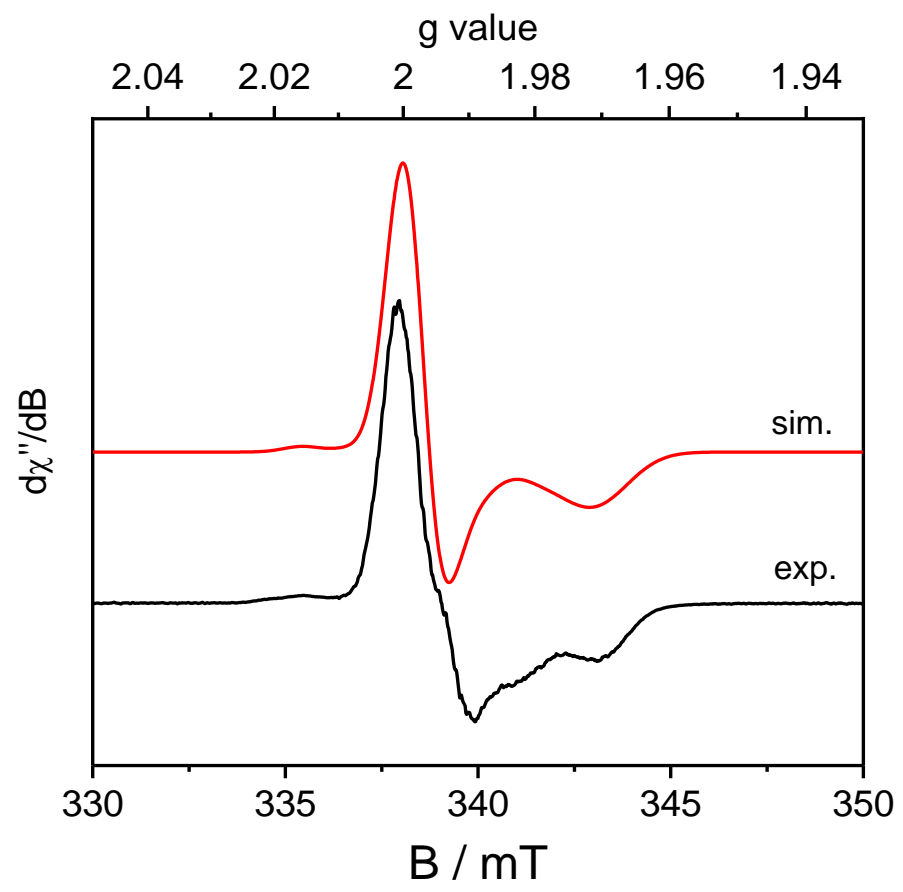

Figure 4. X-band EPR spectrum of $\left[\mathrm{Zr}\left({ }^{\mathrm{Me}} \mathrm{PDP}^{\mathrm{Ph}}\right)_{2}\right]^{1-}$ in frozen $\mathrm{THF} /$ toluene solution recorded at $80 \mathrm{~K}$ (experimental parameters: frequency $=9.463 \mathrm{GHz}$, power $=0.4 \mathrm{~mW}$, modulation: $2 \mathrm{G}$ ). See text for simulation parameters.

To support the spectroscopic studies, full molecule density functional theoretical (DFT) calculations were conducted at the B3LYP level. The geometric parameters from geometry optimization are in excellent agreement with the experimental structure from X-ray crystallography. The spin density distribution obtained via Mulliken population analysis is shown 
in Figure 5 and reveals the highly delocalized nature of the SOMO in $\left[\mathrm{Zr}\left({ }^{\mathrm{Me}} \mathrm{PDP}^{\mathrm{Ph}}\right)_{2}\right]^{1-}$ with near equal contributions of $48 \%$ from the metal center and $52 \%$ from the two ${ }^{\mathrm{Me}} \mathrm{PDP}^{\mathrm{Ph}}$ ligands consistent with the structural data. Further inspection of the molecular orbital manifold shows that the metal character in the SOMO results from close to equal contributions of the $\mathrm{d}_{\mathrm{xz}}$ and $\mathrm{d}_{\mathrm{yz}}$ orbitals that form a degenerate e set under the idealized $D_{2 d}$ symmetric ligand field. This result is surprising given that the $\mathrm{T}_{1}$ state calculated for neutral $\mathrm{Zr}\left({ }^{\mathrm{Me}} \mathrm{PDP}^{\mathrm{Ph}}\right)_{2}$, which can also be described as containing a single electron in the e set, undergoes a Jahn-Teller distortion resulting in a symmetry lowering to $C_{2 v}$. While this effect might be weaker for the doublet ground state of $\left[\mathrm{Zr}\left({ }^{\mathrm{Me}} \mathrm{PDP}^{\mathrm{Ph}}\right)_{2}\right]^{1-}$ compared to a triplet system, calculations using the conductor-like screening model (COSMO) were conducted to simulate the effects of a dielectric medium. This approach has previously been shown to favor localized electronic structures in systems containing redox-active ligands. ${ }^{9}$ Consistent with these previous studies, the optimized geometry using COSMO exhibits $C_{2 v}$ symmetry most clearly established by the two different $\mathrm{Zr}-\mathrm{N}_{\text {pyridine }}$ bond distances $(2.333 \AA$ and $2.235 \AA$ ) for the two ligands. This structure is the result of delocalization of the unpaired electron between the $\mathrm{Zr}$ center (42\%) and only one of the two ${ }^{\mathrm{Me}} \mathrm{PDP}^{\mathrm{Ph}}$ ligands $(58 \%)$ and removes the degeneracy of the $d_{x z}$ and $d_{y z}$ orbitals. It should be noted however, that the electronic structures with $D_{2 d}$ and $C_{2 v}$ symmetry are likely to interconvert via vibronic coupling under experimental conditions. 
Both electronic structures with degenerate or near-degenerate $d_{x z}$ and $d_{y z}$ orbitals are consistent with the observed axial EPR spectrum. Strong spin-orbit coupling in the $d_{x z}, d_{y z}$ manifold results in significant orbital angular momentum contributions and deviation of the $\mathrm{g}_{/ /}$ value from 2.0023. In contrast, spin-orbit coupling involving the $d_{x y}$ orbital that result in deviations for $\mathrm{g} \perp$ are reduced due to the strong destabilization of this orbital by the four pyrrolate $\pi$ donors. Reassuringly, DFT $(\mathrm{CP}-\mathrm{SCF})$ calculations of the $\mathrm{g}$ values for $\left[\mathrm{Zr}\left({ }^{\mathrm{Me}} \mathrm{PDP}^{\mathrm{Ph}}\right)_{2}\right]^{1-}(\mathrm{g} \perp=2.000, \mathrm{~g} / /=$ 1.957) are in excellent agreement with the experimental parameters. Based on the combined experimental and computational results the electronic structure of the reduced from of the photosensitizer, $\left[\mathrm{Zr}\left({ }^{\mathrm{Me}} \mathrm{PDP}^{\mathrm{Ph}}\right)_{2}\right]^{1-}$, is best described as a hybrid of the limiting resonance structures $\left[\mathrm{Zr}^{\mathrm{III}}\left({ }^{\mathrm{Me}} \mathrm{PDP}^{\mathrm{Ph}}{ }^{2-}\right)_{2}\right]^{1-}$ and $\left[\mathrm{Zr}^{\mathrm{IV}}\left({ }^{\mathrm{Me}} \mathrm{PDP}^{\mathrm{Ph} \cdot 3-}\right)\left({ }^{\mathrm{Me}} \mathrm{PDP}^{\mathrm{Ph} 2-}\right)\right]^{1-}$.
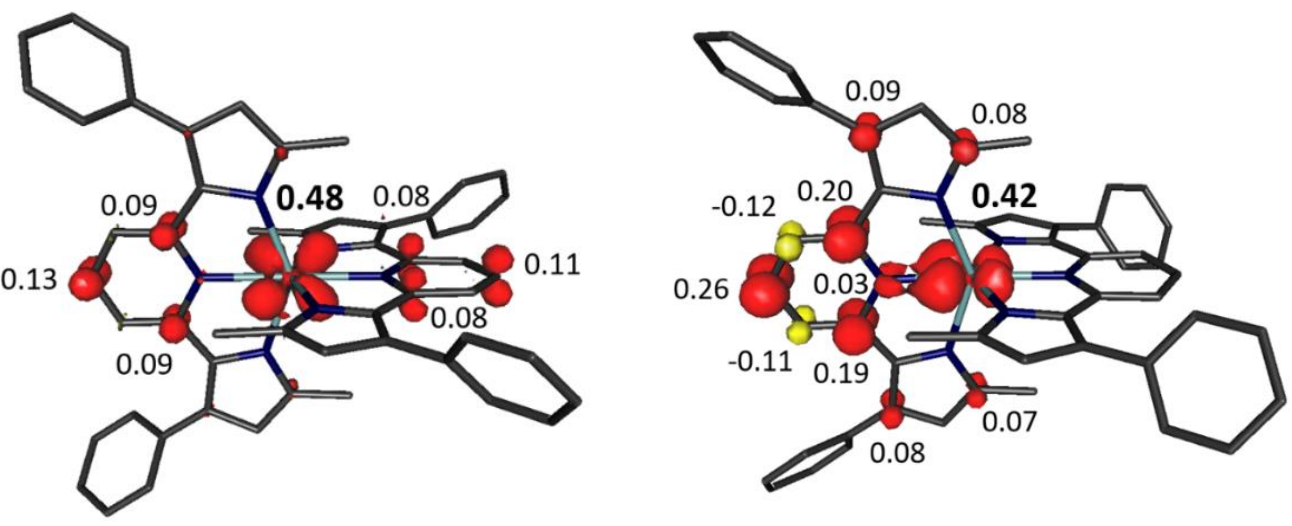

Figure 5. Spin density distribution obtained via Mulliken population analysis for $\left[\mathrm{Zr}\left({ }^{\mathrm{Me}} \mathrm{PDP}^{\mathrm{Ph}}\right)_{2}\right]^{1-}$ with (left) and without (right) using the COSMO approximation. Reprinted with permission from \{Zhang, Y.; Lee, T. S.; Petersen, J. L.; and Milsmann, C.J. Am. Chem. Soc. 2018, 140, 5934-5947\}. Copyright $\{2018\}$ American Chemical Society. 
With the isolated complex $\left[\mathrm{Na}(18 \text {-crown-6)(thf })_{2}\right]\left[\mathrm{Zr}\left({ }^{\mathrm{Me}} \mathrm{PDP}^{\mathrm{Ph}}\right)_{2}\right]$ in hand, the reactivity of the reduced photosensitizer towards benzyl bromide was explored to establish whether $\left[\mathrm{Zr}\left({ }^{\mathrm{Me}} \mathrm{PDP}{ }^{\mathrm{Ph}}\right)_{2}\right]^{1-}$ can act as the active single-electron reductant in the photocatalytic homocoupling reaction. Slow addition of a dilute solution of $\left[\mathrm{Na}(18 \text {-crown-6)(thf })_{2}\right]\left[\mathrm{Zr}\left({ }^{\mathrm{Me} P D P}{ }^{\mathrm{Ph}}\right)_{2}\right]$ in $\mathrm{THF}$ to a solution containing 10 equivalents of benzyl bromide at room temperature resulted in an immediate reaction yielding bibenzyl and $\mathrm{Zr}\left({ }^{\mathrm{Me}} \mathrm{PDP}^{\mathrm{Ph}}\right)_{2}$ as the major products identified by ${ }^{1} \mathrm{H} \mathrm{NMR}$ spectroscopy (Scheme 2 and Figure 6). Slow addition and low concentrations of $\left[\mathrm{Zr}\left({ }^{\mathrm{Me}} \mathrm{PDP}^{\mathrm{Ph}}\right)_{2}\right]^{1-}$, simulating the slow but continuous generation of this species under photoredox catalytic conditions, proved to be critical. High concentrations of the reduced zirconium species resulted in poor yield of bibenzyl and formation of a new diamagnetic zirconium species in addition to $\mathrm{Zr}\left({ }^{\mathrm{Me} P D P}{ }^{\mathrm{Ph}}\right)_{2}$. While this new complex has so far eluded isolation and further characterization, preliminary ${ }^{1} \mathrm{H}$ NMR data indicate a compound with a modified ${ }^{\mathrm{Me}} \mathrm{PDP}{ }^{\mathrm{Ph}}$ ligand likely due to reaction of benzyl radical with a second equivalent of $\left[\mathrm{Zr}\left({ }^{\mathrm{Me}} \mathrm{PDP}^{\mathrm{Ph}}\right)_{2}\right]^{1-}$. These reactivity studies clearly show that $\left[\mathrm{Zr}\left({ }^{\mathrm{Me}} \mathrm{PDP}^{\mathrm{Ph}}\right)_{2}\right]^{1-}$ is a potent one-electron reductant that can facilitate the formation of bibenzyl from benzyl bromide. 
Scheme 2. Reactivity of [Na(18-crown-6)(thf $\left.)_{2}\right]\left[\mathrm{Zr}\left({ }^{\mathrm{Me}} \mathrm{PDP}^{\mathrm{Ph}}\right)_{2}\right]$ with benzyl bromide.
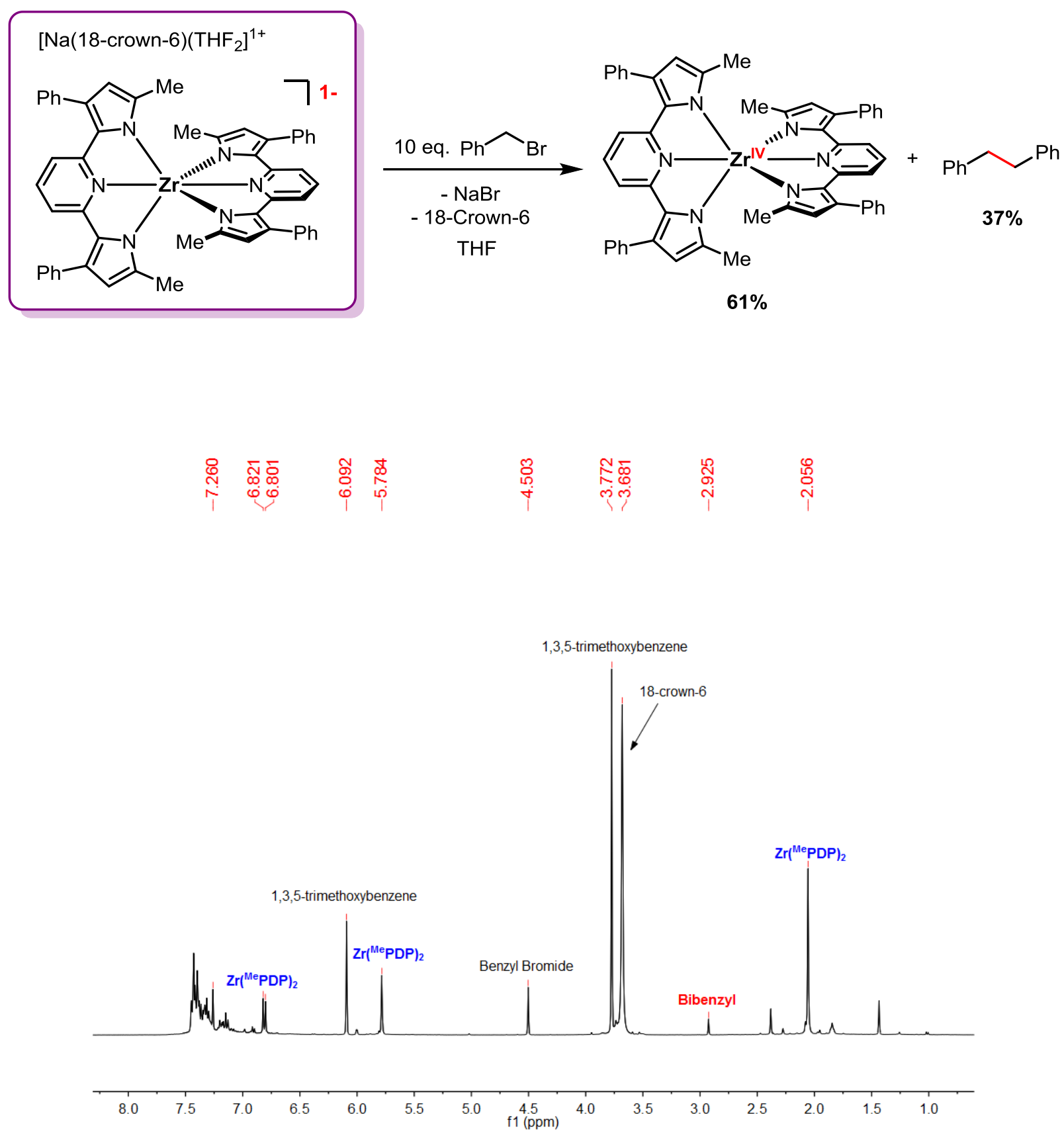

Figure 6. ${ }^{1} \mathrm{H}$ NMR spectrum $\left(\mathrm{CDCl}_{3}\right)$ of the crude reaction mixture after addition of $[\mathrm{Na}(18$ crown-6)(THF) $\left.)_{2}\right]\left[\mathrm{Zr}\left({ }^{\mathrm{Me}} \mathrm{PDP}^{\mathrm{Ph}}\right)_{2}\right]$ to benzyl bromide. 


\subsection{Synthesis, Characterization, and Reactivity of $\left({ }^{\mathrm{R}} \mathrm{BI}\right)_{2}$ Derivatives.}

The versatile PCET pathways reported for a wide variety of benzimidazolium hydrides ${ }^{79}$ motivated further studies of the fate of the sacrificial reductant after photo-induced single-electron transfer (SET). The critical role of the base observed in the optimization of the catalytic conditions indicated that benzimidazolyl radicals, ${ }^{\mathrm{R}} \mathrm{BI}{ }^{\bullet}$, formed via deprotonation of the oxidized reductant, ${ }^{\mathrm{R}} \mathrm{BIH}^{\bullet+}$, could play a key-role during catalytic turnover. Electrochemical studies of 2-arylbenzimidazolium halide salts suggest that the one-electron reduced species could serve as potent single-electron reductants with redox potentials ranging from $-1.80 \mathrm{~V}$ to $-2.10 \mathrm{~V} \mathrm{vs}$. $\mathrm{Fc}^{+} / \mathrm{Fc}$ depending on the substitution patterns. $^{3}$ While synthetic routes to 2-alkyl substituted benzimidazolyl radicals via reduction of benzimidazolium halide salts have been reported, ${ }^{10,11}$ isolation and characterization of 2-aryl substituted derivatives proposed and targeted in this study have remained elusive.

Addition of one equivalent of freshly prepared sodium naphthalenide solution to a suspension of 1,3-dimethyl-2-phenyl-1H-benzimidazolium iodide, $\left({ }^{\mathrm{H}} \mathrm{BI}\right) \mathrm{I}$, in THF resulted in the immediate formation of a clear, yellow solution. Recrystallization of the crude reaction product from toluene and pentane at $-35{ }^{\circ} \mathrm{C}$ yielded colorless crystals of $\left({ }^{\mathrm{H}} \mathrm{BI}\right)_{2}$, the dimerization product of the targeted radical ${ }^{\mathrm{H}} \mathrm{BI}$ (Scheme 3 ). The methoxy-substituted derivative $\left({ }^{\mathrm{MeO}} \mathrm{BI}\right)_{2}$ was prepared via the same protocol. 
Scheme 3. Synthesis of $\left({ }^{\mathrm{H}} \mathrm{BI}\right)_{2}$ via chemical reduction of $\left({ }^{\mathrm{H}} \mathrm{BI}\right) \mathrm{I}$. Representation of the solid state molecular structure of $\left({ }^{\mathrm{H}} \mathrm{BI}\right)_{2}$ at $30 \%$ probability ellipsoids was shown at right. Hydrogen atoms were omitted for clarity.

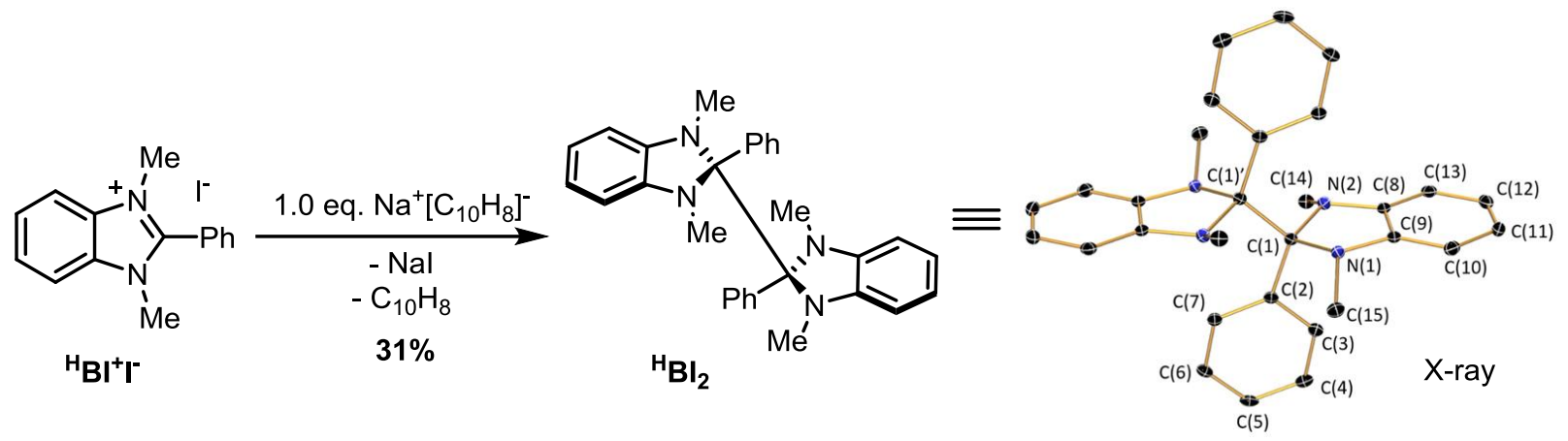

The identity of $\left({ }^{\mathrm{H}} \mathrm{BI}\right)_{2}$ was established by NMR spectroscopy and X-ray crystallography and a representation of the molecular structure in the solid state is shown in Scheme 3. A remarkable feature of this extremely air- and moisture-sensitive compound is the long $\mathrm{C}(1)-\mathrm{C}(1)^{\text {' }}$ bond distance of 1.579(4) $\AA$ between the two halves of the dimer. In combination with significantly broadened resonances observed in the ${ }^{1} \mathrm{H}$ NMR spectrum of $\left({ }^{\mathrm{H}} \mathrm{BI}\right)_{2}$ this weakened $\mathrm{C}-\mathrm{C}$ bond raised questions about a potential equilibrium between the dimeric species and the monomeric radical in solution. Similar equilibria have been established for the corresponding 2-alkyl derivatives via variable temperature EPR studies. ${ }^{11}$ In contrast to these alkyl-substituted species, however, we found no evidence for free radical formation was obtained for $\left({ }^{\mathrm{H}} \mathrm{BI}\right)_{2}$ or $\left({ }^{\mathrm{MeO}} \mathrm{BI}\right)_{2}$ in solution at room temperature via EPR spectroscopy. Consistent with this observation, variable-temperature NMR studies revealed a sharpening of resonances at elevated temperatures, suggesting that the 
broadening can be attributed to restricted rotation about the $\mathrm{C}(1)-\mathrm{C}(1)$ ' bond rather than a dimer/monomer equilibrium.

Despite the lack of detectable amounts of free radical in solution, the reactivity of the two isolable $\left({ }^{\mathrm{R}} \mathrm{BI}\right)_{2}$ derivatives $(\mathrm{R}=\mathrm{H}$ or $\mathrm{OMe})$ was investigated. Addition of $\left({ }^{\mathrm{R}} \mathrm{BI}\right)_{2}$ to a THF solution containing ten equivalents of benzyl bromide resulted in the rapid formation of $\left({ }^{\mathrm{R}} \mathrm{BI}\right) \mathrm{Br}$ and bibenzyl in approximately $2: 1$ ratio. This experiment clearly establishes that $\left({ }^{R} \mathrm{BI}\right)_{2}$ derivatives are competent reductants for the reductive homocoupling of benzyl bromide (Scheme 4 and Figure 7).

In addition to simple redox chemistry, photo-induced electron transfer between $\left({ }^{\mathrm{MeO}} \mathrm{BI}\right)_{2}$ and $\mathrm{Zr}\left({ }^{\mathrm{Me}} \mathrm{PDP}{ }^{\mathrm{Ph}}\right)_{2}$ was investigated via Stern-Volmer quenching experiments. Importantly, no ground state electron transfer between the two compounds was detected, which was readily established by comparison of the electronic absorption spectra of the photosensitizer in the presence and absence of $\left({ }^{\mathrm{MeO}} \mathrm{BI}\right)_{2}$. The Stern-Volmer analysis clearly demonstrates that $\left({ }^{\mathrm{MeO}} \mathrm{BI}\right)_{2}$ acts as a powerful quencher for the excited state of $\mathrm{Zr}\left({ }^{\mathrm{Me}} \mathrm{PDP}^{\mathrm{Ph}}\right)_{2}$ with a quenching rate constant, $\mathrm{k}_{\mathrm{q}}$, of $1.74 \times 10^{9} \mathrm{~L}$ $\mathrm{mol}^{-1} \mathrm{~s}^{-1}$ (Experimental Section).

Scheme 4. Reactivity of $\left({ }^{\mathrm{H}} \mathrm{BI}\right)_{2}$ with benzyl bromide.
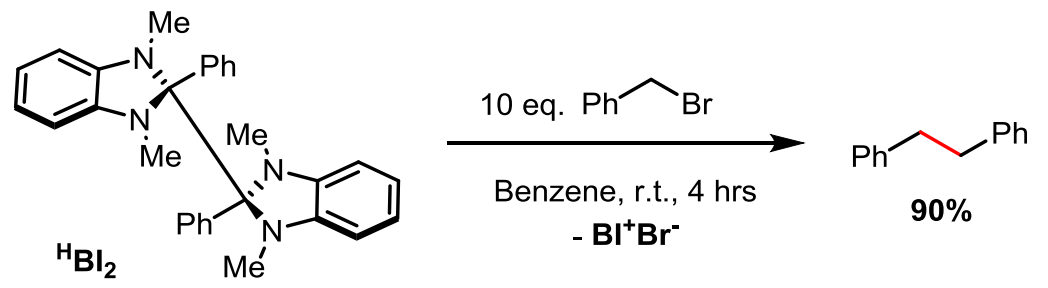


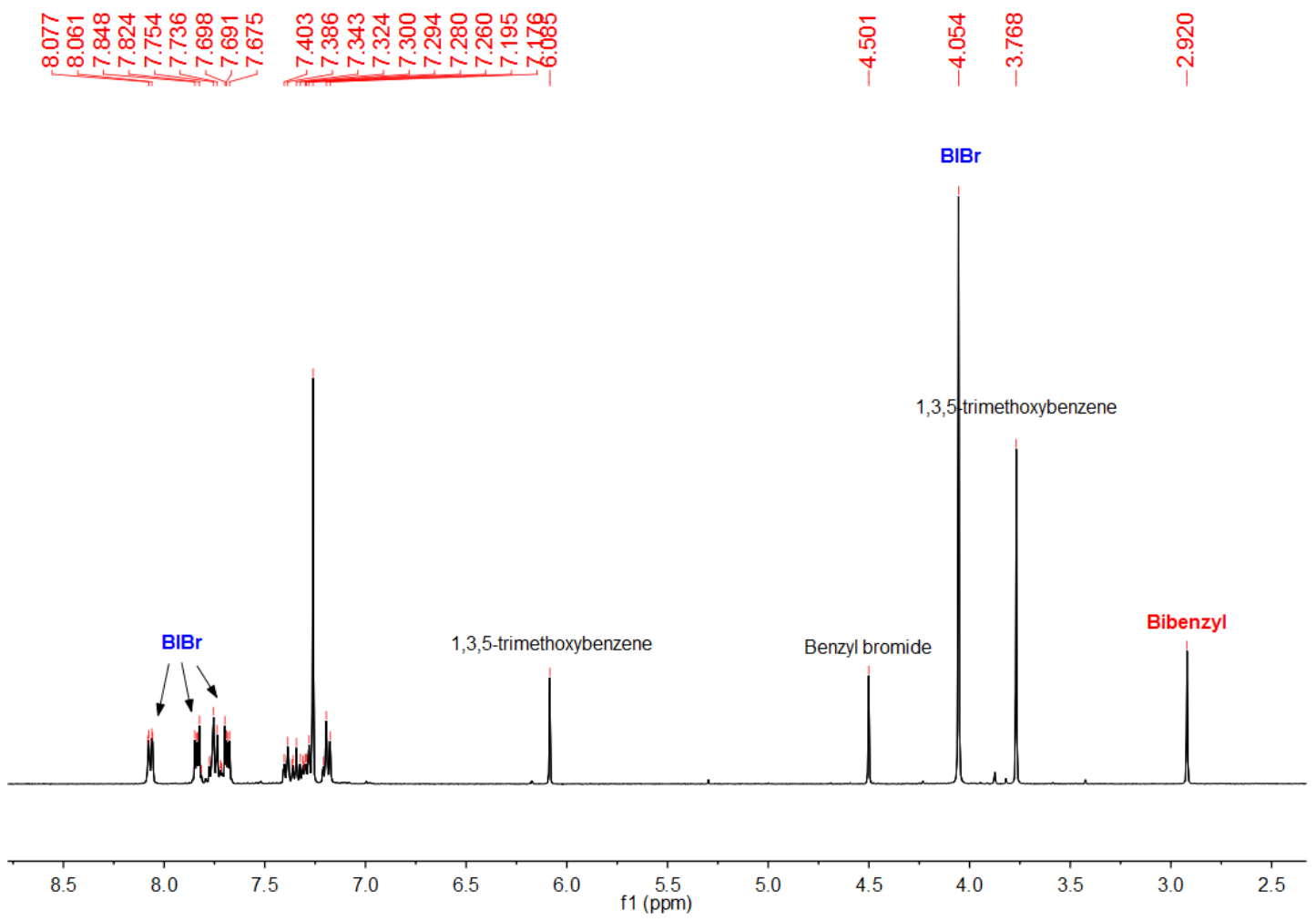

Figure 7. ${ }^{1} \mathrm{H}$ NMR spectrum $\left(\mathrm{CDCl}_{3}\right)$ of the crude reaction mixture after addition of $\left({ }^{\mathrm{H}} \mathrm{BI}\right)_{2}$ to benzyl bromide.

\subsection{Detection of Radical Intermediates During Photoredox Catalytic Turnover.}

Two different experiments were conducted to provide evidence for the generation of radical intermediates via photo-induced SET (Scheme 5). In the first experiment, the photocatalytic reaction was performed in the presence of two equivalents of the stable radical 2,2,6,6-tetramethylpiperidin-1-yl)oxyl (TEMPO). Under these conditions, the formation of bibenzyl and toluene was suppressed completely. Instead, a significant amount of 1-benzyloxy2,2,6,6-tetramethylpiperidine ( ${ }^{\text {Bn }}$ TEMPO) was detected by ${ }^{1} \mathrm{H} \mathrm{NMR}^{12}$ and isolated from the reaction mixture via chromatography. The formation of ${ }^{\text {Bn }}$ TEMPO indicates the presence of benzyl 
radical under catalytic conditions, which is the expected product of the proposed one-electron reduction of benzyl bromide in a photoredox catalytic mechanism.

Scheme 5. Radical trapping experiments using TEMPO and DMPO.

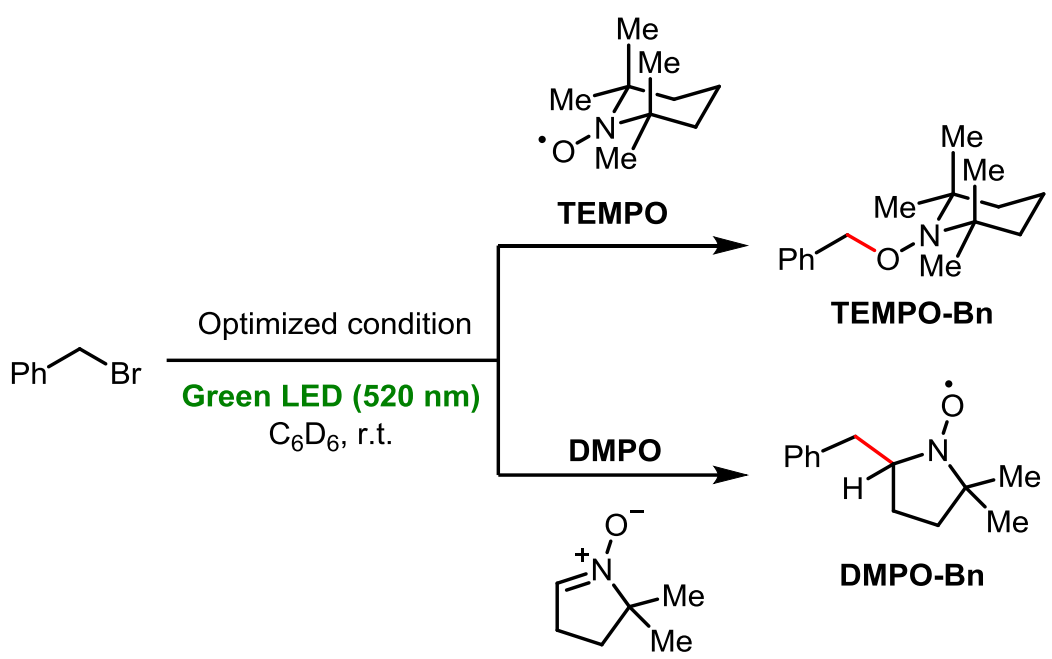

To further corroborate this result, a second radical trapping experiment was performed using 5,5-dimethyl-1-pyrroline- $N$-oxide (DMPO) as a spin trap for the detection of short-lived radical species. An aliquot of the reaction mixture including three equivalents of DMPO was prepared under low light conditions and placed in the cavity of an EPR spectrometer allowing irradiation with green light $\left(\mathrm{LED}, \lambda_{\max }=520 \mathrm{~nm}\right)$ directly in the spectrometer. The EPR spectra of the reaction mixture in the dark and under green light illumination are shown in Figure 8. The signal obtained upon irradiation shows six hyperfine lines of equal intensity and was readily simulated as a doublet of triplets centered at $\mathrm{g}_{\text {iso }}=2.008$ resulting from hyperfine coupling to one proton $\left({ }^{1} \mathrm{H}, \mathrm{I}=1 / 2\right.$, natural abundance $\left.=99.98 \%\right)$ and one nitrogen $\left({ }^{14} \mathrm{~N}, \mathrm{I}=1\right.$, natural abundance 
= 99.64\%) with coupling constants of $\mathrm{A}_{\text {iso }}\left({ }^{1} \mathrm{H}\right)=58 \mathrm{MHz}$ and $\mathrm{A}_{\text {iso }}\left({ }^{14} \mathrm{~N}\right)=39 \mathrm{MHz}$, respectively. These values are in excellent agreement with the EPR parameters reported for the benzyl radical adduct of DMPO $\left({ }^{\mathrm{B} n} \mathrm{DMPO}\right)^{13}$ supporting radical formation and a photoredox catalytic mechanism. The signal intensity for the persistent $N$-oxyl radical rapidly reaches a maximum upon irradiation, which is consistent with the fact that ${ }^{\mathrm{Bn}} \mathrm{DMPO}$ can react with a second equivalent of benzyl radical to generate a diamagnetic species.

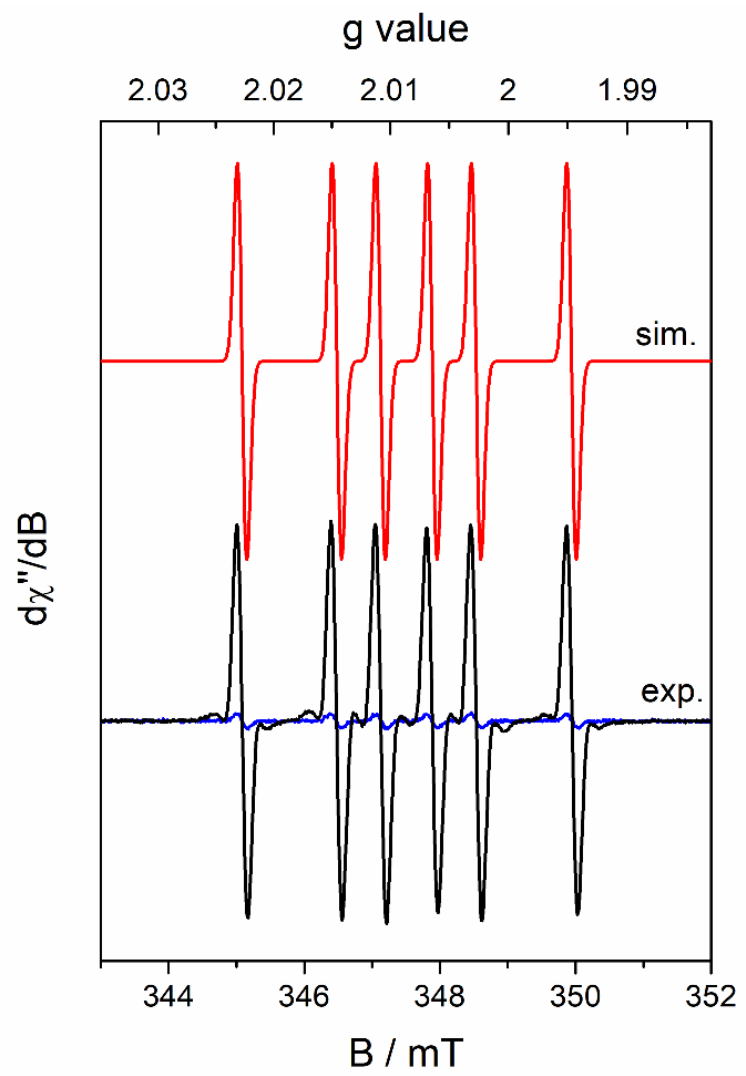

Figure 8. Room temperature X-band EPR spectrum of ${ }^{\mathrm{Bn}} \mathrm{DMPO}$ in benzene solution (black); simulated spectrum (red). ${ }^{\mathrm{Bn}} \mathrm{DMPO}$ was generated under photocatalytic conditions in the presence of DMPO by irradiation (LED, $520 \mathrm{~nm}$ ) in the EPR cavity. The blue line represents the spectrum of the reaction mixture before irradiation. The small amount of ${ }^{\mathrm{Bn}} \mathrm{DMPO}$ is likely due to ambient light irradiation during sample preparation. Reprinted with permission from \{Zhang, Y.; Lee, T. S.; Petersen, J. L.; and Milsmann, C. J. Am. Chem. Soc. 2018, 140, 5934-5947\}. Copyright $\{2018\}$ American Chemical Society. 


\subsection{Proposed Photoredox Catalytic Cycle.}

The combination of the individual experiments presented in this work provides a detailed picture of the mechanism of bibenzyl formation via benzyl bromide homocoupling under photocatalytic conditions (Scheme 6). Visible light absorption by the photosensitizer $\mathrm{Zr}\left({ }^{\mathrm{Me}} \mathrm{PDP}{ }^{\mathrm{Ph}}\right)_{2}$ generates a long-lived excited state, $\mathrm{Zr}\left({ }^{\mathrm{Me}} \mathrm{PDP}^{\mathrm{Ph}}\right) 2_{2}$, with significant ${ }^{3} \mathrm{LMCT}$ character. Photoinduced SET between $\mathrm{Zr}\left({ }^{\mathrm{Me}} \mathrm{PDP}^{\mathrm{Ph}}\right)_{2} *$ and the sacrificial reductant ${ }^{\mathrm{R}} \mathrm{BIH}$ results in reductive quenching of the excited state and yields the highly reducing complex $\left[\mathrm{Zr}\left({ }^{\mathrm{Me}} \mathrm{PDP}{ }^{\mathrm{Ph}}\right)_{2}\right]^{1-}$. This complex can in turn transfer an electron to benzyl bromide resulting in the formation of a benzyl radical, as detected by radical trapping experiments, and regeneration of the photosensitizer. The oxidized reductant ${ }^{\mathrm{R}} \mathrm{BIH}^{++}$is readily deprotonated by $\mathrm{NEt}_{3}$ to generate the strong reductant ${ }^{\mathrm{R}} \mathrm{BI}{ }^{\circ}$, which can either act as a strong reductant and efficient quencher for $\mathrm{Zr}\left({ }^{\mathrm{Me}} \mathrm{PDP}^{\mathrm{Ph}}\right)_{2} *(\mathrm{~A})$ or undergo direct SET with benzyl bromide yielding benzyl radical (B). A third route resulting in dimerization to $\left({ }^{\mathrm{R}} \mathrm{BI}\right)_{2}$ is unlikely under turnover conditions due to the expected low concentration of ${ }^{\mathrm{R}} \mathrm{BI}$. Independent of the pathway, ${ }^{\mathrm{R}} \mathrm{BIH}$ can act as a two-electron donor resulting in the formation of ${ }^{\mathrm{R}} \mathrm{BI}^{+}$, which is consistent with the observation that less than one equivalent of ${ }^{\mathrm{R}} \mathrm{BIH}$ are required for complete conversion of benzyl bromide. Lastly, radical-radical homocoupling yields the final product bibenzyl. This mechanism is akin to the one proposed and investigated recently for the $\left[\operatorname{Ir}(\text { ppy })_{2}(\mathrm{dtbbpy})\right]^{+}\left(\mathrm{ppy}=2\right.$-phenylpyridine, $\mathrm{dtbbpy}=4,4^{\prime}$-di-tert-butyl-2,2'-bipyridine $)$ catalyzed homocoupling of benzylbromide using Hantzsch ester as the sacrificial reductant. ${ }^{2}$ 
Scheme 6. Proposed mechanism for the photoredox catalytic coupling of benzyl bromide with $\mathrm{Zr}\left({ }^{\mathrm{Me}} \mathrm{PDP}{ }^{\mathrm{Ph}}\right)_{2}$ as the photosensitizer.

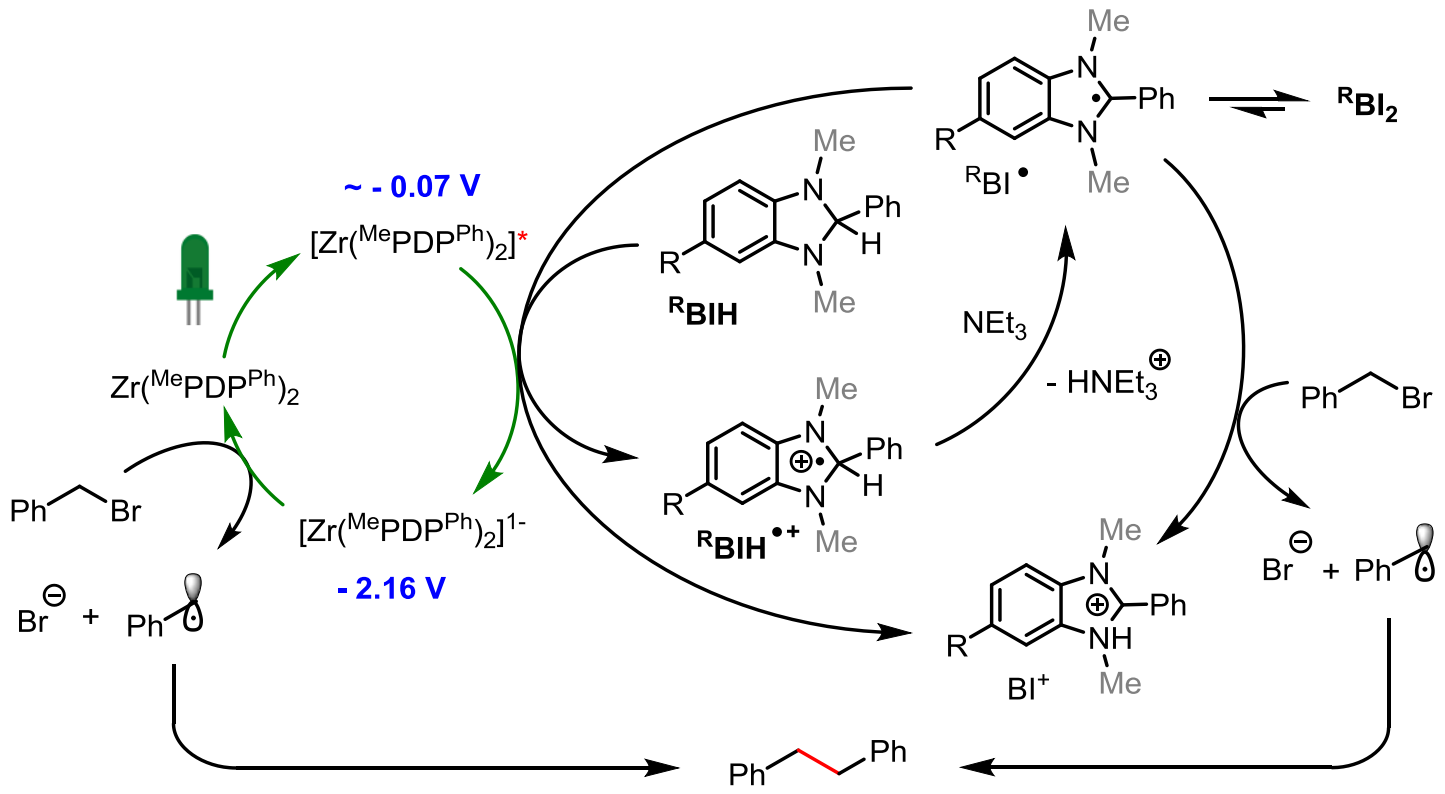

\subsection{Concluding Remarks.}

In this study, we have demonstrated that the excited state of the luminescent zirconium complex $\mathrm{Zr}\left({ }^{\mathrm{Me}} \mathrm{PDP}{ }^{\mathrm{Ph}}\right)_{2}$ exhibits a remarkably long lifetime of $325 \mu$ s that is consistent with phosphorescent emission due to a spin-forbidden $\mathrm{T}_{1} \rightarrow \mathrm{S}_{0}$ transition. This value is among the longest lifetimes reported for transition metal complexes and exceeds the values found in traditional MLCT photosensitizers. Considering results from our previous computational studies of the absorption spectrum of $\mathrm{Zr}\left({ }^{\mathrm{Me}} \mathrm{PDP}^{\mathrm{Ph}}\right)_{2}$, we propose that the excited state is best described as a mixed ${ }^{3} \mathrm{LMCT} /{ }^{3} \mathrm{LLCT}$ state due to high covalency between zirconium and the pyridine moieties of the ligand. Stern-Volmer quenching studies using sacrificial electron donors suggest that the excited state undergoes facile single-electron transfer to generate $\left[\mathrm{Zr}\left({ }^{\mathrm{Me} P D P}{ }^{\mathrm{Ph}}\right)_{2}\right]^{1-}$ under 
photocatalytic conditions. Independent isolation of this highly reducing species allowed us to establish its electronic structure via structural and spectroscopic studies supported by DFT calculations. Our results indicate that the complex is best described as a hybrid of the limiting resonance structures $\left[\mathrm{Zr}^{\mathrm{III}}\left({ }^{\mathrm{Me}} \mathrm{PDP}^{\mathrm{Ph} 2-}\right)_{2}\right]^{1-}$ and $\left[\mathrm{Zr}^{\mathrm{IV}}\left({ }^{\mathrm{Me}} \mathrm{PDP}^{\mathrm{Ph} \cdot 3-}\right)\left({ }^{\mathrm{Me}} \mathrm{PDP}^{\mathrm{Ph}}{ }^{2-}\right)\right]^{1-}$.

To further establish the capacity of $\mathrm{Zr}\left({ }^{\mathrm{Me}} \mathrm{PDP}^{\mathrm{Ph}}\right)_{2}$ to facilitate photoredox processes via photo-induced single-electron transfer, the role of the proposed intermediates $\left[\mathrm{Zr}\left({ }^{\mathrm{Me}} \mathrm{PDP}^{\mathrm{Ph}}\right)_{2}\right]^{1-}$ and ${ }^{\mathrm{R}} \mathrm{BI}{ }^{*}$ was evaluated using the homocoupling of benzyl bromide to bibenzyl as a model reaction. In combination with radical trapping experiments under photocatalytic turnover, these mechanistic studies are consistent with a photoredox catalytic mechanism using $\operatorname{Zr}\left({ }^{\mathrm{Me}} \mathrm{PDP}^{\mathrm{Ph}}\right)_{2}$ as a photosensitizer.

\subsection{Experimental Section.}

General experimental considerations for material handling, physical measurements, X-ray crystallography, and DFT Calculations as well as additional experimental information (i.e. NMR spectra, quenching experiments) can be found in the appendices.

Starting Materials. 4-Methoxy-2-nitroaniline, benzaldehyde, 1,3,5-trimethoxybenzene, benzyl bromide, 2,6-lutidine, triethylamine (NEt $)$, 1,8-diazabicyclo(5.4.0)undec-7-ene (DBU), diisopropylethylamine (DIPEA) and 5,5-Dimethyl-1-pyrroline $N$-oxide (DMPO) were purchased 
from commercial source. $N, N^{\prime}$-dimethyl-2-phenyl-benzo[d]imidazolium iodide $\left({ }^{\mathrm{H}} \mathrm{BI}^{+} \mathrm{I}^{-}\right)^{3}$ was prepared following literature procedures.

Preparation of $\left.\left[\mathrm{Na}(\mathbf{1 8}-\mathrm{crown}-6)(\mathbf{t h f})_{2}\right]\left[\mathbf{Z r} \mathbf{(}^{\mathrm{Me}} \mathbf{P D P}{ }^{\mathrm{Ph}}\right)_{2}\right]$. In the drybox, a $20 \mathrm{~mL}$ scintillation vial was charged with a solution of $\mathrm{Zr}\left({ }^{\mathrm{Me}} \mathrm{PDP}^{\mathrm{Ph}}\right)_{2}(55 \mathrm{mg}, 0.064 \mathrm{mmol})$ and 18-crown-6 (17 mg, 0.064 mmol, 1.01 equiv) in $2 \mathrm{~mL}$ of THF. A freshly prepared solution of sodium naphthalenide (11 $\mathrm{mg}$ naphthalene, $0.070 \mathrm{mmol}, 1.10$ equiv) in THF ( $3 \mathrm{~mL}$ ) was added slowly upon which the color of the reaction mixture changed to dark purple within seconds. The reaction was allowed to stir at room temperature for 3 hours. THF was removed in vacuum and the last traces of the solvent were removed by co-evaporation with $\mathrm{Et}_{2} \mathrm{O}$. The resulting solid residue was washed five times with pentane to remove naphthalene. The crude product was redissolved in THF, filtered, and recrystallized from THF and toluene cooled to $-35{ }^{\circ} \mathrm{C}$. The product was collected by filtration as dark purple crystals (Yield: $70 \mathrm{mg}, 84 \%$ ). X-ray quality single crystals of [Na(18-crown6)(thf $\left.)_{2}\right]\left[\mathrm{Zr}\left({ }^{\mathrm{Me}} \mathrm{PDP}^{\mathrm{Ph}}\right)_{2}\right] \cdot 3 \mathrm{THF}$ were grown from THF and $\mathrm{Et}_{2} \mathrm{O}$ solution at $-35^{\circ} \mathrm{C} .{ }^{1} \mathrm{H}$ NMR $(400$ MHz, THF- $d_{8} ; \delta, \mathrm{ppm}$ ): 22.40 (br), 11.96 (br), 3.58 (s, THF), 3.42 (br, 18-crown-6), 1.73(s, THF), -2.54 (br), -3.19 (br). Three additional signals expected for $D_{2 d}$ symmetric $\left[\mathrm{Zr}\left({ }^{\mathrm{Me}} \mathrm{PDP}^{\mathrm{Ph}}\right)_{2}\right]^{1-}$ could not be detected, which is likely due to paramagnetic broadening. Anal. Calcd. for $\mathrm{C}_{74} \mathrm{H}_{82} \mathrm{~N}_{6} \mathrm{NaO}_{8} \mathrm{Zr}: \mathrm{C}, 68.49 ; \mathrm{H}, 6.37 ; \mathrm{N}, 6.48$; Found: $\mathrm{C}, 65.23 ; \mathrm{H}, 5.83 ; \mathrm{N}, 6.47$. Multiple attempts to obtain more satisfactory elemental analysis were unsuccessful due to the high sensitivity of the compound. 
Preparation of $N, N^{\prime}$-dimethyl-2-phenyl-benzo[d]imidazoline dimer $\left({ }^{\mathrm{H}} \mathrm{BI}\right) 2$. In the drybox, a 50 $\mathrm{mL}$ round-bottom flask was charged with $\left({ }^{\mathrm{H}} \mathrm{BI}\right) \mathrm{I}(160 \mathrm{mg}, 0.457 \mathrm{mmol})$. THF $(10 \mathrm{~mL})$ was added and the resulting suspension was stirred for 30 minutes. A freshly prepared solution of sodium naphthalenide (76 mg naphthalene, $0.502 \mathrm{mmol}, 1.10$ equiv) in THF was added dropwise to the reaction mixture. A clear yellow solution was obtained after completion of the sodium naphthalenide addition. The reaction mixture was allowed to stir at room temperature for $2 \mathrm{~h}$ after which THF was removed in vacuum. The crude product was redissolved in toluene and filtered. Slow diffusion of pentane into the toluene solution at $-35{ }^{\circ} \mathrm{C}$ furnishes colorless crystals. The product was collected by filtration and washed three times with cold pentane. (Yield: $32 \mathrm{mg}, 31 \%$, two crops). ${ }^{1} \mathrm{H}$ NMR (400 MHz, $\left.\mathrm{C}_{6} \mathrm{D}_{6} ; \delta, \mathrm{ppm}\right)$ at $65{ }^{\circ} \mathrm{C}: 7.40$ (br, $4 \mathrm{H}, \mathrm{Ph} H$ ), 7.01 (br, 6H, $\mathrm{Ph} H$ ), $6.78(\mathrm{br}, 4 \mathrm{H}, \mathrm{Ph} H), 6.10(\mathrm{br}, 4 \mathrm{H}, \mathrm{Ph} H), 2.42\left(\mathrm{br}, 12 \mathrm{H}, \mathrm{NCH}_{3}\right)$. The broadening in the spectrum can be attributed to restricted rotation around the newly formed C-C bond. Single crystals suitable for X-ray crystallographic analysis were grown by slow diffusion of pentane into a saturated solution of $\left({ }^{\mathrm{H}} \mathrm{BI}\right)_{2}$ in toluene at $-35{ }^{\circ} \mathrm{C}$. Anal. Calcd for $\mathrm{C}_{30} \mathrm{H}_{30} \mathrm{~N}_{4}: \mathrm{C}, 80.68 ; \mathrm{H}, 6.77 ; \mathrm{N}, 12.55$; Found: $\mathrm{C}$, 80.72; H, 6.93; N, 12.27.

$N, N^{\prime}$-dimethyl-2-phenyl-6-methoxybenzo[d]imidazoline dimer $\left({ }^{\mathrm{MeO}} \mathbf{B I}_{2}\right)$. In the drybox, a 50 $\mathrm{mL}$ round-bottom flask was charged with ${ }^{\mathrm{MeO}} \mathrm{BI}^{+} \mathrm{I}^{-}(180 \mathrm{mg}, 0.474 \mathrm{mmol}, 1.00$ equiv). $10 \mathrm{~mL}$ of THF was added and stir for 30 mins. A solution of pre-formed sodium naphthalenide (79 mg, 0.521 mmol, 1.10 equiv) in THF was added dropwise to the suspension of ${ }^{\mathrm{MeO}} \mathrm{BI}^{+} \mathrm{I}^{-}$in THF. Solution 
becomes clear yellow after addition of sodium naphthalenide. The reaction was allowed to stir at room temperature for 30 mins. THF was removed in vacuo. The crude product was redissolved in toluene and filtered. Layering with pentane at $-35{ }^{\circ} \mathrm{C}$ furnishes off-white solid. The product was filtered and washed with cold pentane three times. (Yield: $80 \mathrm{mg}$, 67\%, two crops). The ${ }^{1} \mathrm{H}$ NMR spectrum of the product is shown in Appendix B and exhibits two distinct species with broadened peak. The two different species were tentatively assigned as diastereomers resulting from the two new stereocenters generated upon C-C bond formation. Restricted rotation around the new C-C bond causes the broadening observed at room temperature. For the major structural isomer: ${ }^{1} \mathrm{H}$ NMR (400 MHz, $\left.\mathrm{C}_{6} \mathrm{D}_{6} ; \delta, \mathrm{ppm}\right)$ : 7.59-7.35 (br, 4H, $\mathrm{Ph} H$ ), 7.10-6.86 (br, 6H, $\mathrm{Ph} H$ ), 6.32-6.00 (br, $6 \mathrm{H}, \mathrm{Ph} H), 3.58-3.43\left(\mathrm{br}, 6 \mathrm{H}, \mathrm{CH}_{3} \mathrm{O}\right), 2.55-2.20\left(\mathrm{br}, 12 \mathrm{H}, \mathrm{NCH}_{3}\right)$. Multiple attempts to obtain single crystals that are suited for X-ray analysis have been unsuccessful. Anal. Calcd for $\mathbf{C}_{32} \mathbf{H}_{34} \mathbf{N}_{4} \mathbf{O}_{2}$ : $\mathrm{C}$, 75.86; H, 6.76; N, 11.06; Found: C, 75.79; H, 6.66; N, 10.39.

\section{Mechanistic Studies.}

Stoichiometric Experiment in Support of a Reduced Zirconium Intermediate. In the drybox, a solution of $\left[\mathrm{Na}(18 \text {-crown-6)(THF) })_{2}\right]\left[\mathrm{Zr}\left({ }^{\mathrm{Me}} \mathrm{PDP}^{\mathrm{Ph}}\right)_{2}\right](24 \mathrm{mg}, 0.185 \mathrm{mmol}, 1.00$ equiv. $)$ in $10 \mathrm{~mL}$ THF was added dropwise over a period of 2 hours to a concentrated benzyl bromide ( $32 \mathrm{mg}, 0.185$ mmol, 10.00 equiv.) solution in $0.5 \mathrm{~mL}$ of THF. Solution turned a luminescent cherry red color upon addition. The reaction was allowed to stir at room temperature for 2 hours. THF was removed 
in vacuo. The resultant solid residue was redissolved in $\mathrm{CDCl}_{3}$ and 1,3,5-trimethoxybenzene was added as an internal standard. The products were analyzed by NMR spectroscopy and the yields are based on internal standard.

Stoichiometric Experiment in Support of ${ }^{\mathrm{R}} \mathbf{B I}$ Radical Intermediate. In the drybox, $\mathrm{BI}_{2}(20 \mathrm{mg}$, $0.045 \mathrm{mmol}, 1.00$ equiv.) or ${ }^{\mathrm{MeO}} \mathrm{BI}_{2}$ (23 mg, 0.059 mmol, 1.00 equiv.) was suspended in $10 \mathrm{~mL}$ of benzene. The solution was added slowly over the period of 30 mins to a concentrated benzyl bromide solution in benzene (10.00 equiv.). A white precipitate was generated within seconds. After 4 hours the solvent was removed. The resultant residue was redissolved in chloroform and 1,3,5-trimethoxybenzene was added as an internal standard. The products were analyzed by NMR spectroscopy and the yields are based on internal standard.

Benzyl Radical Trapping Experiment with TEMPO. In the drybox, a J. Young NMR tube was charged with $\mathrm{Zr}\left({ }^{\mathrm{Me}} \mathrm{PDP}^{\mathrm{Ph}}\right)_{2}\left(2 \mathrm{mg}, 0.002 \mathrm{mmol}, 0.05\right.$ equiv.), ${ }^{\mathrm{MeO}} \mathrm{BIH}$ (6 mg, $0.025 \mathrm{mmol}, 0.70$ equiv.), TEA (7 mg, $0.071 \mathrm{mmol}, 2.00$ equiv.), TEMPO (11 mg, $0.071 \mathrm{mmol}, 2.00$ equiv.) and benzyl bromide ( $6.10 \mathrm{mg}, 0.036 \mathrm{mmol}, 1.00$ equiv). $0.6 \mathrm{~mL}$ of $\mathrm{C}_{6} \mathrm{D}_{6}$ was added. The mixture was placed in a jacketed glass beaker with water cooling and irradiated with green LED light $\left(\lambda_{\max }=\right.$ $520 \mathrm{~nm}$ ). The products were analyzed by NMR spectroscopy and the yields are based on internal standard. 1-Benzyloxy-2,2,6,6-tetramethylpiperidine isolated for characterization was obtained 
via preparative TLC. ${ }^{1} \mathrm{H}$ NMR (400 MHz, $\mathrm{CDCl}_{3} ; \delta$, ppm) 7.38-7.26 (m, $\left.5 \mathrm{H}, \mathrm{Ph} H\right), 4.83(\mathrm{~s}, 2 \mathrm{H}$, $\left.\mathrm{PhCH}_{2}\right), 1.68-1.45\left(\mathrm{~m}, 6 \mathrm{H}, \mathrm{CH}_{2}\right), 1.26\left(\mathrm{~s}, 6 \mathrm{H}, \mathrm{CH}_{3}\right), 1.16\left(\mathrm{~s}, 6 \mathrm{H}, \mathrm{CH}_{3}\right) .{ }^{13} \mathrm{C} \mathrm{NMR}(101 \mathrm{MHz}$, $\left.\mathrm{CDCl}_{3} ; \delta, \mathrm{ppm}\right): 138.47,128.36,127.60,127.43,78.88,60.17,39.88,33.25,20.46,17.28$. Spectral data are in agreement with the literature reported value. ${ }^{12}$

Benzyl Radical Trapping Experiment with DMPO. To the best of our abilities, all manipulations prior to illumination in the EPR spectrometer were carried out protected from ambient light. In the drybox, a $20 \mathrm{~mL}$ vial was charged with $\mathrm{Zr}\left({ }^{\mathrm{Me}} \mathrm{PDP}^{\mathrm{Ph}}\right)_{2}(2 \mathrm{mg}, 0.002 \mathrm{mmol}$, 0.05 equiv.), ${ }^{\mathrm{MeO}} \mathrm{BIH}$ ( $8 \mathrm{mg}, 0.033 \mathrm{mmol}, 0.70$ equiv.), TEA (10 mg, $0.071 \mathrm{mmol}, 2.00$ equiv.), DMPO (16 mg, $0.143 \mathrm{mmol}, 3.00$ equiv.) and benzyl bromide ( $8.14 \mathrm{mg}, 0.048 \mathrm{mmol}, 1.00$ equiv). $0.6 \mathrm{~mL}$ of $\mathrm{C}_{6} \mathrm{H}_{6}$ was added. Approximately $0.2 \mathrm{~mL}$ of the mixture was transferred into an EPR tube that was covered with aluminum foil during transfer to the EPR spectrometer. The tube was placed in the cavity of the spectrometer and a spectrum was acquired in the absence of light. A second spectrum under irradiation with green light ( $520 \mathrm{~nm}$, commercial LED flash light). Optical access to the cavity was provided by a $10 \times 23 \mathrm{~mm}$ grid with $50 \%$ transmittance. 


\section{Determination of Photon Flux and Reaction Quantum Yield.}

Scheme ES1. Schematic representation of the principle of Reinecke's salt actinometry

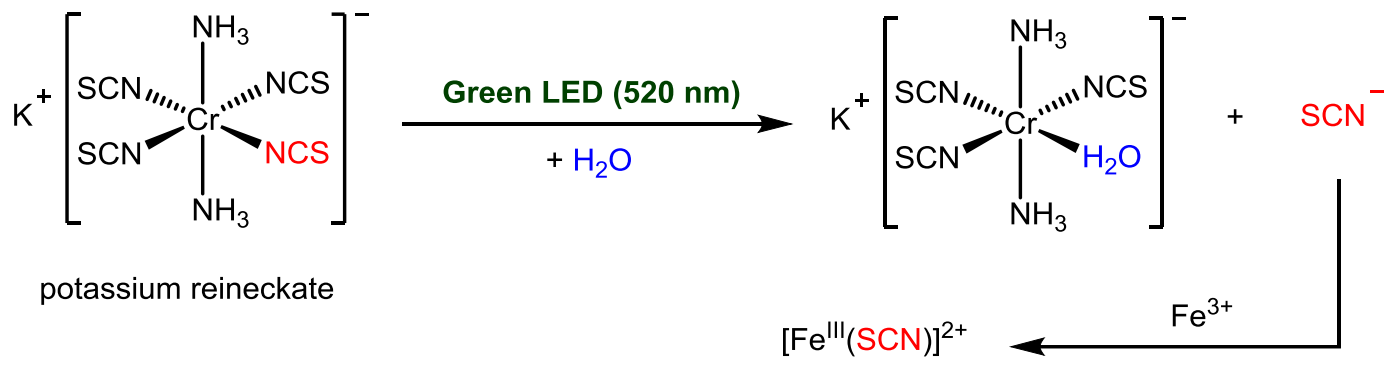

(quantified via UV-Vis)

Determination of the Photon Flux of Green LED $(520 \mathrm{~nm})$ photoreaction setup. The photon

flux of the green LED was determined by Reinecke's salt actinometry. ${ }^{5,6,14}$ The potassium reineckate, $\mathrm{K}\left[\mathrm{Cr}\left(\mathrm{NH}_{3}\right)_{2}(\mathrm{NCS})_{4}\right]$, was synthesized from commercially available $\mathrm{NH}_{4}\left[\mathrm{Cr}\left(\mathrm{NH}_{3}\right)_{2}(\mathrm{NCS})_{4}\right]$ according to a literature procedure. ${ }^{5}$ A $0.01 \mathrm{M}$ solution of potassium reineckate was prepared by dissolving $0.072 \mathrm{~g}$ of $\mathrm{K}\left[\mathrm{Cr}\left(\mathrm{NH}_{3}\right)_{2}(\mathrm{NCS})_{4}\right]$ in $20 \mathrm{~mL}$ deionized water. The absorbance of the solution at $520 \mathrm{~nm}$ was measured to determine the fraction of light absorbed. A second sample of the same $\mathrm{K}\left[\mathrm{Cr}\left(\mathrm{NH}_{3}\right)_{2}(\mathrm{NCS})_{4}\right]$ solution $(2.0 \mathrm{~mL})$ was irradiated at $\lambda=520 \mathrm{~nm}$ for $40 \mathrm{~s}$ at room temperature. The photo-aquation of $\mathrm{K}\left[\mathrm{Cr}\left(\mathrm{NH}_{3}\right)_{2}(\mathrm{NCS})_{4}\right]$ was determined by analysis for free thiocyanate ion $\left(\mathrm{SCN}^{-}\right)$. An aliquot of $0.5 \mathrm{~mL}$ of photolyzed sample was combined with $2.0 \mathrm{~mL}$ of an aqueous $0.1 \mathrm{M} \mathrm{Fe}\left(\mathrm{NO}_{3}\right)_{3} / 0.5 \mathrm{M} \mathrm{HClO}_{4}$ solution. The solution was allowed to stand for $2 \mathrm{~min}$ before the absorbance of $\left[\mathrm{Fe}^{\mathrm{III}}(\mathrm{SCN})\right]^{2+}$ at $450 \mathrm{~nm}$ was recorded. The procedure was then repeated with an unphotolyzed solution of the Reinecke salt to account for thermal reactivity. Three runs were averaged to determine the intensity of light incident on the sample. The photo-aquation of $\mathrm{K}\left[\mathrm{Cr}\left(\mathrm{NH}_{3}\right)_{2}(\mathrm{NCS})_{4}\right]$ was calculated using the following equation: 


$$
\text { mol of } \mathrm{Fe}^{\mathrm{III}}(\mathrm{SCN})^{2+}=\frac{\mathrm{V} \bullet \Delta \mathrm{A}}{\mathrm{l} \bullet \varepsilon}
$$

\begin{tabular}{c|cccc}
\hline Run & $\begin{array}{c}\text { Absorbance of } \\
\text { photolyzed sample } \\
\text { at 450 nm }\end{array}$ & $\begin{array}{c}\text { Absorbance of non- } \\
\text { photolyzed sample } \\
\text { at 450 nm }\end{array}$ & $\Delta \mathrm{A}$ & $\begin{array}{c}{\left[\mathrm{Fe}^{\mathrm{III}}(\mathrm{SCN})\right]^{2+}} \\
(\mathrm{mol})\end{array}$ \\
\hline 1 & 1.933411 & 0.067047 & 1.866364 & $1.0851 \cdot 10^{-6}$ \\
2 & 1.948914 & 0.076675 & 1.872239 & $1.0885 \cdot 10^{-6}$ \\
3 & 1.893036 & 0.0867 & 1.806336 & $1.0502 \cdot 10^{-6}$ \\
\hline
\end{tabular}

Where $\mathrm{V}$ is the total volume $(0.0025 \mathrm{~L})$ of the solution, $\Delta \mathrm{A}$ is the difference in absorbance at $450 \mathrm{~nm}$ between the photolyzed and non-photolyzed solutions, 1 is the path length $(1.0 \mathrm{~cm})$, and $\varepsilon$ is the molar absorptivity at $450 \mathrm{~nm}\left(4300 \mathrm{~L} \mathrm{~mol}^{-1} \mathrm{~cm}^{-1}\right) .{ }^{14}$ The photon flux can be calculated using following equation:

$$
\text { Photon Flux }=\frac{\text { mol of Fe }{ }^{\mathrm{III}}(\mathrm{SCN})^{2+}}{\Phi \bullet \mathrm{t} \bullet \mathrm{f}}
$$

\begin{tabular}{|c|c|c|c|c|}
\hline Run & $\begin{array}{c}{\left[\mathrm{Fe}^{\mathrm{IIII}}(\mathrm{SCN})\right]^{2+}} \\
(\mathrm{mol})\end{array}$ & $\begin{array}{l}\text { Fraction of light } \\
\text { (f) }\end{array}$ & $\begin{array}{c}\text { Radiation time } \\
\text { (s) }\end{array}$ & $\begin{array}{l}\text { Photon flux } \\
\left(\text { einstein } \mathrm{s}^{-1}\right)\end{array}$ \\
\hline 1 & $1.0851 \cdot 10^{-6}$ & 0.843669 & 51 & $8.82 \cdot 10^{-8}$ \\
\hline 2 & $1.0885 \cdot 10^{-6}$ & 0.843822 & 51 & $8.84 \cdot 10^{-8}$ \\
\hline 3 & $1.0502 \cdot 10^{-6}$ & 0.843080 & 50 & $8.71 \cdot 10^{-8}$ \\
\hline Average & - & - & - & $8.79 \cdot 10^{-8}$ \\
\hline
\end{tabular}

Where $\Phi$ is the quantum yield for the Reinecke's salt actinometer $(\Phi=0.286$ at $\lambda=520$ $\mathrm{nm}){ }^{6} \mathrm{t}$ is the time, and $\mathrm{f}$ is the fraction of light absorbed at $\lambda=520 \mathrm{~nm}$. The fraction of light absorbed (f) by this solution was calculated using the equation below, where $\mathrm{A}$ is the measured absorbance of $0.01 \mathrm{M}$ solution of potassium reineckate solution at $520 \mathrm{~nm}$. 
$\mathrm{f}=1-10^{-\mathrm{A}}$

\begin{tabular}{c|cc}
\hline Run & $\begin{array}{c}\text { absorbance of } \mathrm{K}\left[\mathrm{Cr}\left(\mathrm{NH}_{3}\right)_{2}(\mathrm{NCS})_{4}\right] \\
\text { solution at } 520 \mathrm{~nm}\end{array}$ & Fraction of light (f) \\
\hline 1 & 0.805954 & 0.843669 \\
2 & 0.806381 & 0.843822 \\
3 & 0.804321 & 0.843080 \\
\hline
\end{tabular}

Determination of the Quantum Yield of Benzyl Coupling Reaction. In the drybox, a quartz cuvette was charged with $\mathrm{Zr}\left({ }^{\mathrm{Me}} \mathrm{PDP}^{\mathrm{Ph}}\right)_{2}(2 \mathrm{mg}, 0.002 \mathrm{mmol}, 0.05$ equiv. $),{ }^{\mathrm{MeO}} \mathrm{BIH}(9 \mathrm{mg}, 0.033$ mmol, 0.70 equiv.), TEA (10 mg, $0.095 \mathrm{mmol}, 2.00$ equiv.), and benzyl bromide ( $8 \mathrm{mg}, 0.048$ mmol, 1.00 equiv). $3 \mathrm{~mL}$ of benzene was added. The sample was irradiated via photoreaction setup $(\lambda=520 \mathrm{~nm})$ for $3600 \mathrm{~s}$. After irradiation, the yield of product formed was determined by ${ }^{1} \mathrm{H} \mathrm{NMR}$ based on 1,3,5-trimethoxybenzene as internal standard. The quantum yield was determined using equation below. An absorption spectrum of the reaction mixture gave an absorbance value of $>3$ at $520 \mathrm{~nm}$, indicating that essentially all the incident light $(\mathrm{f}>0.999)$ is absorbed by the photocatalyst.

\begin{tabular}{c|cc}
\multicolumn{3}{c}{$\Phi=\frac{\text { mol of product }}{\text { Photon Flux } \bullet \mathrm{t} \bullet \mathrm{f}}$} \\
\hline Run & $\begin{array}{c}\text { mol of Benzyl radical } \\
(2 \mathrm{X} \text { mol of bibenzyl })\end{array}$ & $\Phi$ \\
\hline 1 & $1.31 \cdot 10^{-6}$ & 0.0041 \\
2 & $1.19 \cdot 10^{-6}$ & 0.0038 \\
3 & $1.19 \cdot 10^{-6}$ & 0.0038 \\
\hline Average & - & $\mathbf{0 . 0 0 3 9}$ \\
\hline
\end{tabular}




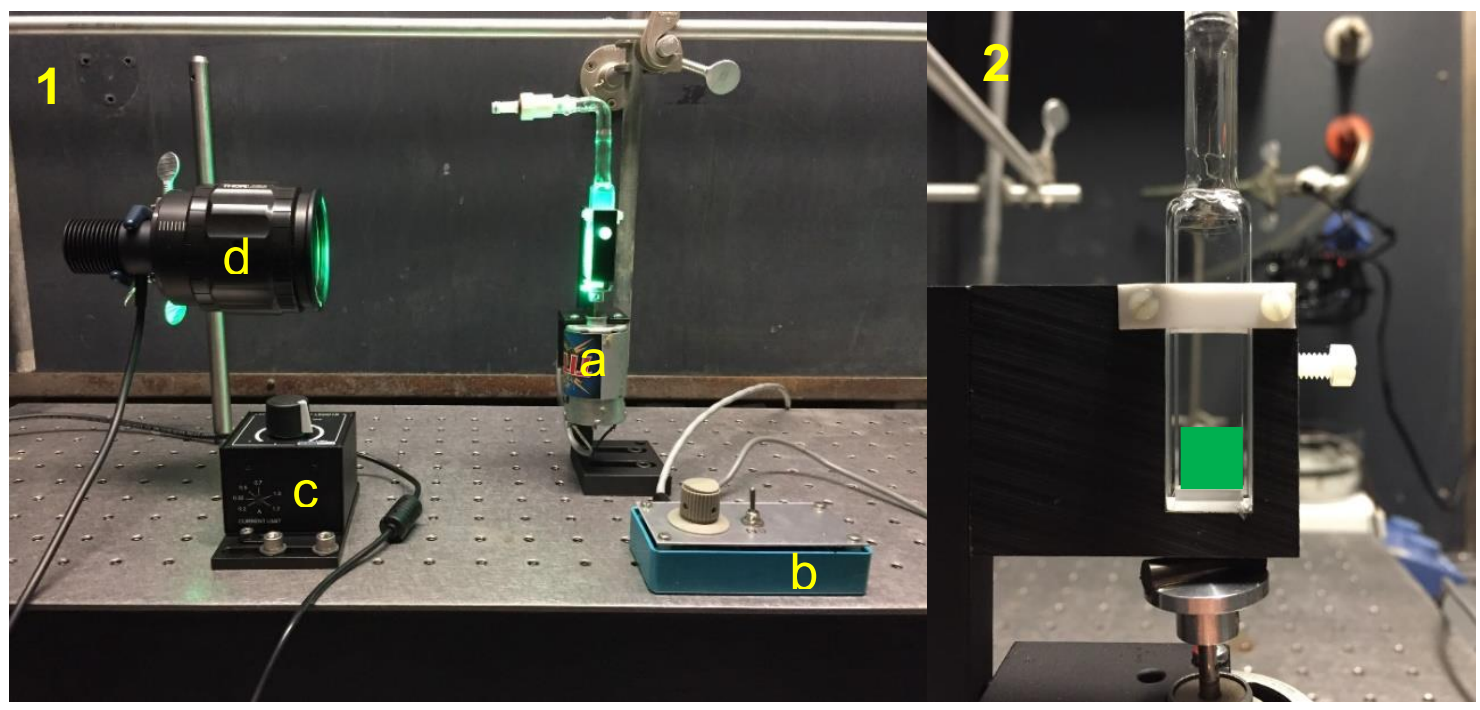

Figure ES1. 1) Photoreaction setup for photon flux measurement and reaction quantum yield determination. a: magnetic stirrer, b: stir rate controller, c: green LED power control; d: high-power green LED with focusing lense. 2) Focus area of the LED $0.9 \mathrm{~cm}$ x $0.9 \mathrm{~cm}$ (green square).

\subsection{Reference.}

(1) Zhang, Y.; Petersen, J. L.; Milsmann, C. J. Am. Chem. Soc. 2016, 138, 13115.

(2) Park, G.; Yi, S. Y.; Jung, J.; Cho, E. J.; You, Y. Chem. - A Eur. J. 2016, 22, 17790.

(3) Zhu, X.-Q.; Zhang, M.-T.; Yu, A.; Wang, C.-H.; Cheng, J.-P. J. Am. Chem. Soc. 2008, 130, 2501.

(4) Kaljurand, I.; Kütt, A.; Sooväli, L.; Rodima, T.; Mäemets, V.; Leito, I.; Koppel, I. A. J. Org. Chem. 2005, 70, 1019.

(5) Wegner, E. E.; Adamson, A. W. J. Am. Chem. Soc. 1966, 88, 394.

(6) Kuhn, H. J.; Braslavsky, S. E.; Schmidt, R. Pure Appl. Chem. 2004, 76, 2105. 
(7) Cismesia, M. A.; Yoon, T. P. Chem. Sci. 2015, 6, 5426.

(8) Gowda, A. S.; Petersen, J. L.; Milsmann, C. Inorg. Chem. 2018, 57, 1919.

(9) Lu, C. C.; Bill, E.; Weyhermüller, T.; Bothe, E.; Wieghardt, K. J. Am. Chem. Soc. 2008, 130, 3181.

(10) Naab, B. D.; Zhang, S.; Vandewal, K.; Salleo, A.; Barlow, S.; Marder, S. R.; Bao, Z. Adv. Mater. 2014, 26, 4268.

(11) Zhang, S.; Naab, B. D.; Jucov, E. V.; Parkin, S.; Evans, E. G. B.; Millhauser, G. L.; Timofeeva, T. V.; Risko, C.; Brédas, J. L.; Bao, Z.; Barlow, S.; Marder, S. R. Chem. - A Eur. J. 2015, 21, 10878.

(12) Yasu, Y.; Koike, T.; Akita, M. Adv. Synth. Catal. 2012, 354, 3414.

(13) Janzen, E. G.; Liu, J. I.-P. J. Magn. Reson. 1973, 9, 510.

(14) Montalti, M.; Credi, A.; Prodi, L.; Gandolfi, M. T. Handbook of Photochemistry, 3rd ed.; Taylor \& Francis: New York, 2006. 


\title{
Chapter 3.
}

\section{Second-Generation Zirconium Photosensitizers: Oxidative Photoredox Reactions with an}

\author{
Air- and Moisture-Stable Photocatalyst
}

\subsection{Introduction.}

In previous chapters, we successfully developed a new molecular photosensitizer based on the earth abundant metal zirconium. ${ }^{1,2}$ The complexes are highly emissive upon visible light irradiation with exceptionally long-lived ${ }^{3} \mathrm{LMCT} /{ }^{3} \mathrm{LLCT}$ excited states of several hundred microseconds. Combined with fully reversible redox events at highly reducing potentials, we were able to carry out three photoredox reactions. Further detailed mechanistic studies revealed the capacity of $\mathrm{Zr}\left({ }^{\mathrm{Me}} \mathrm{PDP}{ }^{\mathrm{Ph}}\right)_{2}$ to facilitate photo-induced single-electron transfer processes that proceed via a reductive quenching mechanism. However, the air- and water-sensitivity of that complex made it impossible to handle under "glove-box free" conditions. In fact, early transition metals (ETM) are known to be extremely oxophilic and have a strong tendency to form metal oxides upon exposition to air and water. The high air/water sensitivity of molecular ETM compounds and low functional group tolerance of oxygen enriched organic substrates have been a long-standing problem in the field of ETM catalysis. Considering molecular ETM's diverse reactivities of catalysts in conducting polymerization, ${ }^{3}$ hydroamination, ${ }^{4}$ and group-transfer catalysis, ${ }^{5}$ it is urgent to find a way of developing more sustainable ETM catalysts. Herein, we report our 
successful efforts towards synthesizing a highly air/proton stable and fully functional zirconium photosensitizer equipped with two $\left[{ }^{\mathrm{Mes}} \mathrm{PDP}^{\mathrm{Ph}}\right]^{2-}$ ligands.

\subsection{Synthesis and Characterization.}

The ligand precursor $\mathrm{H}_{2}{ }^{\mathrm{Mes}} \mathrm{PDP}^{\mathrm{Ph}}$ was readily prepared following the previous method for $\mathrm{H}_{2}{ }^{\mathrm{Me}} \mathrm{PDP}^{\mathrm{Ph}}$. Starting from 2,6-pyridinedicarboxaldehyde and the chalcone derivative 1-(2,4,6trimethylphenyl)-3-phenyl-2-propen-1-one, $\mathrm{H}_{2}{ }^{\mathrm{Mes}} \mathrm{PDP}^{\mathrm{Ph}}$ was obtained on a multigram scale via a straightforward two-step, one-pot protocol. ${ }^{2,6}$ Ligand deprotonation followed by salt metathesis reactions with half an equivalent of $\mathrm{ZrCl}_{4}$ only delivered a trace amount of the desired $\mathrm{Zr}\left({ }^{\mathrm{Mes}} \mathrm{PDP}^{\mathrm{Ph}}\right)_{2}$ after seven days at elevated temperature. Alternatively, direct reaction between one equivalent of $\mathrm{H}_{2}{ }^{\mathrm{Mes}} \mathrm{PDP}^{\mathrm{Ph}}$ and tetrabenzyl zirconium (half an equivalent) at $120{ }^{\circ} \mathrm{C}$ furnished $\mathrm{Zr}\left({ }^{\mathrm{Mes}} \mathrm{PDP}^{\mathrm{Ph}}\right)_{2}$ in $32 \%$ yield after workup (Scheme 1). The low reaction yield is likely due to the side reactions from unselective $\mathrm{C}-\mathrm{H}$ exchange between benzylic protons of different mesityl methyl groups and benzylated zirconium species inter/intra-molecularly. Noticeably, the same reaction at $80{ }^{\circ} \mathrm{C}$ failed to provide any desired product. Such a high kinetic barrier for this reaction is a consequence of the steric bulk of the ligand framework close to the first coordination sphere of the zirconium. 
Scheme 1. Synthesis of $\mathrm{Zr}\left({ }^{\mathrm{Mes}} \mathrm{PDP}^{\mathrm{Ph}}\right)_{2}$.

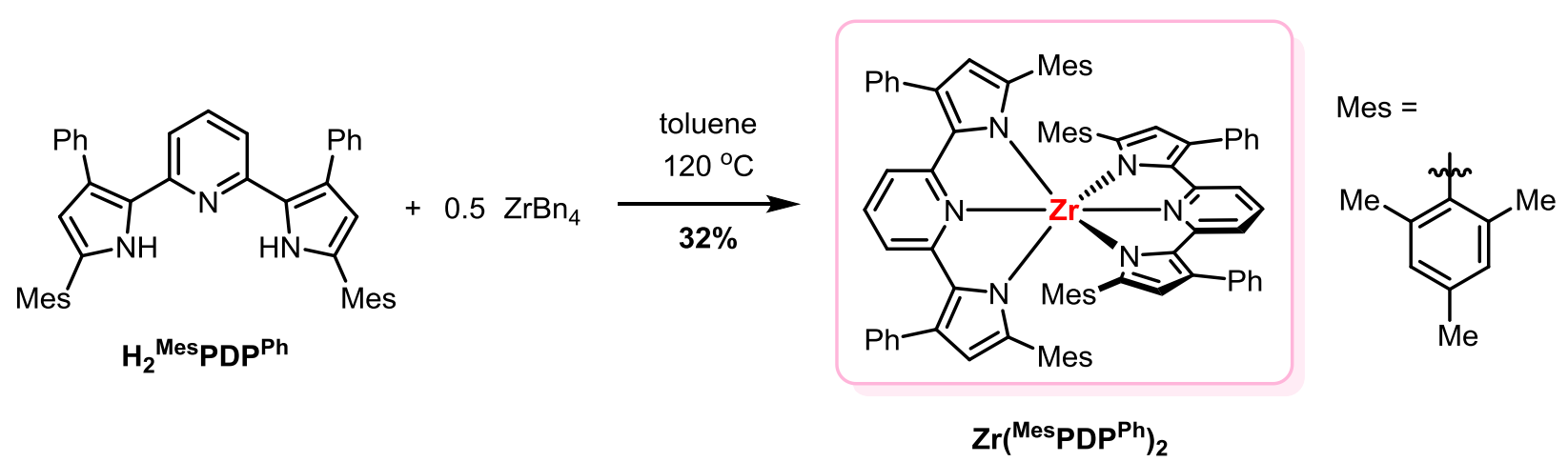

After recrystallization from THF, the $\mathrm{Zr}\left({ }^{\mathrm{Mes}} \mathrm{PDP}^{\mathrm{Ph}}\right)_{2}$ can be readily obtained as highly pure red crystals which are suitable for X-ray crystallographic analysis. The compound crystallized in the triclinic P-1 space group. Two representations of the molecular structure are shown in Figure 1 and important bond lengths and angles are summarized in Table 1. The coordination environment around the central zirconium ion is best described as distorted octahedral with two meridionally coordinating pincer $\left[{ }^{\mathrm{Mes}} \mathrm{PDP} \mathrm{Ph}^{\mathrm{Ph}}{ }^{2-}\right.$ ligands. The geometric constraints enforced by the ligand framework result in reduced average $\mathrm{N}_{\text {pyrrole }}-\mathrm{M}-\mathrm{N}_{\text {pyrrole }}$ angles of $143.53(8)^{\circ}$ for the pincer ligands in $\mathrm{Zr}\left({ }^{\mathrm{Mes}} \mathrm{PDP}{ }^{\mathrm{Ph}}\right)_{2}$, which is significantly higher than what is known for our previous compound $\mathrm{Zr}\left({ }^{\mathrm{Me}} \mathrm{PDP}{ }^{\mathrm{Ph}}\right)_{2}\left(140.00(9)^{\circ}\right) .^{2}$ Upon inspection of the solid state structure, intramolecular $\pi$-stacking was observed between the mesityl moieties on one ligand and pyridine unit of the second ligand. Such an effect brings the two ligands closer to each other and increases their bite angle. The solid state structure of $\mathrm{Zr}\left({ }^{\mathrm{Mes}} \mathrm{PDP} \mathrm{Ph}_{2}^{\mathrm{Ph}}\right)_{2}$ shows only slight deviation from idealized $D_{2 d}$ symmetry, with the two pincer ligands exhibiting a nearly perfectly orthogonal arrangement. The dihedral angle (defined by the three nitrogen atoms of each ligand) between two ligand planes is $89.57^{\circ}$ (ideally 
$90^{\circ}$ ) and $\mathrm{N} 2-\mathrm{Zr} 1-\mathrm{N} 5$ angle is $179.42^{\circ}$ (ideally $180^{\circ}$ ). The ${ }^{1} \mathrm{H}$ NMR spectroscopy data at room temperature for the diamagnetic $\mathrm{Zr}\left({ }^{\mathrm{Mes}} \mathrm{PDP}^{\mathrm{Ph}}\right)_{2}$ is in agreement with $D_{2 d}$ symmetric structures in solution.
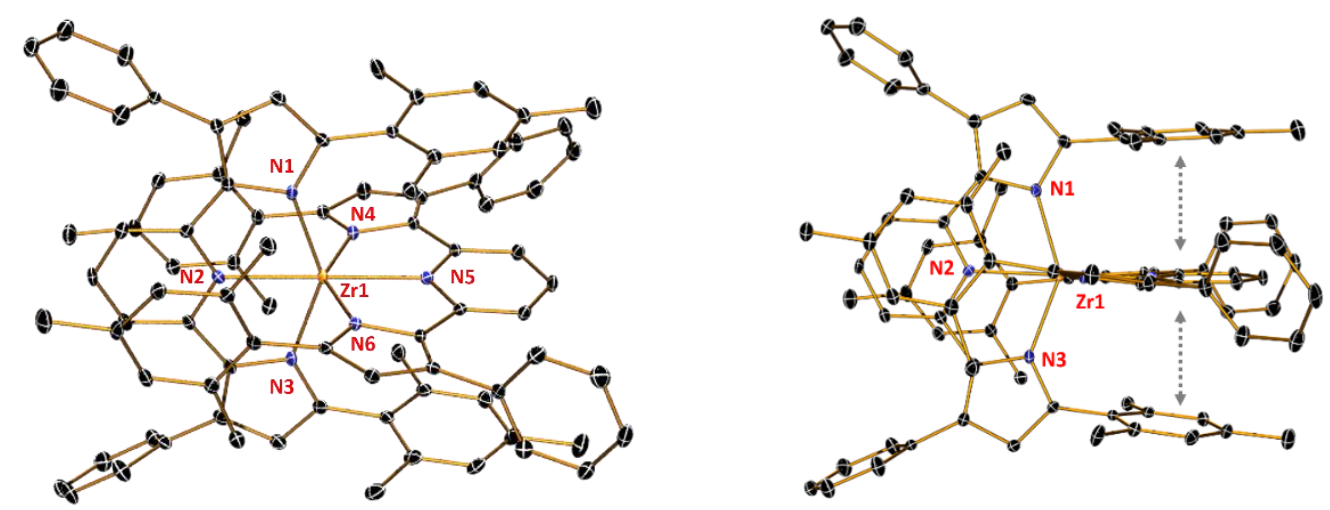

Figure 1. Solid state structure of $\mathrm{Zr}\left({ }^{\mathrm{Mes}} \mathrm{PDP}^{\mathrm{Ph}}\right)_{2}$ at $30 \%$ probability ellipsoids. Side view shown on the left displays $\pi$-stacking effect between two mesityl moiety in one ligand and pyridine unit of second ligand. Hydrogen atoms were omitted for clarity.

Table 1. Selected bond lengths $(\AA)$ and angles $\left({ }^{\circ}\right)$ for $\mathrm{Zr}\left({ }^{\mathrm{Mes}} \mathrm{PDP}^{\mathrm{Ph}}\right)_{2}$.

\begin{tabular}{cc}
\hline & $\mathrm{Zr}\left({ }^{\mathrm{Mes} P D P}{ }^{\mathrm{Ph}}\right)_{2}$ \\
\hline Zr1-N1 & $2.170(2)$ \\
$\mathrm{Zr} 1-\mathrm{N} 2$ & $2.262(2)$ \\
Zr1-N3 & $2.166(2)$ \\
Zr1-N4 & $2.170(2)$ \\
Zr1-N5 & $2.262(2)$ \\
Zr1-N6 & $2.165(2)$ \\
\hline N1-Zr1-N2 & $71.84(8)$ \\
N1-Zr1-N3 & $143.63(8)$ \\
N2-Zr1-N3 & $71.79(8)$ \\
N4-Zr1-N5 & $71.95(7)$ \\
N4-Zr1-N6 & $143.44(7)$ \\
N5-Zr1-N6 & $71.49(8)$ \\
\hline N2-Zr1-N5 & $179.42(8)$ \\
\hline Dihedral angle & 89.57 \\
\hline
\end{tabular}


Further inspection of the crystal structure through a space-filling model for $\operatorname{Zr}\left({ }^{\mathrm{Mes}} \mathrm{PDP}^{\mathrm{Ph}}\right)_{2}$ revealed a tightly packed ligand environment around the metal center (Figure 2, left). By rotating the space-filling model of $\mathrm{Zr}\left({ }^{\mathrm{Mes}} \mathrm{PDP}^{\mathrm{Ph}}\right)_{2}$, we can essentially describe the structure as a "ball of hydrocarbon." The steric enrichment of the $\left[{ }^{\mathrm{Mes}} \mathrm{PDP}^{\mathrm{Ph}}\right]^{2-}$ ligands on the $\mathrm{Zr}\left({ }^{\mathrm{Mes}} \mathrm{PDP}^{\mathrm{Ph}}\right)_{2}$ is in marked contrast with previous $\mathrm{Zr}\left({ }^{\mathrm{Me}} \mathrm{PDP}^{\mathrm{Ph}}\right)_{2}$ (Figure 2, right). $\mathrm{Zr}\left({ }^{\mathrm{Me}} \mathrm{PDP}^{\mathrm{Ph}}\right)_{2}$ is extremely moisturesensitive in both solid state and in solution since it rapidly reacts with water to yield the ligand precursors and $\mathrm{ZrO}_{2}$. From space-filling model of the $\mathrm{Zr}\left({ }^{\mathrm{Me}} \mathrm{PDP}^{\mathrm{Ph}}\right)_{2}$ crystal structure, the metal center (in orange) and highly basic nitrogen atoms (in blue, $\mathrm{pKa}=23$ in DMSO) ${ }^{7}$ are highly exposed to ambient environment which lead to facile hydrolysis by water. Whereas in the case of $\mathrm{Zr}\left({ }^{\mathrm{Mes}} \mathrm{PDP}^{\mathrm{Ph}}\right)_{2}$, we can barely catch sight of zirconium center and basic nitrogen atoms and there is no room possible for water penetration. Consistent with this, $\mathrm{Zr}\left({ }^{\mathrm{Mes}} \mathrm{PDP}^{\mathrm{Ph}}\right)_{2}$ is indeed highly air and water stable and can withstand workup the synthesis under air using "wet" solvents. In fact, the compound was proven to survive in the water enriched DMSO- $d_{6}$ solution for at least 10 days without any noticeable decomposition monitored by ${ }^{1} \mathrm{H}$ NMR. More controlled proton stability tests were also conducted. The $\mathrm{Zr}\left({ }^{\mathrm{Mes}} \mathrm{PDP}^{\mathrm{Ph}}\right)_{2}$ solution was prepared in the air saturated $\mathrm{THF} / \mathrm{HCl}$ (aq.) (9:1 volume ratio, $12 \mathrm{~N}$ concentrated $\mathrm{HCl}$ was used). By monitoring the intensity of $\mathrm{Zr}\left({ }^{\mathrm{Mes}} \mathrm{PDP}^{\mathrm{Ph}}\right)_{2}$ in UV-Vis absorption spectrum over time, $97 \%$ of original absorption intensity remains under ambient condition for 48 hours (see Experimental Section for detail). Similar stability were only found in Zr-MOF (metal organic framework) chemistry or highly oxygenated zirconium clusters. $^{8-10}$ 

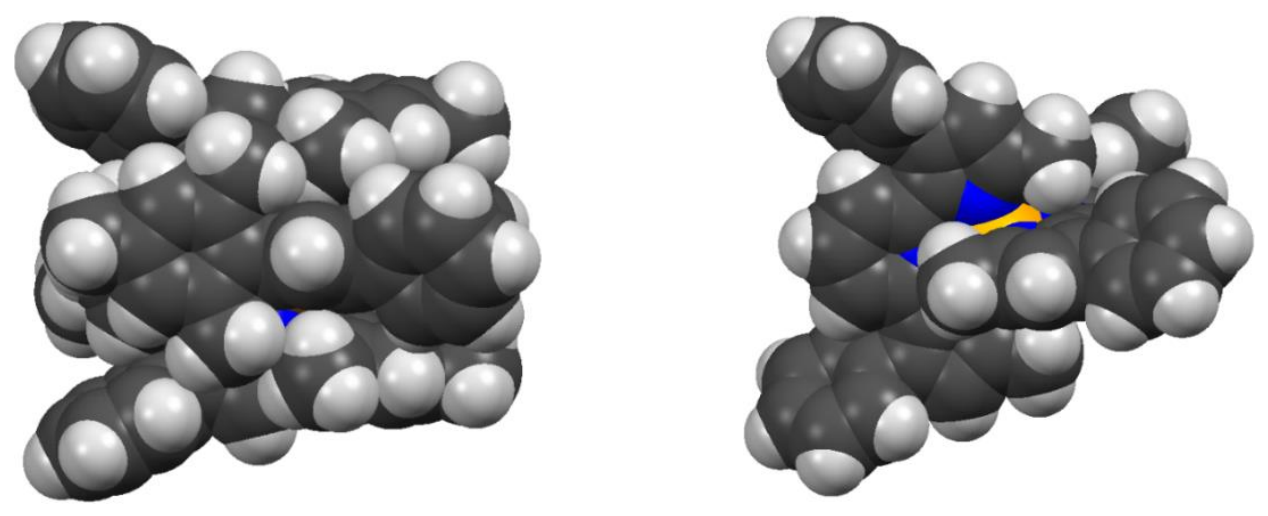

Figure 2. Space-filling models of the solid state structure of $\mathrm{Zr}\left({ }^{\mathrm{Mes}} \mathrm{PDP}^{\mathrm{Ph}}\right)_{2}($ left $)$ and $\mathrm{Zr}\left({ }^{\mathrm{Me}} \mathrm{PDP}{ }^{\mathrm{Ph}}\right)_{2}$ (right). Hydrogen atoms are shown in light gray, carbon atoms are in dark gray, nitrogen atoms are in blue and zirconium is in orange.

\subsection{Photophysical Properties.}

With a highly stable compound in hand, the optical properties of $\mathrm{Zr}\left({ }^{\mathrm{Mes}} \mathrm{PDP}{ }^{\mathrm{Ph}}\right)_{2}$ were studied in benzene, DCM, THF, and DMSO (highly hygroscopic) solutions as well as in PMMA (poly(methyl methacrylate)) film at room temperature. Absorption profiles of $\mathrm{Zr}\left({ }^{\mathrm{Mes}} \mathrm{PDP}^{\mathrm{Ph}}\right)_{2}$ in THF solution are shown in Figure 3 and the spectra recorded in other medium can be found in Appendix A. The absorption maxima $\left(\lambda_{\text {abs-max }}\right)$ for the lowest energy absorption band in various medium are listed in Table 2. The spectroscopic features of $\mathrm{Zr}\left({ }^{\mathrm{Mes}} \mathrm{PDP}^{\mathrm{Ph}}\right)_{2}$ are highly similar to $\mathrm{Zr}\left({ }^{\mathrm{Me}} \mathrm{PDP}{ }^{\mathrm{Ph}}\right)_{2}$ with minor shifts of the four major absorption bands. Changing the solvent from relatively non-polar benzene to highly polar DMSO solution as well as in PMMA shows little solvatochromic behavior for $\mathrm{Zr}\left({ }^{\mathrm{Mes}} \mathrm{PDP}^{\mathrm{Ph}}\right)_{2}$, which the visible light absorption bands shift within 2 $\mathrm{nm}$ of each other. The independence on solvent polarity implies a small dipole moment of $\mathrm{Zr}\left({ }^{\mathrm{Mes}} \mathrm{PDP}{ }^{\mathrm{Ph}}\right)_{2}$ in the ground state. 
The nature of the electronic transitions for new $\mathrm{Zr}\left({ }^{\mathrm{Mes}} \mathrm{PDP}^{\mathrm{Ph}}\right)_{2}$ was studied by time dependent density functional theory (TD-DFT) calculations performed at the B3LYP level. Solvent effects in THF were included using the conductor-like screening model (COSMO). Analogous to previously reported $\mathrm{Zr}\left({ }^{\mathrm{Me}} \mathrm{PDP}^{\mathrm{Ph}}\right)_{2},{ }^{2}$ the lowest energy absorption band is composed of four transitions (two pairs) from an exclusively ligand-centered $\pi$ orbital (HOMO-1 and HOMO) to a degenerate set of orbitals (LUMO and LUMO+1) with $38 \%$ contributions from the metal $\left(\mathrm{d}_{\mathrm{xz}}, \mathrm{d}_{\mathrm{yz}}\right)$. On the basis of this analysis, the transitions giving rise to the absorption band in the visible region are best described as a hybrid ${ }^{1} \mathrm{IL} /{ }^{1} \mathrm{LMCT}$ transition.

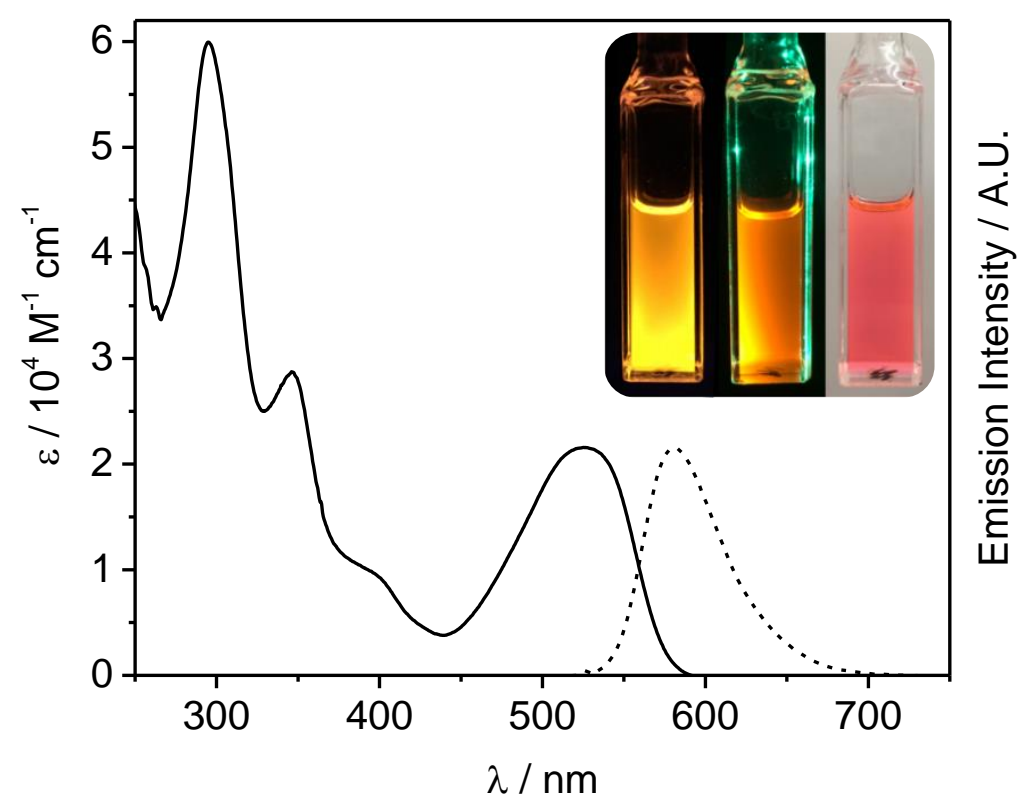

Figure 3. Absorption (solid lines) and emission spectra (dashed lines) of $\mathrm{Zr}\left({ }^{\mathrm{Mes}} \mathrm{PDP}^{\mathrm{Ph}}\right)_{2}$ in THF solution at room temperature. Inset: Photographs of $\mathrm{Zr}\left({ }^{\mathrm{Mes}} \mathrm{PDP}^{\mathrm{Ph}}\right)_{2}$ under UV $(365 \mathrm{~nm})$, Green $(520$ $\mathrm{nm}$ ), and ambient light in THF solution (left) 
Table 2. The absorption $\left({ }^{1} \mathrm{IL} /{ }^{1} \mathrm{LMCT}\right.$ band) and emission maxima recorded in all medium discussed for $\mathrm{Zr}\left({ }^{\mathrm{Mes}} \mathrm{PDP}^{\mathrm{Ph}}\right)_{2}$.

\begin{tabular}{c|c|ccc}
\hline & $\begin{array}{c}\text { Relative } \\
\text { polarity }\end{array}$ & $\lambda_{\text {abs-max }}\left(\mathrm{nm} / \mathrm{cm}^{-1}\right)$ & $\lambda_{\text {em-max }}\left(\mathrm{nm} / \mathrm{cm}^{-1}\right)$ & $\begin{array}{c}\text { FWHM }\left(\mathrm{cm}^{-1}\right) \text { for } \\
\text { emission band }\end{array}$ \\
\hline $\mathrm{C}_{6} \mathrm{H}_{6}$ & 0.111 & $528 / 18940$ & $581 / 17210$ & 1580 \\
$\mathrm{THF}$ & 0.207 & $526 / 19010$ & $580 / 17240$ & 1610 \\
$\mathrm{DCM}$ & 0.309 & $526 / 19010$ & $581 / 17210$ & 1590 \\
DMSO & 0.444 & $526 / 19010$ & $581 / 17210$ & 1650 \\
PMMA film & $/$ & $526 / 19010$ & $599 / 16690$ & 1320 \\
\hline
\end{tabular}

a The values for relative polarity are normalized from measurements of solvent shifts of absorption spectra and were extracted from ref $^{11}$.

$\mathrm{Zr}\left({ }^{\mathrm{Mes}} \mathrm{PDP}^{\mathrm{Ph}}\right)_{2}$ emits orange light upon excitation at the lowest energy absorption maximum

(Figure 3, Figure 4 and Apendix A). The emission peak maxima in various medium are listed in Table 2. Similar to the trend observed for the absorption profile of $\mathrm{Zr}\left({ }^{\mathrm{Mes}} \mathrm{PDP}^{\mathrm{Ph}}\right)_{2}$ in different solvents, the emission maxima are almost identical when switching solvents. The changeless luminescence band position and only slight broadening (indicated by full-width at half-maximum values (FWHM), Table 2) with increasing fluid polarity was observed. The excited state structure distortion seems neglectable, evident only $~ 4 \%$ change in luminescence FWHM when switching solvent with large polarity window (from benzene to DMSO). The experimental observations are consistent with a similar-symmetry of $\mathrm{Zr}\left({ }^{\mathrm{Mes}} \mathrm{PDP}^{\mathrm{Ph}}\right)_{2}$ excited state geometry that has an indistinguishable dipole moment change compared to its ground state structure due to the highly fixed ligand environment. For comparison, $\left[\mathrm{Ru}(\mathrm{bpy})_{3}\right]^{2+}$ has a FWHM of $\sim 2750-3030 \mathrm{~cm}^{-1}$ depending on the solvent employed. ${ }^{12}$ The Stokes shift of the $\operatorname{Zr}\left({ }^{\mathrm{Mes}} \mathrm{PDP}^{\mathrm{Ph}}\right)_{2}$ is $1770 \mathrm{~cm}^{-1}$, which 
is much smaller compare to $\mathrm{Zr}\left({ }^{\mathrm{Me}} \mathrm{PDP}^{\mathrm{Ph}}\right)_{2}\left(2200 \mathrm{~cm}^{-1}\right)$. The smaller energy loss in the excited states for $\mathrm{Zr}\left({ }^{\mathrm{Mes}} \mathrm{PDP}^{\mathrm{Ph}}\right)_{2}$ again features the high rigidity of the new ligand framework, $\left[{ }^{\mathrm{Mes}} \mathrm{PDP}^{\mathrm{Ph}}\right]^{2-}$.

The photoluminescence of $\mathrm{Zr}\left({ }^{\mathrm{Mes}} \mathrm{PDP}^{\mathrm{Ph}}\right)_{2}$ was almost completely quenched in THF solution under air. Conversely, when measuring the emission of $\mathrm{Zr}\left({ }^{\mathrm{Mes}} \mathrm{PDP}^{\mathrm{Ph}}\right)_{2}$ in a PMMA matrix under air, significant luminescence intensity remains (Figure 4). The reason for partial luminescence quenching is currently under investigation. Interestingly, while the absorption profile in PMMA is almost identical compared to those in fluid solution (Appendix A), the emission shows smaller band FWHM and more structured band shape with a large red shift in peak maxima by $\sim 20 \mathrm{~nm}$ in PMMA. This bathochromic shift in a more rigid medium is in marked contrast to examples found in the literature for Mo, W, Re, Ir, and Pt photosensitizers. ${ }^{13-16}$ For those transition metal luminophores, a hypsochromic shift has been related to the destabilization of ${ }^{3}$ MLCT state and typically results from the reverse of the dipole moment in the excited states. ${ }^{13,17,18}$ Thus, the rigidochromic red shift for $\mathrm{Zr}\left({ }^{\mathrm{Mes}} \mathrm{PDP}^{\mathrm{Ph}}\right)_{2}$ in more rigid PMMA suggests the excited state dipole moment has the same orientation as its ground-state counterpart, potentially due to large organic protection that surrounds the $\mathrm{Zr}(\mathrm{PDP})_{2}$ core. 


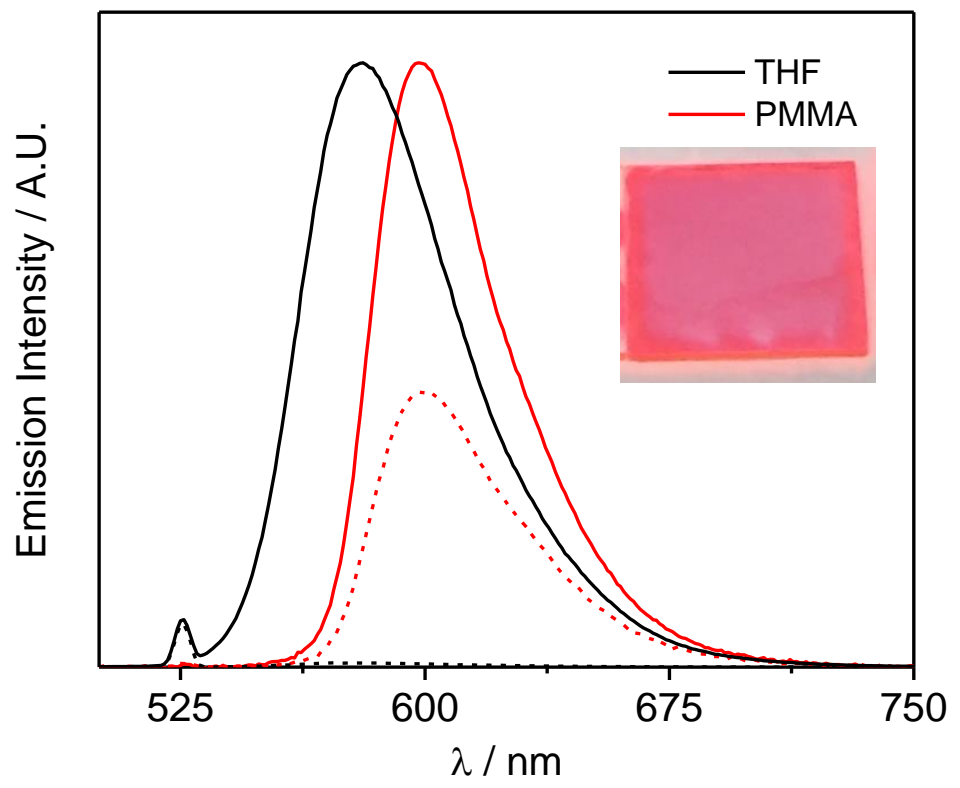

Figure 4. Emission spectra of $\mathrm{Zr}\left({ }^{\mathrm{Mes}} \mathrm{PDP}^{\mathrm{Ph}}\right)_{2}$ in THF under $\mathrm{N}_{2}$ atmosphere (black solid line) and upon exposure to air (black dotted line), as well as in PMMA upon air exposure for 1 minute (red solid line) and 2 hours (red dotted line). Inset: a photograph of the PMMA thin-film sample.

Photoluminescent quantum yield $\left(\Phi_{\mathrm{PL}}\right)$ and lifetime $(\tau)$ of $\mathrm{Zr}\left({ }^{\mathrm{Mes}} \mathrm{PDP}^{\mathrm{Ph}}\right)_{2}$ were determined under optically dilute $(<0.1$ absorbance) conditions in solution of all four solvents at room temperature. As shown in Table $3, \mathrm{Zr}\left({ }^{\mathrm{Mes}} \mathrm{PDP}^{\mathrm{Ph}}\right)_{2}$ exhibits $\Phi_{\mathrm{PL}}$ values ranging from 0.38 to 0.45 in different solvents. The long lifetime of hundreds of microseconds is again consistent with the emission behavior involving spin forbidden transitions from a triplet state. Noticeably, both properties are better than what is known for the benchmark photosensitizers: $\mathrm{Ru}(\mathrm{bpy})_{3}{ }^{2+}\left(\Phi_{\mathrm{PL}}=\right.$ $0.09, \tau=0.9 \mu \mathrm{s})^{19}$ and $\operatorname{Ir}(\mathrm{ppy})_{3}\left(\Phi_{\mathrm{PL}}=0.40, \tau=2.0 \mu \mathrm{s}\right) .{ }^{14}$ When changing solvent from THF to DMSO, the quantum yield and lifetime both decrease with increasing solvent polarity. In non-polar benzene solvent, however, the $\Phi_{\mathrm{PL}}$ and lifetime of $\mathrm{Zr}\left({ }^{\mathrm{Mes}} \mathrm{PDP}^{\mathrm{Ph}}\right)_{2}$ are the lowest. This phenomenon 
implies that the $\pi$-stacking effect between the benzene and ligand's aromatic systems serve as other radiationless pathway.

The radiative $\left(k_{r}\right)$ and non-radiative $\left(k_{n r}\right)$ decay rate constants calculated from the quantum yield and the corresponding lifetime data can be found in Table 3. The value of $k_{n r}$ is larger than $k_{r}$ in all solvent. Furthermore, $k_{r}$ value remains reasonably similar while $k_{n r}$ varies greatly, spanning $688 \mathrm{~s}^{-1}$ within each solvent. The nonradiative decay rates increase in more polar medium except for benzene, which again indicated the importance of solvent polarity and the solvent-solute $\pi$ stacking interaction in influencing $\mathrm{Zr}\left({ }^{\mathrm{Mes}} \mathrm{PDP}^{\mathrm{Ph}}\right)_{2}{ }^{*}$ 's non-radiative decay dynamics. In THF solution, the $\Phi_{\mathrm{PL}}$ of $\mathrm{Zr}\left({ }^{\mathrm{Mes}} \mathrm{PDP}^{\mathrm{Ph}}\right)_{2}$ increases significantly to almost three times that of $\mathrm{Zr}\left({ }^{\mathrm{Me}} \mathrm{PDP}^{\mathrm{Ph}}\right)_{2}(0.12)$ and the lifetime is longer than $325 \mu$ s for $\mathrm{Zr}\left({ }^{\mathrm{Me}} \mathrm{PDP}^{\mathrm{Ph}}\right)_{2}$. Also, in THF, the extracted radiative decay rate constant of $\mathrm{Zr}\left({ }^{\mathrm{Mes}} \mathrm{PDP}^{\mathrm{Ph}}\right)_{2}$ is four fold higher than $\mathrm{Zr}\left({ }^{\mathrm{Me}} \mathrm{PDP}^{\mathrm{Ph}}\right)_{2}(369$ $\left.\mathrm{s}^{-1}\right)$ and a much smaller $k_{n r}$ value for $\operatorname{Zr}\left({ }^{\mathrm{Mes}} \mathrm{PDP}^{\mathrm{Ph}}\right)_{2}\left(1571 \mathrm{~s}^{-1}\right)$ comparing to the $2708 \mathrm{~s}^{-1}$ of $\mathrm{Zr}\left({ }^{\mathrm{Me}} \mathrm{PDP}^{\mathrm{Ph}}\right)_{2}$. The superior excited state decay parameters of $\mathrm{Zr}\left({ }^{\mathrm{Mes}} \mathrm{PDP}^{\mathrm{Ph}}\right)_{2}$ once more highlights a rigid ligand architecture leading to a reduced excited state vibrational cooling process.

Table 3. Excited state decay parameters in various solvent for $\operatorname{Zr}\left({ }^{\mathrm{Mes}} \mathrm{PDP}^{\mathrm{Ph}}\right)_{2}{ }^{\mathrm{a}}{ }^{\mathrm{a}}$

\begin{tabular}{c|c|cccc}
\hline & $\begin{array}{c}\text { relative } \\
\text { polarity }\end{array}$ & $\tau / \mu \mathrm{s}$ & $\Phi_{\mathrm{PL}}$ & $k_{r}\left(\mathrm{~s}^{-1}\right)$ & $k_{n r}\left(\mathrm{~s}^{-1}\right)$ \\
\hline $\mathrm{C}_{6} \mathrm{H}_{6}$ & 0.111 & 290 & 0.38 & 1310 & 2138 \\
$\mathrm{THF}$ & 0.207 & 350 & 0.45 & 1286 & 1571 \\
$\mathrm{DCM}$ & 0.309 & 330 & 0.41 & 1242 & 1788 \\
$\mathrm{DMSO}$ & 0.444 & 270 & 0.39 & 1444 & 2259 \\
\hline
\end{tabular}

${ }^{\mathrm{a}} \mathrm{k}_{\mathrm{r}}=\Phi_{\mathrm{PL}} / \tau, \mathrm{k}_{\mathrm{nr}}=\left(1-\Phi_{\mathrm{PL}}\right) / \tau .{ }^{\mathrm{b}}$ from ref. 11. 
To probe the early excited state properties of $\mathrm{Zr}\left({ }^{\mathrm{Mes}} \mathrm{PDP}^{\mathrm{Ph}}\right)_{2}$, in particular the events related to ISC, transient absorption (TA) spectra have been recorded (Figure 5). When excited at $480 \mathrm{~nm}$ in THF at 250 fs delay time, $\mathrm{Zr}\left({ }^{\mathrm{Mes}} \mathrm{PDP}^{\mathrm{Ph}}\right)_{2}$ displays three excited-state absorption (ESA) band at $\sim 480,570$ and $725 \mathrm{~nm}$ as well as a stimulated emission (SE) band at $610 \mathrm{~nm}$ (Figure 5D). However, this excited state quickly transformed into another state with highly similar features within $2.5 \mathrm{ps}$. The rate constant for this process, $1.0 \mathrm{ps}$, was determined via global analysis (GA, Figure 5B), which was assigned as an internal conversion (IC) process caused by minor geometry rearrangement. After IC, the excited states dynamics observed in the TA spectra are very close to that of $\mathrm{Zr}\left({ }^{\mathrm{Me}} \mathrm{PDP}^{\mathrm{Ph}}\right)_{2}$ previously ascribed. So, this new excited state observed at $2.5 \mathrm{ps}$ was assigned as ${ }^{1}$ MLCT state. Again, this ${ }^{1}$ MLCT state cleanly converted to a long-lived ${ }^{3}$ MLCT state within 200 ps. The GA yielded an intersystem crossing rate constant of $12 \mathrm{ps}$ (Figure 5B). The ISC rate for $\mathrm{Zr}\left({ }^{\mathrm{Mes}} \mathrm{PDP}^{\mathrm{Ph}}\right)_{2}$ is faster than that of $\mathrm{Zr}\left({ }^{\mathrm{Me}} \mathrm{PDP}^{\mathrm{Ph}}\right)_{2}{ }^{*}(18 \mathrm{ps})$, which is likely attributed to a more similar geometry between the singlet and triplet excited states enforced by more rigid ligand system in the case of $\mathrm{Zr}\left({ }^{\mathrm{Mes}} \mathrm{PDP}^{\mathrm{Ph}}\right)_{2}$. 

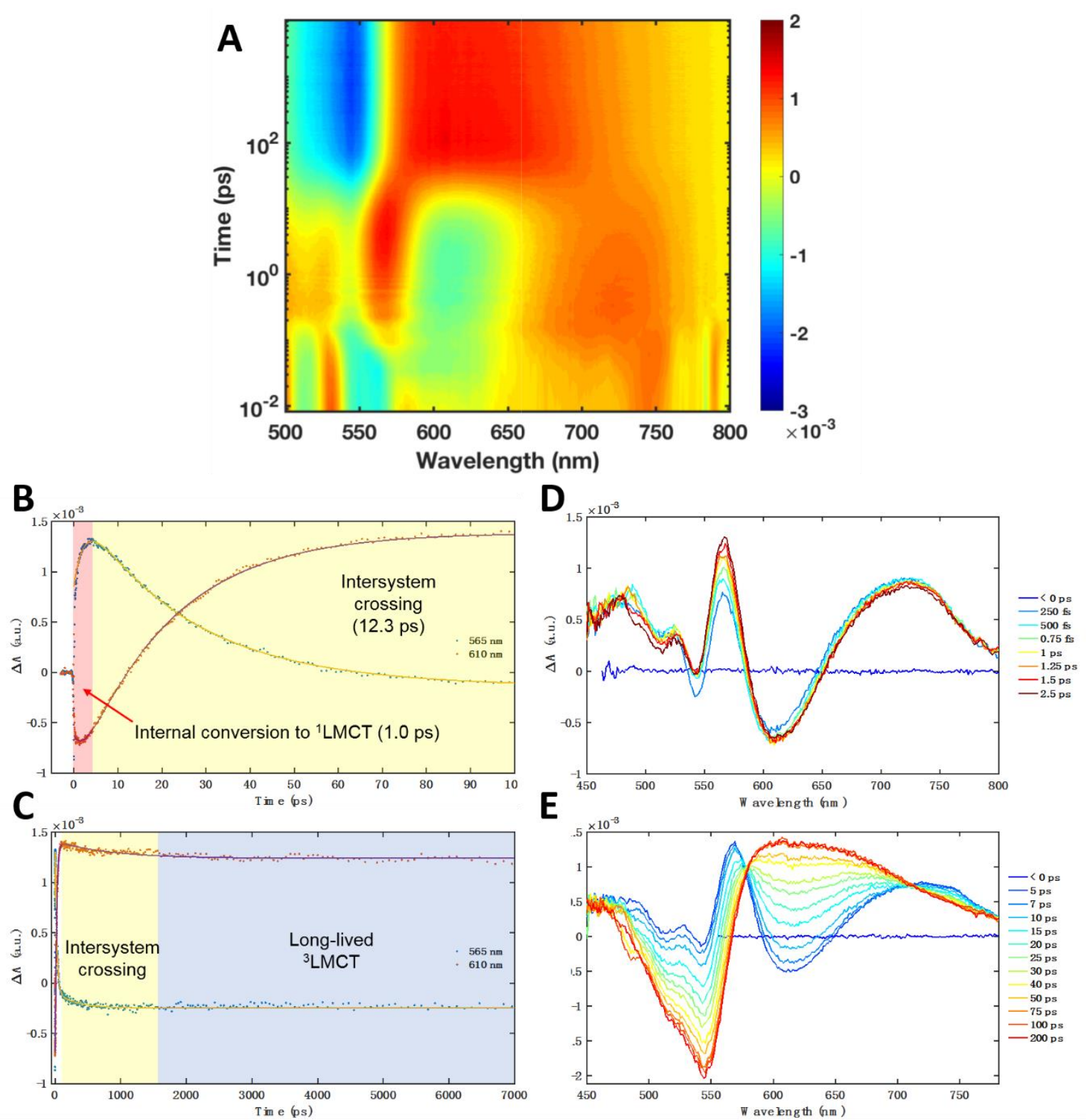

Figure 5. Summary of $\mathrm{TA}$ results for $\mathrm{Zr}\left({ }^{\mathrm{Mes}} \mathrm{PDP}^{\mathrm{Ph}}\right)_{2}$ in $\mathrm{THF}$ at $295 \mathrm{~K}$. (A) Contour map of $\mathrm{Zr}\left({ }^{\mathrm{Mes}} \mathrm{PDP}^{\mathrm{Ph}}\right) \mathrm{TA}$ at $295 \mathrm{~K}$. (B) and (C) Kinetics and fits monitored at $565 \mathrm{~nm}$ and $610 \mathrm{~nm}$ generated by global analysis. (D) and (E) TA spectra at selected delay times ranging from $250 \mathrm{fs}$ to $200 \mathrm{ps}$. 


\subsection{Electrochemical Properties.}

Besides readily accessible photoluminescent excited states, reversible redox chemistry is a second hallmark of most photosensitizers. To establish the electrochemical properties of $\mathrm{Zr}\left({ }^{\mathrm{Mes}} \mathrm{PDP}{ }^{\mathrm{Ph}}\right)_{2}$, cyclic voltammetry $(\mathrm{CV})$ experiments were conducted in THF solution using ferrocene (Fc) as an internal standard (Figure 6). Upon reduction, $\mathrm{Zr}\left({ }^{\mathrm{Mes}} \mathrm{PDP}^{\mathrm{Ph}}\right)_{2}$ displays two fully reversible redox events at $-2.25 \mathrm{~V}$ and $-2.95 \mathrm{~V}$, which were assigned to one-electron reductions of the complex. To our surprise, when applying oxidation potentials, two unprecedented reversible oxidation events were observed at $+0.53 \mathrm{~V}$ and $+0.82 \mathrm{~V}$. Whereas the previous $\mathrm{Zr}\left({ }^{\mathrm{Me}} \mathrm{PDP}{ }^{\mathrm{Ph}}\right)_{2}$ was observed to quickly decompose upon oxidation. Due to the absence of any metal d electron, these oxidation features can readily be assigned as ligand centered oxidations.

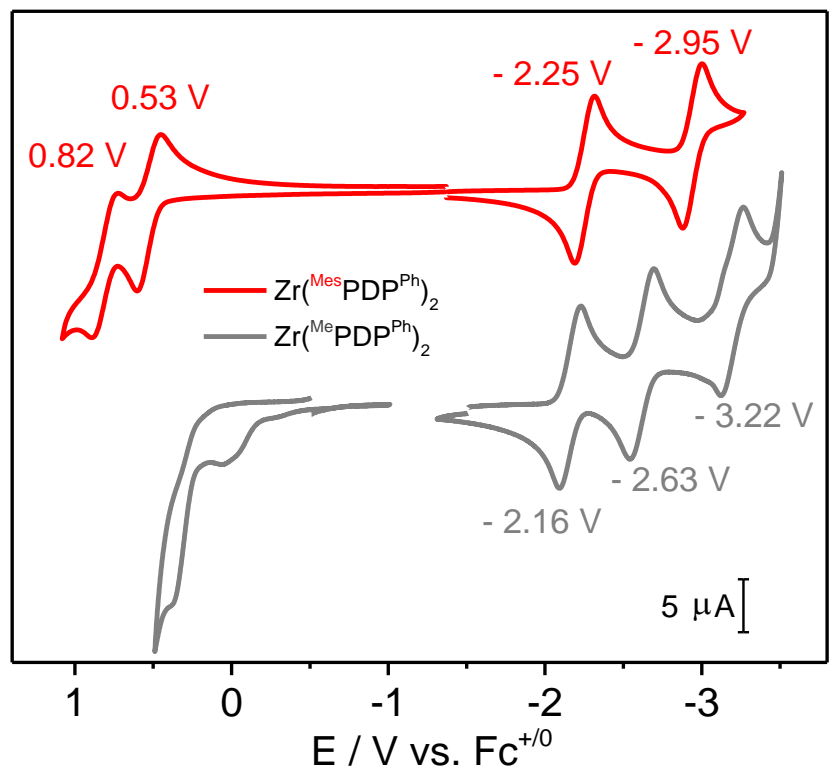

Figure 6. Cyclic voltammogram of $\mathrm{Zr}\left({ }^{\mathrm{Mes}} \mathrm{PDP}^{\mathrm{Ph}}\right)_{2}$ (red) and $\mathrm{Zr}\left({ }^{\mathrm{Me}} \mathrm{PDP}^{\mathrm{Ph}}\right)_{2}$ (gray) in $\mathrm{THF}$ at room temperature (scan rate $200 \mathrm{mV} \mathrm{s}^{-1}, 0.1 \mathrm{M}\left[\mathrm{N}(n-\mathrm{Bu})_{4}\right] \mathrm{PF}_{6}$, glassy carbon working electrode). 
To further investigate the nature of the reversible oxidation process of $\mathrm{Zr}\left({ }^{\mathrm{Mes}} \mathrm{PDP}^{\mathrm{Ph}}\right)_{2}$, we looked at the highest occupied molecular orbital of $\mathrm{Zr}\left({ }^{\mathrm{Mes}} \mathrm{PDP}^{\mathrm{Ph}}\right)_{2}$ from which the electron is removed. From computational results, $41 \%$ of pyrrole $\left(2,5\right.$-postion) character, $11 \% 3-\mathrm{C}_{\text {pyrrole }}$ character and $23 \%$ pyridine (3,5-position) character were found as major contribution to the HOMO as shown in Figure 7. Upon careful inspection of the space-filling model of $\mathrm{Zr}\left({ }^{\mathrm{Mes}} \mathrm{PDP}{ }^{\mathrm{Ph}}\right)_{2}$, we found the $3,5-\mathrm{C}_{\mathrm{pyridine}}$ were protected by the phenyl group and the para-methyl groups of mesityl unit, while the $2,5-\mathrm{C}_{\text {pyrrole }}$ also were blocked by the ortho-methyl groups of the mesityl moieties. Such ligand arrangement is in marked difference comparing to $\mathrm{Zr}\left({ }^{\mathrm{Me}} \mathrm{PDP}^{\mathrm{Ph}}\right)_{2}$, where the major oxidation sites on pyrrole moieties are mostly exposed (Figure 7). The steric protection introduced by the bulky mesityl substituents confers increased stability to the oxidation products compared to $\mathrm{Zr}\left({ }^{\mathrm{Mes}} \mathrm{PDP}^{\mathrm{Ph}}\right)_{2}$ and enables reversible oxidative electrochemistry.
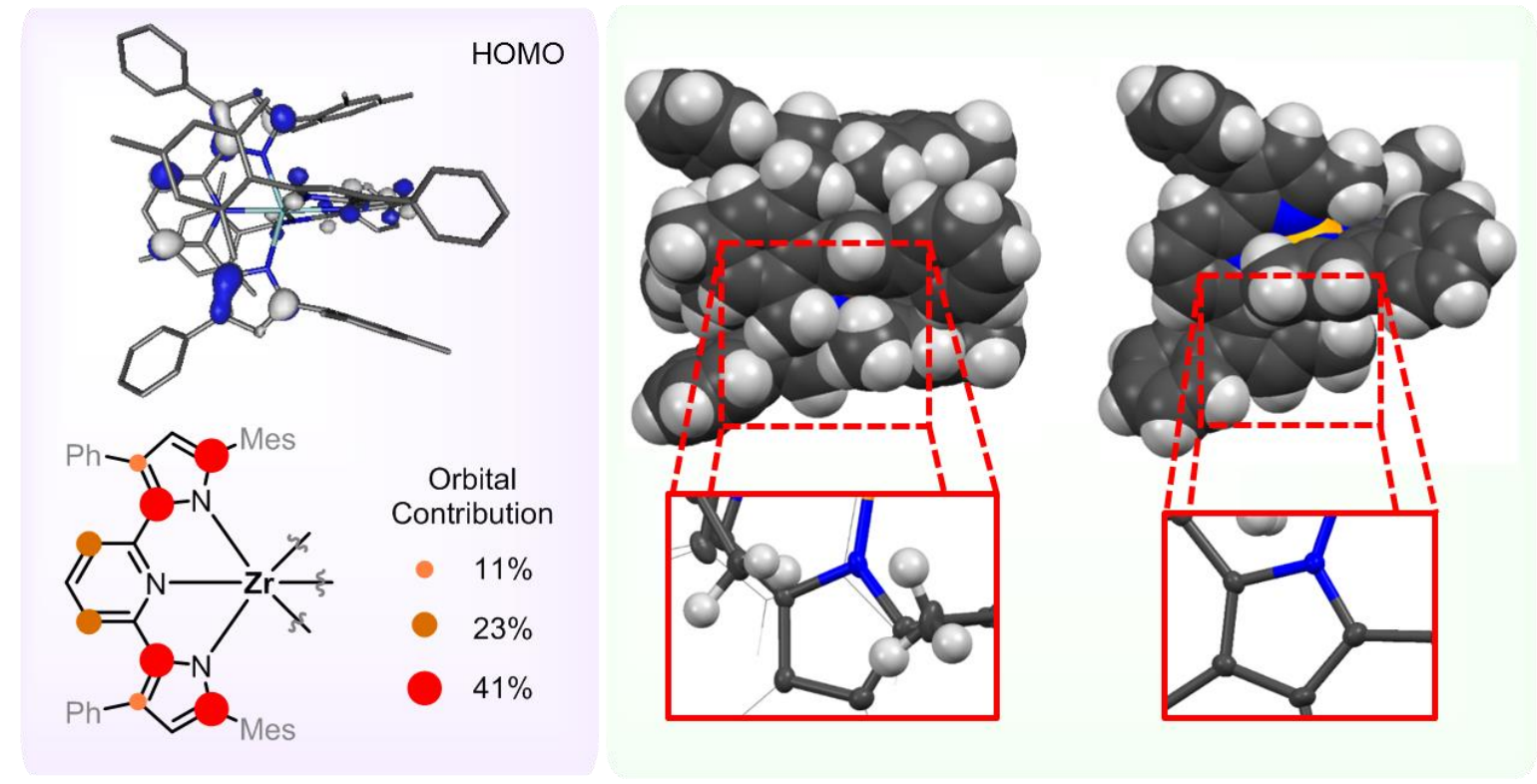

Figure 7. The HOMO of $\mathrm{Zr}\left({ }^{\mathrm{Mes}} \mathrm{PDP}^{\mathrm{Ph}}\right)_{2}$ (left) from DFT calculation, the space-filling model with amplified pyrrole unit for $\mathrm{Zr}\left({ }^{\mathrm{Mes}} \mathrm{PDP}^{\mathrm{Ph}}\right)_{2}$ (middle) and $\mathrm{Zr}\left({ }^{\mathrm{Mes}} \mathrm{PDP}^{\mathrm{Ph}}\right)_{2}$ (right) was shown. 


\subsection{Estimation of Excited State Potentials.}

With both ground state reversible reduction and reversible oxidation electrochemical behavior of $\mathrm{Zr}\left({ }^{\mathrm{Mes}} \mathrm{PDP}^{\mathrm{Ph}}\right)_{2}$ as well as long-lived emissive states in hand, we should now be able to conduct both reductive/oxidative quenching cycles using this new complex. The excited state potential for the $\mathrm{Zr}\left({ }^{\mathrm{Mes}} \mathrm{PDP}^{\mathrm{Ph}}\right)_{2} * /\left[\mathrm{Zr}\left({ }^{\mathrm{Mes}} \mathrm{PDP}^{\mathrm{Ph}}\right)_{2}\right]^{1-}$ and $\mathrm{Zr}\left({ }^{\mathrm{Mes}} \mathrm{PDP}^{\mathrm{Ph}}\right)_{2}{ }^{*} /\left[\mathrm{Zr}\left({ }^{\mathrm{Mes}} \mathrm{PDP}{ }^{\mathrm{Ph}}\right)_{2}\right]^{1+}$ redox couples were estimated as $-0.12 \mathrm{~V}$ vs. $\mathrm{Fc}^{+/ 0}$ and $-1.60 \mathrm{~V}$ vs. $\mathrm{Fc}^{+/ 0}$, respectively, using the RehmWeller formalism (Scheme 2). ${ }^{20}$ The $\mathrm{Zr}\left({ }^{\mathrm{Mes}} \mathrm{PDP}^{\mathrm{Ph}}\right)_{2}$ * not only can serve as a mild oxidant for the reductive quenching chemistry but also maybe used as a strong reducutant for carring out oxidative photoredox reactions.

Scheme 2. Estimation of the excited state potential for $\mathrm{Zr}\left({ }^{\mathrm{Me} P D P}{ }^{\mathrm{Ph}}\right)_{2}$ using Rehm-Weller formalism.

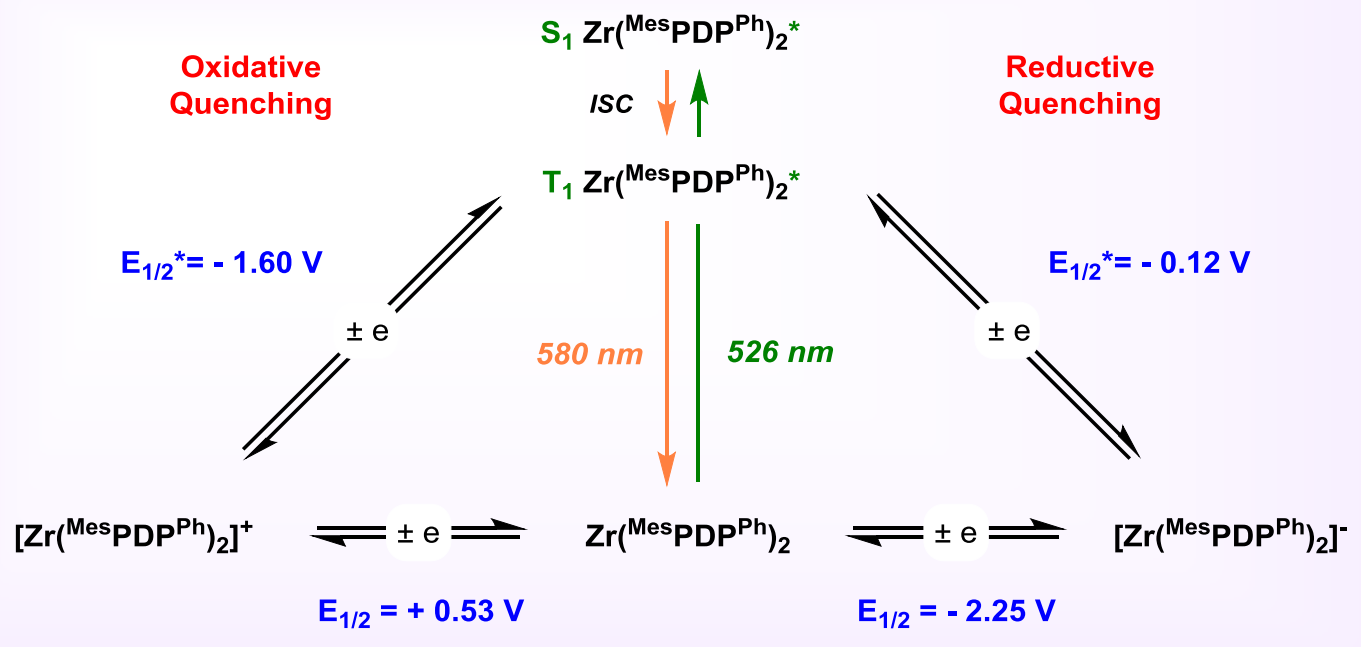




\subsection{Photoredox Catalysis Using $\mathrm{Zr}\left({ }^{\mathrm{Mes}} \mathrm{PDP} \mathrm{Ph}^{\mathrm{Ph}}\right)$.}

To test the abilities of $\mathrm{Zr}\left({ }^{\mathrm{Mes}} \mathrm{PDP}{ }^{\mathrm{Ph}}\right)_{2}$ as a photocatalyst in oxidative photoredox catalysis, atom transfer radical addition (ATRA) reactions were first explored (Scheme 3). Photocatalytic ATRA reactions using alkyl halide and olefin for the construction of complex organic molecules were first achieved in $2010 .^{21}$ This atom economic transformation does not require any external sacrificial electron donor (or acceptor), which is the major advantage over reductive quenching photocatalysis. Irradiation of a mixture of 5-hexen-1-ol and two equivalents of ethyl bromodifluoroacetate in DMSO- $d_{6}$ in the presence of catalytic amount of of $\mathrm{Zr}\left({ }^{\mathrm{Mes}} \mathrm{PDP}{ }^{\mathrm{Ph}}\right)_{2}$ with green LED light $\left(\lambda_{\max }=520 \mathrm{~nm}\right)$ resulted in $81 \%$ yield of desired ethyl 4-bromo-2,2-difluoro-8hydroxyoctanoate in 48 hours. No reaction was observed in the absence of either light or $\mathrm{Zr}\left({ }^{\mathrm{Mes}} \mathrm{PDP}^{\mathrm{Ph}}\right)_{2}$. Under similar reaction condition, diethyl 2-(2-bromo-3-(Bocamino)propyl)malonate (Boc=tert-butoxycarbonyl) can be synthesized in $89 \%$ yield using diethyl bromomalonate and Boc-allylamine.

Encouraged by these results, we sought to carry out direct $\mathrm{C}-\mathrm{H}$ functionalization reactions using $\mathrm{Zr}\left({ }^{\mathrm{Mes}} \mathrm{PDP}{ }^{\mathrm{Ph}}\right)_{2}$. In contrast to traditional methods, direct $\mathrm{C}-\mathrm{H}$ activation-functionalization does not require pre-activation of the substrates and is highly efficient to achieve late stage modification of existing substrates. The oxidative quenching $\mathrm{C}_{\mathrm{sp} 2}-\mathrm{H}$ trifluoromethylation using Togni's reagent II as an electrophilic $\mathrm{CF}_{3}$ source was previously achieved with aniline, indole and benzimidazole derivatives. ${ }^{22-24}$ Here, the $\mathrm{C}-\mathrm{H}$ trifluoromethylation of electron rich arene and 
simple benzene with a slight excess of Togni's reagent II furnishes trifluoromethylated products in moderate to excellent yield using $1 \mathrm{~mol} \% \mathrm{Zr}\left({ }^{\mathrm{Mes}} \mathrm{PDP}^{\mathrm{Ph}}\right)_{2}$. Using our new zirconium photocatalyst, we were able to realize similar reactivity to the precious systems without any external reagents such as base or additive. In fact, $\sim 1: 1$ ratio of 2-iodobenzoic acid was observed after reaction trifluoromethylation of 1,3,5-trimethoxybenzene implying 2-iodobenzoate was generated and served as a base during the reaction. Again, almost no reaction was seen in the absence of zirconium catalyst or in the dark.

Photocatalytic C-H arylation reactions using aryl diazonium salts can be viewed as undergoing a similar reaction pathway to the $\mathrm{C}-\mathrm{H}$ trifluoromethylation. Aryl diazonium salts are well-known quenchers in oxidative photoredox chemistry, which were commonly engaged as radical arylation reagents in cross coupling reactions. ${ }^{25}$ Here, using an excess of benzene in combination of 4-nitrobenzenediazonium salt as the coupling partner, the desired biaryl compound was obtained in $72 \%$ yield using $1 \mathrm{~mol} \% \mathrm{Zr}\left({ }^{\mathrm{Mes}} \mathrm{PDP}^{\mathrm{Ph}}\right)_{2}$. Control experiments ruled out any significant background reactions without light or zirconium catalyst. 
Scheme 3. Selected oxidative quenching photoredox catalysis using $\mathrm{Zr}\left({ }^{\mathrm{Mes}} \mathrm{PDP}{ }^{\mathrm{Ph}}\right)_{2}$.

Atom Transfer Radical Addition:

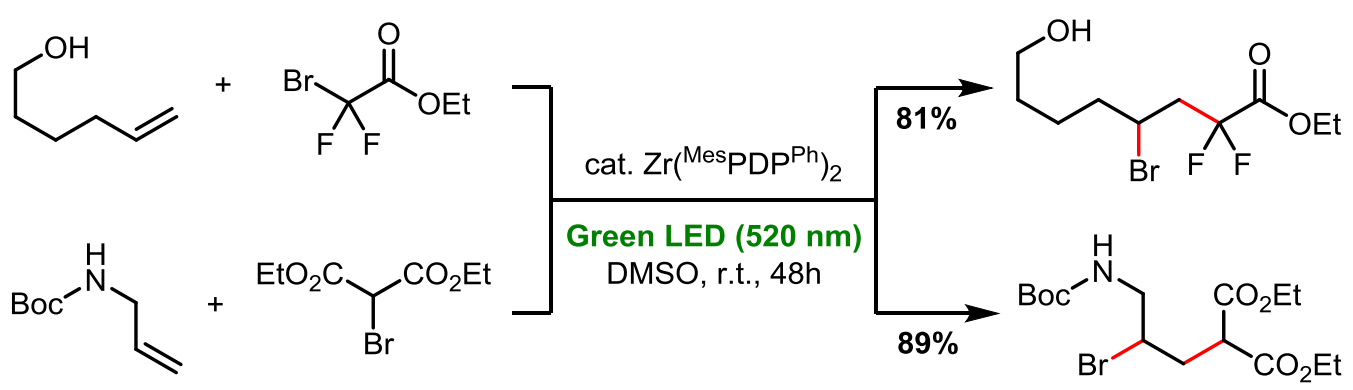

C-H Trifluoromethylation:

$$
\text { Ar-H }
$$

C-H Arylation:<smiles>COc1cc(OC)c(C(F)(F)F)c(OC)c1</smiles>

4 h, $86 \%$<smiles>Nc1ccc(Br)cc1C(F)(F)F</smiles>

22 h, $45 \%$<smiles>FC(F)(F)c1ccccc1</smiles>

$15 \mathrm{~h}, 55 \%$<smiles>FC(F)(F)c1ccc[nH]1</smiles>

$1 \mathrm{~h}, 88 \%$

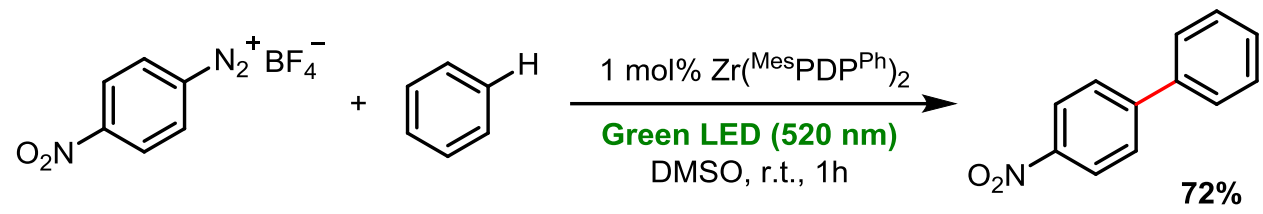

In three oxidative quenching photoredox reactions, the $\mathrm{Zr}\left({ }^{\mathrm{Mes}} \mathrm{PDP} \mathrm{Ph}^{\mathrm{Ph}}\right)_{2}$ served as a replacement for initially developed conditions using Ru or Ir based precious metal catalysts. The photoexcited $\mathrm{Zr}\left({ }^{\mathrm{Mes}} \mathrm{PDP}^{\mathrm{Ph}}\right)_{2} *$ can serve as a strong reductant $\left(\mathrm{E}_{1 / 2}{ }^{+1 / 0 *}=-1.60 \mathrm{~V}\right.$ vs. $\left.\mathrm{Fc}^{+/ 0}\right)$, capable of donating an electron to ethyl bromodifluoroacetate $\left(\mathrm{E}^{\mathrm{red}}=-0.57 \mathrm{~V}\right.$ vs. SCE$){ }^{26}$ Togni's reagent II $\left(\mathrm{E}^{\mathrm{red}}=-1.34 \mathrm{~V} \text { vs. } \mathrm{Fc}^{+/ 0}\right)^{27}$ and 4-nitrobenzenediazonium tetrafluoroborate $\left(\mathrm{E}^{\mathrm{red}}=+0.2 \mathrm{~V}\right.$ vs. SCE$),{ }^{28}$ generating radical anionic species with concurrent oxidization of the photocatalyst to 
$\left[\mathrm{Zr}\left({ }^{\mathrm{Mes}} \mathrm{PDP}^{\mathrm{Ph}}\right)_{2}\right]^{+}$. The radical anion fragmented into an alkyl radical or an aryl radical that can be trapped by an electrophile (olefin or arene). The resulting new radical species can be oxidized by $\left[\mathrm{Zr}\left({ }^{\mathrm{Mes}} \mathrm{PDP}^{\mathrm{Ph}}\right)_{2}\right]^{+}$to deliver a cationic species, which can either combine with halide to complete the ATRA reaction or be deprotonate with a base to provide $\mathrm{C}-\mathrm{H}$ functionalization products (Scheme 4).

Scheme 4. Proposed reaction pathways for three oxidative quenching reactions described here.

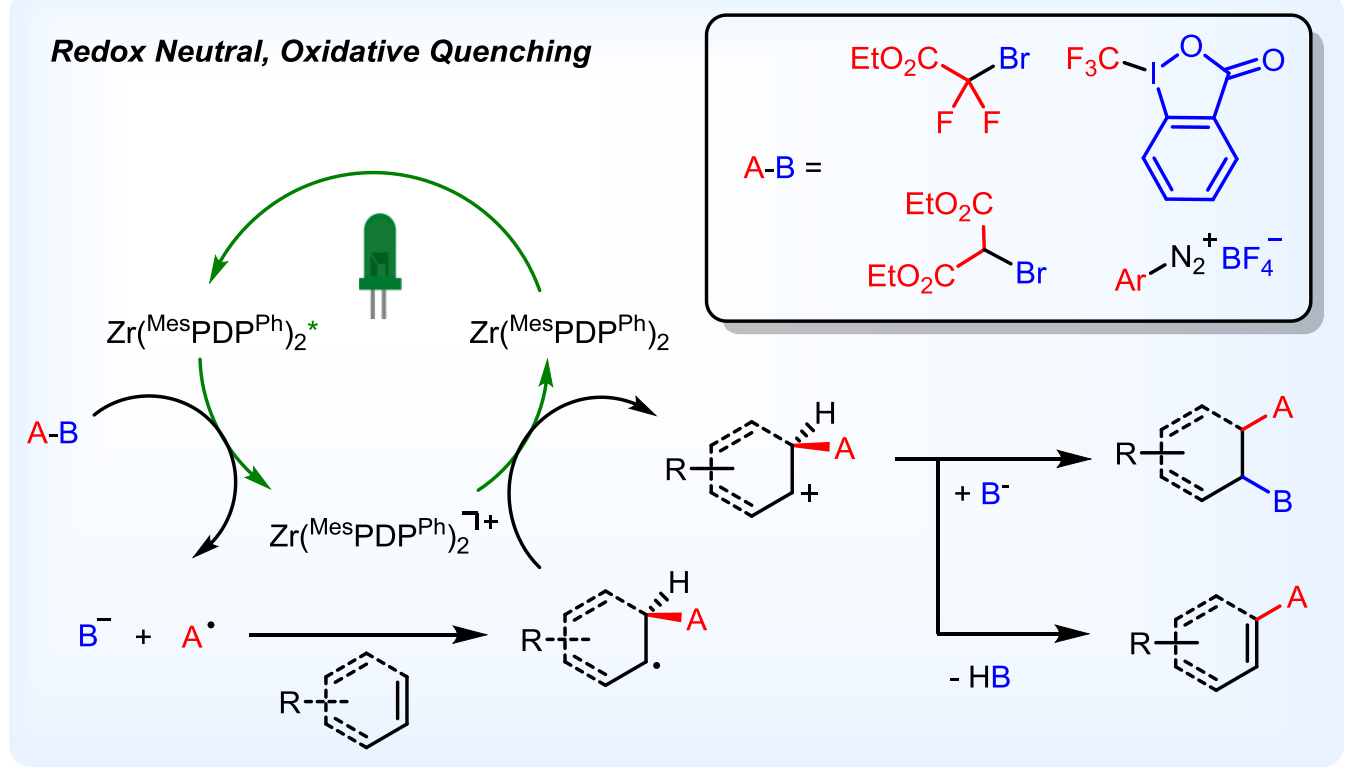

To test if $\mathrm{Zr}\left({ }^{\mathrm{Mes}} \mathrm{PDP}^{\mathrm{Ph}}\right)_{2}$ retains catalytic reactivities as its methyl analogue for reductive quenching photoredox reaction, our benchmark benzyl coupling reaction was conducted with new zirconium complex. For reductive quenching reactions, ${ }^{\mathrm{MeO}} \mathrm{BIH}\left(\mathrm{E}^{\mathrm{ox}}=-0.25 \mathrm{~V} \text { vs. } \mathrm{Fc}^{+/ 0}\right)^{29}$ should be more than sufficient to reduce $\mathrm{Zr}\left({ }^{\mathrm{Mes}} \mathrm{PDP}^{\mathrm{Ph}}\right)_{2} *\left(\mathrm{E}_{1 / 2}{ }^{-1 / 0 *}=-0.12 \mathrm{~V}\right.$ vs. $\left.\mathrm{Fc}^{+/ 0}\right)$. As expected, using 
the same conditions developed previously for $\mathrm{Zr}\left({ }^{\mathrm{Me}} \mathrm{PDP}^{\mathrm{Ph}}\right)_{2}$, desired bibenzyl was obtained in $57 \%$ yield using ${ }^{\mathrm{MeO}} \mathrm{BIH}$ and catalytic amounts of $\mathrm{Zr}\left({ }^{\mathrm{Mes}} \mathrm{PDP}^{\mathrm{Ph}}\right)_{2}$ for 6 hours. This similar reactivity to previous case suggests that the $\mathrm{Zr}\left({ }^{\mathrm{Mes}} \mathrm{PDP}^{\mathrm{Ph}}\right)_{2}$ promotes a photoinduced single electron transfer process in the reaction. ${ }^{2}$

Reduction of aryl halides can be viewed as an extension to the benzyl bromide reduction. Although photocatalytic dehalogenation of aryl halide has been well-established using MLCT photosensitizers $^{30}$ or cerium photosensitizer ${ }^{31}$, no photoredox catalysis experiments were conducted using zirconium species. In established systems, high energy UV light or blue light are required for high yield. In our case, irradiation of 1,3-bis(trifluoromethyl)-5-bromobenzene in the presence of excess "electron $+\mathrm{H}^{*}$ " donor, ${ }^{\mathrm{MeO}} \mathrm{BIH}$, in benzene- $d_{6}$ with low-energy green light led to full conversion of the starting material in 26 hours (Table 4). The desired product ethyl difluoroacetate was obtained in $79 \%$ yield. A control experiment in the absence of light or the zirconium complex resulted in nearly total recovery of the starting material. When testing the reduction of 1-Iodo-2-(2-propenyloxy)benzene, the tandem dehalogenation-cyclization product was formed in $75 \%$ yield instead of direct dehalogenation product. The formation of 3-Methyl2,3-dihydrobenzo[b]furan suggests a radical reaction pathway that is induced by the zirconium photosensitizer (Scheme 5). 
Scheme 5. Selected reductive quenching photoredox catalysis using $\mathrm{Zr}\left({ }^{\mathrm{Mes}} \mathrm{PDP}{ }^{\mathrm{Ph}}\right)_{2}$

\section{Benzyl Coupling:}

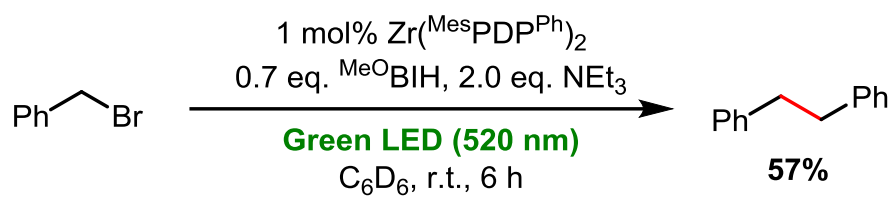

Dehalogenation of Aryl Halide:

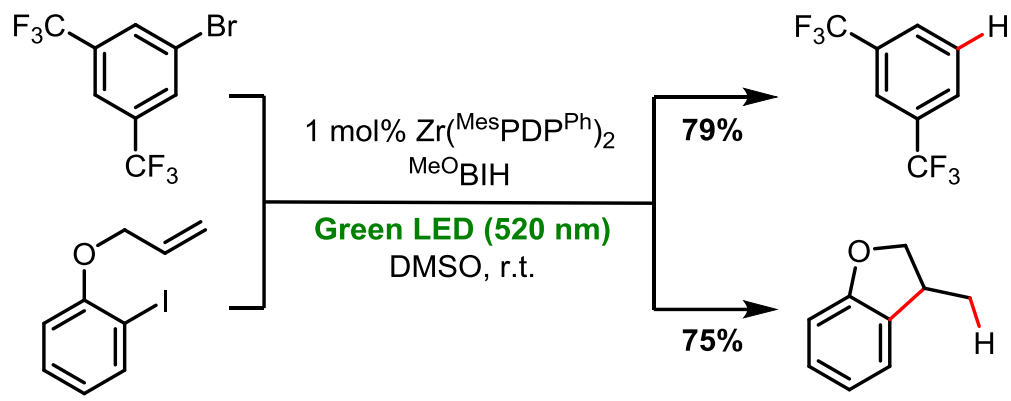

The photoinduced excited state electron transfer properties of $\mathrm{Zr}\left({ }^{\mathrm{Mes}} \mathrm{PDP}{ }^{\mathrm{Ph}}\right)_{2}{ }^{*}$ were further examined with Togni's reagent II and ${ }^{\mathrm{MeO}} \mathrm{BIH}$ via Stern-Volmer quenching analysis (Figure 8). The linear Stern-Volmer fits for both quenchers is indicative of a collisional, outer sphere electron transfer processes, similar to the prior $\mathrm{Zr}\left({ }^{\mathrm{Me}} \mathrm{PDP}^{\mathrm{Ph}}\right)_{2}$ system. However, the significantly slower $\mathrm{Zr}\left({ }^{\mathrm{Mes}} \mathrm{PDP}{ }^{\mathrm{Ph}}\right)_{2} /{ }^{\mathrm{MeO}} \mathrm{BIH}$ quenching rate (Table 4) than $\mathrm{Zr}\left({ }^{\mathrm{Mes}} \mathrm{PDP}^{\mathrm{Ph}}\right)_{2} /{ }^{\mathrm{MeO}} \mathrm{BIH}\left(k_{q}=4.62 \times 10^{8} \mathrm{~L} \mathrm{~mol}^{-}\right.$ $\left.{ }^{1} \mathrm{~s}^{-1}\right)^{1}$ suggests the bulky mesityl inhibited the electron transfer processes between the Zr-pyridinepyrrolide core of $\mathrm{Zr}\left({ }^{\mathrm{Mes}} \mathrm{PDP}{ }^{\mathrm{Ph}}\right)_{2}$ and the quenchers. Nevertheless, the Stern-Volmer results demonstrated that this new catalyst was indeed able to both donate and accept electrons in the excited states. 


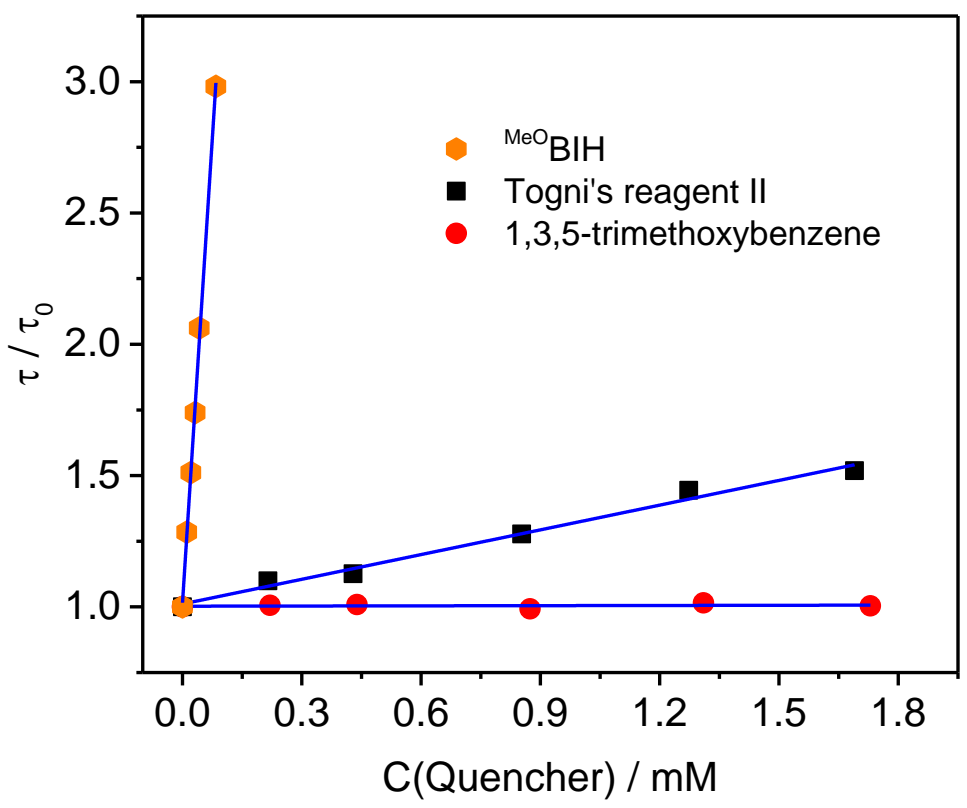

Figure 8. Stern-Volmer plots obtained via time resolved emission spectroscopy.

Table 4. Quenching parameters from Stern-Volmer analysis and redox potentials of ${ }^{\mathrm{R}} \mathrm{BIH}$.

\begin{tabular}{c|cc}
\hline & $K_{\mathrm{SV}} / \mathrm{L} \mathrm{mol}^{-1}$ & $k_{\mathrm{q}} / \mathrm{L} \mathrm{mol}^{-1} \mathrm{~s}^{-1}$ \\
\hline Togni's reagent II & $310 \pm 20$ & $8.97 \times 10^{5}$ \\
${ }^{\text {MeO} B I H}$ & $23600 \pm 500$ & $6.74 \times 10^{7}$ \\
1,35-trimethoxybeznene & no quenching & no quenching \\
\hline
\end{tabular}

\subsection{Photosensitization Properties.}

One important function of photosensitizers coming from its literal meaning, the so-called photosensitization (or energy transfer), allows a photoexcited triplet photosensitizer (i.e. $\left.\mathrm{Ru}(\mathrm{bpy}) 3^{2+*}\right)$ to promote triplet excited states $\left({ }^{1} \mathrm{~T}\right)$ in organic molecules or oxygen. The photosensitization process is essentially an intermolecular spin exchange process, which is 
distinguished from photoredox process that involve single electron redox chemistry. After energy transfer, the photosensitizer decays back to the ground state and is not consumed and thus can be used in a catalytic fashion. Such function of photosensitizer can be employed in energetically uphill catalysis, ${ }^{32}$ photon upconversion ${ }^{33}$ and photodynamic therapy (PDT). ${ }^{34}$

Very importantly, photosensitizers used in the photodynamic therapy provide a safer way of treating human cancer as oppose to traditional chemotherapy. The idea is that when a photosensitizer is in its ${ }^{1} \mathrm{~T}$ excited state, it annihilates with triplet oxygen $\left({ }^{3} \mathrm{O}_{2}\right)$ and produces singlet oxygen $\left({ }^{1} \mathrm{O}_{2}\right)$, which can oxidatively damage cellular components and eventually lead to targetcell death (only within the illuminated area). ${ }^{35}$ Most transition metal photosensitizer used in the PDT are made of precious metal such as $\mathrm{Pt}, \mathrm{Ru}, \mathrm{Rh}$, and $\mathrm{Ir} .{ }^{34}$ Although they are highly effective in generating ${ }^{1} \mathrm{O}_{2}$, the potential of photoinduced ligand dissociation and resulting heavy metal poisoning for biological system (i.e. DNA binding) are the most concerning. Zirconium based photosensitizer would be promising candidate for PDT because "It is also used for surgical implants and prosthetic devices because it is biocompatible; it has no known biological role or toxicity." ${ }^{36}$ says John Emsley, Nature Chemistry 2014, 6, 254.

In a previous section, we established that the $\mathrm{Zr}\left({ }^{\mathrm{Mes}} \mathrm{PDP}^{\mathrm{Ph}}\right)_{2}$ is photoluminescent with a remarkably long-lived emissive state that most likely involves a triplet excited state. In addition, the emission of the $\mathrm{Zr}\left({ }^{\mathrm{Mes}} \mathrm{PDP}^{\mathrm{Ph}}\right)_{2}$ is readily quenched by oxygen in solution which suggests a facile triplet energy transfer process. The ability of generating singlet oxygen using $\mathrm{Zr}\left({ }^{\mathrm{Mes}} \mathrm{PDP}^{\mathrm{Ph}}\right)_{2}$ 
was examined here experimentally by following the disappearance of the $410 \mathrm{~nm}$ absorbance band of 1,3-diphenylisobenzofuran (DPBF), known as a ${ }^{1} \mathrm{O}_{2}$ scavenger,${ }^{37}$ at the initial concentration of $1.1 \times 10^{-4} \mathrm{M}$ in air-saturated THF in the presence of $9.4 \times 10^{-7} \mathrm{M} \mathrm{Zr}\left({ }^{\mathrm{Mes}} \mathrm{PDP}^{\mathrm{Ph}}\right)_{2}$ under green light illumination $\left(530 \mathrm{~nm}, 5.5 \mathrm{~mW} / \mathrm{cm}^{2}\right)$. As shown in Figure 9, over one hundred equivalents of DPBF (1 eq. $\mathrm{Zr}$ ) was fully consumed within 20 mins, which is indictive of highly efficient ${ }^{1} \mathrm{O}_{2}$ production by $\mathrm{Zr}\left({ }^{\mathrm{Mes}} \mathrm{PDP}^{\mathrm{Ph}}\right)_{2}$.

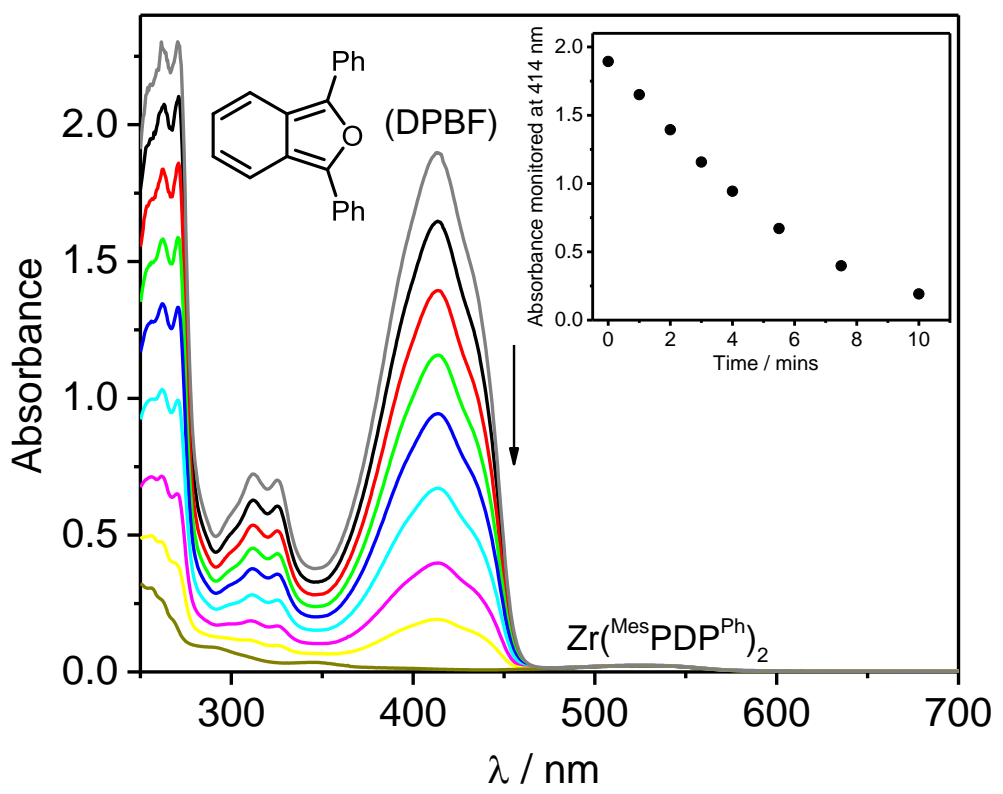

Figure 9. Overlay of absorption spectrums of the mixture of $\mathrm{Zr}\left({ }^{\mathrm{Mes}} \mathrm{PDP}^{\mathrm{Ph}}\right)_{2}\left(9.4 \times 10^{-7} \mathrm{M}\right)$ and DPBF $\left(1.1 \times 10^{-4} \mathrm{M}\right)$ in air saturated THF solution upon irradiation of green light (530 nm, 5.5 $\mathrm{mW} / \mathrm{cm}^{2}$ ) irradiation. Inset: the reaction of DPBF with ${ }^{1} \mathrm{O}_{2}$ plot as a function of time with absorbance monitored at $414 \mathrm{~nm}$. 
Having established the highly effective ${ }^{1} \mathrm{O}_{2}$ generation property of $\mathrm{Zr}\left({ }^{\mathrm{Mes}} \mathrm{PDP}^{\mathrm{Ph}}\right)_{2}$, the $\mathrm{Zr}\left({ }^{\mathrm{Mes}} \mathrm{PDP}^{\mathrm{Ph}}\right)_{2}$ should also capable of transferring energy to organic compounds. Photosensitized $E / Z$ isomerization of stilbene is a thermodynamically uphill reaction. ${ }^{32,38}$ The reaction can test the energy transfer efficiency of photosensitizer to the $E$ or $Z$ isomers. In general, if the triplet energy (Ет) of photosensitizer is smaller than that of the $Z$-isomer but great than that of the $E$-isomer, energy transfer is more thermodynamically favorable to the $E$-isomer, resulting in accumulation of $Z$-isomer. The stilbene isomerization reaction was carried out in benzene- $d_{6}$ solution of stilbene containing $0.25 \mathrm{~mol} \%$ of $\mathrm{Zr}\left({ }^{\mathrm{Mes}} \mathrm{PDP}^{\mathrm{Ph}}\right)_{2}$. After green light irradiate for 15 minutes, the reaction reaches a photostationary state with $Z / E$ ratio of $83: 17$. The $\mathrm{E}_{\mathrm{T}}$ of $\mathrm{Zr}\left({ }^{\mathrm{Mes}} \mathrm{PDP}^{\mathrm{Ph}}\right)_{2}$ was estimated to be $49.3 \mathrm{kcal} / \mathrm{mol}$ according to $\lambda_{\text {em-max, }}$ which is very close to the $\mathrm{E}_{\mathrm{T}}$ of $E$-stilbene $(51 \mathrm{kcal} / \mathrm{mol})^{39}$ but much smaller than the $\mathrm{E}_{\mathrm{T}}$ of $Z$-stilbene $(58 \mathrm{kcal} / \mathrm{mol})^{39}$, thus leading to the buildup of the $Z$ isomer ratio.

Similar reaction condition with chalcone $\left(\mathrm{E}_{\mathrm{T}}=49.2 \mathrm{kcal} / \mathrm{mol}\right)^{40}$ for 2 hours only provide minor higher energy isomer with $Z / E$ ratio of 14:86. Interestingly, prolonged irradiation provides $48 \%$ of a third species in the reaction, which was identified as [2+2] cycloaddition product of the chalcone (Scheme 6). No reaction was observed in the absence of the zirconium catalyst or in the dark for both substrates. The photoexcited $\mathrm{Zr}\left({ }^{\mathrm{Mes}} \mathrm{PDP}^{\mathrm{Ph}}\right)_{2}\left(\mathrm{E}_{1 / 2}{ }^{+1 / 0 *}=-1.60 \mathrm{~V}\right.$ vs. $\left.\mathrm{Fc}^{+/ 0}\right)$ was not able to efficiently transfer electron to either two alkenes (chalcone: $\mathrm{E}_{1 / 2}{ }^{\text {red }}=-1.88 \mathrm{~V} \mathrm{vs} . \mathrm{Fc}^{+/ 0}$ in $\mathrm{MeCN},{ }^{40}$ 
and stilbene is expected to be even lower in potential) due to a significant negative thermodynamic driving force, which tentatively rules out the photoredox reaction mechanism.

Scheme 6. Energy transfer catalysis using $\mathrm{Zr}\left({ }^{\mathrm{Mes}} \mathrm{PDP}^{\mathrm{Ph}}\right)_{2}$.

\section{Energy Transfer}
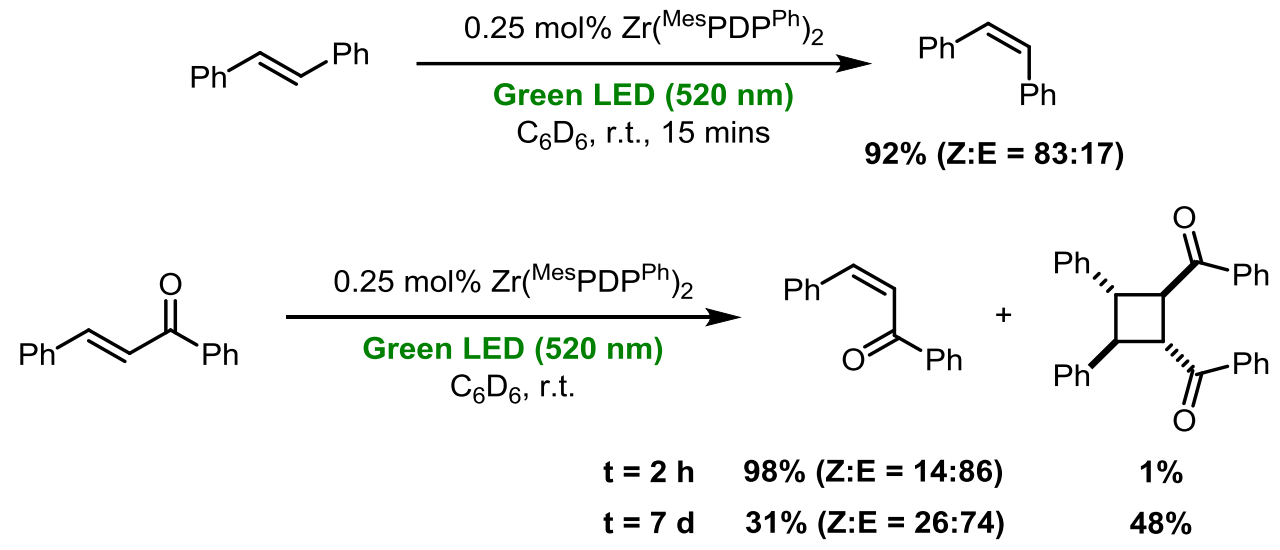

\subsection{Photostability Investigation.}

An ideal photosensitizer has high chemical (photo)stability. The $\mathrm{Zr}\left({ }^{\mathrm{Mes}} \mathrm{PDP}^{\mathrm{Ph}}\right)_{2}$ is highly stable under air, water and low $\mathrm{pH}$ condition as mentioned vide supra. Photostability measurements were performed by irradiation of a $\mathrm{Zr}\left({ }^{\mathrm{Mes}} \mathrm{PDP}^{\mathrm{Ph}}\right)_{2}$ solution $\left(3.9 \times 10^{-6} \mathrm{M}, 9: 1 \mathrm{v} / \mathrm{v} \%\right.$ air saturated $\mathrm{THF} / \mathrm{EtOH})$ in a cuvette at room temperature with intense green light $\left(530 \mathrm{~nm}, 210 \mathrm{~mW} / \mathrm{cm}^{2}\right)$. The absorption spectra were measured at appropriate times during the irradiation (Figure 10). When irradiation of $\mathrm{Zr}\left({ }^{\mathrm{Mes}} \mathrm{PDP}^{\mathrm{Ph}}\right)_{2}$ solution under air for four hours, $97 \%$ of the initial intensity remains. There is no sign of any decomposition under $\mathrm{N}_{2}$ or in the absence of light for the same amount of time. In marked contrast, Rose Bengal, known as a highly effective ${ }^{1} \mathrm{O}_{2}$ generator and also being 
studied as a treatment for melanoma ${ }^{41}$ and breast cancers, ${ }^{42}$ decomposes over $90 \%$ in less than 50 minutes under identical conditions. Commonly used organic photoredox catalyst (i.e. Eosin Y and Rhodamine 6G) that can absorb green light were also tested and shown to be by far less stable than $\mathrm{Zr}\left({ }^{\mathrm{Mes}} \mathrm{PDP}{ }^{\mathrm{Ph}}\right)_{2}$.

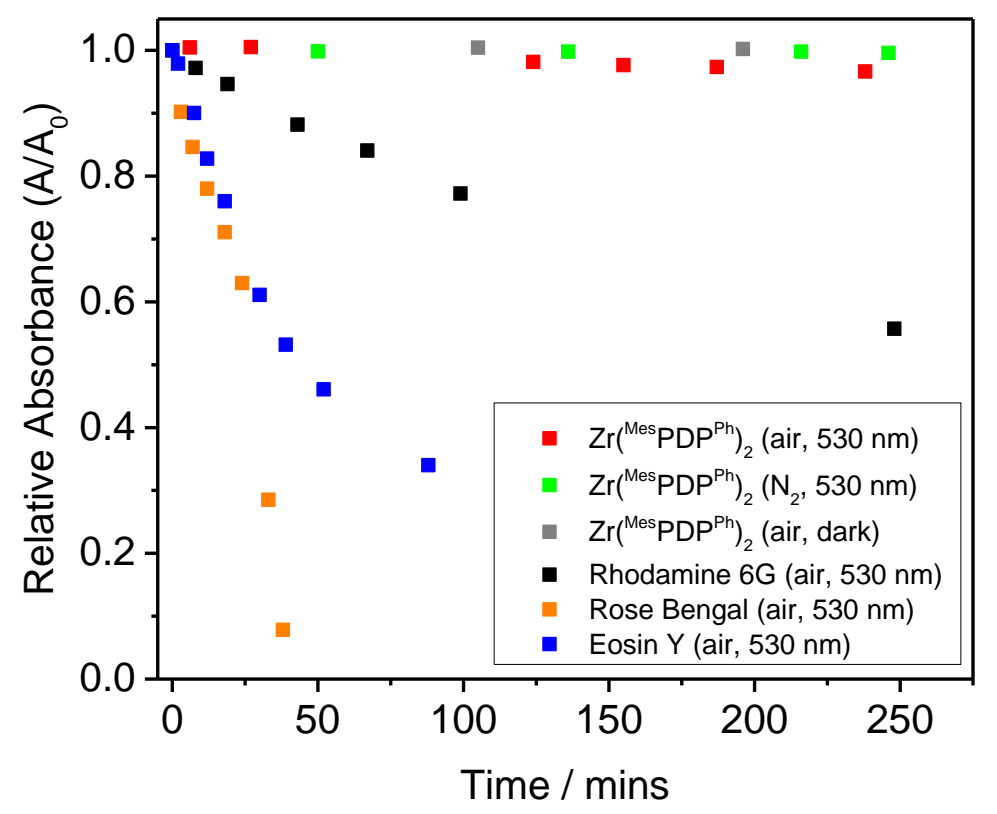

Figure 10. Relative absorbance changes for $\mathrm{Zr}\left({ }^{\mathrm{Mes}} \mathrm{PDP}^{\mathrm{Ph}}\right)_{2}$ and selected dyes upon irradiation of green light.

\subsection{Summary.}

In this chapter, we successfully synthesized a new zirconium photosensitizer, $\mathrm{Zr}\left({ }^{\mathrm{Mes}} \mathrm{PDP}^{\mathrm{Ph}}\right)_{2}$, equipped with two 2,6-bis(5-mesityl-3-phenyl-1H-pyrrol-2-yl)-pyridine, ${ }^{\text {Mes }} \mathrm{PDP}^{\mathrm{Ph}}$, ligands. This zirconium compound was found to be exceptionally stable in wet organic solvents and low $\mathrm{pH}$ solution under air. Upon examining the space-filling model of the crystal structure, we 
found the highly steric demanding ligand framework protects the metal center from small molecule penetration (i.e. $\mathrm{H}_{2} \mathrm{O}, \mathrm{HCl}, \mathrm{O}_{2}$ ). As a result, the complex can easily be manipulated under regular benchtop conditions. Additionally, the oxidation site of the molecule: 2,5-positions of the pyrrole heterocycles are also now protected by the methyl groups of the mesityl moiety, which allows reversible oxidative chemistry. After establishing the optical and electrochemical properties of $\mathrm{Zr}\left({ }^{\mathrm{Mes}} \mathrm{PDP}^{\mathrm{Ph}}\right)_{2}$, we successfully conducted photocatalytic C-H trifluoromethylation, $\mathrm{C}-\mathrm{H}$ arylation and atom transfer radical addition reactions that are commonly considered to undergo oxidative quenching pathways. Additionally, reductive quenching photocatalytic benzyl coupling and aryl

halide reduction can be achieved using $\mathrm{Zr}\left({ }^{\mathrm{Mes}} \mathrm{PDP}^{\mathrm{Ph}}\right)_{2}$. Furthermore, two catalytic reactions as well as ${ }^{1} \mathrm{O}_{2}$ generation that undergoing photoinduced triplet energy transfer processes were established for this new zirconium photosensitizer. The high photostability of $\mathrm{Zr}\left({ }^{\mathrm{Mes}} \mathrm{PDP}^{\mathrm{Ph}}\right)_{2}$ could allow applications at low catalyst loading and more cost-effective than using precious metals. We believe that this robust earth abundant zirconium photosensitizer has high potential to serve as a fully functional replacement for precious metal chromophores in the field of organic photocatalysis.

\subsection{Experimental Section.}

General experimental considerations for material handling, physical measurements, X-ray crystallography, and DFT Calculations as well as additional experimental information (i.e. NMR spectra, quenching experiments) can be found in the appendices. 
Starting Materials. Tetrabenzyl zirconium, ${ }^{43,44}$ 2,6-bis(5-mesityl-3-phenyl-1H-pyrrol-2-yl)pyridine, ${ }^{\text {Mes }} \mathrm{PDP}^{\mathrm{Ph}},{ }^{6}$ and Togni's reagent $\mathrm{II}^{45}$ were prepared following literature procedures. Other compounds were purchased from commercial source.

Preparation of PMMA Film. Dichloromethane $(2 \mathrm{~mL})$ was added to a vial loaded with PMMA (200 mg, $35 \mathrm{kDa})$ and $2 \mathrm{mg}(1 \mathrm{wt} \%)$ of $\mathrm{Zr}\left({ }^{\mathrm{Mes}} \mathrm{PDP}^{\mathrm{Ph}}\right)_{2}$, which was stirred at room temperature under air until completely homogenous. Then the resulting solution was coated on a glass slide via drop-casting method and dried at room temperature. The gas inside the film was evacuated under high vacuum for 2 days and refilled with argon before the optical measurement.

Evaluation of Photostability. Photostability measurements were performed by using the setup in Figure ES1. The light from a green $\left(530 \mathrm{~nm}, 210 \mathrm{~mW} / \mathrm{cm}^{2}\right)$ mounted LED (Thorlabs, Inc., M530L3) powered by a T-Cube LED driver (Thorlabs, Inc., LEDD1B) was focused to a spot by a lens (Thorlabs, Inc., SM2F32-A). Light output was directed onto a standard $10 \mathrm{~mm}$ path length cuvette containing the solutions of interest. The sample solutions were prepared in a 9:1 volume ratio mixture of air saturated THF/EtOH or in THF under $\mathrm{N}_{2}$. Their concentrations were adjusted to be ca. $3.9 \times 10^{-6} \mathrm{M}$. The absorption spectra were measured at appropriate times during the irradiation. The solution temperature, $22 \pm 2{ }^{\circ} \mathrm{C}$, was consistent throughout the duration of the experiment. 


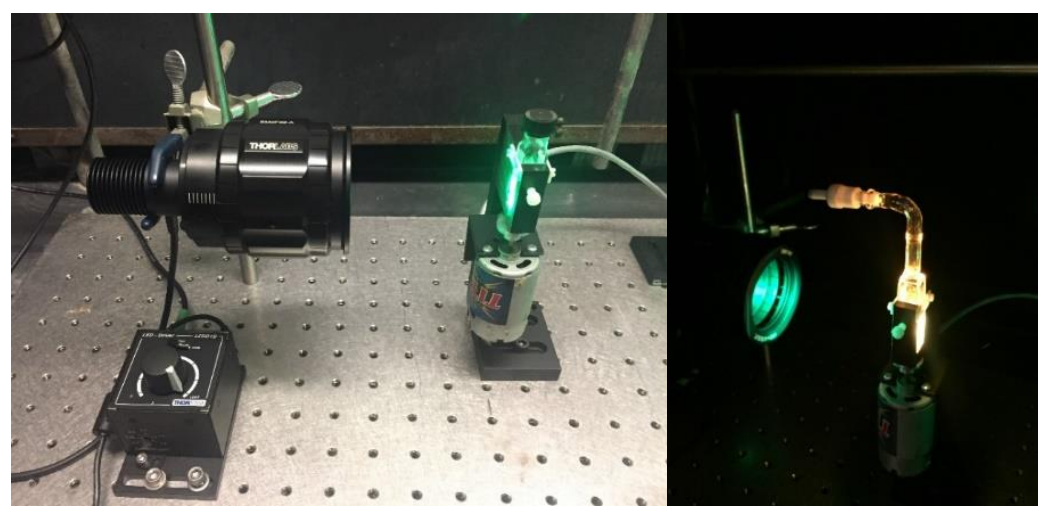

Figure ES1. Photostability measurement setup.

Preparation of $\mathbf{Z r}$ (Mes $\left.^{\text {PDPPh }}\right)_{2}$. Tetrabenzyl zirconium (101 mg, $223 \mathrm{mmol}, 0.53$ equiv) and $\mathrm{H}_{2}{ }^{\mathrm{Mes}} \mathrm{PDP}^{\mathrm{Ph}}$ (251 mg, $450 \mathrm{mmol}, 1.00$ equiv) were loaded in a $50 \mathrm{~mL}$ thick-walled glass vessel in the glovebox. About $6 \mathrm{~mL}$ of toluene was added. The thick-walled vessel was sealed with a PTFE screw cap and heated to $120^{\circ} \mathrm{C}$ for 48 hours. After cooling to room temperature, the reaction vessel was brought back into the glovebox and additional tetrabenzyl zirconium (101 mg, $223 \mathrm{mmol}, 0.53$ equiv) was added. The reaction mixture was heated for another 24 hours at $120{ }^{\circ} \mathrm{C}$ (at this stage the ligand was fully consumed or close to full consumption). Then, the reaction was opened to air. The toluene was removed using rotary evaporator and triturated twice with ethyl acetate to give red solid. The resultant was redissolved with DCM/ethyl acetate and filtered through a plug of silica gel. After removal of DCM, the product was recrystallized from slow evaporation of THF under air. The product was collected as red crystals (Yield: $86 \mathrm{mg}, 32 \%$ ). Mp > $320{ }^{\circ} \mathrm{C} .{ }^{1} \mathrm{H}$ NMR (400 MHz, $\left.\mathrm{C}_{6} \mathrm{D}_{6} ; \delta, \mathrm{ppm}\right): 7.71(\mathrm{~d}, J=8.0 \mathrm{~Hz}, 8 \mathrm{H}), 7.38(\mathrm{t}, J=8.0 \mathrm{~Hz}, 8 \mathrm{H}), 7.21(\mathrm{t}, J=8.0 \mathrm{~Hz}$, 4H), 6.50 (s, 8H, mesityl-CH), 6.49 (d, J = 8.0 Hz, 4H), 6.25 (t, J = 8.0 Hz, 2H, para-PyH), 5.95 
(s, 4H, pyrrole $H$ ), 2.08 (s, 24H, ortho- $\left.\mathrm{CH}_{3}\right), 1.86\left(\mathrm{~s}, 12 \mathrm{H}\right.$, para- $\left.\mathrm{CH}_{3}\right) .{ }^{13} \mathrm{C} \mathrm{NMR}\left(101 \mathrm{MHz}, \mathrm{C}_{6} \mathrm{D}_{6}\right.$;

$\delta, \mathrm{ppm}): 154.59,142.58,139.87,138.39,138.23,136.81,136.01,131.76,130.50,129.71,128.75$

$127.18,115.58,112.79,23.08,20.94$, (one aromatic carbon overlapping). Anal. Calcd for $\mathrm{C}_{44} \mathrm{H}_{32} \mathrm{~N}_{4} \mathrm{Zr} \cdot 2 \mathrm{C}_{4} \mathrm{H}_{8} \mathrm{O}: \mathrm{C}, 79.12 ; \mathrm{H}, 6.36 ; \mathrm{N}, 5.89$. Found: C, 78.93; H, 6.35; N, 5.71. Single crystals suitable for X-ray crystallographic analysis were grown from THF and $\mathrm{Et}_{2} \mathrm{O}$ solution of $\mathrm{Zr}\left({ }^{\mathrm{Mes}} \mathrm{PDP}^{\mathrm{Ph}}\right)_{2}$ in at $-35^{\circ} \mathrm{C}$.

\section{Solubility profile of $\mathrm{Zr}\left({ }^{\mathrm{Mes} P D P} \mathrm{Ph}^{\mathrm{Ph}}\right)$ :}

Good solubility in: THF, benzene, toluene, $\mathrm{DCM}, \mathrm{CHCl}_{3}$

Medium to poor solubility in: acetone, ethyl acetate, $\mathrm{Et}_{2} \mathrm{O}$, DMSO

Insoluble in: $\mathrm{MeCN}, \mathrm{MeOH}, \mathrm{H}_{2} \mathrm{O}$

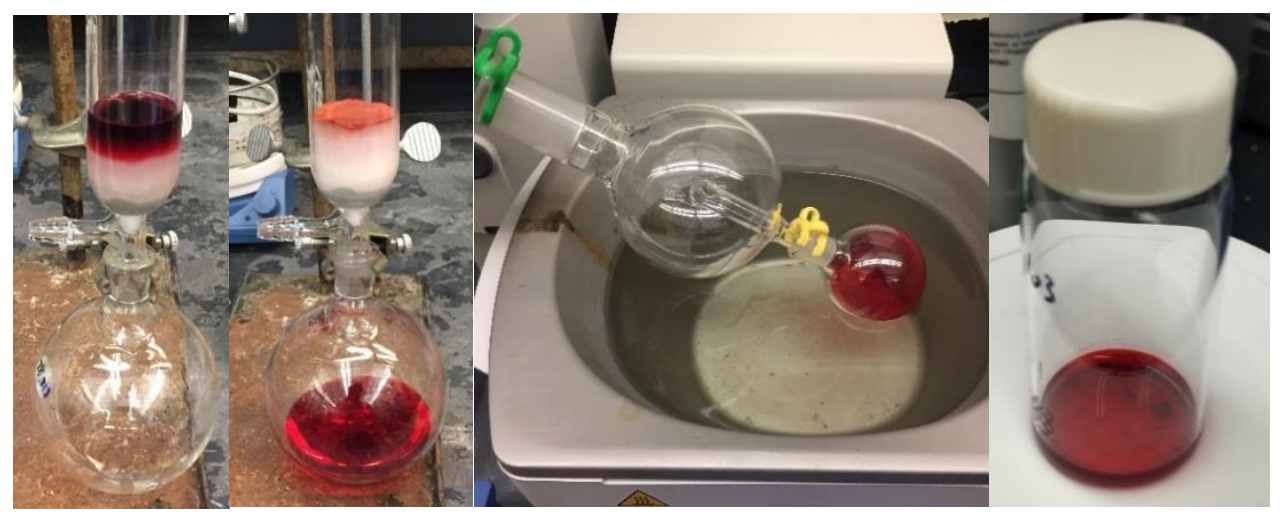

Figure ES2. Graphic workup procedure: 1) Filter through a plug of silica gel. 2) Removal of solvent. 3) Recrystallization from slow evaporation of THF. 


\section{Acid Stability Evaluation}
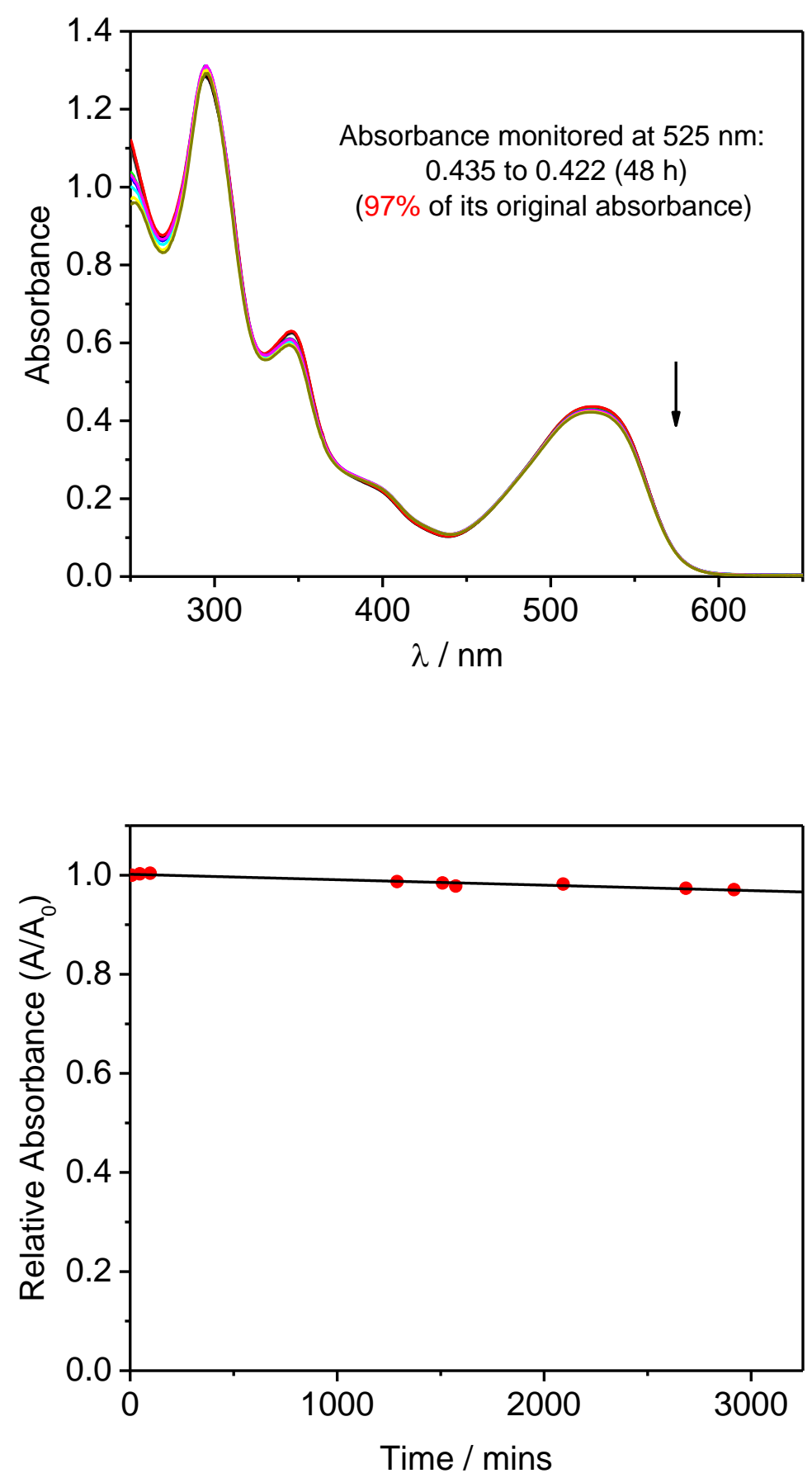

Figure ES3. Overlay of absorption spectrums of $\mathrm{Zr}\left({ }^{\mathrm{Mes}} \mathrm{PDP}^{\mathrm{Ph}}\right)_{2}$ in air saturated $\mathrm{THF} / \mathrm{HCl}$ (aq.) (9:1 volume ratio, $12 \mathrm{~N}$ concentrated $\mathrm{HCl}$ was used) solution under ambient light over period of 48 hours (top). The acid stability plot as a function of time with relative absorbance (bottom). 


\section{Self Triplet-Triplet Annihilation Evaluation}
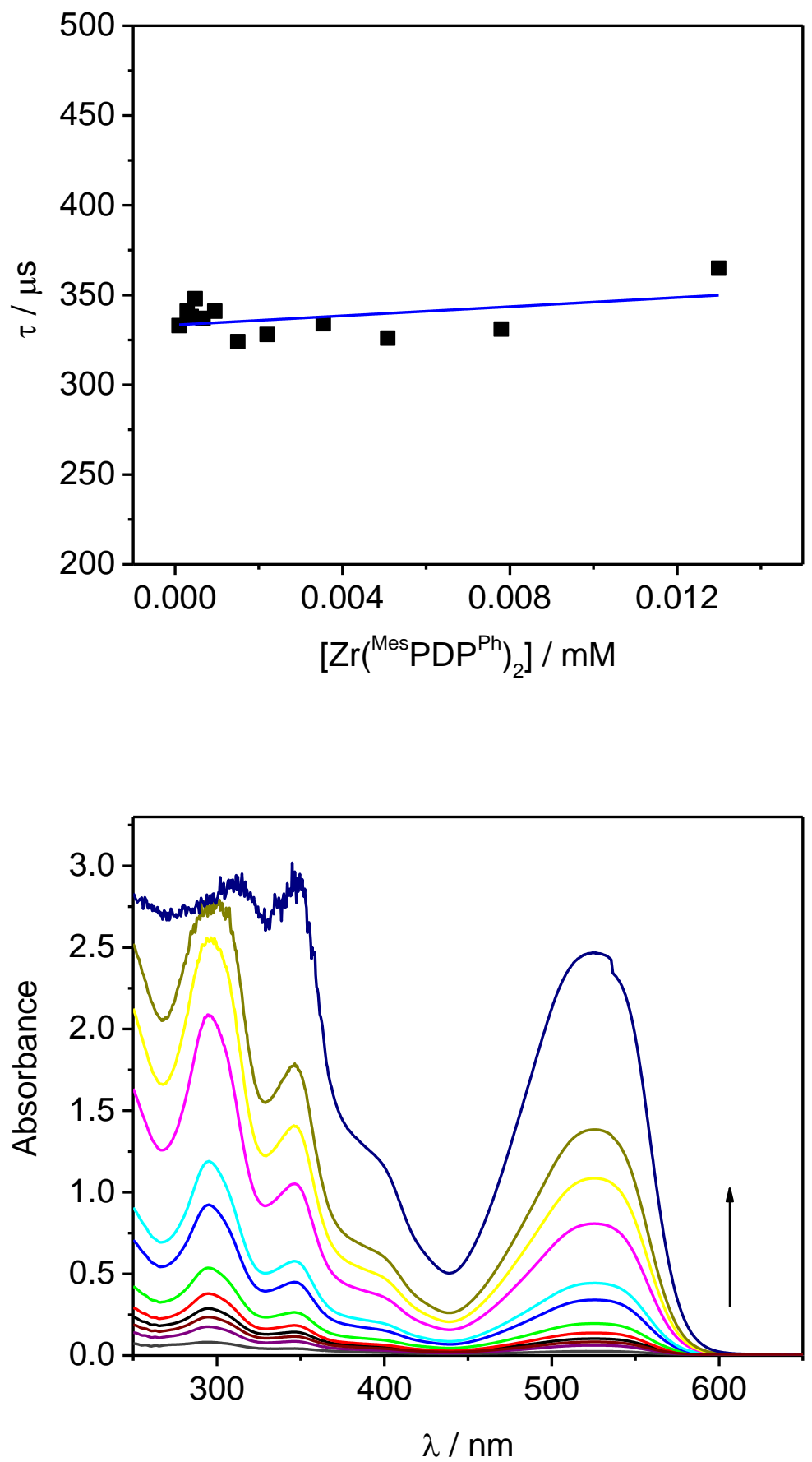

Figure ES4. The lifetime plot as a function of concentration (top). Overlay of absorption spectrums of $\mathrm{Zr}\left({ }^{\mathrm{Mes}} \mathrm{PDP}^{\mathrm{Ph}}\right)_{2}$ in THF solution under $\mathrm{N}_{2}$ with various concentration (bottom). 
Photoredox-Catalyzed Atom Transfer Radical Addition Reactions. In the drybox, a vial was charged with $\mathrm{Zr}\left({ }^{\mathrm{Mes}} \mathrm{PDP}^{\mathrm{Ph}}\right)$ 2, 5-Hexen-1-ol (31 mg, $0.312 \mathrm{mmol}, 1.00$ equiv), and ethyl bromodifluoroacetate. $1.6 \mathrm{~mL}$ of DMSO was added. The vial was taped and brought out of the drybox. The reaction was irradiated with green LED light $\left(\lambda_{\max }=520 \mathrm{~nm}\right)$ with fan cooling. After a suitable amount of time, the reaction vial was opened to air and 1,3,5-trimethoxybenzene was added as an internal standard. The DMSO was then washed away with water and the product was extracted with ethyl acetate. The combined organic layer was dried over $\mathrm{MgSO}_{4}$. The products were analyzed by NMR spectroscopy and the yields are based on internal standard.

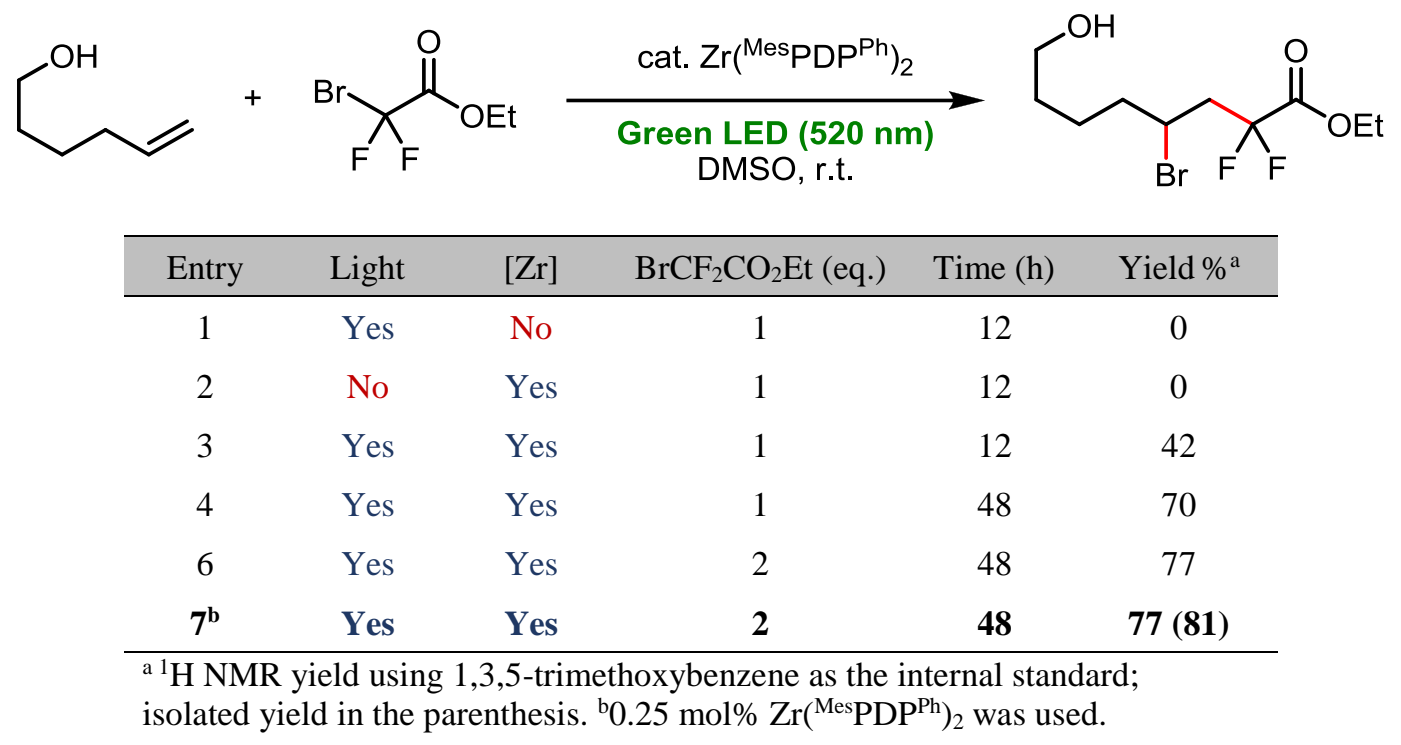




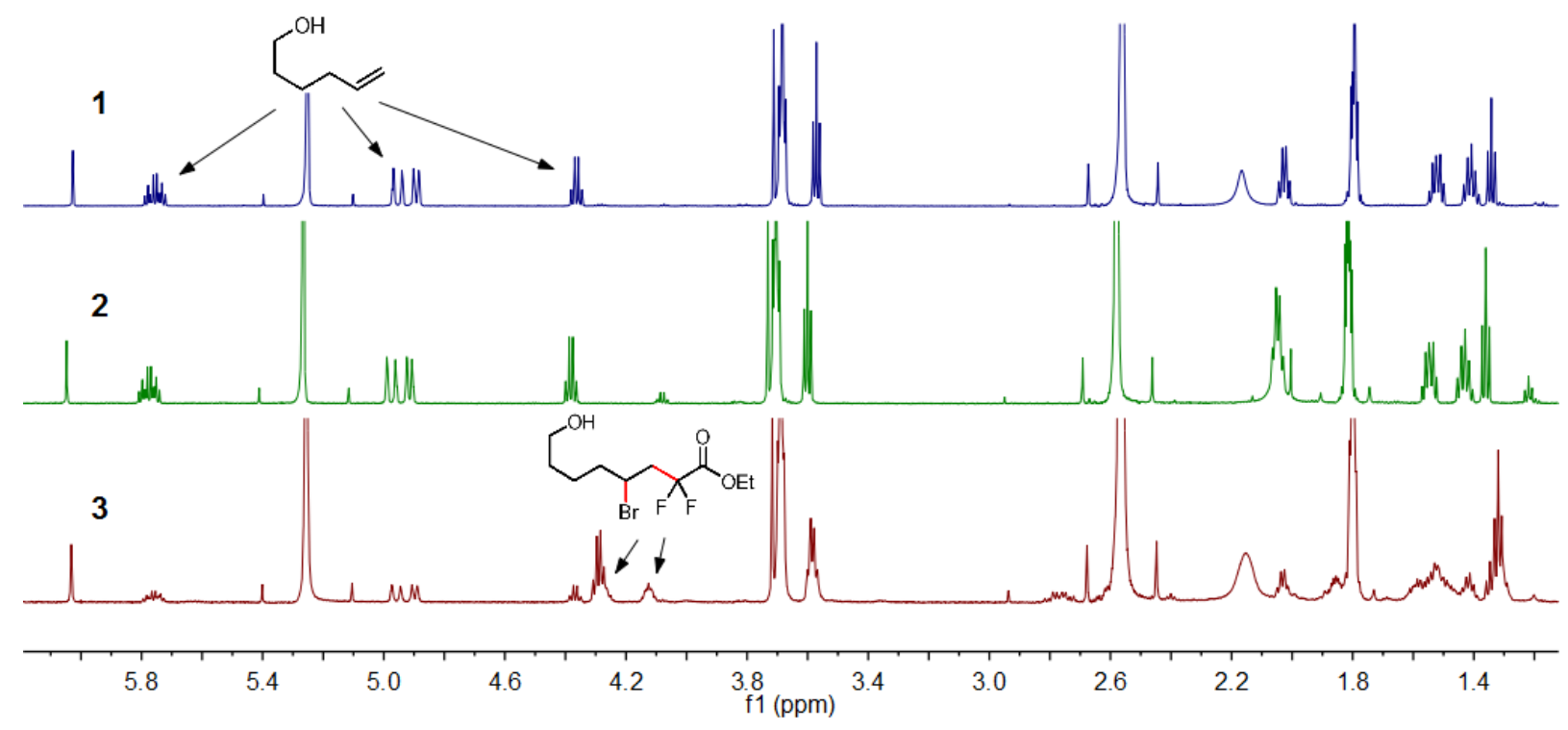

Figure ES5. ${ }^{1} \mathrm{H}$ NMR spectrum of a mixture of 5-Hexen-1-ol and ethyl bromodifluoroacetate in $\mathrm{CDCl}_{3}$ 1) after irradiation $\left.(12 \mathrm{~h}) ; 2\right)$ in the presence of $\mathrm{Zr}\left({ }^{\mathrm{Mes}} \mathrm{PDP}^{\mathrm{Ph}}\right)_{2}$ without irradiation $\left.(12 \mathrm{~h}) ; 3\right)$ in the presence of $\mathrm{Zr}\left({ }^{\mathrm{Mes}} \mathrm{PDP}^{\mathrm{Ph}}\right)_{2}$ after irradiation $(12 \mathrm{~h})$.

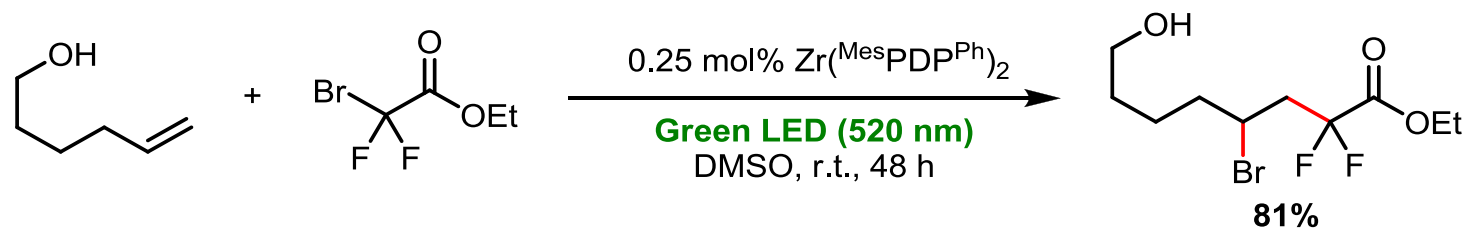

Synthesis of ethyl 4-bromo-2,2-difluoro-8-hydroxyoctanoate. In the drybox, a vial was charged with $\mathrm{Zr}\left({ }^{\mathrm{Mes}} \mathrm{PDP}^{\mathrm{Ph}}\right)_{2}(1 \mathrm{mg}, 0.0008 \mathrm{mmol}, 0.0025$ equiv), 5-Hexen-1-ol (31 mg, $0.312 \mathrm{mmol}, 1.00$ equiv), and ethyl bromodifluoroacetate (126 mg, $0.623 \mathrm{mmol}, 2.00$ equiv). $1.6 \mathrm{~mL}$ of DMSO was added. The vial was taped and brought out of the drybox. The reaction was irradiated with green LED light $\left(\lambda_{\max }=520 \mathrm{~nm}\right)$ with fan cooling. After 48 hours, the reaction was opened to air. The DMSO was then washed away with water and product was extracted with ethyl acetate. The combined organic layer was dried over $\mathrm{MgSO}_{4}$. The product, ethyl 4-bromo-2,2-difluoro-8- 
hydroxyoctanoate, was isolated as a light pink oil (76 $\mathrm{mg}, 81 \%)$ after purification by chromatography on silica gel (7:3, hexane/EtOAc). ${ }^{1} \mathrm{H}$ NMR (400 MHz, $\left.\mathrm{CDCl}_{3} ; \delta, \mathrm{ppm}\right): 4.34$ (q, $J=7.2 \mathrm{~Hz}, 2 \mathrm{H}), 4.22-4.13(\mathrm{~m}, 1 \mathrm{H}), 3.67(\mathrm{t}, J=6.0 \mathrm{~Hz}, 2 \mathrm{H}), 2.91-2.74(\mathrm{~m}, 1 \mathrm{H}), 2.72-2.57$ $(\mathrm{m}, 1 \mathrm{H}), 1.99-1.82(\mathrm{~m}, 2 \mathrm{H}), 1.72-1.50(\mathrm{~m}, 4 \mathrm{H}), 1.37(\mathrm{t}, J=7.2 \mathrm{~Hz}, 3 \mathrm{H}) ;{ }^{1} \mathrm{H}$ NMR data is in agreement with literature reported value..$^{21}$
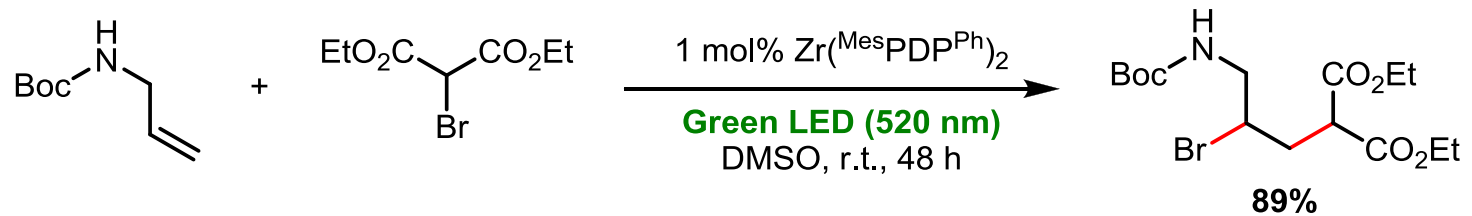

Synthesis of diethyl 2-(2-bromo-3-((tert-butoxycarbonyl)amino)propyl)malonate. In the drybox, a vial was charged with $\mathrm{Zr}\left({ }^{\mathrm{Mes}} \mathrm{PDP}^{\mathrm{Ph}}\right)_{2}$ (4 mg, $0.0031 \mathrm{mmol}, 0.01$ equiv), Boc-allylamine (49 mg, $0.312 \mathrm{mmol}, 1.00$ equiv), and diethyl bromomalonate (149 mg, $0.623 \mathrm{mmol}, 2.00$ equiv). $1.6 \mathrm{~mL}$ of DMSO was added. The vial was taped and brought out of the drybox. The reaction was irradiated with green LED light $\left(\lambda_{\max }=520 \mathrm{~nm}\right)$ with fan cooling. After 48 hours, the reaction was opened to air. The DMSO was then washed away with water and product was extracted with ethyl acetate. The combined organic layer was dried over $\mathrm{MgSO}_{4}$. The product, diethyl 2-(2-bromo-3((tert-butoxycarbonyl)amino)propyl)malonate, was isolated as a light pink oil (110 mg, 89\%) after purification by chromatography on silica gel (17:3, hexane/EtOAc). ${ }^{1} \mathrm{H}$ NMR $\left(400 \mathrm{MHz}, \mathrm{CDCl}_{3}\right.$; $\delta$, ppm): 4.98 (br, $1 \mathrm{H}), 4.28-4.15$ (m, $4 \mathrm{H}), 4.14-4.03$ (m, $1 \mathrm{H}), 3.73(\mathrm{dd}, J=9.6,4.8 \mathrm{H}, 1 \mathrm{H})$, 
$3.59-3.39$ (m, $2 \mathrm{H}), 2.51-2.41(\mathrm{~m}, 1 \mathrm{H}), 2.31-2.18(\mathrm{~m}, 1 \mathrm{H}), 1.43(\mathrm{~s}, 9 \mathrm{H}), 1.30-1.23(\mathrm{~m}, 6$

$\mathrm{H}) ;{ }^{1} \mathrm{H}$ NMR data is in agreement with literature reported value. ${ }^{21}$

Photoredox-Catalyzed C-H Trifluoromethylation of Arenes. In the drybox, a J. Young NMR tube was charged with $\mathrm{Zr}\left({ }^{\mathrm{Mes}} \mathrm{PDP}{ }^{\mathrm{Ph}}\right)_{2}$, 1,3,5-trimethoxybenzene and Togni's Reagent II. About 0.6 $\mathrm{mL}$ of DMSO- $d_{6}$ was added. The mixture was placed in a jacketed glass beaker with water cooling and irradiated with green LED light $\left(\lambda_{\max }=520 \mathrm{~nm}\right)$. After the reaction was complete (as judged by NMR analysis), the products were analyzed by NMR spectroscopy and the yields are based on internal standard.

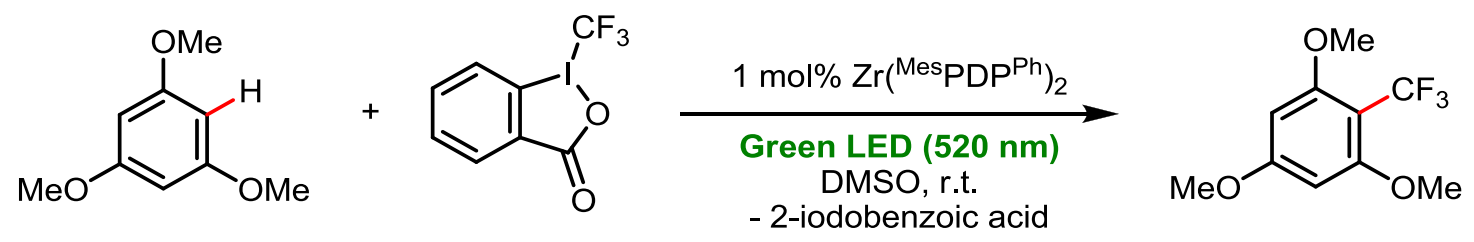

\begin{tabular}{ccccccc}
\hline Entry & Light & {$[\mathrm{Zr}]$} & b (eq.) & Time (h) & Yield \% $^{\mathrm{a}}$ & Conv. \% \\
\hline 1 & Yes & No & 1.25 & 9 & 2 & 2 \\
2 & No & Yes & 1.25 & 14 & 0 & 0 \\
$\mathbf{3}^{\mathbf{b}}$ & Yes & Yes & $\mathbf{1 . 2 5}$ & $\mathbf{4}$ & $\mathbf{8 8}(\mathbf{8 6})$ & $\mathbf{9 4}$ \\
$4^{\text {b }}$ & Yes & Yes & 1.60 & 4 & 75 & 99 \\
\hline
\end{tabular}

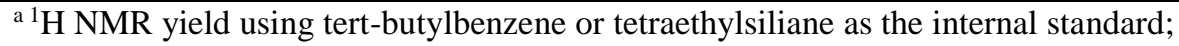
isolated yield isolated yield in the parenthesis. ${ }^{b}$ double $\mathrm{C}-\mathrm{H}$ trifluoromethylated product was formed 


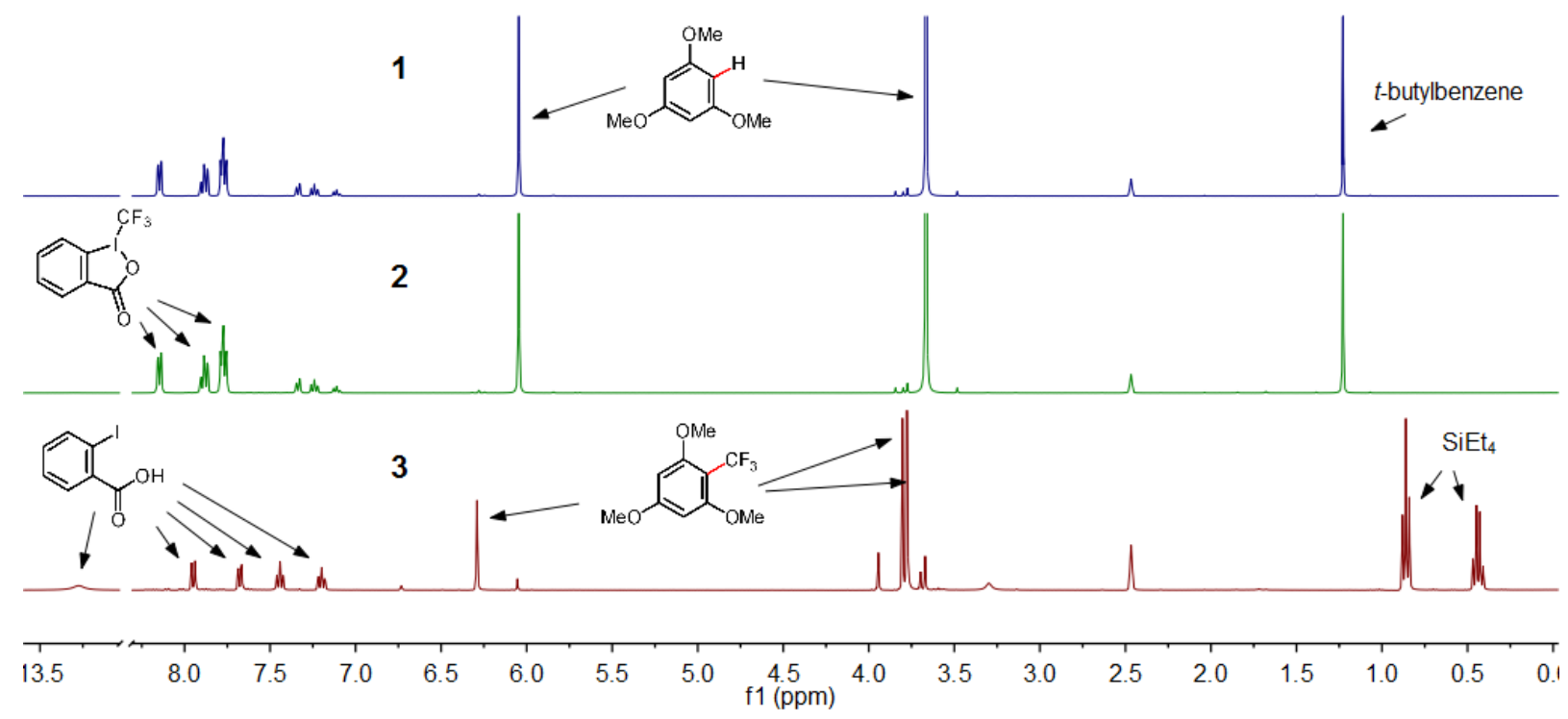

Figure ES6. ${ }^{1} \mathrm{H}$ NMR spectrum of a mixture of 1,3,5-trimethoxybenzene and Togni's Reagent II in DMSO-d $\left.d_{6}\right)$ after irradiation $\left.(9 \mathrm{~h}) ; 2\right)$ in the presence of $\mathrm{Zr}\left({ }^{\mathrm{Mes}} \mathrm{PDP}^{\mathrm{Ph}}\right)_{2}$ without irradiation (14 h); 3 ) in the presence of $\mathrm{Zr}\left({ }^{\mathrm{Mes}} \mathrm{PDP}^{\mathrm{Ph}}\right)_{2}$ after irradiation $(4 \mathrm{~h})$.<smiles>COc1cc(OC)cc(OC)c1</smiles><smiles>O=C1OI(C(F)(F)F)c2ccccc21</smiles>

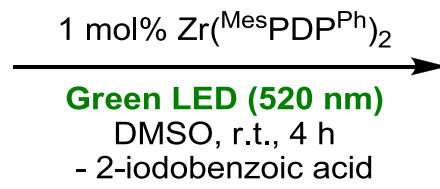<smiles>COc1cc(OC)c(C(F)(F)F)c(OC)c1</smiles>

Synthesis of 1,3,5-trimethoxy-2-(trifluoromethyl)benzene. In the drybox, a vial was charged with $\mathrm{Zr}\left({ }^{\mathrm{Mes} P D P}{ }^{\mathrm{Ph}}\right)_{2}(4 \mathrm{mg}, 0.0032 \mathrm{mmol}, 0.01$ equiv), 1,3,5-trimethoxybenzene (53 $\mathrm{mg}, 0.315$ mmol, 1.00 equiv), and Togni's Reagent II (125 mg, $0.394 \mathrm{mmol}, 1.25$ equiv). $1.6 \mathrm{~mL}$ of DMSO was added. The vial was taped and brought out of the drybox. The reaction irradiated with green LED light $\left(\lambda_{\max }=520 \mathrm{~nm}\right)$ with fan cooling. After 7 hours, the reaction was opened to air. The DMSO was then washed away with water and product was extracted with ethyl acetate. The combined organic layer was dried over $\mathrm{MgSO}_{4}$. The product, 1,3,5-trimethoxy-2- 
(trifluoromethyl)benzene, was isolated as a light pink soild (64 mg, 86\%) after purification by chromatography on silica gel (95:5, hexane/EtOAc). ${ }^{1} \mathrm{H}$ NMR (400 MHz, $\left.\mathrm{CDCl}_{3} ; \delta, \mathrm{ppm}\right): 6.13$ (s, $2 \mathrm{H}), 3.84(\mathrm{~s}, 3 \mathrm{H}), 3.84(\mathrm{~s}, 6 \mathrm{H}) .{ }^{19} \mathrm{~F}$ NMR $\left(376 \mathrm{MHz}, \mathrm{CDCl}_{3}\right.$; $\delta$, ppm): 54.03 ; NMR data is in agreement with literature reported value. ${ }^{46}$

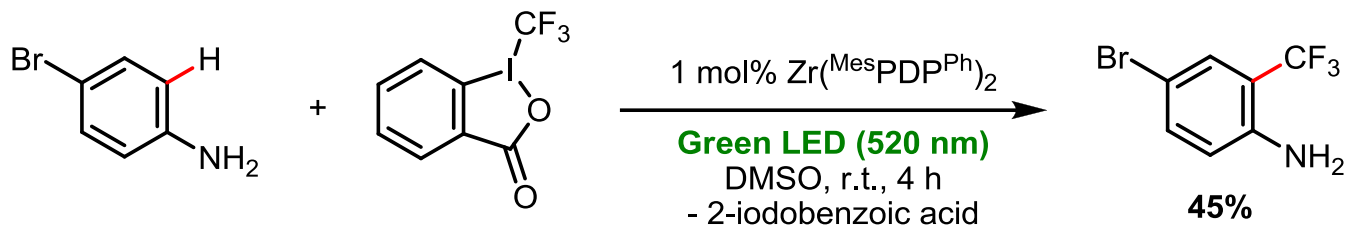

Synthesis of bromo-2-(trifluoromethyl)aniline. In the drybox, a J. Young NMR tube was charged with $\mathrm{Zr}\left({ }^{\mathrm{Mes}} \mathrm{PDP}^{\mathrm{Ph}}\right)_{2}(1 \mathrm{mg}, 0.0008 \mathrm{mmol}, 0.01$ equiv), 4-bromoaniline (14 mg, $0.081 \mathrm{mmol}, 1.00$ equiv), and Togni's Reagent II (39 mg, $0.394 \mathrm{mmol}, 1.50$ equiv). $0.8 \mathrm{~mL}$ of DMSO- $d_{6}$ was added. The mixture was placed in a jacketed glass beaker with water cooling and irradiated with green LED light $\left(\lambda_{\max }=520 \mathrm{~nm}\right)$. After 23 hours, the reaction was opened to air. The DMSO was then washed away with water and product was extracted with ethyl acetate. The combined organic layer was dried over $\mathrm{MgSO}_{4}$. The product, 4-bromo-2-(trifluoromethyl)aniline, was isolated as a brown oil (9 mg, 45\%) after purification by preparative TLC (10:1, hexane/EtOAc). ${ }^{1} \mathrm{H}$ NMR (400 MHz, $\left.\mathrm{CDCl}_{3} ; \delta, \mathrm{ppm}\right): 7.53(\mathrm{~d}, J=2.0 \mathrm{~Hz}, 1 \mathrm{H}), 7.37(\mathrm{dd}, J=8.8,2.0 \mathrm{~Hz}, 1 \mathrm{H}), 6.63(\mathrm{~d}, J=8.4 \mathrm{~Hz}, 2$ $\mathrm{H}),{ }^{19} \mathrm{~F}$ NMR $\left(376 \mathrm{MHz}, \mathrm{CDCl}_{3} ; \delta, \mathrm{ppm}\right): 63.25 ;{ }^{1} \mathrm{H}$ NMR data is in agreement with literature reported value. ${ }^{24}$ 


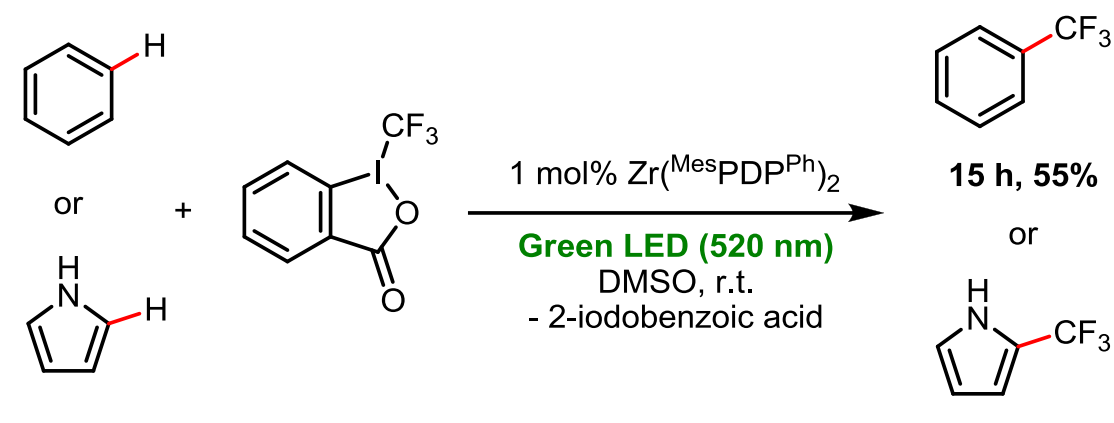

1 h, $88 \%$

Synthesis of $\alpha, \alpha, \alpha$-Trifluorotoluene and 2-(trifluoromethyl)-1H-pyrrole. In the drybox, a J.

Young NMR tube was charged with $\mathrm{Zr}\left({ }^{\mathrm{Mes}} \mathrm{PDP}^{\mathrm{Ph}}\right)_{2}$, benzene (or pyrrole) and Togni's Reagent II (1.50 eq. for benzene; 1.20 eq. for pyrrole). About $0.6 \mathrm{~mL}$ of DMSO- $d_{6}$ was added. The mixture was placed in a jacketed glass beaker with water cooling and irradiated with green LED light $\left(\lambda_{\max }\right.$ $=520 \mathrm{~nm}$ ). After reaction was complete (as judged by NMR analysis), the products were analyzed by NMR spectroscopy and the yields are based on internal standard. The ${ }^{1} \mathrm{H}$ NMR data are in agreement with the literature reported value or matched with commercially available pure material. $^{47}$

Photoredox-Catalyzed C-H Arylation Reaction. In the drybox, a J. Young NMR tube was charged with $\mathrm{Zr}\left({ }^{\mathrm{Mes} P D P}{ }^{\mathrm{Ph}}\right)_{2}(650 \mu \mathrm{g}, 0.0005 \mathrm{mmol}, 0.01$ equiv, from stock solution), 4nitrobenzenediazonium tetrafluoroborate (12 mg, $0.051 \mathrm{mmol}, 1.00$ equiv), benzene (158 mg, 2.03 mmol, 40.00 equiv) and internal standard: tetraethylsiliane. About $0.5 \mathrm{~mL}$ of DMSO- $d_{6}$ was added. 
The mixture was placed in a jacketed glass beaker with water cooling and irradiated with green LED light $\left(\lambda_{\max }=520 \mathrm{~nm}\right)$. After reaction was complete (as judged by NMR analysis), the products were analyzed by NMR spectroscopy and the yields are based on internal standard.

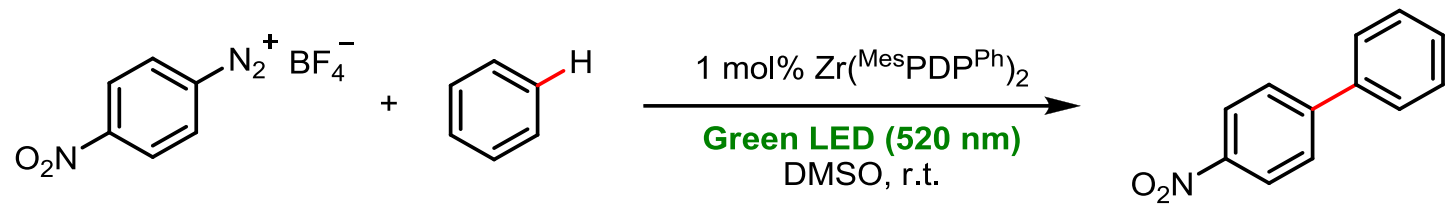

\begin{tabular}{|c|c|c|c|c|c|}
\hline Entry & Light & {$[\mathrm{Zr}]$} & Time (h) & Yield \%a & Conv. $\%^{\mathrm{a}}$ \\
\hline 1 & Yes & No & 1.5 & 12 & 18 \\
\hline 2 & No & Yes & 3 & $<1$ & 3 \\
\hline 3 & Yes & Yes & 1 & 73 (72) & 100 \\
\hline
\end{tabular}

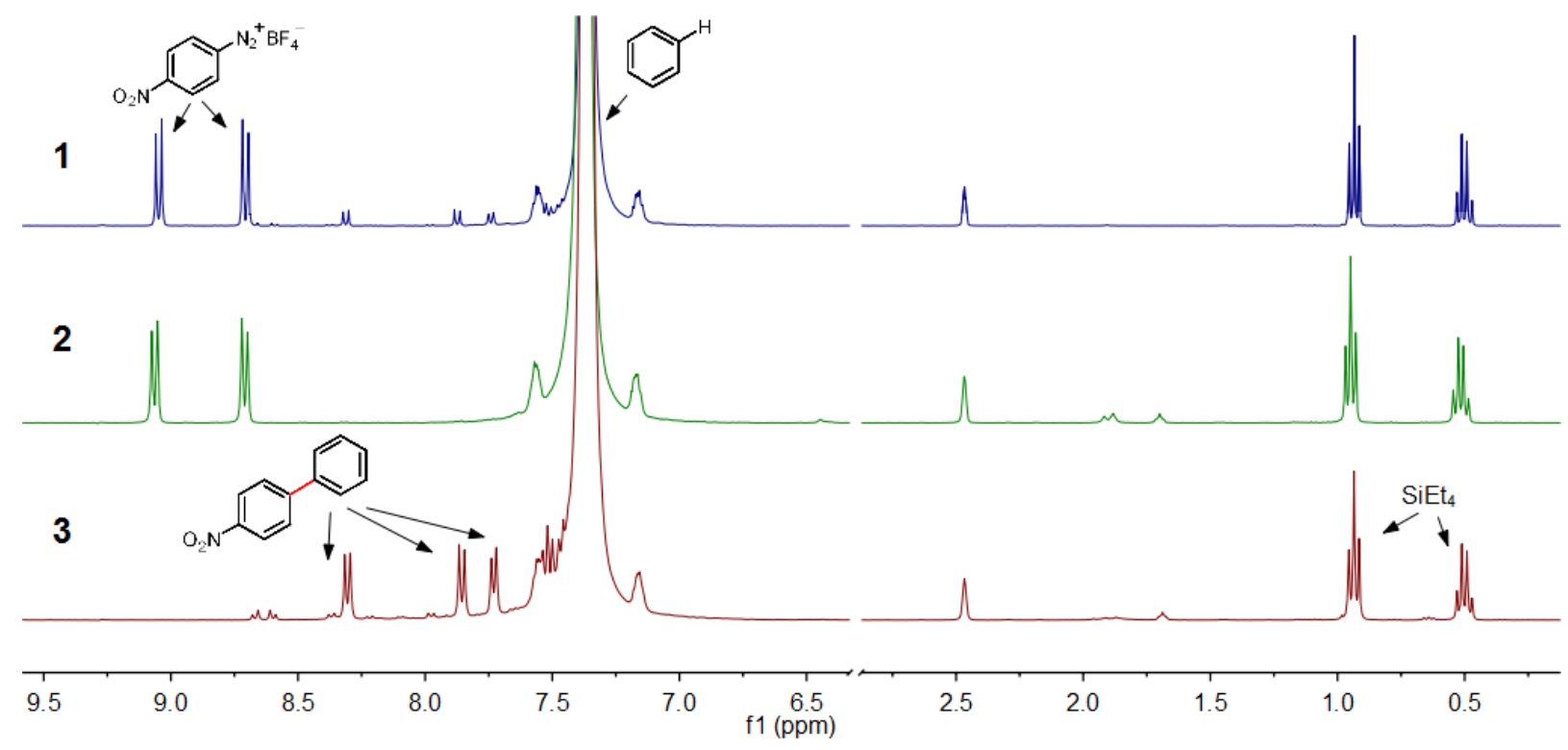

Figure ES7. ${ }^{1} \mathrm{H}$ NMR spectrum of a mixture of 4-nitrobenzenediazonium tetrafluoroborate and benzene in DMSO- $\left.d_{6} 1\right)$ after irradiation $(1.5 \mathrm{~h}) ; 2$ ) in the presence of $\mathrm{Zr}\left({ }^{\mathrm{Mes}} \mathrm{PDP}^{\mathrm{Ph}}\right)_{2}$ without irradiation (3 h); 3) in the presence of $\mathrm{Zr}\left({ }^{\mathrm{Mes}} \mathrm{PDP}^{\mathrm{Ph}}\right)_{2}$ after irradiation $(1 \mathrm{~h})$. 

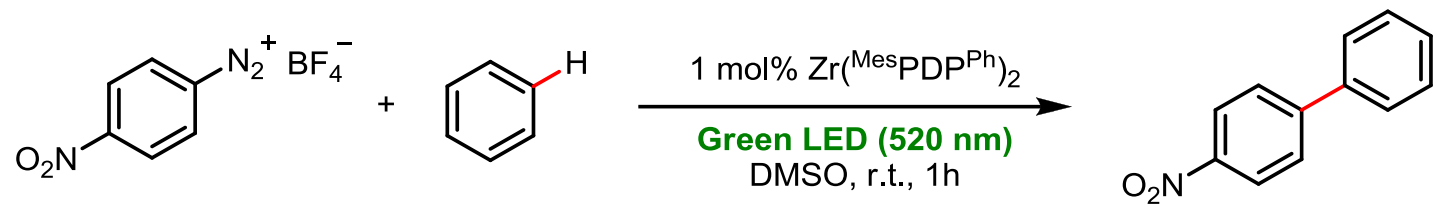

Synthesis of 4-nitrobiphenyl. In the drybox, a vial was charged with $\mathrm{Zr}\left({ }^{\mathrm{Mes}} \mathrm{PDP}^{\mathrm{Ph}}\right)_{2}(5 \mathrm{mg}, 0.0039$ mmol, 0.01 equiv), 4-nitrobenzenediazonium tetrafluoroborate ( $92 \mathrm{mg}, 0.390 \mathrm{mmol}, 1.00$ equiv), and benzene (1.22 g, $15.590 \mathrm{mmol}, 40.00$ equiv). $2.0 \mathrm{~mL}$ of DMSO was added. The vial was taped and brought out of the drybox. The reaction was irradiated with green LED light $\left(\lambda_{\max }=520 \mathrm{~nm}\right)$ with fan cooling. After 1 hour, the reaction was opened to air. The DMSO was then washed away with water and product was extracted with ethyl acetate. The combined organic layer was dried over $\mathrm{MgSO}_{4}$. The product, 4-nitrobiphenyl, was isolated as pale yellow solids (56 mg, 72\%) after purification by chromatography on silica gel (95:5, hexane/EtOAc). ${ }^{1} \mathrm{H}$ NMR (400 MHz, $\mathrm{CDCl}_{3}$; $\delta$, ppm): $8.31(\mathrm{dm}, J=8.8 \mathrm{~Hz}, 2 \mathrm{H}), 7.74(\mathrm{dm}, J=7.2 \mathrm{~Hz}, 2 \mathrm{H}), 7.63(\mathrm{dm}, J=7.2 \mathrm{~Hz}, 2 \mathrm{H}), 7.50$ $(\mathrm{tm}, J=7.2 \mathrm{~Hz}, 2 \mathrm{H}), 7.45(\mathrm{tm}, J=7.2 \mathrm{~Hz}, 1 \mathrm{H}) ;{ }^{1} \mathrm{H}$ NMR data is in agreement with literature reported value. ${ }^{48}$

Photoredox-Catalyzed Coupling of Benzyl Bromide. In the drybox, a J. Young NMR tube was charged with $\mathrm{Zr}\left({ }^{\mathrm{Mes}} \mathrm{PDP}^{\mathrm{Ph}}\right)_{2}\left(1 \mathrm{mg}, 0.00078 \mathrm{mmol}, 0.01\right.$ equiv), ${ }^{\mathrm{MeO}} \mathrm{BIH}(14 \mathrm{mg}, 0.055 \mathrm{mmol}$, 0.70 equiv), benzyl bromide ( $13 \mathrm{mg}, 0.078 \mathrm{mmol}, 1.00$ equiv), triethyl amine ( $16 \mathrm{mg}, 0.156$ mmol, 2.00 equiv) and internal standard: 1,3,5-trimethoxybenzene. About $0.6 \mathrm{~mL}$ of $\mathrm{C}_{6} \mathrm{D}_{6}$ was added. The mixture was placed in a jacketed glass beaker with water cooling and irradiated with 
green LED light $\left(\lambda_{\max }=520 \mathrm{~nm}\right)$. After reaction was complete (as judged by NMR analysis), the products were analyzed by NMR spectroscopy and the yields are based on internal standard.
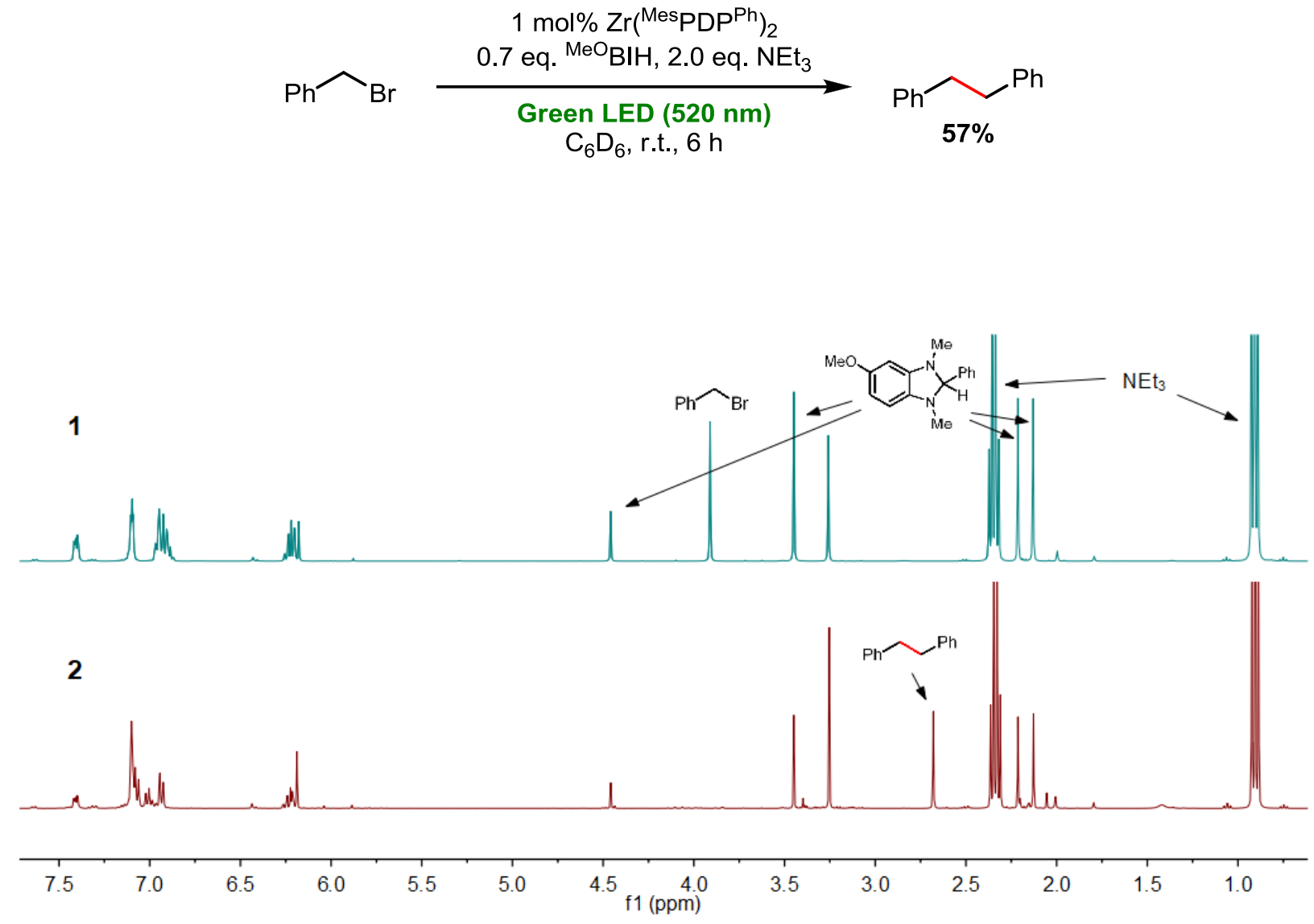

Figure ES8. ${ }^{1} \mathrm{H}$ NMR spectrum of a mixture of benzyl bromide, BIH, and 2,6-lutidine in the presence of $\mathrm{Zr}\left({ }^{\mathrm{Mes}} \mathrm{PDP}^{\mathrm{Ph}}\right)_{2}$ 1) initial spectrum; 2) after irradiation for 6 hours.

Photoredox-Catalyzed Dehalogenation of Aryl Halide. In the drybox, a J. Young NMR tube was charged with $\mathrm{Zr}\left({ }^{\mathrm{Mes}} \mathrm{PDP}^{\mathrm{Ph}}\right)_{2}(1 \mathrm{mg}, 0.00078 \mathrm{mmol}, 0.01$ equiv), 1,3-Bis(trifluoromethyl)-5bromobenzene (23 mg, $0.078 \mathrm{mmol}, 1.00$ equiv), ${ }^{\mathrm{MeO}} \mathrm{BIH}$, and internal standard: 1,3,5trimethoxybenzene. About $0.6 \mathrm{~mL}$ of DMSO- $d_{6}$ was added. The mixture was placed in a jacketed glass beaker with water cooling and irradiated with green LED light $\left(\lambda_{\max }=520 \mathrm{~nm}\right)$. After reaction 
was complete (as judged by NMR analysis), the products were analyzed by NMR spectroscopy and the yields are based on internal standard.

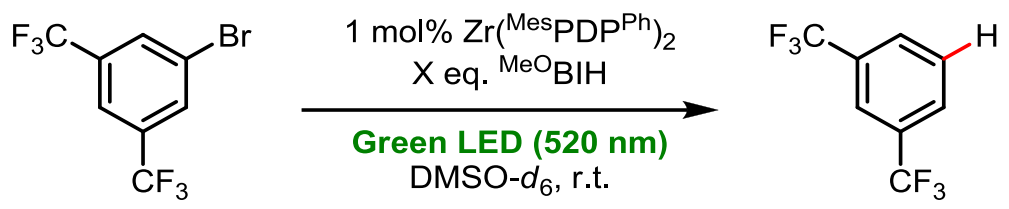

\begin{tabular}{ccccccc}
\hline Entry & Light & {$[\mathrm{Zr}]$} & X (eq.) & Time (h) & Yield \% $\%^{\mathrm{a}}$ & Conv. \% ${ }^{\mathrm{a}}$ \\
\hline 1 & Yes & No & 1.05 & 16 & 4 & 4 \\
2 & No & Yes & 1.05 & 24 & 0 & 0 \\
3 & Yes & Yes & 1.05 & 12 & 70 & 78 \\
$\mathbf{4}$ & Yes & Yes & $\mathbf{1 . 5 0}$ & $\mathbf{2 6}$ & $\mathbf{7 9}$ & $\mathbf{1 0 0}$ \\
\hline
\end{tabular}

${ }^{\text {a }}{ }^{1} \mathrm{H}$ NMR yield using1,3,5-trimethoxybenzene as the internal standard;
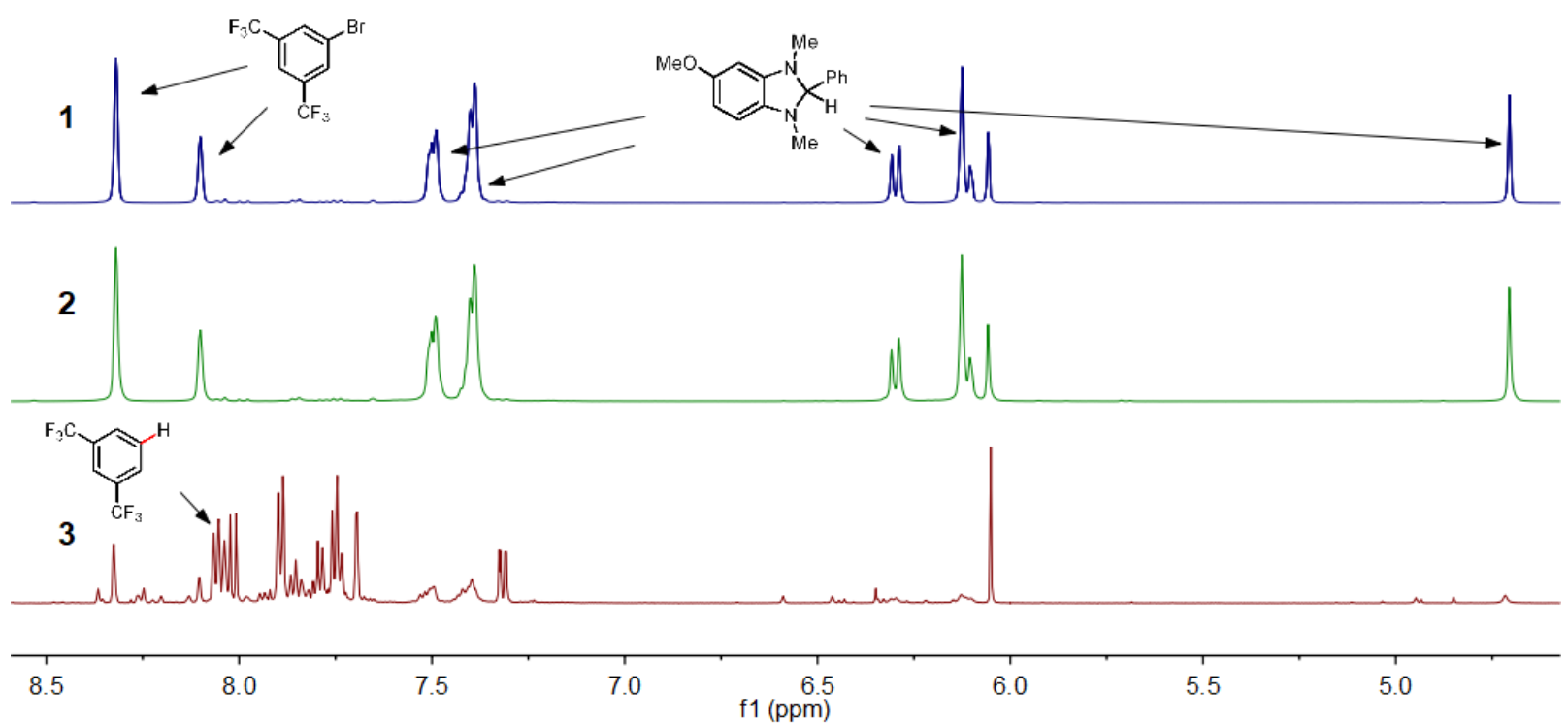

Figure ES9. ${ }^{1} \mathrm{H}$ NMR spectrum of a mixture of 1,3-Bis(trifluoromethyl)-5-bromobenzene and ${ }^{\mathrm{MeO}} \mathrm{BIH}$ in DMSO- $\left.d_{6} 1\right)$ after irradiation $\left.(16 \mathrm{~h}) ; 2\right)$ in the presence of $\mathrm{Zr}\left({ }^{\mathrm{Mes}} \mathrm{PDP}^{\mathrm{Ph}}\right)_{2}$ without irradiation $(24 \mathrm{~h}) ; 3$ ) in the presence of $\mathrm{Zr}\left({ }^{\mathrm{Mes}} \mathrm{PDP}^{\mathrm{Ph}}\right)_{2}$ after irradiation (12 h). 


\section{Synthesis of 3-Methyl-2,3-dihydrobenzo[b]furan}
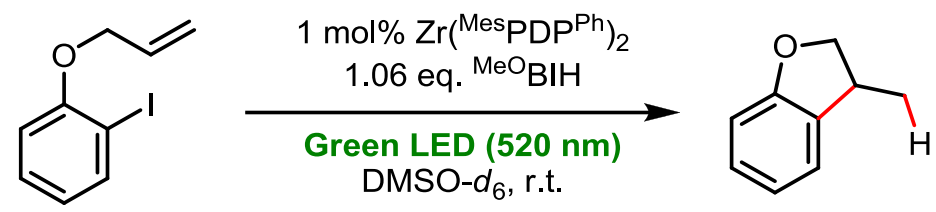

$75 \%$

In the drybox, a J. Young NMR tube was charged with $\mathrm{Zr}\left({ }^{\mathrm{Mes}} \mathrm{PDP}^{\mathrm{Ph}}\right)_{2}(2 \mathrm{mg}, 0.00156 \mathrm{mmol}, 0.01$ equiv), 1-Iodo-2-(2-propenyloxy)benzene (41 mg, $0.156 \mathrm{mmol}, 1.00$ equiv) and ${ }^{\mathrm{MeO}} \mathrm{BIH}$ (42 mg, $0.165 \mathrm{mmol}, 1.06$ equiv). About $0.8 \mathrm{~mL}$ of DMSO- $d_{6}$ was added. The mixture was placed in a jacketed glass beaker with water cooling and irradiated with green LED light $(\lambda \max =520 \mathrm{~nm})$. After reaction was complete (as judged by NMR analysis), the products were analyzed by NMR spectroscopy and the yields are based on internal standard. The ${ }^{1} \mathrm{H}$ NMR data are in agreement with the literature reported value. ${ }^{49}$

Photoisomerization of trans-Stilbene. In the drybox, a J. Young NMR tube was charged with $\mathrm{Zr}\left({ }^{\mathrm{Mes}} \mathrm{PDP}^{\mathrm{Ph}}\right)_{2}(89 \mu \mathrm{g}, 0.00007 \mathrm{mmol}, 0.0025$ equiv, from stock solution $)$, trans-Stilbene (5 mg, $0.028 \mathrm{mmol}, 1.00$ equiv), and internal standard: 1,3,5-trimethoxybenzene. About $0.6 \mathrm{~mL}$ of $\mathrm{C}_{6} \mathrm{D}_{6}$ was added. The mixture was placed in a jacketed glass beaker with water cooling and irradiated with green LED light $\left(\lambda_{\max }=520 \mathrm{~nm}\right)$. After reaction was complete (as judged by NMR analysis), the products were analyzed by NMR spectroscopy and the yields are based on internal standard. 


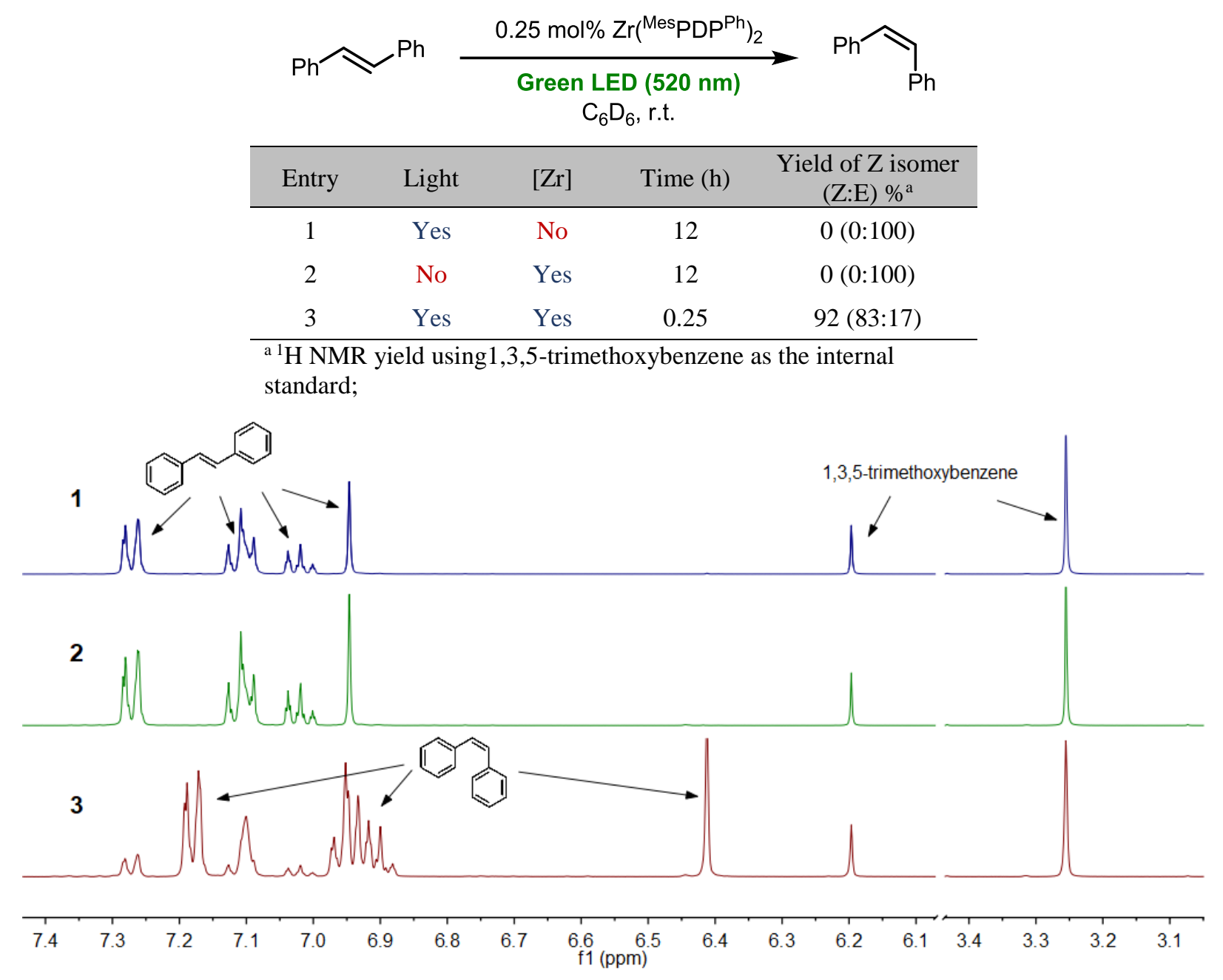

Figure ES10. ${ }^{1} \mathrm{H}$ NMR spectrum of a mixture of trans-Stilbene in $\left.\mathrm{C}_{6} \mathrm{D}_{6} 1\right)$ after irradiation (12 $\mathrm{h}$ ); 2) in the presence of $\mathrm{Zr}\left({ }^{\mathrm{Mes}} \mathrm{PDP}^{\mathrm{Ph}}\right)_{2}$ without irradiation $(12 \mathrm{~h})$; 3) in the presence of $\mathrm{Zr}\left({ }^{\mathrm{Mes}} \mathrm{PDP}^{\mathrm{Ph}}\right)_{2}$ after irradiation (15 mins).

Photoinduced [2+2] Cycloaddition of Chalcone. In the drybox, a J. Young NMR tube was charged with $\mathrm{Zr}\left({ }^{\mathrm{Mes}} \mathrm{PDP}{ }^{\mathrm{Ph}}\right)_{2}\left(123 \mu \mathrm{g}, 9.5 \times 10^{-6} \mathrm{mmol}, 0.0025\right.$ equiv, from stock solution $)$, transStilbene ( $8 \mathrm{mg}, 0.028 \mathrm{mmol}, 1.00$ equiv), and internal standard: 1,3,5-trimethoxybenzene. About $0.6 \mathrm{~mL}$ of $\mathrm{C}_{6} \mathrm{D}_{6}$ was added. The mixture was placed in a jacketed glass beaker with water cooling and irradiated with green LED light $\left(\lambda_{\max }=520 \mathrm{~nm}\right)$. After reaction was complete (as judged by 
NMR analysis), the products were analyzed by NMR spectroscopy and the yields are based on internal standard.

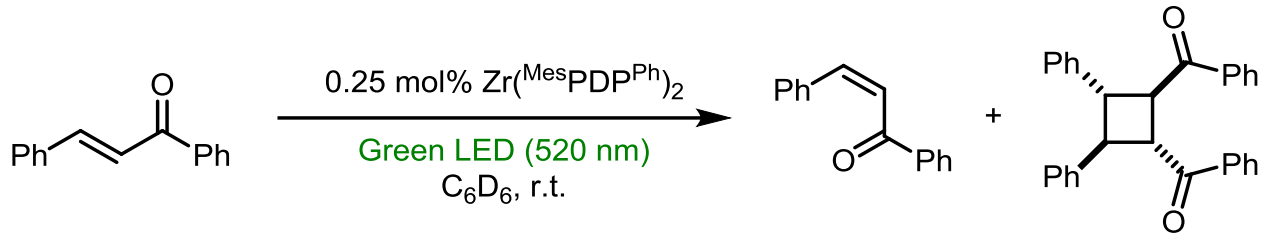

\begin{tabular}{cccccc}
\hline Entry & Light & {$[\mathrm{Zr}]$} & Time & $\begin{array}{c}\text { Yield of Z isomer } \\
(\mathrm{Z}: \mathrm{E}) \%^{\mathrm{a}}\end{array}$ & $\begin{array}{c}\text { Yield of } \\
\text { cyclobutane } \%^{\mathrm{a}}\end{array}$ \\
\hline 1 & Yes & No & $10 \mathrm{~d}$ & $12(12: 88)$ & 0 \\
2 & No & Yes & $1 \mathrm{~d}$ & $0(0: 100)$ & 0 \\
3 & Yes & Yes & $2 \mathrm{~h}$ & $14(14: 86)$ & 1 \\
4 & Yes & Yes & $7 \mathrm{~d}$ & $31(26: 74)$ & 48 \\
\hline
\end{tabular}

${ }^{a}{ }^{1} \mathrm{H}$ NMR yield using1,3,5-trimethoxybenzene as the internal standard;

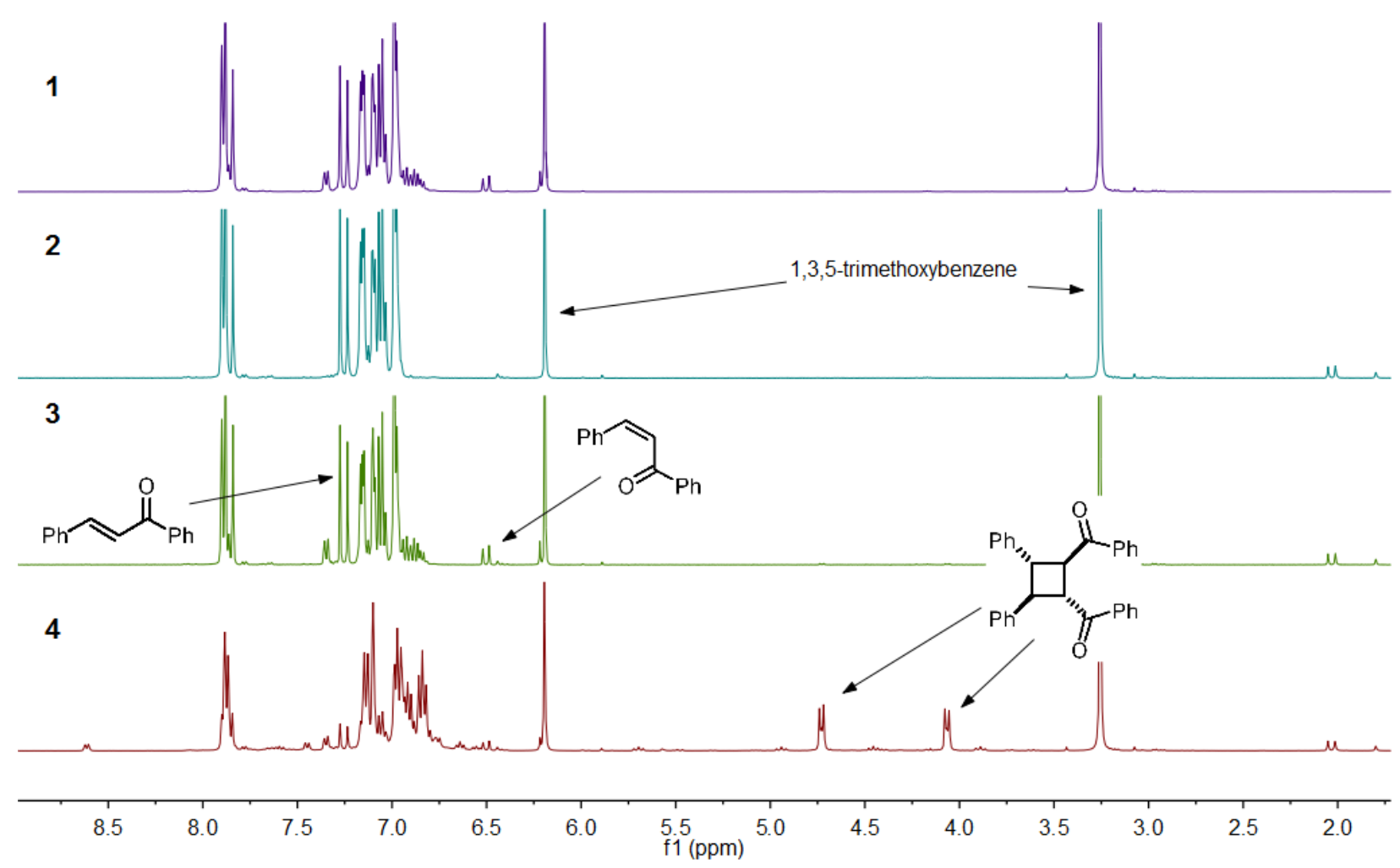

Figure ES11. ${ }^{1} \mathrm{H}$ NMR spectrum of a mixture of chalcone in $\left.\mathrm{C}_{6} \mathrm{D}_{6} 1\right)$ after irradiation (10 d); 2) in the presence of $\mathrm{Zr}\left({ }^{\mathrm{Mes} P D P}{ }^{\mathrm{Ph}}\right)_{2}$ without irradiation $\left.(1 \mathrm{~d}) ; 3\right)$ in the presence of $\mathrm{Zr}\left({ }^{\mathrm{Mes}} \mathrm{PDP}{ }^{\mathrm{Ph}}\right)_{2}$ after irradiation (2 h). 4) in the presence of $\mathrm{Zr}\left({ }^{\mathrm{Mes}} \mathrm{PDP}^{\mathrm{Ph}}\right)_{2}$ after irradiation (7 d). 


\subsection{Reference.}

(1) Zhang, Y.; Lee, T. S.; Petersen, J. L.; Milsmann, C. J. Am. Chem. Soc. 2018, 140, 5934.

(2) Zhang, Y.; Petersen, J. L.; Milsmann, C. J. Am. Chem. Soc. 2016, 138, 13115.

(3) Alt, H. G.; Köppl, A. Chem. Rev. 2000, 100, 1205.

(4) Mueller, T. E.; Hultzsch, K. C.; Yus, M.; Foubelo, F.; Tada, M. Chem. Rev. 2008, 108, 3795.

(5) Evan P. Beaumier; Pearce, A. J.; See, X. Y.; Tonks, I. A. Nat. Rev. Chem. 2019, 3, 15.

(6) Hakey, B. M.; Darmon, J. M.; Zhang, Y.; Petersen, J. L.; Milsmann, C. Inorg. Chem. 2019, $58(2), 1252$.

(7) Bordwell, Frederick, G. Acc. Chem. Res. 1988, 21, 456.

(8) Yuan, S.; Qin, J.; Lollar, C. T.; Zhou, H. ACS Cent. Sci. 2018, 4, 440.

(9) Qiu, R.; Xu, X.; Li, Y.; Zhang, G.; Shao, L.; An, D.; Yin, S. Chem. Commun. 2009, 1679.

(10) Saruhashi, K.; Kobayashi, S. J. Am. Chem. Soc. 2006, 128, 11232.

(11) Reichardt, C. Solvents and Solvent Effects in Organic Chemistry, 3rd ed.; Wiley-VCH Publishers, 2003.

(12) Caspar, J. V.; Meyer, T. J. J. Am. Chem. Soc. 1983, 105, 5583.

(13) Lees, A. J. Comments Inorg. Chem. A J. Crit. Disscussion Curr. Lit. 1995, 17, 319.

(14) King, K. A.; Spellane, P. J.; Watts, R. J. J. Am. Chem. Soc. 1985, 107, 1431. 
(15) Lai, P.-N.; Brysacz, C. H.; Alam, M. K.; Ayoub, N. A.; Gray, T. G.; Bao, J.; Teets, T. S. J. Am. Chem. Soc. 2018, 140, 10198.

(16) Vezzu, D. A. K.; Ravindranathan, D.; Garner, A. W.; Bartolotti, L.; Smith, M. E.; Boyle, P. D.; Huo, S. Inorg. Chem. 2011, 50, 8261.

(17) Kotch, T. G.; Lees, A. J.; Fuerniss, S. J.; Papathomas, K. I.; Snyder, R. W. Inorg. Chem. 1993, 32, 2570 .

(18) Wrighton, M.; Morse, D. L. J. Am. Chem. Soc. 1974, 96, 998.

(19) Arias-Rotondo, D. M.; McCusker, J. K. Chem. Soc. Rev. 2016, 45, 5803.

(20) Rehm, D.; Weller, A. Isr. J. Chem. 1970, 8, 259.

(21) Nguyen, J. D.; Tucker, J. W.; Konieczynska, M. D.; Stephenson, C. R. J. J. Am. Chem. Soc. 2011, 133, 4160 .

(22) Pitre, S. P.; McTiernan, C. D.; Ismaili, H.; Scaiano, J. C. ACS Catal. 2014, 4, 2530.

(23) Gao, G. L.; Yang, C.; Xia, W. Chem. Commun. 2017, 53, 1041.

(24) Xie, J.; Yuan, X.; Abdukader, A.; Zhu, C.; Ma, J. Org. Lett. 2014, 16, 1768.

(25) Roglans, A.; Pla-Quintana, A.; Moreno-Mañas, M. Chem. Rev. 2006, 106, 4622.

(26) Jung, J.; Kim, E.; You, Y.; Cho, E. J. Adv. Synth. Catal. 2014, 356, 2741.

(27) Koike, T.; Akita, M. Acc. Chem. Res. 2016, 49, 1937. 
(28) Allongue, P.; Delamar, M.; Desbat, B.; Fagebaume, O.; Hitmi, R.; Pinson, J.; Savéant, J. M. J. Am. Chem. Soc. 1997, 119, 201.

(29) Zhu, X.-Q.; Zhang, M.-T.; Yu, A.; Wang, C.-H.; Cheng, J.-P. J. Am. Chem. Soc. 2008, 130, 2501.

(30) Nguyen, J. D.; D’Amato, E. M.; Narayanam, J. M. R.; Stephenson, C. R. J. Nat. Chem. 2012, 4,854 .

(31) Yin, H.; Jin, Y.; Hertzog, J. E.; Mullane, K. C.; Carroll, P. J.; Manor, B. C.; Anna, J. M.; Schelter, E. J. J. Am. Chem. Soc. 2016, 138, 16266.

(32) Singh, K.; Staig, S. J.; Weaver, J. D. J. Am. Chem. Soc. 2014, 136, 5275.

(33) Askes, S. H. C.; Bonnet, S. Nat. Rev. Chem. 2018, 2, 437.

(34) Monro, S.; Colón, K. L.; Yin, H.; John Roque, I.; Konda, P.; Gujar, S.; Thummel, R. P.; Lilge, L.; Cameron, C. G.; McFarland, S. A. Chem. Rev. 2018, 119, 797.

(35) Josefsen, L. B.; Boyle, R. W. Met. Based. Drugs 2008, 2008, 1.

(36) Emsley, J. Nat. Chem. 2014, 6, 254.

(37) Yogo, T.; Urano, Y.; Ishitsuka, Y.; Maniwa, F.; Nagano, T. J. Am. Chem. Soc. 2005, 127, 12162.

(38) Lu, J.; Pattengale, B.; Liu, Q.; Yang, S.; Li, S.; Huang, J.; Zhang, J. J. Am. Chem. Soc. 2018, $140,13719$. 
(39) Herkstroeter, W. G.; McClure, D. S. J. Am. Chem. Soc. 1968, 90, 4522.

(40) Lei, T.; Zhou, C.; Huang, M. Y.; Zhao, L. M.; Yang, B.; Ye, C.; Xiao, H.; Meng, Q. Y.; Ramamurthy, V.; Tung, C. H.; Wu, L. Z. Angew. Chemie - Int. Ed. 2017, 56, 15407.

(41) Agarwala, S. S.; Thompson, J.; Smithers, M.; Ross, M.; Coventry, B.; Scoggins, D. M.; Hersey, P.; Wachter, E. J. Clin. Oncol. 2009, 27, 9060.

(42) Alexander, W. Pharm. Ther. 2010, 35, 469.

(43) Radlauer, M. R.; Agapie, T. Organometallics 2014, 33, 3247.

(44) Rong, Y.; Al-Harbi, A.; Parkin, G. Organometallics 2012, 31, 8208.

(45) Eisenberger, P.; Gischig, S.; Togni, A. Chem. - A Eur. J. 2006, 12, 2579.

(46) Du, Y.; Pearson, R. M.; Lim, C. H.; Sartor, S. M.; Ryan, M. D.; Yang, H.; Damrauer, N. H.; Miyake, G. M. Chem. - A Eur. J. 2017, 23, 10962.

(47) Nagib, D. A.; Macmillan, D. W. C. Nature 2011, 480, 224.

(48) Gomes, F.; Narbonne, V.; Blanchard, F.; Maestri, G.; Malacria, M. Org. Chem. Front. 2015, 2, 464 .

(49) Murphy, J. A.; Khan, T. A.; Zhou, S. Z.; Thomson, D. W.; Mahesh, M. Angew. Chemie - Int. Ed. 2005, 117, 1380. 


\section{Chapter 4.}

\section{Tuning the Optical and Electrochemical Properties of Zirconium Based Molecular}

\section{Photosensitizer}

\subsection{Introduction.}

Previously, we have demonstrated that $\mathrm{Zr}$ (IV) complexes bearing pyridine dipyrrolide, PDP, ligands exhibit optical/redox properties comparable to (in some cases, better than) photocatalyst incorporating late transition metals ( $\mathrm{Ir}(\mathrm{III}), \mathrm{Ru}(\mathrm{II}), \mathrm{Cu}(\mathrm{I})) .{ }^{1-3}$ Nonetheless, understanding of the factors that tune the optical and electrochemical properties of zirconium-based chromophore has not been established. Optical/electrochemical properties determine the photochemical applications of a photosensitizer. For example, the appropriate ground state and excited state redox potentials of a photosensitizer are critical to perform organic one-electron redox synthesis. ${ }^{4}$ Also, the capability of absorbing wide range of the sunlight spectrum is important for designing an efficient solar cell. ${ }^{5}$ Moreover, for photodynamic therapy (PDT), the NIR emission from a photosensitizer is often required for deep skin penetration. ${ }^{6}$ Thus, it is crucial to understand the structurephotophysical property relationship in order to tune their properties in a predictable manner towards a given application. To this end, owing to the facile and modular synthesis of the ligand framework, we have prepared several compounds with systematic changes in their ligand systems. 


\subsection{Synthesis of Ligands and Zirconium Complexes.}

The ligand pyridine di-pyrrole $\left(\mathrm{H}_{2}{ }^{\mathrm{R} 1} \mathrm{PDP}^{\mathrm{R} 2}\right)$ framework can be constructed via several different methods (Scheme 1). The ligands 2,6-bis(3,5-diphenyl-1H-pyrrol-2-yl)-pyridine $\left(\mathrm{H}_{2}{ }^{\mathrm{Ph}}{ } \mathrm{PDP}{ }^{\mathrm{Ph}}\right)$, 2,6-bis (5-methyl-1H-pyrrol-2-yl)-pyridine $\left(\mathrm{H}_{2}{ }^{\mathrm{Me}} \mathrm{PDP}^{\mathrm{H}}\right)$, and 2,6-bis(3-methyl-3pentafluorophenyl-1 H-pyrrol-2-yl)-pyridine, $\mathrm{H}_{2}{ }^{\mathrm{Me}} \mathrm{PDP}^{\mathrm{C} 6 \mathrm{~F} 5}$ were synthesized via a general protocol reported previously. ${ }^{7-9}$ The Suzuki coupling of 2,6-dibromopyridine and 1-(tert-butoxycarbonyl)2-pyrroleboronic acid followed by deprotection furnished 2,6-bis(1H-pyrrol-2-yl)-pyridine $\left(\mathrm{H}_{2}{ }^{\mathrm{H}} \mathrm{PDP}^{\mathrm{H}}\right)$ as dark green crystals in $60 \%$ yield. 2,6-bis(3,5-dimethyl-1H-pyrrol-2-yl)-pyridine $\left(\mathrm{H}_{2}{ }^{\mathrm{Me}} \mathrm{PDP}{ }^{\mathrm{Me}}\right)$ was prepared according to the method reported by Caulton and co-workers. ${ }^{10}$

Scheme 1. Ligand Synthesis

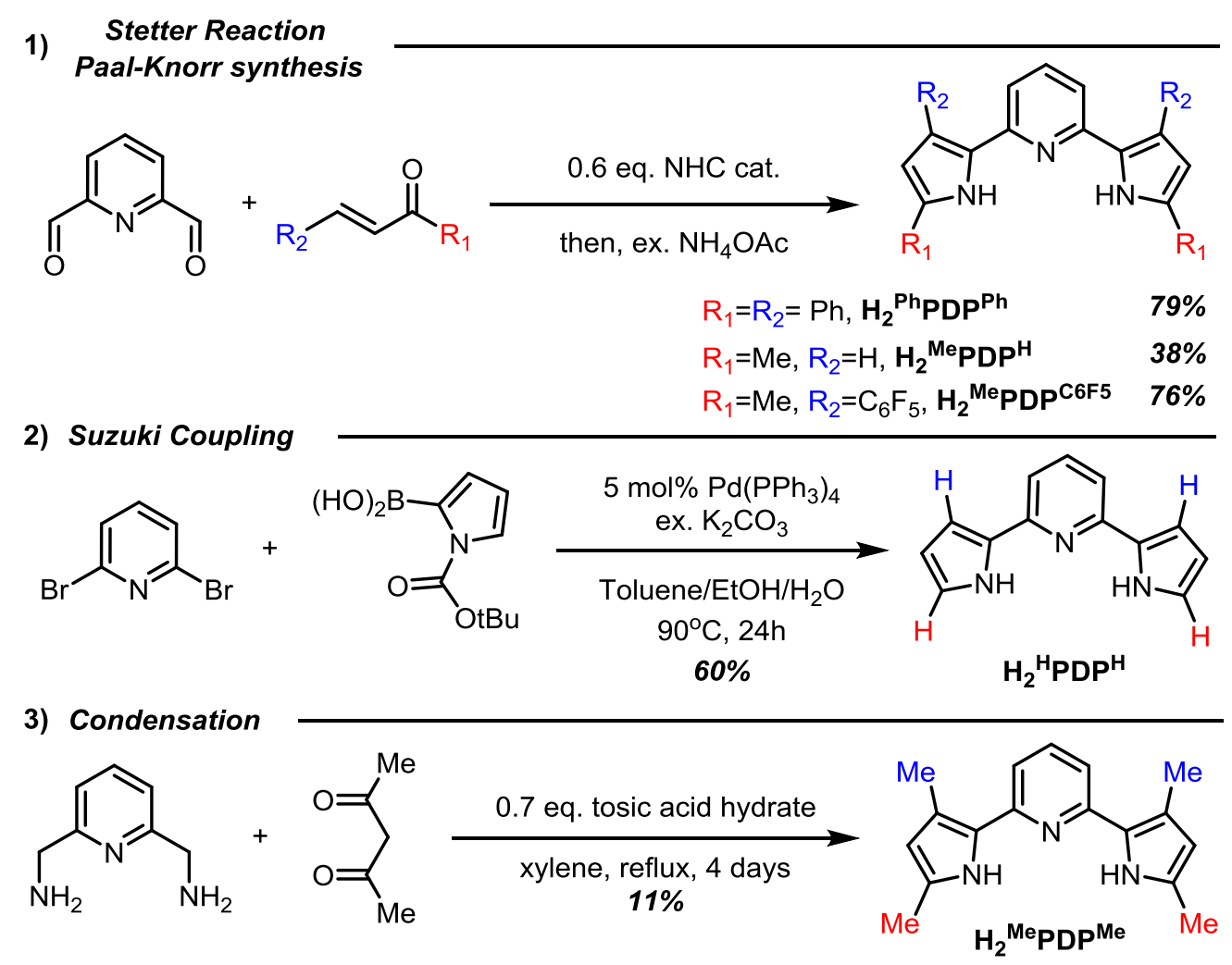


Ligand deprotonation followed by treatment with a $\mathrm{ZrCl}_{4}$ suspension in tetrahydrofuran (THF) provided bis-ligated zirconium complexes: $\mathrm{Zr}\left({ }^{\mathrm{Ph}} \mathrm{PDP}^{\mathrm{Ph}}\right)_{2}, \mathrm{Zr}\left({ }^{\mathrm{Me}} \mathrm{PDP}^{\mathrm{H}}\right)_{2}, \mathrm{Zr}\left({ }^{\mathrm{Me}}{ } \mathrm{PDP}^{\mathrm{C} 6 \mathrm{~F} 5}\right)_{2}$, and $\mathrm{Zr}\left({ }^{\mathrm{Me}} \mathrm{PDP}{ }^{\mathrm{Me}}\right)_{2}$ in good yield, consistent with our previous method. ${ }^{9}$ Similar salt metathesis methods using $\mathrm{H}_{2}{ }^{\mathrm{H}} \mathrm{PDP}^{\mathrm{H}}$ did not furnish the desired $\mathrm{Zr}\left({ }^{\mathrm{H}} \mathrm{PDP}^{\mathrm{H}}\right)_{2}$ but instead gave the bis-THF adduct, $\mathrm{Zr}\left({ }^{\mathrm{H}} \mathrm{PDP}^{\mathrm{H}}\right)_{2}(\mathrm{THF})_{2}$, as a yellow powder upon workup. Alternatively, direct reaction between $\mathrm{H}_{2}{ }^{\mathrm{H} P D P}{ }^{\mathrm{H}}$ and tetrabenzyl zirconium (half an equivalent) in benzene precipitated dark orange, microcrystalline $\mathrm{Zr}\left({ }^{\mathrm{H}} \mathrm{PDP}^{\mathrm{H}}\right)_{2}$ in $91 \%$ yield. Stirring the isolated $\mathrm{Zr}\left({ }^{\mathrm{H}} \mathrm{PDP}^{\mathrm{H}}\right)_{2}$ in THF and subsequent solvent evaporation provided eight-coordinate $\mathrm{Zr}\left({ }^{\mathrm{H}} \mathrm{PDP}^{\mathrm{H}}\right)_{2}(\mathrm{THF})_{2}$, again as a yellow powder. Additionally, heating the solid $\mathrm{Zr}\left({ }^{\mathrm{H}} \mathrm{PDP}^{\mathrm{H}}\right)_{2}(\mathrm{THF})_{2}$ under vacuum results in an orange solid and complete THF dissociation, which was confirmed by ${ }^{1} \mathrm{H}$ NMR spectroscopy, again consistent with a transformation back to the six-coordinate compound (Scheme 2). All observations above are indicative of highly labile THF binding to the zirconium center. 
Scheme 2. Synthesize of zirconium complexes.
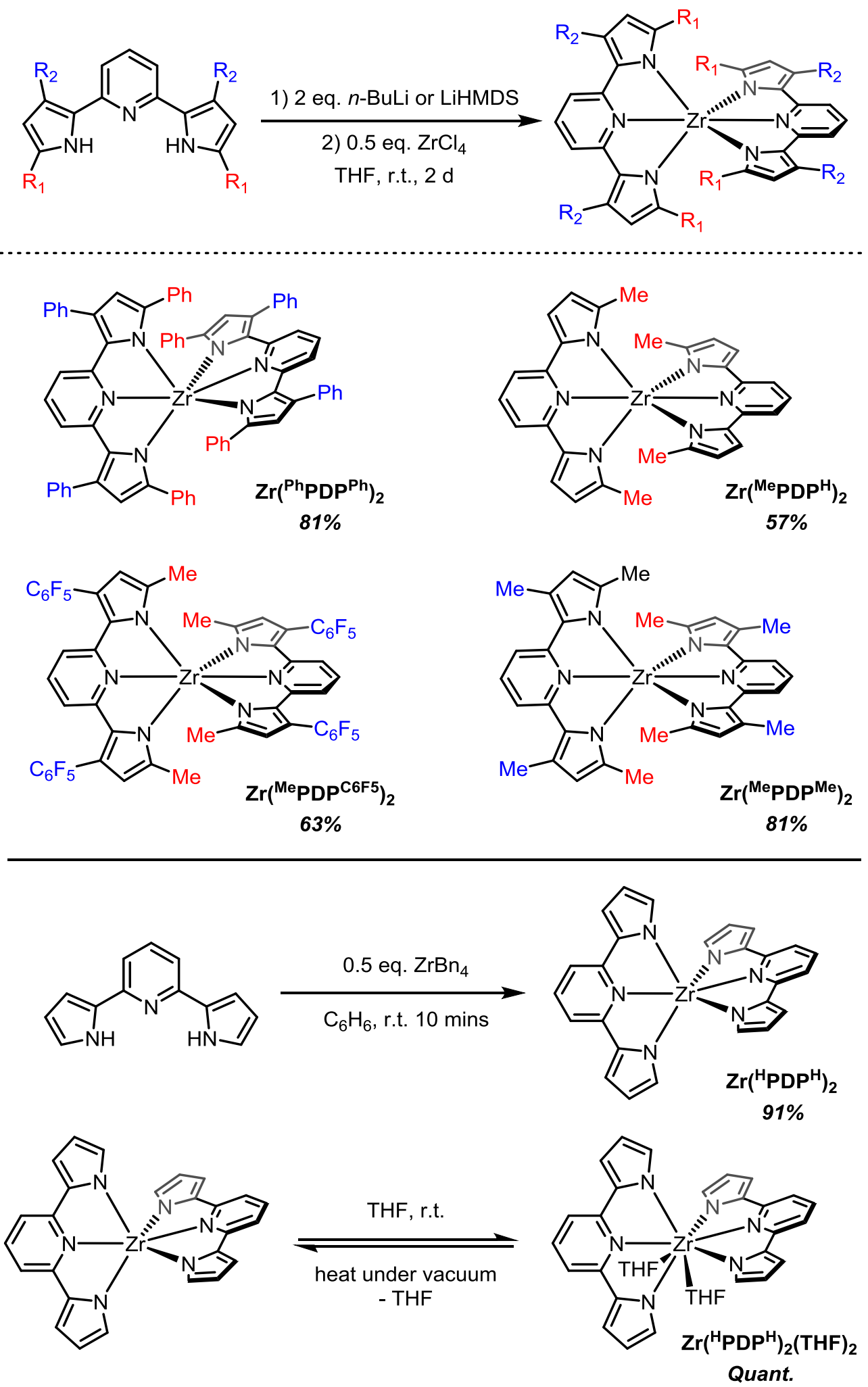


\subsection{Crystallographic Characterization.}

All new zirconium complexes were characterized by single-crystal X-ray diffraction. Data were collected by high resolution X-ray crystallography at $100 \mathrm{~K}$ and the crystallographic details are summarized in the Appendix C. The structures of these compounds along with previously reported $\mathrm{Zr}\left({ }^{\mathrm{Me}} \mathrm{PDP}{ }^{\mathrm{Ph}}\right)_{2}$ and $\mathrm{Zr}\left({ }^{\mathrm{Mes}} \mathrm{PDP}^{\mathrm{Ph}}\right)_{2}$ are depicted in Figure 1. Two independent views for each complex are shown and the selected structural information is listed in Table 1. The coordination environment around the central metal ion for all six-coordinate compounds can be viewed as distorted octahedral with two meridianally coordinating pincer PDP ligands. While the $\mathrm{Zr}\left({ }^{\mathrm{H}} \mathrm{PDP}^{\mathrm{H}}\right)_{2}(\mathrm{THF})_{2}$ is best described as distorted square antiprismatic with a $C_{2}$ axis through the zirconium center, bisecting the two THF oxygens. Noticing that the eight-coordinate $\mathrm{Zr}\left({ }^{\mathrm{H}} \mathrm{PDP}^{\mathrm{H}}\right)_{2}(\mathrm{THF})_{2}$ shows elongation of the $\mathrm{Zr}-\mathrm{N}_{\text {pyridine }}$ and $\mathrm{Zr}-\mathrm{N}_{\text {pyrrolide }}$ bonds by $\sim 2 \mathrm{pm}$ and $\sim 4 \mathrm{pm}$ respectively compared with the longest averaged zirconium ligand bond distance for the other complexes. The extra two oxygen donors produce a less electro-positive zirconium center and thus lead to a modest lengthening of the $\mathrm{Zr}-\mathrm{N}$ bonds of dianionic PDP pincer ligands. 

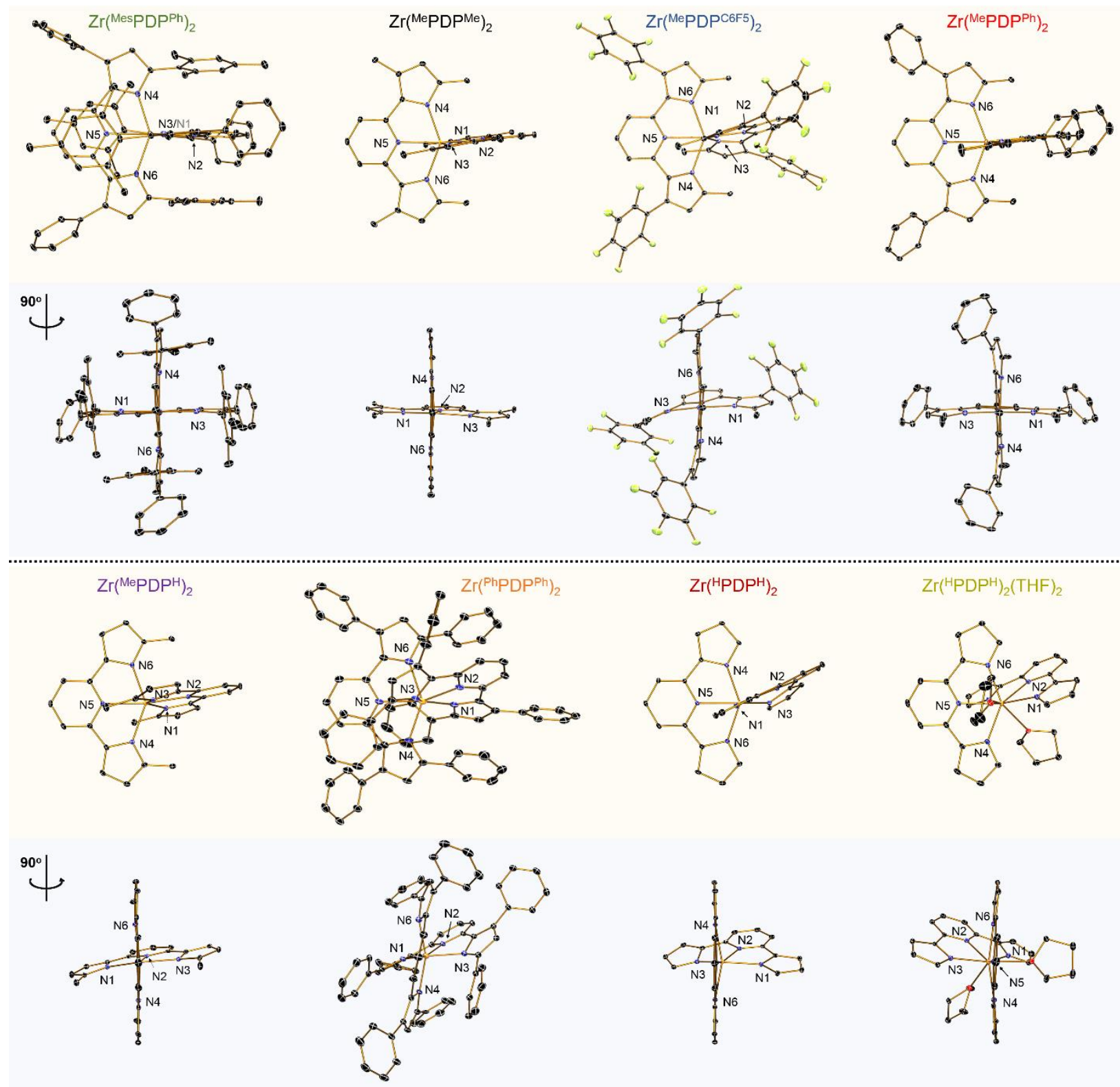

Figure 1. ORTEP representation of the molecular structures of all zirconium complexes with $30 \%$ probability ellipsoids. The structures on the light blue background are rotated $90^{\circ}$ from the structures on the light orange background. Only one of the unique structures for $\mathrm{Zr}\left({ }^{\mathrm{Me}} \mathrm{PDP}^{\mathrm{C} 6 \mathrm{F5}}\right)_{2}$ in the unit cell is shown. Hydrogen atoms were omitted for clarity. 
Table 1. Selected Bond Lengths $(\AA)$ and Angles $\left({ }^{\circ}\right)$

\begin{tabular}{|c|c|c|c|c|c|c|c|c|}
\hline & $\mathrm{Zr}\left({ }^{\mathrm{Mes}} \mathrm{PDP}^{\mathrm{Ph}}\right)_{2}$ & $\mathrm{Zr}\left({ }^{\mathrm{Me}} \mathrm{PDP}^{\mathrm{Me}}\right)_{2}$ & $\begin{array}{c}\mathrm{Zr}\left({ }^{\mathrm{Me}} \mathrm{PDP}\right. \\
\left.\mathrm{C}^{25}\right)_{2}\end{array}$ & $\mathrm{Zr}\left({ }^{\mathrm{Me}} \mathrm{PDP}^{\mathrm{Ph}}\right)_{2}$ & $\mathrm{Zr}\left({ }^{\mathrm{Me}} \mathrm{PDP}^{\mathrm{H}}\right)_{2}$ & $\mathrm{Zr}\left({ }^{\mathrm{Ph}} \mathrm{PDP}^{\mathrm{Ph}}\right)_{2}$ & $\mathrm{Zr}\left({ }^{\mathrm{H}} \mathrm{PDP}^{\mathrm{H}}\right)_{2}$ & $\begin{array}{c}\mathrm{Zr}\left({ }^{\mathrm{H}} \mathrm{PDP}^{\mathrm{H}}\right)_{2} \\
(\mathrm{THF})_{2}\end{array}$ \\
\hline \multirow[t]{2}{*}{$\mathrm{Zr}(1)-\mathrm{N}(1)$} & $2.170(2)$ & $2.1473(16)$ & $2.170(2)$ & $2.150(2)$ & $2.161(2)$ & $2.166(2)$ & $2.1493(10)$ & $2.2181(13)$ \\
\hline & & & $2.165(2)^{\mathrm{a}}$ & & & & & \\
\hline \multirow[t]{2}{*}{$\mathrm{Zr}(1)-\mathrm{N}(2)$} & $2.262(2)$ & $2.3128(15)$ & $2.285(2)$ & $2.289(2)$ & $2.299(2)$ & $2.262(3)$ & $2.2820(10)$ & $2.3329(13)$ \\
\hline & & & $2.311(2)^{\mathrm{a}}$ & & & & & \\
\hline \multirow[t]{2}{*}{$\mathrm{Zr}(1)-\mathrm{N}(3)$} & $2.166(2)$ & $2.1734(16)$ & $2.164(2)$ & $2.184(2)$ & $2.182(2)$ & $2.197(2)$ & $2.1740(10)$ & $2.2220(13)$ \\
\hline & & & $2.175(2)^{\mathrm{a}}$ & & & & & \\
\hline \multirow[t]{2}{*}{$\mathrm{Zr}(1)-\mathrm{N}(4)$} & $2.170(2)$ & $2.1789(16)$ & $2.151(2)$ & $2.144(3)$ & $2.173(2)$ & $2.211(2)$ & $2.1680(10)$ & $2.2303(13)$ \\
\hline & & & $2.183(2)^{\mathrm{a}}$ & & & & & \\
\hline \multirow[t]{2}{*}{$\mathrm{Zr}(1)-\mathrm{N}(5)$} & $2.262(2)$ & $2.3127(16)$ & $2.296(2)$ & $2.300(2)$ & 2.294(2) & $2.267(3)$ & $2.2907(10)$ & $2.3284(13)$ \\
\hline & & & $2.304(2)^{\mathrm{a}}$ & & & & & \\
\hline \multirow[t]{2}{*}{$\mathrm{Zr}(1)-\mathrm{N}(6)$} & $2.165(2)$ & $2.1599(16)$ & $2.183(2)$ & $2.172(2)$ & $2.185(3)$ & $2.160(2)$ & $2.1689(10)$ & $2.2177(13)$ \\
\hline & & & $2.177(2)^{\mathrm{a}}$ & & & & & \\
\hline \multirow[t]{2}{*}{$\mathrm{Zr}-\mathrm{N}_{\text {pyrrole }}($ Ave.) } & 2.168 & 2.165 & 2.167 & 2.163 & 2.175 & 2.184 & 2.165 & 2.222 \\
\hline & & & $2.175^{\mathrm{a}}$ & & & & & \\
\hline \multirow[t]{2}{*}{$\mathrm{Zr}-\mathrm{N}_{\mathrm{py}}$ (Ave.) } & 2.262 & 2.313 & 2.291 & 2.295 & 2.297 & 2.265 & 2.286 & 2.331 \\
\hline & & & $2.308^{\mathrm{a}}$ & & & & & \\
\hline \multirow[t]{2}{*}{ Dihedral } & 89.57 & 89.63 & 87.26 & 88.29 & 88.43 & 72.89 & 76.05 & 68.41 \\
\hline & & & $85.13^{\mathrm{a}}$ & & & & & \\
\hline \multirow[t]{2}{*}{$\mathrm{N}(2)-\mathrm{Zr}(1)-\mathrm{N}(5)$} & $179.42(8)$ & 173.11(6) & 172.91 & $171.76(8)$ & $169.08(9)$ & 153.81(9) & $151.78(4)$ & $134.58(5)$ \\
\hline & & & $177.14^{\mathrm{a}}$ & & & & & \\
\hline
\end{tabular}

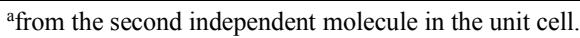

Rigorously speaking, all complexes are $C_{1}$ symmetric in the crystal lattice while NMR spectroscopy suggests that all six-coordinate, bis-ligated zirconium complexes are $D_{2 d}$ symmetric and $\mathrm{Zr}\left({ }^{\mathrm{H}} \mathrm{PDP}^{\mathrm{H}}\right)_{2}(\mathrm{THF})_{2}$ is $C_{2}$ symmetric, indicative of fast fluxional behavior of the two pincer ligands in solution. In the solid state of six-coordinate compounds, however, substituent variations on the pyrrole moieties have significant influence on the distortion from perfect $D_{2 d}$ symmetry. The most reflective parameters for structural distortion are the dihedral angle or flattening angle $\left(\theta_{\mathrm{f}}\right)$ between the two ligand planes (ideally $90^{\circ}$, defined by three nitrogen atoms of each ligand) and the $\mathrm{N}_{\mathrm{py}}(2)-\mathrm{Zr}-\mathrm{N}_{\mathrm{py}}(5)$ angle (ideally $\left.180^{\circ}\right)$ or wagging angle $\left(\theta_{\mathrm{w}}\right)$ as demonstrated in Figure 2. $\mathrm{Zr}\left({ }^{\mathrm{Mes}} \mathrm{PDP}^{\mathrm{Ph}}\right)_{2}$ shows the smallest deviation from $D_{2 d}$ symmetry, with the two pincer ligands 
exhibiting a nearly perfectly orthogonal arrangement with a dihedral angle of $89.57^{\circ}$ and $\mathrm{N}_{\mathrm{py}}(2)-$ $\mathrm{Zr}-\mathrm{N}_{\mathrm{py}}(5)$ angle of $179.42^{\circ}$. Surprisingly, the similarly aromatic-substituted complex, $\mathrm{Zr}\left({ }^{\mathrm{Ph}} \mathrm{PDP}^{\mathrm{Ph}}\right)_{2}$, shows a substantial geometry deformation. The dihedral angle of this compound is $72.89^{\circ}$ with a $\mathrm{N}_{\mathrm{py}}(2)-\mathrm{Zr}-\mathrm{N}_{\mathrm{py}}(5)$ angle of $153.81^{\circ}$. Inspection of the crystal lattice clearly shows intramolecular, inter-ligand $\pi$-stacking between one 5-phenyl group and pyridine moiety of the second ligand, similar to $\mathrm{Zr}\left({ }^{\mathrm{Mes}} \mathrm{PDP}^{\mathrm{Ph}}\right)_{2}$ (chapter 3). However, $\mathrm{Zr}\left({ }^{\mathrm{Ph}} \mathrm{PDP}^{\mathrm{Ph}}\right)_{2}$ shows a unique secondary $\pi$-stacking between the second 5-phenyl group and a pyrrolide of the second ligand. Evidently this $\pi$-stacking and hence structural distortion cannot occur for the mesityl-substituted complex, likely due to the steric demand of the associated methyl groups in the inner coordination sphere. The most dramatic distortion from idealized $D_{2 d}$ geometry are the least functionalized complexes, namely $\mathrm{Zr}\left({ }^{\mathrm{H}} \mathrm{PDP}^{\mathrm{H}}\right)_{2}$ and its THF adduct, $\mathrm{Zr}\left({ }^{\mathrm{H} P D P}{ }^{\mathrm{H}}\right)_{2}(\mathrm{THF})_{2}$. These compounds show dihedral angle, $\theta_{\mathrm{f}}$, deviations of $13.95^{\circ}$ and $21.59^{\circ}$ correspondingly and $\mathrm{N}_{\mathrm{py}}(2)-\mathrm{Zr}-\mathrm{N}_{\mathrm{py}}(5)$ angle, $\theta_{\mathrm{w}}$, deviations of $28.22^{\circ}$ and $45.42^{\circ}$, respectively. The reason could be that the exposed $\operatorname{PDP} \pi$ system resulted from unsubstituted ligand framework of $\mathrm{Zr}\left({ }^{\mathrm{H}} \mathrm{PDP}^{\mathrm{H}}\right)_{2}$ led to strong intermolecular $\pi$ stackings in the lattice, which distorts the geometry for the crystal packing. For the complexes with 5-methyl substituted pyrroles, the $\mathrm{Zr}\left({ }^{\mathrm{Me}} \mathrm{PDP}^{\mathrm{H}}\right)_{2}$ displays the largest structural deformation compared to others. This demonstrated the group distal away of metal center the (3- position) helps in keeping the geometry around zirconium center from the deviation. $\mathrm{Zr}\left({ }^{\mathrm{Me}} \mathrm{PDP}^{\mathrm{C} 6 \mathrm{~F} 5}\right)_{2}$, and $\mathrm{Zr}\left({ }^{\mathrm{Me}} \mathrm{PDP}^{\mathrm{Ph}}\right)_{2}$ gives greater distortion compared with $\mathrm{Zr}\left({ }^{\mathrm{Me}} \mathrm{PDP}^{\mathrm{Me}}\right)_{2}$, which is again likely due to $\pi-\pi$ interaction between aromatic systems of the substituents. 


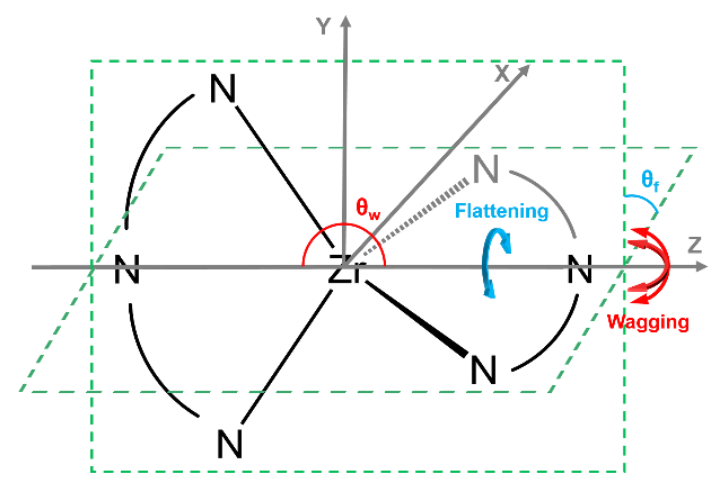

Figure 2. Schematic representation of the distortions in the solid-state structure of zirconium PDP complexes.

Hence, there seems to be a trend that the less bulky substituents on the ligands, the more distortion with the metal complexes from idealized $D_{2 d}$ symmetry in the solid state. In addition, intra- or inter-molecular $\pi$ stacking effects between aromatic rings tend to cause large changes in dihedral angle of two ligand planes and $\mathrm{N}_{\mathrm{py}}(2)-\mathrm{Zr}-\mathrm{N}_{\mathrm{py}}(5)$ angle. Along with the fact that they are $D_{2 d}$ symmetric in room temperature solution by NMR spectroscopy, we propose that both the $\mathrm{N}_{\mathrm{py}}(2)-\mathrm{Zr}-\mathrm{N}_{\mathrm{py}}(5)$ angle and the dihedral angle between ligand planes (rigidity parameters) for these zirconium complexes in the solid state reflects overall rigidities of their ligand framework in solution.

\subsection{Electrochemistry.}

The electrochemical properties of all new zirconium complexes were investigated via cyclic voltammetry $(\mathrm{CV})$. All $\mathrm{CV}$ experiments were conducted with $\left[\mathrm{N}(n-\mathrm{Bu})_{4}\right] \mathrm{PF}_{6}$ as the 
supporting electrolyte $(0.1 \mathrm{M})$ and all potentials were referenced against the $\mathrm{Fc}^{+} / \mathrm{Fc}$ couple using ferrocene $(\mathrm{Fc})$ as an internal standard. The cyclic voltammograms for new zirconium complexes together with earlier reported $\mathrm{Zr}\left({ }^{\mathrm{Me}} \mathrm{PDP}^{\mathrm{Ph}}\right)_{2}$ and $\mathrm{Zr}\left({ }^{\mathrm{Mes}} \mathrm{PDP}^{\mathrm{Ph}}\right)_{2}$ are presented in Figure 3 and SI. The CVs for $\mathrm{Zr}\left({ }^{\mathrm{H}} \mathrm{PDP}^{\mathrm{H}}\right)_{2}$ were conducted in non-coordinating 1,2-difluorobenzene and the remaining zirconium complexes were measured in THF solution. Potentials reported in 1,2difluorobenzene solvent are comparable with the data collected in THF (less than $0.05 \mathrm{~V}$ lower) based on the CVs measured for $\mathrm{Zr}\left({ }^{\mathrm{Me}} \mathrm{PDP}^{\mathrm{Ph}}\right)_{2}$ (Table 2).

Unfortunately, all new complexes exhibit only irreversible oxidation features (mostly broad and unresolved, see Appendix A for details) resulting from insufficient steric protection of ligand oxidation sites compared with $\mathrm{Zr}\left({ }^{\mathrm{Mes}} \mathrm{PDP}^{\mathrm{Ph}}\right)_{2}$. Conversely, all new compounds display at least one single-electron reduction event at highly reducing potential. Considering the similar core structural framework of $\mathrm{Zr}\left({ }^{\mathrm{R} 1} \mathrm{PDP}^{\mathrm{R} 2}\right)_{2}$, analogous natures of reduction events are expected. Notably, $\mathrm{Zr}\left({ }^{\mathrm{Me}} \mathrm{PDP}^{\mathrm{H}}\right)_{2}, \mathrm{Zr}\left({ }^{\mathrm{Me}} \mathrm{PDP}^{\mathrm{Me}}\right)_{2}, \mathrm{Zr}\left({ }^{\mathrm{Mes}} \mathrm{PDP}^{\mathrm{Ph}}\right)_{2}$, and $\mathrm{Zr}\left({ }^{\mathrm{H}} \mathrm{PDP}^{\mathrm{H}}\right)_{2}$ show one less reduction feature than $\mathrm{Zr}\left({ }^{\mathrm{Me}} \mathrm{PDP}^{\mathrm{Ph}}\right)_{2}$ and $\mathrm{Zr}\left({ }^{\mathrm{Ph}} \mathrm{PDP}^{\mathrm{Ph}}\right)_{2}$. It is likely that the potentials for a $3^{\text {rd }}$ reduction event is out of (or on the border of) the potential window for THF or 1,2-difluorobenzene solvents. Poly-fluorinated $\mathrm{Zr}\left({ }^{\mathrm{Me}} \mathrm{PDP}^{\mathrm{C} 6 \mathrm{F5}}\right)_{2}$ shows only one quasi-reversible reduction feature at $-1.85 \mathrm{~V}$. This is likely attributable to C-F bond cleavage of highly electron-accepting pentafluorophenyl moieties upon reduction. Changing only the substituent at the 3-position of the pyrroles from electronwithdrawing $\left(\mathrm{C}_{6} \mathrm{~F}_{5}\right)$ to electron-donating $(\mathrm{Me})$ shifted the first reduction event to more negative 
potential. Similarly, replacing phenyl $\left(\mathrm{Zr}\left({ }^{\mathrm{Ph}} \mathrm{PDP}^{\mathrm{Ph}}\right)_{2}\right)$ with the more electron rich mesityl $\left(\mathrm{Zr}\left({ }^{\mathrm{Mes}} \mathrm{PDP}^{\mathrm{Ph}}\right)_{2}\right)$ at the 5-position of pyrroles led to a $0.16 \mathrm{~V}$ decrease in potential of $\mathrm{E}_{1 / 2}{ }^{(0 / 1-)}$. Finally, the eight-coordinated $\mathrm{Zr}\left({ }^{\mathrm{H}} \mathrm{PDP}^{\mathrm{H}}\right)_{2}(\mathrm{THF})_{2}$ complex has the most negative potential of $-2.45 \mathrm{~V}$ for the first reduction measured in THF.

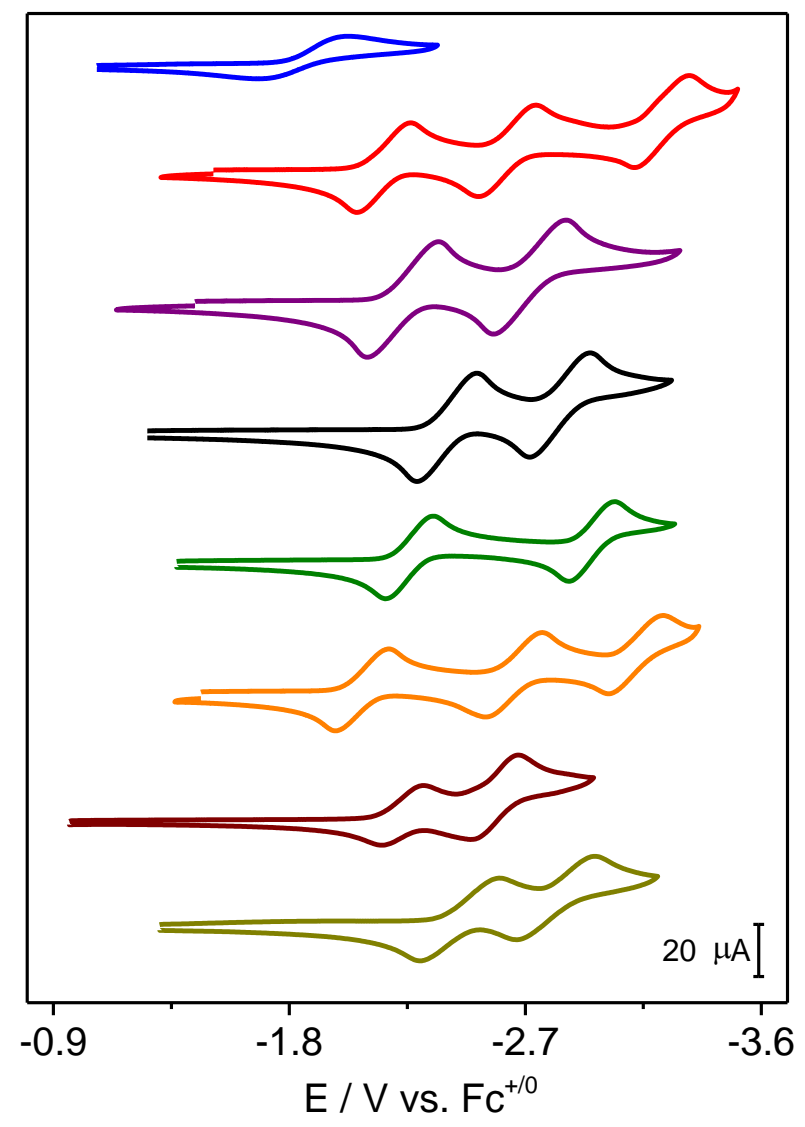

Figure 3. Cyclic voltammogram of $\mathrm{Zr}\left({ }^{\mathrm{Me}} \mathrm{PDP}^{\mathrm{C} 6 \mathrm{~F} 5}\right)_{2}$ (blue), $\mathrm{Zr}\left({ }^{\mathrm{Me}} \mathrm{PDP}^{\mathrm{Ph}}\right)_{2}$ (red), $\mathrm{Zr}\left({ }^{\mathrm{Me}} \mathrm{PDP}^{\mathrm{H}}\right)_{2}$ (purple), $\mathrm{Zr}\left({ }^{\mathrm{Me}} \mathrm{PDP}{ }^{\mathrm{Me}}\right)_{2}$ (black), $\mathrm{Zr}\left({ }^{\mathrm{Mes}} \mathrm{PDP}^{\mathrm{Ph}}\right)_{2}$ (olive), $\mathrm{Zr}\left({ }^{\mathrm{Ph}} \mathrm{PDP}^{\mathrm{Ph}}\right)_{2}$ (orange), $\mathrm{Zr}\left({ }^{\mathrm{H}} \mathrm{PDP}^{\mathrm{H}}\right)_{2}(\mathrm{THF})_{2}$ (dashed dark yellow) in THF and $\mathrm{Zr}\left({ }^{\mathrm{H}} \mathrm{PDP}^{\mathrm{H}}\right)_{2}$ (wine) in 1,2-difluorobenzene at room temperature (scan rate $200 \mathrm{mV} \mathrm{s}^{-1}, 0.1 \mathrm{M}\left[\mathrm{N}(n-\mathrm{Bu})_{4}\right] \mathrm{PF}_{6}$, glassy carbon working electrode). 
Table 2. Redox potentials for $\mathrm{Zr}\left({ }^{\mathrm{R} 1} \mathrm{PDP}^{\mathrm{R} 2}\right)_{2}$ and $\mathrm{Zr}\left({ }^{\mathrm{H}} \mathrm{PDP}^{\mathrm{H}}\right)_{2}(\mathrm{THF})_{2}$ complexes.

\begin{tabular}{|c|c|c|c|}
\hline & $\mathrm{E}_{1 / 2}(0 / 1-) / \mathrm{V}^{\mathrm{a}}$ & $E_{1 / 2}(1-/ 2-) / V^{a}$ & $\mathrm{E}_{1 / 2}(2-/ 3-) / \mathrm{V}^{\mathrm{a}}$ \\
\hline $\mathrm{Zr}\left({ }^{\mathrm{Me}} \mathrm{PDP}^{\mathrm{C} 6 \mathrm{~F} 5}\right)_{2}$ & -1.85 & I & I \\
\hline $\mathrm{Zr}\left({ }^{\mathrm{Me}} \mathrm{PDP}^{\mathrm{Ph}}\right)_{2}{ }^{\mathrm{e}}$ & $-2.16^{\mathrm{b}}\left(-2.14^{\mathrm{c}}\right)$ & $-2.63^{b}\left(-2.57^{c}\right)$ & $-3.22^{b}$ \\
\hline $\mathrm{Zr}\left({ }^{\mathrm{Me}} \mathrm{PDP}^{\mathrm{H}}\right)_{2}$ & -2.21 & -2.70 & I \\
\hline $\mathrm{Zr}\left({ }^{\mathrm{Me}} \mathrm{PDP}^{\mathrm{Me}}\right)_{2}$ & -2.42 & -2.85 & I \\
\hline $\mathrm{Zr}\left({ }^{\mathrm{Mes}} \mathrm{PDP}^{\mathrm{Ph}}\right)_{2}$ & $-2.25^{\mathrm{d}}$ & $-2.95^{\mathrm{d}}$ & l \\
\hline $\mathrm{Zr}\left({ }^{\mathrm{Ph}} \mathrm{PDP}^{\mathrm{Ph}}\right)_{2}$ & -2.09 & -2.67 & -3.13 \\
\hline $\mathrm{Zr}\left({ }^{\mathrm{H}} \mathrm{PDP}^{\mathrm{H}}\right)_{2}$ & $-2.24^{\mathrm{c}}$ & $-2.56^{c}$ & l \\
\hline $\mathrm{Zr}\left({ }^{\mathrm{H}} \mathrm{PDP}^{\mathrm{H}}\right)_{2}(\mathrm{THF})_{2}$ & -2.45 & -2.82 & / \\
\hline
\end{tabular}

In general, ligands consisting of electron-withdrawing groups gives less reducing anionic zirconium species and vice versa. The reduction potential spans nearly $0.6 \mathrm{~V}$ for the $\left[\mathrm{Zr}\left({ }^{\mathrm{R} 1} \mathrm{PDP}^{\mathrm{R} 2}\right)_{2}\right]^{0} /\left[\mathrm{Zr}\left({ }^{\mathrm{R} 1} \mathrm{PDP}^{\mathrm{R} 2}\right)_{2}\right]^{1-}$ redox couple, suggesting high sensitivity to the pyrrole functionalities. Furthermore, the substituent influence on the redox potential was probed by DFT calculations and is discussed vide infra.

\subsection{Density Functional Theory (DFT) Studies.}

To gain further insight into the frontier molecular orbitals and the resulting optical transitions and ground state redox properties, DFT calculations were performed for each zirconium complex. All computations were conducted at the B3LYP level using the crystallographically determined structure as the starting point for geometry optimization. The selected geometric 
parameters after optimization are shown in Table 3. The metal-ligand bond distances are slightly longer than the values determined crystallographically and the largest deviation is observed for the average $\mathrm{Zr}-\mathrm{N}_{\text {pyrrole }}$ bond (6.1 $\mathrm{pm}$ and $7.5 \mathrm{pm}$ for $\mathrm{Zr}\left({ }^{\mathrm{Ph}} \mathrm{PDP}^{\mathrm{Ph}}\right)_{2}$ and $\mathrm{Zr}\left({ }^{\mathrm{Mes}} \mathrm{PDP}^{\mathrm{Ph}}\right)_{2}$, respectively). Notably, for most six-coordinate zirconium compounds except for $\mathrm{Zr}\left({ }^{\mathrm{Mes}} \mathrm{PDP}^{\mathrm{Ph}}\right)_{2}$, the dihedral angle or the $\mathrm{N}_{\mathrm{py}}(2)-\mathrm{Zr}-\mathrm{N}_{\mathrm{py}}(5)$ angle changes more or less significantly after geometry optimization. For example, two ligand planes are much closer to orthogonal with smallest dihedral angles larger than $82.83^{\circ}$. Also, the $\mathrm{N}_{\mathrm{py}}(2)-\mathrm{Zr}-\mathrm{N}_{\mathrm{py}}(5)$ angle largely increases ranging from $3.25^{\circ}$ to $20.68^{\circ}$ compared with solid state structures. The geometry converges closer to a $D_{2 d}$ symmetric equilibrium structure would allow us to better model their properties in solution $\left(D_{2 d}\right)$.

Table 3. Selected structural parameters for geometries of zirconium complexes obtained via DFT Calculations

\begin{tabular}{|c|c|c|c|c|c|c|c|c|}
\hline & $\mathrm{Zr}\left({ }^{\mathrm{Mes}} \mathrm{PDP}^{\mathrm{Ph}}\right)_{2}$ & $\mathrm{Zr}\left({ }^{\mathrm{MePDP}}{ }^{\mathrm{Me}}\right)_{2}$ & $\begin{array}{c}\mathrm{Zr}\left({ }^{\mathrm{Me}} \mathrm{PDP}\right. \\
\left.\mathrm{C}^{\circ} 5\right)_{2}\end{array}$ & $\mathrm{Zr}\left({ }^{\mathrm{Me}} \mathrm{PDP}^{\mathrm{Ph}}\right)_{2}$ & $\mathrm{Zr}\left({ }^{\mathrm{Me}} \mathrm{PDP}^{\mathrm{H}}\right)_{2}$ & $\mathrm{Zr}\left({ }^{\mathrm{Ph}} \mathrm{PDP}^{\mathrm{Ph}}\right)_{2}$ & $\mathrm{Zr}\left({ }^{\mathrm{H} P D P}\right)_{2}$ & $\begin{array}{c}\mathrm{Zr}\left({ }^{\mathrm{H}} \mathrm{PDP}^{\mathrm{H}}\right)_{2} \\
(\mathrm{THF})_{2}\end{array}$ \\
\hline $\mathrm{Zr}(1)-\mathrm{N}(1)$ & 2.228 & 2.194 & 2.196 & 2.192 & 2.194 & 2.236 & 2.191 & 2.243 \\
\hline $\mathrm{Zr}(1)-\mathrm{N}(2)$ & 2.251 & 2.332 & 2.329 & 2.336 & 2.336 & 2.300 & 2.334 & 2.350 \\
\hline $\mathrm{Zr}(1)-\mathrm{N}(3)$ & 2.224 & 2.196 & 2.193 & 2.202 & 2.197 & 2.227 & 2.192 & 2.259 \\
\hline $\mathrm{Zr}(1)-\mathrm{N}(4)$ & 2.233 & 2.198 & 2.206 & 2.190 & 2.191 & 2.233 & 2.183 & 2.257 \\
\hline $\mathrm{Zr}(1)-\mathrm{N}(5)$ & 2.248 & 2.334 & 2.322 & 2.334 & 2.336 & 2.301 & 2.332 & 2.357 \\
\hline $\mathrm{Zr}(1)-\mathrm{N}(6)$ & 2.231 & 2.192 & 2.192 & 2.196 & 2.198 & 2.238 & 2.181 & 2.252 \\
\hline $\begin{array}{c}\mathrm{Zr}-\mathrm{N}_{\text {pyrrole }} \\
\text { (Ave.) }\end{array}$ & 2.229 & 2.195 & 2.197 & 2.195 & 2.195 & 2.259 & 2.187 & 2.253 \\
\hline $\begin{array}{l}\mathrm{Zr}-\mathrm{N}_{\mathrm{py}} \\
\text { (Ave.) }\end{array}$ & 2.250 & 2.333 & 2.326 & 2.335 & 2.336 & 2.301 & 2.333 & 2.354 \\
\hline Dihedral & 89.55 & 89.80 & 89.97 & 89.83 & 89.66 & 84.42 & 82.83 & 63.61 \\
\hline $\begin{array}{c}\mathrm{N}(2)- \\
\operatorname{Zr}(1)-\mathrm{N}(5)\end{array}$ & 179.00 & 177.46 & 176.12 & 179.38 & 179.25 & 174.49 & 161.98 & 135.10 \\
\hline
\end{tabular}


The calculated frontier molecular orbital (HOMO-1, HOMO, LUMO and LUMO+1) energy levels are shown in Figure 4. All six-coordinate zirconium complexes have similar frontier molecular orbital (FMO) compositions but varying FMO energies. We caution that at two ligands are interchangeable in solution around a $C_{2}$ axis that bisects two ligand planes, thus the LUMO and LUMO+1 orbital should be completely degenerate in solution phase. In all cases the HOMO(1) are purely ligand-centered and delocalized onto both ligands. While the essentially degenerate (degenerate e set in ideal $D_{2 d}$ ) LUMO and LUMO+1 are also largely ligand-based but display significant metal $\left(\mathrm{d}_{\mathrm{xz}}, \mathrm{d}_{\mathrm{yz}}\right)$ contribution, ranging from $29.7 \%$ to $38.4 \%$ (average of LUMO and $\mathrm{LUMO}+1)$.

Since the ligand $\pi$-system dominates both sets of FMOs, the FMO energies are highly sensitive to the ligand modification. Installation of a strong electron-withdrawing group (EWG) in $\mathrm{Zr}\left({ }^{\mathrm{Me}} \mathrm{PDP}{ }^{\mathrm{C} 6 \mathrm{~F} 5}\right)_{2}$ led to the most stabilized $\mathrm{HOMO}(-1)$ and $\mathrm{LUMO}(+1)$ of the series. On the other hand, our most electron-rich dimethyl derivative, $\operatorname{Zr}\left({ }^{\mathrm{Me}} \mathrm{PDP}^{\mathrm{Me}}\right)_{2}$, shows the most destabilized $\mathrm{HOMO}(-1)$ and $\operatorname{LUMO}(+1)$ among the six-coordinate complexes. Octa-coordinate $\mathrm{Zr}\left({ }^{\mathrm{H}} \mathrm{PDP}^{\mathrm{H}}\right)_{2}(\mathrm{THF})_{2}$ presents a lower $C_{2}$ symmetry compared to the other complexes, manifesting in significantly altered LUMO and LUMO+1 composition. Here, the metal character of the LUMO has increased to $57.1 \%$ while the LUMO+1 shows only $18.2 \%$ contribution from zirconium dorbitals. Furthermore, in addition to the PDP nitrogen donors, the introduction of two THF donors largely destabilized the LUMOs compared to the six-coordinate congener. The computational 
results nicely reproduce the electrochemical trends observed for the $\left[\mathrm{Zr}\left({ }^{\mathrm{R} 1} \mathrm{PDP}^{\mathrm{R} 2}\right)_{2}\right]^{0} /\left[\mathrm{Zr}\left({ }^{\mathrm{R} 1} \mathrm{PDP}^{\mathrm{R} 2}\right)_{2}\right]^{1-}$ redox couple, with calculated LUMO energies of the zirconium complexes directly correlated with the overall electronic effect of the ligand.

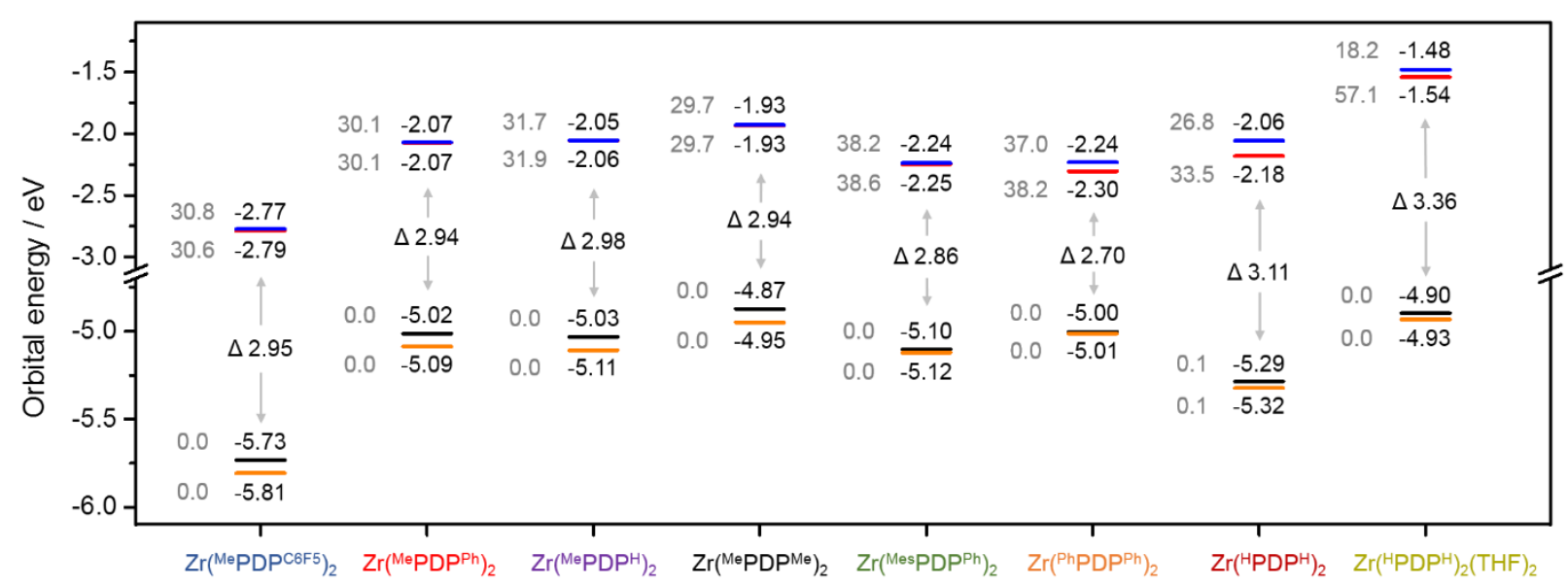

Figure 4. Calculated frontier orbital energies $(\mathrm{eV})$ for zirconium complexes. Computed metal contributions $(\%)$ are shown in gray to the left of orbital energies.

While the computed energies of the frontier orbitals are affected by the electronic influence of the ligand and the complex's coordination environment, the HOMO-LUMO gap ( $\triangle \mathrm{E}_{\text {HOMO-LUMо) }}$ seems more influenced by the substituents at 5-position of pyrroles. Examining the FMOs for cases where the 5-position of the pyrrolide moiety is unchanged for $\left(\mathrm{Zr}\left({ }^{\mathrm{Me}} \mathrm{PDP}^{\mathrm{C} 6 \mathrm{~F} 5}\right)_{2}, \mathrm{Zr}\left({ }^{\mathrm{Me}} \mathrm{PDP}^{\mathrm{Ph}}\right)_{2}\right.$, $\mathrm{Zr}\left({ }^{\mathrm{Me}} \mathrm{PDP}^{\mathrm{H}}\right)_{2}$ and $\left.\mathrm{Zr}\left({ }^{\mathrm{Me}} \mathrm{PDP}{ }^{\mathrm{Me}}\right)_{2}\right), \Delta \mathrm{E}_{\text {HOMO-LUMO }}$ is essentially constant $(\sim 2.95 \mathrm{eV})$ with slight variances within $\pm 0.4 \mathrm{eV}$. On the other hand, functionalizing 5-position with different substituent provides the most dramatic difference in $\Delta \mathrm{E}_{\mathrm{HOMO}}$-LUMO with $\mathrm{Zr}\left({ }^{\mathrm{Mes}} \mathrm{PDP}^{\mathrm{Ph}}\right)_{2}(2.86 \mathrm{eV})$ and $\mathrm{Zr}\left({ }^{\mathrm{Ph}} \mathrm{PDP}^{\mathrm{Ph}}\right)_{2}(2.70 \mathrm{eV})$ having the two smallest HOMO-LUMO energy gaps across the series. The 
5-hydrogen substituted $\mathrm{Zr}\left({ }^{\mathrm{H}} \mathrm{PDP}^{\mathrm{H}}\right)_{2}$ exhibits the largest value for $\Delta \mathrm{E}_{\text {номо-LUмо }}(3.11 \mathrm{eV})$ of all the six-coordinate compounds presented while its THF adduct, $\mathrm{Zr}\left({ }^{\mathrm{H}} \mathrm{PDP}^{\mathrm{H}}\right)_{2}(\mathrm{THF})_{2}$, has a HOMOLUMO energy gap of $3.36 \mathrm{eV}$.

It is well known that extending a given $\pi$-system (i.e. benzene (colorless) vs. graphene (black)) lowers the energy gap between FMOs and leads to a red-shifted absorption profile. Taking a closer look at the structures, it is not difficult to realize that a highly distorted ${ }^{\mathrm{Ph}} \mathrm{PDP}^{\mathrm{Ph}}$ ligand framework shows high level of conjugation between 5-phenyl and PDP core $\pi$ system. In contrast, $\mathrm{Zr}\left({ }^{\mathrm{H}} \mathrm{PDP}^{\mathrm{H}}\right)_{2}$ features only a PDP $\pi$ system without potential conjugation from other groups and thus exhibits largest energy gap. In short, seemly the gap was largely affected by the conjugation with the functionally groups at the 5-position of the pyrroles and minimally influenced by the substituents at the 3-position.

\subsection{Electronic transitions and TD-DFT studies.}

Absorption profiles of $\mathrm{Zr}\left({ }^{\mathrm{R} 1} \mathrm{PDP}^{\mathrm{R} 2}\right)_{2}$ in benzene solution are shown in Figure 5 and the spectra recorded in THF solution can be found in Appendix A. The absorption maxima $\left(\lambda_{\text {abs-max }}\right)$ for the lowest energy absorption band are listed in Table 4 (benzene) and Appendix A (THF). All complexes exhibit one major absorption band in the visible region. Changing the solvent from benzene to THF shows little solvatochromic behavior for $\mathrm{Zr}\left({ }^{\mathrm{R} 1} \mathrm{PDP}^{\mathrm{R} 2}\right)_{2}(\mathrm{R} 1 \neq \mathrm{H})$, with all visible light absorption bands within $5 \mathrm{~nm}$ of each other. To compare the substituent influence alone, all 
photophysical properties in only non-coordinating benzene media are discussed herein. For complexes where only the 3-position was modified (keeping 5-position the same methyl group), the lowest energy absorption band maxima are all within $11 \mathrm{~nm}$ of each other. Conversely, altering the substitution pattern at the 5-position provided the most dramatically shifted absorption maxima, with $\mathrm{Zr}\left({ }^{\mathrm{H}} \mathrm{PDP}^{\mathrm{H}}\right)_{2}$ displaying a maximum at $482 \mathrm{~nm}$ while $\mathrm{Zr}\left({ }^{\mathrm{Ph}} \mathrm{PDP}^{\mathrm{Ph}}\right)_{2}$ showed an absorption maximum at $547 \mathrm{~nm}$. These observations are in excellent agreement with the calculated HOMOLUMO energy gap trends (vide supra). This is further evidence that $\Delta \mathrm{E}_{\text {Hомо-Lumo is highly }}$ sensitive to the substitution pattern at the 5-position of the pyrrole moieties. We thus propose that the colors of these zirconium chromophores can be effectively manipulated by tuning the 5-pyrrole position, i.e. extending conjugation leads to a red shift in the absorption profile.

The nature of the electronic transitions for all new zirconium complexes was studied by time dependent density functional theory (TD-DFT). Calculations were performed at the B3LYP level and solvent effects were included using the conductor-like screening model (COSMO). Analogous to previously reported $\mathrm{Zr}\left({ }^{\mathrm{Me}} \mathrm{PDP}^{\mathrm{Ph}}\right)_{2}$ and $\mathrm{Zr}\left({ }^{\mathrm{Mes}} \mathrm{PDP}^{\mathrm{Ph}}\right)_{2}$, the lowest energy absorption band in all complexes (including $\mathrm{Zr}\left({ }^{\mathrm{H}} \mathrm{PDP}^{\mathrm{H}}\right)_{2}(\mathrm{THF})_{2}$ ) is composed of two pairs of transitions from an exclusively ligand-centered $\pi$ orbital (HOMO-1 and HOMO) to a degenerate set of orbitals (LUMO and LUMO+1) with significant contributions from the metal $\left(\mathrm{d}_{\mathrm{xz}}, \mathrm{d}_{\mathrm{yz}}\right)$. Thus, the transitions giving rise to the absorption band in the visible region are best described as a ${ }^{1} \mathrm{IL} /{ }^{1} \mathrm{LMCT}$. 

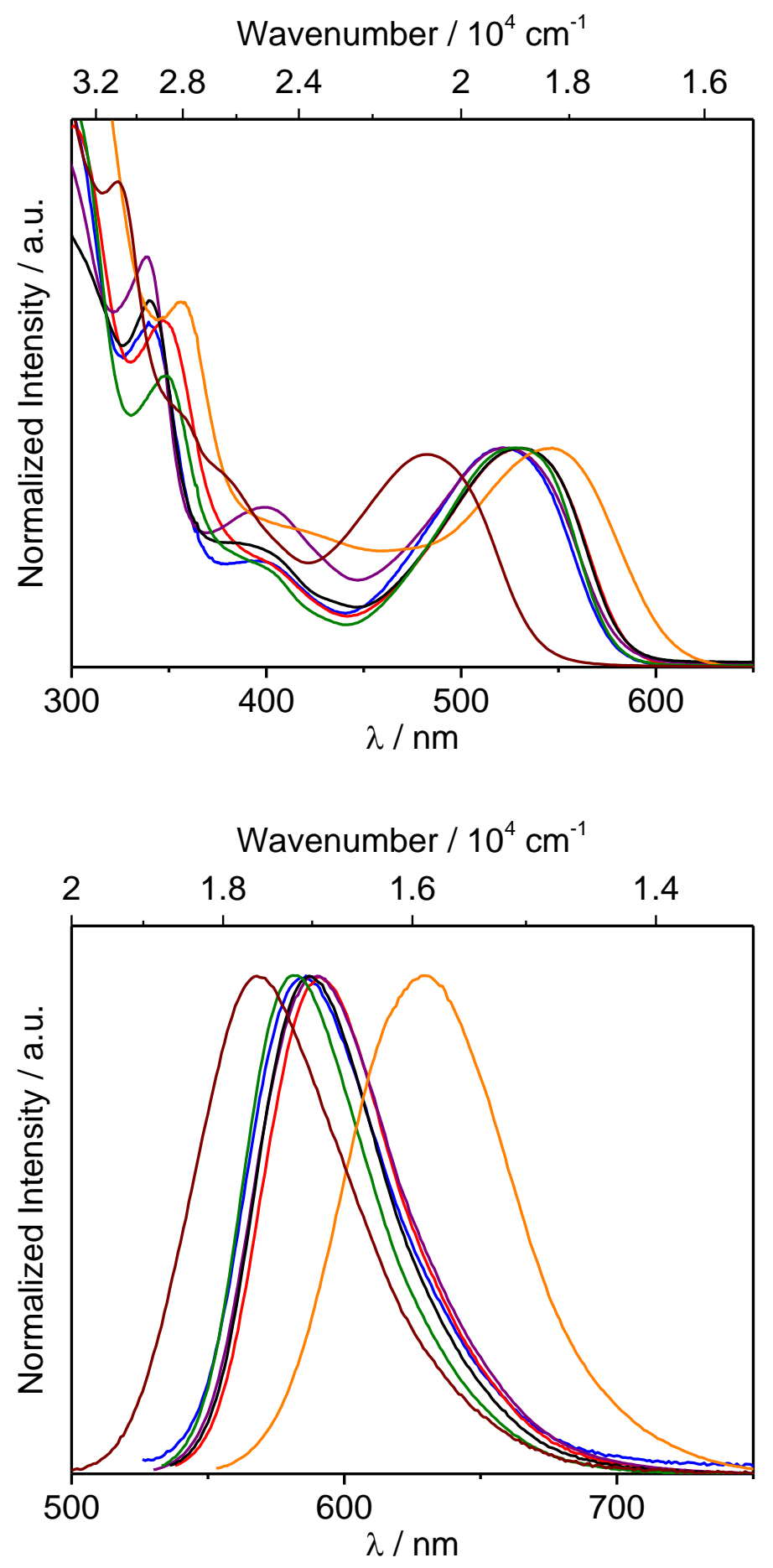

Figure 5. Absorption (top) and emission spectra (bottom, excited at the lowest energy absorption maxima) of $\mathrm{Zr}\left({ }^{\mathrm{Me}} \mathrm{PDP}^{\mathrm{C} 6 \mathrm{~F} 5}\right)_{2}$ (blue), $\mathrm{Zr}\left({ }^{\mathrm{Me}} \mathrm{PDP}^{\mathrm{Ph}}\right)_{2}$ (red), $\mathrm{Zr}\left({ }^{\mathrm{Me}} \mathrm{PDP}^{\mathrm{H}}\right)_{2}$ (purple), $\mathrm{Zr}\left({ }^{\mathrm{Me}} \mathrm{PDP}^{\mathrm{Me}}\right)_{2}$ (black), $\mathrm{Zr}\left({ }^{\mathrm{Mes}} \mathrm{PDP}^{\mathrm{Ph}}\right)_{2}$ (olive), and $\mathrm{Zr}\left({ }^{(\mathrm{Ph}} \mathrm{PDP}^{\mathrm{Ph}}\right)_{2}$ (orange) in benzene solution at room temperature. 
Table 4. The absorption (IL/LMCT band) and emission maxima recorded in benzene solution for zirconium compounds. The dihedral angles between two ligand planes and $\mathrm{N}_{\mathrm{py}}(2)-\mathrm{Zr}-\mathrm{N}_{\mathrm{py}}(5)$ angles were listed.

\begin{tabular}{c|c|c|ccc}
\hline & $\begin{array}{c}\text { Dihedral } \\
\text { angle }\left({ }^{\circ}\right)\end{array}$ & $\begin{array}{c}\mathrm{N}_{\text {py }}(2)-\mathrm{Zr}- \\
\mathrm{N}_{\text {py }}(5)\left({ }^{\circ}\right)\end{array}$ & $\lambda_{\text {abs-max }}\left(\mathrm{nm} / \mathrm{cm}^{-1}\right)$ & $\lambda_{\text {em-max }}\left(\mathrm{nm} / \mathrm{cm}^{-1}\right)$ & Stokes shift $\left(\mathrm{cm}^{-1}\right)$ \\
\hline $\left.\mathrm{Zr}\left({ }^{\mathrm{H} P D P}\right)_{2}\right)_{2}$ & 76.05 & 151.78 & $482 / 20747$ & $568 / 17606$ & 3141 \\
$\mathrm{Zr}\left({ }^{\mathrm{Me}} \mathrm{PDP}^{\mathrm{C} 6 \mathrm{~F} 5}\right)_{2}$ & $86.20^{\mathrm{a}}$ & $175.03^{\mathrm{a}}$ & $521 / 19194$ & $586 / 17065$ & 2129 \\
$\mathrm{Zr}\left({ }^{\mathrm{Me}} \mathrm{PDP}^{\mathrm{H}}\right)_{2}$ & 83.36 & 169.08 & $524 / 19084$ & $590 / 16949$ & 2135 \\
$\mathrm{Zr}\left({ }^{\mathrm{Me}} \mathrm{PDP}^{\mathrm{Me}}\right)_{2}$ & 89.63 & 173.11 & $531 / 18832$ & $587 / 17036$ & 1797 \\
$\mathrm{Zr}\left({ }^{\mathrm{Mes}} \mathrm{PDP}^{\mathrm{Ph}}\right)_{2}$ & 89.57 & 179.42 & $528 / 18939$ & $581 / 17212$ & 1728 \\
$\mathrm{Zr}\left({ }^{\mathrm{Me} P D P}{ }^{\mathrm{Ph}}\right)_{2}$ & 88.29 & 171.76 & $532 / 18797$ & $591 / 16920$ & 1877 \\
$\mathrm{Zr}\left({ }^{\mathrm{Ph}} \mathrm{PDP}^{\mathrm{Ph}}\right)_{2}$ & 72.89 & 153.81 & $547 / 18282$ & $629 / 15898$ & 2383 \\
\hline
\end{tabular}

${ }^{a}$ average angle values of two independent molecules in the unit cell.

\subsection{Substituent Influence of Excited-State Decay Dynamics.}

All new complexes are luminescent upon photoexcitation of the visible absorption band at room temperature. The resulting emission maxima range from $568 \mathrm{~nm}$ to $629 \mathrm{~nm}$ in benzene (Table 4). To investigate energy consumption following the Franck-Condon absorption, we analyzed the energy difference between the absorbance and emission energies ( $\left.\tilde{v}_{\text {abs-max }}-\tilde{v}_{\text {em-max }}\right)$, known as the Stokes shift. According to our previous studies, the nature of the emission for all new $\operatorname{Zr}(\mathrm{PDP})_{2}$ chromophores is most likely thermally activated delayed fluorescence (TADF). Thus, the Stokes shift should correspond to the vibrational geometry relaxation of the first singlet excited state $\left({ }^{1} \mathrm{IL} /{ }^{1} \mathrm{LMCT}\right.$ or $\left.\mathrm{S}_{1}\right)$. The Stokes shifts range from $3141 \mathrm{~cm}^{-1}$ for $\mathrm{Zr}\left({ }^{\mathrm{H}} \mathrm{PDP}^{\mathrm{H}}\right)_{2}$ to $1728 \mathrm{~cm}^{-1}$ for $\mathrm{Zr}\left({ }^{\mathrm{Mes}} \mathrm{PDP}^{\mathrm{Ph}}\right)_{2}$. Comparison with the solid-state structures shows a remarkable correlation between the Stokes shift and distortion from idealized $D_{2 d}$ symmetry. More specifically the aforementioned "rigidity parameters" (dihedral and $\mathrm{N}_{\mathrm{py}}(2)-\mathrm{Zr}_{\mathrm{r}} \mathrm{N}_{\mathrm{py}}(5)$ angles, $\theta_{\mathrm{f}}$ and $\theta_{\mathrm{w}}$ ) elucidate a nearly linear 

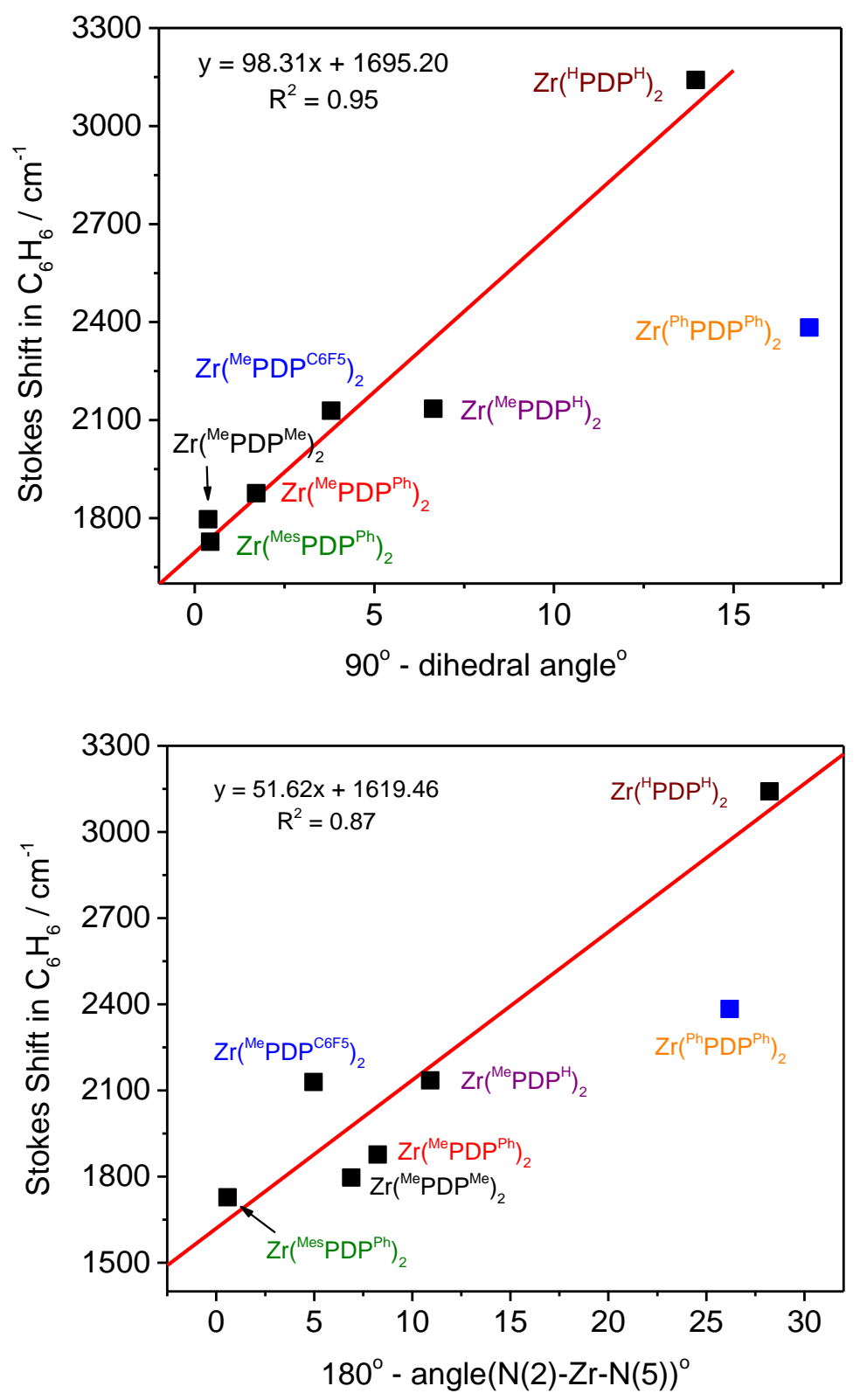

Figure 6. The potential correlation between dihedral angles and $\mathrm{N}_{\mathrm{py}}(2)-\mathrm{Zr}_{\mathrm{r}} \mathrm{N}_{\mathrm{py}}(5)$ angles with Stokes shifts of zirconium complexes in benzene.

relationship between level of geometry distortion and the Stokes shifts, as shown in Figure 6. A notable exception to the observed trend is $\mathrm{Zr}\left({ }^{\mathrm{Ph}} \mathrm{PDP}^{\mathrm{Ph}}\right)_{2}$. This complex shows an unexpectedly large solid-state distortion, attributed to its unique intra-molecular $\pi$-stacking. It appears in this 
case, the observed distortion is not representative of the solution behavior and hence has very little impact on its excited state dynamics. Based on this close correlation with the Stokes shift, we propose the rigidity parameters are closely associated with the vibrational relaxation of the excited $\left(\mathrm{S}_{1}\right)$ state.

Photoluminescent quantum yields $\left(\Phi_{P L}\right)$ and lifetime $(\tau)$ data were collected under optically dilute condition in solution at room temperature (Table 5 (benzene) and Appendix A (THF)). As listed in Table 5, these zirconium complexes have $\Phi_{P L}$ values ranging from 0.10 to 0.38 in benzene solution. All complexes exhibit remarkably long-lived excited states with time constants over hundreds of microseconds, consistent with delayed fluorescence involving triplet states. The quantum yields and lifetimes are on same order of magnitude when changing the substituents which suggests the emissive nature (TADF mechanism) and excited state decay dynamics for $\mathrm{Zr}\left({ }^{\mathrm{R} 1} \mathrm{PDP}^{\mathrm{R} 2}\right)_{2}$ are similar for all of the presented complexes.

The radiative $\left(k_{r}\right)$ and non-radiative $\left(k_{n r}\right)$ decay rate constants were calculated from quantum yield and lifetime measurements. For each zirconium complex in benzene, $k_{n r}$ is much larger than $k_{r}$. Also, $k_{n r}$ varies greatly, spanning almost $3300 \mathrm{~s}^{-1}$. Additionally, the sequence of $k_{n r}$ is in perfect line with the trend of observed lifetime. These observations suggest nonradiative decay pathways are the dominating factor in $\mathrm{Zr}\left({ }^{(\mathrm{R} 1} \mathrm{PDP}^{\mathrm{R} 2}\right)_{2}$ 's excited-state dynamics. 
Table 5. Excited state decay parameters in benzene.

\begin{tabular}{c|c|c|cccc}
\hline $\begin{array}{c}\text { Compound } \\
\text { (\# of C-H bond present } \\
\text { in the molecule) }\end{array}$ & $\begin{array}{c}\text { Dihedral } \\
\text { angle }\left(^{\circ}\right)\end{array}$ & $\begin{array}{c}\mathrm{N}_{\text {py }}(2)-\mathrm{Zr}- \\
\mathrm{N}_{\mathrm{py}}(5)\left({ }^{\circ}\right)\end{array}$ & $\tau / \mu \mathrm{s}$ & $\Phi_{P L}$ & $\mathrm{k}_{\mathrm{r}}\left(\mathrm{s}^{-1}\right)$ & $\mathrm{k}_{\mathrm{nr}}\left(\mathrm{s}^{-1}\right)$ \\
\hline $\mathrm{Zr}\left({ }^{\mathrm{H} P D P}\right)_{2}(18)$ & 76.05 & 151.78 & 413 & 0.28 & 678 & 1743 \\
$\mathrm{Zr}\left({ }^{\mathrm{Me}} \mathrm{PDP}^{\mathrm{C} 6 \mathrm{~F} 5}\right)_{2}(22)$ & $86.20^{\mathrm{a}}$ & $175.03^{\mathrm{a}}$ & 313 & 0.34 & 1086 & 2109 \\
$\mathrm{Zr}\left({ }^{\mathrm{Me}} \mathrm{PDP}^{\mathrm{H}}\right)_{2}(26)$ & 83.36 & 169.08 & 260 & 0.10 & 385 & 3462 \\
$\mathrm{Zr}\left({ }^{\mathrm{Me} P D P}{ }^{\mathrm{Me}}\right)_{2}(34)$ & 89.63 & 173.11 & 576 & 0.22 & 382 & 1354 \\
$\mathrm{Zr}\left({ }^{\mathrm{Mes} P D P}{ }^{\mathrm{Ph}}\right)_{2}(74)$ & 89.57 & 179.42 & 290 & 0.38 & 1310 & 2138 \\
$\mathrm{Zr}\left({ }^{\mathrm{Me}} \mathrm{PDP}^{\mathrm{Ph}}\right)_{2}(42)$ & 88.29 & 171.76 & 474 & 0.27 & 570 & 1540 \\
$\mathrm{Zr}\left({ }^{\mathrm{Ph} P D P}{ }^{\mathrm{Ph}}\right)_{2}(50)$ & 72.89 & 153.81 & 190 & 0.11 & 579 & 4684 \\
\hline
\end{tabular}

${ }^{a}$ average angle values of two independent molecules in the unit cell.

For many TADF emitters, the lifetime can be viewed as the period an excited state molecule is trapped in the triplet state $\left(\mathrm{k}_{\mathrm{isc}}>>\mathrm{k}_{\mathrm{fl}}\right)$, as long as reverse intersystem crossing is sufficiently slow but faster than phosphorescence $\left(\mathrm{k}_{\mathrm{fl}}>>\mathrm{k}_{\mathrm{risc}}>>\mathrm{k}_{\mathrm{ph}}\right)$. In order to emit a photon, an excited state molecule needs to "climb the vibrational ladders" under thermal activation back to the singlet state $\left(\mathrm{S}_{1}\right)$. Such a process, so-called excited state distortion, is a main contributor in determining the radiationless decay of copper based photosensitizers. ${ }^{11-14}$ These distortions are more difficult for rigid molecules (less-closely spaced vibrational levels) compared to more fluxional structures under thermal conditions. Additionally, it is known that the excited states of transition metal complexes can suffer from radiationless deactivation with vibronically coupled intramolecular C$\mathrm{H}$ oscillators. ${ }^{13}$ This effect is even more dramatic for lanthanide photosensitizers, where C-H vibrational quenching has been considered as the dominant excited state deactivation pathway in many cases. ${ }^{15,16}$ 
Except for $\mathrm{Zr}\left({ }^{\mathrm{Mes}} \mathrm{PDP}^{\mathrm{Ph}}\right)_{2}, \mathrm{Zr}\left({ }^{\mathrm{H}} \mathrm{PDP}^{\mathrm{H}}\right)_{2}$, and $\mathrm{Zr}\left({ }^{\mathrm{Me}} \mathrm{PDP}^{\mathrm{C} 6 \mathrm{~F} 5}\right)_{2}$, the emission lifetimes increased with the rigidity of the ligand framework, i.e. in the order of $\mathrm{Zr}\left({ }^{\mathrm{Ph}} \mathrm{PDP}^{\mathrm{Ph}}\right)_{2}(190 \mu \mathrm{s})$, $\mathrm{Zr}\left({ }^{\mathrm{Me}} \mathrm{PDP}^{\mathrm{H}}\right)_{2}(260 \mu \mathrm{s}), \mathrm{Zr}\left({ }^{\mathrm{Me}} \mathrm{PDP}^{\mathrm{Ph}}\right)_{2}(474 \mu \mathrm{s})$, and $\mathrm{Zr}\left({ }^{\mathrm{Me}} \mathrm{PDP}^{\mathrm{Me}}\right)_{2}(576 \mu \mathrm{s})$. There appears to be a trend that the more flexible ligand framework (on the basis of the "rigidity parameters" from crystal structure) lead to shorter excited lifetime within these four complexes. The overall distortion angle was oversimplified as deviation from $90^{\circ}$ for dihedral angle plus the difference from $180^{\circ}$ for $\mathrm{N}_{\mathrm{py}}(2)-\mathrm{Zr}-\mathrm{N}_{\mathrm{py}}(5)$ angle, which following the same order as lifetime decays for these four complexes, ranging from $43.30^{\circ}$ for $\mathrm{Zr}\left({ }^{\mathrm{Ph}} \mathrm{PDP}^{\mathrm{Ph}}\right)_{2}$ to $7.62^{\circ}$ for $\mathrm{Zr}\left({ }^{\mathrm{Me}} \mathrm{PDP}^{\mathrm{Me}}\right)_{2}$.

Based on this trend, it is expected $\mathrm{Zr}\left({ }^{\mathrm{Mes}} \mathrm{PDP}^{\mathrm{Ph}}\right)_{2}$ * would have the longest-lived triplet state due to its exceptionally rigid ligand environment (overall distortion angle $=1.01^{\circ}$ ). However, the lifetime value of $\operatorname{Zr}\left({ }^{\mathrm{Mes}} \mathrm{PDP}^{\mathrm{Ph}}\right)_{2} *(290 \mu$ s $)$ is only fifth longest of the series in benzene solution. On the other hand, $\mathrm{Zr}\left({ }^{\mathrm{H}} \mathrm{PDP}^{\mathrm{H}}\right)_{2}$ is the second most flexible complex with an overall distortion angle of $42.17^{\circ}$ (very close to $\mathrm{Zr}\left({ }^{\mathrm{Ph}} \mathrm{PDP}^{\mathrm{Ph}}\right)_{2}$ ) but its lifetime $(413 \mu \mathrm{s})$ is third longest. Here, we noticed $\mathrm{Zr}\left({ }^{\mathrm{Mes}} \mathrm{PDP}^{\mathrm{Ph}}\right)_{2}$ contains the most $\mathrm{C}-\mathrm{H}$ bonds $(74)$ across the series, while $\mathrm{Zr}\left({ }^{\mathrm{H}} \mathrm{PDP}^{\mathrm{H}}\right)_{2}$ contains the fewest (18 C-H bonds). In our scenario, high frequency $\mathrm{C}-\mathrm{H}$ vibrational overtones ( $v_{\text {Harmonic }}=5$, $E_{v i b, C-H} \sim 16,500 \mathrm{~cm}^{-1}$ ) could potentially couple to the triplet excited state, thereby participating in electronic-to-vibrational energy transfer resulting in non-radiative deactivation. Thus, increasing the number of proximal $\mathrm{C}-\mathrm{H}$ oscillators as in $\mathrm{Zr}\left({ }^{\mathrm{Mes}} \mathrm{PDP}^{\mathrm{Ph}}\right)_{2}$ would increase radiationless decay and lower the observed lifetime, as observed. Conversely, fewer nearby C-H oscillators would 
decrease non-radiative decay and increase lifetime, consistent with observations for $\mathrm{Zr}\left({ }^{\mathrm{H}} \mathrm{PDP}^{\mathrm{H}}\right)_{2}$. These analyses suggest the excited state decay dynamics of zirconium photosensitizers are associated with non-radiative decay pathways that are likely controlled by 1) the rigidity of ligand framework and 2) number of $\mathrm{C}-\mathrm{H}$ oscillators.

\subsection{Photoinduced Electron Transfer.}

We have previously established that $\mathrm{Zr}\left({ }^{\mathrm{Me}} \mathrm{PDP}^{\mathrm{Ph}}\right)_{2}$ * undergoes efficient photoinduced single electron transfer (SET) with a sacrificial reductant to render strongly reducing $\left[\mathrm{Zr}\left({ }^{\mathrm{Me}} \mathrm{PDP}^{\mathrm{Ph}}\right)_{2}\right]^{-}$. This catalytic system was subsequently used in reductive organic reactions. More recently, our group established that $\mathrm{Zr}\left({ }^{\mathrm{Mes}} \mathrm{PDP}^{\mathrm{Ph}}\right)_{2}$ can undergo reversible oxidative and reductive events, making it suitable for both types of redox transformations. This comprehensive reactivity was attributed to the complex's unique steric protection of the generated ligand-based SOMO. In this work, we systematically shifted the ground state redox potentials and tuned photoluminescent properties of zirconium photosensitizers by ligand modifications. The understanding of the properties will help us to identify more potent zirconium photocatalysts.

The combination of electrochemical data and emission energies through Rehm-Weller formalism provided estimated excited oxidation potential of zirconium complexes (Table 6). The resulting excited state potentials range from $-0.30 \mathrm{~V}$ to $+0.15 \mathrm{~V}$ vs. $\mathrm{Fc}^{+/ 0}$, which are considered as mild oxidants. ${ }^{17}$ Unfortunately, the complexes with more reducing ground state potentials $\left(\mathrm{E}_{1 / 2}{ }^{0 / 1}\right)$ 
usually show less reactive (oxidizing) excited states, indicating the electrochemical properties of the ground state complex have significant influence on the excited state redox potential.

Table 6. Estimation of the excited state potential for zirconium complexes ${ }^{\mathrm{a}}$

\begin{tabular}{c|ccc}
\hline & $\begin{array}{c}\mathrm{E}_{1 / 2}(0 /-1) / \\
\text { V vs. } \mathrm{Fc}^{+/ 0}\end{array}$ & $\begin{array}{c}\mathrm{E}_{0,0} / \\
\mathrm{eV}\end{array}$ & $\begin{array}{c}\mathrm{E}_{1 / 2} * / \\
\mathrm{V} \mathrm{vs.} \mathrm{Fc}^{+/ 0}\end{array}$ \\
\hline $\mathrm{Zr}\left({ }^{\mathrm{H} P D P}\right)_{2}{ }^{\mathrm{b}}$ & -2.24 & 2.18 & -0.06 \\
$\mathrm{Zr}\left({ }^{\mathrm{H} P D P}\right)_{2}(\mathrm{THF})_{2}$ & -2.45 & 2.18 & -0.27 \\
$\mathrm{Zr}\left({ }^{\mathrm{Me} P D P}{ }^{\mathrm{C} 6 \mathrm{~F} 5}\right)_{2}$ & -1.85 & 2.00 & +0.15 \\
$\mathrm{Zr}\left({ }^{\mathrm{Me}} \mathrm{PDP}^{\mathrm{H}}\right)_{2}$ & -2.21 & 2.02 & -0.19 \\
$\mathrm{Zr}\left({ }^{\mathrm{Me}} \mathrm{PDP}^{\mathrm{Me}}\right)_{2}$ & -2.42 & 2.12 & -0.30 \\
$\mathrm{Zr}\left({ }^{\mathrm{Mes}} \mathrm{PDP}^{\mathrm{Ph}}\right)_{2}{ }^{\mathrm{c}}$ & -2.25 & 2.14 & -0.11 \\
$\mathrm{Zr}\left({ }^{\mathrm{Me}} \mathrm{PDP}^{\mathrm{Ph}}\right)_{2}{ }^{\mathrm{c}}$ & -2.16 & 2.09 & -0.07 \\
$\mathrm{Zr}\left({ }^{\mathrm{Ph}} \mathrm{PDP}^{\mathrm{Ph}}\right)_{2}$ & -2.09 & 1.96 & -0.13 \\
\hline
\end{tabular}

${ }^{a}$ value obtained from THF were used. ${ }^{b}$ value obtained from aromatic solvent were used. ${ }^{c}$ from previous chapters.

To further explore the photoinduced SET dependence on ligand modification, Stern-Volmer analyses were performed for selected complexes varying only at the 3-pyrrolide position, namely $\mathrm{Zr}\left({ }^{\mathrm{Me}} \mathrm{PDP}^{\mathrm{C} 6 \mathrm{~F} 5}\right)_{2}, \mathrm{Zr}\left({ }^{\mathrm{Me}} \mathrm{PDP}^{\mathrm{Ph}}\right)_{2}, \mathrm{Zr}\left({ }^{\mathrm{Me}} \mathrm{PDP}^{\mathrm{H}}\right)_{2}$, and $\mathrm{Zr}\left({ }^{\mathrm{Me}} \mathrm{PDP}^{\mathrm{Me}}\right)_{2}$. 1,3-dimethyl-2(2,4,6-trimethoxyphenyl)-2,3-dihydro-1H-benzo-[d]imidazole, ${ }^{\mathrm{TriMeO}} \mathrm{BIH}$, was recognized as a potent enough reductant (-0.33 V vs. $\mathrm{Fc}^{+/ 0}$ in $\mathrm{MeCN}$, see Appendix A for more detail) to quench the excited states of the selected complexes (Figure 7). The corresponding Stern-Volmer constants, $K_{S V}$, and the corresponding quenching rate constants, $k_{q}$, are summarized in Table 7. All four compounds were strongly quenched by ${ }^{\mathrm{Tr} M e O} \mathrm{BIH}$ with large Stern-Volmer constants. Moreover, 
the strong correlation between excited state potential of the zirconium complexes and the quenching rate supports a typical photoinduced SET process.

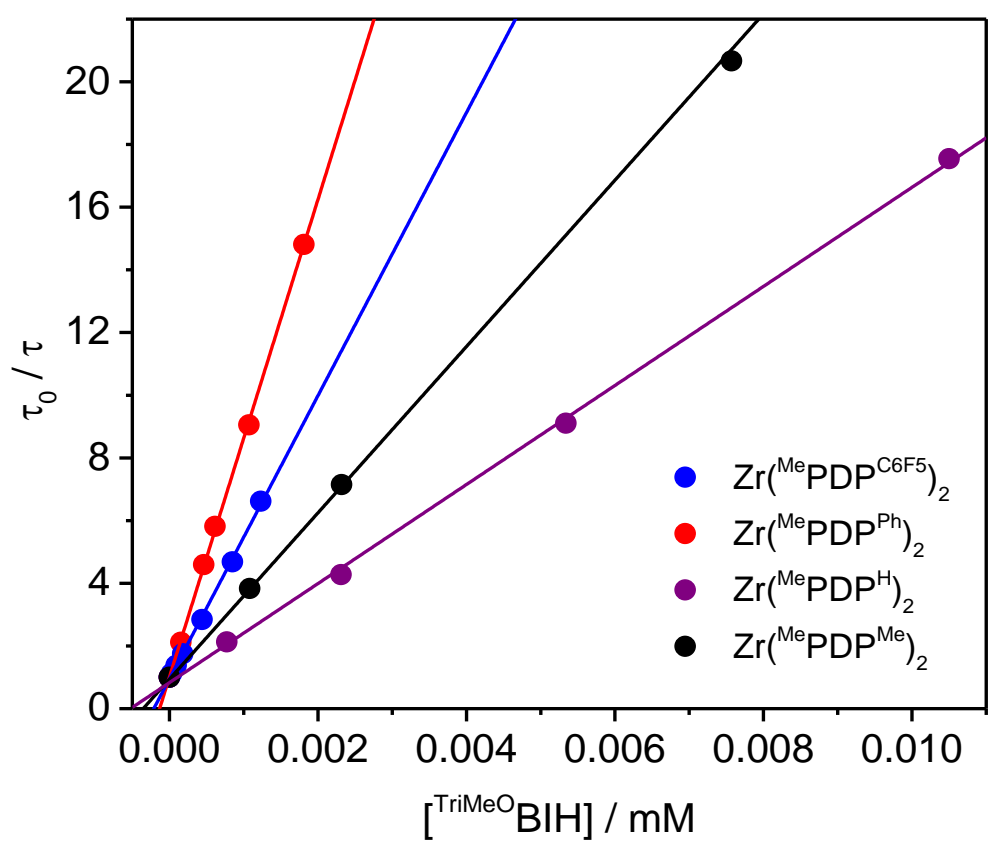

Figure 7. Stern-Volmer plots obtained via time resolved emission spectroscopy.

Table 7. Quenching parameters from Stern-Volmer analysis and redox potentials

\begin{tabular}{c|ccc}
\hline & $\begin{array}{c}K_{\mathrm{Sv}} / \\
\mathrm{L} \mathrm{mol}^{-1}\end{array}$ & $\begin{array}{c}k_{\mathrm{q}} / 10^{8} \\
\mathrm{~L} \mathrm{~mol}^{-1} \mathrm{~s}^{-1}\end{array}$ & $\begin{array}{c}\mathrm{E}_{1 / 2} * / \\
\mathrm{V} \mathrm{vs.} \mathrm{Fc}\end{array}$ \\
\hline $\mathrm{Zr}\left({ }^{\mathrm{Me}} \mathrm{PDP}^{\mathrm{C} 6 \mathrm{F5}}\right)_{2}$ & $446,000 \pm 5,300$ & 31.00 & +0.15 \\
$\mathrm{Zr}\left({ }^{\mathrm{Me}} \mathrm{PDP}^{\mathrm{Ph}}\right)_{2}$ & $763,000 \pm 3,800$ & 23.48 & -0.07 \\
$\mathrm{Zr}\left({ }^{\mathrm{Me}} \mathrm{PDP}^{\mathrm{H}}\right)_{2}$ & $158,000 \pm 1,600$ & 11.54 & -0.19 \\
$\mathrm{Zr}\left({ }^{\mathrm{Me}} \mathrm{PDP}^{\mathrm{Me}}\right)_{2}$ & $265,000 \pm 1,500$ & 4.89 & -0.30 \\
\hline
\end{tabular}




\subsection{Catalytic Photoredox Dehalogenation of Aryl Halides.}

Having established the excited state electron transfer processes between these zirconium photosensitizers and ${ }^{\mathrm{TriMeO}} \mathrm{BIH}$, we sought to utilize the more negative potentials of the reduced species to perform more challenging reductive photoredox reactions than what has been performed with zirconium photocatalysts. The reduction of unactivated aryl carbon-halide bonds are considered difficult to achieve due to the highly negative reduction potentials of the associated molecules $\left(\mathrm{E}_{\mathrm{red}}=-1.59 \sim-2.24 \mathrm{~V}\right.$ vs. SCE for iodobenzene). ${ }^{18}$ The investigations commenced by evaluating the dehalogenation of 1-bromo-4-iodobenzene as a model reaction (Table 8). Under irradiation with green LEDs for 37 hours in the presence of highly reducing $10 \mathrm{~mol} \%$ $\mathrm{Zr}\left({ }^{\mathrm{Me}} \mathrm{PDP}^{\mathrm{Me}}\right)_{2}\left(\mathrm{E}_{1 / 2}{ }^{0 /-1}=-2.42 \mathrm{~V}\right)$ and one equivalent of ${ }^{\mathrm{TriMeO}} \mathrm{BIH}$, we observe full consumption of 1-bromo-4-iodobenzene and the desired product, bromobenzene, was formed in $85 \%$ yield without notable byproducts. Control experiments showed that both light and the zirconium photocatalyst were essential to achieve high reactivity and only a small amount of the deiodination product (4\%) was detected after $42 \mathrm{~h}$ using $20 \mathrm{~mol} \%$ free ligand $\left(\mathrm{H}_{2}{ }^{\mathrm{Me}} \mathrm{PDP}^{\mathrm{Me}}\right)$. When the less reducing $\mathrm{Zr}\left({ }^{\mathrm{Me}} \mathrm{PDP}^{\mathrm{H}}\right)_{2}$ photosensitizer $\left(\mathrm{E}_{1 / 2}{ }^{0 /-1}=-2.24 \mathrm{~V}\right)$ was employed, only a $51 \%$ yield of desired product was observed after $88 \mathrm{~h}$ of irradiation. With $\mathrm{Zr}\left({ }^{\mathrm{Me}} \mathrm{PDP}^{\mathrm{C} 6 \mathrm{~F} 5}\right)_{2}\left(\mathrm{E}_{1 / 2}{ }^{0 /-1}=-1.85 \mathrm{~V}\right)$ as the photocatalyst, $16 \%$ of product was formed after $20 \mathrm{~h}$ of irradiation. Interestingly, although $\mathrm{Zr}\left({ }^{\mathrm{Me}} \mathrm{PDP}^{\mathrm{C} 6 \mathrm{~F} 5}\right)_{2}$ was no longer detected by NMR after $20 \mathrm{~h}$, the reaction still proceeded with irradiation and the color of the reaction mixture is still red, indicating catalyst modification processes under reducing 
conditions rather than catalyst decomposition (i.e. ligand dissociation). It should be noted that although reduced $\mathrm{Zr}\left({ }^{\mathrm{H}} \mathrm{PDP}^{\mathrm{H}}\right)_{2}(\mathrm{THF})_{2}$ is a stronger reductant $\left(-2.45 \mathrm{~V}\right.$ vs $\left.\mathrm{Fc}^{+/ 0}\right)$, high energy blue light $\left(\lambda_{\max -a b s}=430 \mathrm{~nm}\right)$ is required for the excitation and was not investigated.

Table 8. Control experiments for reductive dehalogenation of 1-bromo-4-iodo-benzene.

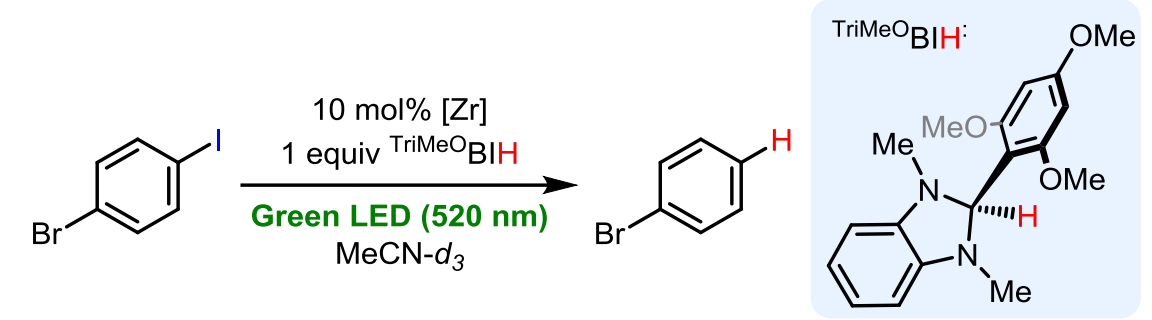

\begin{tabular}{|c|c|c|c|c|c|}
\hline Entry & Light & {$[\mathrm{Zr}]$} & $\mathrm{E}_{1 / 2}(\mathrm{~V})^{\mathrm{a}}$ & Time (h) & $\begin{array}{c}\text { Yield } \\
\text { (Conv.) \% }\end{array}$ \\
\hline 1 & No & $\mathrm{Zr}\left({ }^{\mathrm{Me}} \mathrm{PDP}^{\mathrm{Me}}\right)_{2}{ }^{\mathrm{c}}$ & -2.42 & 112 & $0(0)$ \\
\hline 2 & Yes & No & I & 51 & $3(5)$ \\
\hline $3^{\mathrm{d}}$ & Yes & No & l & 42 & $4(/)$ \\
\hline 4 & Yes & $\mathrm{Zr}\left({ }^{\mathrm{Me}} \mathbf{P D P} \mathrm{P}^{\mathrm{Me}}\right)_{2}{ }^{\mathrm{c}}$ & -2.42 & 37 & $85(100)$ \\
\hline 5 & Yes & $\mathrm{Zr}\left({ }^{\mathrm{Me}} \mathrm{PDP}^{\mathrm{H}}\right)_{2}$ & -2.21 & 88 & $51(65)$ \\
\hline 6 & Yes & $\mathrm{Zr}\left({ }^{\mathrm{Me}} \mathrm{PDP} \mathrm{P}^{\mathrm{Ph}}\right)_{2}{ }^{\mathrm{e}}$ & -2.16 & I & I \\
\hline $7^{\mathrm{f}}$ & Yes & $\mathrm{Zr}\left({ }^{\mathrm{Me}} \mathrm{PDP}^{\mathrm{C} 6 \mathrm{~F} 5}\right)_{2}$ & -1.85 & 20 & $16(23)$ \\
\hline
\end{tabular}

Next, $\mathrm{Zr}\left({ }^{\mathrm{Me}} \mathrm{PDP}^{\mathrm{Me}}\right)_{2}(10 \mathrm{~mol} \%)$ was selected as the photocatalyst to survey the scope of this dehalogenation protocol (Scheme 3). To prevent product loss during workup and to obtain a more reliable comparison between the reaction efficiency over different substrates, ${ }^{1} \mathrm{H}$ NMR spectroscopy was used to determine reaction yields and conversions $( \pm 5 \%)$. Generally, this method works cleanly for aryl iodide, bromide, and chloride substrates and shows good tolerance 
with ester, trifluoromethyl, cyano, and methoxy functional groups. High yields were observed with electron-neutral or electron-rich aryl iodides, electron-deficient aryl bromides and electron-poor aryl chloride substrates in reasonable amount of time. For more electron-rich/neutral aryl bromides or chlorides, only poor to moderate conversions/yields were obtained after long reaction times. The dehalogenation reaction of $O$-allyl-2-iodophenol resulted in $67 \%$ of reductive cyclization product, 3-methyl dihydrobenzofuran, which is indictive of a SET dehalogenation reaction pathway.

Scheme 3. Scope of aryl halide dehalogenation

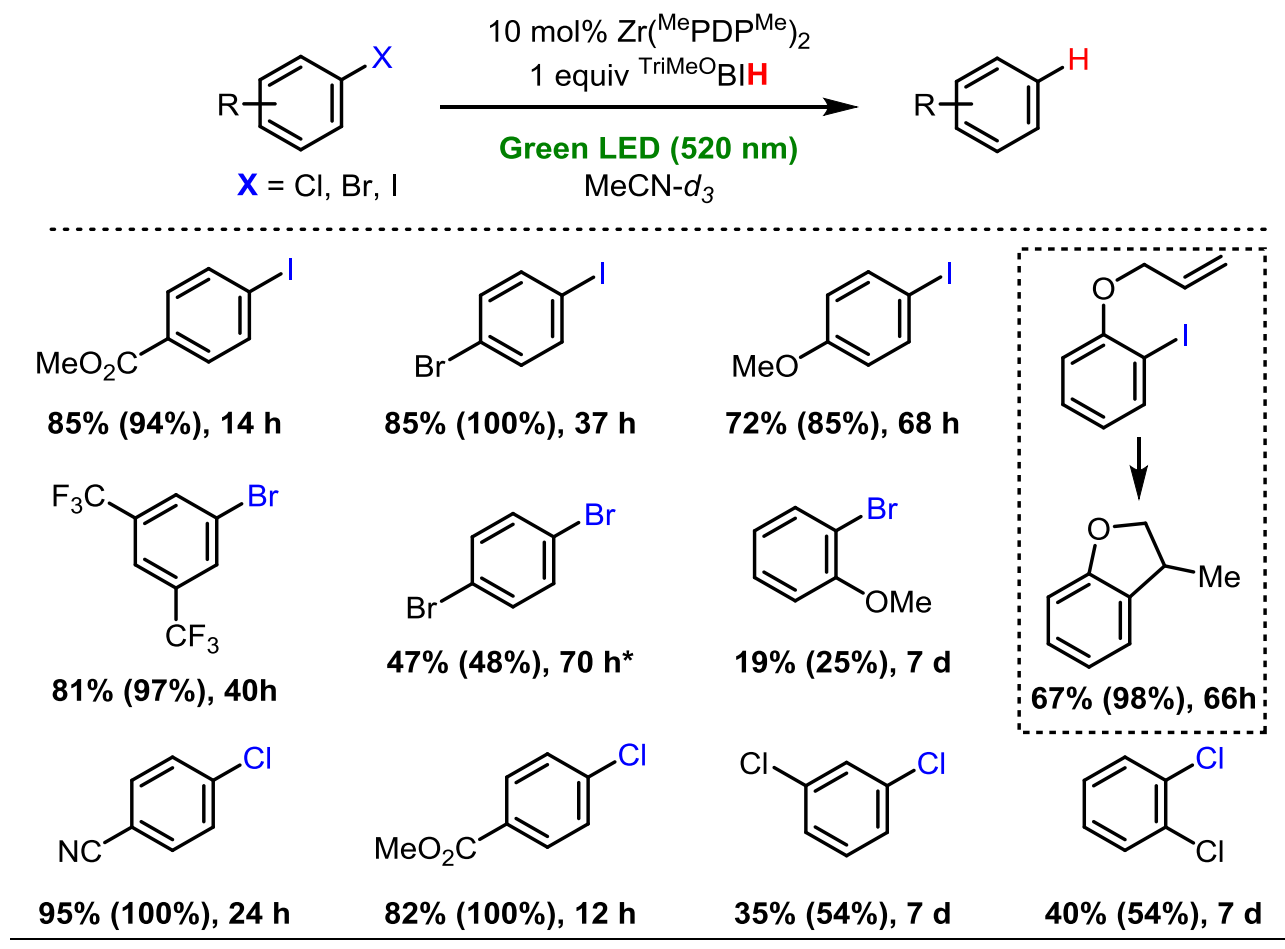

${ }^{a 1} \mathrm{H}$ NMR yields (conversion in parentheses) obtained quantitatively by using $1,3,5-$ trimethoxybenzene as internal standard. 


\subsection{Summary.}

Modular PDP ligand synthesis allowed us to access a series of zirconium photosensitizers bearing substituents with different electronic and steric profiles. With the help of X-ray crystallography, the steric bulkiness of these complexes was defined by two parameters: dihedral angle of two ligand planes and $\mathrm{N}_{\mathrm{py}}(2)-\mathrm{Zr}-\mathrm{N}_{\mathrm{py}}(5)$ angle, or the "rigidity parameters". Cyclic voltammetry experiments demonstrate the ground state redox potential of the zirconium complexes is strongly dependent on the electronic effect of pyrrole substituents, where the $\left[\mathrm{Zr}\left({ }^{\mathrm{R} 1} \mathrm{PDP}^{\mathrm{R} 2}\right)_{2}\right]^{0} /$ $\left[\mathrm{Zr}\left({ }^{\mathrm{R} 1} \mathrm{PDP}^{\mathrm{R} 2}\right)_{2}\right]^{1-}$ spans $\sim 0.6 \mathrm{~V}$ across the series. The DFT calculated LUMOs energies further confirmed the trends observed electrochemically. The absorption profiles along with the computed HOMO-LUMO energy gap of the complexes revealed the color of the zirconium chromophore were controlled by 5 -substitution of ligand pyrrole moieties according to their conjugation with the PDP $\pi$ system.

All new zirconium complexes were photoluminescent with several hundreds of microseconds of emission lifetime. The factors influence non-radiative decay pathways during $\mathrm{Zr}(\mathrm{PDP})_{2}$ 's TADF process were discussed: 1) a nearly linear relationship between Stokes shifts and the compound's rigidity indicates the energy loss during internal conversion of ${ }^{1} \mathrm{IL} /{ }^{1} \mathrm{LMCT}$ state is associated with fluxionality of ligand framework. 2) The lifetime of the triplet state also seems to suffer from excited state structural distortion arising from the degrees of ligand motions cooperative with $\mathrm{C}-\mathrm{H}$ vibrational quenching. The understanding of structure-properties 
relationship provided us the insights for tuning the properties of zirconium-based photosensitizer toward the a given application. Along with general easy synthesis, there is still plenty of room for the design and development of new library of ligands with properties that suitable for the fine optical/electrochemical tuning of luminescent zirconium complexes.

Although the $\mathrm{Zr}\left({ }^{\mathrm{R} 1} \mathrm{PDP}^{\mathrm{R} 2}\right)_{2}$ * have limited oxidation power to perform challenge oxidation reactions, in combination with commonly used BIH derivatives as a sacrificial electron donor, will produce highly reducing zirconium anion for the reduction of difficult substrates. In this work, we presented a general aryl halide dehalogenation protocol using a potent photocatalyst, $\mathrm{Zr}\left({ }^{\mathrm{Me}} \mathrm{PDP}{ }^{\mathrm{Me}}\right)_{2}$. We believe that this work demonstrated a good example of accomplishing a challenge organic transformation by coupling renewable energy resource and earth abundant material.

\subsection{Experimental Section.}

General experimental considerations for material handling, physical measurements, X-ray crystallography, and DFT Calculations as well as additional experimental information (i.e. NMR spectra, quenching experiments, additional optical and CV properties) can be found in the appendices. 
Starting Materials. Aryl halides that are used for photocatalytic dehalogenation reaction were purchased from commercial source. Tetrabenzyl zirconium were prepared following literature procedures. ${ }^{19,20}$

Preparation of 2,6-bis(3,5-diphenyl-1H-pyrrol-2-yl)pyridine $\left(\mathrm{H}_{2}{ }^{\mathrm{Ph}} \mathrm{PDP}{ }^{\mathrm{Ph}}\right)$ : The synthesis was carried out according to a modified literature procedure. ${ }^{8}$ 2,6-Pyridinedicarboxaldehyde $(2.00 \mathrm{~g}$, $14.80 \mathrm{mmol}, 1.00$ equiv), 1,3-Diphenylprop-2-en-1-one (6.17 g, $29.60 \mathrm{mmol}, 2.00$ equiv), and 3benzyl-5-(2-hydroxyethyl)-4-methyl-thiazolium chloride (2.395 g, $8.88 \mathrm{mmol}, 0.6$ equiv), were mixed in a $250 \mathrm{~mL}$ Schlenk flask under an argon atmosphere. Absolute ethanol was added and the mixture was heated to reflux. A solution of sodium tert-butoxide ( $853 \mathrm{mg}, 8.88 \mathrm{mmol}, 0.6$ equiv) in ethanol was added via syringe and heating was continued for 24 hours. The reaction was cooled to room temperature and ammonium acetate $(6.85 \mathrm{~g}, 88.81 \mathrm{mmol}, 6.00$ equiv) was added to the mixture. The reaction mixture was heated to reflux open to air for 24 hours. The solid precipitate was collected via filtration, washed with cold ethanol, and dried under high vacuum to yield the desired product as a pale yellow solid (Yield: 6.018 g, 79\%). M.p. $231-233{ }^{\circ} \mathrm{C} .{ }^{1} \mathrm{H}$ NMR $(400$ MHz, $\left.\mathrm{C}_{6} \mathrm{D}_{6} ; \delta, \mathrm{ppm}\right): 9.50$ (s, 2H, NH), 7.59 (d, $\left.J=7.2 \mathrm{~Hz}, 4 \mathrm{H}, \mathrm{Ph} H\right), 7.32(\mathrm{~d}, J=7.6 \mathrm{~Hz}, 4 \mathrm{H}$, $\mathrm{Ph} H), 7.24(\mathrm{t}, J=7.6 \mathrm{~Hz}, 4 \mathrm{H}, \mathrm{Ph} H), 7.18-7.10(\mathrm{~m}, 8 \mathrm{H}, \mathrm{Py} H \& \mathrm{Ph} H), 7.05(\mathrm{t}, J=7.2 \mathrm{~Hz}, 2 \mathrm{H}$, $\mathrm{Ph} H), 6.72(\mathrm{~d}, J=8.0 \mathrm{~Hz}, 1 \mathrm{H}$, para-Py $H), 6.68(\mathrm{~d}, J=2.4 \mathrm{~Hz}, 2 \mathrm{H}$, Pyrrole $H) .{ }^{13} \mathrm{C}$ NMR $(101 \mathrm{MHz}$, $\left.\mathrm{C}_{6} \mathrm{D}_{6} ; \delta, \mathrm{ppm}\right): 150.83,137.75,136.65,133.39,132.41,129.76,129.20,128.92,128.15127 .55$, 
127.12, 126.88, 124.48, 117.89, 110.89. HRMS (ESI) calcd for $\mathrm{C}_{37} \mathrm{H}_{28} \mathrm{~N}_{3}^{+}[\mathrm{M}+\mathrm{H}]^{+} \mathrm{m} / \mathrm{z} 514.22777$;

Found 514.22885.

Preparation of 2,6-bis(5-methyl-1H-pyrrol-2-yl)pyridine $\left(\mathrm{H}_{2}{ }^{\mathrm{Me}} \mathbf{P D P} \mathrm{P}^{\mathrm{H}}\right)$ : The synthesis was carried out according to a modified literature procedure. ${ }^{9} 2,6$-Pyridinedicarboxaldehyde $(2.00 \mathrm{~g}$, $14.80 \mathrm{mmol}, 1.00$ equiv), methyl vinyl ketone (2.59 g, $37.00 \mathrm{mmol}, 2.50$ equiv), and 3-benzyl-5(2-hydroxyethyl)-4-methyl-thiazolium chloride (2.395 g, $8.88 \mathrm{mmol}, 0.6$ equiv), were mixed in a $250 \mathrm{~mL}$ Schlenk flask under an argon atmosphere. Absolute ethanol was added and the mixture was heated to reflux. A solution of sodium tert-butoxide ( $853 \mathrm{mg}, 8.88 \mathrm{mmol}, 0.6$ equiv) in ethanol was added via syringe and heating was continued for 24 hours. The reaction was cooled to room temperature and ammonium acetate $(11.41 \mathrm{~g}, 148.02 \mathrm{mmol}, 10.00$ equiv) was added to the mixture. The reaction mixture was heated to reflux open to air. After 24 hours, the solvent was removed. The resultant was diluted with $\mathrm{H}_{2} \mathrm{O}$ and the crude product was extracted with DCM three times. The combined organic layers were washed with brine and dried over $\mathrm{Na}_{2} \mathrm{SO}_{4}$. Removal of the DCM and purification by silica gel column chromatography using hexane : ethyl acetate $(20: 1)$ as eluent furnished $\mathrm{H}_{2}{ }^{\mathrm{Me}} \mathrm{PDP}^{\mathrm{H}}$ as an yellow solid (Yield: $1.34 \mathrm{~g}, 38 \%$ ). M.p. $211-213{ }^{\circ} \mathrm{C} .{ }^{1} \mathrm{H}$ NMR (400 MHz, C6 $\left.\mathrm{D}_{6} ; \delta, \mathrm{ppm}\right): 10.65$ (s, 2H, NH), 7.15 - 7.05 (m, 3H, para-PyH \& meta-PyH), $6.72(\mathrm{t}, J=3.2 \mathrm{~Hz}, 2 \mathrm{H}$, Pyrrole $H), 5.88(\mathrm{~m}, 2 \mathrm{H}, \mathrm{PhH}), 1.64\left(\mathrm{~s}, 6 \mathrm{H}, \mathrm{CH}_{3}\right) .{ }^{13} \mathrm{C} \mathrm{NMR}(101 \mathrm{MHz}$, $\left.\mathrm{C}_{6} \mathrm{D}_{6} ; \delta, \mathrm{ppm}\right): 151.27,138.17,131.50,129.65,114.11,109.84,109.21,12.22$. HRMS (ESI) calcd for $\mathrm{C}_{15} \mathrm{H}_{16} \mathrm{~N}_{3}+[\mathrm{M}+\mathrm{H}]^{+} \mathrm{m} / \mathrm{z} 238.13387$; Found 238.13378. 
Preparation of 2,6-bis(1H-pyrrol-2-yl)pyridine $\left(\mathrm{H}_{2}{ }^{\mathrm{H}} \mathrm{PDP}^{\mathrm{H}}\right)$ : The synthesis was carried out according to a modified literature procedure. ${ }^{21}$ 2,6-Dibromopyridine (3.6 g, $15.20 \mathrm{mmol}, 1.00$ equiv), 1-(tert-butoxycarbonyl)-2-pyrroleboronic Acid (9.4 g, $44.53 \mathrm{mmol}, 2.93$ equiv), $\mathrm{K}_{2} \mathrm{CO}_{3}$ (18.90 g, $136.77 \mathrm{mmol}, 9.00$ equiv) and $\mathrm{Pd}\left(\mathrm{PPh}_{3}\right)_{4}(878 \mathrm{mg}, 0.760 \mathrm{mmol}, 0.05$ equiv) was placed in a $250 \mathrm{~mL}$ flask under an argon atmosphere. Then, $80 \mathrm{~mL}$ of deaerated toluene : $\mathrm{EtOH}: \mathrm{H}_{2} \mathrm{O}(9$ : $3: 4)$ solution was added via cannula transfer. The reaction mixture was heated at $90{ }^{\circ} \mathrm{C}$ under argon for $24 \mathrm{~h}$. After cooling to room temperature, the solvent was removed. The residue was extracted with in EtOAc and then passed through silica gel to remove bronic acids and palladium compounds. After removal of the solvent, the residue was treated with ethylene glycol (50 $\mathrm{ml})$ and heated at $160^{\circ} \mathrm{C}$ for $1 \mathrm{~h}$ under an argon atmosphere. After cooling to room temperature, the mixture was extracted with $\mathrm{CHCl}_{3}$. The organic layer was washed with $\mathrm{H}_{2} \mathrm{O}$ and brine and dried over $\mathrm{Na}_{2} \mathrm{SO}_{4}$. Removal of the $\mathrm{CHCl}_{3}$ and recrystallization from $\mathrm{CHCl}_{3}$ and hexane furnished $\mathrm{H}_{2}{ }^{\mathrm{H} D D P}{ }^{\mathrm{H}}$ as a green-yellow solid (Yield: 1.922 g, 60\%; one crop). M.p. $189-191{ }^{\circ} \mathrm{C} .{ }^{1} \mathrm{H}$ NMR (400 MHz, $\left.\mathrm{CDCl}_{3} ; \delta, \mathrm{ppm}\right): 9.65$ (s, 2H, NH), 7.61 (t, $\left.J=8.0 \mathrm{~Hz}, 1 \mathrm{H}, \mathrm{Py} H\right), 7.34$ (d, $J=8.0 \mathrm{~Hz}, 2 \mathrm{H}, \mathrm{Py} H$ ), 6.90 (m, 2H, Pyrrole $H), 6.74$ (m, 2H, Pyrrole $H), 6.31$ (m, 2H, Pyrrole $H) .{ }^{13} \mathrm{C}$ NMR (101 MHz, $\left.\mathrm{CDCl}_{3} ; \delta, \mathrm{ppm}\right): 149.76,137.32,131.56,119.71,115.34,110.45,107.53$. HRMS (ESI) calcd for $\mathrm{C}_{13} \mathrm{H}_{12} \mathrm{~N}_{3}^{+}[\mathrm{M}+\mathrm{H}]^{+} \mathrm{m} / \mathrm{z} 210.10257$; Found 210.10249.

Preparation of 2,6-bis(3,5-dimethyl-1H-pyrrol-2-yl)pyridine $\left(\mathrm{H}_{2}{ }^{\mathrm{Me}} \mathrm{PDP}{ }^{\mathrm{Me}}\right)$ : The synthesis was carried out according to a modified literature procedure. ${ }^{10}$ Bis-(aminomethyl)pyridine $(2.44 \mathrm{~g}$, 
$17.79 \mathrm{mmol}, 1.00$ equiv), acetylacetone ( $3.65 \mathrm{~g}, 36.46 \mathrm{mmol}, 2.05$ equiv) and tosic acid hydrate ( $2.14 \mathrm{~g}, 12.45 \mathrm{mmol}, 0.70$ equiv) were added to a $250 \mathrm{~mL}$ flask charged with $150 \mathrm{~mL}$ of xylene. The reaction flask was fitted with a Dean-Stark trap and a reflux condenser. The mixture was refluxed for 4 days. After it was cooled, the crude material was passed through a column of silica. Removal of the xylene and recrystallization from ethyl acetate and hexane furnished $\mathrm{H}_{2}{ }^{\mathrm{Me}} \mathrm{PDP}{ }^{\mathrm{Me}}$ as a yellow solid (Yield: $527 \mathrm{mg}, 11 \%$; one crop). M.p. $203-205{ }^{\circ} \mathrm{C} .{ }^{1} \mathrm{H}$ NMR (400 MHz, $\mathrm{C}_{6} \mathrm{D}_{6}$; $\delta$, ppm): 10.19 (s, 2H, NH), 7.29 (dd, $J=8.8,7.2 \mathrm{~Hz}, 1 \mathrm{H}$, para-PyH), $7.18(\mathrm{~d}, J=8.0 \mathrm{~Hz}, 2 \mathrm{H}$, $m e t a-\mathrm{Py} H), 5.75(\mathrm{~d}, J=2.8 \mathrm{~Hz}, 2 \mathrm{H}, \mathrm{Pyrrole} H), 2.34\left(\mathrm{~s}, 6 \mathrm{H}, \mathrm{CH}_{3}\right), 1.69\left(\mathrm{~s}, 6 \mathrm{H}, \mathrm{CH}_{3}\right) .{ }^{13} \mathrm{C}$ NMR (101 MHz, $\left.\mathrm{C}_{6} \mathrm{D}_{6} ; \delta, \mathrm{ppm}\right): 151.90,137.57,129.44,125.90,120.63,114.81,112.35,14.57$ (d, $J=$ 2.6 Hz), 12.24. HRMS (ESI) calcd for $\mathrm{C}_{17} \mathrm{H}_{20} \mathrm{~N}_{3}{ }^{+}[\mathrm{M}+\mathrm{H}]^{+} \mathrm{m} / \mathrm{z}$ 266.16517; Found 266.16491.

Preparation of 2,6-bis(5-methyl-3-pentafluorophenyl-1H-pyrrol-2-yl)pyridine $\left(\mathbf{H}_{2}{ }^{\text {Me }} \mathbf{P D P}{ }^{\mathbf{C} 655}\right)$ : The synthesis was carried out according to a modified literature procedure. ${ }^{9} \mathrm{~A}$ $250 \mathrm{~mL}$ Schlenk flask was charged with 2,6-pyridinedicarboxaldehyde $(1.000 \mathrm{~g}, 7.400 \mathrm{mmol}, 1.00$ equiv), (E)-4-pentafluorophenylbut-3-en-2-one (3.530 g, $14.95 \mathrm{mmol}, 2.02$ equiv), and 3-benzyl5-(2-hydroxyethyl)-4-methylthiazolium chloride (1.198 g, $4.44 \mathrm{mmol}, 0.60$ equiv) under an argon atmosphere. Absolute ethanol was added followed by a solution of sodium tert-butoxide $(0.427 \mathrm{~g}$, $4.44 \mathrm{mmol}, 0.60$ equiv) in ethanol via syringe. The mixture was refluxed for 24 hours. Followed by cooling to room temperature and opening to air, ammonium acetate $(3.423 \mathrm{~g}, 44.4 \mathrm{mmol}, 6.00$ equiv) was added to the mixture. The reaction mixture was again refluxed for 24 hours. The 
resulting orange-red solution was reduced to a thick goo via rotary evaporation. This was then dissolved in EtOAc, washed twice with a saturated sodium bicarbonate solution, twice with $\mathrm{H}_{2} \mathrm{O}$, and twice with brine. Removal of the EtOAc and purification by silica gel column chromatography using hexane : EtOAc $(8: 1)$ as eluent furnished $\mathrm{H}_{2}{ }^{\mathrm{Me}} \mathrm{PDP}^{\mathrm{C} 6 \mathrm{~F} 5}$ as an orange-yellow solid (Yield: 1.611 g, 76\%). M.p. $184-186{ }^{\circ} \mathrm{C} .{ }^{1} \mathrm{H}$ NMR (400 MHz, $\left.\mathrm{C}_{6} \mathrm{D}_{6} ; \delta, \mathrm{ppm}\right): 9.02$ (s, 2H, NH), 6.88 (t, $J=7.6 \mathrm{~Hz}, 1 \mathrm{H}, \mathrm{Py} H), 6.66$ (d, $J=8.0 \mathrm{~Hz}, 2 \mathrm{H}, \mathrm{Py} H), 5.97$ (d, $J=2.4 \mathrm{~Hz}, 2 \mathrm{H}$, Pyrrole $H), 1.83(\mathrm{~s}$, $\left.6 \mathrm{H}, \mathrm{CH}_{3}\right) .{ }^{13} \mathrm{C}$ NMR (101 MHz, $\left.\mathrm{C}_{6} \mathrm{D}_{6} ; \delta, \mathrm{ppm}\right): 150.3,144.9(\mathrm{dm}, J=245 \mathrm{~Hz}), 140.4(\mathrm{dm}, J=252$ $\mathrm{Hz}), 138.2(\mathrm{dm}, J=251 \mathrm{~Hz}), 137.6,130.4,128.5,116.2,112.7(\mathrm{td}, J=18.4,3.8 \mathrm{~Hz}), 111.7,107.4$, 12.4. ${ }^{19} \mathrm{~F}$ NMR (376 MHz, $\mathrm{C}_{6} \mathrm{D}_{6}$; $\delta$, ppm): -140.1 (dd, $\left.J=23.7,7.9 \mathrm{~Hz}\right),-156.7(\mathrm{t}, J=21.8 \mathrm{~Hz}),-$ $162.6\left(\mathrm{td}, J=23.7,8.3 \mathrm{~Hz}\right.$ ). HRMS (ESI) Anal. Calcd. for $\mathrm{C}_{27} \mathrm{H}_{14} \mathrm{~F}_{10} \mathrm{~N}_{3}{ }^{+}[\mathrm{M}+\mathrm{H}]^{+} \mathrm{m} / \mathrm{z}$ 570.10226; Found 570.10205 .

Preparation of $\mathbf{Z r}\left({ }^{\text {MePDP }}{ }^{\mathbf{C} 655}\right)_{2}$ : LiHMDS (181 mg, $1.08 \mathrm{mmol}, 2.02$ equiv) in THF was added slowly to a $20 \mathrm{~mL}$ vial charged with a solution of $\mathrm{H}_{2}{ }^{\mathrm{Me}} \mathrm{PDP}^{\mathrm{C} 6 \mathrm{~F} 5}$ (300 $\mathrm{mg}, 0.527 \mathrm{mmol}, 1.00$ equiv) in $3 \mathrm{~mL}$ of THF. The reaction was stirred for 2 hours at room temperature to generate a luminescent dark green-yellow solution of the deprotonated ligand. A solution of $\mathrm{ZrCl}_{4}(64 \mathrm{mg}, 0.274 \mathrm{mmol}$, 0.52 equiv) in $3 \mathrm{~mL}$ of THF was added in small portions to the deprotonated ligand over 20 mins. The reaction mixture was allowed to stir at room temperature and the color of the solution slowly changed to emissive red. After 2 days, THF was removed in vacuo and triturated with $\mathrm{Et}_{2} \mathrm{O}$ three times. The solid residue was then dissolved in a minimum amount of ether and filtered through 
celite. The crude product was purified by recrystallization (pentane/ether $2: 1$ ) at $-35{ }^{\circ} \mathrm{C}$ (Yield: $207 \mathrm{mg}, 63 \%) .{ }^{1} \mathrm{H}$ NMR (400 MHz, $\left.\mathrm{C}_{6} \mathrm{D}_{6} ; \delta, \mathrm{ppm}\right): 6.73$ (t, $\left.J=8.0 \mathrm{~Hz}, 2 \mathrm{H}, \mathrm{Py} H\right), 6.41$ (d, $J=7.6$ $\mathrm{Hz}, 4 \mathrm{H}, \mathrm{Py} H), 5.70$ (s, 4H, Pyrrole $H$ ), $2.08\left(\mathrm{~s}, 12 \mathrm{H}, \mathrm{CH}_{3}\right) .{ }^{13} \mathrm{C}$ NMR (100 MHz, $\left.\mathrm{C}_{6} \mathrm{D}_{6} ; \delta, \mathrm{ppm}\right)$ : 154.2, $144.6(\mathrm{dm}, J=246 \mathrm{~Hz}), 143.4,141.6,140.7(\mathrm{dm}, J=252 \mathrm{~Hz}), 138.2(\mathrm{dm}, J=247 \mathrm{~Hz})$, 137.2, 114.5, 112.5, 111.5, $111.3(\mathrm{td}, J=18.7,3.5 \mathrm{~Hz}), 14.3 \mathrm{ppm} .{ }^{19} \mathrm{~F}$ NMR $\left(376 \mathrm{MHz}, \mathrm{C}_{6} \mathrm{D}_{6} ; \delta\right.$, ppm): $-139.6(\mathrm{dd}, J=24.1,7.9 \mathrm{~Hz}),-155.2(\mathrm{t}, J=21.4 \mathrm{~Hz}),-162.0(\mathrm{td}, J=23.7,7.9 \mathrm{~Hz})$. Anal. Calcd. for $\mathrm{C}_{54} \mathrm{H}_{22} \mathrm{~F}_{20} \mathrm{~N}_{6} \mathrm{Zr}$ : C, 52.90; H, 1.81; N, 6.85. Found: C, 52.79; H, 1.71; N, 6.62. Single crystals suitable for X-ray crystallographic analysis were grown from pentane/Et $2 \mathrm{O} 2$ :1solution of $\mathrm{Zr}\left({ }^{\mathrm{Me}} \mathrm{PDP}^{\mathrm{C} 6 \mathrm{F5}}\right)_{2}$ at $-35^{\circ} \mathrm{C}$.

Preparation of $\mathbf{Z r}\left({ }^{\mathrm{H} P D P}{ }^{\mathrm{H}}\right)_{2}$ : A solution of tetrabenzyl zirconium $(109 \mathrm{mg}, 0.239 \mathrm{mmol}, 1.00$ equiv) in $1 \mathrm{~mL}$ of toluene was added slowly to a $20 \mathrm{~mL}$ vial charged with a solution of $\mathrm{H}_{2}{ }^{\mathrm{H}} \mathrm{PDP}^{\mathrm{H}}$ (100 mg, $0.478 \mathrm{mmol}, 2.00$ equiv) in $2 \mathrm{~mL}$ of benzene. The reaction was stirred for $10 \mathrm{mins}$ at room temperature and the desired product crystalized out while stirring. The reaction was then filtered and the solid was washed three times with benzene. The product was collected as an dark orange microcrystalline solid (Yield: $110 \mathrm{mg}, 91 \%) .{ }^{1} \mathrm{H}$ NMR (400 MHz, $\mathrm{C}_{6} \mathrm{D}_{6} ; \delta$, ppm): 6.83 (t, $J=8.0 \mathrm{~Hz}, 2 \mathrm{H}$, para $-\mathrm{Py} H), 6.80(\mathrm{~d}, J=1.6 \mathrm{~Hz}, 4 \mathrm{H}$, Pyrrole $H), 6.54(\mathrm{dd}, J=3.2,0.8 \mathrm{~Hz}, 4 \mathrm{H}$, Pyrrole $H), 6.44(\mathrm{~d}, J=8.0 \mathrm{~Hz}, 2 \mathrm{H}$, meta-PyH$), 6.06(\mathrm{t}, J=2.8 \mathrm{~Hz}, 4 \mathrm{H}$, Pyrrole $H) .{ }^{13} \mathrm{C}$ NMR $(101$ $\left.\mathrm{MHz}, \mathrm{C}_{6} \mathrm{D}_{6} ; \delta, \mathrm{ppm}\right): 154.63,142.64,140.56,131.44,112.00,111.55,111.23$. Anal. Calcd for $\mathrm{C}_{26} \mathrm{H}_{18} \mathrm{~N}_{6} \mathrm{Zr}$ : C, 61.75; H, 3.59; N, 16.62. Found: C, 61.59; H, 3.98; N, 16.33. Single crystals 
suitable for X-ray crystallographic analysis were grown from a saturated solution of $\mathrm{Zr}\left({ }^{\mathrm{H}} \mathrm{PDP}^{\mathrm{H}}\right)_{2}$ in $\mathrm{C}_{6} \mathrm{D}_{6}$ at room temperature.

Preparation of $\mathbf{Z r}\left({ }^{\mathbf{P h}}{ }^{\mathbf{P D P}}{ }^{\mathbf{P h}}\right)_{2}$ : $\mathrm{n}$-BuLi (0.499 mL (1.6 M solution in hexanes), $0.798 \mathrm{mmol}, 2.05$ equiv) was added slowly to a $20 \mathrm{~mL}$ vial charged with a solution of $\mathrm{H}_{2}{ }^{\mathrm{Me}} \mathrm{PDP}^{\mathrm{H}}(200 \mathrm{mg}, 0.389$ mmol, 1.00 equiv) in $5 \mathrm{~mL}$ of THF. The reaction was stirred for 2 hours at room temperature to generate a luminescent dark red-orange solution of the deprotonated ligand. A solution of $\mathrm{ZrCl}_{4}$ (47 $\mathrm{mg}, 0.202 \mathrm{mmol}, 0.52$ equiv) in $3 \mathrm{~mL}$ of THF was added in small portions to the deprotonated ligand over 20 mins. The reaction mixture was allowed to stir at room temperature and the color of the solution slowly changed to emissive red. After 2 days, THF was removed in vacuo and triturated with $\mathrm{Et}_{2} \mathrm{O}$ three times. The solid residue was washed three times with benzene to remove any unreacted $\mathrm{Li}_{2}{ }^{\mathrm{Ph}} \mathrm{PDP}{ }^{\mathrm{Ph}}$ and potential mono-ligated zirconium species. The crude product was dried in vacuo, redissolved in DCM, and filtered to remove $\mathrm{LiCl}$ and potentially unreacted $\mathrm{ZrCl}_{4}$. Removal of the solvent in vacuo provided a red microcrystalline solid (Yield: $176 \mathrm{mg}, 81 \%$ ). ${ }^{1} \mathrm{H}$ NMR (600 MHz, $\left.\mathrm{CDCl}_{3} ; \delta, \mathrm{ppm}\right): 7.44-7.37(\mathrm{~m}, 16 \mathrm{H}, \mathrm{Ph} H), 7.35-7.28(\mathrm{~m}, 12 \mathrm{H}, \mathrm{Ph} H), 6.97-$ $6.89(\mathrm{~m}, 12 \mathrm{H}, \mathrm{Ph} H), 6.81$ (t, $J=7.8 \mathrm{~Hz}, 2 \mathrm{H}$, para-PyH), 6.35 (d, $J=7.8 \mathrm{~Hz}, 4 \mathrm{H}, \mathrm{Py} H), 6.09$ (s, 4H, Pyrrole $H) .{ }^{13} \mathrm{C}$ NMR (151 MHz, $\left.\mathrm{CDCl}_{3} ; \delta, \mathrm{ppm}\right): 153.56,145.66,140.13,136.82,135.78$, 135.49, 129.27, 129.26, 128.42, 128.24, 126.97, 126.85, 126.77, 113.73, 113.00. Anal. Calcd for $\mathrm{C}_{74} \mathrm{H}_{50} \mathrm{~N}_{6} \mathrm{Zr} \cdot \mathrm{Et}_{2} \mathrm{O}: \mathrm{C}, 78.82 ; \mathrm{H}, 5.09 ; \mathrm{N}, 7.07$. Found: C, 79.10; H, 5.16; N, 7.22. Single crystals 
suitable for X-ray crystallographic analysis were grown from saturated $\mathrm{Et}_{2} \mathrm{O}$ solution of $\mathrm{Zr}\left({ }^{\mathrm{Ph} P D P}{ }^{\mathrm{Ph}}\right)_{2}$ at $-35^{\circ} \mathrm{C}$.

Preparation of $\mathbf{Z r}\left({ }^{\left({ }^{M e}\right.} \mathbf{P D P}^{\mathrm{H}}\right)_{2}: \mathrm{n}$-BuLi (2.23 mL (1.6 M solution in hexanes), $3.58 \mathrm{mmol}, 2.02$ equiv) was added slowly to a $20 \mathrm{~mL}$ vial charged with a solution of $\mathrm{H}_{2}{ }^{\mathrm{Me}} \mathrm{PDP}^{\mathrm{H}}(420 \mathrm{mg}, 1.77$ mmol, 1.00 equiv) in $5 \mathrm{~mL}$ of THF. The reaction was stirred for 2 hours at room temperature to generate a luminescent dark green-orange solution of the deprotonated ligand. A solution of $\mathrm{ZrCl}_{4}$ (227 $\mathrm{mg}, 0.973 \mathrm{mmol}, 0.55$ equiv) in $3 \mathrm{~mL}$ of THF was added in small portions to the deprotonated ligand over 20 mins. The reaction mixture was allowed to stir at room temperature and the color of the solution slowly changed to emissive red. After 2 days, THF was removed in vacuo and triturated with $\mathrm{Et}_{2} \mathrm{O}$ three times. The solid residue was washed three times with $\mathrm{Et}_{2} \mathrm{O}$ to remove any unreacted $\mathrm{Li}_{2}{ }^{\mathrm{Me}} \mathrm{PDP}^{\mathrm{H}}$ and potential mono-ligated zirconium species. The crude product was dried in vacuo, redissolved in $\mathrm{DCM}$, and filtered to remove $\mathrm{LiCl}$ and potentially unreacted $\mathrm{ZrCl}_{4}$. Removal of the solvent in vacuo provided a red microcrystalline solid (Yield: $283 \mathrm{mg}, 57 \%$ ). ${ }^{1} \mathrm{H}$ NMR (400 MHz, $\left.\mathrm{C}_{6} \mathrm{D}_{6} ; \delta, \mathrm{ppm}\right): 6.83(\mathrm{t}, J=8.0 \mathrm{~Hz}, 2 \mathrm{H}$, para-PyH), $6.53(\mathrm{~d}, J=3.2 \mathrm{~Hz}, 4 \mathrm{H}$, Pyrrole $H$ ), 6.45 (d, $J=8.0 \mathrm{~Hz}, 4 \mathrm{H}$, meta-Py $H), 5.76$ (dd, $J=3.2,0.8 \mathrm{~Hz}, 4 \mathrm{H}$, Pyrrole $H$ ), 2.01 (s, 12H, $\left.\mathrm{CH}_{3}\right) .{ }^{13} \mathrm{C}$ NMR (101 MHz, $\left.\mathrm{C}_{6} \mathrm{D}_{6} ; \delta, \mathrm{ppm}\right): 154.72,142.39,141.93,140.25,111.83,111.01$, 110.36, 14.70. Anal. Calcd for $\mathrm{C}_{30} \mathrm{H}_{26} \mathrm{~N}_{6} \mathrm{Zr} \cdot{ }^{1} / 6$ DCM: C, 62.91; H, 4.61; N, 14.59. Found: C, 63.17; H, 4.59; N, 14.36. Single crystals suitable for X-ray crystallographic analysis were grown from pentane/THF 1:1 solution of $\mathrm{Zr}\left({ }^{\mathrm{Me}} \mathrm{PDP}^{\mathrm{H}}\right)_{2}$ at $-35{ }^{\circ} \mathrm{C}$. 
Preparation of $\mathbf{Z r}\left({ }^{\text {MePDPMe }}{ }^{\text {Me }}\right.$ : n-BuLi (2.54 mL (1.6 M solution in hexanes), 4.07 mmol, 2.05 equiv) was added slowly to a $20 \mathrm{~mL}$ vial charged with a solution of $\mathrm{H}_{2}{ }^{\mathrm{Me}} \mathrm{PDP}^{\mathrm{Me}}(527 \mathrm{mg}, 1.99$ mmol, 1.00 equiv) in $5 \mathrm{~mL}$ of THF. The reaction was stirred for 2 hours at room temperature to generate a luminescent dark green-orange solution of the deprotonated ligand. A solution of $\mathrm{ZrCl}_{4}$ ( $241 \mathrm{mg}, 1.03 \mathrm{mmol}, 0.52$ equiv) in $3 \mathrm{~mL}$ of THF was added in small portions to the deprotonated ligand over 20 mins. The reaction mixture was allowed to stir at room temperature and the color of the solution slowly changed to emissive red. After 2 days, THF was removed in vacuo and triturated with $\mathrm{Et}_{2} \mathrm{O}$ three times. The solid residue was washed three times with $\mathrm{Et}_{2} \mathrm{O}$ to remove any unreacted $\mathrm{Li}_{2}{ }^{\mathrm{Me}} \mathrm{PDP}{ }^{\mathrm{Me}}$ and potential mono-ligated zirconium species. The crude product was dried in vacuo, redissolved in $\mathrm{DCM}$, and filtered to remove $\mathrm{LiCl}$ and potentially unreacted $\mathrm{ZrCl}_{4}$. Removal of the solvent in vacuo provided a red microcrystalline solid (Yield: $494 \mathrm{mg}, 81 \%$ ). ${ }^{1} \mathrm{H}$ NMR (400 MHz, $\left.\mathrm{CDCl}_{3} ; \delta, \mathrm{ppm}\right): 7.54(\mathrm{t}, J=8.0 \mathrm{~Hz}, 2 \mathrm{H}$, para-PyH), $6.87(\mathrm{~d}, J=8.0 \mathrm{~Hz}, 4 \mathrm{H}$, meta-PyH), $5.52(\mathrm{~s}, 4 \mathrm{H}$, Pyrrole $H), 2.27\left(\mathrm{~s}, 12 \mathrm{H}, \mathrm{CH}_{3}\right), 1.86\left(\mathrm{~s}, 12 \mathrm{H}, \mathrm{CH}_{3}\right) .{ }^{13} \mathrm{C} \mathrm{NMR}(101 \mathrm{MHz}$, $\left.\mathrm{CDCl}_{3} ; \delta, \mathrm{ppm}\right): 154.87,141.77,140.71,135.86,124.29,113.22,110.43,14.49,13.35$. Anal. Calcd for $\mathrm{C}_{34} \mathrm{H}_{34} \mathrm{~N}_{6} \mathrm{Zr}$ : C, 66.09; H, 5.55; N, 13.60. Found: C, 65.83; H, 5.47; N, 13.38 Single crystals suitable for X-ray crystallographic analysis were grown from dilute THF solution of $\mathrm{Zr}\left({ }^{\mathrm{Me}} \mathrm{PDP}{ }^{\mathrm{Me}}\right)_{2}$ at $-35^{\circ} \mathrm{C}$. 
General procedure for photocatalytic dehalogenation of aryl halides. In the drybox, a J. Young NMR tube was charged with $\mathrm{Zr}\left({ }^{\mathrm{Me}} \mathrm{PDP}^{\mathrm{Me}}\right)_{2}$ (0.10 equiv, from stock solution), ${ }^{\mathrm{Tr} M{ }^{2}}{ }^{\mathrm{BIH}}(1.00$ equiv), and aryl halide (1.00 equiv). About $0.6 \mathrm{~mL}$ of $\mathrm{MeCN}-d_{3}$ was added. 1,3,5trimethoxybenzene (from stock solution) was added as an internal standard. The mixture was placed in a jacketed glass beaker with water cooling and irradiated with green LED light $\left(\lambda_{\max }=\right.$ $520 \mathrm{~nm})$. The reaction was monitored by NMR to judge the completion. The products were analyzed by NMR spectroscopy and the yields (conversion) are based on internal standard. The NMR spectroscopic data of dehalogenated products in $\mathrm{MeCN}-d_{3}$ were established from commercially available pure materials.

\subsection{Reference.}

(1) McMillin, D. R.; Buckner, M. T.; Ahn, B. T. Inorg. Chem. 1977, 16, 943.

(2) Durham, B.; Caspar, J. V.; Nagle, J. K.; Meyer, T. J. J. Am. Chem. Soc. 1982, 104, 4803.

(3) King, K. A.; Spellane, P. J.; Watts, R. J. J. Am. Chem. Soc. 1985, 107, 1431.

(4) Prier, C. K.; Rankic, D. A.; MacMillan, D. W. C. Chem. Rev. 2013, 113, 5322.

(5) Hagfeldt, A.; Boschloo, G.; Sun, L.; Kloo, L.; Pettersson, H. Chem. Rev. 2010, 110, 6595.

(6) Monro, S.; Colón, K. L.; Yin, H.; John Roque, I.; Konda, P.; Gujar, S.; Thummel, R. P.; Lilge, L.; Cameron, C. G.; McFarland, S. A. Chem. Rev. 2018, 119, 797. 
(7) Hakey, B. M.; Darmon, J. M.; Zhang, Y.; Petersen, J. L.; Milsmann, C. Inorg. Chem. 2019, $58,1252$.

(8) Tanaka, K.; Nagata, T. Bull. Chem. Soc. Jpn. 2002, 75, 2469.

(9) Zhang, Y.; Petersen, J. L.; Milsmann, C. J. Am. Chem. Soc. 2016, 138, 13115.

(10) Komine, N.; Buell, R. W.; Chen, C.-H.; Hui, A. K.; Pink, M.; Caulton, K. G. Inorg. Chem. 2014, 53, 1361 .

(11) Eggleston, K.; Mcmillin, D. R.; Koenig, K. S.; Pallenberg, A. J.; Corporation, P.; Ne, A. Inorg. Chem. 1997, 36, 172.

(12) Paggio, A. A. Del; Mcmillin, D. R. Inorg. Chem. 1983, 22, 691.

(13) Browne, W. R.; Vos, J. G. Coord. Chem. Rev. 2001, 219-221, 761.

(14) Mara, M. W.; Fransted, K. A.; Chen, L. X. Coord. Chem. Rev. 2015, 282-283, 2.

(15) Yin, H.; Carroll, P. J.; Manor, B. C.; Anna, J. M.; Schelter, E. J.; . J. Am. Chem. Soc. 2016, $138,5984$.

(16) Bunzli, J.-C. G.; Piguet, C. Chem. Soc. Rev. 2005, 34, 1048.

(17) Connelly, N. G.; Geiger, W. E. Chem. Rev. 1996, 96, 877.

(18) Nguyen, J. D.; D’Amato, E. M.; Narayanam, J. M. R.; Stephenson, C. R. J. Nat. Chem. 2012, 4,854 . 
(19) Radlauer, M. R.; Agapie, T. Organometallics 2014, 33, 3247.

(20) Rong, Y.; Al-Harbi, A.; Parkin, G. Organometallics 2012, 31, 8208.

(21) Kuzuhara, D.; Miyake, S.; Moriyama, H.; Tamura, Y.; Aratani, N.; Yamada, H. Tetrahedron Lett. 2015, 56, 5564. 


\section{Chapter 5.}

\section{Photoluminescence of Seven-Coordinate Zirconium and Hafnium Complexes with 2,2'- Pyridylpyrrolide Ligands}

(The major part of this chapter was published in Chem. Eur. J. 2019, 25, 3042)

\subsection{Introduction.}

In chapters 1-4, the synthesis, characterization, and application of novel photoluminescent zirconium compounds: $\mathrm{Zr}\left({ }^{\mathrm{R} 1} \mathrm{PDP}^{\mathrm{R} 2}\right)_{2}\left(\mathrm{H}_{2}{ }^{\mathrm{R} 1} \mathrm{PDP}^{\mathrm{R} 2}=\right.$ 2,6-bis(5-R1-3-R2-1H-pyrrol-2-yl)pyridine; $\left.\mathrm{R} 1=\mathrm{H}, \mathrm{Me}, \mathrm{Mes}, \mathrm{Ph} ; \mathrm{R} 2=\mathrm{H}, \mathrm{Me}, \mathrm{Ph}, \mathrm{C}_{6} \mathrm{~F}_{5}\right)$ were extensively discussed. These complexes exhibit strong absorption bands in the visible region of the spectrum, which was identified as a mixed ${ }^{1} \mathrm{LMCT} /{ }^{1}$ ILCT transition. The resulting luminescent triplet state exhibits a remarkably long lifetime of hundreds of microseconds and undergoes photoinduced single-electron transfer to generate the strong reductant $\left[\mathrm{Zr}\left({ }^{\mathrm{R} 1} \mathrm{PDP}^{\mathrm{R} 2}\right)_{2}\right]^{1-1} \cdot{ }^{1}$ The properties of $\mathrm{Zr}\left({ }^{\mathrm{R} 1} \mathrm{PDP}{ }^{\mathrm{R} 2}\right)_{2}$ as a photosensitizer were established in multiple representative photoredox-catalytic reactions.

Inspired by these results, we sought to further investigate the luminescent properties of group 4 coordination compounds containing other electron-rich $\mathrm{N}$-heterocycle ligands. Due to their close relationship to the pyridine dipyrrolide (PDP) ligand system, substituted 2,2'pyridylpyrrolide ligands ( $\mathrm{PMP}=$ pyridine monopyrrolide) were identified as promising candidates to support photoluminescence via LMCT. While various favorable aspects of the coordination 
chemistry of PMP compounds including rich redox chemistry, ${ }^{2-4}$ stabilization of high oxidation states, ${ }^{5,6}$ and photoluminescent properties $^{7-9}$ have been reported for late transition metals, few reports are available for early metals. ${ }^{10}$

Here we describe the synthesis and characterization of seven-coordinate zirconium and hafnium species carrying three ${ }^{\mathrm{Me}} \mathrm{PMP} \mathrm{Pe}^{\mathrm{Me}}$ ligands $\left({ }^{\mathrm{Me}} \mathrm{PMP}^{\mathrm{Me}}=3,5\right.$-dimethyl-2-(2-pyridyl)pyrrolide). These complexes are rare examples of group 4 compounds exhibiting photoluminescence in solution at room temperature. The optical properties were established by steady-state and timeresolved emission spectroscopy and further analyzed via TD-DFT calculations. Variable temperature ${ }^{1} \mathrm{H}$ NMR spectroscopic studies revealed highly fluxional structures for the complexes in solution which are consistent with the observed lifetime and quantum yield data.

\subsection{Synthesis and Crystallographic Characterization.}

The ligand precursor 3,5-dimethyl-2-(2-pyridyl)pyrrole $\left(\mathrm{H}^{\mathrm{Me}} \mathrm{PMP} \mathrm{Me}^{\mathrm{e}}\right)$ was synthesized according to a literature reported procedure via condensation of acetylacetone and 2(aminomethyl)pyridine. ${ }^{11}$ Addition of one equivalent of $n$-BuLi to $\mathrm{H}^{\mathrm{Me}} \mathrm{PMP}{ }^{\mathrm{Me}}$ resulted in clean deprotonation yielding $\mathrm{Li}^{\mathrm{Me}} \mathrm{PMP}^{\mathrm{Me}}$. Salt metathesis reactions with 0.33 equivalent $\mathrm{MCl}_{4}(\mathrm{M}=\mathrm{Zr}$, Hf) led to the formation of the corresponding tris-ligated complexes $\left({ }^{\mathrm{Me}} \mathrm{PMP}{ }^{\mathrm{Me}}\right)_{3} \mathrm{ZrCl}$ (orange powder) and ( $\left.{ }^{\mathrm{Me}} \mathrm{PMP}{ }^{\mathrm{Me}}\right)_{3} \mathrm{HfCl}$ (yellow powder) in $53 \%$ and $46 \%$ yield, respectively (Scheme 1). 
Scheme 1. Synthesis of $\left({ }^{\mathrm{Me}} \mathrm{PMP}{ }^{\mathrm{Me}}\right)_{3} \mathrm{MCl}(\mathrm{M}=\mathrm{Zr}$, Hf).
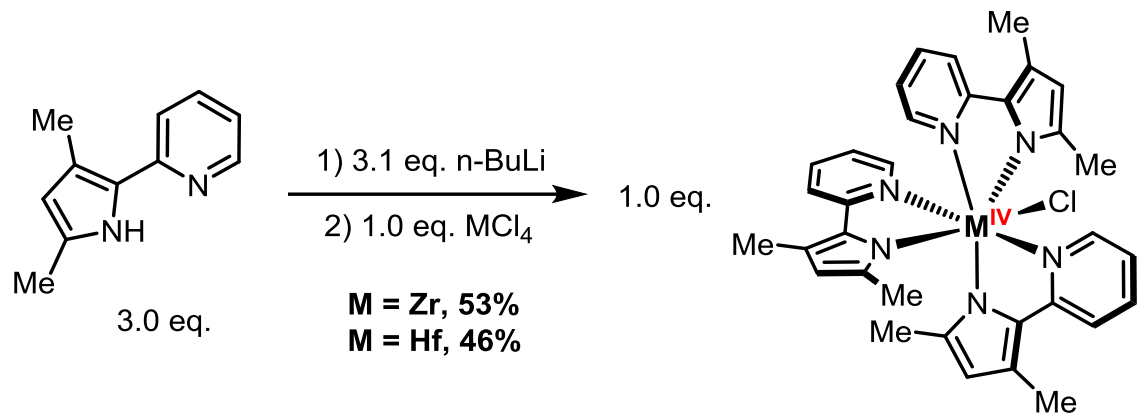

After recrystallization from $\mathrm{THF} /$ pentane, the solid-state structures of both compounds were determined by single-crystal X-ray diffraction (Figure 1). The two complexes are isostructural and crystallize in the monoclinic space group $\mathrm{P} 2{ }_{1} / \mathrm{c}$ exhibiting only minor differences in the unit cell parameters. Selected bond lengths and angles are listed in Table 1. The basic coordination geometry around the zirconium or hafnium center can be viewed as a highly distorted chloride-capped octahedron. Even though several structural isomers are conceivable (vide infra), the pyridine mono-pyrrole units adopt a single arrangement in the solid state. The three $\kappa^{2}-$ chelating ligands are disposed around the metal center in a $C_{1}$-symmetric propeller-like fashion reminiscent of a mer-type geometry in octahedral complexes with asymmetric bidentate ligands. The chloro ligand caps one of the two trigonal faces of the octahedron that are flanked by one heterocycle form each chelating ligand and are intersected by the pseudo- $C_{3}$ axis of the compound. More specifically, two pyridine units and one pyrrole are in cis position with respect to the chlorine atom, while the remaining pyridine ring and two pyrroles are oriented on the opposite side of the central metal ion. The small bite angle of the PMP ligand facilitates the formation of 7-coordinate 
species. The bite angles $\left(\mathrm{N}_{\text {pyridine- }} \mathrm{M}-\mathrm{N}_{\text {pyrrole }}\right)$ for the ligands that have the pyrrole unit cis to chloride are $69.61^{\circ}$ for $\mathrm{Zr}$ and $70.15^{\circ}$ for $\mathrm{Hf}$, which are slightly smaller than for the ligands that have the pyrrole trans to the chloride ligand (av. $71.34^{\circ}$ for $\mathrm{Zr}$ and av. $71.74^{\circ}$ for $\mathrm{Hf}$ ). Consistent with the effective ionic radii for the two metal centers $\left(\mathrm{Zr}^{\mathrm{IV}}=86 \mathrm{pm}\right.$ and $\left.\mathrm{Hf}^{\mathrm{IV}}=85 \mathrm{pm}\right)$, the average $\mathrm{M}-\mathrm{N}$ bond distances are slightly shorter for the Hf complex. The $\mathrm{Zr}-\mathrm{Cl}$ bond length of 2.462(1) $\AA$ in $\left({ }^{\mathrm{Me}} \mathrm{PMP}{ }^{\mathrm{Me}}\right)_{3} \mathrm{ZrCl}$ is comparable to previously reported values for $\mathrm{L}_{3} \mathrm{ZrCl}$ complexes including $(\mathrm{Siam})_{3} \mathrm{ZrCl} \quad(\mathrm{Siam}=N, N$-bis(trimethylsilyl)benzamidinato $) \quad(2.464 \AA), \quad\left[\kappa^{2}-\right.$ $\left.\mathrm{C}_{4} \mathrm{H}_{3} \mathrm{~N}\left(\mathrm{CH}_{2} \mathrm{NMe}_{2}\right)\right]_{3} \mathrm{ZrCl}(2.459 \AA)$, and tris(aminopyridinato) zirconium chloride $(2.480 \AA) .{ }^{12-15}$ Similarly, the $\mathrm{Hf}-\mathrm{Cl}$ distance of $2.444(1) \AA$ of $\left({ }^{\mathrm{Me}} \mathrm{PMP}{ }^{\mathrm{Me}}\right)_{3} \mathrm{HfCl}$ is consistent with $\mathrm{Hf}-\mathrm{Cl}$ bond lengths in other seven-coordinate $\mathrm{L}_{3} \mathrm{HfCl}$ compounds $(2.39$ - $2.48 \AA) .{ }^{16-19}$
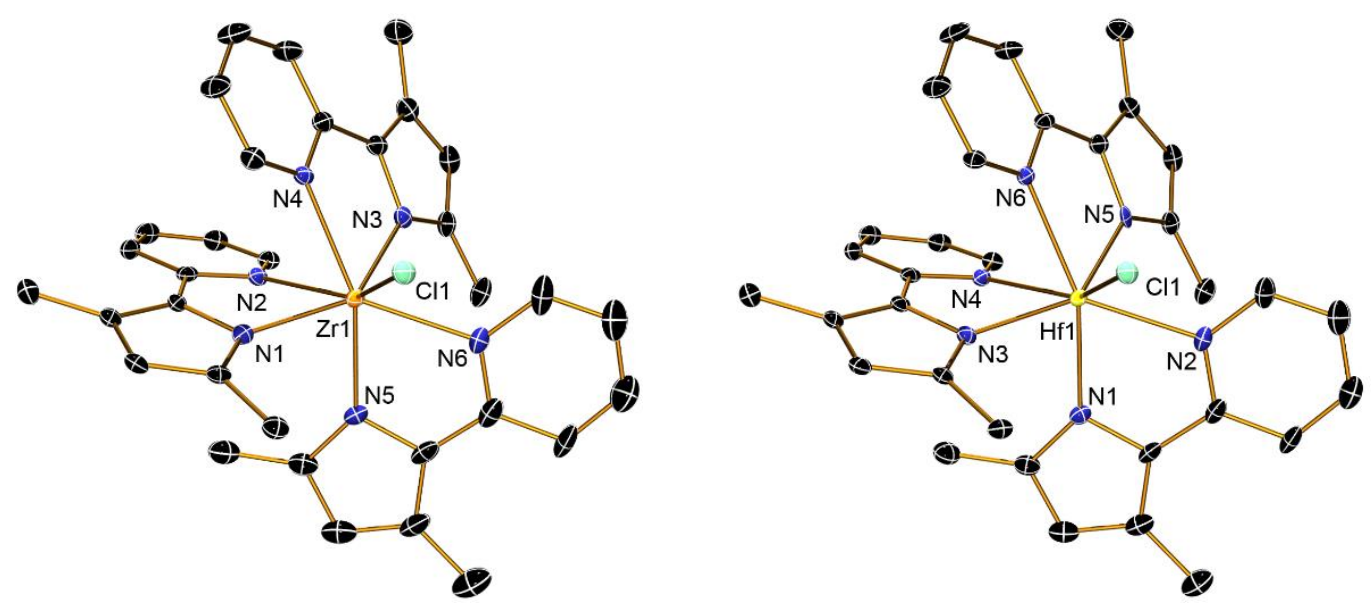

Figure 1. Representations of the molecular structures of $\left({ }^{\mathrm{Me}} \mathrm{PMP}{ }^{\mathrm{Me}}\right)_{3} \mathrm{ZrCl}$ (left) and $\left({ }^{\mathrm{Me}} \mathrm{PMP}{ }^{\mathrm{Me}}\right)_{3} \mathrm{HfCl}$ (right) with $30 \%$ probability ellipsoids. Hydrogen atoms were omitted for clarity. Reprinted with permission from \{Zhang, Y.; Akhmedov. N. G.; Petersen, J. L.; and Milsmann, C. Chem. Eur. J. 2019, 25, 3042\}. Copyright $\{2019\}$ Wiley-VCH Verlag GmbH \& Co. 
Table 1. Selected bond lengths $(\AA)$ and angles $\left({ }^{\circ}\right)$ for $\left({ }^{\mathrm{Me}} \mathrm{PMP}{ }^{\mathrm{Me}}\right)_{3} \mathrm{MCl}(\mathrm{M}=\mathrm{Zr}, \mathrm{Hf})$.

\begin{tabular}{c|c|c|c} 
& Bond Length $(\stackrel{\AA}{\mathbf{A}})$ & & Bond Length $(\stackrel{\AA}{)})$ \\
\hline Zr1-N1 & $2.204(4)$ & Hf1-N1 & $2.201(4)$ \\
Zr1-N2 & $2.368(4)$ & Hf1-N2 & $2.353(4)$ \\
Zr1-N3 & $2.221(4)$ & Hf1-N3 & $2.201(4)$ \\
Zr1-N4 & $2.363(4)$ & Hf1-N4 & $2.346(4)$ \\
Zr1-N5 & $2.231(4)$ & Hf1-N5 & $2.222(4)$ \\
Zr1-N6 & $2.304(4)$ & Hf1-N6 & $2.292(4)$ \\
Zr1-Cl1 & $2.462(1)$ & Hf1-Cl1 & $2.444(1)$ \\
\hline & Bite Angle $\left(^{\circ}\right)$ & & Bite Angle $\left(^{\circ}\right)$ \\
\hline N2-Zr1-N1 & $69.61(14)$ & N2-Hf1-N1 & $70.16(14)$ \\
N4-Zr1-N3 & $71.32(14)$ & N4-Hf1-N3 & $71.61(16)$ \\
N6-Zr1-N5 & $71.36(16)$ & N6-Hf1-N5 & $71.90(14)$ \\
\hline
\end{tabular}

\subsection{Solution Dynamics.}

The structures of the two $\left({ }^{\mathrm{Me}} \mathrm{PMP}{ }^{\mathrm{Me}}\right)_{3} \mathrm{MCl}(\mathrm{M}=\mathrm{Zr}$, Hf) complexes in solution were investigated by variable temperature (VT) NMR spectroscopy. The ${ }^{1} \mathrm{H}$ NMR spectra acquired at $+19{ }^{\circ} \mathrm{C}$ and $-90{ }^{\circ} \mathrm{C}$ in toluene- $d_{8}$ for the $\mathrm{Zr}$ complex are shown in Figure 2 whereas the corresponding spectra for the hafnium analog are presented in the Experimental Section and Appendix B. For both compounds, the ${ }^{1} \mathrm{H}$ NMR spectra recorded in benzene- $d_{6}$ or toluene- $d_{8}$ solution at room temperature exhibit seven resonances indicating that all three chelate ligands are equivalent on the NMR time scale. This is in stark contrast to the solid-state structures that show $C_{1}$-symmetric coordination environments in which the three PMP ligands should be magnetically and chemically inequivalent resulting in twenty-one peaks in the ${ }^{1} \mathrm{H}$ NMR spectrum. Significant line broadening was observed for two signals, one each in the aromatic and aliphatic region of the 
spectra, which were subsequently assigned to the ortho-pyridine protons (H2) and the methyl protons adjacent to the pyrrolide nitrogen $\left(\mathrm{CH}_{3}-10\right)$, respectively. At elevated temperatures the linewidth of these resonances decreased markedly suggesting a dynamic process as the reason for signal broadening and equilibration of the ligands. Unexpectedly, the ${ }^{1} \mathrm{H}$ NMR spectra recorded in toluene- $d_{8}$ at $-90{ }^{\circ} \mathrm{C}$ do not exhibit the expected 21 resonances for a single compound with $C_{1}$ symmetry but display two sets of signals consistent with two distinct $C_{1}$ symmetric isomers. Each peak was unambiguously assigned to one of the two species based on 2D NMR correlation experiments (gCOSY, NOESY, gHSQC, $\mathrm{gHMBC}$ ) at $-90^{\circ} \mathrm{C}$. The ratio between the major and minor isomers was determined to be approximately 5:3 in the case of the $\mathrm{Zr}$ complex and 10:3 for the Hf analog (Figure ES1).

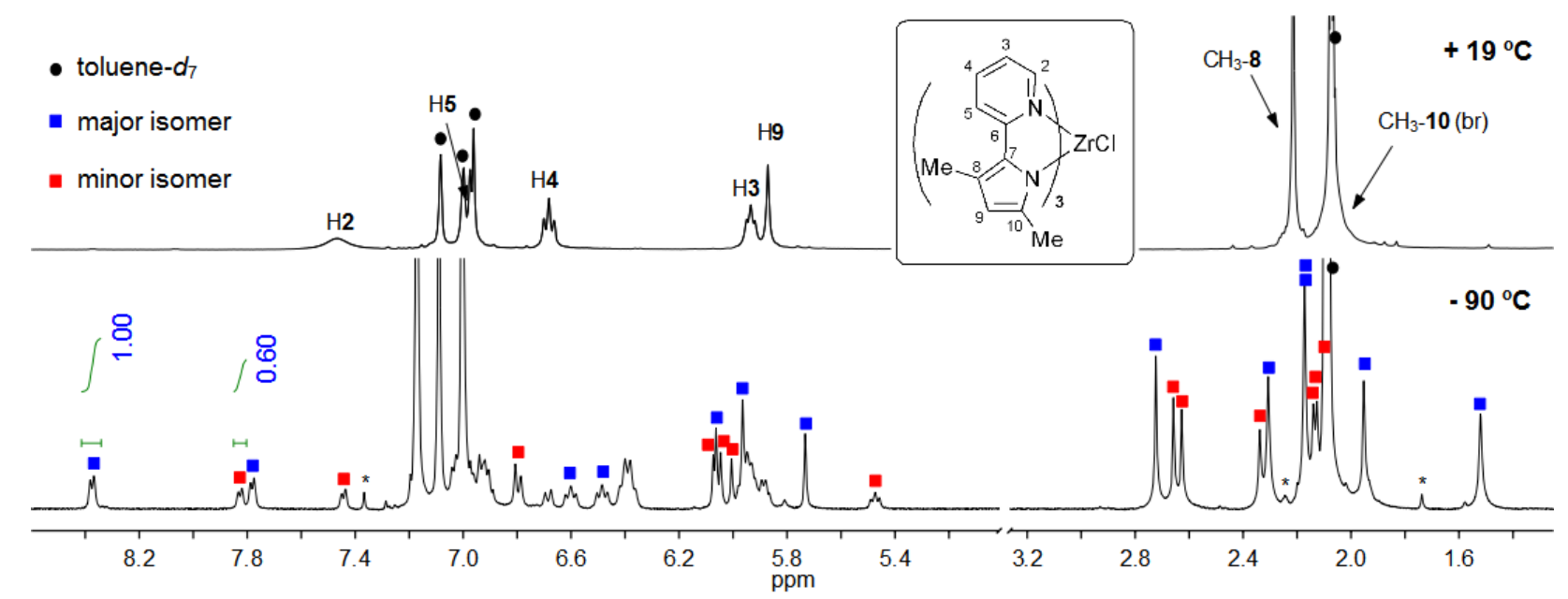

Figure 2. $400 \mathrm{MHz}{ }^{1} \mathrm{H}$ NMR spectra of $\left({ }^{\mathrm{Me}} \mathrm{PMP}{ }^{\mathrm{Me}}\right)_{3} \mathrm{ZrCl}$ in toluene- $d_{8}$ at $+19{ }^{\circ} \mathrm{C}$ (top) and $-90{ }^{\circ} \mathrm{C}$ (bottom). At $-90^{\circ} \mathrm{C}$, two sets of signals correspond to the two interconverting major (blue square) and minor (red square) isomers (partial assignment). Asterisks denote signals from small amounts of an unidentified impurity. Reprinted with permission from \{Zhang, Y.; Akhmedov. N. G.; Petersen, J. L.; and Milsmann, C. Chem. Eur. J. 2019, 25, 3042\}. Copyright $\{2019\}$ Wiley-VCH Verlag GmbH \& Co. 
To gain further insight into the kinetics of the dynamic process that interconverts the two isomers and renders the PMP ligands equivalent at room temperature, line shape analyses were performed (Figure 3, Figure 4 and Appendix A). Kinetic parameters were obtained at temperatures between $213 \mathrm{~K}$ and $329 \mathrm{~K}$ using the gNMR program. Eyring analyses afforded activation parameters of $\Delta H^{\dagger}=10.7 \pm 0.2 \mathrm{kcal} / \mathrm{mol}, \Delta S^{\ddagger}=-6.5 \pm 1.0 \mathrm{cal} \mathrm{K}^{-1} \mathrm{~mol}^{-1}$ and $\Delta G^{\ddagger}(298 \mathrm{~K})=12.6$ $\mathrm{kcal} / \mathrm{mol}$ for $\left({ }^{\mathrm{Me}} \mathrm{PMP}{ }^{\mathrm{Me}}\right)_{3} \mathrm{ZrCl}$ and $\Delta H^{*}=8.6 \pm 0.2 \mathrm{kcal} / \mathrm{mol}, \Delta S^{\ddagger}=-16.5 \pm 1.0 \mathrm{cal} \mathrm{K}^{-1} \mathrm{~mol}^{-1}$ and $\Delta G^{\ddagger}(298 \mathrm{~K})=13.5 \mathrm{kcal} / \mathrm{mol}$ for $\left({ }^{\mathrm{Me}} \mathrm{PMP}{ }^{\mathrm{Me}}\right)_{3} \mathrm{HfCl}$. The small negative $\Delta S^{\ddagger}$ values in both cases suggest more ordered transition states and disfavor an isomerization mechanism via complete M$\mathrm{N}$ or $\mathrm{M}-\mathrm{Cl}$ bond cleavage and a six-coordinate intermediate. Fluxional behavior has also been observed by VT-NMR in seven- and eight-coordinate zirconium and titanium complexes with related 2-(diphenylphosphino)pyrrolide ligands. ${ }^{20}$ For these complexes, however, rapid phosphine dissociation was suggested as the likely pathway for isomerization.

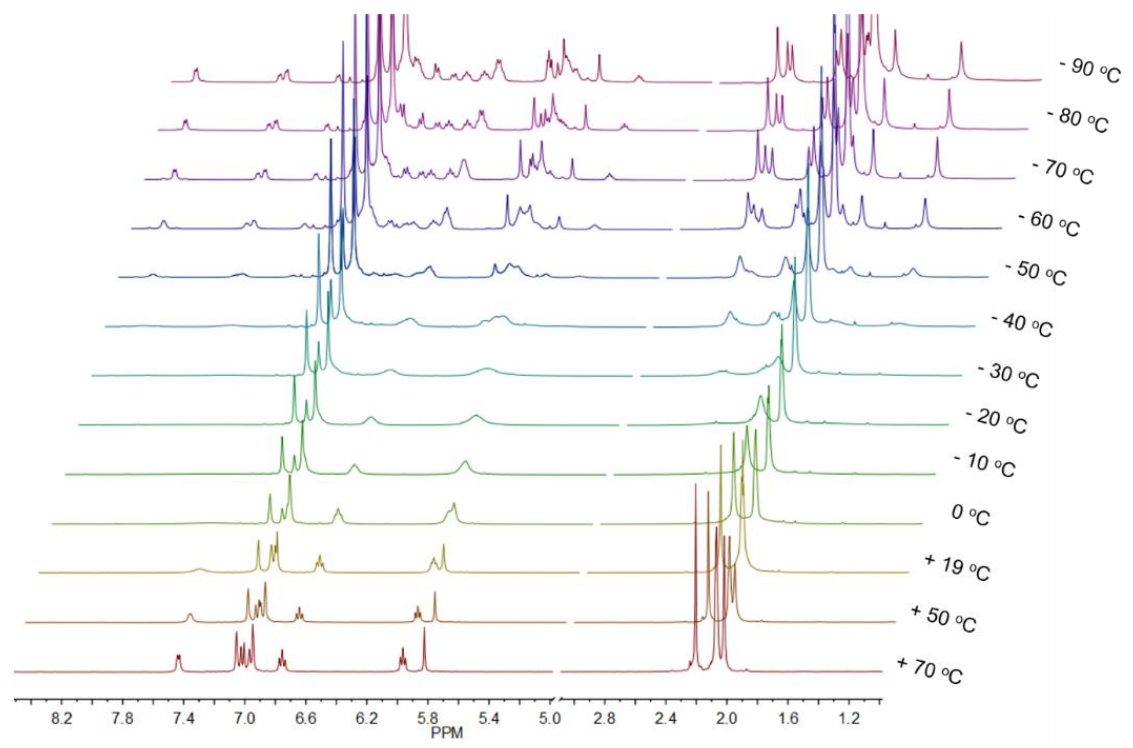

Figure 3. $400 \mathrm{MHz}{ }^{1} \mathrm{H}$ NMR spectra (aromatic and alkyl region) of $\left({ }^{\mathrm{Me}} \mathrm{PMP}{ }^{\mathrm{Me}}\right)_{3} \mathrm{ZrCl}$ in toluene$d_{8}$ at temperatures ranging from +70 to $-90^{\circ} \mathrm{C}$. 


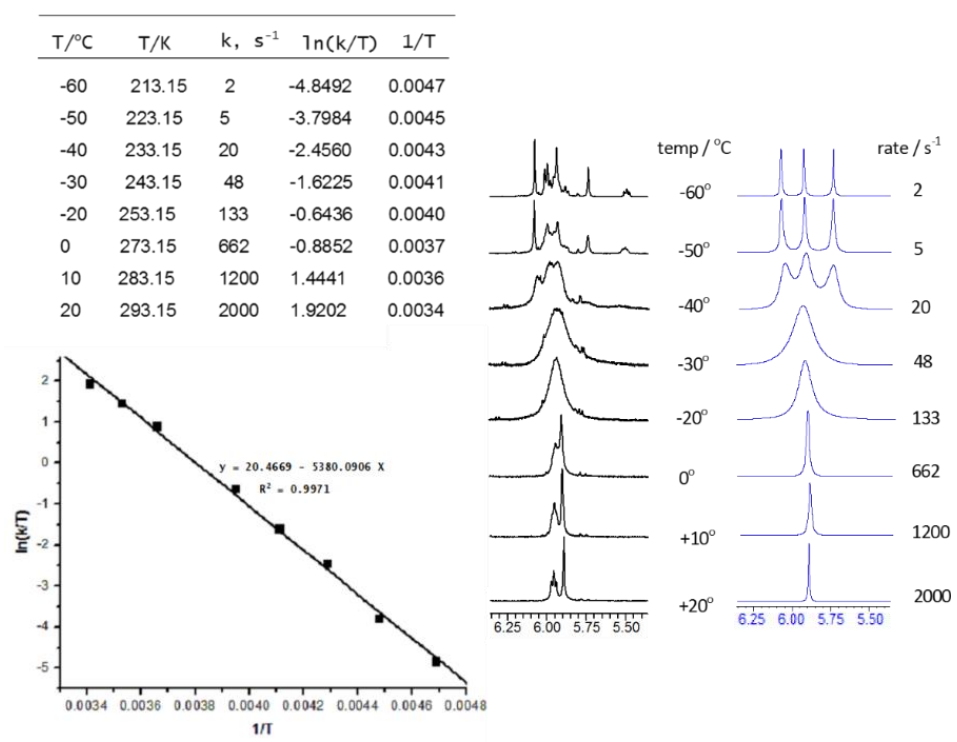

Figure 4. Eyring plot of $\ln (\mathrm{k} / \mathrm{T})$ vs. $1 / \mathrm{T}$ for rate constants obtained by line shape simulation of pyrrole proton signal for $\left({ }^{\mathrm{Me}} \mathrm{PMP}{ }^{\mathrm{Me}}\right)_{3} \mathrm{ZrCl}$ at temperatures between $213 \mathrm{~K}$ and $293 \mathrm{~K}$.

\subsection{Computational Studies of Isomerism.}

To further explore the energy profile for different isomers and elucidate the identity of the two isomers observable at low temperature, density functional theory (DFT) calculations were performed for $\left({ }^{\mathrm{Me}} \mathrm{PMP}{ }^{\mathrm{Me}}\right)_{3} \mathrm{ZrCl}$. All computed geometries were optimized without imposing any geometry constraints and verified as local minima of the potential energy surface via numerical frequency calculations. Due to the asymmetry of the ${ }^{\mathrm{Me}} \mathrm{PMP} \mathrm{P}^{\mathrm{Me}}$ ligands, a large number of potential structures had to be taken into account. To derive the number of possible isomers, it is again instructional to visualize the basic geometry of the compound as a distorted capped octahedron. Initially disregarding the chloro ligand, four stereoisomers can be constructed for an octahedral arrangement of the three chelating ligands. The relative placement of the pyrrole ligands results in 
fac- and mer-isomers with $C_{3}$ and $C_{1}$ symmetry, respectively, as shown in Figure 5. The propellerlike arrangement of the chelating ligands generates two possible enantiomers for each configuration. The chloro ligand can then be placed on each of the eight trigonal faces of the octahedral structures to generate a seven-coordinate environment resulting in eight $C_{1}$-symmetric structures derived from each of the mer-enantiomers and $2 C_{3}$ symmetric and $2 C_{1}$ symmetric structures derived from each of the fac-enantiomers for a total of 24 stereoisomers (12 pairs of enantiomers).

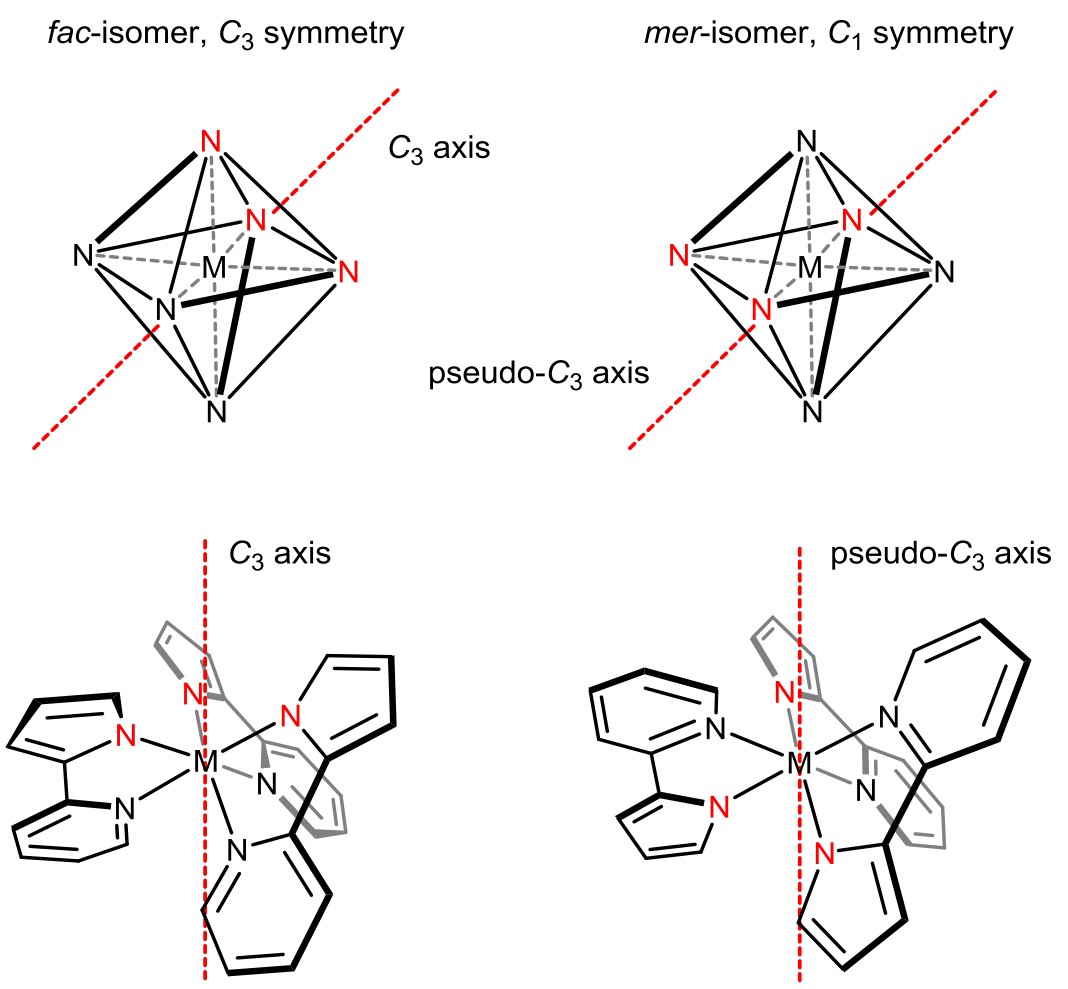

Figure 5. Stereoisomers for octahedral coordination environments with three asymmetric bidentate ligands. The possible seven-coordinate structures can be derived by placing the capping chloro ligand on one of the eight trigonal faces of the octahedral structures. Reprinted with permission from \{Zhang, Y.; Akhmedov. N. G.; Petersen, J. L.; and Milsmann, C. Chem. Eur. J. 2019, 25, 3042\}. Copyright $\{2019\}$ Wiley-VCH Verlag GmbH \& Co. 
Consistent with the structure observed by X-ray crystallography, the lowest energy conformation was found to be the $C_{1}$-symmetric structure 1a (Figure 6) derived from the octahedral mer-isomer, in which the chloro ligand is placed along the pseudo- $C_{3}$ axis of the molecule adjacent to one pyrrole and two pyridine rings. However, a second structure $\mathbf{1 b}$ of almost identical energy $(\Delta \mathrm{G}(298 \mathrm{~K})=0.1 \mathrm{kcal} / \mathrm{mol})$ was found and identified as the isomer in which the chloro ligand is placed on the second trigonal face bisected by the pseudo- $C_{3}$ axis and adjacent to one pyridine and two pyrrole heterocycles. Interestingly, performing the calculations assuming a temperature of $183 \mathrm{~K}\left(-90^{\circ} \mathrm{C}\right)$ resulted in a reversal of the energy ordering of $\mathbf{1 a}$ and $\mathbf{1 b}$ $(\Delta \mathrm{G}(183 \mathrm{~K})=0.3 \mathrm{kcal} / \mathrm{mol})$. While these energy differences are too small to unambiguously assign 1a or $\mathbf{1 b}$ as the major isomer observed by low-temperature ${ }^{1} \mathrm{H}$ NMR spectroscopy, the predicted isomeric ratio of approximately $5: 4$ for both temperatures obtained via $\Delta \mathrm{G}=-\mathrm{RT} \cdot \ln \mathrm{K}$ is consistent with the experimental data. Two additional, $C_{3}$ symmetric isomers, $\mathbf{1 c}$ and $\mathbf{1 d}$, derived by placing the chloro ligand along the $C_{3}$ axis of the fac-isomer were found to be $3.1 \mathrm{kcal} / \mathrm{mol}$ (adjacent to three pyrrole rings) and $5.7 \mathrm{kcal} / \mathrm{mol}$ (adjacent to three pyridine rings) higher in energy, respectively, at $298 \mathrm{~K}$. According to these values and consistent with the NMR data these isomers should not be experimentally observable. All remaining stereoisomers containing a chloro ligand capping any of the remaining trigonal faces not bisected by the $C_{3}$ or pseudo- $C_{3}$ axes were found to be significantly higher in energy $(\Delta \mathrm{G}>10 \mathrm{kcal} / \mathrm{mol})$ or converged to one of the isomers 1a-d during geometry optimization. 


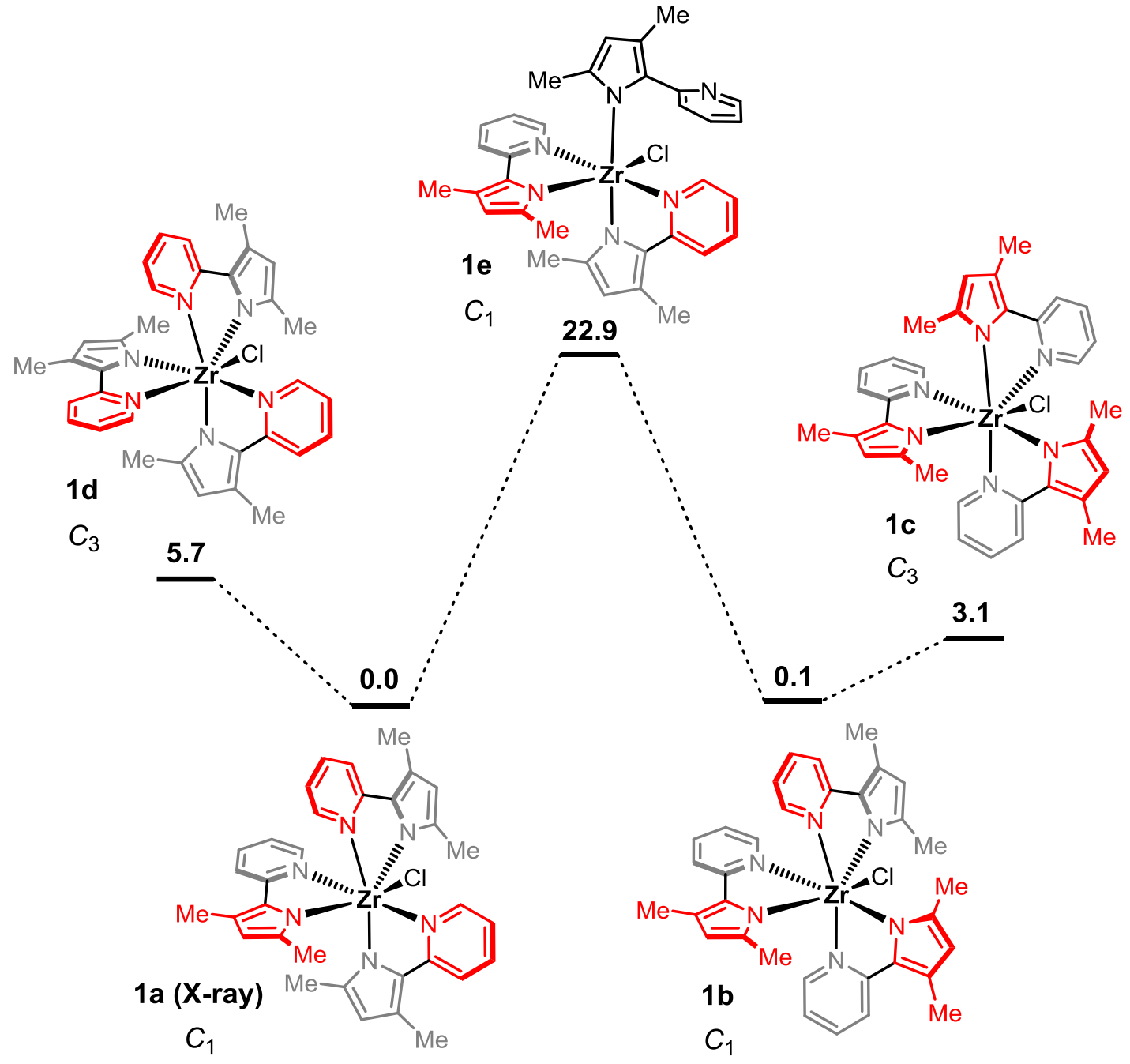

Figure 6. Comparison of the structures and relative energies (in $\mathrm{kcal} / \mathrm{mol}$ ) of the four lowest energy isomers for seven-coordinate $\left({ }^{\mathrm{Me}} \mathrm{PMP}{ }^{\mathrm{Me}}\right) \mathrm{ZrCl}$ (1a-1d). Heterocycles adjacent to the chloro ligand are shown in red. Structure 1e obtained after dissociation of a pyridine unit of one of the ${ }^{\mathrm{Me}} \mathrm{PMP}^{\mathrm{Me}}$ ligands was identified as the lowest energy isomer with six-coordinate geometry around the central metal ion. Reprinted with permission from \{Zhang, Y.; Akhmedov. N. G.; Petersen, J. L.; and Milsmann, C. Chem. Eur. J. 2019, 25, 3042\}. Copyright $\{2019\}$ Wiley-VCH Verlag GmbH \& Co.

Several six-coordinate geometries obtained via dissociation of the pyridine subunit of one of the PMP ligands were computed to probe the potential for isomerization via a dissociative mechanism. The optimized structures were found to be significantly higher in energy $(\Delta G>20$ 
$\mathrm{kcal} / \mathrm{mol}$ ) than the seven-coordinate complexes. The high energy requirement for $\mathrm{Zr}-\mathrm{N}_{\mathrm{py}}$ bond cleavage predicted by these calculations further discredits a dissociative mechanism considering that the experimentally determined barrier for isomerization is only $12.6 \mathrm{kcal} / \mathrm{mol}$.

\subsection{Photophysical Properties.}

Consistent with the solid state appearance of the complexes, solutions of $\left({ }^{\mathrm{Me}} \mathrm{PMP}{ }^{\mathrm{Me}}\right)_{3} \mathrm{ZrCl}$ and $\left({ }^{\mathrm{Me}} \mathrm{PMP}{ }^{\mathrm{Me}}\right)_{3} \mathrm{HfCl}$ show a bright orange and intense yellow color, respectively. Electronic absorption spectra recorded under inert atmosphere in rigorously dry tetrahydrofuran (THF) are shown in Figure 7. Both compounds exhibit very similar absorption profiles with three bands between $250-1000 \mathrm{~nm}$. Two very intense absorption bands $\left(\varepsilon>35,000 \mathrm{M}^{-1} \mathrm{~cm}^{-1}\right)$ are observed for each complex in the UV region of the spectrum. For $\left({ }^{\mathrm{Me}} \mathrm{PMP}{ }^{\mathrm{Me}}\right)_{3} \mathrm{HfCl}$, the two peak maxima at $302 \mathrm{~nm}$ and $329 \mathrm{~nm}$ are clearly resolved, while overlapping bands are observed for $\left({ }^{\mathrm{Me}} \mathrm{PMP}{ }^{\mathrm{Me}}\right)_{3} \mathrm{ZrCl}$ with a maximum at $304 \mathrm{~nm}$ and a shoulder at $331 \mathrm{~nm}$. The positions of these features are almost identical with the absorption maxima of $\mathrm{H}^{\mathrm{Me}} \mathrm{PMP}{ }^{\mathrm{Me}}$ in THF (300 nm and 325 $\mathrm{nm}$ ) and were tentatively assigned as $\pi-\pi^{*}$ transitions within the PMP ligands. More importantly, a single absorption band with a maximum at $445 \mathrm{~nm}\left(\varepsilon=14,500 \mathrm{M}^{-1} \mathrm{~cm}^{-1}\right)$ is observed in the visible part of the spectrum for $\left({ }^{\mathrm{Me}} \mathrm{PMP}{ }^{\mathrm{Me}}\right)_{3} \mathrm{ZrCl}$. A similar lowest-energy band with a maximum at $430 \mathrm{~nm}\left(\varepsilon=21,700 \mathrm{M}^{-1} \mathrm{~cm}^{-1}\right)$ is observed for $\left({ }^{\mathrm{Me}} \mathrm{PMP}{ }^{\mathrm{Me}}\right)_{3} \mathrm{HfCl}$. The large extinction coefficients in combination with the absence of any absorption bands in the visible part of the spectrum for the 
ligand precursor $\mathrm{H}^{\mathrm{Me}} \mathrm{PMP} \mathrm{Pe}^{\mathrm{Me}}$ are consistent with significant LMCT character in these spectral features. This is further supported by the blue-shift of the absorption band for $\mathrm{Hf}$ compared to $\mathrm{Zr}$, which reflects an increase in d orbital energy from $\mathrm{Zr}$ to $\mathrm{Hf}$.

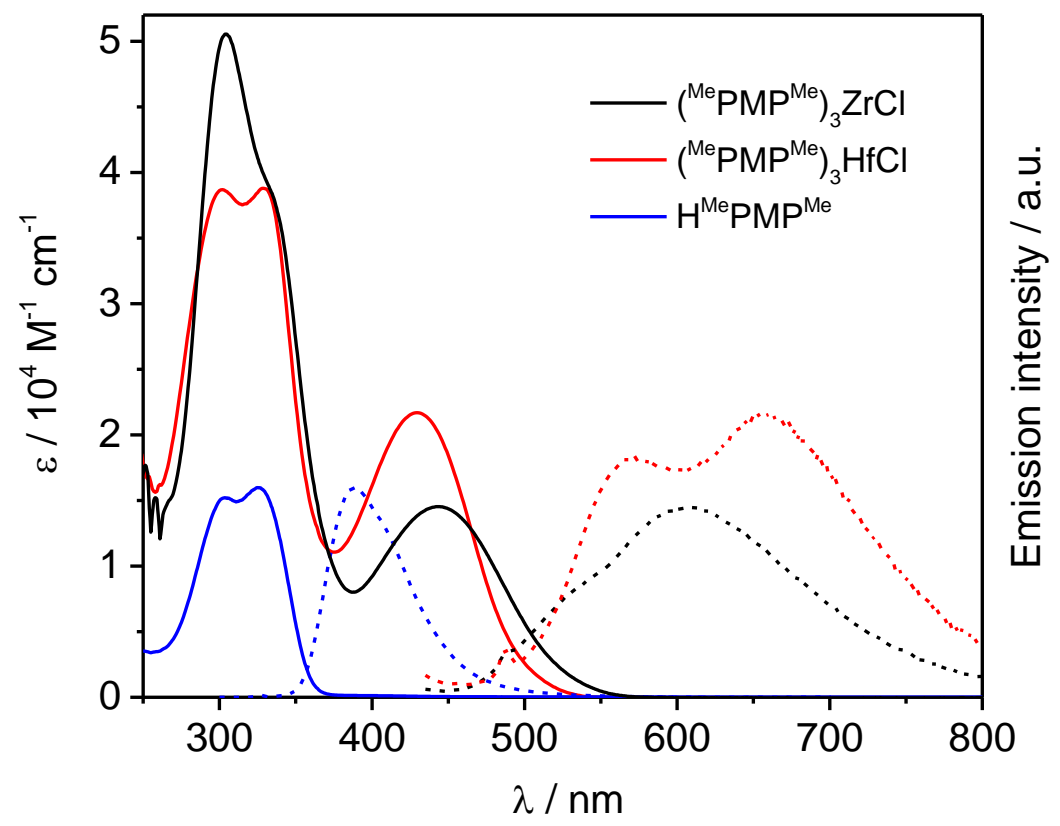

Figure 7. Absorption (solid lines) and emission spectra (dotted lines) of $\left({ }^{\mathrm{Me}} \mathrm{PMP}{ }^{\mathrm{Me}}\right)_{3} \mathrm{MCl}(\mathrm{M}=$ $\mathrm{Zr}, \mathrm{Hf})$ and $\mathrm{H}^{\mathrm{Me}} \mathrm{PMP} \mathrm{Me}^{\mathrm{Me}}$ in THF solution at room temperature.

Photoexcitation into the band observed in the visible region at room temperature in THF solution results in photoluminescence with two overlapping emission bands with peak maxima at $569 \mathrm{~nm}$ and $656 \mathrm{~nm}$ for $\left({ }^{\mathrm{Me} P M P}{ }^{\mathrm{Me}}\right)_{3} \mathrm{HfCl}$ (Figure 7). For $\left({ }^{\mathrm{Me}} \mathrm{PMP}{ }^{\mathrm{Me}}\right)_{3} \mathrm{ZrCl}$, the two features are broader and more strongly overlapping resulting in a single maximum at $608 \mathrm{~nm}$ and a shoulder at $542 \mathrm{~nm}$. Photoluminescent quantum yields of $\Phi_{\mathrm{em}}=0.010$ and 0.007 for the zirconium and hafnium 
complex, respectively, were determined under optically dilute conditions via comparative method using $\left[\mathrm{Ru}(\mathrm{bpy})_{3}\right] \mathrm{Cl}_{2}$ in air-saturated acetonitrile solution $\left(\Phi_{\mathrm{em}}=0.018\right)$ as the standard. The low emission quantum yields indicate predominant deactivation of the excited state via non-radiative pathways. This is consistent with the large structural flexibility of the complexes in solution demonstrated by the variable temperature NMR studies, which allows for facile thermal deactivation via easily accessible vibrational modes.

Time-resolved emission data for both complexes are shown in Figure 8. For $\left({ }^{\mathrm{Me}} \mathrm{PMP}{ }^{\mathrm{Me}}\right)_{3} \mathrm{HfCl}$, the data were readily fit using a single exponential decay with a time constant of $\tau_{\mathrm{p}}=49 \mu \mathrm{s}$. The long lifetime of the emissive state indicates phosphorescent emission from a long-lived triplet excited state. However, the immediate drop in emission intensity after the excitation source was switched off indicates a second emissive process with significantly shorter lifetime. Attempts to determine the lifetime using an excitation light source with a pulse width of $1.2 \mathrm{~ns}$ were unsuccessful suggesting that the emission is likely due to fluorescence with a lifetime of $\tau_{\mathrm{f}}<1 \mathrm{~ns}$. The relative intensity of the fluorescent versus phosphorescent emission is wavelength dependent, which was shown by lifetime measurements at different detection wavelength ( $554 \mathrm{~nm}$ and $650 \mathrm{~nm}$, Figure 8D). Based on these results the two overlapping emission bands observed in the steady-state emission spectrum correspond to two separate emission processes from a singlet excited state $\left(\lambda_{\max }=569 \mathrm{~nm}\right)$ and a triplet state $\left(\lambda_{\max }=656 \mathrm{~nm}\right)$. As expected, fluorescence occurs at higher energy than phosphorescence. Dual emission in luminescent compounds is relatively rare 
because it requires similar time constants for intersystem crossing (ISC) and fluorescent emission from the singlet excited state. For most transition metal photosensitizers, rapid ISC outcompetes fluorescence and exclusively favors phosphorescence. In contrast, ISC in organic chromophores is often too slow to allow for significant triplet emission. Nevertheless, several examples of dual emission have been reported for systems with mixed LLCT/MLCT or metal-perturbed $\pi \rightarrow \pi^{*}$ excited states. ${ }^{21-25}$ The dual emission observed for $\left({ }^{\mathrm{Me}} \mathrm{PMP}{ }^{\mathrm{Me}}\right)_{3} \mathrm{HfCl}$ is likely due to the mixed LLCT/LMCT character of the optical transitions determined by TD-DFT (vide infra).

Accurate modelling of the luminescence decay observed for $\left({ }^{\mathrm{Me}} \mathrm{PMP}{ }^{\mathrm{Me}}\right)_{3} \mathrm{ZrCl}$ required a biexponential fit, yielding two time constants $\tau_{\mathrm{p}}=50 \mu \mathrm{s}$ and $\tau_{\mathrm{p}}=21 \mu \mathrm{s}$. At this point, the reason for the biexponential behavior is unclear, but could be related to the presence of two isomers with distinct radiative decay rates in the excited state. While this hypothesis is supported by the fast equilibrium between two isomers established via variable temperature NMR studies for the ground state, it is put in question by the single exponential decay for the $\mathrm{Hf}$ analog that exhibits a nearly identical ground state equilibrium. Similar to its hafnium congener, $\left({ }^{\mathrm{Me}} \mathrm{PMP}{ }^{\mathrm{Me}}\right)_{3} \mathrm{ZrCl}$ exhibits a second, fast emission process likely due to fluorescence, for which an emission lifetime of $\tau_{\mathrm{f}}=5$ ns was determined. The intensity of fluorescence versus phosphorescence was again wavelength dependent as shown by lifetime measurements detected at 565 and $650 \mathrm{~nm}$ (Figure 8C). A summary of the emission data for $\left({ }^{\mathrm{Me}} \mathrm{PMP}{ }^{\mathrm{Me}}\right)_{3} \mathrm{ZrCl}$ and $\left({ }^{\mathrm{Me}} \mathrm{PMP}{ }^{\mathrm{Me}}\right)_{3} \mathrm{HfCl}$ is provided in Table 2. 

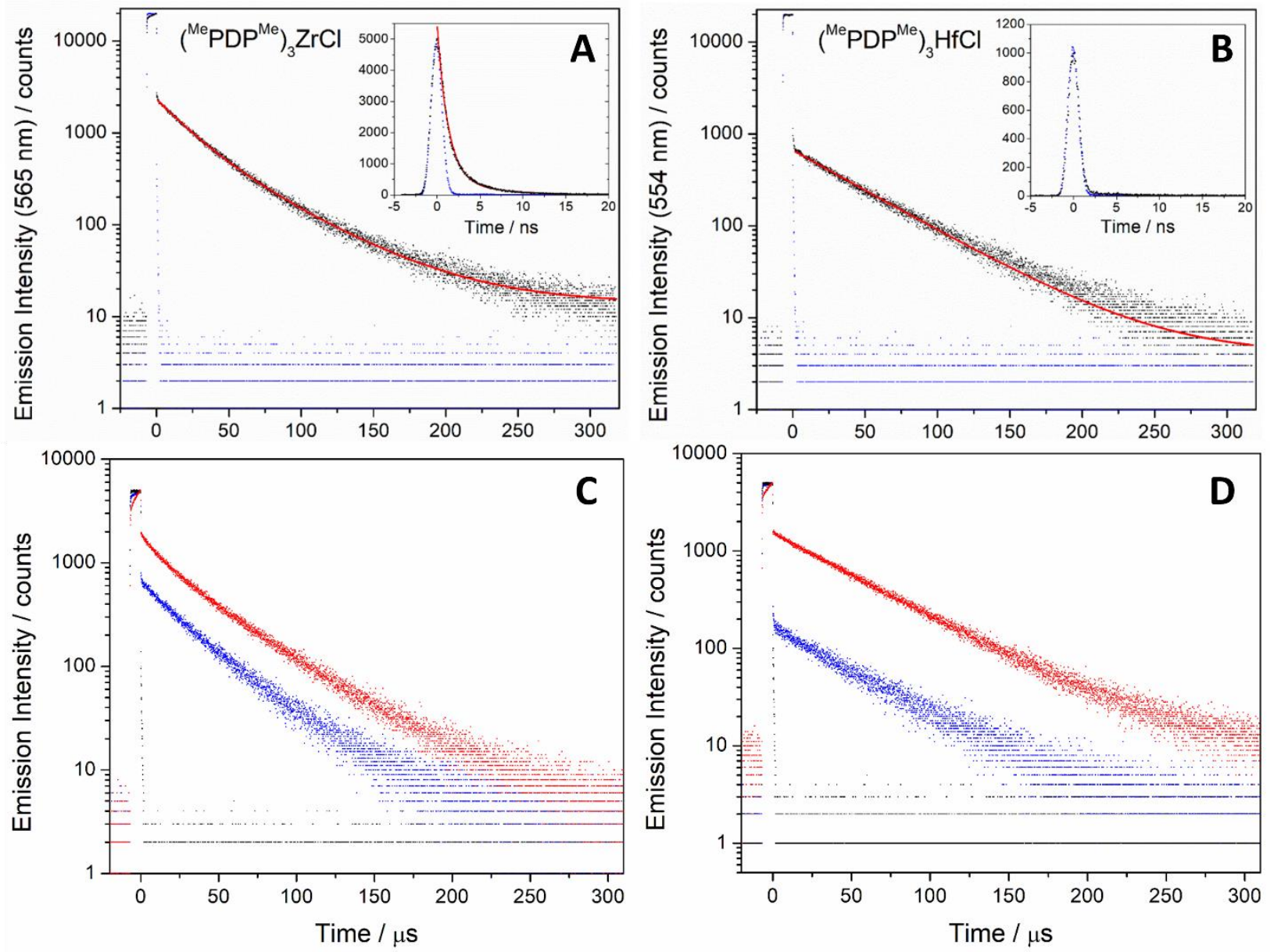

Figure 8. Time-resolved emission data (black) for $\left({ }^{\mathrm{Me}} \mathrm{PMP}{ }^{\mathrm{Me}}\right)_{3} \mathrm{ZrCl}(\mathrm{A})$ and $\left({ }^{\mathrm{Me}} \mathrm{PMP}{ }^{\mathrm{Me}}\right)_{3} \mathrm{HfCl}(\mathrm{B})$ in THF solution at room temperature. The data displayed in blue show the time profile of the excitation pulse. Red lines represent exponential fits of the data. The insets represent data collected using nanosecond excitation pulses in an attempt to determine fast emission processes. Timeresolved emission data for $\left({ }^{\mathrm{Me}} \mathrm{PMP}{ }^{\mathrm{Me}}\right)_{3} \mathrm{ZrCl}(\mathrm{C})$ and $\left({ }^{\mathrm{Me}} \mathrm{PMP}{ }^{\mathrm{Me}}\right)_{3} \mathrm{HfCl}(\mathrm{D})$ in THF solution at room temperature. Data shown in red were detected at an emission wavelength of $650 \mathrm{~nm}$, while data shown in blue were detected at $565 \mathrm{~nm}$.

Table 2. Summary of emission properties for $\left({ }^{\mathrm{Me}} \mathrm{PMP}{ }^{\mathrm{Me}}\right)_{3} \mathrm{MCl}(\mathrm{M}=\mathrm{Zr}$, Hf).

\begin{tabular}{c|cccc}
\hline & $\lambda_{\mathrm{em}} / \mathrm{nm}^{[\mathrm{a}]}$ & $\Phi_{\mathrm{em}}$ & $\tau_{\mathrm{P}} / \mu \mathrm{s}$ & $\tau_{\mathrm{F}} / \mathrm{ns}$ \\
\hline$\left({ }^{\mathrm{Me}} \mathrm{PMP}{ }^{\mathrm{Me}}\right)_{3} \mathrm{ZrCl}$ & 565 & 0.010 & 21 & 5 \\
$\left({ }^{\mathrm{Me} P M P}{ }^{\mathrm{Me}}\right)_{3} \mathrm{HfCl}$ & 554 & 0.007 & 49 & ${ }_{-}^{[\mathrm{b}]}$ \\
\hline
\end{tabular}

${ }^{\mathrm{a}}$ peak maximum. ${ }^{\mathrm{b}}$ not determined. 


\subsection{TD-DFT Studies.}
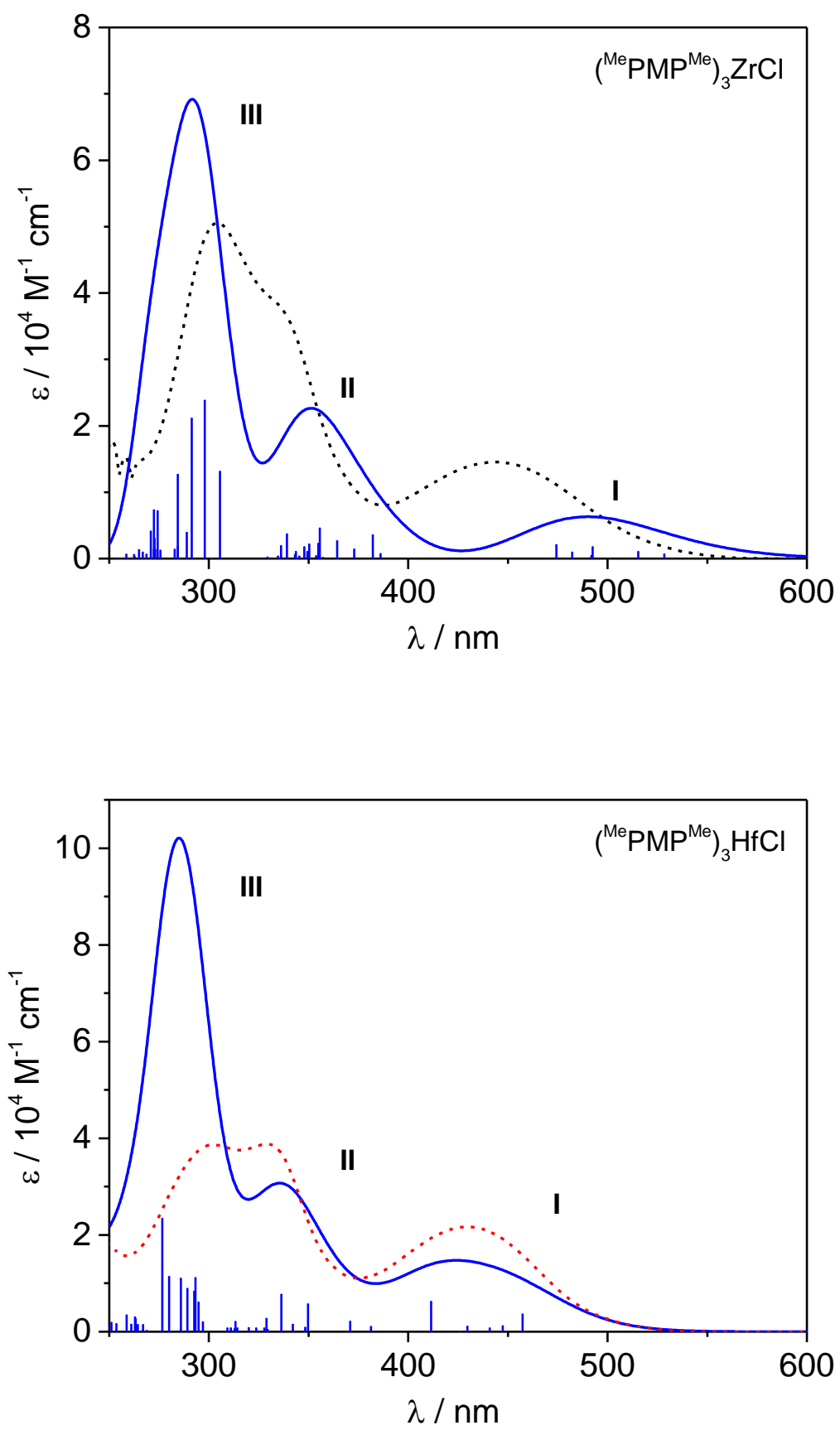

Figure 9. Electronic absorption spectra of $\left({ }^{\mathrm{Me}} \mathrm{PMP}^{\mathrm{Me}}\right)_{3} \mathrm{ZrCl}$ (top) and ( $\left.{ }^{\mathrm{Me}} \mathrm{PMP}{ }^{\mathrm{Me}}\right)_{3} \mathrm{HfCl}$ (bottom) obtained via TD-DFT calculations (line broadening $3000 \mathrm{~cm}^{-1}$, FWHM). The stick plots indicate the positions and relative intensities of individual transitions. The major contributions to the states in the visible region are listed in Table 3. The experimental spectra are shown as dotted lines for comparison. 
To establish the nature of the electronic transitions for $\left({ }^{\mathrm{Me}} \mathrm{PMP}{ }^{\mathrm{Me}}\right)_{3} \mathrm{ZrCl}$ and $\left({ }^{\mathrm{Me}} \mathrm{PMP}{ }^{\mathrm{Me}}\right)_{3} \mathrm{HfCl}$, TD-DFT calculations were carried out at the B3LYP level of theory. The conductor-like screening model (COSMO) was employed to model the solvent effects of THF. Based on the observation of two isomers in solution by ${ }^{1} \mathrm{H}$ NMR spectroscopy, separate TD-DFT calculations were conduct using the geometric parameters for the structures $\mathbf{1 a}$ and $\mathbf{1 b}$. For both $\mathrm{Zr}$ and $\mathrm{Hf}$, the computed spectra of the two isomers are nearly identical and only the spectra for 1a will be discussed in detail in the following section. The calculated electronic absorption spectra for $\left({ }^{\mathrm{Me}} \mathrm{PMP} \mathrm{Me}_{3} \mathrm{ZrCl}\right.$ and $\left({ }^{\mathrm{Me}} \mathrm{PMP}{ }^{\mathrm{Me}}\right)_{3} \mathrm{HfCl}$ are shown in Figure 9 using Gaussian line shapes with a linewidth of $3000 \mathrm{~cm}^{-1}$ (fwhm) for each calculated transition.

Consistent with the experimental spectra, three main features are observed and labeled as I-III. The positions of the absorption maxima between experiment and computation show reasonable to excellent agreement for $\mathrm{Zr}$ and $\mathrm{Hf}$, respectively. Notably, the calculations reproduce the blueshift for absorption band I in the visible part of the spectrum upon changing the metal from $\mathrm{Zr}$ to Hf. For both metals, the relative intensities of feature I and II are reproduced well, however, the calculations overestimate the intensity of III. Due to the low symmetry of the seven-coordinate geometry, a large number of electronic transitions exhibit significant intensity. As a result, the analysis of the individual transitions proved to be rather complicated. The most intense TD-DFT states contributing to band $\mathbf{I}$ for $\left({ }^{\mathrm{Me}} \mathrm{PMP}{ }^{\mathrm{Me}}\right)_{3} \mathrm{ZrCl}$ and $\left({ }^{\mathrm{Me}} \mathrm{PMP} \mathrm{Pe}_{3}\right)_{3} \mathrm{HfCl}$ are listed in Table 3. Analyses for the UV bands are provided in the Appendix D. For each state, the contributing single 
electron TD-DFT excitations with a weight of more than $10 \%$ are listed. Diagrams depicting the relevant frontier molecular orbitals (MOs) are shown in Figure 10 to help visualize the individual donor and acceptor MOs for each single-electron excitation. Due to their nearly identical structures, the $\mathrm{MO}$ schemes for $\left({ }^{\mathrm{Me}} \mathrm{PMP}{ }^{\mathrm{Me}}\right)_{3} \mathrm{ZrCl}$ and $\left({ }^{\mathrm{Me}} \mathrm{PMP}{ }^{\mathrm{Me}}\right)_{3} \mathrm{HfCl}$ are very similar and the most prominent differences arise due to the nature of the central metal ion.

Table 3. Vertical electronic excitation energies and main excitations contributing to the visible absorption bands I of $\left({ }^{\mathrm{Me}} \mathrm{PMP}{ }^{\mathrm{Me}}\right)_{3} \mathrm{MCl}(\mathrm{M}=\mathrm{Zr}$, Hf) obtained via TD-DFT calculations.

\begin{tabular}{|c|c|c|c|c|c|}
\hline M & State & $\mathrm{E}, \mathrm{cm}^{-1}(\lambda, \mathrm{nm})$ & $f_{\text {osc }}$ & $\begin{array}{l}\text { Excitations } \\
\text { (weight) }{ }^{\mathrm{a}}\end{array}$ & Character \\
\hline \multirow{6}{*}{$\mathrm{Zr}^{\mathrm{b}}$} & 1 & $18925.5(528.4)$ & 0.010 & $164 \rightarrow 165(0.93)$ & $\begin{array}{c}{ }^{1} \mathrm{IL} /{ }^{1} \mathrm{LMCT} \\
(47 \%)\end{array}$ \\
\hline & 2 & $19402.5(515.4)$ & 0.015 & $\begin{array}{l}164 \rightarrow 166(0.84) \\
163 \rightarrow 165(0.12)\end{array}$ & $\begin{array}{c}{ }^{1} \mathrm{IL} /{ }^{1} \mathrm{LMCT} \\
(47 \%)\end{array}$ \\
\hline & 3 & $20306.2(492.5)$ & 0.025 & $\begin{array}{l}163 \rightarrow 165(0.75) \\
164 \rightarrow 166(0.10)\end{array}$ & $\begin{array}{c}{ }^{1} \mathrm{IL} /{ }^{1} \mathrm{LMCT} \\
(47 \%)\end{array}$ \\
\hline & 4 & 20330.5 (491.9) & 0.007 & $\begin{array}{l}163 \rightarrow 166(0.72) \\
162 \rightarrow 165(0.22)\end{array}$ & $\begin{array}{c}{ }^{1} \mathrm{IL} /{ }^{1} \mathrm{LMCT} \\
(40 \%)\end{array}$ \\
\hline & 5 & $20736.0(482.3)$ & 0.014 & $\begin{array}{l}162 \rightarrow 165(0.64) \\
162 \rightarrow 166(0.20) \\
163 \rightarrow 166(0.12)\end{array}$ & $\begin{array}{c}{ }^{1} \mathrm{IL} /{ }^{1} \mathrm{LMCT} \\
(47 \%)\end{array}$ \\
\hline & 6 & $21083.3(474.3)$ & 0.029 & $\begin{array}{l}162 \rightarrow 166(0.67) \\
163 \rightarrow 166(0.10)\end{array}$ & $\begin{array}{c}{ }^{1} \mathrm{IL} /{ }^{1} \mathrm{LMCT} \\
(40 \%)\end{array}$ \\
\hline \multirow{6}{*}{$\mathrm{Hf}^{\mathrm{c}}$} & 1 & $21867.1(457.3)$ & 0.051 & $180 \rightarrow 181(0.92)$ & $\begin{array}{c}{ }^{1} \mathrm{IL} /{ }^{1} \mathrm{LMCT} \\
(21 \%)\end{array}$ \\
\hline & 2 & $22681.8(440.9)$ & 0.012 & $179 \rightarrow 181(0.86)$ & $\begin{array}{c}{ }^{1} \mathrm{IL} /{ }^{1} \mathrm{LMCT} \\
(21 \%)\end{array}$ \\
\hline & 3 & $22351.4(447.4)$ & 0.018 & $180 \rightarrow 182(0.75)$ & $\begin{array}{c}{ }^{1} \mathrm{IL} /{ }^{1} \mathrm{LMCT} \\
(23 \%)\end{array}$ \\
\hline & 4 & $23486.9(425.8)$ & 0.001 & $\begin{array}{l}178 \rightarrow 181(0.79) \\
179 \rightarrow 182(0.14)\end{array}$ & $\begin{array}{c}{ }^{1} \mathrm{IL} /{ }^{1} \mathrm{LMCT} \\
(21 \%)\end{array}$ \\
\hline & 5 & $23276.9(429.6)$ & 0.017 & $\begin{array}{l}178 \rightarrow 182(0.37) \\
179 \rightarrow 182(0.35) \\
178 \rightarrow 181(0.14)\end{array}$ & $\begin{array}{c}{ }^{1} \mathrm{IL} /{ }^{1} \mathrm{LMCT} \\
(23 \%)\end{array}$ \\
\hline & 6 & $24303.2(411.5)$ & 0.088 & $\begin{array}{l}178 \rightarrow 182(0.53) \\
179 \rightarrow 182(0.33)\end{array}$ & $\begin{array}{c}{ }^{1} \mathrm{IL} /{ }^{1} \mathrm{LMCT} \\
(23 \%)\end{array}$ \\
\hline
\end{tabular}

${ }^{\mathrm{a}}$ Only excitations with a weight larger than 0.1 are shown. ${ }^{\mathrm{b}}$ HOMO 164, LUMO $165 .{ }^{\mathrm{c}}$ HOMO 180, LUMO 181. 
For both complexes, six TD-DFT states contribute to band I, which is observed in the visible part of the spectrum. The major contributions to these states originate from five frontier MOs (three doubly filled donor orbitals and two empty acceptor orbitals) that can be further characterized by their contributions from the PMP ligands and the metal center. For all five orbitals, contributions from the chloro ligand are negligible. Independent of the metal center, the three donor orbitals, HOMO, HOMO-1, and HOMO-2, are completely PMP centered with major contributions from the $\pi$-systems of the pyrrolide heterocycles. Consequently, the energies of these orbitals are nearly identical between the $\mathrm{Zr}$ and $\mathrm{Hf}$ complex. In contrast, the two acceptor orbitals, LUMO and LUMO+1, exhibit significant contributions from the metal and the PMP pyridine moieties. For $\mathrm{Zr}$, the metal character for the LUMO and LUMO-1 was computed at $47 \%$ and $40 \%$, respectively, while the same orbitals in the Hf analogue show a reduced metal character of 23 and $21 \%$. Based on these assignments, the transitions in the visible region of the spectrum are best described as mixed ${ }^{1} \mathrm{LLCT} /{ }^{1} \mathrm{LMCT}$ states with higher $\mathrm{LMCT}$ contributions for $\left({ }^{\mathrm{Me}} \mathrm{PMP}{ }^{\mathrm{Me}}\right)_{3} \mathrm{ZrCl}$ compared to $\left({ }^{\mathrm{Me}} \mathrm{PMP}{ }^{\mathrm{Me}}\right)_{3} \mathrm{HfCl}$.

Absorption bands II and III observed in the UV region of the spectrum contain contributions from a multitude of TD-DFT states. Some of these states are best described as pure ${ }^{1}$ LLCT states with negligible metal character in the acceptor orbital $(<10 \%)$, while others display majority ${ }^{1} \mathrm{LMCT}$ contributions with up to $61 \%$ metal character in the acceptor orbital of the predominant single-electron excitation. 

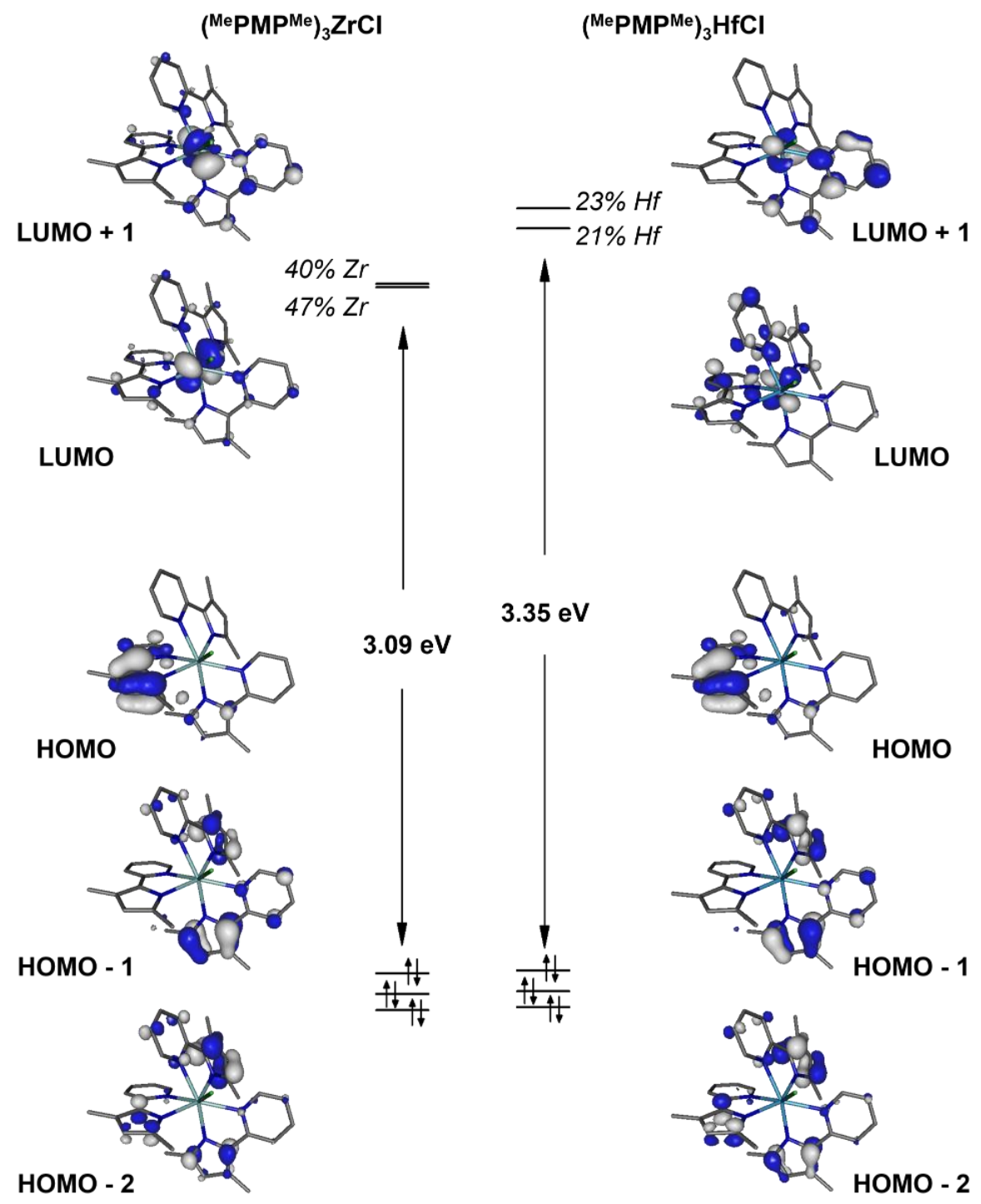

Figure 10. Frontier molecular orbital diagram of $\left({ }^{\mathrm{Me}} \mathrm{PMP}{ }^{\mathrm{Me}}\right)_{3} \mathrm{MCl}(\mathrm{M}=\mathrm{Zr}$, Hf) obtained from TDDFT calculation. Reprinted with permission from \{Zhang, Y.; Akhmedov. N. G.; Petersen, J. L.; and Milsmann, C. Chem. Eur. J. 2019, 25, 3042\}. Copyright $\{2019\}$ Wiley-VCH Verlag GmbH \& Co. 


\subsection{Electrochemical Properties.}

Besides readily accessible photoluminescent excited states, reversible redox chemistry is a second hallmark of most photosensitizers. To investigate the electrochemical properties of $\left({ }^{\mathrm{Me}} \mathrm{PMP}{ }^{\mathrm{Me}}\right)_{3} \mathrm{ZrCl}$ and $\left({ }^{\mathrm{Me}} \mathrm{PMP}{ }^{\mathrm{Me}}\right)_{3} \mathrm{HfCl}$, cyclic voltammetry $(\mathrm{CV})$ experiments were conducted (Figure 11). All CV measurements were carried out using a glassy carbon working electrode in THF solution containing $0.1 \mathrm{M}$ tetra-( $n$-butyl)ammonium hexafluorophosphate, $\left[n\right.$ - $\left.\mathrm{Bu}_{4} \mathrm{~N}\right]\left[\mathrm{PF}_{6}\right]$, as the supporting electrolyte and all values were referenced using ferrocene $(\mathrm{Fc})$ as an internal standard. Two barely separate, irreversible oxidation events were observed for each compound at approximately $0.5 \mathrm{~V}$. Due to the presence of $\mathrm{d}^{0}$ metal centers, these features can readily be assigned as ligand centered oxidations followed by rapid decomposition of the cationic species. This is also consistent with the DFT calculations, which show that the highest occupied molecular orbitals in both compounds are three near degenerate orbitals localized predominantly on the pyrrolide units of the PMP ligands. Upon reduction, $\left({ }^{\mathrm{Me}} \mathrm{PMP}{ }^{\mathrm{Me}}\right)_{3} \mathrm{ZrCl}$ and $\left({ }^{\mathrm{Me}} \mathrm{PMP}{ }^{\mathrm{Me}}\right)_{3} \mathrm{HfCl}$ display significantly different behavior. The zirconium complex exhibits a fully reversible redox event at $\mathrm{E}_{1 / 2}=-2.29 \mathrm{~V}$ and a quasi-reversible feature with $\mathrm{E}_{\mathrm{pc}}=-2.74 \mathrm{~V}$. In contrast, the $\mathrm{Hf}$ analogue shows two irreversible reduction waves at $\mathrm{E}_{\mathrm{pc}}=-2.60 \mathrm{~V}$ and $-3.19 \mathrm{~V}$. Increasing the scan rate $(2-5 \mathrm{~V} / \mathrm{s})$ improves the reversibility of the first feature in the CV but also leads to significant distortions of the signals due to the high internal resistance of the electrolyte solution typical for THF (Figure 12). While the exact reason for the difference in reversibility of the first reduction event is not clear 
at this point, the more negative reduction potential for $\left({ }^{\mathrm{Me}} \mathrm{PMP}{ }^{\mathrm{Me}}\right)_{3} \mathrm{HfCl}$ is consistent with the higher LUMO energy obtained via DFT compared to $\left({ }^{\mathrm{Me}} \mathrm{PMP}{ }^{\mathrm{Me}}\right)_{3} \mathrm{ZrCl}$. In fact, the difference in the cathodic peak potentials $\left(\Delta \mathrm{E}_{\mathrm{pc}}=0.22 \mathrm{~V}\right)$ for the first reduction event closely matches the difference in LUMO energy of $0.25 \mathrm{eV}$ predicted by DFT.

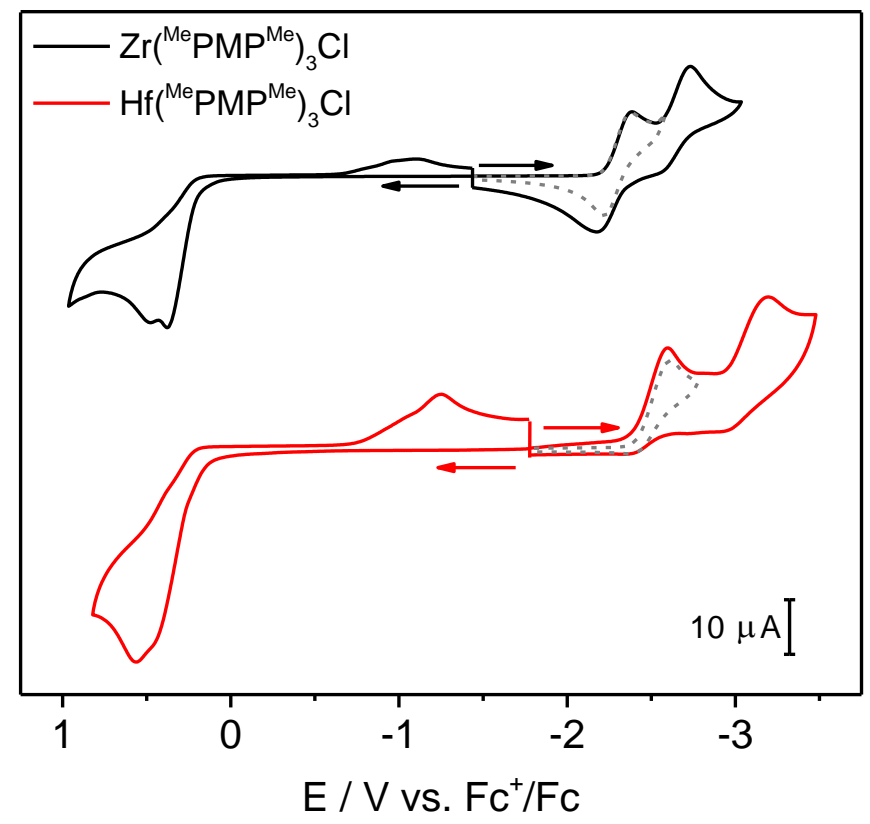

Figure 11. Cyclic voltammogram of $\left({ }^{\mathrm{Me}} \mathrm{PMP}{ }^{\mathrm{Me}}\right)_{3} \mathrm{MCl}(\mathrm{M}=\mathrm{Zr}$, Hf $)$ in THF at room temperature (scan rate $50 \mathrm{mV} / \mathrm{s}$ (top trace) and $200 \mathrm{mV} / \mathrm{s}$ (bottom trace), $0.1 \mathrm{M}\left[\mathrm{N}(n-\mathrm{Bu})_{4}\right] \mathrm{PF}_{6}$, glassy carbon working electrode). The signals observed between $-1.0 \mathrm{~V}$ and $-1.5 \mathrm{~V}$ are due to unidentified decomposition products resulting from the irreversible oxidation processes and are absent in oxidative scans with maximum potentials of $0 \mathrm{~V}$. Reprinted with permission from \{Zhang, Y.; Akhmedov. N. G.; Petersen, J. L.; and Milsmann, C. Chem. Eur. J. 2019, 25, 3042\}. Copyright $\{2019\}$ Wiley-VCH Verlag GmbH \& Co. 

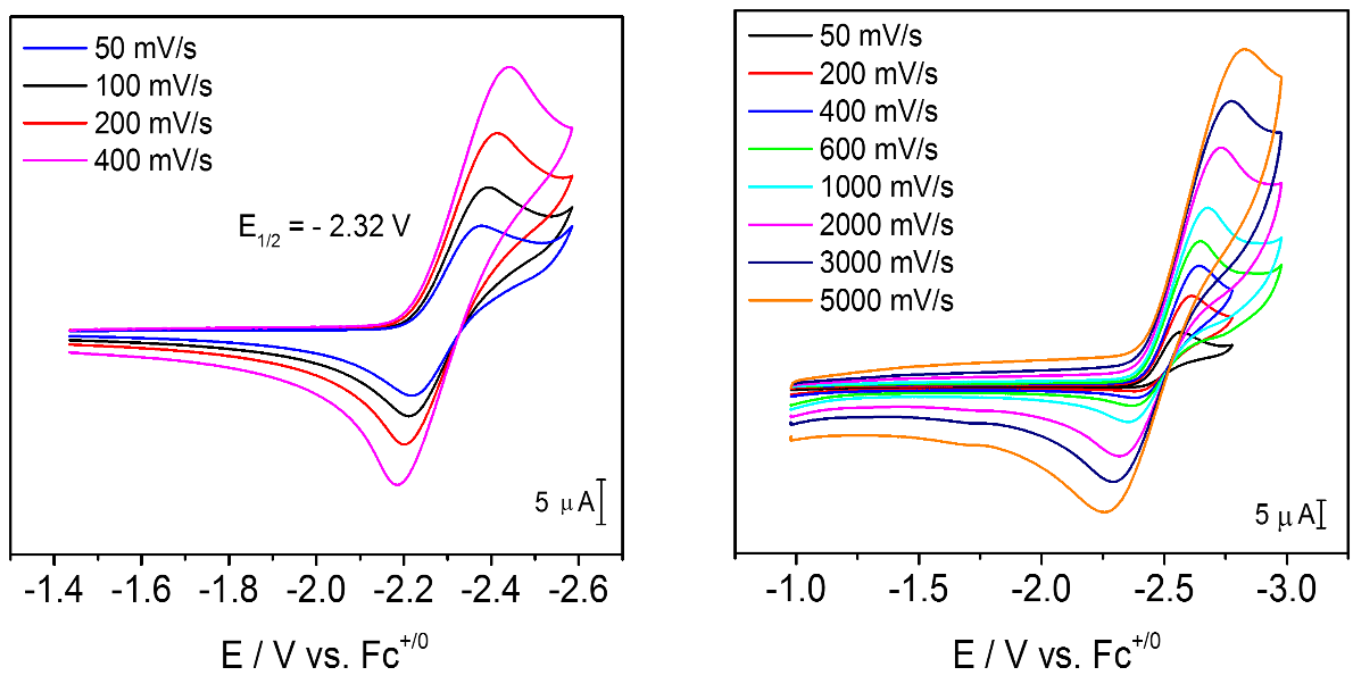

Figure 12. Cyclic voltammograms of first reduction wave for $\left({ }^{\mathrm{Me}} \mathrm{PDP}{ }^{\mathrm{Me}}\right)_{3} \mathrm{ZrCl}$ (left) and $\left({ }^{\mathrm{Me}} \mathrm{PMP}{ }^{\mathrm{Me}}\right)_{3} \mathrm{HfCl}$ (right) in THF at room temperature at different scan rates $\left(0.1 \mathrm{M}\left[\mathrm{N}(n-\mathrm{Bu})_{4}\right] \mathrm{PF}_{6}\right.$, glassy carbon working electrode).

\subsection{Photoredox catalysis.}

With optical and electrochemical data in hand, the dehalogenation of ethyl bromodifluoroacetate was investigated using $\left({ }^{\mathrm{Me}} \mathrm{PMP}^{\mathrm{Me}}\right)_{3} \mathrm{ZrCl}$ as the photosensitizer to establish its utility in photoredox catalysis. Based on the irreversibility of the redox chemistry for $\left({ }^{\mathrm{Me}} \mathrm{PMP}{ }^{\mathrm{Me}}\right)_{3} \mathrm{HfCl}$, no catalysis experiments were conducted for this species. Irradiation $\left(\lambda_{\max }=462\right.$ $\mathrm{nm}$ ) of a mixture of ethyl bromodifluoroacetate and 1,3-dimethyl-2-phenyl- 2,3-dihydro-1H-7methylbenzo-[d]imidazole, ${ }^{\mathrm{Me}} \mathrm{BIH}$, in benzene- $d_{6}$ in the presence of $\left({ }^{\mathrm{Me}} \mathrm{PMP}{ }^{\mathrm{Me}}\right)_{3} \mathrm{ZrCl}$ at room temperature in full conversion of the starting material within 30 minutes (Table 4). The desired product ethyl difluoroacetate was obtained in $85 \%$ yield. A control experiment in the absence of light resulted in full recovery of the starting material. A second control experiment in the absence 
of $\left({ }^{\mathrm{Me}} \mathrm{PMP}{ }^{\mathrm{Me}}\right)_{3} \mathrm{ZrCl}$ showed slow conversion to the dehalogenated product consistent with the observation that $\mathrm{BIH}$ derivatives can undergo photochemical reactions in the absence of photosensitizers. ${ }^{26,27}$ However, the reduced rate of conversion clearly shows that $\left({ }^{\mathrm{Me}} \mathrm{PMP}{ }^{\mathrm{Me}}\right)_{3} \mathrm{ZrCl}$ acts as a photosensitizer in this transformation.

Table 4. Summary of photocatalytic experiments.

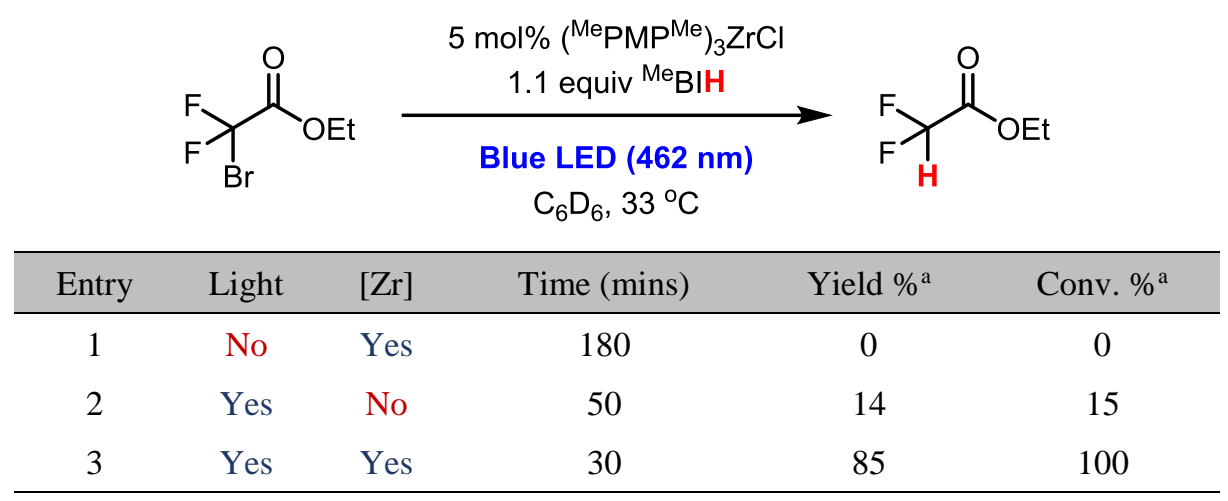

${ }^{\text {al}} \mathrm{H}$ NMR yield using1,3,5-trimethoxybenzene as the internal standard.

\subsection{Conclusion.}

The two isostructural, seven-coordinate complexes $\left({ }^{\mathrm{Me}} \mathrm{PMP}{ }^{\mathrm{Me}}\right)_{3} \mathrm{ZrCl}$ and $\left({ }^{\mathrm{Me}} \mathrm{PMP}{ }^{\mathrm{Me}}\right)_{3} \mathrm{HfCl}$ have been synthesized and characterized. While the solid-state molecular structures are best described as $C_{1}$-symmetric, highly distorted chloride capped octahedra, variable-temperature $1 \mathrm{H}$ NMR studies revealed a highly dynamic equilibrium in solution at room temperature due to fast interconversion between two geometric isomers. The activation parameters obtained via Eyring analyses suggest an isomerization process that does not require ligand dissociation for both 
complexes. Computational analysis of the possible isomers of $\left({ }^{\mathrm{Me}} \mathrm{PMP}{ }^{\mathrm{Me}}\right)_{3} \mathrm{ZrCl}$ via density functional theory provided additional insight into the structures of the two observed isomers and further supports a non-dissociative isomerization pathway.

Cyclic voltammetry experiments established a reversible reduction event for $\left({ }^{\mathrm{Me}} \mathrm{PMP}{ }^{\mathrm{Me}}\right)_{3} \mathrm{ZrCl}$ under strongly reducing conditions. In contrast, $\left({ }^{\mathrm{Me}} \mathrm{PMP}{ }^{\mathrm{Me}}\right)_{3} \mathrm{HfCl}$ does not exhibit any reversible redox chemistry.

Both complexes show strong absorption bands in the visible region, which were assigned to mixed LLCT/LMCT transitions via time-dependent density functional theory. The amount of LMCT character correlates with the nature of the central metal ion and is predicted at $40-47 \%$ for $\left({ }^{\mathrm{Me}} \mathrm{PMP}{ }^{\mathrm{Me}}\right)_{3} \mathrm{ZrCl}$ and $21-23 \%$ for $\left({ }^{\mathrm{Me}} \mathrm{PMP}{ }^{\mathrm{Me}}\right)_{3} \mathrm{HfCl}$ consistent with the difference in d orbital energies. Both complexes are photoluminescent upon excitation with visible light at room temperature in solution with emission maxima at $565 \mathrm{~nm}$ and $554 \mathrm{~nm}$ for the $\mathrm{Zr}$ and $\mathrm{Hf}$ complex, respectively. As determined by time-resolved emission spectroscopy, the observed luminescence spectra are due to a combination of phosphorescence and fluorescence characterized by excited state lifetimes in the ms and low to sub-ns time-scale, respectively. The low quantum yields of $1.0 \%$ $(\mathrm{Zr})$ and $0.7 \%(\mathrm{Hf})$ for the two $\left({ }^{\mathrm{Me}} \mathrm{PMP}{ }^{\mathrm{Me}}\right)_{3} \mathrm{MCl}$ compounds is consistent with facile non-radiative deactivation of the excited states due to the highly flexible molecular structures.

This study highlights the potential to design new photoluminescent transition metal complexes based on group 4 metals. The combination with pyridine mono-pyrrole ligands as 
examples for electron-rich $\pi$-donor ligands allows contributions from ligand-to-metal charge transfer transitions, which leads to emissive excited states with remarkably long lifetimes in the $\mu$ s range. These insights should prove valuable to further the development of photoactive molecules based on earth-abundant elements that exhibit distinct features compared to the more traditional precious metal photosensitizers.

\subsection{Experimental Section.}

General experimental considerations for material handling, physical measurements, X-ray crystallography, and DFT Calculations as well as additional experimental information (i.e. NMR spectra) can be found in the appendices.

Starting Materials. 3,5-dimethyl-2-(2-pyridyl)pyrrole $\left(\mathrm{H}^{\mathrm{Me}} \mathrm{PMP} \mathrm{P}^{\mathrm{Me}}\right)$ was prepared following a literature procedure. ${ }^{11}$

Synthesis of $\left({ }^{\mathrm{Me} P M P M e}\right)_{3} Z \mathbf{Z C l}: n$-BuLi $(1.65 \mathrm{~mL}, 1.6 \mathrm{M}$ solution in hexanes, $2.64 \mathrm{mmol}, 1.02$ equiv) was added slowly to a $20-\mathrm{mL}$ vial charged with a solution of $\mathrm{H}^{\mathrm{Me}} \mathrm{PMP} \mathrm{Me}^{\mathrm{Me}}(445 \mathrm{mg}, 2.58$ mmol, 1.00 equiv) in $5 \mathrm{~mL}$ of THF. The reaction was stirred for $1 \mathrm{~h}$ at room temperature to generate a luminescent dark green-yellow solution of the deprotonated ligand. A THF solution of $\mathrm{ZrCl}_{4}$ (205 $\mathrm{mg}, 0.878 \mathrm{mmol}, 0.34$ equiv) was added in small portions to the deprotonated ligand. The reaction mixture was allowed to stir at room temperature. After $24 \mathrm{~h}$, THF was removed under vacuum. The solid residue was triturated twice with diethyl ether and washed five times with diethyl ether. 
The crude product was redissolved in DCM and filtered to remove LiCl. Removal of the solvent under vacuum provided an orange power (Yield: $290 \mathrm{mg}, 53 \%$, based on Zr). ${ }^{1} \mathrm{H}$ NMR (400 MHz, $\left.\mathrm{C}_{6} \mathrm{D}_{6} ; \delta, \mathrm{ppm}\right): 7.58$ (br, 3H, Py-ortho- $H$ ), 7.01 (d, $J=8.4 \mathrm{~Hz}, 3 \mathrm{H}, \mathrm{Py} H$ ), 6.67 (ddd, $J=8.4,7.2$, $1.6 \mathrm{~Hz}, 3 \mathrm{H}, \mathrm{Py} H$ ), 5.96 (t, $J=6.4 \mathrm{~Hz}, 3 \mathrm{H}, \mathrm{Py} H$ ), 5.95 (s, 3H, Pyrrole $H$ ), 2.23 (s, 9H, CH3). 2.17 (br, 9H, $\left.\mathrm{CH}_{3}\right) .{ }^{13} \mathrm{C}$ NMR (100 MHz, $\left.\mathrm{C}_{6} \mathrm{D}_{6} ; \delta, \mathrm{ppm}\right): 155.26,149.40,144.40,138.27,134.77,124.99$, 117.07, 116.62, 116.18, 16.98, 14.66. Anal. Calcd for $\mathrm{C}_{33} \mathrm{H}_{33} \mathrm{~N}_{6} \mathrm{ZrCl}$ : C, 61.90; H, 5.19; N, 13.12 . Found: C, 61.56; H, 5.54; N, 12.40. Single crystals suitable for X-ray crystallographic analysis were grown by slow diffusion of pentane into a saturated solution of $\left({ }^{\mathrm{Me}} \mathrm{PMP}{ }^{\mathrm{Me}}\right)_{3} \mathrm{ZrCl}$ in THF at $35{ }^{\circ} \mathrm{C}$.

Synthesis of ( $\left.{ }^{\mathrm{Me} P M P M e}\right)_{3} \mathbf{H f C l}: n$-BuLi $(1.09 \mathrm{~mL}, 1.6 \mathrm{M}$ solution in hexanes, $1.74 \mathrm{mmol}, 1.00$ equiv) was added slowly to a $20-\mathrm{mL}$ vial charged with a solution of $\mathrm{H}^{\mathrm{Me}} \mathrm{PMP}{ }^{\mathrm{Me}}(300 \mathrm{mg}, 1.74$ mmol, 1.00 equiv) in $5 \mathrm{~mL}$ of THF. The reaction was stirred for 1 hour at room temperature to generate a luminescent dark green-yellow solution of the deprotonated ligand. A THF solution of $\mathrm{HfCl}_{4}$ (138 $\mathrm{mg}, 0.575 \mathrm{mmol}, 0.33$ equiv) was added in small portions to the deprotonated ligand and the reaction mixture was allowed to stir at room temperature. After $24 \mathrm{~h}$, THF was removed under vacuum. The solid residue was triturated twice with diethyl ether and washed five times with diethyl ether. The crude product was redissolved in benzene and filtered to remove LiCl. Removal of the solvent under vacuum provided yellow solids (Yield: $192 \mathrm{mg}, 46 \%$, based on Hf). ${ }^{1} \mathrm{H}$ NMR (400 MHz, $\mathrm{C}_{6} \mathrm{D}_{6} ; \delta$, ppm): 7.61 (br, 3H, Py-ortho- $H$ ), 7.02 (d, $\left.J=8.4 \mathrm{~Hz}, 3 \mathrm{H}, \mathrm{Py} H\right), 6.68$ (ddd, $J$ 
$=8.4,6.8,1.2 \mathrm{~Hz}, 3 \mathrm{H}, \mathrm{Py} H), 5.99$ (t, $J=6.4 \mathrm{~Hz}, 3 \mathrm{H}, \mathrm{Py} H), 5.98(\mathrm{~s}, 3 \mathrm{H}$, Pyrrole $H), 2.25$ (s, 9H, $\left.\mathrm{CH}_{3}\right) .2 .13$ (br, 9H, $\left.\mathrm{CH}_{3}\right) .{ }^{13} \mathrm{C} \mathrm{NMR}\left(100 \mathrm{MHz}, \mathrm{C}_{6} \mathrm{D}_{6} ; \delta, \mathrm{ppm}\right): 155.23,149.54,145.20,138.21$, 135.18, 125.48, 117.30, 116.99, 116.36, 16.91, 14.65. Anal. Calcd for $\mathrm{C}_{33} \mathrm{H}_{33} \mathrm{~N}_{6} \mathrm{HfCl}$ : C, 54.47; $\mathrm{H}$, 4.57; N, 11.55; Found: C, 54.76; H, 4.27; N, 10.56. Single crystals suitable for X-ray crystallographic analysis were grown by slow diffusion of pentane into a saturated solution of $\left({ }^{\mathrm{Me}} \mathrm{PMP}{ }^{\mathrm{Me}}\right)_{3} \mathrm{HfCl}$ in $\mathrm{THF}$ at $-35^{\circ} \mathrm{C}$.

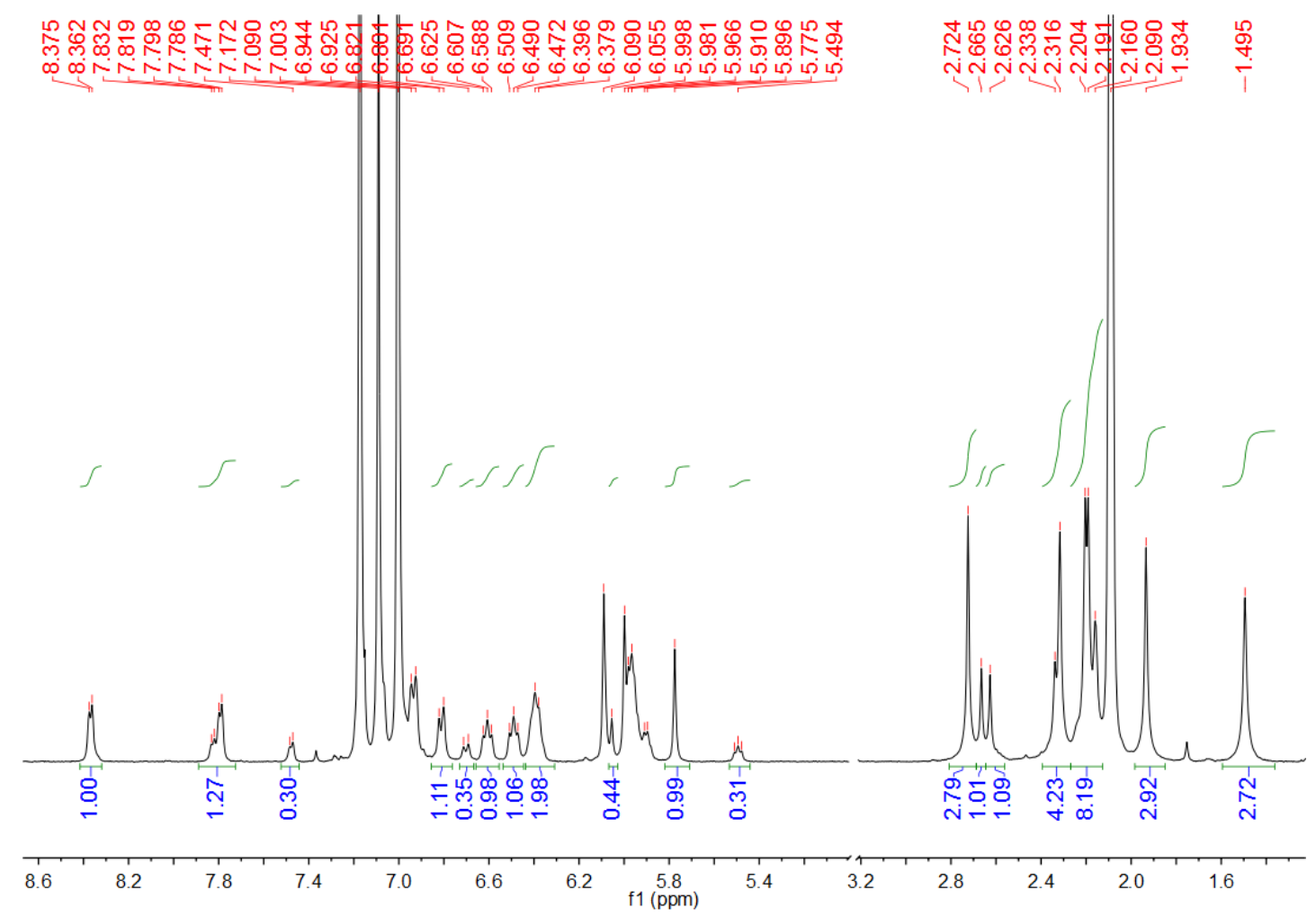

Figure ES1. $400 \mathrm{MHz}{ }^{1} \mathrm{H}$ NMR spectra (aromatic and alkyl region) of $\left({ }^{\mathrm{Me}} \mathrm{PMP}{ }^{\mathrm{Me}}\right)_{3} \mathrm{HfCl}$ in toluene$d_{8}$ at $-90^{\circ} \mathrm{C}$. 
Procedure for the Photocatalytic Reduction of Ethyl Bromodifluoroacetate: In the drybox, a

J. Young NMR tube was charged with $\left({ }^{\mathrm{Me}} \mathrm{PMP}{ }^{\mathrm{Me}}\right)_{3} \mathrm{ZrCl}\left(1 \mathrm{mg}, 0.002 \mathrm{mmol}, 0.05\right.$ equiv), ${ }^{\mathrm{Me}} \mathrm{BIH}$ ( $8 \mathrm{mg}, 0.034 \mathrm{mmol}, 1.10$ equiv), ethyl bromodifluoroacetate $(6.4 \mathrm{mg}, 0.031 \mathrm{mmol}, 1.00$ equiv), and 1,3,5-trimethoxybenzene (internal standard). Benzene- $d_{6}(0.6 \mathrm{~mL})$ was added. The mixture was placed in a jacketed glass beaker with water cooling and irradiated with blue LED light $\left(\lambda_{\max }\right.$ $=462 \mathrm{~nm}$ ). The products were analyzed by NMR spectroscopy and yields were determined based on internal standard.

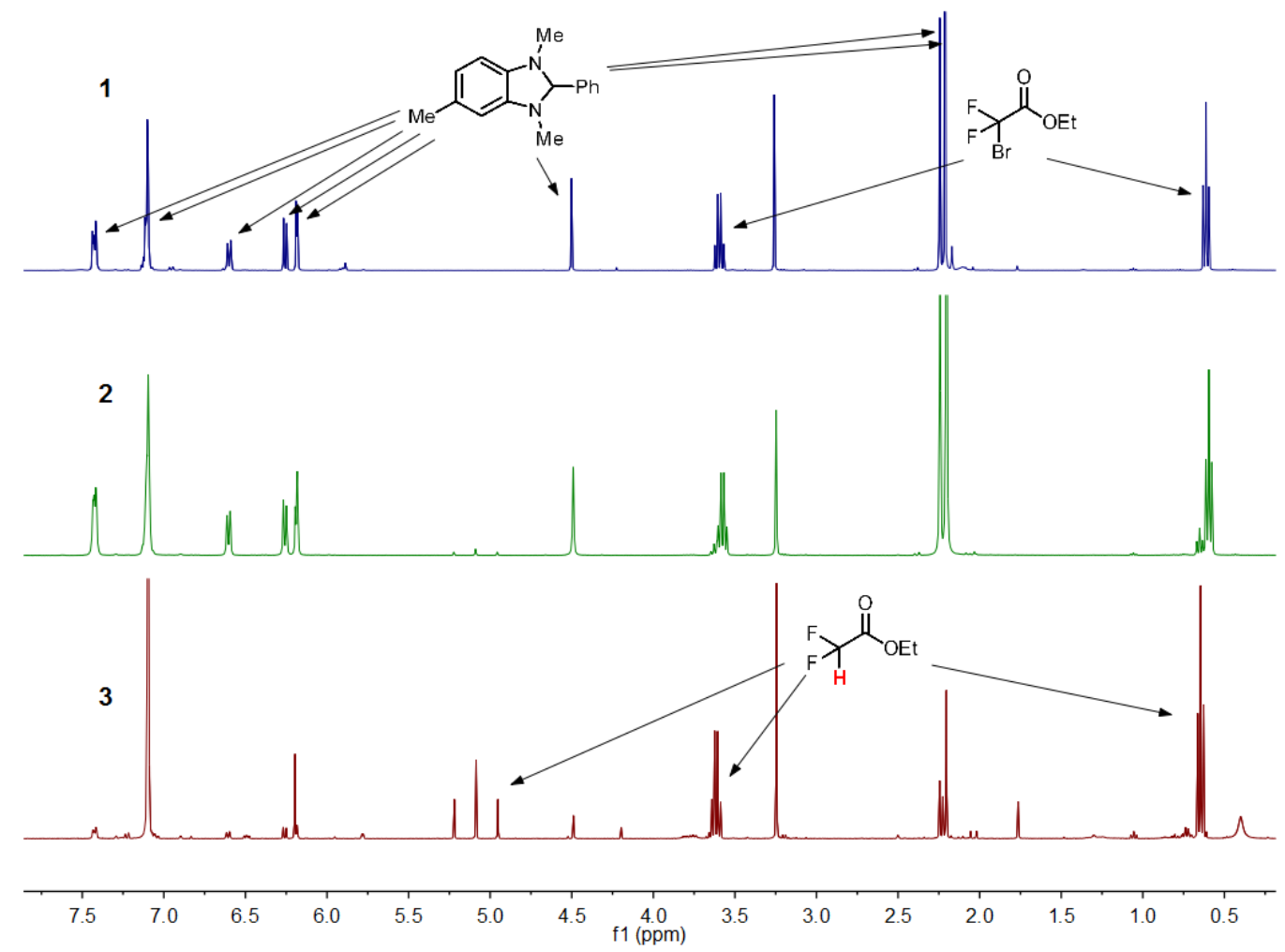

Figure ES2. ${ }^{1} \mathrm{H}$ NMR spectrum of a mixture of ${ }^{\mathrm{Me}} \mathrm{BIH}$ and ethyl bromodifluoroacetate in $\mathrm{C}_{6} \mathrm{D}_{6}$ (1) in the presence of $\left({ }^{\mathrm{Me}} \mathrm{PMP}{ }^{\mathrm{Me}}\right)_{3} \mathrm{ZrCl}$ without irradiation $(180 \mathrm{mins}) ;(2)$ without $\left({ }^{\mathrm{Me}} \mathrm{PMP}{ }^{\mathrm{Me}}\right)_{3} \mathrm{ZrCl}$ after irradiation (60 mins); (3) in the presence of $\left({ }^{\mathrm{Me}} \mathrm{PMP}{ }^{\mathrm{Me}}\right)_{3} \mathrm{ZrCl}$ after irradiation (30 mins). 


\section{11. Reference.}

(1) Zhang, Y.; Lee, T. S.; Petersen, J. L.; Milsmann, C. J. Am. Chem. Soc. 2018, 140, 5934.

(2) Flores, J. A.; Andino, J. G.; Tsvetkov, N. P.; Pink, M.; Wolfe, R. J.; Head, A. R.; Lichtenberger, D. L.; Massa, J.; Caulton, K. G. Inorg. Chem. 2011, 50, 8121.

(3) Searles, K.; Das, A. K.; Buell, R. W.; Pink, M.; Chen, C.-H.; Pal, K.; Morgan, D. G.; Mindiola, D. J.; Caulton, K. G. Inorg. Chem. 2013, 52, 5611.

(4) Tsvetkov, N. P.; Chen, C. H.; Andino, J. G.; Lord, R. L.; Pink, M.; Buell, R. W.; Caulton, K. G. Inorg. Chem. 2013, 52, 9511.

(5) Schouteeten, S.; Allen, O. R.; Haley, A. D.; Ong, G. L.; Jones, G. D.; Vicic, D. A. J. Organomet. Chem. 2006, 691, 4975.

(6) McBee, J. L.; Escalada, J.; Tilley, T. D. J. Am. Chem. Soc. 2009, 131, 12703.

(7) Mastropietro, T. F.; La Deda, M.; Godbert, N.; Ricciardi, L.; Szerb, E. I.; Ghedini, M.; Aiello, I. J. Organomet. Chem. 2015, 786, 55.

(8) Krylova, V. A.; Djurovich, P. I.; Aronson, J. W.; Haiges, R.; Whited, M. T.; Thompson, M. E. Organometallics 2012, 31, 7983.

(9) Klappa, J. J.; Geers, S. A.; Schmidtke, S. J.; Macmanus-spencer, L. A.; Mcneill, K. Dalton Trans. 2004, 883.

(10) Dissanayake, A. A.; Odom, A. L. Chem. Commun. 2012, 48, 440. 
(11) Klappa, J. J.; Rich, A. E.; McNeill, K. Org. Lett. 2002, 4, 435.

(12) Hitchcock, P. B.; Lappert, M. F.; Merle, P. G. Dalton Trans. 2007, 585.

(13) Yan, L.; Wang, X.; Zhou, M. Inorg. Chem. Commun. 2016, 65, 32.

(14) Huang, J.; Chi, L.; Yu, R.; Jiang, G. J.; Yang, W.; Lee, G.; Peng, S. Organometallics 2001, 20,5788 .

(15) Walther, D.; Fischer, R.; Goerls, H.; Koch, J.; Schweder, B. J. Organomet. Chem. 1996, 508, 13.

(16) Zhang, Y.; Xie, J.-R.; Guo, J.-P.; Wei, X.-H.; Huang, S.-P.; Liu, D.-S. Inorg. Chim. Acta 2009, 362, 583 .

(17) Hsieh, K. C.; Chang, J. C.; Lee, M. T.; Hu, C. H.; Hung, C. H.; Lee, H. M.; Huang, J. H.; Wang, M. H.; Lee, T. Y. Inorg. Chim. Acta 2004, 357, 3517.

(18) Zhou, M.; Tong, H.; Wei, X.; Liu, D. J. Organomet. Chem. 2007, 692, 5195.

(19) Yelamos, C.; Heeg, M. J.; Winter, C. H. Inorg. Chem. 1999, 38, 1871.

(20) Dunn, P. L.; Reath, A. H.; Clouston, L. J.; Young, V. G.; Tonks, I. A. Polyhedron 2014, 84, 111.

(21) Kunkely, H.; Pawlowski, V.; Strasser, A.; Vogler, A. Inorg. Chem. Commun. 2008, 11, 415.

(22) Geist, F.; Jackel, A.; Winter, R. F. Inorg. Chem. 2015, 54, 10946. 
(23) Kozhevnikov, D. N.; Kozhevnikov, V. N.; Shafikov, M. N.; Prokhorov, A. M.; Bruce, D. W.; Gareth Williams, J. A. Inorg. Chem. 2011, 50, 3804.

(24) Cheng, Y.-M.; Yeh, Y.-S.; Ho, M.-L.; Chou, P.-T.; Chen, P.-S.; Chi, Y. Inorg. Chem. 2005, $44,4594$.

(25) Knör, G.; Strasser, A. Inorg. Chem. Commun. 2002, 5, 993.

(26) Hasegawa, E.; Nagakura, Y.; Izumiya, N.; Matsumoto, K.; Tanaka, T.; Miura, T.; Ikoma, T.; Iwamoto, H.; Wakamatsu, K. J. Org. Chem. 2018, 83, 10813.

(27) Hasegawa, E.; Izumiya, N.; Miura, T.; Ikoma, T.; Iwamoto, H.; Takizawa, S. Y.; Murata, S. J. Org. Chem. 2018, 83, 3921. 


\section{Chapter 6.}

\section{Photochemical C-C Bond Formation in Luminescent Zirconium Complexes with CNN \\ Pincer Ligands}

(The major part of this chapter was published in Organometallics 2018, 37, 4488)

\subsection{Introduction}

In previous chapters, the successful design of zirconium photosensitizers on the basis of pyridine pyrrolide ligand scaffold were discussed. Here we describe the synthesis and characterization of two photoluminescent zirconium complexes with 2-phenyl-6-(pyrrol-2yl)pyridine (CNN) ligands. These ligands can be viewed as a hybrid between the strongly $\pi$ accepting 2-phenylpyridine (ppy) ligands most prominently employed in the design of luminescent iridium complexes ${ }^{1}$ and the $\pi$-donating pyridylpyrrolide ligands featured in our previous studies. The physical properties of the new complexes were established via a combined experimental and computational approach and the photochemical reactivity was investigated. Minor changes to the substitution pattern of the ligand backbone resulted in a dramatic shift in the primary reactivity of the complexes from photoinduced outer-sphere electron transfer to photochemical intramolecular C-C bond formation. 


\subsection{Synthesis and Characterization.}

The two ligand precursors 2-phenyl-6-(5-methyl-3-phenyl-1H-pyrrol-2-yl)pyridine, $\mathrm{H}_{2}{ }^{\mathrm{H}} \mathrm{CNN}$, and 2-(3,5-dimethyl-phenyl)-6-(5-methyl-3-phenyl-1H-pyrrol-2-yl)pyridine, $\mathrm{H}_{2}{ }^{\mathrm{Me}} \mathrm{CNN}$, were prepared from commercially available starting materials via a straightforward three-step protocol outlined in Scheme 1. The direct reaction of $\mathrm{H}_{2}{ }^{\mathrm{H}} \mathrm{CNN}$ with 0.5 equiv of $\mathrm{ZrBn}_{4}$ in benzene solution at $80{ }^{\circ} \mathrm{C}$ resulted in clean formation of $\mathrm{Zr}\left({ }^{\mathrm{H}} \mathrm{CNN}\right)_{2}$, which was isolated in excellent yield. The synthesis of $\mathrm{Zr}\left({ }^{\mathrm{Me}} \mathrm{CNN}\right)_{2}$ employing $\mathrm{H}_{2}{ }^{\mathrm{Me}} \mathrm{CNN}$ required more forcing conditions of $130{ }^{\circ} \mathrm{C}$ in a pressure tube and provided only a modest yield of the desired homoleptic zirconium complex after workup. The more challenging $\mathrm{C}-\mathrm{H}$ activation step for $\mathrm{H}_{2}{ }^{\mathrm{Me}} \mathrm{CNN}$ is consistent with the increased steric profile imposed by the additional methyl groups in the ortho-position of the newly formed $\mathrm{Zr}-\mathrm{C}$ bond. The ${ }^{1} \mathrm{H}$ and ${ }^{13} \mathrm{C}$ NMR spectra of $\mathrm{Zr}\left({ }^{\mathrm{H}} \mathrm{CNN}\right)_{2}$ and $\mathrm{Zr}\left({ }^{\mathrm{Me}} \mathrm{CNN}\right)_{2}$ are consistent with $C_{2}$ symmetric molecules with equivalent pincer ligands in solution. Most prominently, both complexes exhibit a significantly downfield shifted resonance for the ipso-carbon of the $\mathrm{Zr}-\mathrm{Ph}$ moiety, which can be found at $191.5 \mathrm{ppm}$ and $191.9 \mathrm{ppm}$ for $\mathrm{Zr}\left({ }^{\mathrm{H}} \mathrm{CNN}\right)_{2}$ and $\mathrm{Zr}\left({ }^{\mathrm{Me}} \mathrm{CNN}\right)_{2}$, respectively. Both compounds are moisture-sensitive in the solid state and in solution and react with water to yield the ligand precursors and $\mathrm{ZrO}_{2}$. The complexes are stable under an atmosphere of dry oxygen in the absence of light but react with $\mathrm{O}_{2}$ upon irradiation with visible light in solution furnishing dark red solids that have so far eluded characterization due to their insolubility in organic solvents. 
Scheme 1. Synthesis of $\mathrm{Zr}\left({ }^{\mathrm{H}} \mathrm{CNN}\right)_{2}$ and $\mathrm{Zr}\left({ }^{\mathrm{Me}} \mathrm{CNN}\right)_{2} .{ }^{\text {a }}$ Solid state structure of $\mathrm{Zr}\left({ }^{\mathrm{H}} \mathrm{CNN}\right)_{2}$ at $30 \%$ probability ellipsoids was shown in the bottom left. Hydrogen atoms were omitted for clarity.

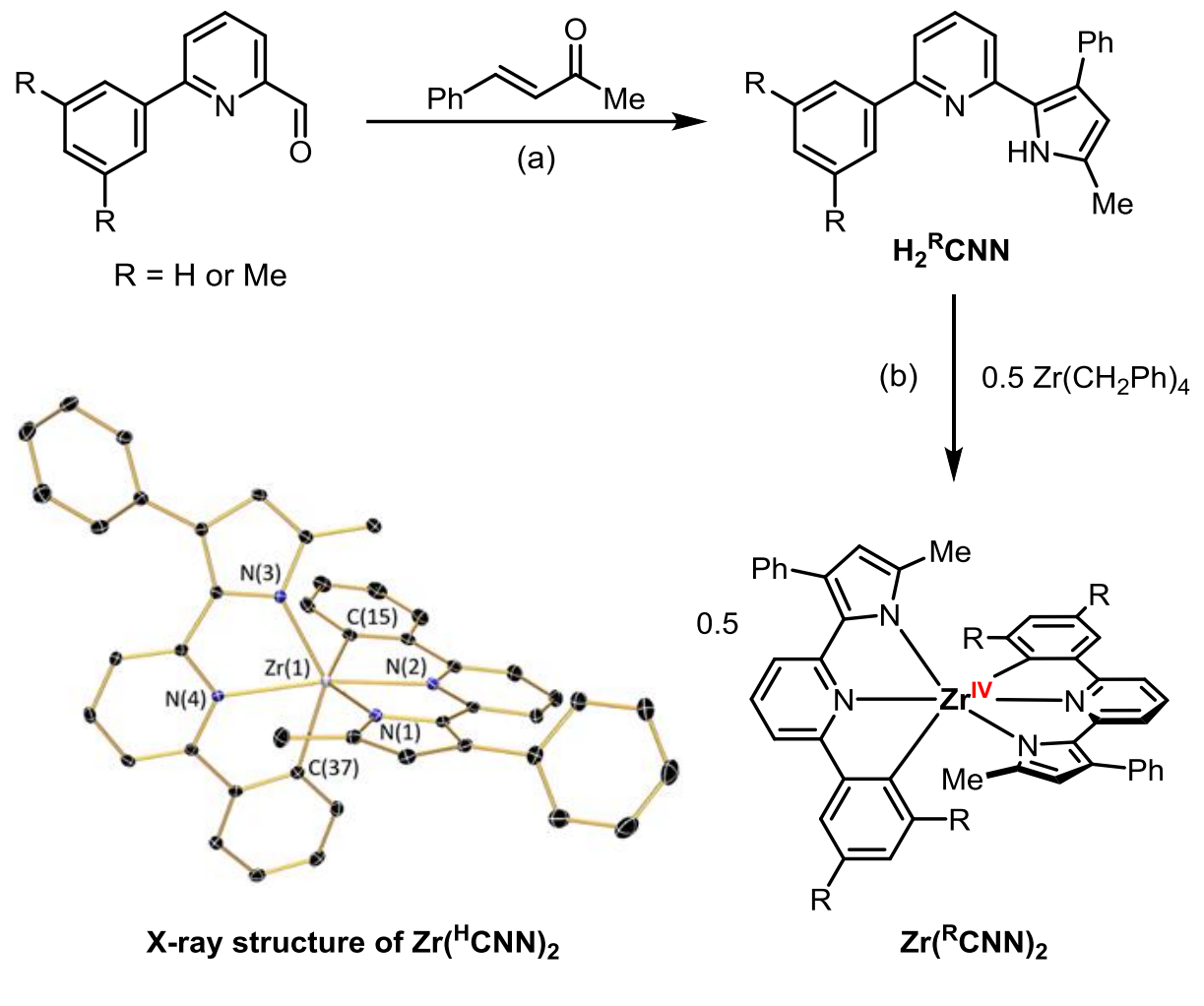

aReagents and conditions: (a) 1) 3-benzyl-5-(2-hydroxyethyl)-4-methyl-thiazolium chloride (50 mol\%), $\mathrm{NaO}^{\mathrm{t}} \mathrm{Bu}(50 \mathrm{~mol} \%)$, EtOH, reflux; 2) $\mathrm{NH}_{4} \mathrm{OAc}, \mathrm{EtOH}$, reflux; (b) $\mathrm{C}_{6} \mathrm{H}_{6}, 80^{\circ} \mathrm{C}(\mathrm{R}=\mathrm{H})$ or $130{ }^{\circ} \mathrm{C}(\mathrm{R}=\mathrm{Me})$.

Single crystals of $\mathrm{Zr}\left({ }^{\mathrm{H}} \mathrm{CNN}\right)_{2} \cdot \mathrm{Et}_{2} \mathrm{O}$ suitable for crystallographic analysis by $\mathrm{X}$-ray diffraction were obtained by cooling a saturated solution of the complex in diethyl ether to $-35^{\circ} \mathrm{C}$. The compound crystallizes in the monoclinic space group $C 2 / c$ and a representation of the molecular structure of $\mathrm{Zr}\left({ }^{\mathrm{H}} \mathrm{CNN}\right)_{2}$ is shown in Scheme 1. Important bond lengths and angles are summarized in Table 1. The coordination environment around the central zirconium ion is best described as a distorted octahedron. The most significant deviation from idealized octahedral geometry is imposed by the small bite angles of the pincer ligand with $\mathrm{N}_{\mathrm{py}}-\mathrm{Zr}-\mathrm{C}_{\mathrm{Ph}}$ and $\mathrm{N}_{\mathrm{py}}-\mathrm{Zr}-$ 
$\mathrm{N}_{\text {pyrrole }}$ angles slightly below $70^{\circ}$. A second, smaller distortion is apparent from the $\mathrm{N}_{\mathrm{py}}-\mathrm{Zr}-\mathrm{N}_{\mathrm{py}}$ angle of $170.50(6)^{\circ}$ for the trans-coordinating pyridine units. The two planes defined by the donor atoms of the pincers are nearly perpendicular with an angle of $85.66^{\circ}$ and both ligand backbones exhibit only minor deviations from planarity. While the molecule does not lie on a crystallographic $C_{2}$ axis, the differences between the two ligands are generally within experimental error and the solid state structure is consistent with the $C_{2}$ symmetry in solution observed by NMR spectroscopy.

Table 1. Selected bond lengths $(\AA)$ and angles $\left({ }^{\circ}\right)$ for $\mathrm{Zr}\left({ }^{\mathrm{H}} \mathrm{CNN}\right)_{2}$.

\begin{tabular}{cc}
\hline & $\mathrm{Zr}\left({ }^{\mathrm{H}} \mathrm{CNN}\right)_{2}$ \\
\hline $\mathrm{Zr}(1)-\mathrm{N}(1)$ & $2.179(2)$ \\
$\mathrm{Zr}(1)-\mathrm{N}(2)$ & $2.330(2)$ \\
$\mathrm{Zr}(1)-\mathrm{C}(15)$ & $2.256(2)$ \\
$\mathrm{Zr}(1)-\mathrm{N}(3)$ & $2.169(2)$ \\
$\mathrm{Zr}(1)-\mathrm{N}(4)$ & $2.345(2)$ \\
$\mathrm{Zr}(1)-\mathrm{C}(37)$ & $2.268(2)$ \\
\hline $\mathrm{N}(1)-\mathrm{Zr}(1)-\mathrm{N}(2)$ & $69.70(6)$ \\
$\mathrm{N}(1)-\mathrm{Zr}(1)-\mathrm{C}(15)$ & $138.02(7)$ \\
$\mathrm{N}(2)-\operatorname{Zr}(1)-\mathrm{C}(15)$ & $69.50(7)$ \\
$\mathrm{N}(3)-\mathrm{Zr}(1)-\mathrm{N}(4)$ & $68.60(6)$ \\
$\mathrm{N}(3)-\operatorname{Zr}(1)-\mathrm{C}(37)$ & $137.56(7)$ \\
$\mathrm{N}(4)-\mathrm{Zr}(1)-\mathrm{C}(37)$ & $69.85(7)$ \\
\hline $\mathrm{N}(2)-\mathrm{Zr}(1)-\mathrm{N}(4)$ & $170.50(6)$ \\
\hline
\end{tabular}

\subsection{Electrochemistry.}

The electrochemical properties of $\mathrm{Zr}\left({ }^{\mathrm{H}} \mathrm{CNN}\right)_{2}$ and $\mathrm{Zr}\left({ }^{\mathrm{Me}} \mathrm{CNN}\right)_{2}$ were studied via cyclic voltammetry $(\mathrm{CV})$. All $\mathrm{CV}$ experiments were conducted with $\left[\mathrm{N}(n-\mathrm{Bu})_{4}\right] \mathrm{PF}_{6}$ as the supporting 
electrolyte $(0.1 \mathrm{M})$ and all potentials were referenced against the $\mathrm{Fc}^{+} / \mathrm{Fc}$ couple using ferrocene $(\mathrm{Fc})$ as an internal standard. The $\mathrm{CVs}$ for the two zirconium complexes measured in 1,2difluorobenzene solution are shown in Figure $1 . \mathrm{Zr}\left({ }^{\mathrm{H}} \mathrm{CNN}\right)_{2}$ undergoes two fully reversible redox events at $-2.27 \mathrm{~V}$ and $-2.64 \mathrm{~V}$, which were assigned to one-electron reductions of the complex. Two irreversible redox processes are observed with anodic peak potentials of $0.41 \mathrm{~V}$ and $0.53 \mathrm{~V}$ and are likely due to ligand-centered oxidation events. An additional feature around $-1 \mathrm{~V}$ is related to these irreversible oxidations and is absent in CVs with turnaround potentials at $0 \mathrm{~V}$. The peak separation between the two oxidation events is solvent dependent with slightly larger peak separation and potentials at $0.46 \mathrm{~V}$ and $0.68 \mathrm{~V}$ in THF solution. In both solvents, the reversibility of the reduction events is negatively affected if the CV scans are conducted with an initial sweep direction towards positive potential, which highlights the irreversibility of the oxidation processes.

On first glance, the redox properties of $\mathrm{Zr}\left({ }^{\mathrm{Me}} \mathrm{CNN}\right)_{2}$ seem nearly identical to those of $\mathrm{Zr}\left({ }^{\mathrm{H}} \mathrm{CNN}\right)_{2}$. Two reversible reductions can be detected at $-2.26 \mathrm{~V}$ and $-2.63 \mathrm{~V}$ indicating that the introduction of electron-donating methyl substituents has only a limited effect on the reduction potentials of the complex compared to the unsubstituted system. In contrast, a significant change is observed upon oxidation of the complex. A single, irreversible oxidation with an anodic peak maximum at $0.51 \mathrm{~V}$ is observed for $\mathrm{Zr}\left({ }^{\mathrm{Me}} \mathrm{CNN}\right)_{2}$. While the oxidation potential is comparable to those for the two events observed for $\mathrm{Zr}\left({ }^{\mathrm{H}} \mathrm{CNN}\right)_{2}$, this redox process has no negative influence on the two reduction events when scans are run towards positive potentials first. This behavior is 
consistent with a reversible electrochemical/chemical (EC) process and is reflected in the wellbehaved reductive feature with a cathodic peak potential of $-1.06 \mathrm{~V}$. While the nature of the reversible chemical process following oxidation of $\mathrm{Zr}\left({ }^{\mathrm{Me}} \mathrm{CNN}\right)_{2}$ is unknown at this point, it is likely that the steric protection introduced by the methyl substituents confers increased stability to the product compared to $\mathrm{Zr}\left({ }^{\mathrm{H}} \mathrm{CNN}\right)_{2}$ and enables reversible (electro)chemistry.

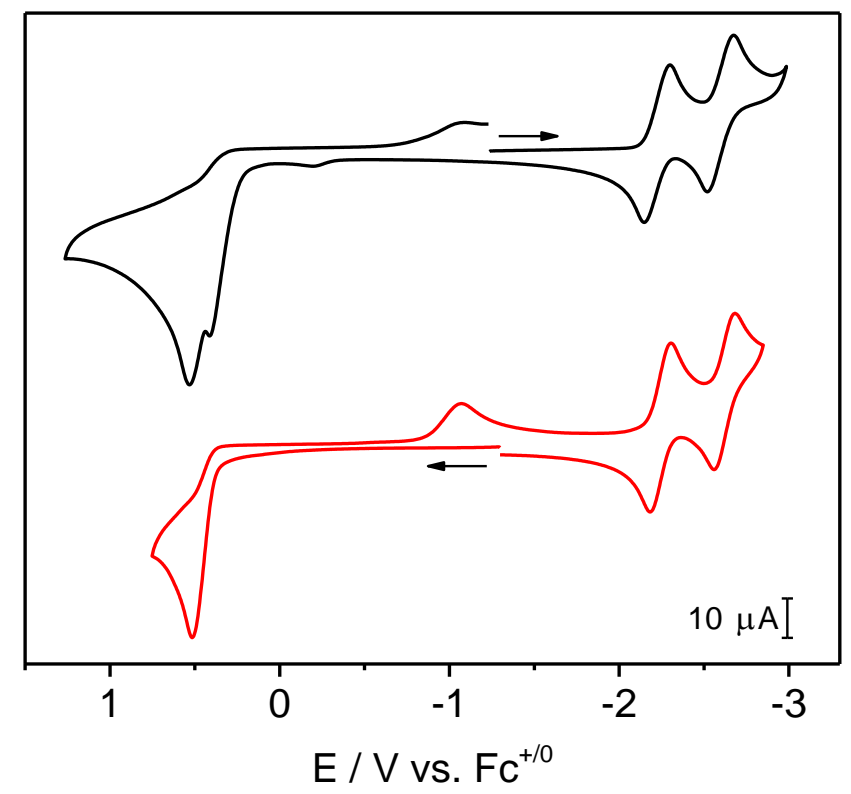

Figure 1. Cyclic voltammograms of $\mathrm{Zr}\left({ }^{\mathrm{H}} \mathrm{CNN}\right)_{2}$ (black, top) and $\mathrm{Zr}\left({ }^{\mathrm{Me}} \mathrm{CNN}\right)_{2}$ (red, bottom) in 1,2difluorobenzene (glassy carbon working electrode, $0.1 \mathrm{M}\left[n-\mathrm{Bu}_{4} \mathrm{~N}\right]\left[\mathrm{PF}_{6}\right]$, scan rate $200 \mathrm{mV} / \mathrm{s}, 295$ $\mathrm{K})$.

\subsection{Optical Properties.}

The optical properties of $\mathrm{Zr}\left({ }^{\mathrm{H}} \mathrm{CNN}\right)_{2}, \mathrm{Zr}\left({ }^{\mathrm{Me}} \mathrm{CNN}\right)_{2}$, and their corresponding ligand precursors $\mathrm{H}_{2}{ }^{\mathrm{R}} \mathrm{CNN}(\mathrm{R}=\mathrm{H}, \mathrm{Me}$ ) were studied in benzene solution at room temperature. The 
electronic absorption spectra of all four compounds are shown in Figure 2. Both ligand precursors exhibit a single absorption band in the UV region of the spectrum with a peak maximum at 341 $\mathrm{nm}\left(\varepsilon=19,300 \mathrm{M}^{-1} \mathrm{~cm}^{-1}\right)$ and $340 \mathrm{~nm}\left(\varepsilon=20,240 \mathrm{M}^{-1} \mathrm{~cm}^{-1}\right)$ for $\mathrm{H}_{2}{ }^{\mathrm{H}} \mathrm{CNN}$ and $\mathrm{H}_{2}{ }^{\mathrm{Me}} \mathrm{CNN}$, respectively. In contrast, both $\mathrm{Zr}\left({ }^{\mathrm{H}} \mathrm{CNN}\right)_{2}$ and $\mathrm{Zr}\left({ }^{\mathrm{Me}} \mathrm{CNN}\right)_{2}$ possess a single strong absorption band in the visible region of the spectrum with maxima at $470 \mathrm{~nm}\left(\varepsilon=14,270 \mathrm{M}^{-1} \mathrm{~cm}^{-1}\right)$ and $471 \mathrm{~nm}(\varepsilon$ $\left.=12,410 \mathrm{M}^{-1} \mathrm{~cm}^{-1}\right)$, respectively. An additional absorption band is observed at $325 \mathrm{~nm}(\varepsilon=25,560$ $\left.\mathrm{M}^{-1} \mathrm{~cm}^{-1}\right)$ for $\mathrm{Zr}\left({ }^{\mathrm{H}} \mathrm{CNN}\right)_{2}$. A similar feature for $\mathrm{Zr}\left({ }^{\mathrm{Me}} \mathrm{CNN}\right)_{2}$ is split into two overlapping signals with maxima at $340 \mathrm{~nm}\left(\varepsilon=22,790 \mathrm{M}^{-1} \mathrm{~cm}^{-1}\right)$ and $316 \mathrm{~nm}\left(\varepsilon=22,400 \mathrm{M}^{-1} \mathrm{~cm}^{-1}\right)$. Analogous to our previous studies for the closely related complex $\mathrm{Zr}\left({ }^{\mathrm{Me}} \mathrm{PDP}^{\mathrm{Ph}}\right)_{2}{ }^{2,3}$ the occurrence of a new absorption band with high extinction coefficient in the visible region illustrates significant impact of the central zirconium ion on the optical properties of the compounds likely due to ligand-tometal charge transfer contributions.

The steady-state emission spectra obtained upon excitation at the lowest energy absorption maximum for each compound mirror the trends observed for the absorption spectra (Figure 2). The emission profiles for the free ligand precursors are almost indistinguishable with emission maxima at $412 \mathrm{~nm}$ and $410 \mathrm{~nm}$ for $\mathrm{H}_{2}{ }^{\mathrm{H}} \mathrm{CNN}$ and $\mathrm{H}_{2}{ }^{\mathrm{Me}} \mathrm{CNN}$, respectively. The emission profiles for the zirconium species are significantly red-shifted compared to the ligand precursors but are nearly identical between the two complexes with maxima at $562 \mathrm{~nm}$ and $565 \mathrm{~nm}$ for $\mathrm{Zr}\left({ }^{\mathrm{H}} \mathrm{CNN}\right)_{2}$ and $\mathrm{Zr}\left({ }^{\mathrm{Me}} \mathrm{CNN}\right)_{2}$, respectively. It is again notable that the introduction of electron-donating substituents 
to the phenyl moieties has a negligible effect on the absorption and emission profiles. Combined with the observations from the electrochemical data this suggests that the phenyl units should have limited contributions to the frontier molecular orbitals involved in the optical transitions as well as outer-sphere electron transfer.
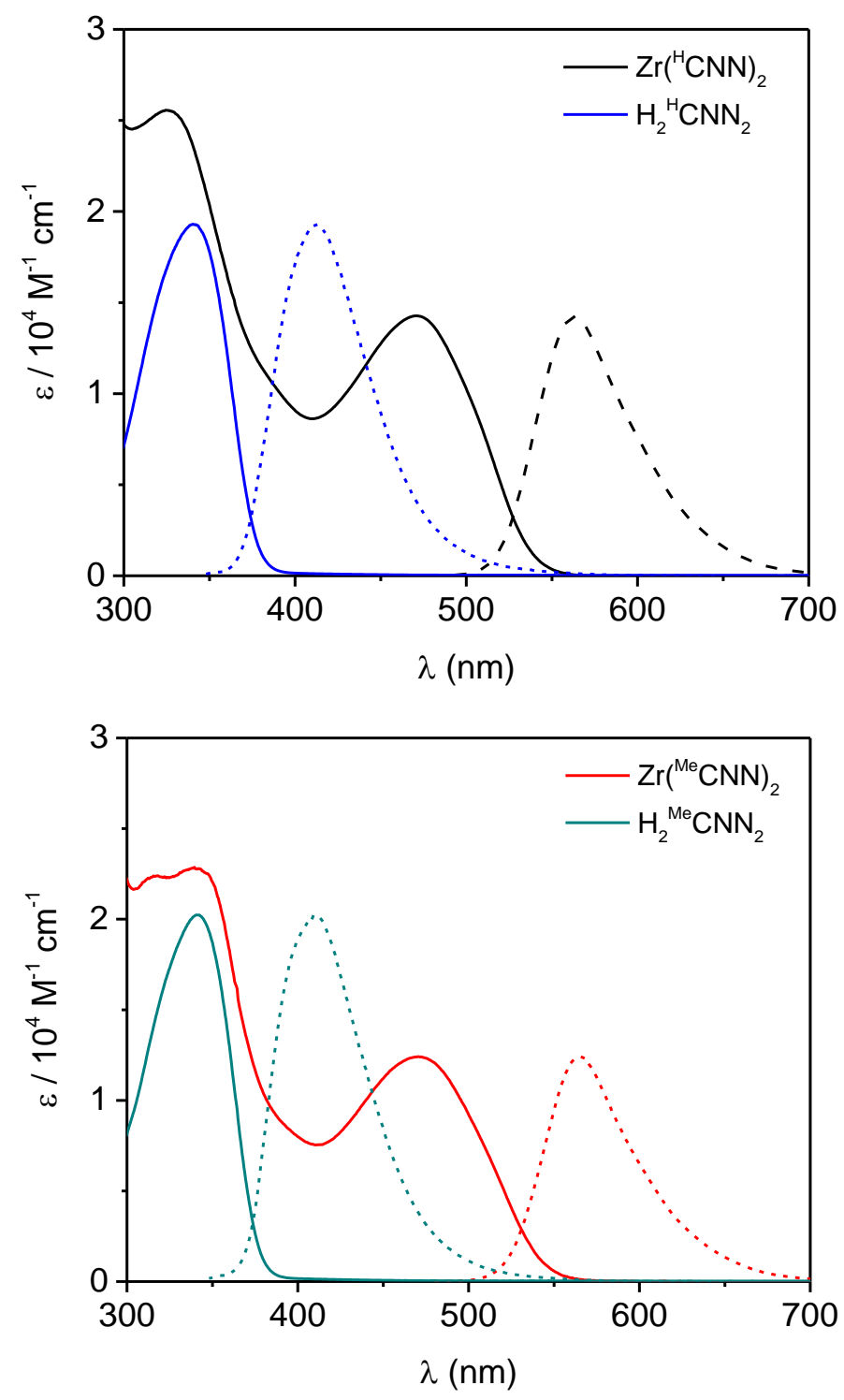

Figure 2. Optical properties of $\mathrm{Zr}\left({ }^{\mathrm{H}} \mathrm{CNN}\right)_{2}$ (top, black), $\mathrm{Zr}\left({ }^{\mathrm{Me}} \mathrm{CNN}\right)_{2}$ (bottom, red) and the corresponding ligand precursors $\mathrm{H}_{2}{ }^{\mathrm{H}} \mathrm{CNN}$ (blue) and $\mathrm{H}_{2}{ }^{\mathrm{Me}} \mathrm{CNN}$ (cran) recorded in benzene solution at room temperature. Solid lines represent the UV-vis absorption profiles and dotted lines show the emission spectra obtained upon excitation at the lowest absorption maximum. 
While the absorption and emission profiles are mostly unperturbed by the addition of methyl substituents, the excited state lifetimes reveal dramatic differences between $\operatorname{Zr}\left({ }^{\mathrm{H}} \mathrm{CNN}\right)_{2}$ and $\mathrm{Zr}\left({ }^{\mathrm{Me}} \mathrm{CNN}\right)_{2}$. As shown in Figure 3, both complexes exhibit long-lived emissive states consistent with phosphorescence. The absence of fast decay pathways upon termination of the excitation pulse is consistent with efficient inter-system crossing to a long-lived triplet state in both complexes. While the time-resolved emission data for $\operatorname{Zr}\left({ }^{\mathrm{Me}} \mathrm{CNN}\right)_{2}$ can be readily fit by a single exponential decay with a lifetime of $\tau=412 \mu$ s, the data for $\mathrm{Zr}\left({ }^{\mathrm{H}} \mathrm{CNN}\right)_{2}$ is more complicated and can only be fit satisfactorily using a bi-exponential approach. This behavior is consistent with two separate decay pathways, in which the majority of the molecules in the excited state decay to the ground state via a faster process with a lifetime of $\tau_{1}=77 \mu$ s while a smaller portion can access a slower process with $\tau_{2}=296 \mu$ s. This significant change in excited state lifetime is also reflected in the emission quantum yields of $\Phi=0.03$ and $\Phi=0.18$ obtained via comparative method for $\mathrm{Zr}\left({ }^{\mathrm{H}} \mathrm{CNN}\right)_{2}$ and $\mathrm{Zr}\left({ }^{\mathrm{Me}} \mathrm{CNN}\right)_{2}$, respectively. With experimental values of $\Phi$ and $\tau$ in hand, the rate constants for radiative decay were determined via $k_{r}=\Phi / \tau$ as $390 \mathrm{~s}^{-1}$ and $437 \mathrm{~s}^{-1}$ for $\mathrm{Zr}\left({ }^{\mathrm{H}} \mathrm{CNN}\right)_{2}$ and its methyl-substituted analog, respectively. The similarity of the obtained $k_{r}$ values suggests that the methyl substituents in $\mathrm{Zr}\left({ }^{\mathrm{Me}} \mathrm{CNN}\right)_{2}$ exert little influence on the rate of phosphorescent emission but are essential for minimizing non-radiative decay pathways by lowering $\mathrm{k}_{\mathrm{nr}}$ $\left(\tau=1 /\left(\mathrm{k}_{\mathrm{r}}+\mathrm{k}_{\mathrm{nr}}\right)\right)$. The limited influence of these substituents on the electronic properties established via steady-state absorption and emission spectroscopy implies that this outcome is primarily due to steric effect. 

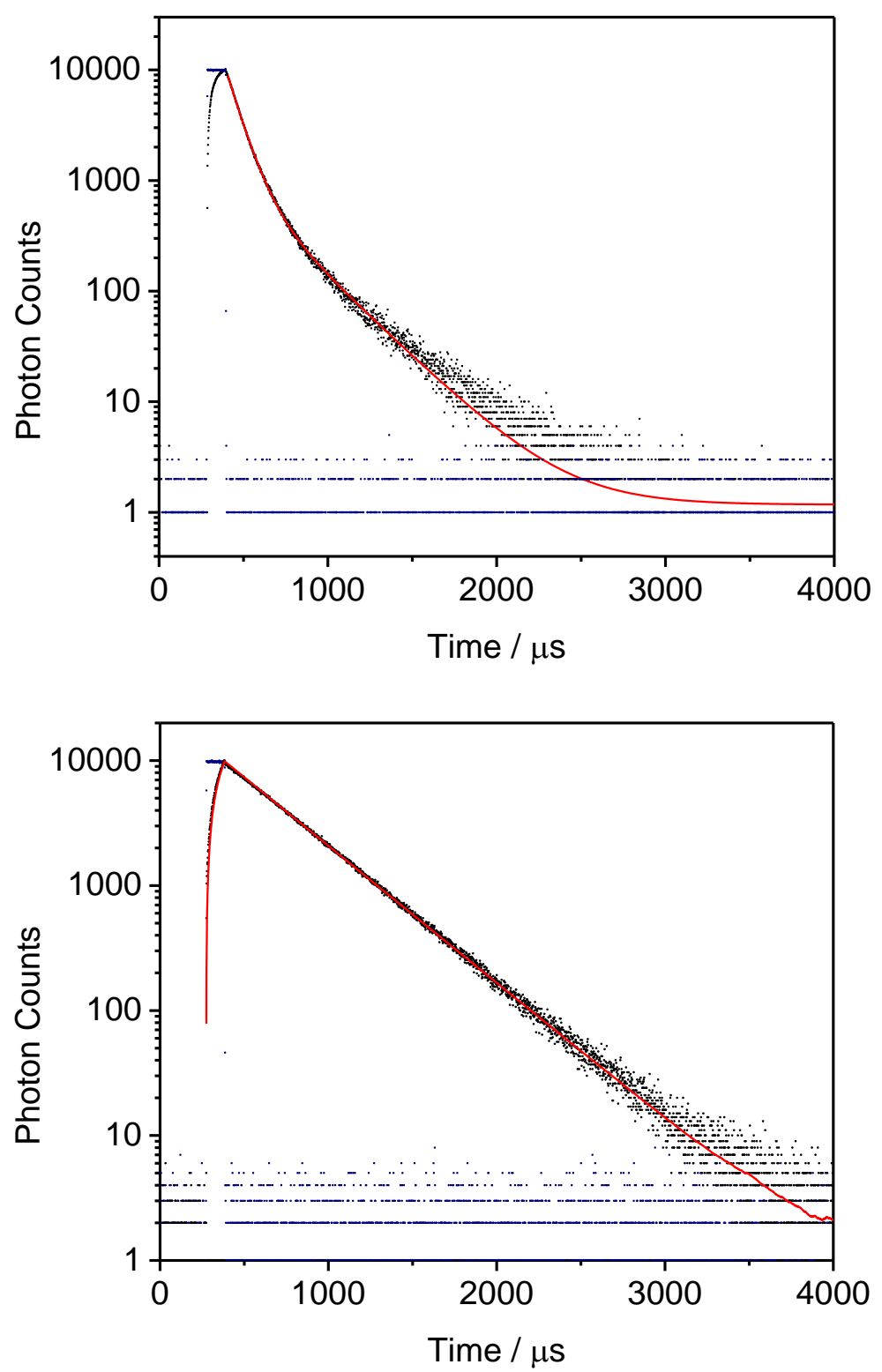

Figure 3. Time-resolved emission data (black) for $\mathrm{Zr}\left({ }^{\mathrm{H}} \mathrm{CNN}\right)_{2}$ (top) and $\mathrm{Zr}\left({ }^{\mathrm{Me}} \mathrm{CNN}\right)_{2}$ (bottom) in benzene solution at room temperature. The data displayed in blue show the time profile of the excitation pulse. Red lines represent exponential fits of the data; fit parameters are provided in the main text. 


\subsection{Density Functional Theory.}

To gain further insight into the frontier molecular orbitals and the resulting optical transitions, ground state and time-dependent density functional theory, (TD-)DFT, calculations were performed for $\mathrm{Zr}\left({ }^{\mathrm{H} C N N}\right)_{2}$. All computations were conducted at the B3LYP level using the crystallographically determined geometry of the untruncated complex as the starting point for geometry optimization. The geometric parameters after optimization shown in Table 2 are in excellent agreement with the experimental data and reproduce the approximately $C_{2}$ symmetric structure observed in the solid state. The largest deviation between corresponding bond distances between the two ligands is observed for the $\mathrm{Zr}-\mathrm{N}_{\text {pyrrole }}$ bonds $(2.2 \mathrm{pm})$. For all remaining bonds the deviation is less than $1 \mathrm{pm}$. As is typically observed for DFT calculations, ${ }^{4}$ the computed zirconium-ligand bond lengths are slightly overestimated by 4-5 pm, while all intraligand bond distances are within 1-2 pm of the experimental values. The optimized structure reproduces the slight deviation from $180^{\circ}$ for the $\mathrm{N}_{\mathrm{py}}-\mathrm{Zr}-\mathrm{N}_{\mathrm{py}}$ angle of the trans-coordinating pyridine rings providing a value of $168.4^{\circ}\left(\exp .170 .5^{\circ}\right)$. The angle between the two planes defined by the three donor atoms of each pincer ligand is also well reproduced at $87.1^{\circ}$ (exp. 85.7 $7^{\circ}$. The electronic absorption spectrum obtained via TD-DFT calculations based on the optimized geometry is shown in Figure 4. The conductor-like screening model (COSMO) was used to simulate a dielectric medium corresponding to the solvent benzene used during experimental data acquisition. ${ }^{5}$ 


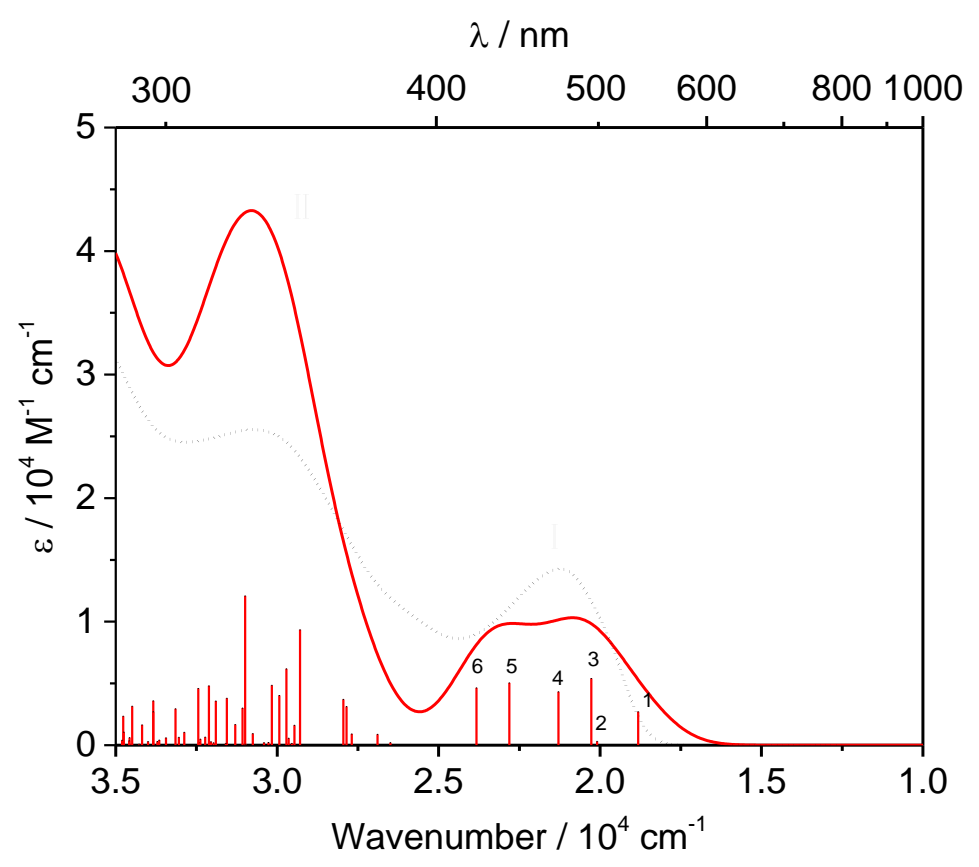

Figure 4. Electronic absorption spectrum of $\mathrm{Zr}\left({ }^{\mathrm{H} C N N}\right)_{2}$ in benzene obtained via TD-DFT calculations (red line, FWHM of $2500 \mathrm{~cm}^{-1}$ ). The stick plot indicates the positions and relative intensities of individual transitions. The major contributions to each numbered state are listed in Table 2. The experimental spectrum is shown as a dotted black line for comparison.

The calculated spectrum is in good agreement with the experimental data. Six TD-DFT states contribute to the absorption band observed in the visible region of the spectrum. The main single-electron excitations contributing to each state are listed in Table 2. A molecular orbital diagram depicting the frontier molecular orbitals (HOMO-1 to LUMO+2) involved in these excitations is provided in Figure 5. Consistent with a central zirconium ion in the $+\mathrm{IV}$ oxidation state $\left(d^{0}\right)$ the doubly occupied donor orbitals (HOMO and HOMO-1) exhibit no contributions from the metal $d$ orbitals and are exclusively ligand centered. The three main acceptor orbitals contain varying amounts of zirconium character ranging from $20 \%$ for the $\mathrm{LUMO}+1$ to $30 \%$ for the 
LUMO+2. Based on this analysis, the transitions giving rise to the absorption band in the visible region are best described as mixed intra-ligand (IL) and ligand-to-metal charge transfer (LMCT) transitions albeit with minor LMCT character of only $20-30 \%$. A closer inspection of the frontier MOs also provides an explanation for the limited influence of the substituents on the phenyl rings on the visible absorption profile of $\mathrm{Zr}\left({ }^{\mathrm{H}} \mathrm{CNN}\right)_{2}$ compared to $\mathrm{Zr}\left({ }^{\mathrm{Me}} \mathrm{CNN}\right)_{2}$ : Neither the donor nor the acceptor orbitals show significant contributions from the $\pi$-system of the phenyl rings. The maximum contribution can be found for the LUMO and amounts to less than $10 \%$ phenyl character for this orbital.

Table 2. Vertical electronic excitation energies and main excitations contributing to the absorption bands of $\mathrm{Zr}\left({ }^{\mathrm{H}} \mathrm{CNN}\right)_{2}$ obtained via TD-DFT calculations

\begin{tabular}{ccccc}
\hline $\begin{array}{c}\text { TD-DFT } \\
\text { State }\end{array}$ & $\begin{array}{c}\text { Energy } / \mathrm{cm}^{-1} \\
(\lambda / \mathrm{nm})\end{array}$ & $\mathrm{f}_{\text {osc }}$ & $\begin{array}{c}\text { Excitations } \\
(\text { weight })^{\mathrm{a}, \mathrm{b}}\end{array}$ & $\begin{array}{c}\text { Character } \\
(\% \mathrm{\%} M \mathrm{CT})\end{array}$ \\
\hline 1 & $18820.3(531.3)$ & 0.031 & $181 \rightarrow 182(0.98)$ & ${ }^{1} \mathrm{IL} /{ }^{1} \mathrm{LMCT}(26 \%)$ \\
2 & $20089.5(497.8)$ & 0.004 & $\begin{array}{c}180 \rightarrow 182(0.80) \\
181 \rightarrow 183(0.19)\end{array}$ & ${ }^{1} \mathrm{IL} /{ }^{1} \mathrm{LMCT}(26 \%)$ \\
3 & $20268.4(493.4)$ & 0.062 & $181 \rightarrow 183(0.77)$ & ${ }^{1} \mathrm{IL} /{ }^{1} \mathrm{LMCT}(20 \%)$ \\
4 & $21286.9(469.8)$ & 0.050 & $180 \rightarrow 182(0.18)$ & \\
5 & $22811.1(438.4)$ & 0.058 & $181 \rightarrow 184(0.86)$ & ${ }^{1} \mathrm{IL} /{ }^{1} \mathrm{LMCT}(30 \%)$ \\
6 & $23829.7(419.6)$ & 0.054 & $180 \rightarrow 184(0.86)$ & ${ }^{1} \mathrm{IL} /{ }^{1} \mathrm{LMCT}(30 \%)$ \\
\hline
\end{tabular}

${ }^{\mathrm{a}}$ Only excitations with a weight larger than 0.1 are shown. ${ }^{\mathrm{b}} \mathrm{HOMO}$ 181, LUMO 182. 

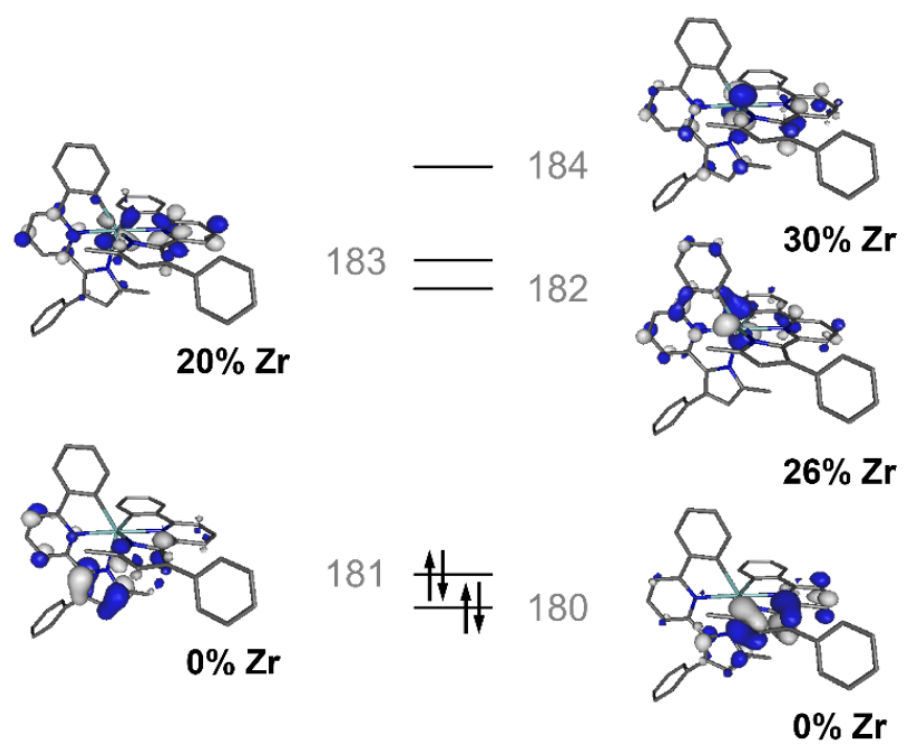

$0 \% \mathrm{Zr}$

Figure 5. Frontier molecular orbital diagram showing the donor and acceptor orbitals contributing to the TD-DFT excitations computed in the visible region of the electronic absorption spectrum. The gray numbers to the right correspond to the MO number with 181 being the HOMO and 182 being the LUMO. Reprinted with permission from \{Zhang, Y.; Petersen, J. L.; and Milsmann, C. Organometallics 2018, 37, 4488-4499\}. Copyright \{2018\} American Chemical Society.

The UV region exhibits a more complex pattern of transitions with a multitude of states giving rise to a single broad absorption feature consistent with the experimental data. A more detailed analysis of the most intense transitions in this area is provided in the Appendix D.

The electronic structure of the emissive triplet state was also explored by DFT calculations. The optimized geometry obtained for the lowest energy triplet state shows a substantial distortion from the close to $C_{2}$ symmetric structure computed for the singlet ground state (Table 3 ). The most significant changes are a shortening of the $\mathrm{Zr}-\mathrm{N}_{\mathrm{py}}$ bond length by almost $10 \mathrm{pm}$ and distortions within the pyridine pyrrole moiety for one of the two pincer ligands. The structural parameters for 
the second pincer are very similar to those found in the singlet ground state. Among the intraligand distances, the most characteristic difference between the two ligands is found for the $\mathrm{C}(3)-\mathrm{C}(4)$ bond length $(\Delta(\mathrm{C}(3)-\mathrm{C}(4))=7.8 \mathrm{pm})$ in the pyrrole ring and the $\mathrm{N}(2)-\mathrm{C}(5)$ bond length of the pyridine ring $(\Delta(\mathrm{N}(2)-\mathrm{C}(5))=3.7 \mathrm{pm})$. Both bonds are elongated compared to the second pincer ligand of the triplet state and the corresponding bonds in the singlet ground state. Altogether, these structural changes are consistent with a triplet excited state that contains a majority contribution from an intraligand charge transfer ( $\left.{ }^{3} \mathrm{ILCT}\right)$ process, in which an electron is transferred from the predominantly pyrrole-centered $\mathrm{HOMO}$ of the singlet ground state $(\mathrm{C}(3)-\mathrm{C}(4)$ bonding) to the mixed pyridine- and zirconium-based LUMO (N(2)-C(5) antibonding, $\mathrm{Zr}(1)-\mathrm{N}(2)$ bonding). The partial metal character of one of the two resulting SOMOs in the triplet excited state is reflected in the spin density distribution (20\% Zr) shown in Figure 6.

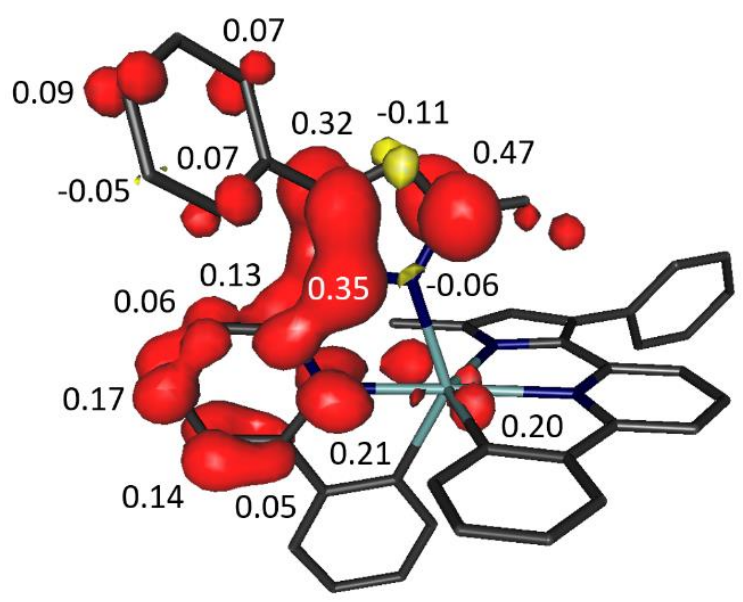

Figure 6. Spin density distribution for the lowest energy triplet state of $\mathrm{Zr}\left({ }^{\mathrm{H}} \mathrm{CNN}\right)_{2}$ obtained via Mulliken population analysis. Reprinted with permission from \{Zhang, Y.; Petersen, J. L.; and Milsmann, C. Organometallics 2018, 37, 4488-4499\}. Copyright $\{2018\}$ American Chemical Society. 
To computationally approximate the emissive triplet-to-singlet transition responsible for the observed phosphorescence of $\mathrm{Zr}\left({ }^{\mathrm{H}} \mathrm{CNN}\right)_{2}$ TD-DFT calculations including spin-forbidden transitions were performed. Initial calculations were conducted based on the structure obtained for the triplet excited state assuming emission from the triplet following the Franck-Condon principle. To our surprise, the lowest triplet-to-singlet transition was predicted to occur at $723 \mathrm{~nm}$, significantly red-shifted with respect to the experimental emission maximum at $562 \mathrm{~nm}$. However, calculations using the same approach based on the more symmetric singlet geometry provided a more accurate value of $568 \mathrm{~nm}$ for the lowest triplet-to-singlet transition. A similar situation was observed in our previous study for the closely related complex $\mathrm{Zr}\left({ }^{\mathrm{Me}} \mathrm{PDP}^{\mathrm{Ph}}\right)_{2} \cdot{ }^{2}$ Based on these results we propose that emission from the triplet to the singlet state occurs from a symmetric structure closer to the equilibrium geometry of the singlet ground state in which spin-orbit coupling is maximized due to contributions from a degenerate set of metal d orbitals. According to the computed asymmetric structure of the triplet state, such a transition would likely have to occur from a vibrationally excited state of the triplet state, which could provide an explanation for the long phosphorescence lifetime observed experimentally. More detailed spectroscopic studies supporting this hypothesis are currently underway in our laboratory. 
Table 3. Selected Bond Distances for the $\mathrm{S}_{0}$ and $\mathrm{T}_{1}$ Geometries of $\mathrm{Zr}\left({ }^{\mathrm{H}} \mathrm{CNN}\right)_{2}$ obtained via DFT Calculations. Reprinted with permission from \{Zhang, Y.; Petersen, J. L.; and Milsmann, C. Organometallics 2018, 37, 4488-4499\}. Copyright \{2018\} American Chemical Society.

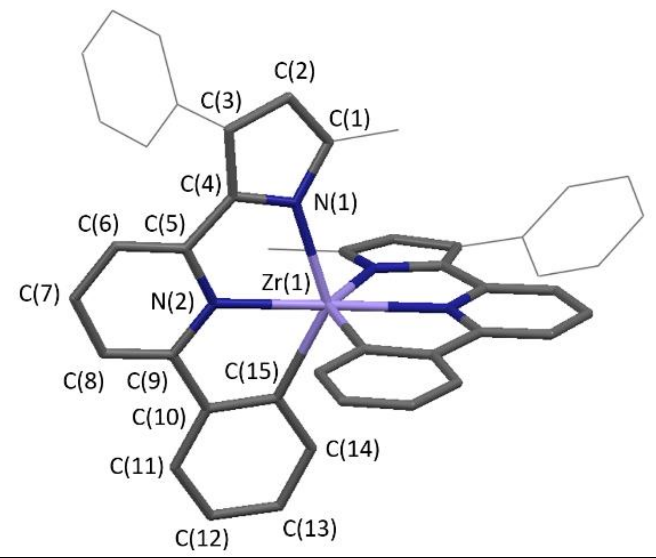

\begin{tabular}{lcccc}
\hline & \multicolumn{2}{c}{ Singlet $(\mathrm{RKS})^{\mathrm{a}}$} & \multicolumn{2}{c}{ Triplet (UKS3) } \\
& Ligand 1 & Ligand 2 & Ligand 1 & Ligand 2 \\
\hline $\mathrm{Zr}(1)-\mathrm{N}(1)$ & 2.208 & 2.230 & 2.229 & 2.266 \\
$\mathrm{Zr}(1)-\mathrm{N}(2)$ & 2.376 & 2.366 & 2.380 & 2.290 \\
$\mathrm{Zr}(1)-\mathrm{C}(15)$ & 2.287 & 2.290 & 2.299 & 2.286 \\
\hline $\mathrm{N}(1)-\mathrm{C}(1)$ & 1.369 & 1.369 & 1.367 & 1.386 \\
$\mathrm{C}(1)-\mathrm{C}(2)$ & 1.384 & 1.387 & 1.384 & 1.403 \\
$\mathrm{C}(2)-\mathrm{C}(3)$ & 1.416 & 1.411 & 1.416 & 1.387 \\
$\mathrm{C}(3)-\mathrm{C}(4)$ & 1.400 & 1.397 & 1.401 & 1.479 \\
$\mathrm{~N}(1)-\mathrm{C}(4)$ & 1.390 & 1.392 & 1.390 & 1.371 \\
$\mathrm{C}(4)-\mathrm{C}(5)$ & 1.439 & 1.434 & 1.440 & 1.416 \\
\hline $\mathrm{N}(2)-\mathrm{C}(5)$ & 1.359 & 1.358 & 1.360 & 1.397 \\
$\mathrm{C}(5)-\mathrm{C}(6)$ & 1.404 & 1.405 & 1.404 & 1.401 \\
$\mathrm{C}(6)-\mathrm{C}(7)$ & 1.380 & 1.379 & 1.380 & 1.383 \\
$\mathrm{C}(7)-\mathrm{C}(8)$ & 1.393 & 1.395 & 1.392 & 1.405 \\
$\mathrm{C}(8)-\mathrm{C}(9)$ & 1.390 & 1.388 & 1.391 & 1.389 \\
$\mathrm{~N}(2)-\mathrm{C}(9)$ & 1.354 & 1.354 & 1.355 & 1.365 \\
\hline $\mathrm{C}(9)-\mathrm{C}(10)$ & 1.475 & 1.474 & 1.476 & 1.469 \\
$\mathrm{C}(10)-\mathrm{C}(11)$ & 1.398 & 1.397 & 1.399 & 1.399 \\
$\mathrm{C}(11)-\mathrm{C}(12)$ & 1.389 & 1.389 & 1.388 & 1.388 \\
$\mathrm{C}(12)-\mathrm{C}(13)$ & 1.391 & 1.391 & 1.391 & 1.392 \\
$\mathrm{C}(13)-\mathrm{C}(14)$ & 1.393 & 1.394 & 1.393 & 1.393 \\
$\mathrm{C}(14)-\mathrm{C}(15)$ & 1.399 & 1.399 & 1.401 & 1.400 \\
$\mathrm{C}(10)-\mathrm{C}(15)$ & 1.410 & 1.410 & 1.411 & 1.412 \\
\hline $\mathrm{N} 0 \mathrm{sym}$ &
\end{tabular}

${ }^{\mathrm{a}}$ No symmetry constraints were applied during geometry optimization. 


\subsection{Photoredox Properties of $\mathrm{Zr}\left({ }^{\mathrm{H}} \mathrm{CNN}\right)_{2}$ and $\mathrm{Zr}\left({ }^{\mathrm{Me}} \mathrm{CNN}\right)_{2}$.}

By combining the information obtained from the electrochemical and steady-state emission measurements the excited state redox potentials of the two zirconium complexes were estimated. The emission maxima were used as first-order approximations for the energy difference, $E_{0}$, between the triplet excited state and the ground state. With $E_{0}$ values of $2.21 \mathrm{eV}$ and $2.19 \mathrm{eV}$ and ground state redox potentials, $E_{1 / 2}\left([\mathrm{Zr}] /[\mathrm{Zr}]^{1-}\right)$, of $-2.27 \mathrm{~V}$ and $-2.26 \mathrm{~V}$ the excited state potentials, $E_{1 / 2}\left([\mathrm{Zr}]^{*} /[\mathrm{Zr}]^{1-}\right)$, were calculated as $-0.06 \mathrm{~V}$ and $-0.07 \mathrm{~V}$ for $\mathrm{Zr}\left({ }^{\mathrm{H}} \mathrm{CNN}\right)_{2}$ and $\mathrm{Zr}\left({ }^{\mathrm{Me}} \mathrm{CNN}\right)_{2}$,

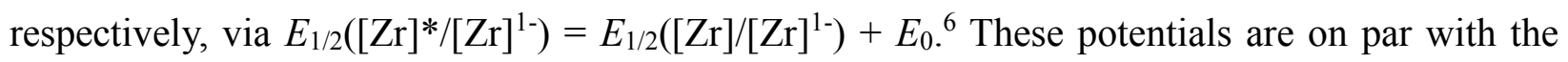
excited state redox potential of $\mathrm{Zr}\left({ }^{\mathrm{Me}} \mathrm{PDP}{ }^{\mathrm{Ph}}\right)_{2}$, which can act as a photosensitizer for reductive photoredox reactions. ${ }^{3}$ Notably, the more negative ground state redox potentials of $\mathrm{Zr}\left({ }^{\mathrm{R}} \mathrm{CNN}\right)_{2}$ compared to $\mathrm{Zr}\left({ }^{\mathrm{Me}} \mathrm{PDP}{ }^{\mathrm{Ph}}\right)_{2}$ are offset by the blue-shifted emission profiles, which indicate increased energy storage in the excited state.

With the excited state potentials in hand, $\mathrm{Zr}\left({ }^{\mathrm{H}} \mathrm{CNN}\right)_{2}$ and $\mathrm{Zr}\left({ }^{\mathrm{Me}} \mathrm{CNN}\right)_{2}$ were tested as photosensitizers in the reductive homocoupling of benzyl bromide to bibenzyl. This well-studied reaction has been employed by several research groups as a benchmark system for reductive photoredox transformations using various precious metal and earth-abundant photosensitizers. ${ }^{7-9}$ Using our previously reported conditions $^{2}$ with 1,3-dimethyl-2-phenyl-2,3-dihydro-1H-7methoxybenzo[ $d]$ imidazole, ${ }^{\mathrm{MeO}} \mathrm{BIH}$, as the sacrificial reductant and triethylamine as the base the desired coupling product was obtained in $40 \%$ yield after irradiation with blue light $\left(\mathrm{LED}, \lambda_{\max }=\right.$ 
$462 \mathrm{~nm}$ ) for 20 hours in the presence of $5 \mathrm{~mol} \% \mathrm{Zr}\left({ }^{\mathrm{Me}} \mathrm{CNN}\right)_{2}$ (Table 4). The outcome of the reaction changed dramatically when $\mathrm{Zr}\left({ }^{\mathrm{H}} \mathrm{CNN}\right)_{2}$ was used as the photosensitizer under otherwise identical conditions. While only a small amount of bibenzyl (10\% yield) was obtained, ${ }^{1} \mathrm{H}$ NMR spectroscopy indicated complete decomposition of $\mathrm{Zr}\left({ }^{\mathrm{H}} \mathrm{CNN}\right)_{2}$. Further experiments showed that catalyst decomposition occurred rapidly within only 2 hours of irradiation and without consumption of sacrificial reductant but providing a consistent amount of bibenzyl (10\%).

Table 4. Photoredox catalytic homocoupling of benzyl bromide with $\mathrm{Zr}\left({ }^{\mathrm{R}} \mathrm{CNN}\right)_{2}$ as catalysts.

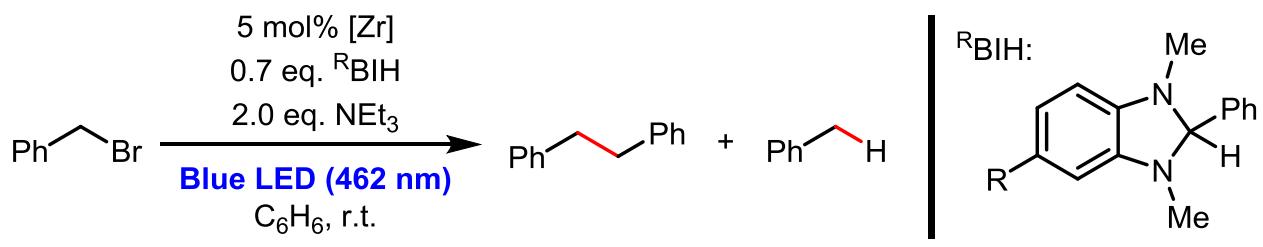

\begin{tabular}{|c|c|c|c|c|c|c|}
\hline \multirow{2}{*}{ Entry } & \multirow{2}{*}[\mathrm{Zr}]{} & \multirow{2}{*}{${ }^{\mathrm{R}} \mathrm{BIH}$} & \multirow{2}{*}{ Time (h) } & \multicolumn{2}{|c|}{ Yield $^{a} \%$} & \multirow{2}{*}{ Conv ${ }^{a, c}$} \\
\hline & & & & b & c & \\
\hline 1 & $\mathrm{Zr}\left({ }^{\mathrm{H}} \mathrm{CNN}\right)_{2}$ & ${ }^{\mathrm{H}} \mathrm{BIH}$ & $2^{b}$ & 10 & 0 & 16 \\
\hline 2 & $\mathrm{Zr}\left({ }^{\mathrm{Me}} \mathrm{CNN}\right)_{2}$ & ${ }^{\mathrm{H}} \mathrm{BIH}$ & 20 & 26 & 5 & 67 \\
\hline 3 & $\mathrm{Zr}\left({ }^{\mathrm{Me}} \mathrm{CNN}\right)_{2}$ & ${ }^{\mathrm{MeO}} \mathrm{BIH}$ & 20 & 40 & 9 & 95 \\
\hline
\end{tabular}

Inspired by these observations, direct photoreactions between benzyl bromide and $\mathrm{Zr}\left({ }^{\mathrm{R}} \mathrm{CNN}\right)_{2}$ were investigated. Initial control experiments conducted in $\mathrm{C}_{6} \mathrm{D}_{6}$ solution established that both complexes are photo-stable upon irradiation with blue light $(72 \mathrm{~h})$ and that neither zirconium complex reacts directly with benzyl bromide in the absence of light. Furthermore, the 
methyl substituted complex $\mathrm{Zr}\left({ }^{\mathrm{Me}} \mathrm{CNN}\right)_{2}$ reacts only sluggishly in the presence of 10 equivalents of benzyl bromide even upon prolonged irradiation with blue light. Analysis of the reaction mixture by ${ }^{1} \mathrm{H}$ NMR spectroscopy after 4 days of irradiation revealed a complex mixture of products in addition to unreacted starting material (Figure ES2). In contrast, clean conversion to a new diamagnetic species was observed under similar conditions for $\mathrm{Zr}\left({ }^{\mathrm{H}} \mathrm{CNN}\right)_{2}$ within 4 hours of irradiation on a small scale in an NMR tube (Figure ES1). An equimolar amount of bibenzyl was detected as the only byproduct of the reaction. Preparative scale reactions required longer irradiation times of up to $24 \mathrm{~h}$ but allowed isolation of the new zirconium species in $64 \%$ yield. The most remarkable feature of this complex immediately detectable by ${ }^{13} \mathrm{C}$ NMR spectroscopy is the absence of a downfield shifted signal indicative of a $\mathrm{Zr}-\mathrm{Ph}$ bond, which suggests photochemical $\mathrm{Zr}-\mathrm{C}$ bond cleavage.

The identity of the zirconium complex $\mathrm{Zr}(\mathrm{DPDP}) \mathrm{Br}_{2}\left(\mathrm{H}_{4} \mathrm{DPDP}=2,2^{\prime}\right.$-bis(6-(5-methyl-3phenyl-1H-pyrrol-2-yl)-pyridin-2-yl)biphenyl) was established by X-ray diffraction and a representation of the molecular structure is shown in Figure 7. The structure confirms the absence of a $\mathrm{Zr}-\mathrm{C}$ bond and reveals $\mathrm{C}-\mathrm{C}$ bond formation between the two ipso-C atoms of the $\mathrm{Zr}\left({ }^{\mathrm{H}} \mathrm{CNN}\right)_{2}$ starting material. It is noteworthy that the solid state molecular structure of $\mathrm{Zr}(\mathrm{DPDP}) \mathrm{Br}_{2}$ exhibits $C_{1}$ symmetry, which is inconsistent with the data obtained via NMR spectroscopy in solution that suggests higher symmetry with equivalent pyrrole and pyridine heterocycles. The appearance of higher symmetry in solution is likely due to a fast dynamic process that renders the heterocycles 
equivalent on the NMR timescale. While the mechanism of the overall transformation (Table 5) is not clear at this point and likely proceeds via single-electron steps, $\mathrm{Zr}(\mathrm{DPDP}) \mathrm{Br}_{2}$ can be viewed as the product of a formal $\mathrm{C}-\mathrm{C}$ reductive elimination with concomitant oxidation by two equivalents of benzyl bromide. Formal aryl-aryl reductive eliminations in zirconium complexes have been reported previously for diaryl zirconocene derivatives ${ }^{10-12}$ and a diphenyl zirconium complex with redox-active ligands. ${ }^{13}$ However, these examples require either activation by UV light or occur under thermal conditions upon treatment with strong single electron oxidants. To the best of our knowledge, the system presented herein represents the first example for photochemical aryl-aryl bond formation at zirconium using visible light.

Table 5. Photochemical reaction of $\mathrm{Zr}\left({ }^{\mathrm{H}} \mathrm{CNN}\right)_{2}$ with benzyl bromide.

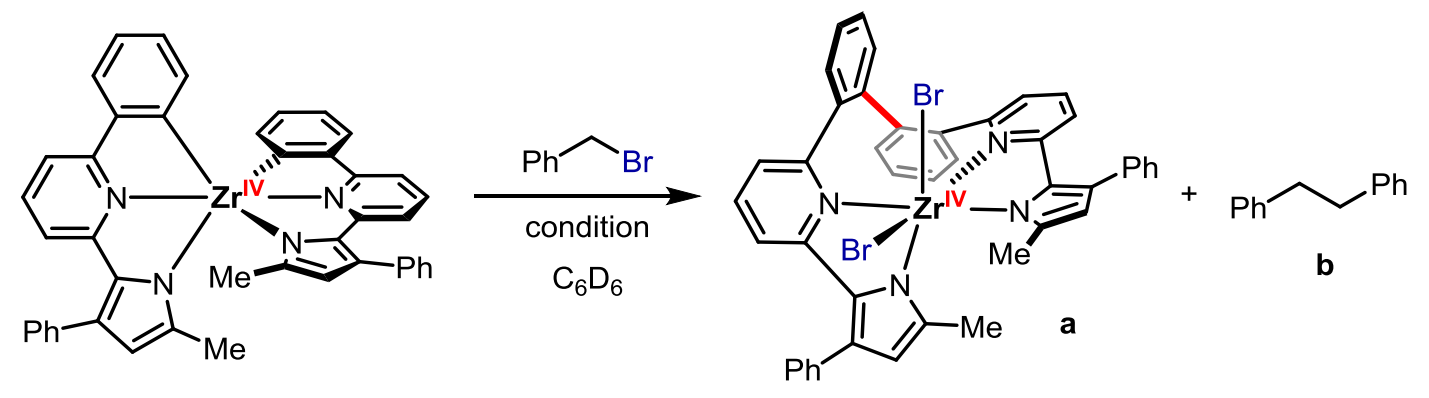

\begin{tabular}{|c|c|c|c|c|c|c|}
\hline \multirow{2}{*}{ Entry } & \multirow{2}{*}{$\begin{array}{l}\text { Blue } \\
\text { Light }\end{array}$} & \multirow{2}{*}{$\begin{array}{c}\text { Temp. } \\
\left({ }^{\circ} \mathrm{C}\right)\end{array}$} & \multirow{2}{*}{$\begin{array}{l}\text { Time } \\
\text { (h) }\end{array}$} & \multicolumn{2}{|c|}{ Yield $^{\mathrm{a}} \%$} & \multirow{2}{*}{ Conv. } \\
\hline & & & & $\mathbf{a}$ & $\mathbf{b}$ & \\
\hline 1 & No & r.t. & 20 & 0 & 0 & 0 \\
\hline 2 & Yes & r.t. & 4 & $83(64)$ & 81 & 100 \\
\hline 3 & No & 120 & 48 & 12 & 15 & 100 \\
\hline
\end{tabular}




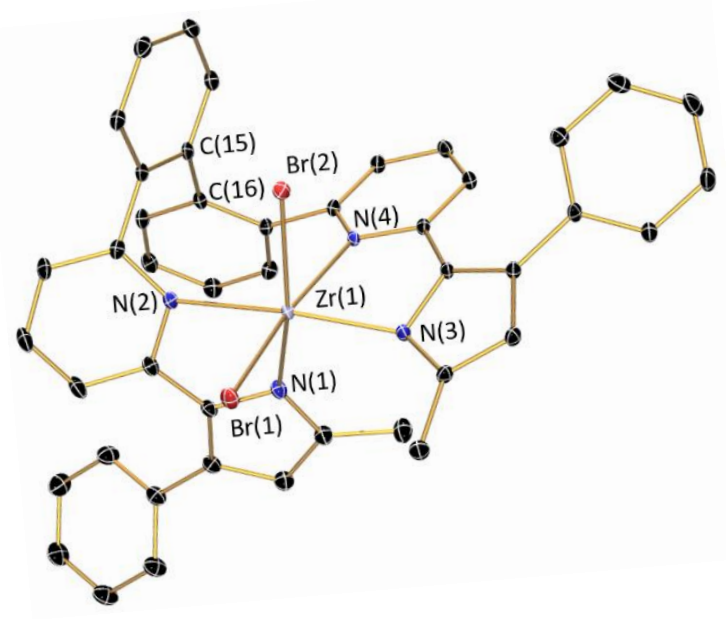

Figure 7. Solid state molecular structure of $\mathrm{Zr}(\mathrm{DPDP}) \mathrm{Br}_{2}$ at $30 \%$ probability ellipsoids. Hydrogen atoms were omitted for clarity. Reprinted with permission from \{Zhang, Y.; Petersen, J. L.; and Milsmann, C. Organometallics 2018, 37, 4488-4499\}. Copyright $\{2018\}$ American Chemical Society.

On the basis of the observed photochemical reactivity of $\mathrm{Zr}\left({ }^{\mathrm{H}} \mathrm{CNN}\right)_{2}$, dibenzyl disulfide was employed as an alternative mild oxidant to promote oxidative $\mathrm{C}-\mathrm{C}$ bond formation between the two ${ }^{\mathrm{H}} \mathrm{CNN}$ ligands. Upon irradiation with blue light, clean conversion to $\mathrm{Zr}(\mathrm{DPDP})(\mathrm{SBn})_{2}$ was observed and the complex was isolated in $75 \%$ yield (Scheme 2). Control experiments in the absence of light confirmed the photochemical nature of this transformation as no reaction was observed under dark conditions. 
Scheme 2. Photochemical reaction of $\mathrm{Zr}\left({ }^{\mathrm{H}} \mathrm{CNN}\right)_{2}$ with dibenzyl disulfide.
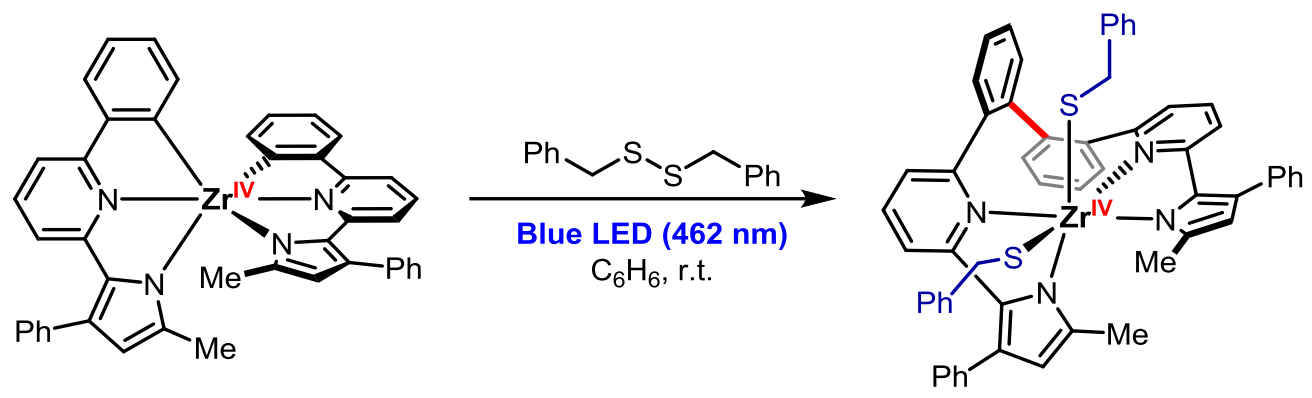

As a final control experiment the reaction between both $\mathrm{Zr}\left({ }^{\mathrm{R}} \mathrm{CNN}\right)_{2}$ complexes and iodine was explored to address whether the $\mathrm{C}-\mathrm{C}$ bond formation could be induced in the absence of light by sufficiently strong oxidants. Both compounds react readily but unselectively with $\mathrm{I}_{2}$ providing a complex mixture of products and highlighting the remarkable selectivity of the photoreactivity of $\mathrm{Zr}\left({ }^{\mathrm{H}} \mathrm{CNN}\right)_{2}$ with mild oxidants.

The combination of the photochemical experiments with the data from time-resolved emission spectroscopy (vide supra) provides an interesting starting point for mechanistic considerations. The bi-exponential decay profile and reduced lifetime for $\operatorname{Zr}\left({ }^{\mathrm{H}} \mathrm{CNN}\right)_{2}$ compared to $\mathrm{Zr}\left({ }^{\mathrm{Me}} \mathrm{CNN}\right)_{2}$ suggests that the unsubstituted complex can undergo an intramolecular photochemical process upon visible light excitation that is not available to the more sterically protected complex. However, the long-time photostability of $\mathrm{Zr}\left({ }^{\mathrm{H}} \mathrm{CNN}\right)_{2}$ established by NMR spectroscopy after prolonged irradiation in the absence of oxidants indicates that this process must be fully reversible. More detailed studies supporting this hypothesis are currently underway in our laboratory. 


\subsection{Conclusion.}

The luminescent early transition metal complexes $\mathrm{Zr}\left({ }^{\mathrm{H}} \mathrm{CNN}\right)_{2}$ and $\mathrm{Zr}\left({ }^{\mathrm{Me}} \mathrm{CNN}\right)_{2}$ were successfully synthesized and characterized and their electrochemical and optical properties were established. The complexes exhibit rich electron-transfer chemistry with two reversible singleelectron reductions at chemically accessible potentials. The introduction of methyl groups adjacent to the zirconium-carbon bond of the phenyl ring enables an additional reversible EC process in $\mathrm{Zr}\left({ }^{\mathrm{Me}} \mathrm{CNN}\right)_{2}$. Both compounds can access long-lived excited states upon excitation with visible light resulting in phosphorescent emission with lifetimes in the microsecond range and luminescence quantum yields of $3 \%$ for $\mathrm{Zr}\left({ }^{\mathrm{H}} \mathrm{CNN}\right)_{2}$ and $18 \%$ for $\mathrm{Zr}\left({ }^{\mathrm{Me}} \mathrm{CNN}\right)_{2}$ in benzene solution at room temperature. Density functional theoretical calculations allowed the assignment of the absorption bands in the visible region as mixed IL/LMCT transitions with $20-30 \%$ LMCT character. Computational studies of the lowest energy triplet state are consistent with a mixed ${ }^{3} \mathrm{IL} /{ }^{3} \mathrm{LMCT}$ state and revealed a significant distortion from the $C_{2}$ symmetric structure of the singlet ground state that likely contributes to the remarkably long emission lifetimes.

The absence of methyl substituents adjacent to the $\mathrm{Zr}-\mathrm{C}$ bond in $\mathrm{Zr}\left({ }^{\mathrm{H}} \mathrm{CNN}\right)_{2}$ compared to $\mathrm{Zr}\left({ }^{\mathrm{Me}} \mathrm{CNN}\right)_{2}$ has a pronounced effect on the photochemical reactivity of the complexes. While the predominant mode of reactivity for $\mathrm{Zr}\left({ }^{\mathrm{Me}} \mathrm{CNN}\right)_{2}$ is photoinduced outer-sphere electron transfer that enables photoredox catalysis, $\mathrm{Zr}\left({ }^{\mathrm{H}} \mathrm{CNN}\right)_{2}$ undergoes $\mathrm{C}-\mathrm{C}$ reductive elimination upon photoexcitation in the presence of mild oxidants resulting in the formation of $\mathrm{Zr}(\mathrm{DPDP}) \mathrm{X}_{2}(\mathrm{X}=$ 
$\mathrm{Br}$ or $\mathrm{SBn}$ ) complexes. This difference in photoreactivity between the two complexes is also apparent from time-resolved emission studies that show a simple single-exponential decay for $\mathrm{Zr}\left({ }^{\mathrm{Me}} \mathrm{CNN}\right)_{2}$ and a more complex bi-exponential behavior for $\mathrm{Zr}\left({ }^{\mathrm{H}} \mathrm{CNN}\right)_{2}$.

\subsection{Experimental Section}

General experimental considerations for material handling, physical measurements, X-ray crystallography, and DFT Calculations as well as additional experimental information (i.e. NMR spectra) can be found in the appendices.

Starting Materials. Tetrabenzyl zirconium, ${ }^{14}$ 2-phenyl-6-pyridincarboxaldehyde, ${ }^{15-17}$ and 6-(3,5Dimethylphenyl)-2-pyridinecarboxyaldehyde ${ }^{18}$ were prepared following literature procedures.

Preparation of 2-phenyl-6-(5-methyl-3-phenyl-1H-pyrrol-2-yl)pyridine, $\mathrm{H}_{2}{ }^{\mathrm{H}} \mathrm{CNN}$ : 2-phenyl6-pyridincarboxaldehyde (2.00 g, $10.92 \mathrm{mmol}, 1.00$ equiv), 4-phenyl-3-buten-2-one (1.76 g, 12.01 mmol, 1.10 equiv), and 3-benzyl-5-(2-hydroxyethyl)-4-methyl-thiazolium chloride (1.47 g, 5.46 mmol, 0.5 equiv), were mixed in a $250 \mathrm{~mL}$ Schlenk flask under an argon atmosphere. $10 \mathrm{~mL}$ of absolute ethanol were added. A solution of sodium tert-butoxide (525 mg, $5.46 \mathrm{mmol}, 0.5$ equiv) in ethanol was added via syringe and the mixture was heated to $80{ }^{\circ} \mathrm{C}$ for 1 hours during which the 1,4-diketone intermediate precipitated out. The reaction was cooled to room temperature. The solid was collected via filtration and wash three times with cold ethanol. Then, the 1,4-diketone intermediate was mixed with ammonium acetate $(8.41 \mathrm{~g}, 109.17 \mathrm{mmol}, 10.00$ equiv) in $10 \mathrm{~mL}$ of 
absolute ethanol and the reaction mixture was heated to reflux. After 12 hours, the solvent was removed. The resulting residue was diluted with $\mathrm{H}_{2} \mathrm{O}$ and the product was extracted with ethyl acetate three times. The combined organic layers were washed with saturated $\mathrm{NaHCO}_{3}$ solution, brine, and dried over $\mathrm{Na}_{2} \mathrm{SO}_{4}$. Removal of ethyl acetate and drying under high vacuum yielded the desired product as a brown solid (Yield: 2.456 g, 72\%). M.p. 112 - $113{ }^{\circ} \mathrm{C} .{ }^{1} \mathrm{H}$ NMR (400 MHz, $\left.\mathrm{C}_{6} \mathrm{D}_{6} ; \delta, \mathrm{ppm}\right): 9.30(\mathrm{br}, 1 \mathrm{H}), 8.06(\mathrm{~d}, J=7.2 \mathrm{~Hz}, 2 \mathrm{H}), 7.61(\mathrm{~d}, J=7.2 \mathrm{~Hz}, 2 \mathrm{H}), 7.40-7.10(\mathrm{~m}$, 7H), $7.04(\mathrm{~d}, J=7.6 \mathrm{~Hz}, 1 \mathrm{H}), 6.89(\mathrm{t}, J=7.6 \mathrm{~Hz}, 1 \mathrm{H}), 6.08(\mathrm{~s}, 1 \mathrm{H}), 1.82(\mathrm{~s}, 3 \mathrm{H}) .{ }^{13} \mathrm{C} \mathrm{NMR}(101$ $\mathrm{MHz}, \mathrm{C}_{6} \mathrm{D}_{6} ; \delta$, ppm): 156.89, 151.39, 140.41, 138.59, 136.93, 129.90, 129.34, 129.05, 128.89, 128.89, 127.41, 126.81, 126.31, 126.06, 118.09, 117.10, 111.54, 12.60. HRMS (ESI) calcd for $\mathrm{C}_{22} \mathrm{H}_{19} \mathrm{~N}_{2}{ }^{+}[\mathrm{M}+\mathrm{H}]^{+} \mathrm{m} / \mathrm{z}$ 311.15428; Found 311.15409.

Preparation of 2-(3,5-dimethyl-phenyl)-6-(5-methyl-3-phenyl-1H-pyrrol-2-yl)pyridine, $\mathbf{H}^{\mathrm{Me}}$ CNN: 6-(3,5-Dimethylphenyl)-2-pyridinecarboxyaldehyde (2.60 g, $12.31 \mathrm{mmol}, 1.00$ equiv), 4-phenyl-3-buten-2-one (1.89 g, $12.92 \mathrm{mmol}, 1.05$ equiv), and 3-benzyl-5-(2-hydroxyethyl)-4methyl-thiazolium chloride (1.68 g, $6.15 \mathrm{mmol}, 0.5$ equiv), were mixed in a $250 \mathrm{~mL}$ Schlenk flask under an argon atmosphere. $10 \mathrm{~mL}$ of absolute ethanol was added. A solution of sodium tertbutoxide (591 mg, $6.15 \mathrm{mmol}, 0.5$ equiv) in ethanol was added via syringe and the mixture was heated to $70{ }^{\circ} \mathrm{C}$ for 1 hours during which the 1,4-diketone intermediate precipitated. The reaction was cooled to room temperature. The solid was collected via filtration and washed three times with cold ethanol. Then, the 1,4-diketone intermediate was mixed with ammonium acetate $(9.49 \mathrm{~g}$, 
$123.07 \mathrm{mmol}, 10.00$ equiv) in $10 \mathrm{~mL}$ of absolute ethanol and the reaction mixture was heated to reflux. After 12 hours, the solvent was removed and the resulting residue was diluted with $\mathrm{H}_{2} \mathrm{O}$. The product was extracted with ethyl acetate three times and the combined organic layers were washed with saturated $\mathrm{NaHCO}_{3}$ solution, brine, and dried over $\mathrm{Na}_{2} \mathrm{SO}_{4}$. Removal of the ethyl acetate and drying under high vacuum yielded the desired product as a light brown solid (Yield: 3.02 g, 73\%). M.p. $148-150{ }^{\circ} \mathrm{C} .{ }^{1} \mathrm{H}$ NMR (400 MHz, $\mathrm{C}_{6} \mathrm{D}_{6} ; \delta$, ppm): 9.58 (br, $\left.1 \mathrm{H}\right), 7.79(\mathrm{~s}, 2 \mathrm{H})$, $7.63(\mathrm{dm}, J=6.8 \mathrm{~Hz}, 2 \mathrm{H}), 7.39(\mathrm{~d}, J=8.0 \mathrm{~Hz}, 1 \mathrm{H}), 7.26(\mathrm{tm}, J=7.6 \mathrm{~Hz}, 1 \mathrm{H}), 7.16(\mathrm{tt}, J=8.0,1.2$ $\mathrm{Hz}, 1 \mathrm{H}), 7.07(\mathrm{~d}, J=7.6 \mathrm{~Hz}, 1 \mathrm{H}), 6.92(\mathrm{t}, J=8.0 \mathrm{~Hz}, 1 \mathrm{H}), 6.88(\mathrm{~s}, 1 \mathrm{H}), 6.06(\mathrm{~d}, J=3.2 \mathrm{~Hz}, 1 \mathrm{H})$, $2.22(\mathrm{~s}, 6 \mathrm{H}), 1.77$ (s, 3H). ${ }^{13} \mathrm{C}$ NMR (101 MHz, $\left.\mathrm{C}_{6} \mathrm{D}_{6} ; \delta, \mathrm{ppm}\right): 157.60,151.52,140.50,138.70$, 138.16, 136.84, 130.84, 129.91, 129.44, 128.89, 126.76, 126.23, 126.11, 125.54, 118.23, 117.48, 111.48, 21.49, 12.48. HRMS (ESI) calcd for $\mathrm{C}_{24} \mathrm{H}_{23} \mathrm{~N}_{2}{ }^{+}[\mathrm{M}+\mathrm{H}]^{+} \mathrm{m} / \mathrm{z} 339.18558$; Found 339.18514 .

Preparation of $\mathbf{Z r}\left({ }^{\mathrm{H}} \mathbf{C N N}\right)_{2}$ : A solution of tetrabenzyl zirconium (587 mg, $1.29 \mathrm{mmol}$, 0.50 equiv) in $3 \mathrm{~mL}$ of benzene was added to a $50 \mathrm{~mL}$ thick-walled glass vessel containing a solution of $\mathrm{H}_{2} \mathrm{CNN}$ ( $800 \mathrm{mg}, 2.58 \mathrm{mmol}, 1.00$ equiv) in $5 \mathrm{~mL}$ of benzene. The thick-walled vessel was sealed with a PTFE screw cap and heated to $80^{\circ} \mathrm{C}$ overnight, resulting in a brown solution. After cooling to room temperature, the reaction vessel was brought back into the glovebox and reaction mixture was concentrated in vacuo until large amount of orange solid precipitated. The solid was collected by filtration, washed three times with $\mathrm{Et}_{2} \mathrm{O}$, and dried in vacuum. The product was collected as a light orange solid (Yield: $856 \mathrm{mg}, 94 \%) .{ }^{1} \mathrm{H}$ NMR (400 MHz, $\left.\mathrm{C}_{6} \mathrm{D}_{6} ; \delta, \mathrm{ppm}\right): 7.73$ (d, J=6.4 Hz, 
2H), $7.64(\mathrm{~d}, J=6.8 \mathrm{~Hz}, 4 \mathrm{H}), 7.43(\mathrm{~d}, J=8.4 \mathrm{~Hz}, 2 \mathrm{H}), 7.34-7.22(\mathrm{~m}, 6 \mathrm{H}), 7.19(\mathrm{~d}, J=7.2 \mathrm{~Hz}$, 2H), $6.91(\mathrm{t}, J=7.6 \mathrm{~Hz}, 2 \mathrm{H}), 6.86-6.77(\mathrm{~m}, 4 \mathrm{H}), 6.73(\mathrm{~d}, \mathrm{~J}=7.6 \mathrm{~Hz}, 2 \mathrm{H}), 5.93(\mathrm{~s}, 2 \mathrm{H}), 2.00(\mathrm{~s}$, $6 \mathrm{H}) .{ }^{13} \mathrm{C}$ NMR (101 MHz, $\left.\mathrm{C}_{6} \mathrm{D}_{6} ; \delta, \mathrm{ppm}\right): 191.45,164.37,157.09,145.99,141.94,141.50,138.09$, 135.31, 134.13, 131.39, 129.97, 129.81, 129.09, 128.81, 127.13, 122.65, 116.31, 114.04, 112.10, 14.33. Anal. Calcd for $\mathrm{C}_{44} \mathrm{H}_{32} \mathrm{~N}_{4} \mathrm{Zr} \cdot \mathrm{Et}_{2} \mathrm{O}$ : C, 73.71; H, 5.41; N, 7.16. Found: C, 73.70; H, 5.54; N, 7.13. Single crystals suitable for X-ray crystallographic analysis were grown from a saturated solution of $\mathrm{Zr}\left({ }^{\mathrm{H}} \mathrm{CNN}\right)_{2}$ in $\mathrm{Et}_{2} \mathrm{O}$ at $-35{ }^{\circ} \mathrm{C}$.

Preparation of $\mathbf{Z r}\left({ }^{\mathrm{Me}} \mathbf{C N N}\right) 2$ : A solution of tetrabenzyl zirconium (202 mg, $443 \mathrm{mmol}$, 0.50 equiv) in $3 \mathrm{~mL}$ of benzene was added to a $50 \mathrm{~mL}$ thick-walled glass vessel containing a solution of $\mathrm{H}_{2}\left({ }^{\mathrm{Me}} \mathrm{CNN}\right)(300 \mathrm{mg}, 886 \mathrm{mmol}, 1.00$ equiv) in $5 \mathrm{~mL}$ of benzene. The thick-walled vessel was sealed with a PTFE screw cap and heated to $130{ }^{\circ} \mathrm{C}$ for 36 hours, resulting in a brown solution. After cooling to room temperature, the reaction vessel was brought back into the glovebox and the solvent was removed in vacuo. The crude product was redissolved in $3 \mathrm{~mL}$ of $\mathrm{Et}_{2} \mathrm{O}$. Then pentane was added to precipitate the solid product, which was collected by filtration. The resulting solid was washed ten times with $\mathrm{Et}_{2} \mathrm{O}$ and dried in vacuum. The product was collected as an orange solid (Yield: $145 \mathrm{mg}, 43 \%) .{ }^{1} \mathrm{H}$ NMR (400 MHz, $\left.\mathrm{C}_{6} \mathrm{D}_{6} ; \delta, \mathrm{ppm}\right): 7.62$ (d, J=7.2 Hz, 4H), 7.38 $(\mathrm{dd}, J=7.2,1.6 \mathrm{~Hz}, 2 \mathrm{H}), 7.28(\mathrm{tm}, J=7.2 \mathrm{~Hz}, 4 \mathrm{H}), 7.20-7.16(\mathrm{~m}, 4 \mathrm{H}), 6.85-6.77(\mathrm{~m}, 4 \mathrm{H}), 6.45$ $(\mathrm{s}, 2 \mathrm{H}), 5.81(\mathrm{~s}, 2 \mathrm{H}), 2.42(\mathrm{~s}, 6 \mathrm{H}), 2.08(\mathrm{~s}, 6 \mathrm{H}), 2.00(\mathrm{~s}, 6 \mathrm{H}) .{ }^{13} \mathrm{C} \mathrm{NMR}\left(101 \mathrm{MHz}, \mathrm{C}_{6} \mathrm{D}_{6} ; \delta, \mathrm{ppm}\right)$ : $191.87,164.62,156.84,146.33,143.57,141.66,141.43,138.35,138.28,136.03,132.55,130.96$, 
$129.96,128.78,127.05,120.75,116.03,114.50,112.31,23.02,21.56,14.69$. Anal. Calcd for $\mathrm{C}_{48} \mathrm{H}_{40} \mathrm{~N}_{4} \mathrm{Zr} \cdot \mathrm{Et}_{2} \mathrm{O}: \mathrm{C}, 74.51 ; \mathrm{H}, 6.01 ; \mathrm{N}, 6.68$. Found: C, 74.37; H, 5.59; N, 6.97.

Preparation of $\mathbf{Z r}$ (DPDP)Br2: Benzyl bromide (169 mg, $989 \mathrm{mmol}, 7.00$ equiv) was added to a $50 \mathrm{~mL}$ thick-walled glass vessel containing a solution of $\mathrm{Zr}\left({ }^{\mathrm{H}} \mathrm{CNN}\right)_{2}(100 \mathrm{mg}, 141 \mathrm{mmol}, 1.00$ equiv) in $10 \mathrm{~mL}$ of benzene. The thick-walled vessel was sealed with a PTFE screw cap and irradiated with blue LED light $\left(\lambda_{\max }=462 \mathrm{~nm}\right)$ for 24 hours, resulting in a dark red solution. The reaction vessel was brought back into the glovebox and the solvent was removed in vacuo. After evaporation of benzene, the crude product was recrystallized from THF and $\mathrm{Et}_{2} \mathrm{O}$ cooled to $-35^{\circ} \mathrm{C}$. The analytically pure product was collected as a red crystal (Yield: $79 \mathrm{mg}, 64 \%) .{ }^{1} \mathrm{H}$ NMR (400 $\left.\mathrm{MHz}, \mathrm{C}_{6} \mathrm{D}_{6} ; \delta, \mathrm{ppm}\right): 7.48(\mathrm{~d}, J=7.2 \mathrm{~Hz}, 4 \mathrm{H}), 7.22-7.10(\mathrm{~m}, 10 \mathrm{H}), 6.90(\mathrm{t}, J=7.2 \mathrm{~Hz}, 2 \mathrm{H}), 6.85$ (t, $J=7.2 \mathrm{~Hz}, 2 \mathrm{H}), 6.71(\mathrm{~d}, J=7.2 \mathrm{~Hz}, 2 \mathrm{H}), 6.59(\mathrm{t}, J=8.4 \mathrm{~Hz}, 2 \mathrm{H}), 6.36(\mathrm{~d}, J=6.8 \mathrm{~Hz}, 2 \mathrm{H}), 6.02$ (s, 2H), 2.34 (s, 6H). ${ }^{13} \mathrm{C}$ NMR (101 MHz, $\left.\mathrm{C}_{6} \mathrm{D}_{6} ; \delta, \mathrm{ppm}\right): 158.21,156.22,143.47,140.21,140.12$ $139.43,137.89,133.33,130.82,130.41,129.91,129.86,128.96,128.89,127.47,127.32,120.62$, 117.42, 115.40, 17.70. Anal. Calcd for $\mathrm{C}_{44} \mathrm{H}_{32} \mathrm{Br}_{2} \mathrm{~N}_{4} \mathrm{Zr}$ : C, 60.90; H, 3.72; N, 6.46; Found: C, 61.10; $\mathrm{H}, 4.04 ; \mathrm{N}, 6.16$. X-ray quality crystals of $\mathrm{Zr}(\mathrm{DPDP})_{2} \mathrm{Br}_{2}$ were grown from $\mathrm{THF}$ and $\mathrm{Et}_{2} \mathrm{O}$ solution cooled to $-35^{\circ} \mathrm{C}$.

Preparation of $\mathbf{Z r ( D P D P ) ( S B n ) 2 : ~ D i b e n z y l ~ d i s u l f i d e ~ ( 8 8 ~ m g , ~} 356 \mathrm{mmol}, 1.20$ equiv) was added to a $50 \mathrm{~mL}$ thick-walled glass vessel containing a solution of $\mathrm{Zr}\left({ }^{\mathrm{H}} \mathrm{CNN}\right)_{2}(210 \mathrm{mg}, 297 \mathrm{mmol}, 1.00$ equiv) in $10 \mathrm{~mL}$ of benzene. The thick-walled vessel was sealed with a PTFE screw cap and 
irradiated with blue LED light $\left(\lambda_{\max }=462 \mathrm{~nm}\right)$ for 38 hours, resulting in a bright orange solution. The reaction vessel was brought back into the glovebox and the solvent was removed in vacuum. After evaporation of benzene, the resulting solid was washed multiple times with $\mathrm{Et}_{2} \mathrm{O}$ and gave analytically pure product as a light orange solid (Yield: $211 \mathrm{mg}, 75 \%) .{ }^{1} \mathrm{H}$ NMR $\left(400 \mathrm{MHz}, \mathrm{C}_{6} \mathrm{D}_{6}\right.$; $\delta$, ppm): $7.61(\mathrm{~d}, J=7.2 \mathrm{~Hz}, 4 \mathrm{H}), 7.32(\mathrm{~d}, J=7.2 \mathrm{~Hz}, 2 \mathrm{H}), 7.28(\mathrm{~d}, J=7.2 \mathrm{~Hz}, 4 \mathrm{H}), 7.23(\mathrm{t}, J=$ $7.6 \mathrm{~Hz}, 4 \mathrm{H}), 7.18-7.11(\mathrm{~m}, 4 \mathrm{H}), 7.02(\mathrm{t}, J=7.6 \mathrm{~Hz}, 4 \mathrm{H}), 6.92(\mathrm{t}, J=7.6 \mathrm{~Hz}, 4 \mathrm{H}), 6.69(\mathrm{td}, J=$ 7.6, $1.2 \mathrm{~Hz}, 2 \mathrm{H}), 6.64(\mathrm{dd}, J=8.4,7.6 \mathrm{~Hz}, 2 \mathrm{H}), 6.45(\mathrm{~d}, J=7.6 \mathrm{~Hz}, 2 \mathrm{H}), 6.30(\mathrm{~d}, J=7.2 \mathrm{~Hz}, 2 \mathrm{H})$, $6.21(\mathrm{~s}, 2 \mathrm{H}), 4.34(\mathrm{~d}, J=14.0 \mathrm{~Hz}, 2 \mathrm{H}), 4.24(\mathrm{~d}, J=14.0 \mathrm{~Hz}, 2 \mathrm{H}), 2.40(\mathrm{~s}, 6 \mathrm{H}) \cdot{ }^{13} \mathrm{C}$ NMR $(101$ $\left.\mathrm{MHz}, \mathrm{C}_{6} \mathrm{D}_{6} ; \delta, \mathrm{ppm}\right): 158.03,154.99,144.87,143.72,141.45,139.41,138.43,138.32,133.35$, $129.82,129.73,129.61,129.33,129.17,129.07,128.82,128.59,127.49,127.03,126.22,119.21$, 115.97, 115.86, 40.45, 17.24. Anal. Calcd for $\mathrm{C}_{58} \mathrm{H}_{46} \mathrm{~N}_{4} \mathrm{~S}_{2} \mathrm{Zr}$ : C, 72.99; H, 4.86; N, 5.87; Found: C, 72.09; H, 4.86; N, 5.78. 


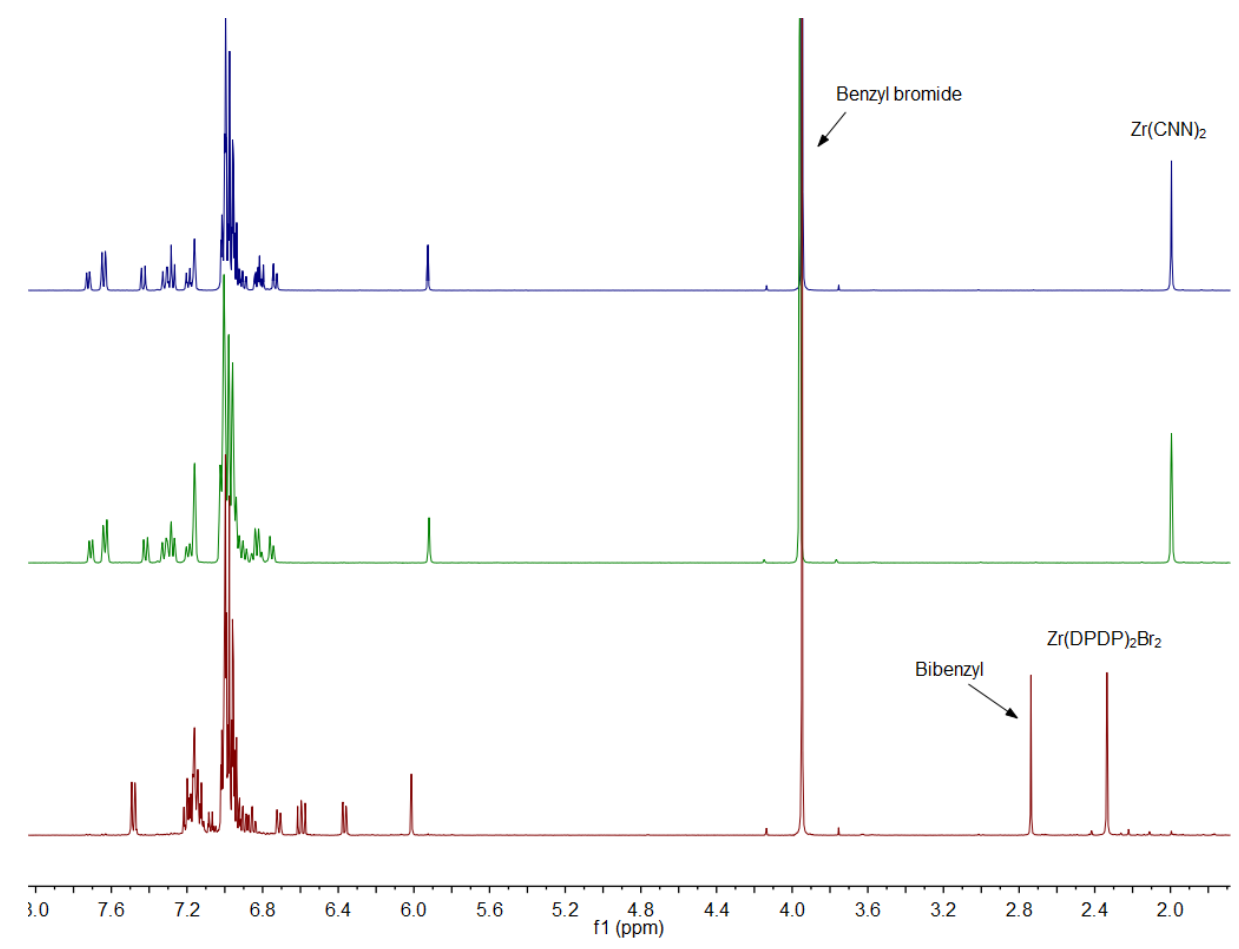

Figure ES1. ${ }^{1} \mathrm{H}$ NMR spectrum of a reaction mixture of $\mathrm{Zr}\left({ }^{\mathrm{H}} \mathrm{CNN}\right)_{2}$ and ten equivalent of benzyl bromide in $\mathrm{C}_{6} \mathrm{D}_{6}$. (top: initial; middle: under dark for $20 \mathrm{~h}$; bottom: irradiation for 4 hours).

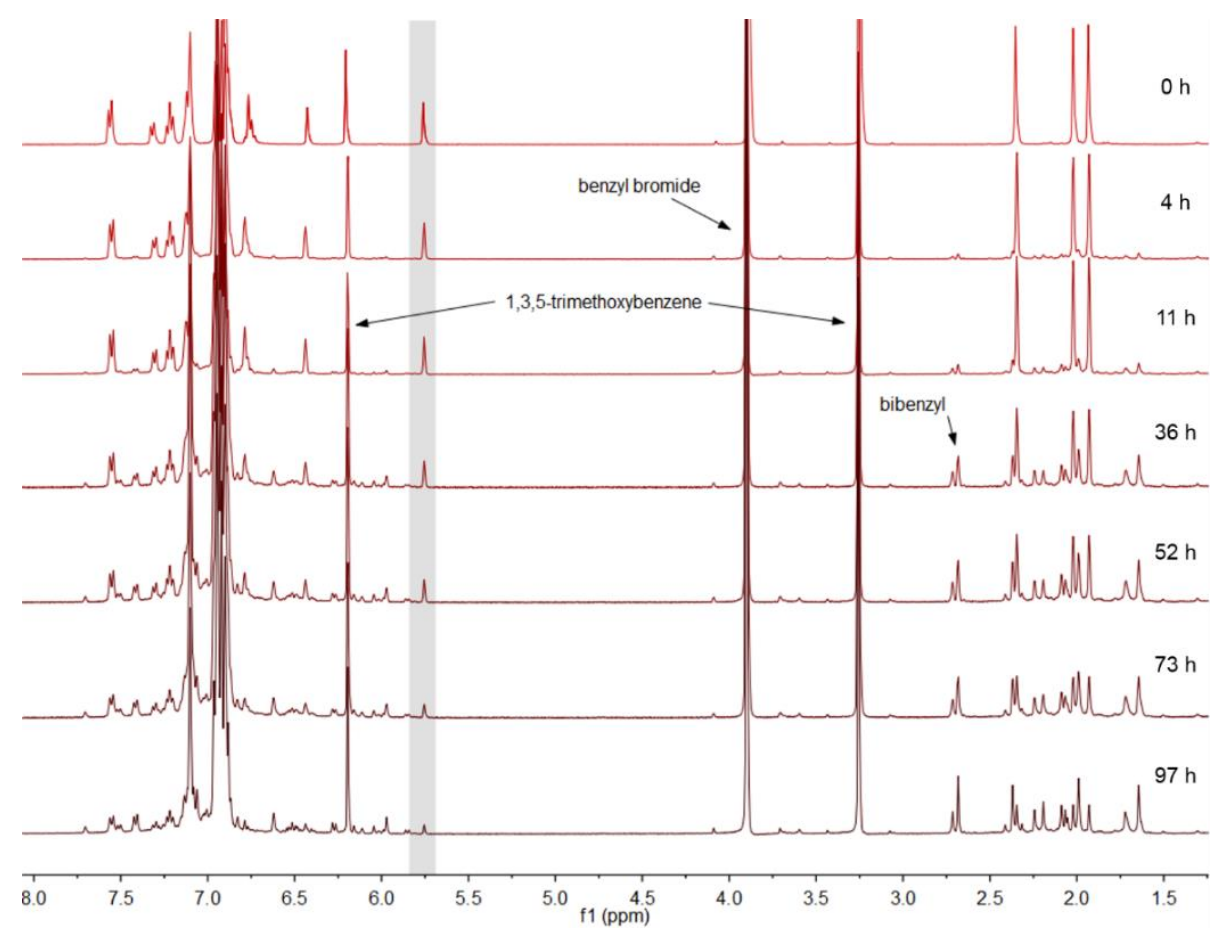

Figure ES2. ${ }^{1} \mathrm{H}$ NMR spectrum of a reaction mixture of $\mathrm{Zr}\left({ }^{\mathrm{Me}} \mathrm{CNN}\right)_{2}$ and ten equivalent of benzyl bromide in $\mathrm{C}_{6} \mathrm{D}_{6}$ with 1,3,5-trimethoxybenzene as internal standard. 


\subsection{Reference.}

(1) King, K. A.; Spellane, P. J.; Watts, R. J. J. Am. Chem. Soc. 1985, 107, 1431.

(2) Zhang, Y.; Lee, T. S.; Petersen, J. L.; Milsmann, C. J. Am. Chem. Soc. 2018, 140, 5934.

(3) Zhang, Y.; Petersen, J. L.; Milsmann, C. J. Am. Chem. Soc. 2016, 138, 13115.

(4) Neese, F. J. Biol. Inorg. Chem. 2006, 11, 702.

(5) Klamt, A.; Schüürmann, G. J. Chem. Soc., Perkin Trans. 2 1993, 799.

(6) Arias-Rotondo, D. M.; McCusker, J. K. Chem. Soc. Rev. 2016, 45, 5803.

(7) Larsen, C. B.; Wenger, O. S. Inorg. Chem. 2018, 57, 2965.

(8) Yin, H.; Carroll, P. J.; Anna, J. M.; Schelter, E. J. J. Am. Chem. Soc. 2015, 137, 9234.

(9) Park, G.; Yi, S. Y.; Jung, J.; Cho, E. J.; You, Y. Chem. - A Eur. J. 2016, 22, 17790.

(10) Wingfors, H.; Svensson, K.; Hagglund, L.; Hedenstierna, S.; Magnusson, R. J. Organomet. Chem. 1977, 134, 189.

(11) Margulieux, G. W.; Semproni, S. P.; Chirik, P. J. Angew. Chemie - Int. Ed. 2014, 53, 9189.

(12) Erker, G.; Kropp, K.; Atwook, J. L.; Hunter, W. E. Organometallics 1983, 2, 1555.

(13) Haneline, M. R.; Heyduk, A. F. J. Am. Chem. Soc. 2006, 128, 8410.

(14) Radlauer, M. R.; Agapie, T. Organometallics 2014, 33, 3247.

(15) Holub, J.; Vantomme, G.; Lehn, J. M. J. Am. Chem. Soc. 2016, 138, 11783. 
(16) Morales-Cerón, J. P.; Lara, P.; López-Serrano, J.; Santos, L. L.; Salazar, V.; Álvarez, E.; Suárez, A. Organometallics 2017, 36, 2460.

(17) Chuang, C. L.; Lim, K.; Chen, Q.; Zubieta, J.; Canary, J. W. Inorg. Chem. 1995, 34, 2562.

(18) Makowska-Grzyska, M. M.; Szajna, E.; Shipley, C.; Arif, A. M.; Mitchell, M. H.; Halfen, J. A.; Berreau, L. M. Inorg. Chem. 2003, 42, 7472. 


\section{Chapter 7.}

\section{A Benchtop-Stable Zirconium Photosensitizer Supported by Pyrrole-Based Schiff Bases}

\subsection{Introduction.}

So far, zirconium-based visible light photosensitizers have been limited to cyclopentadienyl $(\mathrm{Cp}) /$ thiolate and pyridine pyrrolide ligand systems. ${ }^{1-5}$ Expanding the ligand scope could significantly improve the utility of zirconium chromophores and advance the development of early transition metal photosensitizers with diverse properties. In a survey of different ligand architectures for a zirconium photosensitizer, a promising candidate was identified as the $N, N^{\prime}$-bis(2-pyrrylmethylidene)-1,2-phenylenediamine $\left(\mathrm{H}_{2} \mathrm{bppda}\right)$ ligand. As an analogue to the well-studied salen ( $N, N^{\prime}$-bis(salicyldene)ethylenediamine) ligand system and tetradentate porphyrin skeleton, pyrrole-based Schiff base ligands can support metal species in conducting polymerization, ${ }^{6-8}$ hydroamination, ${ }^{9}$ oxygen reduction, ${ }^{10}$ not to mention its versatile coordination chemistry ${ }^{11-16}$ and chemically non-innocence ligand behavior. ${ }^{17}$ Synthetically feasible, the synergistic framework of a strong $\pi$-donating pyrrolide moieties combined with a weak $\pi$ accepting phenylenediamine unit could lead to a low-lying LMCT transition with more metal character. Also, the high coordination number would potentially increase air/kinetic stability of the metal complex. 
While most studies related to the $\mathrm{H}_{2}$ bppda ligand have been reported for traditional applications, few are available in the realm of photochemistry. ${ }^{16,18}$ Herein, we present a new molecular photosensitizer based on earth abundant metal $\mathrm{Zr}(\mathrm{IV})$ coordinated to two bppda ${ }^{2-}$ ligands and demonstrate its unique photophysical and photoredox properties.

\subsection{Synthesis and Characterization.}

The ligand $\mathrm{H}_{2}$ bppda can be constructed via condensation reaction of 1,2-phenylenediamine with pyrrole-2-carboxaldehyde following literature reported procedures. ${ }^{6,9}$ Quite similar to previous synthesis of the $\mathrm{Zr}\left({ }^{\mathrm{H}} \mathrm{PDP}^{\mathrm{H}}\right)_{2}$ complex, direct reaction between $\mathrm{H}_{2}$ bppda and tetrabenzyl zirconium (half an equivalent) in benzene at room temperature precipitated red-orange, microcrystalline $\mathrm{Zr}(\mathrm{bppda})_{2}$ in $94 \%$ yield (Scheme 1) within 30 mins.

Scheme 1. Synthesis of $\mathrm{Zr}\left({ }^{\mathrm{Mes}} \mathrm{PDP}^{\mathrm{Ph}}\right)_{2}$.
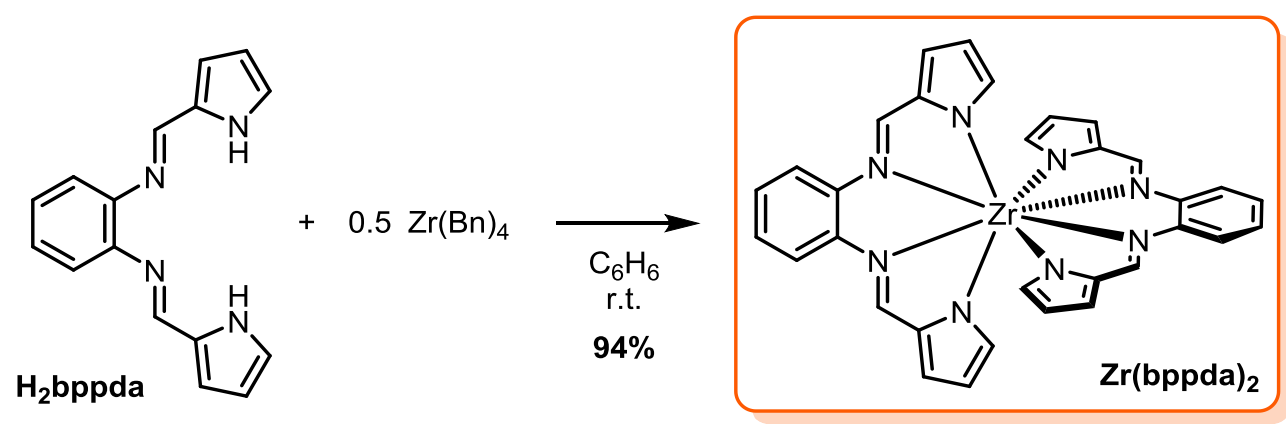
The molecular structure of $\mathrm{Zr}(\mathrm{bppda})_{2}$ was established by X-ray crystallography (Figure 1, left). Important bond lengths and angles are summarized in Table 1. Similar to the reported Ti(bppda) $)_{2}$ structure, ${ }^{9}$ the coordination environment around the central metal ion is best described as highly distorted square antiprism with two meridionally coordinating tetradentate [bppda ${ }^{2-}$ ligands (Figure 1, right). The geometric constraint enforced by the ligand framework results in large ligand bite angles of $207.63(4)^{\circ}\left(360^{\circ}-152.37(4)^{\circ}\right)$. The solid-state structure of $\operatorname{Zr}(\text { bppda })_{2}$ shows small deviation from idealized $D_{2 d}$ symmetry, with the two ligands exhibiting a nearly perfect orthogonal arrangement. The dihedral angle between the two ligand planes (each plane defined by the four nitrogen atoms of one ligand) is $89.20^{\circ}$ (ideally $90^{\circ}$ ). Also, each ligand plane is almost flat, which is reflected in the close-to-ideal sum of four N-Zr-N angles $\left(360.03^{\circ}\right.$ vs. $\left.360^{\circ}\right)$. The ${ }^{1} \mathrm{H}$ NMR spectroscopic data for the diamagnetic $\operatorname{Zr}(\text { bppda })_{2}$ agrees with a $D_{2 d}$ symmetric structure in solution at room temperature.
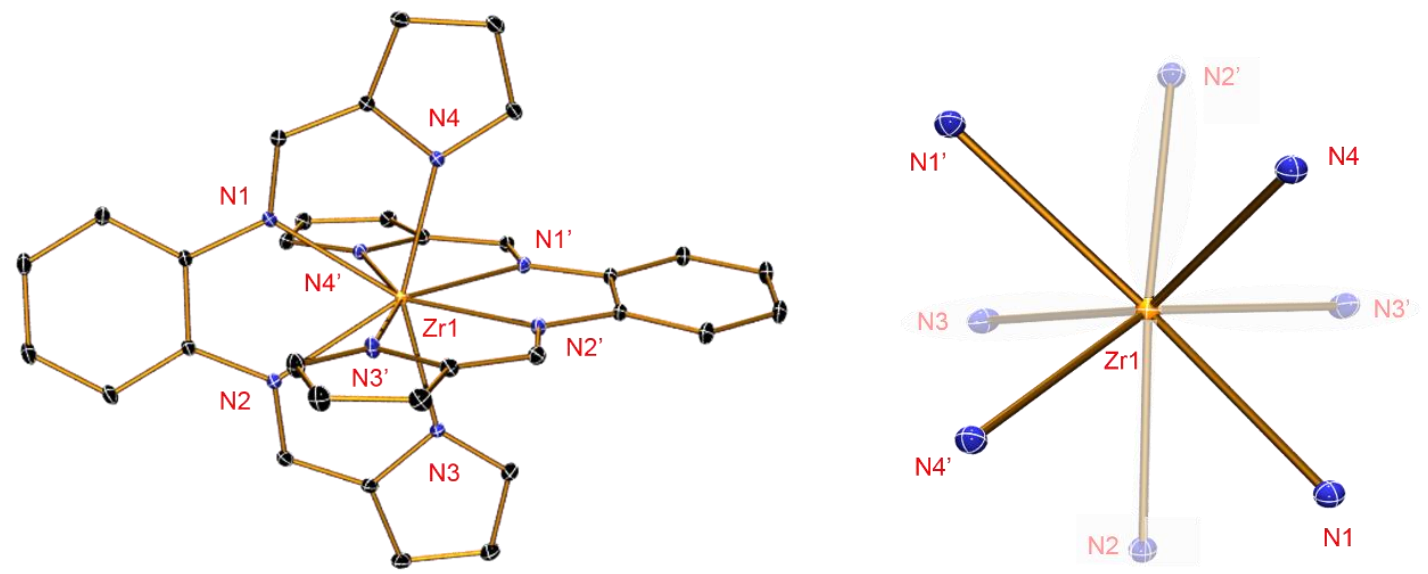

Figure 1. Solid state structure of $\mathrm{Zr}(\mathrm{bppda})_{2}$ at $30 \%$ probability ellipsoids (left). Hydrogen atoms were omitted for clarity. Simplified view of the coordination geometry of zirconium atom (right) from $C_{2}$ 'axis. 
Table 1. Selected bond lengths $(\AA)$ and angles $\left(^{\circ}\right)$ for $\operatorname{Zr}(\text { bppda })_{2}$.

\begin{tabular}{cc} 
& Zr(bppda ${ }_{2}$ \\
\hline Zr1-N1 & $2.3645(12)$ \\
Zr1-N2 & $2.3429(11)$ \\
Zr1-N3 & $2.2652(13)$ \\
Zr1-N4 & $2.2658(13)$ \\
\hline N4-Zr1-N1 & $70.26(4)$ \\
N1-Zr1-N2 & $66.88(4)$ \\
N3-Zr1-N4 & $152.37(4)$ \\
N2-Zr1-N3 & $70.52(4)$ \\
\hline Dihedral angle & 89.20 \\
\hline
\end{tabular}

In addition to its facile synthesis and well-defined molecular structure, $\operatorname{Zr}(\mathrm{bppda})_{2}$ also exhibit favorable air/water stability. Adding two drops of water to a dilute THF solution of $\mathrm{Zr}$ (bppda) ${ }_{2}$ yields essentially no decomposition after two hours. By monitoring the UV/Vis absorbance over time, $93 \%$ of the original absorption intensity remains under ambient conditions for 16 hours (Figure ES1). Furthermore, the $\operatorname{Zr}(\text { bppda })_{2}$ is stable under air in the solid state and can be handled on the benchtop using "wet" solvent. In non-dried $\mathrm{C}_{6} \mathrm{D}_{6}$ solvent, ${ }^{1} \mathrm{H}$ NMR spectrum showed no sign of decomposition after more than two months under ambient environment (Figure 2). Such robust stability under "wet" conditions can be attributed to the crowded inner coordination sphere due to the large coordination number in addition to the highly rigid ligand framework and strong chelating effects of the tetradentate binding mode. 


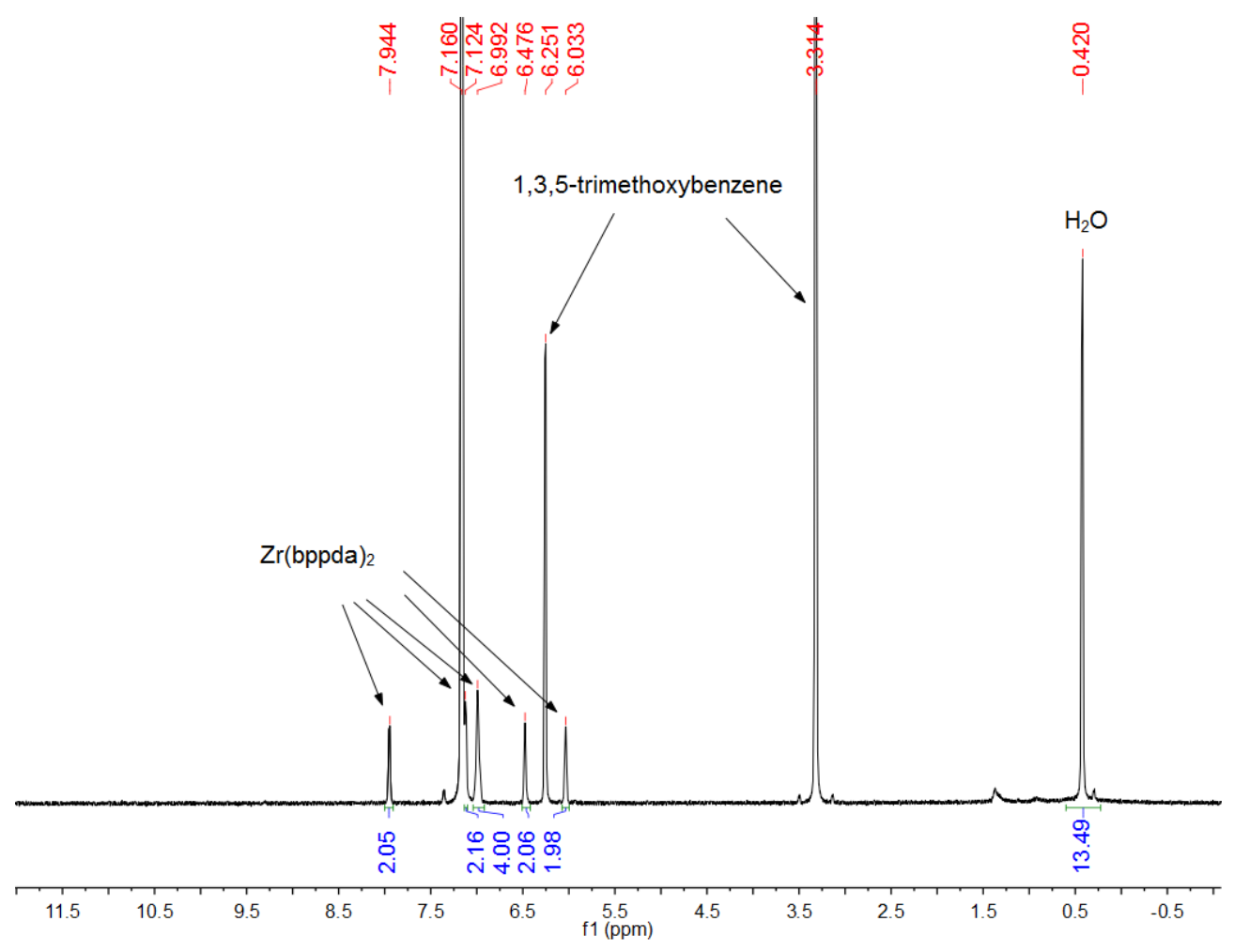

Figure 2. ${ }^{1} \mathrm{H}$ NMR spectra of $\mathrm{Zr}(\text { bppda })_{2}$ in "wet" benzene- $d_{6}$ under ambient conditions for 2 months and 7 days.

\subsection{Optical Properties.}

Electronic absorption and emission spectra recorded for $\mathrm{Zr}(\mathrm{bppda})_{2}$ under inert atmosphere in tetrahydrofuran (THF) are shown in Figure 3. Compared to the pyridine pyrrolide system, $\mathrm{Zr}(\text { bppda })_{2}$ exhibits very different absorption and emission profiles. Two very intense absorption bands with peak maxima at $286 \mathrm{~nm}$ and $324 \mathrm{~nm}$ are observed in the UV region of the spectrum. The solid state and solution appearance of the complex show a dim red-orange color, consistent with the intense blue $\left(\lambda_{\max }=409 \mathrm{~nm}, \varepsilon=52225 \mathrm{M}^{-1} \mathrm{~cm}^{-1}\right)$ and green $\left(\lambda_{\max }=506 \mathrm{~nm} \varepsilon=14731\right.$ $\mathrm{M}^{-1} \mathrm{~cm}^{-1}$ ) light absorption bands with high extinction coefficients shown in the visible region. 
More interestingly, the complex displays structured absorption bands with peak maxima at 480 $\left(v_{0} \rightarrow v_{2}\right), 506\left(v_{0} \rightarrow v_{1}\right)$, and $536 \mathrm{~nm}\left(v_{0} \rightarrow v_{0}\right)$. Excitation at the green light region also give structured emission bands maximum at $567 \mathrm{~nm}\left(v_{0} \rightarrow v_{0}\right)$, as well as two shoulders at approximately $610 \mathrm{~nm}$ $\left(v_{0} \rightarrow v_{1}\right)$ and $639 \mathrm{~nm}\left(v_{0} \rightarrow v_{2}\right)$. The structured luminescence patterns can be attribute to vibronic progressions with vibrational spacing $\sim 980 \mathrm{~cm}^{-1}$, which is consistent by the observation of strong vibrational modes of $1036 \mathrm{~cm}^{-1}$ or $991 \mathrm{~cm}^{-1}$ in the infrared spectrum of $\operatorname{Zr}$ (bppda) 2 (Figure 4).

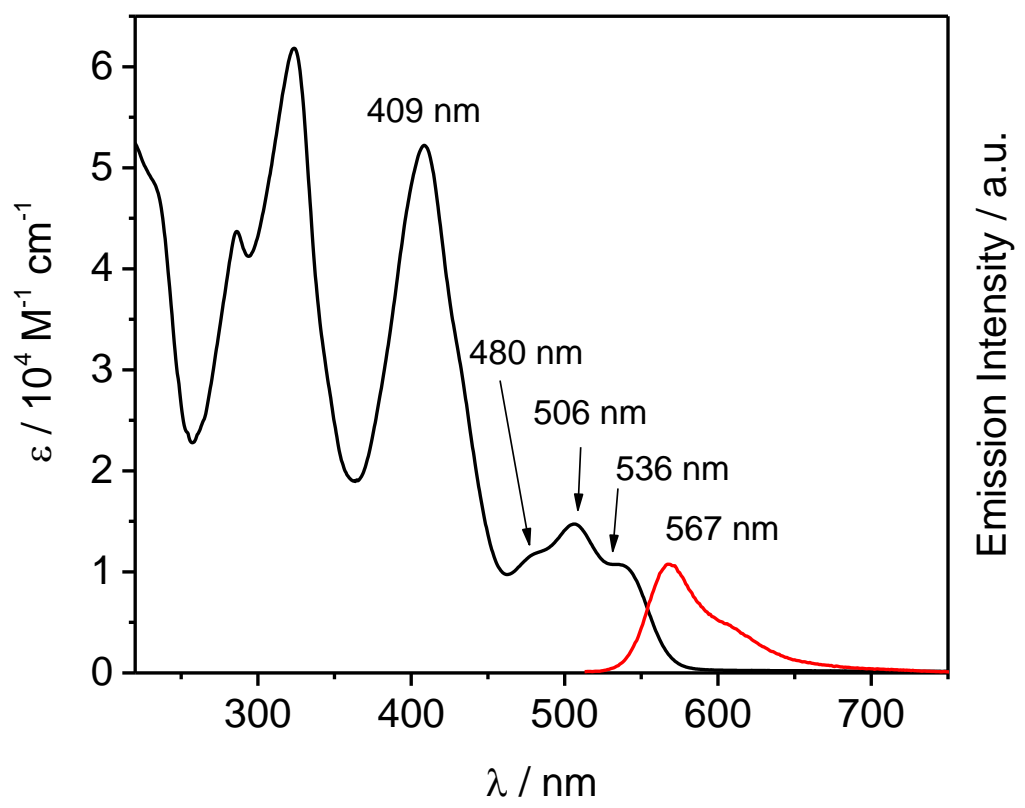

Figure 3. Absorption (black) and emission spectra (red) of $\mathrm{Zr}$ (bppda) 2 in THF solution at room temperature. 


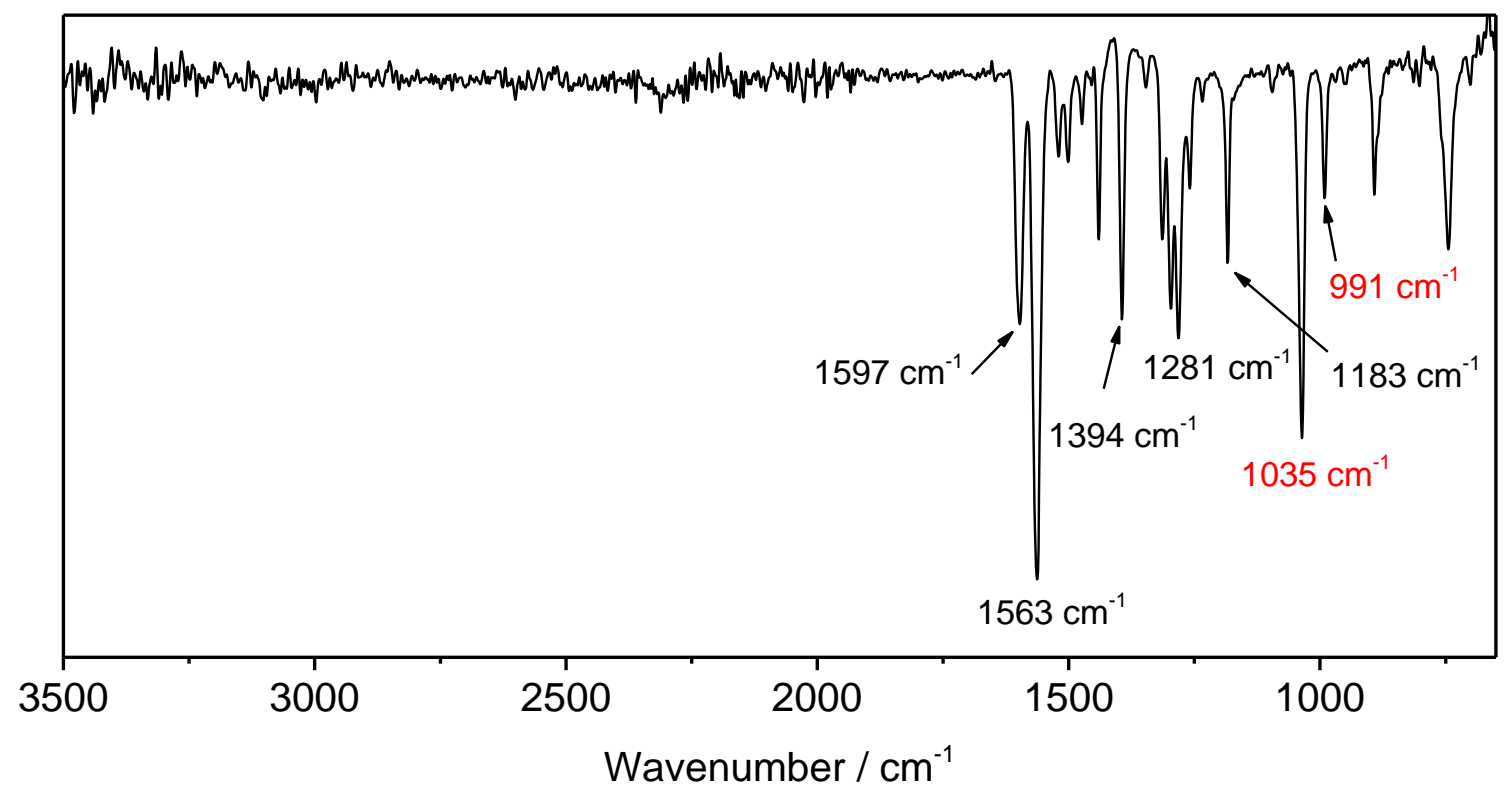

Figure 4. The infrared spectrum of $\mathrm{Zr}(\mathrm{bppda})_{2}$ recorded in neat.

When a sample solution was exposed to air, we observed an immediate reduction of the emission intensity, which was likely due to a triplet oxygen $\left({ }^{3} \mathrm{O}_{2}\right)$ quenching process. However, the emission was not completely quenched after prolonged air exposure (Figure 5). The ratio between the non-quenched component and the original emission was fixed at $1: 2.3$ from the integration of each emission area. More interestingly, the emission band shape under air is identical to that under an inert atmosphere and no shift in the peak maximum was found, thus suggesting a thermally activated delayed fluorescence (TADF) mechanism for the luminescence behavior. The small Stokes shift value of $1020 \mathrm{~cm}^{-1}$ in THF was another indication of fluorescent emission in contrast to phosphorescent emission accompanied by a large energy loss in the excited state. A TADF emitter has proven to be an alternative approach in harvesting both singlet and triplet 
excitons generated in organic light-emitting diodes (OLEDs). ${ }^{19-21} \mathrm{~A}$ zirconium based TADF chromophore could open the door for OLED manufacturers in search of a highly earth abundant replacements.

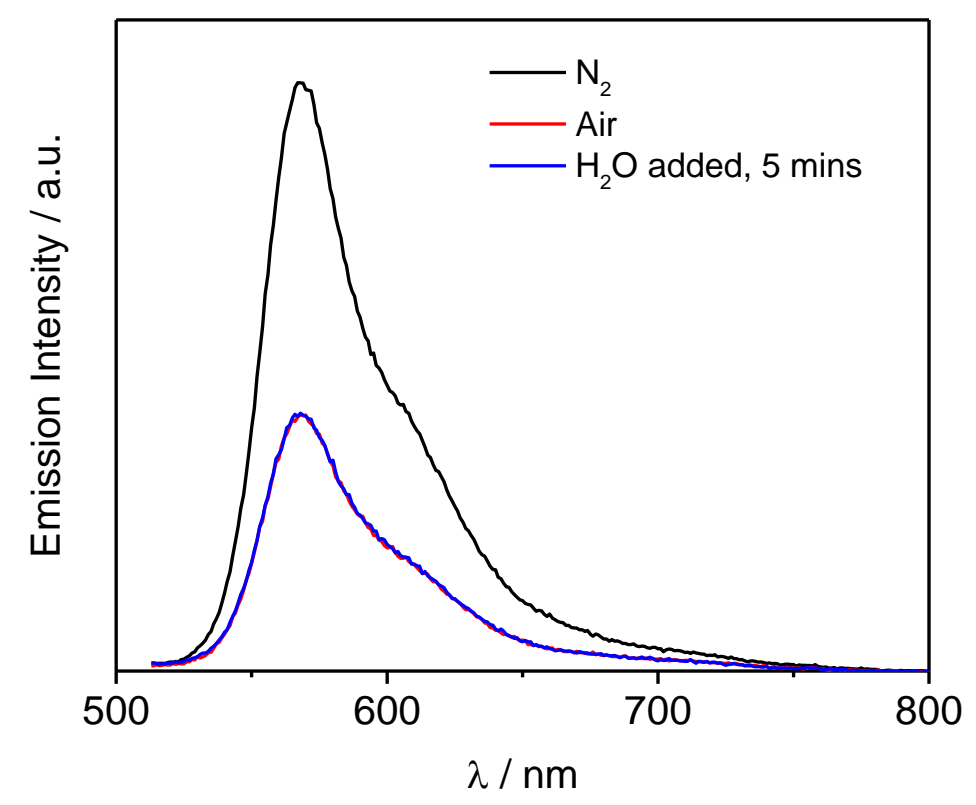

Figure 5. Emission spectra of $\mathrm{Zr}(\mathrm{bppda})_{2}$ in THF under $\mathrm{N}_{2}$ atmosphere (black), upon exposure to air (red), and addition of water (blue).

A luminescence quantum yield, $\Phi$, of 0.004 in THF was determined via a comparative method using Rhodamine $6 \mathrm{G}$ in ethanol as the reference. ${ }^{22}$ The low emission quantum yields indicate deactivation of the excited state predominantly via non-radiative pathways. This can be attributed to the emissive state vibrationally coupled to ligand center $\left({ }^{1} \mathrm{LC}\right)$ states (overlapped absorption bands) that are easily accessible, which allow for facile thermal deactivation via non- 
emissive ${ }^{1} \mathrm{LC}$ states (vide infra). Although the quantum yield is significantly lower than that of our previous PDP system and those reported for common transition metal photosensitizers, the absence of emission from ligand precursor itself indeed highlights the important role of the zirconium center.

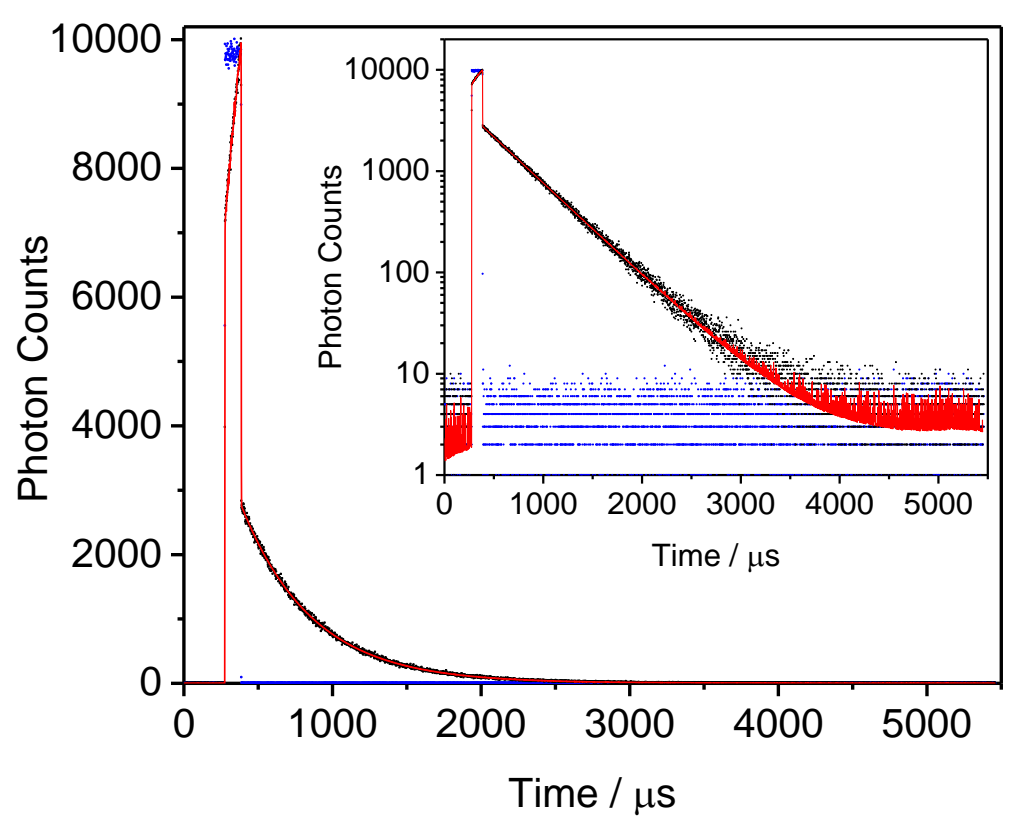

Figure 6. Representative example for time-resolved emission data for $\mathrm{Zr}(\mathrm{bppda})_{2}$ in THF at room temperature (black) detected at $570 \mathrm{~nm}$ upon excitation at $516 \mathrm{~nm}$. The red line shows the fit to a single-exponential decay with $\tau_{1}=479 \mu \mathrm{s}$ and the navy trace is the excitation pulse. Inset: Photon counts of same lifetime date in logarithmic scale.

Time-resolved emission data for $\mathrm{Zr}(\mathrm{bppda})_{2}$ was collected in rigorously deoxygenated THF solution at room temperature and a time-resolved emission trace is shown in Figure 6. Excitation of $\mathrm{Zr}(\mathrm{bppda})_{2}$ was performed at a wavelength of $516 \mathrm{~nm}$ and emission was detected at $570 \mathrm{~nm}$. 
Similar to our previous $\left({ }^{\mathrm{Me}} \mathrm{PMP}{ }^{\mathrm{Me}}\right)_{3} \mathrm{ZrCl}$ complex, the lifetime data consists of a long component and a short component (indicated by the immediate drop in emission intensity after the excitation source was switched off). However, the difference is that the ratio of two lifetime components is non-wavelength dependent. Attempts to determine the lifetime using an excitation light source with a pulse width of $1.2 \mathrm{~ns}$ were unsuccessful suggesting that the emission is likely due to fluorescence with a lifetime of $\tau_{2}<1 \mathrm{~ns}$. The long-lived portion was readily fit using a single exponential decay with a time constant of $\tau_{1}=479 \mu$ s. The strikingly long lifetime implies the emission involves a triplet state $\left(T_{1}\right)$ due to the spin-forbidden $\mathrm{T}_{1} \rightarrow \mathrm{S}_{0}$ relaxation. The fast initial drop implies most of the emission intensity decayed back to the ground state $\left(\mathrm{S}_{0}\right)$ directly from $\mathrm{S}_{1}$ state, which is consistent with partial quenching of the emission in the presence of ${ }^{3} \mathrm{O}_{2}$.

To gain more understanding of the excited-state dynamics, picosecond ultrafast transient absorption (TA) spectroscopy was applied. The 3D-TA contour map of $\mathrm{Zr}(\mathrm{bppda})_{2}$ in benzene at $295 \mathrm{~K}$ is depicted in Figure 7E and spectra at selected delay times are displayed in Figure 7D. At the early time following photoexcitation $\left(\lambda_{\text {pump }}=480 \mathrm{~nm}\right)$, ground-state bleach (GSB) features (500 $\mathrm{nm}-550 \mathrm{~nm}$ ) and three excited state absorption (ESA) bands between 550 and $800 \mathrm{~nm}$ were observed. The intense ESA character was tentatively ascribed to the transiently generated ligand radical of the first singlet excited state $\left(\mathrm{S}_{1}\right)$. These features promptly converted into a long-lived ground-state bleach feature with a maximum at $545 \mathrm{~nm}$ and different ESA features $(550 \mathrm{~nm}-800$ nm) within $500 \mathrm{ps}$ (Figure 7D). The lifetime of this new excited state was so long that there was 

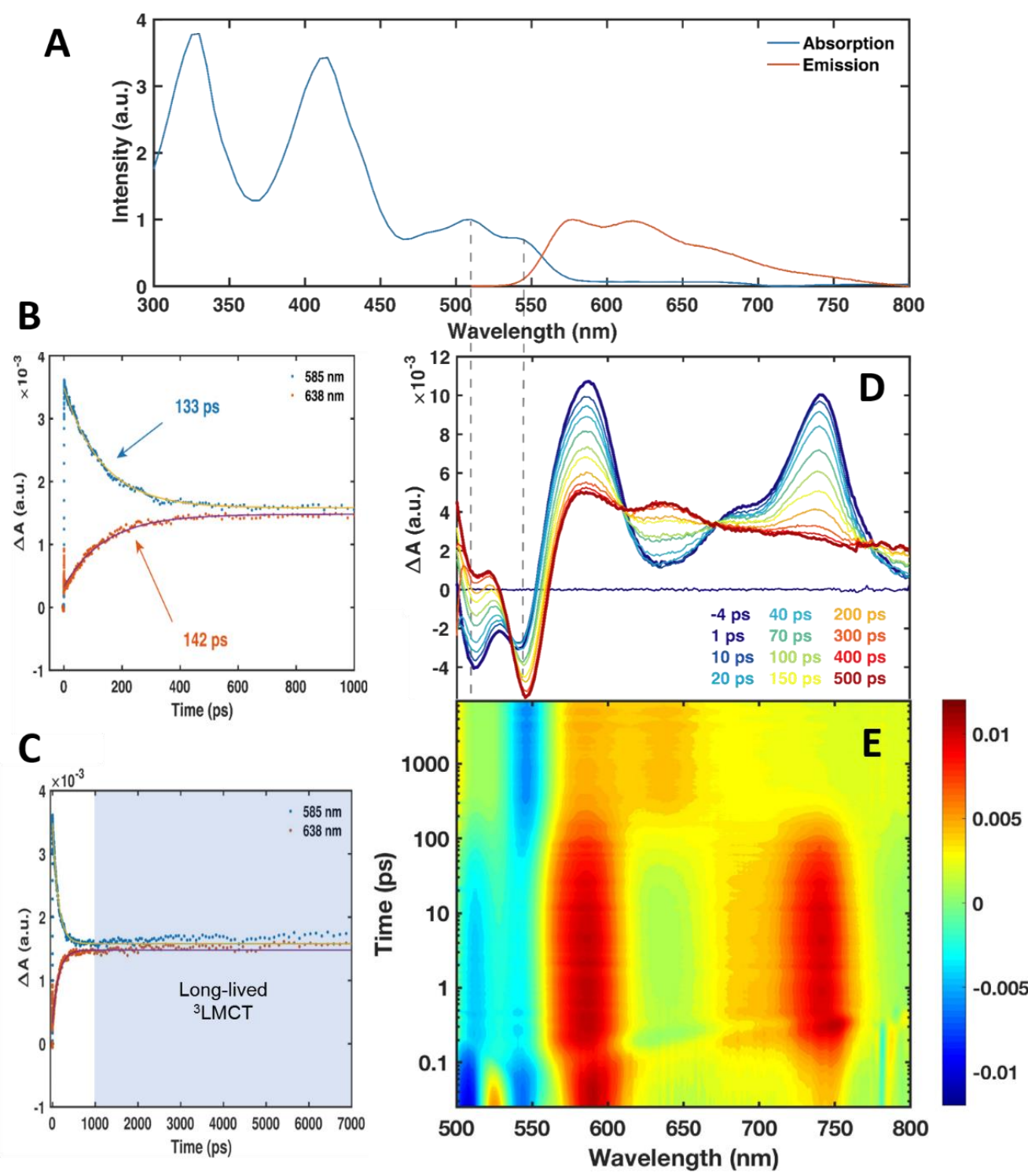

Figure 7. Summary of TA results for $\mathrm{Zr}(\mathrm{bppda})_{2}$ in benzene at $295 \mathrm{~K}$. (A) Room-temperature absorption and emission spectra of $\mathrm{Zr}(\mathrm{bppda})_{2}$ in benzene. (B) and (C) Kinetics and fits monitored at $585 \mathrm{~nm}$ and $638 \mathrm{~nm}$ generated by partial global analysis. (D) TA spectra at selected delay times ranging from $-4 \mathrm{ps}$ (blue) to 500 ps (black). (E) Contour map of $\mathrm{Zr}$ (bppda) 2 TA at $295 \mathrm{~K}$.

no decay within the time scale of TA measurement (Figure 7C, blue background). Multiple isosbestic points during TA conversion are indicative of a highly efficient intersystem crossing process, approximately 100\% (Figure 7D). The global analysis of the kinetic traces at characteristic 
wavelengths provided an intersystem crossing rate constant $\left(k_{\mathrm{ISC}}\right)$ of $141 \mathrm{ps}$, which was much slower than that of zirconium PDP complexes and most transition metal photosensitizers. Such slow ISC rate provide high probability for reverse ISC to outcompete ISC process.

\subsection{TD-DFT Studies.}

To identify the nature of various electronic transitions for $\operatorname{Zr}(\text { bppda })_{2}$, time dependent density functional theory (TD-DFT) calculations were performed at the B3LYP level. Solvent effects in THF were included using the conductor-like screening model (COSMO). The predicted spectrum is in excellent agreement with the experimental data showing four major absorption bands in the range of 250-670 nm, which are labeled with Roman numerals in Figure 8. The main single-electron excitations contributing to each state are listed in Table 2. Distinct from previously reported $\mathrm{Zr}(\mathrm{PDP})_{2}$ complexes, ${ }^{2}$ the lowest energy absorption band of $\mathrm{Zr}(\mathrm{bppda})_{2}$ is composed of one pair of transitions from a degenerate set of exclusively ligand-centered $\pi$ orbital (HOMO-1 and HOMO) to LUMO with $28 \%$ contributions from the metal $\left(\mathrm{d}_{\mathrm{xz}}, \mathrm{d}_{\mathrm{yz}}\right)$. On the basis of this analysis, the transitions giving rise to the lowest-lying absorption band in the visible region are best described as a hybrid ${ }^{1} \mathrm{IL} /{ }^{1} \mathrm{LMCT}$ transition. A considerable contribution to the LUMO comes from $\mathrm{C}=\mathrm{N}$ antibonding orbitals $(29 \%)$, which is expected to cause a large bond elongation in this position of the molecule in the excited state. The second band (II) in the visible region, on the other hand, is made up of transitions involving purely ligand centered donor and acceptor orbitals, which were assigned as ${ }^{1}$ IL transitions. The observed overlap between band I and band II in the 
experimental spectrum allows for the vibrational sublevel between the ${ }^{1} \mathrm{IL} /{ }^{1} \mathrm{LMCT}$ and the ${ }^{1} \mathrm{IL}$ state to couple, which offers further support for the ${ }^{1}$ IL state being the non-radiative decay pathway that is responsible for low quantum yield.

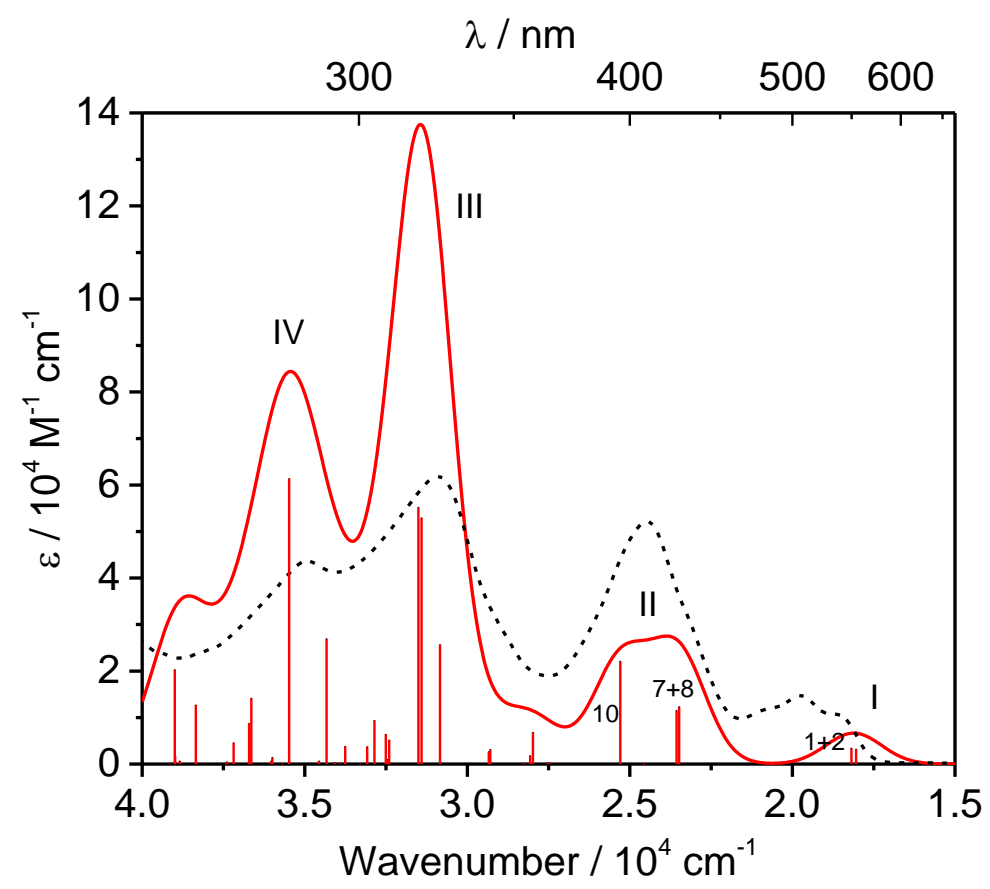

Figure 8. Electronic absorption spectrum of $\mathrm{Zr}(\mathrm{bppda})_{2}$ obtained via TD-DFT calculations (red line, FWHM of $2000 \mathrm{~cm}^{-1}$ ). The stick plot indicates the positions and relative intensities of individual transitions. The major contributions to each numbered state are listed in Table 2. The experimental spectrum is shown as a dotted black line for comparison.

Table 2. Vertical electronic excitation energies and main excitations contributing to the visible absorption bands of $\mathrm{Zr}$ (bppda) $)_{2}$ obtained via TD-DFT calculations

\begin{tabular}{|c|c|c|c|c|c|}
\hline Band & $\begin{array}{l}\text { TD-DFT } \\
\text { State }\end{array}$ & $\begin{array}{c}\text { Energy / cm }{ }^{-1} \\
(\lambda / \mathrm{nm})\end{array}$ & $f_{\text {osc }}$ & $\begin{array}{l}\text { Excitations } \\
\text { (weight) }{ }^{\mathrm{a}, \mathrm{b}}\end{array}$ & $\begin{array}{l}\text { Character } \\
(\% \text { LMCT) }\end{array}$ \\
\hline \multirow{2}{*}{ I } & 1 & $18041.3(554.3)$ & 0.030 & $155 \rightarrow 156(0.95)$ & ${ }^{1} \mathrm{IL} /{ }^{1} \mathrm{LMCT}(28 \%)$ \\
\hline & 2 & $18185.2(549.9)$ & 0.032 & $154 \rightarrow 156(0.95)$ & ${ }^{1} \mathrm{IL} /{ }^{1} \mathrm{LMCT}(28 \%)$ \\
\hline \multirow{3}{*}{ II } & 7 & $23486.7(425.8)$ & 0.114 & $155 \rightarrow 157(0.90)$ & ${ }^{1} \mathrm{IL}(0 \%)$ \\
\hline & 8 & $23562.2(424.4)$ & 0.106 & $154 \rightarrow 157(0.90)$ & ${ }^{1} \mathrm{IL}(0 \%)$ \\
\hline & 10 & $25294.1(395.3)$ & 0.204 & $\begin{array}{l}154 \rightarrow 159(0.33) \\
155 \rightarrow 158(0.27) \\
152 \rightarrow 157(0.23)\end{array}$ & ${ }^{1} \mathrm{IL}(2 \%)$ \\
\hline
\end{tabular}

${ }^{\mathrm{a}}$ Only excitations with a weight larger than 0.1 are shown. ${ }^{\mathrm{b}} \mathrm{HOMO}$ 155, LUMO 156. 


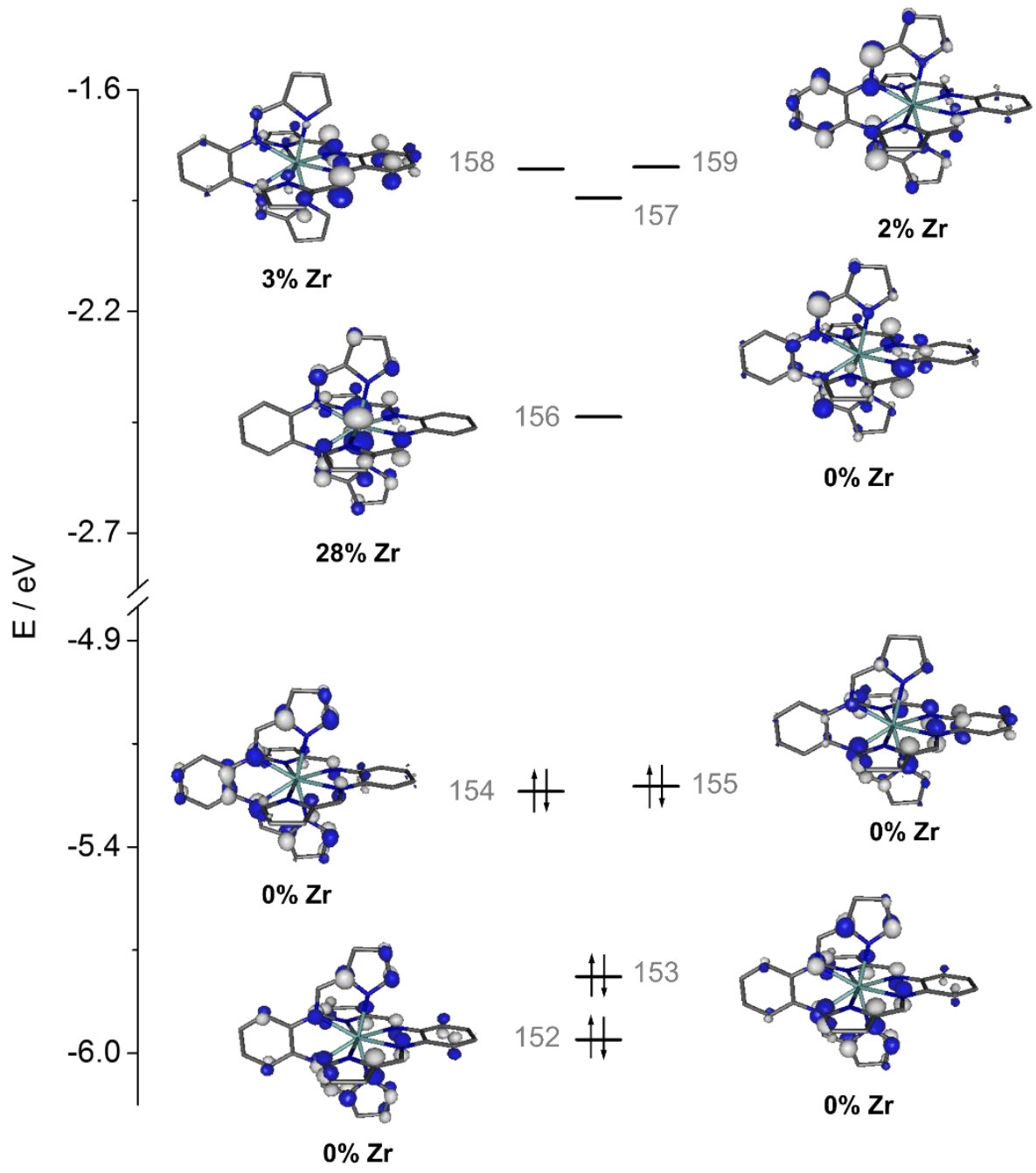

Figure 9. Frontier molecular orbital diagram showing the donor and acceptor orbitals contributing to the TD-DFT excitations computed in the visible region of the electronic absorption spectrum. The gray numbers to the right correspond to the MO number with 155 being the HOMO and 156 being the LUMO.

The electronic structure of the long-lived triplet state was also explored by DFT calculations. Despite the $D_{2 d}$ symmetric starting geometry, the triplet state optimization converges to a lower symmetry structure of $C_{2 v}$ point group. Compare to the ground state structure, the most significant changes are the shortening of the $\mathrm{C} 1-\mathrm{N} 1_{\text {imine }}$ as well as the elongation of the $\mathrm{N} 1_{\text {imine }}-\mathrm{C} 7$ 
bond lengths by $-5.4 \mathrm{pm}$ and $+5.6 \mathrm{pm}$, respectively (Table 3 ). This distortion mode in the excited state can be considered as an anti-symmetric stretching motion for $\mathrm{C} 1-\mathrm{N} 1=\mathrm{C} 7$ fragment, which is likely responsible to the structured absorption bands with vibrational spacing of $\sim 1000 \mathrm{~cm}^{-1}$. Although the stretching frequency of this motion is $1552 \mathrm{~cm}^{-1}$ by ground state numerical frequency calculation, the lowering IR stretching frequency is expected in the excited state due to the weakening of the $\mathrm{C}-\mathrm{N}=\mathrm{C}$ fragment via electron density populating of the $\mathrm{C}-\mathrm{N}=\mathrm{C}$ antibonding orbital. Besides these two major structural changes, the distances for other bonds in the excited state are very similar to those found in the ground state $(< \pm 3 \mathrm{pm})$. Altogether, the distortion results in an $T_{1}$ electronic structure in which the spin density is localized on zirconium and one of the bppda ligands. These structural changes are consistent with a triplet excited state that contains a major contribution from an IL $(72 \%)$ process. The partial metal character of one of the two resulting SOMOs in the ${ }^{1} \mathrm{~T}$ state is reflected in the spin density distribution of $19 \% \mathrm{Zr}$ (Figure 10).

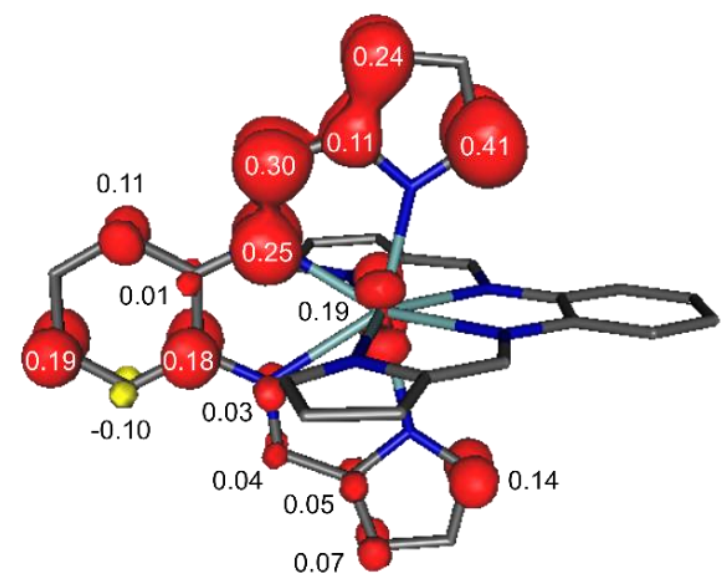

Figure 10. Spin density distribution for the lowest energy triplet state of $\mathrm{Zr}\left({ }^{\mathrm{H}} \mathrm{CNN}\right)_{2}$ obtained via Mulliken population analysis. 
Table 3. Selected bond distances for the $\mathrm{S}_{0}$ and $\mathrm{T}_{1}$ geometries of $\mathrm{Zr}(\text { bppda })_{2}$ obtained via DFT calculations.

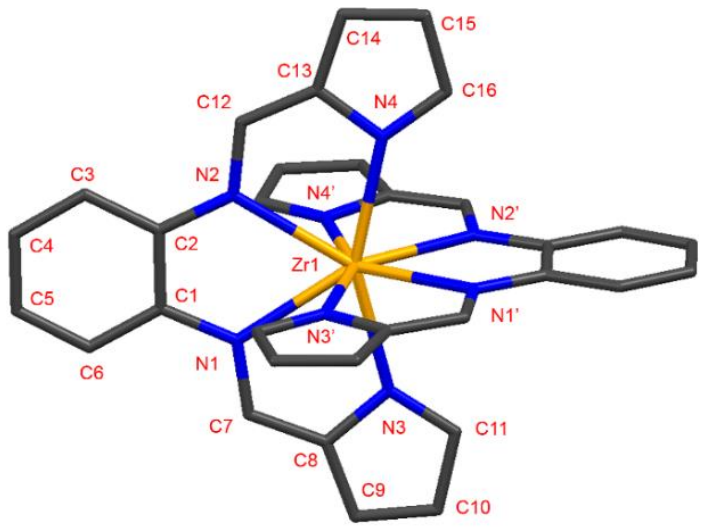

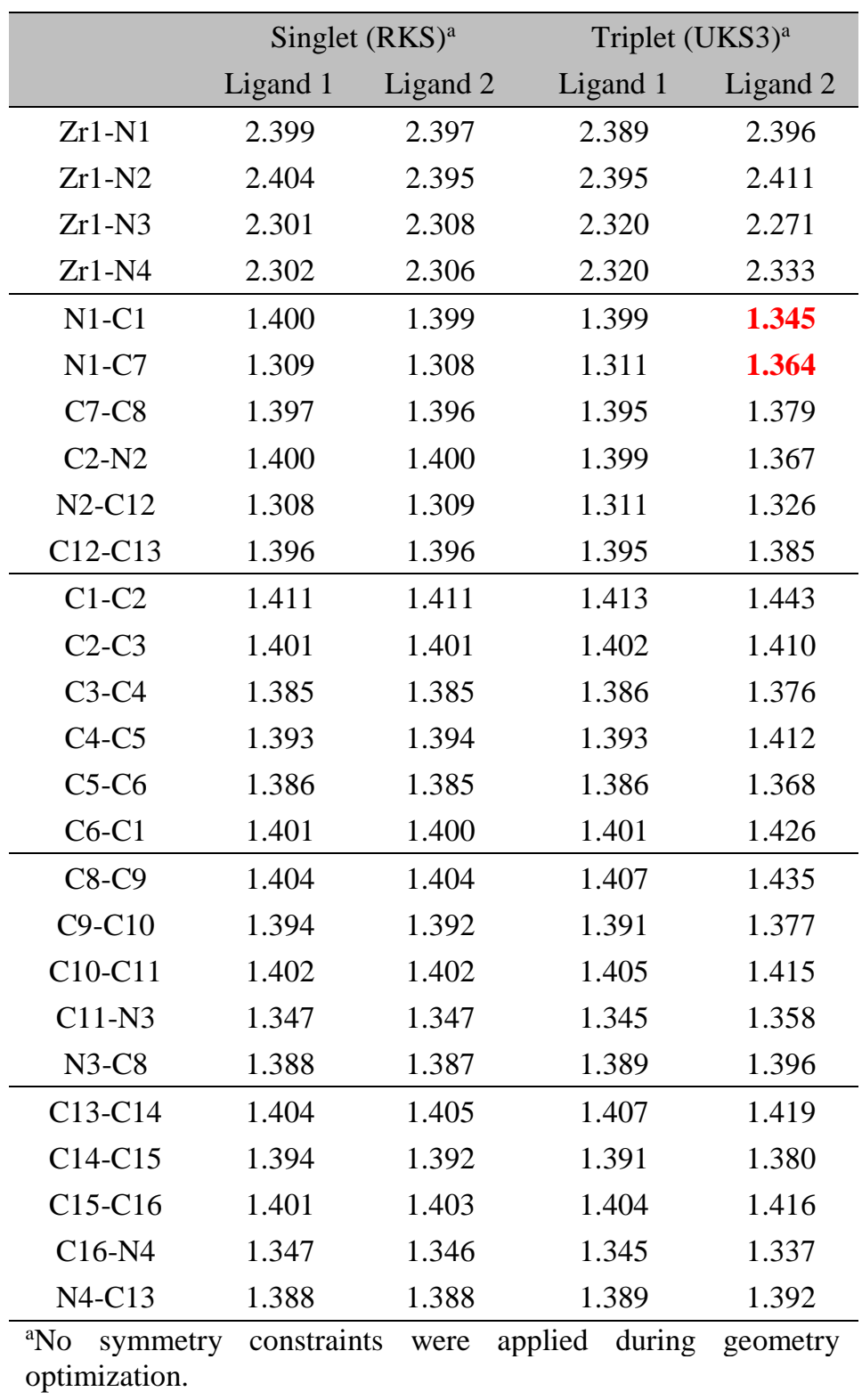


In combination of all experimental photophysical data and TD-DFT results, we propose following simplified decay dynamics for $\operatorname{Zr}\left(\right.$ bppda) 2 (Figure 11): $\operatorname{Zr}(\text { bppda })_{2}$ is excited after Franck-Condon absorption, most of the excited molecules decays via ${ }^{1} \mathrm{LC}$ non-radiative pathway. The remaining $\operatorname{Zr}(\text { bppda })_{2} *$ molecules cross over from the singlet excited state and are "trapped" into a long-lived triplet state. Following a thermal-activated reverse ISC pathway, these $\operatorname{Zr}(\text { bppda })_{2} *$ molecules in the $T_{1}$ are released to the $S_{1}$ state and decay back to ground state. Significant amount of the excited molecules decays back to the ground state almost spontaneously suggesting that the reverse ISC must be faster than ISC and $\operatorname{Zr}(\text { bppda })_{2} *$ favors $S_{1}$ in the equilibrium between $\mathrm{S}_{1}$ and $\mathrm{T}_{1}$.

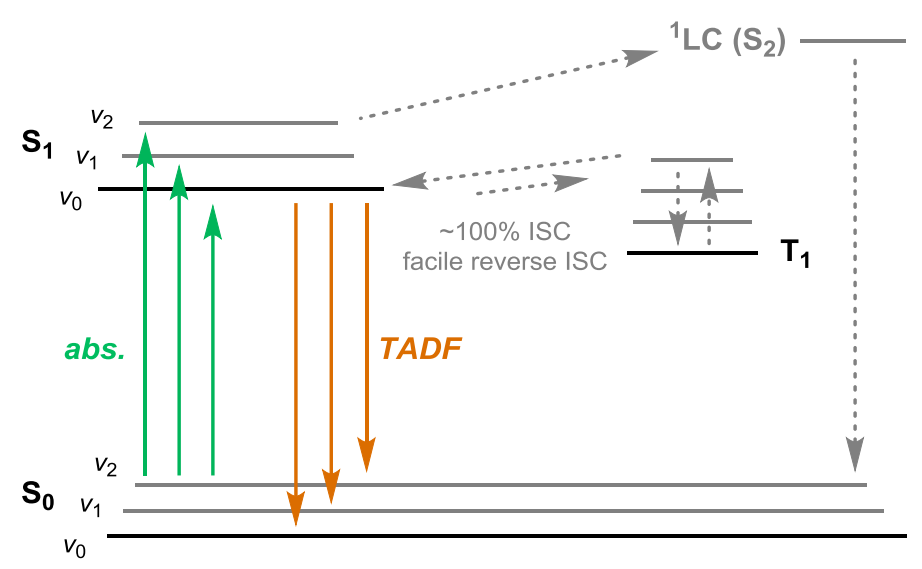

Figure 11. Simplified Jablonski diagram of $\operatorname{Zr}(\text { bppda })_{2}$ constructed from experimental solution data ISC $=$ intersystem crossing. The solid line represents radiative processes and the dotted line shows non-radiative pathways. 


\subsection{Electrochemical Properties.}

To investigate the electrochemical properties of $\mathrm{Zr}(\text { bppda })_{2}$, cyclic voltammetry (CV) experiments were conducted (Figure 12). CV measurements were carried out using a glassy carbon working electrode in THF or $\mathrm{MeCN}$ solution containing $0.1 \mathrm{M}$ tetra-( $n$-butyl)ammonium hexafluorophosphate, $\left[n-\mathrm{Bu}_{4} \mathrm{~N}\right]\left[\mathrm{PF}_{6}\right]$, as the supporting electrolyte and all values were referenced using ferrocene $(\mathrm{Fc})$ as an internal standard. An unresolved irreversible oxidation event was observed. This feature is readily assigned as an oxidation of the ligand framework followed by rapid decomposition of the oxidized product. Similar to the $\operatorname{Zr}(\mathrm{PDP})_{2}$ system, $\operatorname{Zr}(\mathrm{bppda})_{2}$ exhibits multiple reversible reduction chemistry at very negative potentials, where four redox events were observed at $-2.19 \mathrm{~V},-2.56 \mathrm{~V}$ and $-3.00 \mathrm{~V}$ with a quasi-reversible feature at $-3.46 \mathrm{~V}$. The first reduction event can be tentatively assigned as a mixed metal and ligand reduction according to DFT calculated LUMO composition. The rest of reduction events can be attribute to the reduction at Schiff base fragments. 

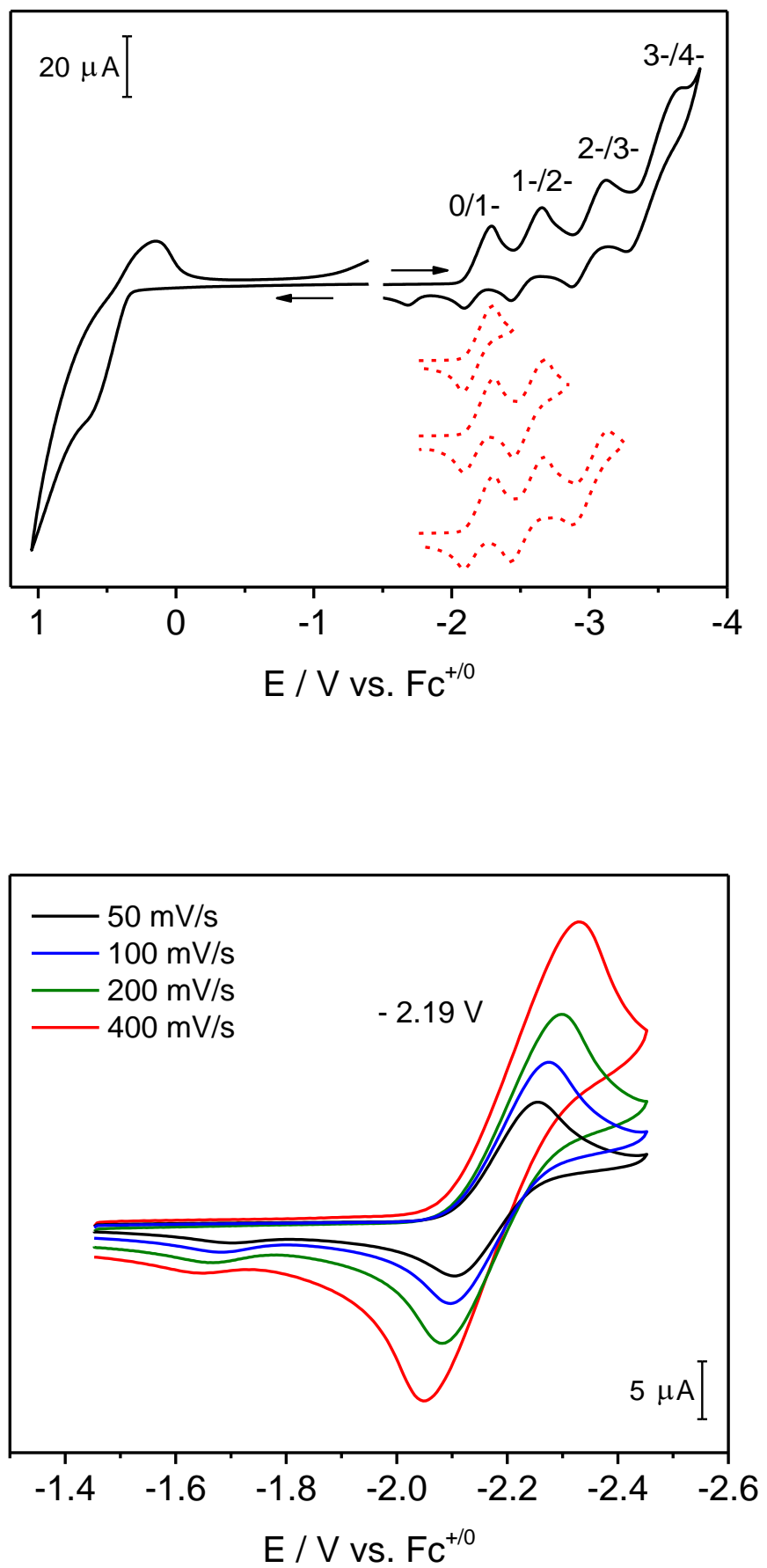

Figure 12. Top: Cyclic voltammogram of $\mathrm{Zr}(\text { bppda) })_{2}$ in THF at room temperature (scan rate 200 $\mathrm{mV} / \mathrm{s}, 0.1 \mathrm{M}\left[\mathrm{N}(n-\mathrm{Bu})_{4}\right] \mathrm{PF}_{6}$, glassy carbon working electrode). Bottom: Cyclic voltammogram for the first reduction event of $\mathrm{Zr}(\mathrm{bppda})_{2}$ at different scan rates $\left(0.1 \mathrm{M}\left[\mathrm{N}(n-\mathrm{Bu})_{4}\right] \mathrm{PF}_{6}\right.$, glassy carbon working electrode). 


\subsection{Photoredox Properties.}

Scheme 2. Estimation of the excited state potential for $\mathrm{Zr}(\mathrm{bppda})_{2}$ using Rehm-Weller formalism.

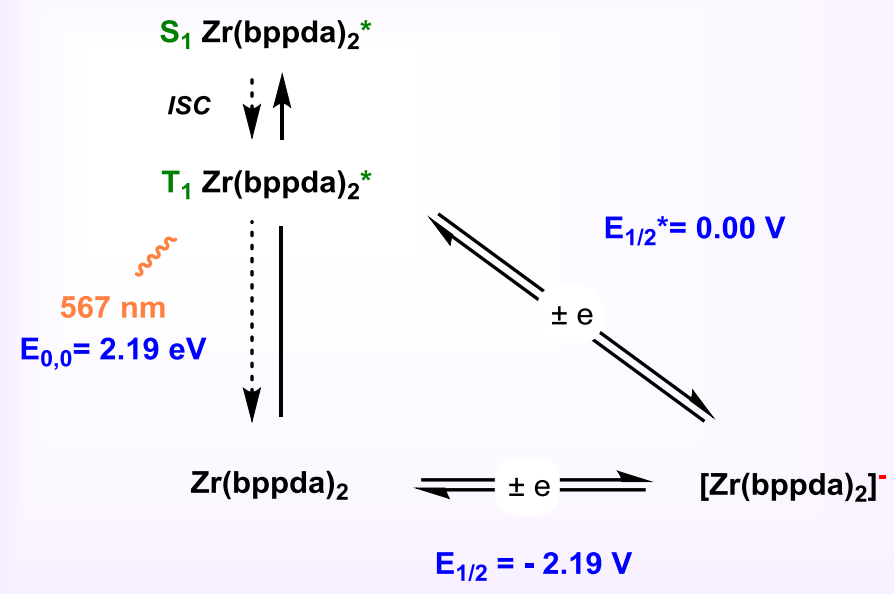

Having established the redox properties and the emission energy, the excited state potential for the redox-couple $\mathrm{Zr}(\text { bppda })_{2}{ }^{*} /\left[\mathrm{Zr}(\mathrm{bppda})_{2}\right]^{1-}$ can be estimated as $0.00 \mathrm{~V}$ vs. $\mathrm{Fc}^{+/ 0}$ using the Rehm-Weller formalism (Scheme 2) ${ }^{23}$ Based on this potential, ferrocene $\left(0.00 \mathrm{~V}\right.$ vs. $\mathrm{Fc}^{+/ 0}$ in $\mathrm{MeCN}$ ) was identified as a potential reductant for $\mathrm{Zr}(\text { bppda })_{2}$. In fact, addition of ferrocene to $\mathrm{Zr}$ (bppda) $)_{2}$ in THF solution lead to a significant reduction of luminescence intensity indicating quenching of the excited state (Figure 13). To quantify the excited state quenching process, SternVolmer studies were conducted for ferrocene with $\operatorname{Zr}(\text { bppda })_{2}{ }^{*}$. The linear dependence of the luminescence intensities on the concentration of the quencher is indicative of diffusion controlled dynamic quenching processes similar to $\mathrm{Zr}(\mathrm{PDP})_{2} /{ }^{\mathrm{R}} \mathrm{BIH}$ system. The strong quenching event was indicated by the high quenching rate constant of $2.98 \times 10^{9} \mathrm{~L} \mathrm{~mol}^{-1} \mathrm{~s}^{-1}$, which is close to the diffusion limit. 

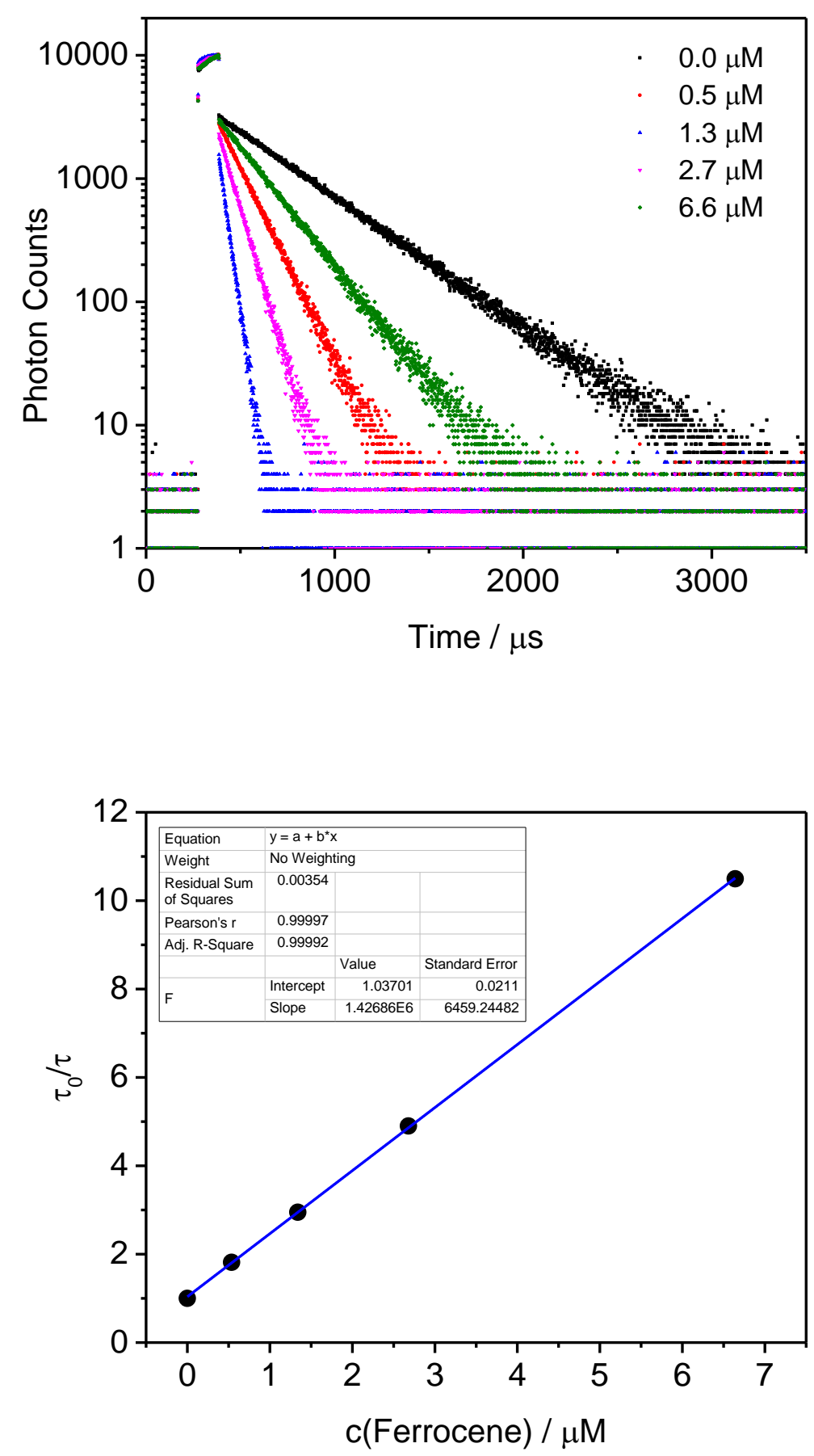

Figure 13. Quenching of $\mathrm{Zr}(\mathrm{bppda})_{2}$ by ferrocene in THF. $\lambda_{\mathrm{ex}}=516 \mathrm{~nm}, \lambda_{\mathrm{em}}=570 \mathrm{~nm}$. Top: Timeresolved luminescence decays at different ferrocene concentration. Bottom: Stern-Volmer analyses. 
Table 4. Quenching parameters from Stern-Volmer analysis and redox potentials of ferrocene.

\begin{tabular}{c|ccc}
\hline & $K_{\mathrm{sv}} / \mathrm{L} \mathrm{mol}^{-1}$ & $k_{\mathrm{q}} / 10^{9} \mathrm{~L} \mathrm{~mol}^{-1} \mathrm{~s}^{-1}$ & $\mathrm{E}_{\mathrm{ox}} / \mathrm{V}$ vs. $\mathrm{Fc}^{+/ 0}$ \\
\hline Ferrocene & $1427000 \pm 6000$ & 2.98 & 0.00 \\
\hline
\end{tabular}

In order to test this new $\mathrm{Zr}(\text { bppda })_{2} / \mathrm{Fc}$ system in performing photoredox reaction, we choose the benchmark benzyl coupling reaction as a model reaction. However, in sharped contrast to $\mathrm{Zr}(\mathrm{PDP})_{2} /{ }^{R} \mathrm{BIH}$ system, the combination of ferrocene as the sacrificial electron donor and $1 \mathrm{~mol} \%$ of $\operatorname{Zr}(\text { bppda })_{2}$ as the photocatalyst failed to carry out any transformation with prolonged reaction time. Although the electron/energy transfer process was proven to be highly efficient, the potentially fast electron back transfer could lead to non-productive pathway. Due to small geometric changes in both $\left[\mathrm{Zr}(\mathrm{bppda})_{2}\right]^{-}$and $\mathrm{Fc}^{+}$, the back electron transfer requires little reorganization energy thus could be as fast as the forward electron transfer. Additionally, this nonproductive pathway should be enhanced under the reaction conditions, because the two ionic products of photoinduced SET $\left(\mathrm{Fc}^{+}\right.$and $\left.\left[\mathrm{Zr}(\mathrm{bppda})_{2}\right]^{-}\right)$are likely to remain in close proximity for facile outer-sphere back electron transfer as the ion-pair formation is favored in the non-polar reaction medium benzene. Catalysis using more polar solvents is currently under investigation.

\subsection{Summary.}

In this chapter, we successfully synthesized an eight-coordinate zirconium photosensitizer, $\mathrm{Zr}$ (bppda) 2 . This zirconium compound was found to be highly stable in wet organic solvents. More 
interestingly, $\mathrm{Zr}(\mathrm{bppda})_{2}$ can access long-lived excited states upon excitation with visible light resulting in TADF emission, evident by the partially ${ }^{3} \mathrm{O}_{2}$ quenched and structurally identical emission bands as well as prompt-delayed lifetime data. The absorption and emission bands exhibit vibronic progression patterns which correspond to a vibrational mode of $\operatorname{Zr}(\mathrm{bppda})_{2}$ at $1036 \mathrm{~cm}^{-1}$ based on IR experiment. Density functional theoretical calculations allowed the assignment of the lowest lying absorption bands in the visible region as mixed ${ }^{1} \mathrm{IL} /{ }^{1} \mathrm{LMCT}$ transitions with $28 \%$

${ }^{1}$ LMCT character. Triplet calculation disclosed that the excited geometry distortion is closely related to an anti-symmetric vibrational stretching mode associated with the Schiff base C-N=C moieties, which is also likely the nature behind the vibrationally resolved absorption and emission bands. The compound also has rich outer sphere electron-transfer chemistry with three reversible single-electron reductions at chemically accessible potentials. Finally, ferrocene was found to be a highly efficient electron transfer reagent to $\operatorname{Zr}(\text { bppda })_{2}{ }^{*}$.

\subsection{Experimental Section.}

General experimental considerations for material handling, physical measurements, X-ray crystallography, and DFT Calculations as well as additional experimental information (i.e. NMR spectra) can be found in the appendices.

Starting Materials. $N, N^{\prime}$-bis(2-pyrrylmethylidene)-1,2-phenylenediamine $\left(\mathrm{H}_{2}\right.$ bppda) ${ }^{6,9}$ was prepared following literature procedures. 
Preparation of $\mathbf{Z r}$ (bppda)2. A solution of tetrabenzyl zirconium ( $130 \mathrm{mg}, 0.286 \mathrm{mmol}, 0.50$ equiv) in $2 \mathrm{~mL}$ of benzene was added slowly to a 20 - $\mathrm{mL}$ vial charged with a solution of $\mathrm{H}_{2}$ bppda (150 $\mathrm{mg}, 0.572 \mathrm{mmol}, 1.00$ equiv) in $3 \mathrm{~mL}$ of benzene. The reaction was stirred for $30 \mathrm{mins}$ at room temperature and the desired product crystalized out while stirring. The reaction was then filtered and the solid was washed three times with $\mathrm{Et}_{2} \mathrm{O}$. The product was collected as dark orange microcrystalline solids (Yield: $164 \mathrm{mg}, 94 \%) .{ }^{1} \mathrm{H}$ NMR (400 MHz, $\left.\mathrm{C}_{6} \mathrm{D}_{6} ; \delta, \mathrm{ppm}\right): 7.94$ (s, 4H, $\mathrm{N}=\mathrm{CH}), 7.12(\mathrm{~s}, 4 \mathrm{H}$, Pyrrole $H), 7.04-6.94(\mathrm{~m}, 8 \mathrm{H}, \mathrm{Ph} H), 6.47(\mathrm{~m}, 4 \mathrm{H}$, Pyrrole $H), 6.04(\mathrm{~m}, 4 \mathrm{H}$, Pyrrole $H) .{ }^{13} \mathrm{C}$ NMR (101 MHz, $\left.\mathrm{C}_{6} \mathrm{D}_{6} ; \delta, \mathrm{ppm}\right): 149.26,142.89,142.34,140.43,126.32,121.80$, 115.76, 113.76. Anal. Calcd for $\mathrm{C}_{26} \mathrm{H}_{18} \mathrm{~N}_{6} \mathrm{Zr}$ : C, 62.82; H, 3.95; N, 18.32. Found: C, 62.97; H, 3.94; N, 18.42. Single crystals suitable for X-ray crystallographic analysis were grown from a saturated solution of $\mathrm{Zr}(\mathrm{bppda})_{2}$ in $\mathrm{C}_{6} \mathrm{D}_{6}$ at room temperature.

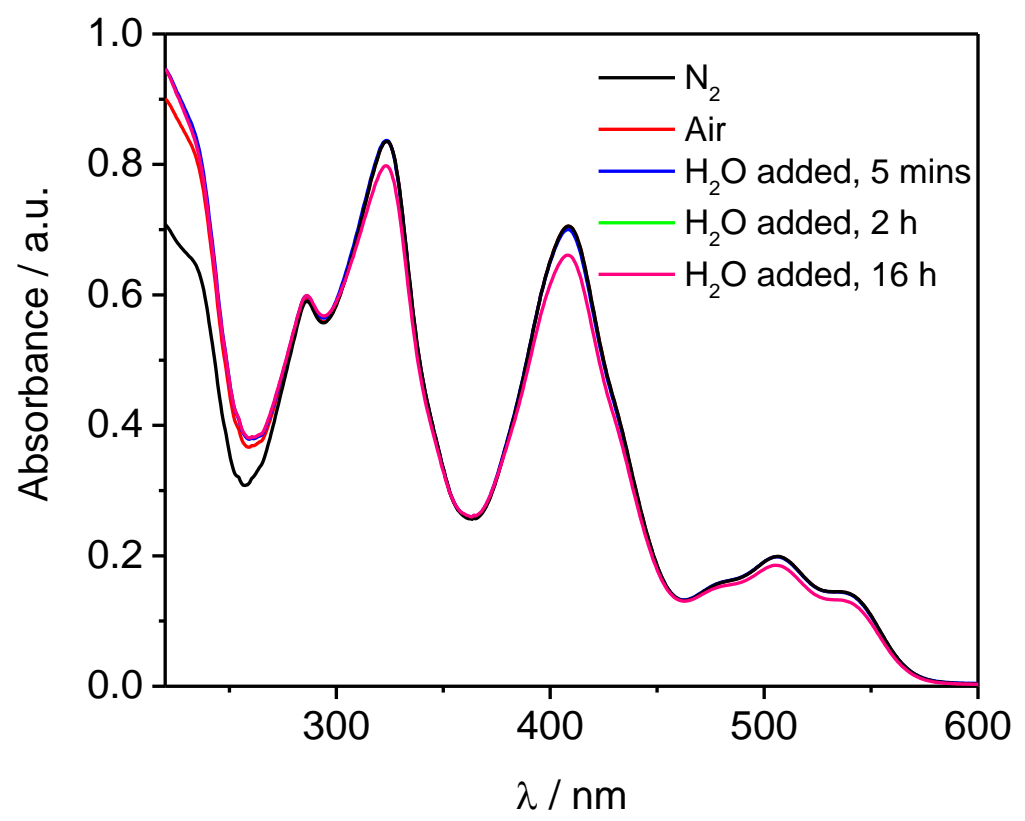

Figure ES1. Overlay of absorption spectrums of $\mathrm{Zr}(\text { bppda) })_{2}$ in THF solution under $\mathrm{N}_{2}$, and air, and under air with water added in ambient light over time. 


\subsection{References.}

(1) Wing-Wah Yam, V.; Qi, G.-Z.; Cheung, K.-K. J. Chem. Soc. Dalt. Trans. 1998, 1819.

(2) Zhang, Y.; Petersen, J. L.; Milsmann, C. J. Am. Chem. Soc. 2016, 138, 13115.

(3) Zhang, Y.; Akhmedov, N. G.; Petersen, J. L.; Milsmann, C. Chem. - A Eur. J. 2019, 25, 3042.

(4) Zhang, Y.; Lee, T. S.; Petersen, J. L.; Milsmann, C. J. Am. Chem. Soc. 2018, 140, 5934.

(5) Zhang, Y.; Petersen, J. L.; Milsmann, C. Organometallics 2018, 37, 4488.

(6) Tabthong, S.; Nanok, T.; Sumrit, P.; Kongsaeree, P.; Prabpai, S.; Chuawong, P.; Hormnirun, P. Macromolecules 2015, 48, 6846.

(7) Zhang, X.-Q.; Lin, M.-S.; Hub, B.; Chen, W.-Q.; Zheng, L.-N.; Wua, J.; Chen, Y.-M.; Zhou, F.-Y.; Li, Y.-H.; WuLi. Polyhedron 2012, 33, 273.

(8) Mu, J. S.; Shi, X. C.; Li, Y. S. J. Polym. Sci. Part A Polym. Chem. 2011, 49, 2700.

(9) Han, X.-Y.; Li, Y.-H.; Zhang, Y.; Wei, H. Chinese J. Chem. 2007, 25, 1334.

(10) Franceschi, F.; Guillemot, G.; Solari, E.; Floriani, C.; Re, N.; Birkedal, H.; Pattison, P. Chem. - A Eur. J. 2001, 7, 1468.

(11) Liang, L. C.; Lee, P. Y.; Lan, W. L.; Hung, C. H. J. Organomet. Chem. 2004, 689, 947.

(12) Male, N. A. H.; Thornton-Pett, M.; Bochmann, M. J. Chem. Soc., Dalt. Trans. 1997, 2487.

(13) Zhang, X.-Q.; Xu, B.; Li, Y.-H.; Li, W. Acta Crystallogr. Sect. E 2008, 64, 437. 
(14) Bacchi, A.; Carcelli, M.; Gabba, L.; Ianelli, S.; Pelagatti, P.; Pelizzi, G.; Rogolino, D. Inorg. Chim. Acta 2003, 342, 229.

(15) Weber, J. H. Inorg. Chem. 1967, 6, 258.

(16) Wang, Y.; Fu, H.; Shen, F.; Sheng, X.; Peng, A.; Gu, Z.; Ma, H.; Ma, J. S.; Yao, J. Inorg. Chem. 2007, 46, 3548 .

(17) Bérubé, C. D.; Gambarotta, S.; Yap, G. P. A.; Cozzi, P. G. Organometallics 2003, 22, 434.

(18) Suresh, D.; Gomes, C. S. B.; Lopes, P. S.; Figueira, C. A.; Ferreira, B.; Gomes, P. T.; Paolo, R. E. Di; MaÅanita, A. L.; Duarte, M. T.; Charas, A.; Morgado, J.; Vila-ViÅosa, D.; Calhorda, M. J. Chem. - A Eur. J. 2015, 21, 9133.

(19) H. Yersin, E. Highly Efficient OLEDs: Materials Based on Thermally Activated Delayed Fluorescence; Wiley-VCH Publishers, 2019.

(20) Uoyama, H.; Goushi, K.; Shizu, K.; Nomura, H.; Adachi, C. Nature 2012, 492, 234.

(21) Hamze, R.; Peltier, J. L.; Sylvinson, D.; Jung, M.; Cardenas, J.; Haiges, R.; Soleilhavoup, M.; Jazzar, R.; Djurovich, P. I.; Bertrand, G.; Thompson, M. E. Science 2019, 363, 601.

(22) Brouwer, A. M. Pure Appl. Chem. 2011, 83, 2213.

(23) Rehm, D.; Weller, A. Isr. J. Chem. 1970, 8, 259. 


\section{Chapter 8.}

\section{Projects in Progress}

\subsection{Tuning the Physical/Optical/Redox Properties of Pyridine Dipyrrolide Zirconium Photosensitizer via Distal Control.}

\section{A Brief Introduction of Zirconium Photosensitizers Towards Water Solubility and}

Bio-Application. Biological systems in nature are mainly composed of water. In order to function in an organism, a chemical must first dissolve in water. Photodynamic therapy (PDT), a novel method of treating cancer, requires a water-soluble photosensitizer in order to penetrate the cell. ${ }^{1}$ In chapter 3, we solved an important air/water stability problem for our first generation zirconium photosensitizer by using a bulky ligand framework: $\mathrm{H}_{2}{ }^{\mathrm{Mes}} \mathrm{PDP}^{\mathrm{Ph}}$. In addition, $\mathrm{Zr}\left({ }^{\mathrm{Mes}} \mathrm{PDP} \mathrm{Ph}_{2}\right.$ could efficiently generates ${ }^{1} \mathrm{O}_{2}$, which could be used to oxidatively damage the cell leading to apoptosis, hence an important feature in photochemotherapy. Unfortunately, the lack of water solubility renders this compound impractical for PDT. In general, functional groups determine the properties of a molecule, including solubility. Here, we describe our initial effort toward developing a watersoluble, tetra-ionic zirconium photosensitizer. 
Synthesis. Inorganic complexes with the best water solubility are typically ionic metal salts.

Due to the high nucleophilicity of dimethylamino functionality, its incorporation opens the door for accessing ionic zirconium photosensitizers. Following similar preparation methods for previous $\mathrm{Zr}\left({ }^{\mathrm{Mes}} \mathrm{PDP}{ }^{\mathrm{Ph}}\right)_{2}$ complexes, a new zirconium complex, $\mathrm{Zr}\left({ }^{\mathrm{Mes}} \mathrm{PDP}^{\mathrm{NMe} 2 \mathrm{Ph}}\right)_{2}\left({ }^{\mathrm{Mes}} \mathrm{PDP}^{\mathrm{NMe} 2 \mathrm{Ph}}=\right.$ 2,6-bis(5-mesityl-3-(4-dimethylaminophenyl)-1H-pyrrol-2-yl)-pyridine), was synthesized. Similar to previous $\mathrm{Zr}\left({ }^{\mathrm{Mes}} \mathrm{PDP}^{\mathrm{Ph}}\right)_{2}$, this new complex is highly stable under ambient wet conditions, which allows for post-synthetic modification. Direct reaction with an electrophile, methyl iodide, under air furnishes the tetra-cationic $\left[\mathrm{Zr}\left({ }^{\mathrm{Mes}} \mathrm{PDP}^{\mathrm{NMe} P \mathrm{Ph}}\right)_{2}\right] \mathrm{I}_{4}\left({ }^{\mathrm{Mes}} \mathrm{PDP}^{\mathrm{NMe} 3 \mathrm{Ph}}=2,6-\right.$ bis $(5$-mesityl-3(4-trimethylammoniumphenyl)-1H-pyrrol-2-yl)-pyridine) in nearly quantitative yield (Scheme 1). The identity of the compound was established with NMR spectroscopy.

The neutral $\mathrm{Zr}\left({ }^{\mathrm{Mes}} \mathrm{PDP}^{\mathrm{Ph}}\right)_{2}$ and $\mathrm{Zr}\left({ }^{\mathrm{Mes}} \mathrm{PDP}^{\mathrm{NMe} 2 \mathrm{Ph}}\right)_{2}$ are very soluble in THF, chlorinated and aromatic solvents. They dissolve poorly in DMSO and are insoluble in $\mathrm{MeCN}$ and protic polar solvents, such as $\mathrm{MeOH}$ and $\mathrm{H}_{2} \mathrm{O}$. On the other hand, $\left[\mathrm{Zr}\left({ }^{\mathrm{Mes}} \mathrm{PDP}^{\mathrm{NMe} 3 \mathrm{Ph}}\right)_{2}\right] \mathrm{I}_{4}$ exhibits nearly reversed solubility profile compares to these two neutral compounds. It could readily dissolve in various polar solvents such as $\mathrm{DMSO}, \mathrm{MeCN}$ and $\mathrm{DMF}$ but is insoluble in chlorinated, aromatic and ethereal solvents. Most interestingly, this highly charged compound can be dissolved in $\mathrm{MeOH}$, a bio-compatible solvent. Although insoluble in water, a solution of $\left[\mathrm{Zr}\left({ }^{\mathrm{Mes}} \mathrm{PDP}^{\mathrm{NMe} P \mathrm{Ph}}\right)_{2}\right] \mathrm{I}_{4}$ in water is obtainable with the aid of a few drops of DMSO. This solution preparation method is commonly used for drugs with low water solubility. ${ }^{2}$ 
Another approach to increase water solubility of the zirconium complex is to incorporate the PEG (polyethylene glycol) group. Using the same synthetic method as $\mathrm{Zr}\left({ }^{\mathrm{Mes}} \mathrm{PDP}{ }^{\mathrm{NMe} 2 \mathrm{Ph}}\right)_{2}$, we successfully synthesized a precursor complex: $\mathrm{Zr}\left({ }^{\mathrm{Mes}} \mathrm{PDP}^{\mathrm{OMePh}}\right)_{2}\left({ }^{\mathrm{Mes}} \mathrm{PDP}^{\mathrm{OMePh}}=2,6\right.$-bis $(5$-mesityl3-(4-methoxyphenyl)-1H-pyrrol-2-yl)-pyridine). The following deprotection-deprotonationPEGylation is currently under experimentation (Scheme 2).

Scheme 1. Synthesis of $\left[\mathrm{Zr}\left({ }^{\mathrm{Mes}} \mathrm{PDP} \mathrm{NMe}^{\mathrm{NPh}}\right)_{2}\right] \mathrm{I}_{4}$.
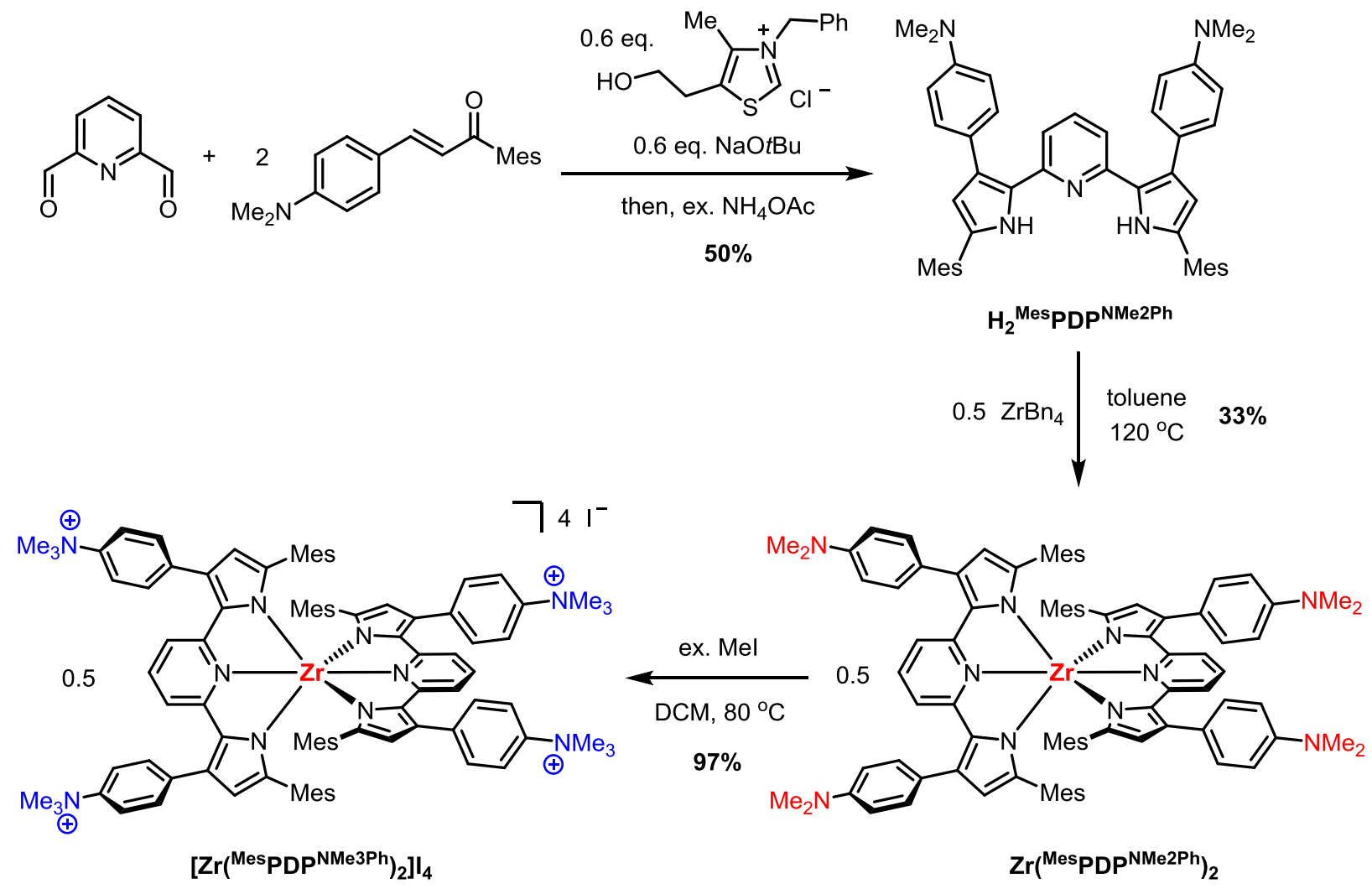
Scheme 2. Progress in synthesizing of $\mathrm{Zr}\left({ }^{\mathrm{Mes}} \mathrm{PDP}^{\mathrm{ORPh}}\right)_{2}$.
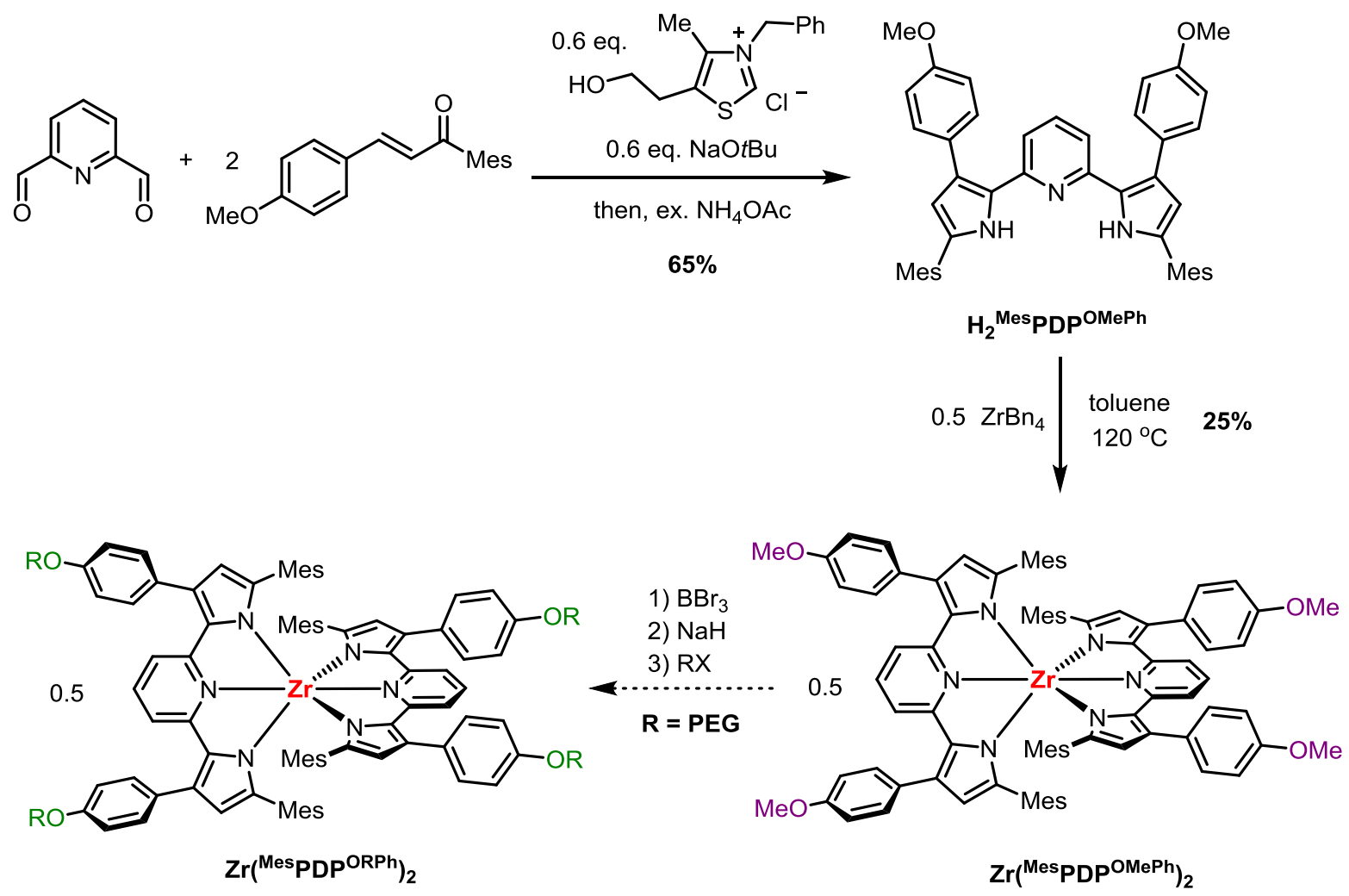

Optical Properties. Absorption and emission profiles for these newly synthesized zirconium complexes in solution are shown in Figure 1. Because of their widely different solubility, $\mathrm{Zr}\left({ }^{\mathrm{Mes}} \mathrm{PDP}^{\mathrm{NMe} 2 \mathrm{Ph}}\right)_{2}$ and $\left[\mathrm{Zr}\left({ }^{\mathrm{Mes}} \mathrm{PDP}^{\mathrm{NMe} 3 \mathrm{Ph}}\right)_{2}\right] \mathrm{I}_{4}$ were measured in $\mathrm{THF}$ and DMF respectively. According to the studies in chapter 3, the solvatochromic effect is almost negligible for the highly rigid $\mathrm{Zr}\left({ }^{\mathrm{Mes}} \mathrm{PDP} \mathrm{Ph}^{\mathrm{Ph}}\right)_{2}$. So, direct comparison of two new complexes between different solvents seems reasonable.

As noted in chapter 4 , the color of the $\operatorname{Zr}(\mathrm{PDP})_{2}$ complexes is highly controlled by 5-pyrrole substitution of the PDP. Since the core structure of $\mathrm{Zr}\left({ }^{\mathrm{Mes}} \mathrm{PDP}^{\mathrm{NMe} 2 \mathrm{Ph}}\right)_{2}$ and $\left[\mathrm{Zr}\left({ }^{\mathrm{Mes}} \mathrm{PDP}^{\mathrm{NMe} 3 \mathrm{Ph}}\right)_{2}\right] \mathrm{I}_{4}$ 
are the same, we expect them to be as rigid as $\mathrm{Zr}\left({ }^{\mathrm{Mes}} \mathrm{PDP}^{\mathrm{Ph}}\right)_{2}$ with no dramatic shift $(>5 \mathrm{~nm}$ ) in absorption and emission features. As anticipated, the tetra-ionic $\left[\mathrm{Zr}\left({ }^{\mathrm{Mes}} \mathrm{PDP}^{\mathrm{NMe} 3 \mathrm{Ph}}\right)_{2}\right] \mathrm{I}_{4}$ displayed almost identical shift compare to the neutral counterpart, $\mathrm{Zr}\left({ }^{\mathrm{Mes}} \mathrm{PDP}^{\mathrm{Ph}}\right)_{2}$. For $\mathrm{Zr}\left({ }^{\mathrm{Mes}} \mathrm{PDP}^{\mathrm{NMe} 2 \mathrm{Ph}}\right)_{2}$, however, the lowest energy absorption and emission band red shifted by 12 and $20 \mathrm{~nm}$ respectively. There is also an additional absorption feature around $400 \mathrm{~nm}$ (Table 1). Trisubstituted amines are known as a common class of chromophores that lead to a red shift of the compound's absorptive features in photochemistry. Thus, the large observed variation suggests the significantly participation of the dimethylamino group in the frontier orbital optical transitions.

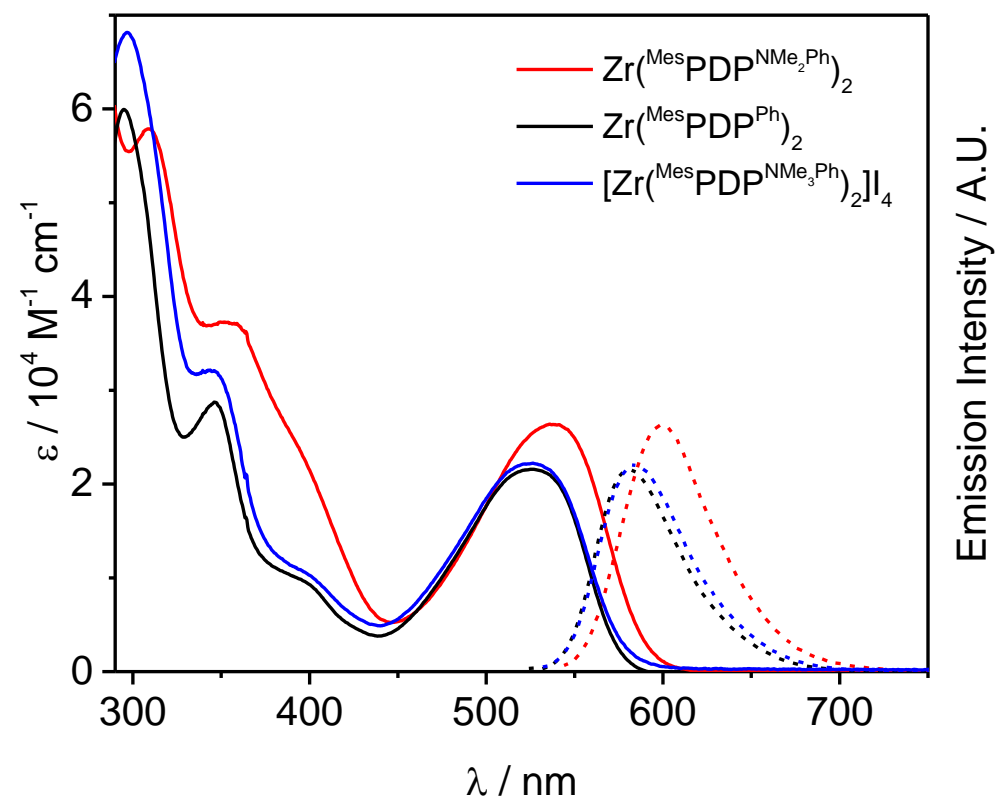

Figure 1. Absorption (solid lines) and emission spectra (dashed lines) of $\operatorname{Zr}\left({ }^{\mathrm{Mes}} \mathrm{PDP}^{\mathrm{Ph}}\right)_{2}$, $\mathrm{Zr}\left({ }^{\mathrm{Mes}} \mathrm{PDP}^{\mathrm{NMe} 2 \mathrm{Ph}}\right)_{2}$ and $\left[\mathrm{Zr}\left({ }^{\mathrm{Mes}} \mathrm{PDP}^{\mathrm{NMe} 3 \mathrm{Ph}}\right)_{2}\right] \mathrm{I}_{4}$ in solution at room temperature. 
Table 1. The absorption ( ${ }^{1} \mathrm{IL} /{ }^{1} \mathrm{LMCT}$ band) and emission maxima recorded in all media discussed for $\mathrm{Zr}\left({ }^{\mathrm{Mes}} \mathrm{PDP}{ }^{\mathrm{Ph}}\right)_{2}, \mathrm{Zr}\left({ }^{\mathrm{Mes}} \mathrm{PDP}{ }^{\mathrm{NMe} 2 \mathrm{Ph}}\right)_{2}$ and $\left[\mathrm{Zr}\left({ }^{\mathrm{Mes}} \mathrm{PDP}^{\mathrm{NMe} 3 \mathrm{Ph}}\right)_{2}\right] \mathrm{I}_{4}$.

\begin{tabular}{c|cc}
\hline & $\lambda_{\text {abs-max }}(\mathrm{nm})$ & $\lambda_{\text {em-max }}(\mathrm{nm})$ \\
\hline $\mathrm{Zr}\left({ }^{\text {Mes }}{ }^{\mathrm{PDP}}{ }^{\mathrm{NMe} 2 \mathrm{Ph}}\right)_{2}$ & 538 & 600 \\
$\mathrm{Zr}\left({ }^{\mathrm{Mes}} \mathrm{PDP}^{\mathrm{Ph}}\right)_{2}$ & 526 & 580 \\
{$\left[\mathrm{Zr}\left({ }^{\mathrm{Mes} P D P}{ }^{\mathrm{NMe} 3 \mathrm{Ph}}\right)_{2}\right] \mathrm{I}_{4}$} & 526 & 584 \\
\hline
\end{tabular}

The origin of the electronic transitions for $\mathrm{Zr}\left({ }^{\mathrm{Mes}} \mathrm{PDP}^{\mathrm{NMe} 2 \mathrm{Ph}}\right)_{2}$ was studied by time dependent density functional theory (TD-DFT) calculations performed at the B3LYP level. Solvent effect was included using the conductor-like screening model (COSMO, THF). The computational results reveal a relatively small HOMO-LUMO energy gap of $2.70 \mathrm{eV}$ compared to that of 2.86 $\mathrm{eV}$ for $\mathrm{Zr}\left({ }^{\mathrm{Mes}} \mathrm{PDP}^{\mathrm{Ph}}\right)_{2}$, which is the same gap as observed for $\mathrm{Zr}\left({ }^{\mathrm{Ph}} \mathrm{PDP}{ }^{\mathrm{Ph}}\right)_{2}$ of the $\mathrm{Zr}(\mathrm{PDP})_{2}$ series. This explains the red shift in absorption features. Furthermore, as depicted in Figure 3, donor orbitals (HOMO and HOMO-1) of the visible absorption band have $10 \%$ contribution from $\mathrm{NMe}_{2}$. The adjacent HOMO-3 and HOMO-4 have even more $\mathrm{NMe}_{2}$ characters $(>20 \%)$ (Table 2), which served as donor orbitals for the second major absorption band and led to the strong absorption band shouldered around $400 \mathrm{~nm}$. 


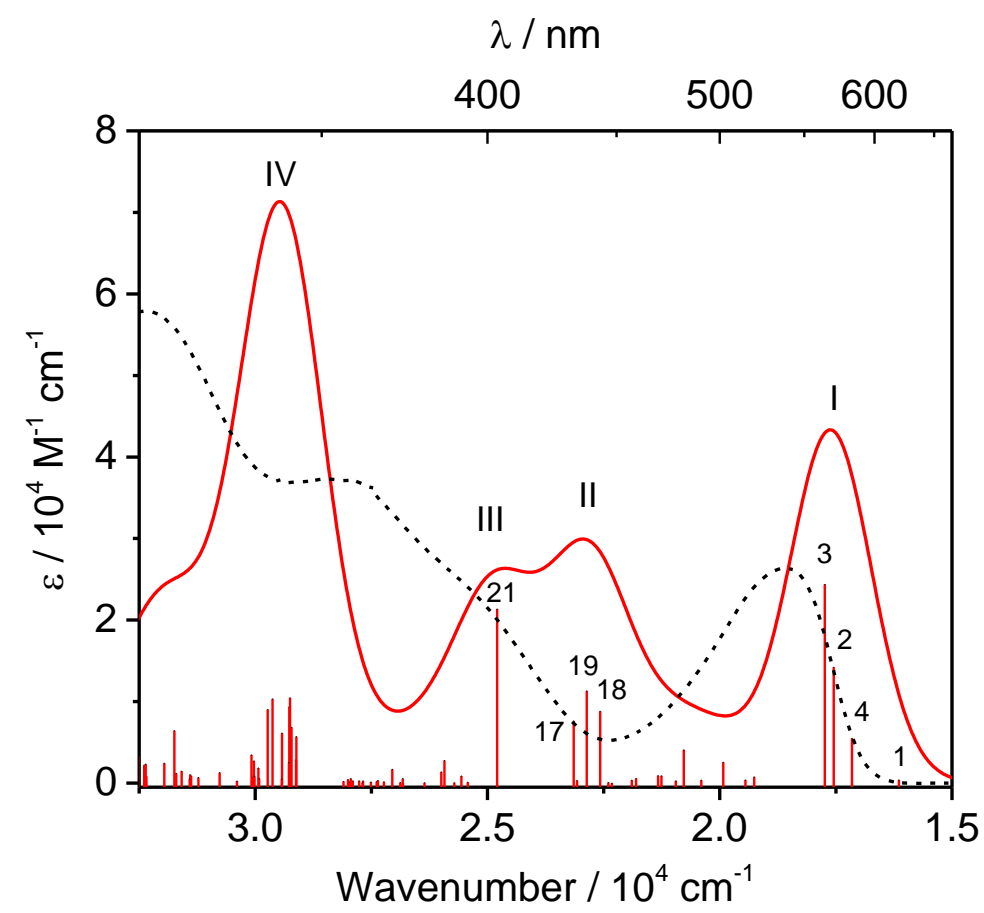

Figure 2. Electronic absorption spectrum of $\mathrm{Zr}\left({ }^{\mathrm{Mes}} \mathrm{PDP}^{\mathrm{NMe2Ph}}\right)_{2}$ in $\mathrm{THF}$ obtained via TD-DFT calculations (red line, FWHM of $2500 \mathrm{~cm}^{-1}$ ). The stick plot indicates the positions and relative intensities of individual transitions. The major contributions to each numbered state are listed in Table 2. The experimental spectrum is shown as a dotted black line for comparison.

Table 2. Vertical electronic excitation energies and main excitations contributing to the absorption bands of $\mathrm{Zr}\left({ }^{\mathrm{Mes}} \mathrm{PDP}^{\mathrm{NMe} 2 \mathrm{Ph}}\right)_{2}$ obtained via TD-DFT calculations

\begin{tabular}{|c|c|c|c|c|c|c|}
\hline Band & $\begin{array}{l}\text { TD-DFT } \\
\text { State }\end{array}$ & $\begin{array}{c}\text { Energy / } \mathrm{cm}^{-1} \\
(\lambda / \mathrm{nm})\end{array}$ & $\mathrm{f}_{\text {osc }}$ & $\begin{array}{l}\text { Excitations } \\
\text { (weight) }{ }^{\mathrm{a}, \mathrm{b}}\end{array}$ & $\begin{array}{l}\mathrm{NMe}_{2} \text { character } \\
\text { in donor orbital }\end{array}$ & $\begin{array}{c}\text { Assignment } \\
(\% \mathrm{LMCT})\end{array}$ \\
\hline \multirow{4}{*}{ I } & 1 & $16143.1(619.5)$ & 0.004 & $383 \rightarrow 384(0.88)$ & $8.4 \%$ & ${ }^{1} \mathrm{IL} /{ }^{1} \mathrm{LMCT}(39 \%)$ \\
\hline & 4 & $17152.4(583.0)$ & 0.051 & $\begin{array}{l}382 \rightarrow 385(0.56) \\
382 \rightarrow 384(0.20) \\
383 \rightarrow 385(0.18)\end{array}$ & $8.0 \%$ & ${ }^{1} \mathrm{IL} /{ }^{1} \mathrm{LMCT}(39 \%)$ \\
\hline & 2 & $17548.1(569.9)$ & 0.131 & $\begin{array}{l}382 \rightarrow 384(0.46) \\
382 \rightarrow 385(0.37)\end{array}$ & $8.0 \%$ & ${ }^{1} \mathrm{IL} /{ }^{1} \mathrm{LMCT}(39 \%)$ \\
\hline & 3 & $17739.3(563.7)$ & 0.225 & $\begin{array}{l}383 \rightarrow 385(0.68) \\
382 \rightarrow 384(0.21)\end{array}$ & $8.4 \%$ & ${ }^{1} \mathrm{IL} /{ }^{1} \mathrm{LMCT}(39 \%)$ \\
\hline \multirow{3}{*}{ II } & 18 & $22574.4(443.0)$ & 0.081 & $381 \rightarrow 386(0.87)$ & $23.5 \%$ & ${ }^{1} \mathrm{IL} /{ }^{1} \mathrm{LMCT}(47 \%)$ \\
\hline & 19 & $22863.7(437.4)$ & 0.104 & $380 \rightarrow 386(0.89)$ & $22.5 \%$ & ${ }^{1} \mathrm{IL} /{ }^{1} \mathrm{LMCT}(47 \%)$ \\
\hline & 17 & $23146.4(432.0)$ & 0.070 & $\begin{array}{l}376 \rightarrow 384(0.48) \\
377 \rightarrow 385(0.32)\end{array}$ & $5.3 \%$ & ${ }^{1} \mathrm{IL} /{ }^{1} \mathrm{LMCT}(39 \%)$ \\
\hline III & 21 & $24794.5(403.3)$ & 0.197 & $379 \rightarrow 386(0.87)$ & $17.3 \%$ & ${ }^{1} \mathrm{IL} /{ }^{1} \mathrm{LMCT}(47 \%)$ \\
\hline
\end{tabular}

${ }^{\mathrm{a}}$ Only excitations with a weight larger than 0.1 are shown. ${ }^{\mathrm{b}} \mathrm{HOMO} 383$, LUMO 384. 

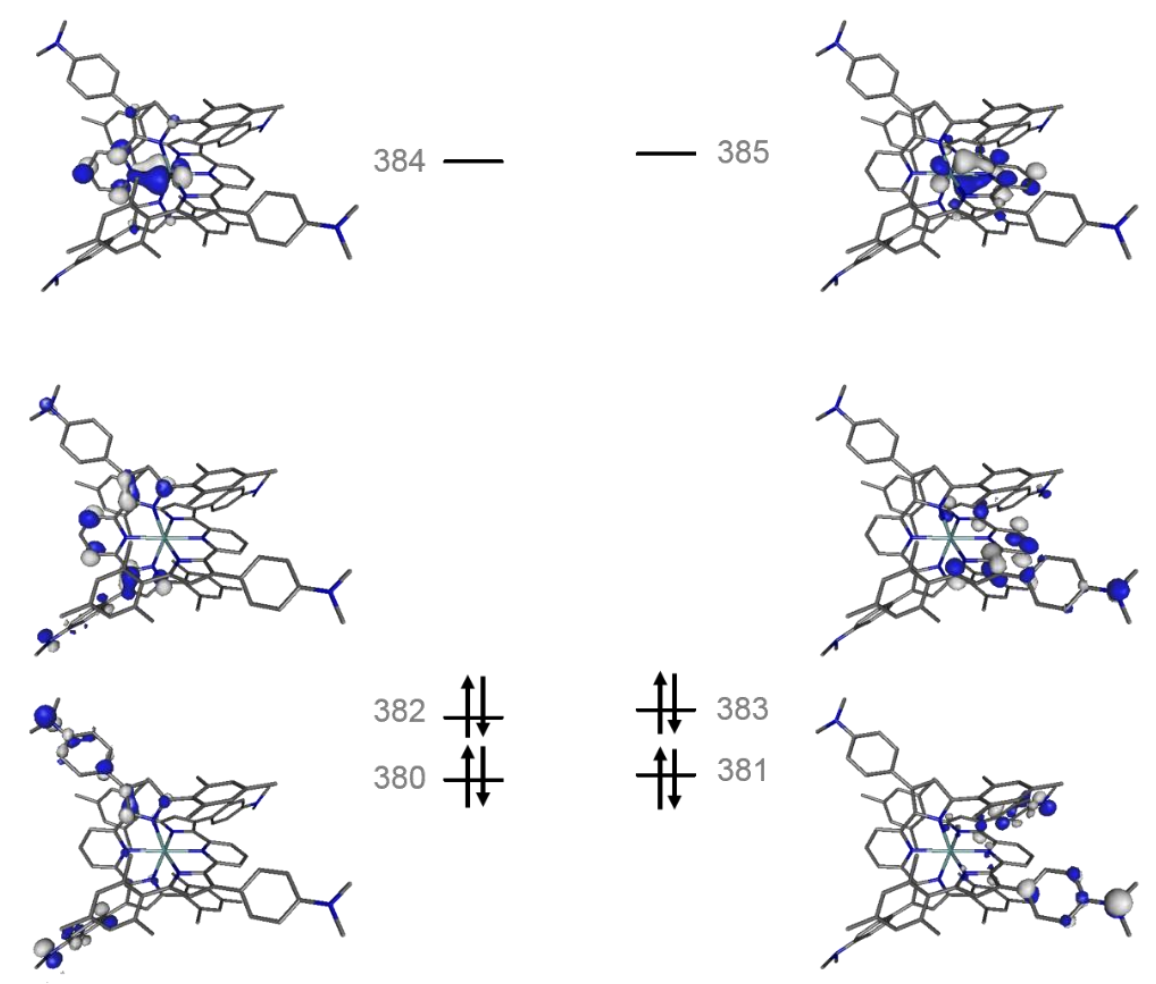

Figure 3. Frontier molecular orbital diagram showing the donor and acceptor orbitals contributing to the TD-DFT excitations computed in the visible region of the electronic absorption spectrum. The gray numbers to the right correspond to the MO number with 383 being the HOMO and 384 being the LUMO.

Photoluminescent quantum yields $\left(\Phi_{\mathrm{PL}}\right)$ and lifetimes $(\tau)$ of the $\operatorname{Zr}\left({ }^{\mathrm{Mes}} \mathrm{PDP}^{\mathrm{NMe} 2 \mathrm{Ph}}\right)_{2}$ and $\left[\mathrm{Zr}\left({ }^{\mathrm{Mes}} \mathrm{PDP}^{\mathrm{NMe} 3 \mathrm{Ph}}\right)_{2}\right] \mathrm{I}_{4}$ were determined at room temperature and under optically dilute conditions ( $<0.1$ absorbance) in THF and DMF solution, respectively. The $\Phi_{\mathrm{PL}} \tau$ value, and excited state decay parameters are listed in Table 3. For $\operatorname{Zr}(\operatorname{PDP})_{2}$, as summarized in chapter 4, the excited state decay dynamics after Franck-Condon absorption are mainly controlled by the ligand framework's rigidity and the number of C-H's high frequency oscillators close to the zirconium center. Despite the indistinguishable core framework, both $\mathrm{Zr}\left({ }^{\mathrm{Mes}} \mathrm{PDP}^{\mathrm{NMe} 2 \mathrm{Ph}}\right)_{2}$ exhibits significantly lower 
quantum efficiencies and shorter lifetimes compared to $\mathrm{Zr}\left({ }^{\mathrm{Mes}} \mathrm{PDP}^{\mathrm{Ph}}\right)_{2}$. This difference suggests additional non-radiative decay paths introduced by the heteroatom-based functional group. The trisubstituted amine group, a strong electron donor, could lead to a non-radiative, intramolecular electron transfer process (Figure 4). ${ }^{3,4}$

Table 3. Excited state decay parameters. ${ }^{\mathrm{a}}$

\begin{tabular}{c|cccc}
\hline & $\tau / \mu \mathrm{s}$ & $\Phi_{\mathrm{PL}}$ & $k_{r}\left(\mathrm{~s}^{-1}\right)$ & $k_{n r}\left(\mathrm{~s}^{-1}\right)$ \\
\hline $\mathrm{Zr}\left({ }^{\text {Mes }} \mathrm{PDP}^{\mathrm{NMe} 2 \mathrm{Ph}}\right)_{2}$ & 207 & 0.23 & 1100 & 3684 \\
$\mathrm{Zr}\left({ }^{\mathrm{Mes}} \mathrm{PDP}^{\mathrm{Ph}}\right)_{2}$ & 350 & 0.45 & 1286 & 1571 \\
{$\left[\mathrm{Zr}\left({ }^{\text {(Mes }} \mathrm{PDP}^{\mathrm{NMe} 3 \mathrm{Ph}}\right)_{2}\right] \mathrm{I}_{4}$} & 261 & $-{ }^{\mathrm{b}}$ & - & - \\
\hline${ }^{\mathrm{a}} \mathrm{k}_{\mathrm{r}}=\Phi_{\mathrm{PL}} / \tau, \mathrm{k}_{\mathrm{nr}}=\left(1-\Phi_{\mathrm{PL}}\right) / \tau$. & ${ }^{\mathrm{b}}$ not obtained yet.
\end{tabular}

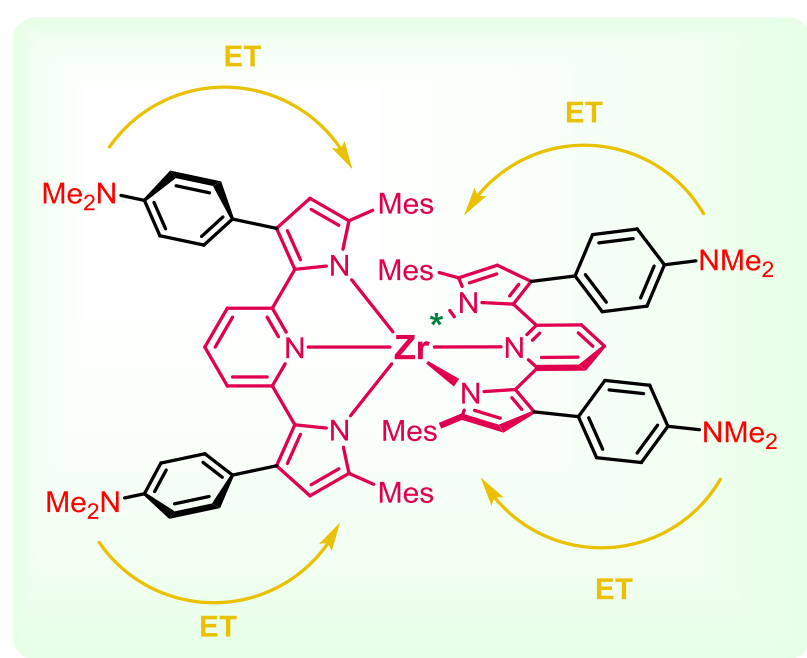

Figure 4. Schematic representation of the proposed non-radiative electron transfer processes.

Electrochemistry. The redox chemistry displayed also drastically differ from the parent $\mathrm{Zr}\left({ }^{\mathrm{Mes}} \mathrm{PDP}^{\mathrm{Ph}}\right)_{2}$ complex. To establish the electrochemical properties, cyclic voltammetry $(\mathrm{CV})$ 
experiments were conducted in THF solution using ferrocene $(\mathrm{Fc})$ as an internal standard (Figure 5). Upon reduction, all three complexes displayed two fully reversible redox events at very negative potential, which were assigned as one-electron reductions for each complex. Between $\mathrm{Zr}\left({ }^{\mathrm{Mes}} \mathrm{PDP}^{\mathrm{NMe} 2 \mathrm{Ph}}\right)_{2}$ and $\left[\mathrm{Zr}\left({ }^{\mathrm{Mes}} \mathrm{PDP}^{\mathrm{NMe} 3 \mathrm{Ph}}\right)_{2}\right] \mathrm{I}_{4}$, the potentials of the first reduction varied significantly, by $\sim 0.5 \mathrm{~V}$ (from -2.38 to $-1.91 \mathrm{~V}$ respectively) . The strong electron-donating power of $\mathrm{NMe}_{2}$ and highly electron-withdrawing ability of $\mathrm{NMe}_{3}{ }^{+}$causes the large shift and shows the importance of substituting at a distal position (away from metal center).

On the other side of $\mathrm{CV}$, when applying oxidation potential, the two new complexes display a distinct change from the parent compound. Similar to $\mathrm{Zr}\left({ }^{\mathrm{Me}} \mathrm{PDP}^{\mathrm{Ph}}\right)_{2}$, two quasi-reversible oxidation events at $+0.55 \mathrm{~V}$ and $+0.72 \mathrm{~V}$ were found for $\mathrm{Zr}\left({ }^{\mathrm{Mes}} \mathrm{PDP}^{\mathrm{NMe} 2 \mathrm{Ph}}\right)_{2}$ suggest oxidation at the pyrrole unit. Except for two oxidation events at higher potentials, multiple new oxidation events around $+0.47 \mathrm{~V}$ were barely resolved. Under identical measurement conditions, the oxidation potential of $N, N$-dimethylaniline is $+0.51 \mathrm{~V}$ (Figure 6), which implies the oxidation of $\mathrm{NMe}_{2}$ functionalities as the unresolved features in the $\mathrm{CV}$ of $\mathrm{Zr}\left({ }^{\mathrm{Mes}} \mathrm{PDP}^{\mathrm{NMe} 2 \mathrm{Ph}}\right)_{2}$. On the basis of electrochemical observation, DFT-calculated HOMO significantly underestimated the importance of $\mathrm{NMe}_{2}$ group ( $<10 \%$ dimethylamino nitrogen character). Considerable changes also happened for $\left[\mathrm{Zr}\left({ }^{\mathrm{Mes}} \mathrm{PDP}^{\mathrm{NMe} 3 \mathrm{Ph}}\right)_{2}\right] \mathrm{I}_{4}$ compared to $\mathrm{Zr}\left({ }^{\mathrm{Me}} \mathrm{PDP}^{\mathrm{Ph}}\right)_{2}$, there was no reversible oxidative events. The irreversible event at $+0.31 \mathrm{~V}$ was tentatively assigned to be iodide oxidation. Currently, we are examining the possibility of displacing $\mathrm{I}^{-}$with a more oxidatively-robust anion such as triflate. In 
general, such simple modifications at a distal position from zirconium PDP core lead to dramatic differences in the electrochemical behavior.

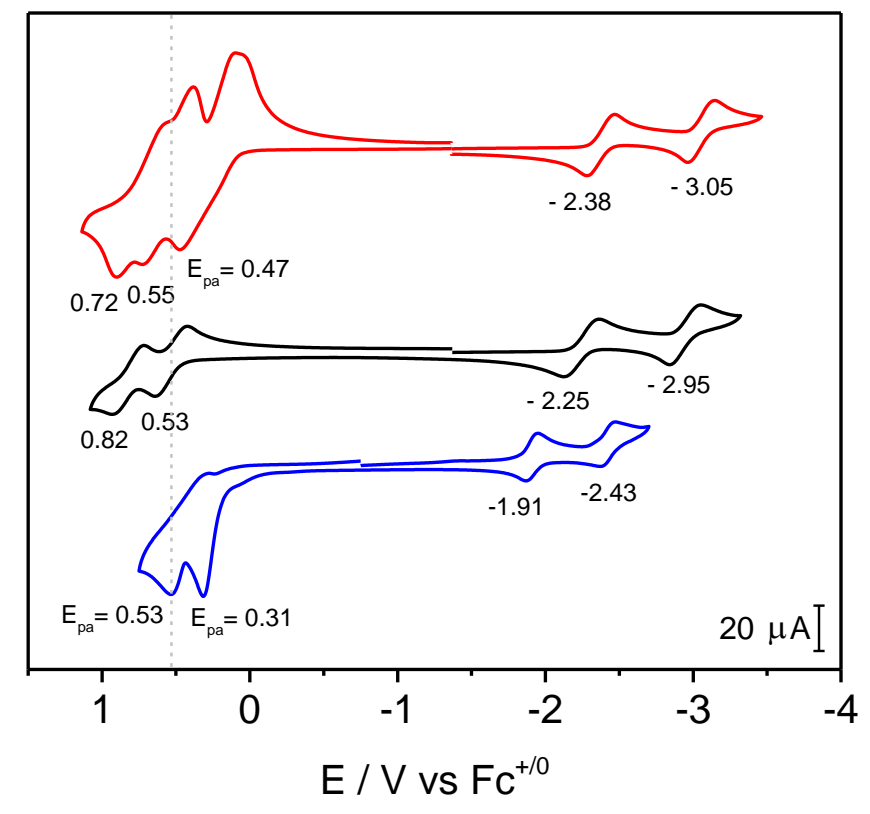

Figure 5. Cyclic voltammogram of $\mathrm{Zr}\left({ }^{\mathrm{Mes}} \mathrm{PDP}^{\mathrm{Ph}}\right)_{2}$ (black) and $\mathrm{Zr}\left({ }^{\mathrm{Mes}} \mathrm{PDP}^{\mathrm{NMe} 2 \mathrm{Ph}}\right)_{2}$ (red) in THF and $\left[\mathrm{Zr}\left({ }^{\mathrm{Mes}} \mathrm{PDP}^{\mathrm{NMe} 3 \mathrm{Ph}}\right)_{2}\right] \mathrm{I}_{4}$ (blue) in DMF at room temperature (scan rate $200 \mathrm{mV} \mathrm{s}^{-1}, 0.1 \mathrm{M}[\mathrm{N}(n-$ $\left.\mathrm{Bu})_{4}\right] \mathrm{PF}_{6}$, glassy carbon working electrode).

\section{Experimental Section.}

General experimental considerations for material handling, physical measurements, X-ray crystallography, and DFT Calculations as well as additional experimental information (i.e. NMR spectra) can be found in the appendices. 
Starting material. 1-(2,4,6-trimethylphenyl)-3-[4-(dimethylamino)phenyl]-prop-2-en-1-one and 1-(2,4,6-trimethylphenyl)-3-(4-methoxyphenyl)-prop-2-en-1-one were synthesized via Aldol condensation of 2,4,6-trimethylphenylacetophenone and 4-(dimethylamino)benzaldehyde (4methoxybenzaldehyde).

Preparation of 1-(2,4,6-trimethylphenyl)-3-[4-(dimethylamino)phenyl]-prop-2-en-1-one. 2,4, 6-trimethylphenylacetophenone ( $8.5 \mathrm{~g}, 52.39 \mathrm{mmol}, 1.0 \mathrm{eq}$.$) and 4-(dimethylamino)benzaldehyde$ (7.82 g, 52.39 mmol, 1.0 eq.) were loaded in a $250-\mathrm{mL}$ flask and ethanol was added. Then an aqueous solution of $\mathrm{NaOH}\left(3.14 \mathrm{~g}, 78.59 \mathrm{mmol}, 1.5\right.$ eq.) was added dropwise (Ethanol : $\mathrm{H}_{2} \mathrm{O}=$ 1:1). After 5 hours of stiring at $60^{\circ} \mathrm{C}$, the reaction was cool to room temperature. The product was extracted with DCM. The combined DCM layer was dried. Solvent removal in vacuo resulted in a viscous liquid. At this point, hexane was added. After a while, the product crystallized out of solution and was filtered before drying $(11.77 \mathrm{~g}, 77 \%)$. The spectroscopic data matches literature value. $^{7}$

Preparation of 1-(2,4,6-trimethylphenyl)-3-(4-methoxyphenyl)-prop-2-en-1-one. Similar to the procedure for 1-(2,4,6-trimethylphenyl)-3-[4-(dimethylamino)phenyl]-prop-2-en-1-one. ${ }^{1} \mathrm{H}$ NMR (400 MHz, $\left.\mathrm{CDCl}_{3} ; \delta, \mathrm{ppm}\right): 7.46(\mathrm{dm}, J=8.8 \mathrm{~Hz}, 2 \mathrm{H}), 7.13(\mathrm{~d}, J=16.0 \mathrm{~Hz}, 1 \mathrm{H}), 6.90$ $(\mathrm{dm}, J=9.2,2 \mathrm{H}), 6.88(\mathrm{~s}, 2 \mathrm{H}), 6.82(\mathrm{~d}, J=16.4 \mathrm{~Hz}, 1 \mathrm{H}), 6.19$ (t, $J=8.0 \mathrm{~Hz}, 1 \mathrm{H}, \mathrm{Py} H), 3.84(\mathrm{~s}$, $\left.6 \mathrm{H}, \mathrm{OCH}_{3}\right), 2.32(\mathrm{~s}, 3 \mathrm{H}), 2.19\left(\mathrm{~s}, 6 \mathrm{H}, \mathrm{CH}_{3}\right)$. 
Preparation of $\mathbf{H}_{2}{ }^{\text {Mes }}$ PDP $^{\mathrm{NMe} 2 \mathrm{Ph}}$. The synthesis was carried out according to a modified literature procedure. ${ }^{8} \quad$ 2,6-Pyridinedicarboxaldehyde $(1.27$ g, $9.40 \mathrm{mmol}, 1.00$ equiv), 1-(2,4,6trimethylphenyl)-3-[4-(dimethylamino)phenyl]-prop-2-en-1-one (5.57 g, $18.99 \mathrm{mmol}, 2.02$ equiv), and 3-benzyl-5-(2-hydroxyethyl)-4-methyl-thiazolium chloride (1.77 g, $6.58 \mathrm{mmol}, 0.700$ equiv), were mixed in a $250-\mathrm{mL}$ Schlenk flask under argon atmosphere. Absolute ethanol was added, and the mixture was heated to reflux. A solution of sodium tert-butoxide $(632 \mathrm{mg}, 6.58 \mathrm{mmol}, 0.700$ equiv) in ethanol was added using a syringe and heating was continued for 24 hours. The reaction was cooled to room temperature and ammonium acetate (14.49 g, $187.98 \mathrm{mmol}, 20.00$ equiv) was added to the mixture. The reaction mixture was heated to reflux open to air for 48 hours. The palletlike precipitate was collected via filtration, grounded into fine powders and suspended in hot ethanol. Then, the suspension was sonicated and filtered again and washed with hot ethanol, dried under high vacuum to yield the desired product as a yellow solid (Yield: $3.2 \mathrm{~g}, 50 \%$ ). ${ }^{1} \mathrm{H}$ NMR (400 MHz, $\left.\mathrm{C}_{6} \mathrm{D}_{6} ; \delta, \mathrm{ppm}\right): 11.65$ (s, 2H, NH), 7.67 (dm, $\left.J=7.2 \mathrm{~Hz}, 4 \mathrm{H}, \mathrm{Ph} H\right), 7.02(\mathrm{ddm}, J=8.0$, $2.0 \mathrm{~Hz}, 2 \mathrm{H}, \mathrm{Py} H), 6.86(\mathrm{dm}, J=6.8 \mathrm{~Hz}, 4 \mathrm{H}, \mathrm{Ph} H), 6.67$ (s, 4H, mesityl- $\mathrm{Ph} H), 6.23$ (tm, $J=8.0$ Hz, 1H, PyH), 6.14 (s, 2H, PyrroleH), 2.61(s, 12H, $\left.\mathrm{NCH}_{3}\right), 2.10$ (s, 12H, ortho- $\left.\mathrm{CH}_{3}\right), 1.95$ (s, 6H, para- $\left.\mathrm{CH}_{3}\right) .{ }^{13} \mathrm{C} \mathrm{NMR}\left(101 \mathrm{MHz}, \mathrm{C}_{6} \mathrm{D}_{6} ; \delta, \mathrm{ppm}\right): 150.84,149.82,139.02,136.85,136.35,133.13$, $130.64,130.55,126.91,125.52,117.44,113.13,112.38,40.39,21.12,20.69$ (two aromatic peaks overlapping). 
Preparation of $\mathbf{H}_{2}{ }^{\text {Mes PDPOMePh}}$ : Similar to the procedure for $\mathrm{H}_{2}{ }^{\text {Mes }}{ }^{\text {PDP }}{ }^{\mathrm{NMe} 2 \mathrm{Ph}}$. (Yield: $5.1 \mathrm{~g}, 65 \%$ ). ${ }^{1} \mathrm{H}$ NMR (400 MHz, $\left.\mathrm{C}_{6} \mathrm{D}_{6} ; \delta, \mathrm{ppm}\right): 11.57$ (s, 2H, NH), $7.60(\mathrm{~d}, J=8.0 \mathrm{~Hz}, 4 \mathrm{H}, \mathrm{Ph} H), 7.05(\mathrm{~d}, J$ $=8.0,4 \mathrm{H}, \mathrm{Ph} H), 6.88(\mathrm{~d}, J=8.0 \mathrm{~Hz}, 2 \mathrm{H}, \mathrm{Py} H), 6.61(\mathrm{~s}, 4 \mathrm{H}$, mesityl- $\mathrm{Ph} H), 6.19(\mathrm{t}, J=8.0 \mathrm{~Hz}, 1 \mathrm{H}$, PyH), 6.07 (s, 2H, Pyrrole $H$ ), 3.39 (s, 6H, $\left.\mathrm{OCH}_{3}\right), 2.03$ (s, 12H, ortho- $\left.\mathrm{CH}_{3}\right), 1.92$ (s, 6H, para$\left.\mathrm{CH}_{3}\right) .{ }^{13} \mathrm{C}$ NMR (101 MHz, $\left.\mathrm{C}_{6} \mathrm{D}_{6} ; \delta, \mathrm{ppm}\right): 158.92,150.30,138.52,136.87,136.17,132.93,130.65$, $130.56,129.88,126.86,125.25,117.19,114.10,112.17,54.52,20.73,20.29$. (one aromatic peak overlapping).

Preparation of Zr( $\left.{ }^{\text {Mes PDP }}{ }^{\text {NMe2PhPh }}\right)$ 2. Tetrabenzyl zirconium (106 mg, $233 \mathrm{mmol}, 0.52$ equiv) and $\mathrm{H}_{2}{ }^{\mathrm{Mes}} \mathrm{PDP}^{\mathrm{Ph}}$ (306 mg, $447 \mathrm{mmol}, 1.00$ equiv) were loaded in a 50-mL thick-walled glass vessel in the glovebox. About $5 \mathrm{~mL}$ of toluene was added. The thick-walled vessel was sealed with a PTFE screw cap and heated to $120^{\circ} \mathrm{C}$ for 24 hours. After cooling to room temperature, the reaction vessel was brought back into the glovebox and additional tetrabenzyl zirconium (106 mg, $233 \mathrm{mmol}, 0.52$ equiv) was added. The reaction mixture was heated for another 24 hours at $120^{\circ} \mathrm{C}$ (at this stage the ligand was fully consumed or close to full consumption). Then, the reaction was opened to air. Toluene was removed using rotary evaporator and triturated twice with ethyl acetate to give red solid. The resultant was redissolved in DCM/ethyl acetate and filtered through a plug of silica gel. After removal of solvent, the product was recrystallized from slow evaporation of THF under air. The product was collected as red crystals (Yield: $105 \mathrm{mg}, 33 \%) .{ }^{1} \mathrm{H}$ NMR $\left(400 \mathrm{MHz}, \mathrm{C}_{6} \mathrm{D}_{6} ; \delta\right.$, ppm): $7.73(\mathrm{~d}, J=8.0 \mathrm{~Hz}, 8 \mathrm{H}), 6.86(\mathrm{~d}, J=7.8 \mathrm{~Hz}, 8 \mathrm{H}), 6.70(\mathrm{~d}, J=8.4 \mathrm{~Hz}, 4 \mathrm{H}), 6.64(\mathrm{~s}, 8 \mathrm{H}$, 
mesityl-CH), 6.39 (t, $J=8.0 \mathrm{~Hz}, 2 \mathrm{H}$, para-Py $H), 6.08(\mathrm{~s}, 4 \mathrm{H}$, pyrrole $H), 2.60\left(\mathrm{~s}, 24 \mathrm{H}, \mathrm{NCH}_{3}\right)$, 2.22 (s, 24H, ortho- $\left.\mathrm{CH}_{3}\right), 1.93$ (s, $12 \mathrm{H}$, para- $\left.\mathrm{CH}_{3}\right) .{ }^{13} \mathrm{C}$ NMR (101 MHz, $\left.\mathrm{C}_{6} \mathrm{D}_{6} ; \delta, p p m\right): 154.98$, $149.93,142.47,140.05,138.05,136.55,136.10,132.30,131.02,130.46,126.40,115.56,112.95$, 112.59, 40.37, 23.31, 21.11 (one aromatic carbon overlapping). Anal. Calcd for $\mathrm{C}_{94} \mathrm{H}_{94} \mathrm{~N}_{10} \mathrm{Zr} \cdot 1$ $\mathrm{C}_{4} \mathrm{H}_{8} \mathrm{O}: \mathrm{C}, 77.07 ; \mathrm{H}, 6.73 ; \mathrm{N}, 9.17$. Found: C, 77.05; H, 6.48; N, 9.20.

Preparation of $\mathbf{Z r}\left({ }^{\text {Mes }}{ }^{2} P^{\text {OMePhPh }}\right){ }_{2}$. Similar to the procedure for $\mathrm{Zr}\left({ }^{\mathrm{Mes}} \mathrm{PDP}^{\mathrm{NMe} 2 \mathrm{PhPh}}\right)_{2}$. (Yield: $106 \mathrm{mg}, 25 \%) .{ }^{1} \mathrm{H}$ NMR (400 MHz, $\left.\mathrm{C}_{6} \mathrm{D}_{6} ; \delta, \mathrm{ppm}\right): 7.66(\mathrm{~d}, J=8.0 \mathrm{~Hz}, 8 \mathrm{H}), 7.05(\mathrm{~d}, J=8.0 \mathrm{~Hz}$, 8H), 6.56 (s, 8H, mesityl-CH), $6.53(\mathrm{~d}, J=7.6 \mathrm{~Hz}, 4 \mathrm{H}), 6.36(\mathrm{t}, J=8.0 \mathrm{~Hz}, 2 \mathrm{H}$, para-PyH), 6.01 (s, $4 \mathrm{H}$, pyrrole $H$ ), $3.40\left(\mathrm{~s}, 12 \mathrm{H}, \mathrm{OCH}_{3}\right), 2.14\left(\mathrm{~s}, 24 \mathrm{H}\right.$, ortho- $\left.\mathrm{CH}_{3}\right), 1.89$ (s, $12 \mathrm{H}$, para- $\left.\mathrm{CH}_{3}\right) \cdot{ }^{13} \mathrm{C}$ $\operatorname{NMR}\left(101 \mathrm{MHz}, \mathrm{C}_{6} \mathrm{D}_{6} ; \delta, \mathrm{ppm}\right): 159.37,154.76,142.49,139.93,138.26,136.77,136.12,131.97$, $130.77,130.43,130.30,115.58,114.34,112.64,54.88,23.20,21.03$. (one aromatic carbon overlapping).

Preparation of $\left[\mathbf{Z r}\left({ }^{\text {Mes }}{ }^{2} P^{\text {NMe3Ph }}\right)_{2}\right] \mathbf{I}_{4}$. MeI $(497 \mathrm{mg}, 3.50 \mathrm{mmol}, 100.00$ equiv $)$ and $\mathrm{Zr}\left({ }^{\text {Mes }} \mathrm{PDP}^{\mathrm{NMe} 2 \mathrm{PhPh}}\right)_{2}(51 \mathrm{mg}, 0.035 \mathrm{mmol}, 1.00$ equiv) were loaded in a J. Young tube under air. About $0.6 \mathrm{~mL}$ of DCM was added. The J. Young tube was sealed with a screw cap and heated to $80{ }^{\circ} \mathrm{C}$ for 24 hours, in which the desired product precipitate out of the solution. After cooling to room temperature, the reaction mixture was filtered before washing the solids with DCM. After drying under air, the product was collected as red powder (Yield: $69 \mathrm{mg}, 97 \%$ ). ${ }^{1} \mathrm{H}$ NMR (400 $\left.\mathrm{MHz}, \mathrm{MeCN}-d_{3} ; \delta, \mathrm{ppm}\right): 7.96(\mathrm{~d}, J=8.4 \mathrm{~Hz}, 8 \mathrm{H}), 7.75(\mathrm{~d}, J=8.4 \mathrm{~Hz}, 8 \mathrm{H}), 7.11(\mathrm{t}, J=8.0 \mathrm{~Hz}$, 
2H, para-PyH), 6.45 (s, 8H, mesityl-CH), $6.44(\mathrm{~d}, J=8.0 \mathrm{~Hz}, 2 \mathrm{H}$, meta-PyH), 5.84 (s, 4H, pyrrole $H$ ), 3.70 (s, 36H, $\left.\mathrm{NCH}_{3}\right), 2.00\left(\mathrm{~s}, 12 \mathrm{H}\right.$, para- $\left.\mathrm{CH}_{3}\right), 1.73$ (s, $24 \mathrm{H}$, ortho- $\left.\mathrm{CH}_{3}\right) .{ }^{13} \mathrm{C} \mathrm{NMR}$ (101 MHz, $\left.\mathrm{C}_{6} \mathrm{D}_{6} ; \delta, \mathrm{ppm}\right): 154.52,146.38,143.03,141.06,140.31,140.28,138.48,136.81,131.60$, $131.54,128.83,128.34,121.51,115.74,114.33,58.22,22.98,21.11$.

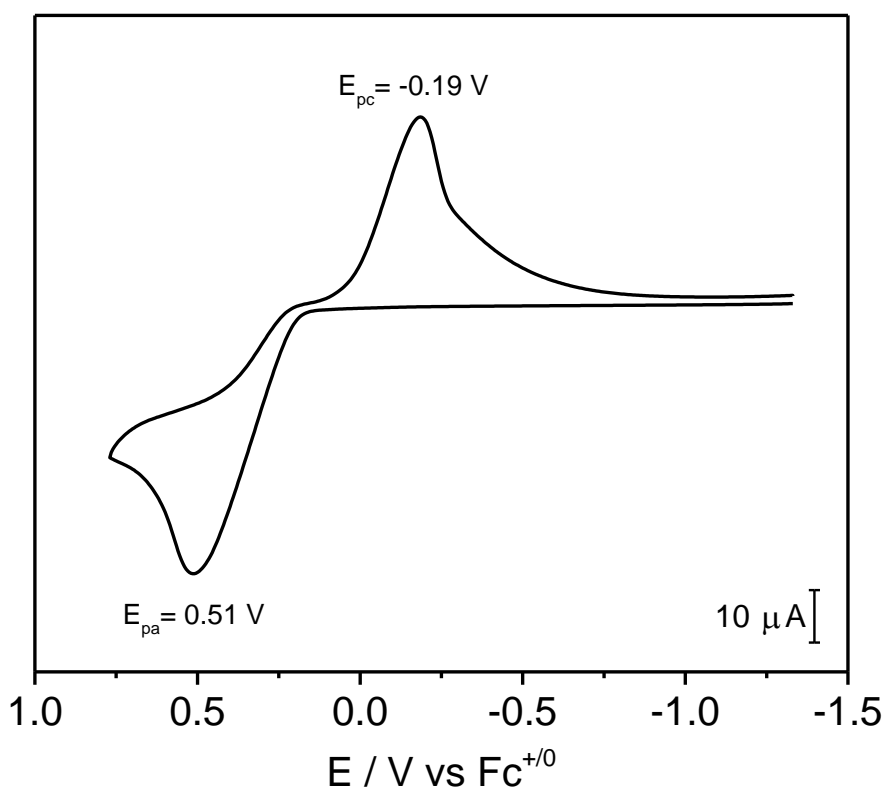

Figure 6. Cyclic voltammogram of $N, N$-dimethylaniline in THF at room temperature (scan rate $200 \mathrm{mV} \mathrm{s}^{-1}, 0.1 \mathrm{M}\left[\mathrm{N}(n-\mathrm{Bu})_{4}\right] \mathrm{PF}_{6}$, glassy carbon working electrode). 


\subsection{Single-Electron-Induced Isomerization of an Octahedral Titanium 2,2'-Pyridylpyrrolide}

\section{Complex.}

Synthesis and Characterization. Synthesizing a titanium analogue as an extension to previous $\left({ }^{\mathrm{Me}} \mathrm{PMP}{ }^{\mathrm{Me}}\right){ }_{3} \mathrm{M}^{\mathrm{IV}} \mathrm{Cl}(\mathrm{M}=\mathrm{Zr}$, Hf $)$ chemistry is a natural progression. Unlike previous synthesis, facile reduction of $\mathrm{Ti}^{\mathrm{IV}}$ by the lithium salt of the ligand prohibits direct salt metathesis with $\mathrm{TiCl}_{4}(\mathrm{THF})_{2}$. Reaction of $\mathrm{TiCl}_{3}(\mathrm{THF})_{3}$ with two equivalents of $\mathrm{Li}^{\mathrm{Me}} \mathrm{PMP}^{\mathrm{Me}}$ resulted in clean formation of a neutral, paramagnetic $\mathrm{Ti}\left({ }^{\mathrm{Me}} \mathrm{PMP}{ }^{\mathrm{Me}}\right)_{3}$ in high yield (Scheme 3 ). The low solubility of $\mathrm{Ti}\left({ }^{\mathrm{Me}} \mathrm{PMP}{ }^{\mathrm{Me}}\right)_{3}$ in non-polar solvent could be problematic for separating the desired product from $\mathrm{KCl}$. The identity of the compound was tentatively assigned by paramagnetic ${ }^{1} \mathrm{H}$ NMR spectroscopy (Figure 7). The 18-resonance pattern suggests a titanium species with low symmetry, likely a mer-isomer where all three ligands are inequivalent. The mer-isomer should have 21 peaks whereas the $f a c$-isomer with a $C_{3}$ axis that trisect the three ligands should only have seven resonances. The absence of three peaks in the ${ }^{1} \mathrm{H}$ NMR spectrum comes from overlapping of the broad paramagnetic peaks.

Scheme 3. Synthesis of $m e r-\mathrm{Ti}\left({ }^{\mathrm{Me}} \mathrm{PMP}^{\mathrm{Me}}\right)_{3}$.

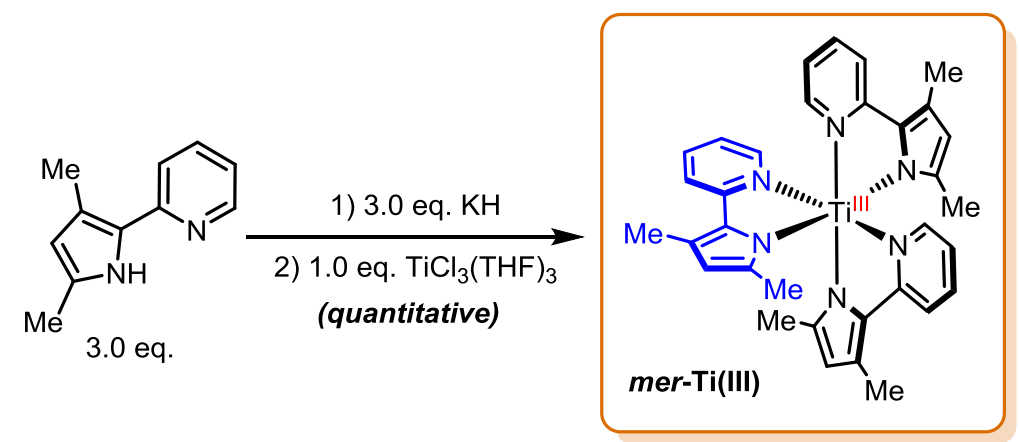




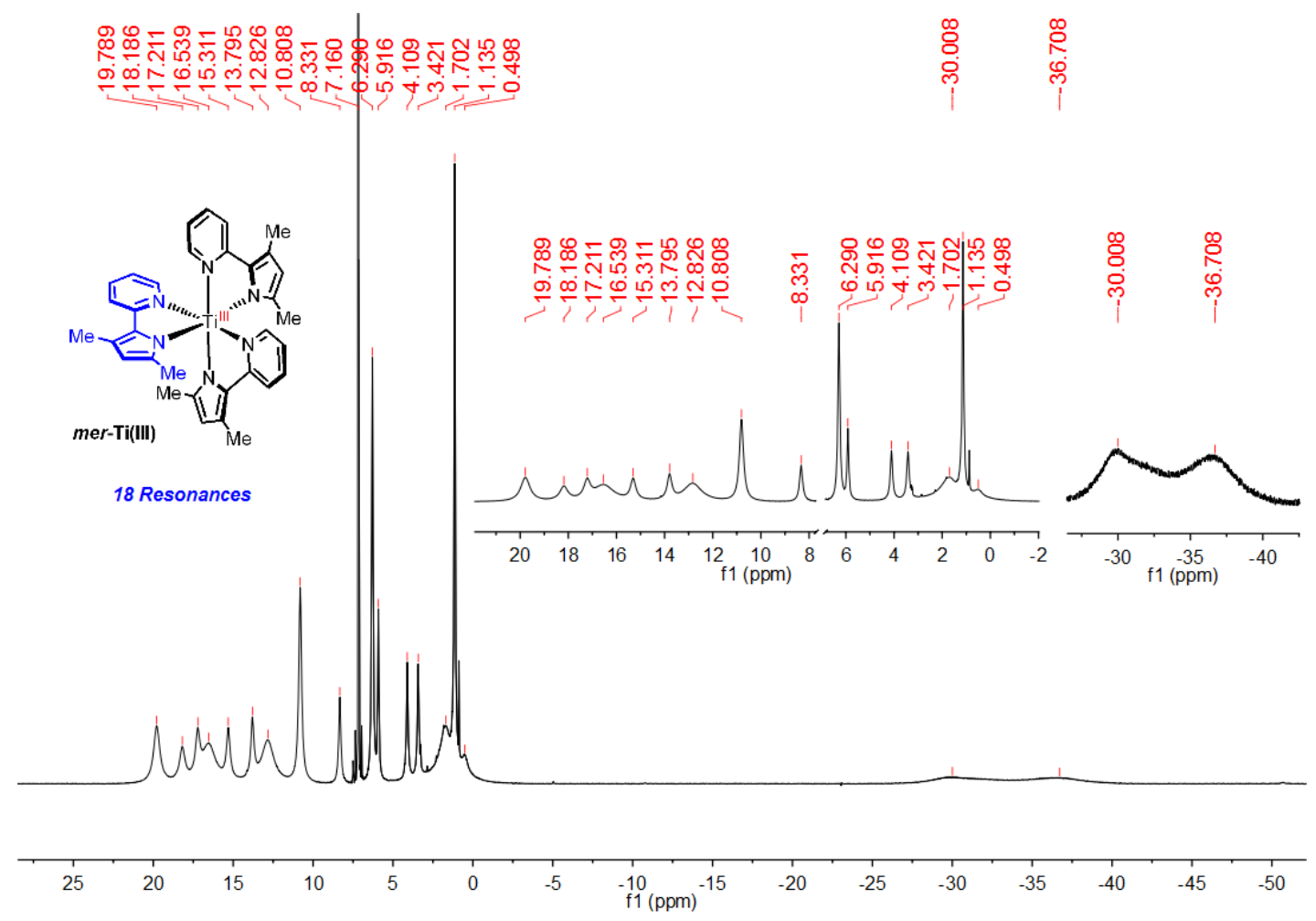

Figure 7. ${ }^{1} \mathrm{H}$ NMR spectra of $m e r-\mathrm{Ti}\left({ }^{\mathrm{Me}} \mathrm{PMP}^{\mathrm{Me}}\right)_{3}$ in benzene- $d_{6}$.

In order to obtain the Ti(IV) PMP compound parallel to previous $\mathrm{Zr}$ (IV) and $\mathrm{Hf}(\mathrm{IV}) \mathrm{PMP}$ complexes, $\mathrm{FcBPh}_{4}$ was recognized as a suitable oxidant for Ti(III) compound with more enough oxidation power $\left(\mathrm{E}_{\mathrm{red}}=0.00 \mathrm{~V} \mathrm{vs} \mathrm{Fc}^{+/ 0}\right)$ according to our experience. As expected, the $\mathrm{Ti}(\mathrm{III} \rightarrow \mathrm{IV})$ oxidation was a clean process (95\% yield). However, to our surprise, oxidation of mer$\mathrm{Ti}\left({ }^{\mathrm{Me}} \mathrm{PMP}{ }^{\mathrm{Me}}\right)_{3}$ with one equivalent of $\mathrm{FcBPh}_{4}$ produced $f a c-\left[\mathrm{Ti}^{\mathrm{IV}}\left({ }^{\mathrm{Me}} \mathrm{PMP}^{\mathrm{Me}}\right)_{3}\right]\left[\mathrm{BPh}_{4}\right]\left(\mathrm{Scheme}^{4}\right)$. The identity of this diamagnetic complex was established by NMR spectrum (Figure 8). Unfortunately, in contrast to luminescent $\mathrm{Zr}(\mathrm{IV})$ and $\mathrm{Hf}(\mathrm{IV})$ tris-PMP complexes, the fac$\left[\mathrm{Ti}^{\mathrm{IV}}\left({ }^{\mathrm{Me}} \mathrm{PMP}^{\mathrm{Me}}\right)_{3}\right]\left[\mathrm{BPh}_{4}\right]$ is not emissive. 


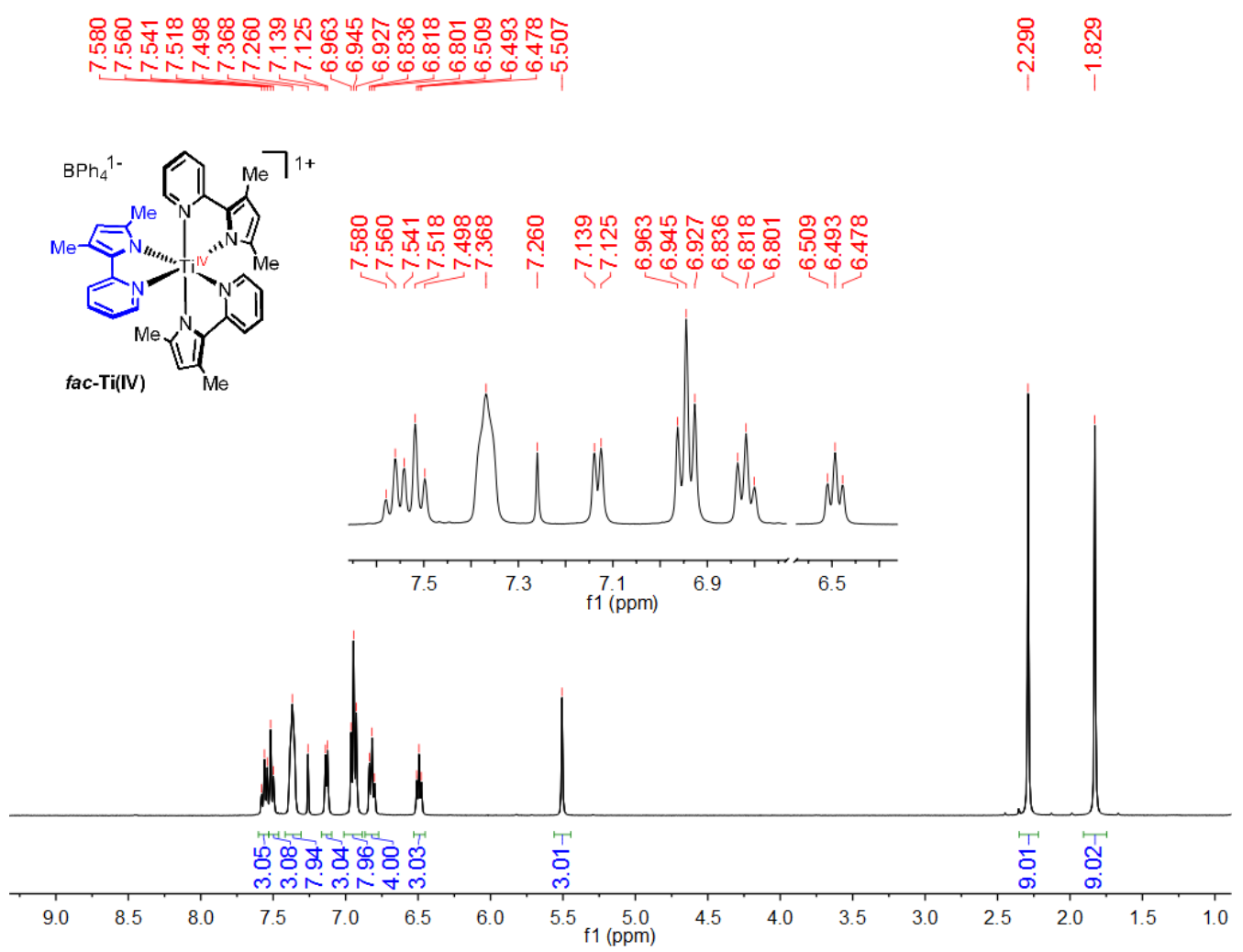

Figure 8. ${ }^{1} \mathrm{H}$ NMR spectra of $f a c-\left[\mathrm{Ti}^{\mathrm{IV}}\left({ }^{\mathrm{Me}} \mathrm{PMP}^{\mathrm{Me}}\right)_{3}\right]\left[\mathrm{BPh}_{4}\right]$ in $\mathrm{CDCl}_{3}$.

To investigate the outer-sphere electron transfer behavior of $f a c-\left[\mathrm{Ti}^{\mathrm{IV}}\left({ }^{\mathrm{Me}} \mathrm{PMP}{ }^{\mathrm{Me}}\right)_{3}\right]\left[\mathrm{BPh}_{4}\right]$, cyclic voltammetry $(\mathrm{CV})$ experiments were performed in THF using ferrocene, $\mathrm{Fc}^{+/ 0}$, as an internal standard. Since metal-centered oxidation can be excluded for Ti(IV) complex, two irreversible oxidation events with peak potentials of $0.61 \mathrm{~V}$ and $1.03 \mathrm{~V}$ were readily assigned as an oxidation of the ligand framework followed by rapid decomposition of the oxidized product. More interestingly, fac-[ $\left.\mathrm{Ti}^{\mathrm{IV}}\left({ }^{\mathrm{Me}} \mathrm{PMP}^{\mathrm{Me}}\right)_{3}\right]\left[\mathrm{BPh}_{4}\right]$ undergoes multiple reversible reductions at very negative potentials:-0.73 V, $-2.50 \mathrm{~V},-2.93 \mathrm{~V}$ and $-3.27 \mathrm{~V}$ (Figure 9). 


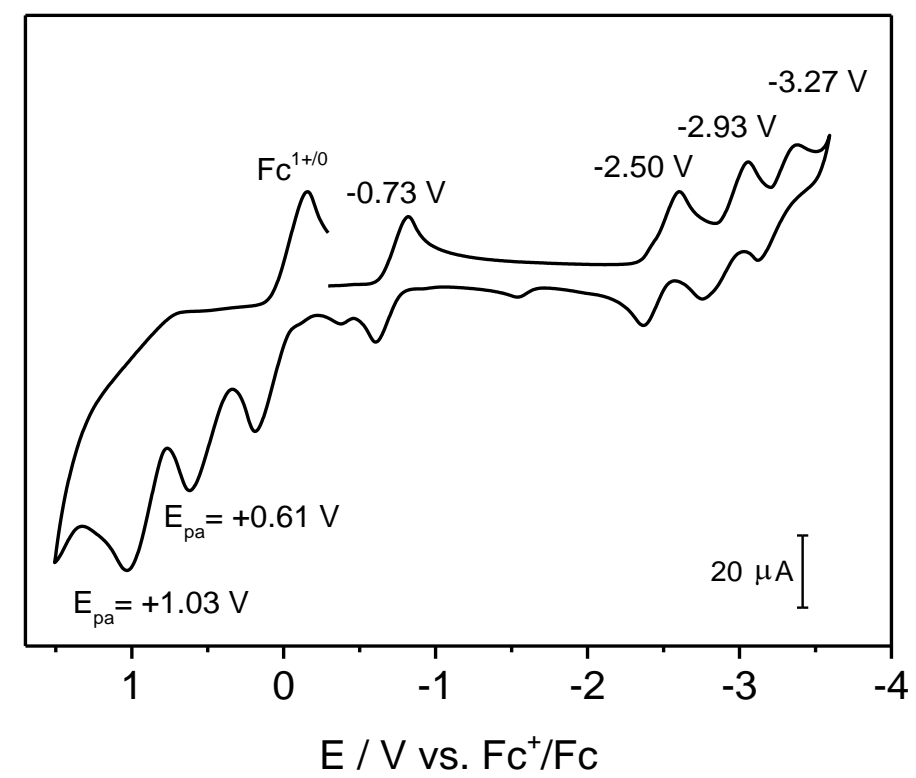

Figure 9. Cyclic voltammogram of $f a c-\left[\mathrm{Ti}^{\mathrm{IV}}\left({ }^{\mathrm{Me}} \mathrm{PMP}^{\mathrm{Me}}\right)_{3}\right]\left[\mathrm{BPh}_{4}\right]$ in THF at room temperature (scan rate $200 \mathrm{mV} / \mathrm{s}, 0.1 \mathrm{M}\left[\mathrm{N}(n-\mathrm{Bu})_{4}\right] \mathrm{PF}_{6}$, glassy carbon working electrode).

Scheme 4. Synthesis and reduction of $f a c-\left[\mathrm{Ti}^{\mathrm{IV}}\left({ }^{\mathrm{Me}} \mathrm{PMP}^{\mathrm{Me}}\right)_{3}\right]\left[\mathrm{BPh}_{4}\right]$.

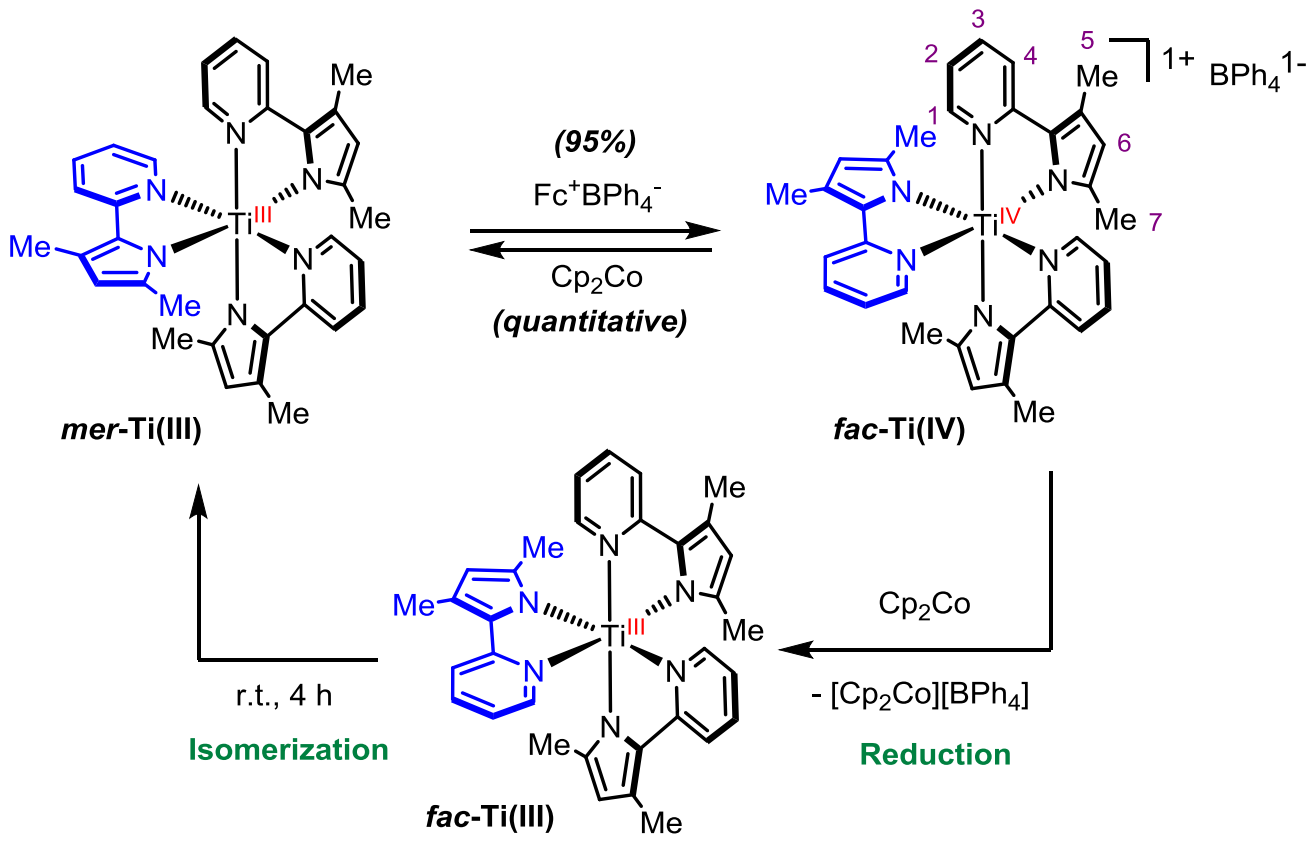


To further investigate this redox-induced isomerization in detail, we decided to take a closer look at $\mathrm{Ti}(\mathrm{IV}) \rightarrow \mathrm{Ti}(\mathrm{III})$ reduction process. As established by $\mathrm{CV}$, Ti(III) is easily accessible with a molecular reductant, cobaltocene $\left(\mathrm{Cp}_{2} \mathrm{Co}, \mathrm{E}_{\mathrm{ox}}=-1.33 \mathrm{~V}\right.$ vs. $\left.\mathrm{Fc}^{+/ 0}\right)$, through direct chemical reduction. A significant amount of yellow solids, $\left[\mathrm{Cp}_{2} \mathrm{Co}\right]\left[\mathrm{BPh}_{4}\right]$, precipitated from a solution of benzene- $d_{6}$ and $f a c-\left[\mathrm{Ti}^{\mathrm{IV}}\left({ }^{\mathrm{Me}} \mathrm{PMP}^{\mathrm{Me}}\right)_{3}\right]\left[\mathrm{BPh}_{4}\right]$ after adding one equivalent of $\mathrm{Cp}_{2} \mathrm{Co}$. Immediately after the instantaneous precipitation, a solution ${ }^{1} \mathrm{H}$ NMR spectrum showed complete conversion of all $\mathrm{Ti}^{\mathrm{IV}}$ starting material and displayed a new paramagnetic compound with seven resonances. This new species can be considered as $f a c-\mathrm{Ti}^{\mathrm{III}}\left({ }^{\mathrm{Me}} \mathrm{PMP}^{\mathrm{Me}}\right)_{3}$ since all three ligands are chemicallyequivalent.

Although at this point the reduction of $\mathrm{Ti}(\mathrm{IV})$ is finished, a new transformation starts happening in this reaction vessel. Monitoring the above reaction showed a slow decay of fac$\mathrm{Ti}^{\mathrm{III}}\left({ }^{\mathrm{Me}} \mathrm{PMP}{ }^{\mathrm{Me}}\right)_{3}$ which was accompanied by the formation of a new paramagnetic species with low-symmetry (Figure 10 and Figure 11). The ${ }^{1} \mathrm{H}$ NMR spectrum for this species is in good agreements with the spectroscopic features for $m e r-\mathrm{Ti}\left({ }^{\mathrm{Me}} \mathrm{PMP}^{\mathrm{Me}}\right)_{3}$ in benzene- $d_{6}$ shown in Figure 7. Thus, this process can be viewed as the conversion of the kinetic product, $f a c-\mathrm{Ti}^{\mathrm{III}}\left({ }^{\mathrm{Me}} \mathrm{PMP}^{\mathrm{Me}}\right)_{3}$, to the thermodynamically more stable $m e r-\mathrm{Ti}^{\mathrm{III}}\left({ }^{\mathrm{Me}} \mathrm{PMP}^{\mathrm{Me}}\right)_{3}$. A thorough Eyring analysis should be conducted to understand the physical nature behind this process to discern between ligand dissociation/large energy barrier or pseudorotation/small energy barrier. 


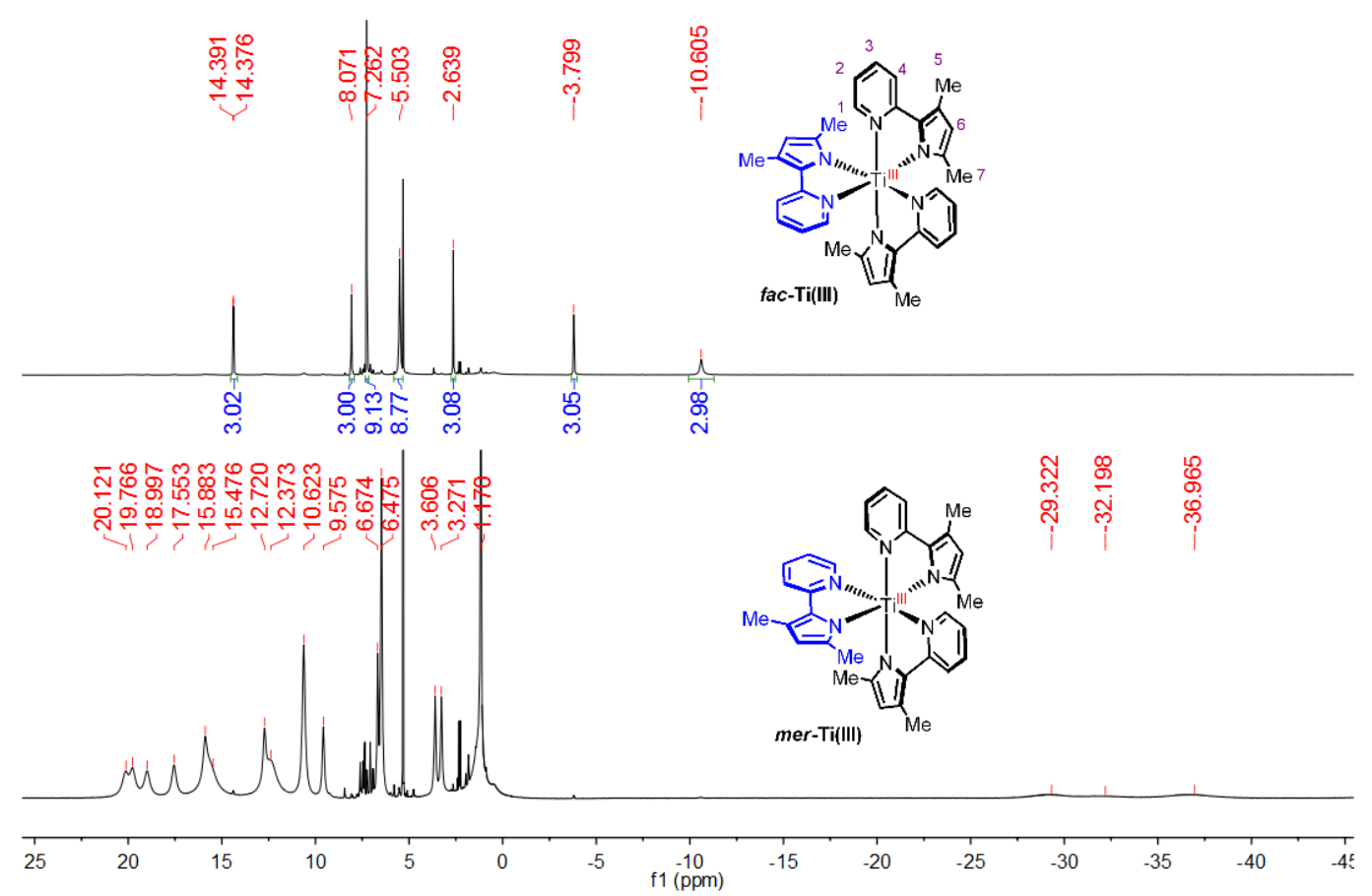

Figure 10. ${ }^{1} \mathrm{H}$ NMR spectra of $f a c-\left[\mathrm{Ti}^{\mathrm{IV}}\left({ }^{\mathrm{Me}} \mathrm{PMP}^{\mathrm{Me}}\right)_{3}\right]\left[\mathrm{BPh}_{4}\right]$ 's with cobaltocene in $\mathrm{CD}_{2} \mathrm{Cl}_{2}$. Top: crude reaction mixture after 5 minutes of reduction (no starting material left), tentatively assigned as $f a c-\mathrm{Ti}^{\mathrm{III}}\left({ }^{\mathrm{Me}} \mathrm{PMP}{ }^{\mathrm{Me}}\right)_{3}$. Bottom: crude reaction mixture after 4 hours, $m e r-\mathrm{Ti}^{\mathrm{III}}\left({ }^{\mathrm{Me}} \mathrm{PMP}{ }^{\mathrm{Me}}\right)_{3}$

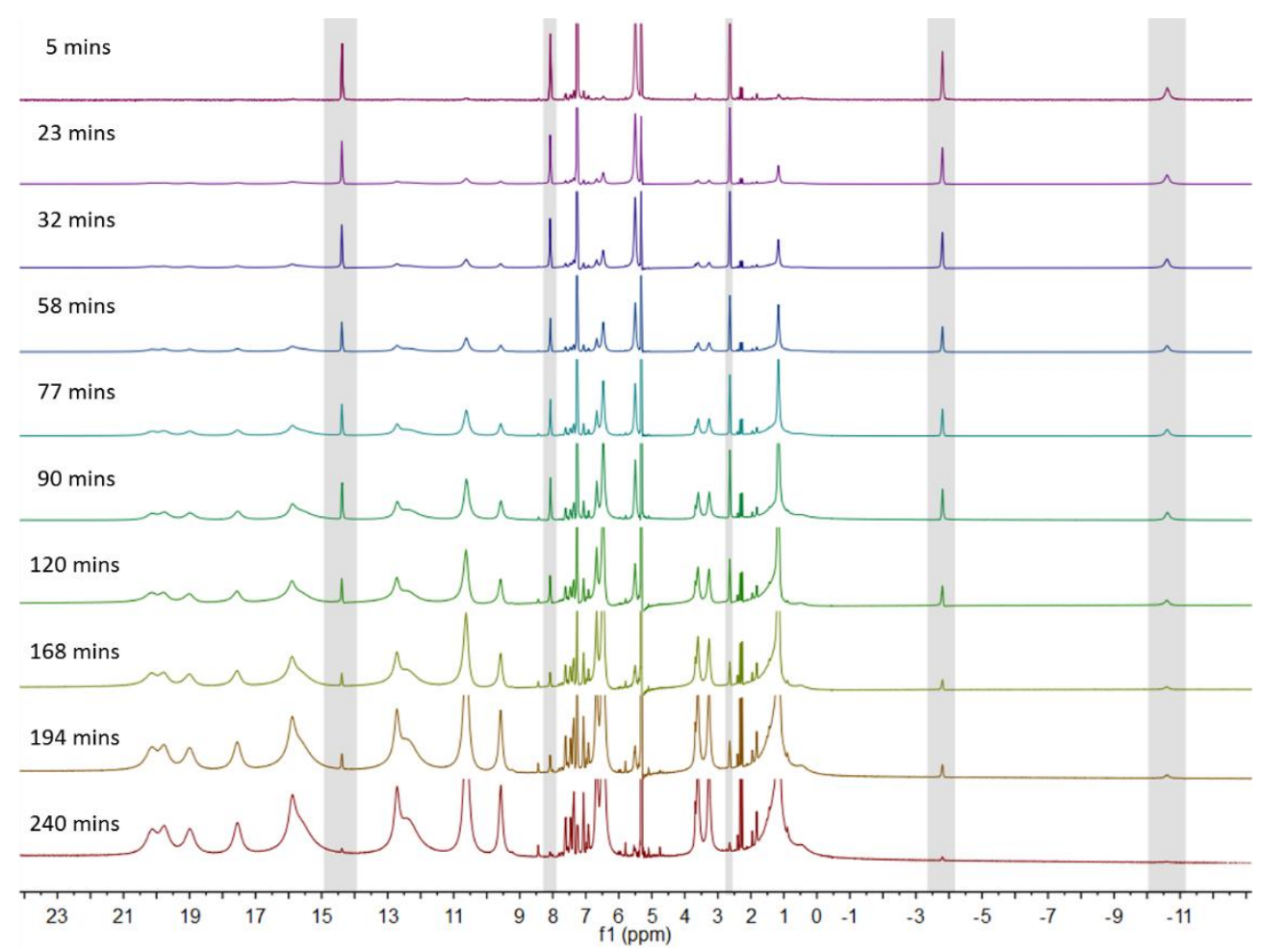

Figure 11. Isomerization of $f a c-\mathrm{Ti}^{\mathrm{III}}\left({ }^{\mathrm{Me}} \mathrm{PMP}{ }^{\mathrm{Me}}\right)_{3}$ to $m e r-\mathrm{Ti}^{\mathrm{iII}}\left({ }^{\mathrm{Me}} \mathrm{PMP}^{\mathrm{Me}}\right)_{3}$ overtime monitored by ${ }^{1} \mathrm{H} \mathrm{NMR}$ in $\mathrm{CD}_{2} \mathrm{Cl}_{2}$ at room temperature. 
DFT Calculation. From experimental data, mer-Ti ${ }^{\mathrm{III}}\left({ }^{\mathrm{Me}} \mathrm{PMP}^{\mathrm{Me}}\right)_{3}$ and $f a c$ $\left[\mathrm{Ti}^{\mathrm{IV}}\left({ }^{\mathrm{Me}} \mathrm{PMP}{ }^{\mathrm{Me}}\right)_{3}\right]^{+}$were two thermodynamic products whereas $f a c-\mathrm{Ti}^{\mathrm{III}}\left({ }^{\mathrm{Me}} \mathrm{PMP}{ }^{\mathrm{Me}}\right)_{3}$ and $m e r-$ $\left[\mathrm{Ti}^{\mathrm{iV}}\left({ }^{\mathrm{Me}} \mathrm{PMP} \mathrm{Me}_{3}\right]^{+}\right.$were the kinetic products for the corresponding oxidation state. Probing the energy profiles for all four isomers via numerical frequency calculations provided further insight to the experimental observations (Figure 12). All structures have no imaginary frequencies and thereby confirms the minima nature of these stationary points after geometry optimization. The calculated energies are listed in Table 4.

Consistent with the NMR observations, the $f a c$-isomer was $2.22 \mathrm{kcal} / \mathrm{mol}$ more stable than the $m e r$-isomer for $+\mathrm{IV}$ oxidation state. Also, $m e r-\mathrm{Ti}^{\mathrm{III}}\left({ }^{\mathrm{Me}} \mathrm{PMP}{ }^{\mathrm{Me}}\right)_{3}$ is $4.04 \mathrm{kcal} / \mathrm{mol}$ lower in energy than its $f a c$-congener at + III oxidation state. For the Ti(III) isomer pair, isomerization induced by the Jahn-Teller distortion could lead to a more favoured electronic structure for the unpaired d electron. However, for the $\mathrm{d}^{0} \mathrm{Ti}(\mathrm{IV})$ complexes, Jahn-Teller effect does not exist. One potential reason might relate to the different steric environment of two isomers. 


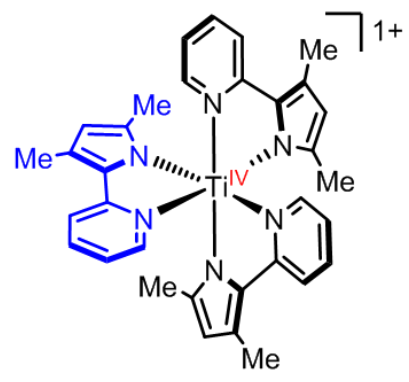

fac-Ti(IV)

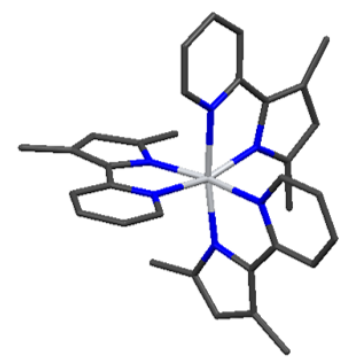

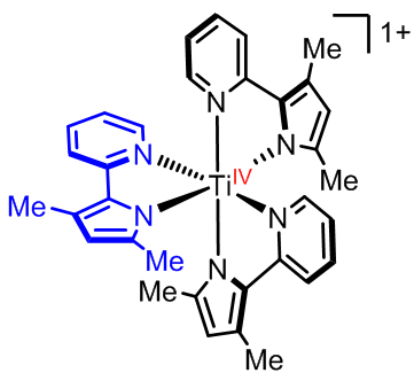

mer-Ti(IV)

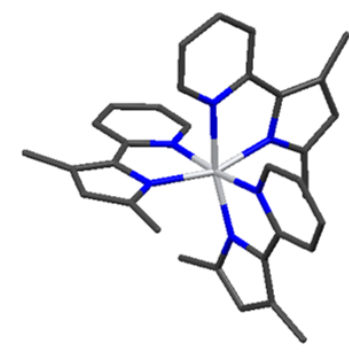

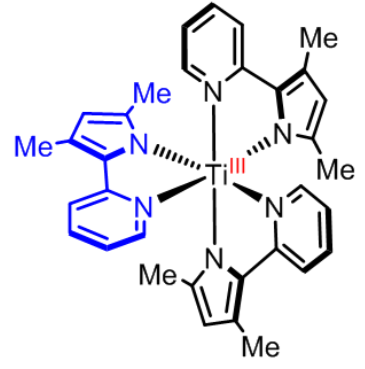

fac-Ti(III)

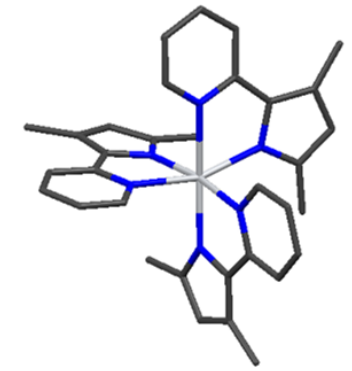

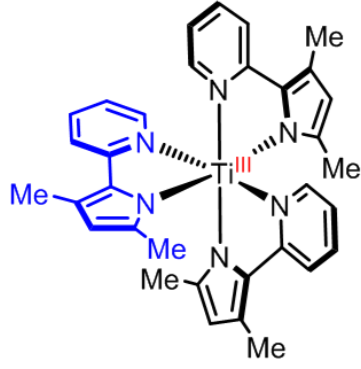

mer-Ti(III)

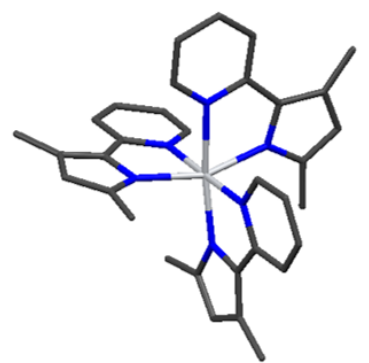

Figure 12. Chemdraw (top) and Mercury drawing (bottom) of DFT-optimized geometries of four isomers.

Table 4. Thermodynamic parameters from numerical frequency calculations at $298 \mathrm{~K}$.

\begin{tabular}{c|cc|cc}
\hline & $f a c$-Ti(IV) & mer-Ti(IV) & $f a c$-Ti(III) & mer-Ti(III) \\
\hline $\begin{array}{c}\text { Gibbs free enthalpy (Eh) } \\
\begin{array}{c}\text { Relative Gibbs free } \\
\text { enthalpy (kcal/mol) }\end{array}\end{array}$ & -2452.98197 & -2452.97843 & -2453.16914 & -2453.17557 \\
\hline
\end{tabular}

${ }^{a}$ the relative Gibbs free enthalpy for more stable isomer was set to 0 .

Outlook. The unique combination of redox controlled fac/mer-isomerization and intrinsic polymerization properties of group 4 complexes inspired the following hypothesis: If Ti(III) and Ti(IV) are both active in olefin polymerization (after dissociation of a ligand), changing the catalyst's oxidation state $\left(\mathrm{Ti}^{\mathrm{III} / \mathrm{IV}}\right)$ alters its chirality $(\mathrm{mer} / \mathrm{fac})$, and hence offers control over polyalkene's tacticity. In principle, the amount of reductant/oxidant and the time at which the redox 
reagent is added during polymerization could influence the tacticity/relative stereochemistry of polymer products. This can be a promising project when collaborating with polymer scientists.

\section{Experimental Section.}

General experimental considerations for material handling, physical measurements, X-ray crystallography, and DFT Calculations as well as additional experimental information (i.e. NMR spectra) can be found in the appendices.

Synthesis of $\boldsymbol{m e r}$-Ti ${ }^{\mathrm{III}}\left({ }^{\mathrm{Me}} \mathbf{P M P}{ }^{\mathrm{Me}}\right)$ 3. KH (24 $\mathrm{mg}, 0.598 \mathrm{mmol}, 3.0$ equiv) was added slowly to a 20-mL vial containing a solution of $\mathrm{H}_{2}{ }^{\mathrm{Me}} \mathrm{PDP}(103 \mathrm{mg}, 0.598 \mathrm{mmol}, 3.0$ equiv) in $3 \mathrm{~mL}$ of THF. The reaction was stirred for 1 hour at room temperature and generated a luminescent dark greenyellow solution of deprotonated ligand. $\mathrm{TiCl}_{3}(\mathrm{THF})_{3}(73 \mathrm{mg}, 0.197 \mathrm{mmol}, 1.00$ equiv) was added to the deprotonated ligand in small portions over a period of 10 mins. After 12 hours of stirring at room temperature, the volatiles were removed in vacuo. The residue was redissolved in benzene, despite the product's low solubility, to filter out $\mathrm{LiCl}$ through celite. After evaporation of benzene, the crude product was recrystallized from equal amounts of THF and pentane cooled to $-35^{\circ} \mathrm{C}$. The product was collected by filtration as dark brown solids. ${ }^{1} \mathrm{H}$ NMR $\left(400 \mathrm{MHz}, \mathrm{C}_{6} \mathrm{D}_{6} ; \delta\right.$, ppm): $19.79,18.19,17.21,16.54,15.31,13.80,12.83,10.81,8.33,6.29,5.92,4.11,3.42,1.70,1.14,0.50$ $-30.01,-36.71$. 
Synthesis of $f \boldsymbol{a c}$ - $\left[\mathbf{T i}^{\mathrm{IV}}\left({ }^{\mathrm{Me}} \mathbf{P M P}{ }^{\mathrm{Me}}\right)_{3}\right]\left[\mathbf{B P h}_{4}\right]: \mathrm{FcBPh}_{4}(110 \mathrm{mg}, 0.218 \mathrm{mmol}, 1.02$ equiv) was added to a $20-\mathrm{mL}$ vial containing a solution of $m e r-\mathrm{Ti}^{\mathrm{III}}\left({ }^{\mathrm{Me}} \mathrm{PMP}^{\mathrm{Me}}\right)_{3}(120 \mathrm{mg}, 0.214 \mathrm{mmol}, 1.00$ equiv $)$ in $3 \mathrm{~mL}$ of THF. The reaction was stirred overnight at room temperature. After evaporation of benzene, the crude product was washed with $\mathrm{Et}_{2} \mathrm{O}$. The analytically pure product was collected as dark green crystals (Yield: $179 \mathrm{mg}, 95 \%) .{ }^{1} \mathrm{H}$ NMR (400 MHz, $\left.\mathrm{CDCl}_{3} ; \delta, \mathrm{ppm}\right): 7.56(\mathrm{t}, J=8.0$ Hz, 3H, PyH), 7.52 (t, J=8.0 Hz, 3H, PyH), $7.37(\mathrm{~m}, 8 \mathrm{H}, \mathrm{BPh} H), 7.13(\mathrm{~d}, J=5.6 \mathrm{~Hz}, 3 \mathrm{H}, \mathrm{Py} H)$, $6.95(\mathrm{t}, J=7.2 \mathrm{~Hz}, 8 \mathrm{H}, \mathrm{BPh} H), 6.82(\mathrm{t}, J=7.2 \mathrm{~Hz}, 4 \mathrm{H}, \mathrm{BPh} H), 6.49(\mathrm{t}, J=6.0 \mathrm{~Hz}, 3 \mathrm{H}, \mathrm{Py} H), 5.51$ (s, 3H, PyrroleH), 2.29 (s, 9H, $\left.\mathrm{CH}_{3}\right), 1.83\left(\mathrm{~s}, 9 \mathrm{H}, \mathrm{CH}_{3}\right) .{ }^{13} \mathrm{C} \mathrm{NMR}\left(101 \mathrm{MHz}, \mathrm{CDCl}_{3} ; \delta, \mathrm{ppm}\right)$ : $164.44(\mathrm{q}, J=49.1 \mathrm{~Hz}, \mathrm{BC}), 154.21,145.38,143.93,142.10,136.43,133.53,126.42,125.64$, $125.62,125.59,125.56,121.74,120.84,120.26,113.89,14.68,13.87$. 


\subsection{Synthesis and Characterization of Mix-Ligated Zirconium 2,2'-Pyridylpyrrolide}

\section{Complex.}

Introduction. Our previous investigation on the seven-coordinate capped-octahedral $\mathrm{Zr}$ PMP complex showed a dual fluorescent and phosphorescent emission behavior. Solution dynamics due to pseudorotation of the ligand framework influences the photophysical properties of the complexes. Therefore, a well-defined octahedral structure could lead to a significant change in the optical properties. This section focuses on the synthesis of three octahedral mix-ligated bisPMP Zr(IV) complexes and describe a preliminary investigation of their photo/redox properties. Also, the newly synthesized $\left({ }^{\mathrm{Me}} \mathrm{PMP}{ }^{\mathrm{Me}}\right)_{2} \mathrm{ZrCl}_{2}$ and $\left({ }^{\mathrm{Me}} \mathrm{PMP}{ }^{\mathrm{Me}}\right)_{2} \mathrm{Zr}\left(\mathrm{NMe}_{2}\right)_{2}$ can serve as precursors for complexes bearing three bidentate ligands, whose geometry resembles that of octahedral group 8 and group 9 photosensitizers.

Synthesis and Characterization. Two bis-PMP ligated zirconium complexes: $\left({ }^{\mathrm{Me}} \mathrm{PMP}{ }^{\mathrm{Me}}\right)_{2} \mathrm{ZrCl}_{2}$ and $\left({ }^{\mathrm{Me}} \mathrm{PMP}{ }^{\mathrm{Me}}\right)_{2} \mathrm{Zr}\left(\mathrm{NMe}_{2}\right)_{2}$ were prepared (Scheme 5). Direct addition of ligand precursor into a benzene solution of $\mathrm{ZrCl}_{2}\left(\mathrm{Et}_{2} \mathrm{O}\right) \mathrm{Ns}_{2}\left(\mathrm{Ns}_{=} \mathrm{CH}_{2} \mathrm{SiMe}_{3}\right)$ at room temperature resulted in formation of $\left({ }^{\mathrm{Me}} \mathrm{PMP}^{\mathrm{Me}}\right)_{2} \mathrm{ZrCl}_{2}$, which was isolated as orange solid in $65 \%$ yield. Similarly, the one-pot reaction of $\mathrm{H}^{\mathrm{Me}} \mathrm{PMP} \mathrm{Pe}^{\mathrm{Me}}$ with $\mathrm{Zr}\left(\mathrm{NMe}_{2}\right)_{4}$ in $\quad \mathrm{Et}_{2} \mathrm{O}$ provided dark yellow $\left({ }^{\mathrm{Me} P M P}{ }^{\mathrm{Me}}\right)_{2} \mathrm{Zr}\left(\mathrm{NMe}_{2}\right)_{2}$ in nearly quantitative yield. 
Both complexes were fully characterized by NMR spectroscopy. A solid state structure was obtained for $\left({ }^{\mathrm{Me}} \mathrm{PMP}^{\mathrm{Me}}\right)_{2} \mathrm{ZrCl}_{2}$. Addition of one equivalent of catechol to a solution of $\left({ }^{\mathrm{Me}} \mathrm{PMP}{ }^{\mathrm{Me}}\right)_{2} \mathrm{Zr}\left(\mathrm{NMe}_{2}\right)_{2}$ in toluene furnished $\left({ }^{\mathrm{Me}} \mathrm{PMP}{ }^{\mathrm{Me}}\right)_{2} \mathrm{Zr}\left(\mathrm{O}_{2} \mathrm{C}_{6} \mathrm{H}_{4}\right)$ in $39 \%$ yield after workup. The $\left({ }^{\mathrm{Me}} \mathrm{PMP}{ }^{\mathrm{Me}}\right)_{2} \mathrm{Zr}\left(\mathrm{O}_{2} \mathrm{C}_{6} \mathrm{H}_{4}\right)$ has very limited solubility in benzene, $\mathrm{CDCl}_{3}$, THF, and dry DMSO$d_{6}$. These three complexes displays one set of ligand resonances in the respective NMR spectra, which corresponds to $C_{2}$-symmetric structures in solution (Figure 13 and Appendix B).

Scheme 5. Synthesis of $\left({ }^{\mathrm{Me}} \mathrm{PMP}{ }^{\mathrm{Me}}\right)_{2} \mathrm{ZrCl}_{2},\left({ }^{\mathrm{Me}} \mathrm{PMP}{ }^{\mathrm{Me}}\right)_{2} \mathrm{Zr}\left(\mathrm{NMe}_{2}\right)_{2}$ and $\left({ }^{\mathrm{Me}} \mathrm{PMP}{ }^{\mathrm{Me}}\right)_{2} \mathrm{Zr}\left(\mathrm{O}_{2} \mathrm{C}_{6} \mathrm{H}_{4}\right)$. Xray structure at $30 \%$ probability ellipsoids is shown at the top right corner. Hydrogen atoms were omitted for clarity.
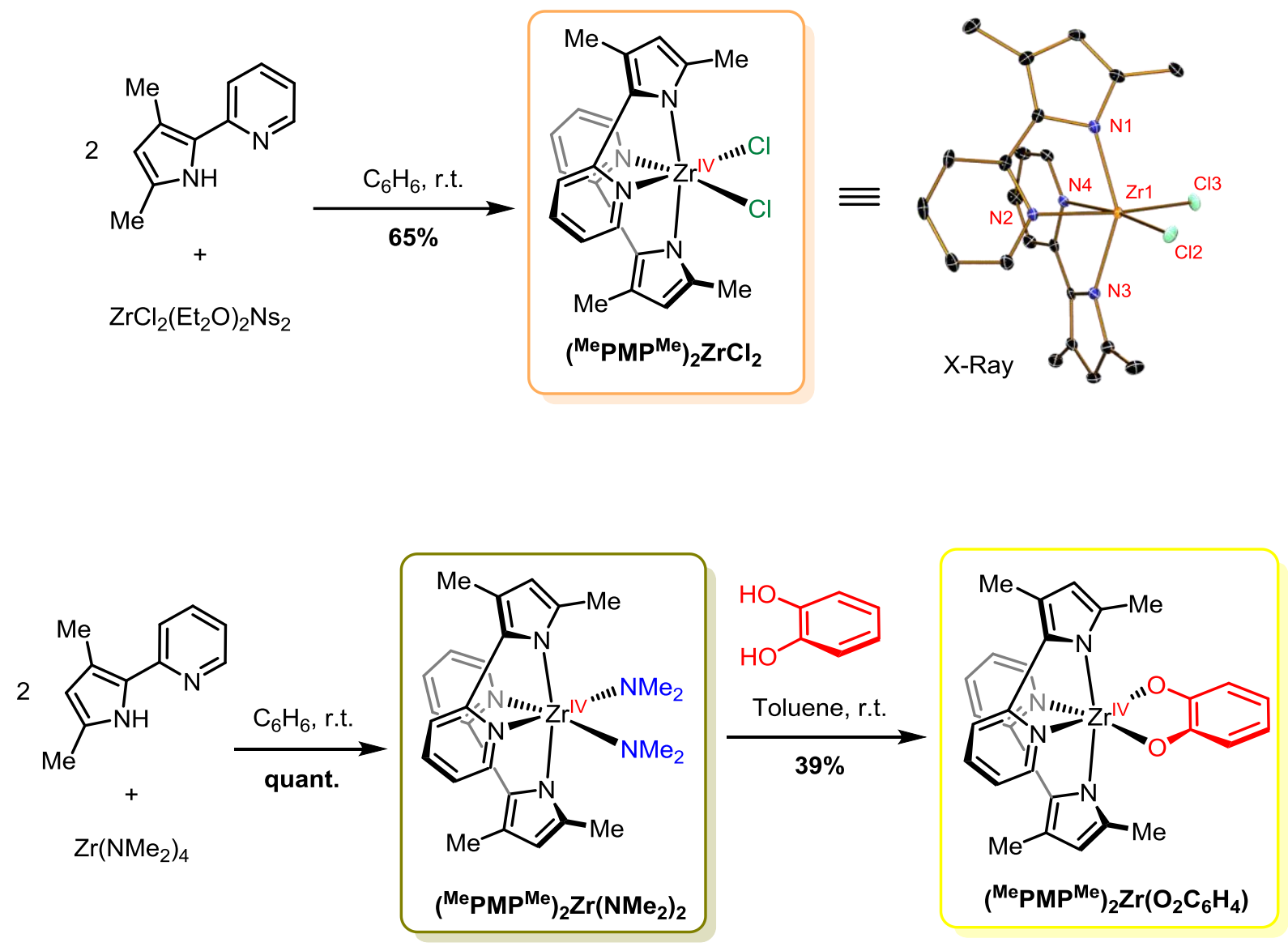


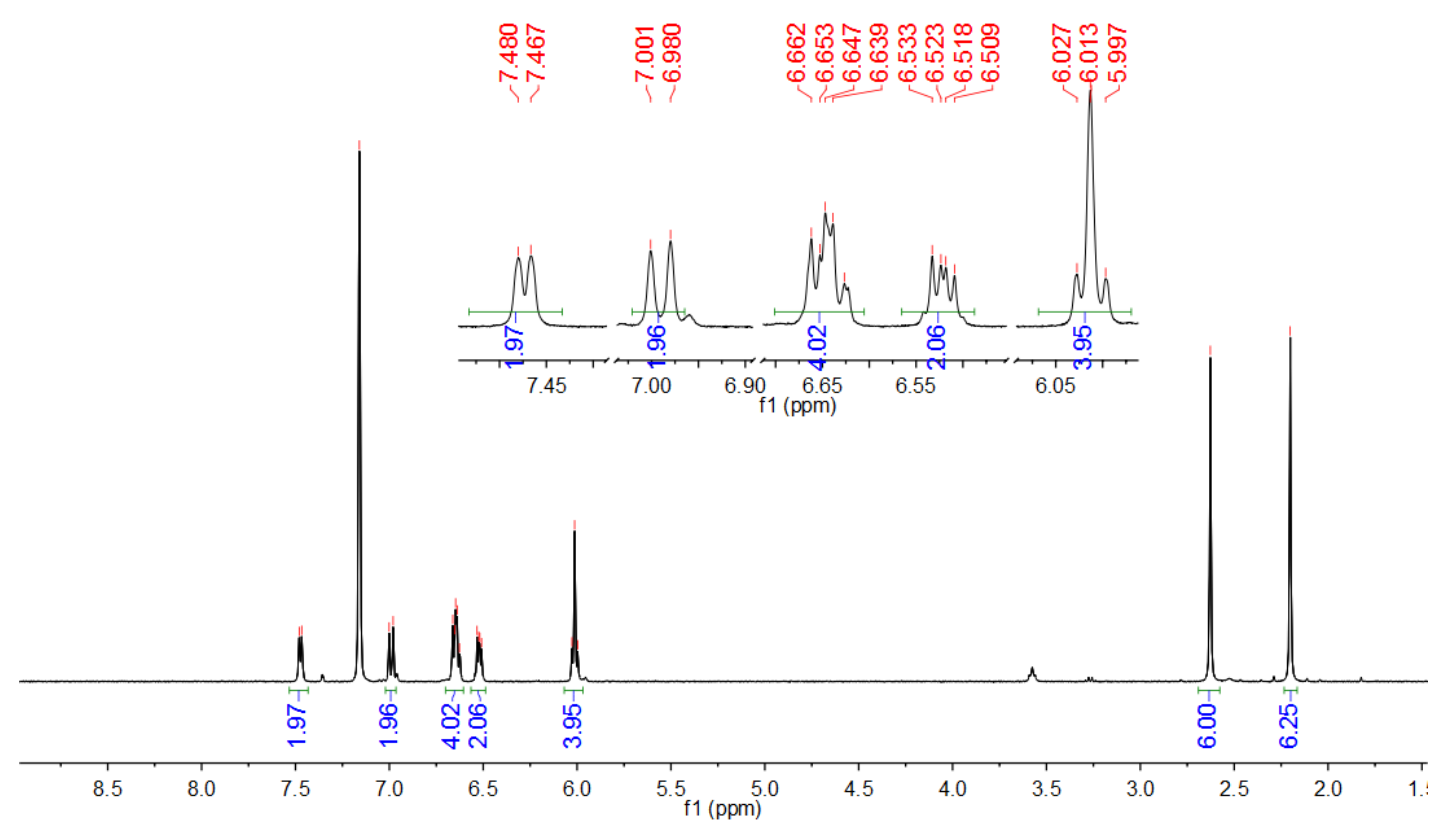

Figure 13. ${ }^{1} \mathrm{H}$ NMR spectra of $\left({ }^{\mathrm{Me}} \mathrm{PMP}{ }^{\mathrm{Me}}\right)_{2} \mathrm{Zr}\left(\mathrm{O}_{2} \mathrm{C}_{6} \mathrm{H}_{4}\right)$ in benzene- $d_{6}$.

Optical Properties. The optical properties for $\left({ }^{\mathrm{Me}} \mathrm{PMP}{ }^{\mathrm{Me}}\right)_{2} \mathrm{ZrCl}_{2},\left({ }^{\mathrm{Me}} \mathrm{PMP}{ }^{\mathrm{Me}}\right)_{2} \mathrm{Zr}\left(\mathrm{NMe}_{2}\right)_{2}$, and $\left({ }^{\mathrm{Me}} \mathrm{PMP}{ }^{\mathrm{Me}}\right)_{2} \mathrm{Zr}\left(\mathrm{O}_{2} \mathrm{C}_{6} \mathrm{H}_{4}\right)$ were investigated (Figure 14). All complexes showed blue-purple light absorption and emitted green light upon excitation at their band maxima. Noteworthy was the similar absorption and emission features between $\left({ }^{\mathrm{Me}} \mathrm{PMP}{ }^{\mathrm{Me}}\right)_{2} \mathrm{ZrCl}_{2}$ and $\left({ }^{\mathrm{Me}} \mathrm{PMP}{ }^{\mathrm{Me}}\right)_{3} \mathrm{ZrCl}$. The extinction coefficient of the octahedral complex was $\sim 30 \%$ lower than that of the seven-coordinate compound, which is consistent with also 33\% less in PMP ligand. Changing the auxiliary ligand from chloride to dimethylamide produce a blue shift of the the visible light absorption and emission features. However, altering the two monodentate dimethylamide to the bidentate catecholate only had a small influence on the lowest energy absorption and emission profiles. 

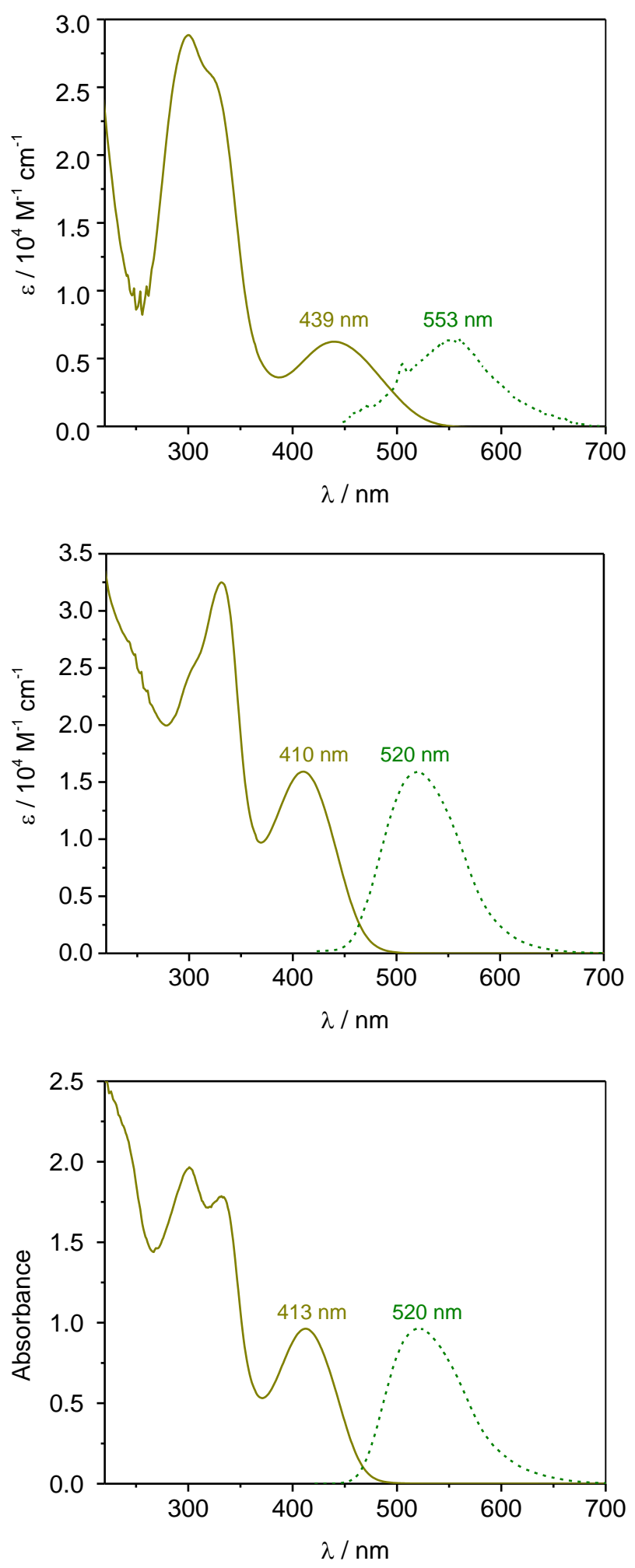

Figure 14. Absorption (solid lines) and emission spectra (dashed lines) of ( $\left.{ }^{\mathrm{Me}} \mathrm{PMP}^{\mathrm{Me}}\right)_{2} \mathrm{ZrCl}_{2}$ (top), $\left({ }^{\mathrm{Me} P M P}{ }^{\mathrm{Me}}\right)_{2} \mathrm{Zr}\left(\mathrm{NMe}_{2}\right)_{2}$ (middle) and $\left({ }^{\mathrm{Me}} \mathrm{PMP}^{\mathrm{Me}}\right)_{2} \mathrm{Zr}\left(\mathrm{O}_{2} \mathrm{C}_{6} \mathrm{H}_{4}\right)$ (bottom) in THF solution at room temperature. 
DFT Calculations. To establish the nature of the electronic transitions of three complexes, TD-DFT calculations were carried out at the B3LYP level of theory. The conductor-like screening model (COSMO) was employed to model the solvent effects of THF. For ( $\left.{ }^{\mathrm{Me}} \mathrm{PMP}{ }^{\mathrm{Me}}\right)_{2} \mathrm{ZrCl}_{2}$ and $\left({ }^{\mathrm{Me}} \mathrm{PMP}{ }^{\mathrm{Me}}\right)_{2} \mathrm{Zr}\left(\mathrm{O}_{2} \mathrm{C}_{6} \mathrm{H}_{4}\right)$, two major transitions from HOMO $\rightarrow$ LUMO and HOMO-1 $\rightarrow$ LUMO constructed the first visible absorption band. For $\left({ }^{\mathrm{Me}} \mathrm{PMP}^{\mathrm{Me}}\right)_{2} \mathrm{Zr}\left(\mathrm{NMe}_{2}\right)_{2}$, two pairs of major transitions from $\mathrm{HOMO}(-1) \rightarrow \mathrm{LUMO}(+1)$ composed the first visible absorption band. As shown in Figure 15, the donor orbitals for all three complexes were completely PMP centered with major contributions from the $\pi$-systems of the pyrrolide heterocycles. In contrast, the acceptor orbitals exhibited significant contributions from the metal and the PMP pyridine moieties. Based on these assignments, the transitions in the visible region of the spectrum are best described as mixed ${ }^{1}$ LLCT $/{ }^{1}$ LMCT states.

For $\left({ }^{\mathrm{Me}} \mathrm{PMP}{ }^{\mathrm{Me}}\right)_{2} \mathrm{Zr}\left(\mathrm{NMe}_{2}\right)_{2}$ and $\left({ }^{\mathrm{Me}} \mathrm{PMP}{ }^{\mathrm{Me}}\right)_{2} \mathrm{Zr}\left(\mathrm{O}_{2} \mathrm{C}_{6} \mathrm{H}_{4}\right)$, the frontier transitions had almost no contribution from the amide or catecholate groups, hence consistent with their similar absorption profiles. For $\left({ }^{\mathrm{Me}} \mathrm{PMP}{ }^{\mathrm{Me}}\right)_{2} \mathrm{ZrCl}_{2}$ complex, some notable chlorine character was observed in the LUMO which also contained contribution from $\mathrm{Zr}$ and the PMP ligands. Thus, lead to a shift in absorption features (Figure 15). 


\section{LUMO+1}

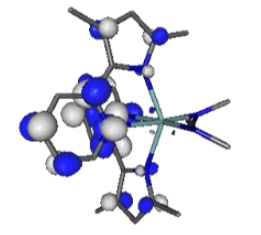

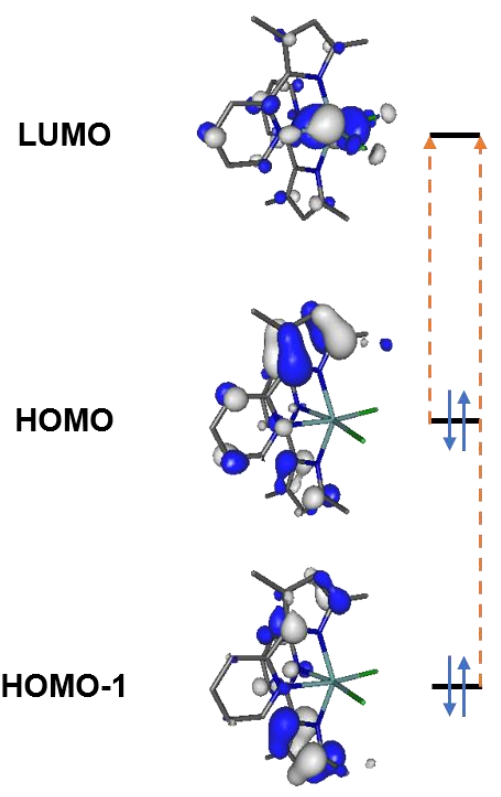

(MePMPMe) ${ }_{2} \mathrm{ZrCl}_{2}$
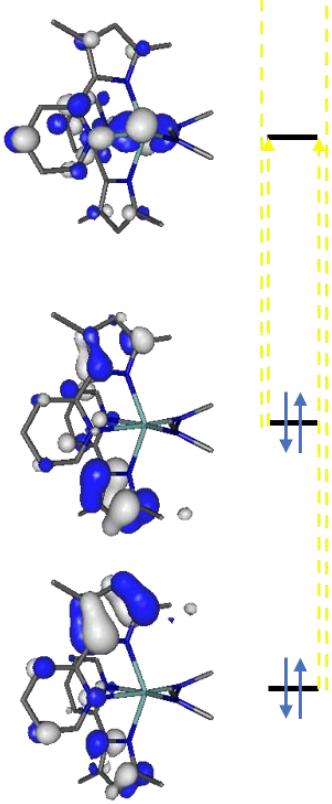

$\left({ }^{\text {MePMPMe }}\right)_{2} \mathrm{Zr}\left(\mathrm{NMe}_{2}\right)_{2}$
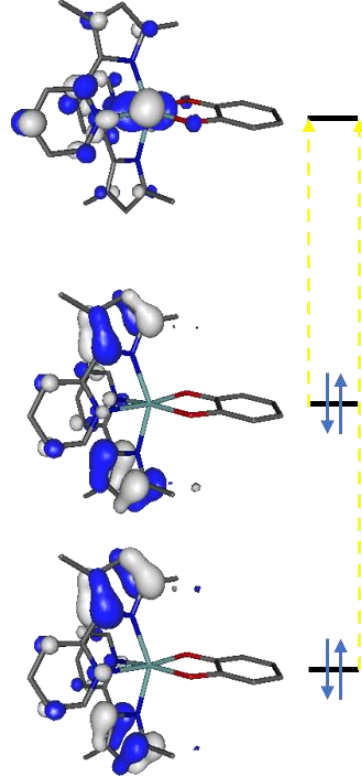

('MePMPMe $)_{2} \mathrm{Zr}\left(\mathrm{O}_{2} \mathrm{C}_{6} \mathrm{H}_{4}\right)$

Figure 15. Frontier transitions that compose visible light absorption band for $\left({ }^{\mathrm{Me}} \mathrm{PMP}^{\mathrm{Me}}\right)_{2} \mathrm{ZrCl}_{2}$ (left), ( $\left.{ }^{\mathrm{Me}} \mathrm{PMP}{ }^{\mathrm{Me}}\right)_{2} \mathrm{Zr}\left(\mathrm{NMe}_{2}\right)_{2}$ (middle) and ( $\left.{ }^{\mathrm{Me}} \mathrm{PMP}^{\mathrm{Me}}\right)_{2} \mathrm{Zr}\left(\mathrm{O}_{2} \mathrm{C}_{6} \mathrm{H}_{4}\right)$ (right).

Electrochemistry. Catecholate is known as an oxidatively non-innocent ligand when combining with many transition metals. However, a $\mathrm{CV}$ of $\left({ }^{\mathrm{Me}} \mathrm{PMP}{ }^{\mathrm{Me}}\right)_{2} \mathrm{Zr}\left(\mathrm{O}_{2} \mathrm{C}_{6} \mathrm{H}_{4}\right)$ in $\mathrm{DCM}$ displayed no reversible redox event (Figure 16). From DFT calculation, the HOMO is pyrrole based and does not possess any catecholate contribution. The unprotected pyrrole oxidation is known to be highly unstable and lead to irreversibility of the oxidation events. 


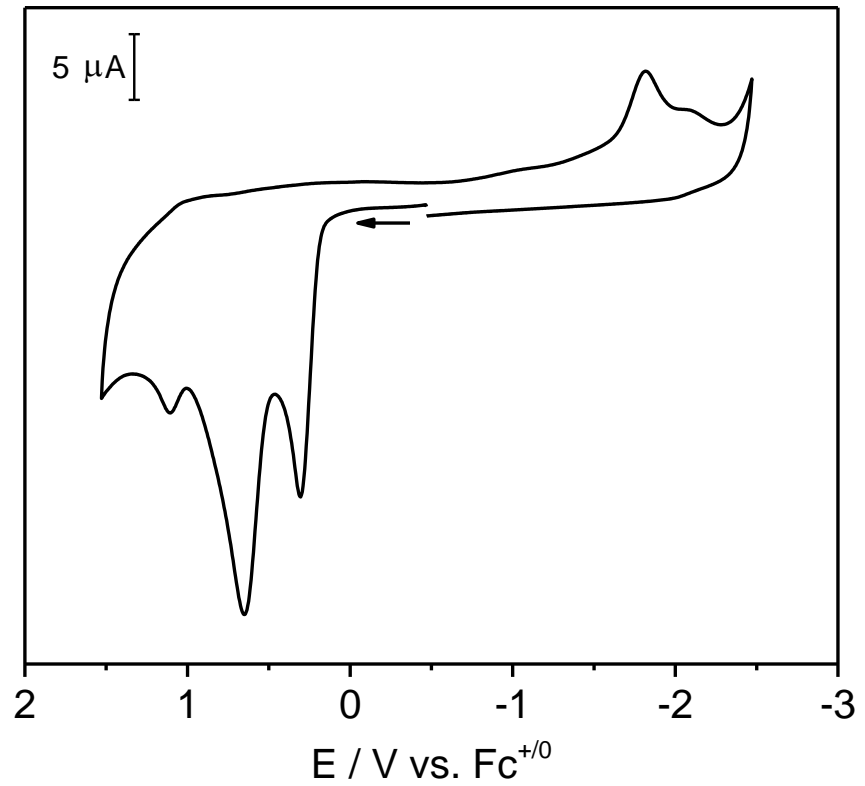

Figure 16. Cyclic voltammogram of $\left({ }^{\mathrm{Me}} \mathrm{PMP}^{\mathrm{Me}}\right)_{2} \mathrm{Zr}\left(\mathrm{O}_{2} \mathrm{C}_{6} \mathrm{H}_{4}\right)$ in $\mathrm{DCM}$ at room temperature (scan rate $200 \mathrm{mV} \mathrm{s}^{-1}, 0.1 \mathrm{M}\left[\mathrm{N}(n-\mathrm{Bu})_{4}\right] \mathrm{PF}_{6}$, glassy carbon working electrode).

Outlook. In order to design an octahedral PMP zirconium photosensitizer with drastically different optical and redox properties than the complexes presented, the auxiliary ligand should be easier to oxidized than pyrrole thus can contribute significantly to the frontier orbitals.

\section{Experimental Section.}

General experimental considerations for material handling, physical measurements, X-ray crystallography, and DFT Calculations as well as additional experimental information (i.e. NMR spectra) can be found in the appendices. 
Preparation of ( $\left.{ }^{\mathrm{Me} P M P}{ }^{\mathrm{Me}}\right)_{2} \mathbf{Z r C l}_{2}$ : A solution of $\mathrm{H}^{\mathrm{Me}} \mathrm{PMP}^{\mathrm{Me}}(200 \mathrm{mg}, 1.16 \mathrm{mmol}, 2.00$ equiv) in $3 \mathrm{~mL}$ of benzene was added to a $20-\mathrm{mL}$ vial containing a solution of $\mathrm{ZrCl}_{2}\left(\mathrm{Et}_{2} \mathrm{O}\right) \mathrm{Ns}_{2}(321 \mathrm{mg}$, $0.66 \mathrm{mmol}, 1.14$ equiv) in $2 \mathrm{~mL}$ of $\mathrm{Et}_{2} \mathrm{O}$. The reaction was stirred for 24 hours at room temperature. Then the solvent was removed and the crude mixture was washed 3 times with $\mathrm{Et}_{2} \mathrm{O}$. The resulted solid was redissolved in benzene and filtered through celite. After removing benzene in vacuo, the product was collected as light orange solids (Yield: $190 \mathrm{mg}, 56 \%) .{ }^{1} \mathrm{H} \mathrm{NMR}\left(400 \mathrm{MHz}, \mathrm{C}_{6} \mathrm{D}_{6} ; \delta\right.$, ppm): $7.26(\mathrm{~d}, J=6.0 \mathrm{~Hz}, 2 \mathrm{H}), 6.77(\mathrm{~d}, J=8.8 \mathrm{~Hz}, 2 \mathrm{H}), 6.50(\mathrm{t}, J=8.4 \mathrm{~Hz}, 2 \mathrm{H}), 5.90(\mathrm{~s}, 2 \mathrm{H}), 5.87$ (t, $J=7.2 \mathrm{~Hz}, 2 \mathrm{H}), 2.88$ (s, 6H), 2.05 (s, 6H). ${ }^{13} \mathrm{C}$ NMR (101 MHz, $\left.\mathrm{C}_{6} \mathrm{D}_{6} ; \delta, \mathrm{ppm}\right): 155.34,147.92$, $141.75,139.13,133.99,126.83,118.09,117.38,116.57,17.92,14.31$. Single crystals suitable for X-ray crystallographic analysis were grown from a saturated solution of $\left({ }^{\mathrm{Me}} \mathrm{PMP}^{\mathrm{Me}}\right)_{2} \mathrm{ZrCl}_{2}$ in $\mathrm{Et}_{2} \mathrm{O}$ at $-35^{\circ} \mathrm{C}$.

Preparation of $\left({ }^{\mathrm{Me}} \mathrm{PMP} \mathrm{Pe}_{\mathbf{2}}\right)_{2} \mathbf{Z r}\left(\mathbf{N M e}_{2}\right)_{2}$ : A solution of $\mathrm{H}^{\mathrm{Me}} \mathrm{PMP} \mathrm{Pe}^{\mathrm{Me}}(300 \mathrm{mg}, 1.74 \mathrm{mmol}, 2.00$ equiv) in $3 \mathrm{~mL}$ of $\mathrm{Et}_{2} \mathrm{O}$ was added to a 20 - $\mathrm{mL}$ vial containing a solution of $\mathrm{Zr}\left(\mathrm{NMe}_{2}\right)_{4}(233 \mathrm{mg}$, $0.87 \mathrm{mmol}, 1.00$ equiv) in $5 \mathrm{~mL}$ of $\mathrm{Et}_{2} \mathrm{O}$. The reaction was stirred for 3 hours at room temperature. Then the solvent was removed. The product was collected as dark yellow solids (Yield: Quantitative). ${ }^{1} \mathrm{H}$ NMR (400 MHz, $\left.\mathrm{C}_{6} \mathrm{D}_{6} ; \delta, \mathrm{ppm}\right): 7.33(\mathrm{~d}, J=5.2 \mathrm{~Hz}, 2 \mathrm{H}), 7.09(\mathrm{~d}, J=9.2 \mathrm{~Hz}$, 2H), $6.70(\mathrm{tm}, J=6.0 \mathrm{~Hz}, 2 \mathrm{H}), 6.20(\mathrm{~s}, 2 \mathrm{H}), 6.02(\mathrm{tm}, J=7.2 \mathrm{~Hz}, 2 \mathrm{H}), 3.01\left(\mathrm{~s}, 12 \mathrm{H}, \mathrm{NCH}_{3}\right), 2.63$ (s, 6H), 2.33 (s, 6H). ${ }^{13} \mathrm{C}$ NMR (101 MHz, $\left.\mathrm{C}_{6} \mathrm{D}_{6} ; \delta, \mathrm{ppm}\right): 155.71,147.57,141.87,137.67,133.64$ $124.81,117.58,116.47,115.54,43.48,16.40,15.21$. 
Preparation of ( $\left.{ }^{\mathrm{Me}} \mathbf{P M P}{ }^{\mathrm{Me}}\right)_{2} \mathbf{Z r}\left(\mathbf{O}_{2} \mathbf{C}_{6} \mathbf{H}_{4}\right)$ : A solution of catechol (42 mg, $0.38 \mathrm{mmol}, 1.00$ equiv) in $5 \mathrm{~mL}$ of toluene was added to a $20-\mathrm{mL}$ vial containing a solution of $\left({ }^{\mathrm{Me}} \mathrm{PMP}{ }^{\mathrm{Me}}\right)_{2} \mathrm{Zr}\left(\mathrm{NMe}_{2}\right)_{2}(199$ $\mathrm{mg}, 0.38 \mathrm{mmol}, 1.00$ equiv) in $5 \mathrm{~mL}$ of toluene. The reaction was stirred at room temperature until no color changes in color occurred. Due to poor solubility, the desired product precipitated out of the solution, which was filtered and washed with toluene and THF. After drying under vacuum, the product was collected as bright yellow solids (Yield: $80 \mathrm{mg}, 39 \%) .{ }^{1} \mathrm{H} \mathrm{NMR}\left(400 \mathrm{MHz}, \mathrm{C}_{6} \mathrm{D}_{6}\right.$; $\delta, \mathrm{ppm}): 7.47(\mathrm{~d}, J=5.2 \mathrm{~Hz}, 2 \mathrm{H}), 6.99(\mathrm{~d}, J=8.4 \mathrm{~Hz}, 2 \mathrm{H}), 6.68-6.60(\mathrm{~m}, 4 \mathrm{H}$, Рy $H \&$ catecholateCH), $6.52(\mathrm{~m}, 2 \mathrm{H}$, catecholateCH), $6.01(\mathrm{t}, J=6.0 \mathrm{~Hz}, 2 \mathrm{H}), 6.01(\mathrm{~s}, 2 \mathrm{H}), 6.86-6.77$ $(\mathrm{m}, 4 \mathrm{H}), 6.73(\mathrm{~d}, J=7.6 \mathrm{~Hz}, 2 \mathrm{H}), 2.63\left(\mathrm{~s}, 6 \mathrm{H}, \mathrm{CH}_{3}\right), 2.20\left(\mathrm{~s}, 6 \mathrm{H}, \mathrm{CH}_{3}\right) .{ }^{13} \mathrm{C} \mathrm{NMR}\left(101 \mathrm{MHz}, \mathrm{C}_{6} \mathrm{D}_{6}\right.$; $\delta$, ppm): 155.98, 154.17, 148.06, 142.94, 138.51, 133.43, 125.44, 121.27, 120.83, 118.08, 116.98, $115.88,16.38,14.71$. 


\subsection{Zirconium Acted Like Nickel with the Help of Light.}

Introduction. In 1995, Takahashi and co-workers discovered the only example of $\mathrm{C}_{\mathrm{sp} 2}-\mathrm{X}$ $(\mathrm{X}=\mathrm{Cl}, \mathrm{Br})$ oxidative addition to in situ generated zirconocene(II) (Scheme 6), ${ }^{9}$ a basic transformation popular for late transition metals (LTMs). The microscopic reverse, reductive elimination, is also a common elementary step in LTM organometallic reactions. However, only few reports are related to zirconium organometallic complexes. Due to the highly reducing nature of $\mathrm{Zr}(\mathrm{II})$, reductive elimination of the remarkably stable $\mathrm{Zr}(\mathrm{IV})$ requires energetic $\mathrm{UV}$ light or a strong oxidant (Scheme 6). ${ }^{10-12}$ Although the history of diaryl $\mathrm{Zr}(\mathrm{IV})$ reductive elimination can be traced back to 1980 s, no catalytic cross coupling reaction was shown in a traditional sense (oxidative addition $\rightarrow$ transmetalation $\rightarrow$ reductive elimination). During the investigation of concerted oxidative addition/reductive elimination properties of $\mathrm{Zr}\left({ }^{\mathrm{H}} \mathrm{CNN}\right)_{2}$ (Chapter 6), we collected many zirconium organometallic transformations from old literatures and connected them into this work: a zirconium-catalyzed Kumada cross-coupling reaction. 
Scheme 6. Previous works.

Takahashi, 1995

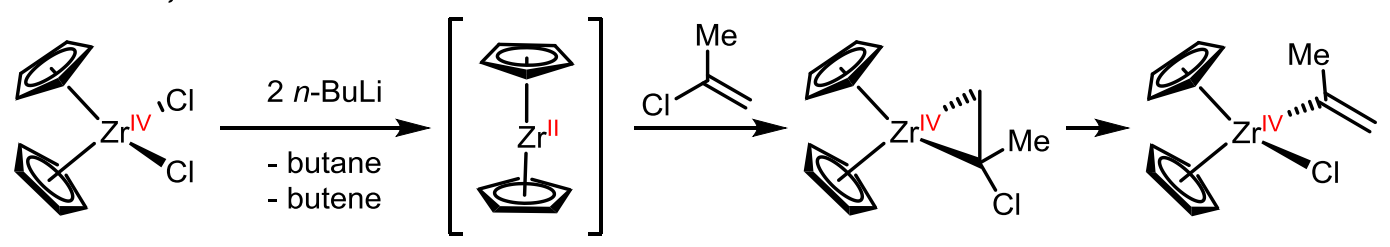

Brubaker, 1981 \& Burk, 1990

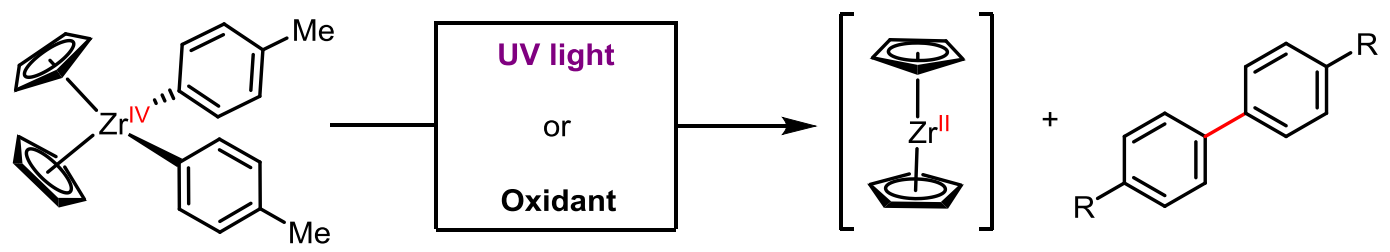

Erker, 1983

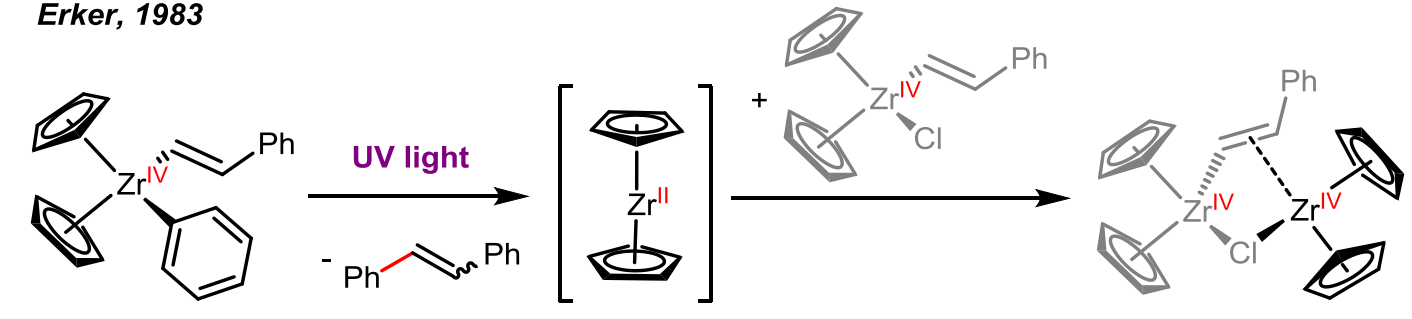

Results and Discussion. According to the elementary steps reported in literature, $\mathrm{Cp}_{2} \mathrm{Zr}^{\mathrm{II}}$

once generated can oxidatively add haloalkene. Next, salt metathesis using an organometallic reagent could allow formation of a mixed $\mathrm{Cp}_{2} \operatorname{ZrAr}($ alkenyl) complex. Then, reductive elimination followed by photoexcitation would furnish the desired cross-coupled product and regenerate zirconocene. Based on this hypothesis, our study commenced with reaction design. The selected reactants were $\beta$-chlorostyrene (for oxidative addition) and tolylmagnesium bromide (for transmetalation). Evaluation of the reaction conditions for the photocatalytic cross-coupling are listed in Table 5. 
Table 5. Condition optimization: precatalyst, concentration, time and catalyst loading.
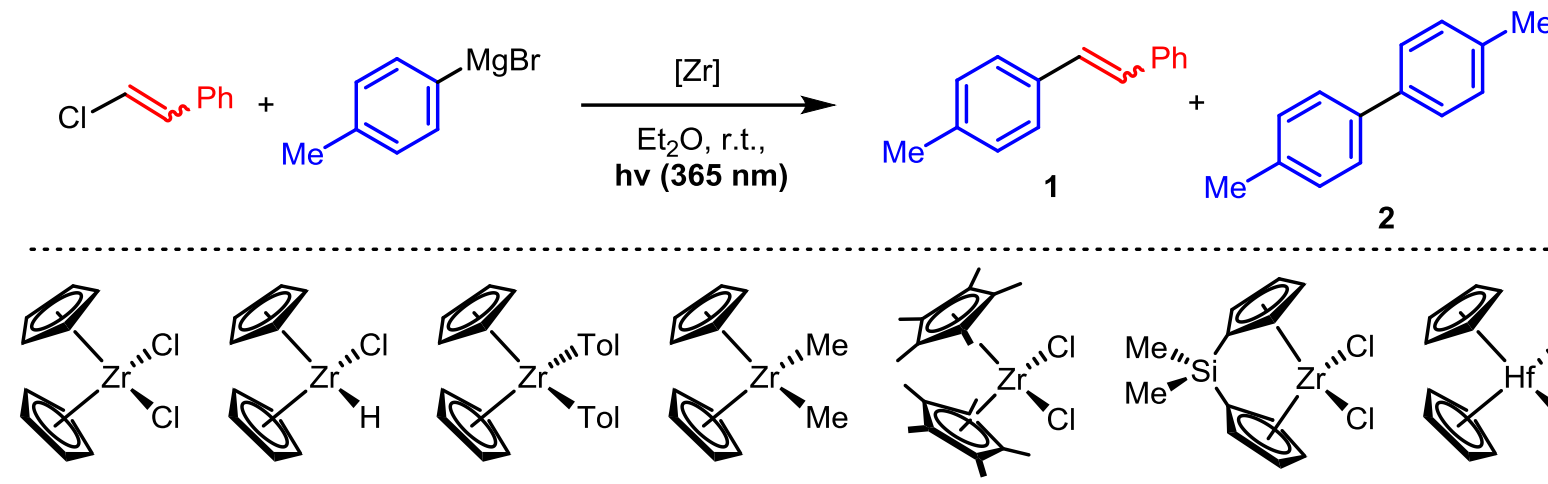

b
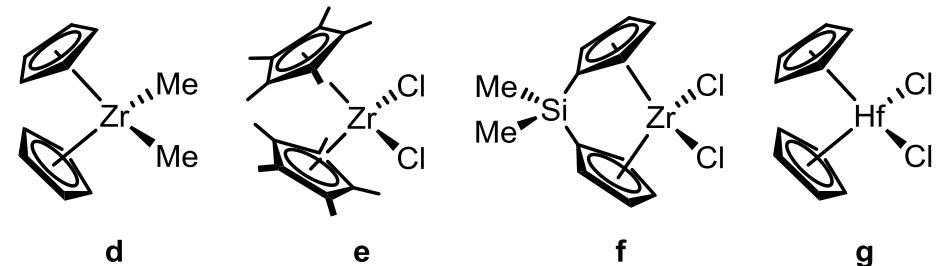

\begin{tabular}{|c|c|c|c|c|c|}
\hline \multirow{2}{*}{ Entry $^{a}$} & \multirow{2}{*}{$\begin{array}{l}\text { Pre-catalyst } \\
\quad(\mathrm{mol} \%)\end{array}$} & \multirow{2}{*}{$\begin{array}{l}\text { Conc. } \\
\text { (M) }\end{array}$} & \multirow{2}{*}{ Time (h) } & \multicolumn{2}{|c|}{ Yield ${ }^{\mathrm{b}} \%$} \\
\hline & & & & $1(Z: E)$ & 2 \\
\hline 1 & $\mathrm{a}(20)$ & 0.050 & 4 & $15(93: 7)$ & 54 \\
\hline 2 & $\mathrm{a}(20)$ & 0.050 & 8 & 35 (93:7) & 59 \\
\hline 3 & $\mathrm{a}(20)$ & 0.050 & 16 & $50(93: 7)$ & 65 \\
\hline 4 & $\mathrm{a}(20)$ & 0.050 & 23 & 53 (91:9) & 70 \\
\hline $5^{c}$ & $\mathrm{a}(20)$ & 0.050 & 16 & $50(93: 7)$ & 71 \\
\hline 6 & b (20) & 0.050 & 16 & $26(92: 8)$ & 69 \\
\hline 7 & c (20) & 0.050 & 16 & 63 (94:6) & 82 \\
\hline 8 & $\mathrm{~d}(20)$ & 0.050 & 16 & $19(87: 13)$ & 40 \\
\hline 9 & e (20) & 0.050 & 16 & $<1$ & 35 \\
\hline 10 & $f(20)$ & 0.050 & 16 & $38(86: 14)$ & 71 \\
\hline 11 & $\mathrm{~g}(20)$ & 0.050 & 16 & $9(86: 14)$ & 53 \\
\hline 13 & a (5) & 0.050 & 16 & 35 (91:9) & 37 \\
\hline 14 & $\mathrm{a}(10)$ & 0.050 & 16 & 37 (91:9) & 45 \\
\hline 15 & $\mathrm{a}(15)$ & 0.050 & 16 & $53(93: 7)$ & 58 \\
\hline 16 & $\mathrm{a}(25)$ & 0.050 & 16 & $43(94: 6)$ & 76 \\
\hline 17 & a (15) & 0.025 & 16 & 59 (91:9) & 64 \\
\hline 18 & c (15) & 0.025 & 16 & $61(92: 8)$ & 64 \\
\hline 19 & $c(15)$ & 0.050 & 16 & $46(92: 8)$ & 59 \\
\hline 20 & $c(15)$ & 0.100 & 16 & 37 (93:7) & 54 \\
\hline 21 & c (20) & 0.025 & 16 & $59(92: 8)$ & 71 \\
\hline 22 & c (25) & 0.025 & 16 & $56(93: 7)$ & 82 \\
\hline
\end{tabular}

${ }^{a}$ General conditions: $\beta$-chlorostyrene $(\mathrm{E} / \mathrm{Z}=43 / 57), p$-tolyl magnesiumbromide (1.4 eq., $0.5 \mathrm{M}_{\text {in }} \mathrm{Et}_{2} \mathrm{O}$ ), pre-catalyst, $\mathrm{Et}_{2} \mathrm{O}$, r.t., $40 \mathrm{~W}$ black CFL. ${ }^{\mathrm{b}}{ }^{1} \mathrm{H}$ NMR yield using 1,3,5-trimethoxybenzene as the internal standard and based on $\beta$ chlorostyrene. ${ }^{\mathrm{c}}$ Using 2.0 eq. of $p$-tolyl magnesiumbromide. 
Most of the initial condition attempts gave the desired cross-coupled product. A higher yield than catalyst loading confirmed our hypothesis that the reaction could function in a catalytic fashion. The best performance was entry 7: 63\% of 4-methyl-stilbene was formed using $20 \mathrm{~mol} \%$ $\mathrm{Cp}_{2} \mathrm{Zr}(\mathrm{Tol})_{2}$ at $0.05 \mathrm{M}_{\text {in }} \mathrm{Et}_{2} \mathrm{O}$ under $365 \mathrm{~nm}$ light irradiation for 16 hours. Further evaluation using $15 \mathrm{~mol} \%$ of the cost-effective $\mathrm{Cp}_{2} \mathrm{ZrCl}_{2}$ at $0.025 \mathrm{M}$ concentration produced similar amount of 4 methyl-stilbene and less homo-coupled byproduct (Table 5, Entry 17). After examining the solvent effect, benzene was found to be the best solvent for this reaction and provided 4-methyl-stilbene in $71 \%$ yield (Table 6, Entry 5). Control experiments showed that both light and the zirconium catalyst were essential for high reactivity.

Table 6. Condition optimization: solvent screening.<smiles>Cc1ccc(-c2ccc(C)cc2)cc1</smiles>

\begin{tabular}{cccc}
\hline \multirow{2}{*}{ Entry $^{\mathrm{a}}$} & \multirow{2}{*}{ Solvent } & \multicolumn{2}{c}{ Yield $^{\mathrm{b}} \%$} \\
\cline { 3 - 4 } & & $\mathbf{1}(\boldsymbol{E}: \boldsymbol{Z})$ & $\mathbf{2}$ \\
\hline 1 & $\mathrm{Et}_{2} \mathrm{O}$ & $59(91: 9)$ & 64 \\
2 & $\mathrm{MTBE}$ & $61(92: 8)$ & 58 \\
3 & $\mathrm{CPME}$ & $58(92: 8)$ & 58 \\
4 & THF & $13(67: 33)$ & 85 \\
$\mathbf{5}$ & Benzene & $\mathbf{7 1}(\mathbf{8 8 : 1 2})$ & $\mathbf{6 1}$ \\
$6^{\mathrm{c}}$ & Benzene & 0 & 13 \\
$7^{\mathrm{d}}$ & Benzene & 0 & 13 \\
8 & Toluene & $54(91: 9)$ & 53 \\
\hline
\end{tabular}

${ }^{\mathrm{a}}$ General conditions: $\beta$-chlorostyrene $(\mathrm{E} / \mathrm{Z}=43 / 57), \quad p$-tolyl magnesiumbromide (1.4 equiv., $0.5 \mathrm{M}$ in $\left.\mathrm{Et}_{2} \mathrm{O}\right), \mathrm{Cp}_{2} \mathrm{ZrCl}_{2}(0.15$ equiv), Solvent (0.025 M), r.t., 16 hrs, $40 \mathrm{~W}$ black CFL. ${ }^{\mathrm{b}}{ }^{1} \mathrm{H}$ NMR yield using 1,3,5-trimethoxybenzene as the internal standard and based on $\beta$-chlorostyrene. ${ }^{\mathrm{c}}$ No $\mathrm{Cp}_{2} \mathrm{ZrCl}_{2} .{ }^{\mathrm{d}}$ No light. 
Mechanistic Insights. Having optimized reaction conditions, detailed stochiometric studies were performed (Scheme 7). Firstly, a solution of $\mathrm{Cp}_{2} \mathrm{Zr}(\mathrm{Tol})_{2}$ (prepared by salt metathesis) reacted with $\beta$-chlorostyrene in the presence of light to give $\mathrm{Cp}_{2} \mathrm{ZrCl}(\mathrm{CH}=\mathrm{CHPh})$ and 4,4 dimethylbiphenyl (Figure 19). This reaction modelled the catalyst activation step. Following the literature procedures, independently prepared $\mathrm{Cp}_{2} \mathrm{ZrCl}(\mathrm{CH}=\mathrm{CHPh})^{12,13}$ readily transmetalated with tolyl lithium reagent to form a mixed alkenyl/aryl compound, $\mathrm{Cp}_{2} \mathrm{ZrTol}(\mathrm{CH}=\mathrm{CHPh}) .{ }^{14} \mathrm{In}$ the presence of light, $\mathrm{Cp}_{2} \mathrm{ZrTol}(\mathrm{CH}=\mathrm{CHPh})$ alone could reductive eliminate within 30 minutes to give a mixture of $43 \%$ " $\mathrm{Cp}_{2} \mathrm{Zr}\left(\eta^{2}-\mathrm{TolCH}=\mathrm{CHPh}\right)$ " (highly likely although not fully characterized) and $47 \%$ of the cross-coupling product $\mathrm{TolCH}=\mathrm{CHPh}$ (Figure 21). After confirming good stability of " $\mathrm{Cp}_{2} \mathrm{Zr}\left(\eta^{2}-\mathrm{TolCH}=\mathrm{CHPh}\right)$ " in the dark, excess of $\beta$-chlorostyrene was added to the reaction mixture. After six days in the dark, " $\mathrm{Cp}_{2} \mathrm{Zr}\left(\eta^{2}-\mathrm{TolCH}=\mathrm{CHPh}\right) "$ slowly converted into $\mathrm{Cp}_{2} \mathrm{ZrCl}(\mathrm{CH}=\mathrm{CHPh})($ Figure 22$)$, which was indicative of a process that involved ligand exchange between $\mathrm{ClCH}=\mathrm{CHPh}$ and $\mathrm{TolCH}=\mathrm{CHPh}$ followed by oxidative addition of $\mathrm{ClCH}=\mathrm{CHPh}$ to " $\mathrm{Cp}_{2} \mathrm{Zr}$ "I". Finally, to combine reductive eliminative, ligand exchange and oxidative addition in one pot, photo-irradiation of $\mathrm{Cp}_{2} \mathrm{ZrTol}(\mathrm{CH}=\mathrm{CHPh})$ in the presence of $\beta$-chlorostyrene delivered $\mathrm{Cp}_{2} \mathrm{ZrCl}(\mathrm{CH}=\mathrm{CHPh})$ in $55 \%$ yield (Figure 23$)$. 
Scheme 7. Mechanistic studies.

Precatalysts Entering Catalytic Cycle

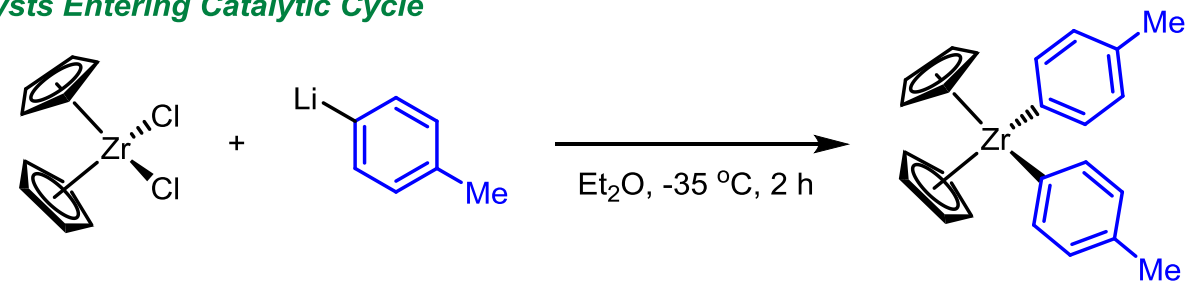<smiles>Cc1ccc(-c2ccc(C)cc2)cc1</smiles>

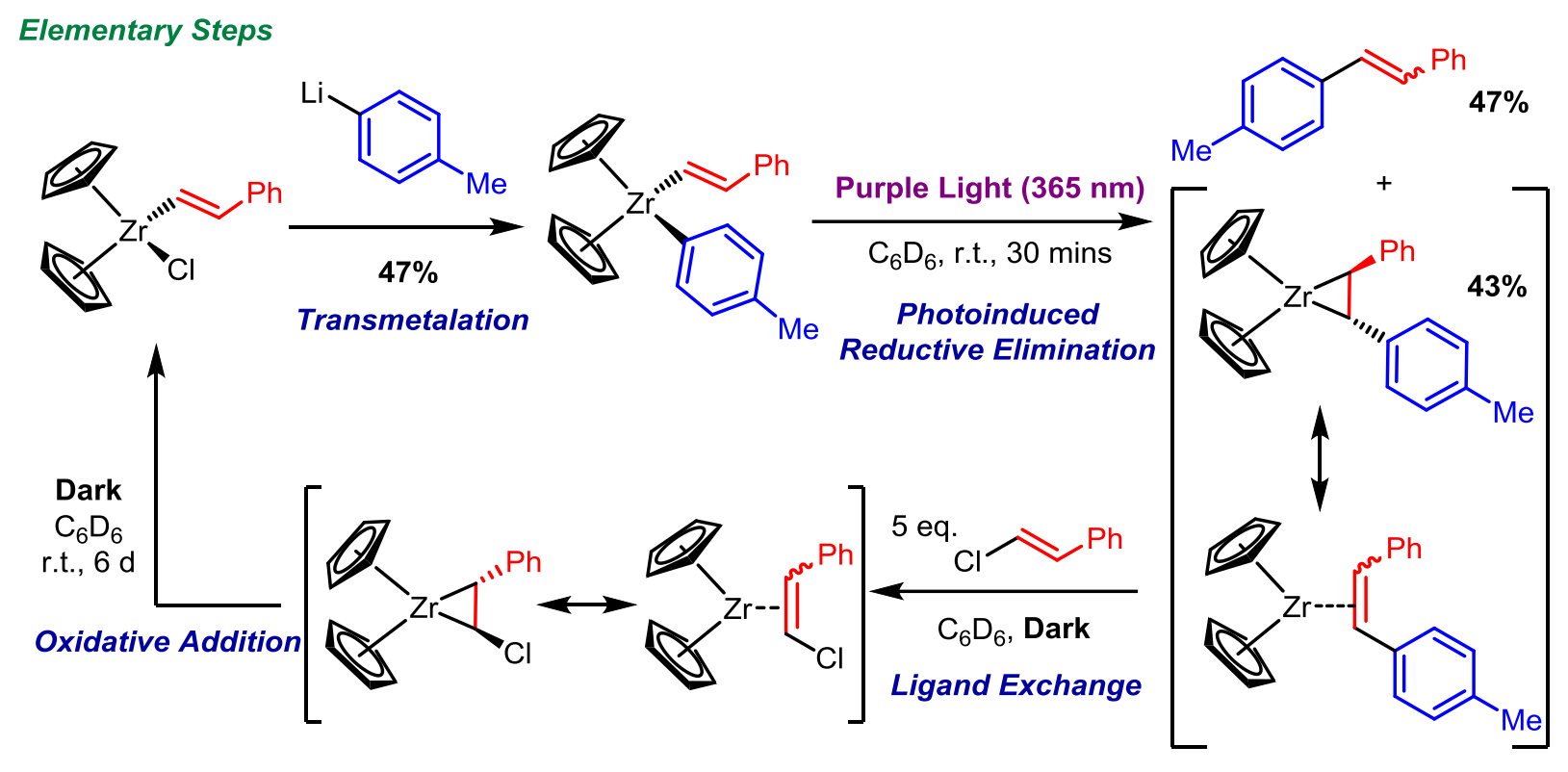

Reductive Elimination, Ligand Exchange and Oxidative Addition: Three in One

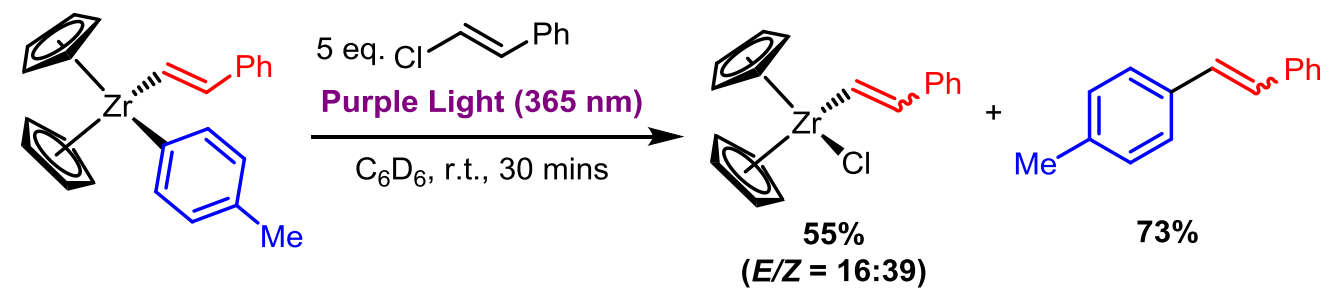




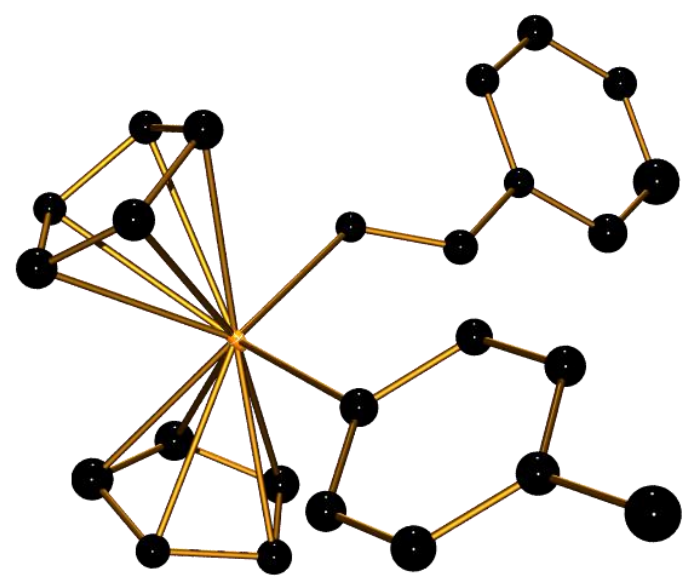

Figure 17. Preliminary crystal structure of $\mathrm{Cp}_{2} \mathrm{ZrTol}(\mathrm{CH}=\mathrm{CHPh})$ at $30 \%$ probability ellipsoids. Hydrogen atoms were omitted for clarity. This is the first example of solid state structure for mixed alkenyl/aryl zirconocene complex.

Proposed Mechanism. The combination of individual experiments in this work provides a detailed picture of the mechanism for a zirconium-catalyzed Kumada cross-coupling under photocatalytic conditions (Figure 18). Salt metathesis of $\mathrm{Cp}_{2} \mathrm{Zr}^{\mathrm{IV}} \mathrm{Cl}_{2}$ with tolylmagnesium bromide forms the $\mathrm{Cp}_{2} \mathrm{Zr}^{\mathrm{IV}}(\mathrm{Tol})_{2}$ precatalyst. Once it enters the catalytic cycle, photoinduced reductive elimination generates the highly reactive " $\mathrm{Cp}_{2} \mathrm{Zr}^{\mathrm{II}}$ ". In large excess of $\beta$-chlorostyrene, coordination following oxidation addition lead to $\mathrm{Cp}_{2} \mathrm{Zr}^{\mathrm{IV}} \mathrm{Cl}(\mathrm{CH}=\mathrm{CHPh})$ formation. After transmetalation with tolylmagnesium bromide to make $\mathrm{Cp}_{2} \mathrm{Zr}^{\mathrm{IV}} \mathrm{Tol}(\mathrm{CH}=\mathrm{CHPh})$, photoexcitation induces reductive elimination and effectively delivers a trapped zirconocene(II), " $\mathrm{Cp}_{2} \mathrm{Zr}^{\mathrm{II}}\left(\eta^{2}\right.$ TolCH=CHPh)." Finally, ligand exchange with $\beta$-chlorostyrene furnishes the desired crosscoupling product and regenerates the reactive low valent zirconocene species " $\mathrm{Cp}_{2} \mathrm{Zr}^{\mathrm{II}}\left(\eta^{2}\right.$ $\mathrm{ClCH}=\mathrm{CHPh}) "$. 


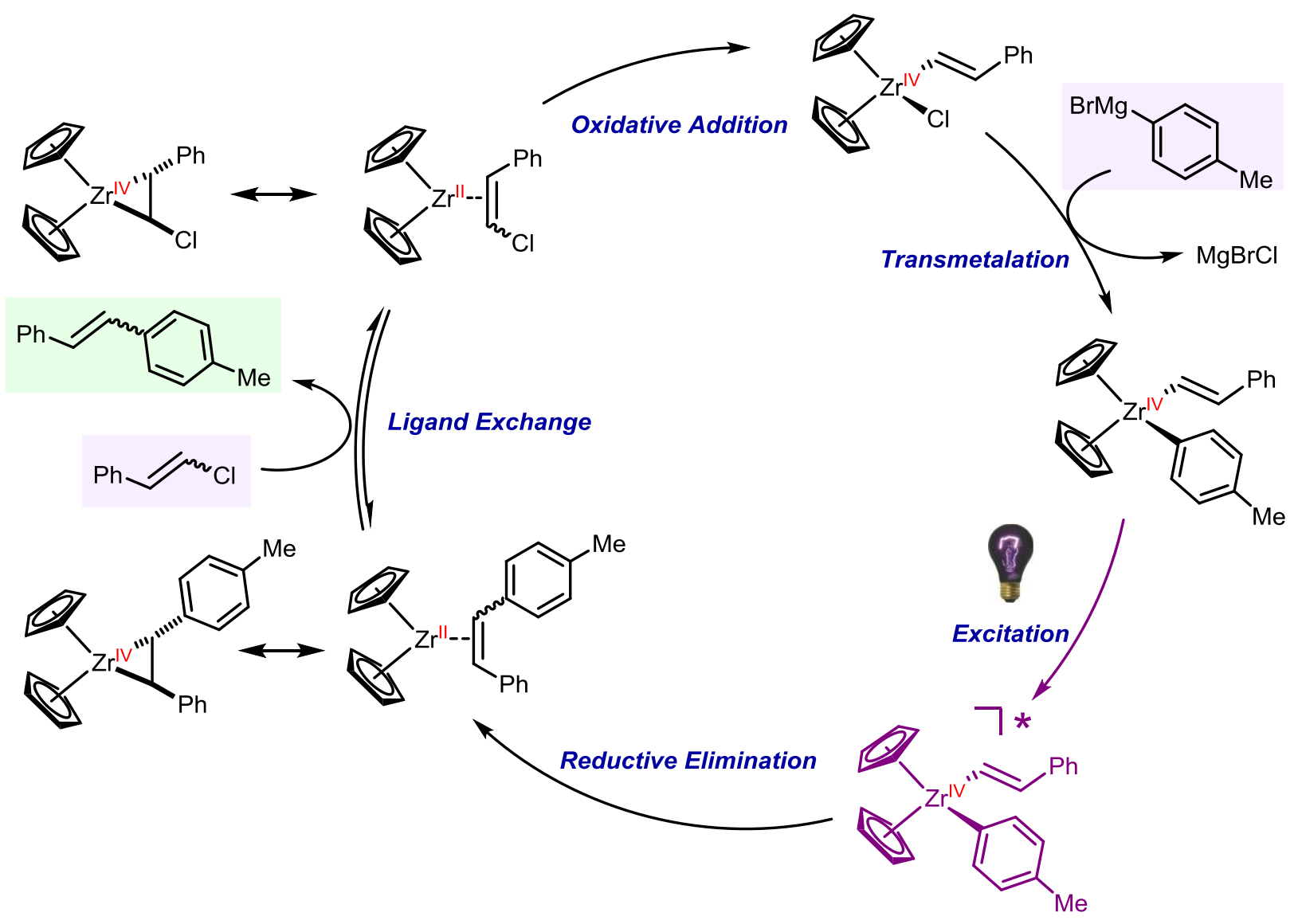

Figure 18. Proposed catalytic cycle.

\section{Experimental Section.}

General experimental considerations for material handling, physical measurements, as well as additional experimental information (i.e. NMR spectra) can be found in the appendices.

Preparation of Toyl(styryl)zirconocene. To a $3 \mathrm{~mL}$ benzene solution of zirconocene hydrochloride (200 mg, $0.776 \mathrm{mmol}, 1.00$ eq.) was added phenylacetylene (79 mg, $0.776 \mathrm{mmol}$, 1.00 eq.). After stirring at room temperature for 2 hours, the solution was concentrated to $\sim 0.5 \mathrm{~mL}$ before adding $3 \mathrm{~mL}$ of $\mathrm{Et}_{2} \mathrm{O}$ and cooling to $-35^{\circ} \mathrm{C}$. Then, a solution of phenyllithium $(73 \mathrm{mg}, 0.737$ 
mmol, 0.95 equiv) in $3 \mathrm{~mL}$ of $\mathrm{Et}_{2} \mathrm{O}$ was slowly added to the cold reaction mixture. With stirring, the reaction mixture was allowed to warm to room temperature. Solvents were removed in vacuo. Benzene was added to the residue. Filtration and removal of the benzene in vacuo resulted in a brown gel. When $\mathrm{Et}_{2} \mathrm{O}$ was added, the desired toyl(styryl)zirconocene crystalized out. ${ }^{1} \mathrm{H}$ NMR (400 MHz, C6 6 ; $\delta, p p m): 8.07(\mathrm{~d}, J=18.8 \mathrm{~Hz}, 1 \mathrm{H}), 7.47$ (d, $J=7.2 \mathrm{~Hz}, 2 \mathrm{H}), 7.27$ (t, $J=7.6 \mathrm{~Hz}$, 2H), 7.16-7.04 (m, 5H), $6.95(\mathrm{~d}, J=18.8 \mathrm{~Hz}, 1 \mathrm{H}), 5.84(\mathrm{~s}, 10 \mathrm{H}), 2.25(\mathrm{~s}, 3 \mathrm{H}) .{ }^{13} \mathrm{C}$ NMR $(101$ $\left.\mathrm{MHz}, \mathrm{C}_{6} \mathrm{D}_{6} ; \delta, \mathrm{ppm}\right): 180.58,180.19,142.79,140.12,135.47,134.45,128.94,127.25,126.50$, 111.71, 21.49 (complex slowly decomposed during ${ }^{13} \mathrm{C}$ NMR data acquisition). Single crystals suitable for X-ray crystallographic analysis were grown from a saturated solution of toyl(styryl)zirconocene in $\mathrm{Et}_{2} \mathrm{O}$ solution. 

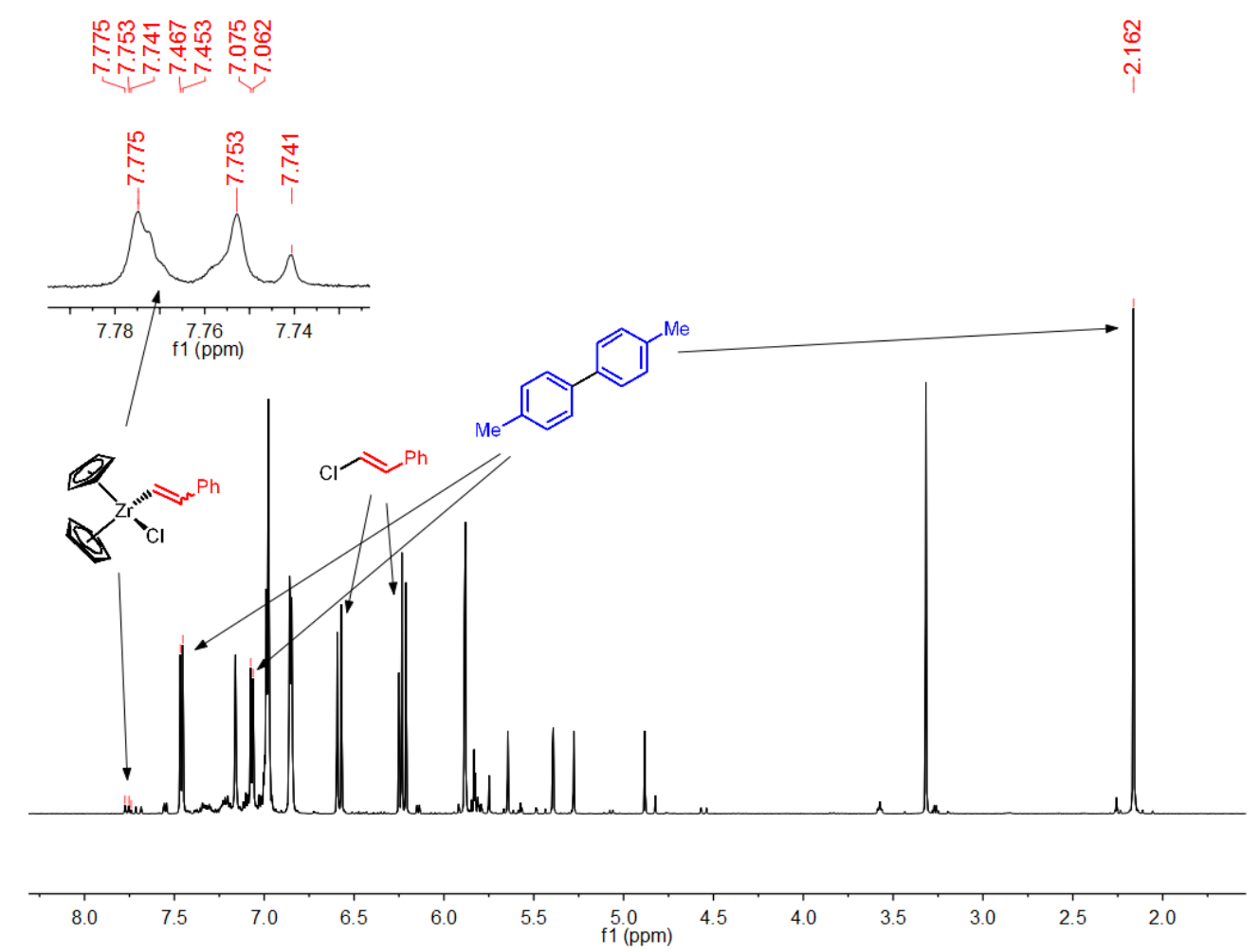

Figure 19. ${ }^{1} \mathrm{H}$ NMR spectra of $\mathrm{Cp}_{2} \mathrm{ZrTol}_{2}+\mathrm{ClCH}=\mathrm{CHPh}$ under $365 \mathrm{~nm}$ light for $2 \mathrm{~h}$ in $\mathrm{C}_{6} \mathrm{D}_{6}$.

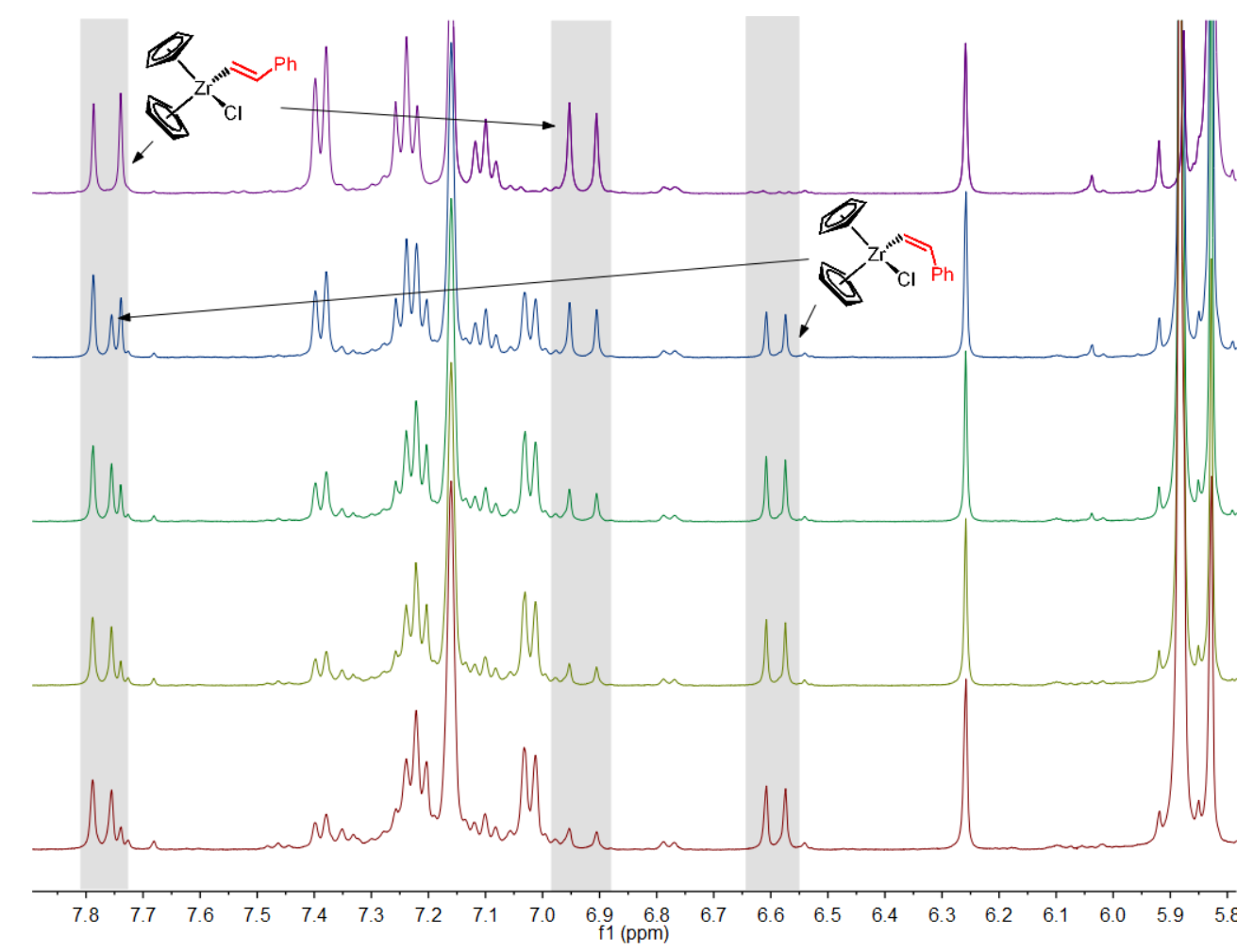

Figure 20. ${ }^{1} \mathrm{H}$ NMR spectra of $\mathrm{Cp}_{2} \mathrm{ZrCl}(\mathrm{CH}=\mathrm{CHPh})$ under $365 \mathrm{~nm}$ light over time in $\mathrm{C}_{6} \mathrm{D}_{6}$. 


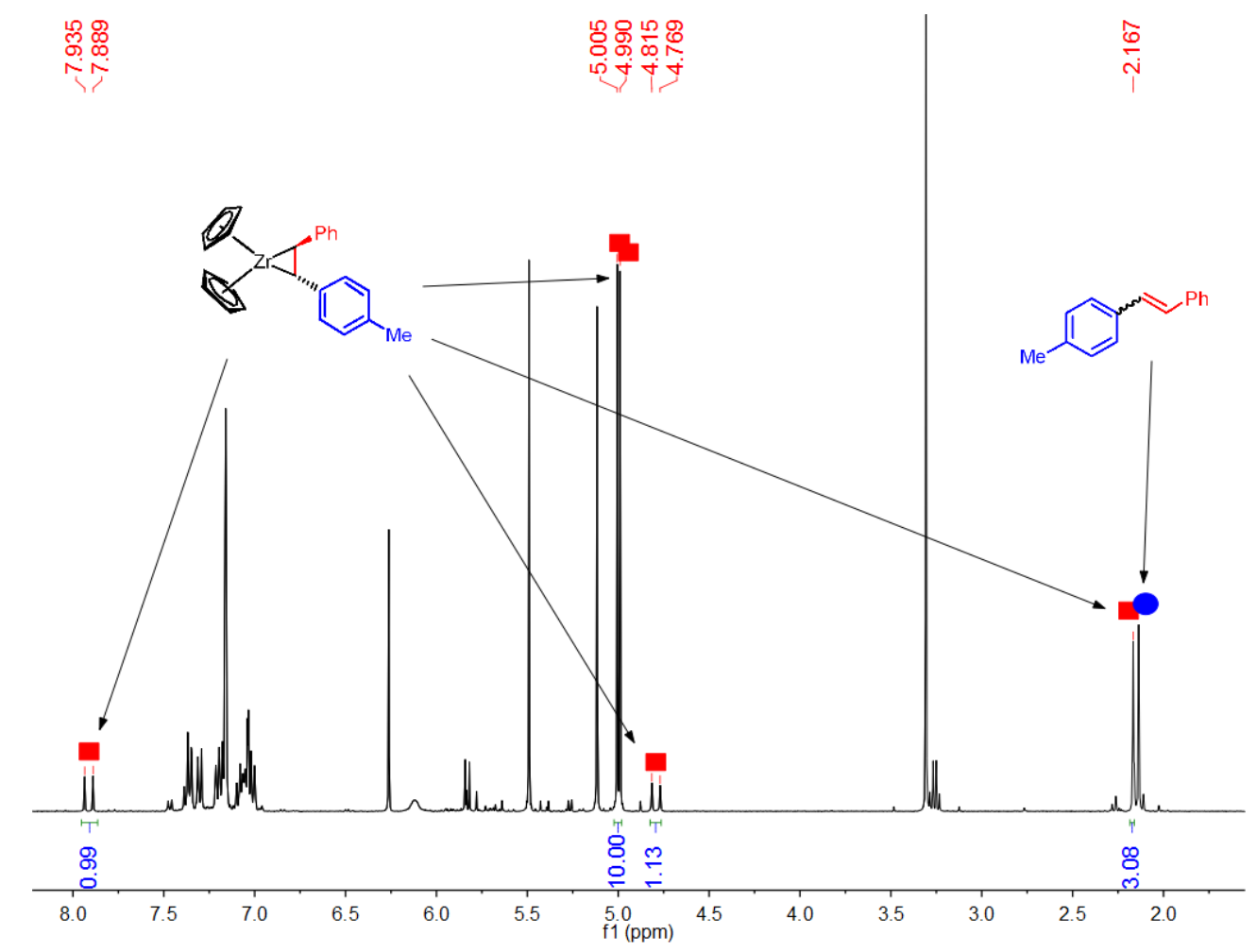

Figure 21. ${ }^{1} \mathrm{H}$ NMR spectra of $\mathrm{Cp}_{2} \mathrm{ZrTol}(\mathrm{CH}=\mathrm{CHPh})$ under $365 \mathrm{~nm}$ light for $0.5 \mathrm{~h}$ in $\mathrm{C}_{6} \mathrm{D}_{6}$.
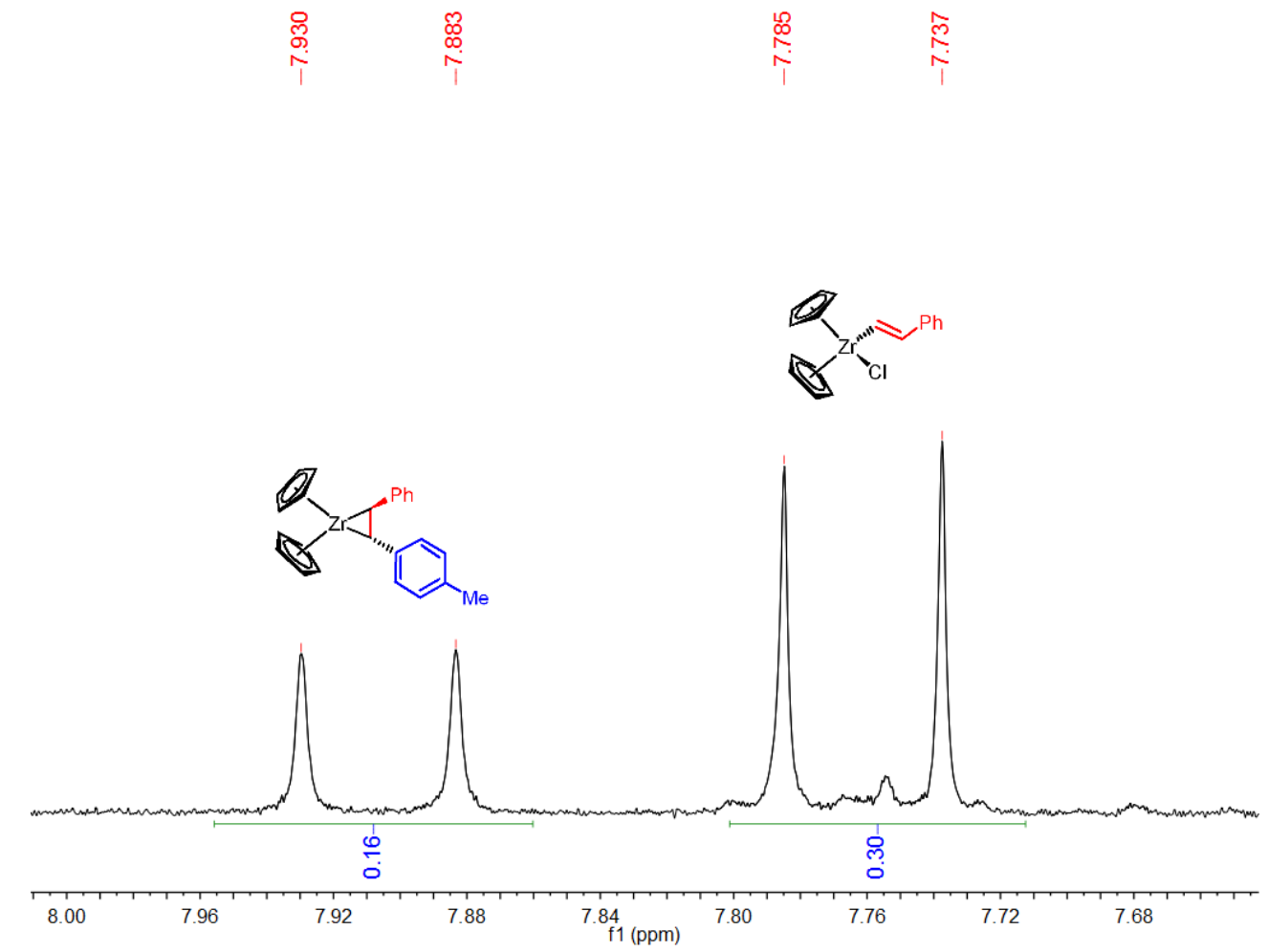

Figure 22. ${ }^{1} \mathrm{H} \mathrm{NMR}$ spectra of $\mathrm{Cp}_{2} \mathrm{Zr}\left(\eta^{2}-\mathrm{TolCH}=\mathrm{CHPh}\right)+\mathrm{ClCH}=\mathrm{CHPh}$ in the dark for 6 days in $\mathrm{C}_{6} \mathrm{D}_{6}$. 


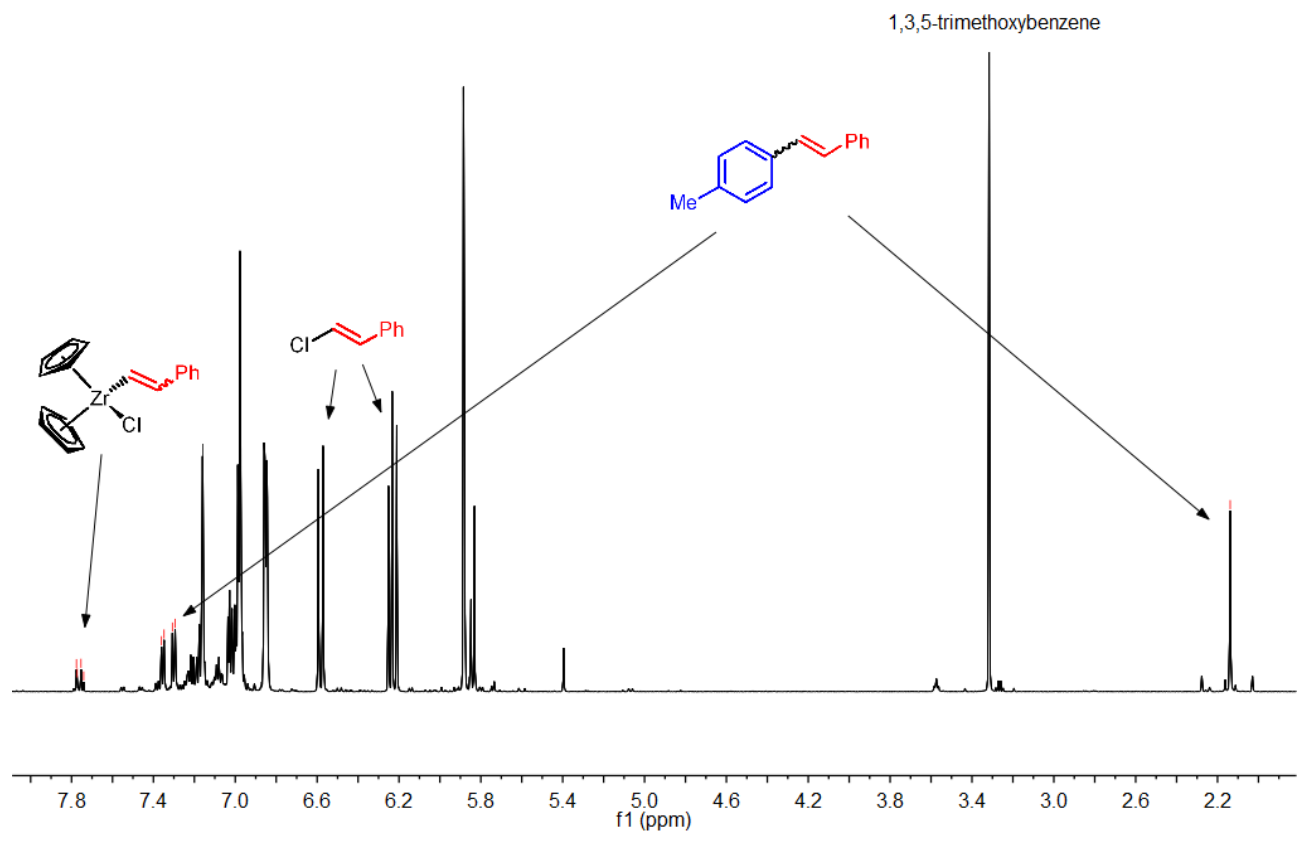

Figure 23. ${ }^{1} \mathrm{H}$ NMR spectra of $\mathrm{Cp}_{2} \mathrm{ZrTol}(\mathrm{CH}=\mathrm{CHPh})+\mathrm{ClCH}=\mathrm{CHPh}$ under $365 \mathrm{~nm}$ light for 0.5 $\mathrm{h}$ in $\mathrm{C}_{6} \mathrm{D}_{6}$. 


\subsection{Synthesis and Characterization of High Valent Niobium and Tantalum Complexes as Analogues of Pyridine dipyrrolide Zirconium(IV) Photosensitizers.}

Synthesis and Characterization. Addition of two equivalents of $n$-BuLi to $\mathrm{H}_{2}{ }^{\mathrm{Me}} \mathrm{PDP}^{\mathrm{Ph}}$ resulted in clean deprotonation yielding $\mathrm{Li}_{2}{ }^{\mathrm{Me}} \mathrm{PDP}^{\mathrm{Ph}}$. Treatment of $\mathrm{MCl}_{4}(\mathrm{~L})_{2}\left(\mathrm{NbCl}_{4}(\mathrm{THF})_{2}\right.$ and $\mathrm{TaCl}_{4}(\text { tmeda) })_{2}$, tmeda $=$ tetramethylethylenediamine) with two equivalents of $\mathrm{Li}_{2}{ }^{\mathrm{Me}} \mathrm{PDP}^{\mathrm{Ph}}$ at room temperature provided $\mathrm{Nb}^{\mathrm{IV}}\left({ }^{\mathrm{Me}} \mathrm{PDP}^{\mathrm{Ph}}\right)_{2}$ and $\mathrm{Ta}^{\mathrm{IV}}\left({ }^{\mathrm{Me}} \mathrm{PDP}^{\mathrm{Ph}}\right)_{2}$ in $54 \%$ and $15 \%$ yield, respectively (Scheme 8). Both complexes are extremely air sensitive, likely being oxidized by oxygen. Indeed, the $\mathrm{d}^{0}$ congeners for both $\mathrm{d}^{1}$ complexes can be readily obtained from one-electron oxidation by ferrocenium $\left(\mathrm{Fc}^{+}\right)$salts. Interestingly, $\mathrm{FcBArF}_{24}$ works well in the case of $\mathrm{Nb}^{\mathrm{IV}} \rightarrow \mathrm{Nb}^{\mathrm{V}}$, but gives unidentified products for $\mathrm{Ta}^{\mathrm{IV}} \rightarrow \mathrm{Ta}^{\mathrm{V}}$. Instead, using $\mathrm{FcBPh}_{4}$ as an oxidant furnishes a relatively clean transformation to give $\left[\mathrm{Ta}^{\mathrm{V}}\left({ }^{\mathrm{Me}} \mathrm{PDP}^{\mathrm{Ph}}\right)_{2}\right][\mathrm{BPh} 4]$. It is worth noting that $\left[\mathrm{Ta}^{\mathrm{V}}\left({ }^{\mathrm{Me}} \mathrm{PDP}^{\mathrm{Ph}}\right)_{2}\right][\mathrm{BPh} 4]$ is highly unstable and decomposes entirely overnight under $\mathrm{N}_{2}$ at room temperature in $\mathrm{CDCl}_{3}$. Better stability was found in THF- $d_{8}$ solution, but decomposition still takes place over time. On the other hand, $\left[\mathrm{Nb}^{\mathrm{V}}\left({ }^{\mathrm{Me}} \mathrm{PDP}^{\mathrm{Ph}}\right)_{2}\right]\left[\mathrm{BArF}_{24}\right]$ can survive in $\mathrm{CDCl}_{3}$ for an extended period of time before noticeable decomposition is observed. 
Scheme 8. Synthesis of $\mathrm{Nb}^{\mathrm{IV}}\left({ }^{\mathrm{Me}} \mathrm{PDP}^{\mathrm{Ph}}\right)_{2}, \quad\left[\mathrm{Nb}^{\mathrm{V}}\left({ }^{\mathrm{Me}} \mathrm{PDP}^{\mathrm{Ph}}\right)_{2}\right]\left[\mathrm{BArF}{ }_{24}\right], \mathrm{Ta}^{\mathrm{IV}}\left({ }^{\mathrm{Me}} \mathrm{PDP}{ }^{\mathrm{Ph}}\right)_{2}$, and $\left[\mathrm{Ta}^{\mathrm{V}}\left({ }^{\mathrm{Me}} \mathrm{PDP}^{\mathrm{Ph}}\right)_{2}\right]\left[\mathrm{BPh}_{4}\right]$.
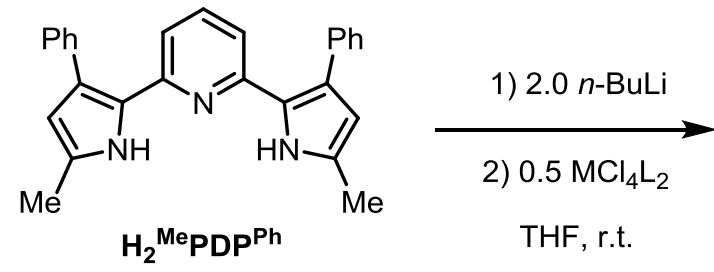

$\mathrm{M}=\mathrm{Nb}, 54 \%$

$\mathrm{M}=\mathrm{Ta}, 15 \%$
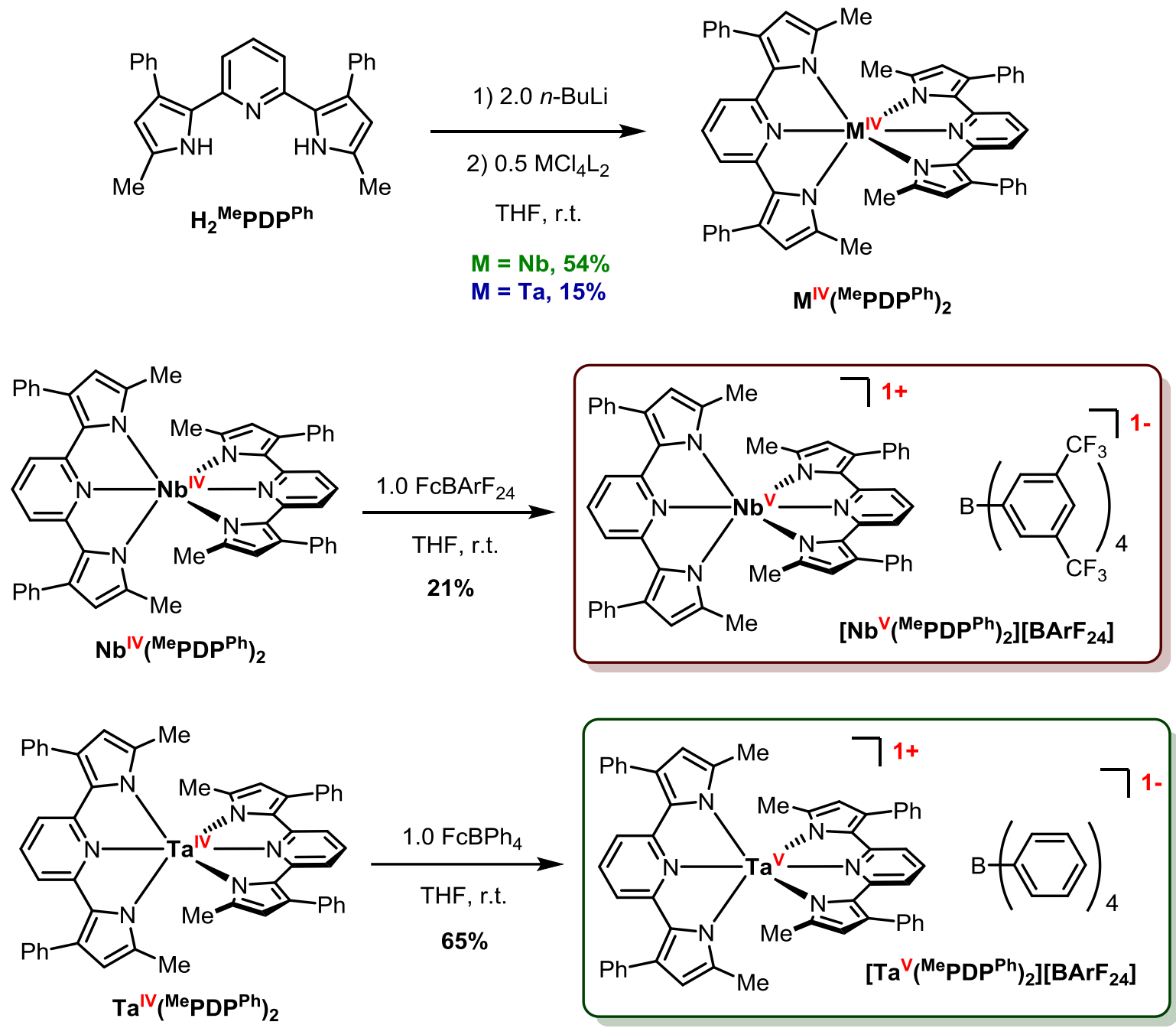

The molecular structures of the two $\mathrm{Nb}$ complexes were established by X-ray diffraction. The structures of $\mathrm{Nb}^{\mathrm{IV}}\left({ }^{\mathrm{Me}} \mathrm{PDP}^{\mathrm{Ph}}\right)_{2}$ and $\left[\mathrm{Nb}^{\mathrm{V}}\left({ }^{\mathrm{Me}} \mathrm{PDP}^{\mathrm{Ph}}\right)_{2}\right][\mathrm{BArF} 24]$ are shown in Figure 24 and selected structural parameters are listed in Table 7. In both complexes, the coordination environment around the central metal ion is best described as distorted octahedral with two meridionally coordinated tridentate ${ }^{\mathrm{Me}} \mathrm{PDP}^{\mathrm{Ph} 2-}$ ligands. Similar to $\mathrm{Zr}(\mathrm{PDP})_{2}$ analogues, the 
geometric constraints enforced by the ligand framework result in reduced average $\mathrm{N}_{\text {pyrrol}}-\mathrm{M}-\mathrm{N}_{\text {pyrrol }}$ angles of $144.01(6)^{\circ}$, and $142.70(5)^{\circ}$ in $\mathrm{Nb}^{\mathrm{IV}}\left({ }^{\mathrm{Me}} \mathrm{PDP}^{\mathrm{Ph}}\right)_{2}$ and $\left[\mathrm{Nb}^{\mathrm{V}}\left({ }^{\mathrm{Me}} \mathrm{PDP}^{\mathrm{Ph}}\right)_{2}\right]\left[\mathrm{BArF} \mathrm{B}_{24}\right]$, respectively. The two tridentate ligands exhibit nearly perpendicular orientation in both complexes as indicated by the angle between the $\mathrm{N}(1)-\mathrm{N}(2)-\mathrm{N}(3)$ and the $\mathrm{N}(4)-\mathrm{N}(5)-\mathrm{N}(6)$ planes. No significant changes in the intra-ligand bond distances are observed between $\mathrm{Nb}^{\mathrm{IV}}\left({ }^{\mathrm{Me}} \mathrm{PDP}^{\mathrm{Ph}}\right)_{2}$ and the one-electron oxidized complex $\left[\mathrm{Nb}^{\mathrm{V}}\left({ }^{\mathrm{Me}} \mathrm{PDP}^{\mathrm{Ph}}\right)_{2}\right]^{+}$ion (Appendix C), indicating metal-centered oxidation and $\mathrm{a}+\mathrm{V}$ oxidation state for the $\mathrm{Nb}$ ion in $\left[\mathrm{Nb}^{\mathrm{V}}\left({ }^{\mathrm{Me}} \mathrm{PDP}^{\mathrm{Ph}}\right)_{2}\right]\left[\mathrm{BArF}_{24}\right]$. Consistent with this assignment, the average $\mathrm{Nb}-\mathrm{N}_{\text {pyrrole }}$ bond length decreases from $2.1058(15) \AA$ in the neutral complex to $2.0536(14) \AA$ in the cationic compound. The average $\mathrm{Nb}-\mathrm{N}_{\text {pyridine }}$ distance remains similar with 2.1884(14) $\AA$ and 2.2045(13) $\AA$ in $\mathrm{Nb}^{\mathrm{IV}}\left({ }^{\mathrm{Me}} \mathrm{PDP}^{\mathrm{Ph}}\right)_{2}$ and $\left[\mathrm{Nb}^{\mathrm{V}}\left({ }^{\mathrm{Me}} \mathrm{PDP}^{\mathrm{Ph}}\right)_{2}\right]^{+}$, respectively. The ${ }^{1} \mathrm{H}$ NMR spectroscopy data for paramagnetic $\mathrm{Nb}^{\mathrm{IV}}\left({ }^{\mathrm{Me}} \mathrm{PDP}^{\mathrm{Ph}}\right)_{2}$ and $\mathrm{Ta}^{\mathrm{IV}}\left({ }^{\mathrm{Me}} \mathrm{PDP}^{\mathrm{Ph}}\right)_{2}$ as well as for diamagnetic $\left[\mathrm{Nb}^{\mathrm{V}}\left({ }^{\mathrm{Me}} \mathrm{PDP}^{\mathrm{Ph}}\right)_{2}\right]\left[\mathrm{BArF}{ }_{24}\right]$ and $\left[\mathrm{Ta}^{\mathrm{V}}\left({ }^{\mathrm{Me}} \mathrm{PDP}^{\mathrm{Ph}}\right)_{2}\right]\left[\mathrm{BPh}_{4}\right]$ are in agreement with $D_{2 d}$ symmetric structures in solution (Figure 25- Figure 28). 

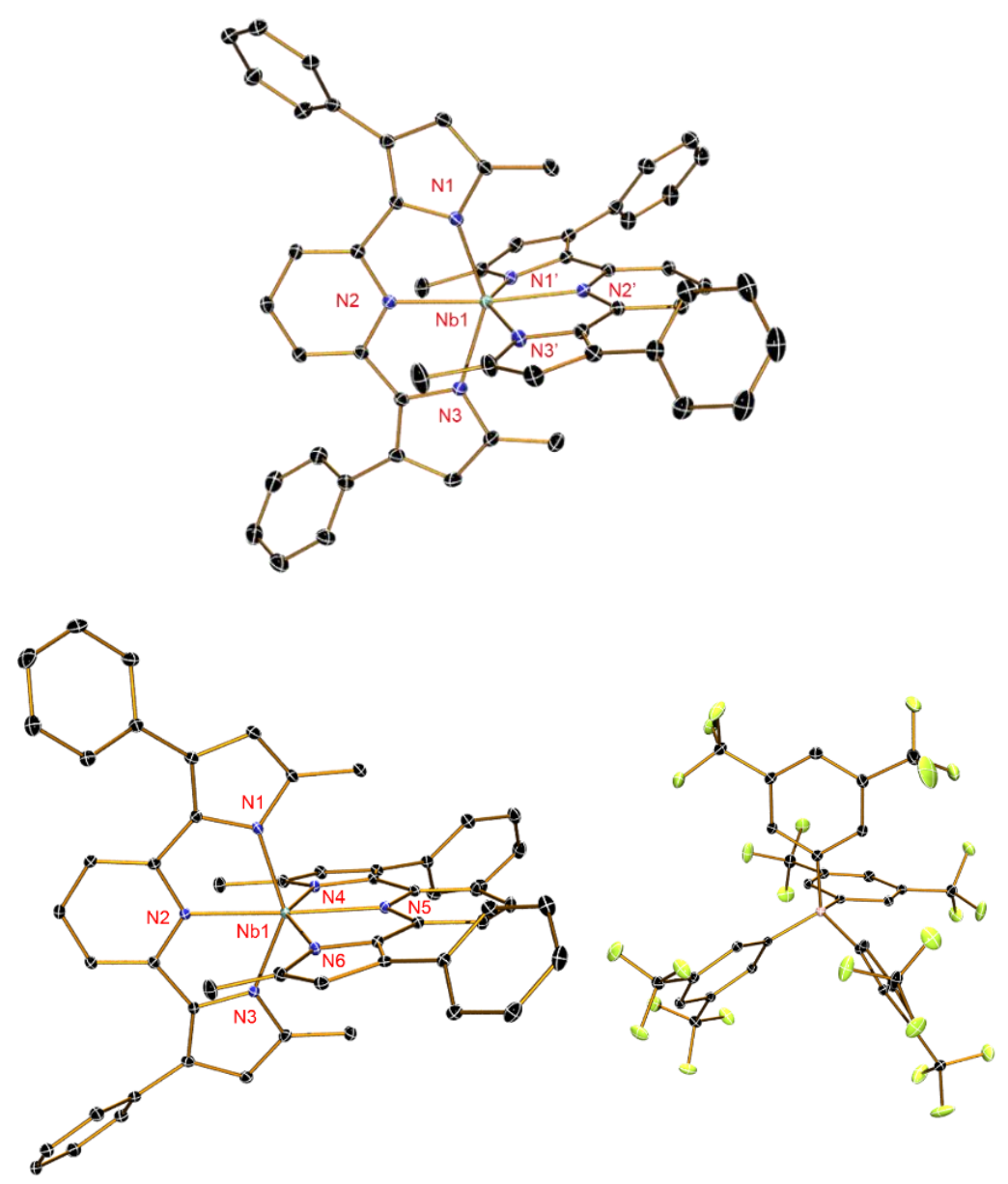

Figure 24. Solid state structure of $\mathrm{Nb}^{\mathrm{IV}}\left({ }^{\mathrm{Me}} \mathrm{PDP}^{\mathrm{Ph}}\right)_{2}$ (top) and $\left[\mathrm{Nb}^{\mathrm{V}}\left({ }^{\mathrm{Me}} \mathrm{PDP}^{\mathrm{Ph}}\right)_{2}\right][\mathrm{BArF} 24]$ (bottom) at $30 \%$ probability ellipsoids. Hydrogen atoms were omitted for clarity.

Table 7. Selected bond lengths $(\AA)$ and angles $\left(^{\circ}\right)$ for $\mathrm{Nb}^{\mathrm{IV}}\left({ }^{\mathrm{Me}} \mathrm{PDP}^{\mathrm{Ph}}\right)_{2}$ and $\left[\mathrm{Nb}^{\mathrm{V}}\left(\mathrm{Me}^{\mathrm{PePP}}{ }^{\mathrm{Ph}}\right)_{2}\right][\mathrm{BArF} 24]$.

\begin{tabular}{ccc} 
& $\mathrm{Nb}^{\mathrm{IV}}\left({ }^{\mathrm{Me}} \mathrm{PDP}^{\mathrm{Ph}}\right)_{2}{ }^{\mathrm{a}}$ & {$\left[\mathrm{Nb}^{\mathrm{V}}\left(\mathrm{Me}^{\mathrm{MeP}}{ }^{\mathrm{Ph}}\right)_{2}\right]\left[\mathrm{BArF}_{24}\right]$} \\
\hline $\mathrm{Nb} 1-\mathrm{N} 1$ & $2.1026(15)$ & $2.0604(14)$ \\
$\mathrm{Nb} 1-\mathrm{N} 2$ & $2.1884(14)$ & $2.2055(13)$ \\
$\mathrm{Nb} 1-\mathrm{N} 3$ & $2.1091(15)$ & $2.0400(14)$ \\
$\mathrm{Nb} 1-\mathrm{N} 4$ & & $2.0709(14)$ \\
$\mathrm{Nb} 1-\mathrm{N} 5$ & & $2.2034(13)$ \\
$\mathrm{Nb} 1-\mathrm{N} 6$ & & $2.0431(14)$ \\
\hline $\mathrm{N} 3-\mathrm{Nb} 1-\mathrm{N} 1$ & $144.01(6)$ & $142.78(5)$ \\
$\mathrm{N} 4-\mathrm{Nb} 1-\mathrm{N} 6$ & & $142.62(5)$ \\
\hline Dihedral angle & 86.20 & 86.77 \\
\hline
\end{tabular}

${ }^{\mathrm{a}}$ two ligands are related by symmetry. 


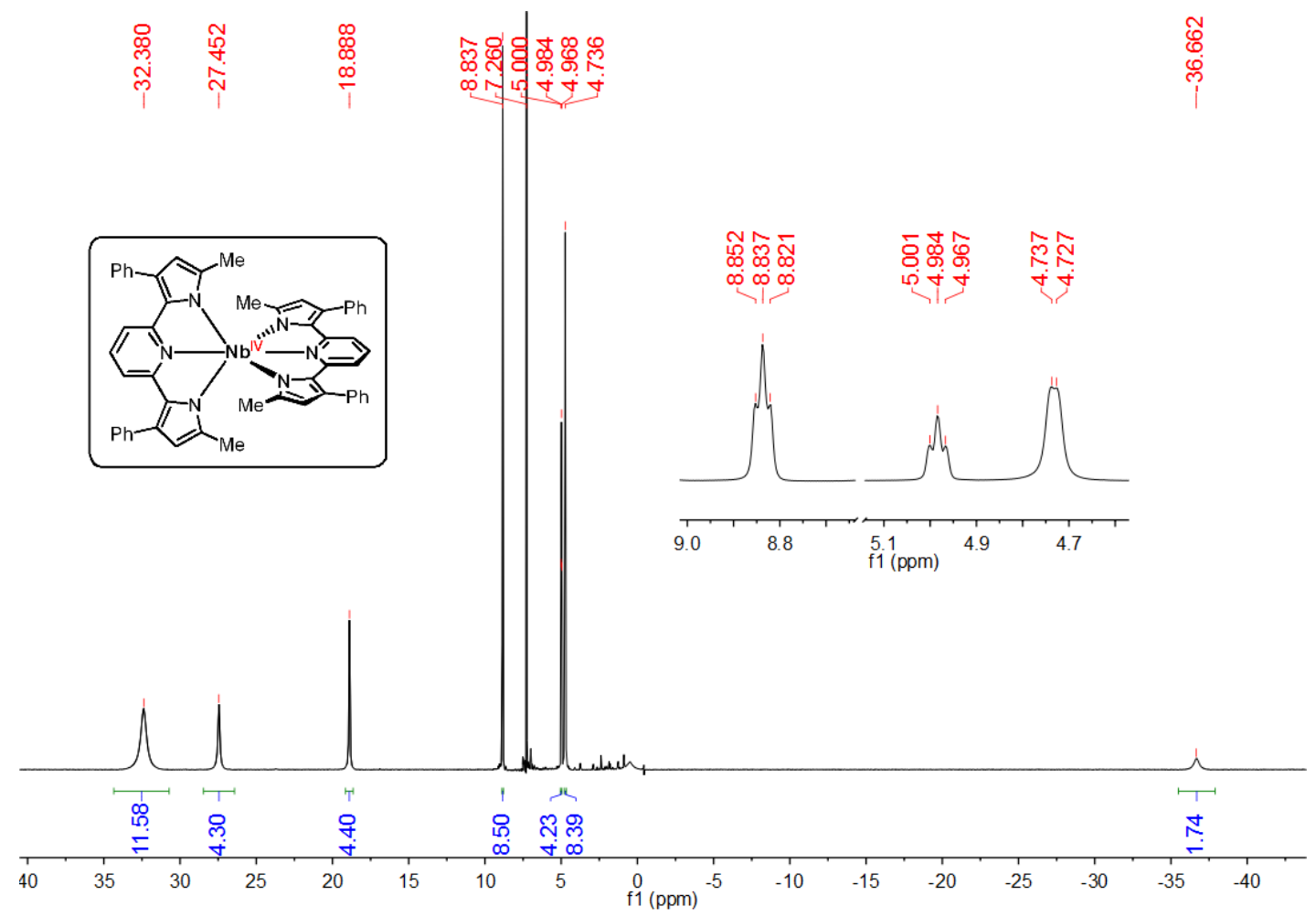

Figure 25. ${ }^{1} \mathrm{H}$ NMR spectra of $\mathrm{Nb}^{\mathrm{IV}}\left({ }^{\mathrm{Me}} \mathrm{PDP}^{\mathrm{Ph}}\right)_{2}$ in $\mathrm{CDCl}_{3}$.

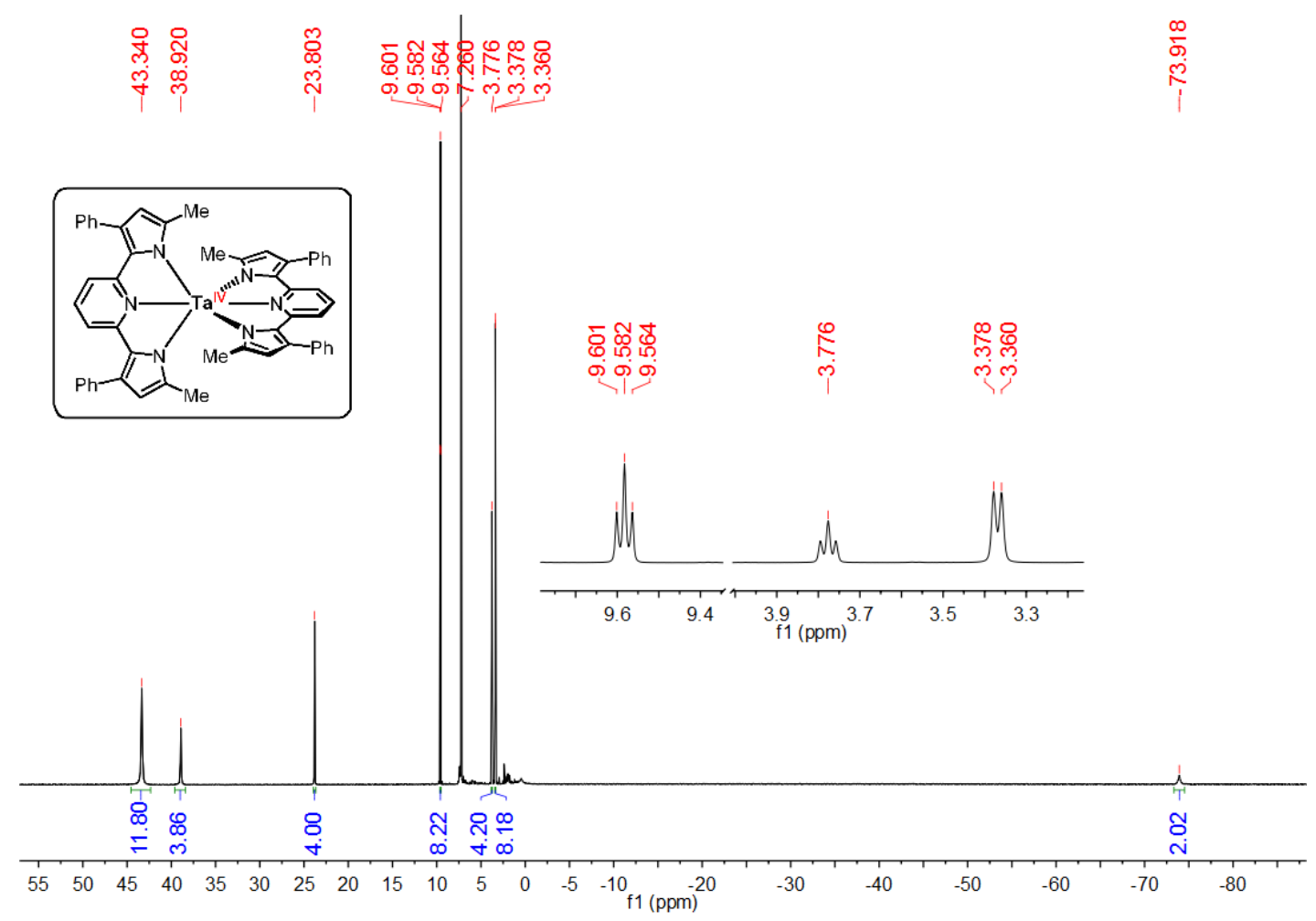

Figure 26. ${ }^{1} \mathrm{H}$ NMR spectra of $\mathrm{Ta}^{\mathrm{IV}}\left({ }^{\mathrm{Me}} \mathrm{PDP}^{\mathrm{Ph}}\right)_{2}$ in $\mathrm{CDCl}_{3}$. 


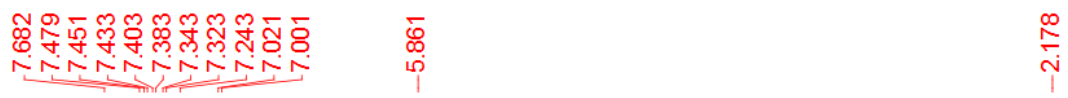

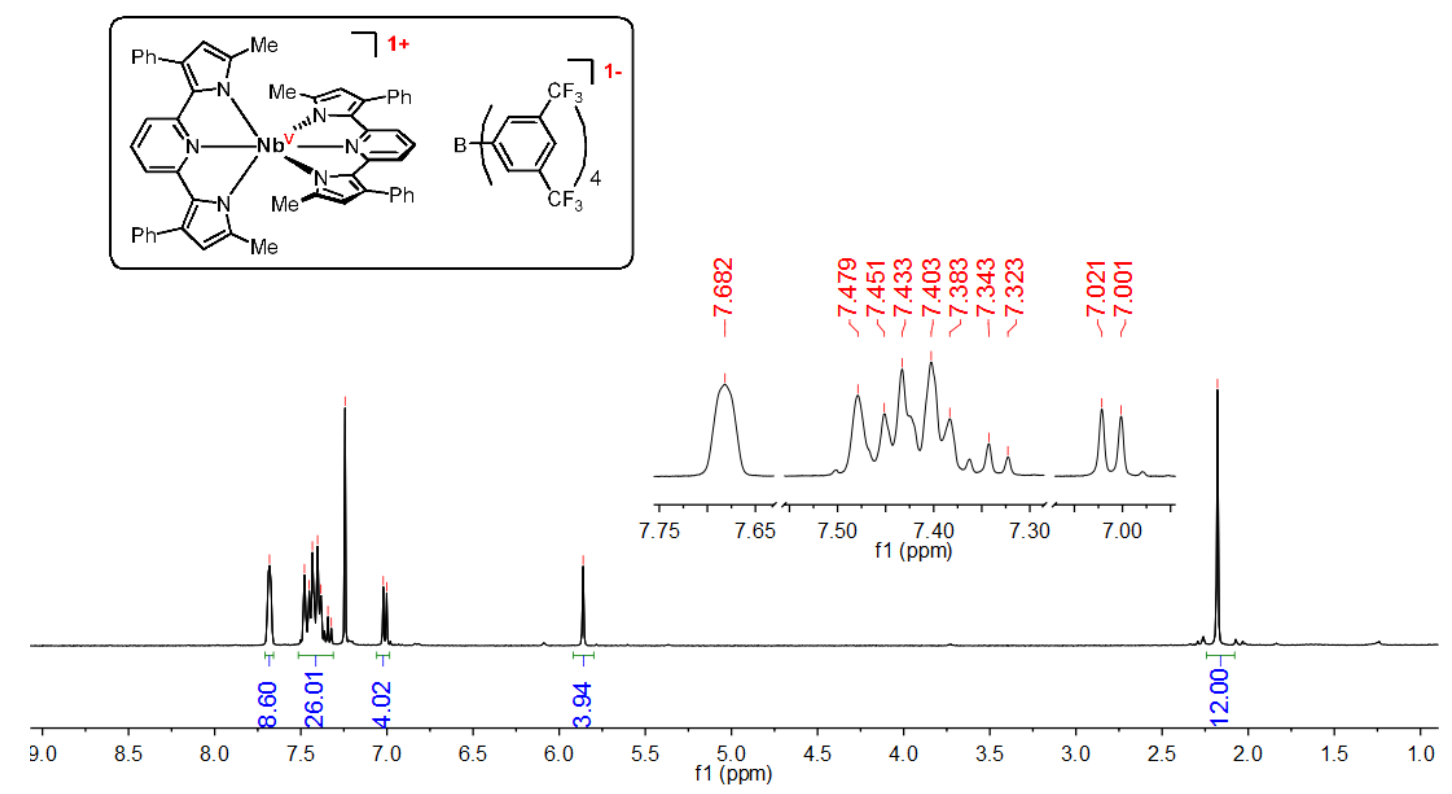

Figure 27. ${ }^{1} \mathrm{H} \mathrm{NMR}$ spectra of $\left[\mathrm{Nb}^{\mathrm{V}}\left({ }^{\mathrm{Me}} \mathrm{PDP}^{\mathrm{Ph}}\right)_{2}\right]\left[\mathrm{BArF}{ }_{24}\right]$ in $\mathrm{CDCl}_{3}$.

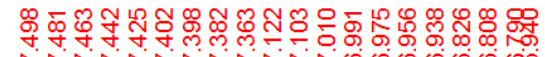

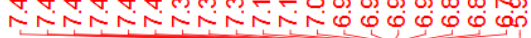

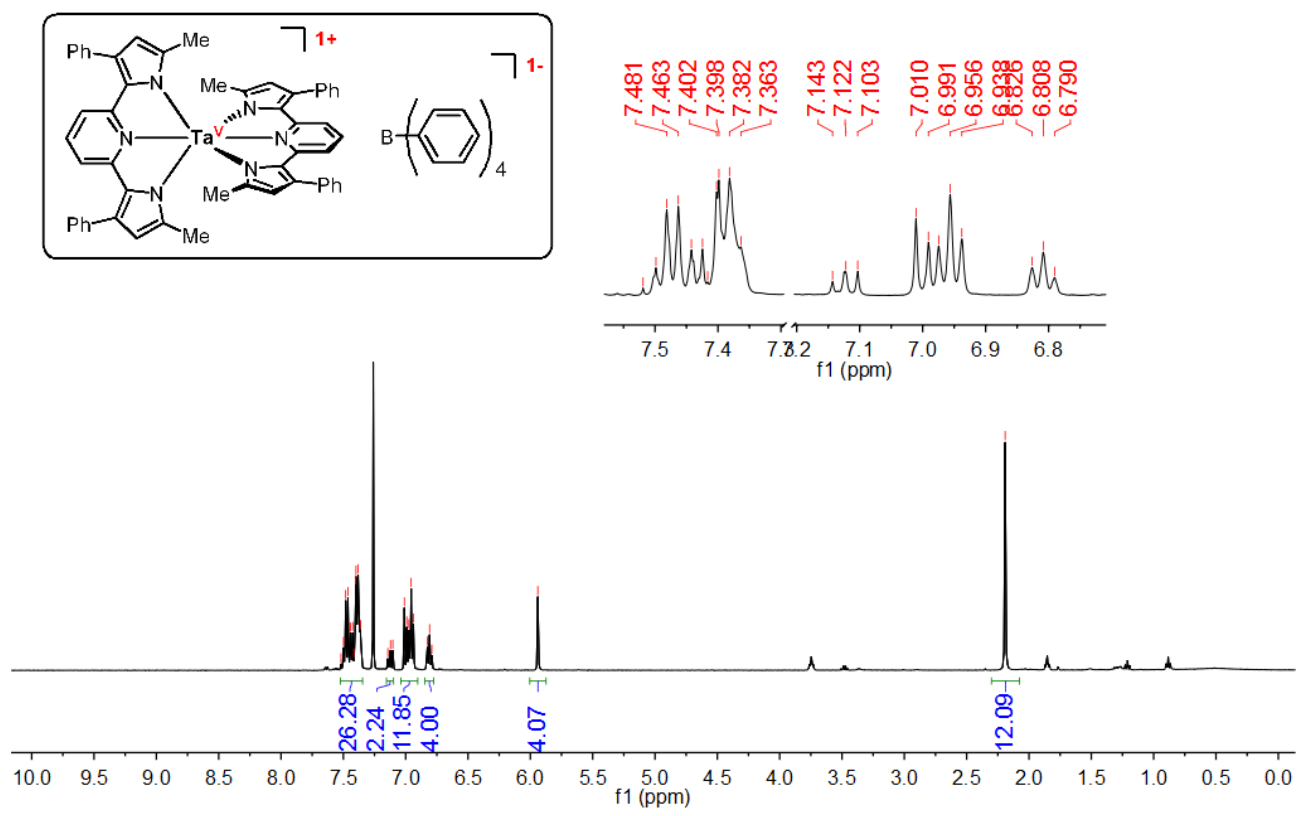

Figure 28. ${ }^{1} \mathrm{H}$ NMR spectra of $\left[\mathrm{Ta}^{\mathrm{V}}\left({ }^{\mathrm{Me}} \mathrm{PDP}^{\mathrm{Ph}}\right)_{2}\right]\left[\mathrm{BPh}_{4}\right]$ in $\mathrm{CDCl}_{3}$. 
Despite their structural similarities, the optical properties of $\mathrm{Nb}^{\mathrm{IV}}\left({ }^{\mathrm{Me}} \mathrm{PDP}^{\mathrm{Ph}}\right)_{2}$ and $\left[\mathrm{Nb}^{\mathrm{V}}\left({ }^{\mathrm{Me}} \mathrm{PDP}^{\mathrm{Ph}}\right)_{2}\right]\left[\mathrm{BArF}{ }_{24}\right]$ are quite different. $\mathrm{Nb}^{\mathrm{IV}}\left({ }^{\mathrm{Me}} \mathrm{PDP}^{\mathrm{Ph}}\right)_{2}$ exhibits a dark green color and its $\mathrm{d}^{0}$ analog is dark brown in THF solutions. Electronic absorption spectra for both complexes as well as the emission spectrum of $\left[\mathrm{Nb}^{\mathrm{V}}\left({ }^{\mathrm{Me}} \mathrm{PDP}^{\mathrm{Ph}}\right)_{2}\right]^{+}$upon excitation at $461 \mathrm{~nm}$ are shown in Figure 29. The spectrum of $\mathrm{Nb}^{\mathrm{IV}}\left({ }^{\mathrm{Me}} \mathrm{PDP}^{\mathrm{Ph}}\right)_{2}$ exhibits two absorption bands above $400 \mathrm{~nm}$ with maxima at $671 \mathrm{~nm}\left(\varepsilon=9897 \mathrm{M}^{-1} \mathrm{~cm}^{-1}\right)$ and $507 \mathrm{~nm}\left(\varepsilon=7600 \mathrm{M}^{-1} \mathrm{~cm}^{-1}\right)$, which are tentatively assigned as charge transfer bands based on their intensities. Even stronger absorption bands were observed in the $\mathrm{UV}$ region at $353 \mathrm{~nm}\left(\varepsilon=46691 \mathrm{M}^{-1} \mathrm{~cm}^{-1}\right), 321 \mathrm{~nm}\left(\varepsilon=55378 \mathrm{M}^{-1} \mathrm{~cm}^{-1}\right)$, and $244 \mathrm{~nm}(\varepsilon=$ $55628 \mathrm{M}^{-1} \mathrm{~cm}^{-1}$ ). No emission bands were detected upon excitation at wavelengths corresponding to these absorption maxima. The spectrum obtained for $\left[\mathrm{Nb}^{\mathrm{V}}\left({ }^{\mathrm{Me}} \mathrm{PDP}^{\mathrm{Ph}}\right)_{2}\right]\left[\mathrm{BArF}_{24}\right]$ shows similar features with red-shifted absorption maxima and varying intensity. A broad absorption band was observed in the near infrared (NIR) region with a maximum at $805 \mathrm{~nm}\left(\varepsilon=2374 \mathrm{M}^{-1} \mathrm{~cm}^{-1}\right)$ and a blue light absorption band at $461 \mathrm{~nm}\left(\varepsilon=22370 \mathrm{M}^{-1} \mathrm{~cm}^{-1}\right)$. Additional bands maxima at $371 \mathrm{~nm}$ $\left(\varepsilon=29619 \mathrm{M}^{-1} \mathrm{~cm}^{-1}\right)$ and $314 \mathrm{~nm}\left(\varepsilon=33283 \mathrm{M}^{-1} \mathrm{~cm}^{-1}\right)$ are located in the UV part of the spectrum. In contrast to the $\mathrm{d}^{0}$ zirconium analog, excitation at the lowest energy absorption band fails to invoke any reliable emission signal. Only an excitation at $461 \mathrm{~nm}$ resulted in a strong emission which could be caused by a small amount of highly emissive impurity in the sample. Similarly, the lowest energy absorption band for $\mathrm{Ta}^{\mathrm{IV}}\left({ }^{\mathrm{Me}} \mathrm{PDP}^{\mathrm{Ph}}\right)_{2}$ is blue shifted compared to its $\mathrm{d}^{0}$ congener (Figure 30). No consistent emission behavior was detected for either of the two Ta complexes. Due to the higher effective nuclear charge $\left(Z_{\text {eff }}\right)$ for the third row Ta center, the energy of tantalum $d$ 
orbitals is higher than niobium. Such a difference produces a larger HOMO-LUMO gap for Ta complexes under an identical ligand environment. As analyzed, we observed blue shifted behaviors of the absorption bands for both $\mathrm{Ta}^{\mathrm{IV}}\left({ }^{\mathrm{Me}} \mathrm{PDP}^{\mathrm{Ph}}\right)_{2}$ and $\left[\mathrm{Ta}^{\mathrm{V}}\left({ }^{\mathrm{Me}} \mathrm{PDP}^{\mathrm{Ph}}\right)_{2}\right]\left[\mathrm{BPh}_{4}\right]$ compared to its niobium analogs of the same oxidation states.

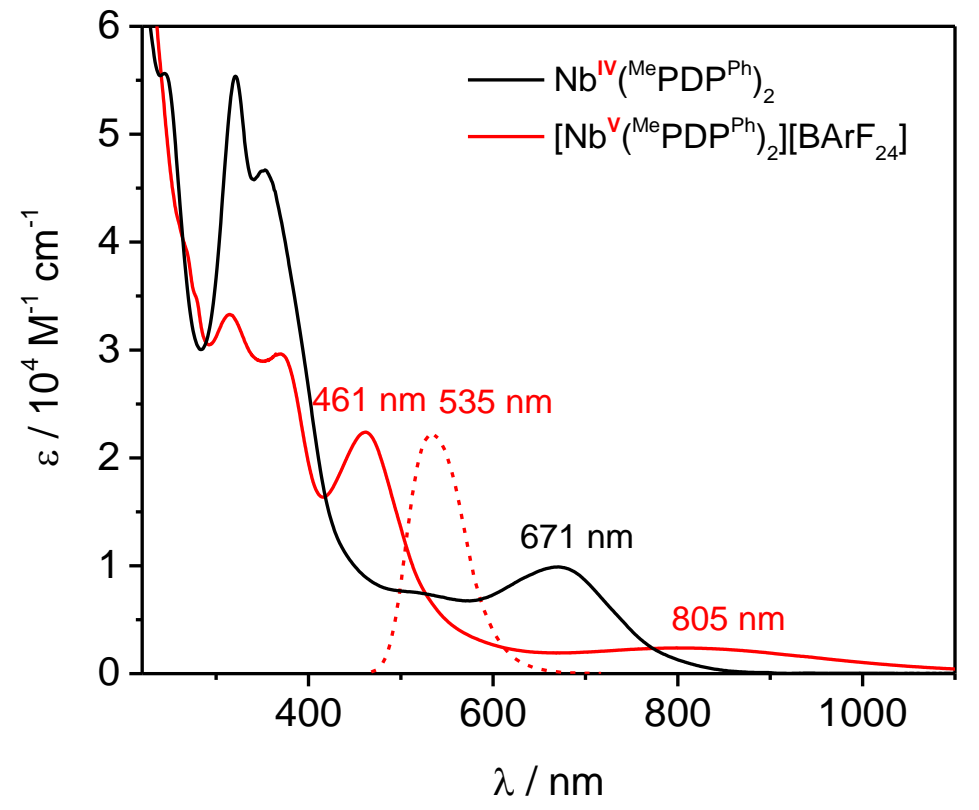

Figure 29. Absorption (solid lines) spectra of $\mathrm{Nb}^{\mathrm{IV}}\left({ }^{\mathrm{Me}} \mathrm{PDP}^{\mathrm{Ph}}\right)_{2}$ and $\left[\mathrm{Nb}^{\mathrm{V}}\left({ }^{\mathrm{Me}} \mathrm{PDP}^{\mathrm{Ph}}\right)_{2}\right]^{+}$as well as emission spectra (dashed lines) for $\left[\mathrm{Nb}^{\mathrm{V}}\left({ }^{\mathrm{Me}} \mathrm{PDP}^{\mathrm{Ph}}\right)_{2}\right]^{+}$excited at $461 \mathrm{~nm}$ in THF solution at room temperature 


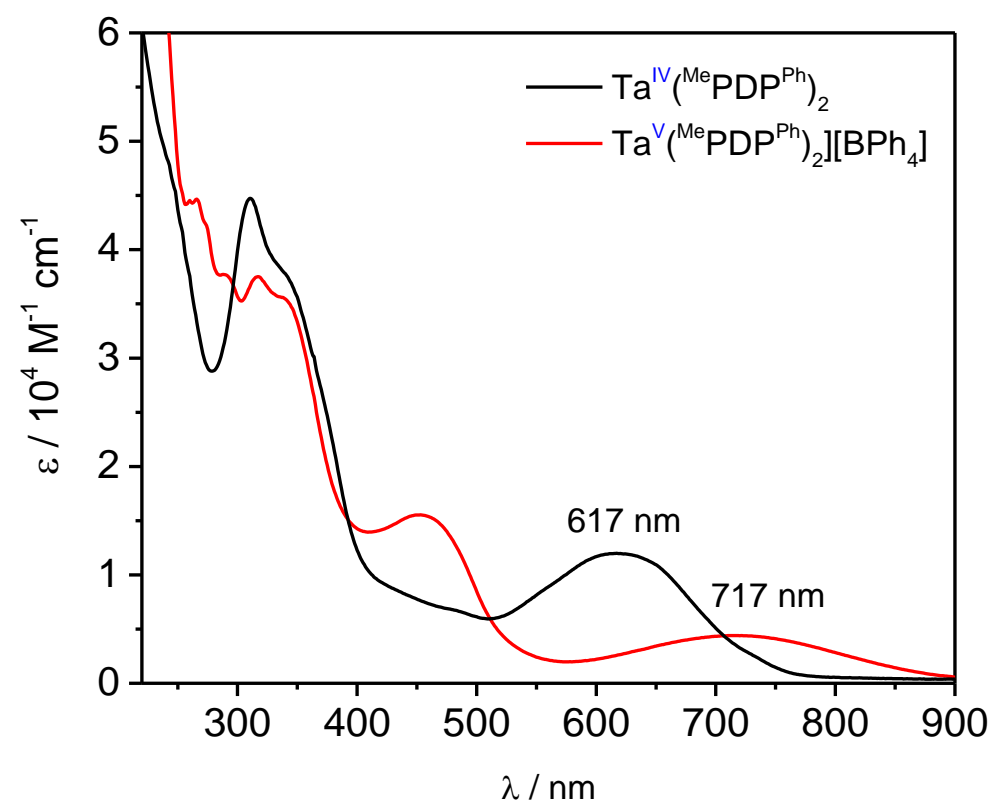

Figure 30. Absorption spectrum of $\mathrm{Ta}^{\mathrm{IV}}\left({ }^{\mathrm{Me}} \mathrm{PDP}^{\mathrm{Ph}}\right)_{2}$ and $\left[\mathrm{Ta}^{\mathrm{V}}\left({ }^{\mathrm{Me}} \mathrm{PDP}^{\mathrm{Ph}}\right)_{2}\right]^{+}$in $\mathrm{THF}$ solution at room temperature

The nature of the electronic transitions for $\left[\mathrm{Nb}^{\mathrm{V}}\left({ }^{\mathrm{Me}} \mathrm{PDP}^{\mathrm{Ph}}\right)_{2}\right]^{+}$and $\left[\mathrm{Ta}^{\mathrm{V}}\left({ }^{\mathrm{Me}} \mathrm{PDP}^{\mathrm{Ph}}\right)_{2}\right]^{+}$were established by time-dependent density functional theory (TD-DFT) calculations at the B3LYP level of theory. Analogous to $\mathrm{Zr}\left({ }^{\mathrm{Me}} \mathrm{PDP}^{\mathrm{Ph}}\right)_{2}$, the lowest lying absorption band in both complexes corresponds to a transition from an exclusively ligand centered $\pi$ orbital to a degenerate set of orbitals (e) with significant contributions from the metal $\left(\mathrm{d}_{\mathrm{xz}}, \mathrm{d}_{\mathrm{yz}}\right)$ and the pyridine rings of the ligands. The metal character of the acceptor orbitals was found to be $52 \%$ in the case of $\left[\mathrm{Nb}^{\mathrm{V}}\left({ }^{\mathrm{Me}} \mathrm{PDP}^{\mathrm{Ph}}\right)_{2}\right]^{+}$and $41 \%$ for $\left[\mathrm{Ta}^{\mathrm{V}}\left({ }^{\mathrm{Me}} \mathrm{PDP}^{\mathrm{Ph}}\right)_{2}\right]^{+}$in agreement with significant LMCT contributions. 
To investigate the potential for outer sphere electron transfer, cyclic voltammetry (CV) experiments were performed for stable $\mathrm{Nb}^{\mathrm{IV}}\left({ }^{\mathrm{Me}} \mathrm{PDP}^{\mathrm{Ph}}\right)_{2}$ and $\mathrm{Ta}^{\mathrm{IV}}\left({ }^{\mathrm{Me}} \mathrm{PDP}^{\mathrm{Ph}}\right)_{2}$ in THF using ferrocene, $\mathrm{Fc}^{+/ 0}$, as an internal standard (Figure 31). Interestingly, both compounds undergo multiple reductions at negative potentials. The $\mathrm{CV}$ of $\mathrm{Nb}^{\mathrm{IV}}\left({ }^{\mathrm{Me}} \mathrm{PDP}^{\mathrm{Ph}}\right)_{2}$ exhibits three fully reversible redox waves at $-0.40 \mathrm{~V},-1.58 \mathrm{~V}$, and $-2.65 \mathrm{~V}$ followed by a quasi-reversible redox event at $-2.97 \mathrm{~V}$. For $\mathrm{Ta}^{\mathrm{IV}}\left({ }^{\mathrm{Me}} \mathrm{PDP}^{\mathrm{Ph}}\right)_{2}$, reversible redox events were observed at $-1.69 \mathrm{~V}$ and $-2.57 \mathrm{~V}$ with a quasi-reversible feature at $-2.92 \mathrm{~V}$. The first reduction event can be tentatively assigned as a predominantly metal centered reduction to $\left[\mathrm{M}^{\mathrm{III}}\left({ }^{\mathrm{Me}} \mathrm{PDP}^{\mathrm{Ph}}\right)_{2}\right]^{1-}(\mathrm{M}=\mathrm{Nb}, \mathrm{Ta})$. The more negative potential for Ta is in agreement with the generally more difficult reduction of third vs. second row transition metals. The similar potentials for the second and third reduction events indicate primarily ligand centered reductions. Other than reductions, a fully reversible oxidation event at $-0.40 \mathrm{~V}$ was observed for $\mathrm{Nb}^{\mathrm{IV}}\left({ }^{\mathrm{Me}} \mathrm{PDP}^{\mathrm{Ph}}\right)_{2}$. On the other hand, an irreversible oxidation feature with peak potential of $-0.65 \mathrm{~V}$ can be found for $\mathrm{Ta}^{\mathrm{IV}}\left({ }^{\mathrm{Me}} \mathrm{PDP}^{\mathrm{Ph}}\right)_{2}$. Based on spin density calculations, the unpaired d electron for both neutral complexes $\mathrm{M}^{\mathrm{IV}}\left({ }^{\mathrm{Me}} \mathrm{PDP}^{\mathrm{Ph}}\right)_{2}(\mathrm{M}=\mathrm{Nb}$, Ta $)$ are clearly located at the metal center (Figure 32). Thus, these oxidation features are readily assigned as metal centered oxidations. The irreversibility for $\mathrm{Ta}(\mathrm{IV}) \rightarrow \mathrm{Ta}(\mathrm{V})$ event is in line with the NMR observed instability of the $\left[\mathrm{Ta}^{\mathrm{V}}\left({ }^{\mathrm{Me}} \mathrm{PDP}^{\mathrm{Ph}}\right)_{2}\right][\mathrm{BPh} 4]$ in solution. 

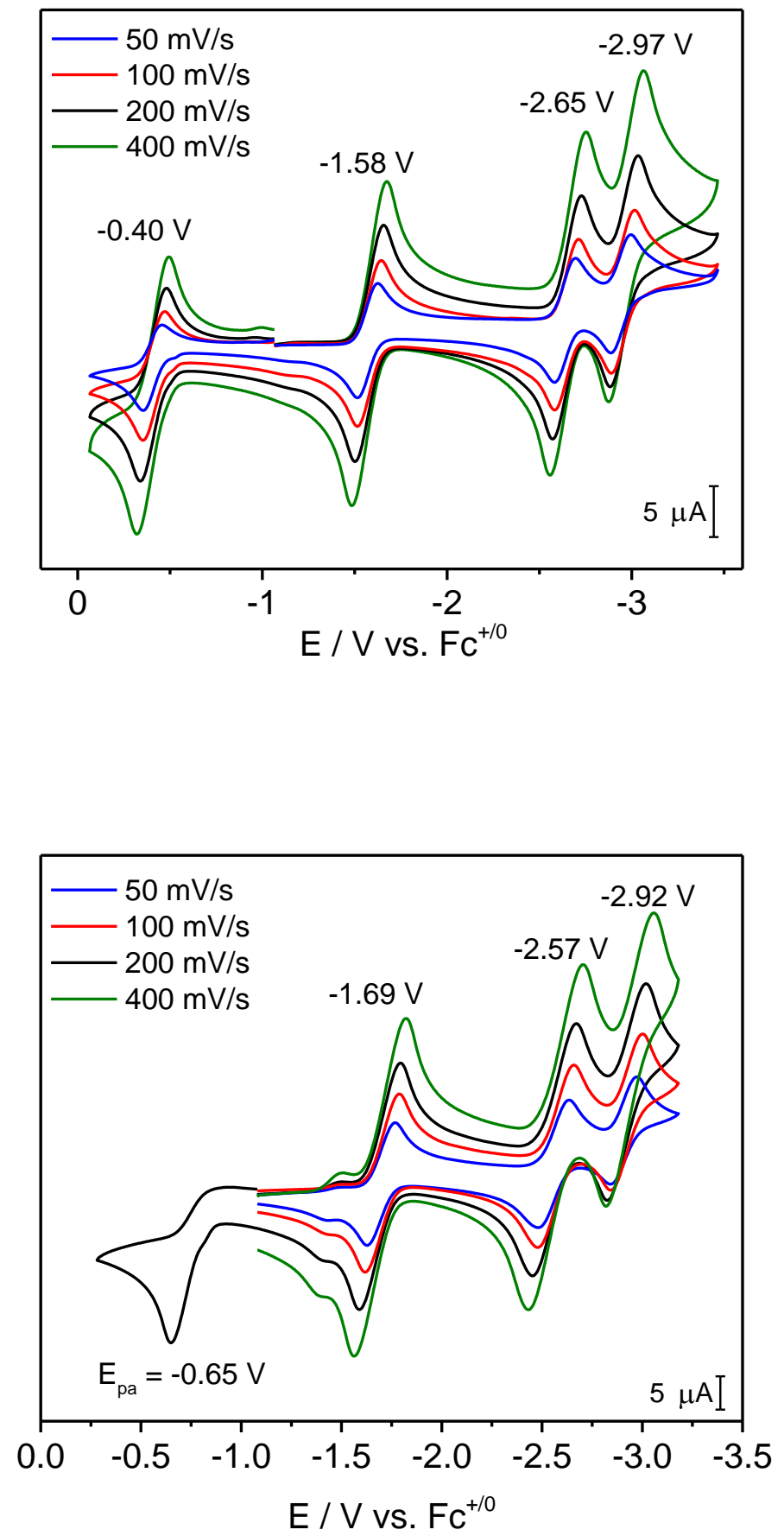

Figure 31. Cyclic voltammogram of $\mathrm{Nb}^{\mathrm{IV}}\left({ }^{\mathrm{Me}} \mathrm{PDP}^{\mathrm{Ph}}\right)_{2}$ (top) and $\mathrm{Ta}^{\mathrm{IV}}\left({ }^{\mathrm{Me}} \mathrm{PDP}^{\mathrm{Ph}}\right)_{2}$ (bottom) in $\mathrm{THF}$ at room temperature $\left(0.1 \mathrm{M}\left[\mathrm{N}(n-\mathrm{Bu})_{4}\right] \mathrm{PF}_{6}\right.$, glassy carbon working electrode). 

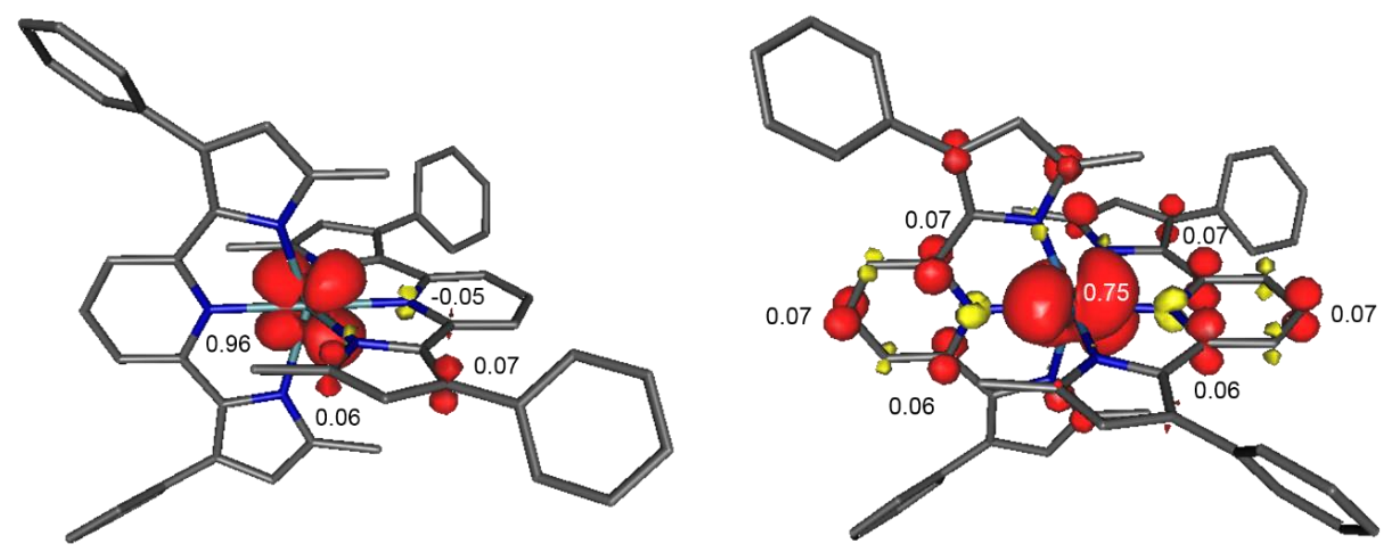

Figure 32. Spin density distribution for the ground states of $\mathrm{Nb}^{\mathrm{IV}}\left({ }^{\mathrm{Me}} \mathrm{PDP}^{\mathrm{Ph}}\right)_{2}$ (left) and $\mathrm{Ta}^{\mathrm{IV}}\left({ }^{\mathrm{Me}} \mathrm{PDP}^{\mathrm{Ph}}\right)_{2}$ (right) obtained via Mulliken population analysis.

\section{Experimental Section.}

General experimental considerations for material handling, physical measurements, X-ray crystallography, and DFT Calculations as well as additional experimental information can be found in the appendices.

Preparation of $\mathbf{N b}\left({ }^{\mathrm{Me}} \mathbf{P D P}{ }^{\mathrm{Ph}}\right)$ 2: $n$ - $\mathrm{BuLi}(1.00 \mathrm{~mL}$ (1.6 M solution in hexanes), $1.61 \mathrm{mmol}, 2.02$ equiv) was added slowly to a $20 \mathrm{~mL}$ vial charged with a solution of $\mathrm{H}_{2}{ }^{\mathrm{Me}} \mathrm{PDP}^{\mathrm{Ph}}(310 \mathrm{mg}, 0.796$ mmol, 1.00 equiv) in $5 \mathrm{~mL}$ of THF. The reaction was stirred for 2 hours at room temperature to generate a luminescent dark green-yellow solution of the deprotonated ligand. A solution of $\mathrm{NbCl}-$ $4(\mathrm{THF})_{2}(156 \mathrm{mg}, 0.414 \mathrm{mmol}, 0.52$ equiv) was added in small portions to the deprotonated ligand. The reaction mixture was allowed to stir at room temperature and the color of the solution slowly changed to dark green. After 24 hours, THF was removed in vacuo. The solid residue was washed three times with $\mathrm{Et}_{2} \mathrm{O}$. Then the crude product was dried in vacuo, redissolved in DCM, and filtered. 
Removal of the solvent in vacuo provided dark green solids (Yield: $185 \mathrm{mg}, 54 \%$ ). ${ }^{1} \mathrm{H}$ NMR (400 $\left.\mathrm{MHz}, \mathrm{CDCl}_{3} ; \delta, \mathrm{ppm}\right): 32.38$ (br, 12H, $\left.\mathrm{CH}_{3}\right), 27.45$ (br, 4H), 18.89 (s, 4H), 8.84 (t, $J=6.4 \mathrm{~Hz}$, 8H), $4.98(\mathrm{t}, J=6.8 \mathrm{~Hz}, 4 \mathrm{H}), 4.74(\mathrm{~d}, J=4.0 \mathrm{~Hz}, 8 \mathrm{H}),-36.66(\mathrm{br}, 2 \mathrm{H}$, para-PyH). Single crystals suitable for X-ray crystallographic analysis were grown by slow diffusion of $\mathrm{Et}_{2} \mathrm{O}$ into a THF solution of $\mathrm{Nb}\left({ }^{\mathrm{Me}} \mathrm{PDP}{ }^{\mathrm{Ph}}\right)_{2}$ at $-35^{\circ} \mathrm{C}$.

Preparation of Ta( $\left(^{\mathrm{Me} P D P}{ }^{\mathrm{Ph}}\right) 2: n-\mathrm{BuLi}(0.972 \mathrm{~mL}(1.6 \mathrm{M}$ solution in hexanes), $1.56 \mathrm{mmol}, 2.02$ equiv) was added slowly to a $20 \mathrm{~mL}$ vial charged with a solution of $\mathrm{H}_{2}{ }^{\mathrm{Me}} \mathrm{PDP}^{\mathrm{Ph}}$ (310 mg, 0.77 mmol, 1.00 equiv) in $5 \mathrm{~mL}$ of THF. The reaction was stirred for 2 hours at room temperature to generate a luminescent dark green-yellow solution of the deprotonated ligand. A solution of $\mathrm{TaCl}_{4}$ (tmeda) (176 mg, $0.401 \mathrm{mmol}, 0.52$ equiv) was added in small portions to the deprotonated ligand. The reaction mixture was allowed to stir at room temperature and the color of the solution slowly changed to blue-green. After 24 hours, THF was removed in vacuo. The solid residue was washed three times with benzene. Then the crude product was dried in vacuo, redissolved in DCM and filtered. Removal of the solvent in vacuo provided dark blue solids (Yield: $56 \mathrm{mg}, 15 \%$ ). ${ }^{1} \mathrm{H}$ NMR (400 MHz, $\left.\mathrm{CDCl}_{3} ; \delta, \mathrm{ppm}\right): 43.34\left(\mathrm{br}, 12 \mathrm{H}, \mathrm{CH}_{3}\right), 38.92$ (br, 4H), 23.80 (s, 4H), 9.58 (t, $J$ $=7.2 \mathrm{~Hz}, 8 \mathrm{H}), 3.78(\mathrm{t}, J=7.2 \mathrm{~Hz}, 4 \mathrm{H}), 3.37(\mathrm{~d}, J=7.2 \mathrm{~Hz}, 8 \mathrm{H}),-73.92(\mathrm{br}, 2 \mathrm{H}$, para-PyH$)$.

Synthesis of [ $\left.\mathbf{N b}^{\mathrm{V}}\left({ }^{\mathrm{MePDP}}{ }^{\mathrm{Ph}}\right)_{2}\right]\left[\mathrm{BArF}_{24}\right] . \mathrm{FcBArF}_{24}(58 \mathrm{mg}, 0.055 \mathrm{mmol}, 1.00$ equiv) was added to

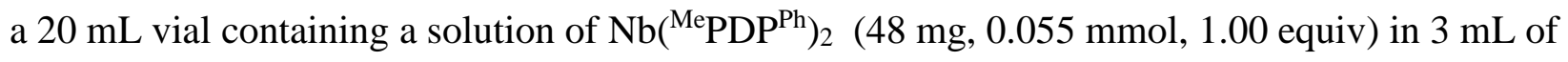
THF. The reaction was stirred for 30 mins at room temperature. After evaporation of THF, the 
crude product was washed with hexane. Then, the crude product was dried in vacuo, redissolved in $\mathrm{Et}_{2} \mathrm{O}$ and filtered. Concentration of $\mathrm{Et}_{2} \mathrm{O}$ solution in vacuum followed by a filtration provides desired product as brown crystalline soilds (Yield: $20 \mathrm{mg}, 21 \%$, one crop). ${ }^{1} \mathrm{H}$ NMR (400 MHz, $\left.\mathrm{CDCl}_{3} ; \delta, \mathrm{ppm}\right): 7.68(\mathrm{br}, 8 \mathrm{H}), 7.50-7.30(\mathrm{~m}, 26 \mathrm{H}), 7.01(\mathrm{~d}, J=8.0 \mathrm{~Hz}, 4 \mathrm{H}), 5.86(\mathrm{~s}, 4 \mathrm{H}$, pyrrole $H)$, $2.18\left(\mathrm{~s}, 12 \mathrm{H}, \mathrm{CH}_{3}\right) .{ }^{13} \mathrm{C} \mathrm{NMR}\left(101 \mathrm{MHz}, \mathrm{CDCl}_{3} ; \delta, \mathrm{ppm}\right): 161.81$ (q, $\left.J=49.4 \mathrm{~Hz}, \mathrm{BC}\right), 153.50$, $145.40,143.97,136.48,135.23,134.92,132.31,129.61,129.31,128.99\left(\mathrm{q},{ }^{2} J=28.7 \mathrm{~Hz}, \mathrm{~F}_{3} \mathrm{C}-C\right)$, $128.73,124.67\left(\mathrm{q},{ }^{1} J=271 \mathrm{~Hz}, \mathrm{~F}_{3} C\right), 117.56,115.56,113.66,14.97 .{ }^{19} \mathrm{~F}$ NMR $\left(376 \mathrm{MHz}, \mathrm{CDCl}_{3}\right.$; $\delta, \mathrm{ppm}$ ):-62.49. Single crystals suitable for X-ray crystallographic analysis were grown by slow evaporation of $\mathrm{Et}_{2} \mathrm{O}$ solution of $\left[\mathrm{Nb}^{\mathrm{V}}\left({ }^{\mathrm{Me}} \mathrm{PDP}^{\mathrm{Ph}}\right)_{2}\right]\left[\mathrm{BArF}_{24}\right]$.

Synthesis of [Ta $\left.{ }^{\mathrm{V}}\left({ }^{\mathrm{Me}} \mathbf{P D P}{ }^{\mathrm{Ph}}\right)_{2}\right]\left[\mathbf{B P h}_{4}\right] . \mathrm{FcBPh}_{4}(16 \mathrm{mg}, 0.031 \mathrm{mmol}, 1.00$ equiv) was added to a 20 $\mathrm{mL}$ vial containing a solution of $\mathrm{Nb}\left({ }^{\mathrm{Me}} \mathrm{PDP}^{\mathrm{Ph}}\right)_{2}(30 \mathrm{mg}, 0.031 \mathrm{mmol}, 1.00$ equiv) in $5 \mathrm{~mL}$ of THF. The reaction was stirred for 2 hours at room temperature. After evaporation of THF, the crude product was washed with pentane, $\mathrm{Et}_{2} \mathrm{O}$ and benzene. The product was collected as dark yellowgreen soilds (Yield: $26 \mathrm{mg}, 56 \%) .{ }^{1} \mathrm{H}$ NMR (400 MHz, $\mathrm{CDCl}_{3} ; \delta$, ppm): 7.52-7.34 (m, 26H), 7.12 (t, $J=7.6 \mathrm{~Hz}, 2 \mathrm{H}), 7.04-6.92(\mathrm{~m}, 12 \mathrm{H}), 6.81(\mathrm{t}, J=7.2 \mathrm{~Hz}, 4 \mathrm{H}), 5.94(\mathrm{~s}, 4 \mathrm{H}$, pyrrole $H), 2.19(\mathrm{~s}$, $\left.12 \mathrm{H}, \mathrm{CH}_{3}\right)$. 


\subsection{Reference.}

(1) Monro, S.; Colón, K. L.; Yin, H.; John Roque, I.; Konda, P.; Gujar, S.; Thummel, R. P.; Lilge, L.; Cameron, C. G.; McFarland, S. A. Chem. Rev. 2018, 119, 797.

(2) Mannhold, R. Molecular Drug Properties: Measurement and Prediction; Wiley-VCH Publishers.

(3) Malzkuhn, S.; Guo, X.; Häussinger, D.; Wenger, O. S. J. Phys. Chem. A 2019, 123, 96.

(4) Schmidt, H. C.; Larsen, C. B.; Wenger, O. S. Angew. Chemie - Int. Ed. 2018, 57, 6696.

(5) Wehlin, S. A. M.; Troian-Gautier, L.; Sampaio, R. N.; Marcélis, L.; Meyer, G. J. J. Am. Chem. Soc. 2018, 140, 7799.

(6) Troian-Gautier, L.; Turlington, M. D.; Wehlin, S. A. M.; Maurer, A. B.; Brady, M. D.; Swords, W. B.; Meyer, G. J. Chem. Rev. 2019, acs. chemrev.8b00732.

(7) Unoh, Y.; Hirano, K.; Satoh, T.; Miura, M. J. Org. Chem. 2013, 78, 5096.

(8) Tanaka, K.; Nagata, T. Bull. Chem. Soc. Jpn. 2002, 75, 2469.

(9) Takahashi, T.; Kotora, M.; Fischer, R.; Nishihara, Y.; Nakajima, K.; Takahashi, T. J. Am. Chem. Soc. 1995, 117, 11039.

(10) Burk, M. J.; Turnas, W.; Ward, M. D.; Wheeler, D. R. J. Am. Chem. Soc. 1990, 112, 6133.

(11) Tung, H.; Brubaker, C. H. J. Inorg. Chim. Acta 1981, 52, 197. 
(12) Czisch, P.; Erker, G. J. Organomet. Chem. 1983, 253, C9.

(13) Hart, D. W.; Blackburn, T. F.; Schwartz, J. J. Am. Chem. Soc. 1975, 97, 679.

(14) Erker, G.; Kropp, K.; Atwook, J. L.; Hunter, W. E. Organometallics 1983, 2, 1555. 


\section{Appendix A.}

\section{Additional Physical Measurement Results}

\section{A.1. General Considerations.}

\section{Material Handling.}

All air- and moisture-sensitive manipulations were carried out using standard Schlenk line and cannula techniques or in an MBraun inert atmosphere drybox containing an atmosphere of purified nitrogen. Solvents for air- and moisture-sensitive manipulations were dried and deoxygenated using a Glass Contour Solvent Purification System and stored over $4 \AA$ molecular sieves. All solids were dried under high vacuum, all liquids were dried over $\mathrm{CaH}_{2}$ and vacuum transferred into oven dried glassware in order to bring into the glovebox. High boiling substrates were degassed, dried over $\mathrm{CaH}_{2}$ and filtered through celite in the glovebox. Tetrabutylammonium hexafluorophosphate for electrochemical experiments was ground into a fine power and dried under vacuum at $150{ }^{\circ} \mathrm{C}$ for $48 \mathrm{~h}$ to remove any trace amounts of water. Deuterated solvents for NMR spectroscopy were distilled from sodium metal $\left(\mathrm{C}_{6} \mathrm{D}_{6}\right.$ and $\left.\mathrm{C}_{7} \mathrm{D}_{8}\right), \mathrm{CaH}_{2}\left(\mathrm{CD}_{2} \mathrm{Cl}_{2}\right.$ and $\left.\mathrm{CDCl}_{3}\right)$ or molecular sieve $\left(\mathrm{MeCN}-d_{3}\right)$. 


\section{Physical Measurements.}

Cyclic voltammetry measurements were conducted under nitrogen atmosphere inside an MBraun drybox using a Gamry Interface 1000 electrochemical workstation in a single compartment cell using $1 \mathrm{mM}$ sample solutions in THF or 1,2-difluorobenzene with $0.1 \mathrm{M}$ tetrabutylammonium hexafluorophosphate as supporting electrolyte. A three electrode setup was employed with a glassy carbon electrode as working electrode, a platinum sheet as the counter electrode and a silver wire as a quasi-reference electrode. Ferrocene was added as an internal standard after completion of the measurements and all potentials are referenced versus the $\mathrm{Fc}^{+} / \mathrm{Fc}$ couple. Continuous wave EPR spectra were recorded on an X-band Bruker EMX spectrometer equipped with an EMX standard resonator and a Bruker ER041XG microwave bridge. The spectra were simulated using EasySpin for MATLAB. ${ }^{1}$ High resolution mass spectra were obtained on a Thermo Finnigan Linear Trapping Quadrupole mass spectrometer. Elemental analyses were performed at Robertson Microlit Laboratories, Inc., in Ledgewood, NJ. Melting points were taken on a Mel-Temp ${ }^{\circledR}$ melting point apparatus.

Electronic absorption spectra were recorded using a Shimadzu UV-1800 spectrophotometer in gastight quartz cuvettes with a $10 \mathrm{~mm}$ path length fitted with J-Young valves. Extinction coefficients are reported with three significant figures. Emission spectra were obtained in $10 \mathrm{~mm}$ path length gastight quartz cuvettes with J-Young valves using a Shimadzu RF-5301 PC spectrofluorophotometer. Time-resolved emission data were collected using a Horiba Jobin Yvon 
Fluorolog-3 Spectrofluorometer equipped with a single photon counting module in multi-channel scaler mode and a $456 \mathrm{~nm}$ spectraLED pulsed excitation light source. Emission lifetimes were determined using the provided decay analysis software package, DAS v6.1.

\section{Photoluminescence Quantum Yield Determination.}

The photoluminescence quantum yield of all complexes described were determined via comparative method. ${ }^{2,3}$ Rhodamine $6 \mathrm{G}$ in ethanol $(\Phi=0.94)$ was used as a standard. ${ }^{4}$ For $\mathrm{Zr}\left({ }^{\mathrm{H}} \mathrm{PDP}^{\mathrm{H}}\right)_{2}$ in THF, Coumarin153 in ethanol $(\Phi=0.38)$ was used. ${ }^{5}$ The quantum yield was calculated by using the following equation:

$$
\Phi_{\mathrm{X}}=\Phi_{\mathrm{ST}}\left(\frac{\operatorname{Grad}_{\mathrm{X}}}{\operatorname{Grad}_{\mathrm{ST}}}\right)\left(\frac{\mathrm{n}_{\mathrm{X}}^{2}}{\mathrm{n}_{\mathrm{ST}}^{2}}\right)
$$

The subscripts X and ST stand for the sample and the standard, respectively. $\Phi$ is the photoluminescence quantum yield. Grad is the gradient from the plot of integrated photoluminescence intensity versus absorbance, and $\mathrm{n}$ is the refractive index of the solvent.

\section{Stern-Volmer Quenching Experiments.}

Samples for Stern-Volmer quenching experiments with quenchers were prepared individually in the drybox from stock solutions of zirconium photosensitizer and the corresponding quencher in THF. Emission intensities were obtained via numerical integration of the experimental 
spectra and Stern-Volmer plots generated using the absolute concentration of the quencher for the corresponding sample. The final concentration of zirconium photosensitizer for each measurement is almost identical to ensure the decrease in emission is caused by quencher. An electronic absorption spectrum was recorded for each sample after the luminescence measurement to confirm the integrity of the sample. Alternatively, the quenching effciency of a quencher could also monitered by time resolved emission measurement. The Stern-Volmer constant or quenching rate was calculated by using the following equation:

$$
\frac{I_{0}}{I_{x}}=1+k_{\mathrm{SV}} \times[\mathrm{Q}]=1+k_{q} \times \tau_{0} \times[\mathrm{Q}]
$$

The subscripts 0 and $x$ stand for the sample without quencher and the sample with quencher, respectively. I is the integrated photoluminescence emission intensity or lifetime value. [Q] is the absolute concentration of the quencher. $k_{\mathrm{Sv}}$ (Stern-Volmer constant) is the gradient from the plot of integrated photoluminescence intensity (or lifetime value) versus quencher concentration. Kq is the quenching rate, which can be obtained from $k_{\mathrm{Sv}}$ divide the original lifetime of the photosensitizer.

\section{Reference.}

(1) Stoll, S.; Schweiger, A. J. Magn. Reson. 2006, 178, 42.

(2) Würth, C.; Grabolle, M.; Pauli, J.; Spieles, M.; Resch-genger, U. Nat. Protoc. 2013, 8, 1535. 
(3) Brouwer, A. M. Pure Appl. Chem. 2011, 83, 2213.

(4) Fischer, M.; Georges, J. Chem. Phys. Lett. 1996, 260, 115.

(5) Jones II, G.; Jackson, W. R.; Choi, C. Y.; Bergmark, W. R. J. Phys. Chem. 1985, 89, 294. 


\section{A.2. Addition Data for Chapter 1.}

\section{Quenching Experiments}

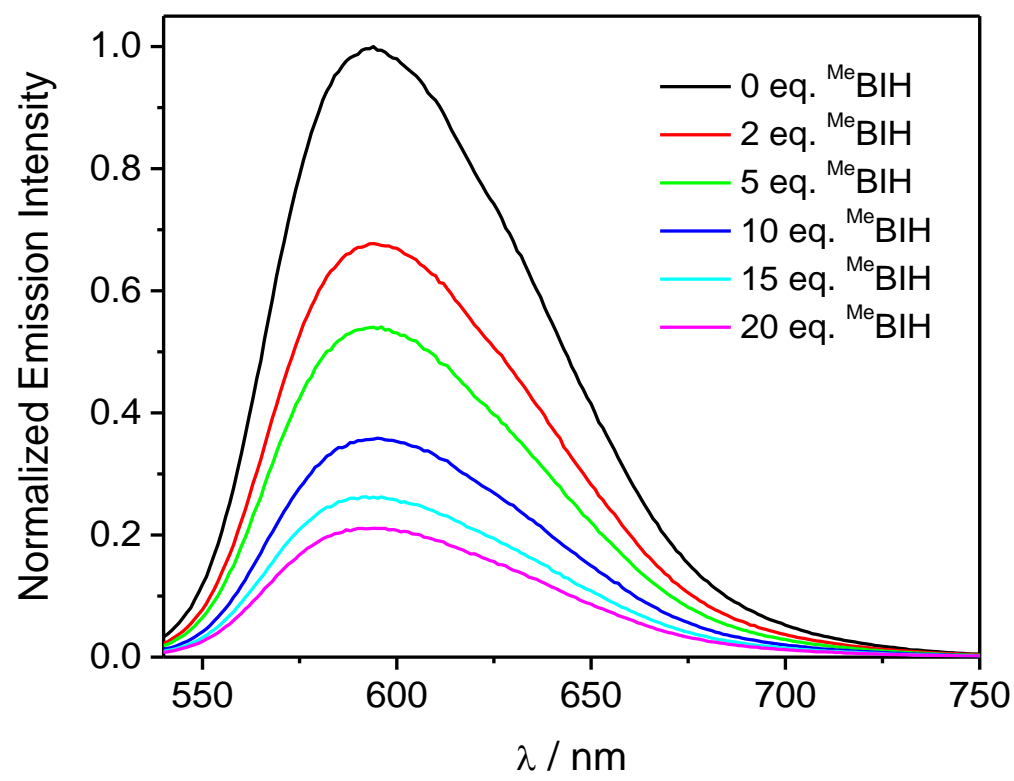

Figure A1. Emission spectra of $\mathrm{Zr}\left({ }^{\mathrm{Me}} \mathrm{PDP}{ }^{\mathrm{Ph}}\right)_{2}$ upon excitation at $527 \mathrm{~nm}$ in THF solution in the presence of varying amounts of ${ }^{\mathrm{Me}} \mathrm{BIH}$.

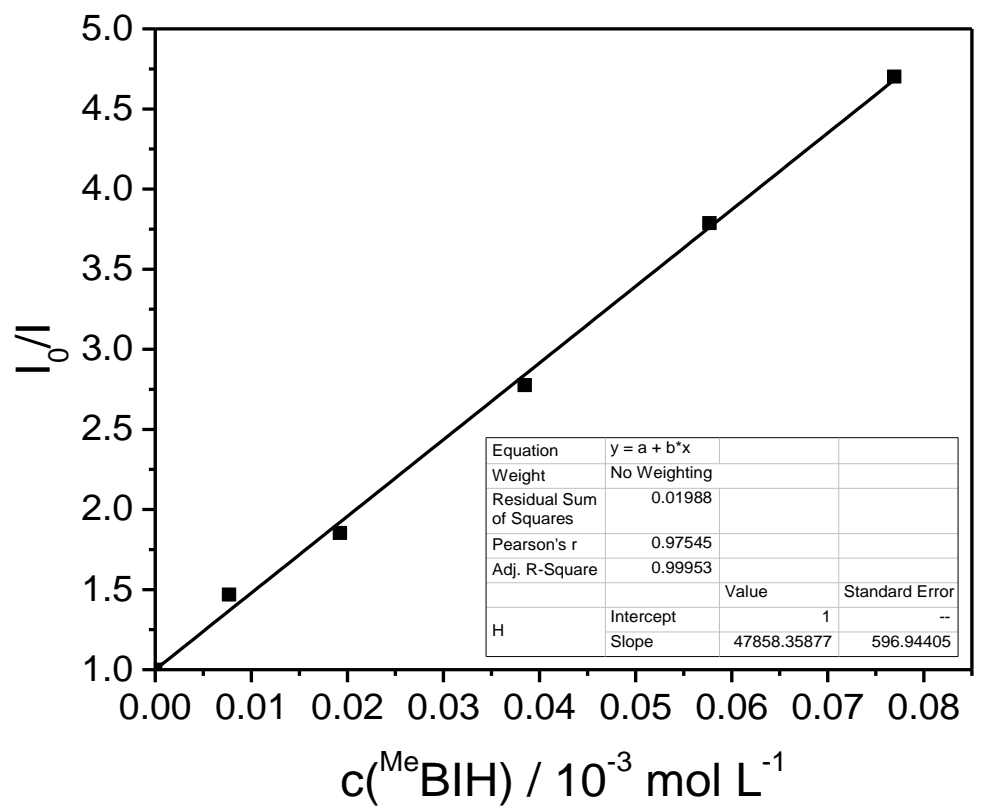

Figure A2. Stern-Volmer quenching of $\mathrm{Zr}\left({ }^{\mathrm{Me}} \mathrm{PDP}^{\mathrm{Ph}}\right)_{2}$ by ${ }^{\mathrm{Me}} \mathrm{BIH}$ in anhydrous THF under inert atmosphere. 


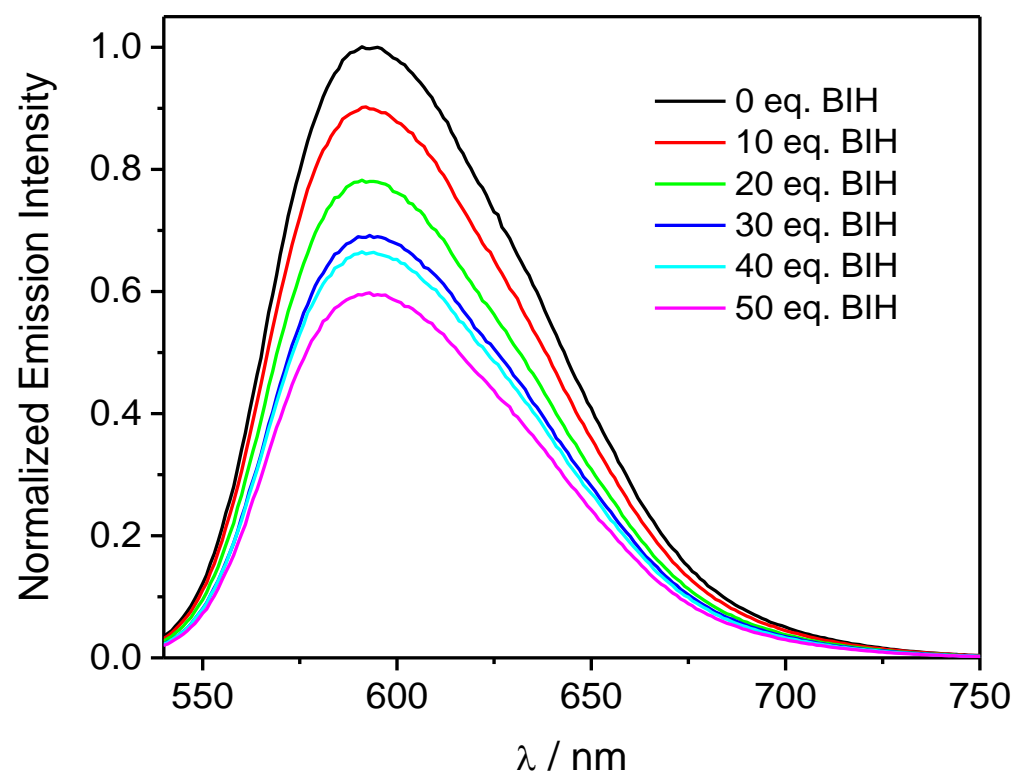

Figure A3. Emission spectra of $\mathrm{Zr}\left({ }^{\mathrm{Me}} \mathrm{PDP}{ }^{\mathrm{Ph}}\right)_{2}$ upon excitation at $527 \mathrm{~nm}$ in THF solution in the presence of varying amounts of BIH.

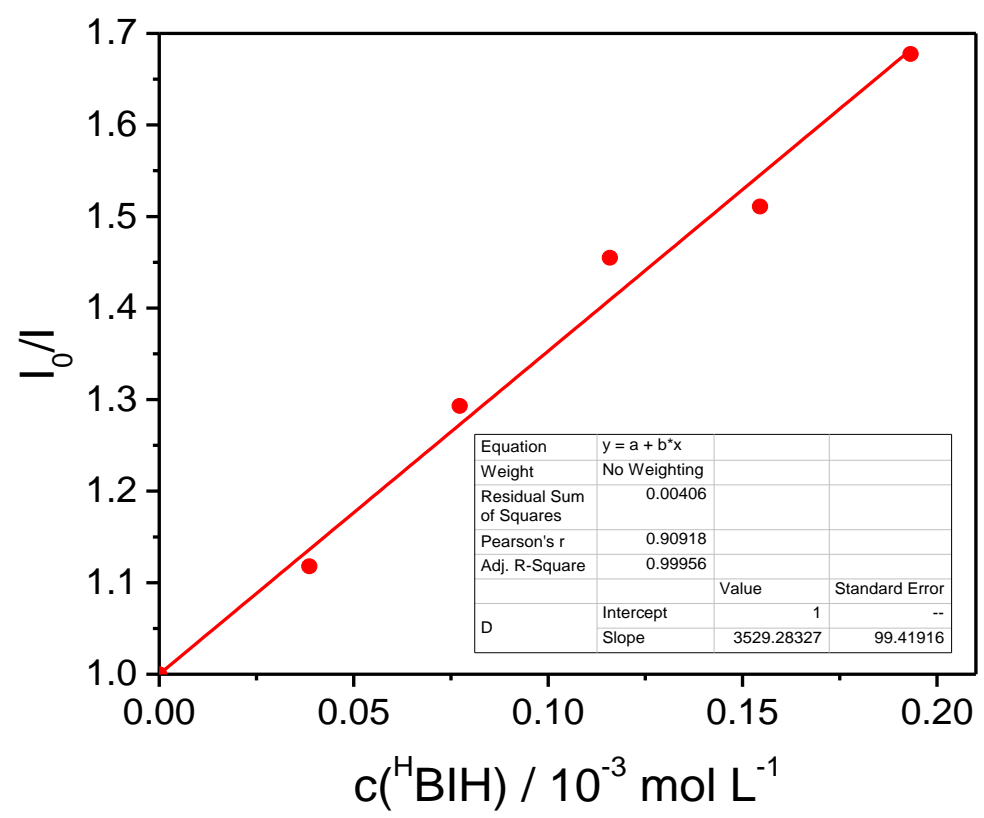

Figure A4. Stern-Volmer quenching of $\mathrm{Zr}\left({ }^{\mathrm{Me}} \mathrm{PDP}^{\mathrm{Ph}}\right)_{2}$ by $\mathrm{BIH}$ in anhydrous THF under inert atmosphere. 


\section{Experimental Setup for Photoredox Reactions.}

All photoredox experiments were performed using commercially available LED light strips with an emission maximum at $520 \mathrm{~nm}$. Constant room temperature conditions were maintained using a waterbath in a jacketed glass beaker with water cooling.

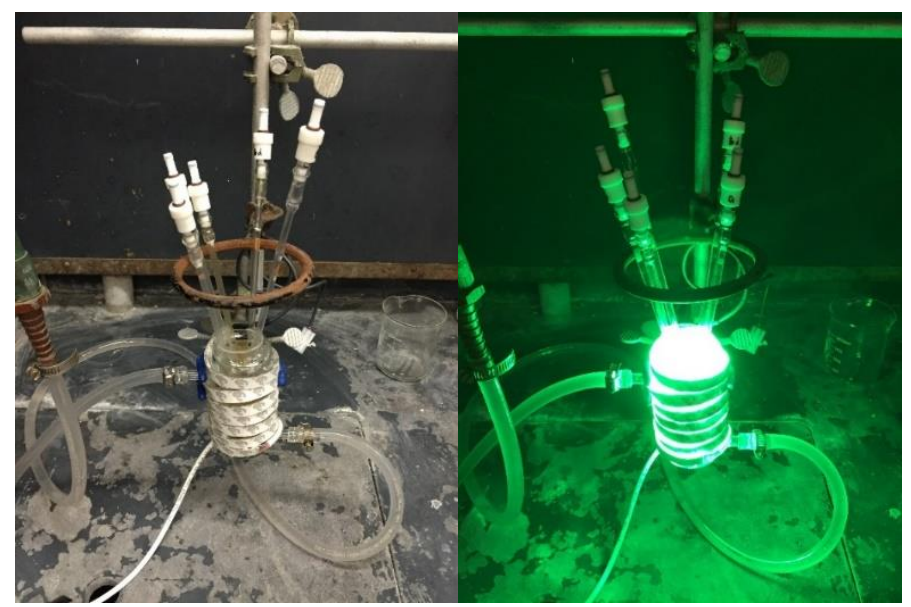

Figure A5. Experimental setup for irradiation of NMR tubes.

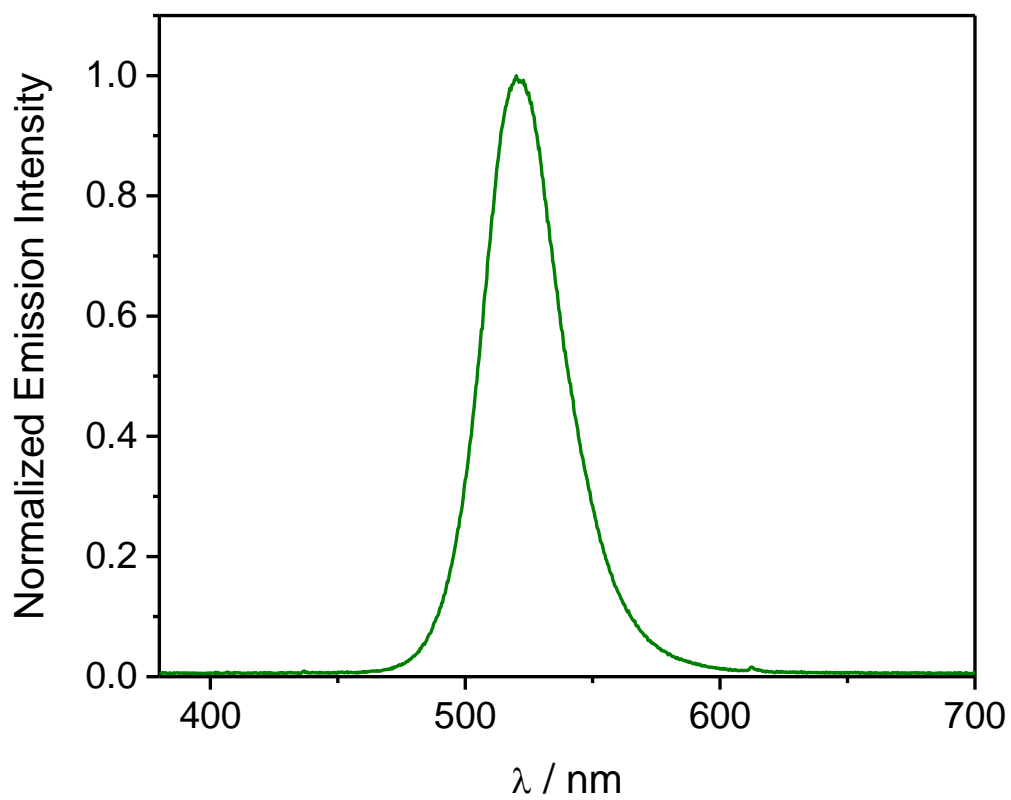

Figure A6. Emission profile of LED light strips used for photo-reactions $\left(\lambda_{\max }=520 \mathrm{~nm}\right)$. 


\section{A.3. Addition Data for Chapter 2.}

\section{Quenching Experiments}

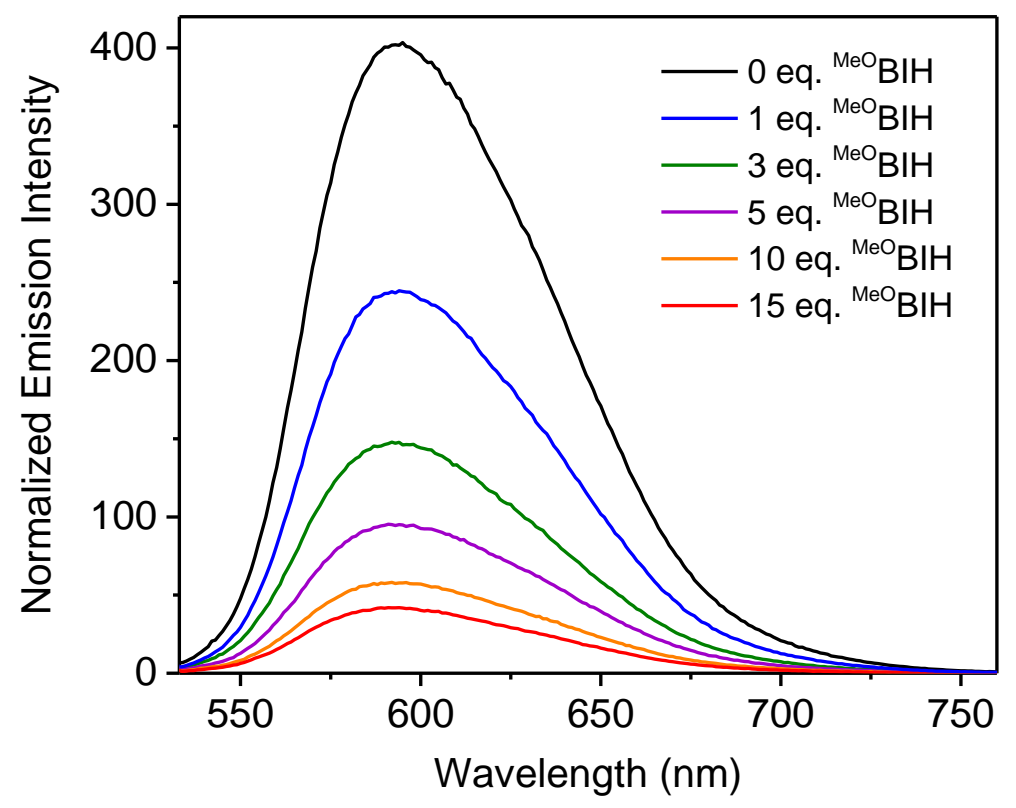

Figure A7. Emission spectra of $\mathrm{Zr}\left({ }^{\mathrm{Me}} \mathrm{PDP}^{\mathrm{Ph}}\right)_{2}$ in $\mathrm{THF}$ solution with varying amounts of ${ }^{\mathrm{MeO}} \mathrm{BIH}$.

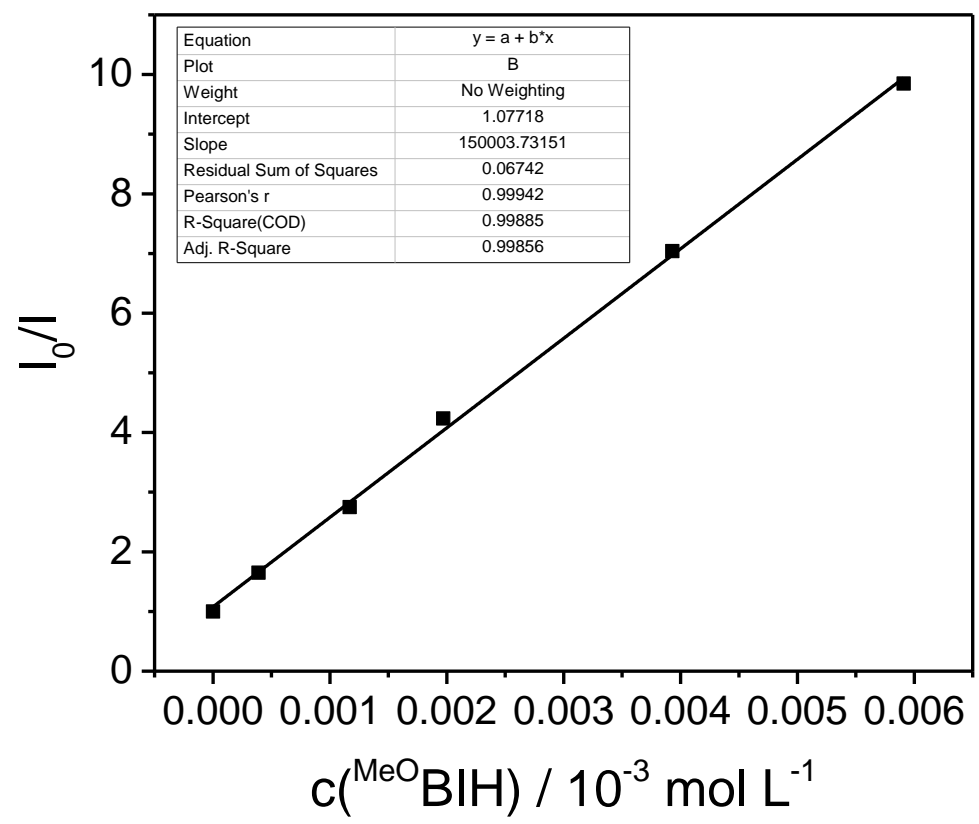

Figure A8. Stern-Volmer quenching of $\mathrm{Zr}\left({ }^{\mathrm{Me}} \mathrm{PDP}^{\mathrm{Ph}}\right)_{2}$ by ${ }^{\mathrm{MeO}} \mathrm{BIH}$ in anhydrous THF under $\mathrm{N}_{2}$. 

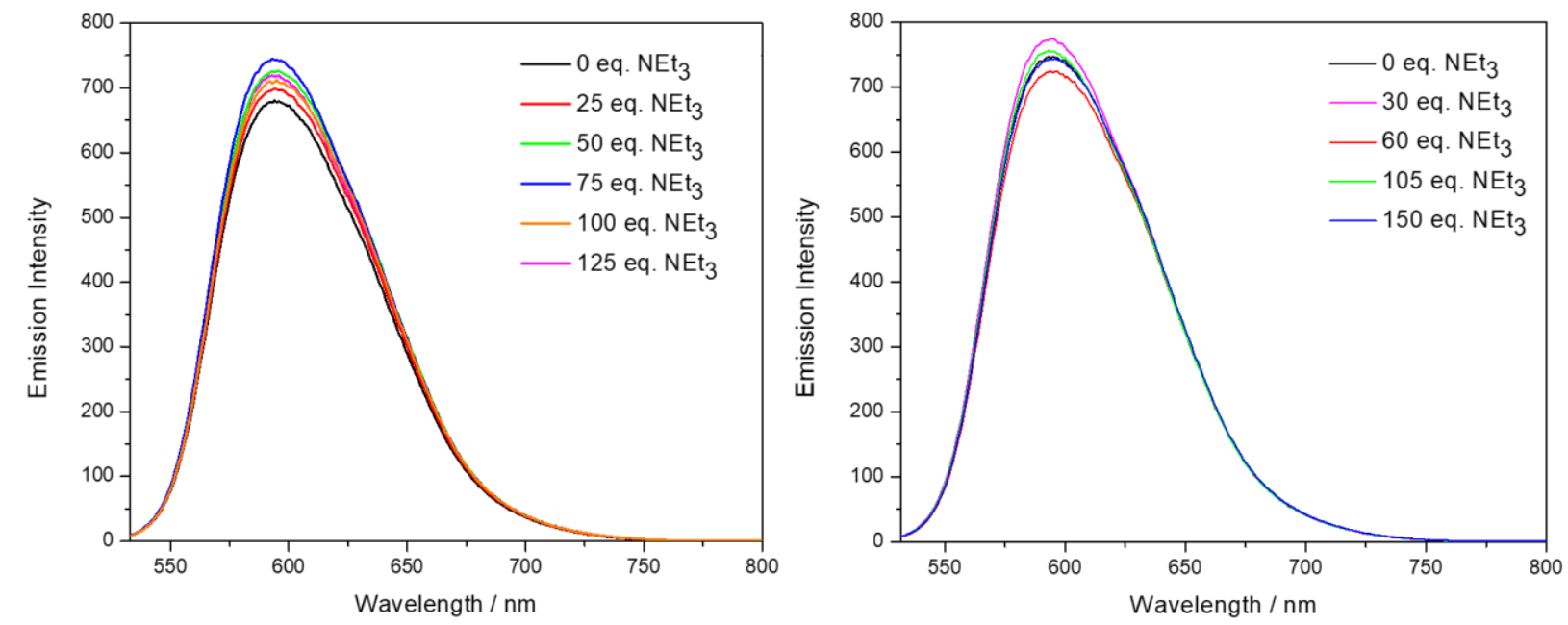

Figure A9. Emission spectra of $\mathrm{Zr}\left({ }^{\mathrm{Me}} \mathrm{PDP}^{\mathrm{Ph}}\right)_{2}$ upon excitation at $527 \mathrm{~nm}$ in THF solution in the presence of varying amounts of $\mathrm{NEt}_{3}$. The two graphs show the results of two independent series of experiments. Despite the visible changes in peak height between measurements, the overall difference in the integrated intensities is less than $2 \%$ and likely due to experimental errors.

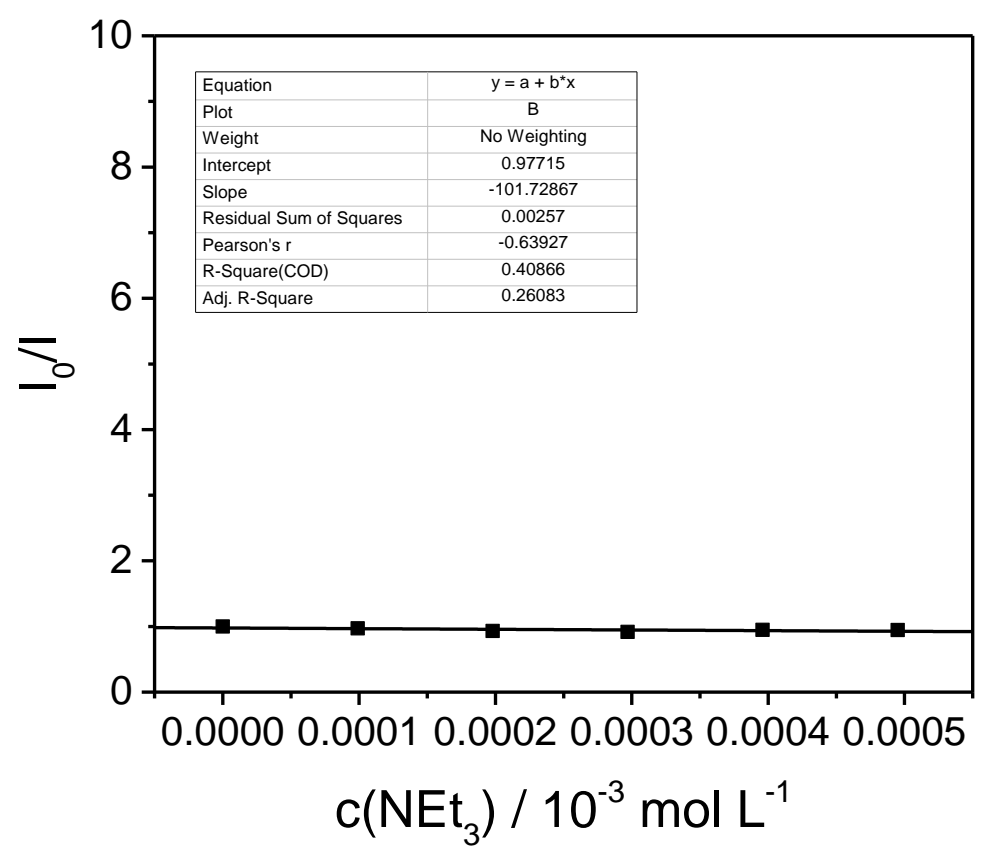

Figure A10. Stern-Volmer quenching of $\mathrm{Zr}\left({ }^{\mathrm{Me}} \mathrm{PDP}^{\mathrm{Ph}}\right)_{2}$ by $\mathrm{NEt}_{3}$ in anhydrous THF under inert atmosphere. 


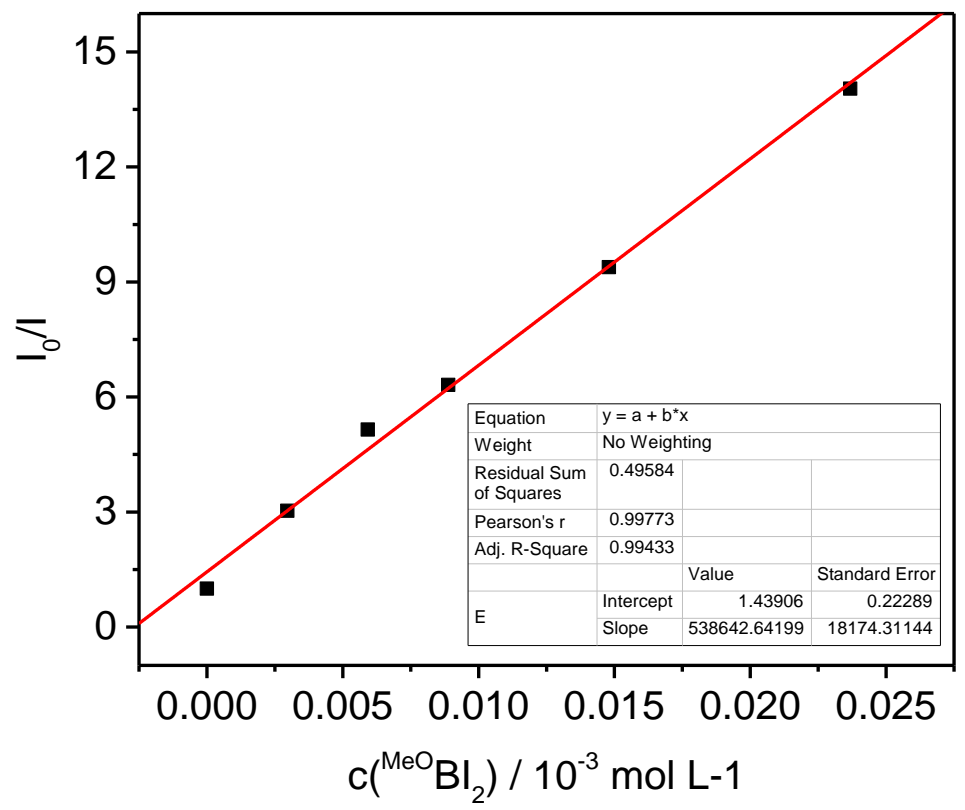

Figure A11. Stern-Volmer quenching of $\mathrm{Zr}\left({ }^{\mathrm{Me}} \mathrm{PDP}^{\mathrm{Ph}}\right)_{2}$ by ${ }^{\mathrm{MeO}} \mathrm{BI}_{2}$ in anhydrous THF under inert atmosphere. 


\section{A.4. Addition Data for Chapter 3.}

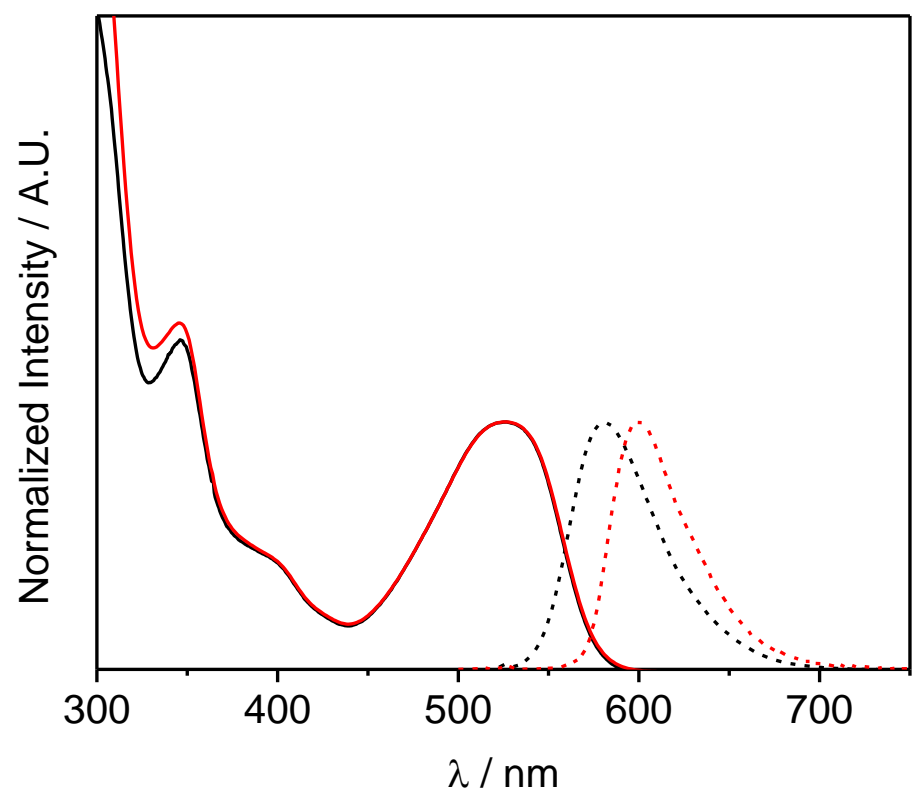

Figure A12. Absorption (solid lines) and emission spectra (dotted lines) of $\mathrm{Zr}\left({ }^{\mathrm{Mes} P D P}{ }^{\mathrm{Ph}}\right)_{2}$ in $\mathrm{THF}$ solution (black) under $\mathrm{N}_{2}$ and PMMA film under air (red) at room temperature.

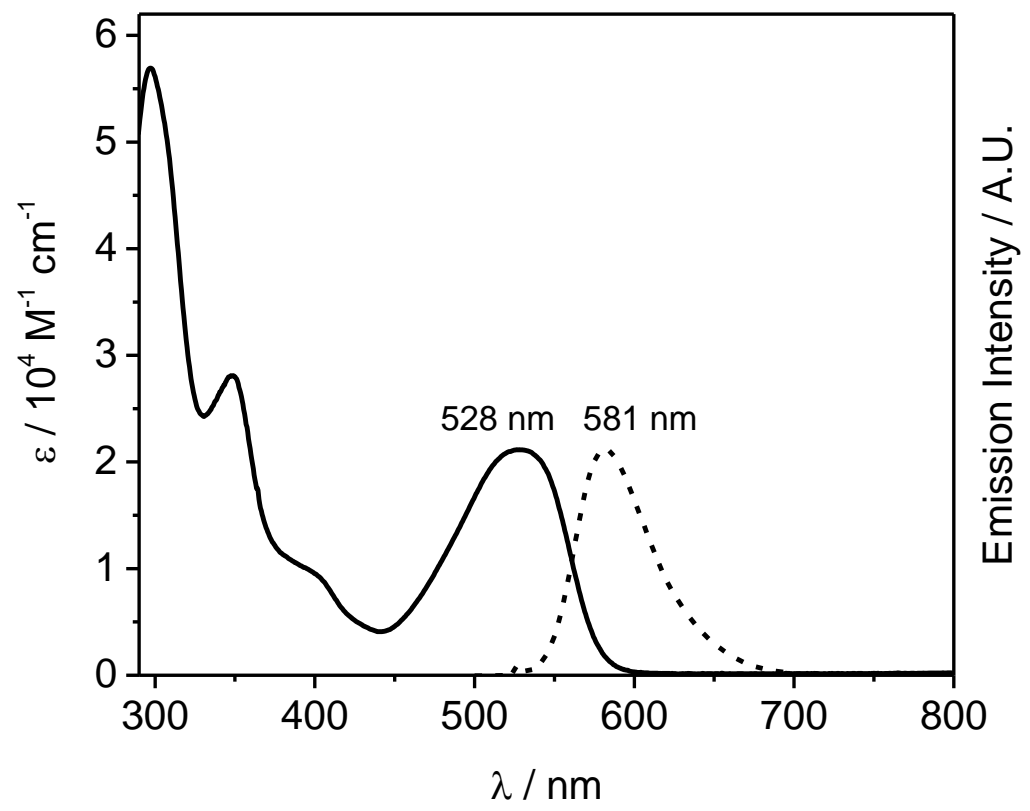

Figure A13. Absorption (solid lines) and emission spectra (dotted lines) of $\mathrm{Zr}\left({ }^{\mathrm{Mes}} \mathrm{PDP}{ }^{\mathrm{Ph}}\right)_{2}$ in benzene solution at room temperature. 


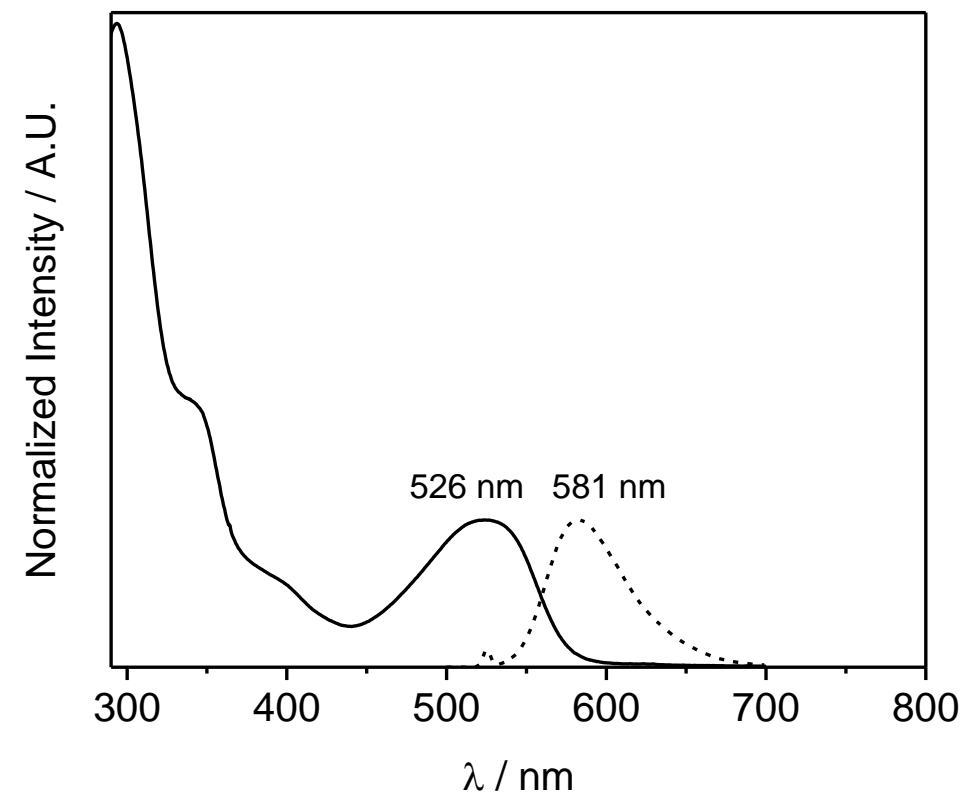

Figure A14. Absorption (solid lines) and emission spectra (dotted lines) of $\mathrm{Zr}\left({ }^{\mathrm{Mes}} \mathrm{PDP}^{\mathrm{Ph}}\right)_{2}$ in DMSO solution at room temperature.

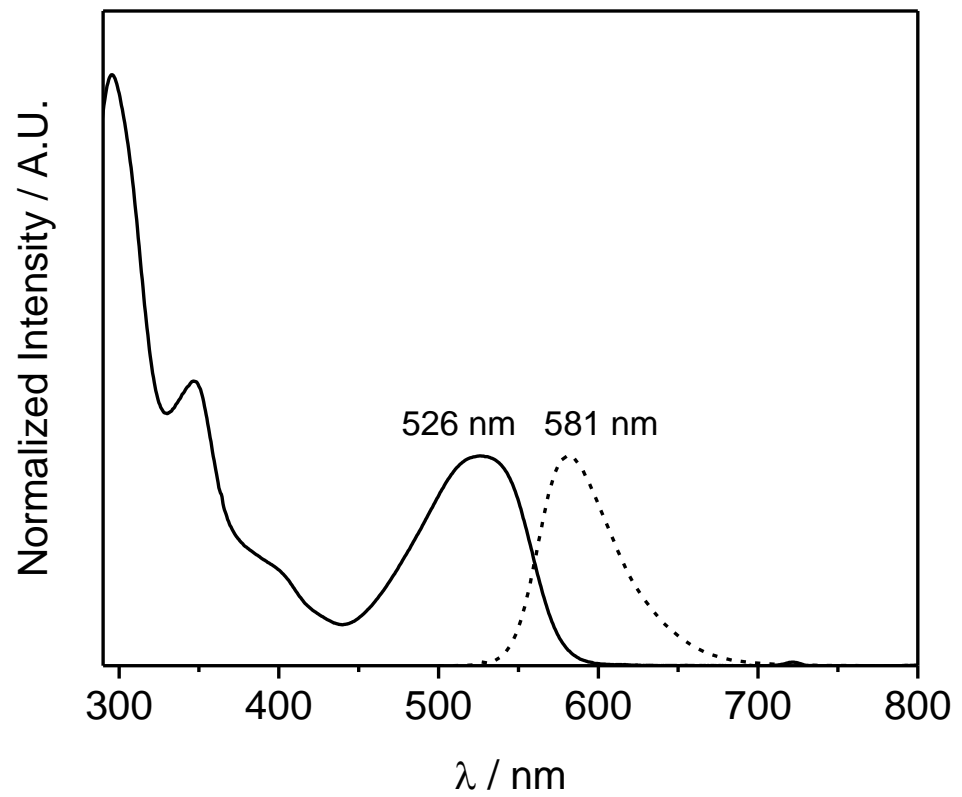

Figure A15. Absorption (solid lines) and emission spectra (dotted lines) of $\mathrm{Zr}\left({ }^{\mathrm{Mes}} \mathrm{PDP}^{\mathrm{Ph}}\right)_{2}$ in $\mathrm{DCM}$ solution at room temperature. 


\section{Photoluminescence Quantum Yield Determination}

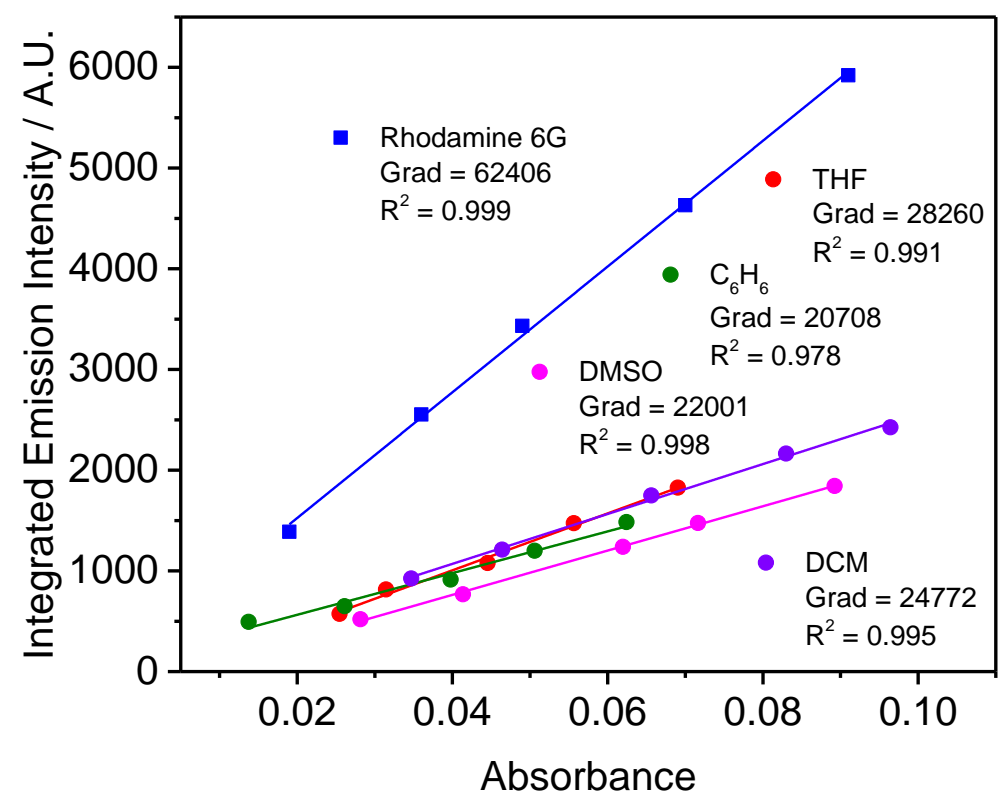

Figure A16. Plot of absorbance at $488 \mathrm{~nm}$ versus integration of the emission spectrum for Rhodamine 6G in ethanol $(\Phi=0.94), \mathrm{Zr}\left({ }^{\mathrm{Mes} P D P}{ }^{\mathrm{Ph}}\right)_{2}(\Phi=0.45)$ in THF, $\mathrm{Zr}\left({ }^{\mathrm{Mes}} \mathrm{PDP}^{\mathrm{Ph}}\right)_{2}(\Phi=0.38)$ in benzene, $\mathrm{Zr}\left({ }^{\mathrm{Mes} P D P}{ }^{\mathrm{Ph}}\right)_{2}(\Phi=0.41)$ in $\mathrm{DCM}$ and $\mathrm{Zr}\left({ }^{\mathrm{Mes}} \mathrm{PDP}^{\mathrm{Ph}}\right)_{2}(\Phi=0.39)$ in DMSO. The lines represent linear fits of the data and the gradients used for the quantum yield determination is shown next to the corresponding fit. 


\section{Fit of Time-Resolved Emission Data}

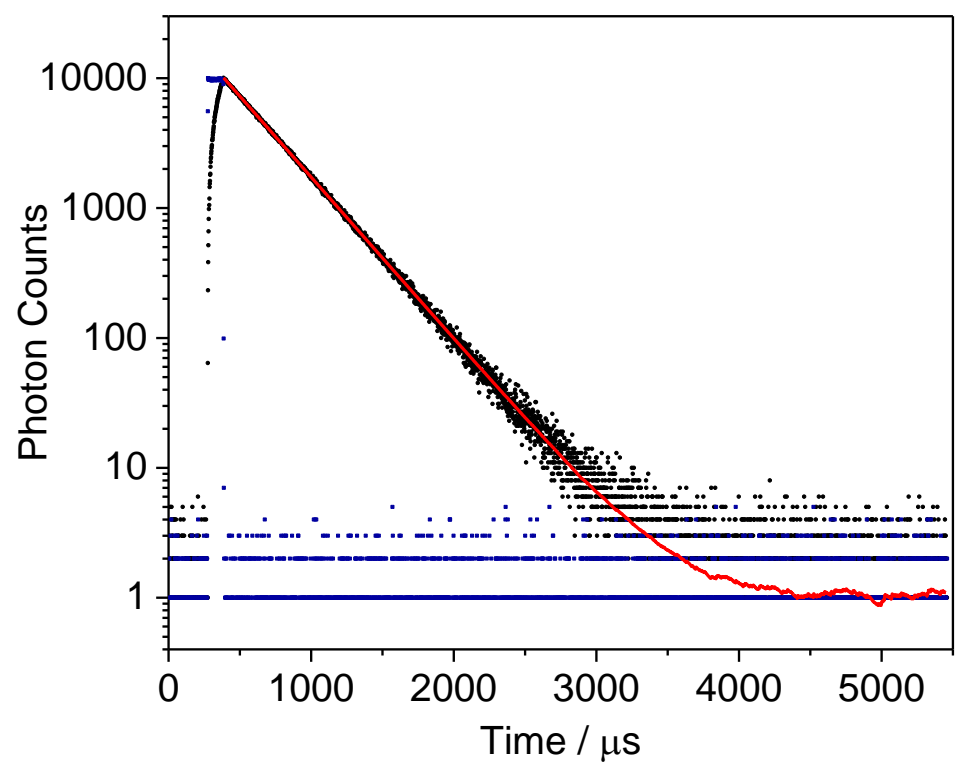

Figure A17. Representative example for time-resolved emission data for $\mathrm{Zr}\left({ }^{\mathrm{Mes}} \mathrm{PDP}{ }^{\mathrm{Ph}}\right)_{2}$ in $\mathrm{THF}$ at room temperature (black) detected at $580 \mathrm{~nm}$ upon excitation at $516 \mathrm{~nm}$. The red line shows the fit to a single-exponential decay with $\tau=350 \mu$ s and the navy trace is the excitation pulse.

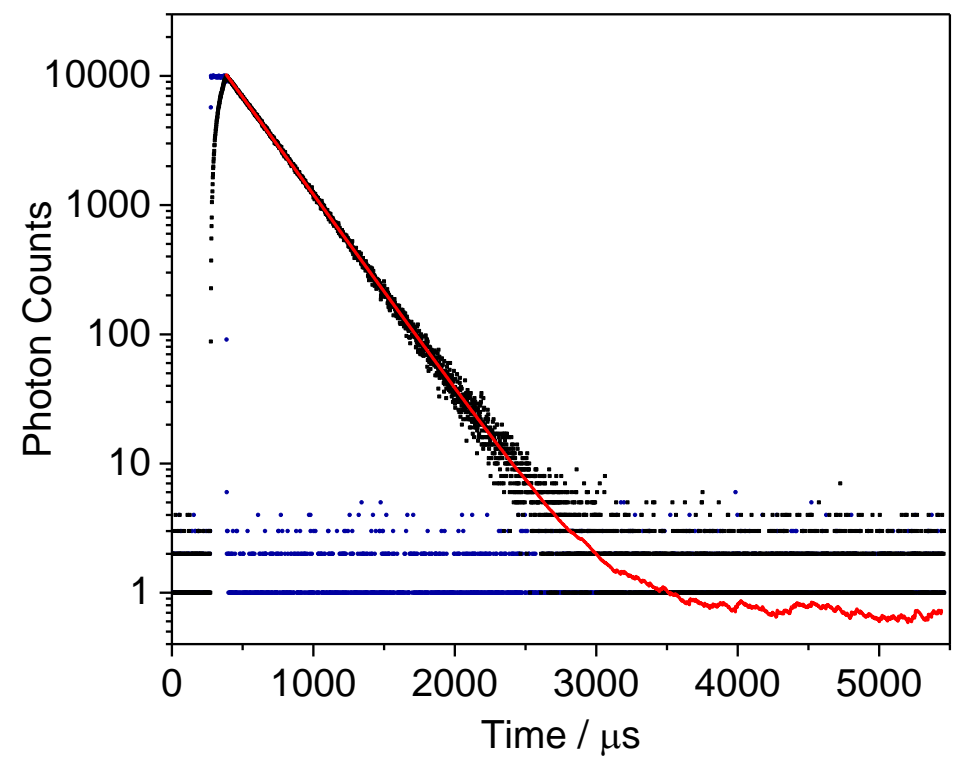

Figure A18. Representative example for time-resolved emission data for $\mathrm{Zr}\left({ }^{\mathrm{Mes} P D P}{ }^{\mathrm{Ph}}\right)_{2}$ in benzene at room temperature (black) detected at $581 \mathrm{~nm}$ upon excitation at $516 \mathrm{~nm}$. The red line shows the fit to a single-exponential decay with $\tau=290 \mu$ s and the navy trace shows the excitation pulse. 


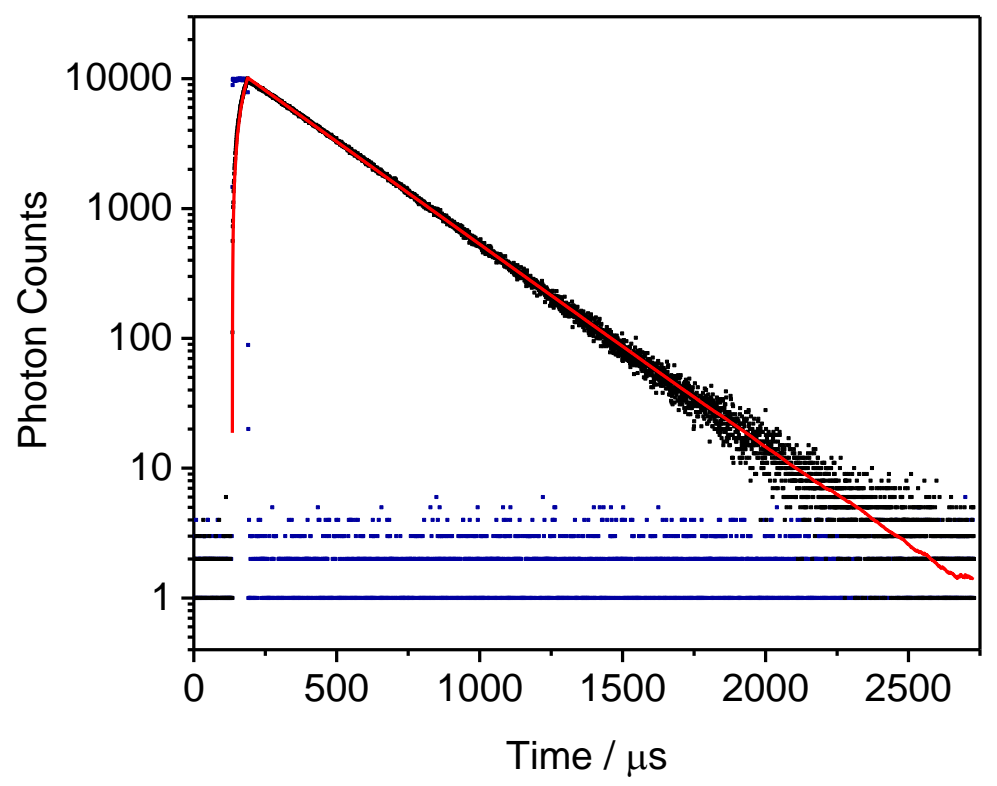

Figure A19. Representative example for time-resolved emission data for $\mathrm{Zr}\left({ }^{\mathrm{Mes}} \mathrm{PDP}{ }^{\mathrm{Ph}}\right)_{2}$ in DMSO at room temperature (black) detected at $610 \mathrm{~nm}$ upon excitation at $516 \mathrm{~nm}$. The red line shows the fit to a single-exponential decay with $\tau=270 \mu$ s and the navy trace shows the excitation pulse.

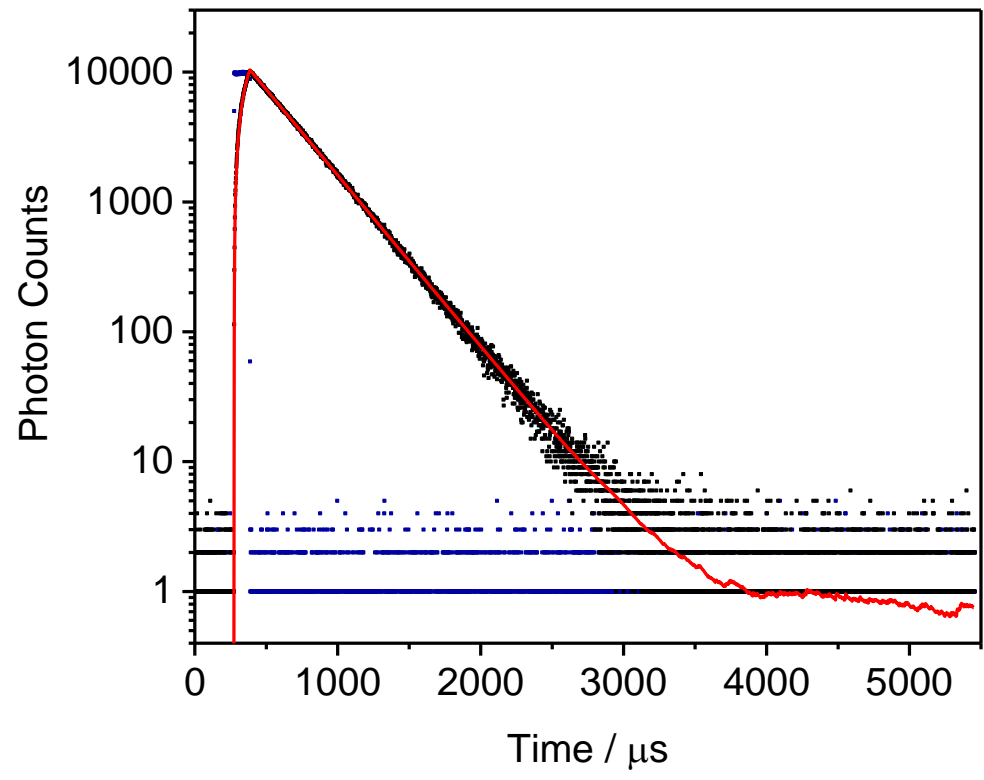

Figure A20. Representative example for time-resolved emission data for $\mathrm{Zr}\left({ }^{\mathrm{Mes} P D P}{ }^{\mathrm{Ph}}\right)_{2}$ in $\mathrm{DCM}$ at room temperature (black) detected at $610 \mathrm{~nm}$ upon excitation at $516 \mathrm{~nm}$. The red line shows the fit to a single-exponential decay with $\tau=330 \mu$ s and the navy trace shows the excitation pulse. 


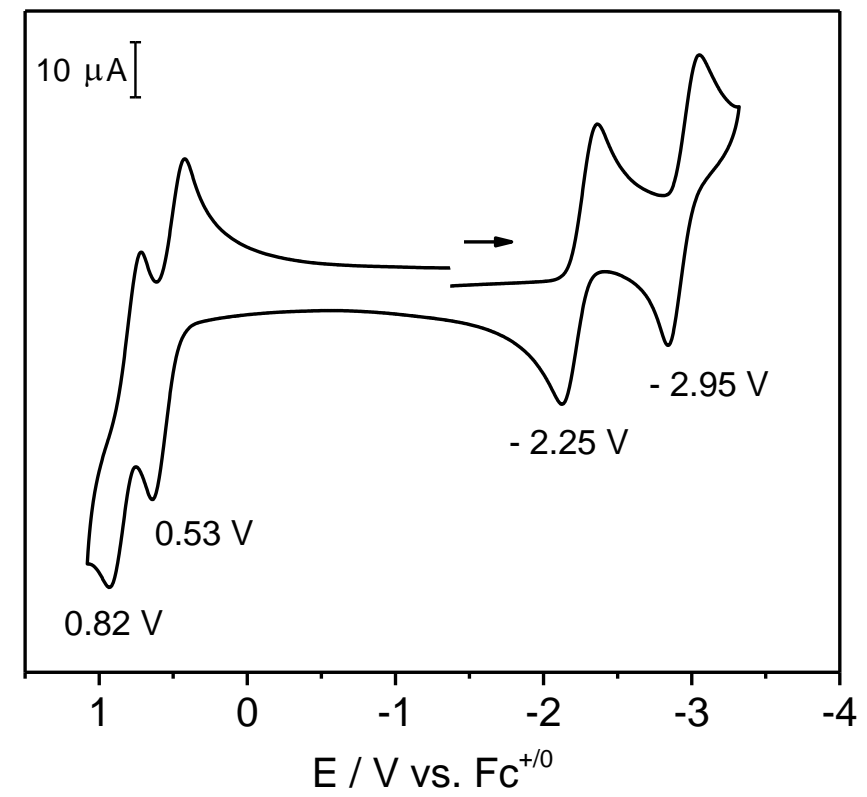

Figure A21. Cyclic voltammogram of $\mathrm{Zr}\left({ }^{\mathrm{Mes}} \mathrm{PDP}^{\mathrm{Ph}}\right)_{2}$ in $\mathrm{THF}$ at room temperature (scan rate 200 $\mathrm{mV} \mathrm{s}^{-1}, 0.1 \mathrm{M}\left[\mathrm{N}(n-\mathrm{Bu})_{4}\right] \mathrm{PF}_{6}$, glassy carbon working electrode).

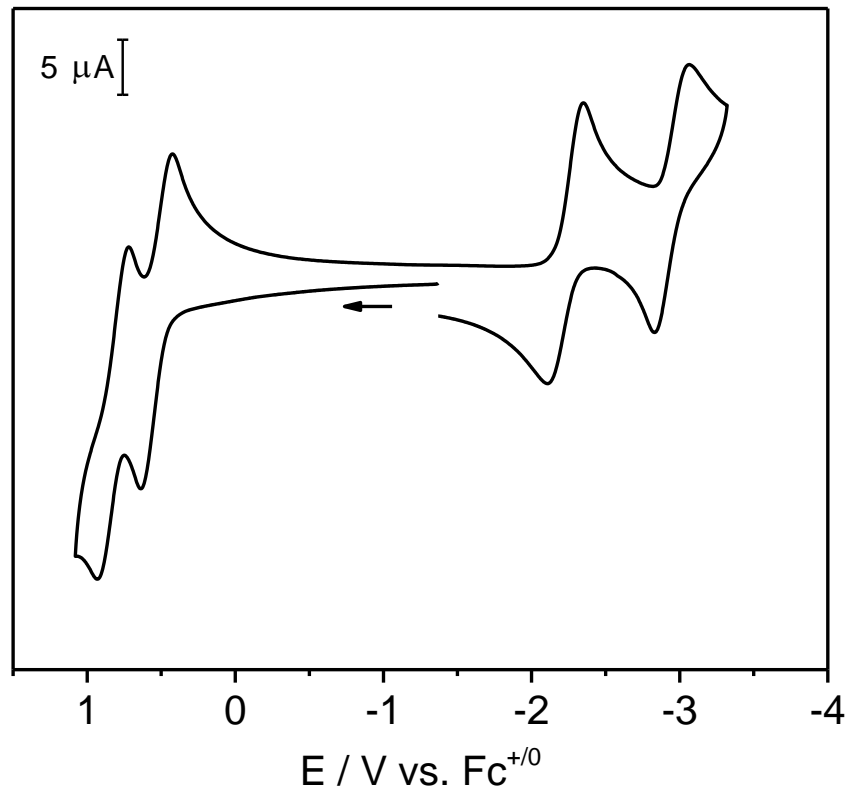

Figure A22. Cyclic voltammogram of $\mathrm{Zr}\left({ }^{\mathrm{Mes}} \mathrm{PDP}^{\mathrm{Ph}}\right)_{2}$ in $\mathrm{THF}$ at room temperature (scan rate 200 $\mathrm{mV} \mathrm{s}^{-1}, 0.1 \mathrm{M}\left[\mathrm{N}(n-\mathrm{Bu})_{4}\right] \mathrm{PF}_{6}$, glassy carbon working electrode). 


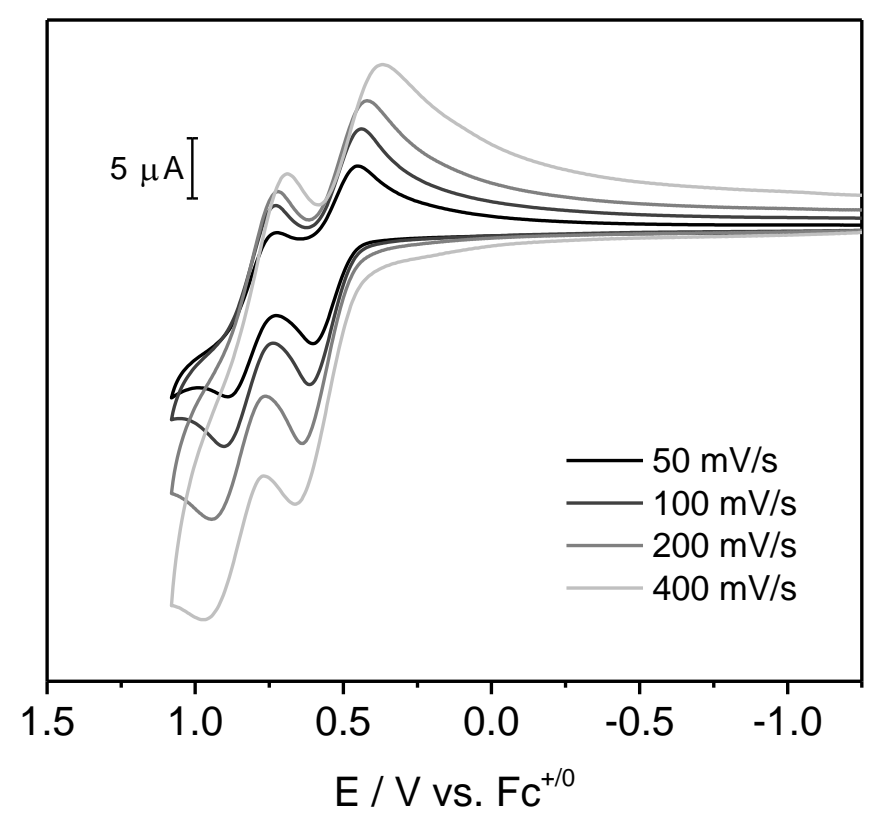

Figure A23. Cyclic voltammogram of $\mathrm{Zr}\left({ }^{\mathrm{Mes}} \mathrm{PDP} \mathrm{P}^{\mathrm{Ph}}\right)_{2}$ in $\mathrm{THF}$ at room temperature at different scan rates $\left(0.1 \mathrm{M}\left[\mathrm{N}(n-\mathrm{Bu})_{4}\right] \mathrm{PF}_{6}\right.$, glassy carbon working electrode).

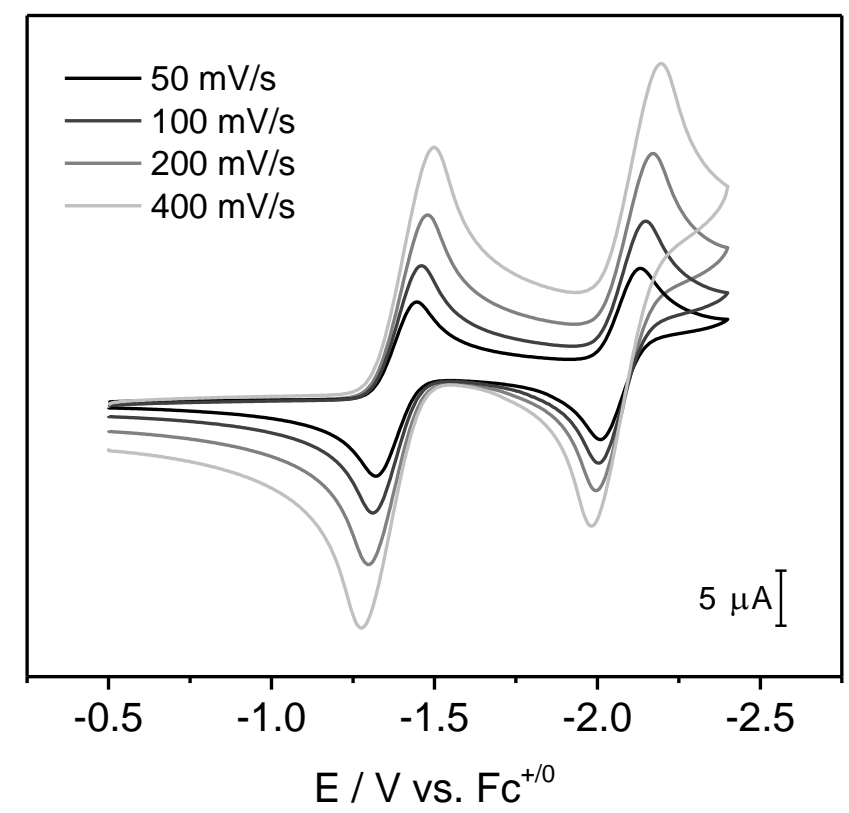

Figure A24. Cyclic voltammogram of $\mathrm{Zr}\left({ }^{\mathrm{Mes}} \mathrm{PDP} \mathrm{P}^{\mathrm{Ph}}\right)_{2}$ in $\mathrm{THF}$ at room temperature at different scan rates $\left(0.1 \mathrm{M}\left[\mathrm{N}(n-\mathrm{Bu})_{4}\right] \mathrm{PF}_{6}\right.$, glassy carbon working electrode). 


\section{Quenching Experiments}
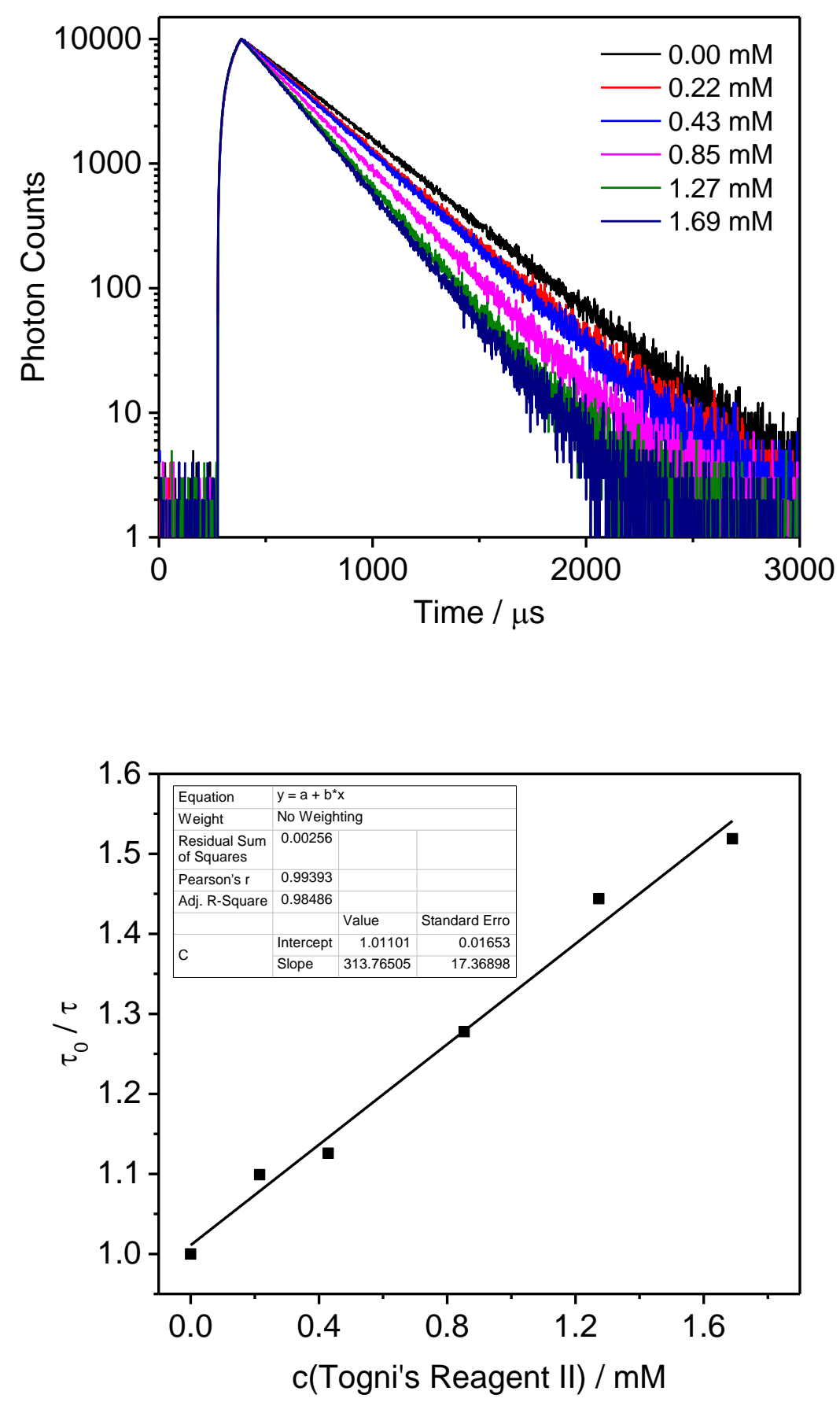

Figure A25. Quenching of $\mathrm{Zr}\left({ }^{\mathrm{Mes}} \mathrm{PDP}^{\mathrm{Ph}}\right)_{2}$ by Togni's reagent II in THF. $\lambda_{\mathrm{ex}}=516 \mathrm{~nm}, \lambda_{\mathrm{em}}=580$ nm. Top: Time-resolved luminescence decays at different Togni's reagent II concentration. Bottom: Stern-Volmer analyses. 

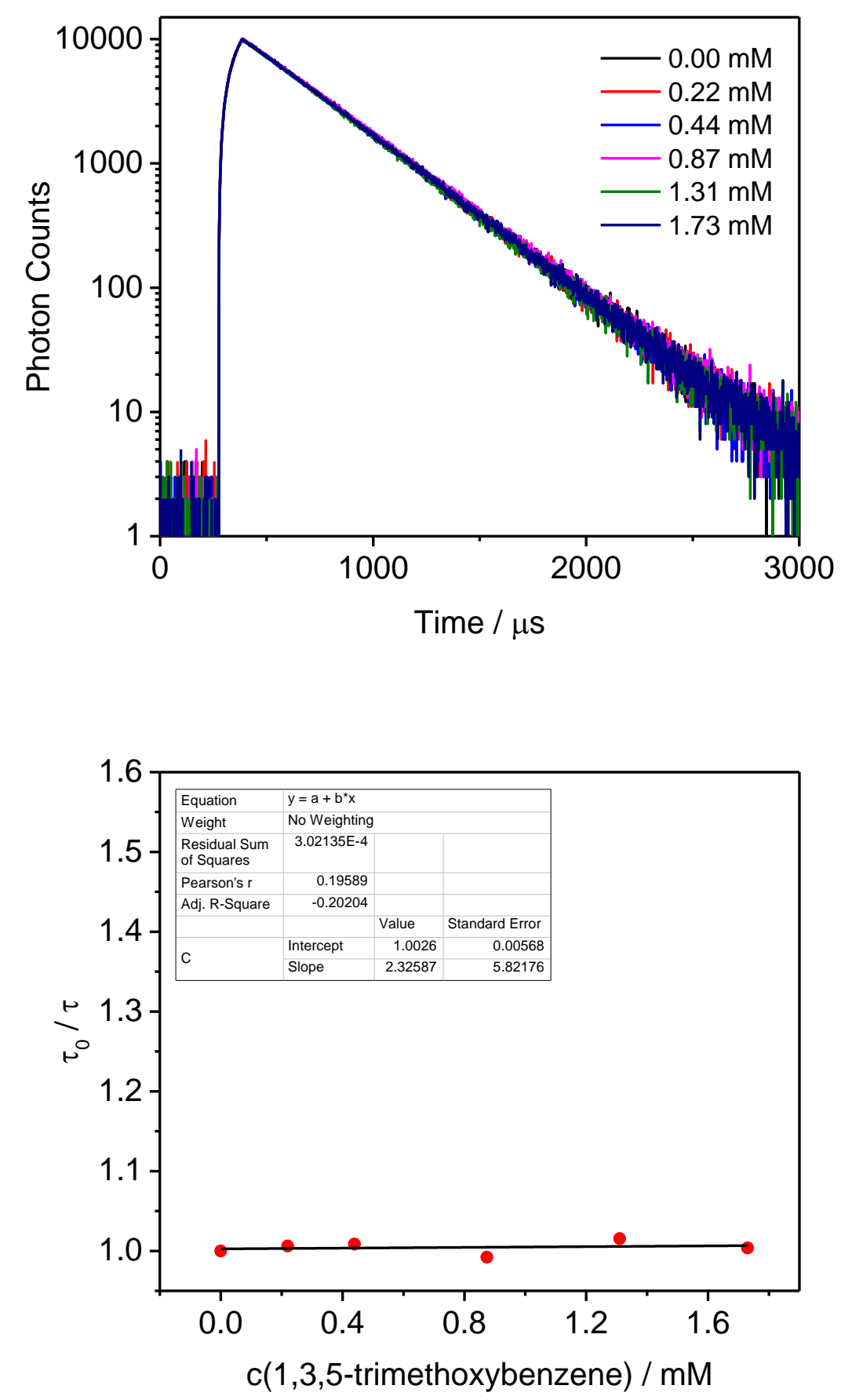

Figure A26. Quenching of $\mathrm{Zr}\left({ }^{\mathrm{Mes}} \mathrm{PDP}^{\mathrm{Ph}}\right)_{2}$ by 1,3,5-trimethoxybenzene in THF. $\lambda_{\mathrm{ex}}=516 \mathrm{~nm}, \lambda_{\mathrm{em}}$ $=580 \mathrm{~nm}$. Top: Time-resolved luminescence decays at different 1,3,5-trimethoxybenzene concentration. Bottom: Stern-Volmer analyses. 

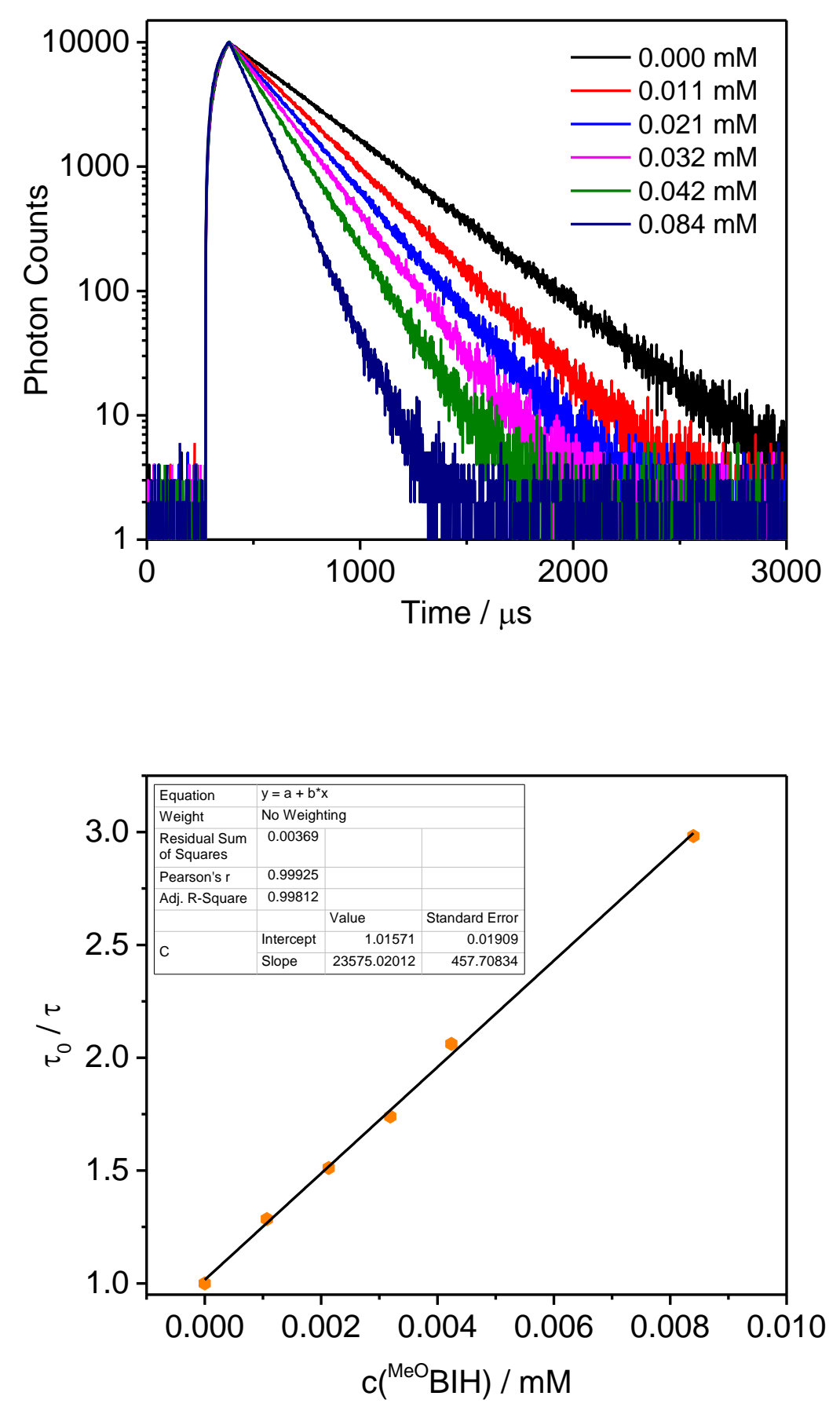

Figure A27. Quenching of $\mathrm{Zr}\left({ }^{\mathrm{Mes}} \mathrm{PDP}^{\mathrm{Ph}}\right)_{2}$ by ${ }^{\mathrm{MeO}} \mathrm{BIH}$ in THF. $\lambda_{\mathrm{ex}}=516 \mathrm{~nm}, \lambda_{\text {em }}=580 \mathrm{~nm}$. Top: Time-resolved luminescence decays at different ${ }^{\mathrm{MeO}} \mathrm{BIH}$ concentration. Bottom: Stern-Volmer analyses. 


\section{Experimental Setup for Photoreactions.}

All photo-reactions were performed using commercially available LED light strips with an emission maximum at $520 \mathrm{~nm}$. Constant room temperature conditions were maintained using a jacketed glass beaker with water cooling or fan.

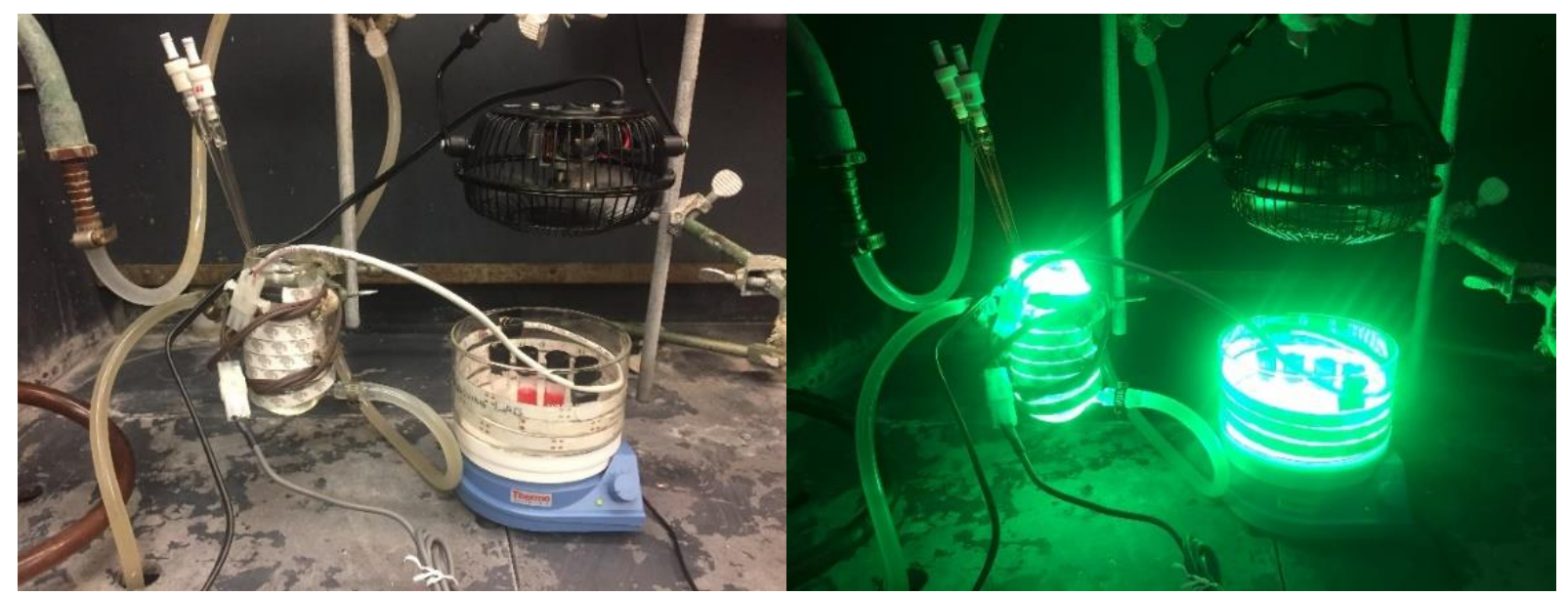

Figure A28. Experimental setup for irradiation of NMR tubes and vials. 


\section{A.5. Addition Data for Chapter 4.}
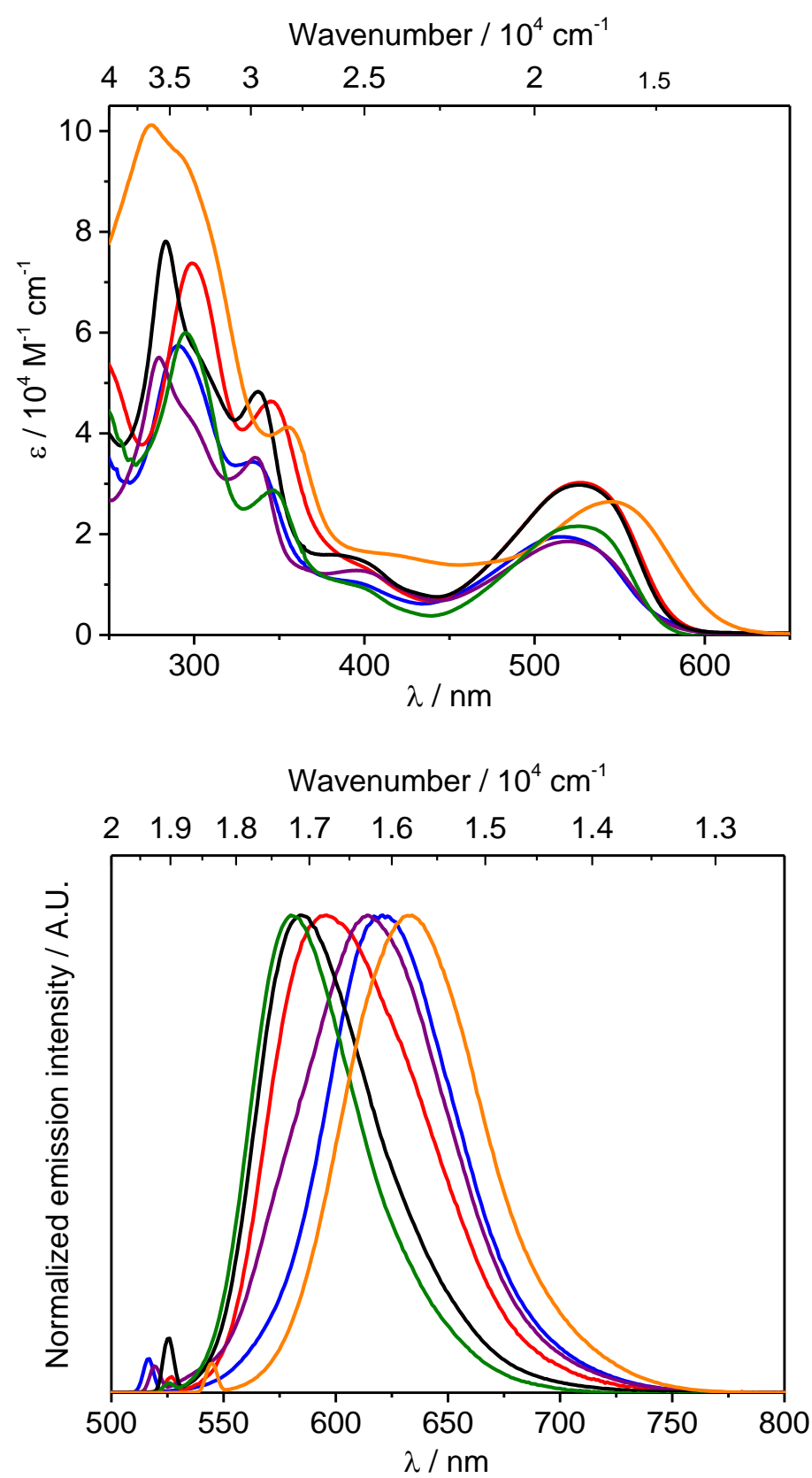

Figure A29. Absorption (top) and emission spectra (bottom, excited at the lowest energy absorption maxima) of $\mathrm{Zr}\left({ }^{\mathrm{Me}} \mathrm{PDP}^{\mathrm{C} 6 \mathrm{~F} 5}\right)_{2}$ (blue), $\mathrm{Zr}\left({ }^{\mathrm{Me}} \mathrm{PDP}^{\mathrm{Ph}}\right)_{2}$ (red), $\mathrm{Zr}\left({ }^{\mathrm{Me}} \mathrm{PDP}^{\mathrm{H}}\right)_{2}$ (purple), $\mathrm{Zr}\left({ }^{\mathrm{Me}} \mathrm{PDP}{ }^{\mathrm{Me}}\right)_{2}$ (black), $\mathrm{Zr}\left({ }^{\mathrm{Mes}} \mathrm{PDP}{ }^{\mathrm{Ph}}\right)_{2}$ (olive), and $\mathrm{Zr}\left({ }^{\mathrm{Ph}} \mathrm{PDP}^{\mathrm{Ph}}\right)_{2}$ (orange) in THF solution at room temperature. 


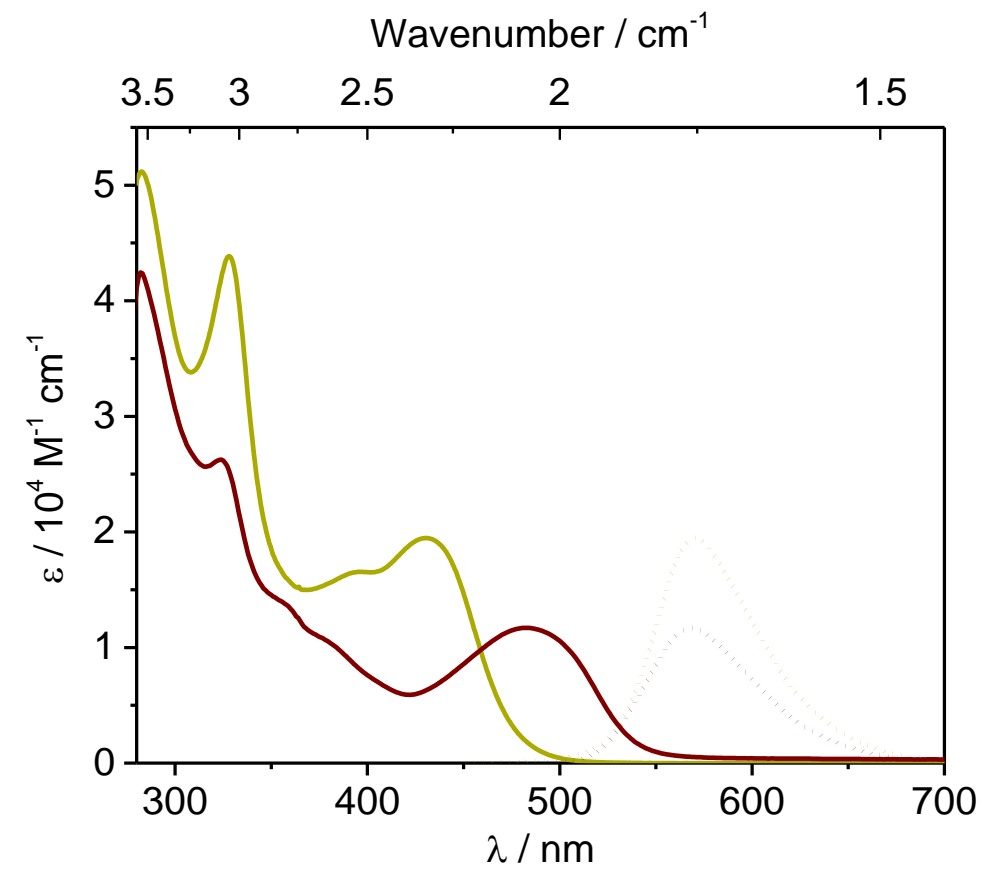

Figure A30. Absorption (solid line) and emission spectra (dotted line, excited at the lowest energy absorption maxima) of $\mathrm{Zr}\left({ }^{\mathrm{H}} \mathrm{PDP}^{\mathrm{H}}\right)_{2}$ (wine) in benzene solution and $\mathrm{Zr}\left({ }^{\mathrm{H}} \mathrm{PDP}^{\mathrm{H}}\right)_{2}(\mathrm{THF})_{2}$ (dark yellow) in THF solution at room temperature.

Table A1. The absorption (IL/LMCT band) and emission maxima recorded in THF solution for zirconium compounds. The dihedral angles between two ligand planes and $\mathrm{N}_{\mathrm{py}}(2)-\mathrm{Zr}-\mathrm{N}_{\mathrm{py}}(5)$ angles were listed.

\begin{tabular}{|c|c|c|c|c|c|}
\hline & \multirow{2}{*}{$\begin{array}{l}\text { Dihedral } \\
\text { angle }\left(^{\circ}\right)\end{array}$} & \multirow{2}{*}{$\begin{array}{l}\mathrm{N}_{\mathrm{py}}(2)-\mathrm{Zr}- \\
\mathrm{N}_{\mathrm{py}}(5)\left({ }^{\circ}\right)\end{array}$} & \multicolumn{3}{|c|}{ THF } \\
\hline & & & $\lambda_{\text {abs-max }}\left(\mathrm{nm} / \mathrm{cm}^{-1}\right)$ & $\lambda_{\text {em-max }}\left(\mathrm{nm} / \mathrm{cm}^{-1}\right)$ & Stokes shift $\left(\mathrm{cm}^{-1}\right)$ \\
\hline $\mathrm{Zr}\left({ }^{\mathrm{H}} \mathrm{PDP}^{\mathrm{H}}\right)_{2}$ & 76.05 & 151.78 & - & - & - \\
\hline $\mathrm{Zr}\left({ }^{\mathrm{H}} \mathrm{PDP}^{\mathrm{H}}\right)_{2}(\mathrm{THF})_{2}$ & 68.41 & 134.58 & $430 / 23256$ & $570 / 17544$ & 5712 \\
\hline $\mathrm{Zr}\left({ }^{\mathrm{Me}} \mathrm{PDP}^{\mathrm{C} 6 \mathrm{~F} 5}\right)_{2}$ & $86.20^{\mathrm{a}}$ & $175.03^{\mathrm{a}}$ & $516 / 19380$ & $621 / 16103$ & 3277 \\
\hline $\mathrm{Zr}\left({ }^{\mathrm{Me}} \mathrm{PDP}^{\mathrm{H}}\right)_{2}$ & 83.36 & 169.08 & $520 / 19231$ & $613 / 16313$ & 2918 \\
\hline $\mathrm{Zr}\left({ }^{\mathrm{Me}} \mathrm{PDP}^{\mathrm{Me}}\right)_{2}$ & 89.63 & 173.11 & $527 / 18975$ & $584 / 17123$ & 1852 \\
\hline $\mathrm{Zr}\left({ }^{\mathrm{Mes}} \mathrm{PDP}^{\mathrm{Ph}}\right)_{2}$ & 89.57 & 179.42 & $526 / 19011$ & $580 / 17241$ & 1770 \\
\hline $\mathrm{Zr}\left({ }^{\mathrm{Me}} \mathrm{PDP}{ }^{\mathrm{Ph}}\right)_{2}$ & 88.29 & 171.76 & $527 / 18975$ & $596 / 16779$ & 2197 \\
\hline $\mathrm{Zr}\left({ }^{\mathrm{Ph}} \mathrm{PDP}^{\mathrm{Ph}}\right)_{2}$ & 72.89 & 153.81 & $545 / 18349$ & $634 / 15773$ & 2576 \\
\hline
\end{tabular}

aaverage angle values of two independent molecules in the unit cell. 


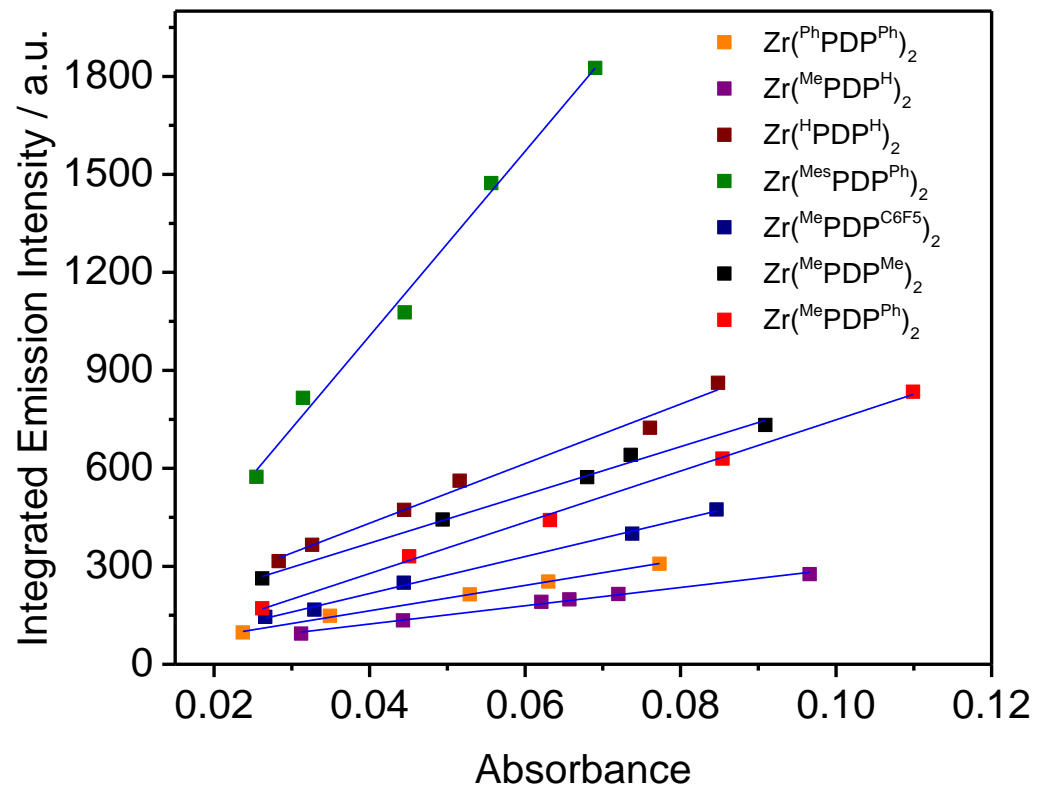

Figure A31. Plot of absorbance at $488 \mathrm{~nm}$ (for $\mathrm{Zr}\left({ }^{\mathrm{H} P D P}{ }^{\mathrm{H}}\right)_{2}$ in THF, absorbance at $421 \mathrm{~nm}$ was recorded) versus integration of the emission spectrum for $\mathrm{Zr}\left({ }^{\mathrm{R} 1} \mathrm{PDP}^{\mathrm{R} 2}\right)_{2}$ in THF. The blue lines represent linear fits of the data.

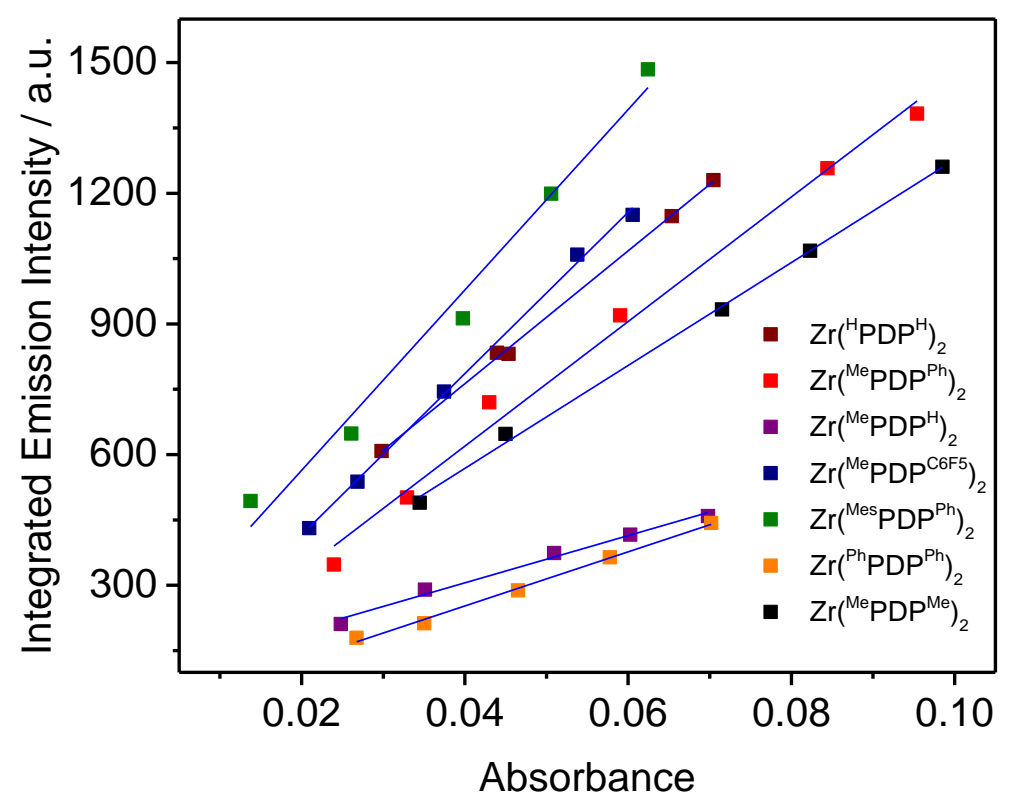

Figure A32. Plot of absorbance at $488 \mathrm{~nm}$ versus integration of the emission spectrum for $\mathrm{Zr}\left({ }^{\mathrm{R} 1} \mathrm{PDP}^{\mathrm{R} 2}\right)_{2}$ in $\mathrm{C}_{6} \mathrm{H}_{6}$. The blue lines represent linear fits of the data. 
Table A2. The gradients used for the quantum yield determination.

\begin{tabular}{c|cccc}
\hline & Gradient / THF & $\Phi / \mathrm{THF}$ & Gradient $/ \mathrm{C}_{6} \mathrm{H}_{6}$ & $\Phi / \mathrm{C}_{6} \mathrm{H}_{6}$ \\
\hline $\mathrm{Zr}\left({ }^{\mathrm{Me} P D P}{ }^{\mathrm{C} 6 \mathrm{~F} 5}\right)_{2}$ & 5657 & 0.09 & 18514 & 0.34 \\
$\mathrm{Zr}\left({ }^{\mathrm{Me}} \mathrm{PDP}{ }^{\mathrm{Ph}}\right)_{2}$ & 7847 & 0.12 & 14304 & 0.27 \\
$\mathrm{Zr}\left({ }^{\mathrm{Me}} \mathrm{PDP}^{\mathrm{H}}\right)_{2}$ & 2800 & 0.05 & 5419 & 0.10 \\
$\mathrm{Zr}\left({ }^{\mathrm{Me}}{ }^{2} P^{\mathrm{Me}}\right)_{2}$ & 7390 & 0.14 & 11815 & 0.22 \\
$\mathrm{Zr}\left({ }^{\mathrm{H} P D P}\right)_{2}$ & 9120 & 0.13 & 15245 & 0.28 \\
$\mathrm{Zr}\left({ }^{\mathrm{Ph} P D P}{ }^{\mathrm{Ph}}\right)_{2}$ & 3887 & 0.06 & 6212 & 0.11 \\
$\mathrm{Zr}\left({ }^{\mathrm{Mes} P D P}{ }^{\mathrm{Ph}}\right)_{2}$ & 28260 & 0.45 & 20708 & 0.38 \\
\hline
\end{tabular}

${ }^{\mathrm{a}}$ Gradient $=62406$ for Rhodamine $6 \mathrm{G}$ in ethanol and gradient $=29455$ for Coumarin 153 in ethanol .

Table A3. Excited state decay parameters in THF.

\begin{tabular}{|c|c|c|c|c|c|c|}
\hline \multirow{2}{*}{$\begin{array}{c}\text { Compound } \\
\text { (\# of C-H bond present } \\
\text { in the molecule) }\end{array}$} & \multirow{2}{*}{$\begin{array}{l}\text { Dihedral } \\
\text { angle }\left({ }^{\circ}\right)\end{array}$} & \multirow{2}{*}{$\begin{array}{l}\mathrm{N}_{\text {py }}(2)-\mathrm{Zr}- \\
\mathrm{N}_{\mathrm{py}}(5)\left({ }^{\circ}\right)\end{array}$} & \multicolumn{4}{|c|}{ THF } \\
\hline & & & $\tau(\mu \mathrm{s})$ & $\Phi_{P L}$ & $\mathrm{k}_{\mathrm{r}}\left(\mathrm{s}^{-1}\right)$ & $\mathrm{k}_{\mathrm{nr}}\left(\mathrm{s}^{-1}\right)$ \\
\hline $\mathrm{Zr}\left({ }^{\mathrm{H}} \mathrm{PDP}^{\mathrm{H}}\right)_{2}(18)$ & 76.05 & 151.78 & - & - & - & - \\
\hline $\mathrm{Zr}\left({ }^{\mathrm{H}} \mathrm{PDP}^{\mathrm{H}}\right)_{2}(\mathrm{THF})_{2}(34)$ & 68.41 & 134.58 & 609 & 0.13 & 213 & 1429 \\
\hline $\mathrm{Zr}\left({ }^{\mathrm{Me}} \mathrm{PDP}^{\mathrm{C} 6 \mathrm{~F} 5}\right)_{2}(22)$ & $86.20^{\mathrm{a}}$ & $175.03^{\mathrm{a}}$ & 137 & 0.09 & 657 & 5912 \\
\hline $\mathrm{Zr}\left({ }^{\mathrm{Me}} \mathrm{PDP}^{\mathrm{H}}\right)_{2}(26)$ & 83.36 & 169.08 & 168 & 0.05 & 298 & 5655 \\
\hline $\mathrm{Zr}\left({ }^{\mathrm{Me}} \mathrm{PDP}^{\mathrm{Me}}\right)_{2}(34)$ & 89.63 & 173.11 & 581 & 0.14 & 241 & 1480 \\
\hline $\mathrm{Zr}\left({ }^{\mathrm{Mes}} \mathrm{PDP}^{\mathrm{Ph}}\right)_{2}(74)$ & 89.57 & 179.42 & 350 & 0.45 & 1286 & 1571 \\
\hline $\mathrm{Zr}\left({ }^{\mathrm{Me}} \mathrm{PDP}^{\mathrm{Ph}}\right)_{2}(42)$ & 88.29 & 171.76 & 325 & 0.12 & 369 & 2708 \\
\hline $\mathrm{Zr}\left({ }^{\mathrm{Ph}} \mathrm{PDP}^{\mathrm{Ph}}\right)_{2}(50)$ & 72.89 & 153.81 & 184 & 0.06 & 326 & 5109 \\
\hline
\end{tabular}


Fit of Time-Resolved Emission Data.
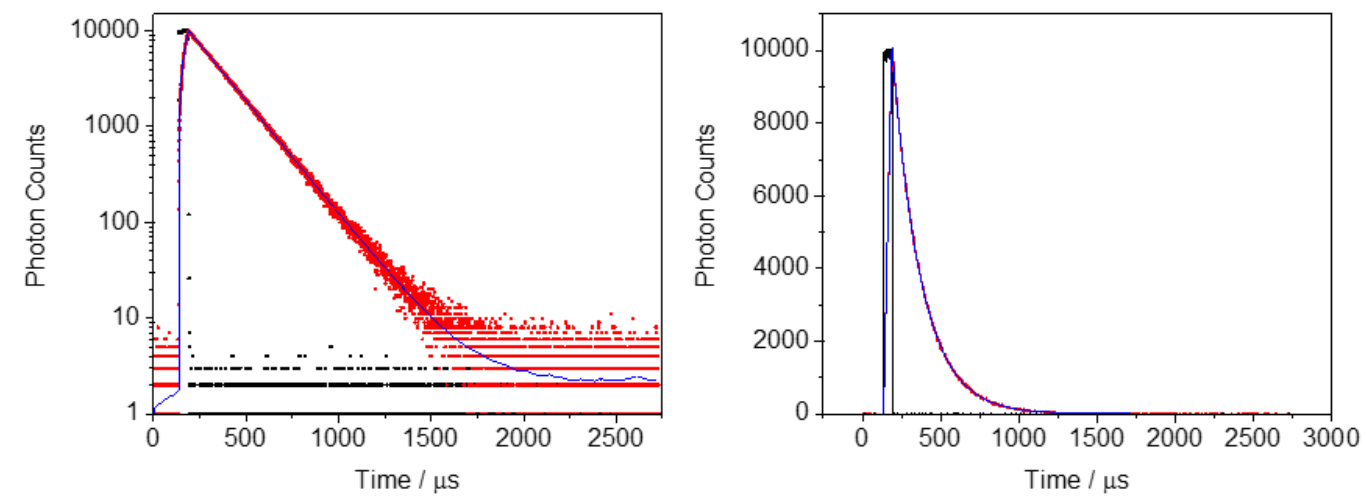

Figure A33. Representative example for time-resolved emission data for $\mathbf{Z r}\left({ }^{\mathbf{P h}} \mathbf{P D P} \mathbf{P}^{\mathbf{P h}}\right)_{\mathbf{2}}$ in $\mathrm{THF}$ at room temperature (red) detected at $\lambda_{\text {em max }}$ upon excitation at $516 \mathrm{~nm}$. The navy line shows the fit to a single-exponential decay with $\tau_{0}=184 \mu$ s and the black trace shows the excitation pulse.
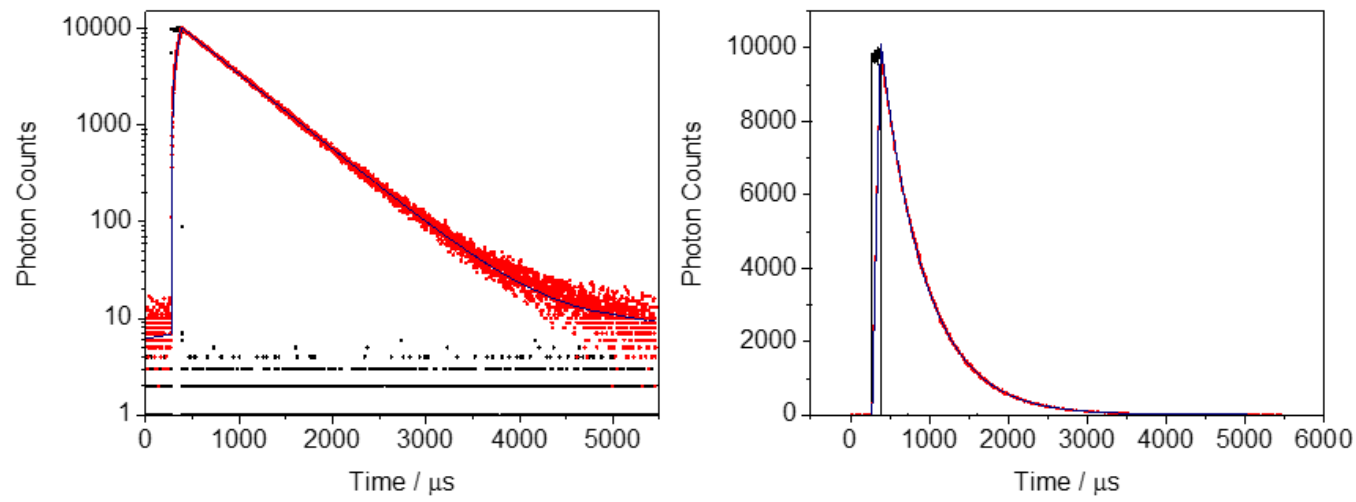

Figure A34. Representative example for time-resolved emission data for $\mathbf{Z r}\left({ }^{\mathbf{M e}} \mathbf{P D P} \mathbf{P}^{\mathbf{M e}}\right)_{\mathbf{2}}$ in $\mathrm{THF}$ at room temperature (red) detected at $\lambda_{\mathrm{em} \text { max }}$ upon excitation at $516 \mathrm{~nm}$. The navy line shows the fit to a single-exponential decay with $\tau_{0}=581 \mu$ s and the black trace shows the excitation pulse.
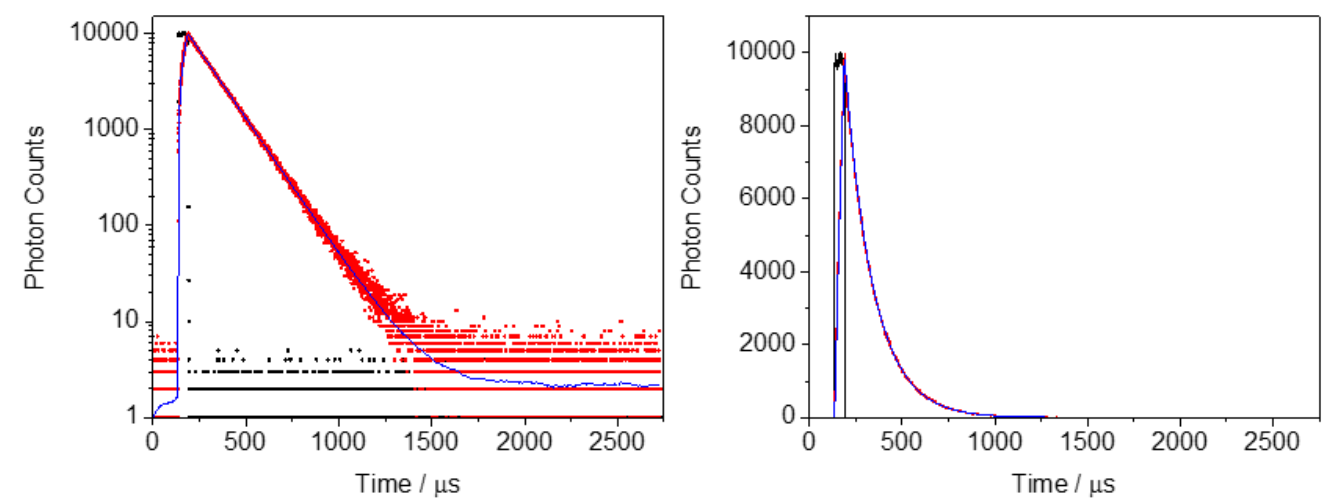

Figure A35. Representative example for time-resolved emission data for $\mathbf{Z r}\left({ }^{\mathbf{M e}} \mathbf{P D P} \mathbf{P}^{\mathbf{H}}\right)_{2}$ in $\mathrm{THF}$ at room temperature (red) detected at $\lambda_{\text {em max }}$ upon excitation at $516 \mathrm{~nm}$. The navy line shows the fit to a single-exponential decay with $\tau_{0}=168 \mu$ s and the black trace shows the excitation pulse. 

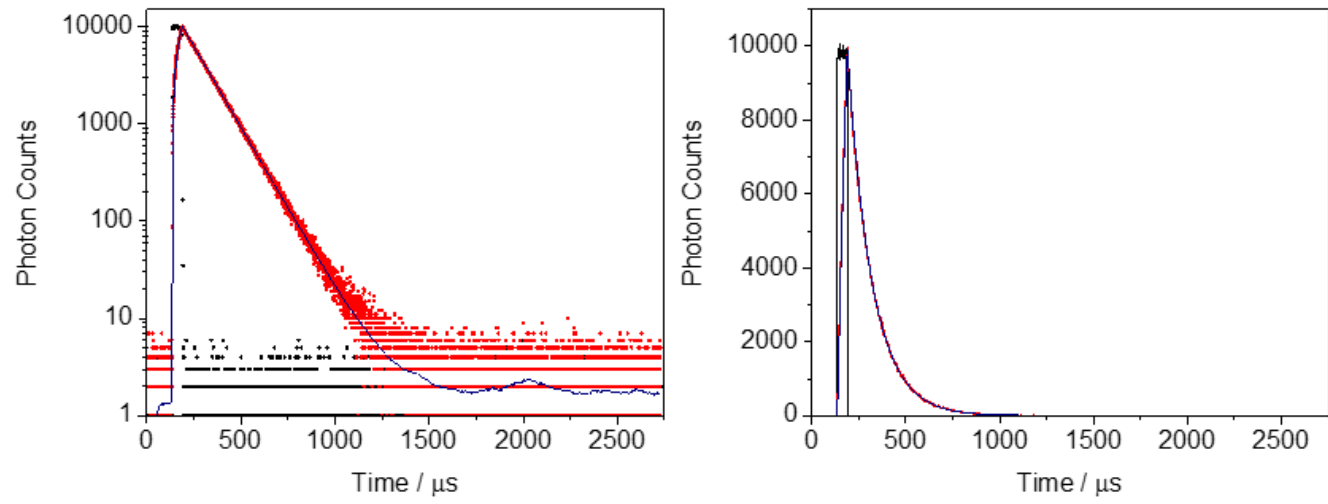

Figure A36. Representative example for time-resolved emission data for $\mathbf{Z r}\left({ }^{\text {MePDP }}{ }^{\mathbf{C} 6 \mathbf{F 5}}\right)_{2}$ in THF at room temperature (red) detected at $\lambda_{\text {em max }}$ upon excitation at $516 \mathrm{~nm}$. The navy line shows the fit to a single-exponential decay with $\tau_{0}=137 \mu$ s and the black trace shows the excitation pulse.
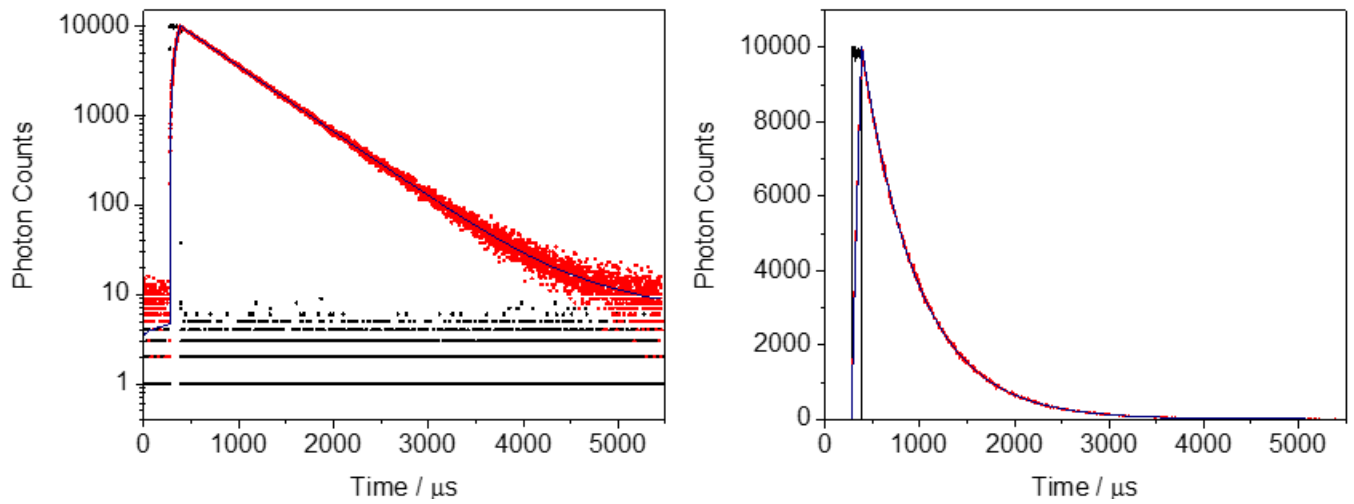

Figure A37. Representative example for time-resolved emission data for $\mathbf{Z r}\left({ }^{\mathbf{H}} \mathbf{P D P}{ }^{\mathbf{H}}\right)_{2}$ in $\mathrm{THF}$ at room temperature (red) detected at $\lambda_{\text {em max }}$ upon excitation at $516 \mathrm{~nm}$. The navy line shows the fit to a single-exponential decay with $\tau_{0}=609 \mu$ s and the black trace shows the excitation pulse.
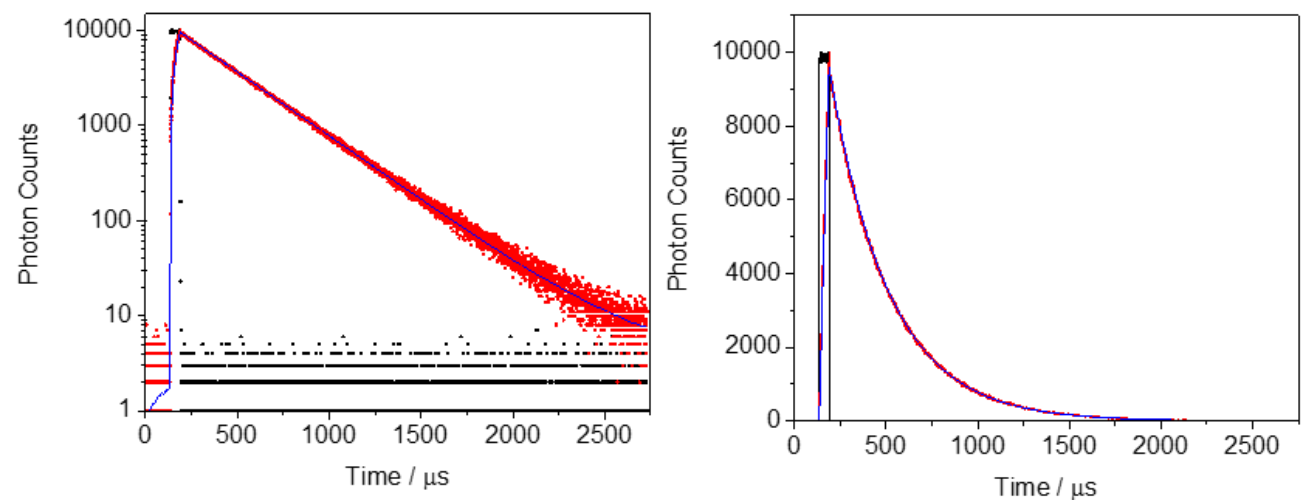

Figure A38. Representative example for time-resolved emission data for $\mathbf{Z r}\left({ }^{\mathbf{M e}} \mathbf{P D P} \mathbf{P}^{\mathbf{P h}}\right)_{\mathbf{2}}$ in $\mathrm{THF}$ at room temperature (red) detected at $\lambda_{\text {em max }}$ upon excitation at $516 \mathrm{~nm}$. The navy line shows the fit to a single-exponential decay with $\tau_{0}=325 \mu$ s and the black trace shows the excitation pulse. 

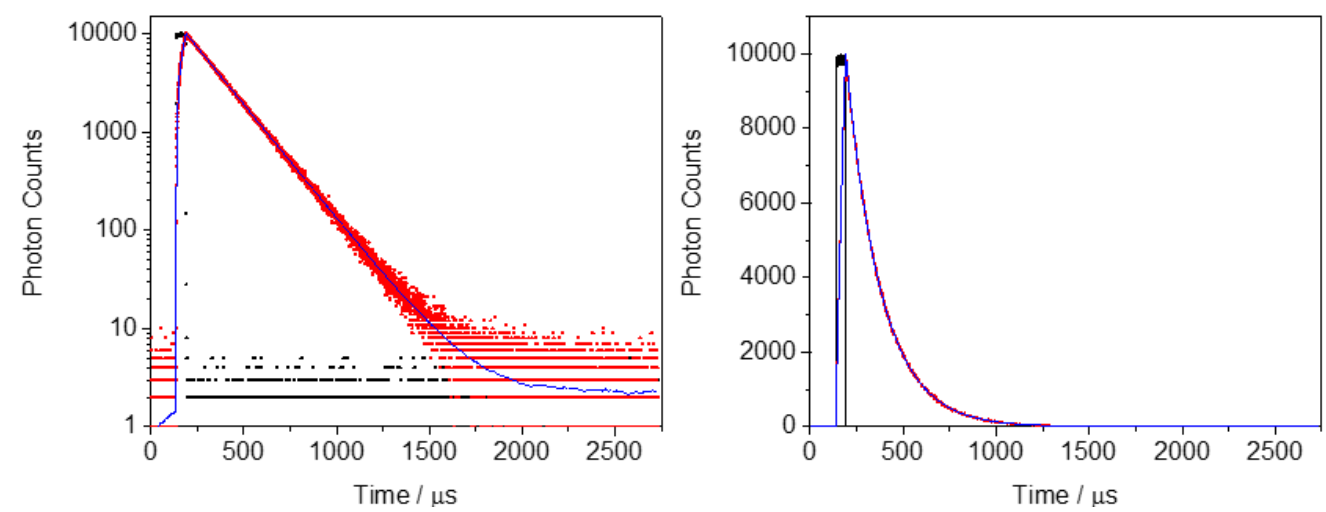

Figure A39. Representative example for time-resolved emission data for $\mathbf{Z r}\left({ }^{\mathbf{P h}} \mathbf{P D P} \mathbf{P}^{\mathbf{P h}}\right)_{\mathbf{2}}$ in $\mathrm{C}_{6} \mathrm{H}_{6}$ at room temperature (red) detected at $\lambda_{\text {em max }}$ upon excitation at $516 \mathrm{~nm}$. The navy line shows the fit to a single-exponential decay with $\tau_{0}=190 \mu$ s and the black trace shows the excitation pulse.
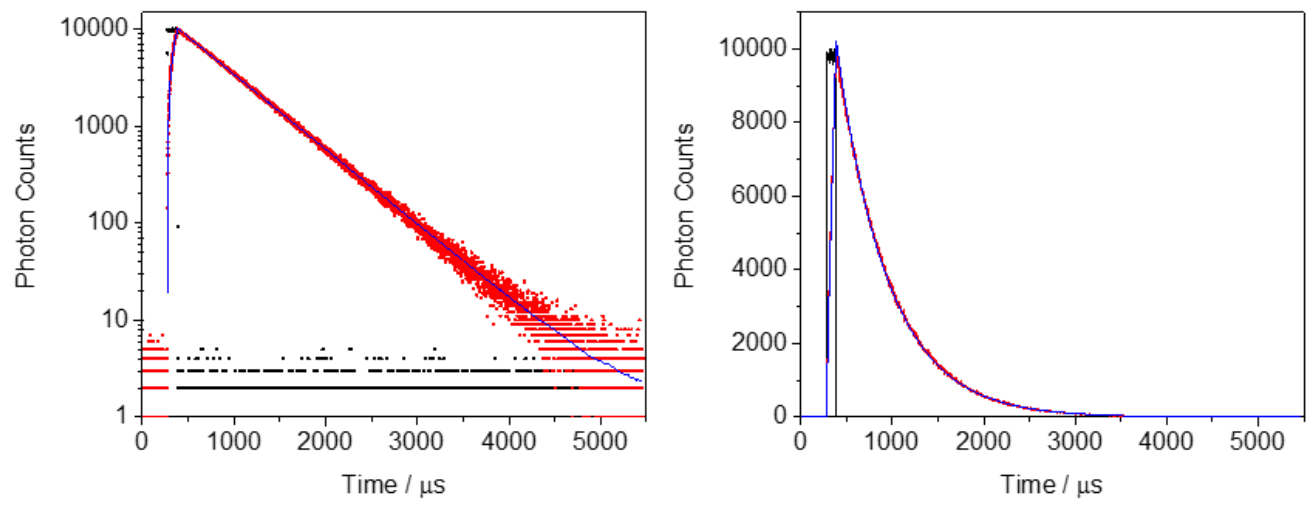

Figure A40. Representative example for time-resolved emission data for $\mathbf{Z r}\left({ }^{\mathbf{M e}} \mathbf{P D P} \mathbf{P e}^{\mathbf{M e}}\right)_{\mathbf{2}}$ in $\mathrm{C}_{6} \mathrm{H}_{6}$ at room temperature (red) detected at $\lambda_{\mathrm{em} \text { max }}$ upon excitation at $516 \mathrm{~nm}$. The navy line shows the fit to a single-exponential decay with $\tau_{0}=576 \mu$ s and the black trace shows the excitation pulse.
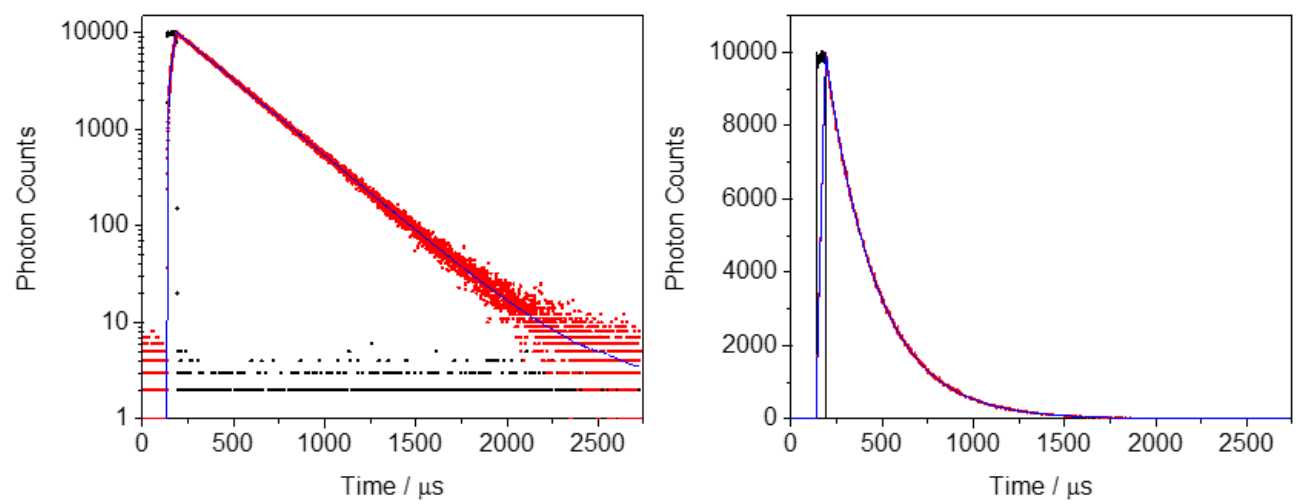

Figure A41. Representative example for time-resolved emission data for $\mathbf{Z r}\left({ }^{\mathbf{M e}} \mathbf{P D P} \mathbf{P}^{\mathbf{H}}\right)_{\mathbf{2}}$ in $\mathrm{C}_{6} \mathrm{H}_{6}$ at room temperature (red) detected at $\lambda_{\text {em max }}$ upon excitation at $516 \mathrm{~nm}$. The navy line shows the fit to a single-exponential decay with $\tau_{0}=260 \mu$ s and the black trace shows the excitation pulse. 

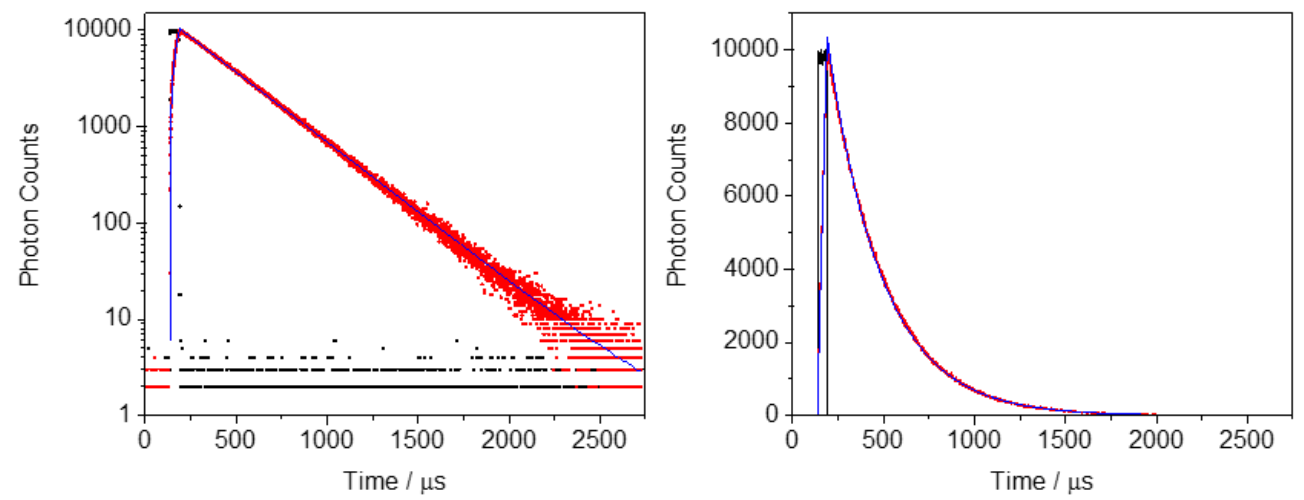

Figure A42. Representative example for time-resolved emission data for $\mathbf{Z r}\left({ }^{\mathbf{M e}} \mathbf{P D P} \mathbf{P}^{\mathbf{C 6 5 5}}\right)_{2}$ in $\mathrm{C}_{6} \mathrm{H}_{6}$ at room temperature (red) detected at $\lambda_{\text {em max }}$ upon excitation at $516 \mathrm{~nm}$. The navy line shows the fit to a single-exponential decay with $\tau_{0}=313 \mu$ s and the black trace shows the excitation pulse.
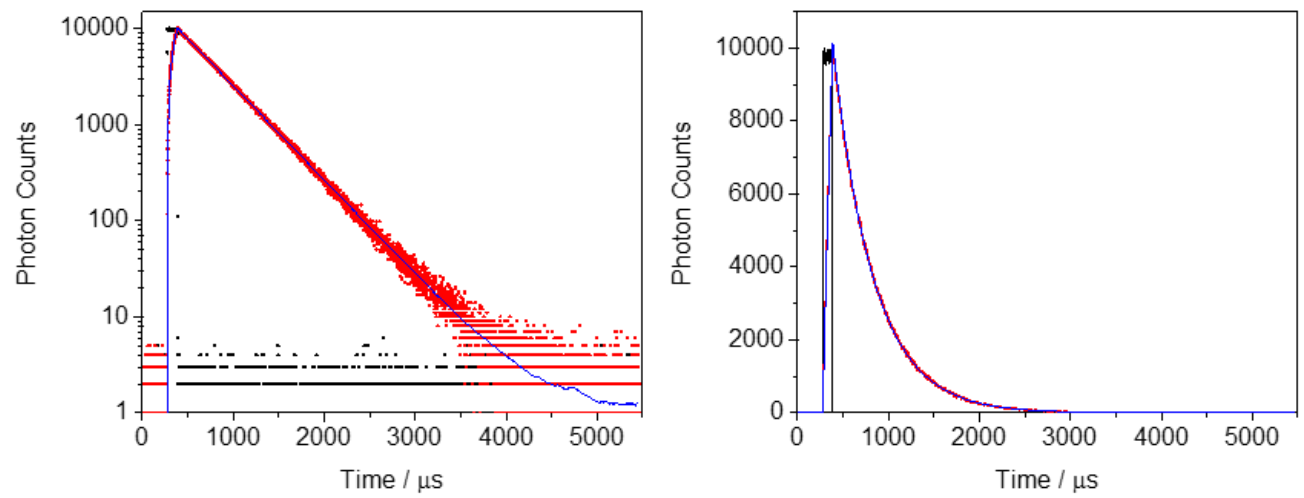

Figure A43. Representative example for time-resolved emission data for $\mathbf{Z r}\left({ }^{\mathbf{H}} \mathbf{P D P} \mathbf{P}^{\mathbf{H}}\right)_{2}$ in $\mathrm{C}_{6} \mathrm{H}_{6}$ at room temperature (red) detected at $\lambda_{\text {em max }}$ upon excitation at $516 \mathrm{~nm}$. The navy line shows the fit to a single-exponential decay with $\tau_{0}=413 \mu$ s and the black trace shows the excitation pulse.
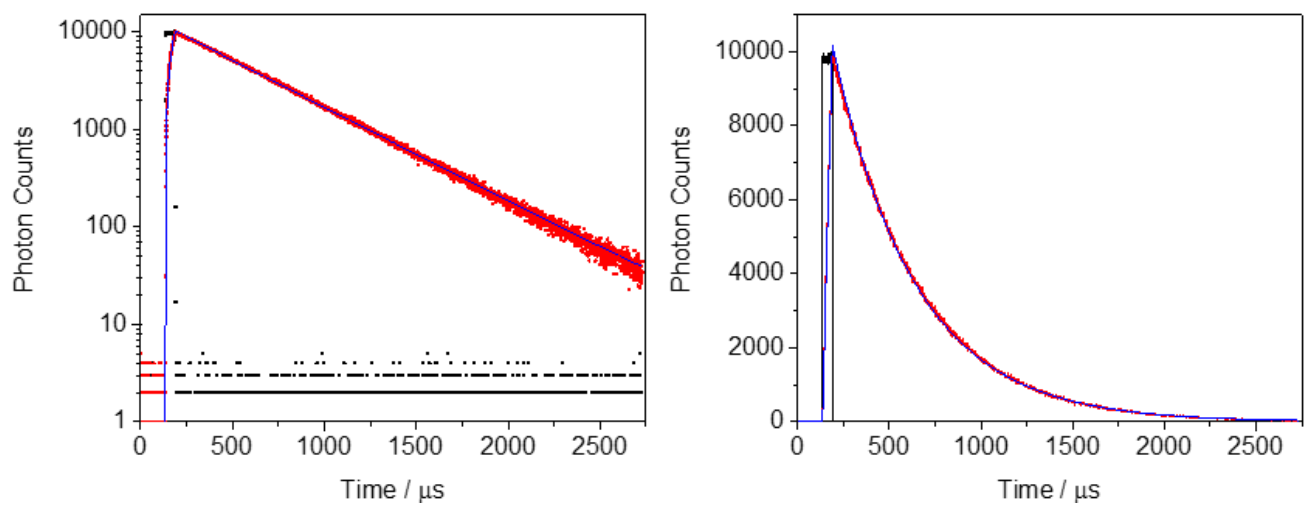

Figure A44. Representative example for time-resolved emission data for $\mathbf{Z r}\left({ }^{\mathbf{M e}} \mathbf{P D P} \mathbf{P}^{\mathbf{P h}}\right)_{2}$ in $\mathrm{C}_{6} \mathrm{H}_{6}$ at room temperature (red) detected at $\lambda_{\text {em max }}$ upon excitation at $516 \mathrm{~nm}$. The navy line shows the fit to a single-exponential decay with $\tau_{0}=474 \mu$ s and the black trace shows the excitation pulse. 


\section{Additional Electrochemistry Data}
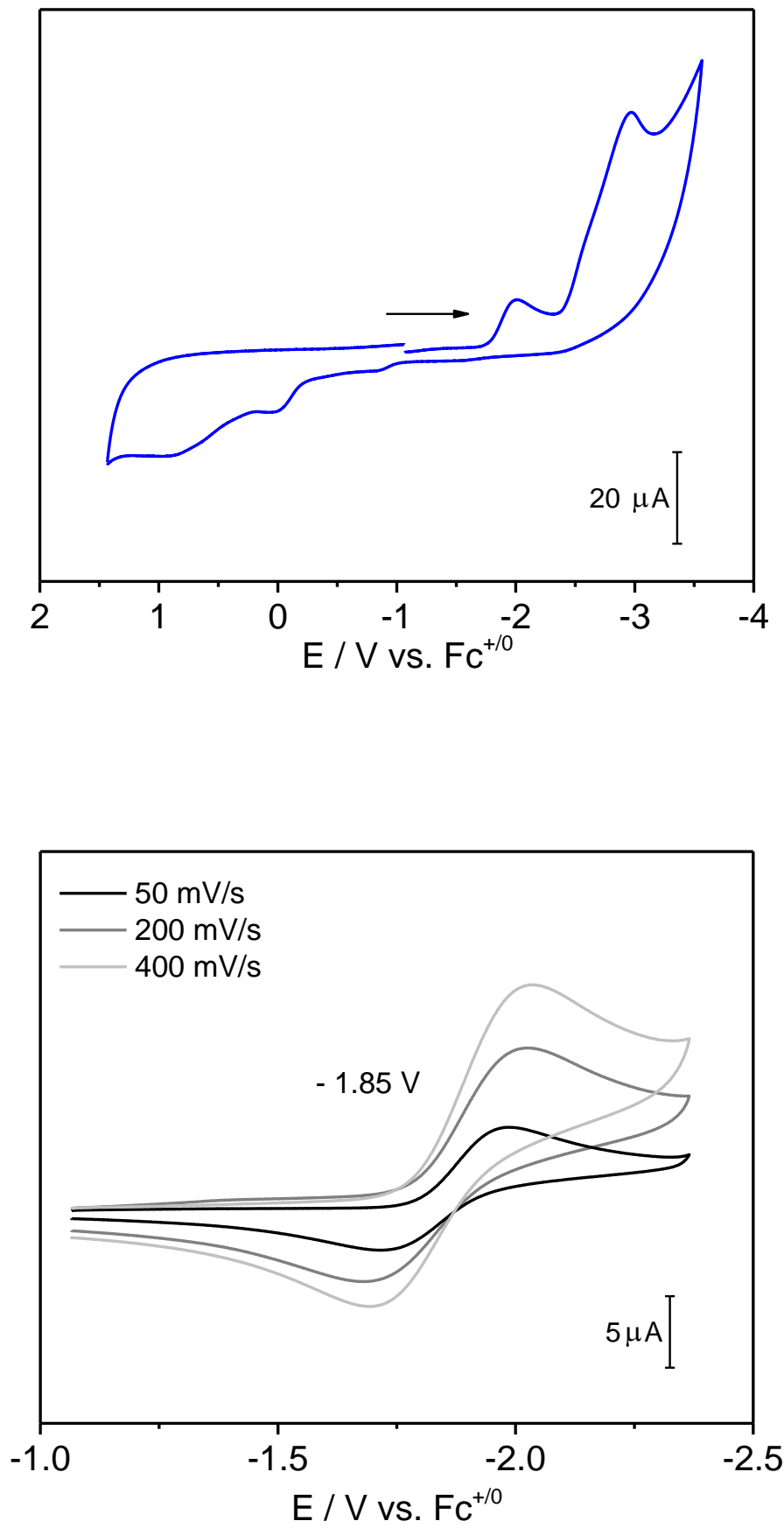

Figure A45. Top: Cyclic voltammogram of $\mathrm{Zr}\left({ }^{\mathrm{Me}} \mathrm{PDP}^{\mathrm{C} 6 \mathrm{~F} 5}\right)_{2}$ in $\mathrm{THF}$ at room temperature (scan rate $200 \mathrm{mV} \mathrm{s}^{-1}, 0.1 \mathrm{M}\left[\mathrm{N}(n-\mathrm{Bu})_{4}\right] \mathrm{PF}_{6}$, glassy carbon working electrode). Bottom: Cyclic voltammogram of $\mathrm{Zr}\left({ }^{\mathrm{Me}} \mathrm{PDP}^{\mathrm{C} 6 \mathrm{~F} 5}\right)_{2}$ in THF at different scan rates. 

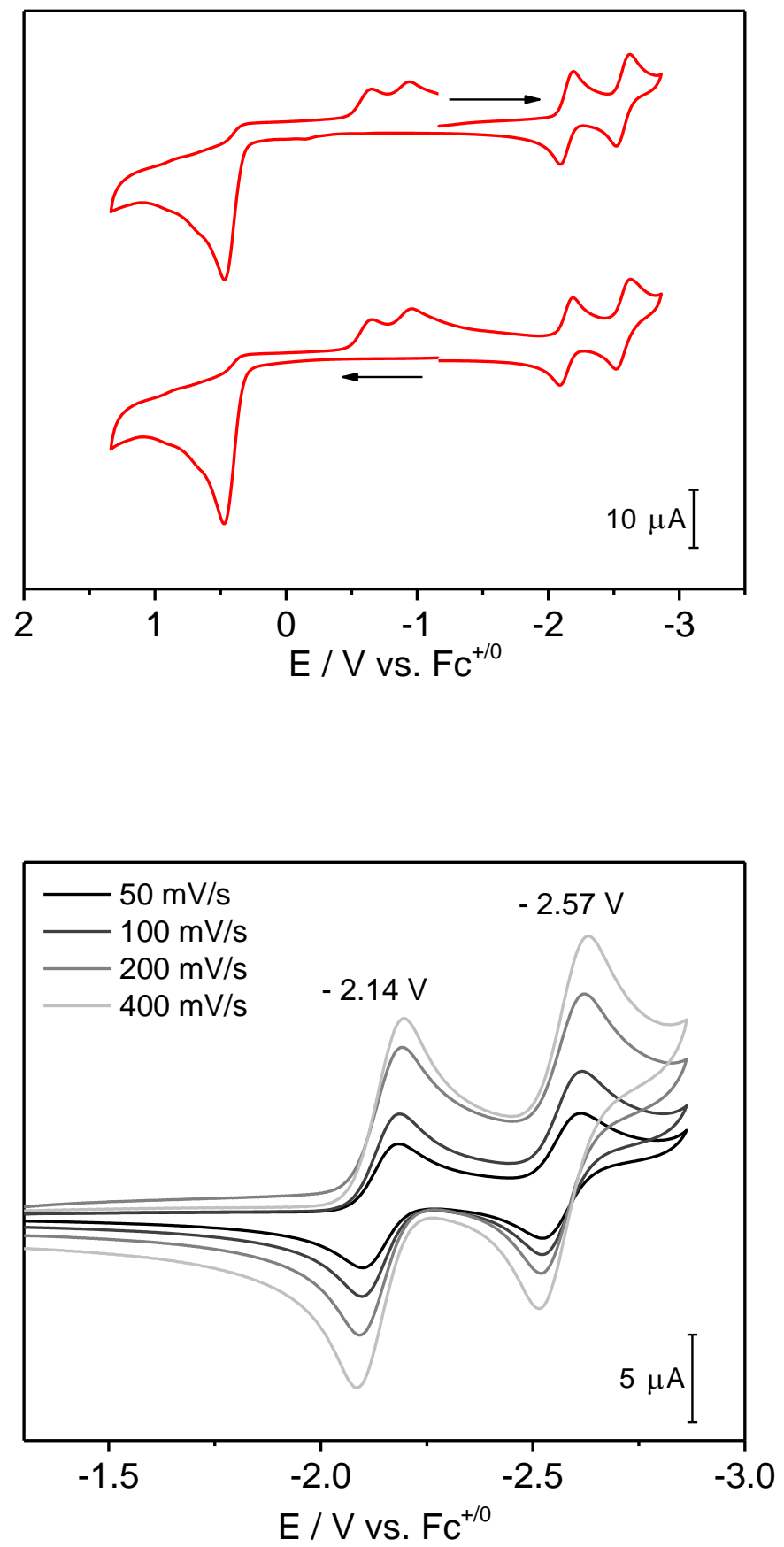

Figure A46. Top: Cyclic voltammogram of $\mathrm{Zr}\left({ }^{\mathrm{Me}} \mathrm{PDP}^{\mathrm{Ph}}\right)_{2}$ in 1,2-difluorobenzene at room temperature (scan rate $200 \mathrm{mV} \mathrm{s}^{-1}, 0.1 \mathrm{M}\left[\mathrm{N}(n-\mathrm{Bu})_{4}\right] \mathrm{PF}_{6}$, glassy carbon working electrode). Bottom: Cyclic voltammogram of $\mathrm{Zr}\left({ }^{\mathrm{Me}} \mathrm{PDP}{ }^{\mathrm{Ph}}\right)_{2}$ in 1,2-difluorobenzene at different scan rates. 

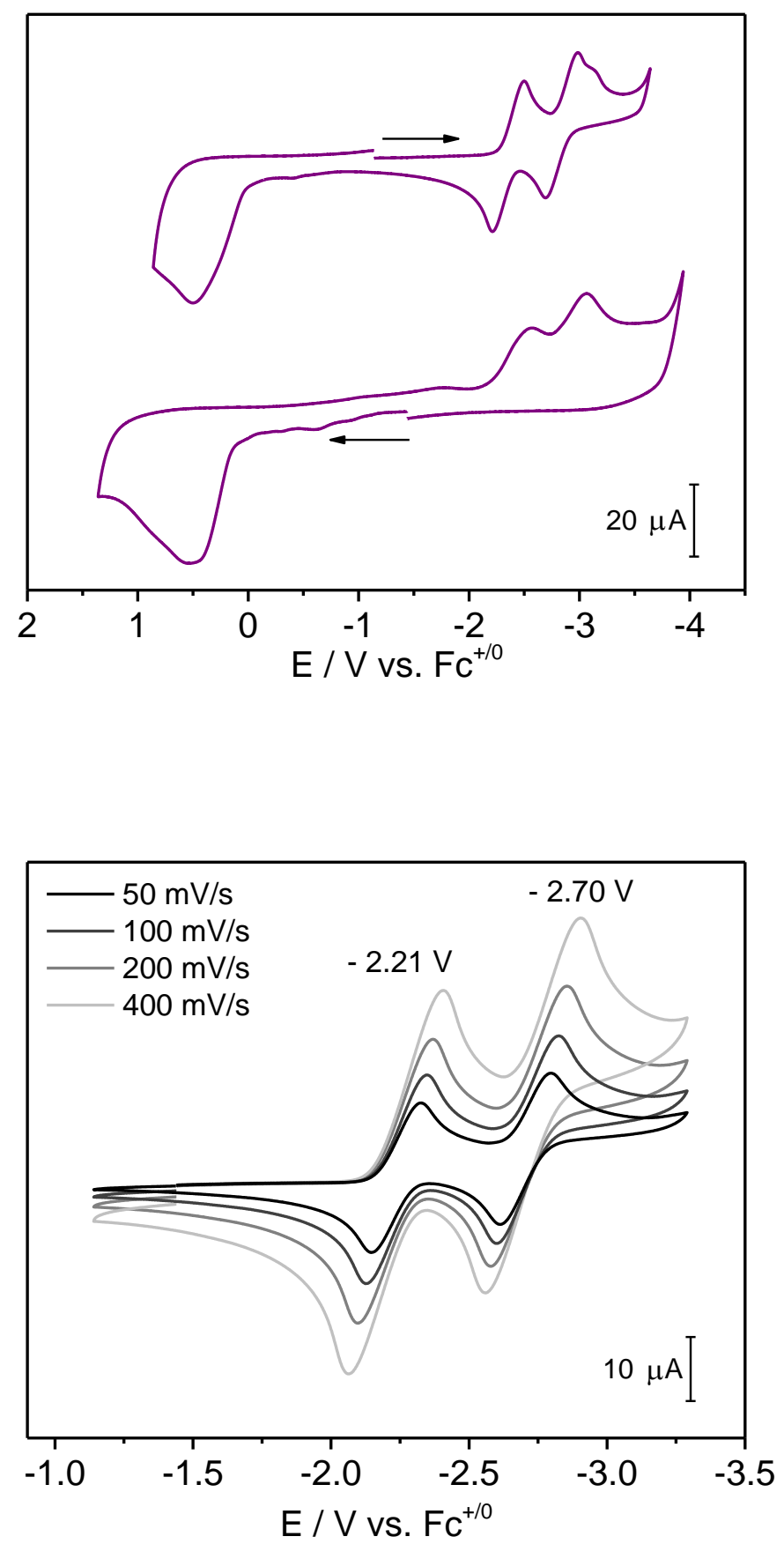

Figure A47. Top: Cyclic voltammogram of $\mathrm{Zr}\left({ }^{\mathrm{Me}} \mathrm{PDP}^{\mathrm{H}}\right)_{2}$ in $\mathrm{THF}$ at room temperature (scan rate $200 \mathrm{mV} \mathrm{s}^{-1}, 0.1 \mathrm{M}\left[\mathrm{N}(n-\mathrm{Bu})_{4}\right] \mathrm{PF}_{6}$, glassy carbon working electrode). Bottom: Cyclic voltammogram of $\mathrm{Zr}(\mathrm{MePDP}) 2$ in THF at different scan rates. 

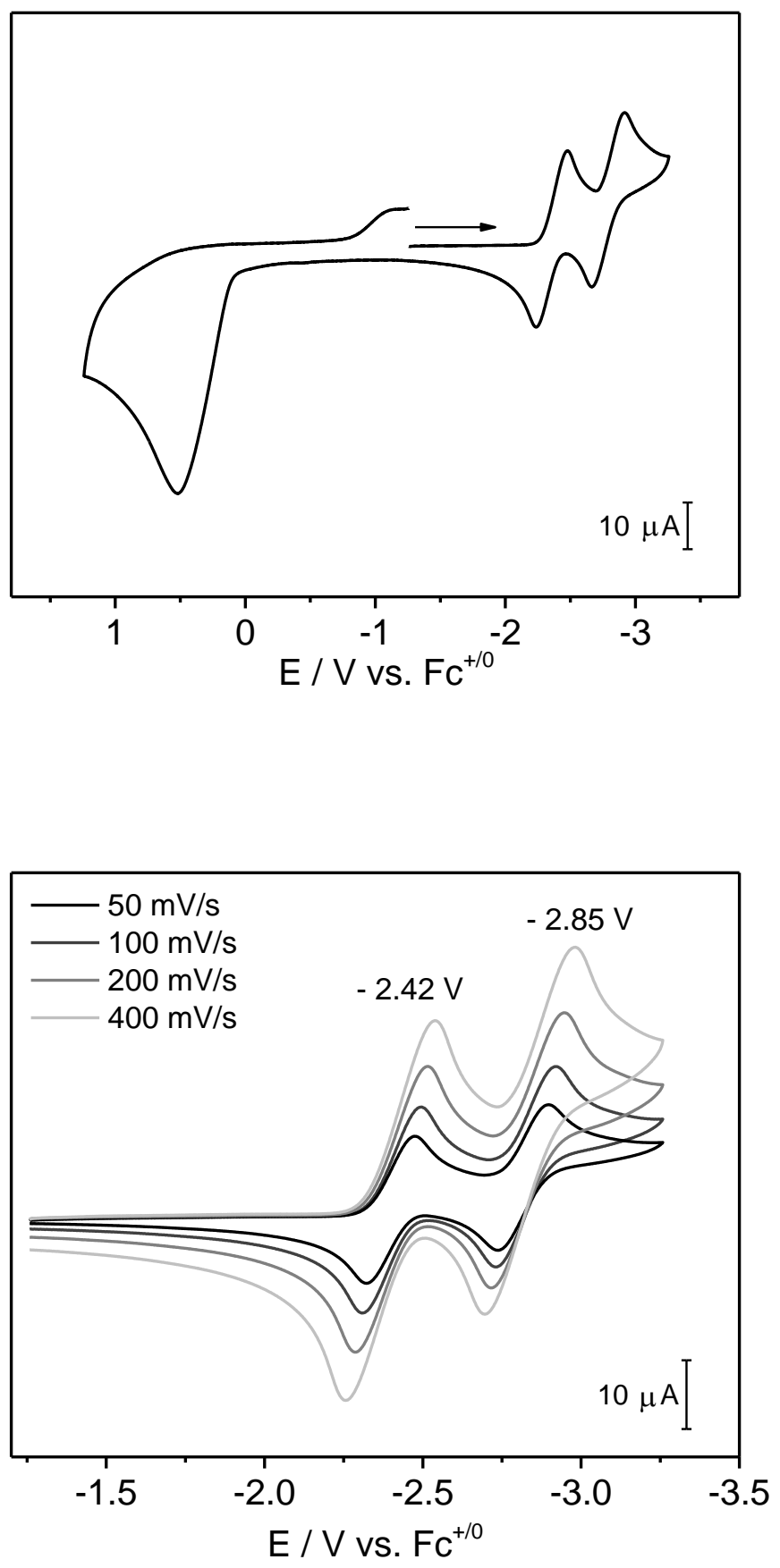

Figure A48. Top: Cyclic voltammogram of $\mathrm{Zr}\left({ }^{\mathrm{Me} P D P}{ }^{\mathrm{Me}}\right)_{2}$ in $\mathrm{THF}$ at room temperature (scan rate $200 \mathrm{mV} \mathrm{s}^{-1}, 0.1 \mathrm{M}\left[\mathrm{N}(n-\mathrm{Bu})_{4}\right] \mathrm{PF}_{6}$, glassy carbon working electrode). Bottom: Cyclic voltammogram of $\mathrm{Zr}\left({ }^{\mathrm{Me}} \mathrm{PDP}{ }^{\mathrm{Me}}\right)_{2}$ in THF at different scan rates. 

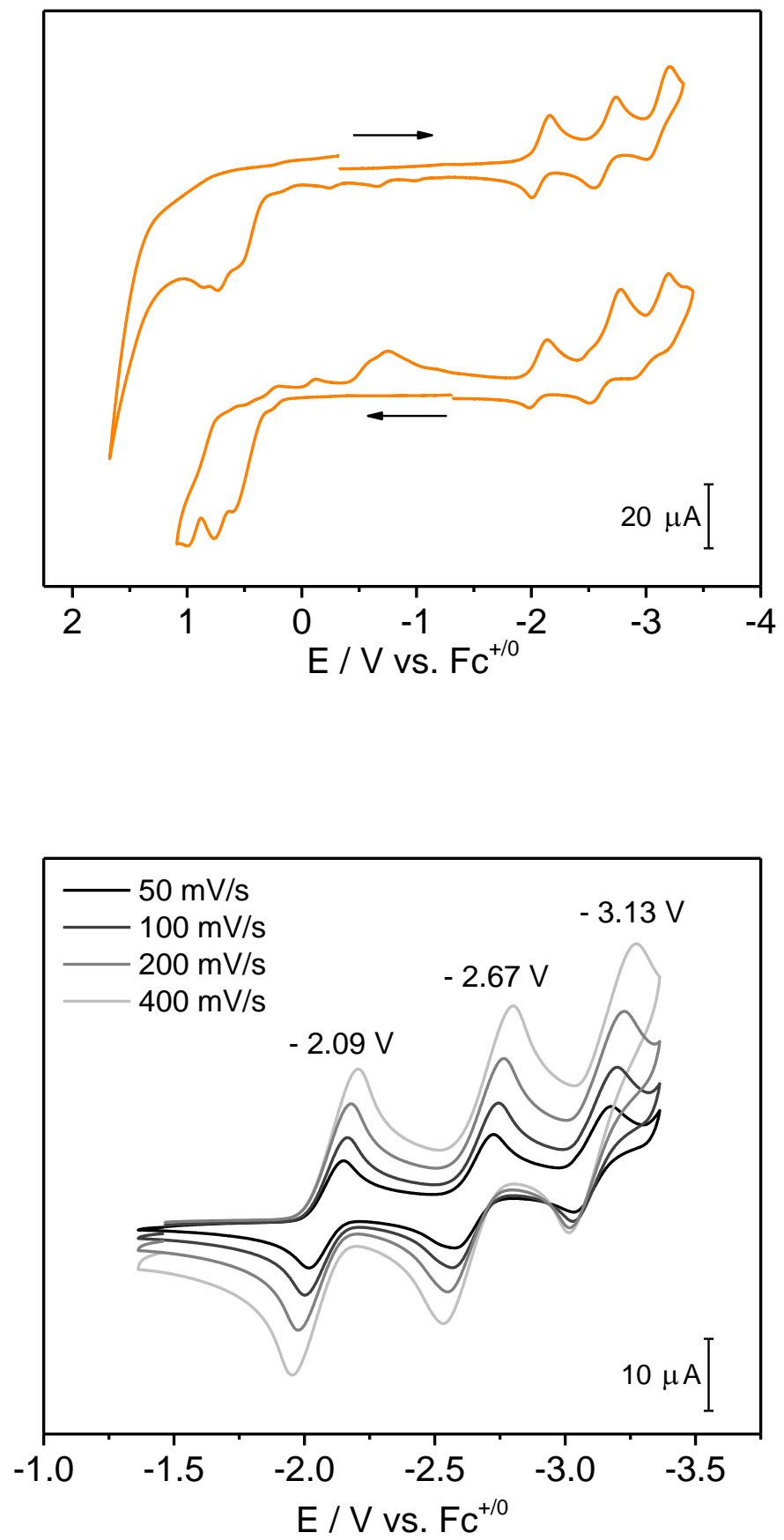

Figure A49. Top: Cyclic voltammogram of $\mathrm{Zr}\left({ }^{\mathrm{PhPDP}}{ }^{\mathrm{Ph}}\right)_{2}$ in $\mathrm{THF}$ at room temperature (scan rate $200 \mathrm{mV} \mathrm{s}^{-1}, 0.1 \mathrm{M}\left[\mathrm{N}(n-\mathrm{Bu})_{4}\right] \mathrm{PF}_{6}$, glassy carbon working electrode). Bottom: Cyclic voltammogram of $\mathrm{Zr}\left({ }^{\mathrm{Ph}} \mathrm{PDP}^{\mathrm{Ph}}\right)_{2}$ in THF at different scan rates. 

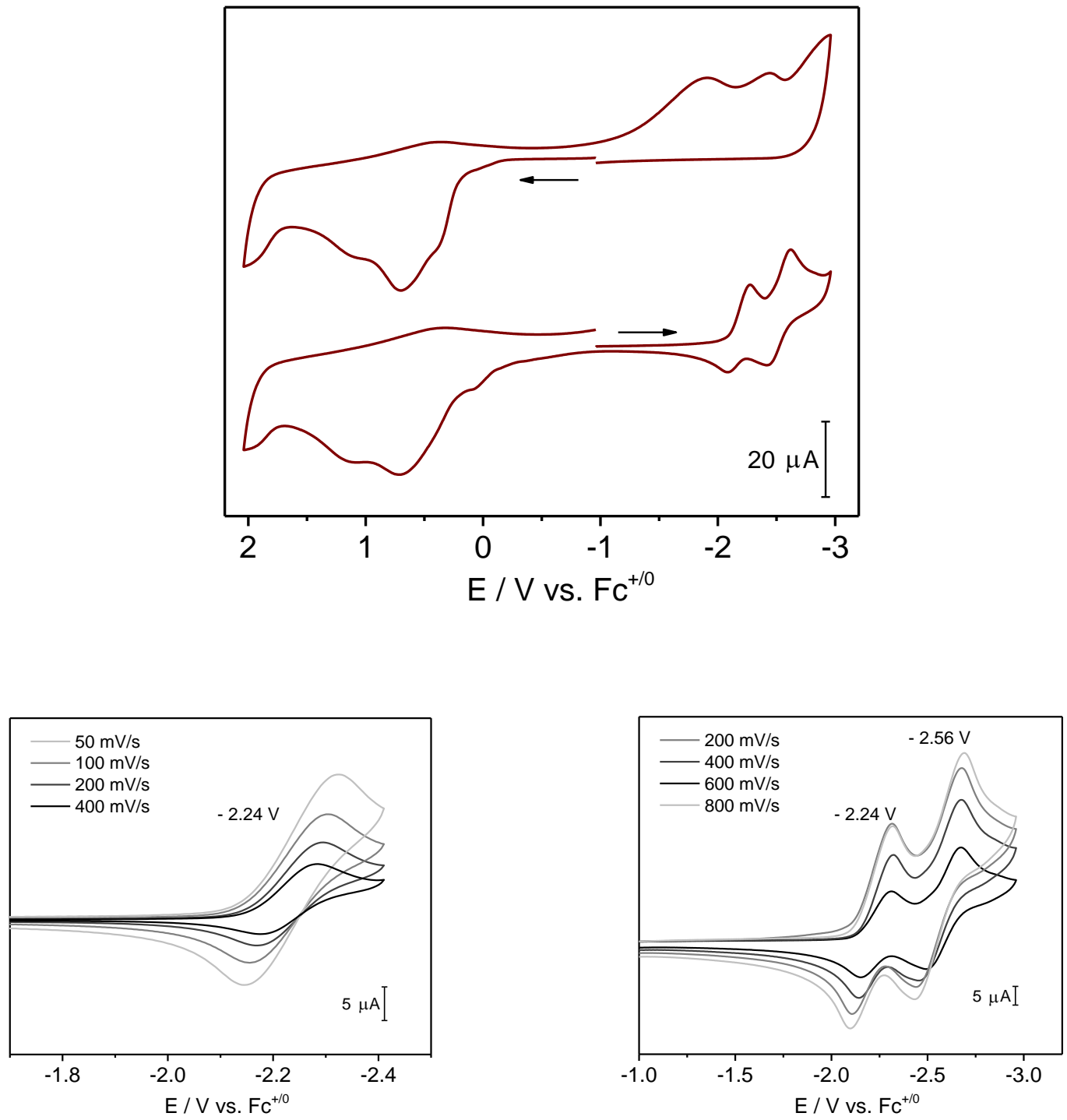

Figure A50. Top: Cyclic voltammogram of $\mathrm{Zr}\left({ }^{\mathrm{H}} \mathrm{PDP}^{\mathrm{H}}\right)_{2}$ in 1,2-difluorobenzene at room temperature (scan rate $200 \mathrm{mV} \mathrm{s}^{-1}, 0.1 \mathrm{M}\left[\mathrm{N}(n-\mathrm{Bu})_{4}\right] \mathrm{PF}_{6}$, glassy carbon working electrode). Bottom: Cyclic voltammogram of $\mathrm{Zr}\left({ }^{\mathrm{H}} \mathrm{PDP}^{\mathrm{H}}\right)_{2}$ in 1,2-difluorobenzene at different scan rates. 

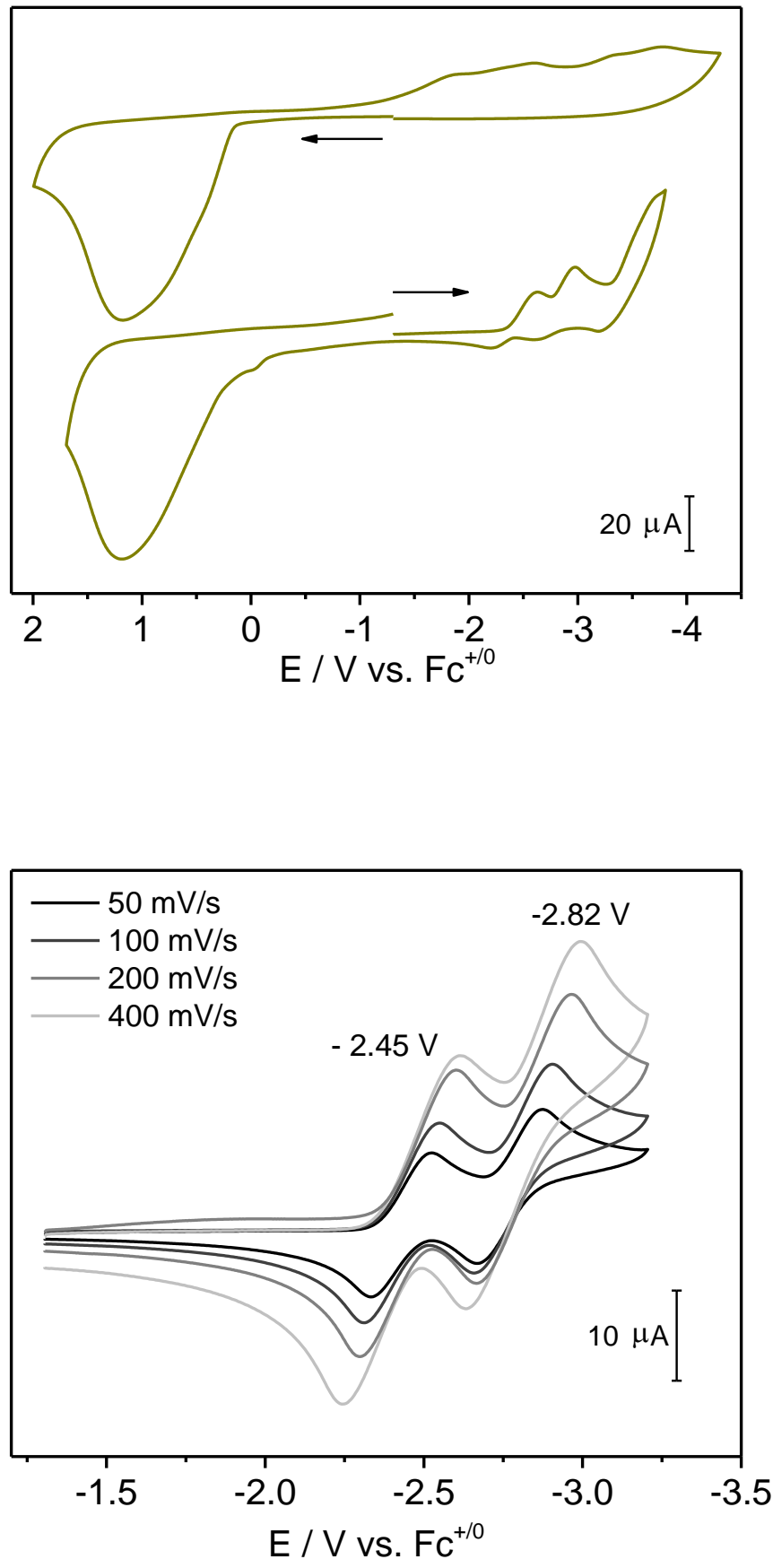

Figure A51. Top: Cyclic voltammogram of $\mathrm{Zr}\left({ }^{\mathrm{H}} \mathrm{PDP}^{\mathrm{H}}\right)_{2}$ in $\mathrm{THF}$ at room temperature (scan rate $200 \mathrm{mV} \mathrm{s}^{-1}, 0.1 \mathrm{M}\left[\mathrm{N}(n-\mathrm{Bu})_{4}\right] \mathrm{PF}_{6}$, glassy carbon working electrode). Bottom: Cyclic voltammogram of $\mathrm{Zr}\left({ }^{\mathrm{H}} \mathrm{PDP}^{\mathrm{H}}\right)_{2}$ in THF at different scan rates. 


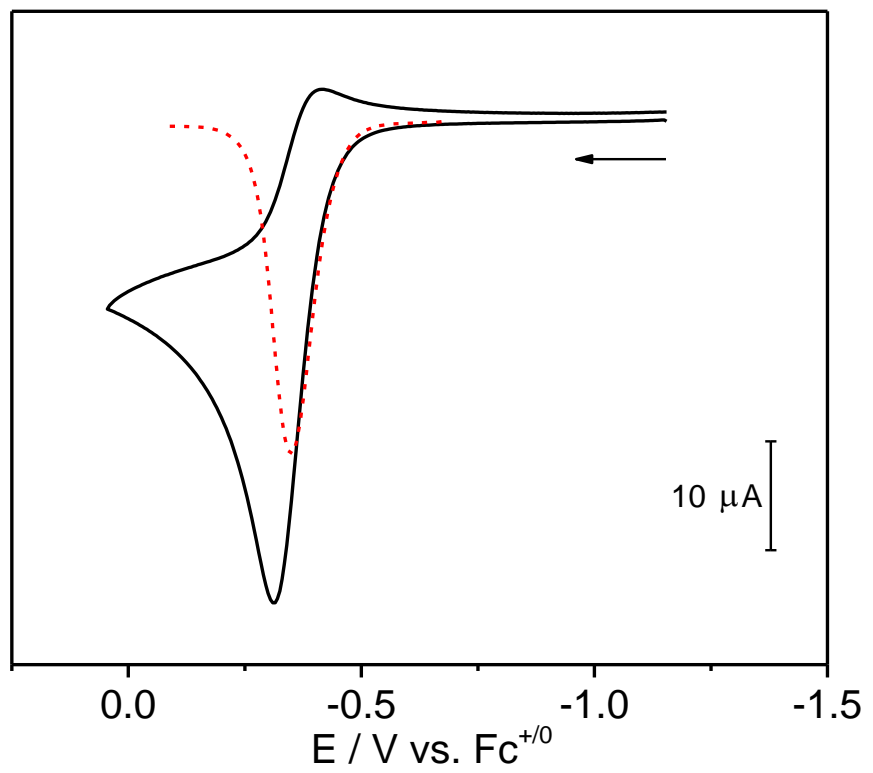

Figure A52. Cyclic voltammogram of ${ }^{\mathrm{TriMeO}} \mathrm{BIH}$ in $\mathrm{MeCN}$ at room temperature (black solid line, scan rate $200 \mathrm{mV} \mathrm{s}^{-1}, 0.1 \mathrm{M}\left[\mathrm{N}(n-\mathrm{Bu})_{4}\right] \mathrm{PF}_{6}$, glassy carbon working electrode). Square-wave voltammogram measured under same condition is shown in red dashed line. 
Quenching Experiments.
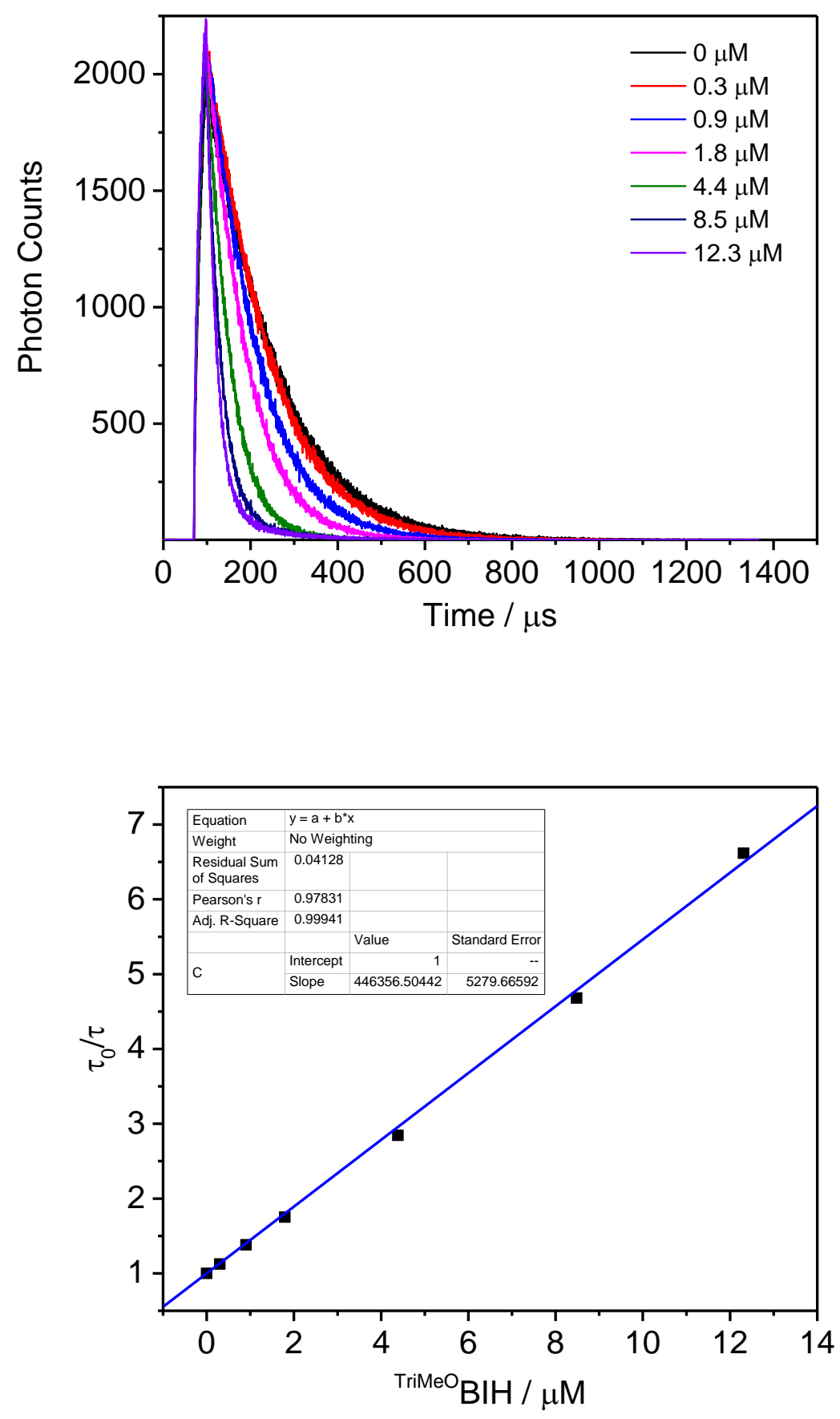

Figure A53. Quenching of $\mathrm{Zr}\left({ }^{\mathrm{Me}} \mathrm{PDP}^{\mathrm{C} 6 \mathrm{F5}}\right)_{2}$ by ${ }^{\mathrm{TriMeO}} \mathrm{BIH}$ in THF. $\lambda_{\mathrm{ex}}=516 \mathrm{~nm}, \lambda_{\mathrm{em}}=620 \mathrm{~nm}$. Top: Time-resolved luminescence decays at different ${ }^{\mathrm{TriMeO}} \mathrm{BIH}$ concentration. Bottom: Stern-Volmer analyses. 

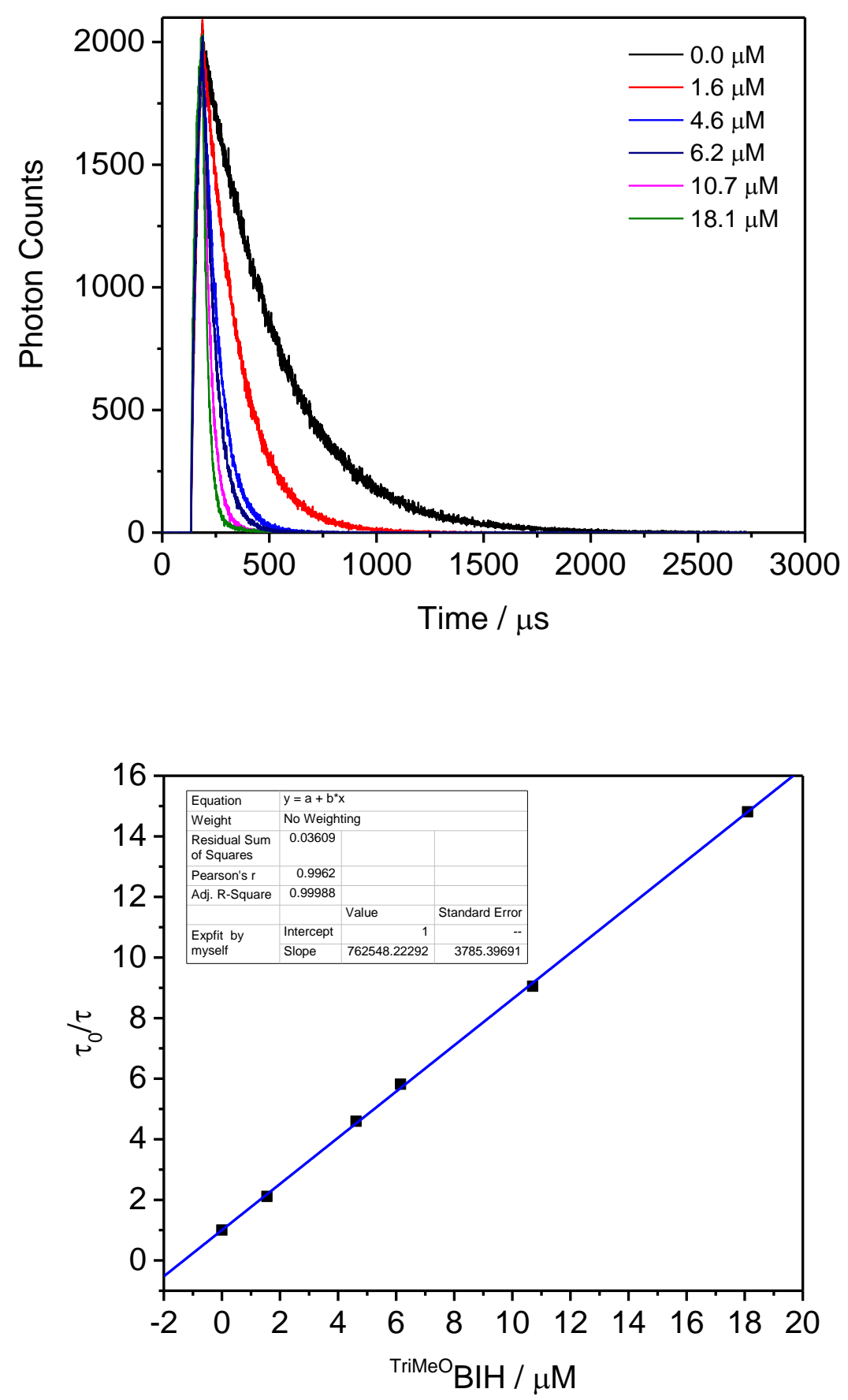

Figure A54. Quenching of $\mathrm{Zr}\left({ }^{\mathrm{Me}} \mathrm{PDP}^{\mathrm{Ph}}\right)_{2}$ by ${ }^{\mathrm{TriMeO}} \mathrm{BIH}$ in THF. $\lambda_{\mathrm{ex}}=516 \mathrm{~nm}, \lambda_{\mathrm{em}}=596 \mathrm{~nm}$. Top: Time-resolved luminescence decays at different ${ }^{\mathrm{TriMeO}} \mathrm{BIH}$ concentration. Bottom: Stern-Volmer analyses. 

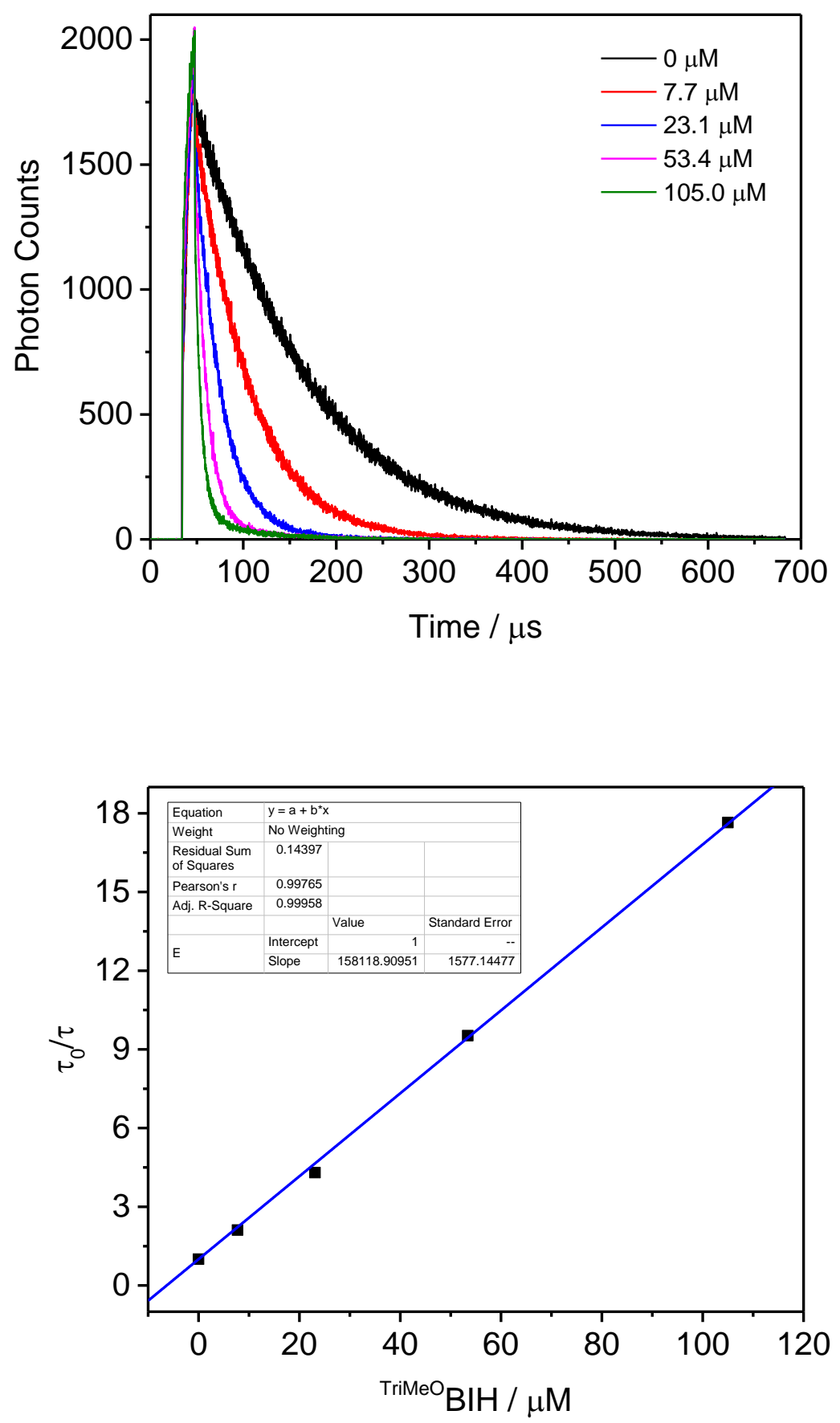

Figure A55. Quenching of $\mathrm{Zr}\left({ }^{\mathrm{Me}} \mathrm{PDP}^{\mathrm{H}}\right)_{2}$ by ${ }^{\mathrm{TriMeO}} \mathrm{BIH}$ in THF. $\lambda_{\mathrm{ex}}=516 \mathrm{~nm}, \lambda_{\mathrm{em}}=614 \mathrm{~nm}$. Top: Time-resolved luminescence decays at different ${ }^{\mathrm{TriMeO}} \mathrm{BIH}$ concentration. Bottom: Stern-Volmer analyses. 

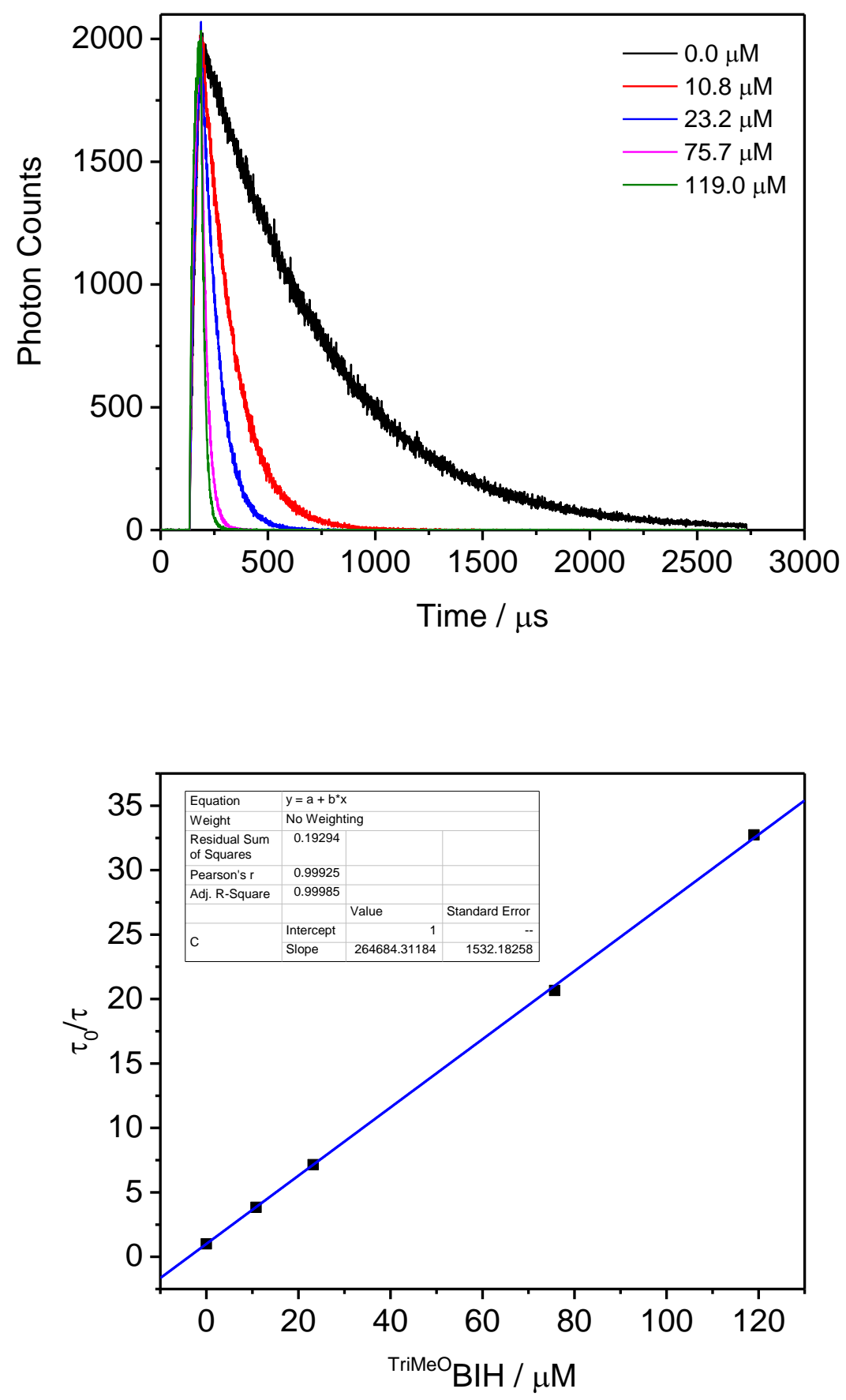

Figure A56. Quenching of $\mathrm{Zr}\left({ }^{\mathrm{Me}} \mathrm{PDP}{ }^{\mathrm{Me}}\right)_{2}$ by ${ }^{\mathrm{TriMeO}} \mathrm{BIH}$ in THF. $\lambda_{\mathrm{ex}}=516 \mathrm{~nm}, \lambda_{\mathrm{em}}=584 \mathrm{~nm}$. Top: Time-resolved luminescence decays at different ${ }^{\mathrm{TriMeO}} \mathrm{BIH}$ concentration. Bottom: Stern-Volmer analyses. 


\section{A.6. Addition Data for Chapter 5.}

Time-Resolved Emission Data for $\mathrm{H}_{2}{ }^{\mathrm{R}} \mathrm{CNN}$ and $\mathrm{LiH}^{\mathrm{R}} \mathrm{CNN}(\mathrm{R}=\mathrm{H}$, Me)
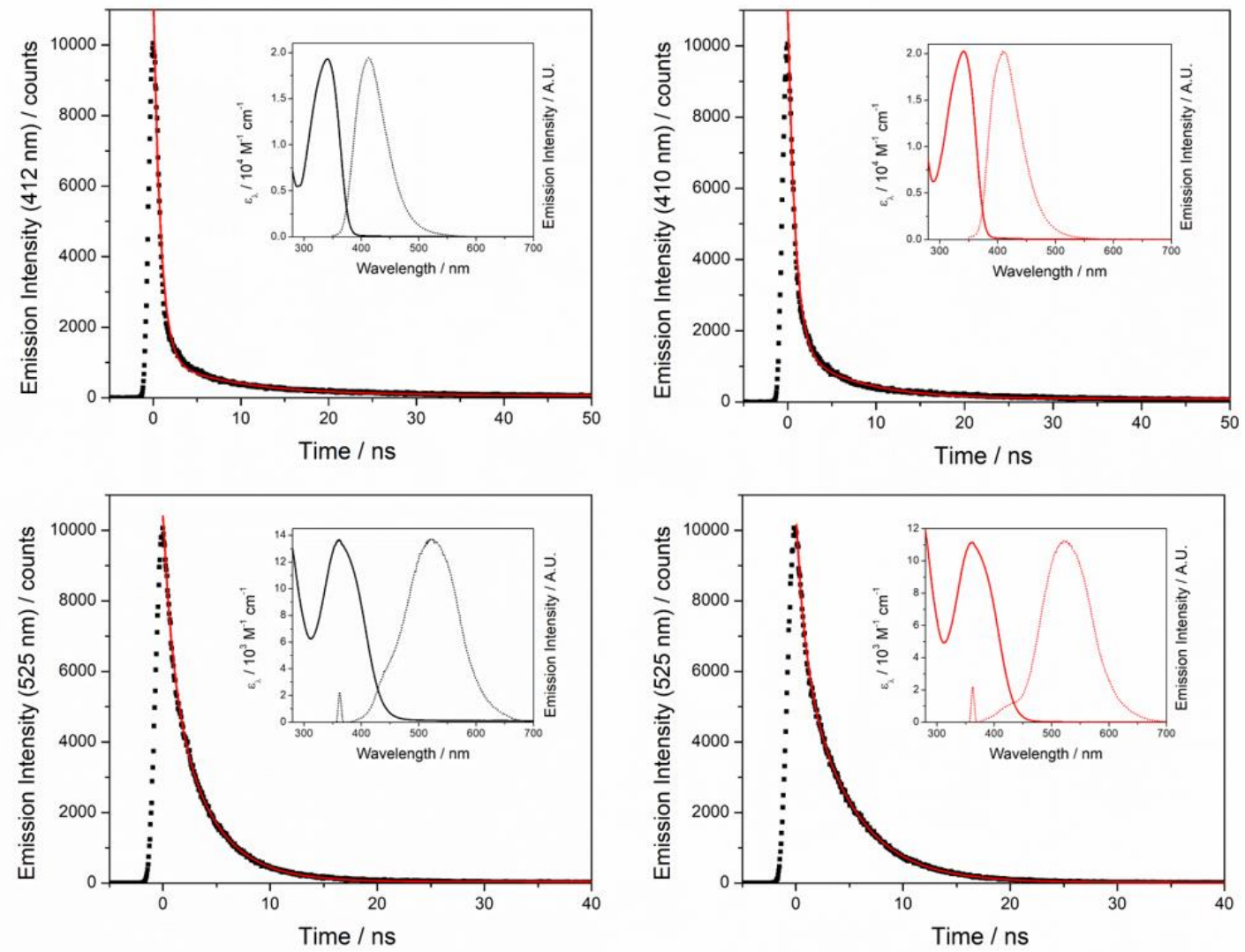

Figure A57. Time-resolved emission data for $\mathrm{H}_{2}{ }^{\mathrm{H}} \mathrm{CNN}$ (top left), $\mathrm{H}_{2}{ }^{\mathrm{Me}} \mathrm{CNN}$ (top right), $\mathrm{LiH}^{\mathrm{H}} \mathrm{CNN}$ (bottom left), and $\mathrm{LiH}^{\mathrm{Me}} \mathrm{CNN}$ (bottom right). All data were collected in benzene solution at room temperature. 
Quantum Yield Determination.

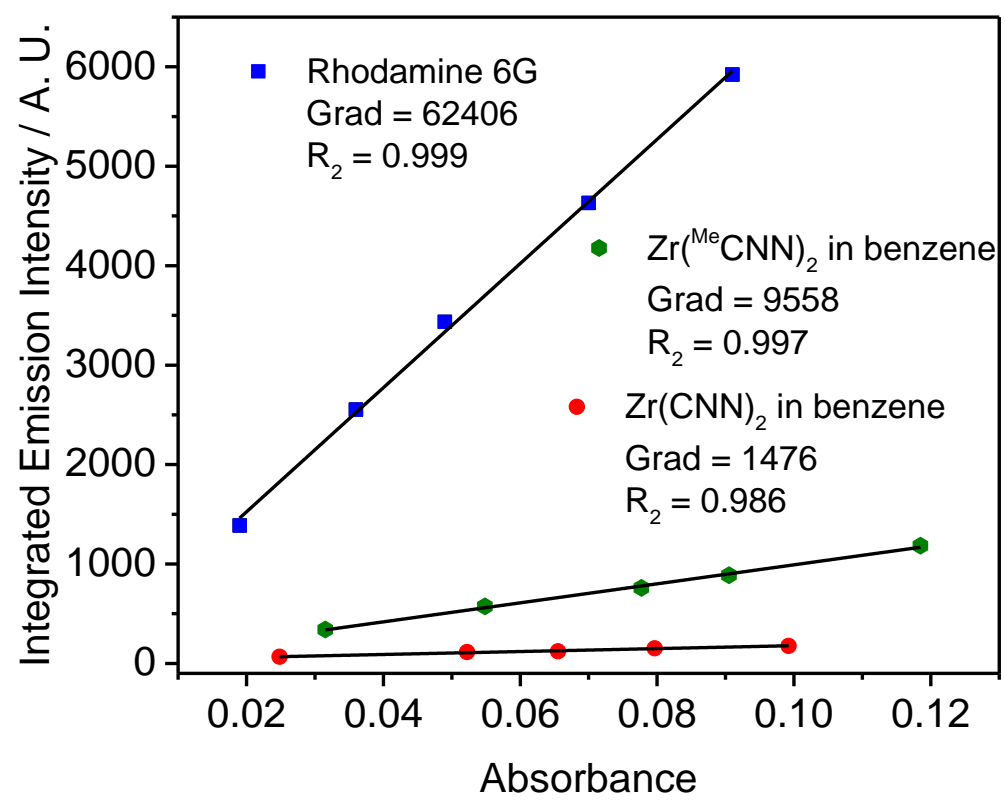

Figure 58. Plot of absorbance at $488 \mathrm{~nm}$ versus integration of the emission spectrum for Rhodamine 6G in ethanol $(\Phi=0.94), \operatorname{Zr}(\mathrm{CNN})_{2}(\Phi=0.03)$ and $\mathrm{Zr}\left({ }^{\mathrm{Me}} \mathrm{CNN}\right)_{2}(\Phi=0.18)$ in benzene. The black lines represent linear fits of the data and the gradients used for the quantum yield determination is shown next to the corresponding fit. 


\section{Additional Electrochemistry Data}

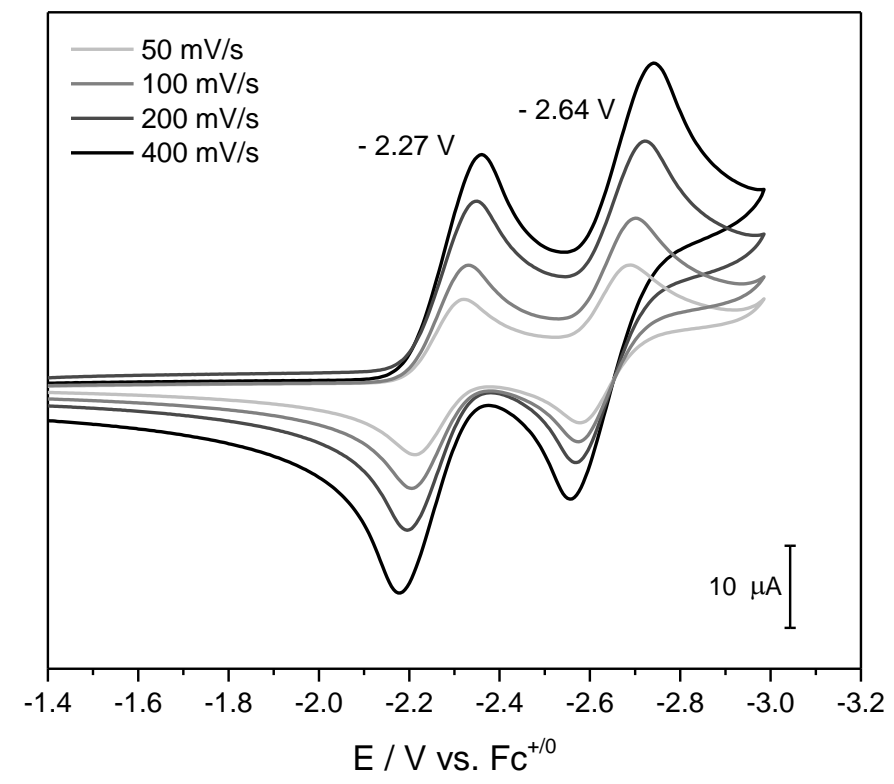

Figure A59. Cyclic voltammogram of $\mathrm{Zr}(\mathrm{CNN})_{2}$ in 1,2-difluorobenzene at room temperature at different scan rates (o.1 $\mathrm{M}\left[\mathrm{N}(\mathrm{n}-\mathrm{Bu})_{4}\right] \mathrm{PF}_{6}$, glassy carbon working electrode).

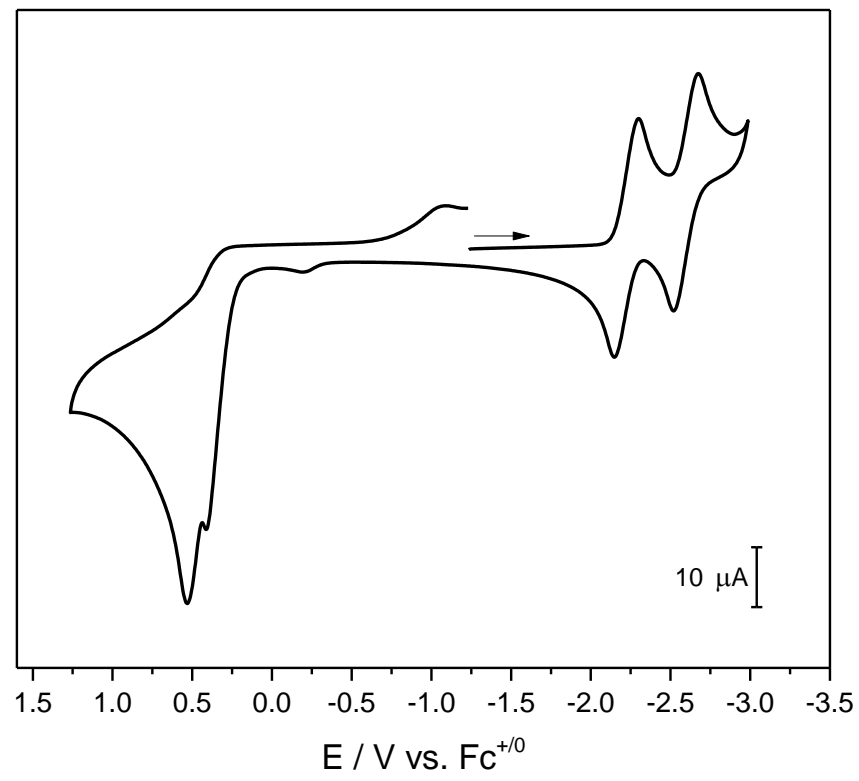

Figure 60. Cyclic voltammogram of $\mathrm{Zr}(\mathrm{CNN})_{2}$ in 1,2-difluorobenzene at room temperature (scan rate $200 \mathrm{mV} \mathrm{s}^{-1}, 0.1 \mathrm{M}\left[\mathrm{N}(\mathrm{n}-\mathrm{Bu})_{4}\right] \mathrm{PF}_{6}$, glassy carbon working electrode). Two irreversible oxidations are observed at $\mathrm{E}_{\mathrm{pa}}=0.41$ and $0.53 \mathrm{~V}$, while two reversible reduction events can be identified at $\mathrm{E}_{1 / 2}=-2.27$ and $-2.64 \mathrm{~V}$. 


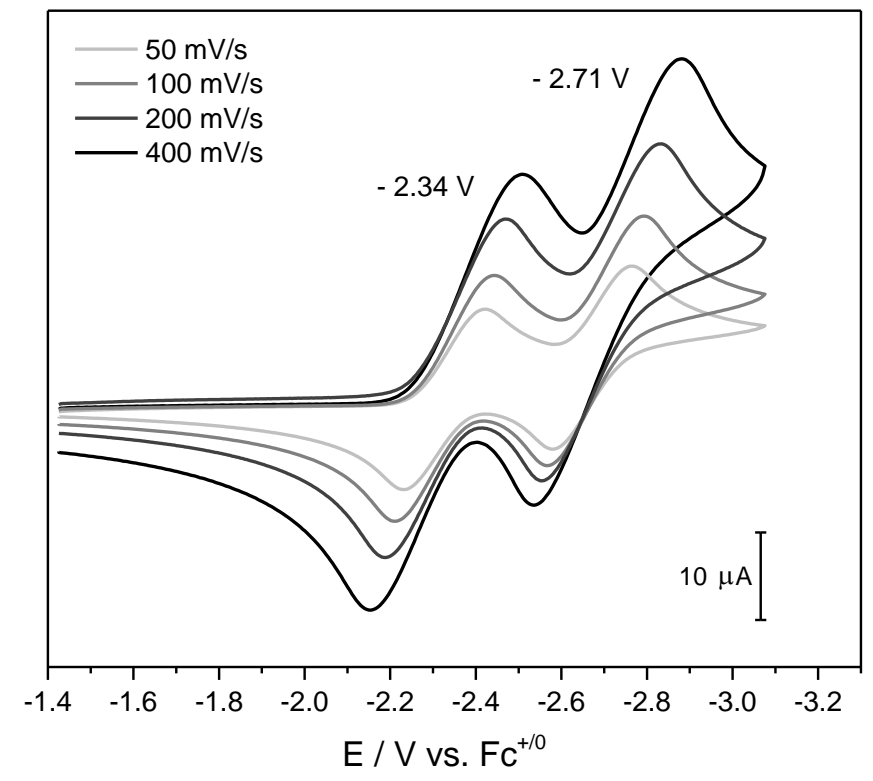

Figure A61. Cyclic voltammogram of $\mathrm{Zr}(\mathrm{CNN})_{2}$ in $\mathrm{THF}$ at room temperature at different scan rates (o.1 $\mathrm{M}\left[\mathrm{N}(\mathrm{n}-\mathrm{Bu})_{4}\right] \mathrm{PF}_{6}$, glassy carbon working electrode).

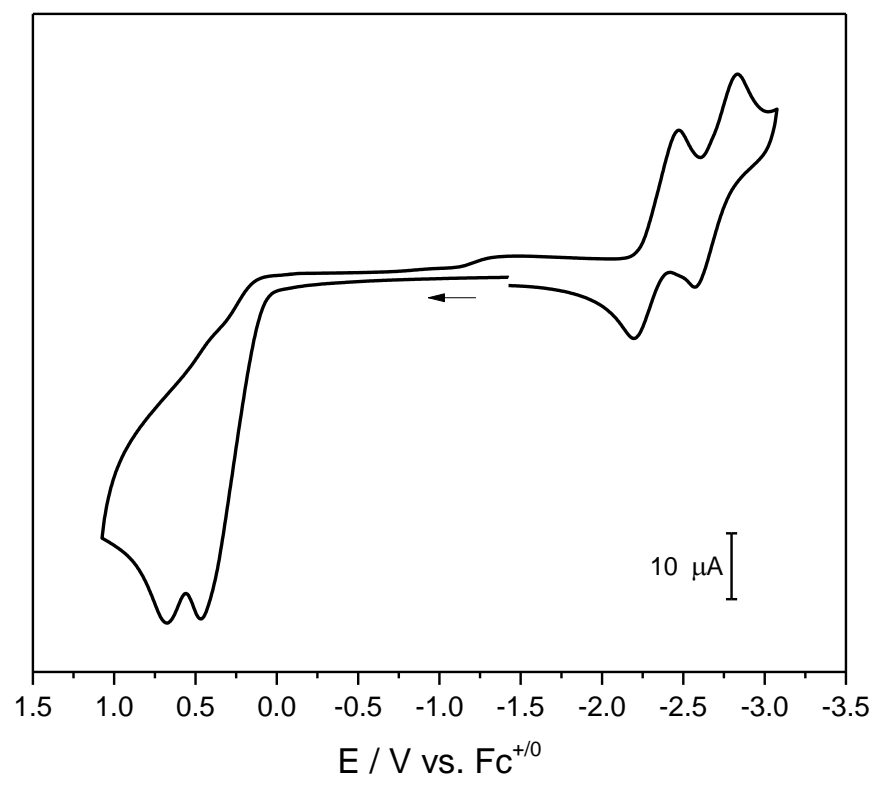

Figure A62. Cyclic voltammogram of $\mathrm{Zr}(\mathrm{CNN})_{2}$ in THF at room temperature (scan rate $200 \mathrm{mV}$ $\mathrm{s}^{-1}, 0.1 \mathrm{M}\left[\mathrm{N}(\mathrm{n}-\mathrm{Bu})_{4}\right] \mathrm{PF}_{6}$, glassy carbon working electrode). Two irreversible oxidations are observed at $\mathrm{E}_{\mathrm{pa}}=0.46$ and $0.68 \mathrm{~V}$, while two reversible reduction events can be identified at $\mathrm{E}_{1 / 2}$ $=-2.34$ and $-2.71 \mathrm{~V}$. 


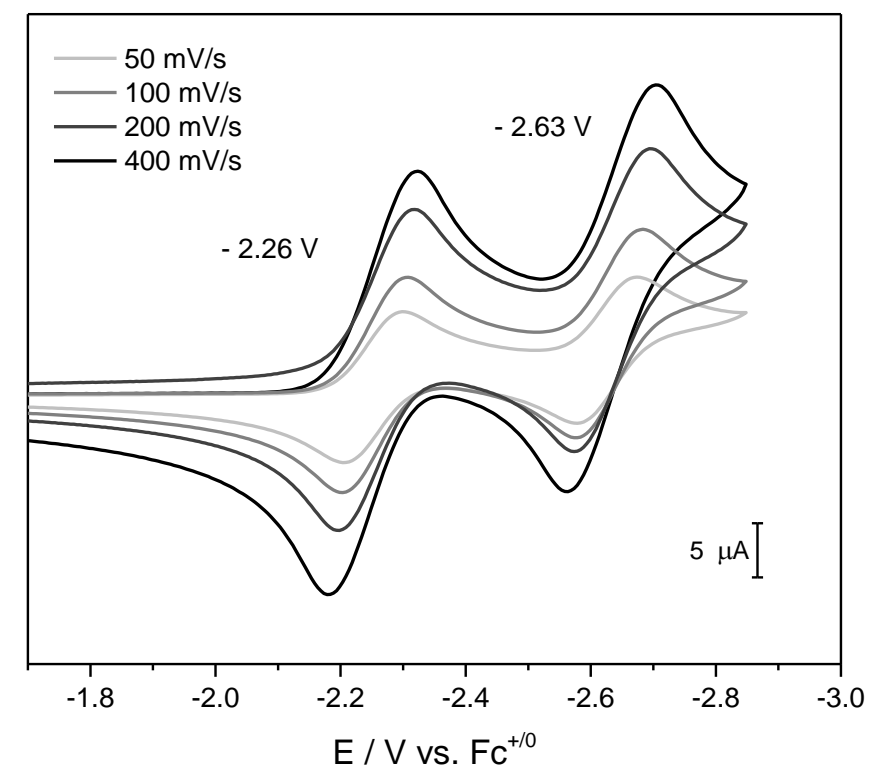

Figure A63. Cyclic voltammogram of $\mathrm{Zr}\left({ }^{\mathrm{Me}} \mathrm{CNN}\right)_{2}$ in 1,2-difluorobenzene at room temperature at different scan rates (o.1 $\mathrm{M}\left[\mathrm{N}(\mathrm{n}-\mathrm{Bu})_{4}\right] \mathrm{PF}_{6}$, glassy carbon working electrode).

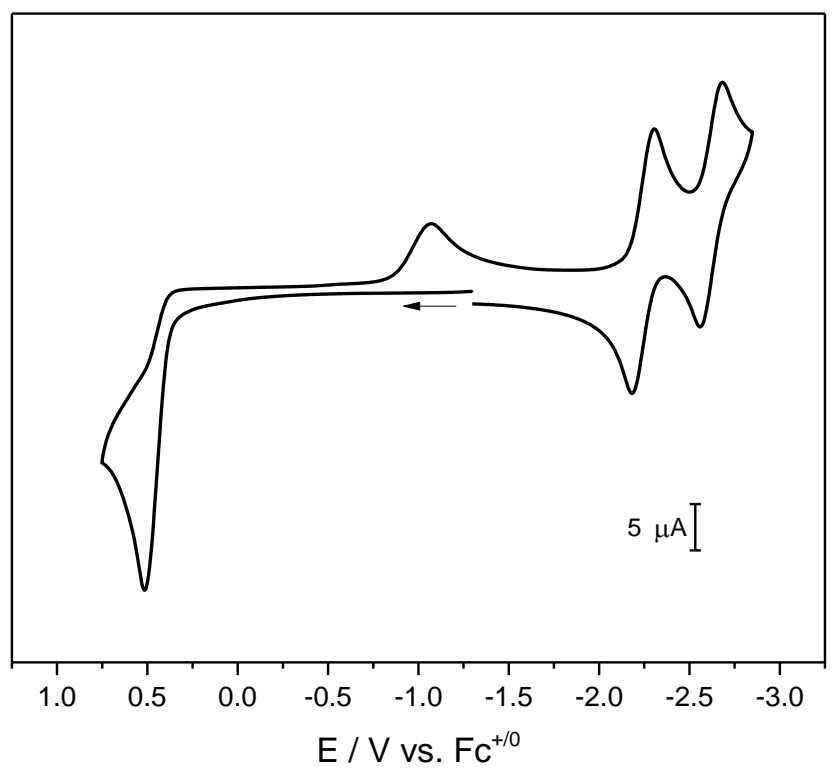

Figure A64. Cyclic voltammogram of $\mathrm{Zr}\left({ }^{\mathrm{Me}} \mathrm{CNN}\right)_{2}$ in 1,2-difluorobenzene at room temperature (scan rate $200 \mathrm{mV} \mathrm{s}^{-1}, 0.1 \mathrm{M}\left[\mathrm{N}(\mathrm{n}-\mathrm{Bu})_{4}\right] \mathrm{PF}_{6}$, glassy carbon working electrode). One irreversible oxidation are observed at $\mathrm{E}_{\mathrm{pa}}=0.51 \mathrm{~V}$, while two reversible reduction events can be identified at $\mathrm{E}_{1 / 2}=-2.26$ and $-2.63 \mathrm{~V}$ 


\section{Experimental Setup for Photoreactions}

All photo-reactions were performed using commercially available LED light strips with an emission maximum at $462 \mathrm{~nm}$. Constant room temperature conditions were maintained using a water bath in a jacketed glass beaker with water cooling.

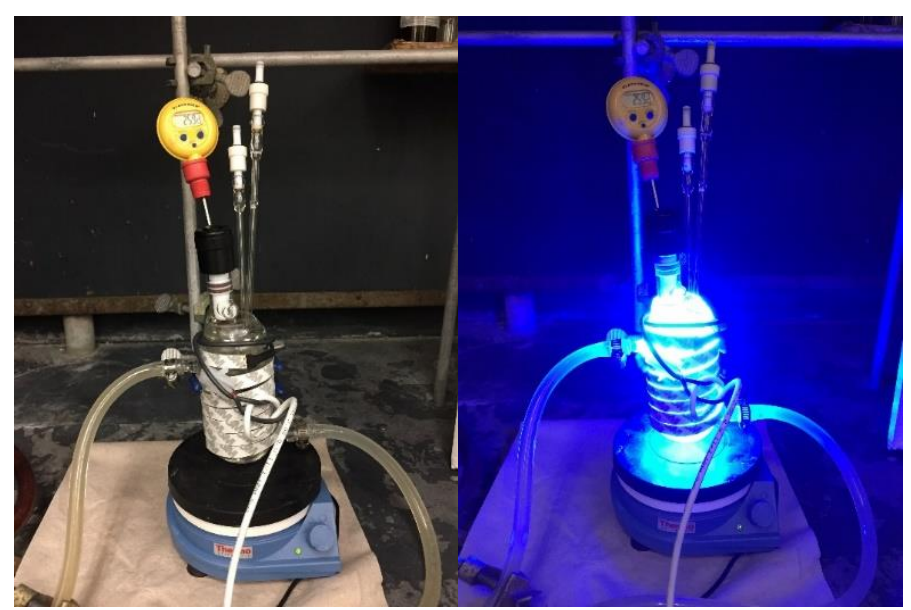

Figure A65. Experimental setup for irradiation of NMR tubes and thick-walled glass vessels with Teflon screw caps.

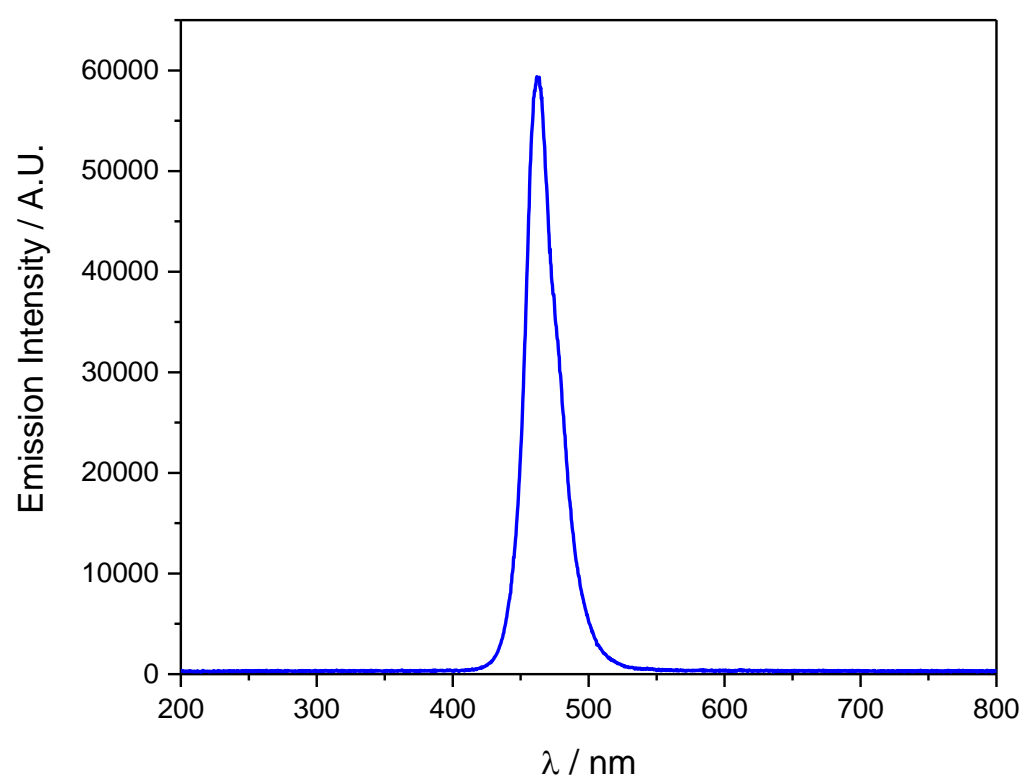

Figure A66. Emission profile of LED light strips used for photo-reactions $\left(\lambda_{\max }=462 \mathrm{~nm}\right)$. 


\section{A.7. Addition Data for Chapter 6.}

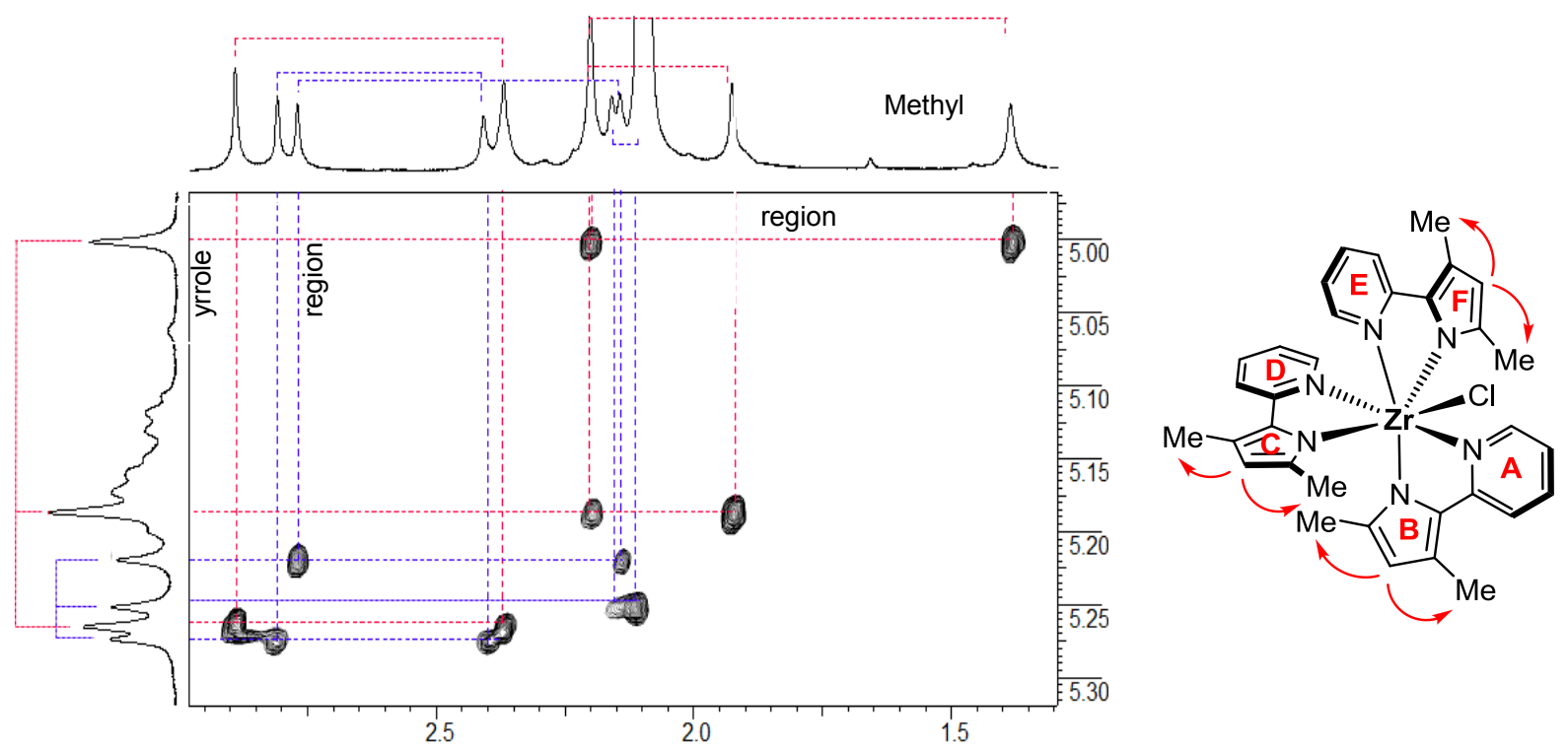

Figure A67. The expanded portion of the gCOSY spectrum for $\left({ }^{\mathrm{Me}} \mathrm{PMP}{ }^{\mathrm{Me}}\right)_{3} \mathrm{ZrCl}$ at $-90{ }^{\circ} \mathrm{C}$. The red line corresponds to the major isomer and blue dashed line corresponds to the minor isomer.

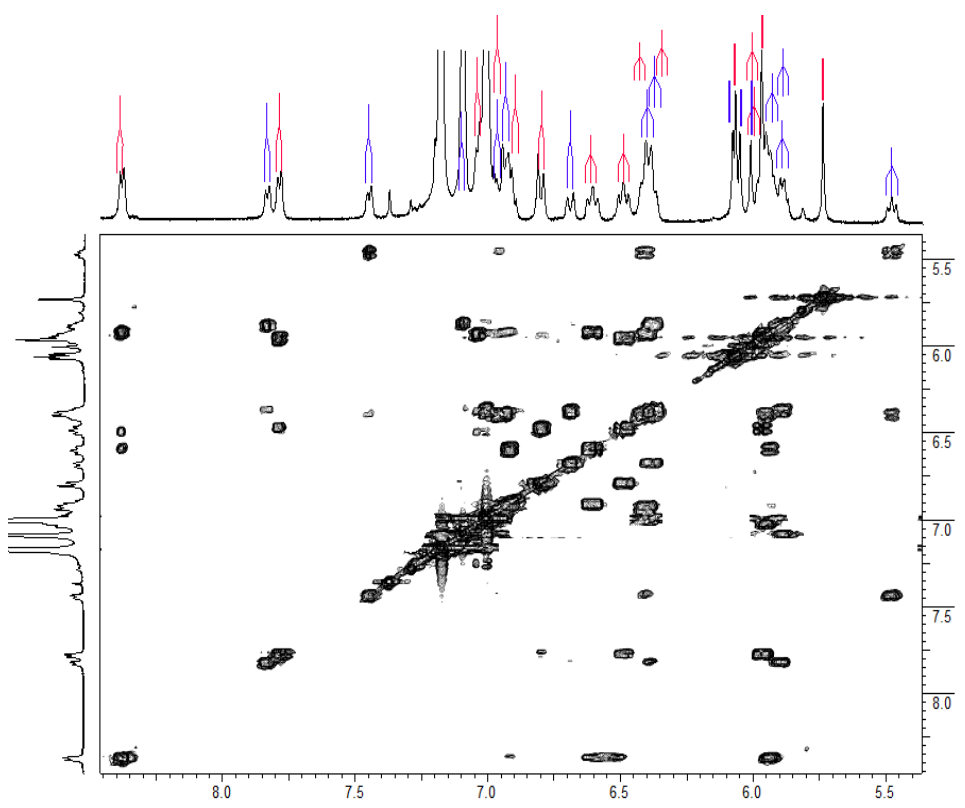

Figure A68. The expanded aromatic proton region of the gCOSY spectrum for $\left({ }^{\mathrm{Me}} \mathrm{PMP}{ }^{\mathrm{Me}}\right)_{3} \mathrm{ZrCl}$ at $-90{ }^{\circ} \mathrm{C}$. The contour plot of the gCOSY spectrum reveals for major and minor isomers for spin system of three different pyridine units and three different pyrrole units respectively. Expected number of doublets (12) and triplets (12) for both isomers are shown by red (major isomer) and blue (minor isomer) stick diagrams. 


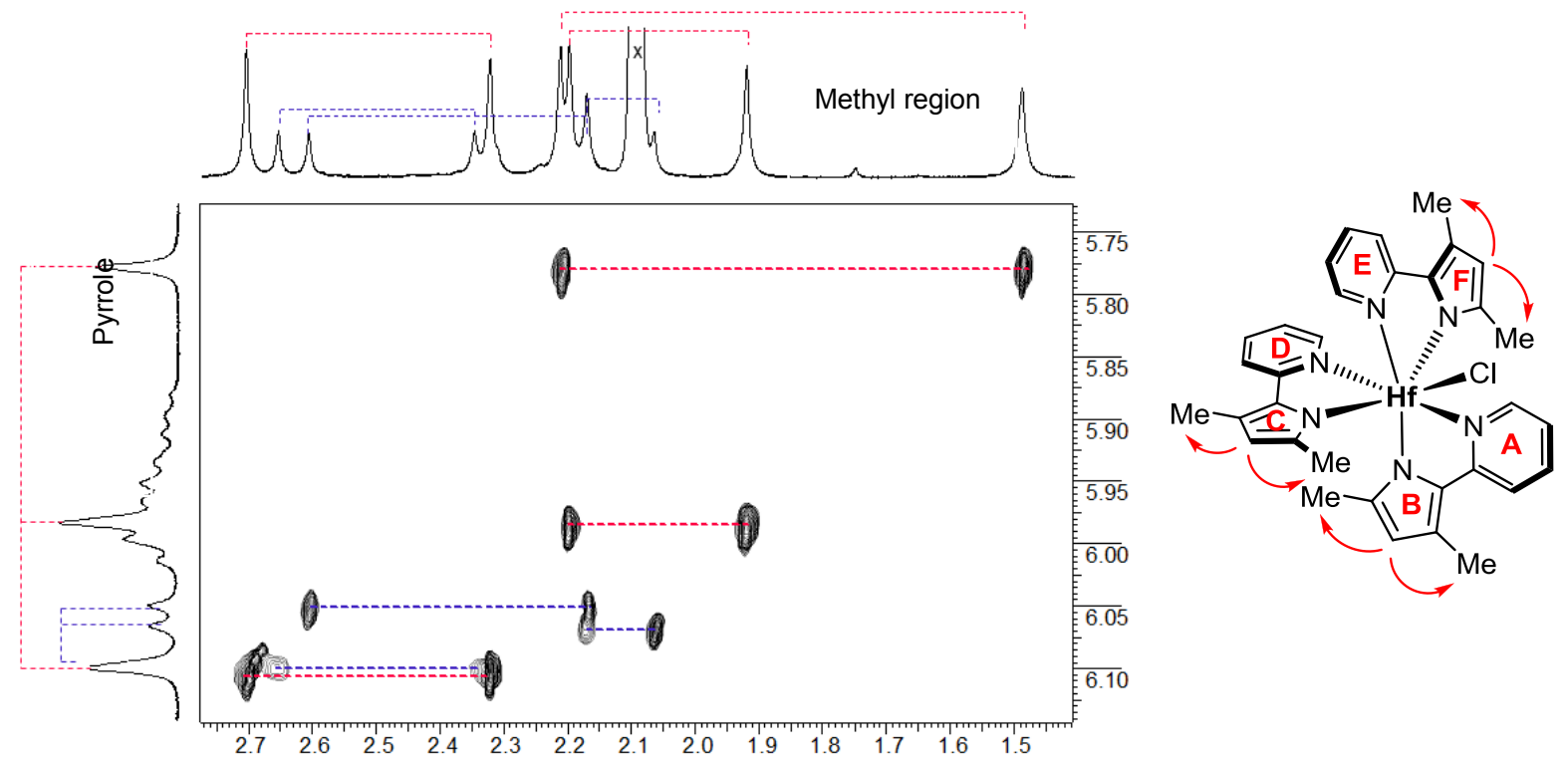

Figure A69. The expanded portion of the gCOSY spectrum for $\left({ }^{\mathrm{Me}} \mathrm{PMP}{ }^{\mathrm{Me}}\right)_{3} \mathrm{HfCl}$ at $-90{ }^{\circ} \mathrm{C}$. The red line corresponds to the major isomer and blue dashed line corresponds to the minor isomer.

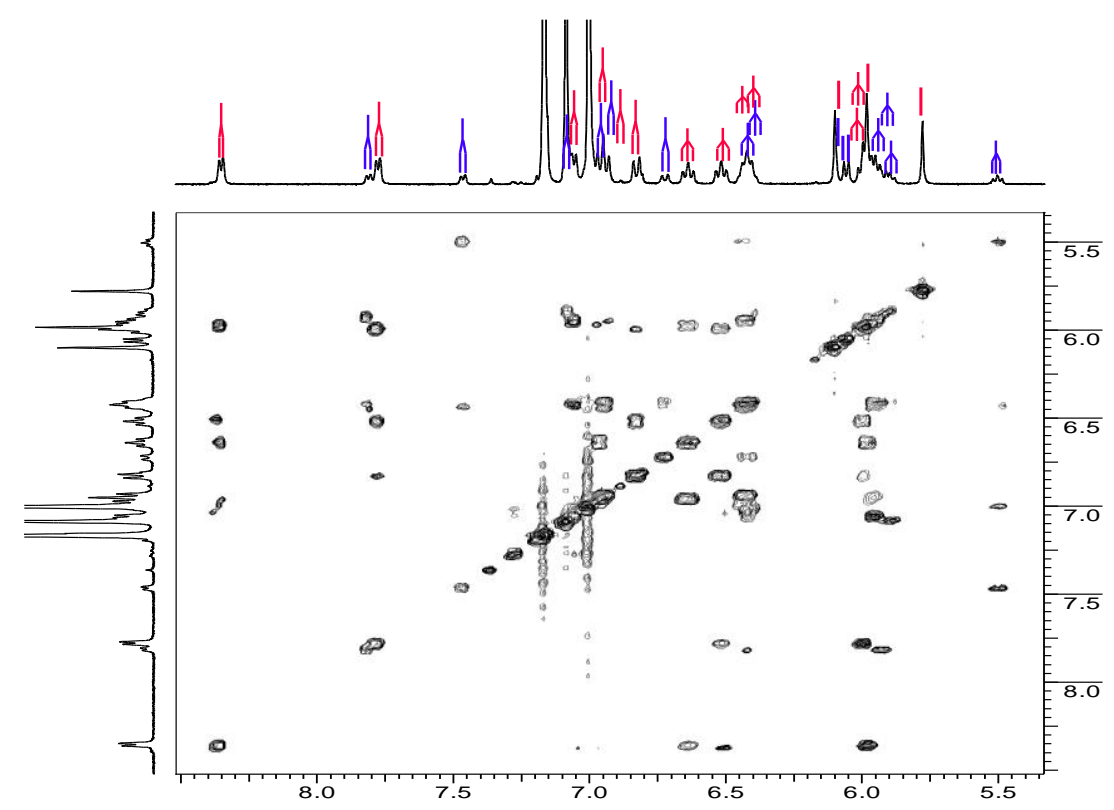

Figure A70. The expanded aromatic proton region of the gCOSY spectrum for $\left({ }^{\mathrm{Me}} \mathrm{PMP}{ }^{\mathrm{Me}}\right)_{3} \mathrm{HfCl}$ at $-90{ }^{\circ} \mathrm{C}$. The contour plot of the gCOSY spectrum reveals for major and minor isomers for spin system of three different pyridine units and three different pyrrole units respectively. Expected number of doublets (12) and triplets (12) for both isomers are shown by red (major isomer) and blue (minor isomer) stick diagrams. 


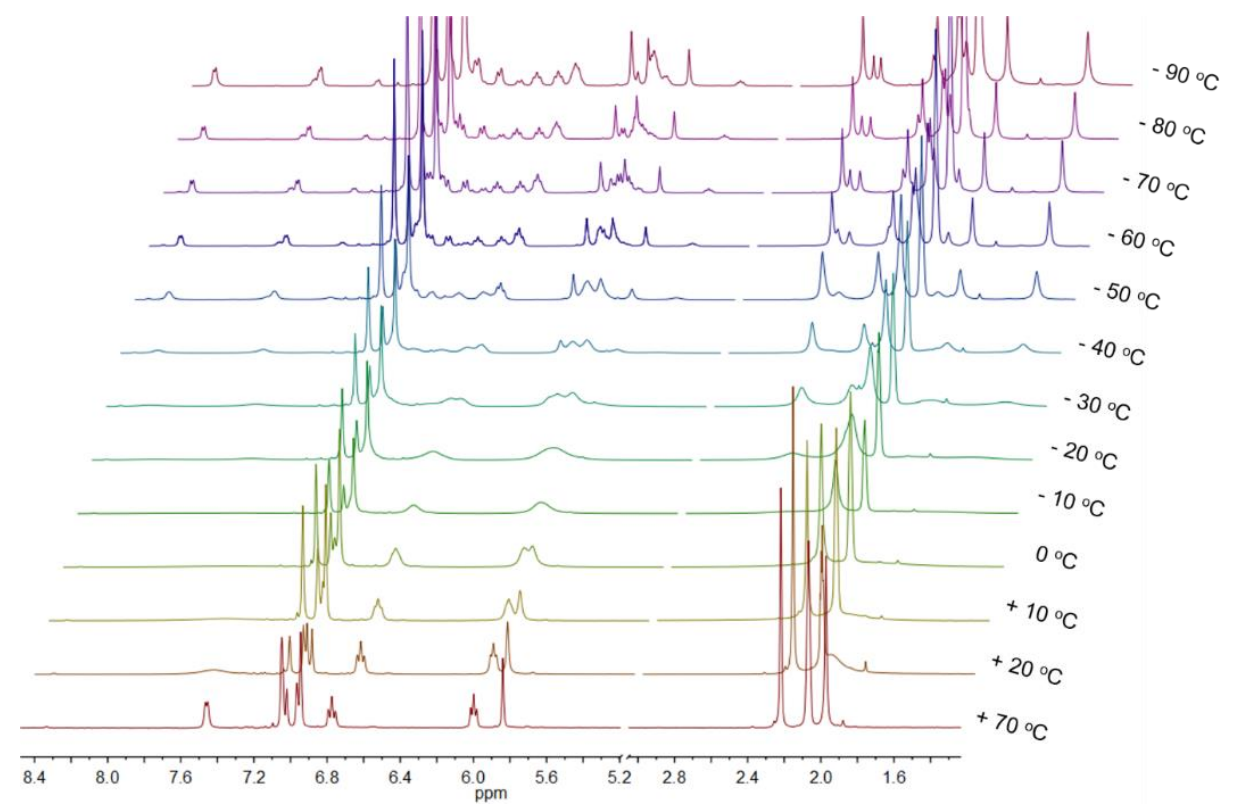

Figure A71. $400 \mathrm{MHz}^{1} \mathrm{H}$ NMR spectra (aromatic and alkyl region) of ( $\left.{ }^{\mathrm{Me}} \mathrm{PMP}{ }^{\mathrm{Me}}\right)_{3} \mathrm{HfCl}$ in toluene$d_{8}$ at temperatures ranging from +70 to $-90^{\circ} \mathrm{C}$.

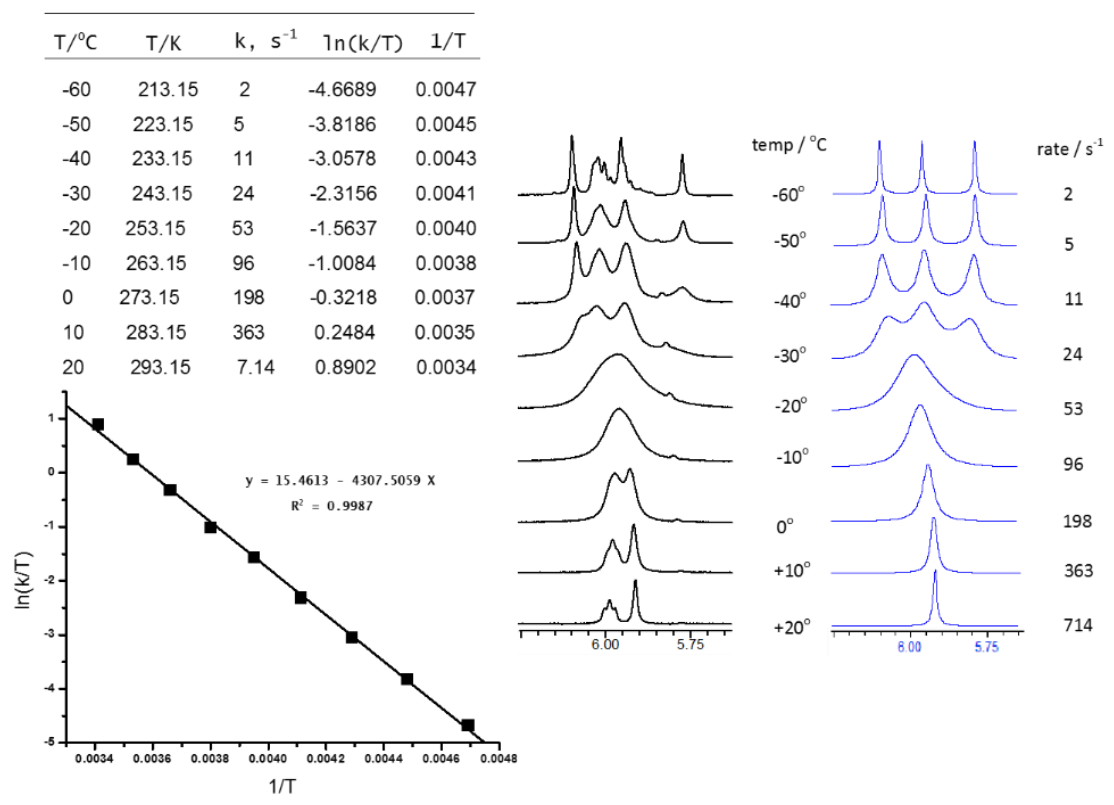

Figure A72. Eyring plot of $\ln (\mathrm{k} / \mathrm{T})$ vs. $1 / \mathrm{T}$ for rate constants obtained by line shape simulation of pyrrole proton signal for $\left({ }^{\mathrm{Me}} \mathrm{PMP}{ }^{\mathrm{Me}}\right)_{3} \mathrm{ZrCl}$ at temperatures between $213 \mathrm{~K}$ and $293 \mathrm{~K}$. 


\section{Spectroscopic Data}

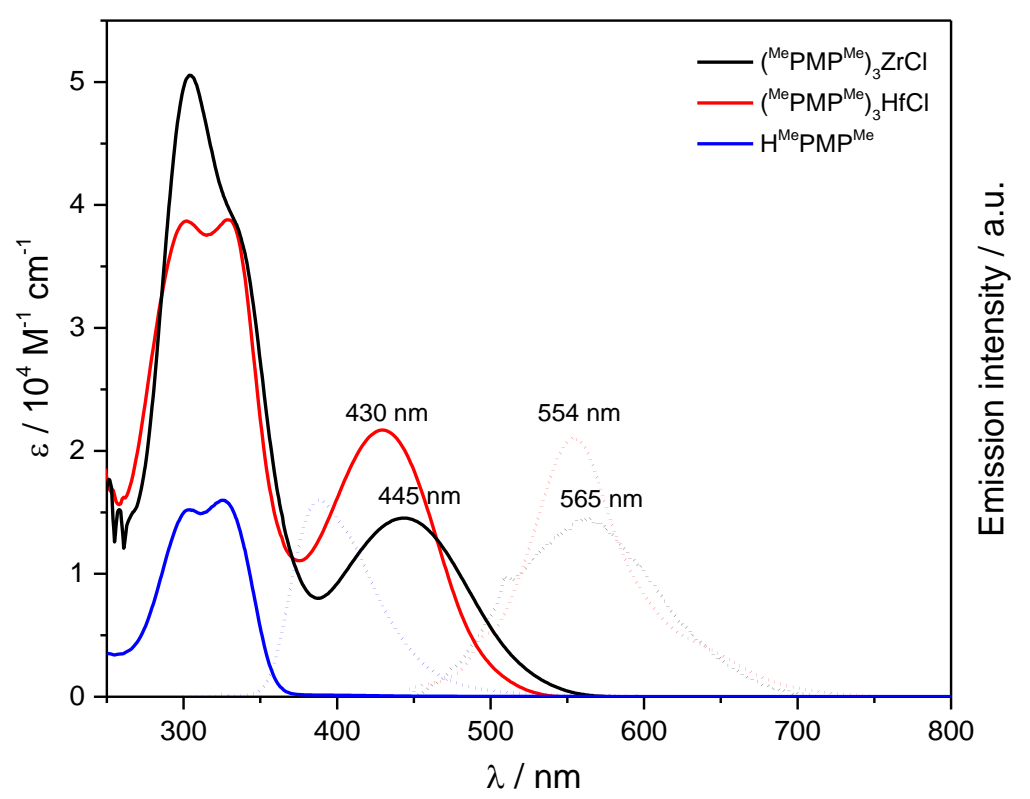

Figure A73. Absorption (solid lines) and uncorrected emission spectra (dotted lines) of $\left({ }^{\mathrm{Me}} \mathrm{PMP}{ }^{\mathrm{Me}}\right)_{3} \mathrm{MCl}(\mathrm{M}=\mathrm{Zr}, \mathrm{Hf})$ and $\mathrm{H}^{\mathrm{Me}} \mathrm{PMP}^{\mathrm{Me}}$ in THF solution at room temperature.

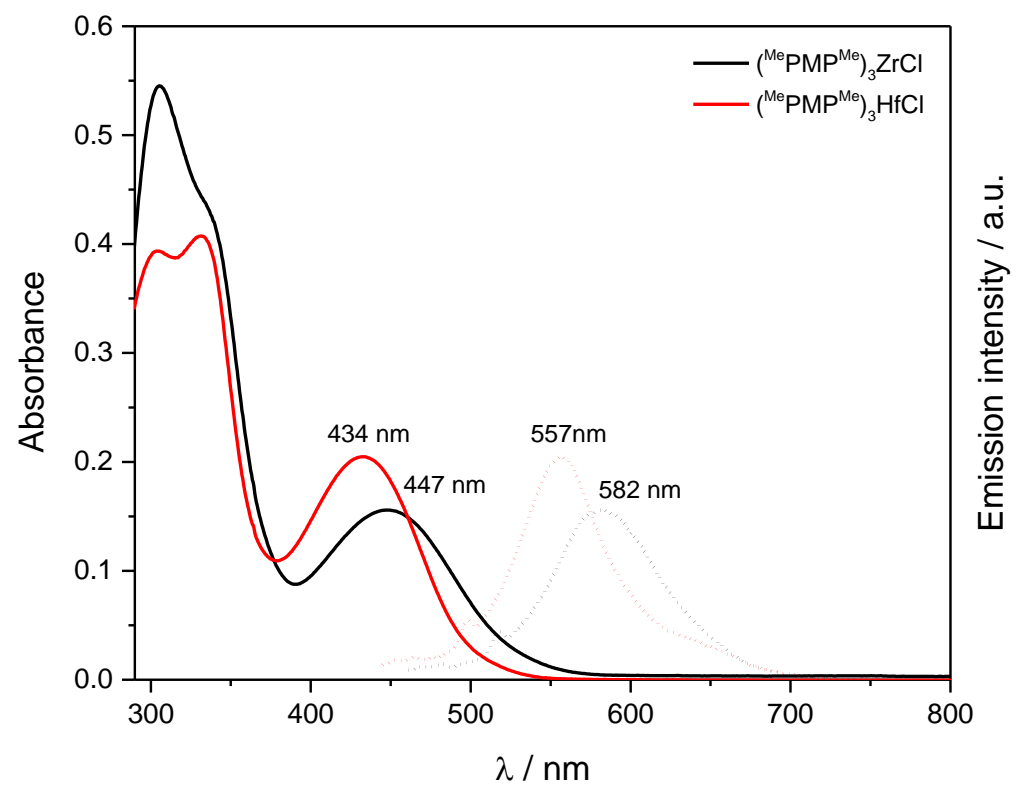

Figure A74. Absorption (solid lines) and uncorrected emission spectra (dotted lines) of $\left({ }^{\mathrm{Me}} \mathrm{PMP}{ }^{\mathrm{Me}}\right)_{3} \mathrm{MCl}\left(\mathrm{M}=\mathrm{Zr}\right.$, Hf) and $\mathrm{H}^{\mathrm{Me}} \mathrm{PMP}^{\mathrm{Me}}$ in toluene solution at room temperature. 
Quantum Yield Determination.

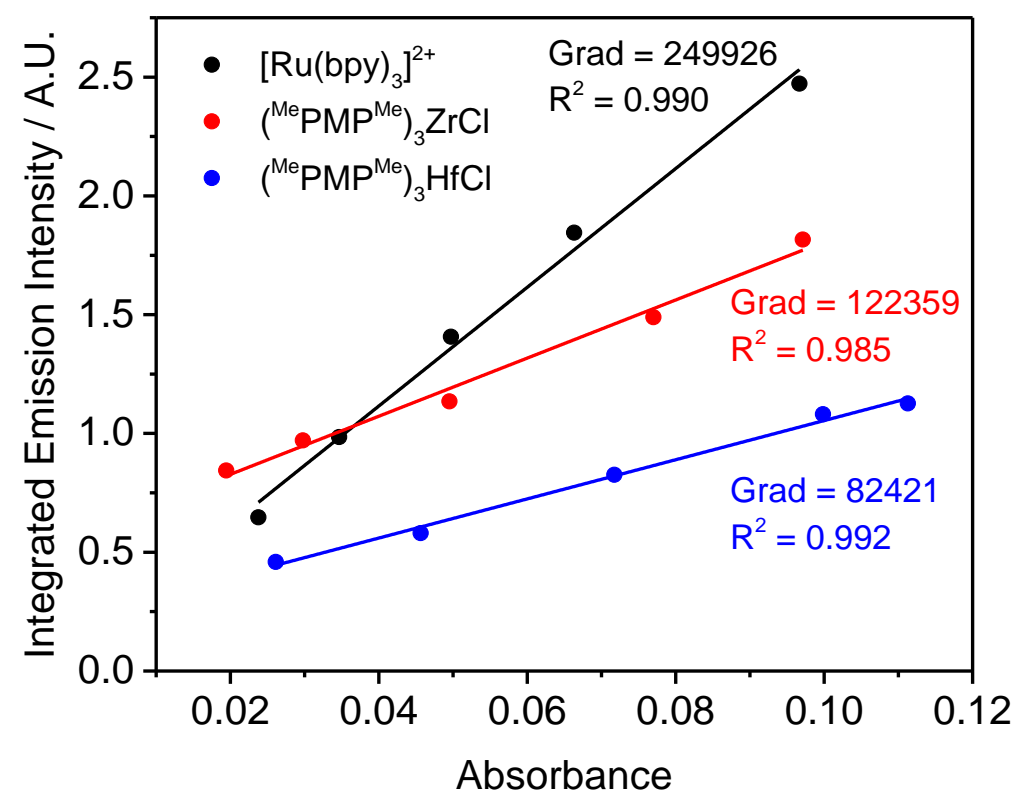

Figure A75. Plot of absorbance at $450 \mathrm{~nm}$ versus integration of the emission spectrum for $\left[\mathrm{Ru}(\mathrm{bpy})_{3}\right] \mathrm{Cl}_{2}$ in air-saturated acetonitrile $(\Phi=0.018)$ and $\left({ }^{\mathrm{Me}} \mathrm{PMP}^{\mathrm{Me}}\right)_{3} \mathrm{MCl}(\mathrm{M}=\mathrm{Zr}$, Hf $)$ in THF. The straight lines represent linear fits of the data and the gradients used for the quantum yield determination is shown next to the corresponding fit. 


\section{A.8. Addition Data for Chapter 7 .}

\section{Photoluminescence Quantum Yield Determination}

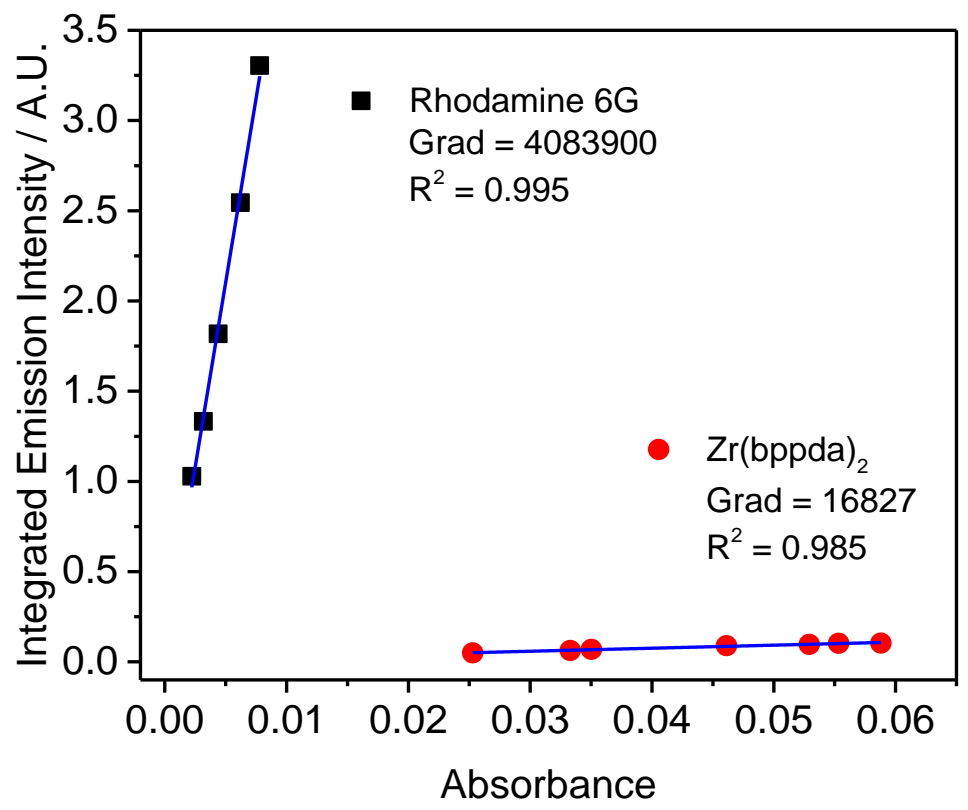

Figure A76. Plot of absorbance at $488 \mathrm{~nm}$ versus integration of the emission spectrum for Rhodamine 6G in ethanol $(\Phi=0.94), \operatorname{Zr}(\mathrm{bppda})_{2}(\Phi=0.004)$ in THF. The blue lines represent linear fits of the data and the gradients used for the quantum yield determination is shown next to the corresponding fit.

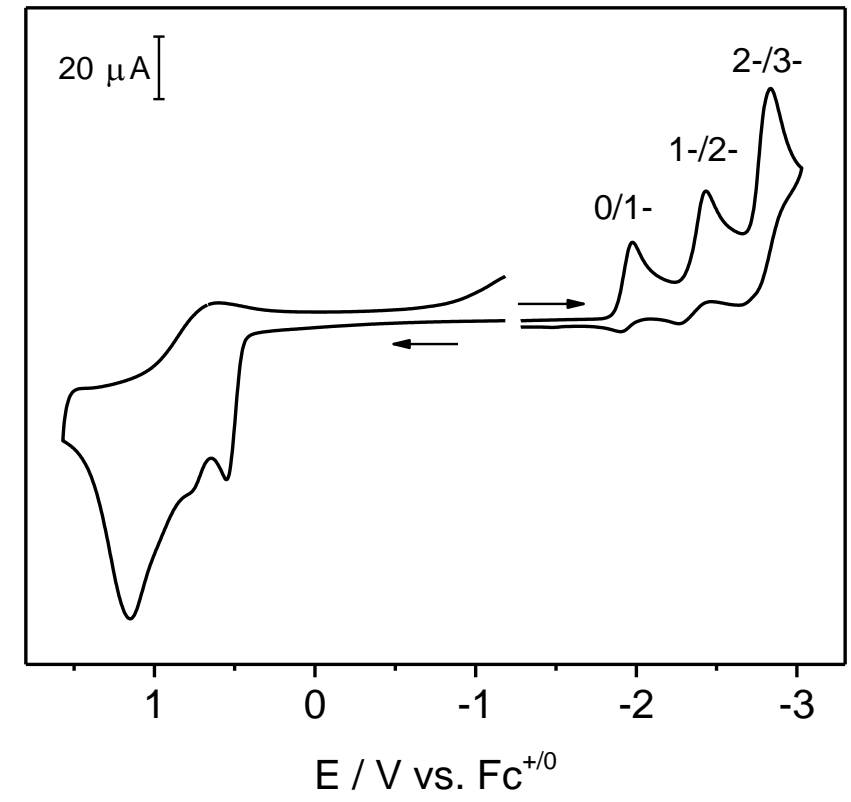

Figure A77. Cyclic voltammogram of $\mathrm{Zr}(\mathrm{bppda})_{2}$ in $\mathrm{MeCN}$ at room temperature (scan rate 200 $\mathrm{mV} \mathrm{s}^{-1}, 0.1 \mathrm{M}\left[\mathrm{N}(n-\mathrm{Bu})_{4}\right] \mathrm{PF}_{6}$, glassy carbon working electrode). 


\section{A.9. Addition Data for Chapter 8.}

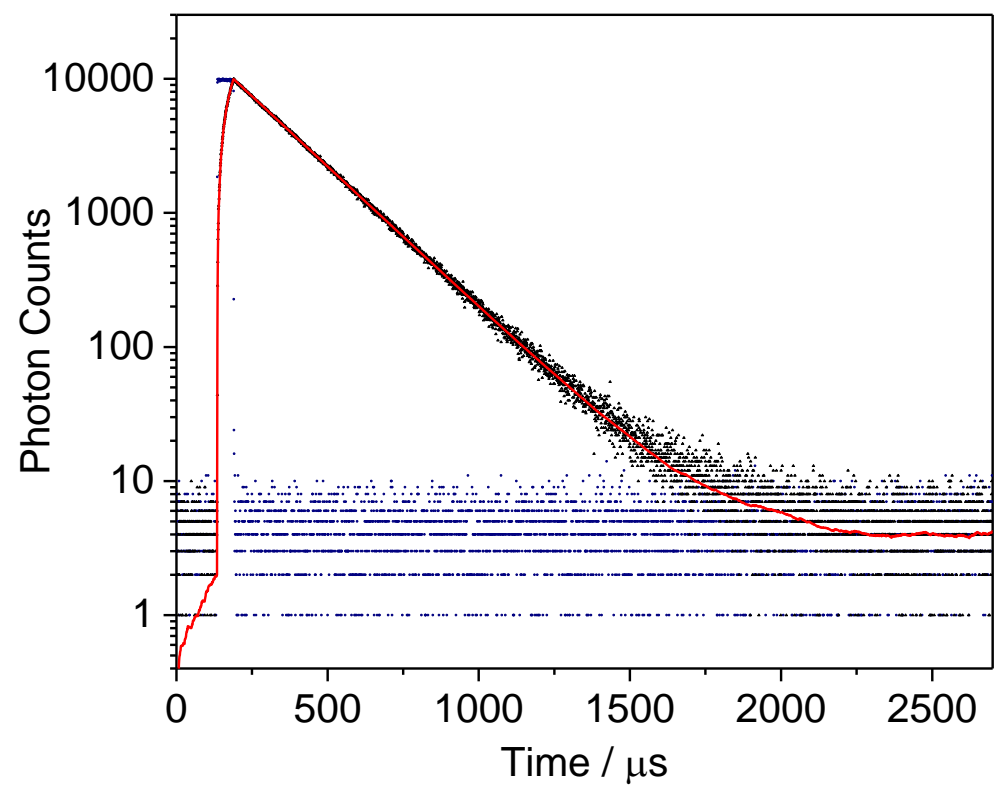

Figure 78. Representative example for time-resolved emission data for $\mathrm{Zr}\left({ }^{\mathrm{Mes}} \mathrm{PDP}^{\mathrm{NMe} 2 \mathrm{Ph}}\right)_{2}$ in THF at room temperature (black) detected at $600 \mathrm{~nm}$ upon excitation at $516 \mathrm{~nm}$. The red line shows the fit to a single-exponential decay with $\tau_{1}=207 \mu$ s and the navy trace is the excitation pulse.

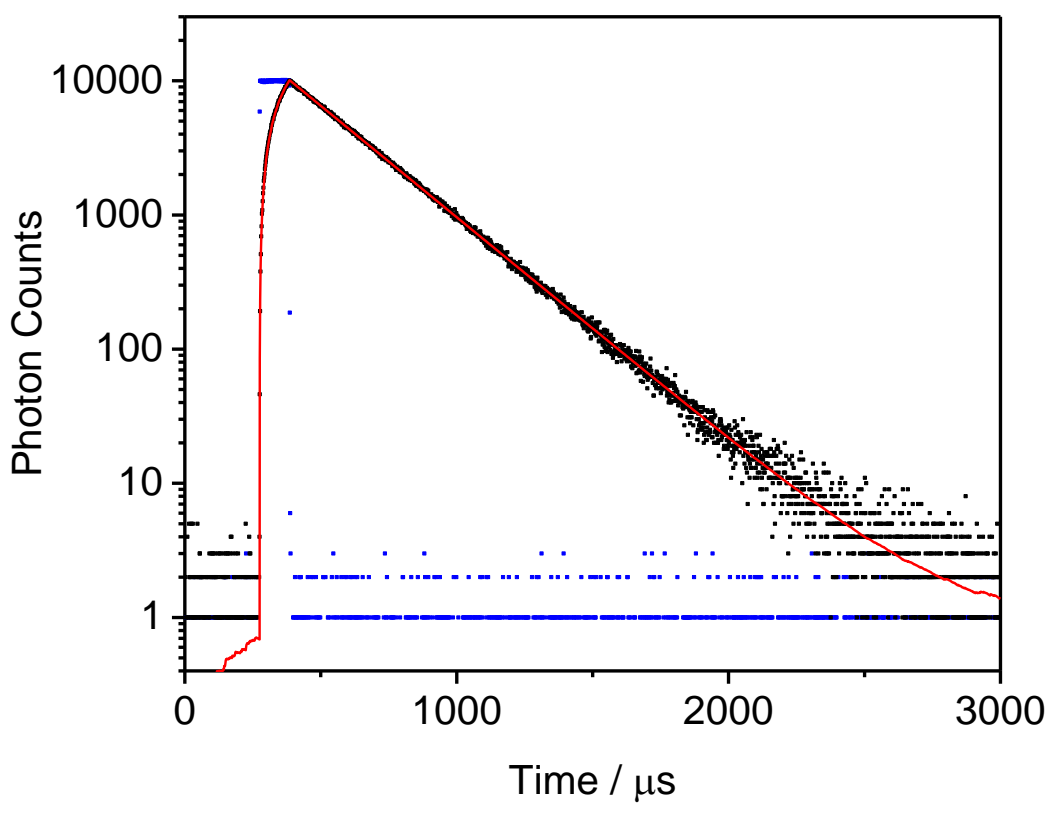

Figure 79. Representative example for time-resolved emission data for $\left[\mathrm{Zr}\left({ }^{\mathrm{Mes}} \mathrm{PDP}^{\mathrm{NMe} 3 \mathrm{Ph}}\right)_{2}\right] \mathrm{I}_{4}$ in THF at room temperature (black) detected at $600 \mathrm{~nm}$ upon excitation at $516 \mathrm{~nm}$. The red line shows the fit to a single-exponential decay with $\tau_{1}=261 \mu$ s and the blue trace is the excitation pulse. 


\section{Appendix B}

\section{NMR Spectrum}

\section{General Consideration.}

${ }^{1} \mathrm{H}$ and ${ }^{13} \mathrm{C}\left\{{ }^{1} \mathrm{H}\right\}$ NMR spectra were recorded on an Agilent $400 \mathrm{MHz}$ spectrometer, JOEL $400 \mathrm{MHz}$ YH spectrometer or a Varian INOVA $600 \mathrm{MHz}$ spectrometer. All chemical shifts are reported relative to $\mathrm{SiMe}_{4}$ using ${ }^{1} \mathrm{H}$ (residual) chemical shifts of the solvent as a secondary standard. To obtain NMR spectra free of solvent molecules present in the crystal lattice, which could overlap with signals from the complex in question, the compounds were first dissolved in a small amount of deuterated solvent, which was then removed in vacuum to co-evaporate the co-crystallized solvent molecules. Fresh deuterated solvent was then added to the residue to obtain a (close to) solvent-free NMR spectrum. 

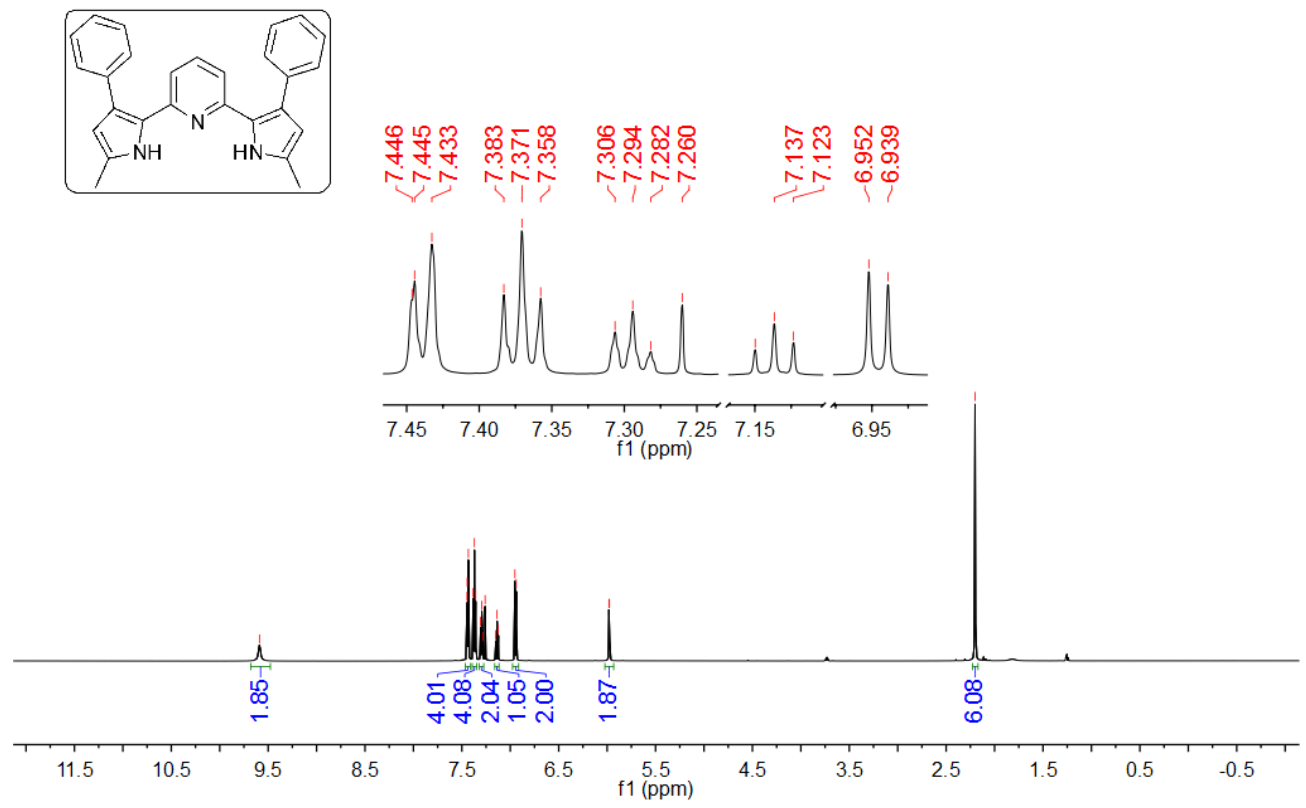

Figure B1. ${ }^{1} \mathrm{H}$ NMR spectrum of $\mathrm{H}_{2}{ }^{\mathrm{Me}} \mathrm{PDP}^{\mathrm{Ph}}$ in $\mathrm{CDCl}_{3}$.
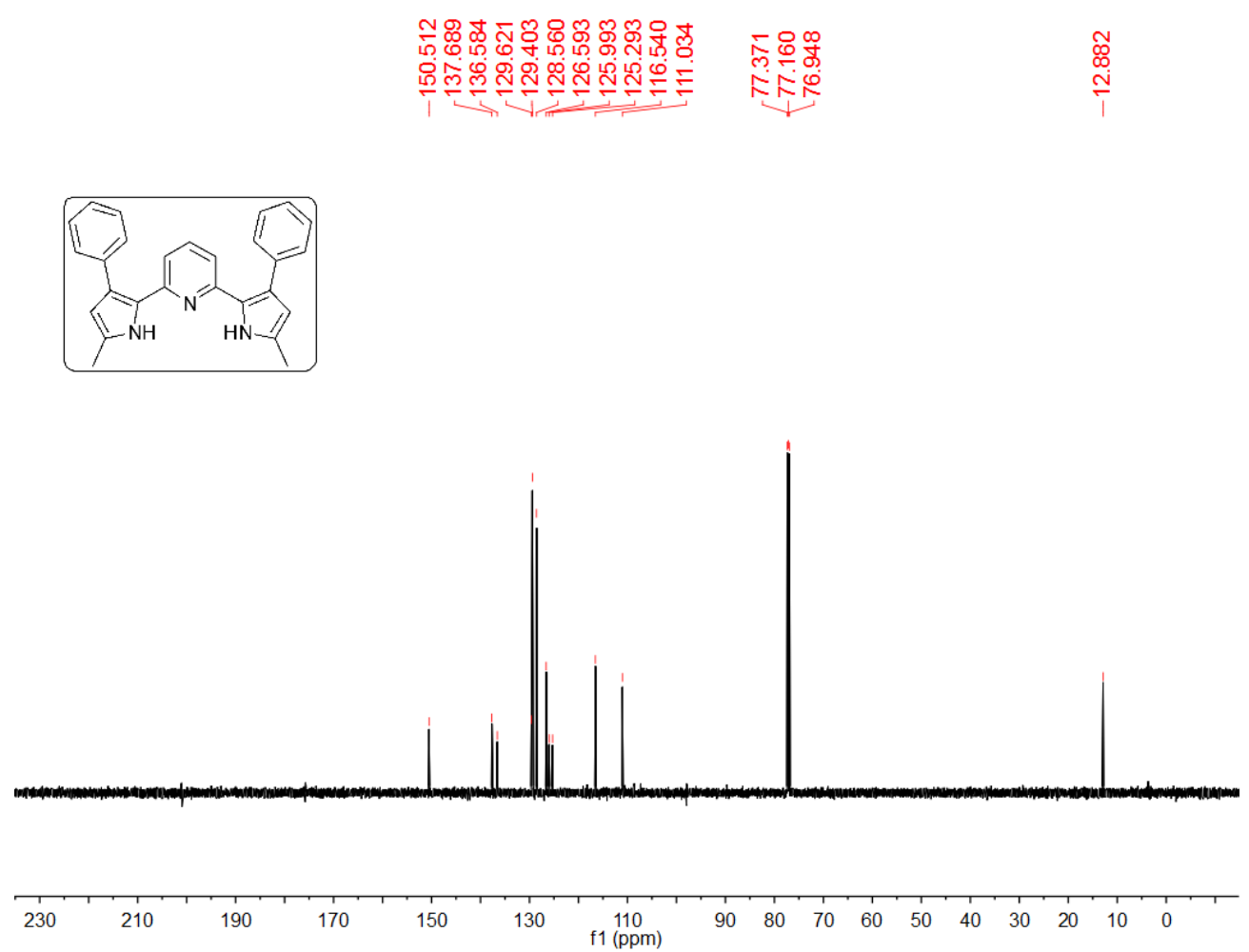

Figure B2. ${ }^{13} \mathrm{C}$ NMR spectrum of $\mathrm{H}_{2}{ }^{\mathrm{Me}} \mathrm{PDP}^{\mathrm{Ph}}$ in $\mathrm{CDCl}_{3}$. 

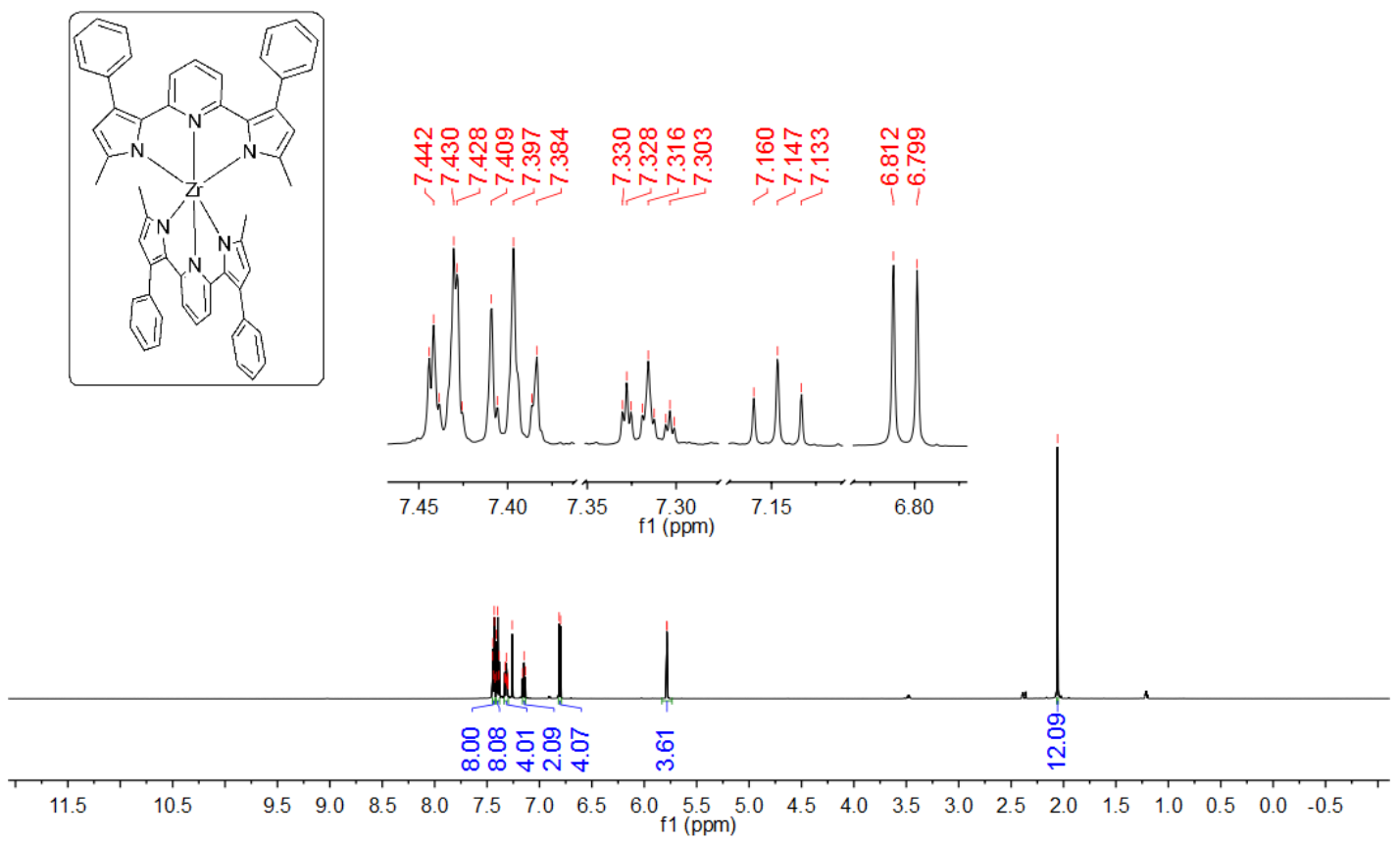

Figure B3. ${ }^{1} \mathrm{H}$ NMR spectrum of $\mathrm{Zr}\left({ }^{\mathrm{Me}} \mathrm{PDP}^{\mathrm{Ph}}\right)_{2}$ in $\mathrm{CDCl}_{3}$.

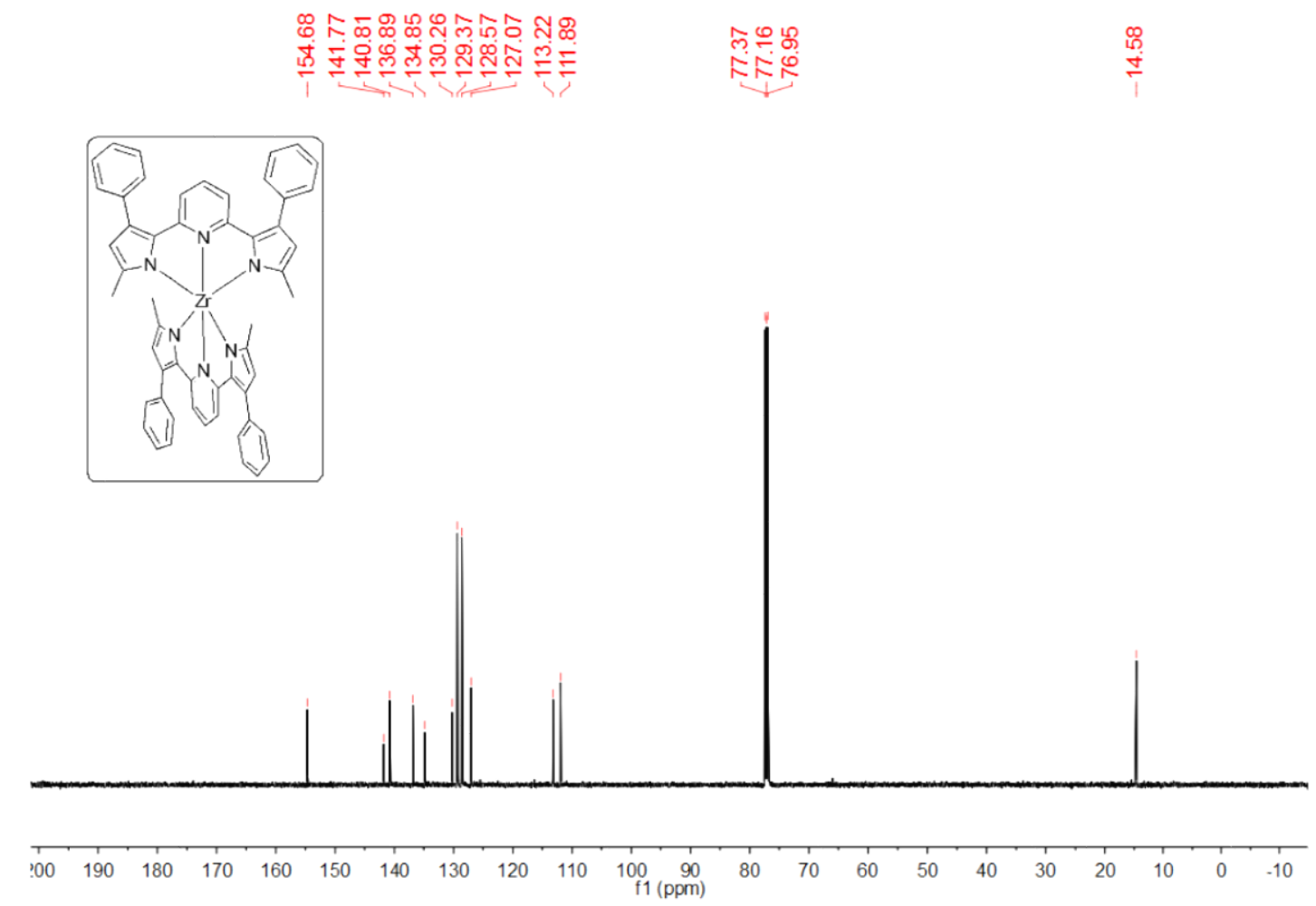

Figure B4. ${ }^{13} \mathrm{C}$ NMR spectrum of $\mathrm{Zr}\left({ }^{\mathrm{Me}} \mathrm{PDP}^{\mathrm{Ph}}\right)_{2}$ in $\mathrm{CDCl}_{3}$. 


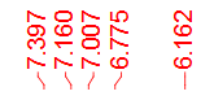

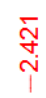
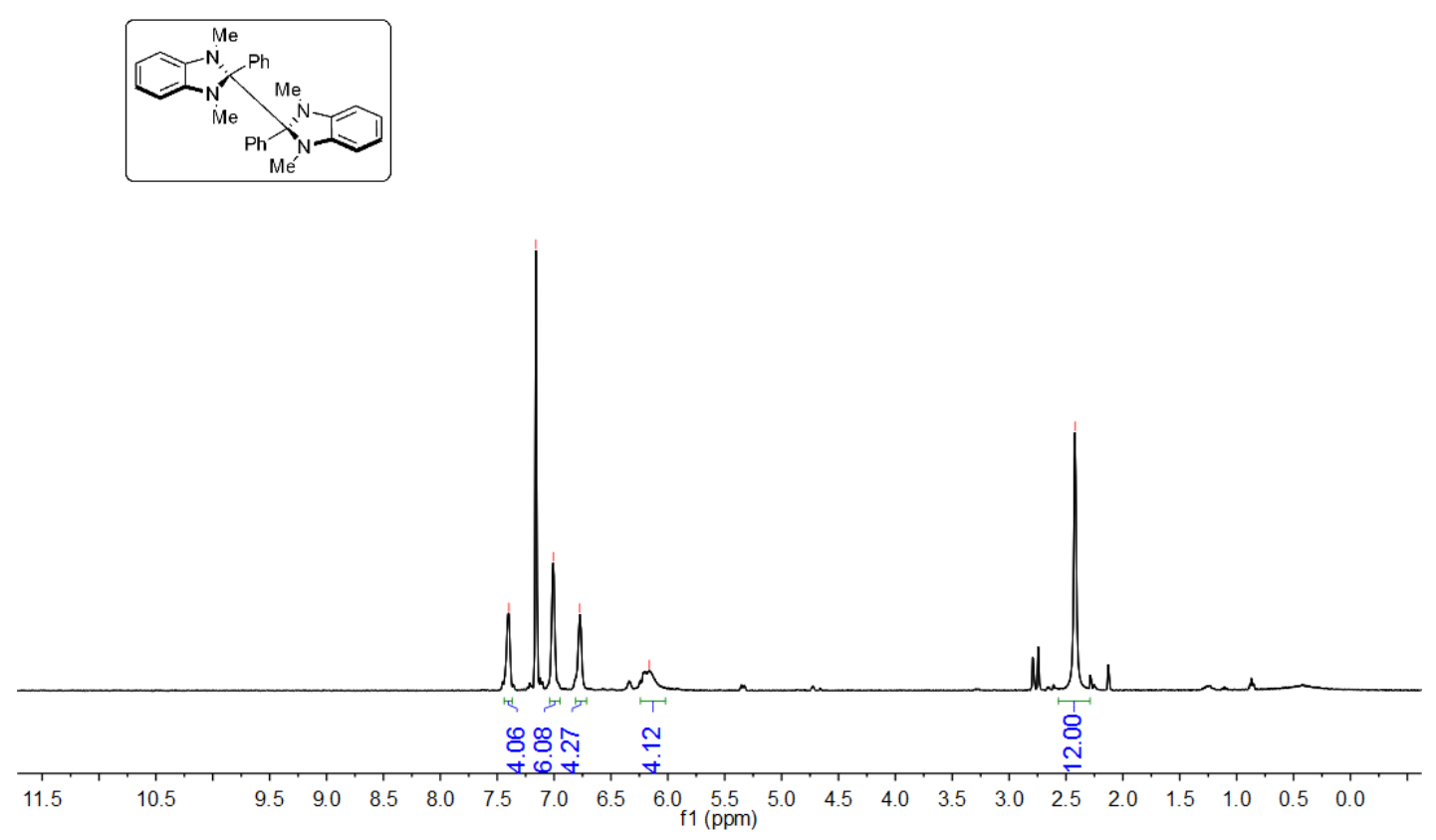

Figure B5. ${ }^{1} \mathrm{H}$ NMR spectrum of $\left({ }^{\mathrm{H}} \mathrm{BI}\right)_{2}$ in $\mathrm{C}_{6} \mathrm{D}_{6}$ at $65{ }^{\circ} \mathrm{C}$.

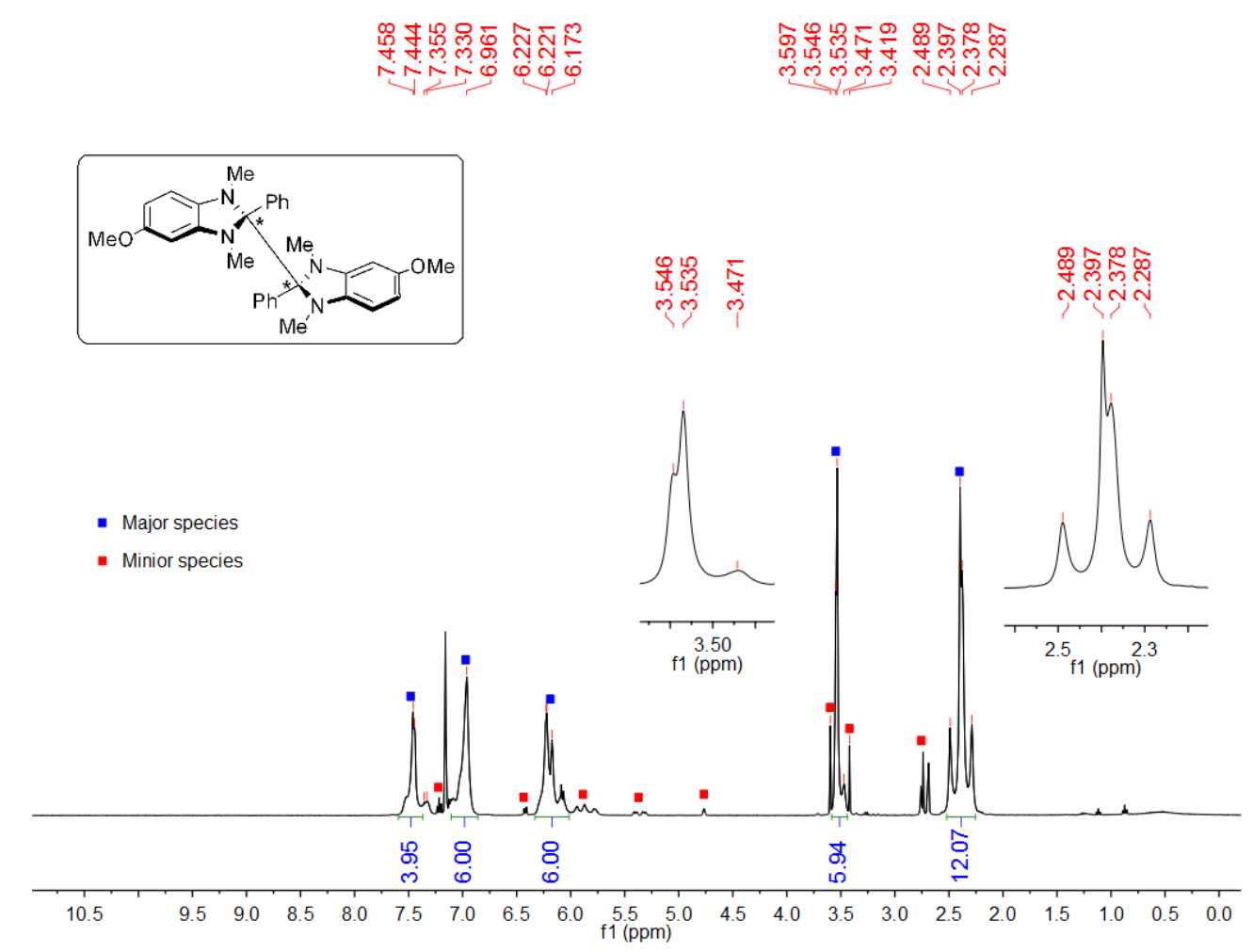

Figure B6. ${ }^{1} \mathrm{H}$ NMR spectrum of $\left({ }^{\mathrm{MeO}} \mathrm{BI}\right)_{2}$ in $\mathrm{C}_{6} \mathrm{D}_{6}$. 


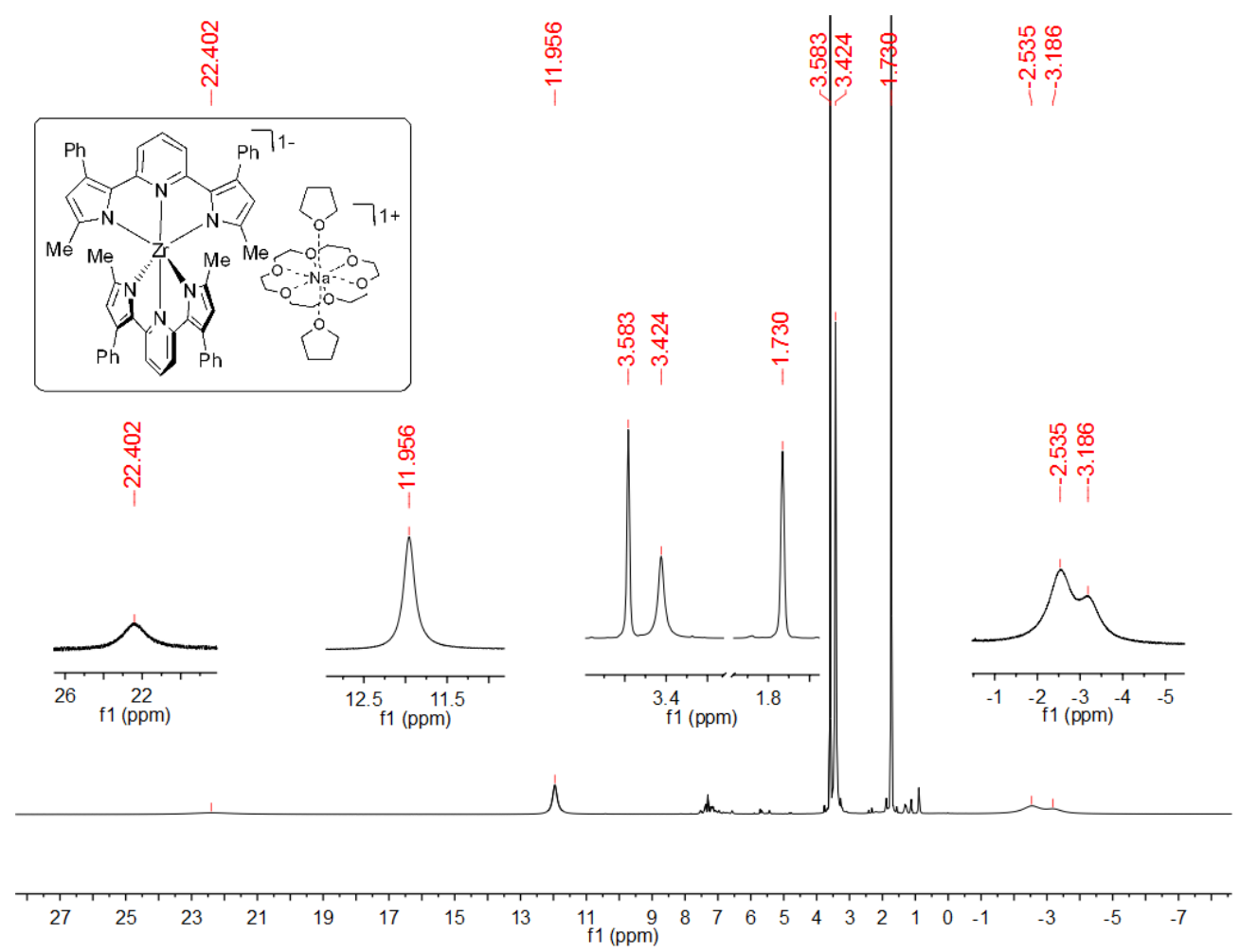

Figure B7. ${ }^{1} \mathrm{H}$ NMR spectrum of $\left[\mathrm{Na}(18 \text {-crown-6)(THF) })_{2}\right]\left[\mathrm{Zr}\left({ }^{\mathrm{Me}} \mathrm{PDP}^{\mathrm{Ph}}\right)_{2}\right]$ in THF-d8.

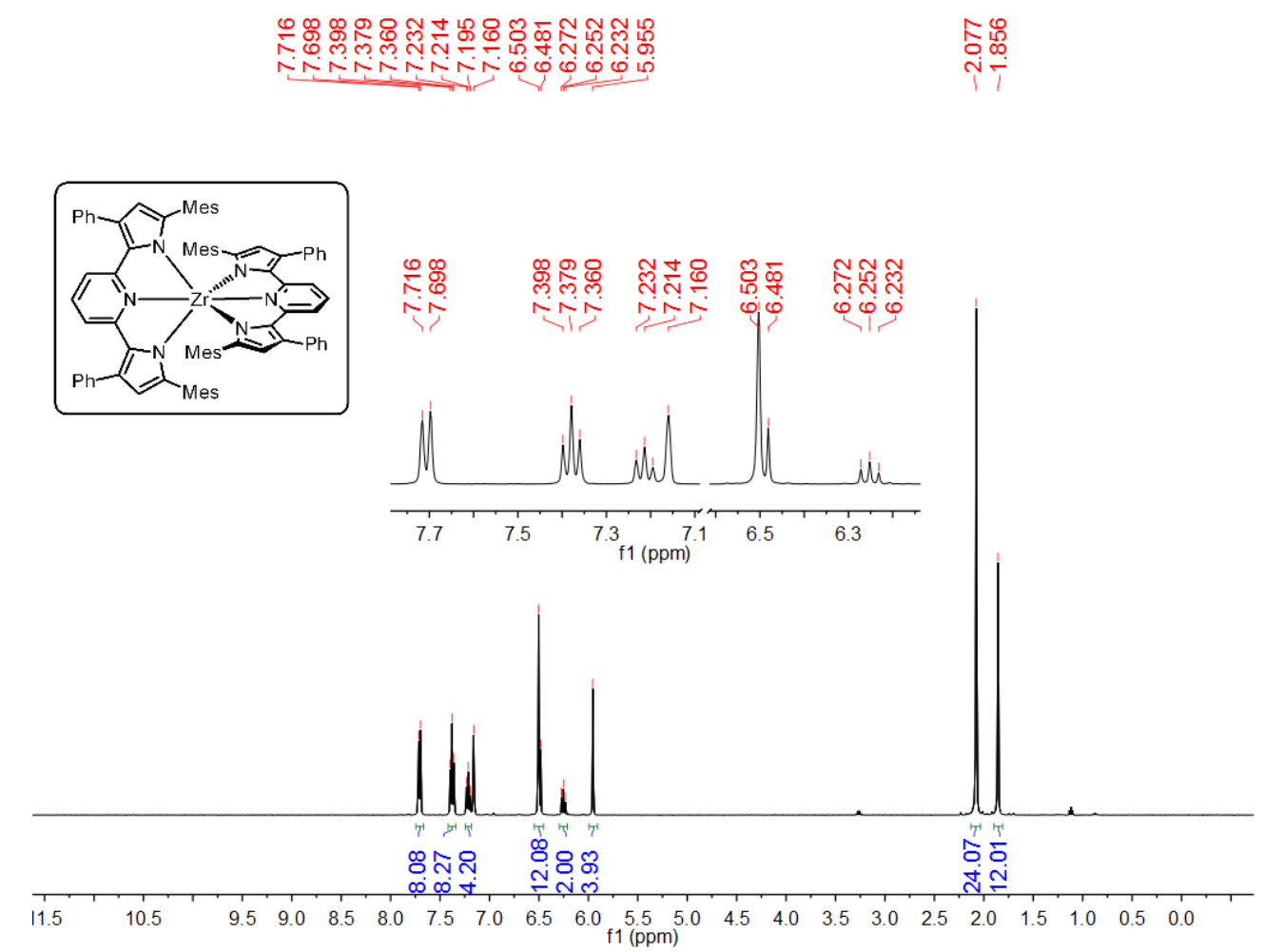

Figure B8. ${ }^{1} \mathrm{H}$ NMR spectrum of $\mathrm{Zr}\left({ }^{\mathrm{Mes}} \mathrm{PDP}^{\mathrm{Ph}}\right)_{2}$ in $\mathrm{C}_{6} \mathrm{D}_{6}$. 


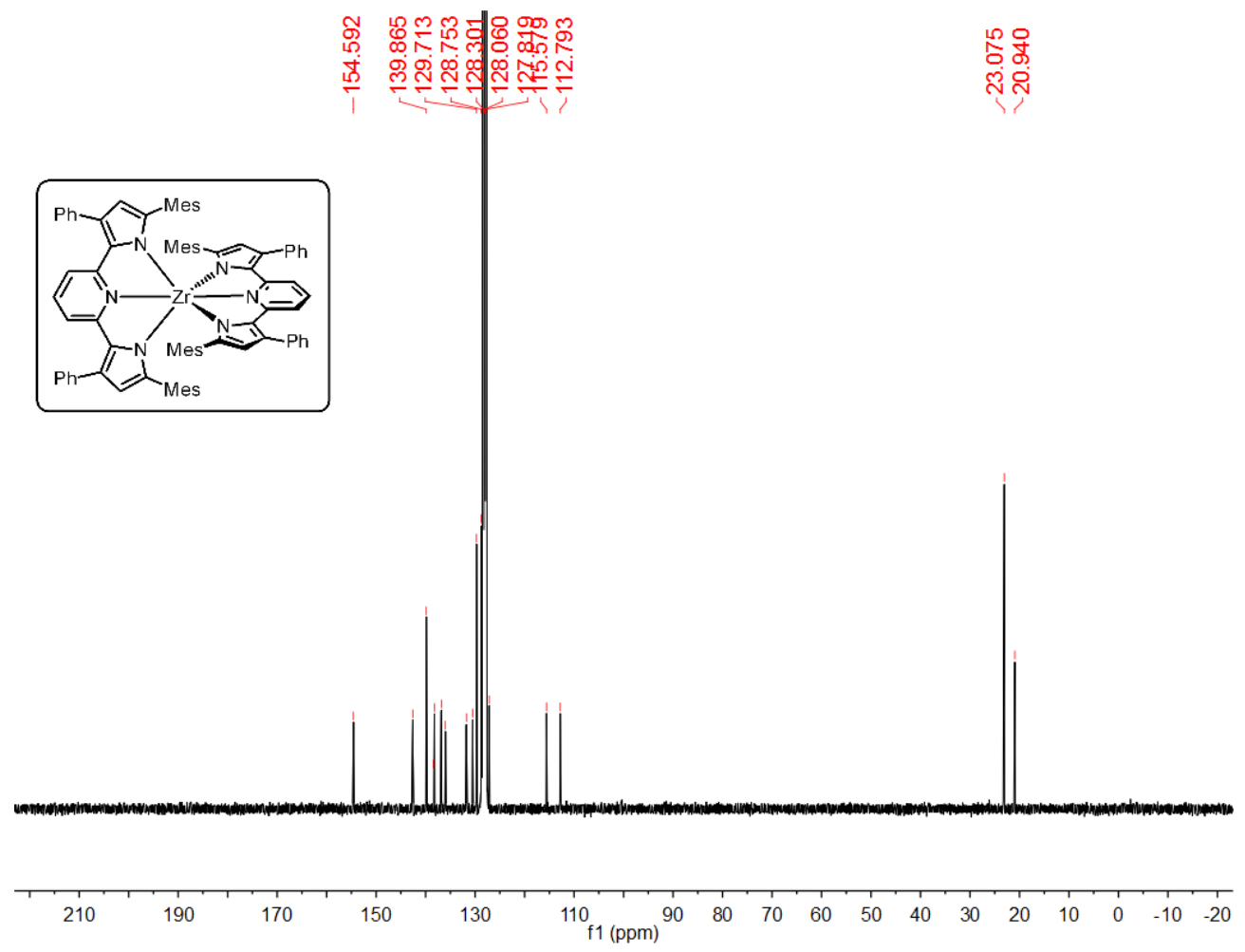

Figure B9. ${ }^{13} \mathrm{C}$ NMR spectrum of $\mathrm{Zr}\left({ }^{\mathrm{Mes}} \mathrm{PDP}^{\mathrm{Ph}}\right)_{2}$ in $\mathrm{C}_{6} \mathrm{D}_{6}$.

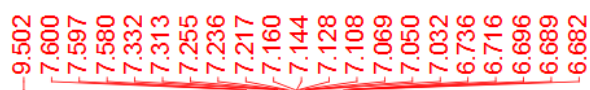
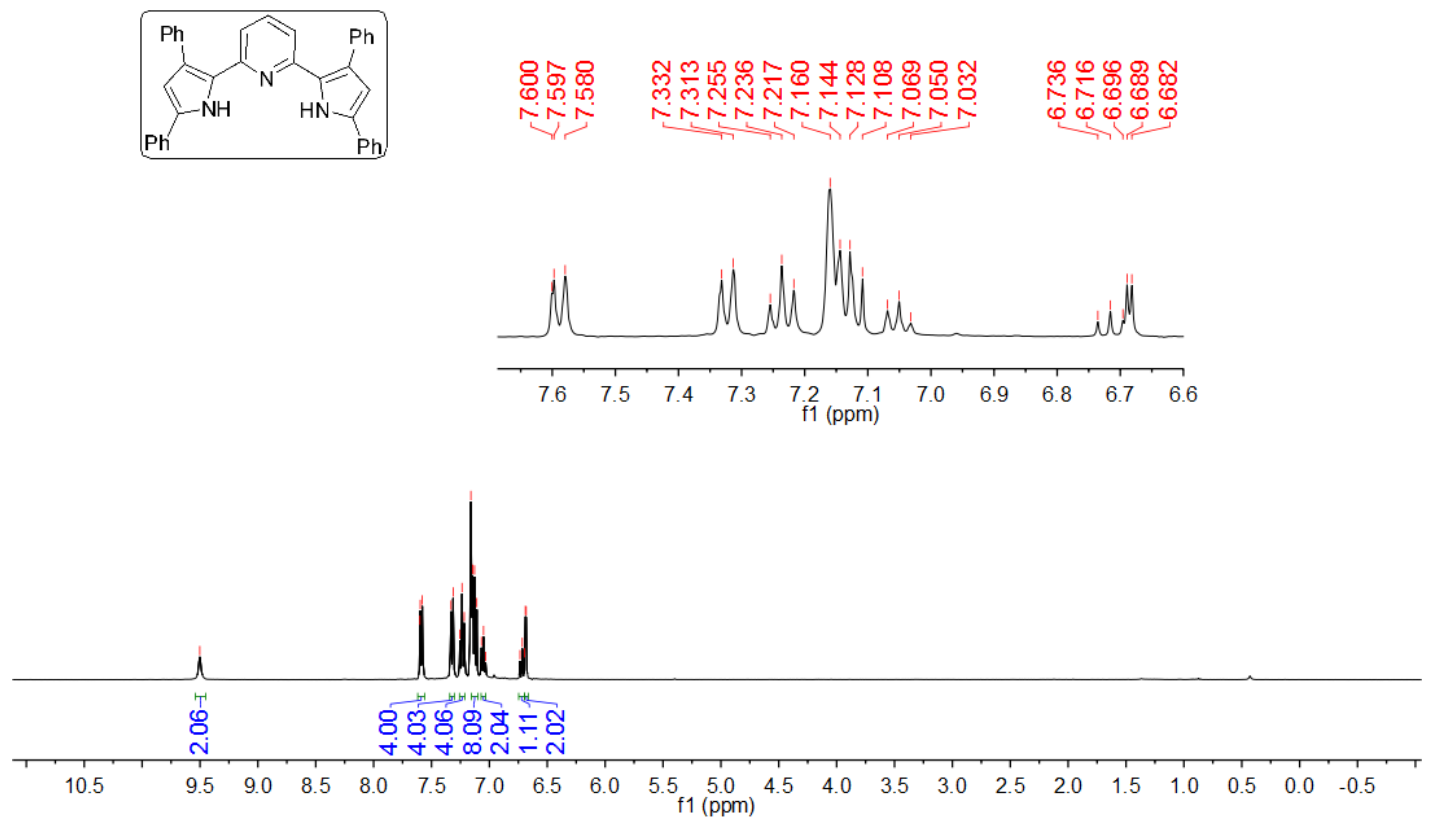

Figure B10. ${ }^{1} \mathrm{H}$ NMR spectrum of $\mathrm{H}_{2}\left({ }^{\mathrm{Ph}} \mathrm{PDP}^{\mathrm{Ph}}\right)_{2}$ in $\mathrm{C}_{6} \mathrm{D}_{6}$. 


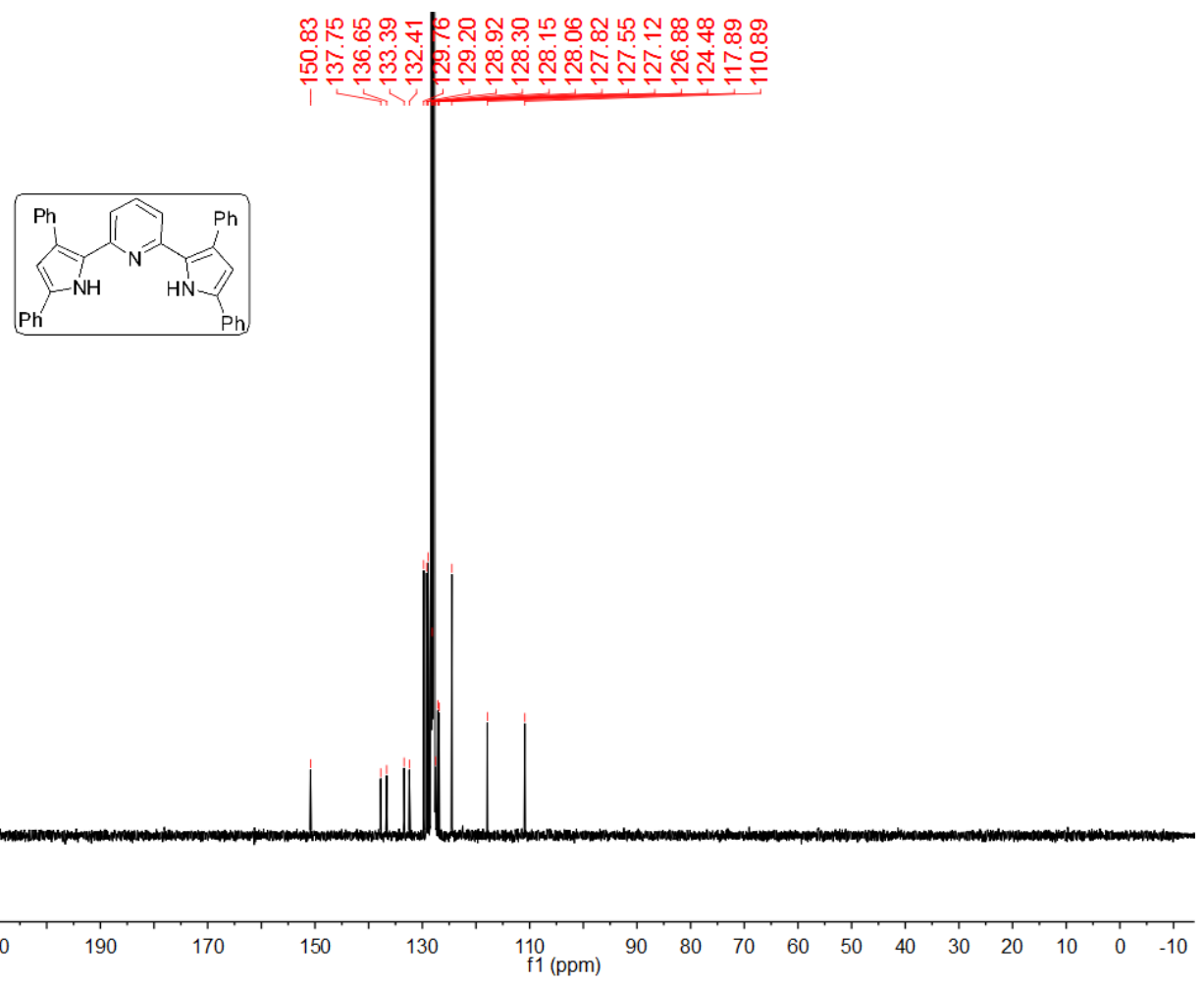

Figure B11. ${ }^{13} \mathrm{C}$ NMR spectrum of $\mathrm{H}_{2}\left({ }^{\mathrm{Ph}} \mathrm{PDP}^{\mathrm{Ph}}\right)_{2}$ in $\mathrm{C}_{6} \mathrm{D}_{6}$.

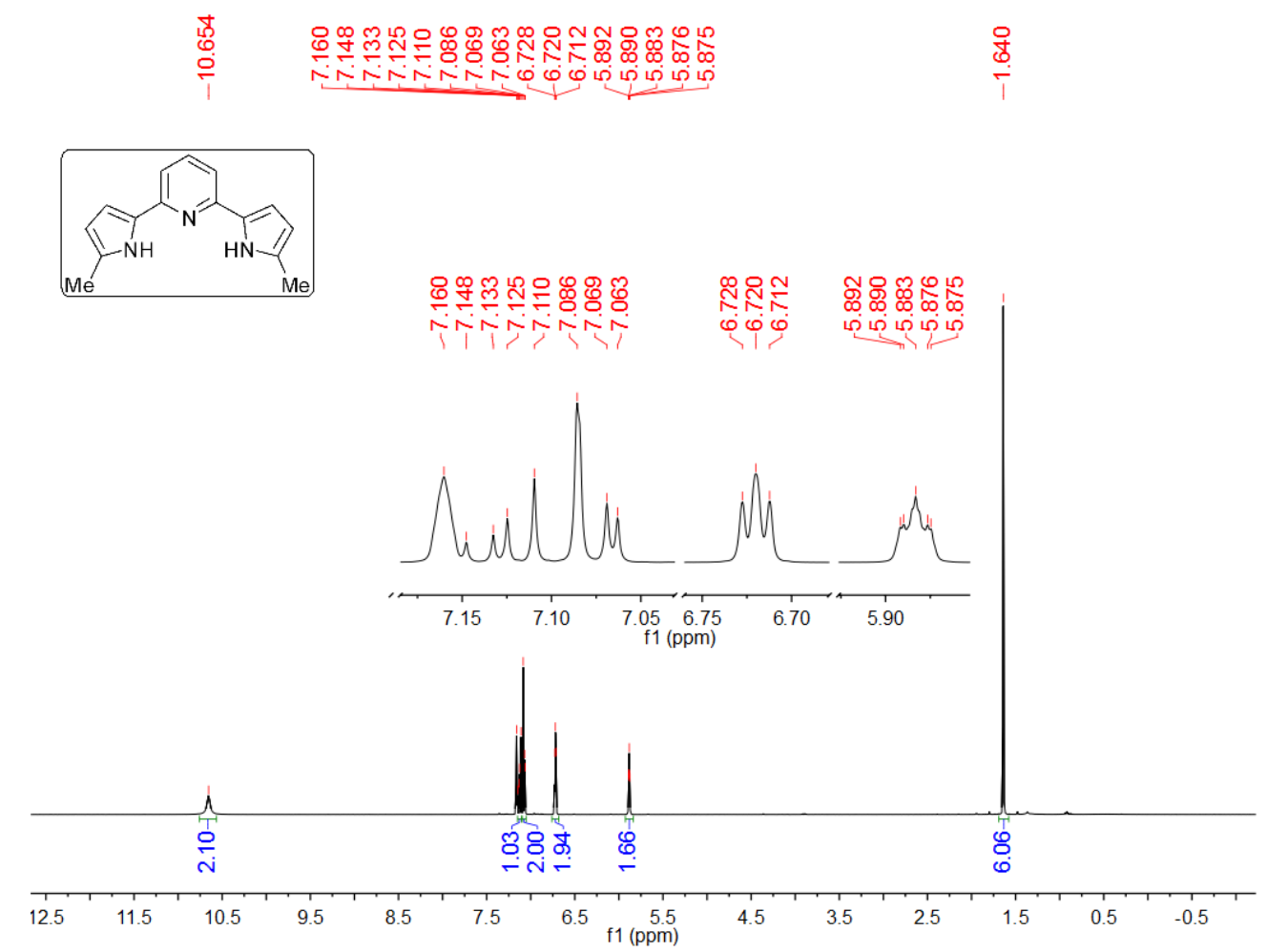

Figure B12. ${ }^{1} \mathrm{H}$ NMR spectrum of $\mathrm{H}_{2}\left({ }^{\mathrm{Me}} \mathrm{PDP}^{\mathrm{H}}\right)_{2}$ in $\mathrm{C}_{6} \mathrm{D}_{6}$. 

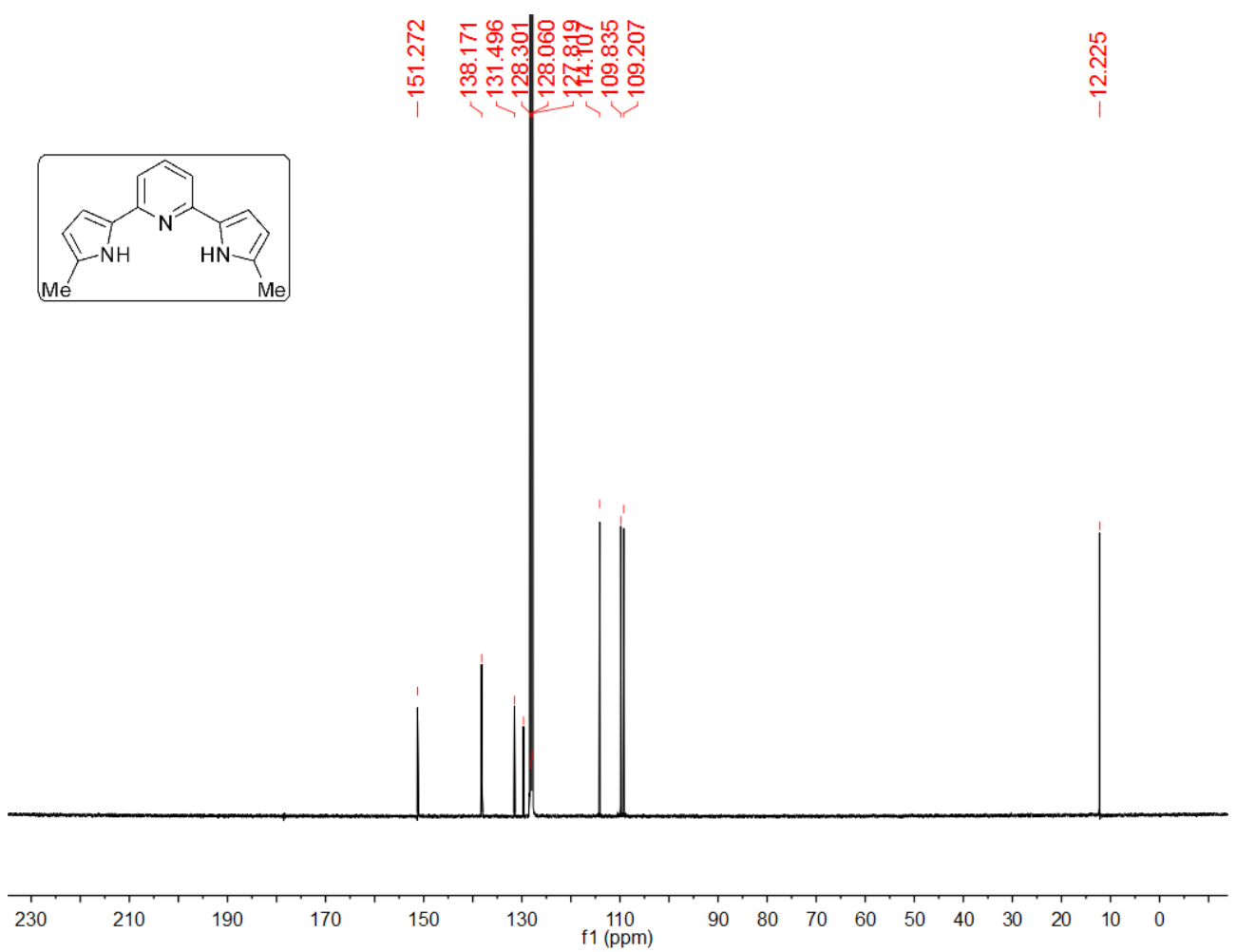

Figure B13. ${ }^{13} \mathrm{C}$ NMR spectrum of $\mathrm{H}_{2}\left({ }^{\mathrm{Me}} \mathrm{PDP}^{\mathrm{H}}\right)_{2}$ in $\mathrm{C}_{6} \mathrm{D}_{6}$.

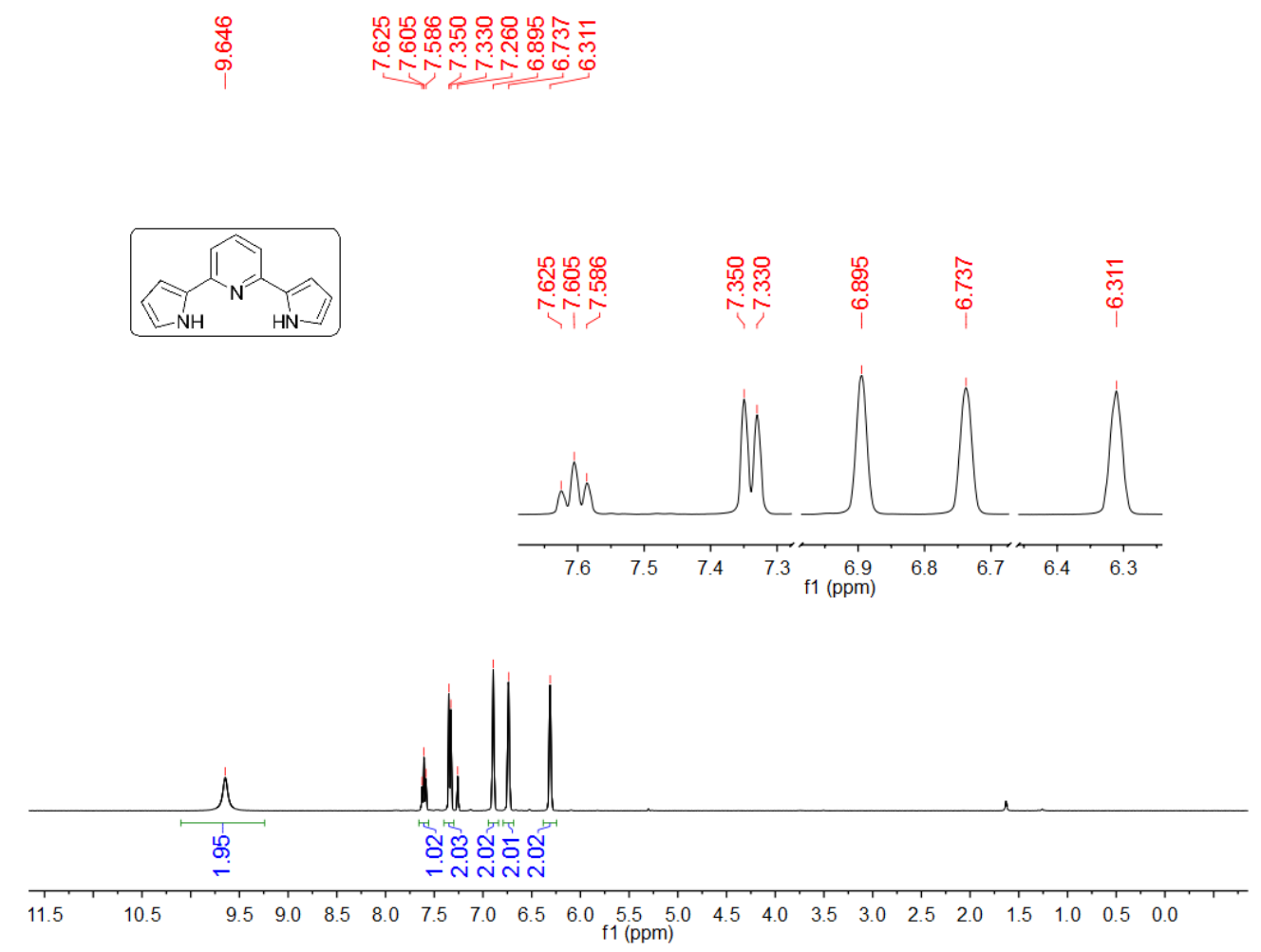

Figure B14. ${ }^{1} \mathrm{H}$ NMR spectrum of $\mathrm{H}_{2}\left({ }^{\mathrm{H}} \mathrm{PDP}^{\mathrm{H}}\right)_{2}$ in $\mathrm{C}_{6} \mathrm{D}_{6}$. 

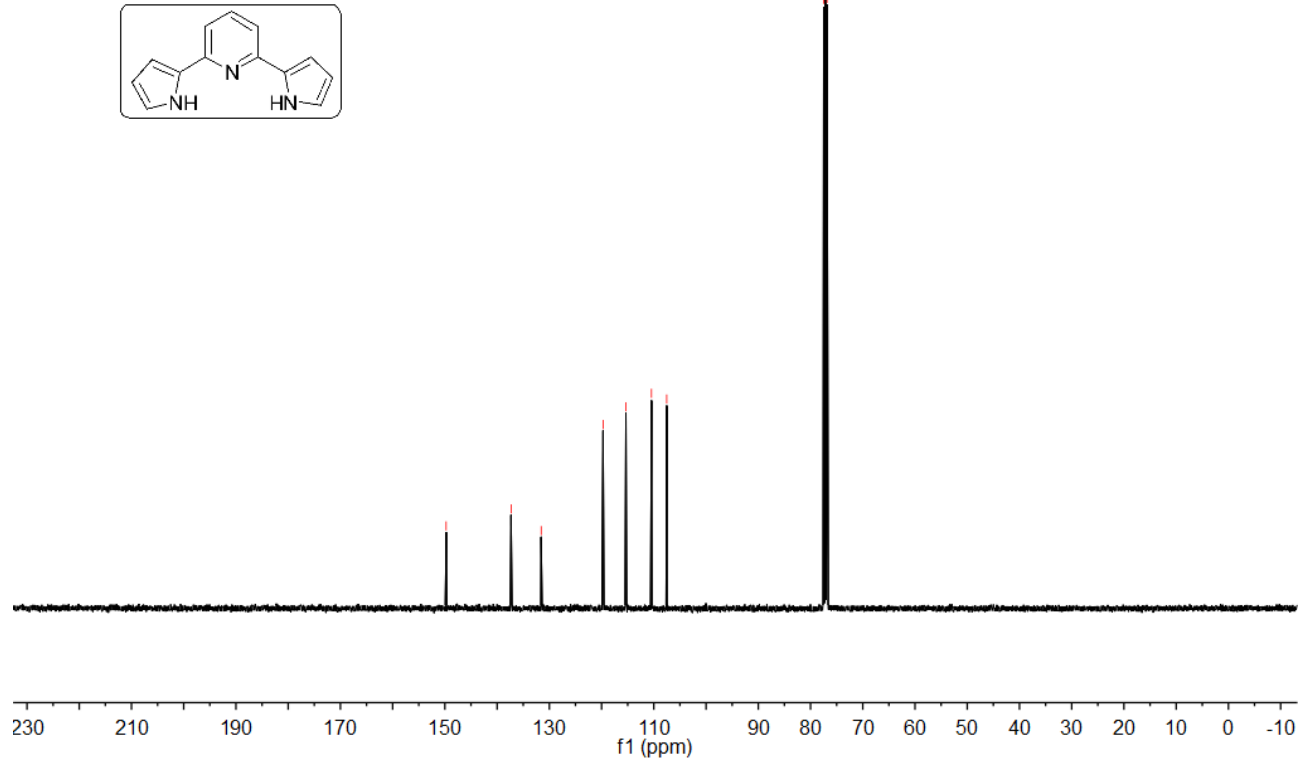

Figure B15. ${ }^{13} \mathrm{C}$ NMR spectrum of $\mathrm{H}_{2}\left({ }^{\mathrm{H}} \mathrm{PDP}^{\mathrm{H}}\right)_{2}$ in $\mathrm{C}_{6} \mathrm{D}_{6}$.
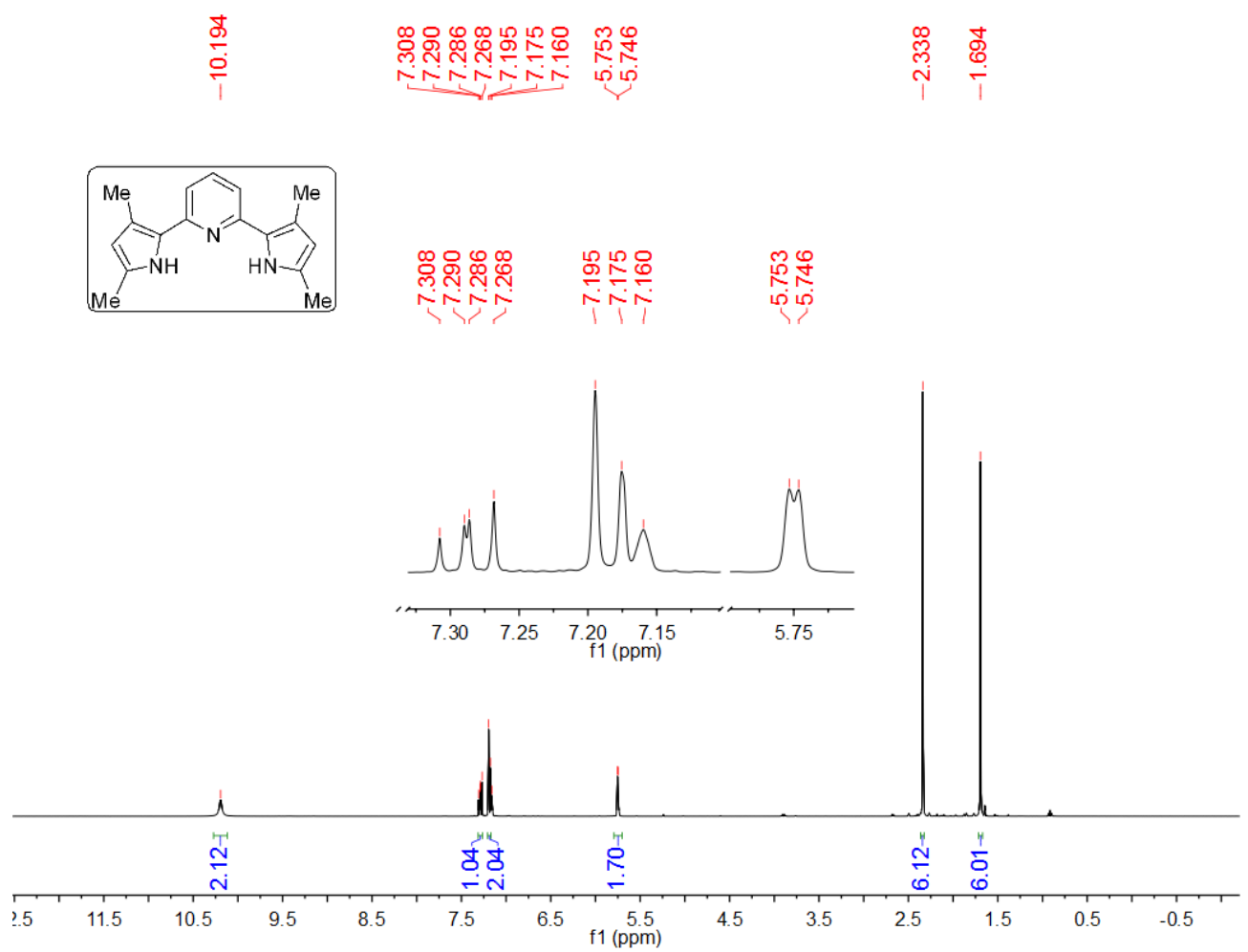

Figure B16. ${ }^{1} \mathrm{H}$ NMR spectrum of $\mathrm{H}_{2}\left({ }^{\mathrm{Me}} \mathrm{PDP}{ }^{\mathrm{Me}}\right)_{2}$ in $\mathrm{C}_{6} \mathrm{D}_{6}$. 

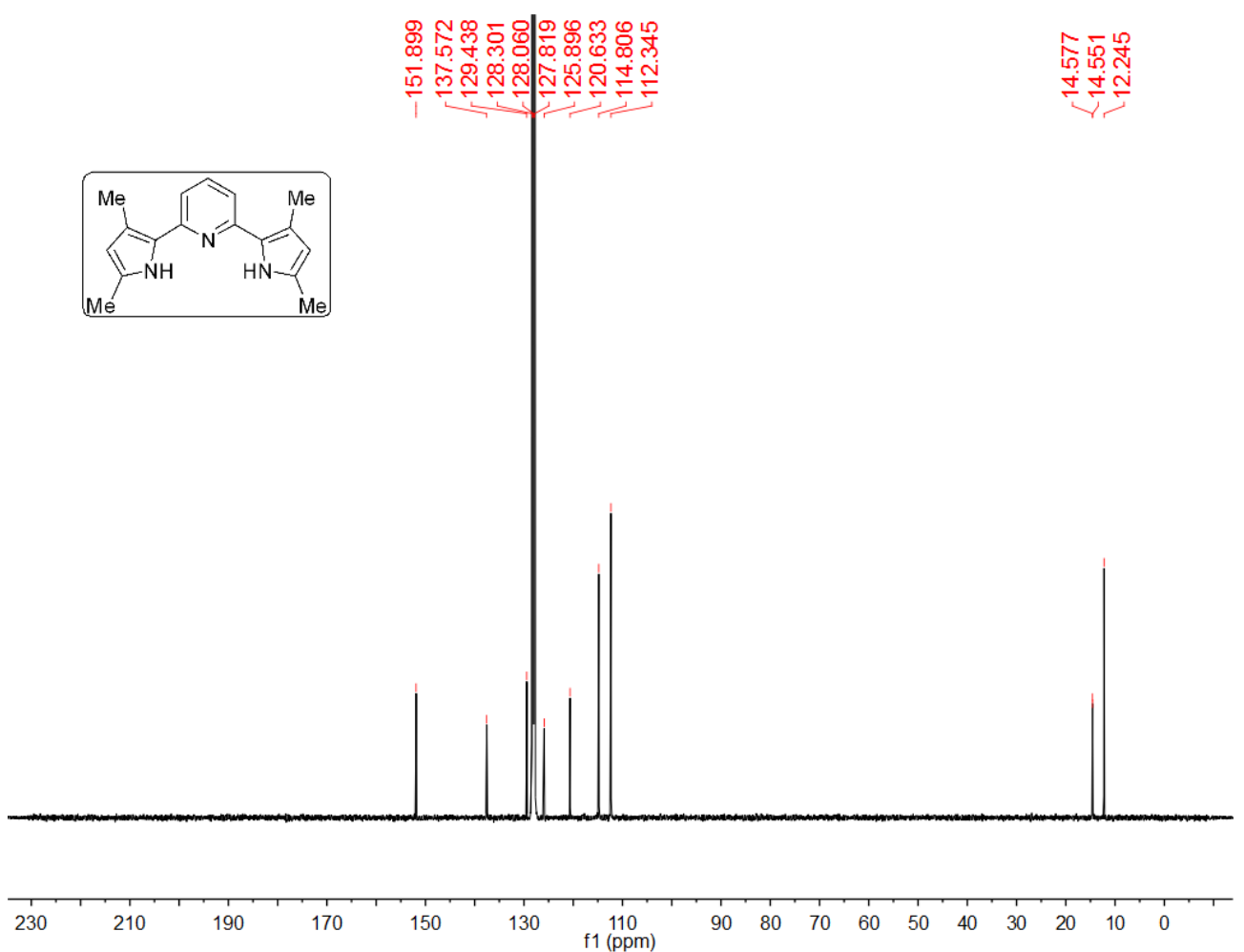

Figure B17. ${ }^{13} \mathrm{C}$ NMR spectrum of $\mathrm{H}_{2}\left({ }^{\mathrm{Me}} \mathrm{PDP}^{\mathrm{Me}}\right)_{2}$ in $\mathrm{C}_{6} \mathrm{D}_{6}$.
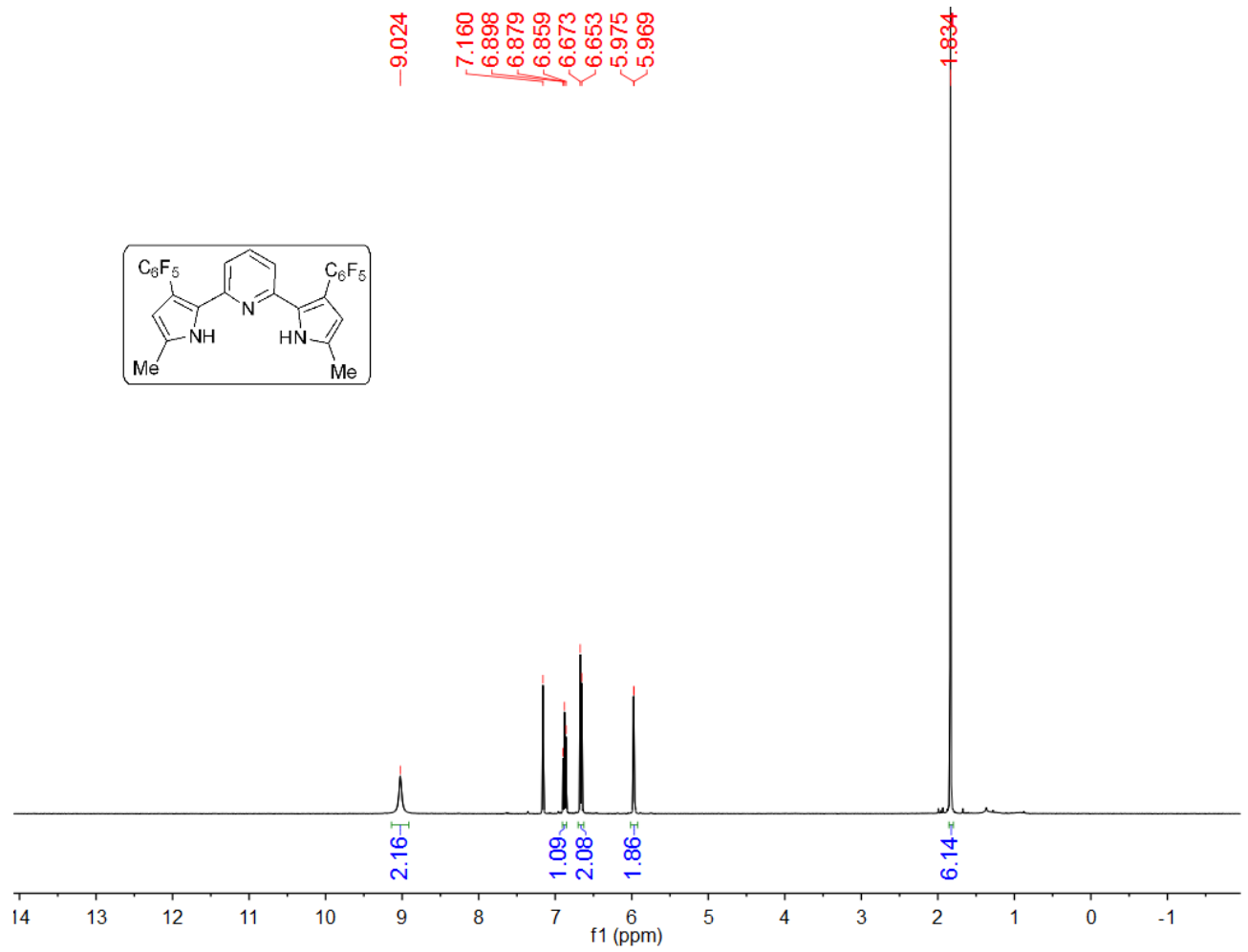

Figure B18. ${ }^{1} \mathrm{H}$ NMR spectrum of $\mathrm{H}_{2}\left({ }^{\mathrm{Me}} \mathrm{PDP}^{\mathrm{C} 6 \mathrm{~F} 5}\right)_{2}$ in $\mathrm{C}_{6} \mathrm{D}_{6}$. 


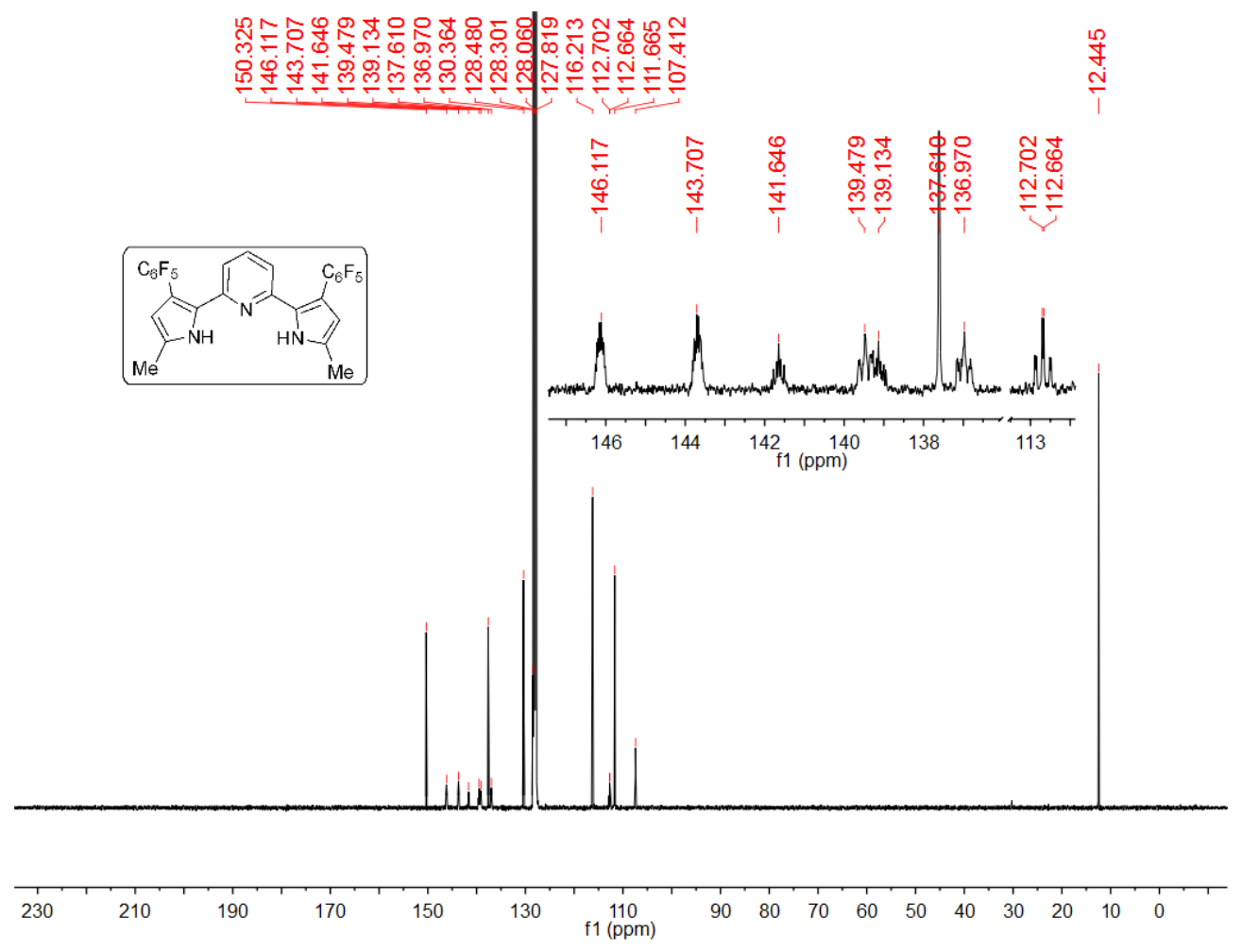

Figure B19. ${ }^{13} \mathrm{C}$ NMR spectrum of $\mathrm{H}_{2}\left({ }^{\mathrm{Me}} \mathrm{PDP} \mathrm{P}^{\mathrm{C}} \mathrm{F5}\right)_{2}$ in $\mathrm{C}_{6} \mathrm{D}_{6}$.
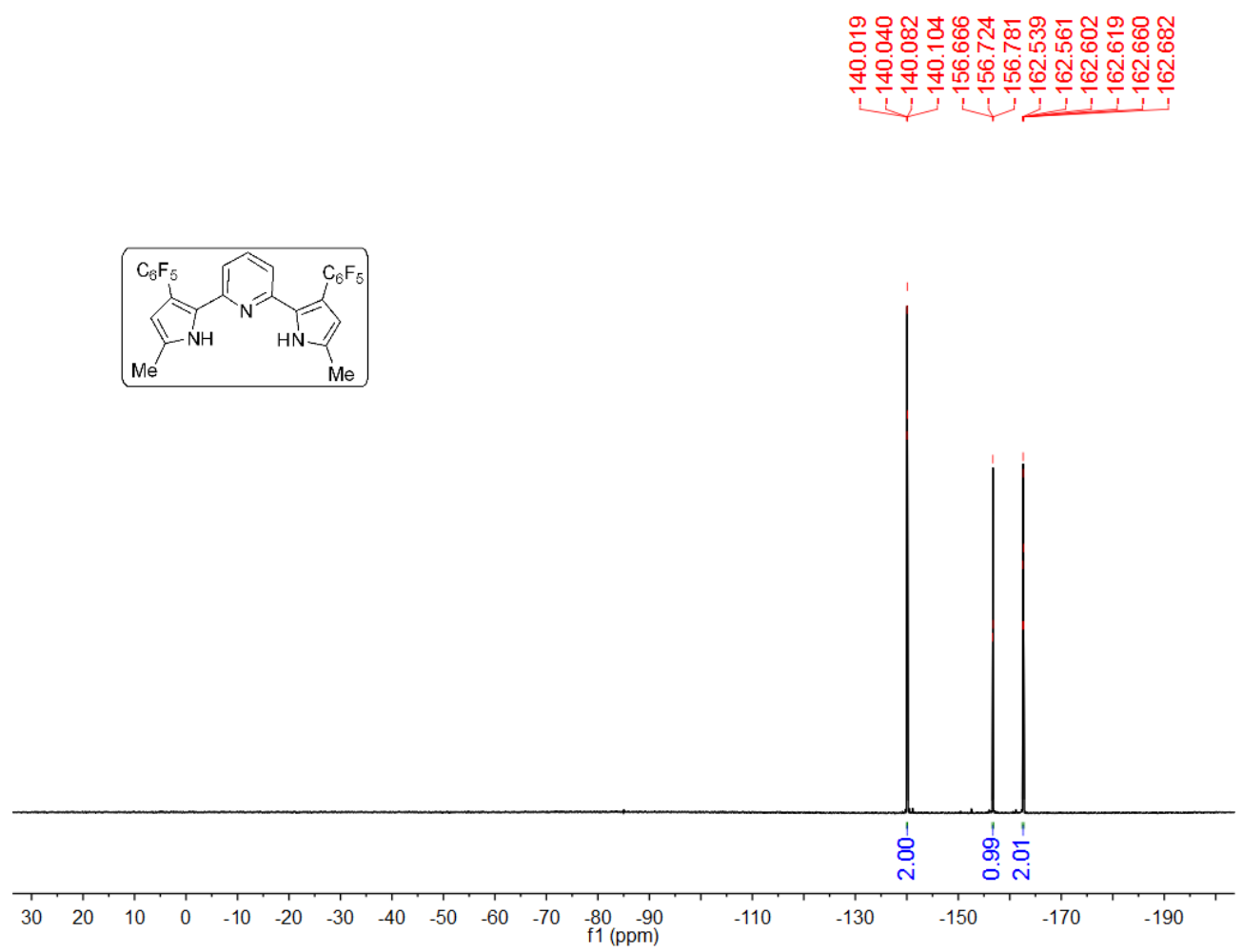

Figure B20. ${ }^{19} \mathrm{~F}$ NMR spectrum of $\mathrm{H}_{2}\left({ }^{\mathrm{Me}} \mathrm{PDP}^{\mathrm{C} 6 \mathrm{~F} 5}\right)_{2}$ in $\mathrm{C}_{6} \mathrm{D}_{6}$. 


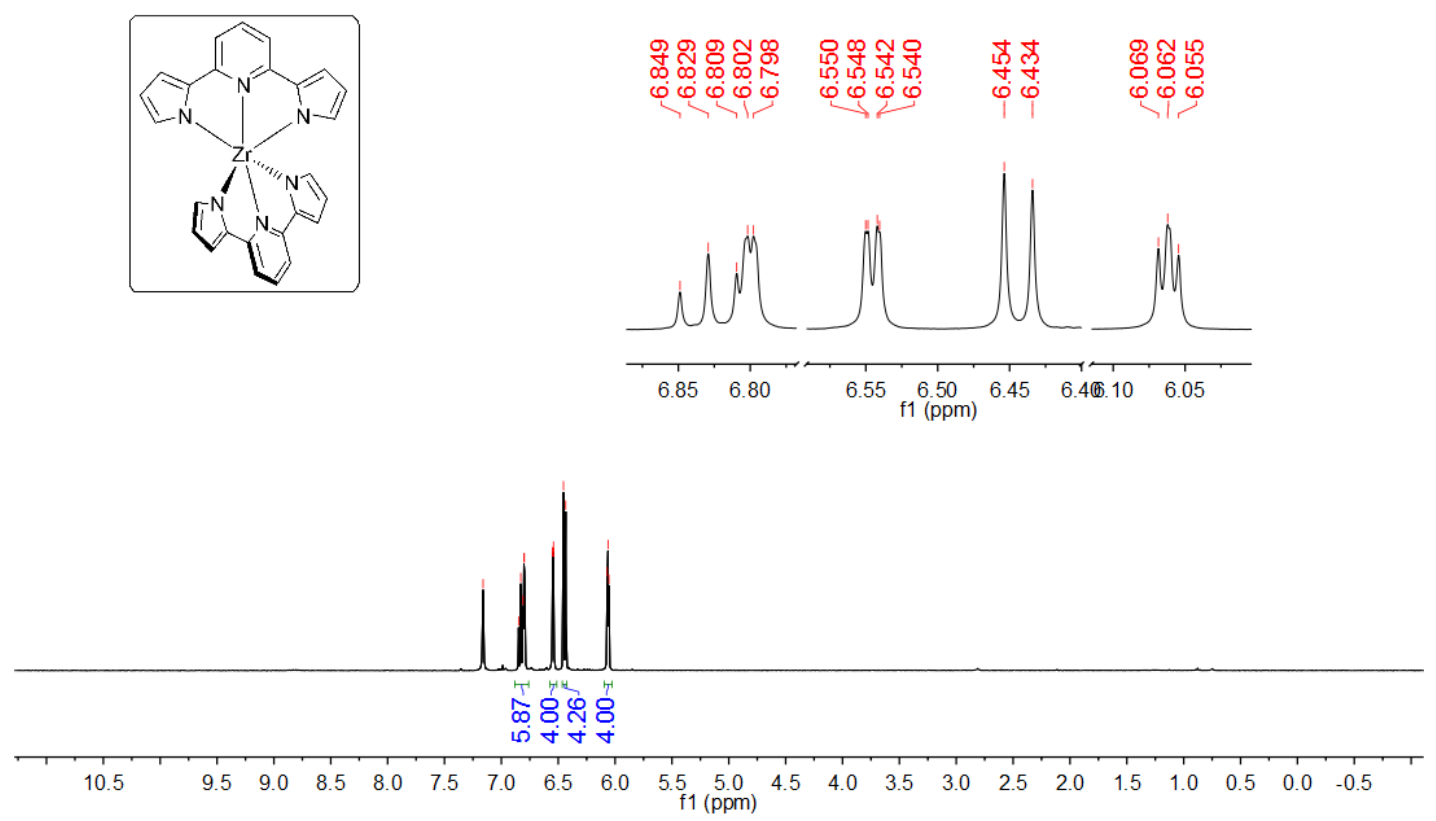

Figure B21. ${ }^{1} \mathrm{H}$ NMR spectrum of $\mathrm{Zr}\left({ }^{\mathrm{H}} \mathrm{PDP}^{\mathrm{H}}\right)_{2}$ in $\mathrm{C}_{6} \mathrm{D}_{6}$.

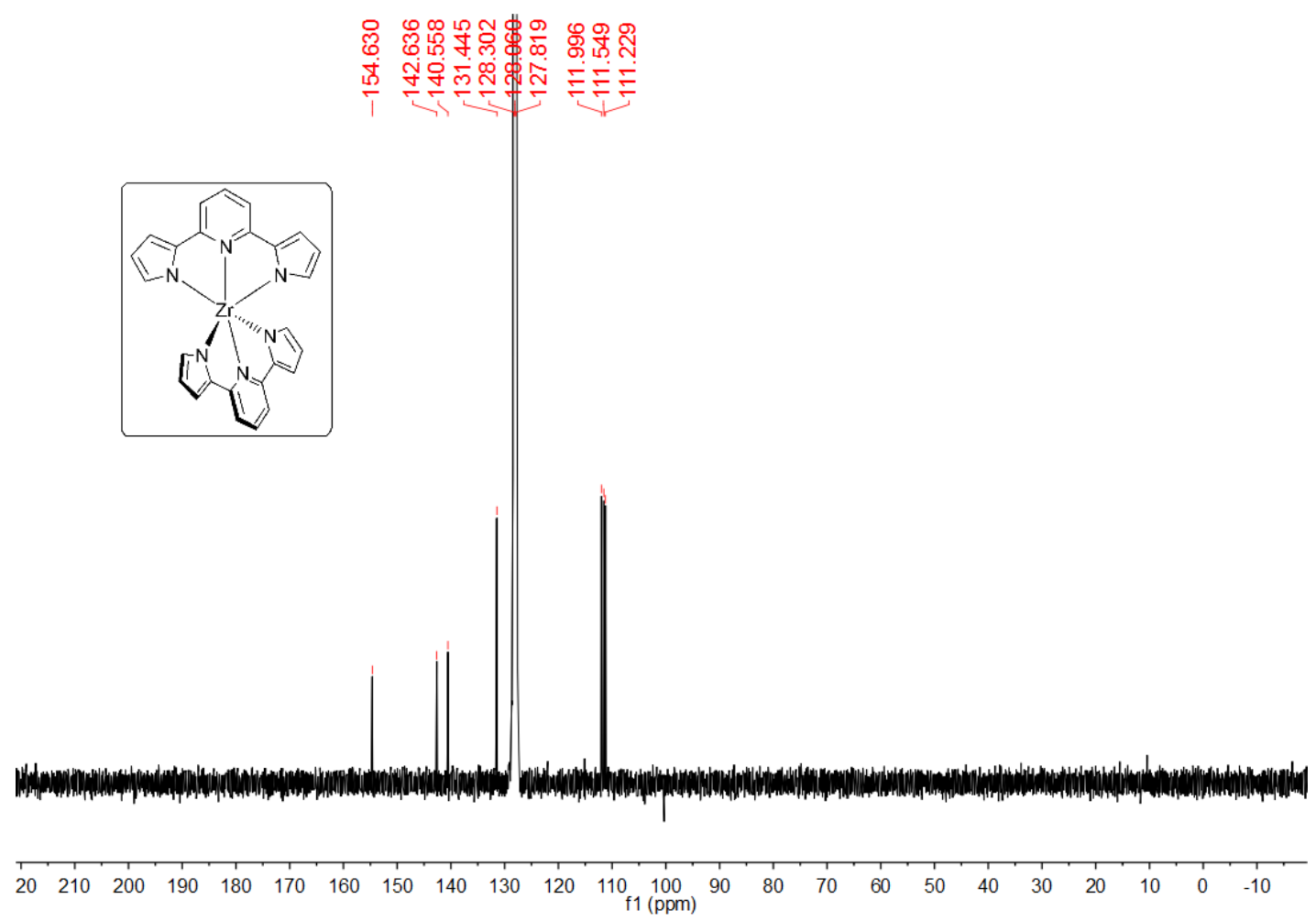

Figure B22. ${ }^{13} \mathrm{C} \mathrm{NMR}$ spectrum of $\mathrm{Zr}\left({ }^{\mathrm{H}} \mathrm{PDP}^{\mathrm{H}}\right)_{2}$ in $\mathrm{C}_{6} \mathrm{D}_{6}$. 

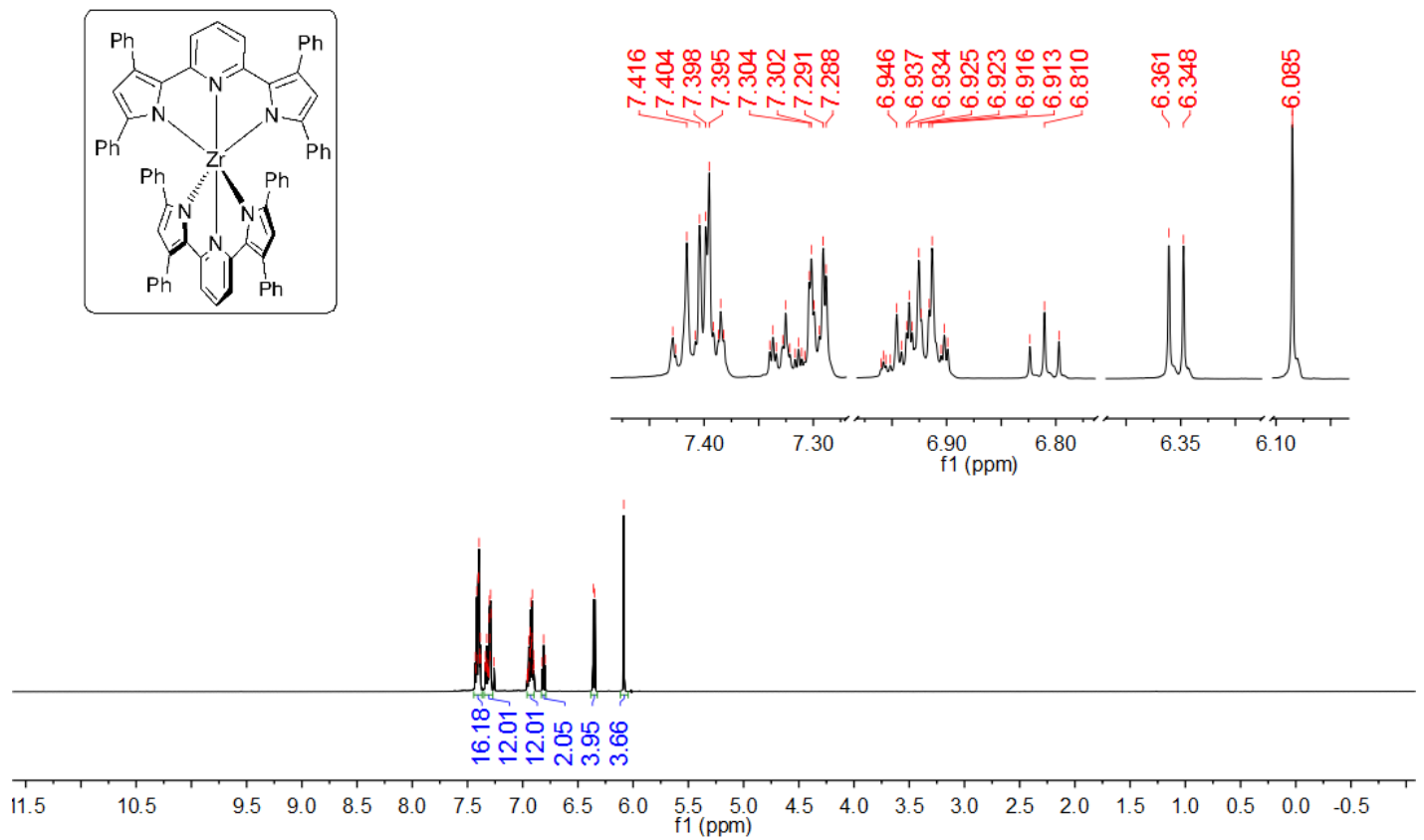

Figure B23. ${ }^{1} \mathrm{H}$ NMR spectrum of $\mathrm{Zr}\left({ }^{\mathrm{Ph}} \mathrm{PDP}^{\mathrm{Ph}}\right)_{2}$ in $\mathrm{CDCl}_{3}$.

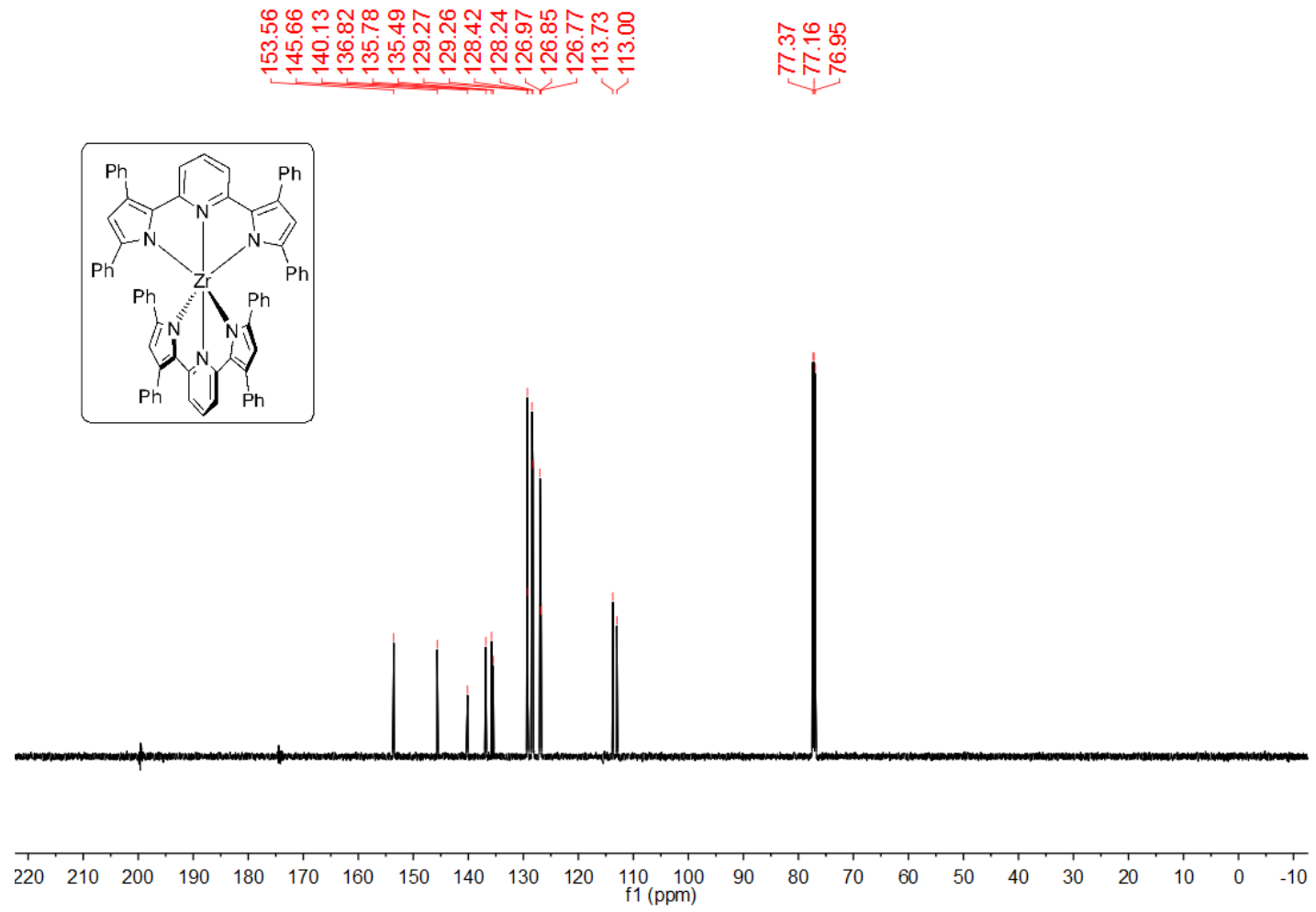

Figure B24. ${ }^{13} \mathrm{C}$ NMR spectrum of $\mathrm{Zr}\left({ }^{\mathrm{Ph}} \mathrm{PDP}^{\mathrm{Ph}}\right)_{2}$ in $\mathrm{CDCl}_{3}$. 


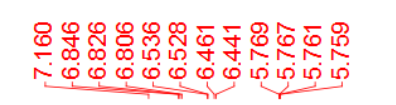

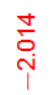
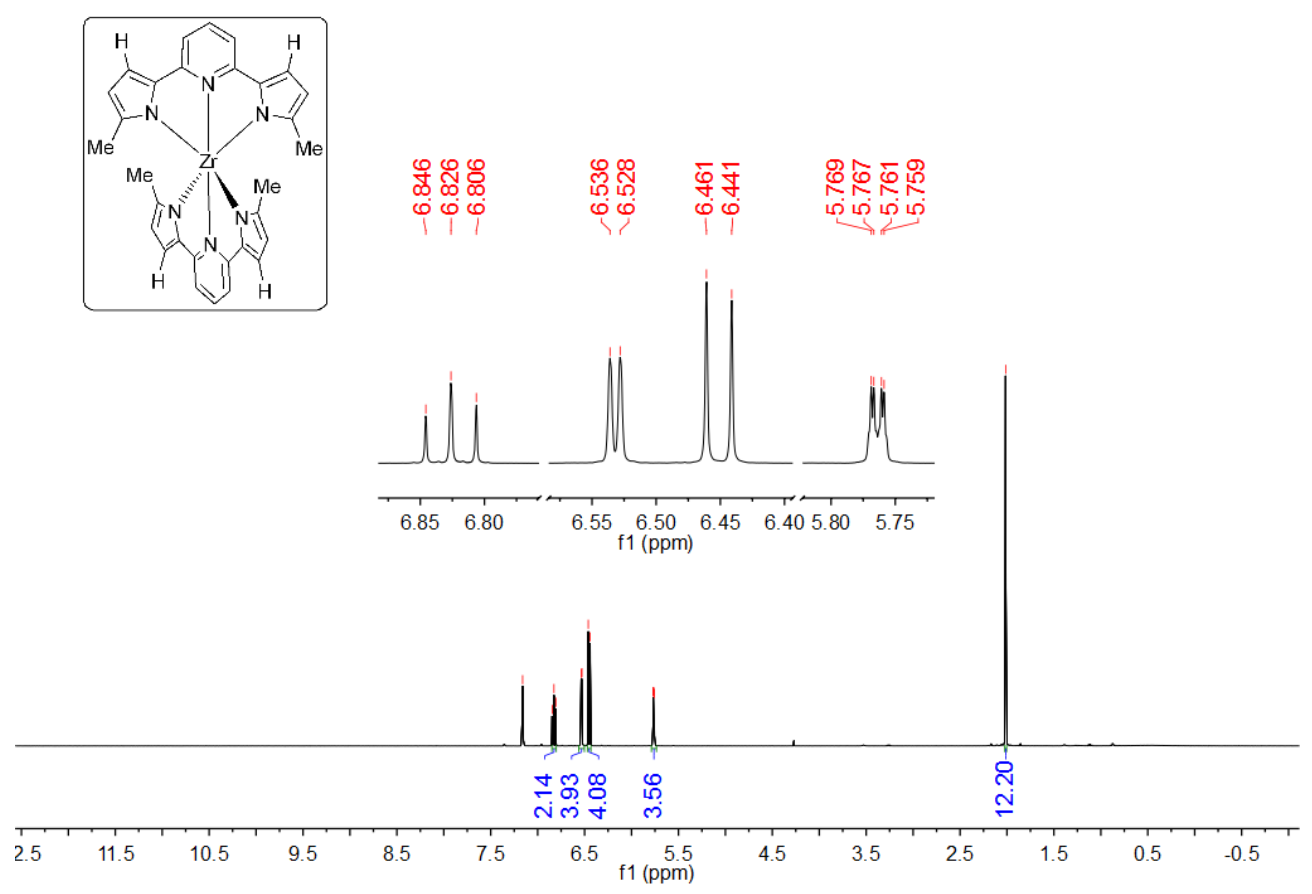

Figure B25. ${ }^{1} \mathrm{H}$ NMR spectrum of $\mathrm{Zr}\left({ }^{\mathrm{Me}} \mathrm{PDP}^{\mathrm{H}}\right)_{2}$ in $\mathrm{C}_{6} \mathrm{D}_{6}$.
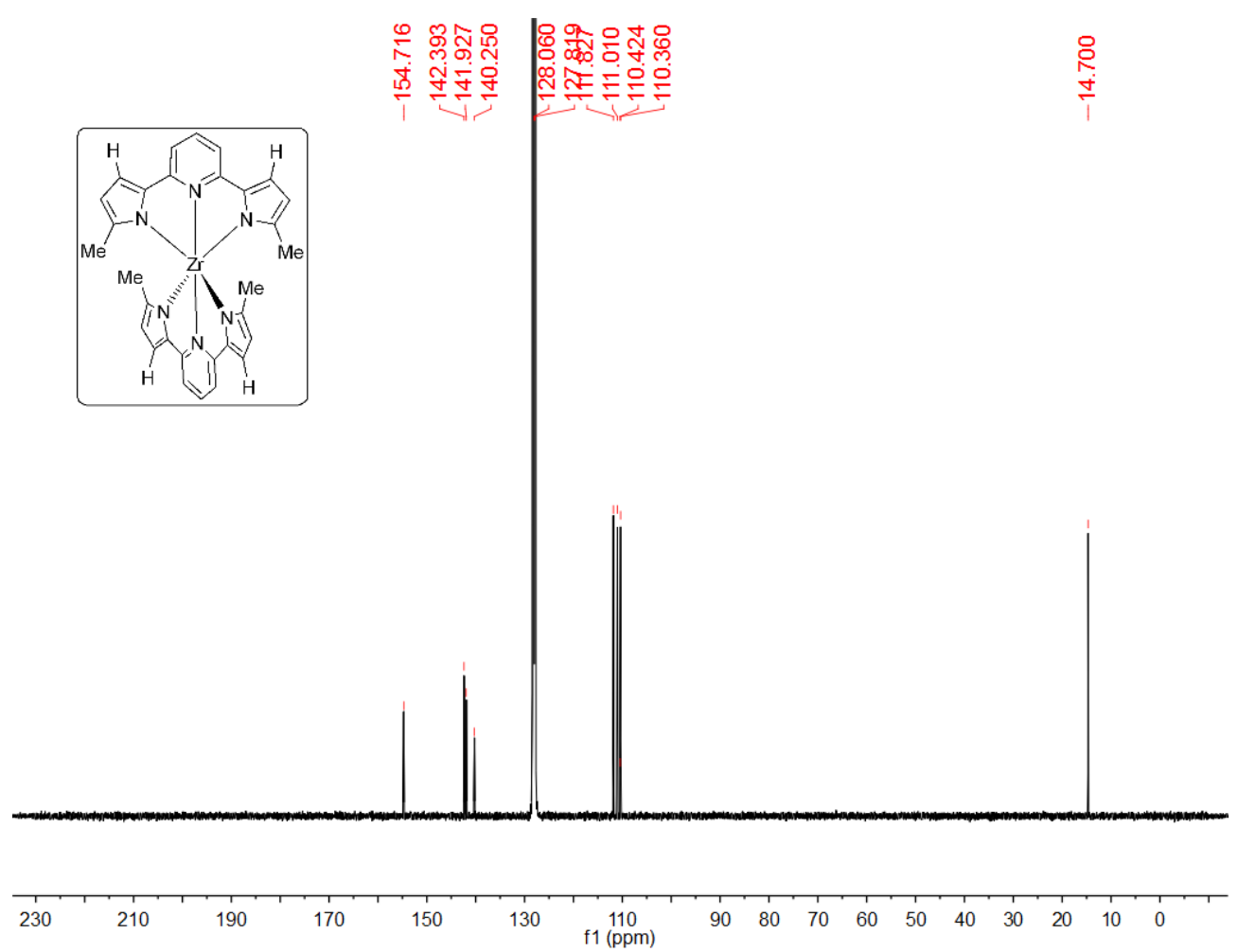

Figure B26. ${ }^{13} \mathrm{C}$ NMR spectrum of $\mathrm{Zr}\left({ }^{\mathrm{Me}} \mathrm{PDP}^{\mathrm{H}}\right)_{2}$ in $\mathrm{C}_{6} \mathrm{D}_{6}$. 


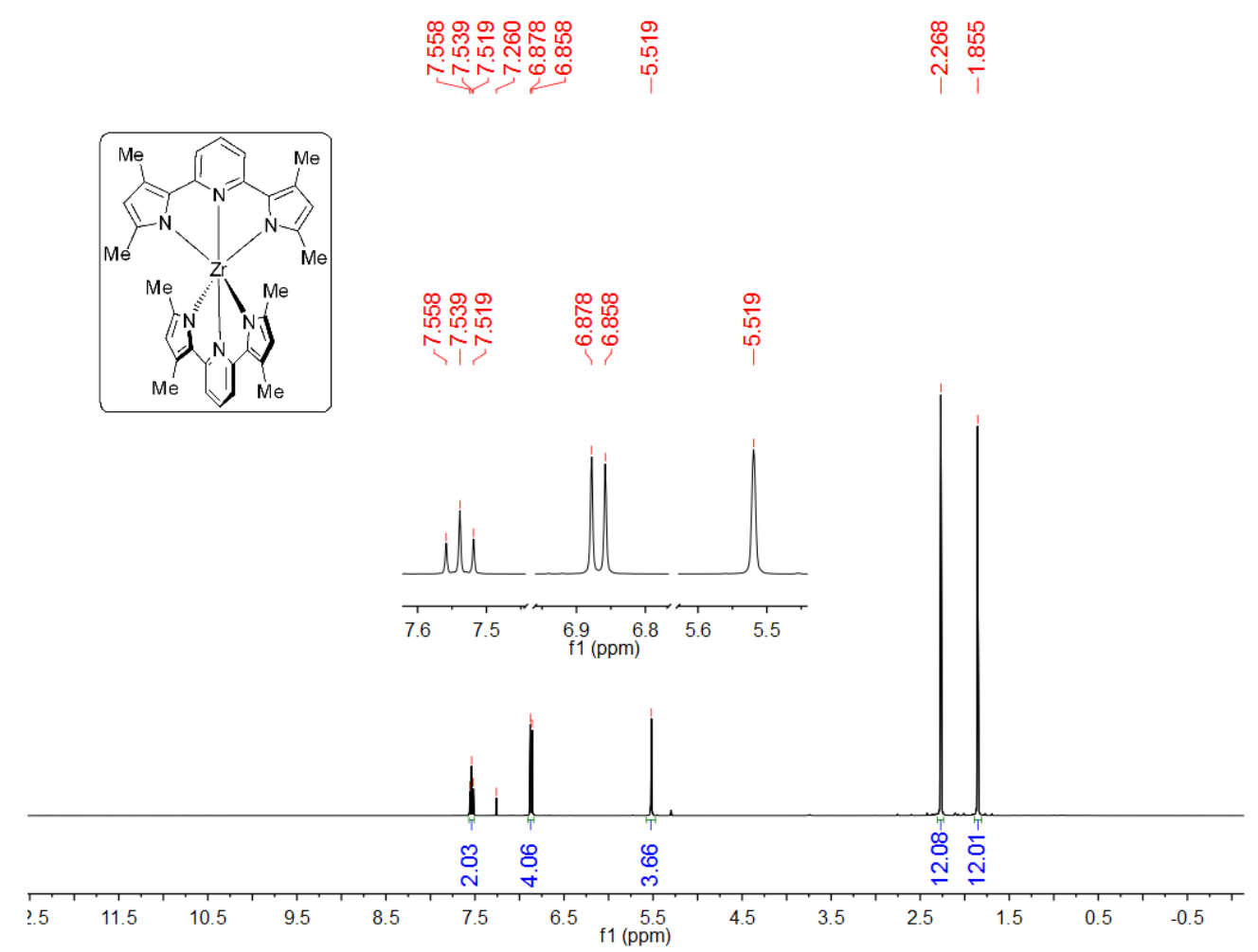

Figure B27. ${ }^{1} \mathrm{H}$ NMR spectrum of $\mathrm{Zr}\left({ }^{\mathrm{Me}} \mathrm{PDP}^{\mathrm{Me}}\right)_{2}$ in $\mathrm{CDCl}_{3}$.
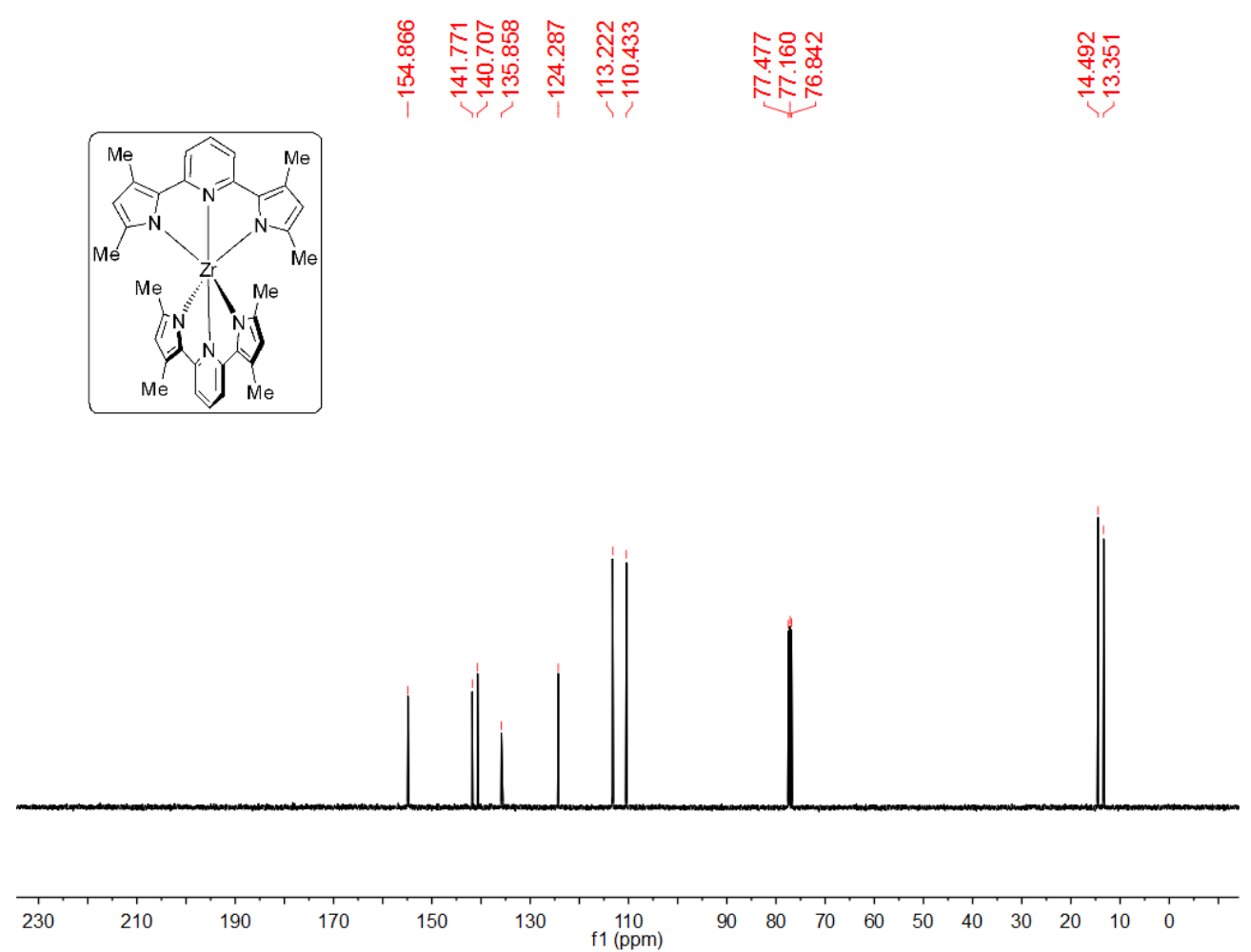

Figure B28. ${ }^{13} \mathrm{C}$ NMR spectrum of $\mathrm{Zr}\left({ }^{\mathrm{Me}} \mathrm{PDP}^{\mathrm{Me}}\right)_{2}$ in $\mathrm{CDCl}_{3}$. 

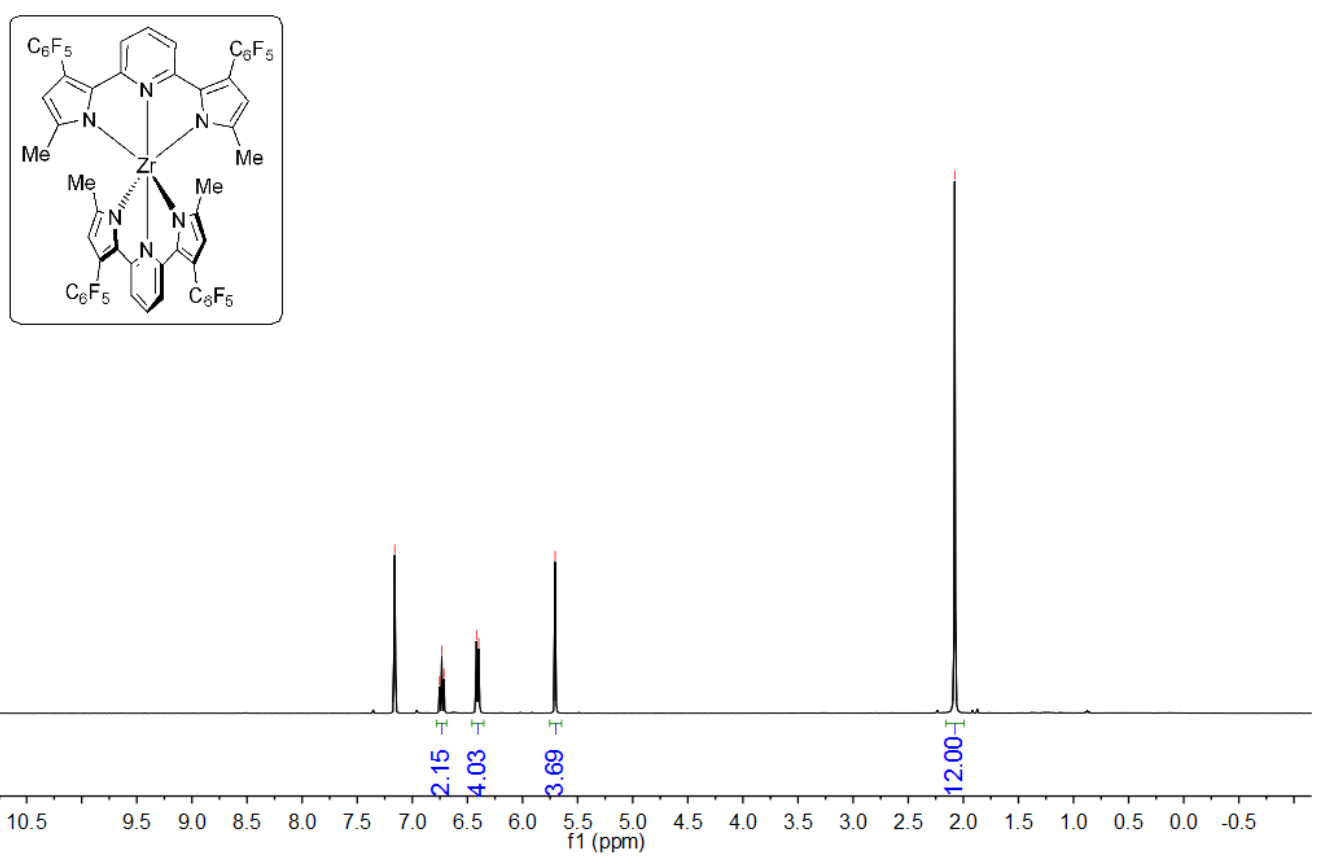

Figure B29. ${ }^{1} \mathrm{H}$ NMR spectrum of $\mathrm{Zr}\left({ }^{\mathrm{Me}} \mathrm{PDP}^{\mathrm{C} 6 \mathrm{~F} 5}\right)_{2}$ in $\mathrm{C}_{6} \mathrm{D}_{6}$.

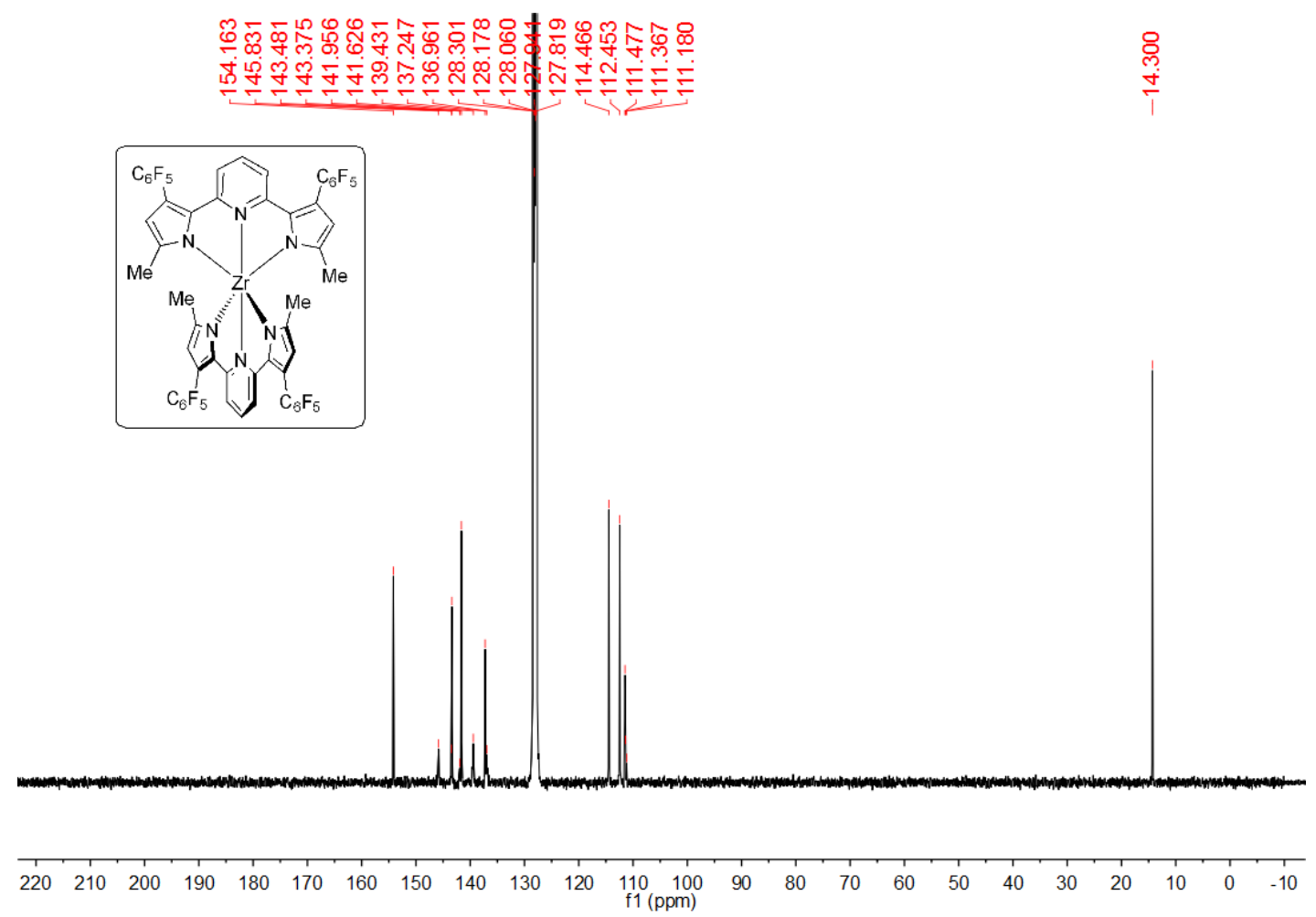

Figure B30. ${ }^{13} \mathrm{C}$ NMR spectrum of $\mathrm{Zr}\left({ }^{\mathrm{Me}} \mathrm{PDP}^{\mathrm{C} 6 \mathrm{F5}}\right)_{2}$ in $\mathrm{C}_{6} \mathrm{D}_{6}$. 


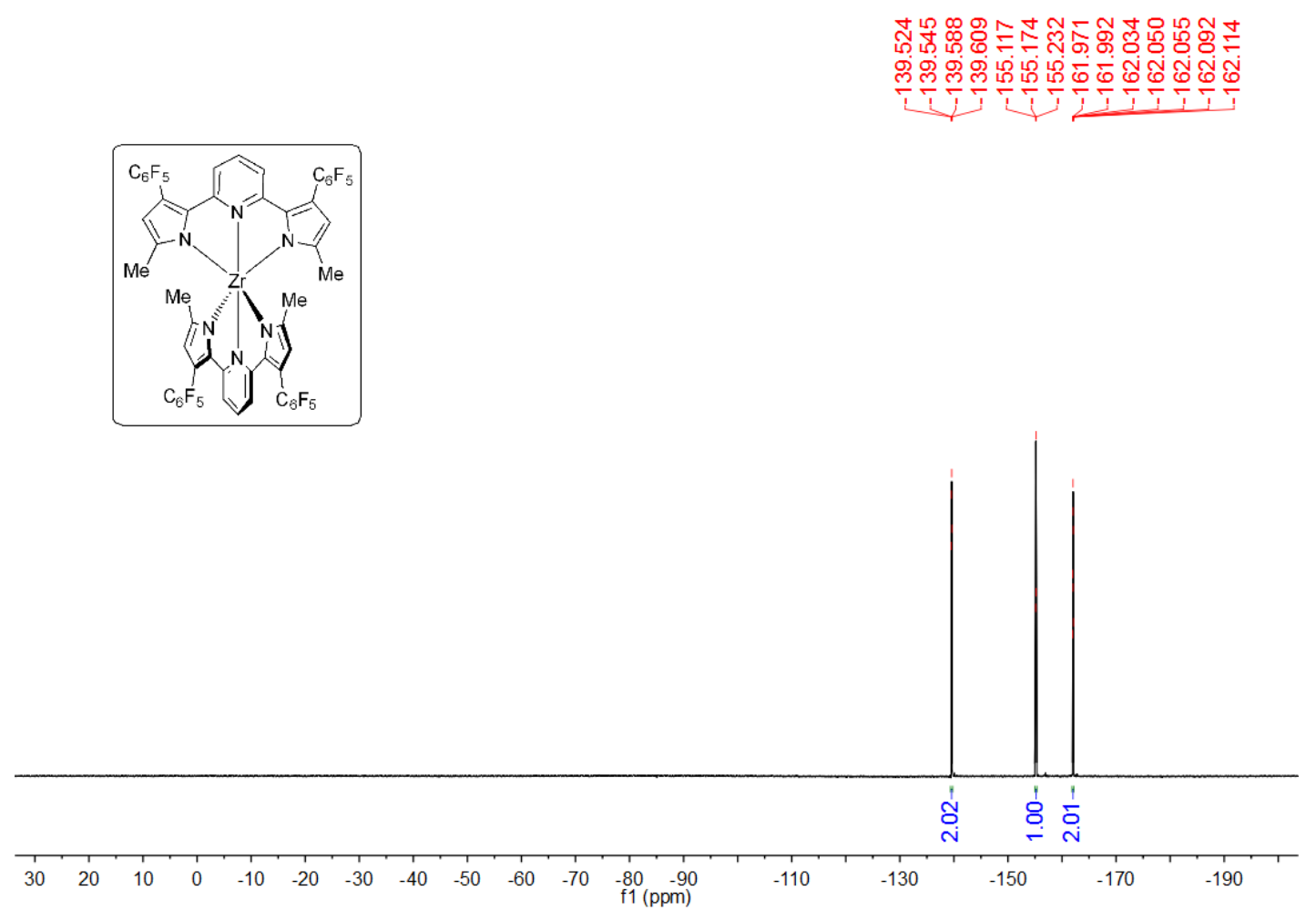

Figure B31. ${ }^{19} \mathrm{~F}$ NMR spectrum of $\mathrm{Zr}\left({ }^{\mathrm{Me}} \mathrm{PDP}^{\mathrm{C} 6 \mathrm{F5}}\right)_{2}$ in $\mathrm{C}_{6} \mathrm{D}_{6}$.

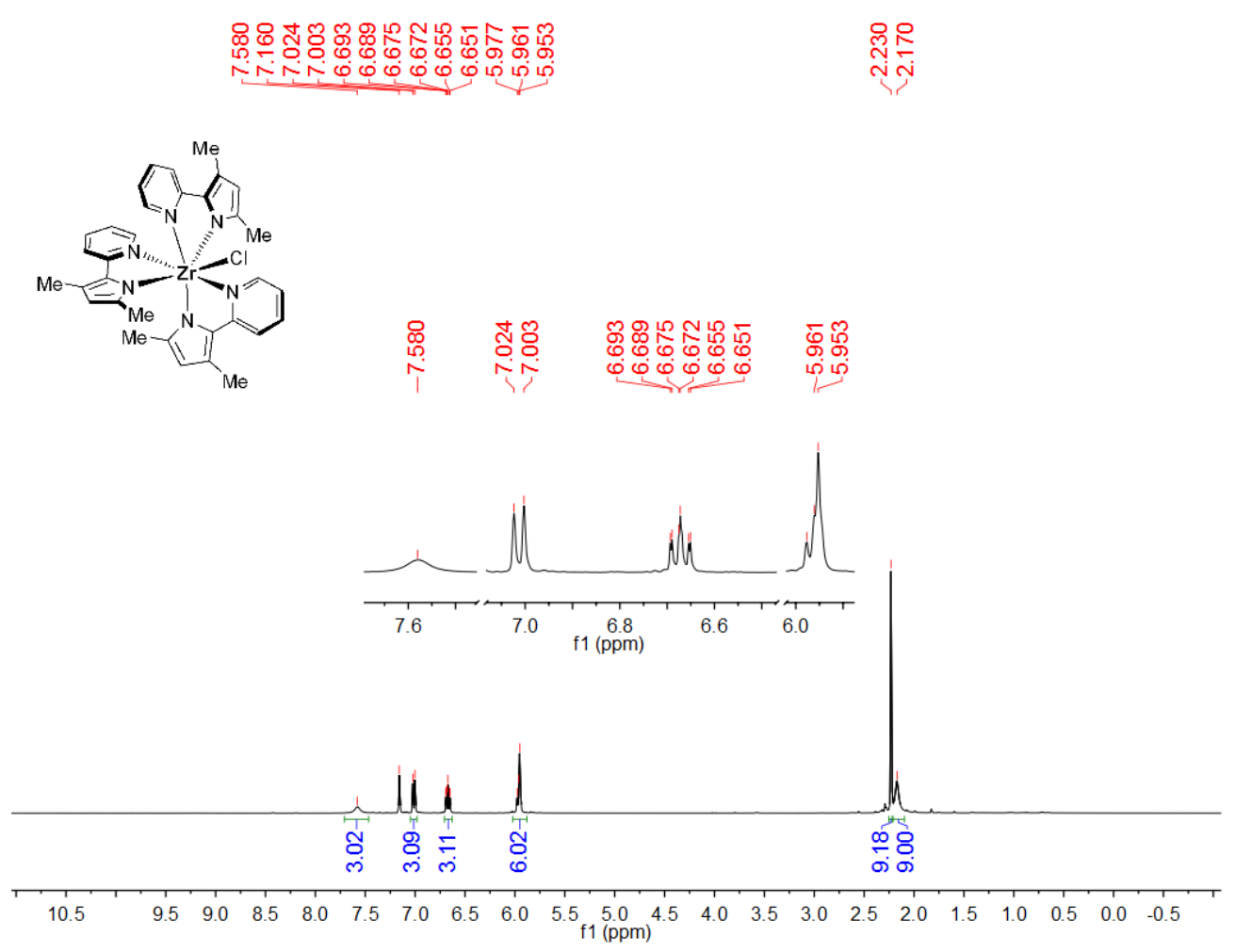

Figure B32. ${ }^{1} \mathrm{H}$ NMR spectrum of $\left({ }^{\mathrm{Me}} \mathrm{PMP}{ }^{\mathrm{Me}}\right)_{3} \mathrm{ZrCl}$ in $\mathrm{C}_{6} \mathrm{D}_{6}$ at room temperature. 

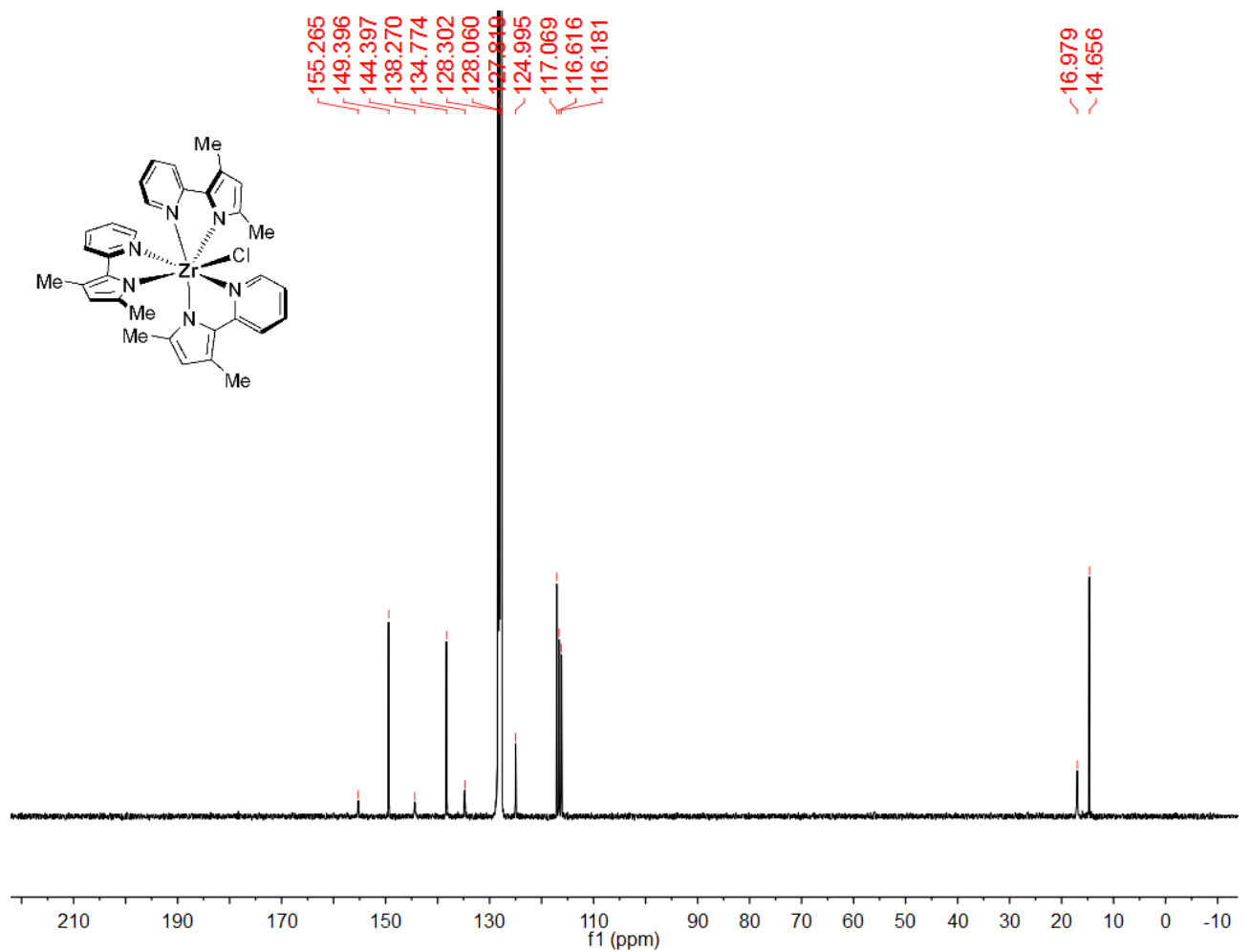

Figure B33. ${ }^{13} \mathrm{C}$ NMR spectrum of $\left({ }^{\mathrm{Me}} \mathrm{PMP}^{\mathrm{Me}}\right)_{3} \mathrm{ZrCl}$ in $\mathrm{C}_{6} \mathrm{D}_{6}$ at room temperature.

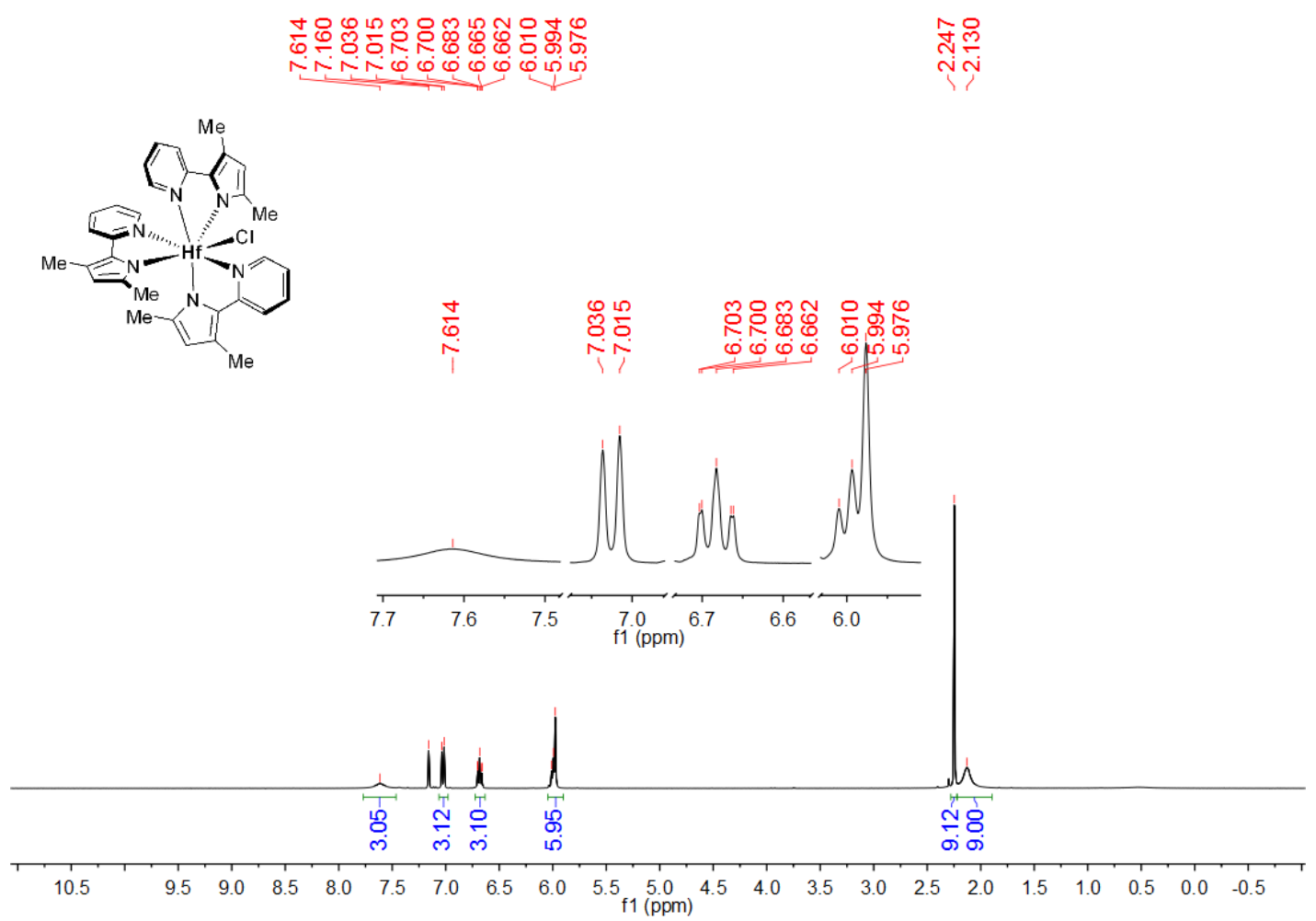

Figure B34. ${ }^{1} \mathrm{H}$ NMR spectrum of $\left({ }^{\mathrm{Me}} \mathrm{PMP}{ }^{\mathrm{Me}}\right)_{3} \mathrm{HfCl}$ in $\mathrm{C}_{6} \mathrm{D}_{6}$ at room temperature. 


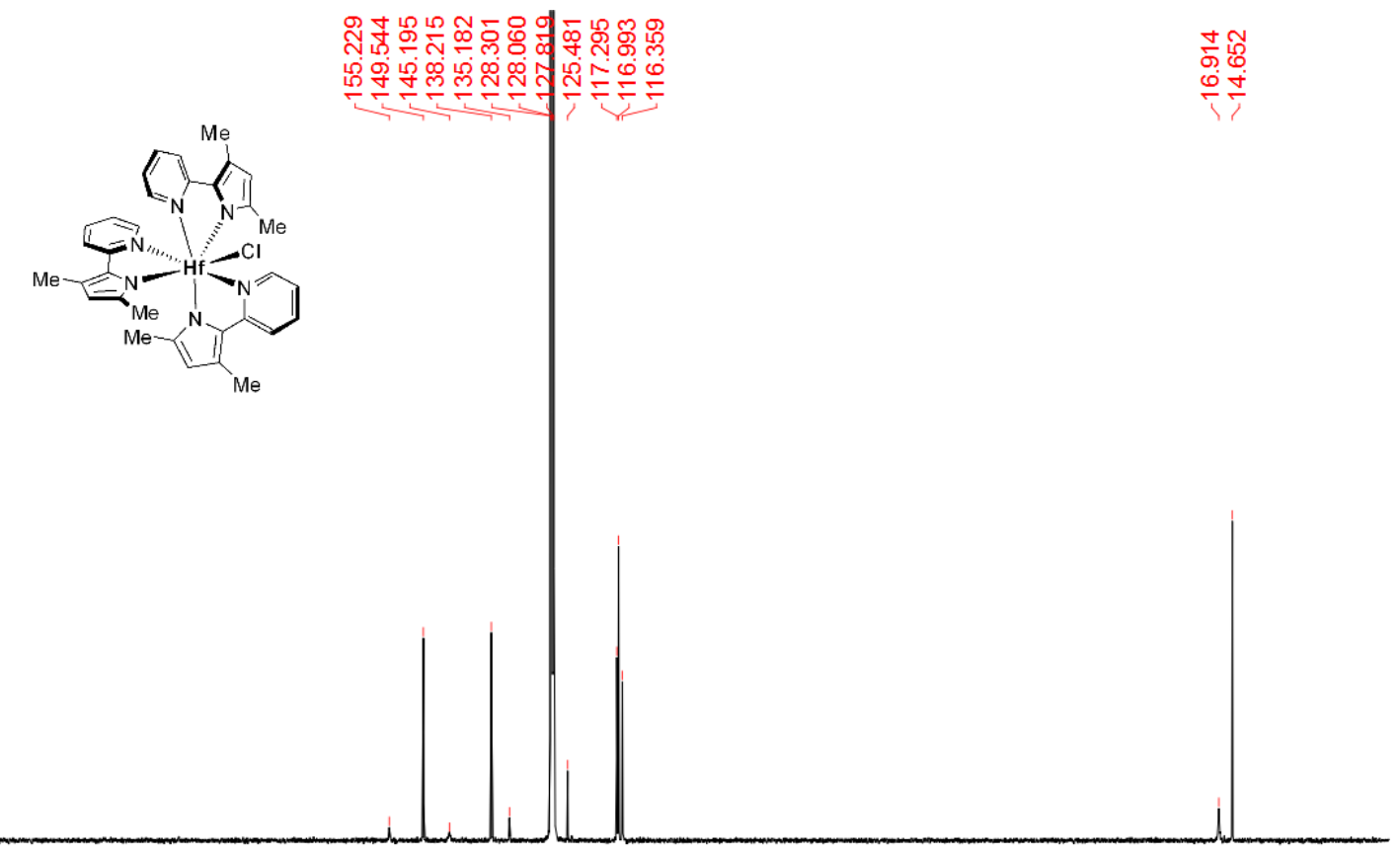

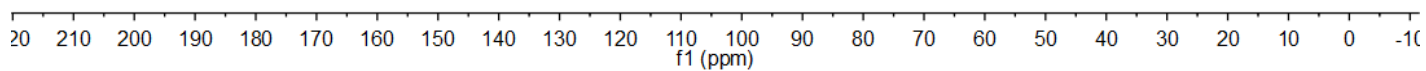

Figure B35. ${ }^{13} \mathrm{C}$ NMR spectrum of $\left({ }^{\mathrm{Me}} \mathrm{PMP}^{\mathrm{Me}}\right)_{3} \mathrm{HfCl}$ in $\mathrm{C}_{6} \mathrm{D}_{6}$ at room temperature.

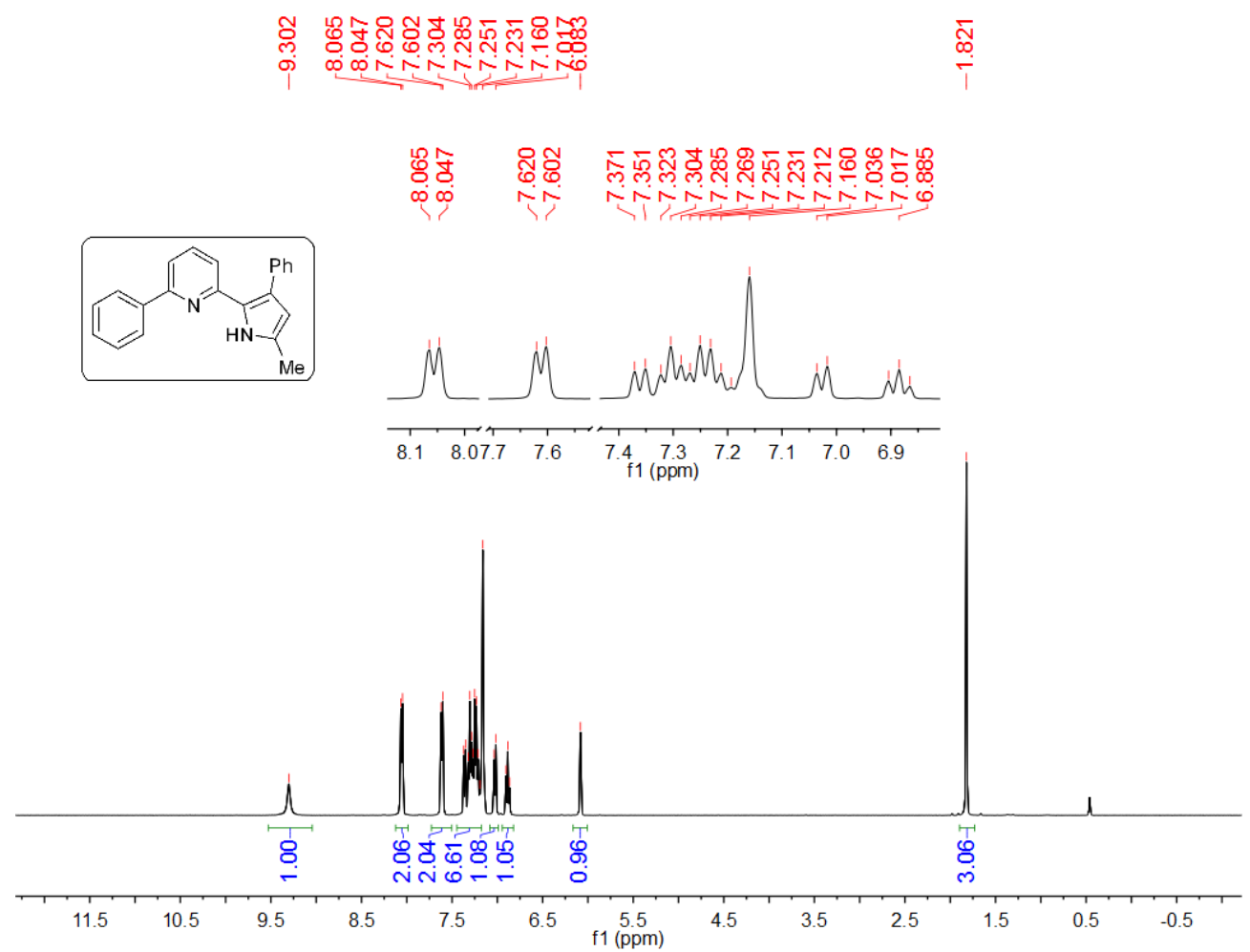

Figure B36. ${ }^{1} \mathrm{H}$ NMR spectrum of $\mathrm{H}_{2}{ }^{\mathrm{H}} \mathrm{CNN}$ in $\mathrm{C}_{6} \mathrm{D}_{6}$. 

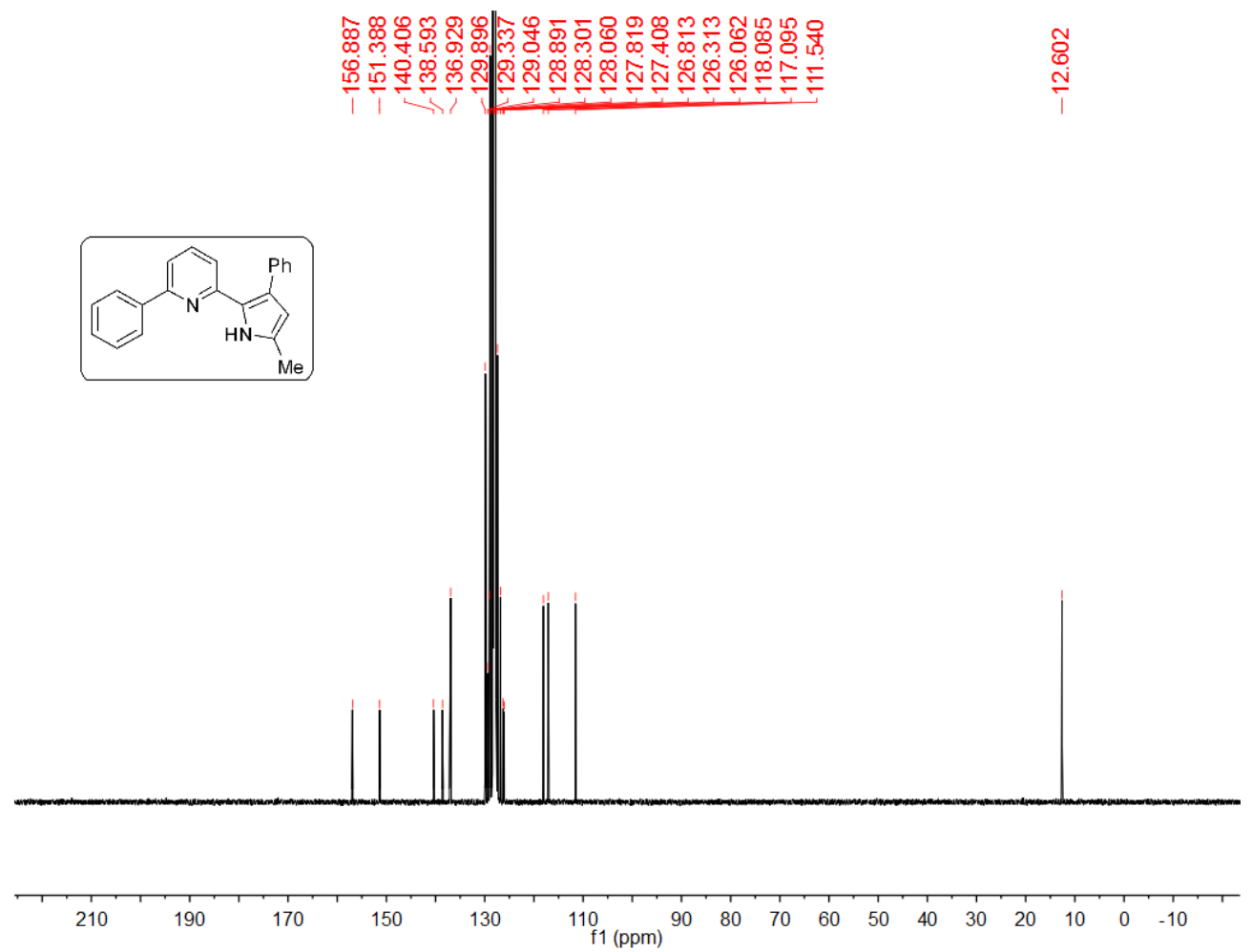

Figure B37. ${ }^{13} \mathrm{C}$ NMR spectrum of $\mathrm{H}_{2}{ }^{\mathrm{H}} \mathrm{CNN}$ in $\mathrm{C}_{6} \mathrm{D}_{6}$.

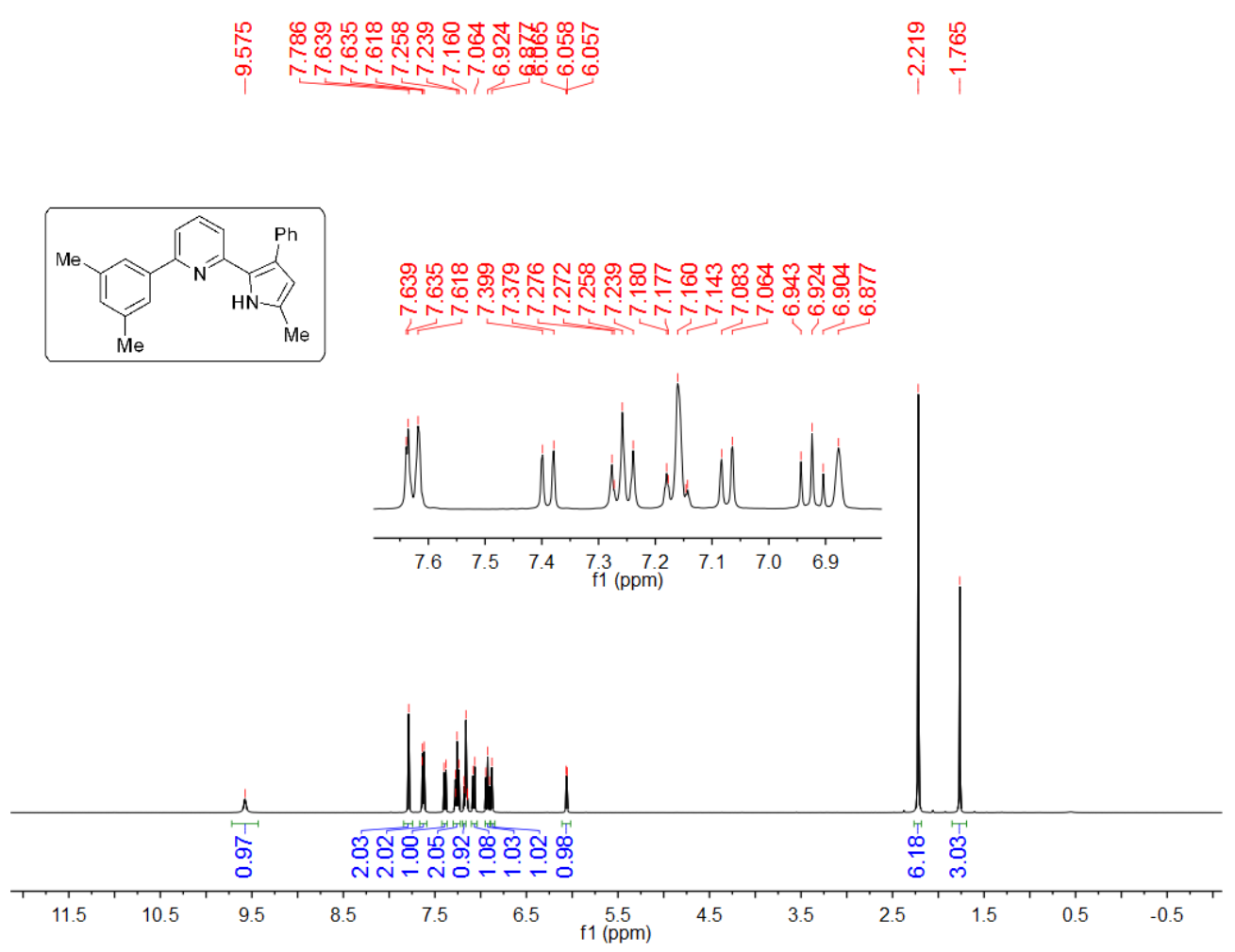

Figure B38. ${ }^{1} \mathrm{H}$ NMR spectrum of $\mathrm{H}_{2}{ }^{\mathrm{Me}} \mathrm{CNN}$ in $\mathrm{C}_{6} \mathrm{D}_{6}$. 


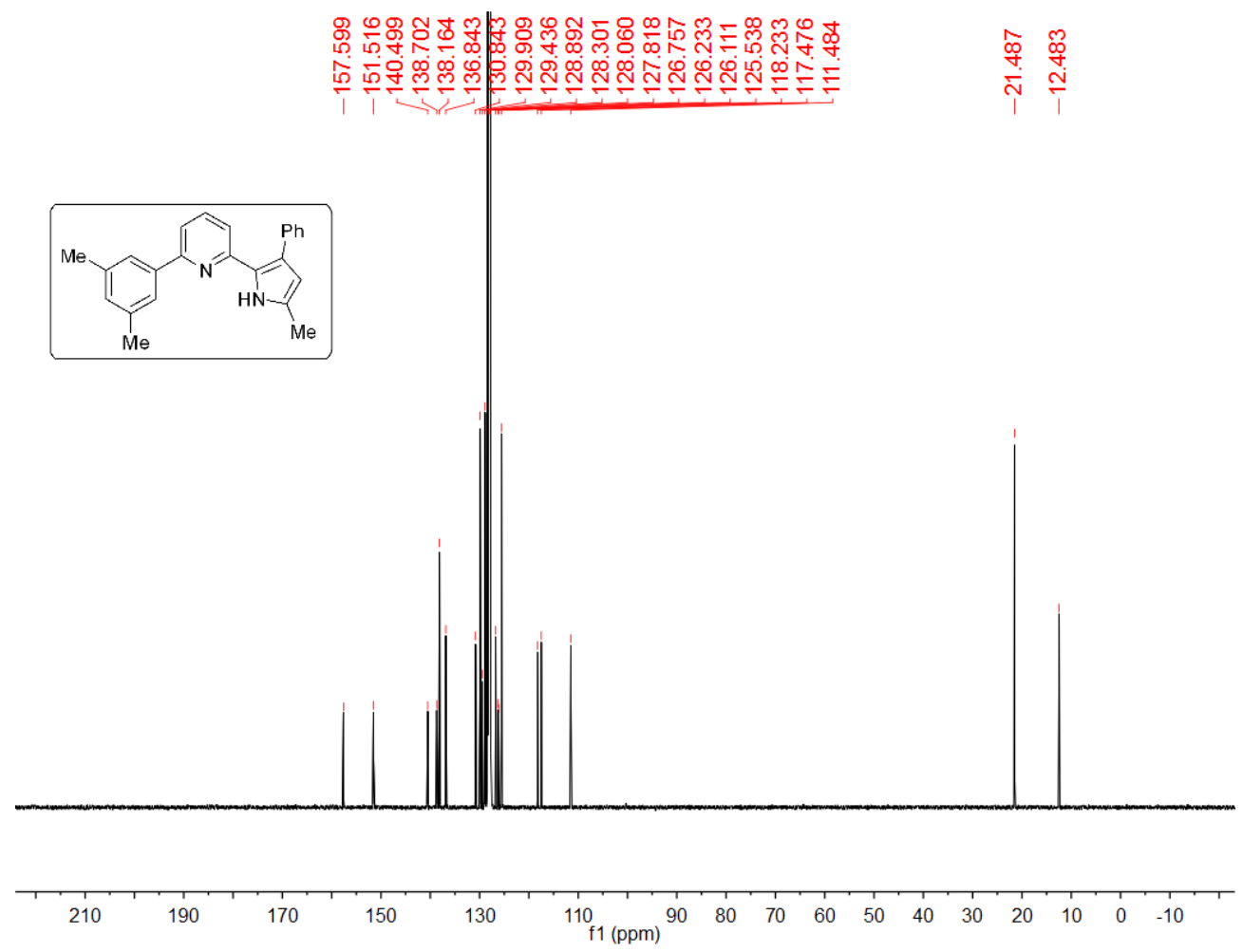

Figure B39. ${ }^{13} \mathrm{C}$ NMR spectrum of $\mathrm{H}_{2}{ }^{\mathrm{Me}} \mathrm{CNN}$ in $\mathrm{C}_{6} \mathrm{D}_{6}$.

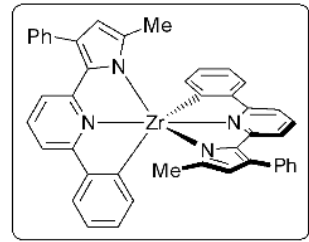

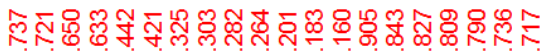

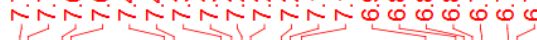
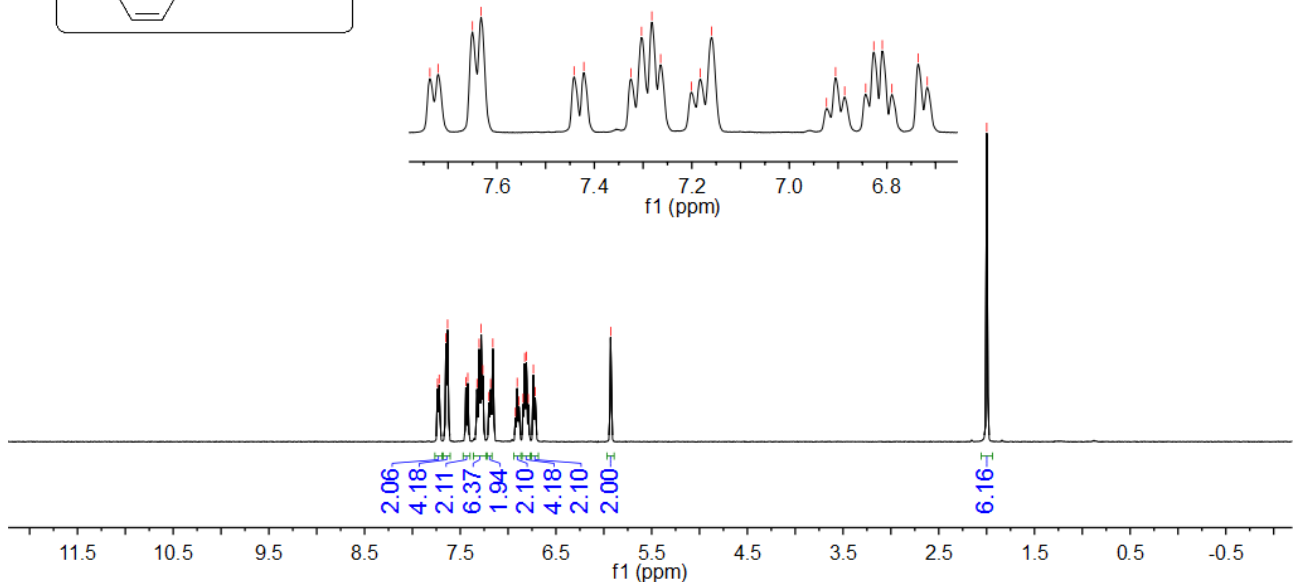

Figure B40. ${ }^{1} \mathrm{H}$ NMR spectrum of $\mathrm{Zr}\left({ }^{\mathrm{H}} \mathrm{CNN}\right)_{2}$ in $\mathrm{C}_{6} \mathrm{D}_{6}$. 


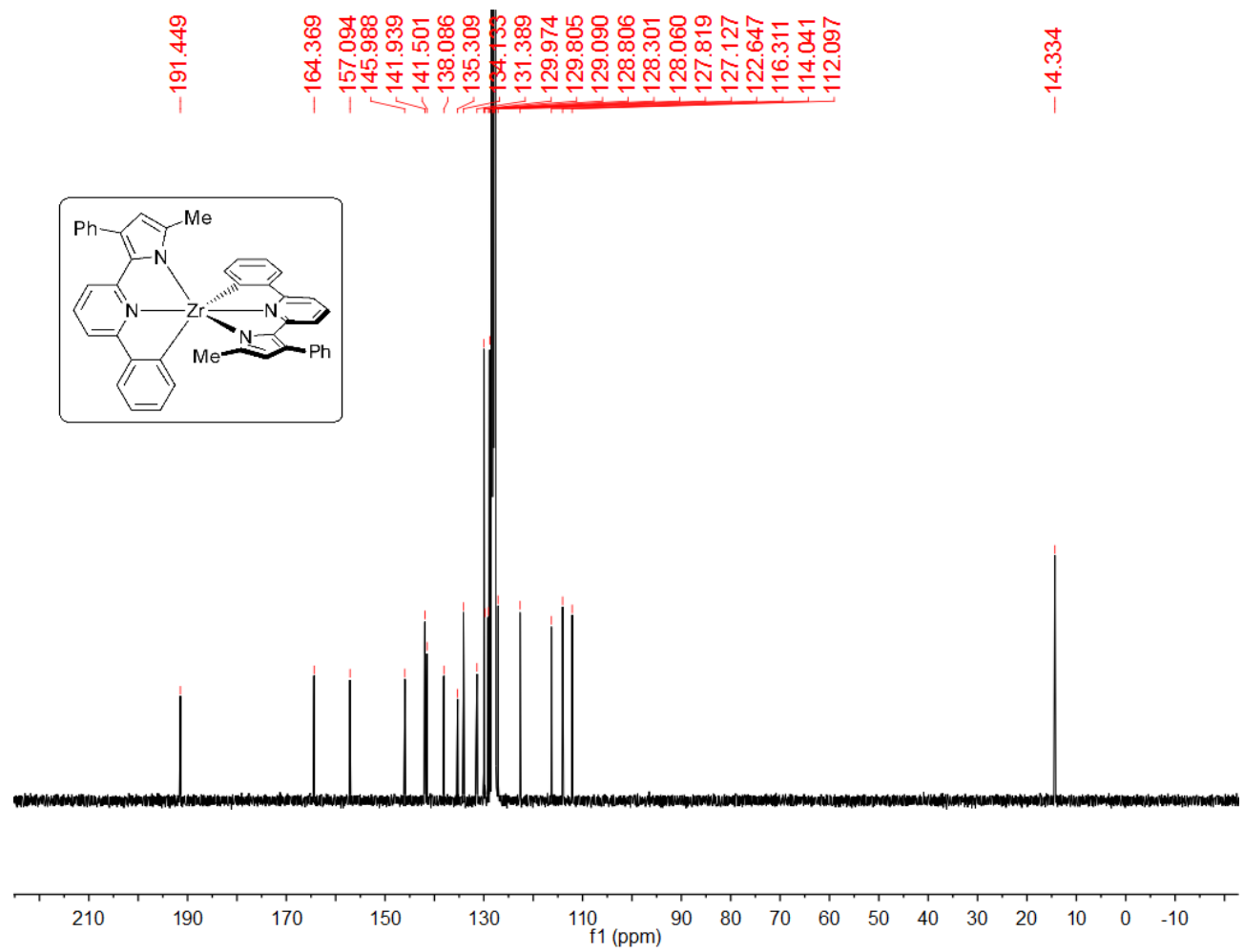

Figure B41. ${ }^{13} \mathrm{C}$ NMR spectrum of $\mathrm{Zr}\left({ }^{\mathrm{H}} \mathrm{CNN}\right)_{2}$ in $\mathrm{C}_{6} \mathrm{D}_{6}$.
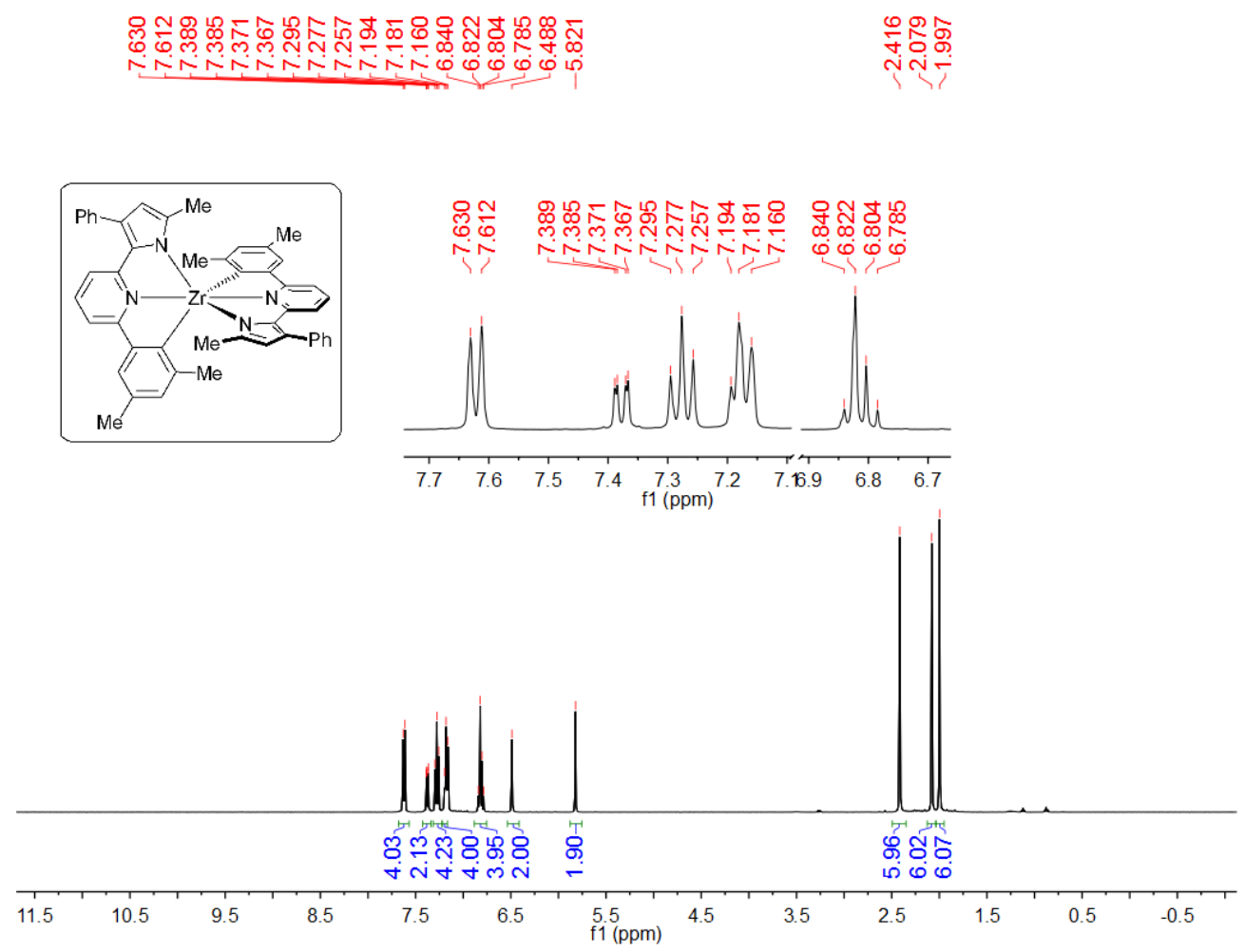

Figure B42. ${ }^{1} \mathrm{H}$ NMR spectrum of $\mathrm{Zr}\left({ }^{\mathrm{Me}} \mathrm{CNN}\right)_{2}$ in $\mathrm{C}_{6} \mathrm{D}_{6}$. 


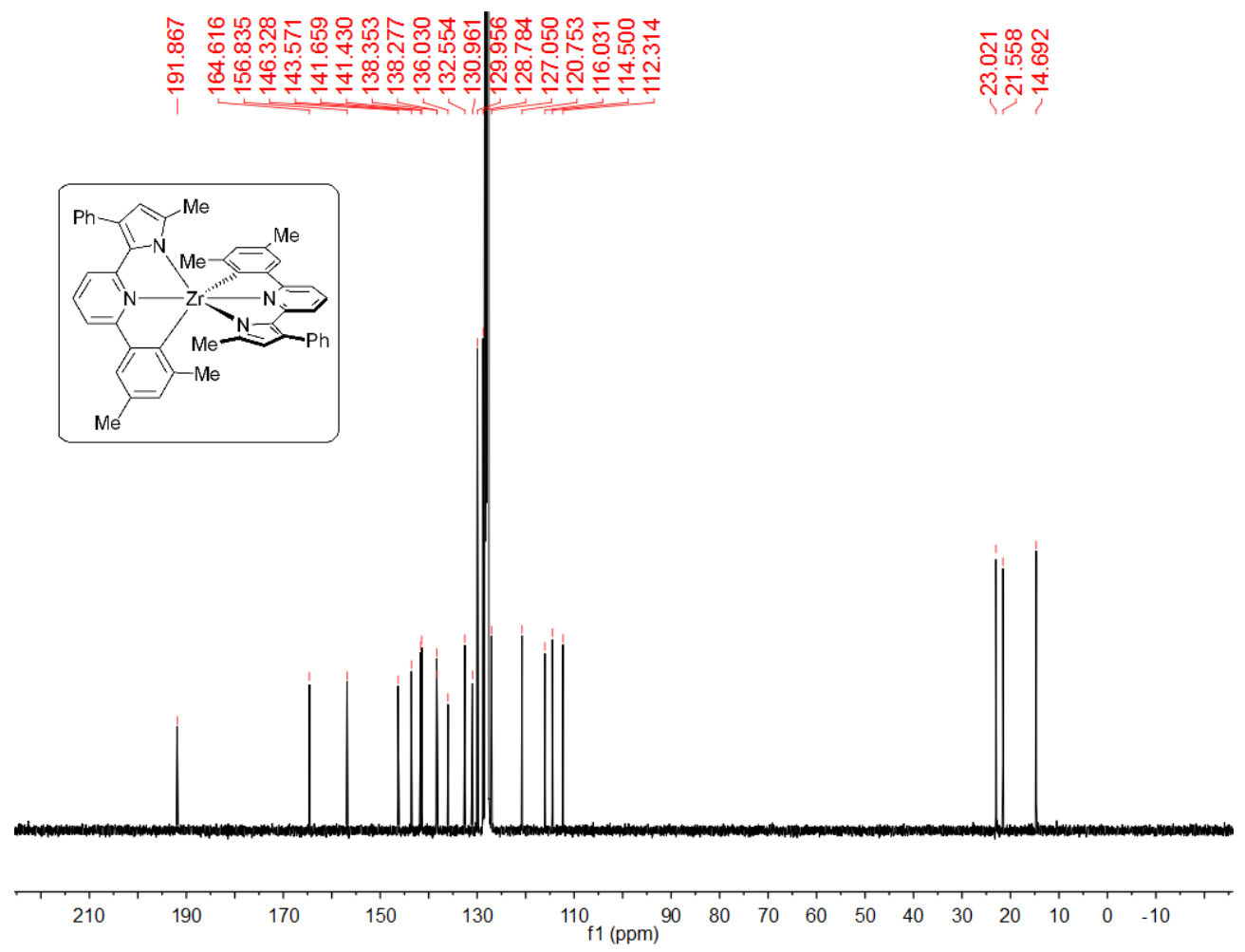

Figure B43. ${ }^{13} \mathrm{C}$ NMR spectrum of $\mathrm{Zr}\left({ }^{\mathrm{Me}} \mathrm{CNN}\right)_{2}$ in $\mathrm{C}_{6} \mathrm{D}_{6}$.
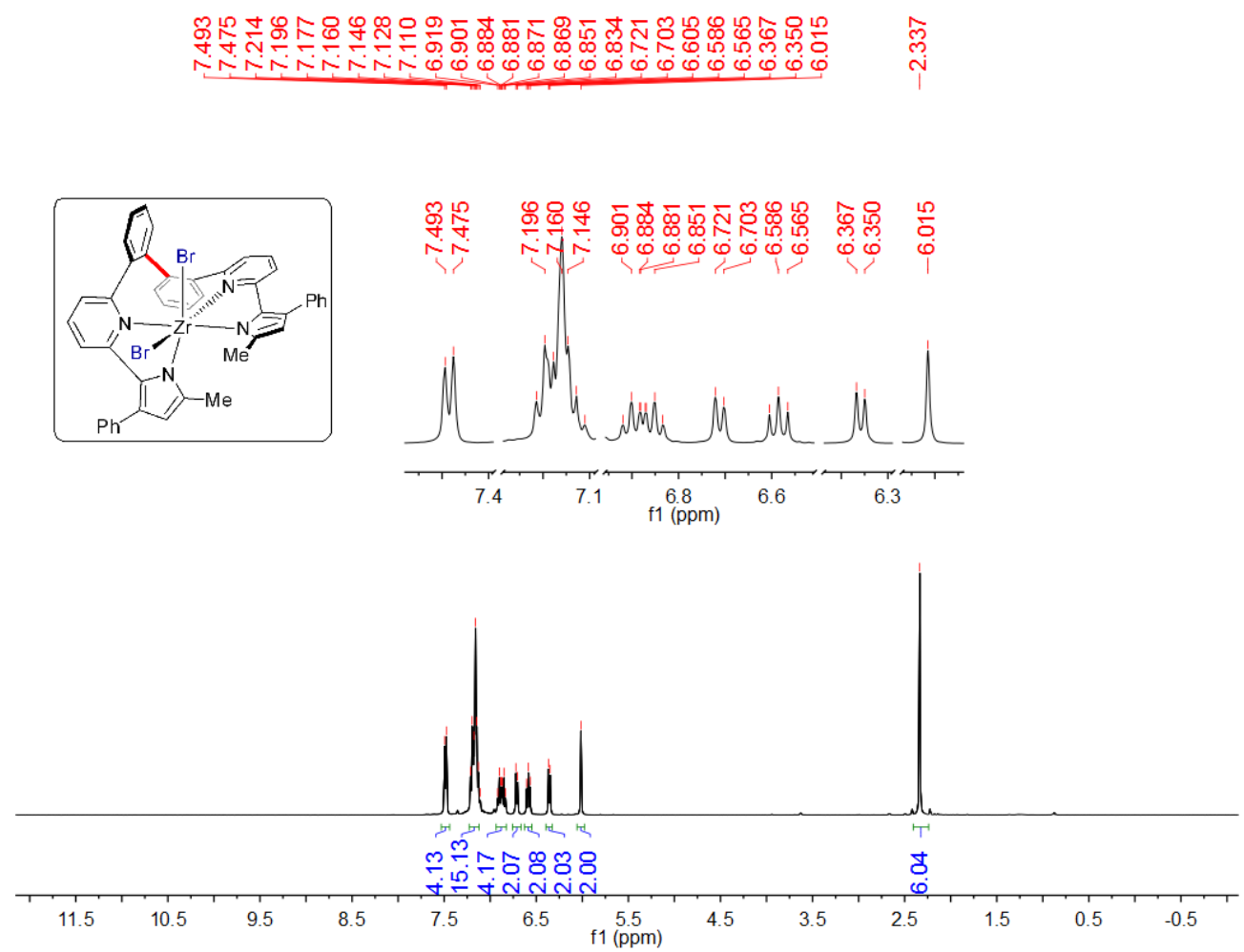

Figure B44. ${ }^{1} \mathrm{H}$ NMR spectrum of $\mathrm{Zr}(\mathrm{DPDP})_{2} \mathrm{Br}_{2}$ in $\mathrm{C}_{6} \mathrm{D}_{6}$. 


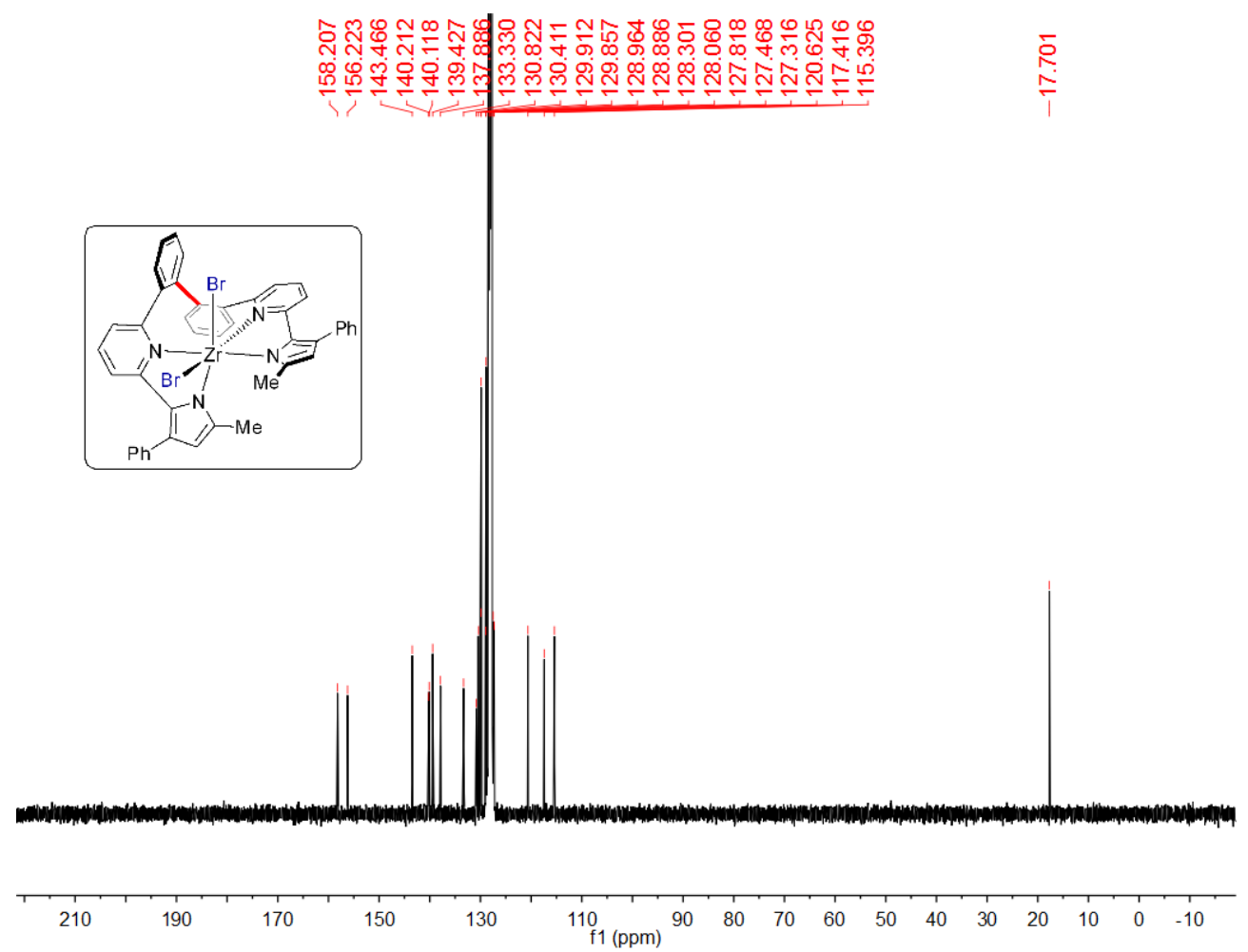

Figure B45. ${ }^{13} \mathrm{C}$ NMR spectrum of $\mathrm{Zr}(\mathrm{DPDP})_{2} \mathrm{Br}_{2}$ in $\mathrm{C}_{6} \mathrm{D}_{6}$.
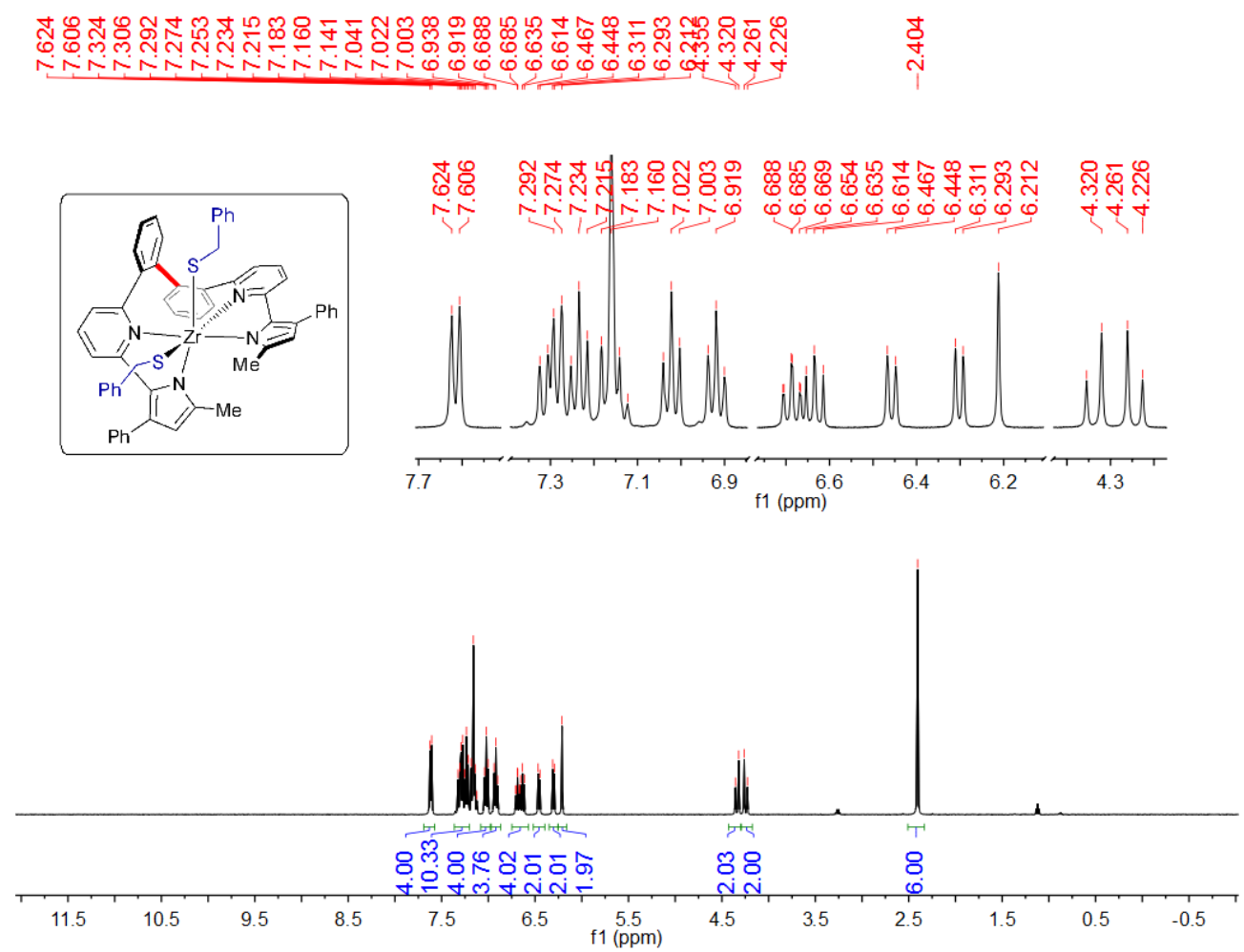

Figure B46. ${ }^{1} \mathrm{H}$ NMR spectrum of $\mathrm{Zr}(\mathrm{DPDP})_{2}(\mathrm{SBn})_{2}$ in $\mathrm{C}_{6} \mathrm{D}_{6}$. 


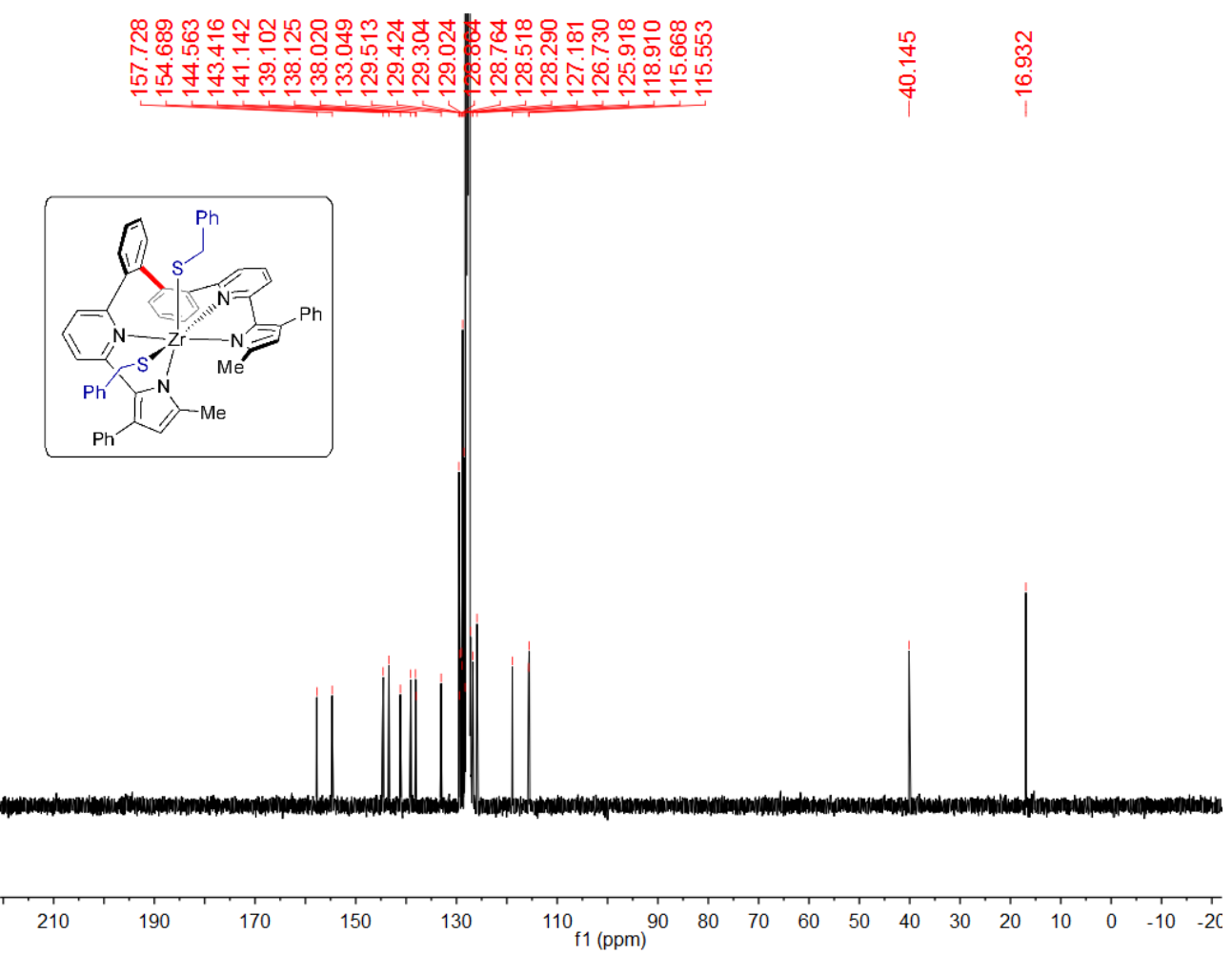

Figure B47. ${ }^{13} \mathrm{C}$ NMR spectrum of $\operatorname{Zr}(\mathrm{DPDP})_{2}(\mathrm{SBn})_{2}$ in $\mathrm{C}_{6} \mathrm{D}_{6}$.

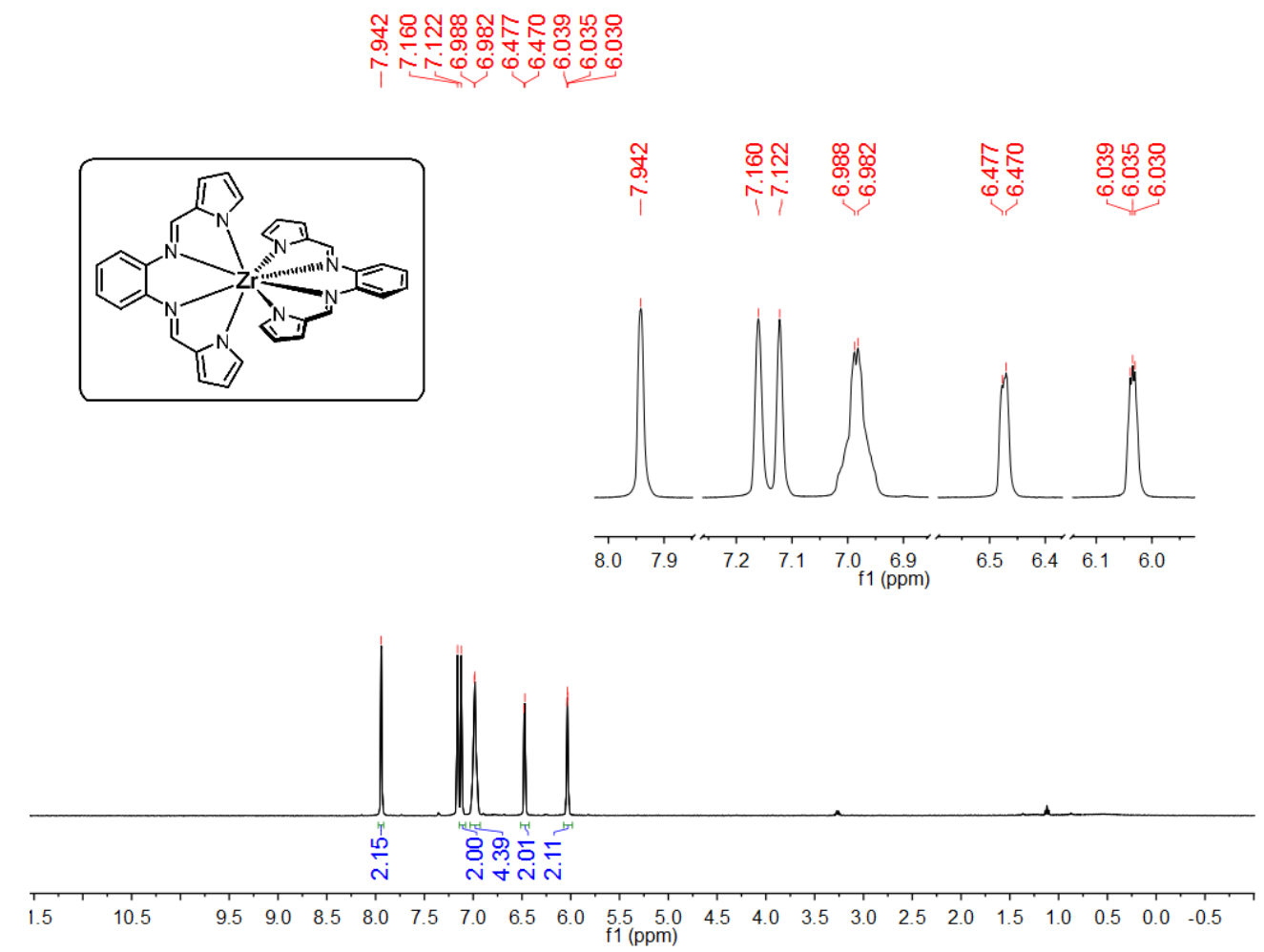

Figure B48. ${ }^{1} \mathrm{H}$ NMR spectrum of $\mathrm{Zr}(\text { bppda })_{2}$ in $\mathrm{C}_{6} \mathrm{D}_{6}$. 


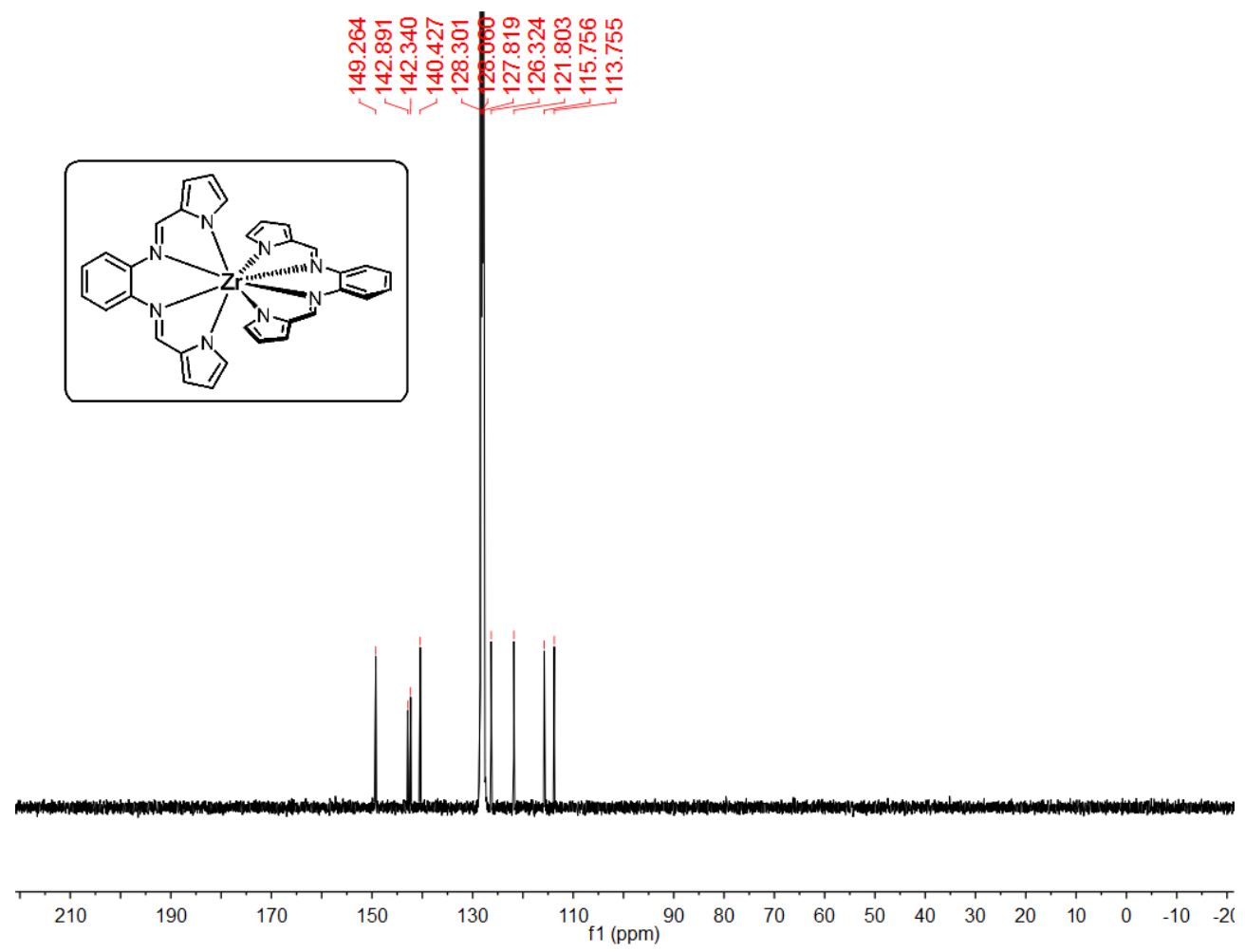

Figure B49. ${ }^{13} \mathrm{C}$ NMR spectrum of $\mathrm{Zr}(\mathrm{bppda})_{2}$ in $\mathrm{C}_{6} \mathrm{D}_{6}$.
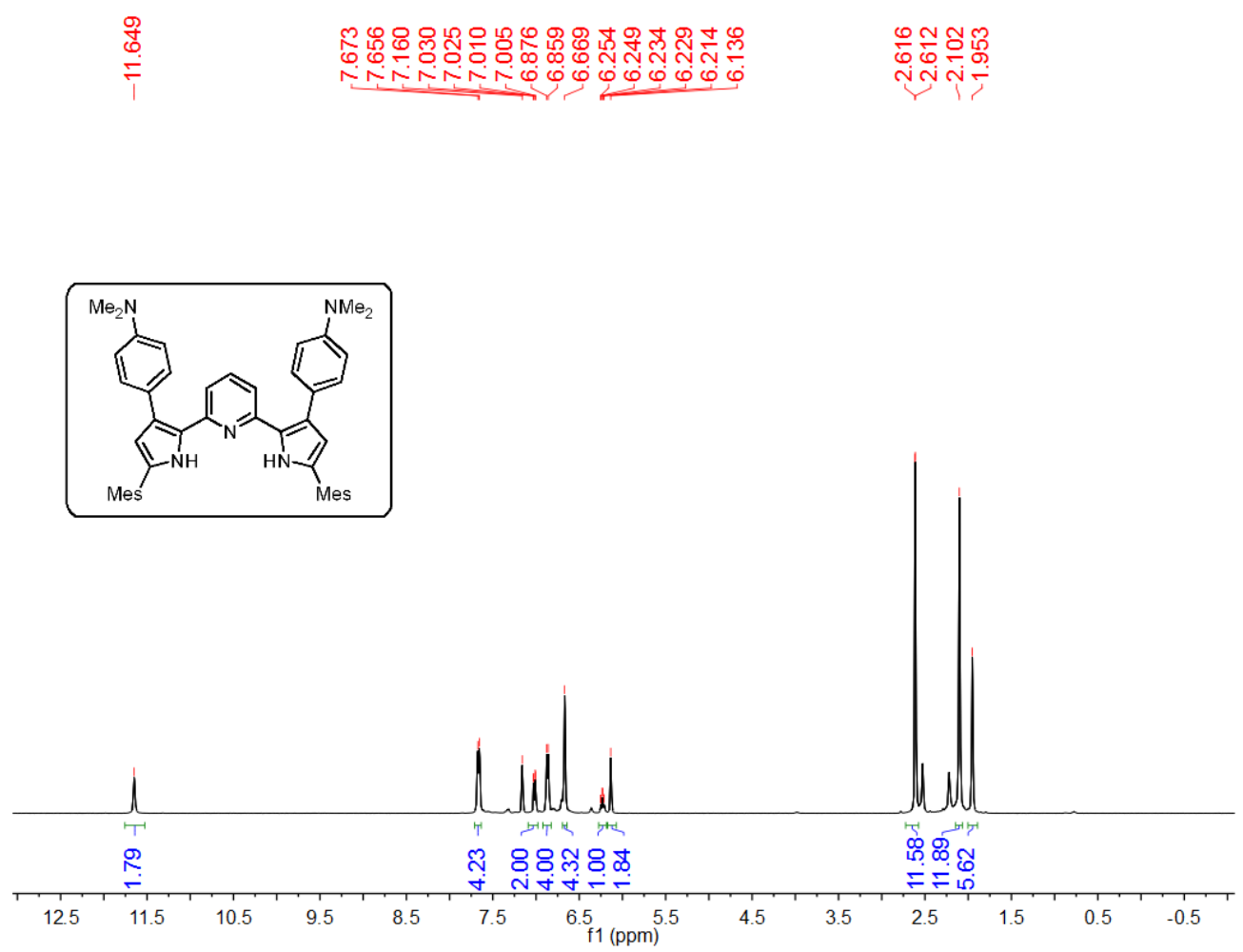

Figure B50. ${ }^{1} \mathrm{H}$ NMR spectrum of $\mathrm{H}_{2}{ }^{\mathrm{Mes}} \mathrm{PDP}^{\mathrm{NMe} 2 \mathrm{Ph}}$ in $\mathrm{C}_{6} \mathrm{D}_{6}$. 


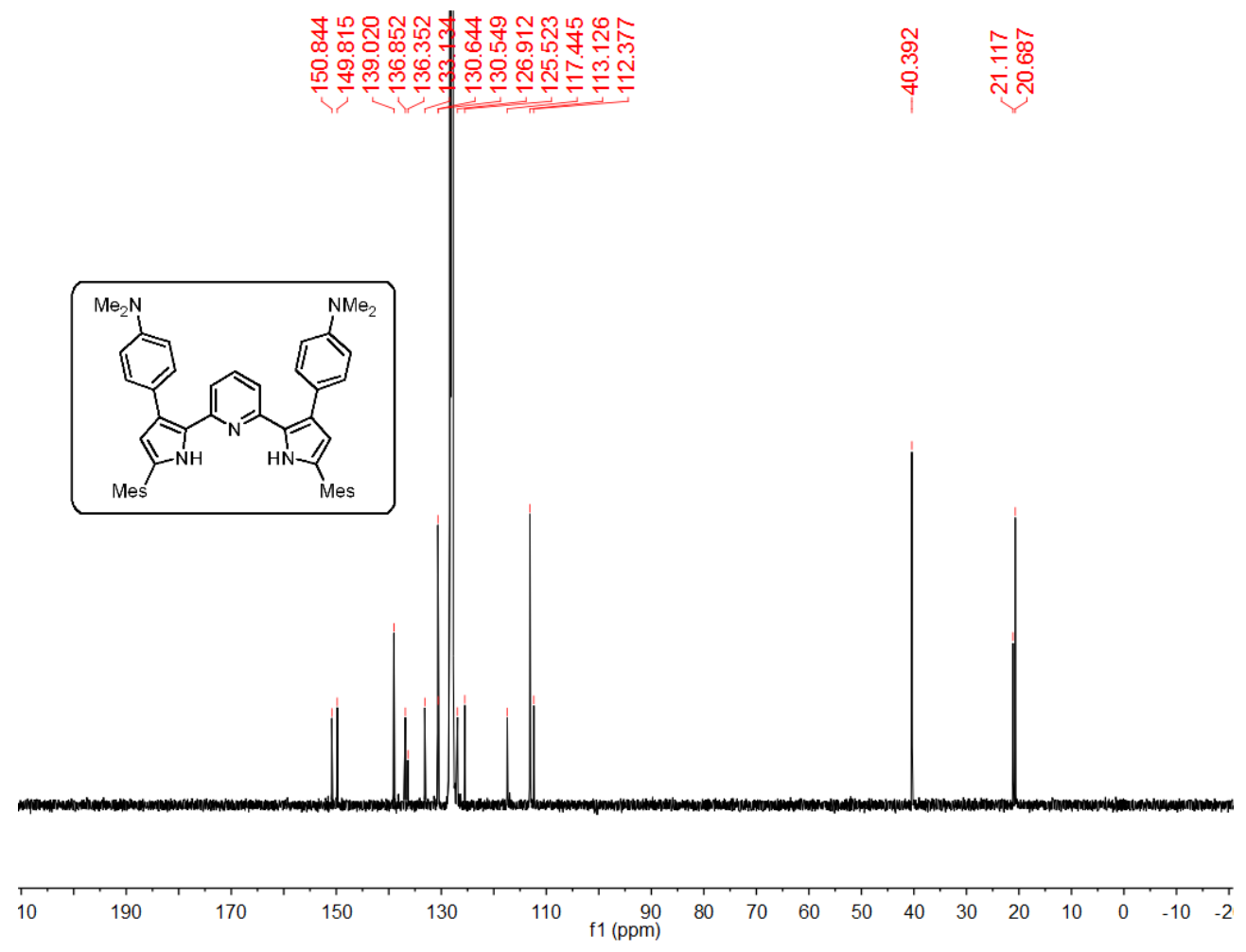

Figure B51. ${ }^{13} \mathrm{C}$ NMR spectrum of $\mathrm{H}_{2}{ }^{\mathrm{Mes}} \mathrm{PDP} \mathrm{PMe}^{\mathrm{NPh}}$ in $\mathrm{C}_{6} \mathrm{D}_{6}$.

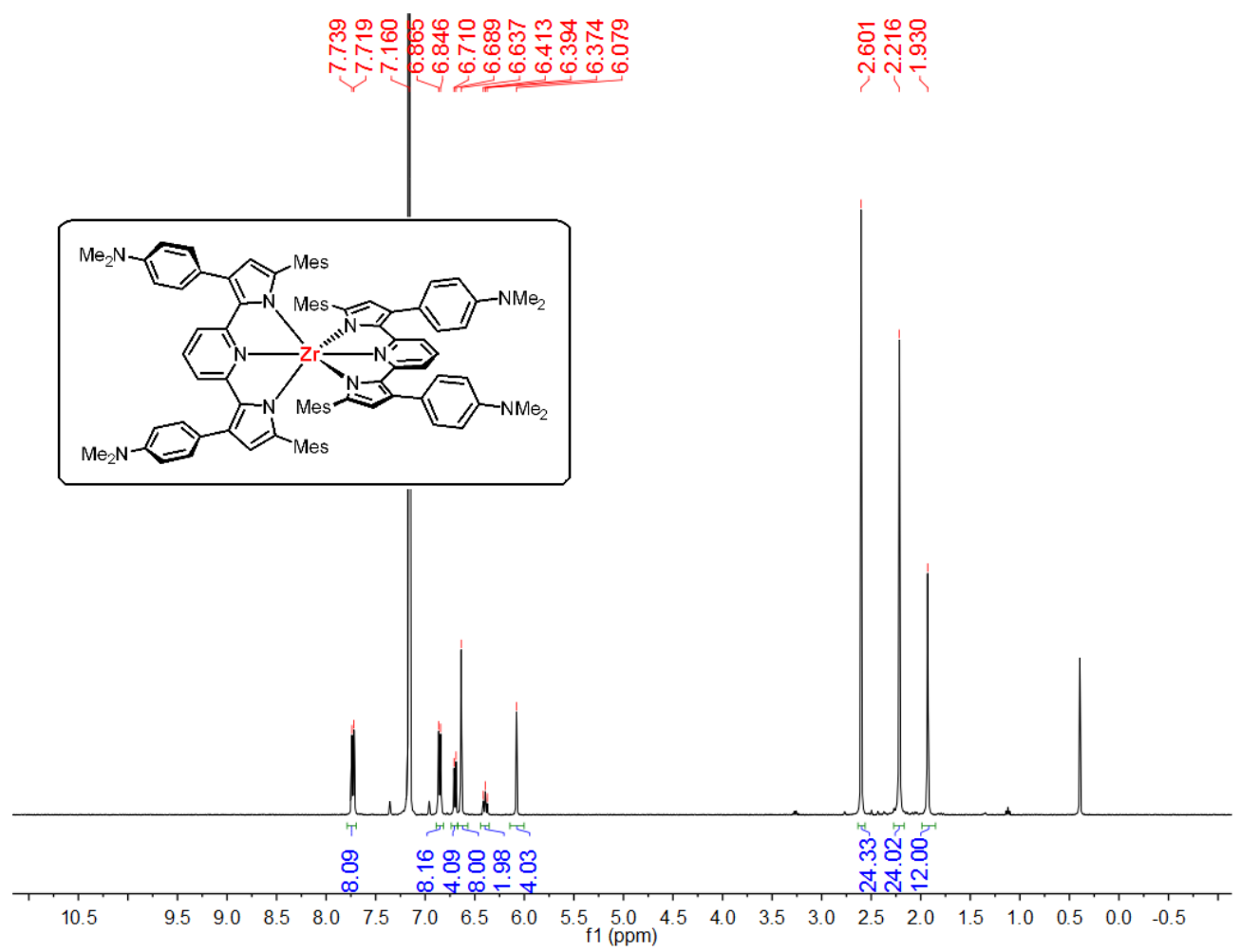

Figure B52. ${ }^{1} \mathrm{H}$ NMR spectrum of $\mathrm{Zr}\left({ }^{\mathrm{Mes}} \mathrm{PDP}^{\mathrm{NMe} 2 \mathrm{PhPh}}\right)_{2}$ in $\mathrm{C}_{6} \mathrm{D}_{6}$. 


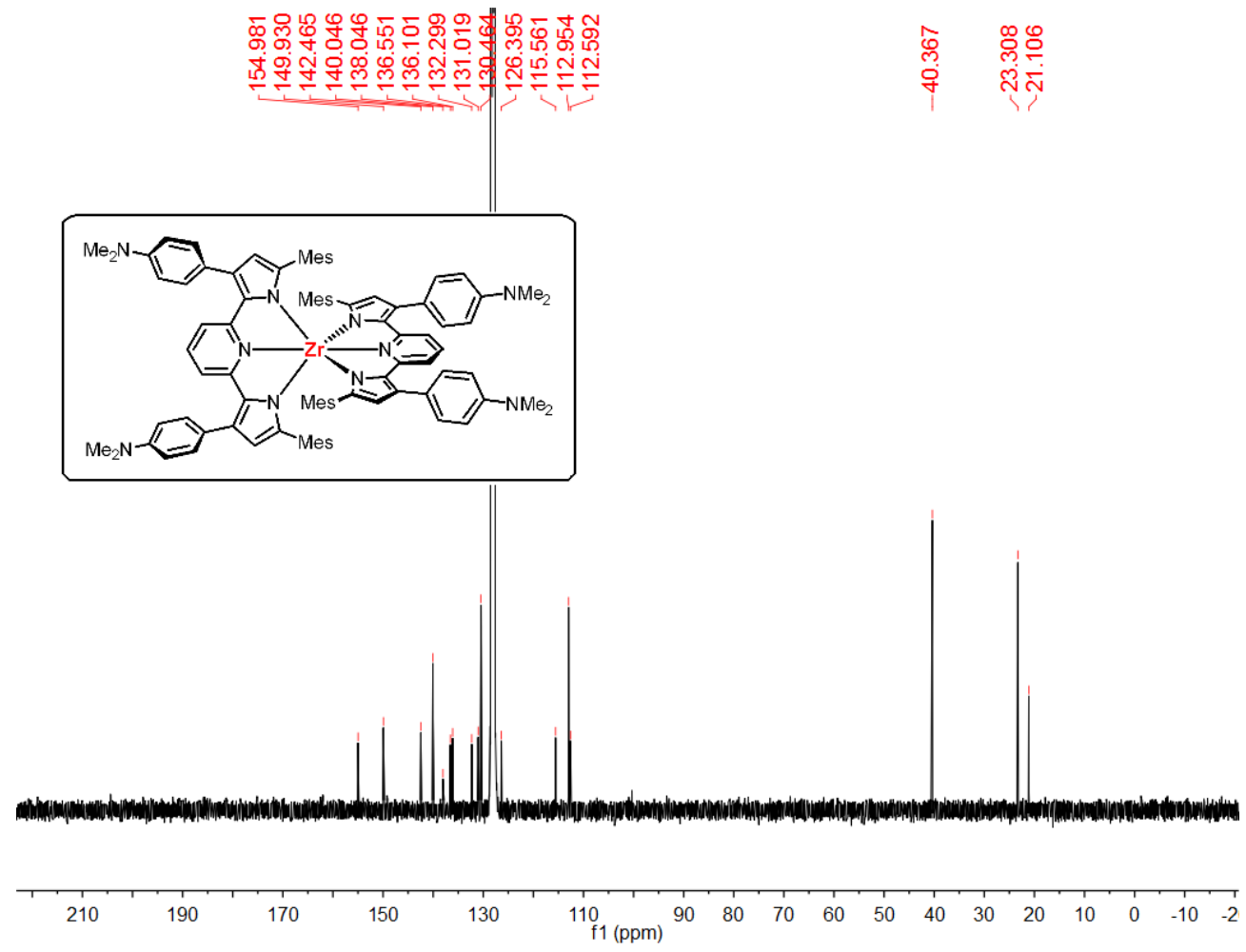

Figure B53. ${ }^{13} \mathrm{C}$ NMR spectrum of $\mathrm{Zr}\left({ }^{\mathrm{Mes}} \mathrm{PDP}^{\mathrm{NMe} 2 \mathrm{PhPh}}\right)_{2}$ in $\mathrm{C}_{6} \mathrm{D}_{6}$.

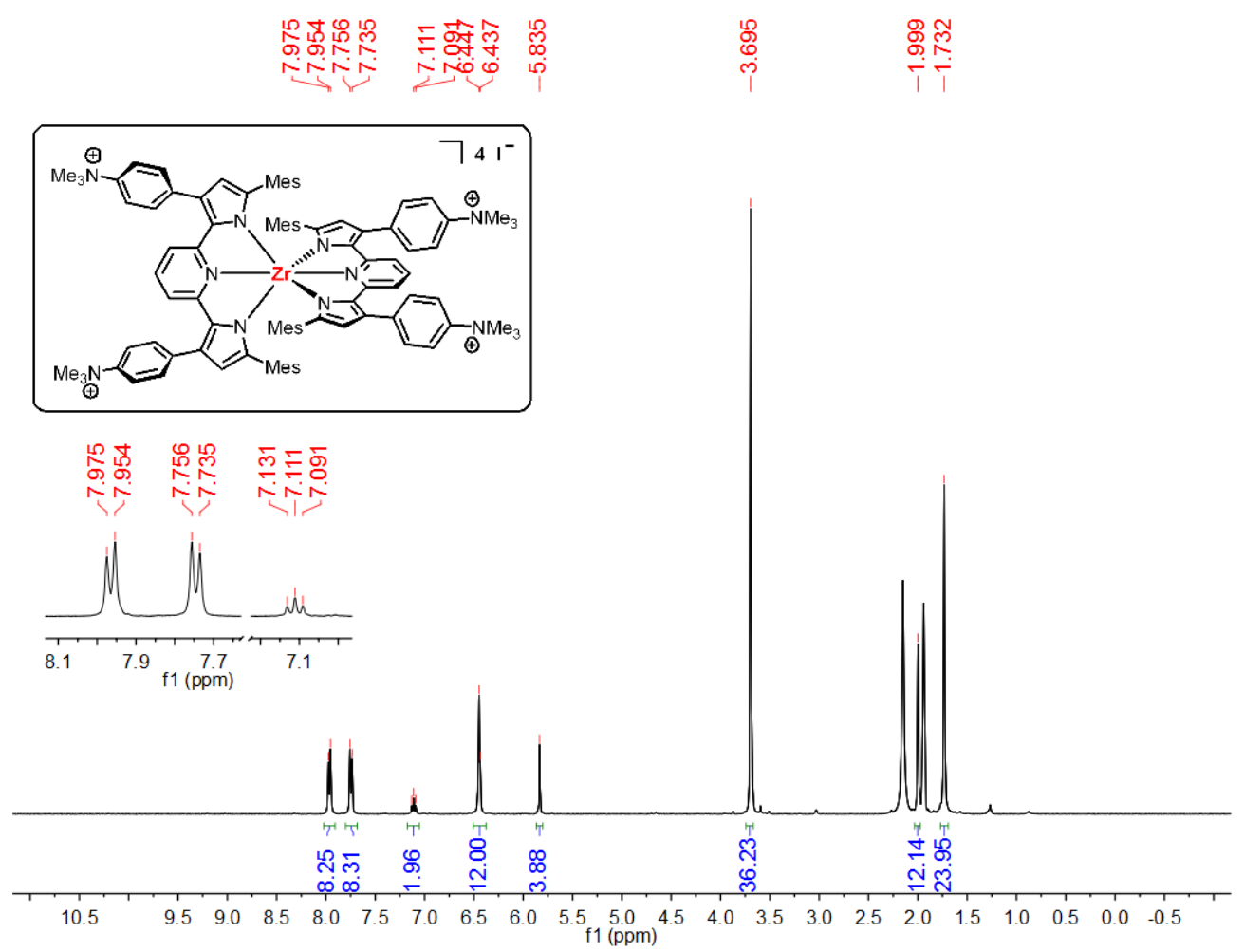

Figure B54. ${ }^{1} \mathrm{H} \mathrm{NMR}$ spectrum of $\left[\mathrm{Zr}\left({ }^{\mathrm{Mes}} \mathrm{PDP}^{\mathrm{NMe} 3 \mathrm{Ph}}\right)_{2}\right] \mathrm{I}_{4}$ in $\mathrm{MeCN}-d_{3}$. 


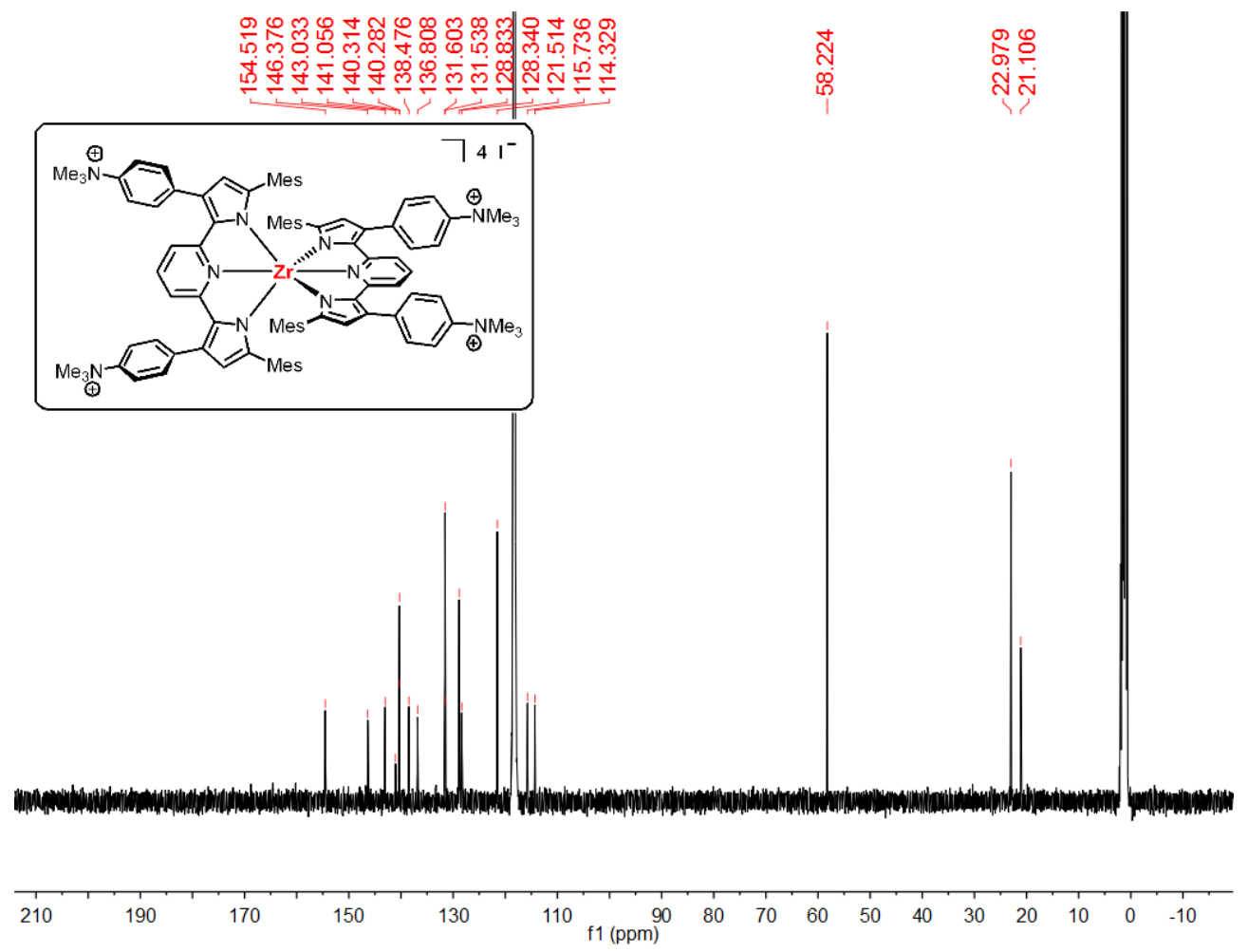

Figure B55. ${ }^{13} \mathrm{C}$ NMR spectrum of $\left[\mathrm{Zr}\left({ }^{\mathrm{Mes}} \mathrm{PDP}^{\mathrm{NMe} 3 \mathrm{Ph}}\right)_{2}\right] \mathrm{I}_{4}$ in $\mathrm{MeCN}-d_{3}$.

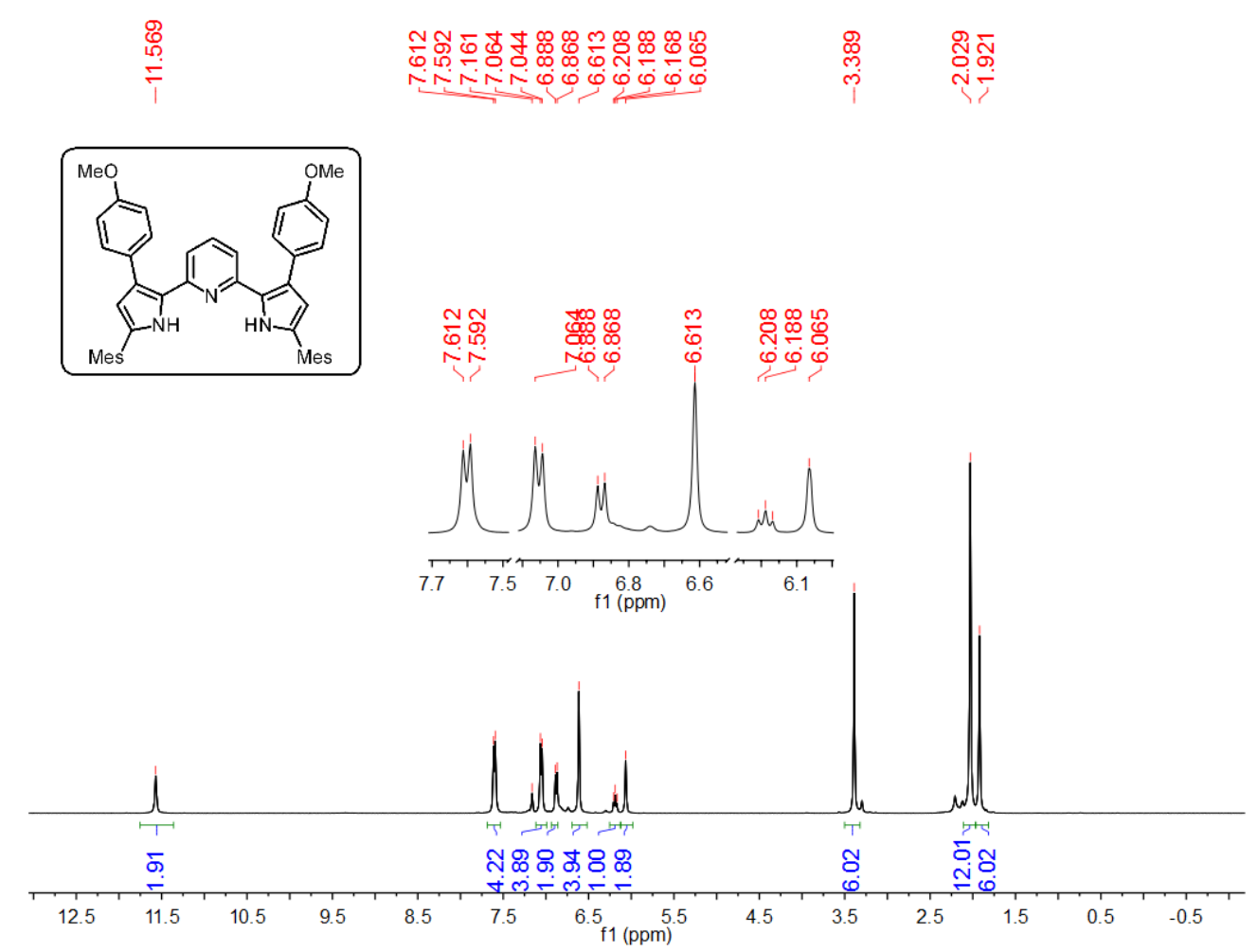

Figure B56. ${ }^{1} \mathrm{H}$ NMR spectrum of $\mathrm{H}_{2}{ }^{\mathrm{Mes}} \mathrm{PDP} \mathrm{OMePh}^{\mathrm{O}}$ in $\mathrm{C}_{6} \mathrm{D}_{6}$. 

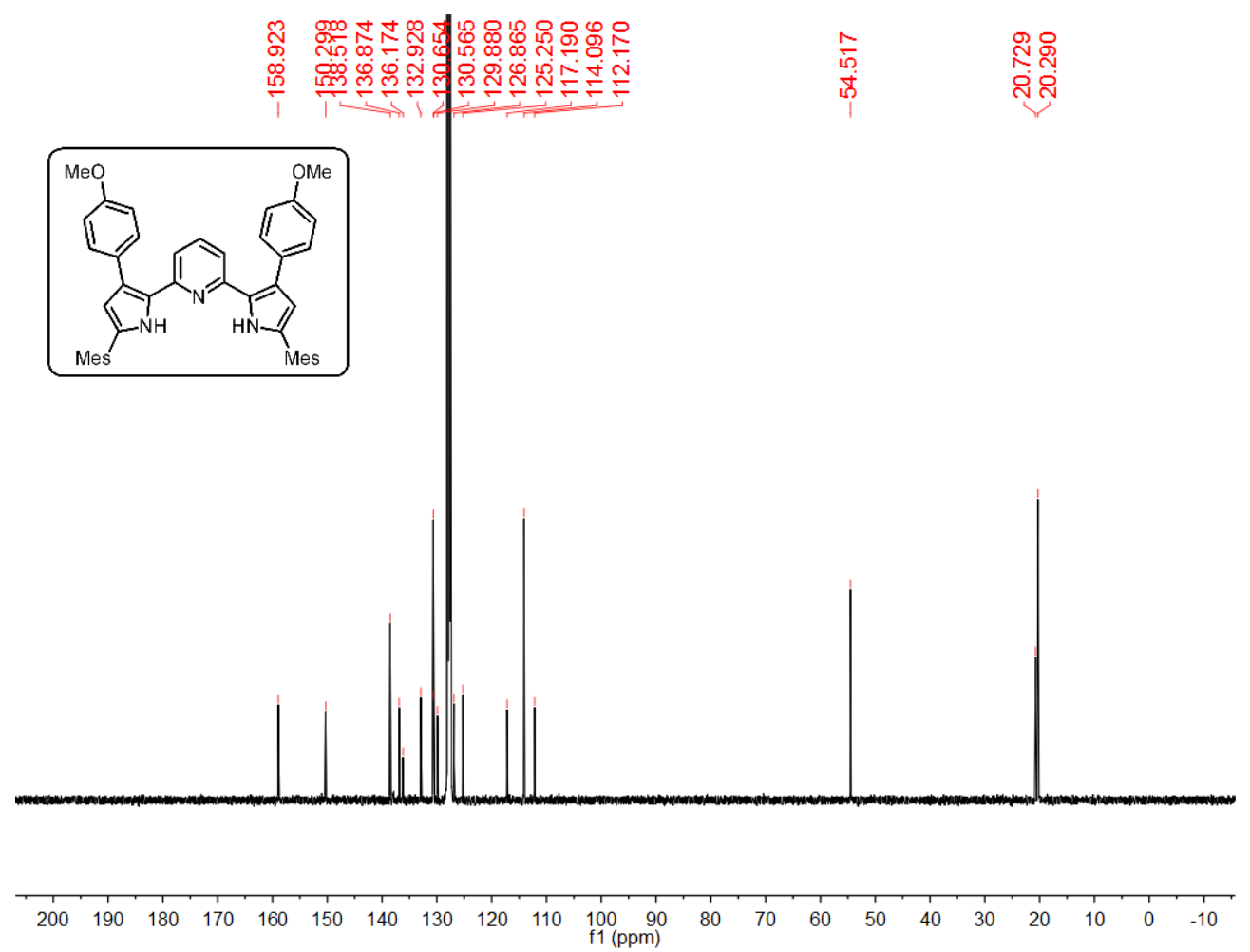

Figure B57. ${ }^{13} \mathrm{C}$ NMR spectrum of $\mathrm{H}_{2}{ }^{\mathrm{Mes}} \mathrm{PDP}^{\mathrm{OMePh}}$ in $\mathrm{C}_{6} \mathrm{D}_{6}$.

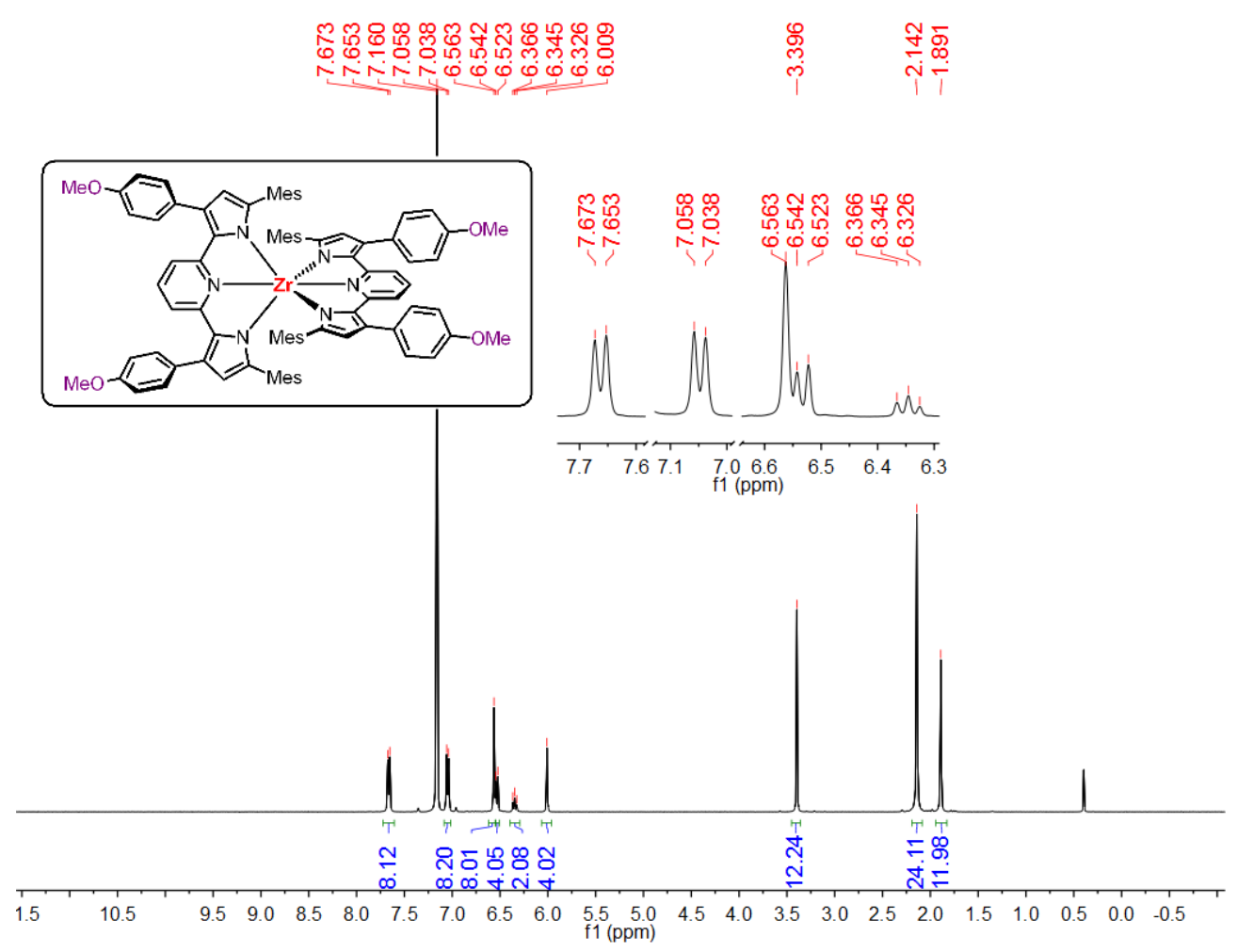

Figure B58. ${ }^{1} \mathrm{H}$ NMR spectrum of $\mathrm{Zr}\left({ }^{\mathrm{Mes}} \mathrm{PDP}^{\mathrm{OMePhPh}}\right)_{2}$ in $\mathrm{C}_{6} \mathrm{D}_{6}$. 


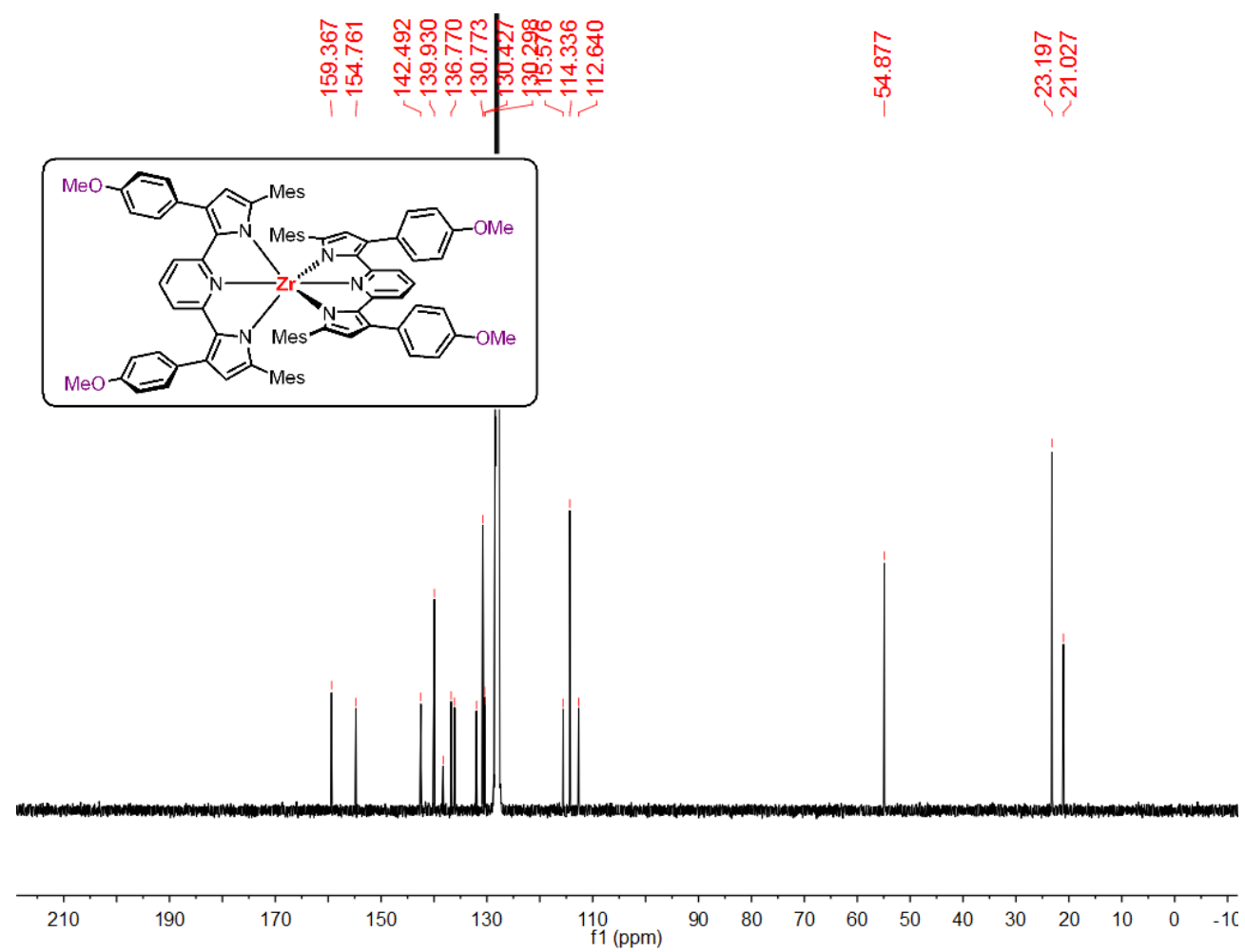

Figure B59. ${ }^{13} \mathrm{C}$ NMR spectrum of $\mathrm{Zr}\left({ }^{\mathrm{Mes}} \mathrm{PDP}^{\mathrm{OMePhPh}}\right)_{2}$ in $\mathrm{C}_{6} \mathrm{D}_{6}$.

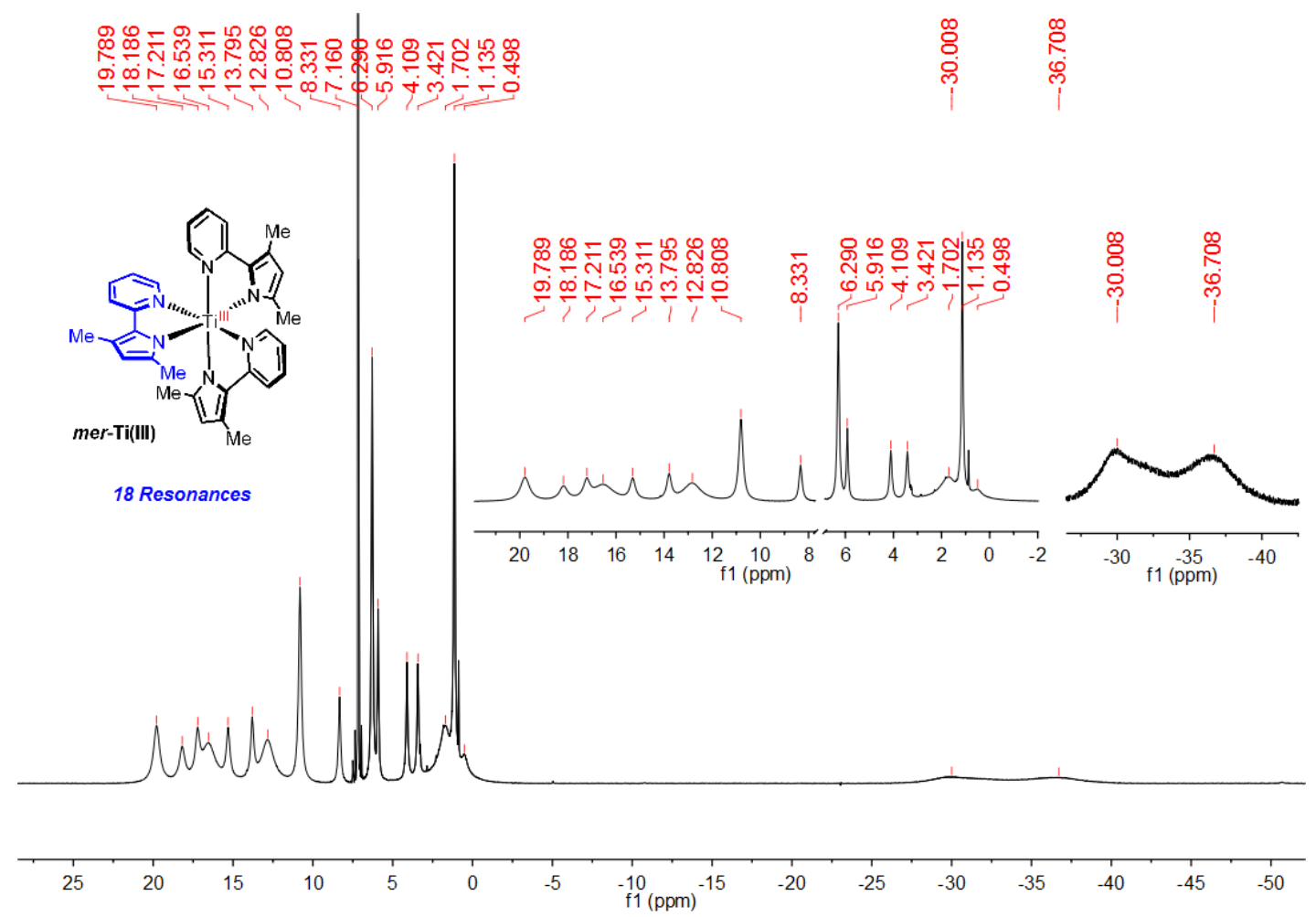

Figure B60. ${ }^{1} \mathrm{H}$ NMR spectra of $m e r-\mathrm{Ti}\left({ }^{\mathrm{Me}} \mathrm{PMP}{ }^{\mathrm{Me}}\right)_{3}$ in Benzene- $d_{6}$. 


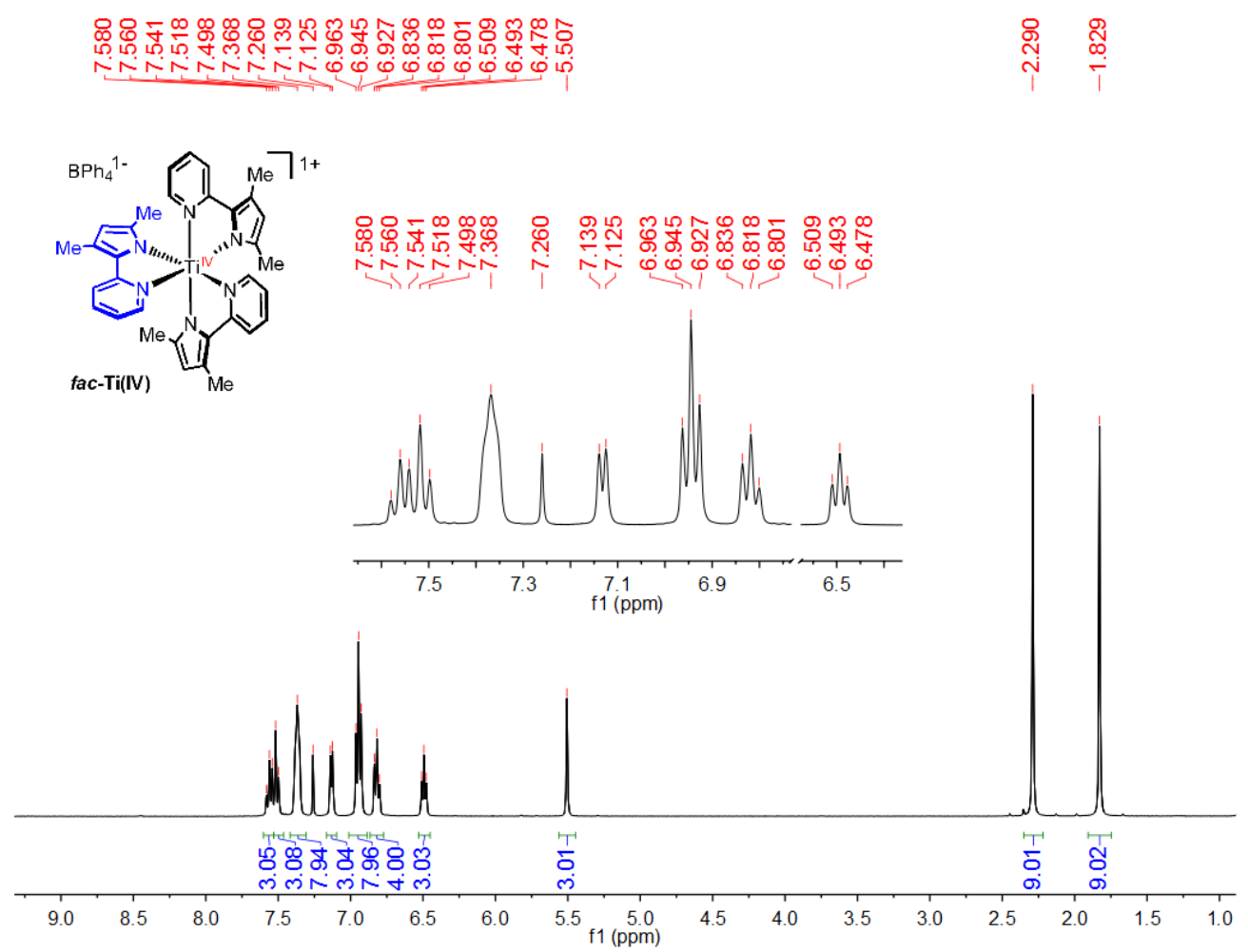

Figure B61. ${ }^{1} \mathrm{H}$ NMR spectra of $f a c-\left[\mathrm{Ti}^{\mathrm{IV}}\left({ }^{\mathrm{Me}} \mathrm{PMP}^{\mathrm{Me}}\right)_{3}\right]\left[\mathrm{BPh}_{4}\right]$ in $\mathrm{CDCl}_{3}$.

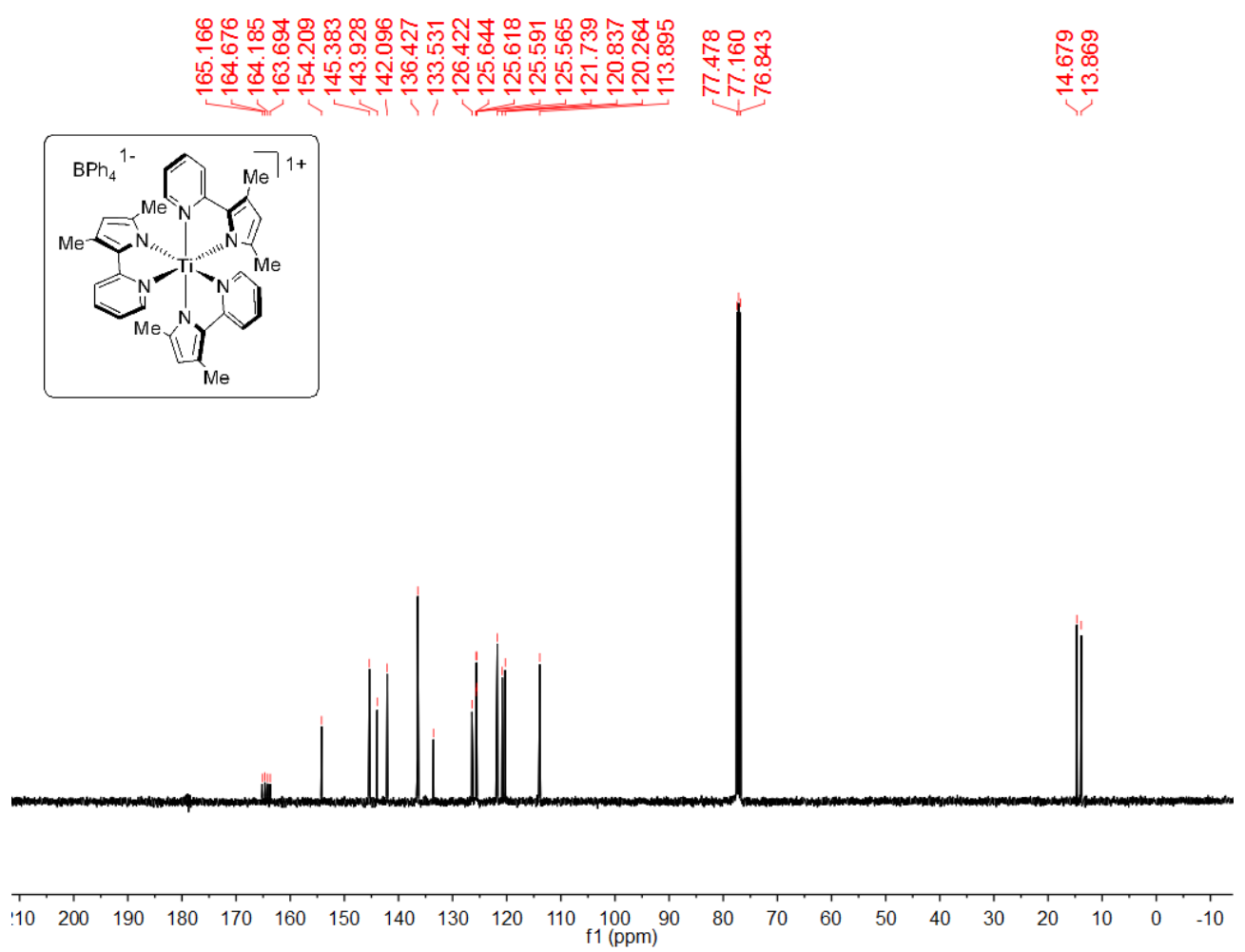

Figure B62. ${ }^{13} \mathrm{C}$ NMR spectra of $f a c-\left[\mathrm{Ti}^{\mathrm{IV}}\left({ }^{\mathrm{Me}} \mathrm{PMP}^{\mathrm{Me}}\right)_{3}\right]\left[\mathrm{BPh}_{4}\right]$ in $\mathrm{CDCl}_{3}$. 


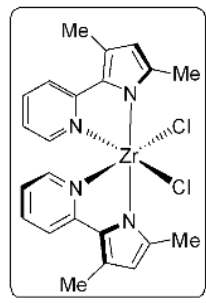

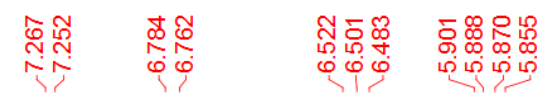
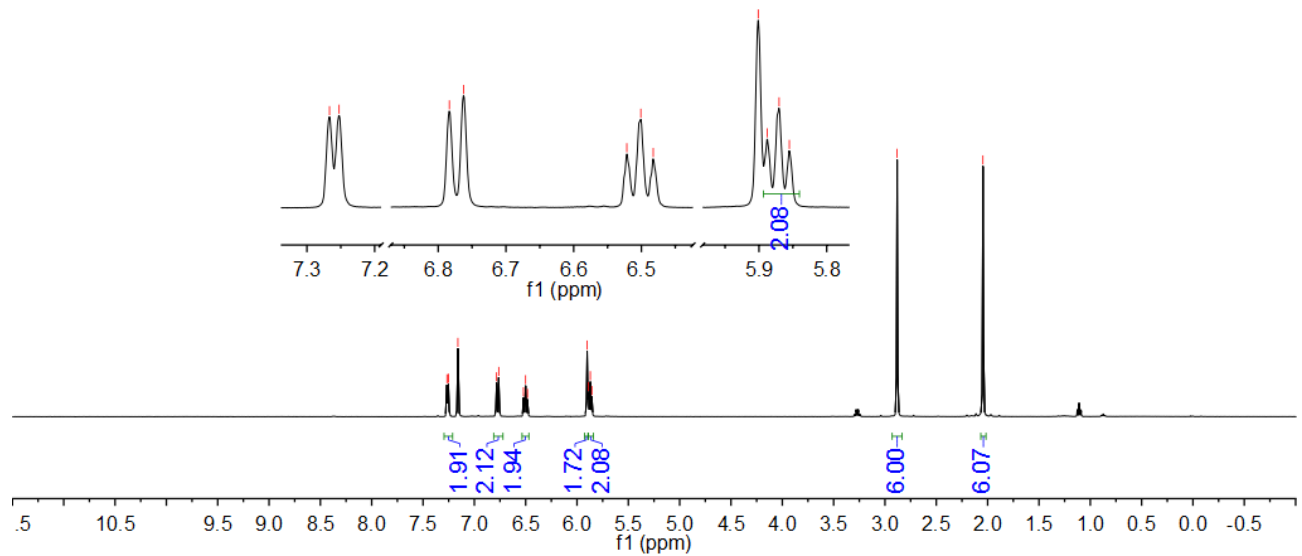

Figure B63. ${ }^{1} \mathrm{H}$ NMR spectra of $\left({ }^{\mathrm{Me}} \mathrm{PMP}{ }^{\mathrm{Me}}\right)_{2} \mathrm{ZrCl}_{2}$ in Benzene- $d_{6}$.
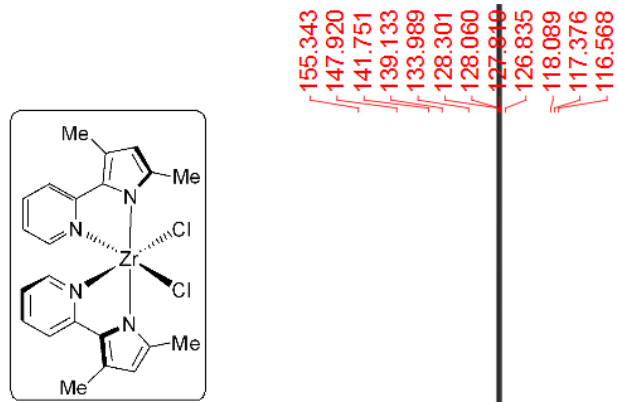

$\overline{\text { s. }}$

난
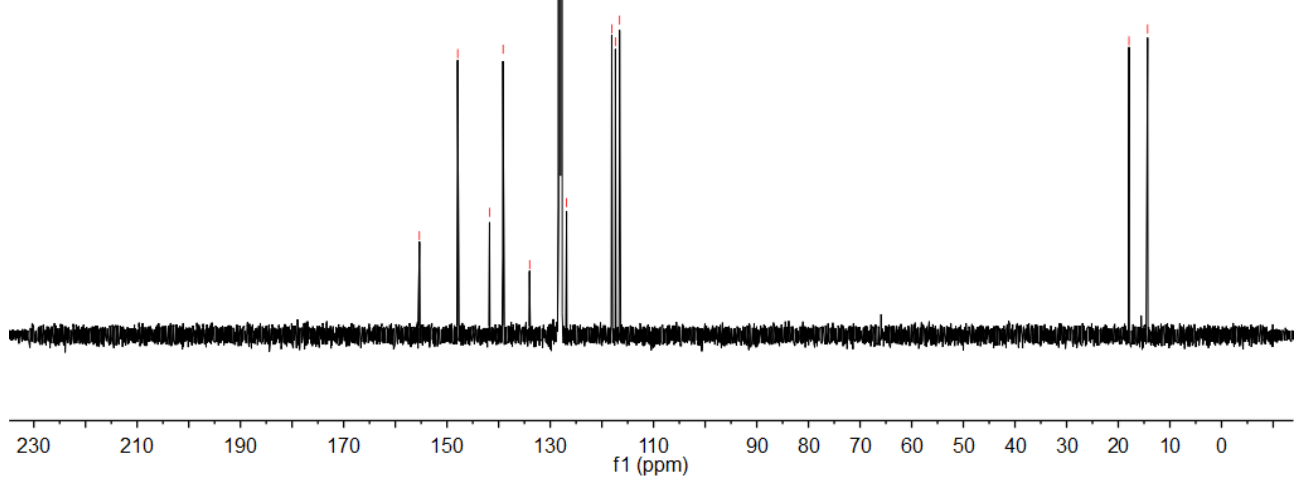

Figure B64. ${ }^{13} \mathrm{C}$ NMR spectra of $\left({ }^{\mathrm{Me}} \mathrm{PMP}{ }^{\mathrm{Me}}\right)_{2} \mathrm{ZrCl}_{2}$ in Benzene- $d_{6}$. 


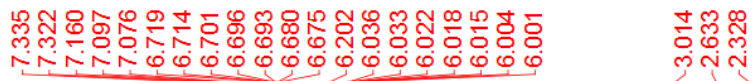<smiles></smiles>

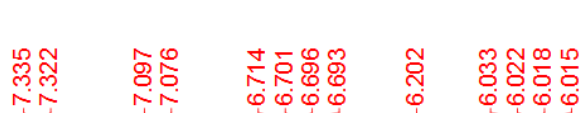
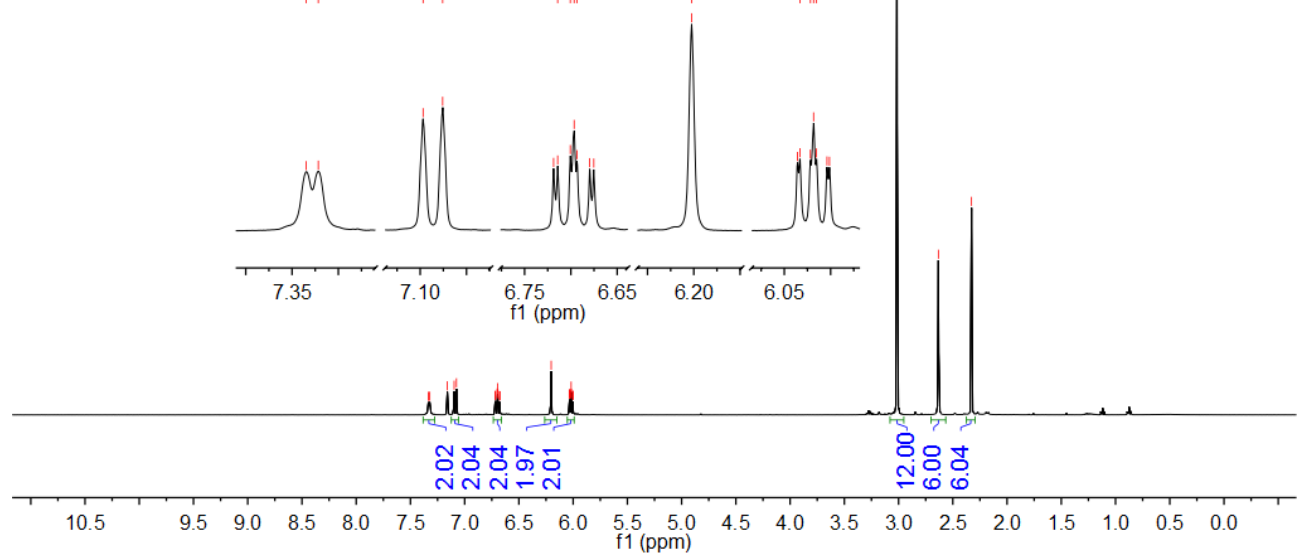

Figure B65. ${ }^{1} \mathrm{H}$ NMR spectra of $\left({ }^{\mathrm{Me}} \mathrm{PMP}{ }^{\mathrm{Me}}\right)_{2} \mathrm{Zr}\left(\mathrm{NMe}_{2}\right)_{2}$ in Benzene- $d_{6}$.
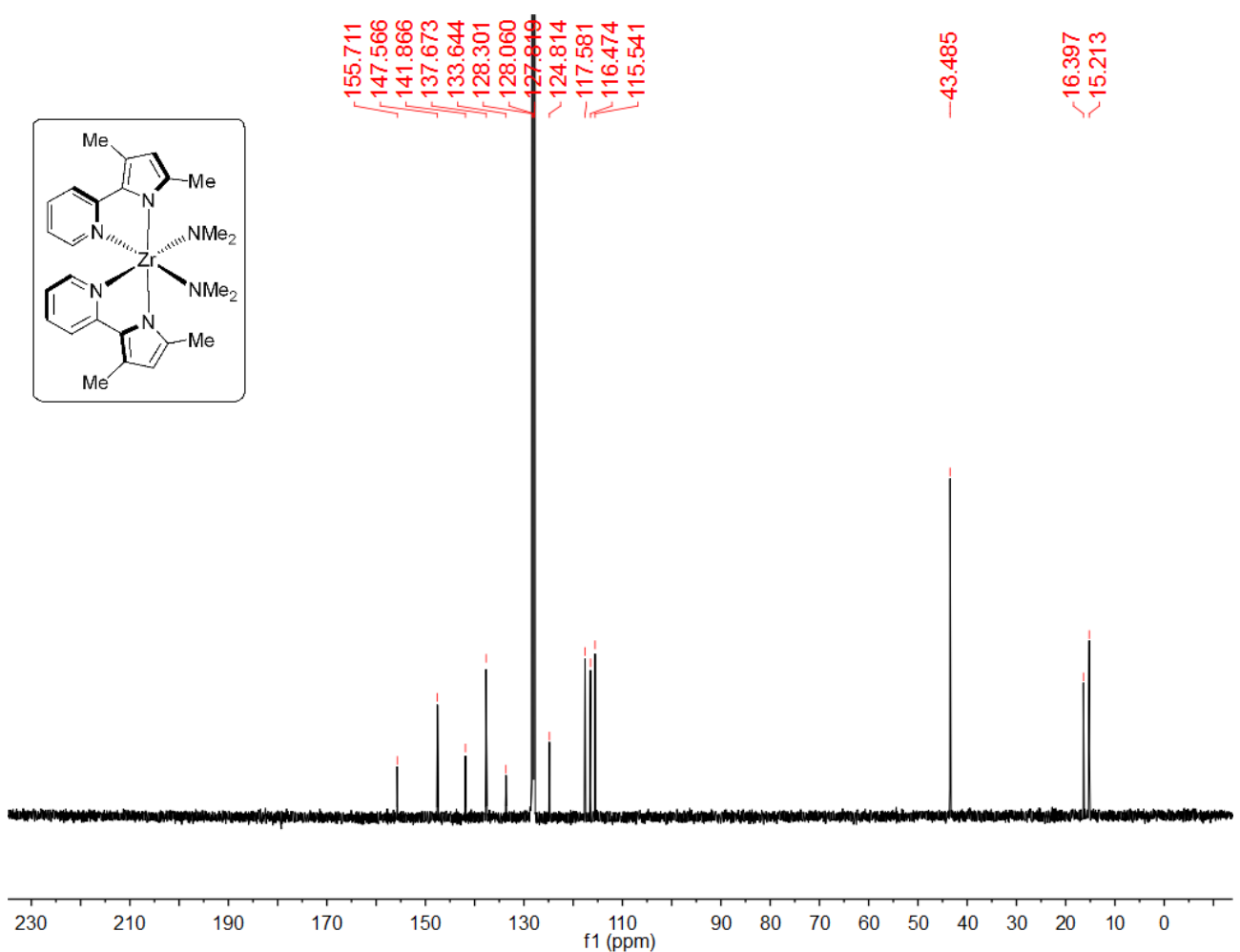

Figure B66. ${ }^{13} \mathrm{C}$ NMR spectra of $\left({ }^{\mathrm{Me}} \mathrm{PMP}{ }^{\mathrm{Me}}\right)_{2} \mathrm{Zr}\left(\mathrm{NMe}_{2}\right)_{2}$ in Benzene- $d_{6}$. 


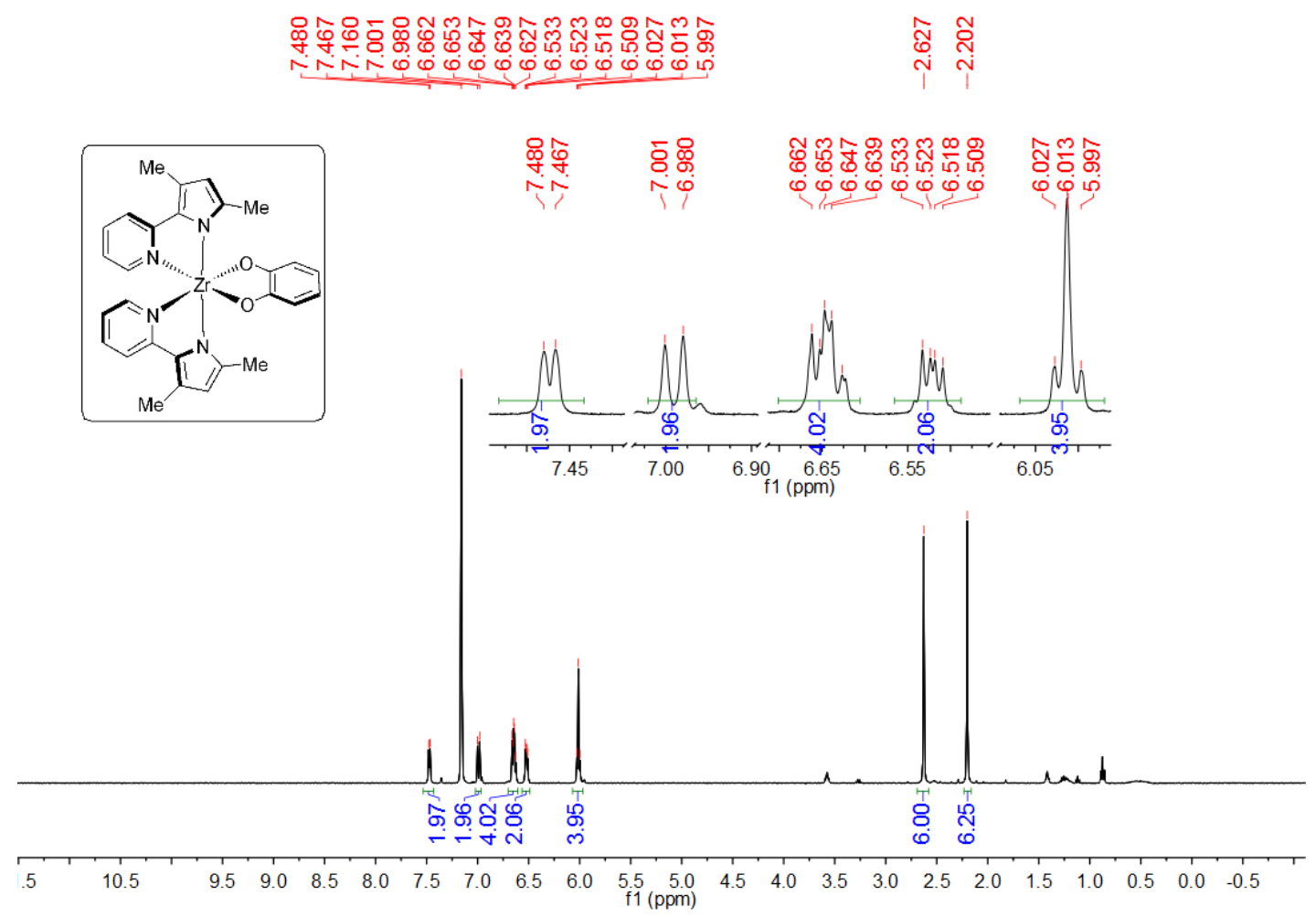

Figure B67. ${ }^{1} \mathrm{H}$ NMR spectra of $\left({ }^{\mathrm{Me}} \mathrm{PMP}^{\mathrm{Me}}\right)_{2} \mathrm{Zr}\left(\mathrm{O}_{2} \mathrm{C}_{6} \mathrm{H}_{4}\right)$ in Benzene- $d_{6}$.

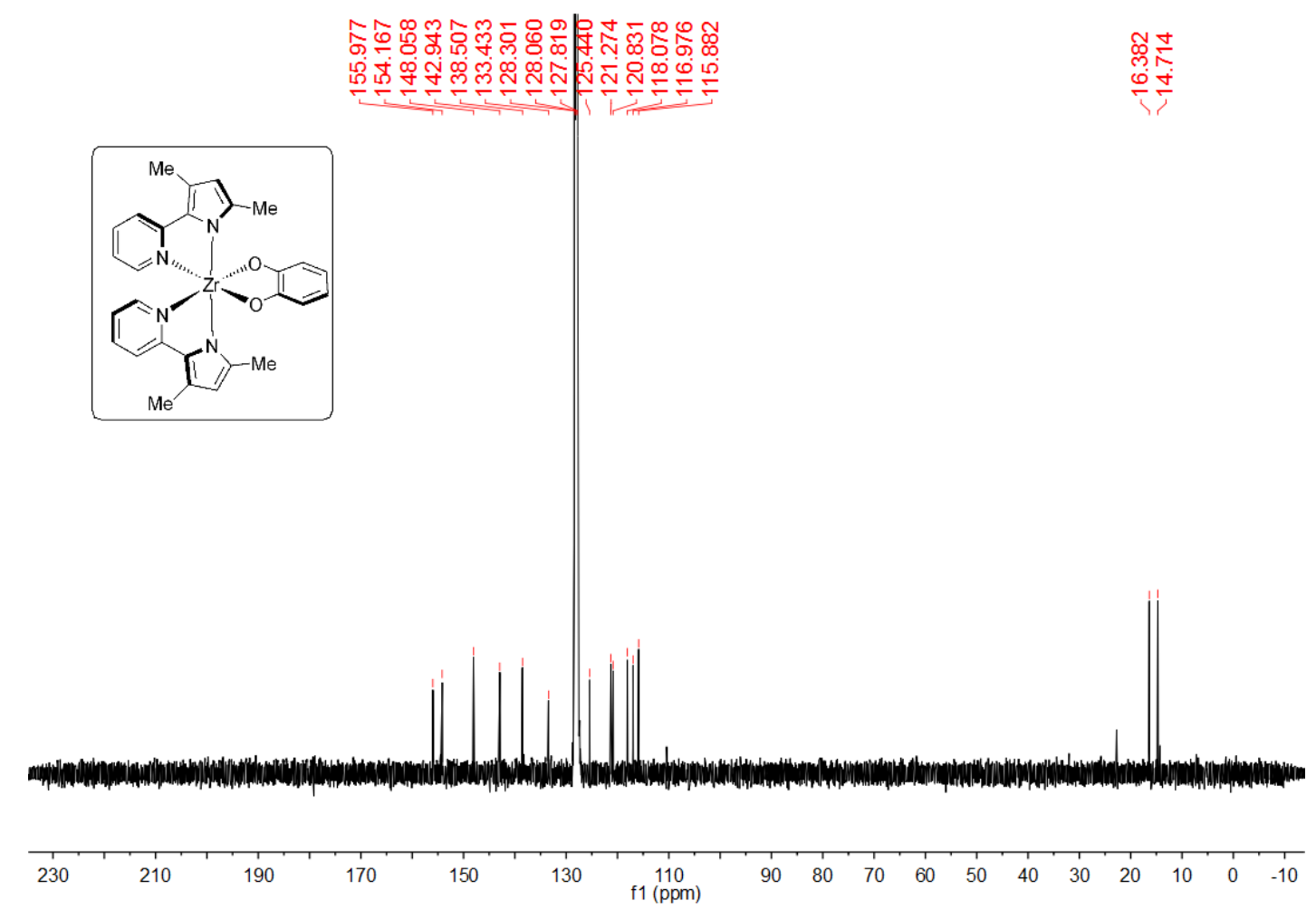

Figure B68. ${ }^{13} \mathrm{C}$ NMR spectra of $\left({ }^{\mathrm{Me}} \mathrm{PMP}{ }^{\mathrm{Me}}\right)_{2} \mathrm{Zr}\left(\mathrm{O}_{2} \mathrm{C}_{6} \mathrm{H}_{4}\right)$ in Benzene- $d_{6}$. 


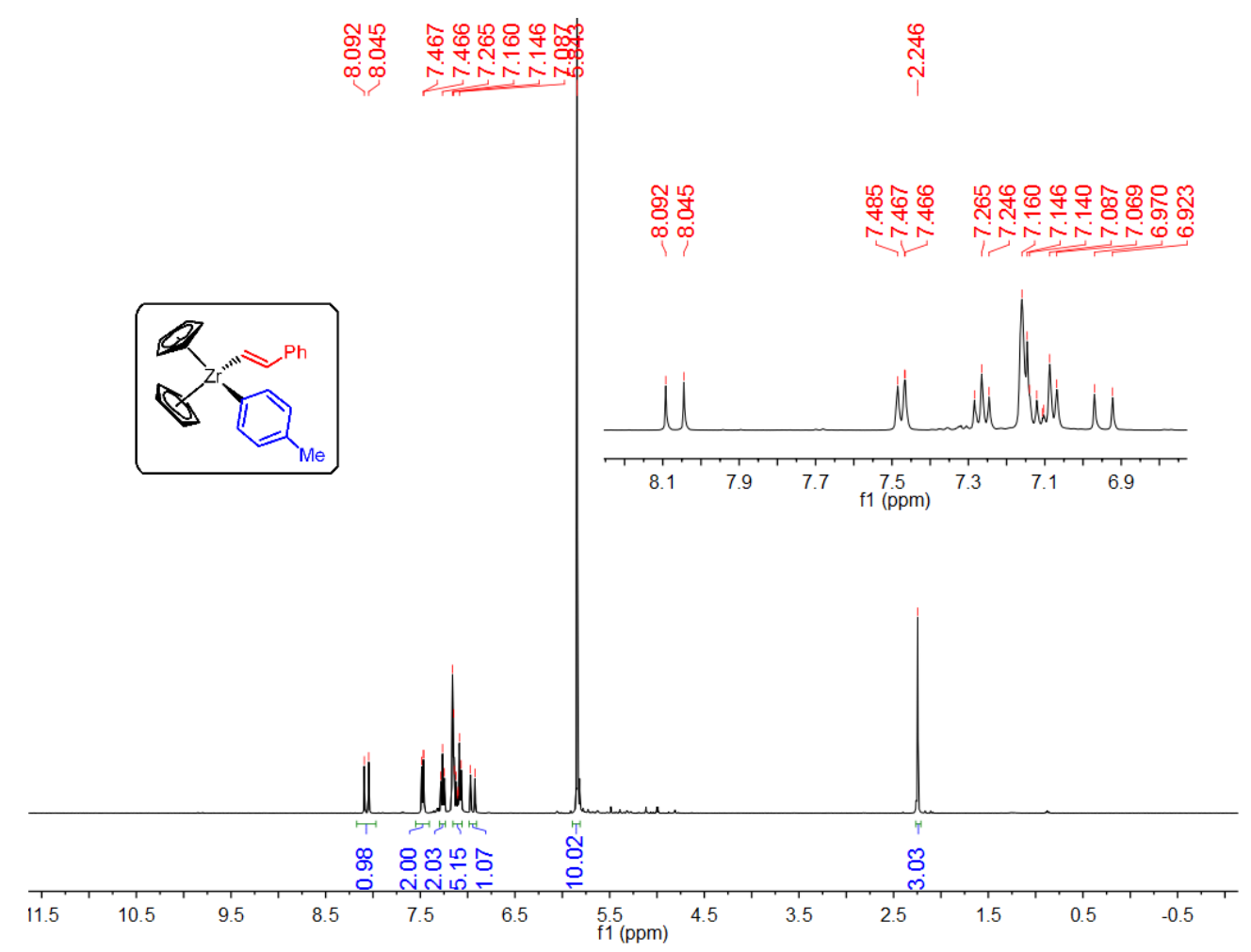

Figure B69. ${ }^{1} \mathrm{H}$ NMR spectra of $\mathrm{Cp}_{2} \mathrm{ZrTol}(\mathrm{CH}=\mathrm{CHPh})$ in Benzene- $d_{6}$.

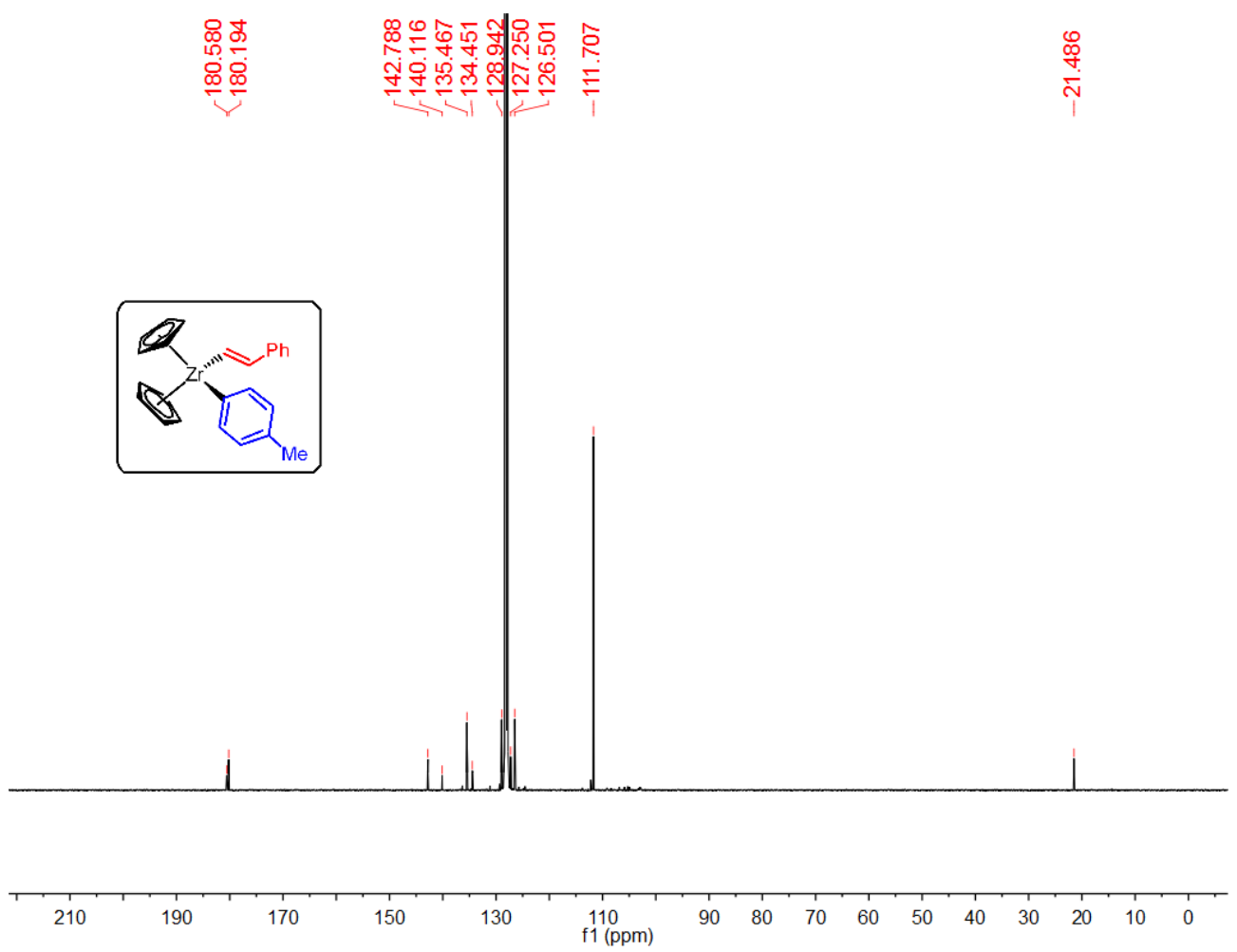

Figure B70. ${ }^{13} \mathrm{C}$ NMR spectra of $\mathrm{Cp}_{2} \mathrm{ZrTol}(\mathrm{CH}=\mathrm{CHPh})$ in Benzene- $d_{6}$. 


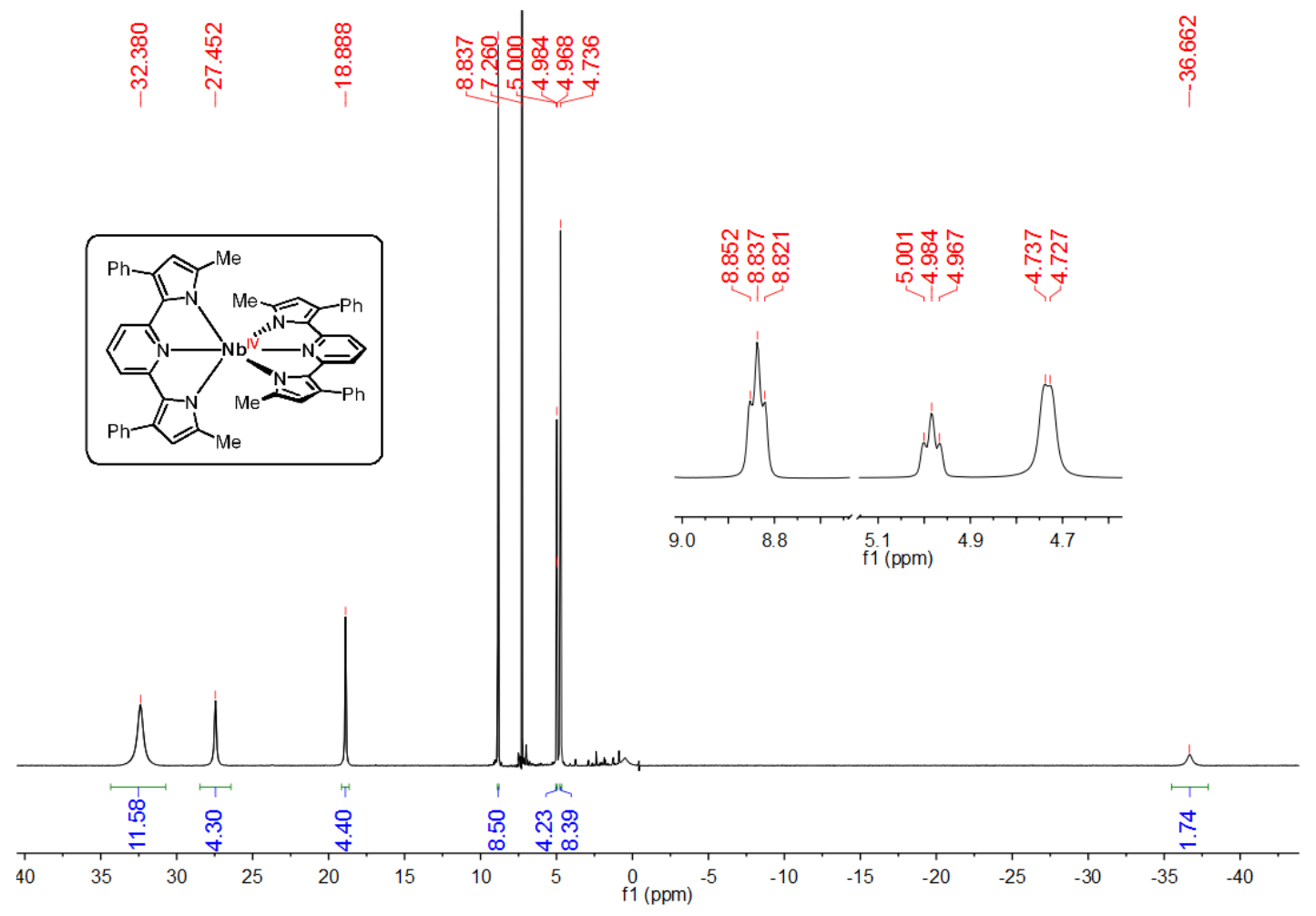

Figure B71. ${ }^{1} \mathrm{H}$ NMR spectra of $\mathrm{Nb}^{\mathrm{IV}}\left({ }^{\mathrm{Me}} \mathrm{PDP}^{\mathrm{Ph}}\right)_{2}$ in $\mathrm{CDCl}_{3}$.

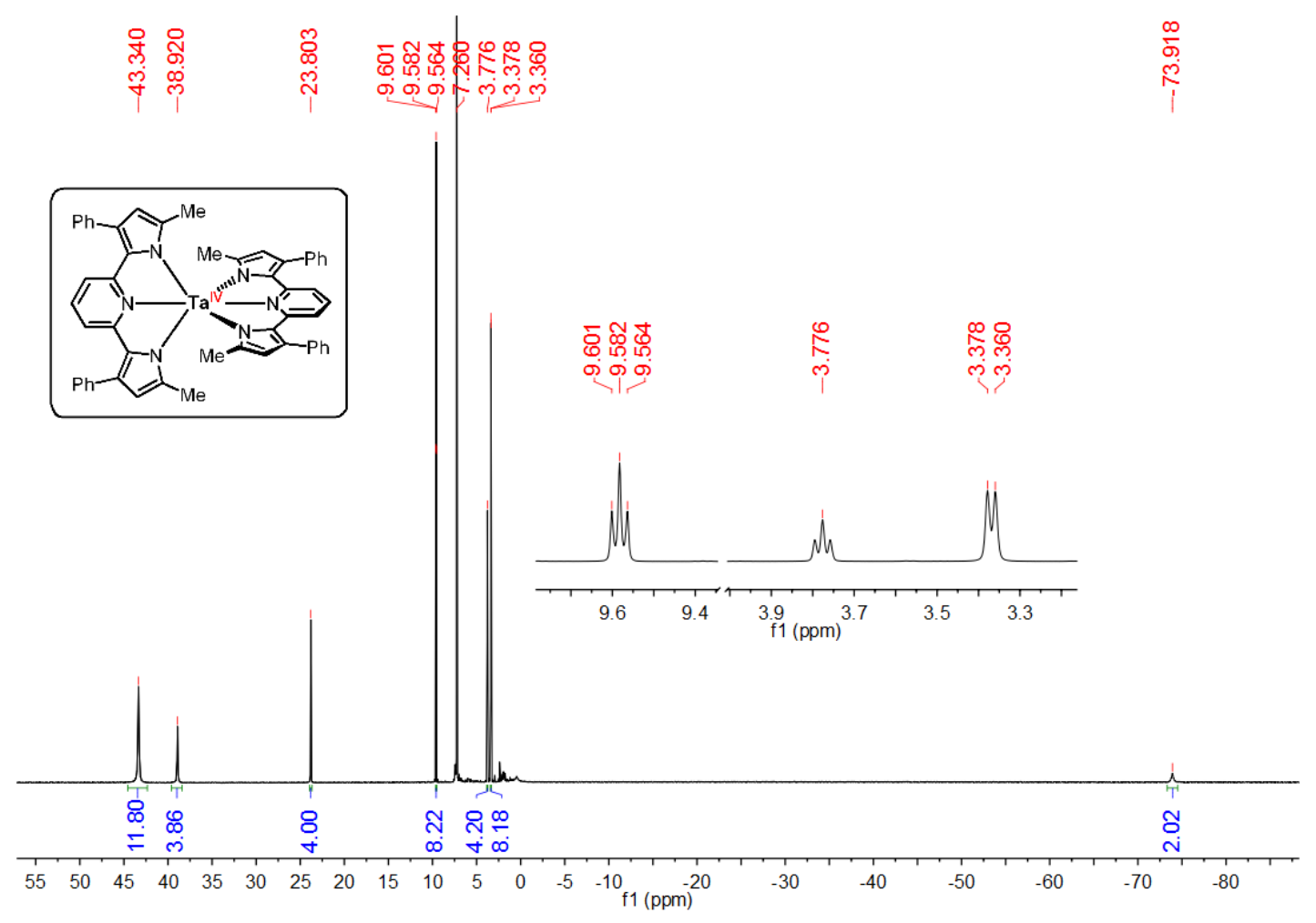

Figure B72. ${ }^{1} \mathrm{H} \mathrm{NMR}$ spectra of $\mathrm{Ta}^{\mathrm{IV}}\left({ }^{\mathrm{Me}} \mathrm{PDP}^{\mathrm{Ph}}\right)_{2}$ in $\mathrm{CDCl}_{3}$. 

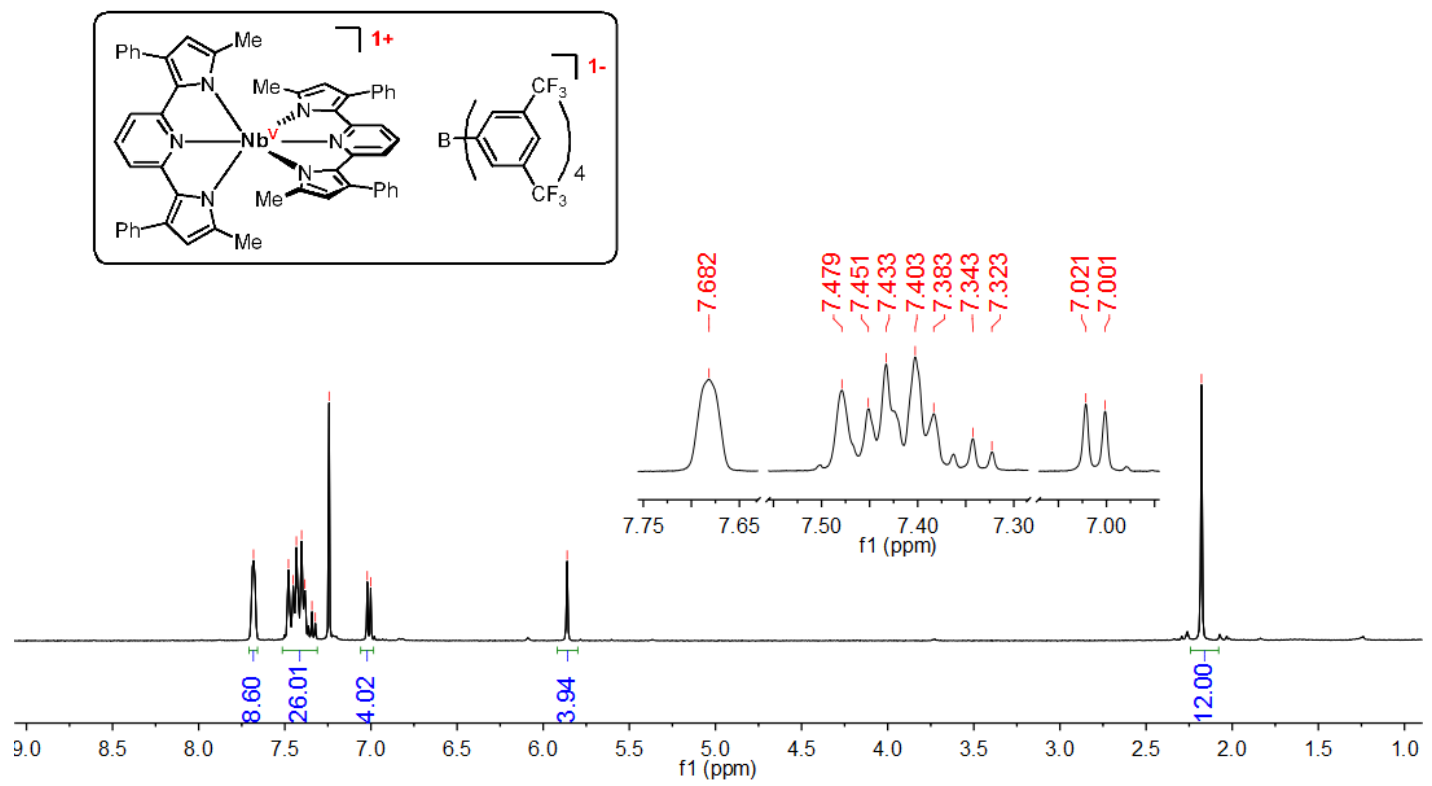

Figure B73. ${ }^{1} \mathrm{H}$ NMR spectra of $\left[\mathrm{Nb}^{\mathrm{V}}\left({ }^{\mathrm{Me}} \mathrm{PDP}^{\mathrm{Ph}}\right)_{2}\right]\left[\mathrm{BArF}_{24}\right]$ in $\mathrm{CDCl}_{3}$.

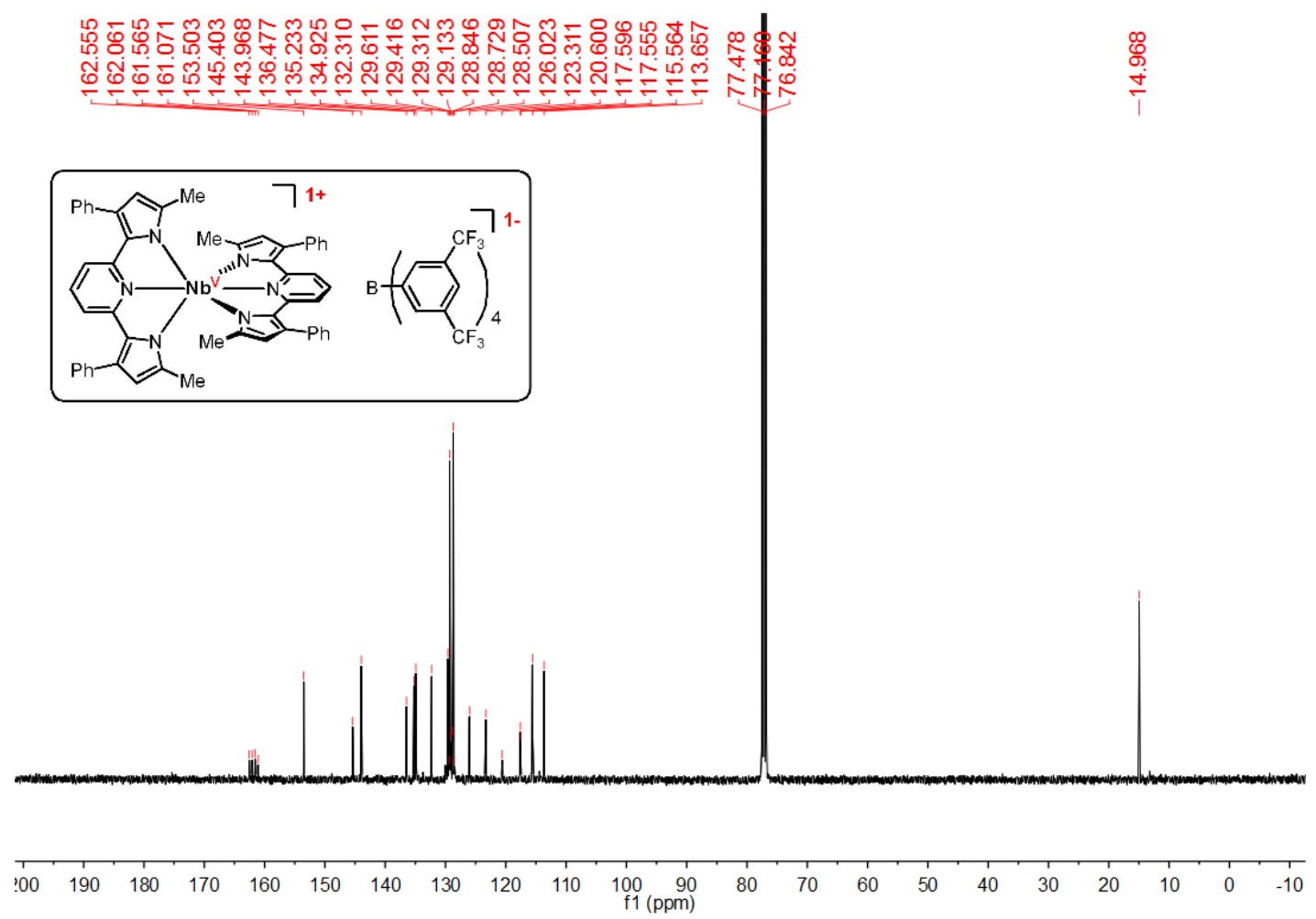

Figure B74. ${ }^{13} \mathrm{C}$ NMR spectra of $\left[\mathrm{Nb}^{\mathrm{V}}\left({ }^{\mathrm{Me}} \mathrm{PDP}^{\mathrm{Ph}}\right)_{2}\right][\mathrm{BArF} 24]$ in $\mathrm{CDCl}_{3}$. 

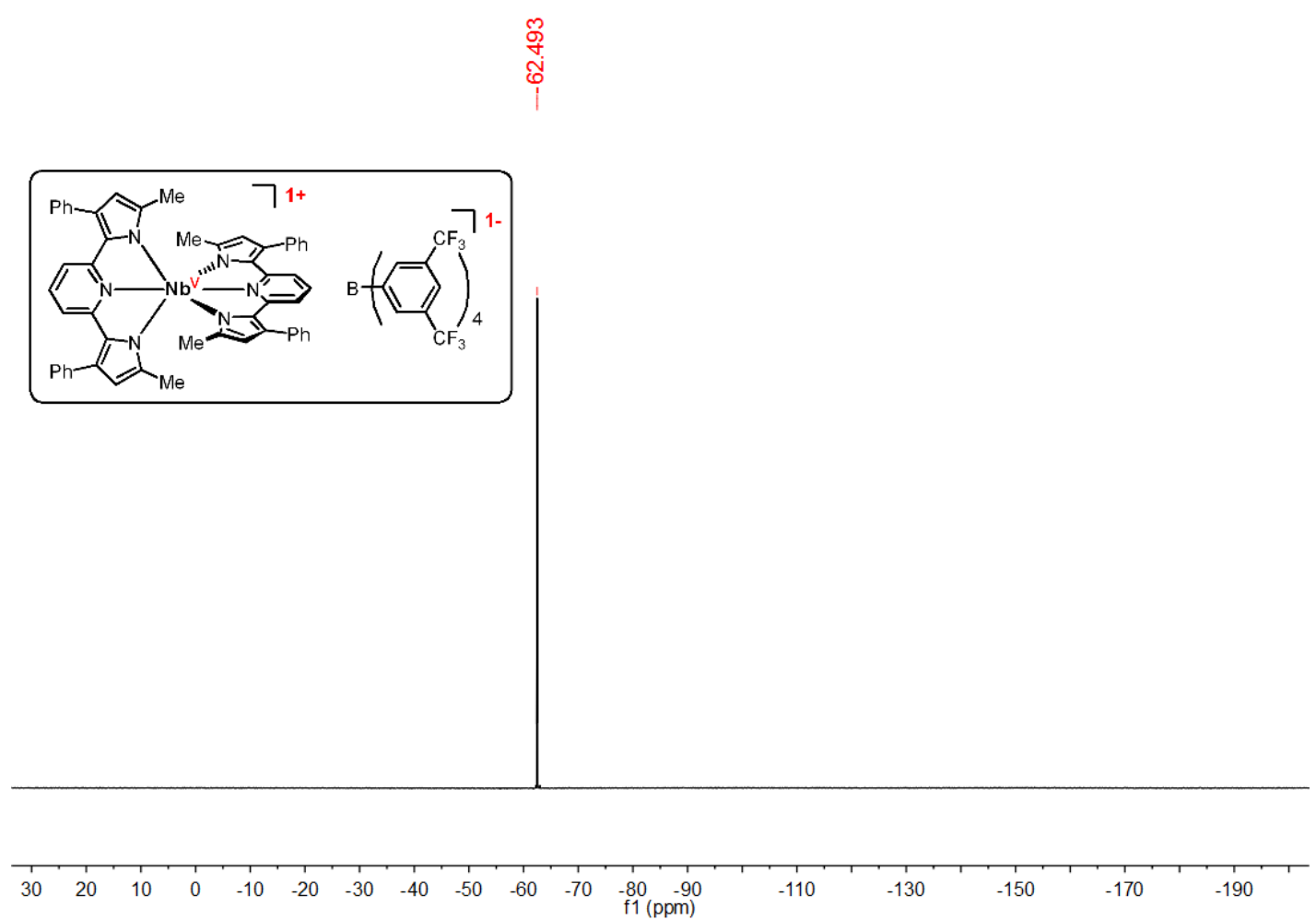

Figure B75. ${ }^{19} \mathrm{~F}$ NMR spectra of $\left[\mathrm{Nb}^{\mathrm{V}}\left({ }^{\mathrm{Me}} \mathrm{PDP}^{\mathrm{Ph}}\right)_{2}\right]\left[\mathrm{BArF}_{24}\right]$ in $\mathrm{CDCl}_{3}$.

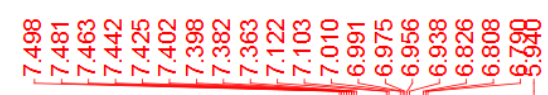

$\frac{\bar{\sigma}}{i}$
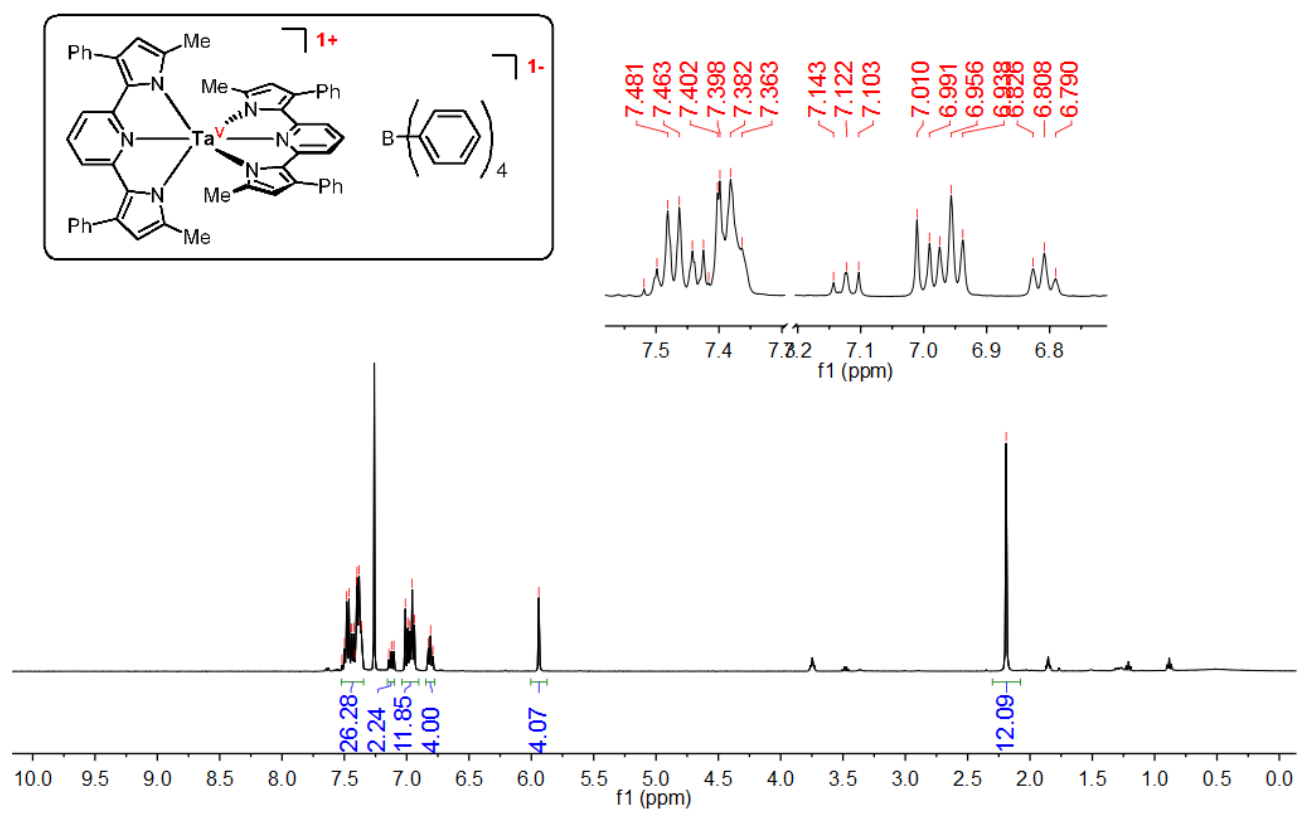

Figure B76. ${ }^{1} \mathrm{H} \mathrm{NMR}$ spectra of $\left[\mathrm{Ta}^{\mathrm{V}}\left({ }^{\mathrm{Me}} \mathrm{PDP}^{\mathrm{Ph}}\right)_{2}\right]\left[\mathrm{BPh}_{4}\right]$ in $\mathrm{CDCl}_{3}$. 


\title{
Appendix C
}

\section{X-ray crystallography}

\author{
Crystallographer: Dr. Jeffery L. Petersen and Dr. Carsten Milsmann
}

\section{General Considerations.}

Single crystals suitable for X-ray diffraction were coated with polyisobutylene oil (SigmaAldrich) in a drybox, transferred to a nylon loop, and then quickly transferred to the goniometer head of a Bruker AXS D8 Venture fixed-chi X-ray diffractometer equipped with a Triumph monochromator, a Mo K $\alpha$ radiation source $(1=0.71073 \AA$ A), and a PHOTON 100 CMOS detector. The samples were cooled to $100 \mathrm{~K}$ with an Oxford Cryostream 700 system and optically aligned. The APEX2 software program (version 2014.1-1) ${ }^{1}$ was used for diffractometer control, preliminary frame scans, indexing, orientation matrix calculations, least-squares refinement of cell parameters, and the data collection. Three sets of 12 frames each were collected using the omega scan method with a $10 \mathrm{~s}$ exposure time. Integration of these frames followed by reflection indexing and least-squares refinement produced a crystal orientation matrix for the crystal lattice that was used for the structural analysis. The data collection strategy was optimized for completeness and redundancy using the Bruker COSMO software suite. The space group was identified, and the data were processed using the Bruker SAINT+ program and corrected for absorption using SADABS. The structures were solved using direct methods (SHELXS) completed by subsequent Fourier 
synthesis and refined by full-matrix least-squares procedures using the programs provided by SHELXL-2014. ${ }^{2}$

\section{Reference.}

(1) APEX2 is a Bruker AXS crystallographic software package for single crystal data collection, reduction and preparation.

(2) Sheldrick, G. M. SHELXL-2014, Crystallographic software package, Bruker AXS, Inc., Madison, Wisconsin, USA. 
Table C1. Compilation of crystallographic data for compounds discussed in this manuscript.

\begin{tabular}{|c|c|c|}
\hline Compound & Identification Code & Location \\
\hline $\mathrm{Zr}\left({ }^{\mathrm{Me}} \mathrm{PDP}{ }^{\mathrm{Ph}}\right)_{2}$ & $\mathrm{~cm} 70 \mathrm{cms}$ & Chapter 1 \\
\hline$\left[\mathrm{Na}(18 \text {-crown-6)(thf })_{2}\right]\left[\mathrm{Zr}\left({ }^{\mathrm{Me}} \mathrm{PDP}^{\mathrm{Ph}}\right)_{2}\right]$ & $\mathrm{cm} 159 \mathrm{cms}$ & Chapter 2 \\
\hline $\mathrm{BI}_{2}$ & $\mathrm{~cm} 116 \mathrm{cms}$ & Chapter 2 \\
\hline $\mathrm{Zr}\left({ }^{\mathrm{Mes}} \mathrm{PDP}^{\mathrm{Ph}}\right)_{2}$ & $\mathrm{~cm} 214 \mathrm{cms}$ & Chapter 3 \\
\hline $\mathrm{Zr}\left({ }^{\mathrm{Me}} \mathrm{PDP} \mathrm{Me}_{2}\right)_{2}$ & $\mathrm{~cm} 95 \mathrm{cms}$ & Chapter 4 \\
\hline $\mathrm{Zr}\left({ }^{\mathrm{Me}} \mathrm{PDP}^{\mathrm{C} 6 \mathrm{~F} 5}\right)_{2}$ & $\mathrm{~cm} 97 \mathrm{cms}$ & Chapter 4 \\
\hline $\mathrm{Zr}\left({ }^{\mathrm{Me}} \mathrm{PDP}^{\mathrm{H}}\right)_{2}$ & $\mathrm{~cm} 78 \mathrm{cms}$ & Chapter 4 \\
\hline $\mathrm{Zr}\left({ }^{\mathrm{Ph}} \mathrm{PDP}^{\mathrm{Ph}}\right)_{2}$ & $\mathrm{~cm} 228 \mathrm{cms}$ & Chapter 4 \\
\hline $\mathrm{Zr}\left({ }^{\mathrm{H}} \mathrm{PDP}^{\mathrm{H}}\right)_{2}$ & $\mathrm{~cm} 172 \mathrm{cms}$ & Chapter 4 \\
\hline $\mathrm{Zr}\left({ }^{\mathrm{H}} \mathrm{PDP}^{\mathrm{H}}\right)_{2}(\mathrm{THF})_{2}$ & $\mathrm{~cm} 178 \mathrm{cms}$ & Chapter 4 \\
\hline$\left({ }^{\mathrm{Me}} \mathrm{PDP}^{\mathrm{Me}}\right)_{3} \mathrm{ZrCl}$ & $\mathrm{cm} 127 \mathrm{cms}$ & Chapter 5 \\
\hline$\left({ }^{\mathrm{Me}} \mathrm{PDP} \mathrm{Me}_{3}\right)_{3} \mathrm{HfCl}$ & $\mathrm{cm} 120 \mathrm{cms}$ & Chapter 5 \\
\hline $\mathrm{Zr}\left({ }^{\mathrm{H}} \mathrm{CNN}\right)_{2}$ & $\mathrm{~cm} 187 \mathrm{cms}$ & Chapter 6 \\
\hline $\mathrm{Zr}(\mathrm{DPDP}) \mathrm{Br}_{2}$ & $\mathrm{~cm} 190 \mathrm{cms}$ & Chapter 6 \\
\hline $\mathrm{Zr}(\mathrm{bppda})_{2}$ & $\mathrm{~cm} 193 \mathrm{cms}$ & Chapter 7 \\
\hline$\left({ }^{\mathrm{Me}} \mathrm{PDP} \mathrm{Me}_{3}\right)_{3} \mathrm{ZrCl}_{2}$ & $\mathrm{~cm} 190 \mathrm{cms}$ & Chapter 8 \\
\hline $\mathrm{Nb}\left({ }^{\mathrm{Me}} \mathrm{PDP}^{\mathrm{Ph}}\right)_{2}$ & $\mathrm{~cm} 160 \mathrm{cms}$ & Chapter 8 \\
\hline$\left[\mathrm{Nb}\left({ }^{\mathrm{Me}} \mathrm{PDP}^{\mathrm{Ph}}\right)_{2}\right]\left[\mathrm{BArF}_{24}\right]$ & $\mathrm{cm} 170 \mathrm{cms}$ & Chapter 8 \\
\hline
\end{tabular}




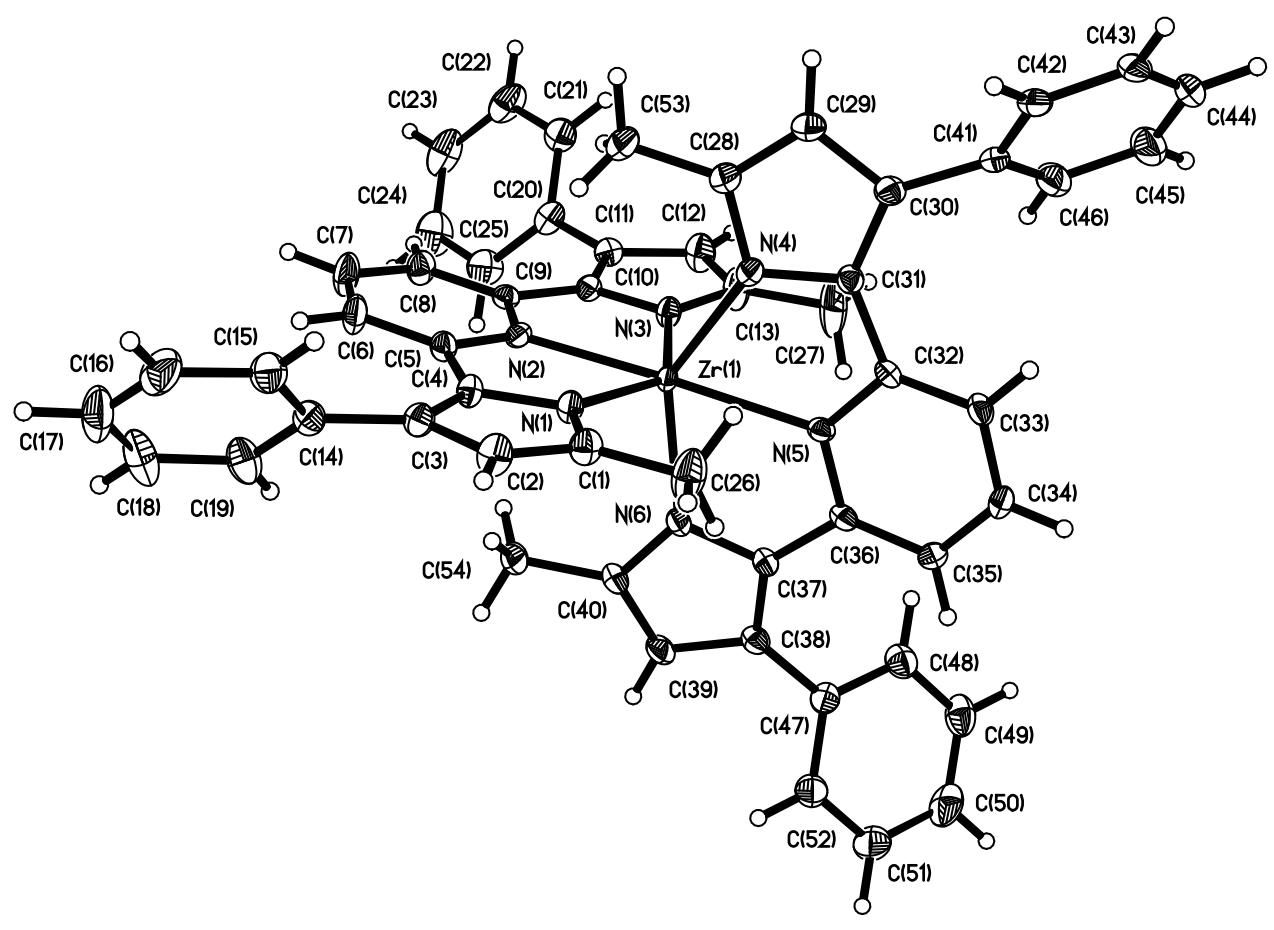

Figure C1. Perspective view of the molecular structure of $\left[\mathrm{C}_{27} \mathrm{H}_{21} \mathrm{~N}_{3}\right]_{2} \mathrm{Zr}$ with the atom labeling scheme for the independent non-hydrogen atoms. The thermal ellipsoids are scaled to enclose $50 \%$ probability. 
Table C2. Crystal data for $\left[\mathrm{C}_{27} \mathrm{H}_{21} \mathrm{~N}_{3}\right]_{2} \mathrm{Zr} \cdot 2 \mathrm{CH}_{2} \mathrm{Cl}_{2} \cdot 1 / 2 \mathrm{C}_{5} \mathrm{H}_{12}$.

$\begin{array}{lll}\text { Identification code } & \mathrm{cm} 70 \mathrm{cms} \\ \text { Chemical formula } & \mathrm{C}_{58.50} \mathrm{H}_{52} \mathrm{Cl}_{4} \mathrm{~N}_{6} \mathrm{Zr} & \\ \text { Formula weight } & 1072.08 \mathrm{~g} / \mathrm{mol} & \\ \text { Temperature } & 140(2) \mathrm{K} \\ \text { Wavelength } & 0.71073 \AA \\ \text { Crystal size } & 0.106 \times 0.207 \times 0.343 \mathrm{~mm} \\ \text { Crystal system } & \text { triclinic } & \\ \text { Space group } & \mathrm{P}-1(\mathrm{No} .2) & \\ \text { Unit cell dimensions } & \mathrm{a}=13.9916(8) \AA \quad \alpha=67.0258(14)^{\circ} \\ & \mathrm{b}=14.6671(8) \AA \quad \beta=64.2263(15)^{\circ} \\ & \mathrm{c}=15.0683(9) \AA & \gamma=80.3251(15)^{\circ} \\ \text { Volume } & 2563.8(3) \AA^{3} & \\ \text { Z (empirical units) } & 2 & \\ \text { Density (calculated) } & 1.389 \mathrm{~g} / \mathrm{cm}^{3} & \\ \text { Absorption coefficient } & 0.468 \mathrm{~mm}^{-1} & \\ \text { F(000) } & 1106 & \end{array}$

Table C3. Data collection and structure refinement for $\left[\mathrm{C}_{27} \mathrm{H}_{21} \mathrm{~N}_{3}\right]_{2} \mathrm{Zr} \cdot 2 \mathrm{CH}_{2} \mathrm{Cl}_{2} \cdot 1 / 2 \mathrm{C}_{5} \mathrm{H}_{12}$.

Theta range for data used in the 2.75 to $27.50^{\circ}$ structural refinement

Index ranges $\quad-18 \leq h \leq 18,-19 \leq \mathrm{k} \leq 19,-19 \leq 1 \leq 19$

Reflections 49991

Independent reflections $\quad 11760[\mathrm{R}(\mathrm{int})=0.0648]$

Coverage of independent $99.9 \%$ reflections

Absorption correction multi-scan

Max. and min. transmission $\quad 0.952$ and 0.856

Refinement method Full-matrix least-squares on $\mathrm{F}^{2}$

Refinement program SHELXL-2014 (Sheldrick, 2014)

Data / restraints / parameters 11760 / 6 / 624

Goodness-of-fit on $\mathrm{F}^{2} \quad 1.055$

Final R indices $\quad 8454$ data; $\mathrm{I}>2 \sigma(\mathrm{I}) \quad \mathrm{R} 1=0.0623, \mathrm{wR} 2=0.1631$

Largest diff. peak and hole $\quad 1.304$ and $-1.814 \mathrm{e}^{-} / \AA^{3}$ 
Table C4. Atomic coordinates and equivalent isotropic atomic displacement parameters $\left(\AA^{2}\right)$ for the non-hydrogen atoms of $\left[\mathrm{C}_{27} \mathrm{H}_{21} \mathrm{~N}_{3}\right]_{2} \mathrm{Zr}$. U(eq) is defined as one third of the trace of the orthogonalized $\mathrm{U}_{\mathrm{ij}}$ tensor.

$\begin{array}{lcccc} & & & & \\ \mathrm{Z} 1 & \mathrm{x} / \mathrm{a} & \mathrm{y} / \mathrm{b} & \mathrm{z} / \mathrm{c} & \mathrm{U}(\mathrm{eq}) \\ \mathrm{N} 1 & 0.70985(2) & 0.59393(2) & 0.67868(2) & 0.01278(6) \\ \mathrm{N} 2 & 0.79078(18) & 0.45779(17) & 0.66859(18) & 0.0172(5) \\ \mathrm{N} 3 & 0.59565(18) & 0.48645(17) & 0.69696(17) & 0.0151(5) \\ \mathrm{N} 4 & 0.55072(18) & 0.65768(17) & 0.71660(18) & 0.0173(5) \\ \mathrm{N} 5 & 0.812281(19) & 0.57757(17) & 0.82075(18) & 0.0173(5) \\ \mathrm{N} 6 & 0.78049(19) & 0.71953(17) & 0.64752(17) & 0.0146(5) \\ \mathrm{C} 1 & 0.8938(2) & 0.67912(17) & 0.51069(17) & 0.0163(5) \\ \mathrm{C} 2 & 0.9094(2) & 0.4287(2) & 0.6545(2) & 0.0211(7) \\ \mathrm{C} 3 & 0.8135(2) & 0.3355(2) & 0.6503(2) & 0.0236(7) \\ \mathrm{C} 4 & 0.7419(2) & 0.3040(2) & 0.6594(2) & 0.0186(7) \\ \mathrm{C} 5 & 0.6307(2) & 0.3805(2) & 0.6714(2) & 0.0174(6) \\ \mathrm{C} 6 & 0.5605(2) & 0.3952(2) & 0.6920(2) & 0.0174(6) \\ \mathrm{C} 7 & 0.4558(3) & 0.3271(2) & 0.7101(3) & 0.0257(7) \\ \mathrm{C} 8 & 0.4212(2) & 0.3534(2) & 0.7312(3) & 0.0300(8) \\ \mathrm{C} 9 & 0.4924(2) & 0.4471(2) & 0.7322(2) & 0.0223(7) \\ \mathrm{C} 10 & 0.4687(2) & 0.5130(2) & 0.7159(2) & 0.0148(6) \\ \mathrm{C} 11 & 0.3760(2) & 0.6104(2) & 0.7231(2) & 0.0146(6) \\ \mathrm{C} 12 & 0.4028(2) & 0.6657(2) & 0.7468(2) & 0.0182(6) \\ \mathrm{C} 13 & 0.5085(2) & 0.7487(2) & 0.7560(3) & 0.0261(7) \\ \mathrm{C} 14 & 0.7986(2) & 0.7425(2) & 0.7377(3) & 0.0261(7) \\ \mathrm{C} 15 & 0.8270(3) & 0.2085(2) & 0.6558(2) & 0.0205(7) \\ \mathrm{C} 16 & 0.8153(3) & 0.1207(2) & 0.7203(3) & 0.0268(8) \\ \mathrm{C} 17 & 0.7726(3) & 0.0308(3) & 0.7163(3) & 0.0374(10) \\ \mathrm{C} 18 & 0.7452(3) & 0.0271(3) & 0.6508(3) & 0.0422(10) \\ \mathrm{C} 19 & 0.7592(3) & 0.1132(3) & 0.5866(3) & 0.0392(8) \\ \mathrm{C} 20 & 0.2689(2) & 0.2037(2) & 0.5877(3) & 0.0295(8) \\ \mathrm{C} 21 & 0.1837(3) & 0.6441(2) & 0.7630(2) & 0.0206(7) \\ \mathrm{C} 22 & 0.0823(3) & 0.6399(2) & 0.8572(3) & 0.0260(8) \\ \mathrm{C} 23 & 0.0648(3) & 0.6183(3) & 0.8761(3) & 0.0352(10) \\ \mathrm{C} 24 & 0.1488(3) & 0.6017(3) & 0.7999(3) & 0.0366(9) \\ \mathrm{C} 25 & 0.2503(3) & 0.6081(3) & 0.7049(3) & 0.0392(9) \\ \mathrm{C} 26 & 0.9695(3) & 0.6284(3) & 0.6866(3) & 0.0298(8) \\ & & 0.4940(3) & 0.6466(3) & 0.0340(8)\end{array}$




\begin{tabular}{|c|c|c|c|c|}
\hline & $\mathrm{x} / \mathrm{a}$ & $\mathrm{y} / \mathrm{b}$ & $\mathrm{z} / \mathrm{c}$ & $\mathrm{U}(\mathrm{eq})$ \\
\hline $\mathrm{C} 27$ & $0.5738(3)$ & $0.8145(3)$ & $0.7356(3)$ & $0.0459(9)$ \\
\hline $\mathrm{C} 28$ & $0.6733(2)$ & $0.5112(2)$ & $0.9223(2)$ & $0.0220(7)$ \\
\hline $\mathrm{C} 29$ & $0.6897(2)$ & $0.5401(2)$ & $0.9909(2)$ & $0.0228(7)$ \\
\hline C30 & $0.7503(2)$ & $0.6287(2)$ & $0.9323(2)$ & $0.0178(6)$ \\
\hline C31 & $0.7708(2)$ & $0.6488(2)$ & $0.8278(2)$ & $0.0152(6)$ \\
\hline C32 & $0.8309(2)$ & $0.7230(2)$ & $0.7275(2)$ & $0.0138(6)$ \\
\hline C33 & $0.9046(2)$ & $0.7887(2)$ & $0.7072(2)$ & $0.0180(6)$ \\
\hline C34 & $0.9573(2)$ & $0.8518(2)$ & $0.6049(2)$ & $0.0196(7)$ \\
\hline C35 & $0.9350(2)$ & $0.8515(2)$ & $0.5240(2)$ & $0.0177(7)$ \\
\hline C36 & $0.8607(2)$ & $0.7846(2)$ & $0.5475(2)$ & $0.0150(6)$ \\
\hline C37 & $0.8302(2)$ & $0.7690(2)$ & $0.4742(2)$ & $0.0172(6)$ \\
\hline C38 & $0.8461(2)$ & $0.8203(2)$ & $0.3697(2)$ & $0.0179(6)$ \\
\hline C39 & $0.8078(2)$ & $0.7573(2)$ & $0.3409(2)$ & $0.0215(7)$ \\
\hline $\mathrm{C} 40$ & $0.7685(2)$ & $0.6725(2)$ & $0.4276(2)$ & $0.0196(7)$ \\
\hline C41 & $0.7727(2)$ & $0.6901(2)$ & $0.9789(2)$ & $0.0183(7)$ \\
\hline $\mathrm{C} 42$ & $0.8127(2)$ & $0.6481(2)$ & $0.0558(2)$ & $0.0213(7)$ \\
\hline $\mathrm{C} 43$ & $0.8269(3)$ & $0.7056(3)$ & $0.1033(2)$ & $0.0268(8)$ \\
\hline C44 & $0.8013(3)$ & $0.8041(3)$ & $0.0756(2)$ & $0.0332(8)$ \\
\hline $\mathrm{C} 45$ & $0.7615(3)$ & $0.8471(3)$ & $0.9997(3)$ & $0.0343(9)$ \\
\hline $\mathrm{C} 46$ & $0.7471(3)$ & $0.7901(2)$ & $0.9517(2)$ & $0.0268(8)$ \\
\hline C47 & $0.8865(2)$ & $0.9220(2)$ & $0.3000(2)$ & $0.0198(7)$ \\
\hline C48 & $0.8557(3)$ & $0.0009(2)$ & $0.3370(2)$ & $0.0255(7)$ \\
\hline C49 & $0.8908(3)$ & $0.0964(2)$ & $0.2687(3)$ & $0.0310(8)$ \\
\hline C50 & $0.9562(3)$ & $0.1139(3)$ & $0.1643(3)$ & $0.0365(9)$ \\
\hline C51 & $0.9863(3)$ & $0.0364(3)$ & $0.1270(3)$ & $0.0352(9)$ \\
\hline C52 & $0.9513(3)$ & $0.9418(2)$ & $0.1939(2)$ & $0.0262(8)$ \\
\hline C53 & $0.6111(3)$ & $0.4259(3)$ & $0.9449(3)$ & $0.0339(9)$ \\
\hline C54 & $0.7182(3)$ & $0.5850(2)$ & $0.4370(2)$ & $0.0275(8)$ \\
\hline
\end{tabular}




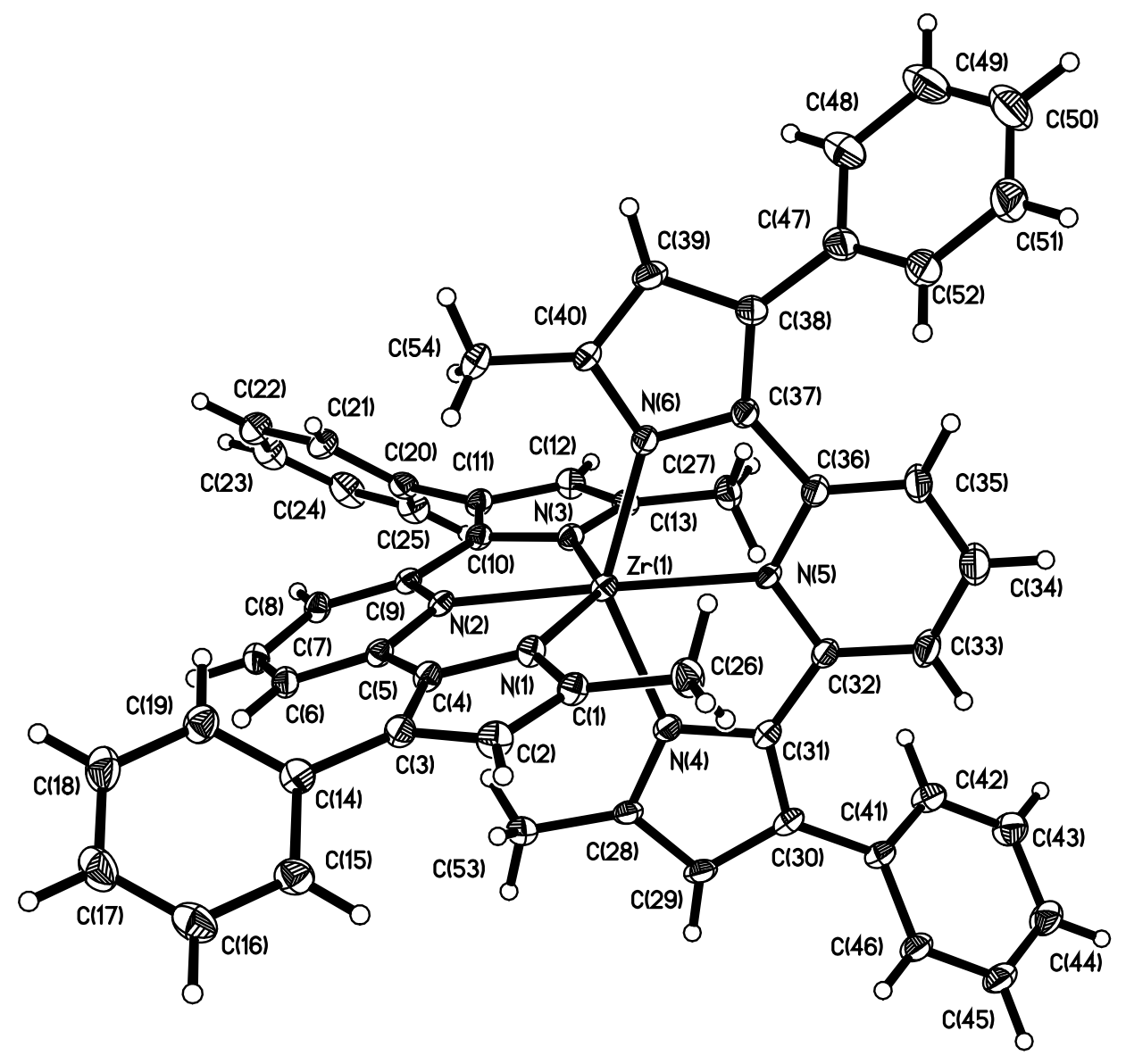

Figure C2. Perspective view of the molecular structure of the $\left[\left(\mathrm{C}_{27} \mathrm{H}_{21} \mathrm{~N}_{3}\right)_{2} \mathrm{Zr}\right]^{-}$mono-anion with the atom labeling scheme for the independent non-hydrogen atoms. The thermal ellipsoids are scaled to enclose $50 \%$ probability. 
Table C5. Crystal data for $\left[\mathrm{Na}\left(\mathrm{C}_{12} \mathrm{H}_{24} \mathrm{O}_{6}\right)(\mathrm{THF})_{2}\right]\left[\left(\mathrm{C}_{27} \mathrm{H}_{21} \mathrm{~N}_{3}\right)_{2} \mathrm{Zr}\right] \cdot 3 \mathrm{THF}$.

\begin{tabular}{|c|c|c|}
\hline \multirow{2}{*}{$\begin{array}{l}\text { Identification code } \\
\text { Chemical formula }\end{array}$} & \multicolumn{2}{|l|}{$\mathrm{cm} 159 \mathrm{cms}$} \\
\hline & \multicolumn{2}{|l|}{$\mathrm{C}_{86} \mathrm{H}_{106} \mathrm{~N}_{6} \mathrm{NaO}_{11} \mathrm{Zr}$} \\
\hline Formula weight & \multicolumn{2}{|l|}{$1513.97 \mathrm{~g} / \mathrm{mol}$} \\
\hline Temperature & \multicolumn{2}{|l|}{$100(2) \mathrm{K}$} \\
\hline Wavelength & \multicolumn{2}{|l|}{$0.71073 \AA$} \\
\hline Crystal size & \multicolumn{2}{|c|}{$0.286 \times 0.319 \times 0.627 \mathrm{~mm}$} \\
\hline Crystal system & \multicolumn{2}{|l|}{ triclinic } \\
\hline Space group & \multicolumn{2}{|l|}{ P (-1) (No. 2) } \\
\hline \multirow[t]{3}{*}{ Unit cell } & $\mathrm{a}=15.0083(8) \AA$ & $\alpha=87.080(2)^{\circ}$ \\
\hline & $\mathrm{b}=16.9522(9) \AA$ & $\beta=65.4520(10)^{\circ}$ \\
\hline & $\mathrm{c}=17.9794(10) \AA$ & $\gamma=67.9260(10)^{\circ}$ \\
\hline Volume, $\AA^{3}$ & \multicolumn{2}{|l|}{$3825.8(4)$} \\
\hline Z & \multicolumn{2}{|l|}{2} \\
\hline Density (calc) & \multicolumn{2}{|l|}{$1.314 \mathrm{~g} / \mathrm{cm}^{3}$} \\
\hline Abs. coefficient & \multicolumn{2}{|l|}{$0.215 \mathrm{~mm}^{-1}$} \\
\hline$F(000)$ & \multicolumn{2}{|l|}{1606} \\
\hline
\end{tabular}

Table C6. Data collection and structure refinement for $\left[\mathrm{Na}\left(\mathrm{C}_{12} \mathrm{H}_{24} \mathrm{O}_{6}\right)\right]\left[\left(\mathrm{C}_{27} \mathrm{H}_{21} \mathrm{~N}_{3}\right)_{2} \mathrm{Zr}\right] \cdot 3\left(\mathrm{OC}_{4} \mathrm{H}_{8}\right)$.

\begin{tabular}{|c|c|}
\hline Theta range & 2.83 to $35.07^{\circ}$ \\
\hline Index ranges & $-24 \leq \mathrm{h} \leq 24,-27 \leq \mathrm{k} \leq 27,-29 \leq 1 \leq 28$ \\
\hline Reflections & 124422 \\
\hline Independent reflections & $33576[\mathrm{R}(\mathrm{int})=0.0418]$ \\
\hline Coverage & $99.2 \%$ \\
\hline Absorption correction & multi-scan \\
\hline Max. and min. trans. & 0.941 and 0.877 \\
\hline Refinement method & Full-matrix least-squares on $\mathrm{F}^{2}$ \\
\hline Refinement program & SHELXL-2014/7 (Sheldrick, 2014) \\
\hline $\begin{array}{l}\text { Data / restraints } \\
\text { parameters }\end{array}$ & $33576 / 0 / 1025$ \\
\hline Goodness-of-fit on $\mathrm{F}^{2}$ & 1.032 \\
\hline \multirow[t]{2}{*}{ Final $\mathrm{R}$ indices } & ${ }^{\text {data; }} \mathrm{R} 1=0.0672, w R 2=0.1467$ \\
\hline & $\mathrm{R} 1=0.1050, \mathrm{wR} 2=0.1728$ \\
\hline
\end{tabular}
Largest diff. peak and 2.734 and $-1.204 \mathrm{e}^{-} / \AA^{3}$
hole 
Table C7. Atomic coordinates and equivalent isotropic atomic displacement parameters $\left(\AA^{2}\right)$ for $\left[\mathrm{Na}\left(\mathrm{C}_{12} \mathrm{H}_{24} \mathrm{O}_{6}\right)(\mathrm{THF})_{2}\right]\left[\left(\mathrm{C}_{27} \mathrm{H}_{21} \mathrm{~N}_{3}\right)_{2} \mathrm{Zr}\right] \cdot 3 \mathrm{THF}$. U(eq) is defined as one third of the trace of the orthogonalized $\mathrm{U}_{\mathrm{ij}}$ tensor.

\begin{tabular}{|c|c|c|c|c|}
\hline & $\mathrm{x} / \mathrm{a}$ & $\mathrm{y} / \mathrm{b}$ & $\mathrm{z} / \mathrm{c}$ & $\mathrm{U}(\mathrm{eq})$ \\
\hline $\mathrm{Zr} 1$ & $0.43887(2)$ & $0.27298(2)$ & $0.27117(2)$ & $0.01434(4)$ \\
\hline N1 & $0.35249(13)$ & $0.39884(10)$ & $0.24568(10)$ & $0.0148(3)$ \\
\hline $\mathrm{N} 2$ & $0.26148(12)$ & $0.31160(10)$ & $0.34644(9)$ & $0.0127(3)$ \\
\hline N3 & $0.41189(13)$ & $0.17025(10)$ & $0.34495(10)$ & $0.0144(3)$ \\
\hline N4 & $0.49096(13)$ & $0.32664(10)$ & $0.34685(10)$ & $0.0154(3)$ \\
\hline N5 & $0.61638(12)$ & $0.22975(10)$ & $0.20659(9)$ & $0.0130(3)$ \\
\hline N6 & $0.49884(13)$ & $0.20027(11)$ & $0.15086(10)$ & $0.0155(3)$ \\
\hline $\mathrm{C} 1$ & $0.39017(15)$ & $0.45543(12)$ & $0.19797(12)$ & $0.0160(3)$ \\
\hline $\mathrm{C} 2$ & $0.30607(17)$ & $0.53203(13)$ & $0.20973(13)$ & $0.0195(3)$ \\
\hline $\mathrm{C} 3$ & $0.21101(15)$ & $0.52405(12)$ & $0.26660(12)$ & $0.0169(3)$ \\
\hline $\mathrm{C} 4$ & $0.24255(15)$ & $0.44074(12)$ & $0.28811(12)$ & $0.0152(3)$ \\
\hline $\mathrm{C} 5$ & $0.19159(15)$ & $0.39297(11)$ & $0.34844(11)$ & $0.0138(3)$ \\
\hline C6 & $0.08634(15)$ & $0.42393(12)$ & $0.40735(12)$ & $0.0167(3)$ \\
\hline $\mathrm{C} 7$ & $0.05081(15)$ & $0.37103(13)$ & $0.46409(12)$ & $0.0175(3)$ \\
\hline $\mathrm{C} 8$ & $0.12039(15)$ & $0.28758(12)$ & $0.46069(12)$ & $0.0162(3)$ \\
\hline $\mathrm{C} 9$ & $0.22567(15)$ & $0.25880(11)$ & $0.40190(11)$ & $0.0138(3)$ \\
\hline $\mathrm{C} 10$ & $0.30921(14)$ & $0.17681(11)$ & $0.39501(11)$ & $0.0137(3)$ \\
\hline C11 & $0.31275(15)$ & $0.10314(12)$ & $0.43430(12)$ & $0.0158(3)$ \\
\hline C12 & $0.42188(16)$ & $0.05084(12)$ & $0.40801(13)$ & $0.0178(3)$ \\
\hline C13 & $0.48049(15)$ & $0.09275(12)$ & $0.35301(11)$ & $0.0149(3)$ \\
\hline $\mathrm{C} 14$ & $0.10522(16)$ & $0.59402(13)$ & $0.29283(12)$ & $0.0185(3)$ \\
\hline $\mathrm{C} 15$ & $0.09452(18)$ & $0.67922(13)$ & $0.30387(14)$ & $0.0227(4)$ \\
\hline $\mathrm{C} 16$ & $0.9961(2)$ & $0.74707(15)$ & $0.32587(15)$ & $0.0276(4)$ \\
\hline $\mathrm{C} 17$ & $0.9074(2)$ & $0.73206(16)$ & $0.33806(16)$ & $0.0289(5)$ \\
\hline $\mathrm{C} 18$ & $0.91619(19)$ & $0.64845(16)$ & $0.32766(16)$ & $0.0277(4)$ \\
\hline C19 & $0.01434(17)$ & $0.58020(14)$ & $0.30409(14)$ & $0.0221(4)$ \\
\hline $\mathrm{C} 20$ & $0.22614(16)$ & $0.07794(12)$ & $0.48957(12)$ & $0.0175(3)$ \\
\hline $\mathrm{C} 21$ & $0.13861(17)$ & $0.08942(13)$ & $0.47378(13)$ & $0.0205(4)$ \\
\hline $\mathrm{C} 22$ & $0.05832(19)$ & $0.06422(14)$ & $0.52623(15)$ & $0.0262(4)$ \\
\hline $\mathrm{C} 23$ & $0.06458(19)$ & $0.02539(14)$ & $0.59473(16)$ & $0.0287(5)$ \\
\hline $\mathrm{C} 24$ & $0.1518(2)$ & $0.01168(14)$ & $0.61058(15)$ & $0.0273(5)$ \\
\hline $\mathrm{C} 25$ & $0.23166(18)$ & $0.03802(13)$ & $0.55863(14)$ & $0.0223(4)$ \\
\hline
\end{tabular}




\begin{tabular}{|c|c|c|c|c|}
\hline & $\mathrm{x} / \mathrm{a}$ & $\mathrm{y} / \mathrm{b}$ & $\mathrm{z} / \mathrm{c}$ & $\mathrm{U}(\mathrm{eq})$ \\
\hline $\mathrm{C} 26$ & $0.50624(17)$ & $0.43092(14)$ & $0.14716(14)$ & $0.0225(4)$ \\
\hline $\mathrm{C} 27$ & $0.59789(16)$ & $0.06385(13)$ & $0.30672(14)$ & $0.0210(4)$ \\
\hline $\mathrm{C} 28$ & $0.43781(16)$ & $0.37711(12)$ & $0.42151(12)$ & $0.0164(3)$ \\
\hline $\mathrm{C} 29$ & $0.51109(17)$ & $0.38230(13)$ & $0.44746(13)$ & $0.0187(3)$ \\
\hline $\mathrm{C} 30$ & $0.61398(16)$ & $0.33126(12)$ & $0.38767(12)$ & $0.0168(3)$ \\
\hline C31 & $0.59900(15)$ & $0.29890(12)$ & $0.32583(12)$ & $0.0154(3)$ \\
\hline C32 & $0.66977(15)$ & $0.24886(13)$ & $0.24575(12)$ & $0.0163(3)$ \\
\hline C33 & $0.77933(17)$ & $0.22225(17)$ & $0.20834(14)$ & $0.0253(4)$ \\
\hline C34 & $0.83694(19)$ & $0.17517(19)$ & $0.13060(15)$ & $0.0319(5)$ \\
\hline $\mathrm{C} 35$ & $0.78319(17)$ & $0.15460(17)$ & $0.09149(14)$ & $0.0262(4)$ \\
\hline $\mathrm{C} 36$ & $0.67388(15)$ & $0.18206(13)$ & $0.13039(12)$ & $0.0173(3)$ \\
\hline $\mathrm{C} 37$ & $0.60697(15)$ & $0.16489(13)$ & $0.09911(11)$ & $0.0158(3)$ \\
\hline $\mathrm{C} 38$ & $0.62444(16)$ & $0.11587(13)$ & $0.03048(12)$ & $0.0177(3)$ \\
\hline C39 & $0.52271(17)$ & $0.12182(14)$ & $0.04165(13)$ & $0.0203(4)$ \\
\hline $\mathrm{C} 40$ & $0.44798(15)$ & $0.17358(13)$ & $0.11493(12)$ & $0.0167(3)$ \\
\hline $\mathrm{C} 41$ & $0.71371(16)$ & $0.31241(13)$ & $0.39570(12)$ & $0.0172(3)$ \\
\hline $\mathrm{C} 42$ & $0.78302(18)$ & $0.22784(13)$ & $0.39011(14)$ & $0.0213(4)$ \\
\hline $\mathrm{C} 43$ & $0.87550(19)$ & $0.20979(15)$ & $0.40017(15)$ & $0.0249(4)$ \\
\hline $\mathrm{C} 44$ & $0.90004(19)$ & $0.27656(15)$ & $0.41649(15)$ & $0.0257(4)$ \\
\hline $\mathrm{C} 45$ & $0.83124(18)$ & $0.36064(15)$ & $0.42368(15)$ & $0.0246(4)$ \\
\hline $\mathrm{C} 46$ & $0.73890(17)$ & $0.37867(14)$ & $0.41350(14)$ & $0.0208(4)$ \\
\hline $\mathrm{C} 47$ & $0.72343(17)$ & $0.06595(15)$ & $0.95813(13)$ & $0.0221(4)$ \\
\hline $\mathrm{C} 48$ & $0.7431(2)$ & $0.98151(16)$ & $0.93338(15)$ & $0.0289(5)$ \\
\hline $\mathrm{C} 49$ & $0.8348(2)$ & $0.93263(19)$ & $0.86496(17)$ & $0.0377(6)$ \\
\hline $\mathrm{C} 50$ & $0.9087(2)$ & $0.9668(2)$ & $0.81954(18)$ & $0.0432(7)$ \\
\hline C51 & $0.8892(2)$ & $0.0511(2)$ & $0.84169(16)$ & $0.0391(6)$ \\
\hline C52 & $0.79725(19)$ & $0.10038(18)$ & $0.91025(14)$ & $0.0293(5)$ \\
\hline C53 & $0.31944(17)$ & $0.41809(15)$ & $0.46338(14)$ & $0.0243(4)$ \\
\hline $\mathrm{C} 54$ & $0.33043(18)$ & $0.20288(17)$ & $0.15345(16)$ & $0.0280(5)$ \\
\hline $\mathrm{Na} 1$ & $0.47383(9)$ & $0.25139(7)$ & $0.75898(6)$ & $0.0305(2)$ \\
\hline $\mathrm{O} 1$ & $0.29044(15)$ & $0.23199(13)$ & $0.85217(11)$ & $0.0330(4)$ \\
\hline $\mathrm{O} 2$ & $0.48714(15)$ & $0.10258(11)$ & $0.82865(11)$ & $0.0289(3)$ \\
\hline $\mathrm{O} 3$ & $0.67198(15)$ & $0.11406(12)$ & $0.70687(11)$ & $0.0292(3)$ \\
\hline $\mathrm{O} 4$ & $0.66845(15)$ & $0.27279(12)$ & $0.67191(11)$ & $0.0305(4)$ \\
\hline O5 & $0.47282(15)$ & $0.39990(12)$ & $0.68670(11)$ & $0.0293(3)$ \\
\hline O6 & $0.28586(16)$ & $0.38438(13)$ & $0.80076(13)$ & $0.0360(4)$ \\
\hline $\mathrm{O} 7$ & $0.46945(14)$ & $0.19192(13)$ & $0.64830(10)$ & $0.0309(4)$ \\
\hline
\end{tabular}




\begin{tabular}{|c|c|c|c|c|}
\hline & $\mathrm{x} / \mathrm{a}$ & $y / b$ & $\mathrm{z} / \mathrm{c}$ & $\mathrm{U}(\mathrm{eq})$ \\
\hline O8 & $0.47912(16)$ & $0.31612(13)$ & $0.86734(11)$ & $0.0330(4)$ \\
\hline C55 & $0.3003(2)$ & $0.16497(19)$ & $0.90319(16)$ & $0.0349(5)$ \\
\hline C56 & $0.3931(2)$ & $0.08763(18)$ & $0.85131(17)$ & $0.0340(5)$ \\
\hline C57 & $0.5781(2)$ & $0.02889(16)$ & $0.77907(17)$ & $0.0331(5)$ \\
\hline C58 & $0.6753(2)$ & $0.04686(17)$ & $0.75706(17)$ & $0.0329(5)$ \\
\hline C59 & $0.7665(2)$ & $0.12917(18)$ & $0.67843(17)$ & $0.0326(5)$ \\
\hline C60 & $0.7594(2)$ & $0.19890(19)$ & $0.62474(16)$ & $0.0325(5)$ \\
\hline C61 & $0.6610(2)$ & $0.34494(19)$ & $0.62730(16)$ & $0.0335(5)$ \\
\hline C62 & $0.5609(2)$ & $0.41857(17)$ & $0.67811(18)$ & $0.0325(5)$ \\
\hline C63 & $0.3765(2)$ & $0.47165(18)$ & $0.7307(2)$ & $0.0392(6)$ \\
\hline C64 & $0.2843(3)$ & $0.4489(2)$ & $0.7474(2)$ & $0.0428(7)$ \\
\hline C65 & $0.1903(2)$ & $0.3708(2)$ & $0.83482(19)$ & $0.0368(6)$ \\
\hline C66 & $0.1986(2)$ & $0.30672(19)$ & $0.89387(18)$ & $0.0364(6)$ \\
\hline C67A & $0.55338(18)$ & $0.18469(16)$ & $0.56829(14)$ & $0.0244(4)$ \\
\hline C68A & $0.51190(19)$ & $0.17621(15)$ & $0.50587(14)$ & $0.0243(4)$ \\
\hline C69A & $0.3912(3)$ & $0.2231(3)$ & $0.5570(2)$ & $0.0250(7)$ \\
\hline C70A & $0.3775(3)$ & $0.1930(3)$ & $0.64052(19)$ & $0.0234(8)$ \\
\hline C67B & $0.55338(18)$ & $0.18469(16)$ & $0.56829(14)$ & $0.0244(4)$ \\
\hline C68B & $0.51190(19)$ & $0.17621(15)$ & $0.50587(14)$ & $0.0243(4)$ \\
\hline C69B & $0.3986(8)$ & $0.1843(9)$ & $0.5578(6)$ & $0.025(2)$ \\
\hline C70B & $0.3737(8)$ & $0.2399(8)$ & $0.6315(6)$ & $0.028(3)$ \\
\hline C71 & $0.5732(2)$ & $0.27682(18)$ & $0.88031(15)$ & $0.0304(5)$ \\
\hline $\mathrm{C} 72$ & $0.5530(2)$ & $0.32688(17)$ & $0.95749(15)$ & $0.0299(5)$ \\
\hline C73 & $0.4321(2)$ & $0.37076(19)$ & $0.00201(16)$ & $0.0346(5)$ \\
\hline C74 & $0.3936(2)$ & $0.3424(3)$ & $0.94693(19)$ & $0.0475(8)$ \\
\hline O9A & $0.1853(3)$ & $0.5568(3)$ & $0.9344(2)$ & $0.0430(11)$ \\
\hline $\mathrm{C} 75 \mathrm{~A}$ & $0.1968(4)$ & $0.6324(4)$ & $0.9487(4)$ & $0.0426(13)$ \\
\hline C76A & $0.2175(9)$ & $0.6209(7)$ & $0.0238(7)$ & $0.050(3)$ \\
\hline C77A & $0.1601(6)$ & $0.5650(4)$ & $0.0722(4)$ & $0.0352(12)$ \\
\hline C78A & $0.1210(6)$ & $0.5413(6)$ & $0.0134(5)$ & $0.0356(13)$ \\
\hline O9B & $0.0631(5)$ & $0.5937(5)$ & $0.0760(4)$ & $0.053(2)$ \\
\hline C75B & $0.1452(10)$ & $0.6002(9)$ & $0.0896(7)$ & $0.051(3)$ \\
\hline C76B & $0.2159(15)$ & $0.6252(14)$ & $0.0164(12)$ & $0.068(7)$ \\
\hline C77B & $0.2002(18)$ & $0.5887(13)$ & $0.9497(9)$ & $0.114(8)$ \\
\hline C78B & $0.1195(19)$ & $0.5547(15)$ & $0.9927(11)$ & $0.092(7)$ \\
\hline $\mathrm{O} 10$ & $0.9635(2)$ & $0.82589(18)$ & $0.05593(16)$ & $0.0588(7)$ \\
\hline C79 & $0.9295(3)$ & $0.9162(2)$ & $0.0590(2)$ & $0.0482(8)$ \\
\hline
\end{tabular}




$\begin{array}{ccccc} & \mathrm{x} / \mathrm{a} & \mathrm{y} / \mathrm{b} & \mathrm{z} / \mathrm{c} & \mathrm{U}(\mathrm{eq}) \\ \mathrm{C} 80 & 0.8478(3) & 0.9533(2) & 0.1463(2) & 0.0471(8) \\ \mathrm{C} 81 & 0.8601(3) & 0.8765(2) & 0.19526(19) & 0.0429(7) \\ \mathrm{C} 82 & 0.9606(3) & 0.8075(2) & 0.1349(2) & 0.0486(8) \\ \mathrm{O} 11 \mathrm{~A} & 0.1271(3) & 0.3261(4) & 0.0945(2) & 0.0635(16) \\ \mathrm{C} 83 \mathrm{~A} & 0.0384(4) & 0.3050(3) & 0.1099(2) & 0.0602(10) \\ \mathrm{C} 86 \mathrm{~A} & 0.0887(3) & 0.3936(3) & 0.1599(2) & 0.0591(10) \\ \text { O11B } & 0.0475(13) & 0.3844(7) & 0.0977(6) & 0.073(5) \\ \mathrm{C} 83 \mathrm{~B} & 0.0384(4) & 0.3050(3) & 0.1099(2) & 0.0602(10) \\ \mathrm{C} 86 \mathrm{~B} & 0.0887(3) & 0.3936(3) & 0.1599(2) & 0.0591(10) \\ \mathrm{C} 84 & 0.9806(3) & 0.3125(2) & 0.2009(2) & 0.0507(8) \\ \mathrm{C} 85 & 0.0264(4) & 0.3619(4) & 0.2339(2) & 0.0702(13)\end{array}$




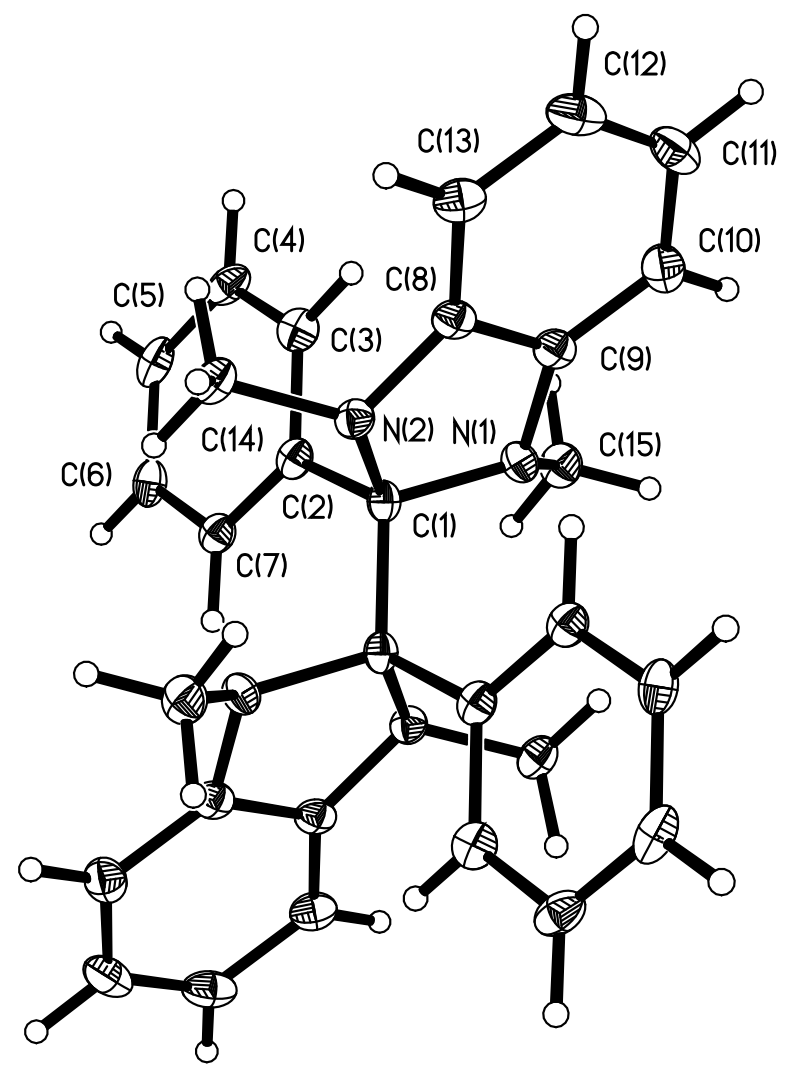

Figure C3. Perspective view of the molecular structure of $\mathrm{C}_{30} \mathrm{H}_{30} \mathrm{~N}_{4}$ with the atom labeling scheme for the independent non-hydrogen atoms. The molecular geometry is constrained by a crystallographic center of inversion. The thermal ellipsoids are scaled to enclose $50 \%$ probability. 
Table C8. Crystal data for $\mathrm{C}_{30} \mathrm{H}_{30} \mathrm{~N}_{4}$.

$\begin{array}{lll}\text { Identification code } & \mathrm{cm} 116 \mathrm{cms} & \\ \text { Empirical formula } & \mathrm{C}_{30} \mathrm{H}_{30} \mathrm{~N}_{4} & \\ \text { Emp. formula weight } & 446.58 \mathrm{~g} / \mathrm{mol} \\ \text { Temperature } & 100(2) \mathrm{K} \\ \text { Wavelength } & 0.71073 \AA \\ \text { Crystal size } & 0.103 \times 0.133 \times 0.240 \mathrm{~mm} \\ \text { Crystal system } & \text { monoclinic } & \\ \text { Space group } & \mathrm{P} 2{ }_{1} / \mathrm{c}(\mathrm{No} .14) & \\ \text { Unit cell dimensions } & \mathrm{a}=10.3038(7) \AA & \alpha=90^{\circ} \\ & \mathrm{b}=16.3680(12) \AA & \beta=104.6300(19)^{\circ} \\ & \mathrm{c}=7.0296(5) \AA & \gamma=90^{\circ}\end{array}$

Volume $\quad 1147.1(1) \AA^{3}$

Z 2

Density (calculated) $\quad 1.293 \mathrm{~g} / \mathrm{cm}^{3}$

Absorption coefficient $\quad 0.077 \mathrm{~mm}^{-1}$

$\mathrm{F}(000) \quad 476$

Table C9. Data collection and structure refinement for $\mathrm{C}_{30} \mathrm{H}_{30} \mathrm{~N}_{4}$.

\begin{tabular}{|c|c|}
\hline Theta range & 3.41 to $25.00^{\circ}$ \\
\hline Index ranges & $-12 \leq \mathrm{h} \leq 12,-19 \leq \mathrm{k} \leq 19,-8 \leq 1 \leq 8$ \\
\hline Reflections & 16829 \\
\hline Independent reflections & $2028[\mathrm{R}(\mathrm{int})=0.0634]$ \\
\hline \multicolumn{2}{|c|}{$\begin{array}{l}\text { Coverage of independent } 99.7 \% \\
\text { reflections }\end{array}$} \\
\hline Absorption correction & multi-scan \\
\hline \multicolumn{2}{|c|}{ Max. and min. transmission 0.992 and 0.982} \\
\hline Refinement method & Full-matrix least-squares on $\mathrm{F}^{2}$ \\
\hline Refinement program & SHELXL-2014/7 (Sheldrick, 2014) \\
\hline $\begin{array}{l}\text { Data / restraints } \\
\text { parameters }\end{array}$ & / 2028 / 0 / 156 \\
\hline Goodness-of-fit on $\mathrm{F}^{2}$ & 1.075 \\
\hline \multirow[t]{2}{*}{ Final $\mathrm{R}$ indices } & 1527 data; $\mathrm{I}>2 \sigma(\mathrm{I}) \quad \mathrm{R} 1=0.0475, \mathrm{wR} 2=0.0901$ \\
\hline & $\mathrm{R} 1=0.0729, \mathrm{wR} 2=0.0996$ \\
\hline
\end{tabular}

Largest diff. peak and hole 0.254 and $-0.210 \mathrm{e}^{-} / \AA^{3}$ 
Table C10. Atomic coordinates and equivalent isotropic atomic displacement parameters $\left(\AA^{2}\right)$ for $\mathrm{C}_{30} \mathrm{H}_{30} \mathrm{~N}_{4}$. $\mathrm{U}(\mathrm{eq})$ is defined as one third of the trace of the orthogonalized $\mathrm{U}_{\mathrm{ij}}$ tensor.

$\begin{array}{lcccc} & \mathrm{x} / \mathrm{a} & \mathrm{y} / \mathrm{b} & \mathrm{z} / \mathrm{c} & \mathrm{U}(\mathrm{eq}) \\ \mathrm{N} 1 & 0.38162(15) & 0.57643(9) & 0.8390(2) & 0.0159(4) \\ \mathrm{N} 2 & 0.34390(15) & 0.50046(9) & 0.0978(2) & 0.0157(4) \\ \mathrm{C} 1 & 0.42276(18) & 0.49823(11) & 0.9471(3) & 0.0149(4) \\ \mathrm{C} 2 & 0.37524(18) & 0.42444(11) & 0.8072(3) & 0.0157(4) \\ \mathrm{C} 3 & 0.23724(19) & 0.42190(12) & 0.7179(3) & 0.0196(4) \\ \mathrm{C} 4 & 0.1807(2) & 0.35999(12) & 0.5889(3) & 0.0209(5) \\ \mathrm{C} 5 & 0.2609(2) & 0.29804(12) & 0.5467(3) & 0.0208(5) \\ \mathrm{C} 6 & 0.3967(2) & 0.29944(11) & 0.6335(3) & 0.0190(4) \\ \mathrm{C} 7 & 0.45364(19) & 0.36195(11) & 0.7621(3) & 0.0168(4) \\ \mathrm{C} 8 & 0.24639(18) & 0.56102(11) & 0.0480(3) & 0.0166(4) \\ \mathrm{C} 9 & 0.26971(18) & 0.60773(11) & 0.8936(3) & 0.0173(4) \\ \mathrm{C} 10 & 0.18759(19) & 0.67189(12) & 0.8146(3) & 0.0218(5) \\ \mathrm{C} 11 & 0.0787(2) & 0.68849(13) & 0.8950(3) & 0.0243(5) \\ \mathrm{C} 12 & 0.0548(2) & 0.64211(13) & 0.0449(3) & 0.0244(5) \\ \mathrm{C} 13 & 0.13831(19) & 0.57680(12) & 0.1243(3) & 0.0203(5) \\ \mathrm{C} 14 & 0.30814(19) & 0.42536(12) & 0.1839(3) & 0.0201(4) \\ \mathrm{C} 15 & 0.3806(2) & 0.58377(12) & 0.6312(3) & 0.0216(5)\end{array}$




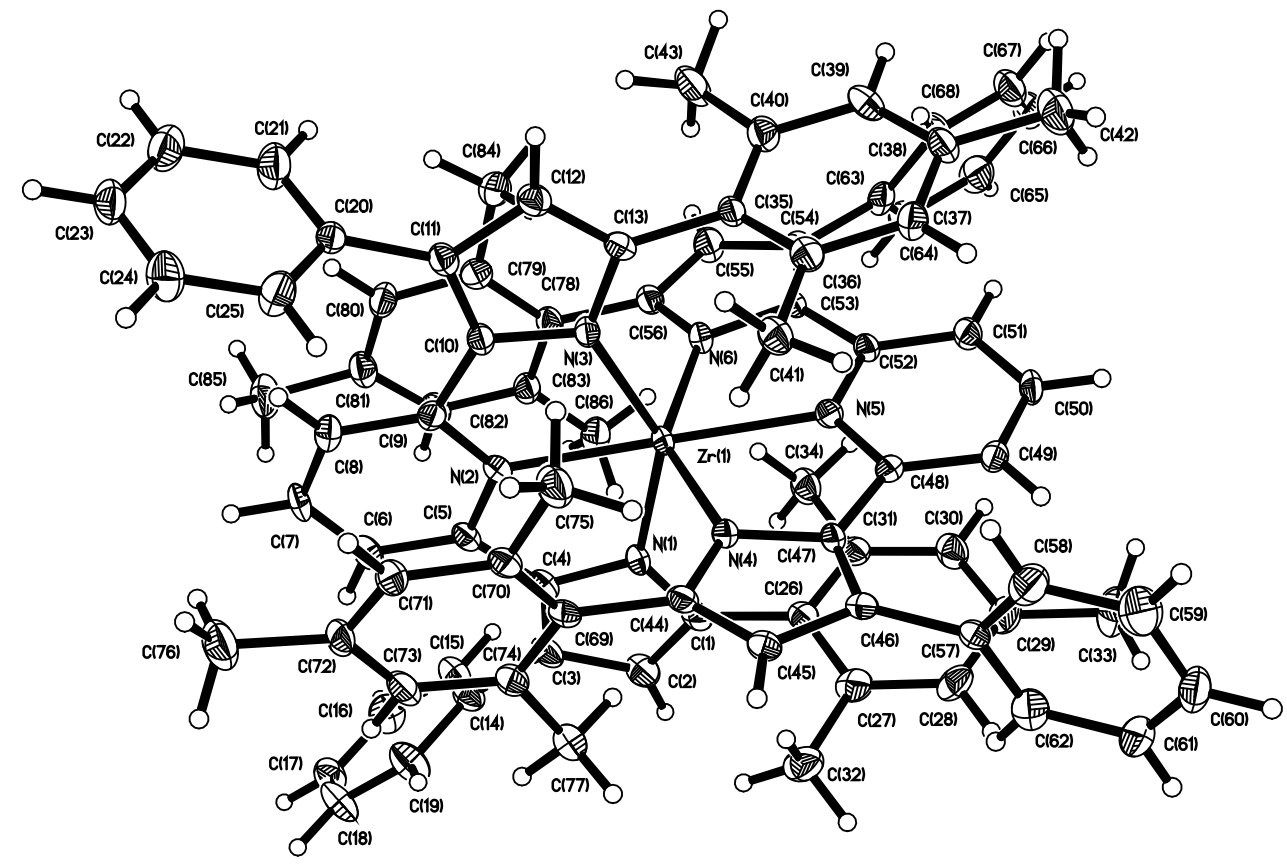

Figure C4. Perspective view of the molecular structure of $\left(\mathrm{C}_{43} \mathrm{H}_{37} \mathrm{~N}_{3}\right)_{2} \mathrm{Zr}$. The thermal ellipsoids are scaled to enclose $50 \%$ probability. 
Table C11. Crystal data for $\left(\mathrm{C}_{43} \mathrm{H}_{37} \mathrm{~N}_{3}\right)_{2} \mathrm{Zr} \cdot 2 \mathrm{THF}$.

$\begin{array}{lll}\text { Identification code } & \mathrm{cm} 214 \mathrm{cms} \\ \text { Chemical formula } & \mathrm{C}_{94} \mathrm{H}_{90} \mathrm{~N}_{6} \mathrm{O}_{2} \mathrm{Zr} & \\ \text { Formula weight } & 1426.93 \mathrm{~g} / \mathrm{mol} & \\ \text { Temperature } & 100(2) \mathrm{K} \\ \text { Wavelength } & 0.71073 \AA \\ \text { Crystal size } & 0.120 \times 0.284 \times 0.323 \mathrm{~mm} \\ \text { Crystal system } & \text { triclinic } & \\ \text { Space group } & \mathrm{P}-1 \text { (No. 2) } & \\ \text { Unit cell } & \mathrm{a}=15.5541(12) \AA & \alpha=111.059(2)^{\circ} \\ & \mathrm{b}=15.9336(12) \AA & \beta=92.984(2)^{\circ} \\ & \mathrm{c}=16.9474(13) \AA & \gamma=110.941(2)^{\circ}\end{array}$

Volume, $\AA^{3} \quad 3581.4(5)$

$\mathrm{Z} \quad 2$

Density (calc) $\quad 1.323 \mathrm{~g} / \mathrm{cm}^{3}$

Abs. coefficient $\quad 0.212 \mathrm{~mm}^{-1}$

$\mathrm{F}(000) \quad 1504$

Table C12. Data collection and structure refinement for $\left(\mathrm{C}_{43} \mathrm{H}_{37} \mathrm{~N}_{3}\right)_{2} \mathrm{Zr} \cdot 2 \mathrm{THF}$.

\begin{tabular}{|c|c|}
\hline Theta range & 2.86 to $27.66^{\circ}$ \\
\hline Index ranges & $-20 \leq \mathrm{h} \leq 20,-20 \leq \mathrm{k} \leq 20,-22 \leq 1 \leq 22$ \\
\hline Reflections & 75504 \\
\hline Independent refls. & $16619[\mathrm{R}(\mathrm{int})=0.1170]$ \\
\hline Coverage & $99.3 \%$ \\
\hline Absorption correction & multi-scan \\
\hline Max. and min. trans. & 0.975 and 0.935 \\
\hline Refinement method & Full-matrix least-squares on $\mathrm{F}^{2}$ \\
\hline Refinement program & SHELXL-2014/7 (Sheldrick, 2014) \\
\hline $\begin{array}{l}\text { Data / restraints } \\
\text { parameters }\end{array}$ & / $16619 / 0 / 940$ \\
\hline Goodness-of-fit on $\mathrm{F}^{2}$ & 1.001 \\
\hline \multirow[t]{2}{*}{ Final $\mathrm{R}$ indices } & $\begin{array}{l}9736 \quad \text { data; } \mathrm{R} 1=0.0551, \mathrm{wR} 2=0.1002 \\
\mathrm{I}>2 \sigma(\mathrm{I})\end{array}$ \\
\hline & $\mathrm{R} 1=0.1317, \mathrm{wR} 2=0.1199$ \\
\hline
\end{tabular}

Largest diff. peak and 0.790 and $-1.243 \mathrm{e}^{-} / \AA^{3}$ hole 
Table C13. Atomic coordinates and equivalent isotropic atomic displacement parameters $\left(\AA^{2}\right)$ for $\left(\mathrm{C}_{43} \mathrm{H}_{37} \mathrm{~N}_{3}\right)_{2} \mathrm{Zr} \cdot 2 \mathrm{THF}$. U(eq) is defined as one third of the trace of the orthogonalized $\mathrm{U}_{\mathrm{ij}}$ tensor.

\begin{tabular}{|c|c|c|c|c|}
\hline & $\mathrm{x} / \mathrm{a}$ & $y / b$ & $\mathrm{z} / \mathrm{c}$ & $\mathrm{U}(\mathrm{eq})$ \\
\hline $\mathrm{Zr} 1$ & $0.24568(2)$ & $0.50359(2)$ & $0.26711(2)$ & $0.01529(8)$ \\
\hline N1 & $0.35936(15)$ & $0.46534(15)$ & $0.21968(14)$ & $0.0175(5)$ \\
\hline $\mathrm{N} 2$ & $0.19404(15)$ & $0.33798(15)$ & $0.21088(14)$ & $0.0151(5)$ \\
\hline N3 & $0.10158(15)$ & $0.44282(14)$ & $0.28124(14)$ & $0.0162(5)$ \\
\hline N4 & $0.30620(14)$ & $0.55830(14)$ & $0.40319(14)$ & $0.0154(5)$ \\
\hline N5 & $0.29873(15)$ & $0.66937(15)$ & $0.32403(14)$ & $0.0149(5)$ \\
\hline N6 & $0.21587(15)$ & $0.54845(14)$ & $0.16612(14)$ & $0.0170(5)$ \\
\hline $\mathrm{C} 1$ & $0.45145(19)$ & $0.51936(19)$ & $0.21876(18)$ & $0.0195(6)$ \\
\hline $\mathrm{C} 2$ & $0.4901(2)$ & $0.4561(2)$ & $0.17317(19)$ & $0.0246(7)$ \\
\hline $\mathrm{C} 3$ & $0.4217(2)$ & $0.35878(19)$ & $0.14522(19)$ & $0.0222(7)$ \\
\hline $\mathrm{C} 4$ & $0.34262(19)$ & $0.36671(18)$ & $0.17445(17)$ & $0.0172(6)$ \\
\hline $\mathrm{C} 5$ & $0.25122(19)$ & $0.29561(18)$ & $0.17124(17)$ & $0.0165(6)$ \\
\hline C6 & $0.2194(2)$ & $0.19380(19)$ & $0.13432(18)$ & $0.0209(7)$ \\
\hline $\mathrm{C} 7$ & $0.1316(2)$ & $0.13819(18)$ & $0.14146(18)$ & $0.0206(7)$ \\
\hline $\mathrm{C} 8$ & $0.07438(19)$ & $0.18096(18)$ & $0.18305(17)$ & $0.0196(6)$ \\
\hline C9 & $0.10678(18)$ & $0.28311(18)$ & $0.21700(17)$ & $0.0163(6)$ \\
\hline $\mathrm{C} 10$ & $0.05594(18)$ & $0.34176(18)$ & $0.25800(17)$ & $0.0157(6)$ \\
\hline $\mathrm{C} 11$ & $0.96544(19)$ & $0.31887(18)$ & $0.27338(17)$ & $0.0172(6)$ \\
\hline $\mathrm{C} 12$ & $0.95558(19)$ & $0.40938(18)$ & $0.30714(17)$ & $0.0192(6)$ \\
\hline $\mathrm{C} 13$ & $0.03812(18)$ & $0.48322(18)$ & $0.31084(17)$ & $0.0161(6)$ \\
\hline $\mathrm{C} 14$ & $0.43542(19)$ & $0.26841(19)$ & $0.09434(19)$ & $0.0207(6)$ \\
\hline $\mathrm{C} 15$ & $0.4426(2)$ & $0.2459(2)$ & $0.0091(2)$ & $0.0272(7)$ \\
\hline $\mathrm{C} 16$ & $0.4571(2)$ & $0.1628(2)$ & $0.9613(2)$ & $0.0310(8)$ \\
\hline $\mathrm{C} 17$ & $0.4640(2)$ & $0.1012(2)$ & $0.9980(2)$ & $0.0279(7)$ \\
\hline C18 & $0.4572(2)$ & $0.1224(2)$ & $0.0826(2)$ & $0.0318(8)$ \\
\hline C19 & $0.4438(2)$ & $0.2055(2)$ & $0.1307(2)$ & $0.0312(8)$ \\
\hline $\mathrm{C} 20$ & $0.89364(18)$ & $0.22009(18)$ & $0.25662(18)$ & $0.0175(6)$ \\
\hline $\mathrm{C} 21$ & $0.8257(2)$ & $0.1669(2)$ & $0.1816(2)$ & $0.0304(8)$ \\
\hline $\mathrm{C} 22$ & $0.7611(2)$ & $0.0729(2)$ & $0.1644(2)$ & $0.0335(8)$ \\
\hline $\mathrm{C} 23$ & $0.7637(2)$ & $0.0309(2)$ & $0.2217(2)$ & $0.0270(7)$ \\
\hline $\mathrm{C} 24$ & $0.8309(2)$ & $0.0832(2)$ & $0.2963(2)$ & $0.0303(8)$ \\
\hline $\mathrm{C} 25$ & $0.8953(2)$ & $0.1770(2)$ & $0.31379(19)$ & $0.0274(7)$ \\
\hline $\mathrm{C} 26$ & $0.49882(18)$ & $0.62889(19)$ & $0.26553(19)$ & $0.0206(7)$ \\
\hline
\end{tabular}




\begin{tabular}{|c|c|c|c|c|}
\hline & $\mathrm{x} / \mathrm{a}$ & $\mathrm{y} / \mathrm{b}$ & $\mathrm{z} / \mathrm{c}$ & $\mathrm{U}(\mathrm{eq})$ \\
\hline $\mathrm{C} 27$ & $0.55500(19)$ & $0.6734(2)$ & $0.34907(19)$ & $0.0238(7)$ \\
\hline $\mathrm{C} 28$ & $0.59810(19)$ & $0.7753(2)$ & $0.38949(19)$ & $0.0253(7)$ \\
\hline $\mathrm{C} 29$ & $0.5886(2)$ & $0.8353(2)$ & $0.35083(19)$ & $0.0255(7)$ \\
\hline $\mathrm{C} 30$ & $0.5356(2)$ & $0.7909(2)$ & $0.26811(19)$ & $0.0247(7)$ \\
\hline C31 & $0.49179(19)$ & $0.68926(19)$ & $0.22399(18)$ & $0.0203(6)$ \\
\hline $\mathrm{C} 32$ & $0.5687(2)$ & $0.6148(2)$ & $0.3973(2)$ & $0.0313(8)$ \\
\hline C33 & $0.6334(2)$ & $0.9455(2)$ & $0.3978(2)$ & $0.0372(8)$ \\
\hline C34 & $0.4390(2)$ & $0.6451(2)$ & $0.13233(18)$ & $0.0260(7)$ \\
\hline $\mathrm{C} 35$ & $0.06110(18)$ & $0.59070(18)$ & $0.33986(18)$ & $0.0165(6)$ \\
\hline $\mathrm{C} 36$ & $0.10737(19)$ & $0.65607(19)$ & $0.42553(18)$ & $0.0189(6)$ \\
\hline $\mathrm{C} 37$ & $0.12870(19)$ & $0.75560(19)$ & $0.45145(18)$ & $0.0209(7)$ \\
\hline C38 & $0.1033(2)$ & $0.79346(19)$ & $0.39714(19)$ & $0.0221(7)$ \\
\hline C39 & $0.0539(2)$ & $0.72786(19)$ & $0.31420(18)$ & $0.0231(7)$ \\
\hline $\mathrm{C} 40$ & $0.03237(19)$ & $0.62727(19)$ & $0.28393(18)$ & $0.0209(6)$ \\
\hline C41 & $0.1312(2)$ & $0.61999(19)$ & $0.49101(18)$ & $0.0216(7)$ \\
\hline $\mathrm{C} 42$ & $0.1275(2)$ & $0.9014(2)$ & $0.4263(2)$ & $0.0349(8)$ \\
\hline $\mathrm{C} 43$ & $0.9809(2)$ & $0.5635(2)$ & $0.19171(19)$ & $0.0319(8)$ \\
\hline $\mathrm{C} 44$ & $0.31109(18)$ & $0.51430(18)$ & $0.45982(17)$ & $0.0164(6)$ \\
\hline $\mathrm{C} 45$ & $0.35944(18)$ & $0.58633(18)$ & $0.54014(18)$ & $0.0183(6)$ \\
\hline C46 & $0.38574(18)$ & $0.67902(18)$ & $0.53597(17)$ & $0.0166(6)$ \\
\hline $\mathrm{C} 47$ & $0.35172(18)$ & $0.65957(17)$ & $0.45158(17)$ & $0.0155(6)$ \\
\hline $\mathrm{C} 48$ & $0.34687(18)$ & $0.72137(18)$ & $0.40731(17)$ & $0.0154(6)$ \\
\hline C49 & $0.38378(18)$ & $0.82326(18)$ & $0.44244(18)$ & $0.0178(6)$ \\
\hline $\mathrm{C} 50$ & $0.36947(19)$ & $0.86968(18)$ & $0.39122(18)$ & $0.0202(7)$ \\
\hline C51 & $0.31972(19)$ & $0.81651(18)$ & $0.30710(18)$ & $0.0200(6)$ \\
\hline C52 & $0.28425(18)$ & $0.71432(18)$ & $0.27324(17)$ & $0.0151(6)$ \\
\hline C53 & $0.23505(18)$ & $0.64670(18)$ & $0.18560(17)$ & $0.0169(6)$ \\
\hline C54 & $0.21245(19)$ & $0.65873(19)$ & $0.11125(18)$ & $0.0208(7)$ \\
\hline C55 & $0.1793(2)$ & $0.56391(19)$ & $0.04315(18)$ & $0.0245(7)$ \\
\hline C56 & $0.18186(19)$ & $0.49801(18)$ & $0.07704(17)$ & $0.0184(6)$ \\
\hline C57 & $0.43923(19)$ & $0.77754(18)$ & $0.60789(17)$ & $0.0167(6)$ \\
\hline C58 & $0.3955(2)$ & $0.8239(2)$ & $0.66665(19)$ & $0.0276(7)$ \\
\hline C59 & $0.4459(2)$ & $0.9165(2)$ & $0.7317(2)$ & $0.0333(8)$ \\
\hline C60 & $0.5419(2)$ & $0.9640(2)$ & $0.73886(19)$ & $0.0290(8)$ \\
\hline C61 & $0.5854(2)$ & $0.9182(2)$ & $0.6810(2)$ & $0.0289(7)$ \\
\hline C62 & $0.5353(2)$ & $0.8259(2)$ & $0.6157(2)$ & $0.0275(7)$ \\
\hline C63 & $0.2233(2)$ & $0.75034(19)$ & $0.10132(18)$ & $0.0208(7)$ \\
\hline
\end{tabular}




\begin{tabular}{|c|c|c|c|c|}
\hline & $\mathrm{x} / \mathrm{a}$ & $\mathrm{y} / \mathrm{b}$ & $\mathrm{z} / \mathrm{c}$ & $\mathrm{U}(\mathrm{eq})$ \\
\hline C64 & $0.2774(2)$ & $0.7781(2)$ & $0.0455(2)$ & $0.0292(7)$ \\
\hline C65 & $0.2873(2)$ & $0.8635(2)$ & $0.0347(2)$ & $0.0331(8)$ \\
\hline C66 & $0.2422(2)$ & $0.9207(2)$ & $0.0787(2)$ & $0.0334(8)$ \\
\hline C67 & $0.1887(2)$ & $0.8941(2)$ & $0.1338(2)$ & $0.0318(8)$ \\
\hline C68 & $0.1790(2)$ & $0.8093(2)$ & $0.14519(19)$ & $0.0271(7)$ \\
\hline C69 & $0.26707(19)$ & $0.40498(18)$ & $0.43268(17)$ & $0.0166(6)$ \\
\hline $\mathrm{C} 70$ & $0.18166(19)$ & $0.35961(19)$ & $0.45400(18)$ & $0.0192(6)$ \\
\hline C71 & $0.1427(2)$ & $0.25758(19)$ & $0.42656(18)$ & $0.0217(7)$ \\
\hline $\mathrm{C} 72$ & $0.1830(2)$ & $0.19848(19)$ & $0.37735(18)$ & $0.0227(7)$ \\
\hline C73 & $0.2694(2)$ & $0.24461(19)$ & $0.35945(18)$ & $0.0229(7)$ \\
\hline C74 & $0.31347(19)$ & $0.34621(19)$ & $0.38780(18)$ & $0.0199(6)$ \\
\hline $\mathrm{C} 75$ & $0.1277(2)$ & $0.4147(2)$ & $0.5030(2)$ & $0.0268(7)$ \\
\hline $\mathrm{C} 76$ & $0.1354(2)$ & $0.0883(2)$ & $0.3425(2)$ & $0.0353(8)$ \\
\hline $\mathrm{C} 77$ & $0.41037(19)$ & $0.3911(2)$ & $0.37380(19)$ & $0.0243(7)$ \\
\hline C78 & $0.15673(19)$ & $0.38986(18)$ & $0.03069(17)$ & $0.0189(6)$ \\
\hline C79 & $0.0685(2)$ & $0.32165(19)$ & $0.02909(17)$ & $0.0213(7)$ \\
\hline C80 & $0.0482(2)$ & $0.22125(19)$ & $0.99041(18)$ & $0.0231(7)$ \\
\hline $\mathrm{C} 81$ & $0.1116(2)$ & $0.18623(19)$ & $0.95124(18)$ & $0.0234(7)$ \\
\hline C82 & $0.1953(2)$ & $0.25384(19)$ & $0.94890(18)$ & $0.0235(7)$ \\
\hline C83 & $0.21970(19)$ & $0.35513(19)$ & $0.98700(17)$ & $0.0204(6)$ \\
\hline $\mathrm{C} 84$ & $0.9935(2)$ & $0.3532(2)$ & $0.06498(19)$ & $0.0252(7)$ \\
\hline C85 & $0.0884(2)$ & $0.07790(19)$ & $0.9119(2)$ & $0.0335(8)$ \\
\hline C86 & $0.3129(2)$ & $0.4213(2)$ & $0.97959(19)$ & $0.0262(7)$ \\
\hline $\mathrm{O} 1$ & $0.90268(19)$ & $0.93005(17)$ & $0.37443(16)$ & $0.0567(7)$ \\
\hline $\mathrm{C} 87$ & $0.8714(3)$ & $0.8725(2)$ & $0.4239(2)$ & $0.0398(9)$ \\
\hline C88 & $0.8336(2)$ & $0.7659(2)$ & $0.3621(2)$ & $0.0418(9)$ \\
\hline C89 & $0.8044(3)$ & $0.7689(3)$ & $0.2766(2)$ & $0.0570(11)$ \\
\hline C90 & $0.8789(3)$ & $0.8664(3)$ & $0.2855(2)$ & $0.0562(11)$ \\
\hline $\mathrm{O} 2$ & $0.7316(2)$ & $0.5093(3)$ & $0.1988(2)$ & $0.0889(10)$ \\
\hline C91 & $0.6981(3)$ & $0.4182(3)$ & $0.1310(2)$ & $0.0415(9)$ \\
\hline C92 & $0.7058(4)$ & $0.3489(3)$ & $0.1672(3)$ & $0.0825(15)$ \\
\hline C93 & $0.6993(3)$ & $0.3906(3)$ & $0.2556(3)$ & $0.0686(13)$ \\
\hline C94 & $0.7526(3)$ & $0.4994(3)$ & $0.2791(2)$ & $0.0518(10)$ \\
\hline
\end{tabular}




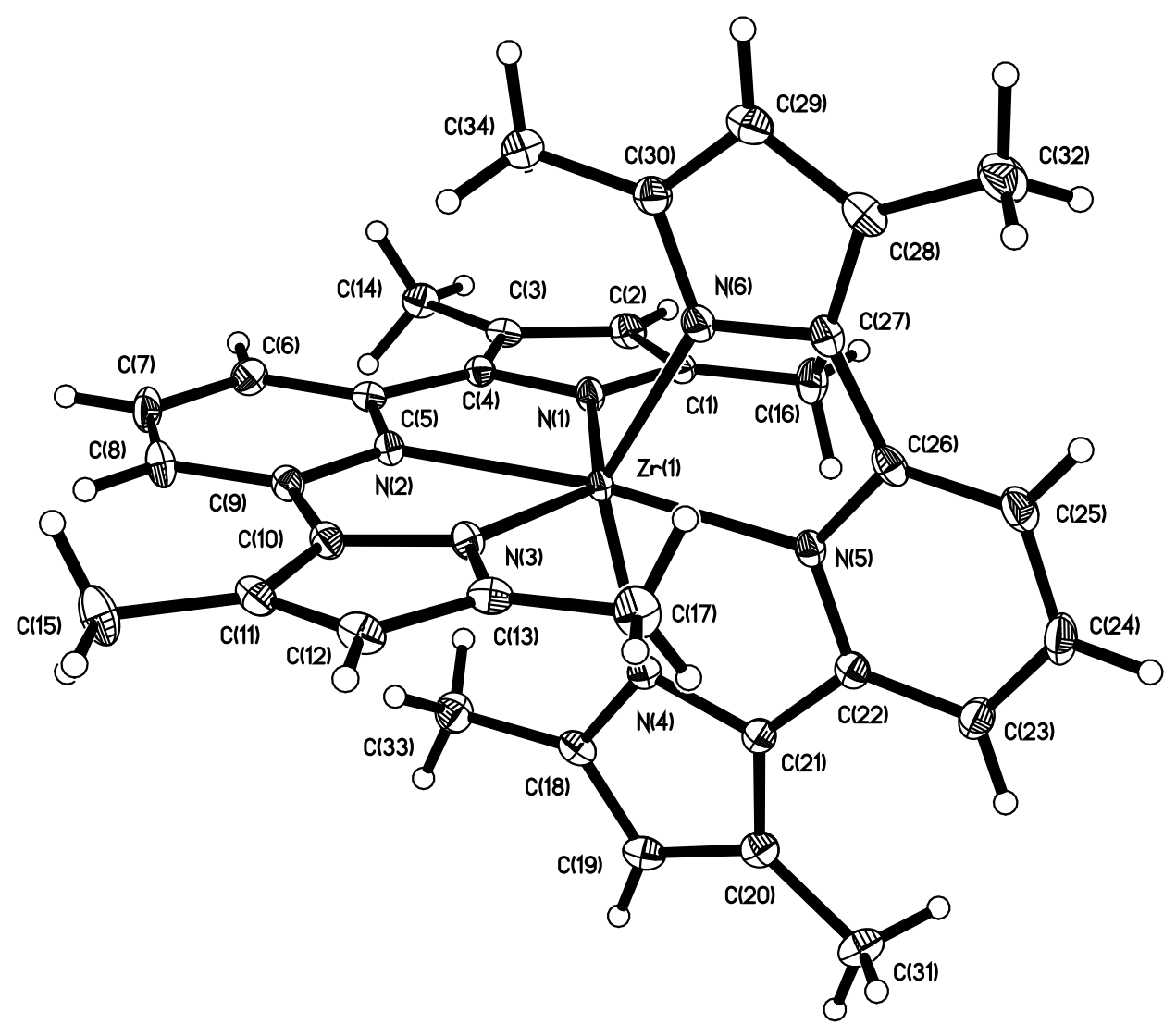

Figure C5. Perspective view of the molecular structure of $\left(\mathrm{C}_{17} \mathrm{H}_{17} \mathrm{~N}_{3}\right)_{2} \mathrm{Zr}$ with the atom labeling scheme for the non-hydrogen atoms. The thermal ellipsoids are scaled to enclose $50 \%$ probability. 
Table C14. Crystal data for $\left(\mathrm{C}_{17} \mathrm{H}_{17} \mathrm{~N}_{3}\right)_{2} \mathrm{Zr} \cdot 2 \mathrm{THF}$.

\begin{tabular}{|c|c|c|}
\hline Identification code & \multicolumn{2}{|l|}{$\mathrm{cm} 95 \mathrm{cms}$} \\
\hline Chemical formula & \multicolumn{2}{|l|}{$\mathrm{C}_{42} \mathrm{H}_{50} \mathrm{~N}_{6} \mathrm{O}_{2} \mathrm{Zr}$} \\
\hline Formula weight & \multicolumn{2}{|l|}{$762.10 \mathrm{~g} / \mathrm{mol}$} \\
\hline Temperature & \multicolumn{2}{|l|}{$100(2) \mathrm{K}$} \\
\hline Wavelength & \multicolumn{2}{|l|}{$0.71073 \AA$} \\
\hline Crystal size & \multicolumn{2}{|c|}{$0.082 \times 0.214 \times 0.593 \mathrm{~mm}$} \\
\hline Crystal system & \multicolumn{2}{|l|}{ monoclinic } \\
\hline Space group & \multicolumn{2}{|c|}{$\mathrm{P} 2{ }_{1} / \mathrm{n}$ (non-standard setting of $\mathrm{P} 2_{1} / \mathrm{c}($ No. 14$)$ ) } \\
\hline \multirow[t]{3}{*}{ Unit cell } & $a=18.0253(8) \AA$ & $\alpha=90^{\circ}$ \\
\hline & $\mathrm{b}=9.1387(4) \AA$ & $\beta=102.0110(14)^{\circ}$ \\
\hline & $\mathrm{c}=22.8408(10) \AA$ & $\gamma=90^{\circ}$ \\
\hline Volume & $3680.1(2) \AA^{3}$ & \\
\hline $\mathrm{Z}$ & 4 & \\
\hline Density (calculated) & $1.375 \mathrm{~g} / \mathrm{cm}^{3}$ & \\
\hline $\begin{array}{l}\text { Absorption } \\
\text { coefficient }\end{array}$ & $0.344 \mathrm{~mm}^{-1}$ & \\
\hline $\mathrm{F}(000)$ & 1600 & \\
\hline
\end{tabular}

Table C15. Data collection and structure refinement for $\left(\mathrm{C}_{17} \mathrm{H}_{17} \mathrm{~N}_{3}\right)_{2} \mathrm{Zr} \cdot 2 \mathrm{THF}$.

Theta range for data used in the structural refinement

2.75 to $27.50^{\circ}$

Index ranges

$-23 \leq \mathrm{h} \leq 23,-11 \leq \mathrm{k} \leq 11,-29 \leq 1 \leq 27$

Reflections

70900

Independent reflections

$8432[\mathrm{R}($ int $)=0.0651]$

Coverage

$99.9 \%$

Absorption correction

multi-scan

Max. and min. trans.

0.972 and 0.822

Refinement method

Full-matrix least-squares on $\mathrm{F}^{2}$

Refinement program

SHELXL-2014 (Sheldrick, 2014)

Data / restraints / parameters 8432 / 0 / 468

Goodness-of-fit on $\mathrm{F}^{2}$

1.045

Final $\mathrm{R}$ indices 6893 data; $\mathrm{I}>2 \sigma(\mathrm{I}) \quad \mathrm{R} 1=0.0346, \mathrm{wR} 2=0.0742$

all data

$\mathrm{R} 1=0.0495, \mathrm{wR} 2=0.0810$

Largest diff. peak and hole 0.530 and $-0.440 \mathrm{e}^{-/} \AA^{3}$ 
Table C16. Atomic coordinates and equivalent isotropic atomic displacement parameters $\left(\AA^{2}\right)$ for $\left(\mathrm{C}_{17} \mathrm{H}_{17} \mathrm{~N}_{3}\right)_{2} \mathrm{Zr} \cdot 2 \mathrm{THF}$. U(eq) is defined as one third of the trace of the orthogonalized $\mathrm{U}_{\mathrm{ij}}$ tensor.

\begin{tabular}{|c|c|c|c|c|}
\hline & $\mathrm{x} / \mathrm{a}$ & $y / b$ & $\mathrm{z} / \mathrm{c}$ & $\mathrm{U}(\mathrm{eq})$ \\
\hline $\mathrm{Zr} 1$ & $0.50719(2)$ & $0.08844(2)$ & $0.78167(2)$ & $0.00951(6)$ \\
\hline N1 & $0.54389(9)$ & $0.31235(17)$ & $0.79054(7)$ & $0.0128(3)$ \\
\hline $\mathrm{N} 2$ & $0.50600(9)$ & $0.18872(17)$ & $0.68854(7)$ & $0.0119(3)$ \\
\hline N3 & $0.45781(9)$ & $0.93462(17)$ & $0.71183(7)$ & $0.0124(3)$ \\
\hline N4 & $0.62009(9)$ & $0.99541(17)$ & $0.81061(7)$ & $0.0125(3)$ \\
\hline N5 & $0.51497(9)$ & $0.96365(17)$ & $0.87080(7)$ & $0.0121(3)$ \\
\hline N6 & $0.40473(9)$ & $0.11986(17)$ & $0.81497(7)$ & $0.0133(3)$ \\
\hline $\mathrm{C} 1$ & $0.57037(11)$ & $0.3947(2)$ & $0.84104(8)$ & $0.0143(4)$ \\
\hline $\mathrm{C} 2$ & $0.59686(11)$ & $0.5266(2)$ & $0.82452(9)$ & $0.0163(4)$ \\
\hline $\mathrm{C} 3$ & $0.58670(11)$ & $0.5303(2)$ & $0.76143(9)$ & $0.0139(4)$ \\
\hline $\mathrm{C} 4$ & $0.55364(10)$ & $0.3974(2)$ & $0.74186(8)$ & $0.0124(4)$ \\
\hline $\mathrm{C} 5$ & $0.53022(10)$ & $0.3290(2)$ & $0.68444(8)$ & $0.0126(4)$ \\
\hline C6 & $0.53100(11)$ & $0.3911(2)$ & $0.62867(9)$ & $0.0160(4)$ \\
\hline $\mathrm{C} 7$ & $0.50726(12)$ & $0.3068(2)$ & $0.57812(9)$ & $0.0187(4)$ \\
\hline $\mathrm{C} 8$ & $0.48316(12)$ & $0.1640(2)$ & $0.58215(9)$ & $0.0182(4)$ \\
\hline $\mathrm{C} 9$ & $0.48229(10)$ & $0.1055(2)$ & $0.63856(8)$ & $0.0131(4)$ \\
\hline $\mathrm{C} 10$ & $0.45786(10)$ & $0.9619(2)$ & $0.65161(8)$ & $0.0135(4)$ \\
\hline $\mathrm{C} 11$ & $0.43022(11)$ & $0.8408(2)$ & $0.61711(9)$ & $0.0152(4)$ \\
\hline $\mathrm{C} 12$ & $0.41241(11)$ & $0.7366(2)$ & $0.65755(9)$ & $0.0158(4)$ \\
\hline $\mathrm{C} 13$ & $0.42873(11)$ & $0.7957(2)$ & $0.71413(9)$ & $0.0145(4)$ \\
\hline $\mathrm{C} 14$ & $0.60758(11)$ & $0.6546(2)$ & $0.72513(9)$ & $0.0161(4)$ \\
\hline $\mathrm{C} 15$ & $0.41953(13)$ & $0.8214(2)$ & $0.55074(9)$ & $0.0229(5)$ \\
\hline $\mathrm{C} 16$ & $0.56787(12)$ & $0.3365(2)$ & $0.90171(9)$ & $0.0193(4)$ \\
\hline $\mathrm{C} 17$ & $0.41874(12)$ & $0.7284(2)$ & $0.77141(9)$ & $0.0196(4)$ \\
\hline $\mathrm{C} 18$ & $0.68406(11)$ & $0.0003(2)$ & $0.78626(9)$ & $0.0141(4)$ \\
\hline C19 & $0.74080(11)$ & $0.9186(2)$ & $0.82101(9)$ & $0.0155(4)$ \\
\hline $\mathrm{C} 20$ & $0.71299(11)$ & $0.8584(2)$ & $0.86911(9)$ & $0.0148(4)$ \\
\hline $\mathrm{C} 21$ & $0.63850(11)$ & $0.9075(2)$ & $0.86153(8)$ & $0.0128(4)$ \\
\hline $\mathrm{C} 22$ & $0.57926(11)$ & $0.8878(2)$ & $0.89437(8)$ & $0.0131(4)$ \\
\hline $\mathrm{C} 23$ & $0.58212(12)$ & $0.7990(2)$ & $0.94444(9)$ & $0.0173(4)$ \\
\hline $\mathrm{C} 24$ & $0.51868(13)$ & $0.7904(2)$ & $0.96961(9)$ & $0.0208(5)$ \\
\hline $\mathrm{C} 25$ & $0.45392(12)$ & $0.8698(2)$ & $0.94640(9)$ & $0.0185(4)$ \\
\hline $\mathrm{C} 26$ & $0.45289(11)$ & $0.9574(2)$ & $0.89635(8)$ & $0.0140(4)$ \\
\hline
\end{tabular}




$\begin{array}{ccccc} & \mathrm{x} / \mathrm{a} & \mathrm{y} / \mathrm{b} & \mathrm{z} / \mathrm{c} & \mathrm{U}(\mathrm{eq}) \\ \mathrm{C} 27 & 0.39093(11) & 0.0454(2) & 0.86507(8) & 0.0140(4) \\ \mathrm{C} 28 & 0.31764(11) & 0.0726(2) & 0.87204(9) & 0.0168(4) \\ \mathrm{C} 29 & 0.28523(11) & 0.1667(2) & 0.82426(9) & 0.0180(4) \\ \mathrm{C} 30 & 0.33921(11) & 0.1942(2) & 0.79055(9) & 0.0151(4) \\ \mathrm{C} 31 & 0.75694(12) & 0.7624(2) & 0.91723(9) & 0.0200(4) \\ \mathrm{C} 32 & 0.27868(12) & 0.0156(3) & 0.91965(10) & 0.0239(5) \\ \mathrm{C} 33 & 0.68631(11) & 0.0845(2) & 0.73082(9) & 0.0193(4) \\ \mathrm{C} 34 & 0.33460(12) & 0.2895(2) & 0.73695(9) & 0.0197(4) \\ \mathrm{O} 1 & 0.60041(9) & 0.71036(19) & 0.55656(7) & 0.0334(4) \\ \mathrm{C} 35 & 0.63693(14) & 0.8368(3) & 0.58654(11) & 0.0301(5) \\ \text { C36 } & 0.72012(14) & 0.7984(3) & 0.60483(11) & 0.0329(6) \\ \text { C37 } & 0.73143(15) & 0.6994(3) & 0.55398(12) & 0.0367(6) \\ \text { C38 } & 0.65556(15) & 0.6211(3) & 0.53738(13) & 0.0389(6) \\ \text { O2 } & 0.63765(14) & 0.5094(2) & 0.04022(9) & 0.0548(6) \\ \text { C39 } & 0.7161(2) & 0.5422(3) & 0.04778(12) & 0.0499(9) \\ \text { C40 } & 0.75639(14) & 0.4567(3) & 0.10327(11) & 0.0289(5) \\ \text { C41 } & 0.69144(13) & 0.4211(3) & 0.13441(10) & 0.0264(5) \\ \text { C42 } & 0.62413(15) & 0.5010(3) & 0.09874(13) & 0.0403(7)\end{array}$




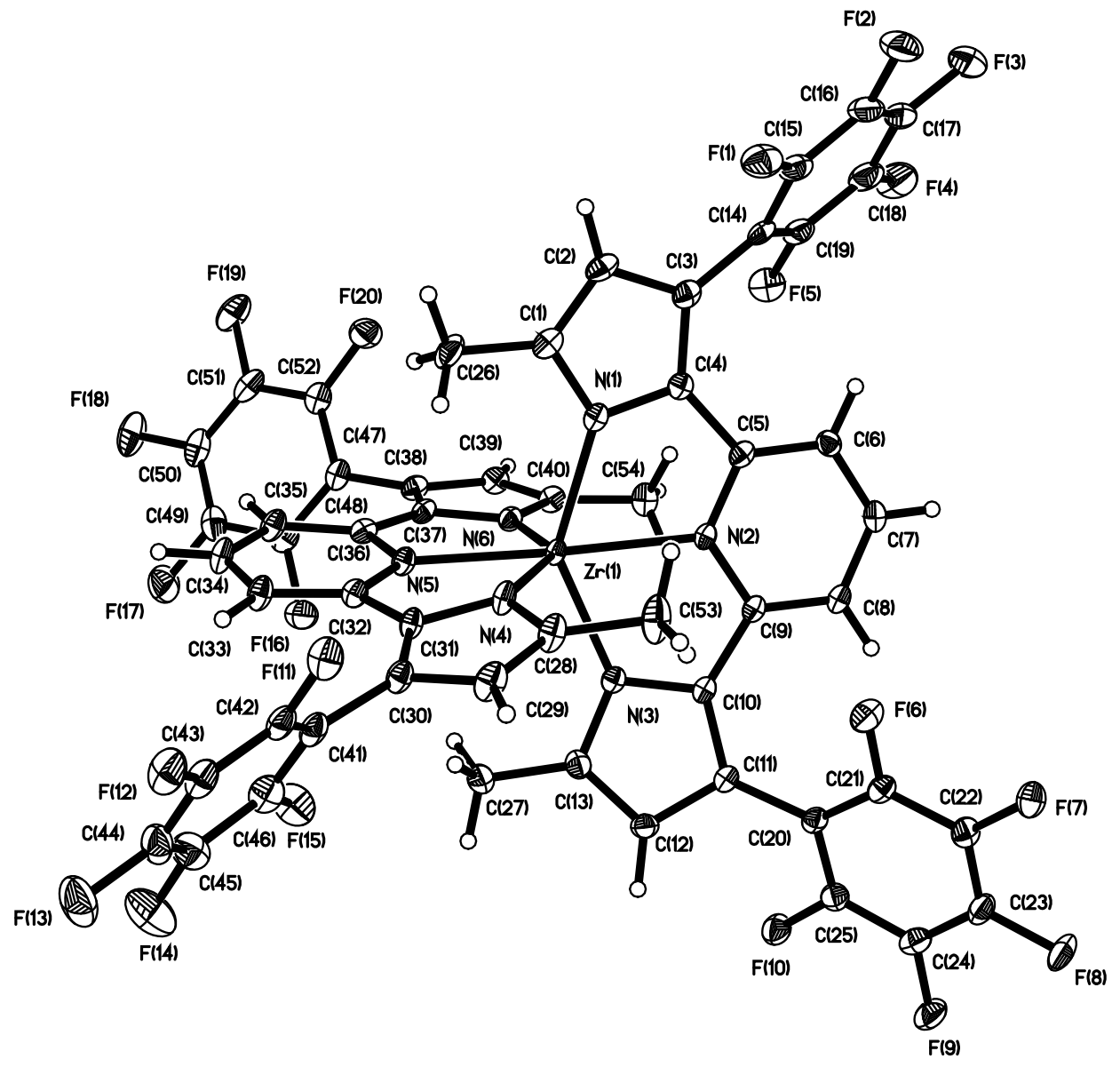

Figure C6. Perspective view of the structure of $\left(\mathrm{C}_{27} \mathrm{H}_{11} \mathrm{~F}_{10} \mathrm{~N}_{3}\right)_{2} \mathrm{Zr}$ (molecule 1) with the atom labeling scheme for the independent non-hydrogen atoms. The thermal ellipsoids are scaled to enclose $50 \%$ probability. 


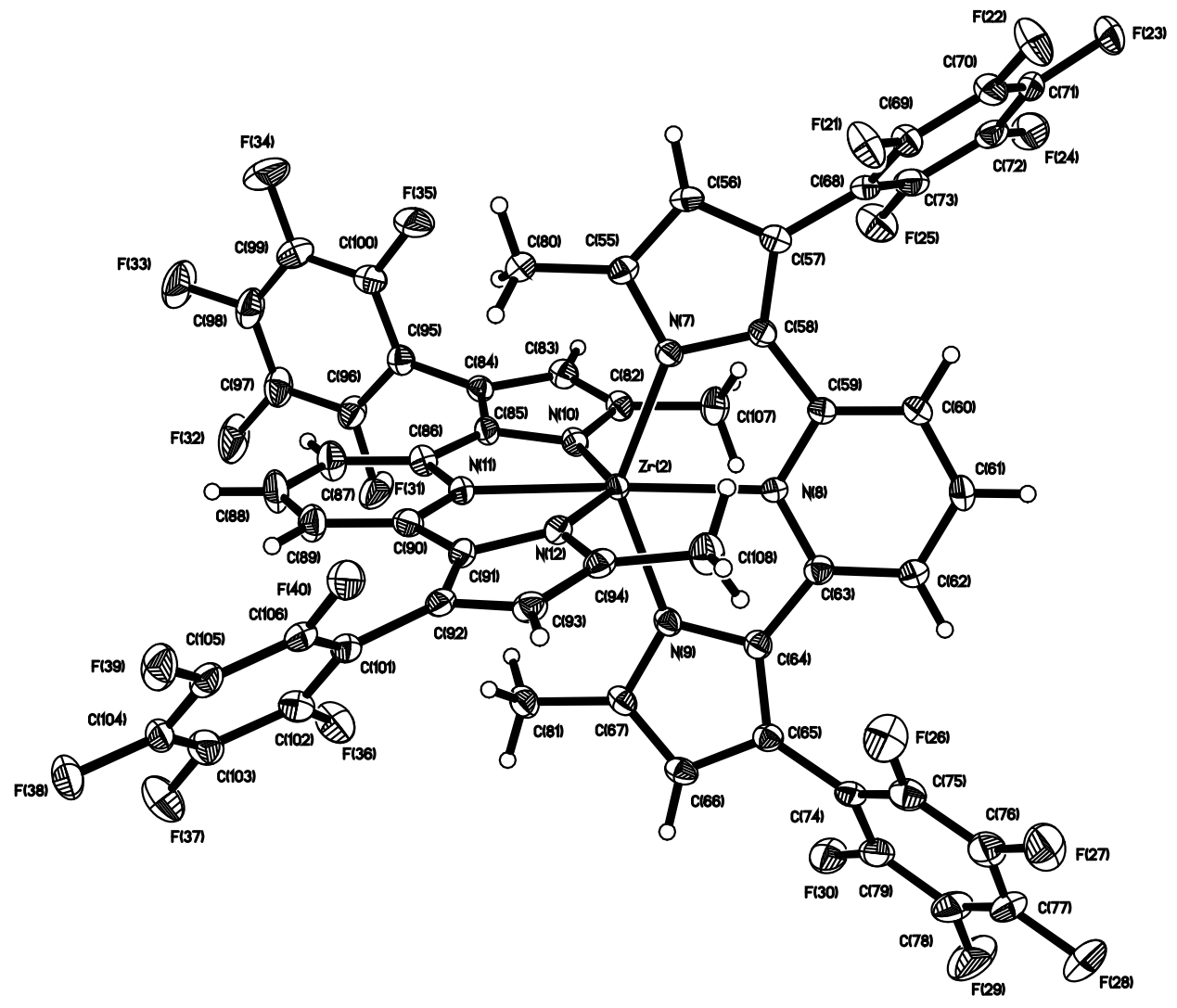

Figure C7. Perspective view of the structure of $\left(\mathrm{C}_{27} \mathrm{H}_{11} \mathrm{~F}_{10} \mathrm{~N}_{3}\right)_{2} \mathrm{Zr}$ (molecule 2) with the atom labeling scheme for the independent non-hydrogen atoms. The thermal ellipsoids are scaled to enclose $50 \%$ probability. 
Table C17. Crystal data for $\left(\mathrm{C}_{27} \mathrm{H}_{11} \mathrm{~F}_{10} \mathrm{~N}_{3}\right)_{2} \mathrm{Zr} \cdot \mathrm{OEt}_{2}$.

$\begin{array}{lll}\text { Ident. code } & \mathrm{cm} 97 \mathrm{cms} \\ \text { Chem. formula } & \mathrm{C}_{58} \mathrm{H}_{32} \mathrm{~F}_{20} \mathrm{~N}_{6} \mathrm{OZr} & \\ \text { Formula weight } & 1300.11 \mathrm{~g} / \mathrm{mol} & \\ \text { Temperature } & 100(2) \mathrm{K} \\ \text { Wavelength } & 0.71073 \AA \\ \text { Crystal size } & 0.182 \times 0.259 \times 0.262 \mathrm{~mm} \\ \text { Crystal system } & \text { triclinic } \\ \text { Space group } & \mathrm{P}(-1)(\mathrm{No} .2) & \\ \text { Unit cell } & \mathrm{a}=15.4311(7) \AA & \quad \alpha=89.2542(14)^{\circ} \\ & \mathrm{b}=15.7762(8) \AA & \beta=87.0739(14)^{\circ} \\ & \mathrm{c}=23.3019(11) \AA & \gamma=64.1745(13)^{\circ}\end{array}$

Volume, $\AA^{3} \quad 5099.2(4)$

$\mathrm{Z} \quad 4$

Density (calc) $\quad 1.694 \mathrm{~g} / \mathrm{cm}^{3}$

Abs. coefficient $0.340 \mathrm{~mm}^{-1}$

$\mathrm{F}(000) \quad 2600$

Table C18. Data collection and structure refinement for $\left(\mathrm{C}_{27} \mathrm{H}_{11} \mathrm{~F}_{10} \mathrm{~N}_{3}\right)_{2} \mathrm{Zr} \cdot \mathrm{OEt}_{2}$.

$\begin{array}{ll}\text { Theta range } & 2.99 \text { to } 27.50^{\circ} \\ \text { Index ranges } & -20 \leq \mathrm{h} \leq 20,-20 \leq \mathrm{k} \leq 20,-30 \leq 1 \leq 30 \\ \text { Reflections } & 101562 \\ \text { Independent refls } & 23399 \text { [R(int) }=0.0521] \\ \text { Coverage } & 99.9 \% \\ \text { Absorption correction } & \text { multi-scan } \\ \text { Max. and min. trans. } & 0.941 \text { and } 0.916 \\ \text { Refinement method } & \text { Full-matrix least-squares on } \mathrm{F}^{2} \\ \text { Refinement program } & \text { SHELXL-2014/7 (Sheldrick, 2014) } \\ \text { Data / restrs / parms } & 23399 / 0 / 1514 \\ \text { Goodness-of-fit on } \mathrm{F}^{2} & 1.018 \quad \\ & 17039 \quad \text { data; } \mathrm{R} 1=0.0460, \mathrm{wR} 2=0.0968 \\ \text { Final R indices } & \mathrm{I}>2 \sigma(\mathrm{I}) \quad \mathrm{R} 1=0.0760, \mathrm{wR} 2=0.1091\end{array}$

Largest diff. peak and 1.329 and $-0.716 \mathrm{e}^{-} / \AA^{3}$ hole 
Table C19. Atomic coordinates and equivalent isotropic atomic displacement parameters $\left(\AA^{2}\right)$ for $\left(\mathrm{C}_{27} \mathrm{H}_{11} \mathrm{~F}_{10} \mathrm{~N}_{3}\right)_{2} \mathrm{Zr} \cdot \mathrm{OEt}_{2}$. U(eq) is defined as one third of the trace of the orthogonalized $\mathrm{U}_{\mathrm{ij}}$ tensor.

$\begin{array}{lcccc} & & & & \\ \text { Zr1 } & \mathrm{x} / \mathrm{a} & \mathrm{y} / \mathrm{b} & \mathrm{z} / \mathrm{c} & \mathrm{U}(\mathrm{eq}) \\ \text { Zr2 } & 0.71138(2) & 0.71280(2) & 0.50600(2) & 0.01209(6) \\ \text { F1 } & 0.13179(2) & 0.34556(2) & 0.13537(2) & 0.01452(6) \\ \text { F2 } & 0.6585(12) & 0.94641(11) & 0.25217(7) & 0.0291(4) \\ \text { F3 } & 0.84170(15) & 0.97294(13) & 0.15117(7) & 0.0407(5) \\ \text { F4 } & 0.94651(13) & 0.85281(16) & 0.11472(7) & 0.0463(5) \\ \text { F5 } & 0.87142(12) & 0.70238(14) & 0.17998(8) & 0.0390(5) \\ \text { F6 } & 0.86853(11) & 0.67303(11) & 0.28002(7) & 0.0270(4) \\ \text { F7 } & 0.96506(12) & 0.05320(10) & 0.53872(7) & 0.0229(4) \\ \text { F8 } & 0.10492(12) & 0.00085(11) & 0.62969(7) & 0.0245(4) \\ \text { F9 } & 0.14624(12) & 0.84344(12) & 0.69335(7) & 0.0284(4) \\ \text { F10 } & 0.05375(11) & 0.73599(11) & 0.67714(7) & 0.0289(4) \\ \text { F11 } & 0.28563(11) & 0.00968(11) & 0.64064(7) & 0.0251(4) \\ \text { F12 } & 0.16792(11) & 0.03031(12) & 0.73395(7) & 0.0302(4) \\ \text { F13 } & 0.22556(14) & 0.90451(13) & 0.82017(8) & 0.0409(5) \\ \text { F14 } & 0.40456(15) & 0.75752(14) & 0.81308(8) & 0.0466(5) \\ \text { F15 } & 0.52179(12) & 0.73438(12) & 0.71972(7) & 0.0326(4) \\ \text { F16 } & 0.78493(13) & 0.32675(12) & 0.58823(7) & 0.0319(4) \\ \text { F17 } & 0.73906(13) & 0.18032(13) & 0.59939(8) & 0.0376(5) \\ \text { F18 } & 0.70619(12) & 0.10171(11) & 0.50509(8) & 0.0350(4) \\ \text { F19 } & 0.71978(12) & 0.16976(11) & 0.40006(8) & 0.0323(4) \\ \text { F20 } & 0.75290(12) & 0.32253(11) & 0.38866(7) & 0.0277(4) \\ \text { F21 } & 0.30652(13) & 0.51957(12) & 0.33225(7) & 0.0317(4) \\ \text { F22 } & 0.39508(13) & 0.63096(13) & 0.35022(8) & 0.0367(4) \\ \text { F23 } & 0.37531(13) & 0.77119(12) & 0.27639(8) & 0.0347(4) \\ \text { F24 } & 0.27374(13) & 0.79418(12) & 0.18084(8) & 0.0338(4) \\ \text { F25 } & 0.18303(13) & 0.68560(12) & 0.16298(7) & 0.0336(4) \\ \text { F26 } & 0.51963(13) & 0.12090(13) & 0.06782(7) & 0.0368(4) \\ \text { F27 } & 0.69827(13) & 0.05533(13) & 0.01958(9) & 0.0427(5) \\ \text { F28 } & 0.72724(14) & 0.04599(15) & 0.90356(10) & 0.0538(6) \\ \text { F29 } & 0.57200(15) & 0.10821(17) & 0.83582(8) & 0.0568(6) \\ \text { F30 } & 0.39365(13) & 0.17598(13) & 0.88363(7) & 0.0323(4) \\ \text { F31 } & 0.73165(13) & 0.49513(16) & 0.01465(8) & 0.0452(5)\end{array}$




\begin{tabular}{|c|c|c|c|c|}
\hline & $\mathrm{x} / \mathrm{a}$ & $\mathrm{y} / \mathrm{b}$ & $\mathrm{z} / \mathrm{c}$ & $\mathrm{U}(\mathrm{eq})$ \\
\hline F32 & $0.54294(14)$ & $0.54030(17)$ & $0.03448(8)$ & $0.0511(6)$ \\
\hline F33 & $0.44731(13)$ & $0.63965(15)$ & $0.12957(10)$ & $0.0505(6)$ \\
\hline F34 & $0.54174(16)$ & $0.69254(17)$ & $0.20607(10)$ & $0.0655(7)$ \\
\hline F35 & $0.72989(14)$ & $0.64722(15)$ & $0.18708(9)$ & $0.0491(6)$ \\
\hline F36 & $0.06305(13)$ & $0.03273(12)$ & $0.13092(7)$ & $0.0320(4)$ \\
\hline F37 & $0.99149(14)$ & $0.90740(13)$ & $0.14996(8)$ & $0.0403(5)$ \\
\hline F38 & $0.01845(12)$ & $0.81425(12)$ & $0.25177(8)$ & $0.0348(4)$ \\
\hline F39 & $0.11665(12)$ & $0.84981(12)$ & $0.33323(7)$ & $0.0305(4)$ \\
\hline F40 & $0.18501(12)$ & $0.97887(11)$ & $0.31632(7)$ & $0.0251(4)$ \\
\hline N1 & $0.66514(15)$ & $0.76100(15)$ & $0.42028(9)$ & $0.0156(5)$ \\
\hline $\mathrm{N} 2$ & $0.81445(15)$ & $0.76389(14)$ & $0.46055(9)$ & $0.0130(4)$ \\
\hline N3 & $0.80988(15)$ & $0.71814(14)$ & $0.56714(9)$ & $0.0144(4)$ \\
\hline N4 & $0.58869(15)$ & $0.81602(15)$ & $0.55387(10)$ & $0.0168(5)$ \\
\hline N5 & $0.61962(15)$ & $0.64361(14)$ & $0.54658(9)$ & $0.0146(4)$ \\
\hline N6 & $0.77981(15)$ & $0.56226(15)$ & $0.48594(9)$ & $0.0146(4)$ \\
\hline N7 & $0.14027(15)$ & $0.43826(15)$ & $0.20030(9)$ & $0.0168(5)$ \\
\hline N8 & $0.26736(15)$ & $0.37090(15)$ & $0.11782(9)$ & $0.0165(5)$ \\
\hline N9 & $0.21432(16)$ & $0.26602(15)$ & $0.05982(9)$ & $0.0183(5)$ \\
\hline N10 & $0.00390(16)$ & $0.45614(16)$ & $0.09951(9)$ & $0.0187(5)$ \\
\hline N11 & $0.00128(16)$ & $0.31242(15)$ & $0.15189(9)$ & $0.0175(5)$ \\
\hline N12 & $0.17325(16)$ & $0.21819(15)$ & $0.18607(9)$ & $0.0177(5)$ \\
\hline $\mathrm{C} 1$ & $0.58533(19)$ & $0.76983(18)$ & $0.39154(12)$ & $0.0190(6)$ \\
\hline $\mathrm{C} 2$ & $0.59513(19)$ & $0.79147(18)$ & $0.33522(12)$ & $0.0197(6)$ \\
\hline $\mathrm{C} 3$ & $0.68549(19)$ & $0.79464(17)$ & $0.32684(11)$ & $0.0170(5)$ \\
\hline $\mathrm{C} 4$ & $0.72644(18)$ & $0.77625(17)$ & $0.38001(11)$ & $0.0145(5)$ \\
\hline $\mathrm{C} 5$ & $0.81073(18)$ & $0.77857(17)$ & $0.40315(11)$ & $0.0142(5)$ \\
\hline C6 & $0.88268(18)$ & $0.79466(17)$ & $0.37377(11)$ & $0.0155(5)$ \\
\hline $\mathrm{C} 7$ & $0.95772(19)$ & $0.79423(18)$ & $0.40419(11)$ & $0.0179(6)$ \\
\hline $\mathrm{C} 8$ & $0.95897(18)$ & $0.78293(17)$ & $0.46290(11)$ & $0.0156(5)$ \\
\hline C9 & $0.88471(17)$ & $0.76991(17)$ & $0.49106(11)$ & $0.0128(5)$ \\
\hline $\mathrm{C} 10$ & $0.87087(18)$ & $0.75906(17)$ & $0.55197(11)$ & $0.0136(5)$ \\
\hline $\mathrm{C} 11$ & $0.90292(17)$ & $0.78276(17)$ & $0.60102(11)$ & $0.0136(5)$ \\
\hline $\mathrm{C} 12$ & $0.86194(18)$ & $0.75269(18)$ & $0.64836(11)$ & $0.0173(5)$ \\
\hline C13 & $0.80598(19)$ & $0.71417(18)$ & $0.62671(11)$ & $0.0175(6)$ \\
\hline $\mathrm{C} 14$ & $0.72622(19)$ & $0.81040(19)$ & $0.27119(11)$ & $0.0180(6)$ \\
\hline $\mathrm{C} 15$ & $0.6737(2)$ & $0.8843(2)$ & $0.23554(12)$ & $0.0224(6)$ \\
\hline $\mathrm{C} 16$ & $0.7115(2)$ & $0.8990(2)$ & $0.18343(12)$ & $0.0292(7)$ \\
\hline
\end{tabular}




\begin{tabular}{|c|c|c|c|c|}
\hline & $\mathrm{x} / \mathrm{a}$ & $\mathrm{y} / \mathrm{b}$ & $\mathrm{z} / \mathrm{c}$ & $\mathrm{U}(\mathrm{eq})$ \\
\hline $\mathrm{C} 17$ & $0.8039(2)$ & $0.8382(2)$ & $0.16496(12)$ & $0.0319(8)$ \\
\hline C18 & $0.8576(2)$ & $0.7628(2)$ & $0.19805(12)$ & $0.0284(7)$ \\
\hline C19 & $0.8179(2)$ & $0.7497(2)$ & $0.24992(12)$ & $0.0221(6)$ \\
\hline $\mathrm{C} 20$ & $0.95944(18)$ & $0.83704(18)$ & $0.60575(11)$ & $0.0156(5)$ \\
\hline $\mathrm{C} 21$ & $0.93975(18)$ & $0.91904(18)$ & $0.57521(11)$ & $0.0164(5)$ \\
\hline $\mathrm{C} 22$ & $0.98869(19)$ & $0.97351(18)$ & $0.58244(11)$ & $0.0183(6)$ \\
\hline $\mathrm{C} 23$ & $0.0584(2)$ & $0.94756(19)$ & $0.62188(12)$ & $0.0209(6)$ \\
\hline $\mathrm{C} 24$ & $0.0790(2)$ & $0.8680(2)$ & $0.65394(12)$ & $0.0208(6)$ \\
\hline $\mathrm{C} 25$ & $0.03024(19)$ & $0.81374(18)$ & $0.64548(11)$ & $0.0182(6)$ \\
\hline $\mathrm{C} 26$ & $0.5062(2)$ & $0.7531(2)$ & $0.42139(13)$ & $0.0254(6)$ \\
\hline $\mathrm{C} 27$ & $0.7463(2)$ & $0.6739(2)$ & $0.65823(12)$ & $0.0249(6)$ \\
\hline $\mathrm{C} 28$ & $0.56854(19)$ & $0.90783(18)$ & $0.56795(12)$ & $0.0204(6)$ \\
\hline $\mathrm{C} 29$ & $0.4991(2)$ & $0.93944(19)$ & $0.61160(13)$ & $0.0228(6)$ \\
\hline $\mathrm{C} 30$ & $0.47426(18)$ & $0.86531(18)$ & $0.62670(12)$ & $0.0178(6)$ \\
\hline C31 & $0.52921(18)$ & $0.79036(18)$ & $0.58995(11)$ & $0.0160(5)$ \\
\hline $\mathrm{C} 32$ & $0.54077(18)$ & $0.69583(18)$ & $0.58126(11)$ & $0.0157(5)$ \\
\hline $\mathrm{C} 33$ & $0.48071(19)$ & $0.65632(18)$ & $0.60272(12)$ & $0.0193(6)$ \\
\hline C34 & $0.50000(19)$ & $0.56606(19)$ & $0.58556(12)$ & $0.0206(6)$ \\
\hline $\mathrm{C} 35$ & $0.58010(19)$ & $0.51326(18)$ & $0.55080(12)$ & $0.0189(6)$ \\
\hline $\mathrm{C} 36$ & $0.64214(18)$ & $0.55236(17)$ & $0.53269(11)$ & $0.0148(5)$ \\
\hline C37 & $0.73285(18)$ & $0.50674(17)$ & $0.50078(11)$ & $0.0150(5)$ \\
\hline C38 & $0.78883(19)$ & $0.41483(18)$ & $0.48137(11)$ & $0.0163(5)$ \\
\hline C39 & $0.87230(19)$ & $0.41456(18)$ & $0.45349(11)$ & $0.0170(5)$ \\
\hline $\mathrm{C} 40$ & $0.86547(18)$ & $0.50369(18)$ & $0.45691(11)$ & $0.0161(5)$ \\
\hline C41 & $0.40756(19)$ & $0.87057(19)$ & $0.67620(12)$ & $0.0197(6)$ \\
\hline $\mathrm{C} 42$ & $0.31686(19)$ & $0.94543(19)$ & $0.68225(12)$ & $0.0194(6)$ \\
\hline $\mathrm{C} 43$ & $0.2557(2)$ & $0.9567(2)$ & $0.72953(13)$ & $0.0232(6)$ \\
\hline $\mathrm{C} 44$ & $0.2850(2)$ & $0.8934(2)$ & $0.77342(13)$ & $0.0283(7)$ \\
\hline $\mathrm{C} 45$ & $0.3746(2)$ & $0.8185(2)$ & $0.76980(13)$ & $0.0288(7)$ \\
\hline $\mathrm{C} 46$ & $0.4346(2)$ & $0.8073(2)$ & $0.72124(13)$ & $0.0250(6)$ \\
\hline $\mathrm{C} 47$ & $0.76822(18)$ & $0.33170(17)$ & $0.48863(12)$ & $0.0169(5)$ \\
\hline $\mathrm{C} 48$ & $0.76599(19)$ & $0.29149(19)$ & $0.54106(12)$ & $0.0211(6)$ \\
\hline C49 & $0.7441(2)$ & $0.2148(2)$ & $0.54744(13)$ & $0.0244(6)$ \\
\hline $\mathrm{C} 50$ & $0.7280(2)$ & $0.17494(19)$ & $0.49996(14)$ & $0.0242(6)$ \\
\hline C51 & $0.73360(19)$ & $0.21019(19)$ & $0.44696(13)$ & $0.0227(6)$ \\
\hline $\mathrm{C} 52$ & $0.75279(19)$ & $0.28803(18)$ & $0.44140(12)$ & $0.0194(6)$ \\
\hline C53 & $0.6210(2)$ & $0.95713(19)$ & $0.53790(14)$ & $0.0278(7)$ \\
\hline
\end{tabular}




\begin{tabular}{|c|c|c|c|c|}
\hline & $\mathrm{x} / \mathrm{a}$ & $\mathrm{y} / \mathrm{b}$ & $\mathrm{z} / \mathrm{c}$ & $\mathrm{U}(\mathrm{eq})$ \\
\hline $\mathrm{C} 54$ & $0.93665(19)$ & $0.53769(18)$ & $0.43327(12)$ & $0.0200(6)$ \\
\hline C55 & $0.07806(19)$ & $0.48333(19)$ & $0.24655(11)$ & $0.0182(6)$ \\
\hline $\mathrm{C} 56$ & $0.1062(2)$ & $0.54598(19)$ & $0.27085(12)$ & $0.0215(6)$ \\
\hline $\mathrm{C} 57$ & $0.18818(19)$ & $0.54106(19)$ & $0.23843(11)$ & $0.0187(6)$ \\
\hline C58 & $0.20756(19)$ & $0.47460(18)$ & $0.19573(11)$ & $0.0173(5)$ \\
\hline C59 & $0.28123(19)$ & $0.43459(19)$ & $0.15045(11)$ & $0.0181(6)$ \\
\hline C60 & $0.3603(2)$ & $0.4530(2)$ & $0.13942(12)$ & $0.0247(6)$ \\
\hline C61 & $0.4258(2)$ & $0.4043(2)$ & $0.09529(13)$ & $0.0277(7)$ \\
\hline C62 & $0.4135(2)$ & $0.3378(2)$ & $0.06296(12)$ & $0.0232(6)$ \\
\hline C63 & $0.33234(19)$ & $0.32269(19)$ & $0.07488(11)$ & $0.0187(6)$ \\
\hline C64 & $0.30556(19)$ & $0.25876(18)$ & $0.04519(11)$ & $0.0180(6)$ \\
\hline C65 & $0.3500(2)$ & $0.18959(19)$ & $0.00324(11)$ & $0.0187(6)$ \\
\hline C66 & $0.2824(2)$ & $0.15490(19)$ & $0.99106(11)$ & $0.0202(6)$ \\
\hline C67 & $0.2016(2)$ & $0.20099(19)$ & $0.02613(11)$ & $0.0185(6)$ \\
\hline C68 & $0.24033(19)$ & $0.59953(19)$ & $0.24785(12)$ & $0.0195(6)$ \\
\hline C69 & $0.2953(2)$ & $0.58836(19)$ & $0.29474(12)$ & $0.0223(6)$ \\
\hline $\mathrm{C} 70$ & $0.3415(2)$ & $0.6446(2)$ & $0.30421(12)$ & $0.0247(6)$ \\
\hline C71 & $0.3330(2)$ & $0.7144(2)$ & $0.26648(13)$ & $0.0244(6)$ \\
\hline $\mathrm{C} 72$ & $0.2814(2)$ & $0.72655(19)$ & $0.21836(13)$ & $0.0238(6)$ \\
\hline $\mathrm{C} 73$ & $0.2352(2)$ & $0.6699(2)$ & $0.20963(12)$ & $0.0238(6)$ \\
\hline $\mathrm{C} 74$ & $0.4492(2)$ & $0.15296(18)$ & $0.97749(12)$ & $0.0210(6)$ \\
\hline $\mathrm{C} 75$ & $0.5307(2)$ & $0.1194(2)$ & $0.01020(13)$ & $0.0263(7)$ \\
\hline $\mathrm{C} 76$ & $0.6227(2)$ & $0.0851(2)$ & $0.98595(15)$ & $0.0305(7)$ \\
\hline $\mathrm{C} 77$ & $0.6378(2)$ & $0.0799(2)$ & $0.92738(15)$ & $0.0349(8)$ \\
\hline $\mathrm{C} 78$ & $0.5596(2)$ & $0.1109(2)$ & $0.89344(14)$ & $0.0348(8)$ \\
\hline C79 & $0.4677(2)$ & $0.1462(2)$ & $0.91851(13)$ & $0.0256(6)$ \\
\hline $\mathrm{C} 80$ & $0.9952(2)$ & $0.4617(2)$ & $0.26269(12)$ & $0.0239(6)$ \\
\hline $\mathrm{C} 81$ & $0.1107(2)$ & $0.1883(2)$ & $0.03056(12)$ & $0.0252(6)$ \\
\hline $\mathrm{C} 82$ & $0.9870(2)$ & $0.54258(19)$ & $0.07621(11)$ & $0.0194(6)$ \\
\hline $\mathrm{C} 83$ & $0.8897(2)$ & $0.5954(2)$ & $0.07146(12)$ & $0.0210(6)$ \\
\hline $\mathrm{C} 84$ & $0.84246(19)$ & $0.54115(19)$ & $0.09213(11)$ & $0.0181(6)$ \\
\hline $\mathrm{C} 85$ & $0.91372(19)$ & $0.45659(19)$ & $0.10882(11)$ & $0.0193(6)$ \\
\hline C86 & $0.9126(2)$ & $0.37451(19)$ & $0.13562(12)$ & $0.0199(6)$ \\
\hline $\mathrm{C} 87$ & $0.8330(2)$ & $0.3563(2)$ & $0.14624(14)$ & $0.0283(7)$ \\
\hline C88 & $0.8448(2)$ & $0.2745(2)$ & $0.17387(14)$ & $0.0314(7)$ \\
\hline C89 & $0.9348(2)$ & $0.2114(2)$ & $0.19037(13)$ & $0.0253(6)$ \\
\hline $\mathrm{C} 90$ & $0.0130(2)$ & $0.23149(19)$ & $0.17863(11)$ & $0.0195(6)$ \\
\hline
\end{tabular}




$\begin{array}{ccccc} & \mathrm{x} / \mathrm{a} & \mathrm{y} / \mathrm{b} & \mathrm{z} / \mathrm{c} & \mathrm{U}(\mathrm{eq}) \\ \mathrm{C} 91 & 0.11138(19) & 0.17523(19) & 0.19331(11) & 0.0180(6) \\ \text { C92 } & 0.16055(19) & 0.08525(19) & 0.21453(11) & 0.0190(6) \\ \text { C93 } & 0.2556(2) & 0.07363(19) & 0.22252(12) & 0.0207(6) \\ \text { C94 } & 0.2618(2) & 0.15398(19) & 0.20425(11) & 0.0196(6) \\ \text { C95 } & 0.7371(2) & 0.57129(19) & 0.09965(12) & 0.0202(6) \\ \text { C96 } & 0.6863(2) & 0.5457(2) & 0.06174(12) & 0.0261(7) \\ \text { C97 } & 0.5895(2) & 0.5686(2) & 0.07121(13) & 0.0312(7) \\ \text { C98 } & 0.5410(2) & 0.6184(2) & 0.11965(15) & 0.0333(7) \\ \text { C99 } & 0.5884(2) & 0.6454(2) & 0.15799(15) & 0.0379(8) \\ \text { C100 } & 0.6853(2) & 0.6215(2) & 0.14765(14) & 0.0306(7) \\ \text { C101 } & 0.12419(19) & 0.01338(18) & 0.22373(12) & 0.0195(6) \\ \text { C102 } & 0.0760(2) & 0.99064(19) & 0.18189(13) & 0.0244(6) \\ \text { C103 } & 0.0387(2) & 0.9255(2) & 0.19098(13) & 0.0272(7) \\ \text { C104 } & 0.0525(2) & 0.87884(19) & 0.24182(13) & 0.0248(6) \\ \text { C105 } & 0.1025(2) & 0.89662(19) & 0.28353(12) & 0.0226(6) \\ \text { C106 } & 0.13776(19) & 0.96310(19) & 0.27423(12) & 0.0203(6) \\ \text { C107 } & 0.0679(2) & 0.5671(2) & 0.06091(13) & 0.0267(7) \\ \text { C108 } & 0.3479(2) & 0.1742(2) & 0.20125(13) & 0.0273(7) \\ \text { O1 } & 0.6722(2) & 0.4806(2) & 0.24470(13) & 0.0658(8) \\ \text { C109 } & 0.7238(3) & 0.5353(3) & 0.32981(17) & 0.0587(12) \\ \text { C110 } & 0.7471(3) & 0.4715(3) & 0.2801(2) & 0.0665(13) \\ \text { C111 } & 0.6164(3) & 0.4397(4) & 0.2675(2) & 0.0802(17) \\ \text { C112 } & 0.5375(3) & 0.4527(3) & 0.2308(2) & 0.0600(11)\end{array}$




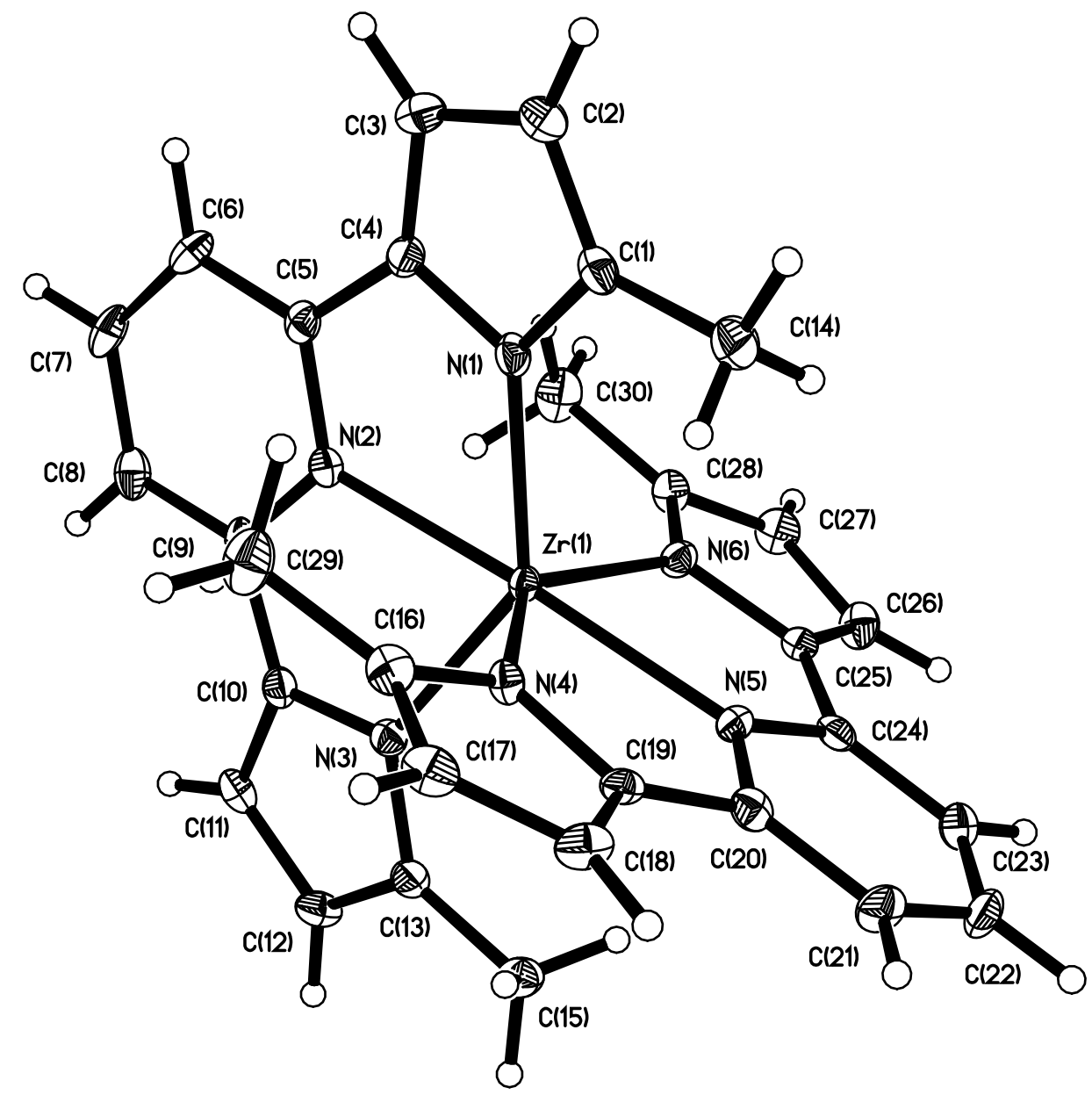

Figure C8. Perspective view of the molecular structure of $\left(\mathrm{C}_{15} \mathrm{H}_{13} \mathrm{~N}_{3}\right)_{2} \mathrm{Zr}$ with the atom labeling scheme for the independent non-hydrogen atoms. The thermal ellipsoids are scaled to enclose $50 \%$ probability. 
Table C20. Crystal data for $\left(\mathrm{C}_{15} \mathrm{H}_{13} \mathrm{~N}_{3}\right)_{2} \mathrm{Zr} \cdot \mathrm{Et}_{2} \mathrm{O}$.

$\begin{array}{lll}\text { Identification code } & \mathrm{cm} 78 \mathrm{cms} & \\ \text { Empirical formula } & \mathrm{C}_{34} \mathrm{H}_{36} \mathrm{~N}_{6} \mathrm{OZr} & \\ \text { Emp. formula weight } & 635.91 \mathrm{~g} / \mathrm{mol} & \\ \text { Temperature } & 100(2) \mathrm{K} & \\ \text { Wavelength } & 0.71073 \AA & \\ \text { Crystal size } & 0.114 \times 0.402 \times 0.407 \mathrm{~mm} \\ \text { Crystal system } & \text { orthorhombic } & \\ \text { Space group } & \text { Pbca }(\mathrm{No} .61) & \\ \text { Unit cell dimensions } & \mathrm{a}=16.0187(7) \AA & \alpha=90^{\circ} \\ & \mathrm{b}=14.0449(7) \AA & \beta=90^{\circ} \\ & \mathrm{c}=26.9193(13) \AA & \gamma=90^{\circ} \\ \text { Volume } & 6056.3(5) \AA & \\ \text { Z } & 8 & \\ \text { Density (calculated) } & 1.395 \mathrm{~g} / \mathrm{cm}^{3} & \\ \text { Absorption coefficient } & 0.401 \mathrm{~mm}^{-1} & \\ \text { F(000) } & 2640 & \end{array}$

Table C21. Data collection and structure refinement for $\left(\mathrm{C}_{15} \mathrm{H}_{13} \mathrm{~N}_{3}\right)_{2} \mathrm{Zr} \cdot \mathrm{Et}_{2} \mathrm{O}$.

Theta range for data used in 2.98 to $27.52^{\circ}$

the structural refinement

Index ranges $\quad-20 \leq \mathrm{h} \leq 17,-17 \leq \mathrm{k} \leq 18,-28 \leq 1 \leq 34$

Reflections 31072

Independent reflections $\quad 6961[\mathrm{R}(\mathrm{int})=0.0769]$

Coverage of independent $99.7 \%$ reflections

Absorption correction multi-scan

Max. and min. trans. $\quad 0.956$ and 0.854

Refinement method $\quad$ Full-matrix least-squares on $\mathrm{F}^{2}$

Refinement program SHELXL-2014 (Sheldrick, 2014)

Data / restraints / parameters $6961 / 0 / 385$

Goodness-of-fit on $\mathrm{F}^{2} \quad 1.029$

Final R indices $\quad 4478$ data; $\mathrm{I}>2 \sigma(\mathrm{I}) \quad \mathrm{R} 1=0.0485, \mathrm{wR} 2=0.0817$

all data $\quad \mathrm{R} 1=0.1042, \mathrm{wR} 2=0.0973$

Largest diff. peak and hole $\quad 0.866$ and $-0.677 \mathrm{e}^{-/} / \AA^{3}$ 
Table C22. Atomic coordinates and equivalent isotropic atomic displacement parameters $\left(\AA^{2}\right)$ for $\left(\mathrm{C}_{15} \mathrm{H}_{13} \mathrm{~N}_{3}\right)_{2} \mathrm{Zr} \cdot \mathrm{Et}_{2} \mathrm{O}$. $\mathrm{U}(\mathrm{eq})$ is defined as one third of the trace of the orthogonalized $\mathrm{U}_{\mathrm{ij}}$ tensor.

\begin{tabular}{|c|c|c|c|c|}
\hline & $\mathrm{x} / \mathrm{a}$ & $\mathrm{y} / \mathrm{b}$ & $\mathrm{z} / \mathrm{c}$ & $\mathrm{U}(\mathrm{eq})$ \\
\hline $\mathrm{Zr} 1$ & $0.87705(2)$ & $0.97233(2)$ & $0.34642(2)$ & $0.01033(8)$ \\
\hline $\mathrm{O} 1$ & $0.19360(16)$ & $0.37266(19)$ & $0.42940(9)$ & $0.0341(6)$ \\
\hline N1 & $0.74408(15)$ & $0.98149(17)$ & $0.35910(9)$ & $0.0137(6)$ \\
\hline N2 & $0.84634(15)$ & $0.11023(17)$ & $0.38867(9)$ & $0.0125(6)$ \\
\hline N3 & $0.98756(15)$ & $0.06290(17)$ & $0.34974(9)$ & $0.0128(5)$ \\
\hline N4 & $0.85897(14)$ & $0.97010(18)$ & $0.26643(9)$ & $0.0127(5)$ \\
\hline N5 & $0.92938(15)$ & $0.83351(17)$ & $0.31408(9)$ & $0.0123(6)$ \\
\hline N6 & $0.91552(15)$ & $0.87865(18)$ & $0.40706(9)$ & $0.0132(6)$ \\
\hline $\mathrm{C} 1$ & $0.67761(18)$ & $0.9262(2)$ & $0.34303(12)$ & $0.0154(7)$ \\
\hline $\mathrm{C} 2$ & $0.60462(19)$ & $0.9630(2)$ & $0.36140(12)$ & $0.0207(8)$ \\
\hline $\mathrm{C} 3$ & $0.6244(2)$ & $0.0442(2)$ & $0.38980(11)$ & $0.0179(7)$ \\
\hline $\mathrm{C} 4$ & $0.70956(19)$ & $0.0547(2)$ & $0.38760(11)$ & $0.0139(7)$ \\
\hline $\mathrm{C} 5$ & $0.76655(19)$ & $0.1272(2)$ & $0.40376(11)$ & $0.0134(7)$ \\
\hline C6 & $0.7475(2)$ & $0.2081(2)$ & $0.43169(12)$ & $0.0178(7)$ \\
\hline $\mathrm{C} 7$ & $0.8105(2)$ & $0.2710(2)$ & $0.44285(12)$ & $0.0208(8)$ \\
\hline $\mathrm{C} 8$ & $0.8918(2)$ & $0.2544(2)$ & $0.42716(11)$ & $0.0172(7)$ \\
\hline $\mathrm{C} 9$ & $0.90865(19)$ & $0.1728(2)$ & $0.39986(11)$ & $0.0135(7)$ \\
\hline $\mathrm{C} 10$ & $0.98833(19)$ & $0.1438(2)$ & $0.38013(11)$ & $0.0138(7)$ \\
\hline $\mathrm{C} 11$ & $0.06870(19)$ & $0.1774(2)$ & $0.38517(11)$ & $0.0152(7)$ \\
\hline $\mathrm{C} 12$ & $0.1197(2)$ & $0.1156(2)$ & $0.35742(11)$ & $0.0173(7)$ \\
\hline $\mathrm{C} 13$ & $0.06984(19)$ & $0.0471(2)$ & $0.33634(11)$ & $0.0160(7)$ \\
\hline $\mathrm{C} 14$ & $0.6909(2)$ & $0.8404(2)$ & $0.31134(13)$ & $0.0208(8)$ \\
\hline $\mathrm{C} 15$ & $0.09493(19)$ & $0.9680(2)$ & $0.30199(12)$ & $0.0210(7)$ \\
\hline $\mathrm{C} 16$ & $0.82110(18)$ & $0.0328(2)$ & $0.23415(11)$ & $0.0161(7)$ \\
\hline $\mathrm{C} 17$ & $0.82925(19)$ & $0.9995(2)$ & $0.18629(12)$ & $0.0180(8)$ \\
\hline $\mathrm{C} 18$ & $0.8724(2)$ & $0.9121(2)$ & $0.18819(11)$ & $0.0169(7)$ \\
\hline C19 & $0.88994(18)$ & $0.8959(2)$ & $0.23750(11)$ & $0.0132(7)$ \\
\hline $\mathrm{C} 20$ & $0.92983(18)$ & $0.8196(2)$ & $0.26399(11)$ & $0.0138(7)$ \\
\hline $\mathrm{C} 21$ & $0.9668(2)$ & $0.7390(2)$ & $0.24373(12)$ & $0.0182(7)$ \\
\hline $\mathrm{C} 22$ & $0.0035(2)$ & $0.6732(2)$ & $0.27510(12)$ & $0.0189(7)$ \\
\hline $\mathrm{C} 23$ & $0.00401(19)$ & $0.6876(2)$ & $0.32608(12)$ & $0.0175(7)$ \\
\hline $\mathrm{C} 24$ & $0.96540(18)$ & $0.7690(2)$ & $0.34511(12)$ & $0.0133(6)$ \\
\hline $\mathrm{C} 25$ & $0.95953(19)$ & $0.7953(2)$ & $0.39658(12)$ & $0.0133(7)$ \\
\hline
\end{tabular}




$\begin{array}{lcccc} & \mathrm{x} / \mathrm{a} & \mathrm{y} / \mathrm{b} & \mathrm{z} / \mathrm{c} & \mathrm{U}(\mathrm{eq}) \\ \mathrm{C} 26 & 0.98877(19) & 0.7550(2) & 0.44007(12) & 0.0174(7) \\ \mathrm{C} 27 & 0.9620(2) & 0.8146(2) & 0.47872(12) & 0.0187(7) \\ \mathrm{C} 28 & 0.9181(2) & 0.8889(2) & 0.45821(11) & 0.0148(7) \\ \mathrm{C} 29 & 0.7788(2) & 0.1209(2) & 0.25289(12) & 0.0234(8) \\ \mathrm{C} 30 & 0.8782(2) & 0.9708(2) & 0.48471(11) & 0.0234(7) \\ \mathrm{C} 31 & 0.0868(3) & 0.4689(4) & 0.46130(19) & 0.0668(15) \\ \mathrm{C} 32 & 0.1760(3) & 0.4541(3) & 0.45878(16) & 0.0450(11) \\ \mathrm{C} 33 & 0.2804(2) & 0.3598(3) & 0.42217(15) & 0.0362(10) \\ \mathrm{C} 34 & 0.2930(2) & 0.2736(3) & 0.39066(16) & 0.0406(11)\end{array}$




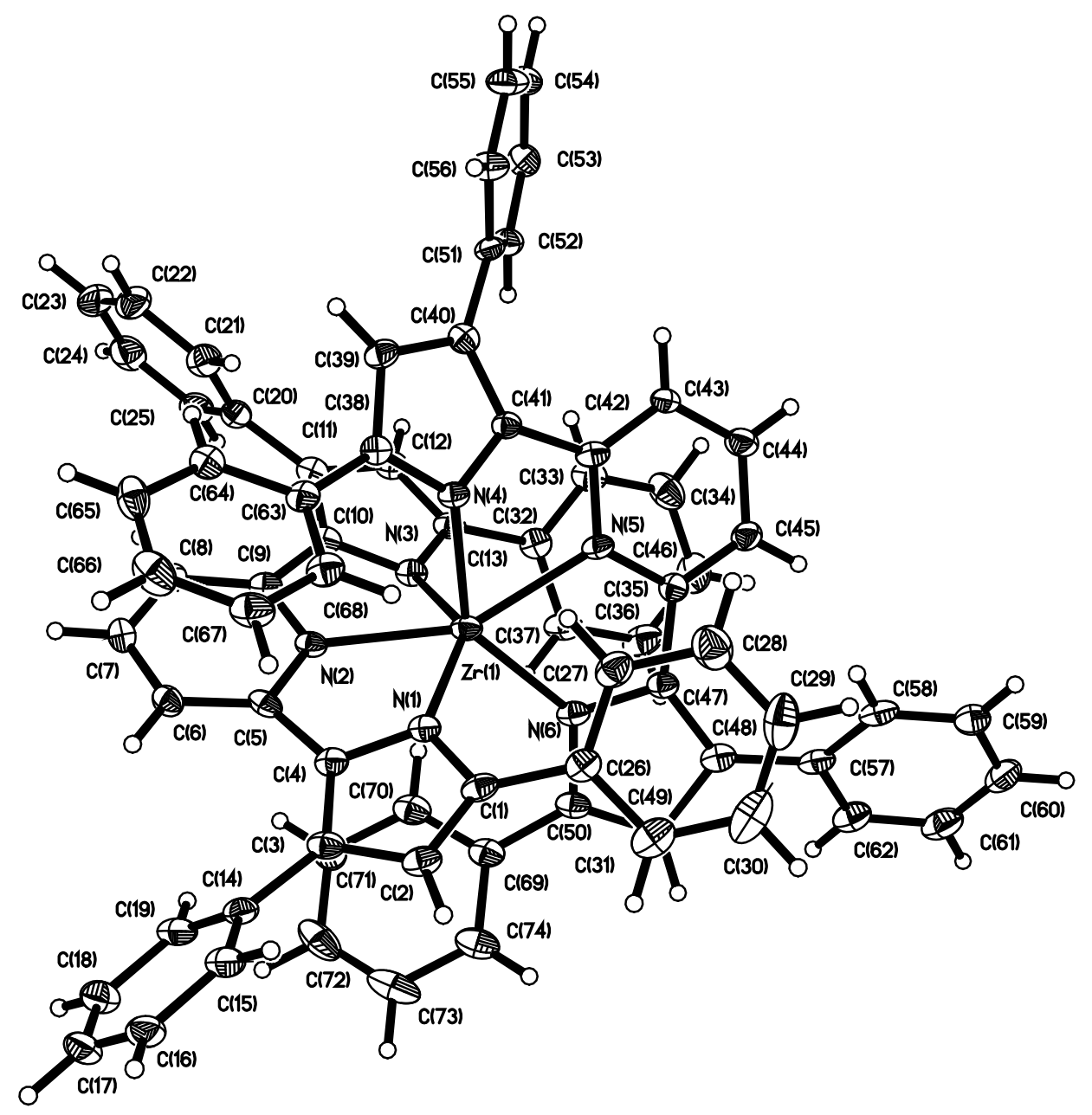

Figure C9. Perspective view of the molecular structure of $\left(\mathrm{C}_{37} \mathrm{H}_{25} \mathrm{~N}_{3}\right){ }_{2} \mathrm{Zr}$ with the atom labeling scheme for the non-hydrogen atoms. The thermal ellipsoids are scaled to enclose $50 \%$ probability. 
Table C23. Crystal data for $\left(\mathrm{C}_{37} \mathrm{H}_{25} \mathrm{~N}_{3}\right)_{2} \mathrm{Zr} \cdot 2 \mathrm{OEt} 2$.

Ident. code $\quad \mathrm{cm} 228 \mathrm{cms}$

Chem. formula $\quad \mathrm{C}_{82} \mathrm{H}_{70} \mathrm{~N}_{6} \mathrm{O}_{2} \mathrm{Zr}$

Formula weight $1262.66 \mathrm{~g} / \mathrm{mol}$

Temperature $100(2) \mathrm{K}$

Wavelength $\quad 0.71073 \AA$

Crystal size $\quad 0.148 \times 0.248 \times 0.431 \mathrm{~mm}$

Crystal system triclinic

Space group $\quad \mathrm{P} \overline{1}$ (No. 2)

Unit cell

$$
\begin{array}{ll}
\mathrm{a}=14.5589(8) \AA & \alpha=80.529(2)^{\circ} \\
\mathrm{b}=14.7207(9) \AA & \beta=85.149(2)^{\circ} \\
\mathrm{c}=15.5027(9) \AA & \gamma=83.381(2)^{\circ}
\end{array}
$$

Volume, $\AA^{3} \quad 3248.1(3)$

$\mathrm{Z} \quad 2$

Density (calc) $\quad 1.291 \mathrm{~g} / \mathrm{cm}^{3}$

Abs. coeff. $\quad 0.224 \mathrm{~mm}^{-1}$

\begin{tabular}{|c|c|}
\hline Theta range & 3.02 to $27.57^{\circ}$ \\
\hline Index ranges & $-18 \leq \mathrm{h} \leq 18,-19 \leq \mathrm{k} \leq 19,-20 \leq 1 \leq 20$ \\
\hline Reflections & 65382 \\
\hline Independent refls. & $14938[\mathrm{R}(\mathrm{int})=0.0548]$ \\
\hline Coverage & $99.3 \%$ \\
\hline Abs. correction & multi-scan \\
\hline Max. and min. trans. & 0.968 and 0.910 \\
\hline Refinement method & Full-matrix least-squares on $\mathrm{F}^{2}$ \\
\hline Refinement program & SHELXL-2014/7 (Sheldrick, 2014) \\
\hline $\begin{array}{l}\text { Data / restraints } \\
\text { parameters }\end{array}$ & $14938 / 0 / 824$ \\
\hline Goodness-of-fit on $\mathrm{F}^{2}$ & 1.071 \\
\hline \multirow[t]{2}{*}{ Final $\mathrm{R}$ indices } & $\begin{array}{l}10457 \\
\mathrm{I}>2 \sigma(\mathrm{I})\end{array} \quad$ data; $\mathrm{R} 1=0.0582, \mathrm{wR} 2=0.1092$ \\
\hline & $\mathrm{R} 1=0.1031, \mathrm{wR} 2=0.1332$ \\
\hline
\end{tabular}

$\mathrm{F}(000) \quad 1320$

Table C24. Data collection and structure refinement for $\left(\mathrm{C}_{37} \mathrm{H}_{25} \mathrm{~N}_{3}\right)_{2} \mathrm{Zr} \cdot 2 \mathrm{OEt}_{2}$.

Largest diff. peak and 0.914 and $-0.762 \mathrm{e}^{-} / \AA^{3}$ hole 
Table C25. Atomic coordinates and equivalent isotropic atomic displacement parameters $\left(\AA^{2}\right)$ for $\left(\mathrm{C}_{37} \mathrm{H}_{25} \mathrm{~N}_{3}\right)_{2} \mathrm{Zr} \cdot 2 \mathrm{OEt}_{2}$. U(eq) is defined as one third of the trace of the orthogonalized $\mathrm{U}_{\mathrm{ij}}$ tensor.

\begin{tabular}{|c|c|c|c|c|}
\hline & $\mathrm{x} / \mathrm{a}$ & $y / b$ & $\mathrm{z} / \mathrm{c}$ & $\mathrm{U}(\mathrm{eq})$ \\
\hline $\mathrm{Zr} 1$ & $0.30744(2)$ & $0.64866(2)$ & $0.68176(2)$ & $0.01792(8)$ \\
\hline N1 & $0.22554(16)$ & $0.58388(17)$ & $0.79328(16)$ & $0.0169(5)$ \\
\hline $\mathrm{N} 2$ & $0.21945(16)$ & $0.54925(17)$ & $0.63907(16)$ & $0.0169(5)$ \\
\hline N3 & $0.35933(17)$ & $0.62097(17)$ & $0.55036(16)$ & $0.0180(5)$ \\
\hline N4 & $0.20711(16)$ & $0.76647(17)$ & $0.63285(15)$ & $0.0158(5)$ \\
\hline N5 & $0.37613(16)$ & $0.78169(17)$ & $0.66436(16)$ & $0.0169(5)$ \\
\hline N6 & $0.43377(17)$ & $0.62659(17)$ & $0.74941(16)$ & $0.0180(5)$ \\
\hline $\mathrm{C} 1$ & $0.2273(2)$ & $0.5889(2)$ & $0.88083(19)$ & $0.0194(6)$ \\
\hline $\mathrm{C} 2$ & $0.1815(2)$ & $0.5185(2)$ & $0.9296(2)$ & $0.0212(7)$ \\
\hline $\mathrm{C} 3$ & $0.1487(2)$ & $0.4675(2)$ & $0.8709(2)$ & $0.0197(6)$ \\
\hline $\mathrm{C} 4$ & $0.1762(2)$ & $0.5105(2)$ & $0.7873(2)$ & $0.0181(6)$ \\
\hline $\mathrm{C} 5$ & $0.1619(2)$ & $0.4999(2)$ & $0.6980(2)$ & $0.0184(6)$ \\
\hline C6 & $0.0973(2)$ & $0.4524(2)$ & $0.6689(2)$ & $0.0197(6)$ \\
\hline $\mathrm{C} 7$ & $0.0915(2)$ & $0.4578(2)$ & $0.5792(2)$ & $0.0226(7)$ \\
\hline $\mathrm{C} 8$ & $0.1511(2)$ & $0.5066(2)$ & $0.5197(2)$ & $0.0221(7)$ \\
\hline C9 & $0.2164(2)$ & $0.5517(2)$ & $0.55186(19)$ & $0.0184(6)$ \\
\hline $\mathrm{C} 10$ & $0.2897(2)$ & $0.6008(2)$ & $0.50253(19)$ & $0.0176(6)$ \\
\hline C11 & $0.3083(2)$ & $0.6299(2)$ & $0.4137(2)$ & $0.0204(7)$ \\
\hline $\mathrm{C} 12$ & $0.3945(2)$ & $0.6668(2)$ & $0.4064(2)$ & $0.0213(7)$ \\
\hline $\mathrm{C} 13$ & $0.4241(2)$ & $0.6606(2)$ & $0.4897(2)$ & $0.0194(6)$ \\
\hline $\mathrm{C} 14$ & $0.0998(2)$ & $0.3836(2)$ & $0.8970(2)$ & $0.0208(7)$ \\
\hline $\mathrm{C} 15$ & $0.0369(2)$ & $0.3755(2)$ & $0.9703(2)$ & $0.0240(7)$ \\
\hline $\mathrm{C} 16$ & $0.9946(2)$ & $0.2951(2)$ & $0.9984(2)$ & $0.0275(8)$ \\
\hline $\mathrm{C} 17$ & $0.0142(2)$ & $0.2208(2)$ & $0.9540(2)$ & $0.0290(8)$ \\
\hline C18 & $0.0767(2)$ & $0.2266(2)$ & $0.8810(2)$ & $0.0298(8)$ \\
\hline C19 & $0.1194(2)$ & $0.3069(2)$ & $0.8536(2)$ & $0.0244(7)$ \\
\hline $\mathrm{C} 20$ & $0.2505(2)$ & $0.6292(2)$ & $0.34028(19)$ & $0.0203(7)$ \\
\hline $\mathrm{C} 21$ & $0.1617(2)$ & $0.6766(2)$ & $0.3397(2)$ & $0.0262(7)$ \\
\hline $\mathrm{C} 22$ & $0.1079(2)$ & $0.6798(3)$ & $0.2697(2)$ & $0.0322(8)$ \\
\hline $\mathrm{C} 23$ & $0.1407(3)$ & $0.6351(3)$ & $0.2001(2)$ & $0.0352(9)$ \\
\hline $\mathrm{C} 24$ & $0.2285(3)$ & $0.5883(3)$ & $0.2003(2)$ & $0.0324(8)$ \\
\hline $\mathrm{C} 25$ & $0.2835(2)$ & $0.5855(2)$ & $0.2694(2)$ & $0.0258(7)$ \\
\hline $\mathrm{C} 26$ & $0.2701(2)$ & $0.6647(2)$ & $0.90760(19)$ & $0.0198(6)$ \\
\hline
\end{tabular}




\begin{tabular}{|c|c|c|c|c|}
\hline & $\mathrm{x} / \mathrm{a}$ & $y / b$ & $\mathrm{z} / \mathrm{c}$ & $\mathrm{U}(\mathrm{eq})$ \\
\hline $\mathrm{C} 27$ & $0.2565(2)$ & $0.7547(2)$ & $0.8617(2)$ & $0.0266(7)$ \\
\hline $\mathrm{C} 28$ & $0.2950(3)$ & $0.8268(3)$ & $0.8874(2)$ & $0.0353(9)$ \\
\hline $\mathrm{C} 29$ & $0.3480(3)$ & $0.8107(3)$ & $0.9596(3)$ & $0.0382(9)$ \\
\hline $\mathrm{C} 30$ & $0.3626(3)$ & $0.7219(3)$ & $0.0048(3)$ & $0.0402(10)$ \\
\hline $\mathrm{C} 31$ & $0.3246(2)$ & $0.6496(3)$ & $0.9790(2)$ & $0.0304(8)$ \\
\hline $\mathrm{C} 32$ & $0.5122(2)$ & $0.6868(2)$ & $0.5128(2)$ & $0.0200(6)$ \\
\hline C33 & $0.5448(2)$ & $0.7694(2)$ & $0.4712(2)$ & $0.0255(7)$ \\
\hline $\mathrm{C} 34$ & $0.6276(2)$ & $0.7947(2)$ & $0.4905(3)$ & $0.0328(8)$ \\
\hline C35 & $0.6806(2)$ & $0.7384(3)$ & $0.5525(3)$ & $0.0338(8)$ \\
\hline $\mathrm{C} 36$ & $0.6504(2)$ & $0.6551(3)$ & $0.5932(2)$ & $0.0301(8)$ \\
\hline $\mathrm{C} 37$ & $0.5670(2)$ & $0.6294(2)$ & $0.5729(2)$ & $0.0258(7)$ \\
\hline C38 & $0.1210(2)$ & $0.7694(2)$ & $0.60122(19)$ & $0.0171(6)$ \\
\hline C39 & $0.1109(2)$ & $0.8406(2)$ & $0.5310(2)$ & $0.0203(7)$ \\
\hline $\mathrm{C} 40$ & $0.1925(2)$ & $0.8846(2)$ & $0.5169(2)$ & $0.0182(6)$ \\
\hline $\mathrm{C} 41$ & $0.2502(2)$ & $0.8384(2)$ & $0.58112(19)$ & $0.0162(6)$ \\
\hline $\mathrm{C} 42$ & $0.3395(2)$ & $0.8540(2)$ & $0.60690(19)$ & $0.0183(6)$ \\
\hline $\mathrm{C} 43$ & $0.3861(2)$ & $0.9324(2)$ & $0.5831(2)$ & $0.0190(6)$ \\
\hline $\mathrm{C} 44$ & $0.4685(2)$ & $0.9357(2)$ & $0.6201(2)$ & $0.0241(7)$ \\
\hline $\mathrm{C} 45$ & $0.5040(2)$ & $0.8620(2)$ & $0.6809(2)$ & $0.0216(7)$ \\
\hline C46 & $0.4558(2)$ & $0.7850(2)$ & $0.7023(2)$ & $0.0177(6)$ \\
\hline $\mathrm{C} 47$ & $0.4820(2)$ & $0.6996(2)$ & $0.76036(19)$ & $0.0181(6)$ \\
\hline $\mathrm{C} 48$ & $0.5465(2)$ & $0.6696(2)$ & $0.8227(2)$ & $0.0196(6)$ \\
\hline C49 & $0.5379(2)$ & $0.5737(2)$ & $0.8495(2)$ & $0.0219(7)$ \\
\hline $\mathrm{C} 50$ & $0.4698(2)$ & $0.5494(2)$ & $0.8041(2)$ & $0.0192(6)$ \\
\hline C51 & $0.2096(2)$ & $0.9606(2)$ & $0.44483(19)$ & $0.0170(6)$ \\
\hline C52 & $0.2883(2)$ & $0.9555(2)$ & $0.3877(2)$ & $0.0208(7)$ \\
\hline C53 & $0.3004(2)$ & $0.0240(2)$ & $0.3162(2)$ & $0.0234(7)$ \\
\hline C54 & $0.2347(2)$ & $0.0992(2)$ & $0.3010(2)$ & $0.0253(7)$ \\
\hline C55 & $0.1562(2)$ & $0.1050(2)$ & $0.3569(2)$ & $0.0292(8)$ \\
\hline C56 & $0.1431(2)$ & $0.0360(2)$ & $0.4278(2)$ & $0.0243(7)$ \\
\hline $\mathrm{C} 57$ & $0.6103(2)$ & $0.7219(2)$ & $0.8586(2)$ & $0.0223(7)$ \\
\hline C58 & $0.5855(2)$ & $0.8117(2)$ & $0.8770(2)$ & $0.0245(7)$ \\
\hline C59 & $0.6462(2)$ & $0.8587(2)$ & $0.9125(2)$ & $0.0276(7)$ \\
\hline C60 & $0.7337(2)$ & $0.8164(3)$ & $0.9320(2)$ & $0.0313(8)$ \\
\hline C61 & $0.7590(2)$ & $0.7271(3)$ & $0.9159(2)$ & $0.0327(8)$ \\
\hline C62 & $0.6988(2)$ & $0.6806(3)$ & $0.8793(2)$ & $0.0272(7)$ \\
\hline C63 & $0.0478(2)$ & $0.7128(2)$ & $0.6420(2)$ & $0.0186(6)$ \\
\hline
\end{tabular}




$\begin{array}{lcccc} & \mathrm{x} / \mathrm{a} & \mathrm{y} / \mathrm{b} & \mathrm{z} / \mathrm{c} & \mathrm{U}(\mathrm{eq}) \\ \mathrm{C} 64 & 0.9852(2) & 0.6873(2) & 0.5892(2) & 0.0216(7) \\ \text { C65 } & 0.9095(2) & 0.6418(2) & 0.6256(2) & 0.0266(7) \\ \text { C66 } & 0.8966(2) & 0.6195(2) & 0.7154(2) & 0.0324(8) \\ \text { C67 } & 0.9585(2) & 0.6432(2) & 0.7689(2) & 0.0275(8) \\ \text { C68 } & 0.0331(2) & 0.6902(2) & 0.7321(2) & 0.0226(7) \\ \text { C69 } & 0.4341(2) & 0.4606(2) & 0.8034(2) & 0.0209(7) \\ \text { C70 } & 0.4085(2) & 0.4379(2) & 0.7262(2) & 0.0244(7) \\ \text { C71 } & 0.3700(2) & 0.3564(2) & 0.7249(3) & 0.0296(8) \\ \text { C72 } & 0.3586(2) & 0.2954(2) & 0.8023(3) & 0.0362(9) \\ \text { C73 } & 0.3862(3) & 0.3158(2) & 0.8793(3) & 0.0383(10) \\ \text { C74 } & 0.4231(2) & 0.3976(2) & 0.8806(2) & 0.0289(8) \\ \text { O1 } & 0.35623(19) & 0.90568(19) & 0.14837(18) & 0.0422(7) \\ \text { C75 } & 0.5143(3) & 0.9243(3) & 0.1506(4) & 0.0692(16) \\ \text { C76 } & 0.4385(3) & 0.8650(3) & 0.1850(3) & 0.0502(11) \\ \text { C77 } & 0.2794(3) & 0.8555(3) & 0.1814(3) & 0.0409(10) \\ \text { C78 } & 0.1934(3) & 0.9088(3) & 0.1417(4) & 0.0617(13) \\ \text { O2 } & 0.1020(3) & 0.0529(2) & 0.7383(2) & 0.0625(9) \\ \text { C79 } & 0.1505(5) & 0.1844(5) & 0.6450(4) & 0.106(3) \\ \text { C80 } & 0.1250(6) & 0.0933(4) & 0.6514(4) & 0.094(2) \\ \text { C81 } & 0.0610(5) & 0.9710(4) & 0.7439(4) & 0.0796(18) \\ \text { C82 } & 0.0344(4) & 0.9322(4) & 0.8350(4) & 0.087(2)\end{array}$




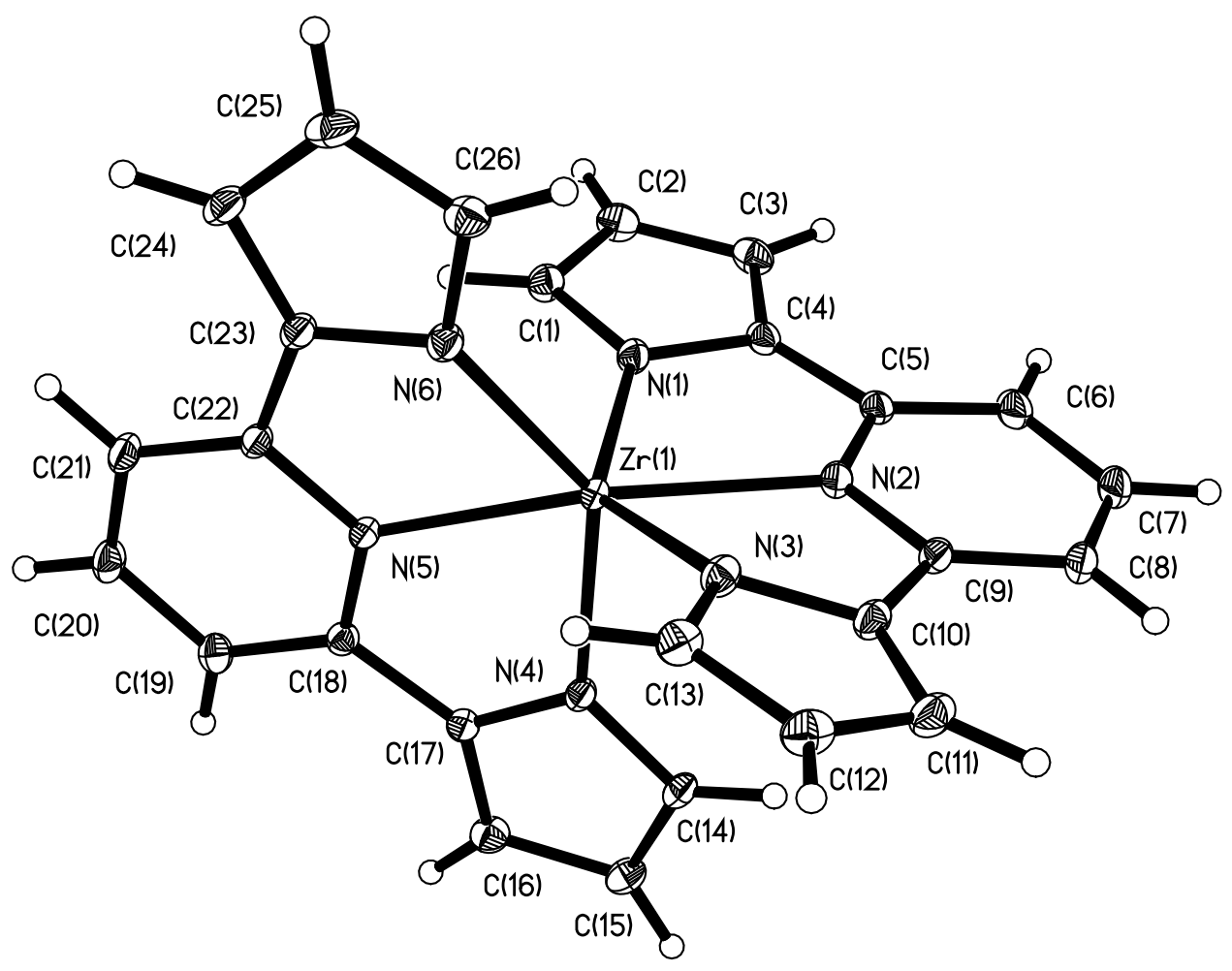

Figure C10. Perspective view of the molecular structure of the $\left(\mathrm{C}_{12} \mathrm{H}_{9} \mathrm{~N}_{3}\right)_{2} \mathrm{Zr}$ with the atom labeling scheme for the independent non-hydrogen atoms. The thermal ellipsoids are scaled to enclose $50 \%$ probability. 
Table C26. Crystal data for $\left(\mathrm{C}_{12} \mathrm{H}_{9} \mathrm{~N}_{3}\right)_{2} \mathrm{Zr}$.

\begin{tabular}{|c|c|c|}
\hline Ident. code & \multicolumn{2}{|l|}{$\mathrm{cm} 172 \mathrm{cms}$} \\
\hline Chem. formula & \multicolumn{2}{|l|}{$\mathrm{C}_{26} \mathrm{H}_{18} \mathrm{~N}_{6} \mathrm{Zr}$} \\
\hline Formula weight & \multicolumn{2}{|l|}{$505.68 \mathrm{~g} / \mathrm{mol}$} \\
\hline Temperature & \multicolumn{2}{|l|}{$100(2) \mathrm{K}$} \\
\hline Wavelength & \multicolumn{2}{|l|}{$0.71073 \AA$} \\
\hline Crystal size & \multicolumn{2}{|c|}{$0.138 \times 0.207 \times 0.515 \mathrm{~mm}$} \\
\hline Crystal system & \multicolumn{2}{|l|}{ monoclinic } \\
\hline Space group & \multicolumn{2}{|c|}{$\mathrm{P} 2_{1} / \mathrm{n}\left(\right.$ No. 14 , non-standard setting of $\left.\left.\mathrm{P} 2_{1} / \mathrm{c}\right)\right)$} \\
\hline \multirow[t]{3}{*}{ Unit cell } & $\mathrm{a}=10.7463(5) \AA$ & $\alpha=90^{\circ}$ \\
\hline & $\mathrm{b}=15.8013(7) \AA$ & $\beta=103.3951(11)^{\circ}$ \\
\hline & $\mathrm{c}=12.5759(5) \AA$ & $\gamma=90^{\circ}$ \\
\hline Volume, $\AA^{3}$ & $2077.36(16)$ & \\
\hline Z & 4 & \\
\hline Density (calc) & $1.617 \mathrm{~g} / \mathrm{cm}^{3}$ & \\
\hline Abs. coefficient & $0.558 \mathrm{~mm}^{-1}$ & \\
\hline $\mathrm{F}(000)$ & 1024 & \\
\hline
\end{tabular}

Table C27. Data collection and structure refinement for $\left(\mathrm{C}_{12} \mathrm{H}_{9} \mathrm{~N}_{3}\right)_{2} \mathrm{Zr}$.

$\begin{array}{ll}\text { Theta range } & 2.84 \text { to } 35.02^{\circ} \\ \text { Index ranges } & -17 \leq \mathrm{h} \leq 15,-25 \leq \mathrm{k} \leq 25,-19 \leq 1 \leq 20 \\ \text { Reflections } & 55855 \\ \text { Independent refls } & 9144 \text { [R(int) }=0.0305] \\ \text { Coverage } & 99.8 \% \\ \text { Absorption correction } & \text { multi-scan } \\ \text { Max. and min. trans. } & 0.927 \text { and } 0.762 \\ \text { Refinement method } & \text { Full-matrix least-squares on } \mathrm{F}^{2} \\ \text { Refinement program } & \text { SHELXL-2014/7 (Sheldrick, 2014) } \\ \text { Data / restrs / parms } & 9144 / 0 / 298 \\ \text { Goodness-of-fit on } \mathrm{F}^{2} & 1.077 \\ \text { Final R indices } & 7720 \quad \text { data; R1 }=0.0292, \text { wR2 }=0.0638 \\ & \mathrm{I}>2 \sigma(\mathrm{I}) \quad \mathrm{R} 1=0.0417, \mathrm{wR} 2=0.0702\end{array}$

Largest diff. peak and 0.617 and $-0.791 \mathrm{e}^{-} / \AA^{3}$ hole 
Table C28. Atomic coordinates and equivalent isotropic atomic displacement parameters $\left(\AA^{2}\right)$ for $\left(\mathrm{C}_{12} \mathrm{H}_{9} \mathrm{~N}_{3}\right)_{2} \mathrm{Zr}$. $\mathrm{U}(\mathrm{eq})$ is defined as one third of the trace of the orthogonalized $\mathrm{U}_{\mathrm{ij}}$ tensor.

\begin{tabular}{|c|c|c|c|c|}
\hline & $\mathrm{x} / \mathrm{a}$ & $y / b$ & $\mathrm{z} / \mathrm{c}$ & $\mathrm{U}(\mathrm{eq})$ \\
\hline $\mathrm{Zr} 1$ & $0.34158(2)$ & $0.10298(2)$ & $0.75354(2)$ & $0.00867(3)$ \\
\hline N1 & $0.26729(10)$ & $0.03757(7)$ & $0.60231(8)$ & $0.01182(17)$ \\
\hline $\mathrm{N} 2$ & $0.44654(10)$ & $0.14630(6)$ & $0.62482(8)$ & $0.01182(17)$ \\
\hline N3 & $0.43798(10)$ & $0.22229(6)$ & $0.80409(9)$ & $0.01295(17)$ \\
\hline N4 & $0.49817(9)$ & $0.02019(6)$ & $0.82878(8)$ & $0.01045(16)$ \\
\hline N5 & $0.26977(9)$ & $0.99937(6)$ & $0.85188(8)$ & $0.01004(16)$ \\
\hline N6 & $0.15625(10)$ & $0.13916(7)$ & $0.77966(9)$ & $0.01228(17)$ \\
\hline $\mathrm{C} 1$ & $0.17057(12)$ & $0.97896(8)$ & $0.57269(10)$ & $0.0139(2)$ \\
\hline $\mathrm{C} 2$ & $0.16066(13)$ & $0.95329(8)$ & $0.46593(10)$ & $0.0159(2)$ \\
\hline $\mathrm{C} 3$ & $0.25591(13)$ & $0.99735(8)$ & $0.42702(10)$ & $0.0154(2)$ \\
\hline $\mathrm{C} 4$ & $0.31960(11)$ & $0.04810(8)$ & $0.51168(9)$ & $0.01223(19)$ \\
\hline $\mathrm{C} 5$ & $0.42284(11)$ & $0.10812(7)$ & $0.52510(10)$ & $0.01225(19)$ \\
\hline C6 & $0.49438(12)$ & $0.12901(9)$ & $0.44943(11)$ & $0.0169(2)$ \\
\hline $\mathrm{C} 7$ & $0.59142(12)$ & $0.18844(9)$ & $0.47940(11)$ & $0.0191(2)$ \\
\hline $\mathrm{C} 8$ & $0.61403(12)$ & $0.22844(9)$ & $0.58076(11)$ & $0.0171(2)$ \\
\hline $\mathrm{C} 9$ & $0.53753(11)$ & $0.20705(7)$ & $0.65222(10)$ & $0.01286(19)$ \\
\hline $\mathrm{C} 10$ & $0.53728(11)$ & $0.24617(7)$ & $0.75607(10)$ & $0.01296(19)$ \\
\hline $\mathrm{C} 11$ & $0.61054(12)$ & $0.30874(8)$ & $0.81769(11)$ & $0.0168(2)$ \\
\hline $\mathrm{C} 12$ & $0.55459(13)$ & $0.32536(8)$ & $0.90697(11)$ & $0.0170(2)$ \\
\hline $\mathrm{C} 13$ & $0.45018(12)$ & $0.27220(7)$ & $0.89569(10)$ & $0.0145(2)$ \\
\hline $\mathrm{C} 14$ & $0.62472(11)$ & $0.01929(8)$ & $0.82484(10)$ & $0.01246(19)$ \\
\hline $\mathrm{C} 15$ & $0.68157(12)$ & $0.94444(8)$ & $0.86770(11)$ & $0.0146(2)$ \\
\hline $\mathrm{C} 16$ & $0.58589(12)$ & $0.89605(8)$ & $0.90083(10)$ & $0.0143(2)$ \\
\hline $\mathrm{C} 17$ & $0.47516(11)$ & $0.94428(7)$ & $0.87625(9)$ & $0.01079(18)$ \\
\hline $\mathrm{C} 18$ & $0.34706(11)$ & $0.93331(7)$ & $0.89139(9)$ & $0.01074(18)$ \\
\hline C19 & $0.30141(12)$ & $0.86505(8)$ & $0.94199(10)$ & $0.0139(2)$ \\
\hline $\mathrm{C} 20$ & $0.17481(12)$ & $0.86703(8)$ & $0.95104(10)$ & $0.0151(2)$ \\
\hline $\mathrm{C} 21$ & $0.09680(12)$ & $0.93611(8)$ & $0.91287(10)$ & $0.0145(2)$ \\
\hline $\mathrm{C} 22$ & $0.14780(11)$ & $0.00284(7)$ & $0.86410(9)$ & $0.01102(18)$ \\
\hline $\mathrm{C} 23$ & $0.08400(11)$ & $0.08073(8)$ & $0.82259(10)$ & $0.01190(19)$ \\
\hline $\mathrm{C} 24$ & $0.96132(11)$ & $0.11122(8)$ & $0.81368(10)$ & $0.0153(2)$ \\
\hline $\mathrm{C} 25$ & $0.95637(12)$ & $0.19140(9)$ & $0.76208(11)$ & $0.0169(2)$ \\
\hline $\mathrm{C} 26$ & $0.07547(12)$ & $0.20601(8)$ & $0.74214(10)$ & $0.0148(2)$ \\
\hline
\end{tabular}




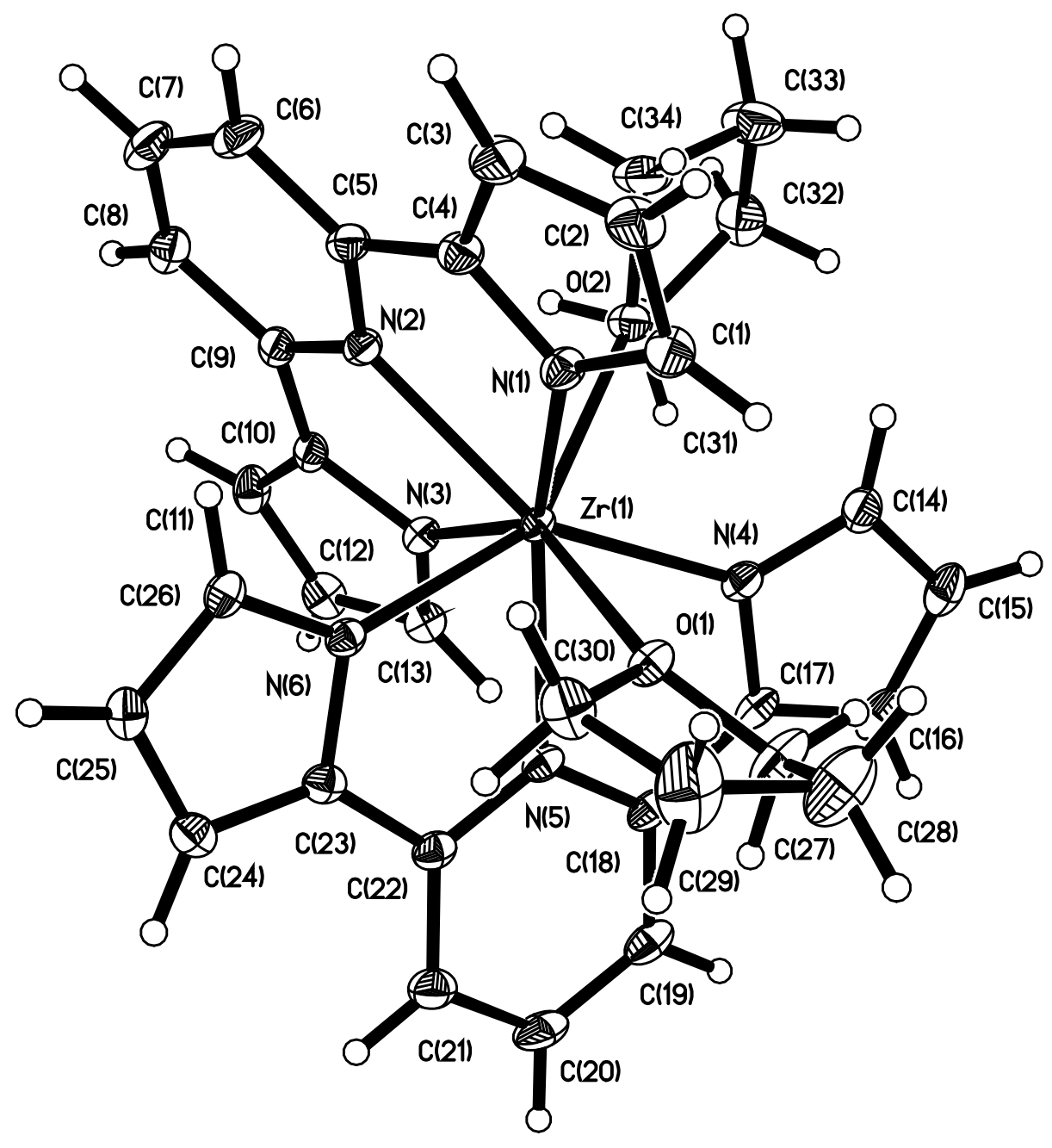

Figure C11. Perspective view of the molecular structure of the $\left(\mathrm{C}_{13} \mathrm{H}_{9} \mathrm{~N}_{3}\right)_{2} \mathrm{Zr}\left(\mathrm{OCC}_{4} \mathrm{H}_{8}\right)_{2}$ with the atom labeling scheme for the independent non-hydrogen atoms. The thermal ellipsoids are scaled to enclose $50 \%$ probability. 
Table C29. Crystal data for $\left(\mathrm{C}_{13} \mathrm{H}_{9} \mathrm{~N}_{3}\right)_{2} \mathrm{Zr}\left(\mathrm{OC}_{4} \mathrm{H}_{8}\right)_{2}$.

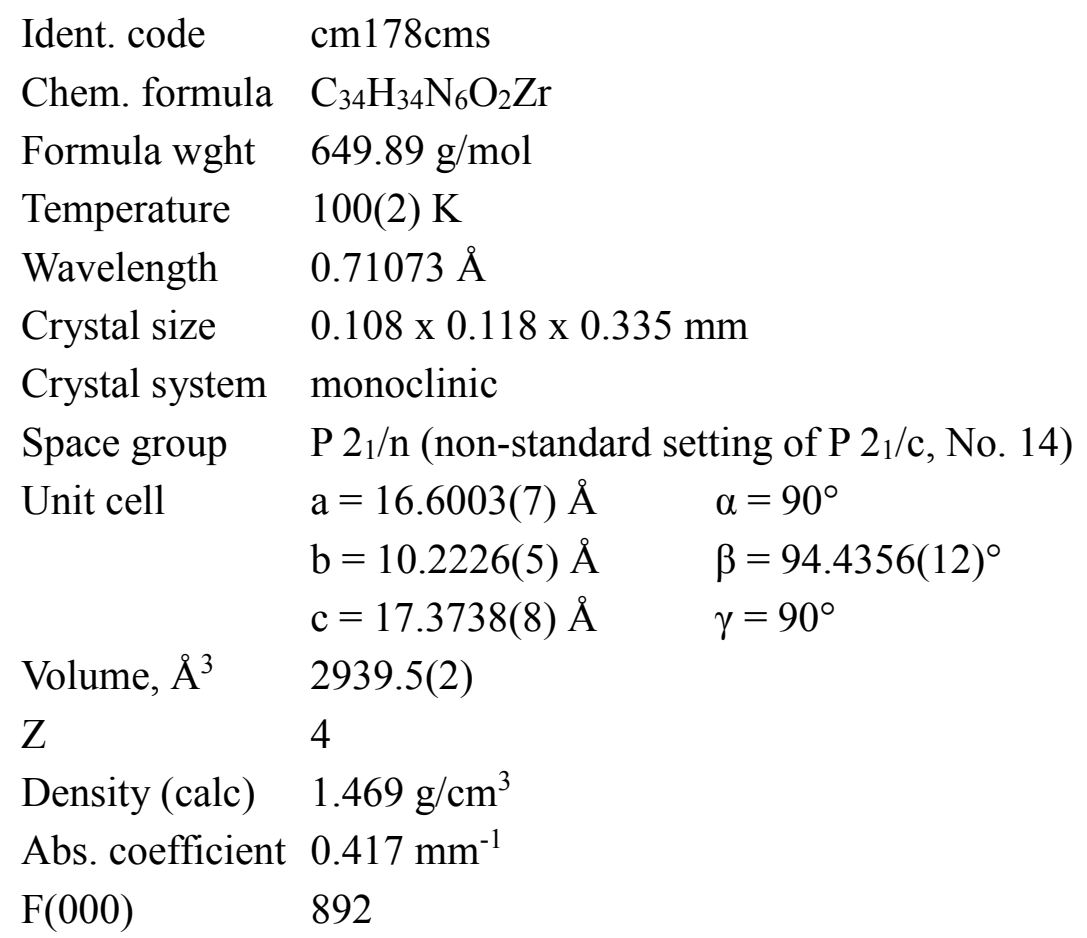

Table C30. Data collection and structure refinement for $\left(\mathrm{C}_{13} \mathrm{H}_{9} \mathrm{~N}_{3}\right)_{2} \mathrm{Zr}\left(\mathrm{OC}_{4} \mathrm{H}_{8}\right)_{2}$.

$\begin{array}{ll}\text { Theta range } & 3.08 \text { to } 30.11^{\circ} \\ \text { Index ranges } & -23 \leq \mathrm{h} \leq 23,-14 \leq \mathrm{k} \leq 14,-24 \leq 1 \leq 24 \\ \text { Reflections } & 65585 \\ \text { Independent refls } & 8641[\mathrm{R}(\text { int })=0.0483] \\ \text { Coverage } & 99.6 \% \\ \text { Absorption correction } & \text { multi-scan } \\ \text { Max. and min. trans. } & 0.956 \text { and } 0.873 \\ \text { Refinement method } & \text { Full-matrix least-squares on } \mathrm{F}^{2} \\ \text { Refinement program } & \text { SHELXL-2014/7 (Sheldrick, 2014) } \\ \text { Data / restrs / parms } & 8641 / 0 / 388 \\ \text { Goodness-of-fit on } \mathrm{F}^{2} & 1.033 \\ & 6690 \quad \text { data; } \mathrm{R} 1=0.0304, \mathrm{wR} 2=0.0622 \\ \text { Final R indices } & \mathrm{I}>2 \sigma(\mathrm{I}) \quad \mathrm{R} 1=0.0529, \mathrm{wR} 2=0.0697 \\ & \text { all data } \\ & \end{array}$

Largest diff. peak and 0.663 and $-0.468 \mathrm{e}^{-/} / \AA^{3}$

hole 
Table C31. Atomic coordinates and equivalent isotropic atomic displacement parameters $\left(\AA^{2}\right)$ for $\left(\mathrm{C}_{13} \mathrm{H}_{9} \mathrm{~N}_{3}\right)_{2} \mathrm{Zr}\left(\mathrm{OC}_{4} \mathrm{H}_{8}\right)_{2}$. U(eq) is defined as one third of the trace of the orthogonalized $\mathrm{U}_{\mathrm{ij}}$ tensor.

\begin{tabular}{|c|c|c|c|c|}
\hline & $\mathrm{x} / \mathrm{a}$ & $y / b$ & $\mathrm{z} / \mathrm{c}$ & $\mathrm{U}(\mathrm{eq})$ \\
\hline $\mathrm{Zr} 1$ & $0.73620(2)$ & $0.83619(2)$ & $0.50327(2)$ & $0.01123(4)$ \\
\hline $\mathrm{O} 1$ & $0.66508(7)$ & $0.65698(11)$ & $0.43619(6)$ & $0.0164(2)$ \\
\hline $\mathrm{O} 2$ & $0.67876(7)$ & $0.03614(11)$ & $0.54683(6)$ & $0.0161(2)$ \\
\hline $\mathrm{N} 1$ & $0.67862(8)$ & $0.91308(13)$ & $0.39297(8)$ & $0.0160(3)$ \\
\hline $\mathrm{N} 2$ & $0.80980(8)$ & $0.01233(13)$ & $0.46000(7)$ & $0.0137(3)$ \\
\hline N3 & $0.83263(8)$ & $0.89395(13)$ & $0.59263(7)$ & $0.0139(3)$ \\
\hline N4 & $0.64555(8)$ & $0.78666(13)$ & $0.58697(8)$ & $0.0161(3)$ \\
\hline N5 & $0.76994(8)$ & $0.64039(12)$ & $0.56621(7)$ & $0.0133(3)$ \\
\hline N6 & $0.83534(8)$ & $0.73717(12)$ & $0.44751(7)$ & $0.0132(3)$ \\
\hline $\mathrm{C} 1$ & $0.60855(10)$ & $0.88344(18)$ & $0.34916(9)$ & $0.0196(3)$ \\
\hline $\mathrm{C} 2$ & $0.60045(11)$ & $0.96140(18)$ & $0.28428(10)$ & $0.0235(4)$ \\
\hline $\mathrm{C} 3$ & $0.66814(11)$ & $0.04451(18)$ & $0.28708(10)$ & $0.0228(4)$ \\
\hline $\mathrm{C} 4$ & $0.71444(10)$ & $0.01323(16)$ & $0.35399(9)$ & $0.0166(3)$ \\
\hline $\mathrm{C} 5$ & $0.78750(10)$ & $0.06850(15)$ & $0.39118(9)$ & $0.0156(3)$ \\
\hline C6 & $0.83252(11)$ & $0.17063(16)$ & $0.36297(10)$ & $0.0206(3)$ \\
\hline $\mathrm{C} 7$ & $0.90080(11)$ & $0.21252(17)$ & $0.40652(10)$ & $0.0225(4)$ \\
\hline $\mathrm{C} 8$ & $0.92282(10)$ & $0.15668(16)$ & $0.47765(10)$ & $0.0190(3)$ \\
\hline C9 & $0.87506(9)$ & $0.05628(15)$ & $0.50372(9)$ & $0.0148(3)$ \\
\hline $\mathrm{C} 10$ & $0.88813(9)$ & $0.98954(15)$ & $0.57665(9)$ & $0.0142(3)$ \\
\hline C11 & $0.94862(10)$ & $0.99759(17)$ & $0.63588(9)$ & $0.0188(3)$ \\
\hline $\mathrm{C} 12$ & $0.93039(10)$ & $0.90321(17)$ & $0.69068(10)$ & $0.0192(3)$ \\
\hline C13 & $0.85983(9)$ & $0.84237(16)$ & $0.66262(9)$ & $0.0157(3)$ \\
\hline C14 & $0.57460(10)$ & $0.84250(17)$ & $0.60624(10)$ & $0.0191(3)$ \\
\hline $\mathrm{C} 15$ & $0.54608(11)$ & $0.77989(17)$ & $0.66900(10)$ & $0.0220(4)$ \\
\hline $\mathrm{C} 16$ & $0.60114(10)$ & $0.67977(17)$ & $0.69034(9)$ & $0.0206(3)$ \\
\hline $\mathrm{C} 17$ & $0.66062(10)$ & $0.68527(15)$ & $0.63890(9)$ & $0.0157(3)$ \\
\hline $\mathrm{C} 18$ & $0.72880(10)$ & $0.60237(15)$ & $0.62673(9)$ & $0.0155(3)$ \\
\hline C19 & $0.75191(10)$ & $0.49165(16)$ & $0.66942(9)$ & $0.0201(3)$ \\
\hline $\mathrm{C} 20$ & $0.81675(11)$ & $0.41878(17)$ & $0.64764(10)$ & $0.0227(4)$ \\
\hline $\mathrm{C} 21$ & $0.85669(10)$ & $0.45520(16)$ & $0.58380(10)$ & $0.0205(3)$ \\
\hline $\mathrm{C} 22$ & $0.83230(9)$ & $0.56860(15)$ & $0.54392(9)$ & $0.0151(3)$ \\
\hline $\mathrm{C} 23$ & $0.86758(9)$ & $0.62135(15)$ & $0.47723(9)$ & $0.0147(3)$ \\
\hline $\mathrm{C} 24$ & $0.92852(10)$ & $0.57845(16)$ & $0.43327(9)$ & $0.0170(3)$ \\
\hline
\end{tabular}




$\begin{array}{lcccc} & \mathrm{x} / \mathrm{a} & \mathrm{y} / \mathrm{b} & \mathrm{z} / \mathrm{c} & \mathrm{U}(\mathrm{eq}) \\ \mathrm{C} 25 & 0.93483(9) & 0.67160(16) & 0.37460(9) & 0.0168(3) \\ \mathrm{C} 26 & 0.87722(9) & 0.76620(16) & 0.38507(9) & 0.0148(3) \\ \mathrm{C} 27 & 0.61098(12) & 0.56319(19) & 0.46689(11) & 0.0289(4) \\ \mathrm{C} 28 & 0.56527(14) & 0.5045(2) & 0.39790(12) & 0.0384(5) \\ \mathrm{C} 29 & 0.62791(13) & 0.5026(2) & 0.33719(14) & 0.0425(6) \\ \mathrm{C} 30 & 0.69260(11) & 0.59969(18) & 0.36581(10) & 0.0234(4) \\ \mathrm{C} 31 & 0.69490(11) & 0.08049(18) & 0.62593(10) & 0.0228(4) \\ \mathrm{C} 32 & 0.62653(11) & 0.17505(18) & 0.64006(11) & 0.0263(4) \\ \mathrm{C} 33 & 0.59230(13) & 0.2150(2) & 0.55867(11) & 0.0334(5) \\ \mathrm{C} 34 & 0.64820(13) & 0.15003(18) & 0.50450(11) & 0.0294(4)\end{array}$




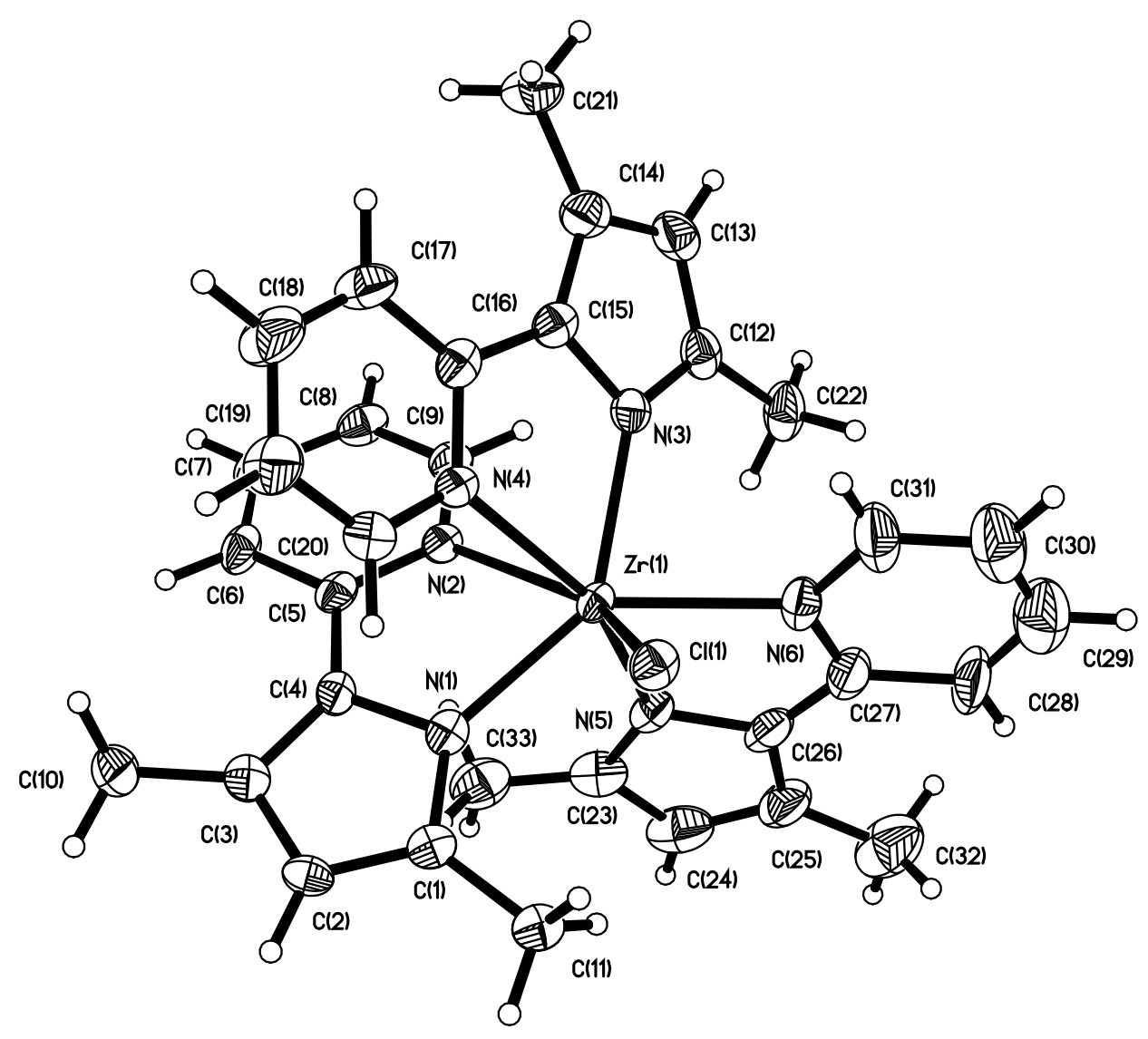

Figure C12. Perspective view of the molecular structure of $\left(\mathrm{C}_{11} \mathrm{H}_{11} \mathrm{~N}_{2}\right)_{3} \mathrm{ZrCl}$ with the atom labeling scheme for the independent non-hydrogen atoms. The thermal ellipsoids are scaled to enclose $50 \%$ probability. 
Table C32. Crystal data for $\left(\mathrm{C}_{11} \mathrm{H}_{11} \mathrm{~N}_{2}\right)_{3} \mathrm{ZrCl}$.

$\begin{array}{lll}\text { Identification code } & \mathrm{cm} 127 \mathrm{cms} \\ \text { Empirical formula } & \mathrm{C}_{33} \mathrm{H}_{33} \mathrm{ClN}_{6} \mathrm{Zr} & \\ \text { Emp. formula weight } & 640.32 \mathrm{~g} / \mathrm{mol} & \\ \text { Temperature } & 100(2) \mathrm{K} & \\ \text { Wavelength } & 0.71073 \AA & \\ \text { Crystal size } & 0.123 \times 0.258 \times 0.290 \mathrm{~mm} \\ \text { Crystal system } & \text { monoclinic } & \\ \text { Space group } & \mathrm{P} 21 / \mathrm{c}(\mathrm{No} .14) & \\ \text { Unit cell dimensions } & \mathrm{a}=11.3708(7) \AA \quad \quad \alpha=90^{\circ} \\ & \mathrm{b}=15.9897(10) \AA \quad \beta=94.2440(18)^{\circ} \\ & \mathrm{c}=15.9559(10) \AA & \gamma=90^{\circ} \\ \text { Volume } & 2893.1(3) \AA^{3} & \\ \text { Z } & 4 & \\ \text { Density (calculated) } & 1.470 \mathrm{~g} / \mathrm{cm}^{3} & \\ \text { Absorption coefficient } & 0.507 \mathrm{~mm}^{-1} & \\ \text { F(000) } & 1320 & \end{array}$

Table C33. Data collection and structure refinement for $\left(\mathrm{C}_{11} \mathrm{H}_{11} \mathrm{~N}_{2}\right)_{3} \mathrm{ZrCl}$.

\begin{tabular}{|c|c|}
\hline Theta range & 2.85 to $25.00^{\circ}$ \\
\hline Index ranges & $-13 \leq \mathrm{h} \leq 13,-19 \leq \mathrm{k} \leq 19,-18 \leq 1 \leq 18$ \\
\hline Reflections & 61507 \\
\hline Independent reflections & $5088[\mathrm{R}(\mathrm{int})=0.0802]$ \\
\hline \multicolumn{2}{|c|}{$\begin{array}{l}\text { Coverage of independent } 99.8 \% \\
\text { reflections }\end{array}$} \\
\hline Absorption correction & multi-scan \\
\hline Max. and min. trans. & 0.940 and 0.867 \\
\hline Refinement method & Full-matrix least-squares on $\mathrm{F}^{2}$ \\
\hline Refinement program & SHELXL-2014/7 (Sheldrick, 2014) \\
\hline $\begin{array}{ll}\text { Data } / \text { restraints } \\
\text { parameters }\end{array}$ & / $5088 / 0 / 376$ \\
\hline Goodness-of-fit on $\mathrm{F}^{2}$ & 1.115 \\
\hline Final $\mathrm{R}$ indices & 3799 data; $\mathrm{I}>2 \sigma(\mathrm{I}) \mathrm{R} 1=0.0541, \mathrm{wR} 2=0.1114$ \\
\hline & $\mathrm{R} 1=0.0850, \mathrm{wR} 2=0.1294$ \\
\hline
\end{tabular}

Largest diff. peak and hole 0.867 and $-0.609 \mathrm{e}^{-/} / \AA^{3}$ 
Table C34. Atomic coordinates and equivalent isotropic atomic displacement parameters $\left(\AA^{2}\right)$ for $\left(\mathrm{C}_{11} \mathrm{H}_{11} \mathrm{~N}_{2}\right)_{3} \mathrm{ZrCl}$. U(eq) is defined as one third of the trace of the orthogonalized $\mathrm{U}_{\mathrm{ij}}$ tensor.

\begin{tabular}{|c|c|c|c|c|}
\hline & $\mathrm{x} / \mathrm{a}$ & $y / b$ & $\mathrm{z} / \mathrm{c}$ & $\mathrm{U}(\mathrm{eq})$ \\
\hline $\mathrm{Zr} 1$ & $0.75059(4)$ & $0.00472(3)$ & $0.78123(3)$ & $0.02008(14)$ \\
\hline $\mathrm{Cl1}$ & $0.83849(11)$ & $0.89638(7)$ & $0.87592(8)$ & $0.0272(3)$ \\
\hline N1 & $0.8832(3)$ & $0.0930(2)$ & $0.8367(2)$ & $0.0221(9)$ \\
\hline $\mathrm{N} 2$ & $0.7914(3)$ & $0.1095(2)$ & $0.6826(2)$ & $0.0218(9)$ \\
\hline N3 & $0.6866(4)$ & $0.9488(2)$ & $0.6588(2)$ & $0.0241(9)$ \\
\hline N4 & $0.9151(3)$ & $0.9594(2)$ & $0.7111(2)$ & $0.0208(9)$ \\
\hline N5 & $0.6241(4)$ & $0.0959(3)$ & $0.8304(3)$ & $0.0266(10)$ \\
\hline N6 & $0.5885(4)$ & $0.9325(3)$ & $0.8211(3)$ & $0.0303(10)$ \\
\hline $\mathrm{C} 1$ & $0.9358(4)$ & $0.1036(3)$ & $0.9156(3)$ & $0.0227(11)$ \\
\hline $\mathrm{C} 2$ & $0.0351(4)$ & $0.1531(3)$ & $0.9110(3)$ & $0.0249(11)$ \\
\hline $\mathrm{C} 3$ & $0.0438(4)$ & $0.1771(3)$ & $0.8275(3)$ & $0.0256(11)$ \\
\hline $\mathrm{C} 4$ & $0.9467(4)$ & $0.1405(3)$ & $0.7825(3)$ & $0.0228(11)$ \\
\hline $\mathrm{C} 5$ & $0.8949(4)$ & $0.1514(3)$ & $0.6994(3)$ & $0.0233(11)$ \\
\hline C6 & $0.9379(5)$ & $0.2041(3)$ & $0.6380(3)$ & $0.0310(13)$ \\
\hline $\mathrm{C} 7$ & $0.8720(5)$ & $0.2161(3)$ & $0.5637(3)$ & $0.0335(13)$ \\
\hline $\mathrm{C} 8$ & $0.7648(5)$ & $0.1770(3)$ & $0.5493(3)$ & $0.0310(12)$ \\
\hline $\mathrm{C} 9$ & $0.7290(4)$ & $0.1233(3)$ & $0.6090(3)$ & $0.0256(11)$ \\
\hline $\mathrm{C} 10$ & $0.1378(5)$ & $0.2303(3)$ & $0.7942(4)$ & $0.0370(14)$ \\
\hline $\mathrm{C} 11$ & $0.8830(5)$ & $0.0702(3)$ & $0.9920(3)$ & $0.0281(12)$ \\
\hline $\mathrm{C} 12$ & $0.5788(5)$ & $0.9408(3)$ & $0.6160(3)$ & $0.0288(12)$ \\
\hline $\mathrm{C} 13$ & $0.5932(5)$ & $0.9091(3)$ & $0.5368(3)$ & $0.0351(13)$ \\
\hline C14 & $0.7123(5)$ & $0.8982(3)$ & $0.5282(3)$ & $0.0327(13)$ \\
\hline $\mathrm{C} 15$ & $0.7690(4)$ & $0.9246(3)$ & $0.6035(3)$ & $0.0254(11)$ \\
\hline $\mathrm{C} 16$ & $0.8925(4)$ & $0.9314(3)$ & $0.6313(3)$ & $0.0255(11)$ \\
\hline $\mathrm{C} 17$ & $0.9869(5)$ & $0.9125(4)$ & $0.5835(4)$ & $0.0372(14)$ \\
\hline C18 & $0.1000(5)$ & $0.9210(4)$ & $0.6179(4)$ & $0.0467(16)$ \\
\hline C19 & $0.1215(5)$ & $0.9458(4)$ & $0.6997(4)$ & $0.0379(14)$ \\
\hline $\mathrm{C} 20$ & $0.0264(4)$ & $0.9643(3)$ & $0.7442(3)$ & $0.0279(12)$ \\
\hline $\mathrm{C} 21$ & $0.7650(6)$ & $0.8624(4)$ & $0.4515(4)$ & $0.0448(15)$ \\
\hline $\mathrm{C} 22$ & $0.4646(4)$ & $0.9663(4)$ & $0.6499(4)$ & $0.0375(14)$ \\
\hline $\mathrm{C} 23$ & $0.6237(5)$ & $0.1801(3)$ & $0.8450(3)$ & $0.0341(13)$ \\
\hline $\mathrm{C} 24$ & $0.5219(6)$ & $0.1999(5)$ & $0.8881(4)$ & $0.0504(17)$ \\
\hline $\mathrm{C} 25$ & $0.4596(5)$ & $0.1268(4)$ & $0.9002(4)$ & $0.0446(16)$ \\
\hline
\end{tabular}




$\begin{array}{lcccc} & \mathrm{x} / \mathrm{a} & \mathrm{y} / \mathrm{b} & \mathrm{z} / \mathrm{c} & \mathrm{U}(\mathrm{eq}) \\ \mathrm{C} 26 & 0.5231(5) & 0.0634(4) & 0.8644(3) & 0.0347(13) \\ \mathrm{C} 27 & 0.5054(5) & 0.9757(4) & 0.8589(3) & 0.0385(14) \\ \mathrm{C} 28 & 0.4078(5) & 0.9326(5) & 0.8875(4) & 0.0517(18) \\ \mathrm{C} 29 & 0.4036(6) & 0.8481(5) & 0.8760(5) & 0.0590(19) \\ \mathrm{C} 30 & 0.4880(6) & 0.8034(5) & 0.8391(5) & 0.059(2) \\ \mathrm{C} 31 & 0.5772(6) & 0.8463(4) & 0.8118(4) & 0.0509(18) \\ \mathrm{C} 32 & 0.3523(6) & 0.1185(5) & 0.9455(5) & 0.066(2) \\ \mathrm{C} 33 & 0.7110(6) & 0.2404(4) & 0.8228(4) & 0.0459(16)\end{array}$




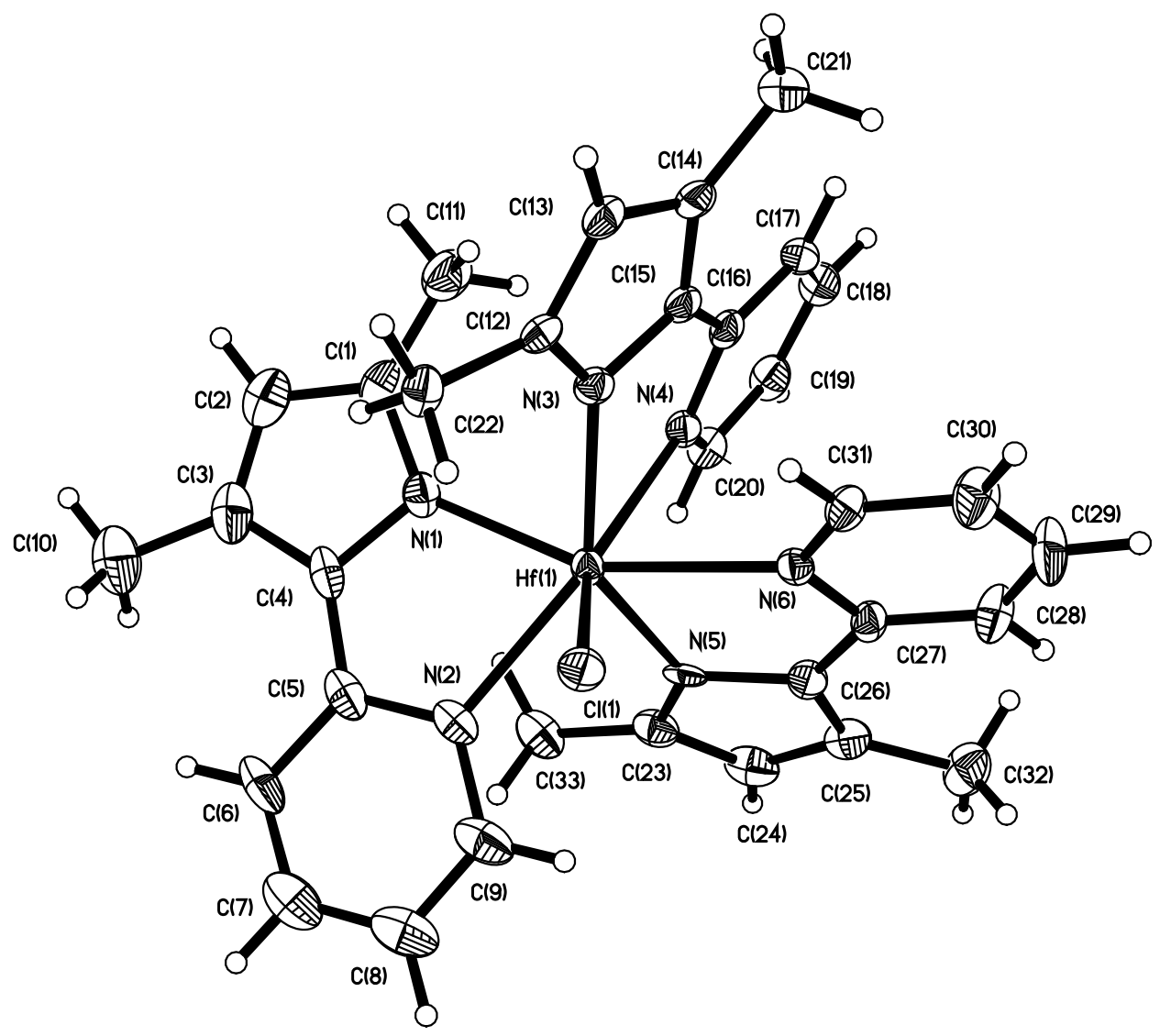

Figure C13. Perspective view of the molecular structure of $\left(\mathrm{C}_{11} \mathrm{H}_{11} \mathrm{~N}_{2}\right)_{3} \mathrm{HfCl}$ with the atom labeling scheme for the independent non-hydrogen atoms. The thermal ellipsoids are scaled to enclose $50 \%$ probability. 
Table C35. Crystal data for $\left(\mathrm{C}_{11} \mathrm{H}_{11} \mathrm{~N}_{2}\right)_{3} \mathrm{HfCl}$.

$\begin{array}{lll}\text { Identification code } & \mathrm{cm} 120 \mathrm{cms} \\ \text { Empirical formula } & \mathrm{C}_{33} \mathrm{H}_{33} \mathrm{ClN}_{6} \mathrm{Hf} & \\ \text { Emp. formula weight } & 727.59 \mathrm{~g} / \mathrm{mol} & \\ \text { Temperature } & 100(2) \mathrm{K} & \\ \text { Wavelength } & 0.71073 \AA \\ \text { Crystal size } & 0.110 \times 0.192 \times 0.247 \mathrm{~mm} \\ \text { Crystal system } & \text { monoclinic } & \\ \text { Space group } & \mathrm{P} 21 / \mathrm{c}(\mathrm{No} .14) & \\ \text { Unit cell dimensions } & \mathrm{a}=11.3847(5) \AA & \alpha=90^{\circ} \\ & \mathrm{b}=16.0130(7) \AA & \beta=94.2195(13)^{\circ} \\ & \mathrm{c}=15.8448(7) \AA & \gamma=90^{\circ} \\ \text { Volume } & 2880.7(2) \AA^{3} & \\ \text { Z } & 4 \\ \text { Density (calculated) } & 1.678 \mathrm{~g} / \mathrm{cm}^{3} & \\ \text { Absorption coefficient } & 3.748 \mathrm{~mm}^{-1} & \\ \text { F(000) } & 1448\end{array}$

Table C36. Data collection and structure refinement for $\left(\mathrm{C}_{11} \mathrm{H}_{11} \mathrm{~N}_{2}\right)_{3} \mathrm{HfCl}$.

\begin{tabular}{|c|c|}
\hline Theta range & 3.11 to $27.50^{\circ}$ \\
\hline Index ranges & $-14 \leq \mathrm{h} \leq 14,-20 \leq \mathrm{k} \leq 20,-20 \leq 1 \leq 19$ \\
\hline Reflections & 27315 \\
\hline Independent reflections & $6615[\mathrm{R}(\mathrm{int})=0.0419]$ \\
\hline \multicolumn{2}{|c|}{$\begin{array}{l}\text { Coverage of independent } 99.8 \% \\
\text { reflections }\end{array}$} \\
\hline Absorption correction & multi-scan \\
\hline Max. and min. trans. & 0.683 and 0.458 \\
\hline Refinement method & Full-matrix least-squares on $\mathrm{F}^{2}$ \\
\hline Refinement program & SHELXL-2014/7 (Sheldrick, 2014) \\
\hline $\begin{array}{l}\text { Data / restraints } \\
\text { parameters }\end{array}$ & / 6615 / 0 / 377 \\
\hline Goodness-of-fit on $\mathrm{F}^{2}$ & 1.062 \\
\hline Final $\mathrm{R}$ indices & 4861 data; $\mathrm{I}>2 \sigma(\mathrm{I}) \mathrm{R} 1=0.0341, \mathrm{wR} 2=0.0611$ \\
\hline & $\mathrm{R} 1=0.0611, \mathrm{wR} 2=0.0720$ \\
\hline
\end{tabular}

Largest diff. peak and hole 2.865 and $-1.783 \mathrm{e}^{-/} \AA^{3}$ 
Table C37. Atomic coordinates and equivalent isotropic atomic displacement parameters $\left(\AA^{2}\right)$ for $\left(\mathrm{C}_{11} \mathrm{H}_{11} \mathrm{~N}_{2}\right)_{3} \mathrm{HfCl}$. U(eq) is defined as one third of the trace of the orthogonalized $\mathrm{U}_{\mathrm{i}}$ tensor.

\begin{tabular}{|c|c|c|c|c|}
\hline & $\mathrm{x} / \mathrm{a}$ & $y / b$ & $\mathrm{z} / \mathrm{c}$ & $\mathrm{U}(\mathrm{eq})$ \\
\hline Hf1 & $0.24965(2)$ & $0.00509(2)$ & $0.21929(2)$ & $0.01667(6)$ \\
\hline $\mathrm{C} 11$ & $0.16283(11)$ & $0.89854(7)$ & $0.12343(8)$ & $0.0238(3)$ \\
\hline $\mathrm{N} 1$ & $0.3759(4)$ & $0.0960(3)$ & $0.1708(3)$ & $0.0231(9)$ \\
\hline $\mathrm{N} 2$ & $0.4103(4)$ & $0.9330(3)$ & $0.1791(3)$ & $0.0250(10)$ \\
\hline $\mathrm{N} 3$ & $0.1173(3)$ & $0.0930(2)$ & $0.1632(2)$ & $0.0191(8)$ \\
\hline $\mathrm{N} 4$ & $0.2106(3)$ & $0.1089(2)$ & $0.3185(2)$ & $0.0192(8)$ \\
\hline N5 & $0.3138(4)$ & $0.9491(2)$ & $0.3409(2)$ & $0.0192(9)$ \\
\hline N6 & $0.0859(3)$ & $0.9601(2)$ & $0.2886(2)$ & $0.0177(8)$ \\
\hline $\mathrm{C} 1$ & $0.3763(5)$ & $0.1807(3)$ & $0.1568(3)$ & $0.0282(12)$ \\
\hline $\mathrm{C} 2$ & $0.4777(5)$ & $0.2003(4)$ & $0.1153(4)$ & $0.0391(14)$ \\
\hline $\mathrm{C} 3$ & $0.5401(5)$ & $0.1276(4)$ & $0.1019(4)$ & $0.0361(14)$ \\
\hline $\mathrm{C} 4$ & $0.4768(5)$ & $0.0636(3)$ & $0.1359(3)$ & $0.0264(12)$ \\
\hline $\mathrm{C} 5$ & $0.4938(5)$ & $0.9758(3)$ & $0.1413(3)$ & $0.0283(12)$ \\
\hline C6 & $0.5903(5)$ & $0.9330(4)$ & $0.1113(4)$ & $0.0395(15)$ \\
\hline $\mathrm{C} 7$ & $0.5957(6)$ & $0.8484(4)$ & $0.1213(4)$ & $0.0455(16)$ \\
\hline $\mathrm{C} 8$ & $0.5111(6)$ & $0.8046(4)$ & $0.1604(4)$ & $0.0461(16)$ \\
\hline $\mathrm{C} 9$ & $0.4208(5)$ & $0.8481(4)$ & $0.1884(4)$ & $0.0362(14)$ \\
\hline $\mathrm{C} 10$ & $0.6492(5)$ & $0.1207(5)$ & $0.0568(4)$ & $0.0488(17)$ \\
\hline $\mathrm{C} 11$ & $0.2880(5)$ & $0.2413(3)$ & $0.1795(4)$ & $0.0364(14)$ \\
\hline $\mathrm{C} 12$ & $0.0650(4)$ & $0.1039(3)$ & $0.0846(3)$ & $0.0193(10)$ \\
\hline C13 & $0.9667(4)$ & $0.1540(3)$ & $0.0895(3)$ & $0.0218(10)$ \\
\hline C14 & $0.9580(4)$ & $0.1778(3)$ & $0.1740(3)$ & $0.0213(10)$ \\
\hline $\mathrm{C} 15$ & $0.0541(4)$ & $0.1400(3)$ & $0.2179(3)$ & $0.0197(10)$ \\
\hline $\mathrm{C} 16$ & $0.1077(4)$ & $0.1509(3)$ & $0.3024(3)$ & $0.0199(10)$ \\
\hline $\mathrm{C} 17$ & $0.0657(5)$ & $0.2032(3)$ & $0.3642(3)$ & $0.0263(12)$ \\
\hline $\mathrm{C} 18$ & $0.1315(5)$ & $0.2151(3)$ & $0.4388(3)$ & $0.0288(12)$ \\
\hline C19 & $0.2395(5)$ & $0.1759(3)$ & $0.4522(3)$ & $0.0273(12)$ \\
\hline $\mathrm{C} 20$ & $0.2740(4)$ & $0.1223(3)$ & $0.3919(3)$ & $0.0220(10)$ \\
\hline $\mathrm{C} 21$ & $0.8641(5)$ & $0.2314(3)$ & $0.2073(4)$ & $0.0315(13)$ \\
\hline $\mathrm{C} 22$ & $0.1170(5)$ & $0.0709(3)$ & $0.0068(3)$ & $0.0241(11)$ \\
\hline $\mathrm{C} 23$ & $0.4222(5)$ & $0.9400(3)$ & $0.3839(3)$ & $0.0254(11)$ \\
\hline $\mathrm{C} 24$ & $0.4076(5)$ & $0.9086(3)$ & $0.4637(3)$ & $0.0296(12)$ \\
\hline $\mathrm{C} 25$ & $0.2874(5)$ & $0.8974(3)$ & $0.4728(3)$ & $0.0263(11)$ \\
\hline
\end{tabular}




$\begin{array}{lcccc} & \mathrm{x} / \mathrm{a} & \mathrm{y} / \mathrm{b} & \mathrm{z} / \mathrm{c} & \mathrm{U}(\mathrm{eq}) \\ \mathrm{C} 26 & 0.2312(4) & 0.9247(3) & 0.3973(3) & 0.0226(11) \\ \mathrm{C} 27 & 0.1083(4) & 0.9316(3) & 0.3693(3) & 0.0203(10) \\ \mathrm{C} 28 & 0.0140(5) & 0.9124(3) & 0.4165(3) & 0.0318(13) \\ \mathrm{C} 29 & 0.9006(5) & 0.9214(4) & 0.3823(4) & 0.0398(15) \\ \mathrm{C} 30 & 0.8794(5) & 0.9464(4) & 0.2996(4) & 0.0325(13) \\ \mathrm{C} 31 & 0.9747(4) & 0.9654(3) & 0.2552(3) & 0.0215(10) \\ \mathrm{C} 32 & 0.2363(5) & 0.8622(4) & 0.5503(3) & 0.0366(14) \\ \mathrm{C} 33 & 0.5356(5) & 0.9655(4) & 0.3496(3) & 0.0305(12)\end{array}$




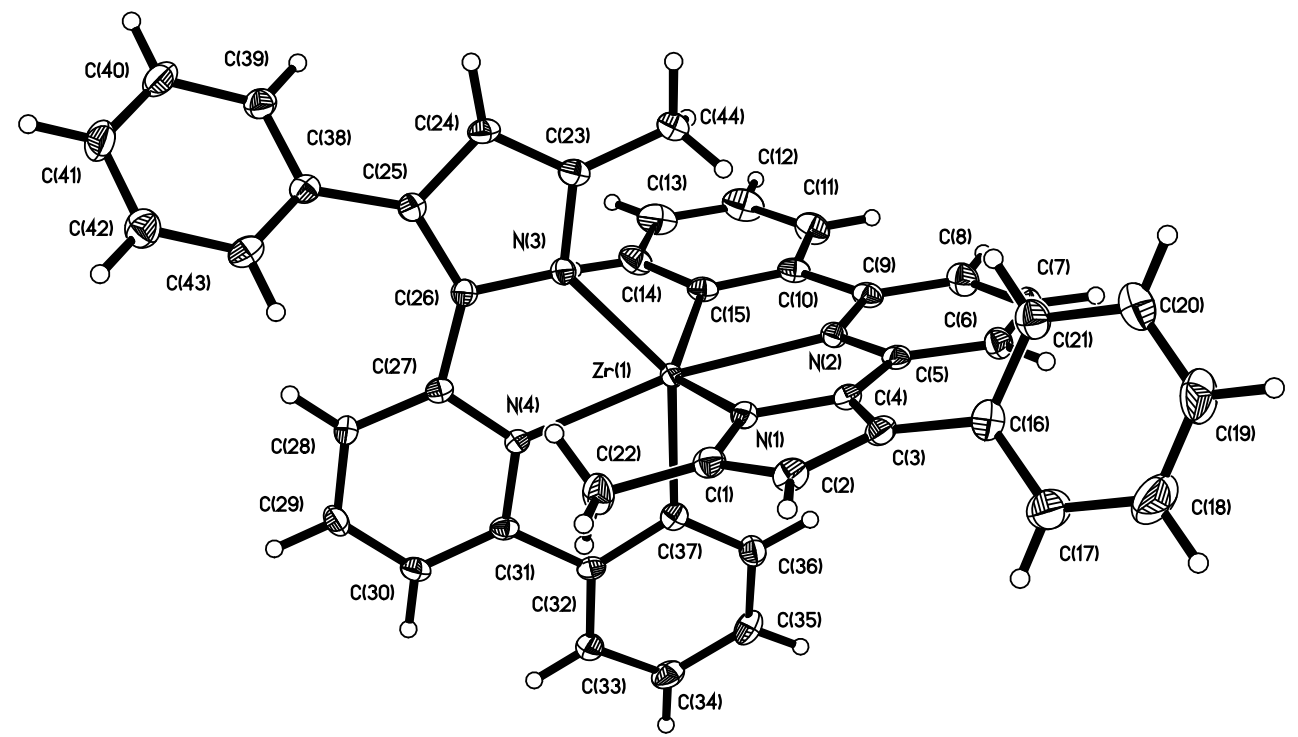

Figure C14. Perspective view of the molecular structure of $\left(\mathrm{C}_{22} \mathrm{H}_{16} \mathrm{~N}_{2}\right)_{2} \mathrm{Zr}$ with the atom labeling scheme for the independent non-hydrogen atoms. The thermal ellipsoids are scaled to enclose $50 \%$ probability. 
Table C38. Crystal data for $\left(\mathrm{C}_{22} \mathrm{H}_{16} \mathrm{~N}_{2}\right)_{2} \mathrm{Zr} \cdot \mathrm{OEt}_{2}$.

$\begin{array}{lll}\text { Identification code } & \mathrm{cm} 187 \mathrm{cms} \\ \text { Empirical formula } & \mathrm{C}_{48} \mathrm{H}_{42} \mathrm{~N}_{4} \mathrm{OZr} & \\ \text { Formula weight } & 782.07 \mathrm{~g} / \mathrm{mol} & \\ \text { Temperature } & 100(2) \mathrm{K} \\ \text { Wavelength } & 0.71073 \AA \\ \text { Crystal size } & 0.044 \times 0.090 \times 0.372 \mathrm{~mm} \\ \text { Crystal system } & \text { monoclinic } & \\ \text { Space group } & \mathrm{C} 2 / \mathrm{c}(\mathrm{No} .15) & \\ \text { Unit cell dimensions } & \mathrm{a}=39.3653(14) \AA \quad \alpha=90^{\circ} \\ & \mathrm{b}=8.6789(3) \AA & \beta=127.5366(10)^{\circ} \\ & \mathrm{c}=27.6486(11) \AA & \gamma=90^{\circ} \\ \text { Volume } & 7490.4(5) \AA^{3} & \\ \text { Z } & 8 & \\ \text { Density (calc.) } & 1.387 \mathrm{~g} / \mathrm{cm}^{3} & \\ \text { Abs. coefficient } & 0.337 \mathrm{~mm}^{-1} & \\ \text { F(000) } & 3248\end{array}$

Table C39. Data collection and structure refinement for $\left(\mathrm{C}_{22} \mathrm{H}_{16} \mathrm{~N}_{2}\right)_{2} \mathrm{Zr} \cdot \mathrm{OEt}_{2}$.

$\begin{array}{ll}\text { Theta range } & 2.89 \text { to } 27.43^{\circ} \\ \text { Index ranges } & -50 \leq \mathrm{h} \leq 50,-11 \leq \mathrm{k} \leq 11,-35 \leq 1 \leq 35 \\ \text { Reflections } & 38295 \\ \text { Independent reflections } & 8504[\mathrm{R}(\mathrm{int})=0.0484] \\ \text { Coverage } & 99.5 \% \\ \text { Absorption correction } & \text { multi-scan } \\ \text { Max. and min. trans. } & 0.985 \text { and } 0.885 \\ \text { Refinement method } & \text { Full-matrix least-squares on } \mathrm{F}^{2} \\ \text { Refinement program } & \text { SHELXL-2014/7 (Sheldrick, 2014) } \\ \text { Data / restraints } & / 8504 / 0 / 491 \\ \text { parameters } & 1.005 \quad \text { data; } \mathrm{R} 1=0.0363, \mathrm{wR} 2=0.0780 \\ \text { Goodness-of-fit on } \mathrm{F}^{2} & 6333 \quad \mathrm{R} 1=0.0638, \mathrm{wR} 2=0.0855 \\ \text { Final R indices } & \mathrm{I}>2 \sigma(\mathrm{I}) \quad \text { all data } \\ & 0.407 \text { and }-0.568 \mathrm{e}^{-} / \AA^{3}\end{array}$


Table C40. Atomic coordinates and equivalent isotropic atomic displacement parameters $\left(\AA^{2}\right)$ for $\left(\mathrm{C}_{22} \mathrm{H}_{16} \mathrm{~N}_{2}\right)_{2} \mathrm{Zr} \cdot \mathrm{OEt}_{2}$. U(eq) is defined as one third of the trace of the orthogonalized $\mathrm{U}_{\mathrm{ij}}$ tensor.

\begin{tabular}{|c|c|c|c|c|}
\hline & $\mathrm{x} / \mathrm{a}$ & $\mathrm{y} / \mathrm{b}$ & $\mathrm{z} / \mathrm{c}$ & $\mathrm{U}(\mathrm{eq})$ \\
\hline $\mathrm{Zr} 1$ & $0.88240(2)$ & $0.12809(2)$ & $0.57846(2)$ & $0.01178(6)$ \\
\hline N1 & $0.90839(5)$ & $0.9327(2)$ & $0.56110(7)$ & $0.0143(4)$ \\
\hline $\mathrm{N} 2$ & $0.95024(5)$ & $0.1870(2)$ & $0.60745(7)$ & $0.0138(4)$ \\
\hline N3 & $0.87449(5)$ & $0.02981(19)$ & $0.64316(7)$ & $0.0138(4)$ \\
\hline $\mathrm{N} 4$ & $0.81007(5)$ & $0.08076(19)$ & $0.53303(7)$ & $0.0124(4)$ \\
\hline $\mathrm{C} 1$ & $0.89178(7)$ & $0.7894(2)$ & $0.53622(9)$ & $0.0175(5)$ \\
\hline $\mathrm{C} 2$ & $0.92076(7)$ & $0.7069(2)$ & $0.53443(10)$ & $0.0180(5)$ \\
\hline $\mathrm{C} 3$ & $0.95765(7)$ & $0.7981(2)$ & $0.55972(9)$ & $0.0167(5)$ \\
\hline $\mathrm{C} 4$ & $0.94893(6)$ & $0.9374(2)$ & $0.57487(9)$ & $0.0141(4)$ \\
\hline $\mathrm{C} 5$ & $0.97086(6)$ & $0.0826(2)$ & $0.59710(9)$ & $0.0142(4)$ \\
\hline $\mathrm{C} 6$ & $0.00953(7)$ & $0.1205(3)$ & $0.60770(9)$ & $0.0185(5)$ \\
\hline $\mathrm{C} 7$ & $0.02697(7)$ & $0.2638(3)$ & $0.63064(10)$ & $0.0213(5)$ \\
\hline $\mathrm{C} 8$ & $0.00678(7)$ & $0.3678(3)$ & $0.64378(10)$ & $0.0213(5)$ \\
\hline C9 & $0.96833(7)$ & $0.3280(2)$ & $0.63181(9)$ & $0.0162(5)$ \\
\hline $\mathrm{C} 10$ & $0.94367(7)$ & $0.4206(2)$ & $0.64523(9)$ & $0.0171(5)$ \\
\hline $\mathrm{C} 11$ & $0.95721(7)$ & $0.5661(3)$ & $0.67278(10)$ & $0.0232(5)$ \\
\hline $\mathrm{C} 12$ & $0.93367(8)$ & $0.6432(3)$ & $0.68719(11)$ & $0.0279(6)$ \\
\hline C13 & $0.89760(8)$ & $0.5770(3)$ & $0.67539(10)$ & $0.0267(6)$ \\
\hline $\mathrm{C} 14$ & $0.88426(7)$ & $0.4330(3)$ & $0.64787(10)$ & $0.0218(5)$ \\
\hline $\mathrm{C} 15$ & $0.90626(7)$ & $0.3514(2)$ & $0.63104(9)$ & $0.0168(5)$ \\
\hline $\mathrm{C} 16$ & $0.99760(7)$ & $0.7491(2)$ & $0.57024(10)$ & $0.0201(5)$ \\
\hline $\mathrm{C} 17$ & $0.99806(8)$ & $0.7070(3)$ & $0.52219(12)$ & $0.0335(6)$ \\
\hline C18 & $0.03579(9)$ & $0.6566(4)$ & $0.53310(13)$ & $0.0436(7)$ \\
\hline C19 & $0.07300(8)$ & $0.6466(3)$ & $0.59187(13)$ & $0.0349(6)$ \\
\hline $\mathrm{C} 20$ & $0.07324(8)$ & $0.6876(3)$ & $0.63971(12)$ & $0.0274(5)$ \\
\hline $\mathrm{C} 21$ & $0.03598(7)$ & $0.7397(3)$ & $0.62934(10)$ & $0.0218(5)$ \\
\hline $\mathrm{C} 22$ & $0.84852(7)$ & $0.7420(3)$ & $0.51611(11)$ & $0.0229(5)$ \\
\hline $\mathrm{C} 23$ & $0.90468(7)$ & $0.0127(2)$ & $0.70515(9)$ & $0.0156(4)$ \\
\hline $\mathrm{C} 24$ & $0.88576(6)$ & $0.9510(2)$ & $0.72892(9)$ & $0.0159(4)$ \\
\hline $\mathrm{C} 25$ & $0.84193(6)$ & $0.9238(2)$ & $0.68058(9)$ & $0.0140(4)$ \\
\hline $\mathrm{C} 26$ & $0.83583(6)$ & $0.9769(2)$ & $0.62810(9)$ & $0.0135(4)$ \\
\hline $\mathrm{C} 27$ & $0.79942(6)$ & $0.0059(2)$ & $0.56552(9)$ & $0.0125(4)$ \\
\hline $\mathrm{C} 28$ & $0.75658(6)$ & $0.9717(2)$ & $0.53852(9)$ & $0.0153(4)$ \\
\hline $\mathrm{C} 29$ & $0.72551(7)$ & $0.0152(3)$ & $0.47890(10)$ & $0.0181(5)$ \\
\hline
\end{tabular}




$\begin{array}{lcccc} & \mathrm{x} / \mathrm{a} & \mathrm{y} / \mathrm{b} & \mathrm{z} / \mathrm{c} & \mathrm{U}(\mathrm{eq}) \\ \mathrm{C} 30 & 0.73641(7) & 0.0936(2) & 0.44657(9) & 0.0174(5) \\ \mathrm{C} 31 & 0.77900(6) & 0.1269(2) & 0.47483(9) & 0.0136(4) \\ \mathrm{C} 32 & 0.79535(6) & 0.2172(2) & 0.44748(9) & 0.0142(4) \\ \mathrm{C} 33 & 0.76812(7) & 0.2903(3) & 0.39105(9) & 0.0187(5) \\ \text { C34 } & 0.78493(7) & 0.3837(3) & 0.36977(10) & 0.0210(5) \\ \mathrm{C} 35 & 0.82879(7) & 0.4004(3) & 0.40408(10) & 0.0221(5) \\ \mathrm{C} 36 & 0.85574(7) & 0.3253(3) & 0.45955(10) & 0.0190(5) \\ \text { C37 } & 0.84021(7) & 0.2328(2) & 0.48374(9) & 0.0148(4) \\ \text { C38 } & 0.81267(6) & 0.8482(2) & 0.68979(9) & 0.0152(4) \\ \text { C39 } & 0.81547(7) & 0.8843(3) & 0.74145(10) & 0.0199(5) \\ \text { C40 } & 0.79076(7) & 0.8063(3) & 0.75395(11) & 0.0255(5) \\ \text { C41 } & 0.76271(8) & 0.6924(3) & 0.71490(11) & 0.0273(6) \\ \text { C42 } & 0.75949(8) & 0.6551(3) & 0.66359(11) & 0.0246(5) \\ \text { C43 } & 0.78443(7) & 0.7313(2) & 0.65131(10) & 0.0198(5) \\ \text { C44 } & 0.95020(7) & 0.0581(3) & 0.73594(10) & 0.0211(5) \\ \text { O1 } & 0.87060(5) & 0.79261(19) & 0.32912(7) & 0.0272(4) \\ \text { C45 } & 0.89050(9) & 0.9632(3) & 0.41004(12) & 0.0374(7) \\ \text { C46 } & 0.86639(9) & 0.8210(3) & 0.37547(11) & 0.0335(6) \\ \text { C47 } & 0.84384(8) & 0.6734(3) & 0.28859(11) & 0.0302(6) \\ \text { C48 } & 0.85155(8) & 0.6493(3) & 0.24261(11) & 0.0306(6)\end{array}$




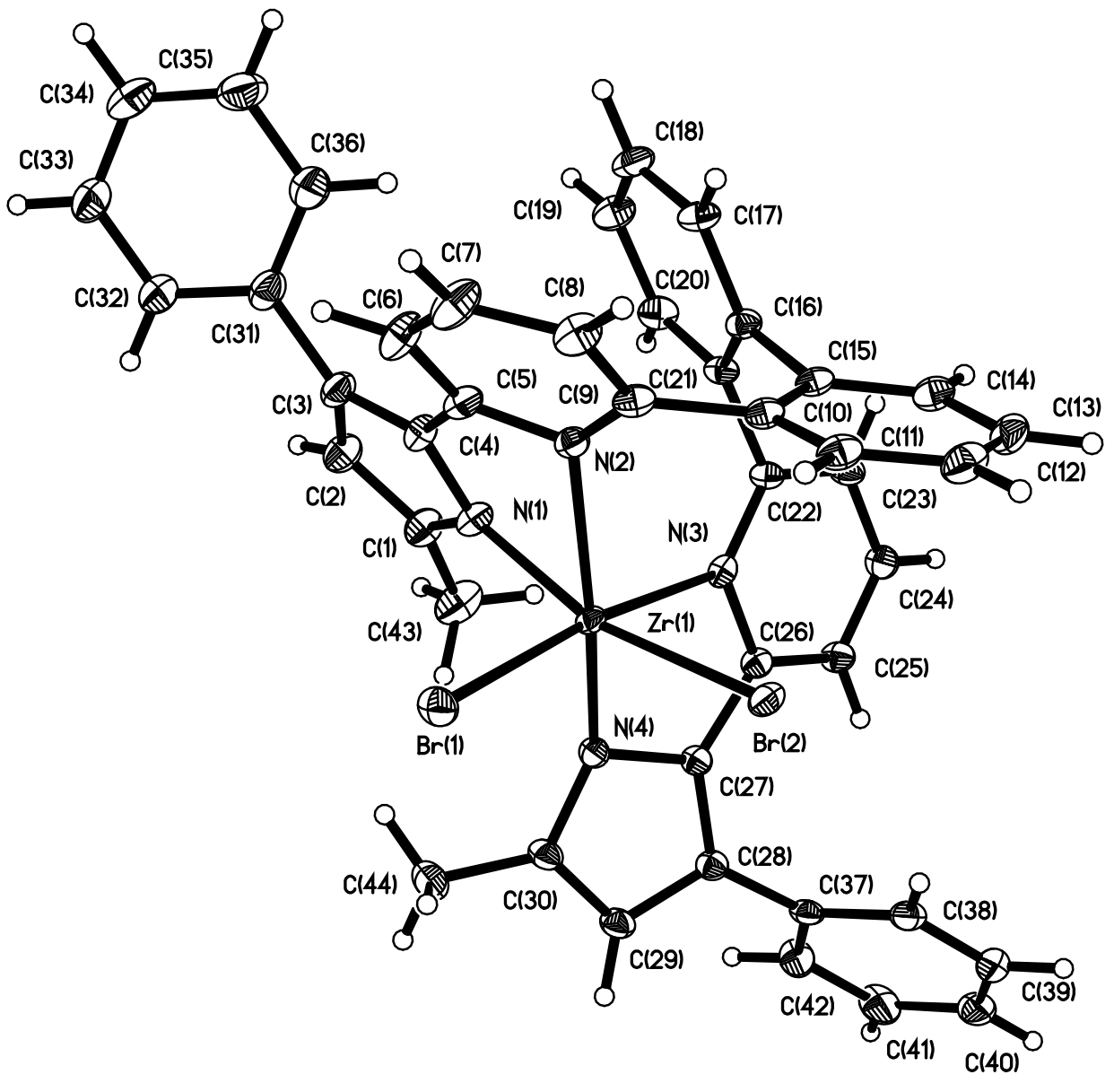

Figure C15. Perspective view of the molecular structure of $\left(\mathrm{C}_{44} \mathrm{H}_{32} \mathrm{~N}_{4}\right) \mathrm{ZrBr}_{2}$ with the atom labeling scheme for the independent non-hydrogen atoms. The thermal ellipsoids are scaled to enclose $50 \%$ probability. 
Table C41. Crystal data for $\left(\mathrm{C}_{44} \mathrm{H}_{32} \mathrm{~N}_{4}\right) \mathrm{ZrBr}_{2} \cdot 2 \mathrm{OEt}_{2}$.

$\begin{array}{lll}\text { Ident. code } & \mathrm{cm} 190 \mathrm{cms} \\ \text { Chemical formula } & \mathrm{C}_{52} \mathrm{H}_{52} \mathrm{Br}_{2} \mathrm{~N}_{4} \mathrm{O}_{2} \mathrm{Zr} \\ \text { Formula weight } & 1016.01 \mathrm{~g} / \mathrm{mol} \\ \text { Temperature } & 100(2) \mathrm{K} \\ \text { Wavelength } & 0.71073 \AA \\ \text { Crystal size } & 0.142 \times 0.177 \times 0.407 \mathrm{~mm} \\ \text { Crystal system } & \mathrm{C}_{52} \mathrm{H}_{52} \mathrm{Br}_{2} \mathrm{~N}_{4} \mathrm{O}_{2} \mathrm{Zr} & \\ \text { Space group } & \mathrm{P}(-1)\left(\mathrm{No}_{2}\right) & \\ \text { Unit cell } & \mathrm{a}=13.2179(7) \AA & \alpha=97.4386(14)^{\circ} \\ & \mathrm{b}=13.7682(7) \AA & \beta=109.5668(13)^{\circ} \\ & \mathrm{c}=13.9044(7) \AA & \gamma=108.4079(13)^{\circ}\end{array}$

Volume, $\AA^{3} \quad 2182.6(2)$

$\mathrm{Z} 2$

Density (calc) $\quad 1.546 \mathrm{~g} / \mathrm{cm}^{3}$

Abs. coefficient $2.130 \mathrm{~mm}^{-1}$

$\mathrm{F}(000) \quad 1036$

Table C42. Data collection and structure refinement for $\left(\mathrm{C}_{44} \mathrm{H}_{32} \mathrm{~N}_{4}\right) \mathrm{ZrBr}_{2} \cdot 2 \mathrm{OEt}_{2}$.

$\begin{array}{ll}\text { Theta range } & 2.99 \text { to } 32.62^{\circ} \\ \text { Index ranges } & -20 \leq \mathrm{h} \leq 20,-20 \leq \mathrm{k} \leq 20,-21 \leq 1 \leq 21 \\ \text { Reflections } & 53880 \\ \text { Independent refls } & 15879[\mathrm{R}(\mathrm{int})=0.0496] \\ \text { Coverage } & 99.6 \% \\ \text { Absorption correction } & \text { multi-scan } \\ \text { Max. and min. trans. } & 0.753 \text { and } 0.479 \\ \text { Refinement method } & \text { Full-matrix least-squares on } \mathrm{F}^{2} \\ \text { Refinement program } & \text { SHELXL-2014/7 (Sheldrick, 2014) } \\ \text { Data / restrs / parms } & 15879 / 0 / 462 \\ \text { Goodness-of-fit on } \mathrm{F}^{2} & 1.024 \quad \text { data; R1 =0.0400, wR2 = } 0.0831 \\ & 10725 \quad \mathrm{R} 1=0.0820, \mathrm{wR} 2=0.0964 \\ \text { Final R indices } & \mathrm{I}>2 \sigma(\mathrm{I}) \quad \text { all data } \quad ~\end{array}$

Largest diff. peak and 1.934 and $-0.962 \mathrm{e}^{-} / \AA^{3}$ hole 
Table C43. Atomic coordinates and equivalent isotropic atomic displacement parameters $\left(\AA^{2}\right)$ for $\left(\mathrm{C}_{44} \mathrm{H}_{32} \mathrm{~N}_{4}\right) \mathrm{ZrBr}_{2}$. U(eq) is defined as one third of the trace of the orthogonalized $\mathrm{U}_{\mathrm{i}}$ tensor.

\begin{tabular}{|c|c|c|c|c|}
\hline & $\mathrm{x} / \mathrm{a}$ & $y / b$ & $\mathrm{z} / \mathrm{c}$ & $\mathrm{U}(\mathrm{eq})$ \\
\hline $\mathrm{Zr} 1$ & $0.13359(2)$ & $0.33486(2)$ & $0.34614(2)$ & $0.01240(5)$ \\
\hline $\mathrm{Br} 1$ & $0.21698(2)$ & $0.53098(2)$ & $0.35418(2)$ & $0.02114(6)$ \\
\hline $\mathrm{Br} 2$ & $0.22644(2)$ & $0.36656(2)$ & $0.54958(2)$ & $0.01757(5)$ \\
\hline $\mathrm{N} 1$ & $0.07749(17)$ & $0.28057(15)$ & $0.17712(15)$ & $0.0182(4)$ \\
\hline $\mathrm{N} 2$ & $0.29187(16)$ & $0.31838(14)$ & $0.31346(15)$ & $0.0152(4)$ \\
\hline N3 & $0.03644(15)$ & $0.15946(14)$ & $0.34470(14)$ & $0.0132(3)$ \\
\hline $\mathrm{N} 4$ & $0.96774(15)$ & $0.32612(14)$ & $0.34291(15)$ & $0.0145(4)$ \\
\hline $\mathrm{C} 1$ & $0.9744(2)$ & $0.24564(19)$ & $0.08922(18)$ & $0.0213(5)$ \\
\hline $\mathrm{C} 2$ & $0.9969(2)$ & $0.2456(2)$ & $0.99964(19)$ & $0.0234(5)$ \\
\hline $\mathrm{C} 3$ & $0.1186(2)$ & $0.27969(19)$ & $0.03012(18)$ & $0.0201(5)$ \\
\hline $\mathrm{C} 4$ & $0.1661(2)$ & $0.30216(18)$ & $0.14009(18)$ & $0.0179(4)$ \\
\hline $\mathrm{C} 5$ & $0.2835(2)$ & $0.33796(18)$ & $0.21832(18)$ & $0.0183(4)$ \\
\hline C6 & $0.3837(2)$ & $0.3900(2)$ & $0.2022(2)$ & $0.0256(5)$ \\
\hline $\mathrm{C} 7$ & $0.4909(2)$ & $0.4164(2)$ & $0.2821(2)$ & $0.0274(6)$ \\
\hline $\mathrm{C} 8$ & $0.4989(2)$ & $0.38457(19)$ & $0.37403(19)$ & $0.0215(5)$ \\
\hline C9 & $0.39829(19)$ & $0.33207(18)$ & $0.38652(18)$ & $0.0168(4)$ \\
\hline $\mathrm{C} 10$ & $0.39647(18)$ & $0.27473(18)$ & $0.46875(18)$ & $0.0159(4)$ \\
\hline $\mathrm{C} 11$ & $0.47083(19)$ & $0.32218(19)$ & $0.57521(18)$ & $0.0193(5)$ \\
\hline $\mathrm{C} 12$ & $0.4660(2)$ & $0.2654(2)$ & $0.6498(2)$ & $0.0242(5)$ \\
\hline C13 & $0.3876(2)$ & $0.1608(2)$ & $0.6193(2)$ & $0.0238(5)$ \\
\hline $\mathrm{C} 14$ & $0.3162(2)$ & $0.11237(19)$ & $0.51321(19)$ & $0.0199(5)$ \\
\hline $\mathrm{C} 15$ & $0.32022(18)$ & $0.16762(18)$ & $0.43670(18)$ & $0.0156(4)$ \\
\hline C16 & $0.25741(19)$ & $0.11109(17)$ & $0.32196(18)$ & $0.0157(4)$ \\
\hline $\mathrm{C} 17$ & $0.3243(2)$ & $0.09996(18)$ & $0.26509(19)$ & $0.0184(4)$ \\
\hline $\mathrm{C} 18$ & $0.2739(2)$ & $0.05150(19)$ & $0.1580(2)$ & $0.0222(5)$ \\
\hline $\mathrm{C} 19$ & $0.1542(2)$ & $0.0110(2)$ & $0.1049(2)$ & $0.0238(5)$ \\
\hline $\mathrm{C} 20$ & $0.0862(2)$ & $0.01876(18)$ & $0.16042(19)$ & $0.0199(5)$ \\
\hline C21 & $0.13608(18)$ & $0.06897(17)$ & $0.26842(18)$ & $0.0150(4)$ \\
\hline $\mathrm{C} 22$ & $0.05448(18)$ & $0.07004(17)$ & $0.32056(17)$ & $0.0141(4)$ \\
\hline $\mathrm{C} 23$ & $0.99245(19)$ & $0.97562(18)$ & $0.33507(19)$ & $0.0182(4)$ \\
\hline $\mathrm{C} 24$ & $0.9088(2)$ & $0.97199(18)$ & $0.37591(19)$ & $0.0183(4)$ \\
\hline $\mathrm{C} 25$ & $0.88710(19)$ & $0.06143(17)$ & $0.39793(18)$ & $0.0170(4)$ \\
\hline C26 & $0.95052(18)$ & $0.15501(17)$ & $0.38092(17)$ & $0.0141(4)$ \\
\hline
\end{tabular}




$\begin{array}{lcccc} & \mathrm{x} / \mathrm{a} & \mathrm{y} / \mathrm{b} & \mathrm{z} / \mathrm{c} & \mathrm{U}(\mathrm{eq}) \\ \mathrm{C} 27 & 0.92438(18) & 0.24883(17) & 0.39120(17) & 0.0139(4) \\ \mathrm{C} 28 & 0.85068(18) & 0.27556(17) & 0.43146(18) & 0.0152(4) \\ \mathrm{C} 29 & 0.84449(19) & 0.36870(18) & 0.40381(18) & 0.0179(4) \\ \mathrm{C} 30 & 0.91552(19) & 0.39810(18) & 0.34988(18) & 0.0171(4) \\ \mathrm{C} 31 & 0.1747(2) & 0.27770(19) & 0.95448(19) & 0.0227(5) \\ \mathrm{C} 32 & 0.1405(2) & 0.3159(2) & 0.8665(2) & 0.0287(6) \\ \text { C33 } & 0.1901(3) & 0.3119(2) & 0.7933(2) & 0.0329(6) \\ \mathrm{C} 34 & 0.2734(3) & 0.2689(2) & 0.8064(2) & 0.0329(6) \\ \mathrm{C} 35 & 0.3058(3) & 0.2278(2) & 0.8919(2) & 0.0333(6) \\ \text { C36 } & 0.2564(2) & 0.2322(2) & 0.9656(2) & 0.0286(6) \\ \text { C37 } & 0.79179(19) & 0.22305(17) & 0.49560(18) & 0.0160(4) \\ \text { C38 } & 0.8562(2) & 0.21157(18) & 0.59310(19) & 0.0192(5) \\ \text { C39 } & 0.8009(2) & 0.1684(2) & 0.6554(2) & 0.0254(5) \\ \text { C40 } & 0.6820(2) & 0.1357(2) & 0.6218(2) & 0.0291(6) \\ \text { C41 } & 0.6172(2) & 0.1462(2) & 0.5255(2) & 0.0302(6) \\ \text { C42 } & 0.6722(2) & 0.1903(2) & 0.4635(2) & 0.0235(5) \\ \text { C43 } & 0.8585(2) & 0.2106(2) & 0.0955(2) & 0.0301(6) \\ \text { C44 } & 0.9334(2) & 0.4900(2) & 0.3027(2) & 0.0243(5)\end{array}$




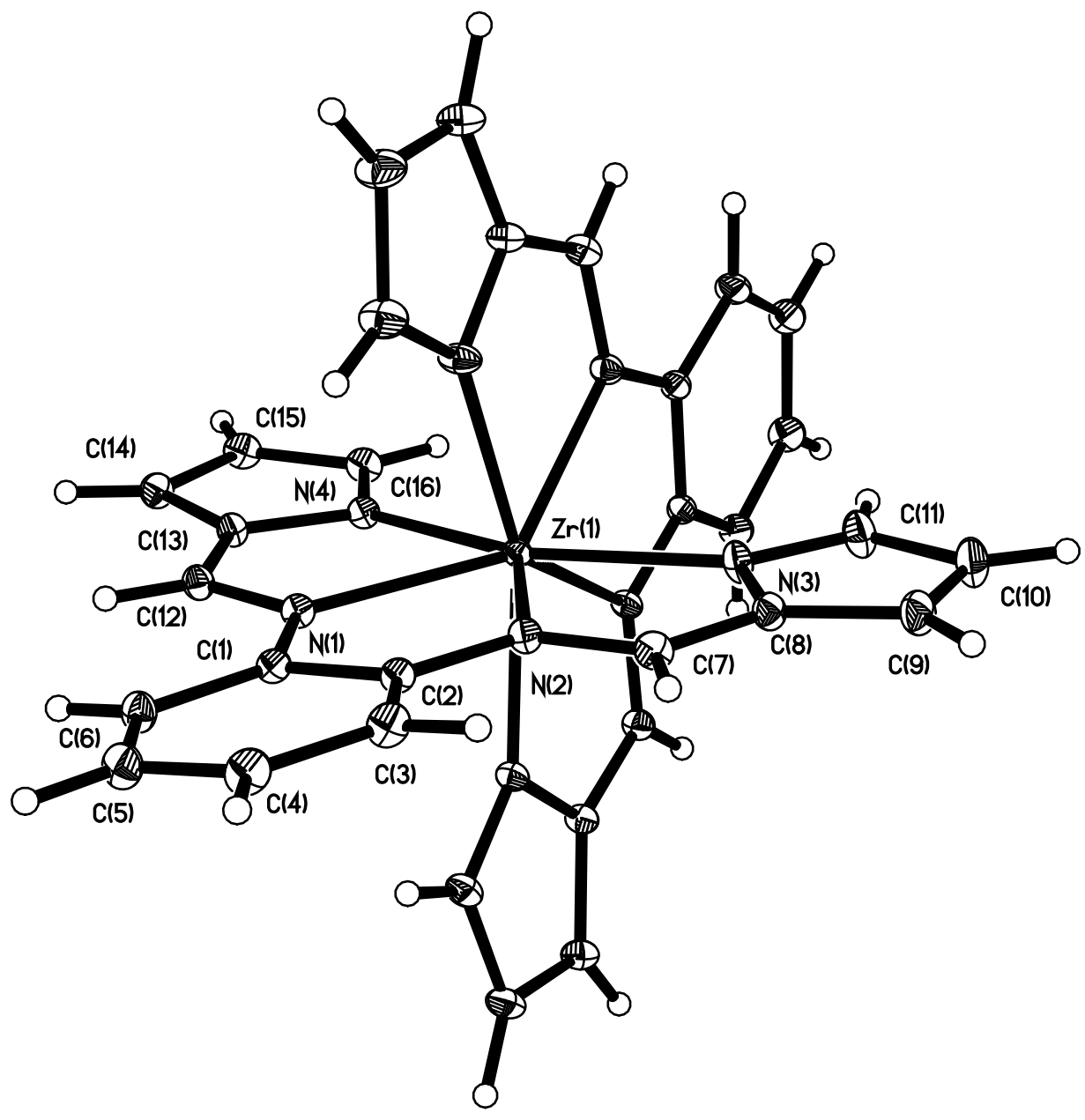

Figure C16. Perspective view of the molecular structure of $\left(\mathrm{C}_{16} \mathrm{H}_{12} \mathrm{~N}_{4}\right)_{2} \mathrm{Zr}$ with the atom labeling scheme for the independent non-hydrogen atoms. The molecule lies on a crystallographic two-fold rotation axis that passes through the $\mathrm{Zr}$ atom. The thermal ellipsoids are scaled to enclose $50 \%$ probability. 
Table C44. Crystal data for $\left(\mathrm{C}_{16} \mathrm{H}_{12} \mathrm{~N}_{4}\right)_{2} \mathrm{Zr} \cdot \mathrm{C}_{6} \mathrm{H}_{6}$.

$\begin{array}{lll}\text { Ident. code } & \mathrm{cm} 193 \mathrm{cms} \\ \text { Empirical formula } & \mathrm{C}_{38} \mathrm{H}_{30} \mathrm{~N}_{8} \mathrm{Zr} & \\ \text { Formula weight } & 689.92 \mathrm{~g} / \mathrm{mol} & \\ \text { Temperature } & 100(2) \mathrm{K} \\ \text { Wavelength } & 0.71073 \AA \\ \text { Crystal size } & 0.266 \times 0.345 \times 0.472 \mathrm{~mm} \\ \text { Crystal system } & \text { trigonal } & \\ \text { Space group } & \mathrm{P} 3{ }_{2} 21(\mathrm{No} .154) & \\ \text { Unit cell parms. } & \mathrm{a}=12.6811(5) \AA & \alpha=90^{\circ} \\ & \mathrm{b}=12.6811(5) \AA & \beta=90^{\circ} \\ & \mathrm{c}=16.8875(7) \AA & \gamma=120^{\circ}\end{array}$

Volume, $\AA^{3} \quad 2351.9(2)$

Z 3

Density (calc.) $\quad 1.461 \mathrm{~g} / \mathrm{cm}^{3}$

Abs. coefficient $\quad 0.393 \mathrm{~mm}^{-1}$

$\mathrm{F}(000) \quad 1062$

Table C45. Data collection and structure refinement for $\left(\mathrm{C}_{16} \mathrm{H}_{12} \mathrm{~N}_{4}\right)_{2} \mathrm{Zr} \cdot \mathrm{C}_{6} \mathrm{H}_{6}$.

$\begin{array}{ll}\text { Theta range } & 3.04 \text { to } 34.98^{\circ} \\ \text { Index ranges } & -20 \leq \mathrm{h} \leq 20,-20 \leq \mathrm{k} \leq 20,-27 \leq 1 \leq 27 \\ \text { Reflections } & 47657 \\ \text { Independent reflections } & 6901[\mathrm{R}(\mathrm{int})=0.0288] \\ \text { Coverage } & 99.8 \% \\ \text { Absorption correction } & \text { multi-scan } \\ \text { Max. and min. trans. } & 0.903 \text { and } 0.836 \\ \text { Refinement method } & \text { Full-matrix least-squares on } \mathrm{F}^{2} \\ \text { Refinement program } & \text { SHELXL-2014/7 (Sheldrick, 2014) } \\ \text { Data / restraints } & / 6901 / 0 / 214 \\ \text { parameters } & 1.060 \quad \text { R } \\ \text { Goodness-of-fit on } \mathrm{F}^{2} & 6540 \quad \text { data; } \mathrm{R} 1=0.0234, \mathrm{wR} 2=0.0565 \\ \text { Final R indices } & \mathrm{I}>2 \sigma(\mathrm{I}) \quad \text { all data } \quad \mathrm{R} 1=0.0269, \mathrm{wR} 2=0.0586\end{array}$

Largest diff. peak and 0.684 and $-0.408 \mathrm{e}^{-/} / \AA^{3}$ hole 
Table C46. Atomic coordinates and equivalent isotropic atomic displacement parameters $\left(\AA^{2}\right)$ for $\left(\mathrm{C}_{16} \mathrm{H}_{12} \mathrm{~N}_{4}\right)_{2} \mathrm{Zr} \cdot \mathrm{C}_{6} \mathrm{H}_{6}$. U(eq) is defined as one third of the trace of the orthogonalized $\mathrm{U}_{\mathrm{ij}}$ tensor.

\begin{tabular}{|c|c|c|c|c|}
\hline & $\mathrm{x} / \mathrm{a}$ & $y / b$ & $\mathrm{z} / \mathrm{c}$ & $\mathrm{U}(\mathrm{eq})$ \\
\hline $\mathrm{Zr} 1$ & 0.0 & $0.60698(2)$ & 0.3333 & $0.00809(4)$ \\
\hline N1 & $0.87786(11)$ & $0.47199(11)$ & $0.43439(7)$ & $0.01016(19)$ \\
\hline $\mathrm{N} 2$ & $0.03754(12)$ & $0.69916(10)$ & $0.45828(7)$ & $0.0106(2)$ \\
\hline N3 & $0.15290(13)$ & $0.80269(11)$ & $0.32407(8)$ & $0.0128(2)$ \\
\hline N4 & $0.87290(12)$ & $0.42131(11)$ & $0.28078(7)$ & $0.01032(19)$ \\
\hline $\mathrm{C} 1$ & $0.88818(13)$ & $0.51079(13)$ & $0.51384(8)$ & $0.0101(2)$ \\
\hline $\mathrm{C} 2$ & $0.97157(14)$ & $0.63472(14)$ & $0.52608(7)$ & $0.01017(19)$ \\
\hline C3 & $0.98390(13)$ & $0.68538(16)$ & $0.60146(8)$ & $0.0140(2)$ \\
\hline $\mathrm{C} 4$ & $0.91801(16)$ & $0.61131(15)$ & $0.66439(8)$ & $0.0157(3)$ \\
\hline $\mathrm{C} 5$ & $0.83939(15)$ & $0.48757(15)$ & $0.65299(8)$ & $0.0154(3)$ \\
\hline C6 & $0.82353(15)$ & $0.43677(14)$ & $0.57793(8)$ & $0.0128(2)$ \\
\hline $\mathrm{C} 7$ & $0.12556(14)$ & $0.81299(13)$ & $0.46293(9)$ & $0.0126(2)$ \\
\hline $\mathrm{C} 8$ & $0.18836(14)$ & $0.87037(13)$ & $0.39357(9)$ & $0.0120(2)$ \\
\hline C9 & $0.28410(16)$ & $0.98876(14)$ & $0.37869(10)$ & $0.0162(3)$ \\
\hline $\mathrm{C} 10$ & $0.30828(16)$ & $0.99400(15)$ & $0.29769(10)$ & $0.0184(3)$ \\
\hline C11 & $0.22654(16)$ & $0.87925(14)$ & $0.26686(9)$ & $0.0169(3)$ \\
\hline $\mathrm{C} 12$ & $0.79409(14)$ & $0.36322(13)$ & $0.41208(8)$ & $0.0112(2)$ \\
\hline $\mathrm{C} 13$ & $0.78805(13)$ & $0.33313(13)$ & $0.33111(8)$ & $0.0107(2)$ \\
\hline C14 & $0.70901(14)$ & $0.22792(13)$ & $0.28889(9)$ & $0.0131(2)$ \\
\hline $\mathrm{C} 15$ & $0.74726(14)$ & $0.25171(14)$ & $0.20988(9)$ & $0.0140(3)$ \\
\hline $\mathrm{C} 16$ & $0.84734(14)$ & $0.37007(14)$ & $0.20751(9)$ & $0.0128(2)$ \\
\hline $\mathrm{C} 17$ & $0.9986(2)$ & 0.0 & 0.6667 & $0.0249(5)$ \\
\hline $\mathrm{C} 18$ & $0.0236(2)$ & $0.9427(2)$ & $0.72690(12)$ & $0.0293(4)$ \\
\hline C19 & $0.1323(3)$ & $0.9425(2)$ & $0.72765(18)$ & $0.0434(7)$ \\
\hline $\mathrm{C} 20$ & $0.2163(2)$ & 0.0 & 0.6667 & $0.0579(15)$ \\
\hline
\end{tabular}




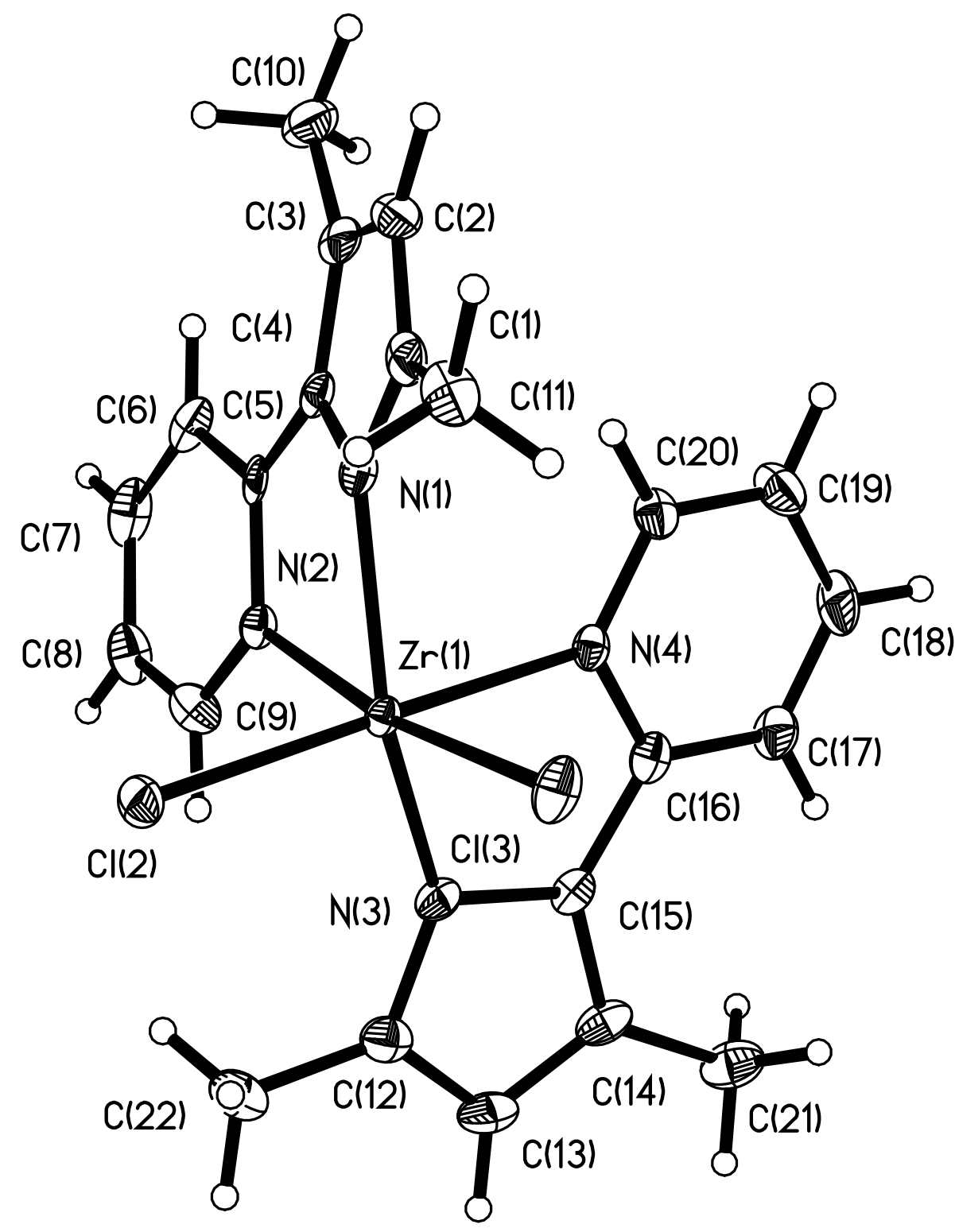

Figure 17. Perspective view of the molecular structure of $\left(\mathrm{C}_{11} \mathrm{H}_{11} \mathrm{~N}_{2}\right)_{2} \mathrm{ZrCl}_{2}$ with the atom labeling scheme for the independent non-hydrogen atoms. The thermal ellipsoids are scaled to enclose $50 \%$ probability. 
Table C47. Crystal data for $\left(\mathrm{C}_{11} \mathrm{H}_{11} \mathrm{~N}_{2}\right)_{2} \mathrm{ZrCl}_{2}$.

$\begin{array}{lll}\text { Identification code } & \mathrm{cm} 104 \mathrm{cms} \\ \text { Chemical formula } & \mathrm{C}_{22} \mathrm{H}_{22} \mathrm{Cl}_{2} \mathrm{~N}_{4} \mathrm{Zr} & \\ \text { Formula weight } & 504.55 \mathrm{~g} / \mathrm{mol} \\ \text { Temperature } & 100(2) \mathrm{K} \\ \text { Wavelength } & 0.71073 \AA \\ \text { Crystal size } & 0.096 \times 0.196 \times 0.387 \mathrm{~mm} \\ \text { Crystal system } & \text { monoclinic } & \\ \text { Space group } & \mathrm{P} 2{ }_{1} / \mathrm{c}(\mathrm{No} .14) & \\ \text { Unit cell } & \mathrm{a}=8.1542(5) \AA & \alpha=90^{\circ} \\ & \mathrm{b}=30.0801(15) \AA & \beta=102.0406(15)^{\circ} \\ & \mathrm{c}=8.9273(4) \AA & \gamma=90^{\circ} \\ \text { Volume, } \AA^{3} & 2141.51(19) & \\ \text { Z } & 4 \\ \text { Density (calc.) } & 1.565 \mathrm{~g} / \mathrm{cm}^{3} & \\ \text { Absorption } & 0.779 \mathrm{~mm}^{-1} & \\ \text { coefficient } & 1024 \\ \text { F(000) } & \end{array}$

Table C48. Data collection and structure refinement for $\left(\mathrm{C}_{11} \mathrm{H}_{11} \mathrm{~N}_{2}\right)_{2} \mathrm{ZrCl}_{2}$.

Theta range for data used in the structural refinement

Index ranges $\quad-10 \leq \mathrm{h} \leq 8,-31 \leq \mathrm{k} \leq 38,-9 \leq 1 \leq 11$

Reflections $\quad 11300$

Independent reflections $\quad 4885[\mathrm{R}$ (int) $=0.0307]$

Coverage $\quad 99.4 \%$

Absorption correction multi-scan

Max. and min. trans. $\quad 0.929$ and 0.752

Refinement method Full-matrix least-squares on $\mathrm{F}^{2}$

Refinement program SHELXL-2014 (Sheldrick, 2014)

$\begin{array}{lll}\text { Data / restraints / } 4885 / 0 / 266 & 0\end{array}$

Goodness-of-fit on $\mathrm{F}^{2} \quad 1.126$

Final R indices $\quad 3959$ data; $\mathrm{I}>2 \sigma(\mathrm{I}) \quad \mathrm{R} 1=0.0516, \mathrm{wR} 2=0.0875$

all data $\quad \mathrm{R} 1=0.0714, \mathrm{wR} 2=0.0925$

Largest diff. peak and hole 0.571 and $-1.035 \mathrm{e}^{-} / \AA^{3}$ 
Table C49. Atomic coordinates and equivalent isotropic atomic displacement parameters $\left(\AA^{2}\right)$ for $\left(\mathrm{C}_{11} \mathrm{H}_{11} \mathrm{~N}_{2}\right)_{2} \mathrm{ZrCl}_{2}$. U(eq) is defined as one third of the trace of the orthogonalized $\mathrm{U}_{\mathrm{ij}}$ tensor.

\begin{tabular}{|c|c|c|c|c|}
\hline & $\mathrm{x} / \mathrm{a}$ & $y / b$ & $\mathrm{z} / \mathrm{c}$ & $\mathrm{U}(\mathrm{eq})$ \\
\hline $\mathrm{Zr} 1$ & $0.04247(4)$ & $0.38292(2)$ & $0.17985(4)$ & $0.01161(9)$ \\
\hline $\mathrm{C} 12$ & $0.20486(11)$ & $0.43534(3)$ & $0.07040(10)$ & $0.0211(2)$ \\
\hline $\mathrm{Cl3}$ & $0.83672(11)$ & $0.36638(3)$ & $0.95027(10)$ & $0.0222(2)$ \\
\hline $\mathrm{N} 1$ & $0.9090(3)$ & $0.42834(9)$ & $0.2995(3)$ & $0.0149(6)$ \\
\hline $\mathrm{N} 2$ & $0.2088(3)$ & $0.39600(9)$ & $0.4194(3)$ & $0.0136(6)$ \\
\hline N3 & $0.1897(3)$ & $0.32238(9)$ & $0.1838(3)$ & $0.0165(6)$ \\
\hline N4 & $0.9180(3)$ & $0.32920(9)$ & $0.3071(3)$ & $0.0139(6)$ \\
\hline $\mathrm{C} 1$ & $0.7532(4)$ & $0.44878(11)$ & $0.2648(4)$ & $0.0193(8)$ \\
\hline $\mathrm{C} 2$ & $0.7134(5)$ & $0.46420(12)$ & $0.3980(4)$ & $0.0217(8)$ \\
\hline $\mathrm{C} 3$ & $0.8457(5)$ & $0.45472(11)$ & $0.5216(4)$ & $0.0200(8)$ \\
\hline $\mathrm{C} 4$ & $0.9660(4)$ & $0.43284(11)$ & $0.4587(4)$ & $0.0151(7)$ \\
\hline $\mathrm{C} 5$ & $0.1335(4)$ & $0.41785(11)$ & $0.5208(4)$ & $0.0154(7)$ \\
\hline C6 & $0.2236(5)$ & $0.42619(12)$ & $0.6706(4)$ & $0.0211(8)$ \\
\hline $\mathrm{C} 7$ & $0.3876(5)$ & $0.41392(13)$ & $0.7105(4)$ & $0.0259(9)$ \\
\hline $\mathrm{C} 8$ & $0.4654(5)$ & $0.39248(12)$ & $0.6069(4)$ & $0.0234(8)$ \\
\hline $\mathrm{C} 9$ & $0.3707(4)$ & $0.38378(13)$ & $0.4634(4)$ & $0.0215(8)$ \\
\hline $\mathrm{C} 10$ & $0.8529(5)$ & $0.46781(13)$ & $0.6849(4)$ & $0.0276(9)$ \\
\hline $\mathrm{C} 11$ & $0.6587(5)$ & $0.45508(13)$ & $0.1052(4)$ & $0.0238(8)$ \\
\hline $\mathrm{C} 12$ & $0.3231(4)$ & $0.30920(12)$ & $0.1214(4)$ & $0.0207(8)$ \\
\hline $\mathrm{C} 13$ & $0.3320(5)$ & $0.26347(13)$ & $0.1226(4)$ & $0.0239(8)$ \\
\hline C14 & $0.2037(5)$ & $0.24651(12)$ & $0.1873(4)$ & $0.0204(8)$ \\
\hline $\mathrm{C} 15$ & $0.1187(4)$ & $0.28314(11)$ & $0.2271(4)$ & $0.0143(7)$ \\
\hline $\mathrm{C} 16$ & $0.9768(4)$ & $0.28711(11)$ & $0.2977(4)$ & $0.0166(7)$ \\
\hline $\mathrm{C} 17$ & $0.8985(5)$ & $0.25139(12)$ & $0.3561(4)$ & $0.0214(8)$ \\
\hline $\mathrm{C} 18$ & $0.7668(5)$ & $0.25865(13)$ & $0.4247(5)$ & $0.0270(9)$ \\
\hline C19 & $0.7100(5)$ & $0.30169(13)$ & $0.4374(5)$ & $0.0259(9)$ \\
\hline $\mathrm{C} 20$ & $0.7879(4)$ & $0.33587(12)$ & $0.3776(4)$ & $0.0186(8)$ \\
\hline $\mathrm{C} 21$ & $0.1672(5)$ & $0.19795(12)$ & $0.2032(5)$ & $0.0281(9)$ \\
\hline $\mathrm{C} 22$ & $0.4353(5)$ & $0.34102(14)$ & $0.0639(5)$ & $0.0284(9)$ \\
\hline
\end{tabular}




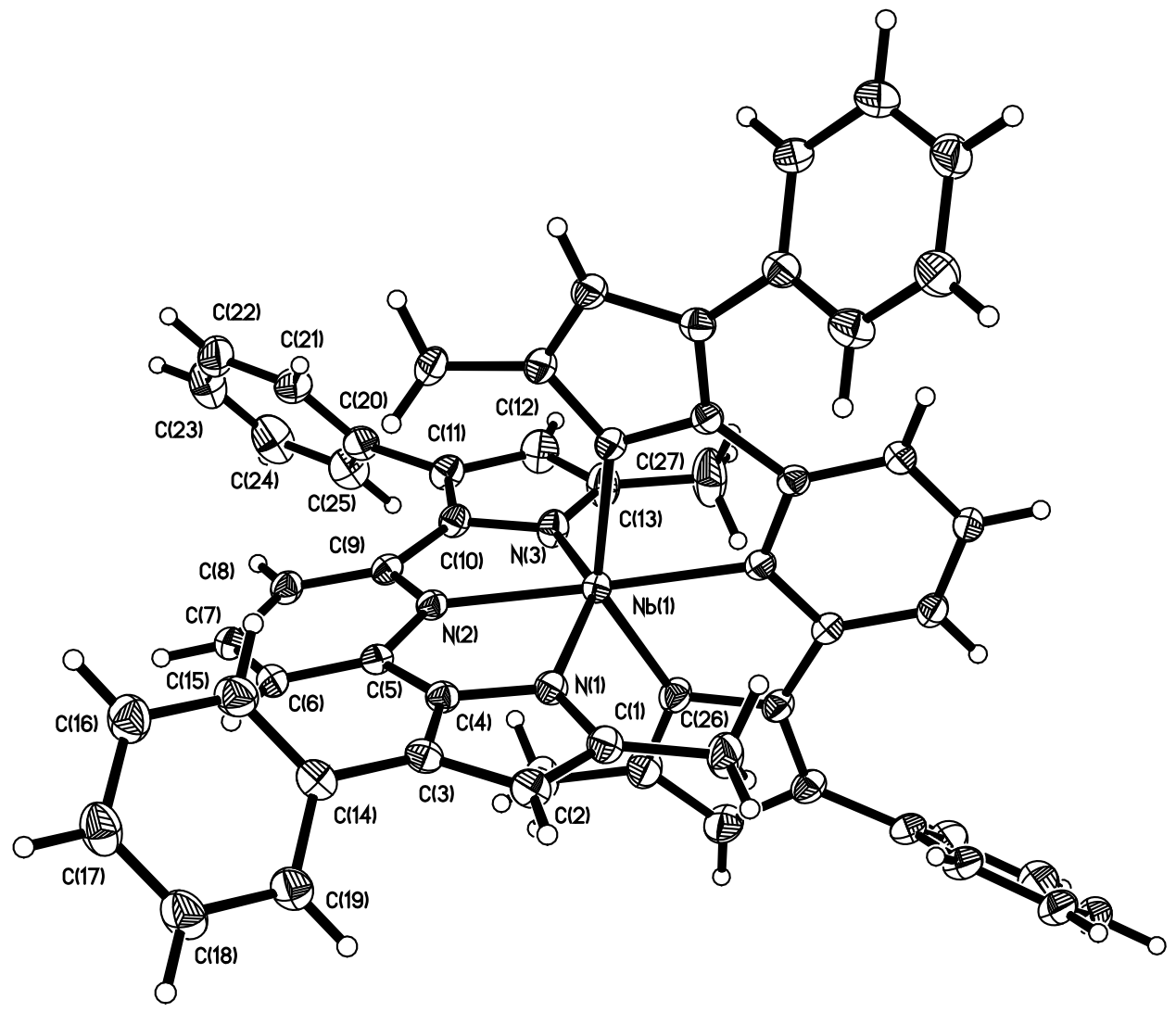

Figure 18. Perspective view of the molecular structure of $\left(\mathrm{C}_{27} \mathrm{H}_{21} \mathrm{~N}_{3}\right)_{2} \mathrm{Nb}$ with the atom labeling scheme for the independent non-hydrogen atoms. The molecular geometry is constrained by a crystallographic two-fold rotation axis. The thermal ellipsoids are scaled to enclose $50 \%$ probability. 
Table C50. Crystal data for $\left(\mathrm{C}_{27} \mathrm{H}_{21} \mathrm{~N}_{3}\right)_{2} \mathrm{Nb} \cdot \mathrm{THF} \cdot \mathrm{OEt}_{2}$.

\begin{tabular}{|c|c|c|}
\hline Ident. code & \multicolumn{2}{|l|}{$\mathrm{cm} 160 \mathrm{cms}$} \\
\hline Chem. formula & \multicolumn{2}{|l|}{$\mathrm{C}_{62} \mathrm{H}_{60} \mathrm{~N}_{6} \mathrm{NbO}_{2}$} \\
\hline Formula weight & \multicolumn{2}{|l|}{$1014.07 \mathrm{~g} / \mathrm{mol}$} \\
\hline Temperature & \multicolumn{2}{|l|}{$100(2) \mathrm{K}$} \\
\hline Wavelength & \multicolumn{2}{|l|}{$0.71073 \AA$} \\
\hline Crystal size & \multicolumn{2}{|c|}{$0.154 \times 0.165 \times 0.697 \mathrm{~mm}$} \\
\hline Crystal system & \multicolumn{2}{|l|}{ monoclinic } \\
\hline Space group & \multicolumn{2}{|l|}{ C 2/c (No. 15) } \\
\hline \multirow[t]{3}{*}{ Unit cell } & $\mathrm{a}=26.4332(11) \AA$ & $\alpha=90^{\circ}$ \\
\hline & $\mathrm{b}=13.0179(5) \AA$ & $\beta=106.8765(12)^{\circ}$ \\
\hline & $\mathrm{c}=15.4198(6) \AA$ & $\gamma=90^{\circ}$ \\
\hline
\end{tabular}

Volume, $\AA^{3} \quad 5077.5(4)$

$\mathrm{Z} \quad 4$

Density (calc) $\quad 1.327 \mathrm{~g} / \mathrm{cm}^{3}$

Abs. coefficient $\quad 0.289 \mathrm{~mm}^{-1}$

$\mathrm{F}(000) \quad 2124$

Table C51. Data collection and structure refinement for $\left(\mathrm{C}_{27} \mathrm{H}_{21} \mathrm{~N}_{3}\right)_{2} \mathrm{Nb} \cdot \mathrm{THF} \cdot \mathrm{OEt}_{2}$.

$\begin{array}{ll}\text { Theta range } & 3.07 \text { to } 32.57^{\circ} \\ \text { Index ranges } & -36 \leq \mathrm{h} \leq 40,-19 \leq \mathrm{k} \leq 18,-23 \leq 1 \leq 23 \\ \text { Reflections } & 30514 \\ \text { Independent refls } & 9225[\mathrm{R}(\mathrm{int})=0.0296] \\ \text { Coverage } & 99.6 \% \\ \text { Absorption correction } & \text { multi-scan } \\ \text { Max. and min. trans. } & 0.957 \text { and } 0.824 \\ \text { Refinement method } & \text { Full-matrix least-squares on } \mathrm{F}^{2} \\ \text { Refinement program } & \text { SHELXL-2014/7 (Sheldrick, 2014) } \\ \text { Data / restrs / parms } & 9225 / 10 / 320 \\ \text { Goodness-of-fit on } \mathrm{F}^{2} & 1.031 \quad \text { data; } \mathrm{R} 1=0.0476, \mathrm{wR} 2=0.1243 \\ & 7868 \quad \mathrm{R} 1=0.0590, \mathrm{wR} 2=0.1331 \\ \text { Final R indices } & \mathrm{I}>2 \sigma(\mathrm{I}) \quad \text { all data } \quad \text {. }\end{array}$

Largest diff. peak and 1.227 and $-0.713 \mathrm{e}^{-/ \AA^{3}}$

hole 
Table C52. Atomic coordinates and equivalent isotropic atomic displacement parameters $\left(\AA^{2}\right)$ for $\left(\mathrm{C}_{27} \mathrm{H}_{21} \mathrm{~N}_{3}\right)_{2} \mathrm{Nb} \cdot \mathrm{THF} \cdot \mathrm{OEt}_{2}$. $\mathrm{U}(\mathrm{eq})$ is defined as one third of the trace of the orthogonalized $\mathrm{U}_{\mathrm{ij}}$ tensor.

\begin{tabular}{|c|c|c|c|c|}
\hline & $\mathrm{x} / \mathrm{a}$ & $\mathrm{y} / \mathrm{b}$ & $\mathrm{z} / \mathrm{c}$ & $\mathrm{U}(\mathrm{eq})$ \\
\hline $\mathrm{Nb} 1$ & 0.5 & $0.88003(2)$ & 0.75 & $0.01661(6)$ \\
\hline $\mathrm{N} 1$ & $0.49164(6)$ & $0.77799(11)$ & $0.64103(10)$ & $0.0184(3)$ \\
\hline $\mathrm{N} 2$ & $0.41533(6)$ & $0.86962(11)$ & $0.68007(10)$ & $0.0170(2)$ \\
\hline N3 & $0.46204(6)$ & $0.99758(12)$ & $0.80168(11)$ & $0.0224(3)$ \\
\hline $\mathrm{C} 1$ & $0.52678(7)$ & $0.72217(14)$ & $0.60779(12)$ & $0.0211(3)$ \\
\hline $\mathrm{C} 2$ & $0.49918(7)$ & $0.65168(15)$ & $0.54524(12)$ & $0.0225(3)$ \\
\hline $\mathrm{C} 3$ & $0.44449(7)$ & $0.66152(13)$ & $0.53806(11)$ & $0.0193(3)$ \\
\hline $\mathrm{C} 4$ & $0.44109(6)$ & $0.74126(13)$ & $0.59603(11)$ & $0.0173(3)$ \\
\hline $\mathrm{C} 5$ & $0.39815(6)$ & $0.80099(13)$ & $0.61044(11)$ & $0.0172(3)$ \\
\hline C6 & $0.34541(7)$ & $0.79977(14)$ & $0.55890(12)$ & $0.0199(3)$ \\
\hline $\mathrm{C} 7$ & $0.31042(7)$ & $0.86849(14)$ & $0.58081(12)$ & $0.0212(3)$ \\
\hline $\mathrm{C} 8$ & $0.32756(7)$ & $0.93579(14)$ & $0.65305(12)$ & $0.0206(3)$ \\
\hline C9 & $0.38105(7)$ & $0.93547(13)$ & $0.70249(12)$ & $0.0182(3)$ \\
\hline $\mathrm{C} 10$ & $0.40699(7)$ & $0.00225(13)$ & $0.77586(12)$ & $0.0197(3)$ \\
\hline $\mathrm{C} 11$ & $0.39086(7)$ & $0.07707(14)$ & $0.82684(13)$ & $0.0228(3)$ \\
\hline C12 & $0.43757(9)$ & $0.12008(16)$ & $0.88466(16)$ & $0.0307(4)$ \\
\hline C13 & $0.48030(8)$ & $0.07090(17)$ & $0.86804(15)$ & $0.0298(4)$ \\
\hline $\mathrm{C} 14$ & $0.40152(7)$ & $0.59676(14)$ & $0.48293(12)$ & $0.0213(3)$ \\
\hline C15 & $0.36297(8)$ & $0.55652(16)$ & $0.51876(14)$ & $0.0274(4)$ \\
\hline $\mathrm{C} 16$ & $0.32240(9)$ & $0.49528(17)$ & $0.46623(15)$ & $0.0304(4)$ \\
\hline $\mathrm{C} 17$ & $0.31995(8)$ & $0.47350(17)$ & $0.37723(15)$ & $0.0312(4)$ \\
\hline $\mathrm{C} 18$ & $0.35853(9)$ & $0.51157(19)$ & $0.34130(15)$ & $0.0335(4)$ \\
\hline C19 & $0.39944(8)$ & $0.57244(16)$ & $0.39378(13)$ & $0.0261(4)$ \\
\hline $\mathrm{C} 20$ & $0.33656(8)$ & $0.10232(16)$ & $0.82699(13)$ & $0.0253(4)$ \\
\hline $\mathrm{C} 21$ & $0.30358(8)$ & $0.02718(18)$ & $0.84499(14)$ & $0.0295(4)$ \\
\hline $\mathrm{C} 22$ & $0.25296(9)$ & $0.0523(2)$ & $0.84855(16)$ & $0.0383(5)$ \\
\hline $\mathrm{C} 23$ & $0.23499(9)$ & $0.1515(2)$ & $0.83423(17)$ & $0.0435(6)$ \\
\hline $\mathrm{C} 24$ & $0.26717(10)$ & $0.2271(2)$ & $0.81642(18)$ & $0.0427(6)$ \\
\hline $\mathrm{C} 25$ & $0.31802(9)$ & $0.20323(18)$ & $0.81313(16)$ & $0.0328(4)$ \\
\hline $\mathrm{C} 26$ & $0.58494(7)$ & $0.74115(17)$ & $0.63839(14)$ & $0.0285(4)$ \\
\hline $\mathrm{C} 27$ & $0.53785(9)$ & $0.0856(2)$ & $0.9138(2)$ & $0.0450(6)$ \\
\hline $\mathrm{O} 1$ & $0.4390(3)$ & $0.5418(5)$ & $0.2176(5)$ & $0.0892(18)$ \\
\hline $\mathrm{C} 28$ & $0.4887(2)$ & $0.4978(5)$ & $0.2380(5)$ & $0.0551(15)$ \\
\hline
\end{tabular}




$\begin{array}{ccccc} & \mathrm{x} / \mathrm{a} & \mathrm{y} / \mathrm{b} & \mathrm{z} / \mathrm{c} & \mathrm{U}(\mathrm{eq}) \\ \mathrm{C} 29 & 0.5274(3) & 0.5711(4) & 0.2961(4) & 0.0536(14) \\ \mathrm{C} 30 & 0.5071(3) & 0.6769(4) & 0.2687(5) & 0.0597(17) \\ \mathrm{C} 31 & 0.4526(3) & 0.6453(7) & 0.1990(6) & 0.086(3) \\ \mathrm{O} 2 & 0.2530(3) & 0.2696(8) & 0.5176(6) & 0.115(3) \\ \mathrm{C} 32 & 0.2120(2) & 0.2665(6) & 0.4249(4) & 0.0589(16) \\ \mathrm{C} 33 & 0.1658(5) & 0.3143(13) & 0.4455(12) & 0.140(5) \\ \mathrm{C} 34 & 0.3007(3) & 0.2119(7) & 0.5020(6) & 0.077(2) \\ \mathrm{C} 35 & 0.3408(5) & 0.2508(12) & 0.5896(8) & 0.120(4)\end{array}$




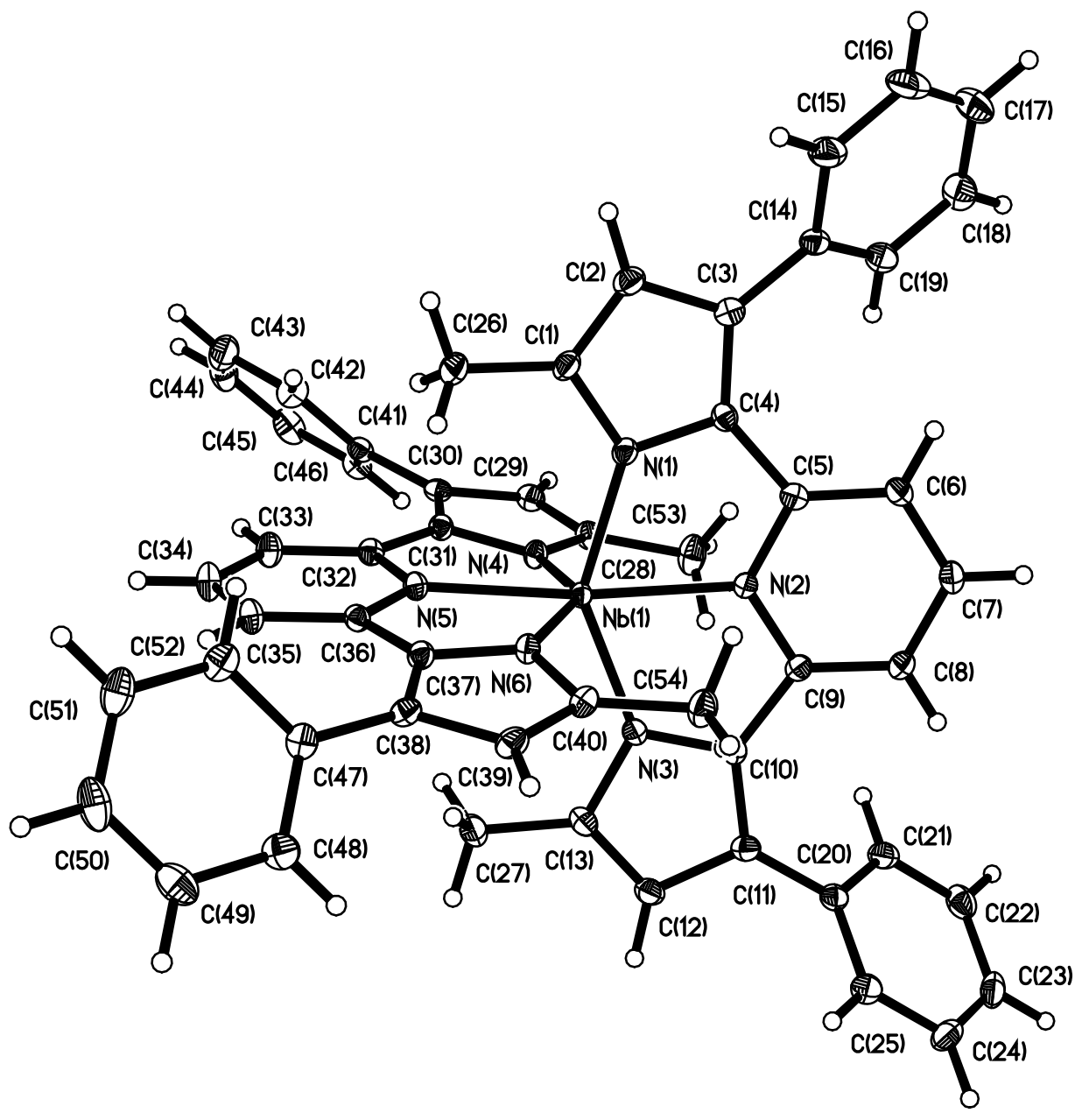

Figure 19. Perspective view of the molecular structure of the $\left[\left(\mathrm{C}_{27} \mathrm{H}_{21} \mathrm{~N}_{3}\right)_{2} \mathrm{Nb}\right]^{+}$cation with the atom labeling scheme for the independent non-hydrogen atoms. The thermal ellipsoids are scaled to enclose $50 \%$ probability. 
Table C53. Crystal data for $\left[\left(\mathrm{C}_{27} \mathrm{H}_{21} \mathrm{~N}_{3}\right)_{2} \mathrm{Nb}\right]\left[\mathrm{B}\left(\mathrm{C}_{6} \mathrm{H}_{3}\left(\mathrm{CF}_{3}\right)_{2}\right)_{4}\right] \cdot \mathrm{C}_{7} \mathrm{H}_{8} \cdot \mathrm{OEt}_{2}$.

$\begin{array}{lll}\text { Ident. code } & \mathrm{cm} 170 \mathrm{cms} \\ \text { Chem. formula } & \mathrm{C}_{97} \mathrm{H}_{72} \mathrm{BF}_{24} \mathrm{~N}_{6} \mathrm{NbO} & \\ \text { Formula weight } & 1897.32 \mathrm{~g} / \mathrm{mol} \\ \text { Temperature } & 100(2) \mathrm{K} \\ \text { Wavelength } & 0.71073 \AA \\ \text { Crystal size } & 0.090 \times 0.226 \times 0.369 \mathrm{~mm} \\ \text { Crystal system } & \text { triclinic } \\ \text { Space group } & \mathrm{P}(-1)(\mathrm{No} .2) & \\ \text { Unit cell } & \mathrm{a}=14.0305(6) \AA & \alpha=106.8232(12)^{\circ} \\ & \mathrm{b}=14.6004(6) \AA & \beta=103.2486(12)^{\circ} \\ & \mathrm{c}=22.4318(9) \AA & \gamma=95.2887(13)^{\circ}\end{array}$

Volume, $\AA^{3} \quad 4219.0(3)$

$\mathrm{Z} 2$

Density (calc) $\quad 1.494 \mathrm{~g} / \mathrm{cm}^{3}$

Abs. coefficient $\quad 0.250 \mathrm{~mm}^{-1}$

$\mathrm{F}(000) \quad 1932$

Table C54. Data collection and structure refinement for $\left[\left(\mathrm{C}_{27} \mathrm{H}_{21} \mathrm{~N}_{3}\right)_{2} \mathrm{Nb}\right]\left[\mathrm{B}\left(\mathrm{C}_{6} \mathrm{H}_{3}\left(\mathrm{CF}_{3}\right)_{2}\right)_{4}\right] \cdot \mathrm{C}_{7} \mathrm{H}_{8} \cdot \mathrm{OEt}_{2}$.

$\begin{array}{ll}\text { Theta range } & 2.80 \text { to } 30.01^{\circ} \\ \text { Index ranges } & -19 \leq \mathrm{h} \leq 19,-20 \leq \mathrm{k} \leq 20,-31 \leq 1 \leq 31 \\ \text { Reflections } & 97026 \\ \text { Independent refls } & 24554[\mathrm{R}(\mathrm{int})=0.0430] \\ \text { Coverage } & 99.6 \% \\ \text { Absorption correction } & \text { multi-scan } \\ \text { Max. and min. trans. } & 0.978 \text { and } 0.913 \\ \text { Refinement method } & \text { Full-matrix least-squares on } \mathrm{F}^{2} \\ \text { Refinement program } & \text { SHELXL-2014/7 (Sheldrick, 2014) } \\ \text { Data / restrs / parms } & 24554 / 0 / 1178 \\ \text { Goodness-of-fit on } \mathrm{F}^{2} & 1.008 \\ \text { Final R indices } & 18542 \text { data; R1 }=0.0403, \mathrm{wR} 2=0.0862 \\ & \mathrm{I}>2 \sigma(\mathrm{I}) \\ \text { Largest diff. peak and hole } & 0.581 \text { and }-0.751 \mathrm{e}-/ \AA^{3}\end{array}$


Table C55. Atomic coordinates and equivalent isotropic atomic displacement parameters $\left(\AA^{2}\right)$ for $\left[\left(\mathrm{C}_{27} \mathrm{H}_{21} \mathrm{~N}_{3}\right)_{2} \mathrm{Nb}\right]\left[\mathrm{B}\left(\mathrm{C}_{6} \mathrm{H}_{3}\left(\mathrm{CF}_{3}\right)_{2}\right)_{4}\right] \cdot \mathrm{C}_{7} \mathrm{H}_{8} \cdot \mathrm{OEt}_{2}$. U(eq) is defined as one third of the trace of the orthogonalized $\mathrm{U}_{\mathrm{ij}}$ tensor.

\begin{tabular}{|c|c|c|c|c|}
\hline & $\mathrm{x} / \mathrm{a}$ & $y / b$ & $\mathrm{z} / \mathrm{c}$ & $\mathrm{U}(\mathrm{eq})$ \\
\hline $\mathrm{Nb} 1$ & $0.62239(2)$ & $0.76839(2)$ & $0.50947(2)$ & $0.01088(4)$ \\
\hline N1 & $0.73027(10)$ & $0.88663(10)$ & $0.52871(6)$ & $0.0131(3)$ \\
\hline $\mathrm{N} 2$ & $0.66958(10)$ & $0.84213(10)$ & $0.61487(6)$ & $0.0119(3)$ \\
\hline N3 & $0.53398(10)$ & $0.70272(10)$ & $0.55113(7)$ & $0.0131(3)$ \\
\hline N4 & $0.71407(10)$ & $0.66510(10)$ & $0.49655(6)$ & $0.0130(3)$ \\
\hline N5 & $0.59563(10)$ & $0.69563(10)$ & $0.40487(6)$ & $0.0121(3)$ \\
\hline N6 & $0.50544(10)$ & $0.81609(10)$ & $0.46140(6)$ & $0.0127(3)$ \\
\hline $\mathrm{C} 1$ & $0.77519(13)$ & $0.91947(12)$ & $0.48717(8)$ & $0.0154(3)$ \\
\hline $\mathrm{C} 2$ & $0.85477(13)$ & $0.99012(13)$ & $0.52351(8)$ & $0.0168(3)$ \\
\hline $\mathrm{C} 3$ & $0.86435(12)$ & $0.00383(12)$ & $0.59031(8)$ & $0.0137(3)$ \\
\hline $\mathrm{C} 4$ & $0.78540(12)$ & $0.94068(12)$ & $0.59194(8)$ & $0.0127(3)$ \\
\hline C5 & $0.74407(12)$ & $0.92125(12)$ & $0.64068(8)$ & $0.0130(3)$ \\
\hline C6 & $0.76833(13)$ & $0.97366(12)$ & $0.70607(8)$ & $0.0155(3)$ \\
\hline C7 & $0.71887(13)$ & $0.94275(13)$ & $0.74536(8)$ & $0.0177(3)$ \\
\hline $\mathrm{C} 8$ & $0.64604(13)$ & $0.86023(12)$ & $0.71992(8)$ & $0.0160(3)$ \\
\hline C9 & $0.62185(12)$ & $0.81129(12)$ & $0.65416(8)$ & $0.0129(3)$ \\
\hline $\mathrm{C} 10$ & $0.54609(12)$ & $0.72831(12)$ & $0.61769(8)$ & $0.0133(3)$ \\
\hline C11 & $0.47450(12)$ & $0.67090(12)$ & $0.63039(8)$ & $0.0146(3)$ \\
\hline $\mathrm{C} 12$ & $0.41451(13)$ & $0.60868(12)$ & $0.56850(8)$ & $0.0163(3)$ \\
\hline C13 & $0.45133(12)$ & $0.62788(12)$ & $0.52149(8)$ & $0.0156(3)$ \\
\hline $\mathrm{C} 14$ & $0.94533(12)$ & $0.06926(12)$ & $0.64354(8)$ & $0.0150(3)$ \\
\hline $\mathrm{C} 15$ & $0.98440(14)$ & $0.15774(14)$ & $0.63889(9)$ & $0.0235(4)$ \\
\hline $\mathrm{C} 16$ & $0.06114(16)$ & $0.22038(15)$ & $0.68854(11)$ & $0.0316(5)$ \\
\hline C17 & $0.10077(14)$ & $0.19655(15)$ & $0.74330(10)$ & $0.0289(4)$ \\
\hline $\mathrm{C} 18$ & $0.06399(13)$ & $0.10882(14)$ & $0.74812(9)$ & $0.0230(4)$ \\
\hline C19 & $0.98765(13)$ & $0.04510(13)$ & $0.69848(8)$ & $0.0176(3)$ \\
\hline $\mathrm{C} 20$ & $0.46315(13)$ & $0.66782(12)$ & $0.69342(8)$ & $0.0154(3)$ \\
\hline $\mathrm{C} 21$ & $0.54350(13)$ & $0.65525(13)$ & $0.73879(9)$ & $0.0183(3)$ \\
\hline $\mathrm{C} 22$ & $0.53216(14)$ & $0.64846(13)$ & $0.79726(9)$ & $0.0213(4)$ \\
\hline $\mathrm{C} 23$ & $0.44168(15)$ & $0.65365(13)$ & $0.81108(9)$ & $0.0216(4)$ \\
\hline $\mathrm{C} 24$ & $0.36153(14)$ & $0.66617(13)$ & $0.76677(9)$ & $0.0209(4)$ \\
\hline $\mathrm{C} 25$ & $0.37200(13)$ & $0.67298(13)$ & $0.70813(9)$ & $0.0183(3)$ \\
\hline $\mathrm{C} 26$ & $0.73938(15)$ & $0.88056(14)$ & $0.41527(8)$ & $0.0219(4)$ \\
\hline
\end{tabular}




\begin{tabular}{|c|c|c|c|c|}
\hline & $\mathrm{x} / \mathrm{a}$ & $\mathrm{y} / \mathrm{b}$ & $\mathrm{z} / \mathrm{c}$ & $\mathrm{U}(\mathrm{eq})$ \\
\hline $\mathrm{C} 27$ & $0.41577(14)$ & $0.58124(14)$ & $0.45002(8)$ & $0.0211(4)$ \\
\hline $\mathrm{C} 28$ & $0.78336(12)$ & $0.63948(12)$ & $0.54187(8)$ & $0.0157(3)$ \\
\hline $\mathrm{C} 29$ & $0.83799(12)$ & $0.57998(12)$ & $0.50993(8)$ & $0.0152(3)$ \\
\hline $\mathrm{C} 30$ & $0.80460(12)$ & $0.56634(11)$ & $0.44257(8)$ & $0.0127(3)$ \\
\hline C31 & $0.72692(12)$ & $0.61846(11)$ & $0.43584(8)$ & $0.0125(3)$ \\
\hline $\mathrm{C} 32$ & $0.65381(12)$ & $0.62972(11)$ & $0.38342(8)$ & $0.0128(3)$ \\
\hline $\mathrm{C} 33$ & $0.63551(13)$ & $0.58030(12)$ & $0.31798(8)$ & $0.0166(3)$ \\
\hline C34 & $0.55822(13)$ & $0.59912(13)$ & $0.27454(8)$ & $0.0180(3)$ \\
\hline $\mathrm{C} 35$ & $0.50011(13)$ & $0.66656(12)$ & $0.29592(8)$ & $0.0159(3)$ \\
\hline $\mathrm{C} 36$ & $0.52007(12)$ & $0.71427(11)$ & $0.36164(8)$ & $0.0122(3)$ \\
\hline $\mathrm{C} 37$ & $0.46760(12)$ & $0.78419(12)$ & $0.39408(8)$ & $0.0129(3)$ \\
\hline C38 & $0.38031(12)$ & $0.81930(12)$ & $0.37748(8)$ & $0.0140(3)$ \\
\hline C39 & $0.36375(13)$ & $0.87419(12)$ & $0.43723(8)$ & $0.0159(3)$ \\
\hline $\mathrm{C} 40$ & $0.44000(13)$ & $0.87276(12)$ & $0.48720(8)$ & $0.0151(3)$ \\
\hline $\mathrm{C} 41$ & $0.84990(12)$ & $0.51005(12)$ & $0.39395(8)$ & $0.0138(3)$ \\
\hline $\mathrm{C} 42$ & $0.86362(13)$ & $0.54026(13)$ & $0.34264(9)$ & $0.0192(4)$ \\
\hline $\mathrm{C} 43$ & $0.90944(14)$ & $0.48796(15)$ & $0.29865(9)$ & $0.0243(4)$ \\
\hline $\mathrm{C} 44$ & $0.94259(14)$ & $0.40399(15)$ & $0.30531(9)$ & $0.0256(4)$ \\
\hline $\mathrm{C} 45$ & $0.93038(14)$ & $0.37332(13)$ & $0.35616(9)$ & $0.0224(4)$ \\
\hline $\mathrm{C} 46$ & $0.88522(13)$ & $0.42593(12)$ & $0.40068(9)$ & $0.0172(3)$ \\
\hline $\mathrm{C} 47$ & $0.31445(13)$ & $0.80329(12)$ & $0.31272(8)$ & $0.0150(3)$ \\
\hline $\mathrm{C} 48$ & $0.21305(13)$ & $0.77159(13)$ & $0.30015(9)$ & $0.0197(4)$ \\
\hline C49 & $0.15023(14)$ & $0.75266(14)$ & $0.23852(10)$ & $0.0255(4)$ \\
\hline $\mathrm{C} 50$ & $0.18823(16)$ & $0.76672(15)$ & $0.18961(9)$ & $0.0269(4)$ \\
\hline C51 & $0.28845(15)$ & $0.80116(14)$ & $0.20200(9)$ & $0.0237(4)$ \\
\hline C52 & $0.35124(14)$ & $0.81973(13)$ & $0.26321(9)$ & $0.0189(4)$ \\
\hline C53 & $0.79394(14)$ & $0.67325(14)$ & $0.61292(8)$ & $0.0220(4)$ \\
\hline C54 & $0.45780(14)$ & $0.92207(13)$ & $0.55795(8)$ & $0.0190(4)$ \\
\hline B1 & $0.28089(13)$ & $0.19949(13)$ & $0.97933(9)$ & $0.0124(3)$ \\
\hline C55 & $0.26823(12)$ & $0.12913(12)$ & $0.90530(8)$ & $0.0129(3)$ \\
\hline C56 & $0.22074(12)$ & $0.03165(12)$ & $0.88169(8)$ & $0.0143(3)$ \\
\hline $\mathrm{C} 57$ & $0.22067(12)$ & $0.97038(12)$ & $0.82147(8)$ & $0.0153(3)$ \\
\hline C58 & $0.27067(13)$ & $0.00259(13)$ & $0.78249(8)$ & $0.0178(3)$ \\
\hline C59 & $0.31860(12)$ & $0.09767(13)$ & $0.80477(8)$ & $0.0166(3)$ \\
\hline C60 & $0.31629(12)$ & $0.15983(12)$ & $0.86447(8)$ & $0.0147(3)$ \\
\hline C61 & $0.16260(14)$ & $0.86969(13)$ & $0.79527(9)$ & $0.0199(4)$ \\
\hline C62 & $0.37396(14)$ & $0.13658(15)$ & $0.76539(8)$ & $0.0222(4)$ \\
\hline
\end{tabular}




\begin{tabular}{|c|c|c|c|c|}
\hline & $\mathrm{x} / \mathrm{a}$ & $\mathrm{y} / \mathrm{b}$ & $\mathrm{z} / \mathrm{c}$ & $\mathrm{U}(\mathrm{eq})$ \\
\hline C63 & $0.29604(12)$ & $0.31349(12)$ & $0.98217(8)$ & $0.0136(3)$ \\
\hline C64 & $0.36615(12)$ & $0.38759(12)$ & $0.03020(8)$ & $0.0144(3)$ \\
\hline C65 & $0.37368(13)$ & $0.48406(12)$ & $0.03144(8)$ & $0.0164(3)$ \\
\hline C66 & $0.31110(14)$ & $0.51019(13)$ & $0.98386(9)$ & $0.0215(4)$ \\
\hline C67 & $0.24064(14)$ & $0.43766(14)$ & $0.93556(9)$ & $0.0231(4)$ \\
\hline C68 & $0.23282(13)$ & $0.34230(13)$ & $0.93541(9)$ & $0.0185(3)$ \\
\hline C69 & $0.44736(14)$ & $0.56081(13)$ & $0.08573(9)$ & $0.0199(4)$ \\
\hline $\mathrm{C} 70$ & $0.17640(18)$ & $0.46153(16)$ & $0.88069(12)$ & $0.0413(6)$ \\
\hline C71 & $0.37964(12)$ & $0.17127(11)$ & $0.02089(8)$ & $0.0123(3)$ \\
\hline $\mathrm{C} 72$ & $0.37475(12)$ & $0.10916(12)$ & $0.05771(8)$ & $0.0137(3)$ \\
\hline $\mathrm{C} 73$ & $0.45861(13)$ & $0.07871(12)$ & $0.08721(8)$ & $0.0145(3)$ \\
\hline C74 & $0.55125(13)$ & $0.10725(12)$ & $0.08023(8)$ & $0.0160(3)$ \\
\hline $\mathrm{C} 75$ & $0.55782(12)$ & $0.16791(12)$ & $0.04334(8)$ & $0.0151(3)$ \\
\hline $\mathrm{C} 76$ & $0.47417(12)$ & $0.19950(12)$ & $0.01476(8)$ & $0.0141(3)$ \\
\hline $\mathrm{C} 77$ & $0.45159(13)$ & $0.01569(13)$ & $0.12843(9)$ & $0.0187(3)$ \\
\hline $\mathrm{C} 78$ & $0.65796(13)$ & $0.20119(13)$ & $0.03681(9)$ & $0.0202(4)$ \\
\hline C79 & $0.18341(12)$ & $0.18366(11)$ & $0.00572(8)$ & $0.0127(3)$ \\
\hline $\mathrm{C} 80$ & $0.08712(12)$ & $0.14815(12)$ & $0.96490(8)$ & $0.0145(3)$ \\
\hline C81 & $0.00493(12)$ & $0.13900(12)$ & $0.98891(8)$ & $0.0158(3)$ \\
\hline $\mathrm{C} 82$ & $0.01510(13)$ & $0.16504(13)$ & $0.05489(9)$ & $0.0180(3)$ \\
\hline $\mathrm{C} 83$ & $0.10958(13)$ & $0.20190(13)$ & $0.09626(8)$ & $0.0166(3)$ \\
\hline $\mathrm{C} 84$ & $0.19095(12)$ & $0.21153(12)$ & $0.07220(8)$ & $0.0147(3)$ \\
\hline $\mathrm{C} 85$ & $0.90272(13)$ & $0.10219(14)$ & $0.94418(9)$ & $0.0211(4)$ \\
\hline $\mathrm{C} 86$ & $0.12140(14)$ & $0.22694(15)$ & $0.16742(9)$ & $0.0230(4)$ \\
\hline $\mathrm{F} 1$ & $0.14699(11)$ & $0.83360(9)$ & $0.84070(6)$ & $0.0408(3)$ \\
\hline $\mathrm{F} 2$ & $0.07311(9)$ & $0.86477(9)$ & $0.75661(6)$ & $0.0346(3)$ \\
\hline F3 & $0.20681(10)$ & $0.80762(9)$ & $0.75908(8)$ & $0.0482(4)$ \\
\hline $\mathrm{F} 4$ & $0.32615(10)$ & $0.19601(10)$ & $0.73849(6)$ & $0.0387(3)$ \\
\hline F5 & $0.38952(10)$ & $0.06670(9)$ & $0.71621(6)$ & $0.0354(3)$ \\
\hline F6 & $0.46325(9)$ & $0.18790(10)$ & $0.80038(5)$ & $0.0358(3)$ \\
\hline F7 & $0.52975(8)$ & $0.52851(8)$ & $0.10890(6)$ & $0.0299(3)$ \\
\hline $\mathrm{F} 8$ & $0.41093(9)$ & $0.59541(9)$ & $0.13671(5)$ & $0.0340(3)$ \\
\hline F9 & $0.47728(10)$ & $0.63717(9)$ & $0.06930(6)$ & $0.0399(3)$ \\
\hline F10 & $0.16149(12)$ & $0.55285(10)$ & $0.89706(9)$ & $0.0685(6)$ \\
\hline F11 & $0.21518(14)$ & $0.44585(16)$ & $0.83011(8)$ & $0.0748(6)$ \\
\hline F12 & $0.08658(11)$ & $0.40619(10)$ & $0.85745(8)$ & $0.0547(4)$ \\
\hline F13 & $0.50037(9)$ & $0.06223(9)$ & $0.19104(5)$ & $0.0295(3)$ \\
\hline
\end{tabular}




$\begin{array}{lcccc} & \mathrm{x} / \mathrm{a} & \mathrm{y} / \mathrm{b} & \mathrm{z} / \mathrm{c} & \mathrm{U}(\mathrm{eq}) \\ \text { F14 } & 0.49154(9) & 0.93576(8) & 0.11103(6) & 0.0279(3) \\ \text { F15 } & 0.35828(8) & 0.98611(9) & 0.12789(6) & 0.0303(3) \\ \text { F16 } & 0.71099(9) & 0.27397(9) & 0.08945(6) & 0.0374(3) \\ \text { F17 } & 0.71278(8) & 0.13060(8) & 0.02933(6) & 0.0286(3) \\ \text { F18 } & 0.65328(8) & 0.23446(9) & 0.98667(6) & 0.0303(3) \\ \text { F19 } & 0.90289(8) & 0.06656(10) & 0.88207(6) & 0.0373(3) \\ \text { F20 } & 0.84648(8) & 0.17193(9) & 0.94707(6) & 0.0274(2) \\ \text { F21 } & 0.85346(8) & 0.03182(9) & 0.95825(7) & 0.0339(3) \\ \text { F22 } & 0.05670(9) & 0.28191(9) & 0.18759(6) & 0.0318(3) \\ \text { F23 } & 0.10730(11) & 0.14744(10) & 0.18529(6) & 0.0394(3) \\ \text { F24 } & 0.21215(9) & 0.27516(10) & 0.20314(5) & 0.0369(3) \\ \text { C87 } & 0.1407(2) & 0.64710(16) & 0.43420(11) & 0.0396(6) \\ \text { C88 } & 0.13293(15) & 0.72605(14) & 0.49267(10) & 0.0263(4) \\ \text { C89 } & 0.21806(16) & 0.77917(15) & 0.54020(10) & 0.0292(4) \\ \text { C90 } & 0.21209(17) & 0.85195(17) & 0.59392(11) & 0.0344(5) \\ \text { C91 } & 0.12080(18) & 0.87360(17) & 0.60140(11) & 0.0346(5) \\ \text { C92 } & 0.03558(17) & 0.82143(17) & 0.55507(11) & 0.0326(5) \\ \text { C93 } & 0.04176(16) & 0.74833(16) & 0.50110(10) & 0.0299(5) \\ \text { O1 } & 0.14911(13) & 0.47759(13) & 0.16598(9) & 0.0442(4) \\ \text { C94 } & 0.2177(3) & 0.5195(2) & 0.27895(14) & 0.0652(9) \\ \text { C95 } & 0.2392(2) & 0.51825(19) & 0.21610(14) & 0.0489(7) \\ \text { C96 } & 0.1604(2) & 0.4746(2) & 0.10449(13) & 0.0492(7) \\ \text { C97 } & 0.0649(3) & 0.4314(2) & 0.05504(14) & 0.0624(8)\end{array}$




\section{Appendix D.}

\section{Additional DFT Calculations}

\section{General Considerations.}

All DFT calculations were performed with the ORCA program package (version 3.0.2). ${ }^{1}$ Geometry optimizations of the complexes and single-point calculations on the optimized geometries were carried out at the B3LYP level of DFT. ${ }^{2-4}$ The all-electron Gaussian basis sets were those developed by the Ahlrichs group. ${ }^{5-7}$ Triple- $\zeta$ quality basis sets def2-TZVP with one set of polarization functions on the metal and on the atoms directly coordinated to the metal center were used. For the carbon and hydrogen atoms, slightly smaller polarized split-valence def2-SVP basis sets were used that were of double- $\zeta$ quality in the valence region and contained a polarizing set of $\mathrm{d}$ functions on the non-hydrogen atoms. Auxiliary basis sets to expand the electron density in the resolution-of-the-identity (RIJCOSX) approach $^{8-10}$ were chosen to match the orbital basis. ${ }^{11-}$

13 The conductor-like screening model (COSMO) was applied to model solvent effects. ${ }^{14}$ All molecular orbital and spin density plots were generated using the program Gabedit. ${ }^{15}$

\section{Reference.}

(1) Neese, F. Wiley Interdiscip. Rev. Comput. Mol. Sci. 2012, 2 (1), 73. 
(2) Becke, A. D. J. Chem. Phys. 1986, 84 (8), 4524.

(3) Becke, A. D. J. Chem. Phys. 1993, 98 (7), 5648.

(4) Lee, C.; Yang, W.; Parr, R. G. Phys. Rev. B 1988, 37, 785.

(5) Schäfer, A.; Horn, H.; Ahlrichs, R. J. Chem. Phys. 1992, 97 (4), 2571.

(6) Schäfer, A.; Huber, C.; Ahlrichs, R. J. Chem. Phys. 1994, 100 (8), 5829.

(7) Weigend, F.; Ahlrichs, R. Phys. Chem. Chem. Phys. 2005, 7 (18), 3297.

(8) Neese, F.; Wennmohs, F.; Hansen, A.; Becker, U. Chem. Phys. 2009, 356 (1-3), 98.

(9) Kossmann, S.; Neese, F. Chem. Phys. Lett. 2009, 481 (4-6), 240.

(10) Neese, F. J. Comput. Chem. 2003, 24 (14), 1740.

(11) Eichkorn, K.; Treutler, O.; Öhm, H.; Häser, M.; Ahlrichs, R. Chem. Phys. Lett. 1995, 240 (4), 283.

(12) Eichkorn, K.; Treutler, O.; Öhm, H.; Häser, M.; Ahlrichs, R. Chem. Phys. Lett. 1995, 242, 652.

(13) Eichkorn, K.; Weigend, F.; Treutler, O.; Ahlrichs, R. Theor. Chem. Acc. 1997, 97 (1-4), 119.

(14) Klamt, A.; Schürmann, G. J. Chem. Soc. Perkin Trans. II 1993, 799.

(15) Allouche, A.-R. J. Comput. Chem. 2011, 32 (1), 174. 


\section{D.1. Additional Information for Chapter 1.}

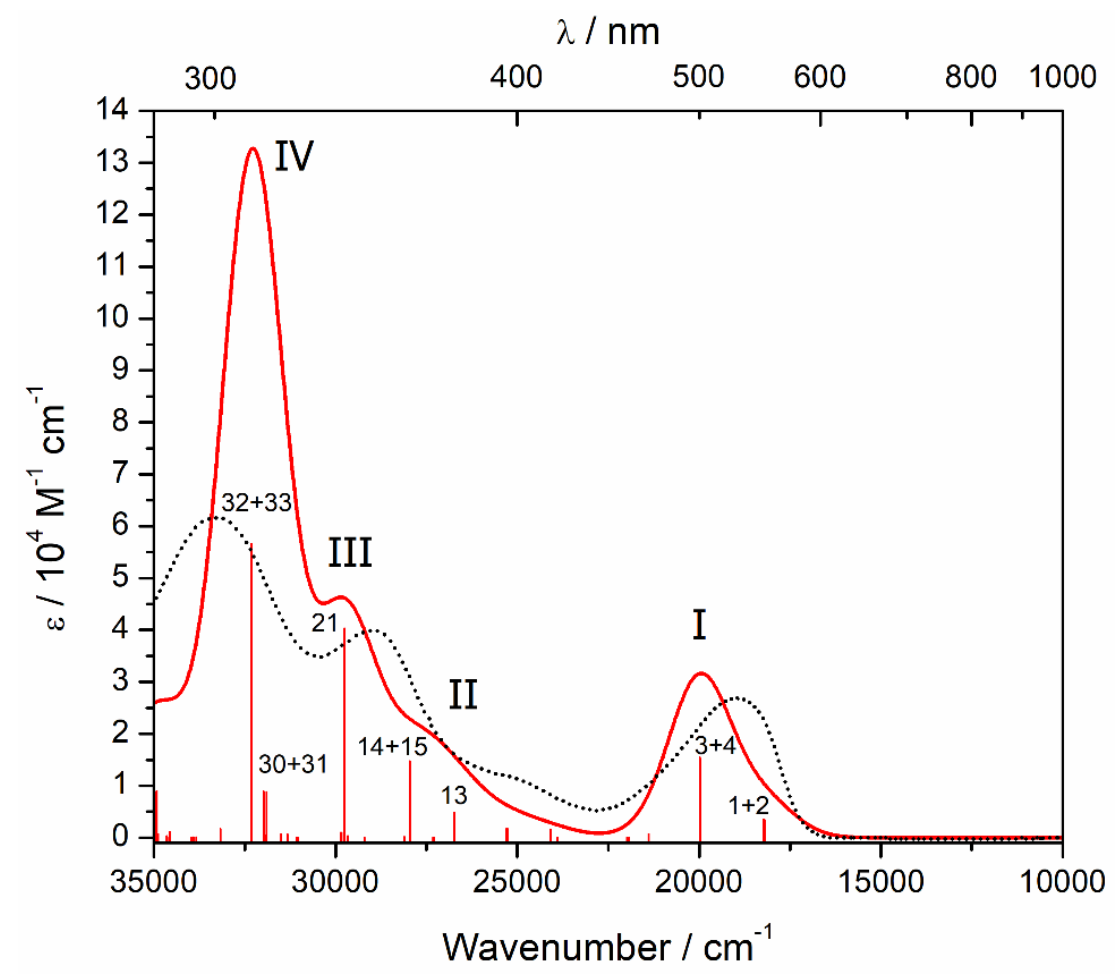

Figure D1. Electronic absorption spectrum of $\mathrm{Zr}\left({ }^{\mathrm{Me}} \mathrm{PDP}\right)_{2}$ obtained via TD-DFT calculations (red line, FWHM of $2000 \mathrm{~cm}^{-1}$ ). The stick plot indicates the positions and relative intensities of individual transitions. Transitions with calculated oscillator strengths larger than 0.03 are labeled according to their TD-DFT state number. The major contributions to each numbered state are listed in Table D1. The experimental spectrum is shown as a dotted black line for comparison. 
Table D1. Vertical Electronic Excitation Energies and Main Excitations Contributing to the Absorption Bands of $\mathrm{Zr}\left({ }^{\mathrm{Me}} \mathrm{PDP}\right)_{2}$ obtained via TD-DFT Calculations.

\begin{tabular}{|c|c|c|c|c|c|}
\hline Band & $\begin{array}{l}\text { TD- } \\
\text { DFT } \\
\text { State }\end{array}$ & $\begin{array}{c}\text { Energy / } \\
\mathrm{cm}^{-1} \\
(\lambda / \mathrm{nm})\end{array}$ & $f_{\text {osc }}$ & $\begin{array}{l}\text { Excitations } \\
\text { (weight) }{ }^{\mathrm{a}, \mathrm{b}}\end{array}$ & $\begin{array}{l}\text { Character } \\
(\% \text { LMCT) }\end{array}$ \\
\hline \multirow{4}{*}{$\mathbf{I}$} & 1 & $\begin{array}{l}18,196 \\
(549.6)\end{array}$ & 0.031 & $223 \rightarrow 224(0.80)$ & $\begin{array}{c}{ }^{1} \mathrm{IL} /{ }^{1} \mathrm{LMCT} \\
(31 \%)\end{array}$ \\
\hline & 2 & $\begin{array}{l}18,230 \\
(548.5)\end{array}$ & 0.032 & $223 \rightarrow 225(0.79)$ & $\begin{array}{c}{ }^{1} \mathrm{IL} /{ }^{1} \mathrm{LMCT} \\
(31 \%)\end{array}$ \\
\hline & 3 & $\begin{array}{l}19,975 \\
(500.6)\end{array}$ & 0.140 & $\begin{array}{l}222 \rightarrow 224(0.71) \\
222 \rightarrow 225(0.15) \\
223 \rightarrow 225(0.10)\end{array}$ & $\begin{array}{c}{ }^{1} \mathrm{IL} /{ }^{1} \mathrm{LMCT} \\
(31 \%)\end{array}$ \\
\hline & 4 & $\begin{array}{l}19,982 \\
(500.4)\end{array}$ & 0.142 & $\begin{array}{l}222 \rightarrow 225(0.71) \\
222 \rightarrow 224(0.15) \\
223 \rightarrow 224(0.10)\end{array}$ & $\begin{array}{c}{ }^{1} \mathrm{IL} /{ }^{1} \mathrm{LMCT} \\
(31 \%)\end{array}$ \\
\hline \multirow{3}{*}{ II } & 13 & $\begin{array}{l}26,739 \\
(374.0)\end{array}$ & 0.044 & $\begin{array}{l}219 \rightarrow 224(0.83) \\
219 \rightarrow 225(0.11)\end{array}$ & $\begin{array}{c}{ }^{1} \mathrm{IL} /{ }^{1} \mathrm{LMCT} \\
(31 \%)\end{array}$ \\
\hline & 14 & $\begin{array}{l}26,745 \\
(373.9)\end{array}$ & 0.044 & $\begin{array}{l}219 \rightarrow 225(0.83) \\
219 \rightarrow 224(0.11)\end{array}$ & $\begin{array}{c}{ }^{1} \mathrm{IL} /{ }^{1} \mathrm{LMCT} \\
(31 \%)\end{array}$ \\
\hline & 15 & $\begin{array}{l}27,956 \\
(357.7)\end{array}$ & 0.136 & $\begin{array}{l}218 \rightarrow 225(0.50) \\
217 \rightarrow 224(0.36)\end{array}$ & $\begin{array}{c}{ }^{1} \mathrm{IL} /{ }^{1} \mathrm{LMCT} \\
(31 \%)\end{array}$ \\
\hline \multirow[t]{5}{*}{ III } & 21 & $\begin{array}{l}29,753 \\
(336.1) \\
\end{array}$ & 0.371 & $219 \rightarrow 226(0.92)$ & $\begin{array}{c}{ }^{1} \mathrm{IL} /{ }^{1} \mathrm{LMCT} \\
(45 \%) \\
\end{array}$ \\
\hline & 30 & $\begin{array}{l}31,901 \\
(313.5)\end{array}$ & 0.081 & $\begin{array}{l}222 \rightarrow 229(0.44) \\
223 \rightarrow 230(0.20) \\
221 \rightarrow 227(0.16)\end{array}$ & $\begin{array}{c}{ }^{1} \mathrm{IL} /{ }^{1} \mathrm{LMCT} \\
(41 \%)\end{array}$ \\
\hline & 31 & $\begin{array}{l}31,981 \\
(312.7)\end{array}$ & 0.082 & $\begin{array}{l}222 \rightarrow 230(0.41) \\
223 \rightarrow 229(0.18) \\
220 \rightarrow 227(0.18)\end{array}$ & $\begin{array}{c}{ }^{1} \mathrm{IL} /{ }^{1} \mathrm{LMCT} \\
(41 \%)\end{array}$ \\
\hline & 32 & $\begin{array}{l}32,322 \\
(309.4)\end{array}$ & 0.522 & $\begin{array}{l}222 \rightarrow 229(0.38) \\
221 \rightarrow 227(0.20) \\
218 \rightarrow 226(0.16)\end{array}$ & $\begin{array}{c}{ }^{1} \mathrm{IL} /{ }^{1} \mathrm{LMCT} \\
(41 \%)\end{array}$ \\
\hline & 33 & $\begin{array}{l}32,325 \\
(309.4)\end{array}$ & 0.517 & $\begin{array}{l}222 \rightarrow 230(0.37) \\
220 \rightarrow 227(0.20) \\
217 \rightarrow 226(0.16)\end{array}$ & $\begin{array}{c}{ }^{1} \mathrm{IL} /{ }^{1} \mathrm{LMCT} \\
(41 \%)\end{array}$ \\
\hline
\end{tabular}

${ }^{a}$ only excitations with a weight larger than 0.1 are shown. ${ }^{b} \mathrm{HOMO} 223$, LUMO 224, 225 (degenerate). 

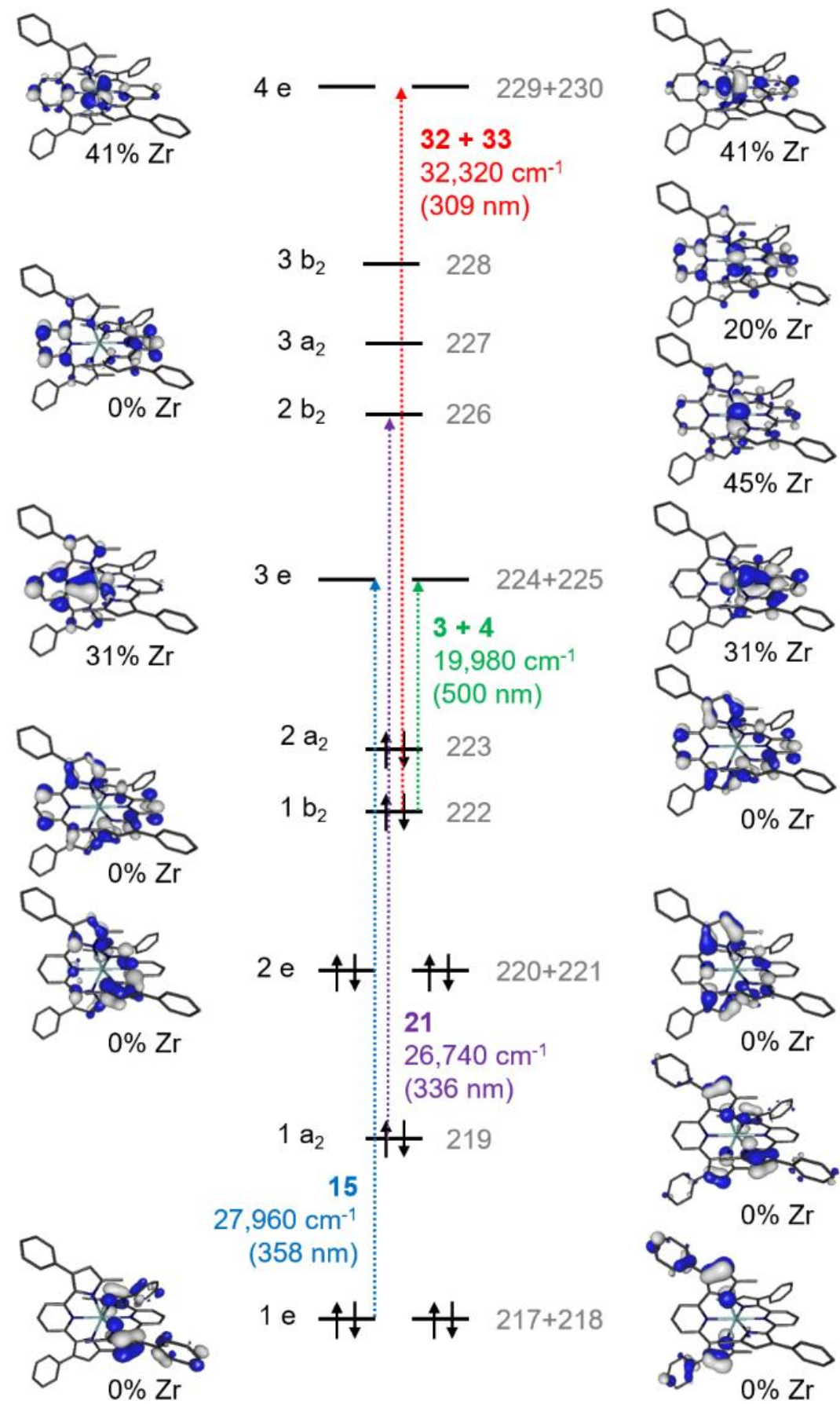

Figure D2. Qualitative MO diagram for $\mathrm{Zr}\left({ }^{\mathrm{Me}} \mathrm{PDP}\right)_{2}$ showing the donor and acceptor orbitals for TD-DFT excitations computed between 285-1000 nm. Symmetry labels shown to the left of each energy level were assigned according to the $\mathrm{D}_{2 \mathrm{~d}}$ point group of the core structure. The gray numbers to the right correspond to the MO number with 223 being the HOMO and 224 and 225 forming a degenerate set of LUMOs. The dotted arrows represent the single electron excitations with the highest weight for the main TD-DFT states of the absorption bands I-IV shown in Figure D1 and Table D1. 


\begin{tabular}{|c|c|c|c|c|c|c|c|}
\hline \multirow{2}{*}{\multicolumn{4}{|c|}{$\begin{array}{c}\text { Optimized Geometries for Compound } \\
\text { Presented in Chapter } 1 .\end{array}$}} & \multirow{3}{*}{$\begin{array}{l}\mathrm{C} \\
\mathrm{C} \\
\mathrm{C}\end{array}$} & \multirow{3}{*}{$\begin{array}{l}3.815672 \\
5.902443\end{array}$} & \multirow{2}{*}{$\begin{array}{l}0.294134 \\
-0.818453\end{array}$} & \multirow{2}{*}{$\begin{array}{l}5.504589 \\
6.045859\end{array}$} \\
\hline & & & & & & & \\
\hline & & & & & & 0.317772 & -2.331164 \\
\hline \multicolumn{4}{|c|}{$\mathrm{Zr}\left({ }^{\mathrm{Me}} \mathbf{P D P} \mathrm{P}^{\mathrm{Ph}}\right)_{2}{ }_{2}$ Singlet } & $\mathrm{C}$ & 3.534580 & 0.501384 & -4.516067 \\
\hline $\mathrm{Zr}$ & -0.02634 & 0.033219 & -0.001960 & $\mathrm{C}$ & 0.976621 & 0.597677 & -4.263861 \\
\hline $\mathrm{N}$ & 2.312684 & -0.025715 & -0.016193 & $\mathrm{C}$ & 4.504842 & 1.507850 & -4.336891 \\
\hline $\mathrm{N}$ & -2.356042 & 0.092772 & -0.013185 & $\mathrm{C}$ & -1.426856 & 0.693982 & -3.285883 \\
\hline $\mathrm{N}$ & 0.745257 & -0.330114 & 2.022182 & $\mathrm{C}$ & 0.060565 & 0.541878 & -3.219631 \\
\hline $\mathrm{N}$ & -0.734768 & 2.078297 & 0.353120 & $\mathrm{C}$ & 3.756701 & -0.460693 & -5.521449 \\
\hline $\mathrm{N}$ & -0.832023 & -1.977296 & -0.342792 & $\mathrm{C}$ & 2.284002 & 0.470097 & -3.716381 \\
\hline $\mathrm{N}$ & 0.735598 & 0.354086 & -2.036129 & $\mathrm{C}$ & -3.050560 & -1.070246 & -0.178034 \\
\hline $\mathrm{C}$ & 0.074823 & -0.489286 & 3.211982 & $\mathrm{C}$ & -2.992825 & 1.290098 & 0.140093 \\
\hline $\mathrm{C}$ & -0.925962 & 4.309192 & 0.609215 & $\mathrm{C}$ & -4.395430 & 1.350995 & 0.100132 \\
\hline $\mathrm{C}$ & 1.457844 & 3.279466 & 0.664037 & $\mathrm{C}$ & -4.455094 & -1.060550 & -0.152192 \\
\hline $\mathrm{C}$ & -0.032854 & 3.246327 & 0.535723 & $\mathrm{C}$ & -5.112402 & 0.162445 & -0.028543 \\
\hline $\mathrm{C}$ & -4.447814 & 4.452244 & 1.555368 & $\mathrm{C}$ & -6.090147 & -5.848639 & -0.923391 \\
\hline $\mathrm{C}$ & -2.246220 & 3.789556 & 0.499017 & $\mathrm{C}$ & 2.974714 & 0.110528 & -1.201839 \\
\hline $\mathrm{C}$ & -2.090330 & 2.401053 & 0.338890 & $\mathrm{C}$ & 4.377591 & 0.048015 & -1.235675 \\
\hline $\mathrm{C}$ & -3.478574 & 4.616812 & 0.545449 & $\mathrm{C}$ & 2.982391 & -0.192943 & 1.161256 \\
\hline $\mathrm{C}$ & -5.588868 & 5.259363 & 1.598096 & $\mathrm{C}$ & 4.386887 & -0.190486 & 1.177958 \\
\hline $\mathrm{C}$ & -4.825503 & 6.439651 & -0.367852 & $\mathrm{C}$ & 5.069463 & -0.084992 & -0.032851 \\
\hline $\mathrm{C}$ & -3.682838 & 5.634208 & -0.408095 & $\mathrm{C}$ & 5.663398 & 1.539579 & -5.118956 \\
\hline $\mathrm{C}$ & -5.785626 & 6.252730 & 0.632289 & $\mathrm{C}$ & 5.877311 & 0.565708 & -6.100795 \\
\hline $\mathrm{C}$ & -3.702455 & -4.350910 & -0.687540 & $\mathrm{C}$ & 4.917120 & -0.431577 & -6.301599 \\
\hline $\mathrm{C}$ & -3.994940 & -5.395312 & 0.211756 & $\mathrm{C}$ & 4.975969 & 0.203257 & 6.279996 \\
\hline $\mathrm{C}$ & -5.807346 & -4.824707 & -1.834353 & $\mathrm{C}$ & -1.417651 & -0.562259 & 3.291939 \\
\hline $\mathrm{C}$ & -2.429545 & -3.598183 & -0.568378 & $\mathrm{H}$ & -0.662541 & 5.353983 & 0.771932 \\
\hline $\mathrm{C}$ & -4.626800 & -4.085265 & -1.717850 & $\mathrm{H}$ & 1.814579 & 2.588156 & 1.445357 \\
\hline $\mathrm{C}$ & -0.189734 & -3.179543 & -0.527464 & $\mathrm{H}$ & 1.793047 & 4.290160 & 0.938688 \\
\hline $\mathrm{C}$ & -5.176362 & -6.134730 & 0.096406 & $\mathrm{H}$ & 1.965111 & 3.000181 & -0.275313 \\
\hline $\mathrm{C}$ & -2.202838 & -2.224725 & -0.372415 & $\mathrm{H}$ & -4.296062 & 3.684905 & 2.319264 \\
\hline $\mathrm{C}$ & -1.137564 & -4.189125 & -0.648941 & $\mathrm{H}$ & -6.325844 & 5.113223 & 2.393439 \\
\hline $\mathrm{C}$ & 1.300002 & -3.294964 & -0.610006 & $\mathrm{H}$ & -4.969943 & 7.216309 & -1.124612 \\
\hline $\mathrm{C}$ & 2.110028 & -0.363847 & 2.301012 & $\mathrm{H}$ & -2.937914 & 5.785106 & -1.194220 \\
\hline $\mathrm{C}$ & 3.557392 & -0.630953 & 4.473192 & $\mathrm{H}$ & -6.681305 & 6.879321 & 0.660648 \\
\hline $\mathrm{C}$ & 4.493535 & -1.663008 & 4.260935 & $\mathrm{H}$ & -3.286001 & -5.619622 & 1.013072 \\
\hline $\mathrm{C}$ & 0.998257 & -0.596881 & 4.245378 & $\mathrm{H}$ & -6.508700 & -4.601647 & -2.643583 \\
\hline $\mathrm{C}$ & 2.304309 & -0.533063 & 3.683670 & $\mathrm{H}$ & -4.406816 & -3.294808 & -2.440057 \\
\hline $\mathrm{C}$ & 5.652922 & -1.755543 & 5.036989 & $\mathrm{H}$ & -5.387670 & -6.935885 & 0.810419 \\
\hline
\end{tabular}




\begin{tabular}{|c|c|c|c|c|c|c|c|}
\hline $\mathrm{H}$ & -0.927715 & -5.243439 & -0.827645 & $\mathrm{C}$ & -0.910013472 & 4.281842765 & 1.016134880 \\
\hline $\mathrm{H}$ & 1.720016 & -2.621321 & -1.375085 & $\mathrm{C}$ & 1.484683430 & 3.282090497 & 1.047816556 \\
\hline & 1.586448 & -4.321619 & -0.880817 & $\mathrm{C}$ & 0.006314050 & 3.241070980 & 0.860832225 \\
\hline $\mathrm{H}$ & 1.791146 & -3.048732 & 0.346914 & $\mathrm{C}$ & -3.806151726 & 5.355212621 & 1.827774972 \\
\hline $\mathrm{H}$ & 4.299953 & -2.406271 & 3.483120 & $\mathrm{C}$ & -2.193382720 & 3.779540571 & 0.747207969 \\
\hline H & 0.763130 & -0.753771 & 5.297822 & $\mathrm{C}$ & -2.007713764 & 2.405017895 & 0.459866823 \\
\hline & 6.363028 & -2.567451 & 4.854586 & $\mathrm{C}$ & -3.431170922 & 4.580685770 & 0.722841477 \\
\hline & 3.097363 & 1.097095 & 5.690276 & $\mathrm{C}$ & -4.949003702 & 6.147024461 & 1.790004139 \\
\hline & 6.811811 & -0.887031 & 6.648894 & $\mathrm{C}$ & -5.363898298 & 5.442475624 & 20168 \\
\hline & 0.737431 & 0.760816 & -5.314455 & $\mathrm{C}$ & -4.230266758 & 4.640242193 & -0.426836657 \\
\hline & 4.339707 & 2.277690 & -3.578301 & $\mathrm{C}$ & -5.730967940 & 6.195563831 & 0.641342474 \\
\hline $\mathrm{H}$ & -1.955237 & -0.232915 & -3.004551 & $\mathrm{C}$ & -3.790067171 & -4.244646922 & 43674 \\
\hline $\mathrm{H}$ & -1.736063 & 0.959798 & -4.307232 & $\mathrm{C}$ & -3.993172604 & -5.512655552 & -0.368359621 \\
\hline $\mathrm{H}$ & -1.785279 & 1.491012 & -2.613487 & $\mathrm{C}$ & -6.024859972 & -4.377197531 & -1.880626457 \\
\hline $\mathrm{H}$ & 3.011122 & -1.243978 & -5.683356 & $\mathrm{C}$ & -2.501373924 & -3.564609856 & -0.774997633 \\
\hline $\mathrm{H}$ & -4.903990 & 2.308301 & 0.192898 & $\mathrm{C}$ & -4.829670126 & -3.695000596 & -1.700861487 \\
\hline $\mathrm{H}$ & -5.009780 & -1.991265 & -0.249785 & $\mathrm{C}$ & -0.266646283 & -3.172728146 & -0.82 \\
\hline $\mathrm{H}$ & -6.205738 & 0.190597 & -0.032693 & $\mathrm{C}$ & -5.189456600 & -6.193402665 & -0.548441478 \\
\hline $\mathrm{H}$ & -7.015357 & -6.424198 & -1.011606 & $\mathrm{C}$ & -2.215684583 & -2.178854274 & -0.455623768 \\
\hline $\mathrm{H}$ & 4.905513 & 0.125898 & -2.183778 & $\mathrm{C}$ & -1.256009413 & -4.155891685 & 99079 \\
\hline $\mathrm{H}$ & 4.922171 & -0.291726 & 2.119609 & $\mathrm{C}$ & 1.198614294 & -3.305 & 9585 \\
\hline $\mathrm{H}$ & 6.162892 & -0.108216 & -0.039490 & $\mathrm{C}$ & 2.093126893 & -0.394386450 & 2.289333463 \\
\hline $\mathrm{H}$ & 6.400988 & 2.332339 & -4.962278 & $\mathrm{C}$ & 3.492041408 & -0.335342139 & 4.500899258 \\
\hline $\mathrm{H}$ & 6.786766 & 0.585013 & -6.707481 & $\mathrm{C}$ & 4.537994537 & -1.264641452 & 4.474457784 \\
\hline $\mathrm{H}$ & 5.075508 & -1.194670 & -7.069248 & $\mathrm{C}$ & 0.984398190 & -0.704413214 & 4.216834244 \\
\hline $\mathrm{H}$ & 5.161066 & 0.937825 & 7.069091 & $\mathrm{C}$ & 2.273433561 & -0.485266264 & 0361 \\
\hline $\mathrm{H}$ & -1.825833 & -1.325065 & 2.608398 & $\mathrm{C}$ & 5.647671152 & -1.113872402 & 5.298793409 \\
\hline $\mathrm{H}$ & -1.896909 & 0.397572 & 3.033489 & $\mathrm{C}$ & 3.588908929 & 0.740728106 & 5.391921614 \\
\hline 2 & -1.730732 & -0.830257 & 4.311465 & $\mathrm{C}$ & 5.735770362 & -0.030569945 & 6.167116727 \\
\hline & & & & $\mathrm{C}$ & 2.139138451 & 0.259882911 & -2.347062446 \\
\hline \multicolumn{4}{|c|}{$\mathrm{Zr}\left({ }^{\mathrm{Me}} \mathrm{PDP}^{\mathrm{Ph}}\right)_{2}{ }_{2}$ Triplet } & $\mathrm{C}$ & 3.608168654 & 0.209549928 & -4.512513623 \\
\hline $\mathrm{Zr}$ & 0.008137103 & 0.035320321 & & $\mathrm{C}$ & 1.077145975 & 0.468537623 & -4.314316854 \\
\hline $\mathrm{N}$ & 2.328154625 & -0.031001388 & -0.020574608 & $\mathrm{C}$ & 4.610737771 & 1.184339384 & -4.452801052 \\
\hline $\mathrm{N}$ & -2.234644531 & 0.109193024 & 0.027333455 & $\mathrm{C}$ & -1.332826712 & 0.723566245 & -3.406151950 \\
\hline $\mathrm{N}$ & 0.738744740 & -0.538783245 & 1.988856693 & $\mathrm{C}$ & 0.141436437 & 0.509668309 & -3.295457081 \\
\hline $\mathrm{N}$ & -0.655709567 & 2.100404692 & 0.507053097 & $\mathrm{C}$ & 3.782988571 & -0.860335366 & -5.398906294 \\
\hline $\mathrm{N}$ & -0.850677792 & -1.974550128 & -0.496901477 & $\mathrm{C}$ & 2.357548626 & 0.315249603 & -3.728471149 \\
\hline iv & 0.772119814 & 0.362597765 & -2.089327739 & $\mathrm{C}$ & -2.993301155 & -1.050885931 & -0.109071550 \\
\hline $\mathrm{C}$ & 0.080201801 & -0.750725934 & 3.169175279 & $\mathrm{C}$ & -2.886667882 & 1.291684649 & 0.292913826 \\
\hline
\end{tabular}




\begin{tabular}{|c|c|c|c|c|c|c|c|}
\hline $\mathrm{C}$ & -4.272047251 & 1.332643996 & 0.469159739 & $\mathrm{H}$ & -1.595991329 & 1.015511156 & -4.423536248 \\
\hline $\mathrm{C}$ & -4.374719041 & -1.039955563 & 0.137723735 & $\mathrm{H}$ & -1.670832371 & 1.515438373 & -2.733253392 \\
\hline $\mathrm{C}$ & -5.023486121 & 0.151865765 & 0.418174727 & $\mathrm{H}$ & 3.013305686 & -1.619777482 & -5.465666786 \\
\hline $\mathrm{C}$ & -6.212565769 & -5.629647739 & -1.304007650 & $\mathrm{H}$ & -4.746724082 & 2.276380441 & 0.689169613 \\
\hline $\mathrm{C}$ & 2.999247539 & 0.087397373 & -1.199804221 & $\mathrm{H}$ & -4.921833244 & -1.969629177 & 0.118571657 \\
\hline $\mathrm{C}$ & 4.397001278 & 0.048632350 & -1.208581692 & $\mathrm{H}$ & -6.086171507 & 0.168494575 & 0.615312009 \\
\hline $\mathrm{C}$ & 2.977006445 & -0.184917682 & 1.167682832 & $\mathrm{H}$ & -7.143787016 & -6.163106064 & -1.447483705 \\
\hline $\mathrm{C}$ & 4.374997957 & -0.165354225 & 1.200698590 & $\mathrm{H}$ & 4.938592583 & 0.117016840 & -2.138307335 \\
\hline $\mathrm{C}$ & 5.066603749 & -0.059089773 & 0.002341448 & $\mathrm{H}$ & 4.899460969 & -0.257334486 & 2.138293697 \\
\hline $\mathrm{C}$ & 5.752452559 & 1.084833673 & -5.240351279 & $\mathrm{H}$ & 6.150343758 & -0.067562806 & 0.011350587 \\
\hline $\mathrm{C}$ & 5.916881424 & 0.008865970 & -6.106263929 & $\mathrm{H}$ & 6.512867549 & 1.854654374 & -5.182991973 \\
\hline $\mathrm{C}$ & 4.926696264 & -0.964180844 & -6.181878880 & $\mathrm{H}$ & 6.807831444 & -0.071518490 & -6.716505580 \\
\hline $\mathrm{C}$ & 4.699699830 & 0.895523984 & 6.212165030 & $\mathrm{H}$ & 5.044994947 & -1.806664985 & -6.852622269 \\
\hline $\mathrm{C}$ & -1.387505070 & -1.022577295 & 3.232870687 & $\mathrm{H}$ & 4.756813758 & 1.741576534 & 6.886339910 \\
\hline $\mathrm{H}$ & -0.666523268 & 5.302161130 & 1.269876178 & $\mathrm{H}$ & -1.688228577 & -1.753385071 & 2.479450518 \\
\hline $\mathrm{H}$ & 1.817827564 & 2.503368584 & 1.738758420 & $\mathrm{H}$ & -1.982445985 & -0.120360585 & 3.067169602 \\
\hline $\mathrm{H}$ & 1.789001397 & 4.245812687 & 1.456752138 & $\mathrm{H}$ & -1.652768079 & -1.422272534 & 4.212716821 \\
\hline $\mathrm{H}$ & 2.018489385 & 3.131016709 & 0.105028989 & & & & \\
\hline $\mathrm{H}$ & -3.201102853 & 5.320329171 & 2.725488095 & & & & \\
\hline $\mathrm{H}$ & -5.231262995 & 6.726912057 & 2.660245912 & & & & \\
\hline $\mathrm{H}$ & -5.956660567 & 5.489121336 & -1.374501398 & & & & \\
\hline $\mathrm{H}$ & -3.944272116 & 4.065633562 & -1.298697744 & & & & \\
\hline $\mathrm{H}$ & -6.617321720 & 6.816450686 & 0.609494069 & & & & \\
\hline $\mathrm{H}$ & -3.208307191 & -5.953095936 & 0.233813957 & & & & \\
\hline $\mathrm{H}$ & -6.808368276 & -3.933020478 & -2.482450317 & & & & \\
\hline $\mathrm{H}$ & -4.685821502 & -2.736070605 & -2.180629495 & & & & \\
\hline $\mathrm{H}$ & -5.327019277 & -7.164693025 & -0.089638655 & & & & \\
\hline $\mathrm{H}$ & -1.077876435 & -5.178542347 & -1.265007132 & & & & \\
\hline $\mathrm{H}$ & 1.558727471 & -2.562570569 & -1.758837464 & & & & \\
\hline $\mathrm{H}$ & 1.443579359 & -4.295600971 & -1.425954161 & & & & \\
\hline $\mathrm{H}$ & 1.755903129 & -3.152135177 & -0.111637179 & & & & \\
\hline $\mathrm{H}$ & 4.471778948 & -2.118053746 & 3.810379762 & & & & \\
\hline $\mathrm{H}$ & 0.754962819 & -0.852138653 & 5.261351263 & & & & \\
\hline $\mathrm{H}$ & 6.444104890 & -1.847860876 & 5.265772153 & & & & \\
\hline $\mathrm{H}$ & 2.782811669 & 1.463225542 & 5.432769777 & & & & \\
\hline $\mathrm{H}$ & 6.602511763 & 0.090522220 & 6.804969502 & & & & \\
\hline $\mathrm{H}$ & 0.874736326 & 0.578762466 & -5.369036876 & & & & \\
\hline $\mathrm{H}$ & 4.485618912 & 2.032014818 & -3.790014355 & & & & \\
\hline 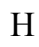 & -1.899571479 & -0.177482153 & -3.153566967 & & & & \\
\hline
\end{tabular}




\begin{tabular}{|c|c|c|c|c|c|c|c|}
\hline \multicolumn{4}{|c|}{ D.2. Additional Information for Chapter 2.} & $\mathrm{C}$ & 9749 & -0.4 & 70571 \\
\hline \multirow{3}{*}{\multicolumn{4}{|c|}{$\begin{array}{c}\text { Optimized Geometries for Compounds } \\
\text { Presented in Chapter } 2 .\end{array}$}} & $\mathrm{C}$ & 5.597905094 & -1.976035348 & 9449 \\
\hline & & & & $\mathrm{C}$ & 3.830559660 & 0.058067190 & 5.601092612 \\
\hline & & & & $\mathrm{C}$ & 5.865978031 & -1.195955878 & 6.016519425 \\
\hline \multirow{2}{*}{\multicolumn{4}{|c|}{$\left[\mathrm{Zr}\left({ }^{\mathrm{Me}} \mathrm{PDP} \mathrm{P}^{\mathrm{Ph}}\right)_{2}\right]^{1-}($ no COSMO) }} & $\mathrm{C}$ & 2.101919908 & 0.357048692 & -2.370964921 \\
\hline & & & & $\mathrm{C}$ & 3.589675815 & 0.467840590 & -4.536982026 \\
\hline 7 & -0.013986766 & 0.102284638 & -0.032447418 & $\mathrm{C}$ & 1.034438568 & 0.547265178 & -4.350478263 \\
\hline & 2.267717922 & 0.027410472 & -0.031645127 & $\mathrm{C}$ & 4.585538710 & 1.445689202 & -4.325533124 \\
\hline & -2.307371159 & 0.122658199 & -0.030254829 & $\mathrm{C}$ & -1.391826515 & 0.714260739 & -3.422388909 \\
\hline & 0.713769055 & -0.197642825 & 2.066473742 & $\mathrm{C}$ & 0.093611234 & 0.545301277 & -3.322847423 \\
\hline v & -0.742126170 & 2.215297021 & 0.157905296 & $\mathrm{C}$ & 3.813094449 & -0.476681934 & -5.561361642 \\
\hline v & -0.774377762 & -2.000736563 & -0.214878356 & $\mathrm{C}$ & 2.326677672 & 0.451790967 & -3.763436914 \\
\hline & 0.735068115 & 0.412617924 & -2.119831190 & $\mathrm{C}$ & -2.996195735 & -1.061872872 & -0.135069848 \\
\hline 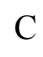 & 0.069814403 & -0.298159808 & 3.271467152 & $\mathrm{C}$ & -2.977693456 & 1.319267386 & 0.062712099 \\
\hline C & -1.022399085 & 4.434457368 & 0.437500113 & $\mathrm{C}$ & -4.379122442 & 1.349182706 & 0.014563648 \\
\hline 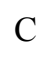 & 1.404390939 & 3.493679369 & 0.367572770 & $\mathrm{C}$ & -4.398277160 & -1.068781739 & -0.102974738 \\
\hline $\mathrm{C}$ & -0.089196814 & 3.407575213 & 0.315003946 & $\mathrm{C}$ & -5.084314627 & 0.146057667 & -0.047326140 \\
\hline $\mathrm{C}$ & -4.537066797 & $4.348861^{\prime}$ & 1.513445706 & $\mathrm{C}$ & -6.036936147 & -5.870924515 & -0.896285782 \\
\hline $\mathrm{C}$ & -2.321155001 & 3.85 & 0.387672159 & $\mathrm{C}$ & 2.95 & 0.154741960 & -1.217696287 \\
\hline 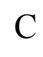 & -2.107858993 & 2.469194201 & 0.210520634 & $\mathrm{C}$ & 4.355869459 & 0.081508491 & 2929 \\
\hline t & -3.574484099 & 4.632996867 & 0.520624453 & $\mathrm{C}$ & 2.945216343 & -0.140469168 & 4154 \\
\hline t & -5.698183785 & 5.116214368 & 1.640034380 & $\mathrm{C}$ & 4.346532015 & -0.129856278 & 1.177403413 \\
\hline F & -4.979676384 & 6.506328353 & -0.198812033 & $\mathrm{C}$ & 5.048242557 & -0.037962091 & -0.026591959 \\
\hline 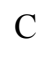 & -3.819511131 & 5.735731534 & -0.325334270 & $\mathrm{C}$ & 5.759368740 & 1.463699940 & -5.083804742 \\
\hline 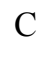 & -5.930151088 & 6.196532659 & 0.780089564 & $\mathrm{C}$ & 5.970382428 & 0.505819226 & -6.082897410 \\
\hline & -3.653653241 & -4.358131219 & -0.601336732 & $\mathrm{C}$ & 4.987076267 & -0.460447315 & -6.321415173 \\
\hline & -3.940834785 & -5.445804836 & 0.250207262 & $\mathrm{C}$ & 4.972404811 & -0.179943438 & 6.372045087 \\
\hline 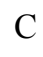 & -5.763444904 & -4.804023741 & -1.760732478 & $\mathrm{C}$ & -1.422658351 & -0.279673484 & 3.386171560 \\
\hline 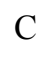 & -2.385751661 & -3.607776055 & -0.453001422 & $\mathrm{H}$ & -0.798433741 & 5.489652668 & 0.598439383 \\
\hline$\tau$ & -4.588861581 & -4.061009299 & -1.616021854 & $\mathrm{H}$ & 1.821238029 & 2.909925508 & 1.206531108 \\
\hline $\mathrm{C}$ & -0.145834051 & -3.207780068 & -0.361767285 & $\mathrm{H}$ & 1.724623723 & 4.538499210 & 0.498403652 \\
\hline $\mathrm{C}$ & -5.114941220 & -6.191849798 & 0.105888304 & $\mathrm{H}$ & 1.872072501 & 3.103955773 & -0.552929380 \\
\hline $\mathrm{C}$ & -2.144991836 & -2.226740151 & -0.276726957 & $\mathrm{H}$ & -4.361061400 & 3.513612544 & 2.195402378 \\
\hline C & -1.099932973 & -4.214625835 & -0.489594133 & $\mathrm{H}$ & -6.426748274 & 4.869025758 & 2.418583971 \\
\hline 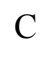 & 1.345551797 & -3.333348837 & -0.395963568 & $\mathrm{H}$ & -5.147110621 & 7.350463505 & -0.874937144 \\
\hline 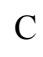 & 2.079574177 & -0.302679644 & 2.306006251 & $\mathrm{H}$ & -3.085020256 & 5.976071868 & -1.098563376 \\
\hline & 3.546394649 & -0.711650923 & 4.452882408 & $\mathrm{H}$ & -6.841692260 & 6.793639401 & 0.874937406 \\
\hline & 4.455277917 & -1.738727086 & 4.117266066 & $\mathrm{H}$ & -3.228676794 & -5.693747089 & 1.041666681 \\
\hline & 1.009376498 & -0.449490269 & 4.287306258 & $\mathrm{H}$ & -6.470176713 & -4.548593870 & -2.556449868 \\
\hline
\end{tabular}




\begin{tabular}{|c|c|c|c|}
\hline & -4 & 307 & -2 \\
\hline & -5.315885908 & -7.0247 & 9 \\
\hline & $-0.8 \mathrm{~s}$ & -5.2 & -0 \\
\hline & 1.789239054 & -2.7 & -1 \\
\hline & 1.637800725 & -4.387672230 & -0.515754109 \\
\hline & 1.811539706 & -2.950509801 & 0.527656309 \\
\hline & 4.246311192 & -2.364412627 & 3.246413633 \\
\hline & 0.79 & -0.5 & 5.3 \\
\hline & 6.281910211 & -2.78 & 4.60 \\
\hline & 3.1 & 23 & 5. \\
\hline & 6.7 & 159 & 0.01 \\
\hline & 0.82 & 53 & -5. \\
\hline & 4.425880502 & 2.201843389 & -3.552605096 \\
\hline & -1.942252858 & -0.218018741 & -3.205810519 \\
\hline & -1.673955749 & 1.041627192 & -4.435500720 \\
\hline & -1.756170041 & 1.473193855 & -2.710828838 \\
\hline & 3.052770177 & -1.240058654 & -5.7 \\
\hline & -4.903654111 & 2.301861412 & 0.042739332 \\
\hline & -4.937998695 & -2.012518206 & -0.139705629 \\
\hline & -6.178198544 & 0.155367804 & -0.053860 \\
\hline & -6.958638259 & -6.449421927 & -1.006262564 \\
\hline & 4.891818463 & 0.139848163 & -2.178650845 \\
\hline & 4.875130710 & -0.207120825 & 2.125148400 \\
\hline & 6.141829572 & -0.059339949 & -0.024111663 \\
\hline & 6.514492758 & 2.232943295 & -4.892780 \\
\hline & 6.893360342 & 0.511923411 & -6.6700536 \\
\hline & 5.140633349 & -1.213441034 & -7.1009028 \\
\hline & 5.169525532 & 0.437560514 & 7.253762383 \\
\hline & -1.891666726 & -0.972509421 & 2.669146277 \\
\hline & -1.848698603 & 0.719843911 & 3.188563040 \\
\hline & -1.732082684 & -0.583153774 & 4.398509801 \\
\hline
\end{tabular}

\begin{tabular}{|c|c|c|c|}
\hline & -0.765322 & -2.073102 & -0.071998 \\
\hline & 0.691077 & 0.226071 & -1.993638 \\
\hline & 0.159818 & -0.318621 & 3.385458 \\
\hline & -0.977987 & 4.389179 & 0.597025 \\
\hline 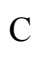 & 1.447970 & 3.442209 & 0.628969 \\
\hline & -0.043974 & 3.353216 & 0.531405 \\
\hline 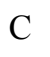 & -4.487391 & 4.403215 & 1.603136 \\
\hline$C$ & -2.274972 & 3.812456 & 0.518377 \\
\hline 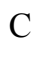 & -2.060376 & 2.422803 & 0.381380 \\
\hline & -3.533478 & 4.598823 & 0.582088 \\
\hline & -5.649577 & 5.179392 & 1.667402 \\
\hline & -4.943882 & 6.395343 & -0.299104 \\
\hline & -3.781182 & 5.618416 & -0.361059 \\
\hline & -5.886665 & 6.175982 & 0.712386 \\
\hline 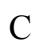 & -3.676489 & -4.268824 & -0.896065 \\
\hline $\mathcal{C}$ & -4.127884 & -5.411580 & -0.205895 \\
\hline C & -5.602500 & -4.478555 & -2.387411 \\
\hline$C_{1}$ & -2.404291 & -3.605621 & -0.528006 \\
\hline 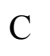 & -4.434306 & -3.819462 & -1.997120 \\
\hline & -0.169126 & -3.290924 & -0.239161 \\
\hline & -5.297821 & -6.073145 & -0.595901 \\
\hline & -2.135412 & -2.250880 & -0.239754 \\
\hline$C$ & -1.141695 & -4.257464 & -0.501924 \\
\hline$C$ & 1.314830 & -3.472272 & -0.158636 \\
\hline C & 2.170619 & -0.246717 & 2.403066 \\
\hline C & 3.674728 & -0.497630 & 4.544218 \\
\hline${ }^{C}$ & 4.638469 & -1.486008 & 4.243930 \\
\hline$C$ & 1.112553 & -0.403110 & 4.394910 \\
\hline$C$ & 2.406112 & -0.380129 & 3.790190 \\
\hline & 5.818821 & -1.599257 & 4.984363 \\
\hline & 3.938820 & 0.357952 & 5.636252 \\
\hline$C$ & 6.069911 & -0.728785 & 6.053345 \\
\hline $\mathcal{U}$ & 2.047812 & 0.222449 & -2.302534 \\
\hline $\mathcal{U}$ & 3.424205 & 0.317577 & -4.551004 \\
\hline $\mathrm{C}$ & 0.882983 & 0.314409 & -4.236922 \\
\hline $\mathrm{C}$ & 4.456638 & 1.262969 & -4.361624 \\
\hline $\mathrm{C}$ & -1.507028 & 0.385874 & -3.226027 \\
\hline & -0.012382 & 0.298414 & -3.174938 \\
\hline & 3.554317 & -0.575518 & -5.638613 \\
\hline
\end{tabular}




\begin{tabular}{|c|c|c|c|}
\hline $\mathrm{C}$ & 2.208323 & 0.285108 & -3.705851 \\
\hline $\mathrm{C}$ & -2.983026 & -1.084135 & -0.072935 \\
\hline $\mathrm{C}$ & -2.945450 & 1.285385 & 0.207416 \\
\hline $\mathrm{C}$ & -4.350669 & 1.331241 & 0.158051 \\
\hline $\mathrm{C}$ & -4.389646 & -1.085917 & -0.052810 \\
\hline $\mathrm{C}$ & -5.057490 & 0.134096 & 0.047351 \\
\hline $\mathrm{C}$ & -6.039530 & -5.610690 & -1.688872 \\
\hline $\mathrm{C}$ & 2.937513 & 0.095619 & -1.164484 \\
\hline $\mathrm{C}$ & 4.331173 & 0.057335 & -1.212847 \\
\hline C & 2.999451 & -0.107340 & 1.223379 \\
\hline $\mathrm{C}$ & 4.395530 & -0.078189 & 1.198221 \\
\hline $\mathrm{C}$ & 5.073791 & -0.010393 & -0.025171 \\
\hline $\mathrm{C}$ & 5.576012 & 1.296651 & -5.199328 \\
\hline $\mathrm{C}$ & 5.693996 & 0.389923 & -6.261103 \\
\hline $\mathrm{C}$ & 4.672411 & -0.542484 & -6.479282 \\
\hline $\mathrm{C}$ & 5.119007 & 0.245515 & 6.380052 \\
\hline $\mathrm{C}$ & -1.333139 & -0.383468 & 3.498555 \\
\hline $\mathrm{H}$ & -0.754879 & 5.448193 & 0.733156 \\
\hline $\mathrm{H}$ & 1.842588 & 2.75 & 190 \\
\hline $\mathrm{H}$ & 1.757320 & 4.464762 & 0.893662 \\
\hline $\mathrm{H}$ & 1.942782 & 3.168918 & -0.318729 \\
\hline $\mathrm{H}$ & -4.308894 & 3.633712 & 2.359039 \\
\hline $\mathrm{H}$ & -6.372460 & 5.005470 & 2.470290 \\
\hline $\mathrm{H}$ & -5.118237 & 7.173227 & -1.048662 \\
\hline $\mathrm{H}$ & -3.052713 & 5.795222 & -1.157315 \\
\hline $\mathrm{H}$ & -6.798226 & 6.778477 & 0.757718 \\
\hline $\mathrm{H}$ & -3.555003 & -5.777507 & 0.650610 \\
\hline $\mathrm{H}$ & -6.170029 & -4.110332 & -3.246914 \\
\hline $\mathrm{H}$ & -4.089349 & -2.946768 & -2.557854 \\
\hline $\mathrm{H}$ & -5.633582 & -6.954097 & -0.041246 \\
\hline $\mathrm{H}$ & -0.960110 & -5.311689 & -0.714081 \\
\hline $\mathrm{H}$ & 1.845825 & -2.786334 & -0.838023 \\
\hline $\mathrm{H}$ & 1.591598 & -4.502458 & -0.429237 \\
\hline $\mathrm{H}$ & 1.699494 & -3.267085 & 0.855366 \\
\hline $\mathrm{H}$ & 4.450638 & -2.176254 & 3.417808 \\
\hline $\mathrm{H}$ & 0.906949 & -0.527309 & 5.459560 \\
\hline $\mathrm{H}$ & 6.547526 & -2.373504 & 4.725171 \\
\hline $\mathrm{H}$ & 3.206945 & 1.129039 & 5.892654 \\
\hline $\mathrm{H}$ & 6.996163 & -0.812088 & 6.628571 \\
\hline
\end{tabular}

$\begin{array}{cccc}\mathrm{H} & 0.618984 & 0.390164 & -5.293085 \\ \mathrm{H} & 4.372888 & 1.986718 & -3.546785 \\ \mathrm{H} & -1.998372 & -0.522368 & -2.835398 \\ \mathrm{H} & -1.843234 & 0.526650 & -4.264265 \\ \mathrm{H} & -1.892533 & 1.234779 & -2.635831 \\ \mathrm{H} & 2.767019 & -1.313603 & -5.816948 \\ \mathrm{H} & -4.874341 & 2.282005 & 0.227829 \\ \mathrm{H} & -4.941441 & -2.020529 & -0.128624 \\ \mathrm{H} & -6.151282 & 0.153141 & 0.040568 \\ \mathrm{H} & -6.950457 & -6.130172 & -1.998841 \\ \mathrm{H} & 4.836052 & 0.098668 & -2.176232 \\ \mathrm{H} & 4.949179 & -0.127043 & 2.134161 \\ \mathrm{H} & 6.166485 & -0.012190 & -0.055470 \\ \mathrm{H} & 6.359298 & 2.040447 & -5.022213 \\ \mathrm{H} & 6.572345 & 0.410738 & -6.912808 \\ \mathrm{H} & 4.748644 & -1.252801 & -7.308437 \\ \mathrm{H} & 5.301527 & 0.928672 & 7.215089 \\ \mathrm{H} & -1.756520 & -1.195564 & 2.881326 \\ \mathrm{H} & -1.825143 & 0.551130 & 3.174717\end{array}$




\begin{tabular}{|c|c|c|c|c|c|c|c|}
\hline \multirow{2}{*}{\multicolumn{4}{|c|}{ D.3. Additional Information for Chapter 3.}} & $\mathrm{C}$ & 5697 & -3.854135587 & -2.38 \\
\hline & & & & 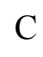 & 0.327377124 & -4.234545453 & -3.698938228 \\
\hline \multirow{2}{*}{\multicolumn{4}{|c|}{$\begin{array}{c}\text { Optimized Geometries for Compounds } \\
\text { Presented in Chapter } 3 .\end{array}$}} & $\mathrm{C}$ & .988192825 & -4.436348735 & -4.127688409 \\
\hline & & & & $\mathrm{C}$ & -2.002841251 & -4.262209804 & -3.182072086 \\
\hline \multirow{2}{*}{\multicolumn{4}{|c|}{$\mathrm{Zr}\left({ }^{\mathrm{Mes}} \mathbf{P D P} P^{\mathrm{Ph}}\right)_{2}$}} & $\mathrm{C}$ & -1.738258457 & -3.882555962 & -1.858502923 \\
\hline & & & & $\mathrm{C}$ & 2.093212787 & -3.739216980 & -1.999328020 \\
\hline & 0.015922640 & 0.002473901 & 0.012525482 & $\mathrm{C}$ & -1.309315667 & -4.837862799 & -5.548997419 \\
\hline & -0.089257611 & -2.131355903 & 0.645624202 & $\mathrm{C}$ & -2.899089058 & -3.774647747 & 818375 \\
\hline & -0.013913407 & -0.018499280 & 2.262849637 & C & 0.348776223 & 3.632767187 & 13707 \\
\hline & 0.085039646 & 2.113936835 & 0.707262611 & C & 1.689016468 & 3.893839058 & 04145 \\
\hline & 2.151786847 & -0.112011217 & -0.629153828 & $\mathrm{C}$ & 1.971977756 & 4.312880185 & 76539 \\
\hline & 0.028520306 & -0.011644305 & -2.235535158 & C & 0.972725367 & 4.488824697 & 6290 \\
\hline & -2.106166881 & 0.096673225 & -0.668580025 & $\mathrm{C}$ & -0.347476582 & 4.250486630 & -3.633977972 \\
\hline & -0.112181241 & -3.363786906 & 0.005676774 & $\mathrm{C}$ & -0.679017756 & 3.845320077 & -2.335707631 \\
\hline & 0.081191266 & -4.360520973 & 0.961654398 & $\mathrm{C}$ & 2.835548764 & 3.761497665 & -0.791521797 \\
\hline & 0.226652397 & -3.752132445 & 2.236765580 & $\mathrm{C}$ & 1.282885738 & 4.930586410 & -5.441355731 \\
\hline & 0.095616162 & -2.371407596 & 2.008602425 & $\mathrm{C}$ & -2.136871090 & 3.698292983 & -1.987135129 \\
\hline & -0.003088673 & -1.225887792 & 2.896990628 & $\mathrm{C}$ & 3.389705056 & -0.164541838 & -0.001358830 \\
\hline & -0.158499464 & -1.272613838 & 4.290698324 & $\mathrm{C}$ & 4.381615146 & 0.011907651 & -0.965081798 \\
\hline & -0.339034428 & -0.075529503 & 18542 & C & 3.767744900 & 0.172336980 & -2.235053955 \\
\hline & -0.346085680 & 1.150668266 & 4.3 & $\mathrm{C}$ & 2.385651065 & 0.070309575 & -1.995128395 \\
\hline & -0.168963089 & 1.165945983 & 2.925594317 & $\mathrm{C}$ & 1.232636751 & -0.008315356 & -2.876097710 \\
\hline & -0.137525058 & 2.340749205 & 2.068176279 & $\mathrm{C}$ & 1.269753903 & -0.149940107 & -4.271366664 \\
\hline & -0.351906383 & 3.715197929 & 2.288598501 & $\mathrm{C}$ & 0.066876041 & -0.304604138 & -4.958042541 \\
\hline & -0.255811835 & 4.322368113 & 1.008088964 & $\mathrm{C}$ & -1.155601580 & -0.301232970 & -4.287121582 \\
\hline & 0.030572033 & 3.340514494 & 0.062368118 & $r$ & -1.161013187 & -0.142456642 & -2.893728921 \\
\hline & 0.513714044 & -4.486060781 & 3.487849406 & C & -2.332859372 & -0.104938684 & -2.032859100 \\
\hline & -0.238186582 & -5.623855146 & 3.840462501 & C & -3.710356384 & -0.283577246 & -2.263051993 \\
\hline & 0.061375478 & -6.352457952 & 4.995404046 & $\mathrm{C}$ & -4.321876372 & -0.187131645 & -0.985231960 \\
\hline & 1.121326241 & -5.962053342 & 5.820315686 & $\mathrm{C}$ & -3.339076773 & 0.065986602 & -0.029572368 \\
\hline & 1.879699352 & -4.836338778 & 5.480116977 & $\mathrm{C}$ & 4.511613491 & 0.430069223 & -3.487426380 \\
\hline & 1.580733269 & -4.107309850 & 4.327005801 & $\mathrm{C}$ & 4.158353825 & 1.485046137 & -4.352853290 \\
\hline & -0.658426817 & 4.482837458 & 3.518764216 & $\mathrm{C}$ & 4.906086297 & 1.751914380 & -5.502287299 \\
\hline & -1.780740347 & 5.336331012 & 3.533926714 & $\mathrm{C}$ & 6.026014077 & 0.972553823 & -5.813418715 \\
\hline & -2.086419750 & 6.110740016 & 4.655857352 & $\mathrm{C}$ & 6.391925032 & -0.075717869 & -4.962665064 \\
\hline & -1.273668857 & 6.053435531 & 5.792687707 & $\mathrm{C}$ & 5.643913670 & -0.343335542 & -3.812474866 \\
\hline & -0.145815306 & 5.225293735 & 5.789039096 & C & -4.471674375 & -0.556972533 & -3.506093745 \\
\hline & 0.162541187 & 4.454510768 & 4.663521424 & C & -5.314213385 & -1.685655966 & -3.565938958 \\
\hline & -0.400916060 & -3.640692323 & -1.445240449 & $\mathrm{C}$ & -6.076102978 & -1.959706342 & -4.704961998 \\
\hline
\end{tabular}




\begin{tabular}{|c|c|c|c|}
\hline & -6.018120832 & -1.107379835 & 41 \\
\hline & -5.201078008 & 0.027530655 & -5.763473094 \\
\hline $\mathrm{C}$ & -4.441263018 & 0.302769401 & -4.622076402 \\
\hline U & 3.702325297 & -0.476376339 & 1.438508053 \\
\hline & 3.920972430 & 0.548740588 & 2.394369945 \\
\hline & 4.387853326 & 0.220821863 & 3.677311768 \\
\hline & 4.679549325 & -1.093370998 & 4.055862994 \\
\hline & 4.481363060 & 46392 & 3.0 \\
\hline & 4.00 & 13 & 1 \\
\hline & 3.723197535 & 2.00 & 87 \\
\hline C & 5.189348075 & -1.429357665 & 1688 \\
\hline $\mathrm{C}$ & 3.843427169 & -2.964513572 & 0.849012712 \\
\hline $\mathrm{C}$ & -3.637637985 & 0.372965898 & 1.414229785 \\
\hline $\mathrm{C}$ & -3.912822880 & 1.710435192 & 1.805513715 \\
\hline $\mathrm{C}$ & -4.31 & 1.98756 & 9462 \\
\hline $\mathrm{C}$ & -4.478098718 & 0.984263612 & 4.079190446 \\
\hline $\mathrm{C}$ & -4.248 & 6824 & 16 \\
\hline $\mathrm{C}$ & -3.845 & 585 & 02 \\
\hline $\mathrm{C}$ & -3.824651868 & 2.8603 & 0.8 \\
\hline $\mathrm{C}$ & -4.902712355 & 29854 & 5.490554613 \\
\hline C & -3.704088242 & -2.115604014 & 2.005600398 \\
\hline $\mathrm{H}$ & 0.129881234 & -5.429435232 & 0.755619130 \\
\hline $\mathrm{H}$ & -0.169893121 & -2.228099329 & 4.810497569 \\
\hline $\mathrm{H}$ & -0.494165997 & -0.099461565 & 6.063344737 \\
\hline $\mathrm{H}$ & -0.501843598 & 2.078220312 & 4.859782132 \\
\hline $\mathrm{H}$ & -0.338062152 & 5.389692124 & 0.8 \\
\hline $\mathrm{H}$ & -1.071292965 & -5.931239996 & 3.20 \\
\hline $\mathrm{H}$ & -0.538664655 & -7.22 & 5.2 \\
\hline H & 1.359487713 & -6.534450322 & $0.1201 / 700 / 7$ \\
\hline $\mathrm{H}$ & 2.716002081 & -4.526349405 & 6.113596393 \\
\hline $\mathrm{H}$ & 2.188319983 & -3.240197780 & 4.056889082 \\
\hline $\mathrm{H}$ & -2.423020653 & 5.380808191 & 2.650379974 \\
\hline$H$ & -2.968868614 & 6.756617464 & 4.643703664 \\
\hline 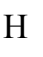 & -1.517350079 & 6.653545524 & 6.673602025 \\
\hline & 0.505990388 & 5.183365713 & 6.666613537 \\
\hline$\pi$ & 1.065506562 & 3.838569615 & 4.662477363 \\
\hline H & 1.149599849 & -4.404620060 & -4.400752598 \\
\hline H & -3.041265445 & -4.448963197 & -3.474237839 \\
\hline $\mathrm{H}$ & 2.747897192 & -4.001619064 & -2.843156562 \\
\hline
\end{tabular}

\begin{tabular}{|c|c|c|c|}
\hline $\mathrm{H}$ & 2.33 & 532 & -1 \\
\hline $\mathrm{I}$ & 8494 & -2.721124560 & -1.676722555 \\
\hline & -2.093066279 & -5.612023839 & -5.584598247 \\
\hline & -0.423009753 & -5.228700199 & -6.072488061 \\
\hline & -1.686333668 & -3.977377173 & 3277 \\
\hline & -3.769 & 10634 & 40805 \\
\hline & 80 & -2 & -( \\
\hline & 7830 & -4.1 & 771 \\
\hline & 034409 & 4.52 & 104 \\
\hline & -1.156548888 & 4.417419931 & -4 \\
\hline & 3.704611451 & 4.342049303 & 17457 \\
\hline $\mathrm{H}$ & 3.15 & 3943 & 290 \\
\hline & 2.562 & 4.1074 & 0.2 \\
\hline & 2.318421516 & 5.291300564 & -5.538759317 \\
\hline & 0.61 & 5.742 & -5.7 \\
\hline & 1.1 & 4.10 & -6 \\
\hline & -2.77 & 3.921181080 & -2 \\
\hline & -2.42 & 4.387327847 & -1 \\
\hline & -2.372388193 & 2.682634644 & 340169 \\
\hline$\Pi$ & 5.453017391 & 0.034693381 & -0.767596722 \\
\hline $\mathrm{H}$ & 2.222084608 & -0.170738642 & -4.796201449 \\
\hline$H$ & 0.083324865 & -0.446073855 & -6.042208103 \\
\hline $\mathrm{H}$ & -2.088457295 & -0.433250652 & -4.827611078 \\
\hline $\mathrm{H}$ & -5.391972055 & -0.247438860 & -0.78 \\
\hline & 3.295281720 & 2.107988159 & -4.1 \\
\hline 11 & 4.61 & 2.51944 & -0.150100449 \\
\hline & 0451 & 1.1 & -6 \\
\hline$\Pi$ & 7.264409875 & -0.691773429 & -5.19 \\
\hline $\mathrm{H}$ & 5.932539185 & -1.167865101 & -3.155177583 \\
\hline $\mathrm{H}$ & -5.358753123 & -2.358171313 & -2.705100900 \\
\hline $\mathrm{H}$ & -6.712870053 & -2.848515219 & -4.730391750 \\
\hline $\mathrm{H}$ & -6.608196603 & -1.326800274 & -6.706271063 \\
\hline & -5.158566128 & 0.709460976 & -6.617999385 \\
\hline$U$ & -3.829049219 & 1.207624636 & -4.586283142 \\
\hline & 4.566037373 & 1.031932680 & 4.390291434 \\
\hline & 4.729200982 & -3.129124518 & 3.347353086 \\
\hline & 2.685565674 & 2.217603483 & 1.761398073 \\
\hline & 4.362687122 & 2.301337008 & 1.208559790 \\
\hline & 3.976099769 & 2.648312357 & 2.907517044 \\
\hline
\end{tabular}




$\begin{array}{crrr}\mathrm{H} & 5.643730761 & -0.554849227 & 5.930401594 \\ \mathrm{H} & 5.943092968 & -2.232708810 & 5.409581040 \\ \mathrm{H} & 4.370019088 & -1.783021740 & 6.090689888 \\ \mathrm{H} & 4.396402599 & -3.847167179 & 1.201750102 \\ \mathrm{H} & 4.199779534 & -2.710639592 & -0.158437446 \\ \mathrm{H} & 2.785260646 & -3.252738559 & 0.758595803 \\ \mathrm{H} & -4.521224851 & 3.026615108 & 3.394281236 \\ \mathrm{H} & -4.413123079 & -1.148422686 & 4.382455539 \\ \mathrm{H} & -4.417645906 & 3.714971844 & 1.195807016 \\ \mathrm{H} & -4.188927131 & 2.582542426 & -0.160438787 \\ \mathrm{H} & -2.786435132 & 3.203713903 & 0.726795748 \\ \mathrm{H} & -5.674946456 & 2.105354541 & 5.505234635 \\ \mathrm{H} & -4.051014987 & 1.699153200 & 6.082216722 \\ \mathrm{H} & -5.304656654 & 0.438692182 & 6.015585412 \\ \mathrm{H} & -4.387309935 & -2.388550904 & 1.187497777 \\ \mathrm{H} & -3.938247300 & -2.759671430 & 2.865654613 \\ \mathrm{H} & -2.687339316 & -2.357953428 & 1.668123414\end{array}$




\section{D.4. Additional Information for Chapter 4.}

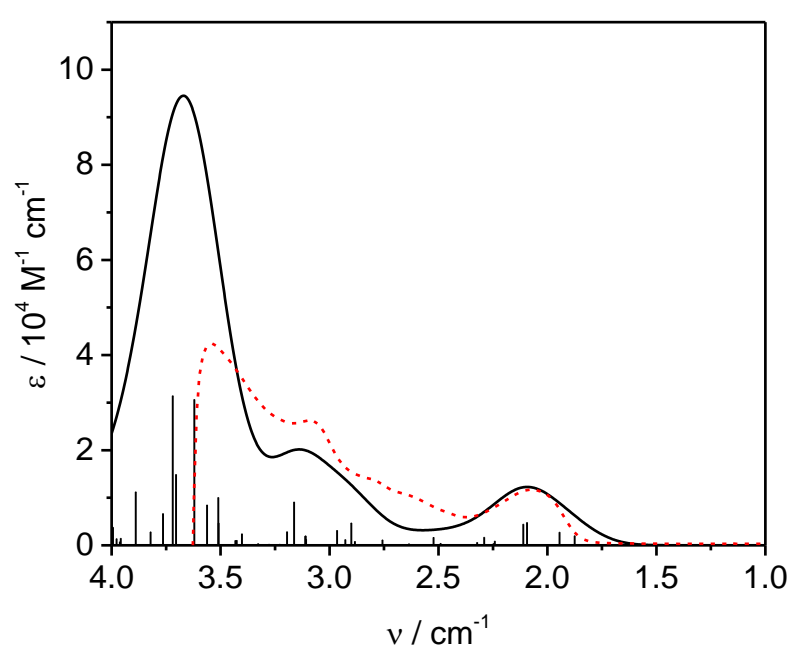

Figure D3. TD-DFT (COSMO, benzene) predicted electronic absorption spectrum of $\mathrm{Zr}\left({ }^{\mathrm{H}} \mathrm{PDP}^{\mathrm{H}}\right)_{2}$ between 40000 and $10000 \mathrm{~cm}^{-1}$ (Black line). The calculated spectrum was plotted using Gaussian line shapes with a fwhm of $3000 \mathrm{~cm}^{-1}$. The vertical bars indicate the position of the predicted transitions. The experimental spectrum in benzene is shown as a red dashed for comparison.

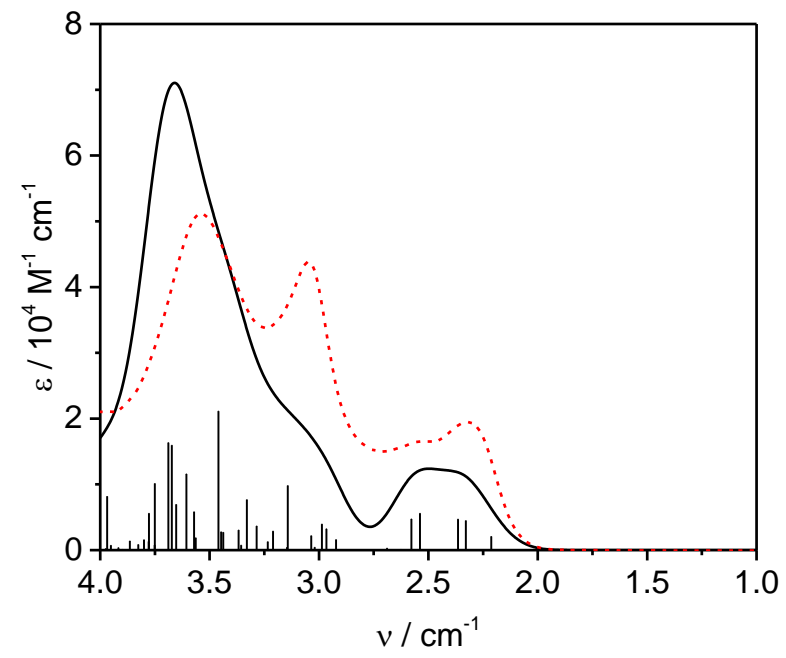

Figure D4. TD-DFT (COSMO, THF) predicted electronic absorption spectrum of $\mathrm{Zr}\left({ }^{\mathrm{H}} \mathrm{PDP}^{\mathrm{H}}\right)_{2}(\mathrm{THF})_{2}$ between 40000 and $10000 \mathrm{~cm}^{-1}$ (Black line). The calculated spectrum was plotted using Gaussian line shapes with a fwhm of $2500 \mathrm{~cm}^{-1}$. The vertical bars indicate the position of the predicted transitions. The experimental spectrum in THF is shown as a red dashed for comparison. 


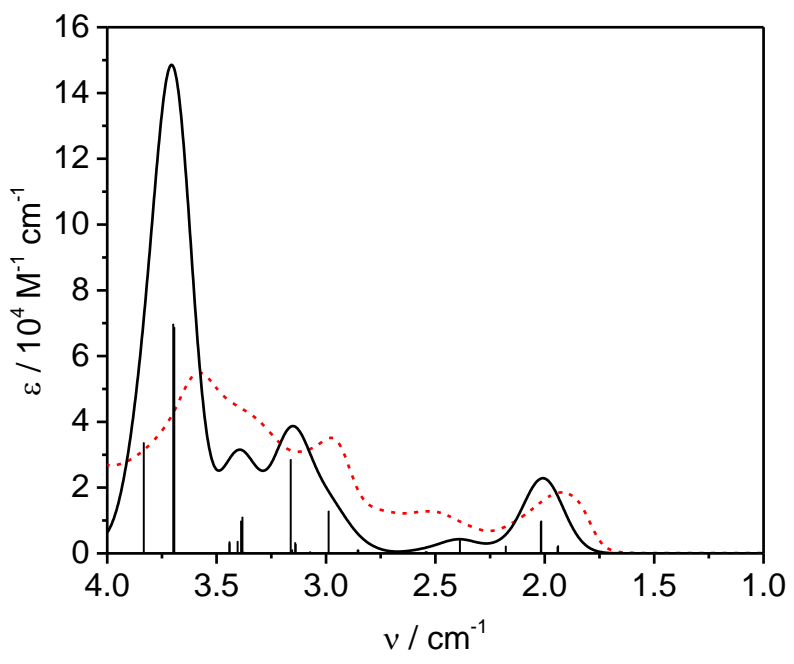

Figure D5. TD-DFT (COSMO, THF) predicted electronic absorption spectrum of $\mathrm{Zr}\left({ }^{\mathrm{Me}} \mathrm{PDP}^{\mathrm{H}}\right)_{2}$ between 40000 and $10000 \mathrm{~cm}^{-1}$ (Black line). The calculated spectrum was plotted using Gaussian line shapes with a fwhm of $2000 \mathrm{~cm}^{-1}$. The vertical bars indicate the position of the predicted transitions. The experimental spectrum in THF is shown as a red dashed for comparison.

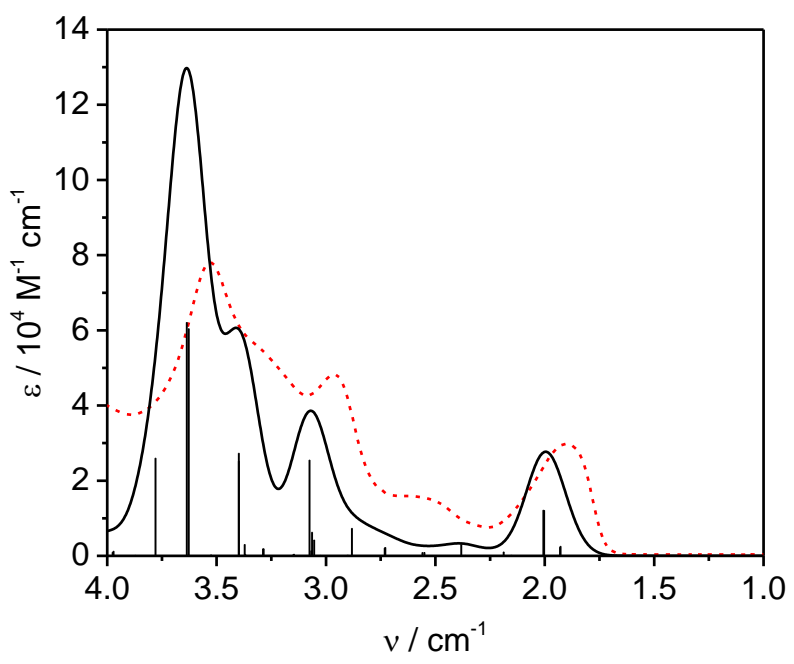

Figure D6. TD-DFT (COSMO, THF) predicted electronic absorption spectrum of $\mathrm{Zr}\left({ }^{\mathrm{Me}} \mathrm{PDP}^{\mathrm{Me}}\right)_{2}$ between 40000 and $10000 \mathrm{~cm}^{-1}$ (Black line). The calculated spectrum was plotted using Gaussian line shapes with a fwhm of $2000 \mathrm{~cm}^{-1}$. The vertical bars indicate the position of the predicted transitions. The experimental spectrum in THF is shown as a red dashed for comparison. 


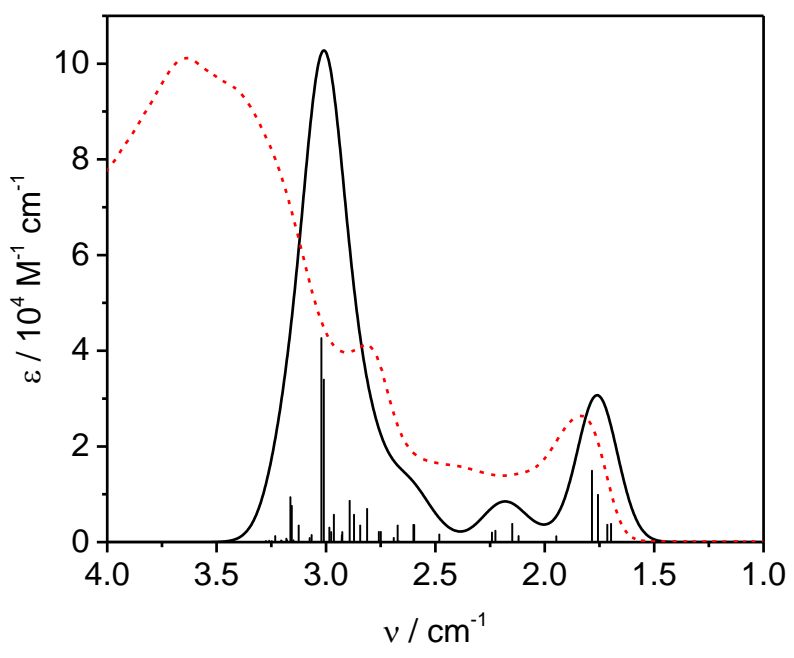

Figure D7. TD-DFT (COSMO, THF) predicted electronic absorption spectrum of $\mathrm{Zr}\left({ }^{\mathrm{Ph}} \mathrm{PDP}^{\mathrm{Ph}}\right)_{2}$ between 40000 and $10000 \mathrm{~cm}^{-1}$ (Black line). The calculated spectrum was plotted using Gaussian line shapes with a fwhm of $2000 \mathrm{~cm}^{-1}$. The vertical bars indicate the position of the predicted transitions. The experimental spectrum in THF is shown as a red dashed for comparison.

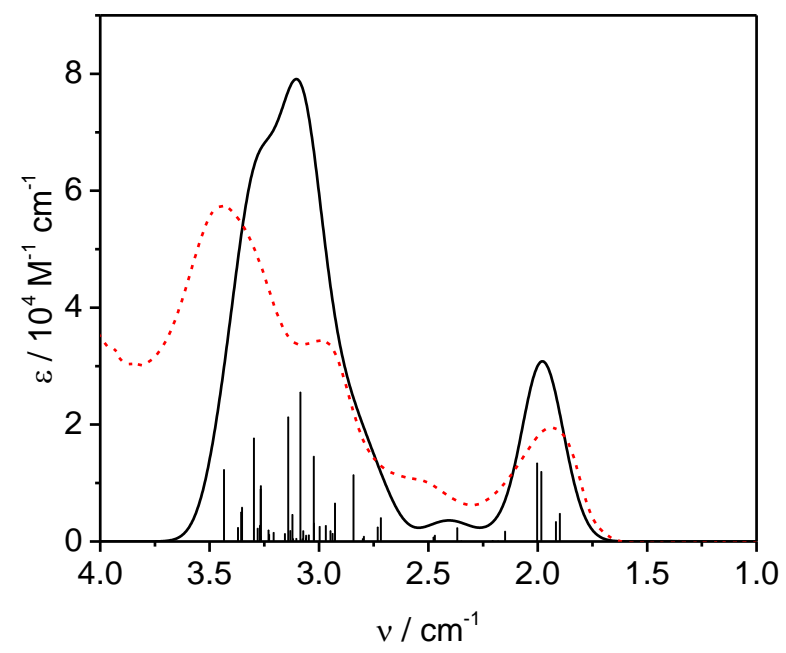

Figure D8. TD-DFT (COSMO, THF) predicted electronic absorption spectrum of $\mathrm{Zr}\left({ }^{\mathrm{Me}} \mathrm{PDP}{ }^{\mathrm{C} 6 \mathrm{~F} 5}\right)_{2}$ between 40000 and $10000 \mathrm{~cm}^{-1}$ (Black line). The calculated spectrum was plotted using Gaussian line shapes with a fwhm of $2000 \mathrm{~cm}^{-1}$. The vertical bars indicate the position of the predicted transitions. The experimental spectrum in THF is shown as a red dashed for comparison. 


\section{Optimized Geometries for Compounds Presented in Chapter 4.}

\section{$\mathbf{Z r}\left({ }^{\mathrm{Ph}} \mathbf{P D P} \mathrm{P}^{\mathrm{Ph}}\right)_{2}$}

$\mathrm{Zr} \quad 0.000000000$

$\mathrm{N} \quad-2.105990500$

C $\quad 0.449347688$

N $\quad-0.139821877$

C -0.385085411

$\mathrm{N} \quad 0.116415469$

C $\quad 4.557132896$

C $\quad-2.870019065$

C -1.352725017

C -2.405203952

C $\quad-0.793767567$

C -1.257995447

C -2.295408162

C -3.617664305

C -3.007571549

C $\quad-4.599288614$

C -3.353618331

C -4.955481516

C -4.327410185

C $\quad 4.356670800$

C 3.899083543

C $\quad-0.066816744$

C 5.525036024

C 5.725955492

C $\quad 0.737035424$

C 0.289997443

C -1.329692138

C $\quad 4.574775050$

C $\quad-0.966356316$

C $\quad 6.202845474$

C -1.769429044

C 2.828092053

C 1.346930241

C 3.441449146

C 1.767598445

$0.000000000 \quad-0.000000000$

$-0.074371859$

0.737622834

$1.383798156 \quad-2.842042072$

$-2.026665824-0.911513153$

$-3.287251536$

$-0.395949894$

$0.187629876-2.289010573$

$0.712890726 \quad-1.981102967$

$-3.644799882-5.833817052$

$-3.858265925-3.934788250$

$-3.196009858 \quad-4.596282320$

$-4.997799478-4.542119119$

$-5.444898829-5.783534512$

$-4.770120091-6.435058027$

$0.025210582 \quad-1.313443883$

$1.031683476 \quad-2.086375368$

$-0.782494410-1.927283486$

$1.209139060-3.429565032$

$-0.592931742-3.263011589$

$0.399952107 \quad-4.024097776$

$1.007286014 \quad 3.568751374$

$2.077479235 \quad 4.362110320$

$3.529462417 \quad 1.559220987$

$0.332546061 \quad 3.971731410$

$1.751879734 \quad 5.925394533$

$4.290272568 \quad 2.434635064$

$4.620200270 \quad 3.715176431$

3.108376795

2.014905981

$2.441956529 \quad 5.529902801$

4.189376648

4.156298001

0.699915499

5.137660480

3.427855273

3.301985535

$3.929708367 \quad-3.803749692$

$5.783974451 \quad-3.344205338$

$4.674535033 \quad-4.814481359$

$4.471911030 \quad-3.051611572$
C 3.011602203

5.976243065

C 1.959891205

6.527244335

$-5.094569193$

C 1.145253453

3.734822895

C 0.981983704

4.269483243

C 0.377880911

3.302365404

C $\quad-0.043889839$

$-0.829579890$$$
1.514933242-4.2
$$$$
0.392246438-5.0
$$$$
\text { C } 0.626012922
$$$$
\text { C } 3.667007453
$$$$
2.431426788-1.8
$$$$
0.614120202
$$$$
\text { C } 3.339352387
$$$$
0.145982850
$$$$
0.523214977
$$$$
0.000000000
$$$$
-1.486473611
$$$$
-1.223092530
$$$$
\text { C } 3.492150697
$$$$
\text { C } 3.110177132
$$$$
\text { C } 4.413184257
$$$$
-0.660474183
$$$$
\text { C } 3.633151406
$$$$
-0.115557650
$$$$
-0.146894094
$$$$
\text { C } \quad-3.345754207
$$$$
\text { C }-2.327574738
$$$$
-0.248125382
$$$$
-0.427926162
$$

C $\quad-3.696397610$

C -1.176482542

$-0.150038240$

$-0.153595551$

C -1.198680283

$-0.000000000$

N -0.000000000

0.151151468

C 1.178750734

0.138684197

C 1.206138543

$-1.966259976$

C -4.923384147

0.358206619

C -5.303475113

$-0.621025174$

C -4.406277125

$-1.791556681$

C -4.235230312

$-0.976523169$

C $\quad-5.798103743$

0.185218603

C $\quad-5.987735856$

$-3.719037086$

C 1.308880537

$-5.204551345$

C -0.592919092

$-3.221285808$

C 1.003548763

$-4.699817508$

C -0.907035203

$\begin{array}{lll}\text { C } & 0.520486335 & -4.720798660 \\ \text { C } & -0.106523487 & -3.706403189\end{array}$

$\begin{array}{lll}\text { C } & -0.106523487 & -3.706403189\end{array}$

$\begin{array}{lll}\text { C } & -0.873693428 & -3.373940881\end{array}$
0.172603549

$-4.449463558$

$-3.051818245$

.236795575

$-5.028102249$

$-1.864241616$

2.318116321

0.111562119

1.054692692

0.737581052

$-3.321613718$

$-2.002941381$

$-3.972360737$

$-1.309316435$

0.124645951

2.103149226

2.358155009

2.968303105

4.371111772

2.301131243

2.962960788

4.366338082

5.616835949

4.117398984

3.648173573

4.412470553

6.079439521

5.324789713

2.976833179

2.853279610

1.706800290

1.591193832

3.550618767

0.987764079

$-2.620427473$ 


\begin{tabular}{|c|c|c|c|c|c|c|c|}
\hline$\gamma$ & -0.836386644 & -4.123329065 & 4578 & $\mathrm{H}$ & 374979 & 6027 & 440 \\
\hline C & -0.420227547 & -2.091731712 & -2.276122169 & $\mathrm{H}$ & -1.223035569 & -5.979745238 & 3.298179089 \\
\hline & 0.005524245 & -0.010950753 & 5.057047612 & $\mathrm{H}$ & -1.099314164 & -5.174338317 & 4651697 \\
\hline & -4.326919602 & 020540 & 1.09 & $\mathrm{H}$ & 0.008198471 & -0.007 & 266 \\
\hline & 883975 & 2.154822005 & -0.573408091 & $\mathrm{H}$ & -5.396481275 & -0.449205413 & 0.907069434 \\
\hline & 2.321245613 & 0.279522369 & 2.089590282 & $\mathrm{H}$ & 5.664762352 & 1.098801599 & -3.791143274 \\
\hline & 4.946185230 & 0.441161772 & -3.293453052 & $\mathrm{H}$ & -1.784136662 & -5.073310493 & 1.058055679 \\
\hline & -3.689133969 & -3.113746950 & -6.327490951 & $\mathrm{H}$ & 0.778081302 & -5.131586548 & 4.530767282 \\
\hline & -2.865265682 & -2.325446757 & -4.124804460 & $\mathrm{H}$ & 1.659276128 & -2.475420179 & 1.252369953 \\
\hline & 0.022685454 & -5.524729648 & -4.04 & $\mathrm{H}$ & 3351 & 7815 & 6023 \\
\hline & 037527 & -6.3 & -6.2 & $\mathrm{H}$ & 1.7 & 79 & 64 \\
\hline & -2.658658973 & 582462 & -7.403811518 & $\mathrm{H}$ & 054031 & 4.447801506 & 9467 \\
\hline & -2.868057588 & 1.998934336 & -4.007622652 & $\mathrm{H}$ & 4.965146669 & 1.582533770 & -1.462042432 \\
\hline & -5.722485785 & -1.227927927 & -3.715748057 & $\mathrm{H}$ & 2.417246814 & -1.899785909 & -1.499788492 \\
\hline & 3.010230508 & 2.631514287 & 4.050180504 & $\mathrm{H}$ & -4.605096045 & 0.544019018 & -5.071922228 \\
\hline & 5.893926269 & -0.497209428 & 3.364182955 & $\mathrm{H}$ & -2.280927717 & 1.703489398 & -1.624279413 \\
\hline & 6.253665970 & 2.039280159 & 6.838815068 & $\mathrm{H}$ & -5.076038360 & -1.573345065 & -1.344368412 \\
\hline & 0.930610763 & 5.211656650 & 4.375433124 & $\mathrm{H}$ & 4.719421040 & 4759 & 3324 \\
\hline & 4.19 & 0483434 & 6.13 & & & & \\
\hline & 7.10 & 0.1 & 58 & \multicolumn{4}{|c|}{$\mathrm{Zr}\left({ }^{\mathrm{Me}} \mathbf{P D P}^{\mathrm{Me}}\right)_{2}$} \\
\hline & -2.75 & 3.0 & 3.6 & r & 69 & -0 & 305 \\
\hline & 3.186941412 & 2.924311937 & -3.572 & $\mathrm{~N}$ & -2.009678255 & 0.289260938 & 22565 \\
\hline & 0.522549452 & 6.216325344 & -2.771795721 & $\mathrm{~N}$ & -0.023819685 & 0.040954279 & 2.336156349 \\
\hline & 4.267961415 & 4.238128872 & -5.382003168 & $\mathrm{~N}$ & 2.058381762 & -0.335918487 & 0.841381874 \\
\hline & 3.497774038 & 6.560605891 & -5.880153314 & $\mathrm{~N}$ & -0.259072216 & -2.136525159 & -0.656504989 \\
\hline & 1.610083419 & 7.540745674 & -4.569750983 & $\mathrm{~N}$ & 0.139354932 & -0.199803783 & -2.325839459 \\
\hline & 1.266316033 & 5.271436989 & -0.312887074 & $\mathrm{~N}$ & 0.381243076 & 1.925502199 & -0.866563963 \\
\hline & -0.221419301 & -1.711395206 & -5.060526910 & $\mathrm{C}$ & -3.183680747 & 0.457869566 & 0.009170914 \\
\hline & 0.790202322 & 2.475916354 & -4.681201820 & $\mathrm{C}$ & -4.226884707 & 0.591373383 & 0.911467768 \\
\hline & 0.372184003 & 0.469058685 & -6.11622650 & $\mathrm{C}$ & -3.695793312 & 0.51 & 2.217 \\
\hline & 5.350427537 & 0.704871606 & 0.85467358 & $\mathrm{C}$ & -2.324069561 & 0.328746 & 2.054598079 \\
\hline & 3.072169559 & -2.351986157 & -3.840255691 & $c$ & -1.222288603 & 0.207542802 & 2.960546324 \\
\hline & -2.141239921 & -0.259305334 & 4.902867255 & $c$ & -1.284649597 & 0.252441768 & 4.358593219 \\
\hline & 2.148832187 & 0.242162483 & 4.898236624 & C & -0.104744780 & 0.149985096 & 5.081265596 \\
\hline $\mathrm{H}$ & -4.775046451 & -2.881758013 & 6.197051285 & $\mathrm{C}$ & 1.115278082 & -0.005504537 & 4.439596978 \\
\hline & -5.458612676 & 1.267176404 & 3.529657912 & $\mathrm{C}$ & 1.135433767 & -0.071098133 & 3.040813528 \\
\hline & -3.553759402 & -2.567594438 & 4.052762731 & $\mathrm{C}$ & 2.288606103 & -0.266311388 & 2.215040399 \\
\hline & -6.329289934 & -1.107361981 & 7.026162808 & $\mathrm{C}$ & 3.644805460 & -0.448551061 & 2.479391979 \\
\hline & -6.670636569 & 0.962336282 & 5.680064371 & $\mathrm{C}$ & 4.254780131 & -0.636470121 & 1.218939736 \\
\hline
\end{tabular}




\begin{tabular}{|c|c|c|c|}
\hline & $3.2711^{\prime}$ & 38765 & 0.2 \\
\hline & -4.482317869 & 0.611493300 & 3.487596381 \\
\hline & 4.347835058 & -0.450931201 & 3.801044402 \\
\hline & -3.245167402 & 0.492458499 & -1.482035826 \\
\hline & 3.425319805 & -0.742133497 & 580065 \\
\hline & -0.492920200 & -3.290331572 & 395815 \\
\hline & -0.542053076 & -4.36 & -0.8 \\
\hline & -0.345450560 & -3.867824709 & -2.1 \\
\hline & -0.176030829 & -2.490854713 & -2.00 \\
\hline & 0.021439996 & -1.415604069 & -2.926866030 \\
\hline & 0.086190975 & -1.517041711 & -4.322099666 \\
\hline & 0.245653751 & -0.357834501 & 597156 \\
\hline & 0.356687700 & 0.879293360 & -4.45 \\
\hline & 0.312 & 3083 & -3.0 \\
\hline & 857 & 488 & -2 \\
\hline & 2624 & 3.46 & -2 \\
\hline & 962 & 4.1 & -1 \\
\hline & 0.572948771 & 3.152305990 & -0.284379780 \\
\hline & -0.328017625 & -4.693966047 & -3.390795434 \\
\hline & 0.821600040 & 4.121550898 & -3.864342932 \\
\hline & -0.680227393 & -3.313068422 & 1.527678008 \\
\hline & 0.597199971 & 3.343333134 & 1.196070165 \\
\hline & -5.265509803 & 0.739193011 & 0.654125257 \\
\hline & -2.231129920 & 0.373100260 & 4.86 \\
\hline & -0.1 & 0 & 0.105 \\
\hline & 2.030271448 & -0.08 & 5.00 \\
\hline & 5.304690630 & -0.816924089 & 1.040094351 \\
\hline & -4.468903750 & -0.328023493 & 4.049318064 \\
\hline & -5.524054478 & 0.851044727 & 3.271182510 \\
\hline $\mathbf{J}$ & -4.098750772 & 1.391329235 & 4.150696664 \\
\hline & 4.326970964 & 0.534756866 & 4.276618507 \\
\hline & 5.393497999 & -0.734511651 & 3.676475682 \\
\hline & 3.898900207 & -1.157280756 & 4.503777552 \\
\hline & -4.239900380 & 0.795464888 & -1.809483993 \\
\hline & -3.030992149 & -0.486628590 & -1.920630848 \\
\hline & -2.528031953 & 1.203431615 & -1.899369248 \\
\hline & 4.440797730 & -1.063043776 & -1.465701029 \\
\hline & 3.233123839 & 0.188346558 & -1.772721492 \\
\hline & 2.739928077 & -1.498325311 & -1.620977707 \\
\hline
\end{tabular}

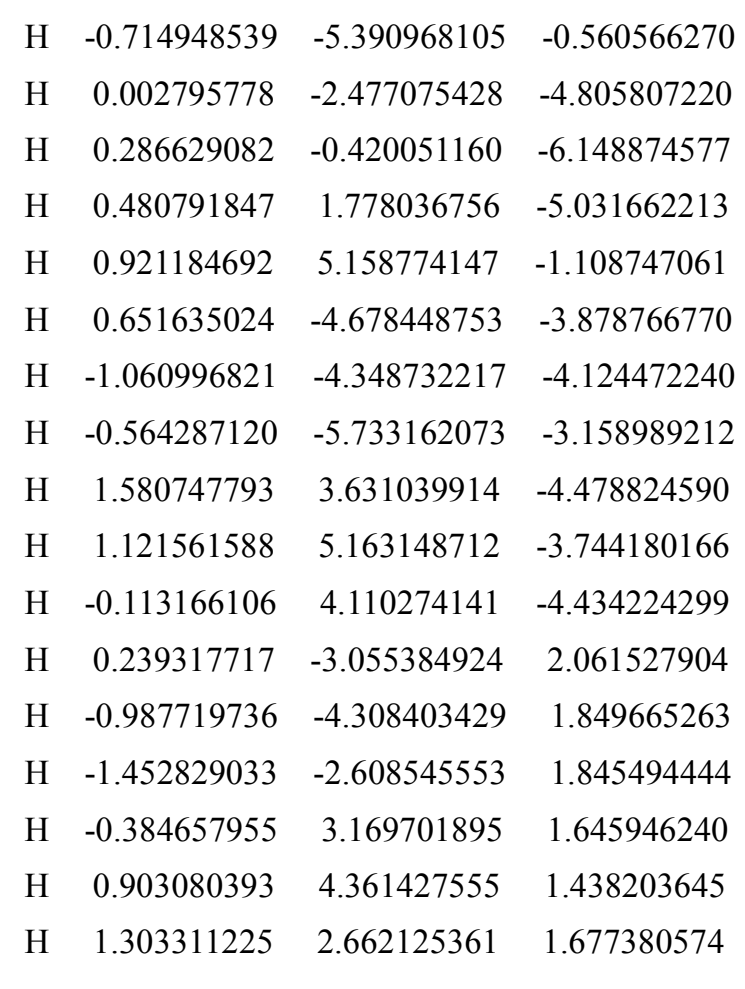




\begin{tabular}{|c|c|c|c|c|c|c|c|}
\hline & 5931 & 707010 & 16444 & $\mathrm{H}$ & 19063535 & 543 & -1.8 \\
\hline & -1.090359393 & 3.184590765 & 1.647587194 & $H$ & -4.336333664 & -1.414414791 & -1.435347485 \\
\hline & 3.042428968 & 1.087709251 & -0.083508752 & $\mathrm{H}$ & -2.598021369 & -1.670583527 & 07902 \\
\hline & 4.100564248 & 1.325384926 & 0.793371 & $\mathrm{H}$ & -3.247783763 & -0.019687684 & -1.62008 \\
\hline & 2928 & 1.040 & 2.101862914 & & & & \\
\hline & 2.316141217 & 0.636624101 & 1.973977688 & \multicolumn{4}{|c|}{$\mathrm{Zr}\left({ }^{\mathrm{H}}{ }^{\mathrm{P} D P^{\mathrm{H}}}\right)_{2}$} \\
\hline & 1.303905631 & 0.237452807 & 2.916156527 & $\mathrm{Zr}$ & -0.071843938 & -0.153052223 & 0.044420845 \\
\hline & 1.453058833 & 0.141221761 & 4.309915916 & $\mathrm{~N}$ & -2.258587784 & -0.091546416 & -0.069095898 \\
\hline & 0.355440106 & -0.260392612 & 5.071997757 & $\mathrm{~N}$ & -0.786965952 & -0.667904997 & 98477 \\
\hline & -0.863984346 & -0.567174769 & 4.46 & N & +659833 & -0.244757477 & 8698 \\
\hline & -0.958892630 & 9676109 & 3.06 & $\mathrm{~N}$ & 0.150072536 & -2.1 & 27 \\
\hline & -2.110728945 & -0.781312893 & 2.259842086 & $\mathrm{~N}$ & 0.024204887 & 0.009947923 & 8818 \\
\hline & -3.397929377 & -1.233781200 & 71928 & $\mathrm{~N}$ & 0.289897445 & $1.911\}$ & 242 \\
\hline & -4.049140874 & -1.385411487 & 1.292391831 & $\mathrm{C}$ & -3.207908953 & 0.186951985 & 8741 \\
\hline & -3.141418011 & -1.023299750 & 0.298385813 & $\mathrm{C}$ & -4.482237777 & -0.005995039 & 0.350516113 \\
\hline & 3.021219451 & 1.253915495 & -1.570534645 & $\mathrm{C}$ & -4.311472549 & -0.423350804 & -0.992140273 \\
\hline & -3.337270021 & -1.029394445 & -1.184683511 & $\mathrm{C}$ & -2.936925150 & -0.467533015 & -1.222133398 \\
\hline & 1.523276802 & -4.969174102 & -1.208967497 & $\mathrm{C}$ & 31873 & 16431 & 466 \\
\hline & 0.982899710 & -3.752474059 & -3.588703957 & $\mathrm{C}$ & -2.56677 & -1.182062849 & -3.63 \\
\hline & 037 & -1.69 & -5.0 & $\mathrm{C}$ & -1.620244588 & -1.419849018 & -4.632316012 \\
\hline & -0.463941546 & 0.45 & -6.1 & $\mathrm{C}$ & 13 & 439 & -4 \\
\hline & -1.013729042 & 2.437254172 & -4.738414271 & $\mathrm{C}$ & 0.142736040 & -0.879362375 & 9388 \\
\hline H & -1.512382274 & 4.286126238 & -2.952934051 & $\mathrm{C}$ & 1.495910021 & -0.652105453 & 87106 \\
\hline I & -1.755281789 & 5.219029902 & -0.401245697 & $\mathrm{C}$ & 2.746960835 & -0.732479632 & 211143 \\
\hline & 0.124123451 & -3.091132083 & 1.667457875 & $\mathrm{C}$ & 3.698861371 & -0.360763875 & -2.262934496 \\
\hline & 1.783535442 & -2.467109346 & 1.555289738 & $\mathrm{C}$ & 2.987731249 & -0.071965044 & -1.102868777 \\
\hline & 1.476708569 & -4.204412433 & 1.353063762 & $\mathrm{C}$ & 0.190994518 & -3.376810154 & 0.357425313 \\
\hline & -1.470298126 & 4.143074000 & 2.028884821 & $\mathrm{C}$ & 0.109287460 & -4.360710695 & 1.335781682 \\
\hline & -0.073040558 & 3.042027230 & 2.050803815 & $\mathrm{C}$ & 0.012781586 & -3.692214999 & 2.582 \\
\hline & -1.721980758 & 2.385 & 2.067501325 & $\mathrm{C}$ & 0.038331580 & -2.326 & 2.30 \\
\hline & 5.089398806 & 1.679959966 & 0.504370804 & $\mathrm{C}$ & -0.015960766 & -1.128664345 & 3.108 \\
\hline 1 & 4.207988351 & 1.129201101 & 3.028604421 & $\mathrm{C}$ & -0.082902145 & -1.052988312 & 4.509387897 \\
\hline & 2.408566463 & 0.385123717 & 4.775479771 & $\mathrm{C}$ & -0.091000551 & 0.207844560 & 5.108364690 \\
\hline & 0.454683262 & -0.342078001 & 6.158172441 & $\mathrm{C}$ & -0.015363166 & 1.370024030 & 4.336309662 \\
\hline $\mathrm{H}$ & -1.725857679 & -0.890110244 & 5.048972328 & $\mathrm{C}$ & 0.055809956 & 1.241283347 & 2.941089752 \\
\hline $\mathrm{H}$ & -3.814841252 & -1.443261976 & 3.524398609 & $\mathrm{C}$ & 0.186613219 & 2.306457895 & 1.974730240 \\
\hline 11 & -5.066290169 & -1.734805319 & 1.119631694 & $\mathrm{C}$ & 0.256194243 & 3.695702588 & 2.054915819 \\
\hline & 2.866524034 & 0.294263183 & -2.093020181 & $\mathrm{C}$ & 0.404545882 & 4.170366998 & 0.725715265 \\
\hline & 3.975594509 & 1.673556133 & -1.919814571 & $\mathrm{C}$ & 0.421978883 & 3.053339521 & -0.100445909 \\
\hline
\end{tabular}




\begin{tabular}{|c|c|c|c|c|c|c|c|}
\hline $\mathrm{H}$ & -2.919683910 & 56809 & 1.871839668 & $\mathrm{C}$ & 41749 & 7744 & -2 \\
\hline $\mathrm{H}$ & -5.423647655 & 0.148661170 & 0.875460060 & $\mathrm{C}$ & 0.826787592 & -2.216038944 & 2.239400244 \\
\hline $\mathrm{H}$ & -5.096651427 & -0.66 & -1.70 & $\mathrm{C}$ & 270697015 & 439 & -0.22 \\
\hline $\mathrm{H}$ & -3.633933054 & 0030 & -3.8 & $\mathrm{C}$ & 62 & 06 & -3 \\
\hline $\mathrm{H}$ & 432929 & 904645 & 4533 & $\mathrm{C}$ & 6718036 & 0.353695149 & 0.3113 \\
\hline $\mathrm{H}$ & 0.490823208 & -1.441511928 & -5.149065693 & $\mathrm{C}$ & 1.337950256 & -4.196697929 & 1.301004663 \\
\hline $\mathrm{H}$ & 2.954984145 & -1.030374385 & -4.272085411 & $\mathrm{C}$ & -1.645617062 & 3.283557754 & 2.309197052 \\
\hline $\mathrm{H}$ & 4.778968081 & -0.303431801 & -2.392770774 & $\mathrm{C}$ & 1.287709080 & -3.503653412 & 2.531795727 \\
\hline $\mathrm{H}$ & 3.361362360 & 0.263084132 & -0.13 & $\mathrm{C}$ & 3.334582745 & -2.233985308 & 80611 \\
\hline 11 & 0.292837014 & -3.49 & -0.7 & C & 086 & 751 & 554 \\
\hline $\mathrm{H}$ & 0.125599079 & -5.4 & 1. & C & 761 & 3429 & 197 \\
\hline $\mathrm{H}$ & -0.067352121 & -4.151793657 & 3.567 & $\mathrm{C}$ & 1.959502682 & -2.283198085 & -3.5 \\
\hline $\mathrm{H}$ & -0.124085275 & -1.964844764 & 5.10 & $\mathrm{C}$ & 0.698824765 & 49615 & 077 \\
\hline $\mathrm{H}$ & -0.148474031 & 0.289677006 & 6.197696089 & $\mathrm{C}$ & -4.490833115 & -0.960684560 & 3273 \\
\hline $\mathrm{H}$ & -0.002410272 & 2.357824644 & 4.798809096 & $\mathrm{C}$ & -0.228575557 & 1.255104900 & 4.382189993 \\
\hline $\mathrm{H}$ & 0.208088247 & 4.296677030 & 2.962238172 & $\mathrm{C}$ & -2.511226462 & -1.478489329 & -3.368813826 \\
\hline $\mathrm{H}$ & 0.502018045 & 5.206269228 & 0.403727588 & $\mathrm{C}$ & -4.048717316 & -2.386873092 & 0.887728687 \\
\hline \multirow[t]{2}{*}{$\mathrm{H}$} & 0.544765510 & 3.002985436 & -1.1 & $\mathrm{C}$ & 0.321564494 & 0.191094044 & 5.102610395 \\
\hline & & & & $\mathrm{C}$ & 1.097865970 & -1.615080613 & -2.6 \\
\hline \multicolumn{4}{|c|}{$\mathrm{Zr}\left({ }^{\mathrm{H}} \mathrm{PDP} \mathrm{P}^{\mathrm{H}}\right)_{2}(\mathrm{THF})_{2}$} & $\mathrm{C}$ & 435 & 1713 & 1.6 \\
\hline $\mathrm{Zr}$ & 0.106504672 & 307 & 0. & $\mathrm{C}$ & -2.5 & 296 & 27 \\
\hline $\mathrm{O}$ & -2.199338476 & -0.895754364 & 0.787 & $\mathrm{C}$ & 1.019973913 & 3.964392036 & -2. \\
\hline $\mathrm{N}$ & 0.596269030 & -2.095707239 & 0.875658723 & $\mathrm{C}$ & 0.497769794 & 1.714562054 & 39735 \\
\hline $\mathrm{N}$ & -0.903643009 & 1.807799489 & 0.737600952 & $\mathrm{C}$ & 0.564350101 & 3.184753641 & 458226 \\
\hline $\mathrm{C}$ & -2.330837483 & -0.812178289 & -2.158448857 & $\mathrm{H}$ & -3.072335458 & -0.319600426 & -1.534872170 \\
\hline $\mathrm{N}$ & 2.227620919 & 0.498389166 & 0.507726571 & $\mathrm{H}$ & 0.821031052 & -3.470905242 & -0.748630646 \\
\hline $\mathrm{O}$ & 0.551834546 & 1.759352815 & -1.663432798 & $\mathrm{H}$ & 1.265522912 & 3.116435995 & -0.279161099 \\
\hline $\mathrm{N}$ & 0.058115010 & -0.005185220 & 2.368019156 & $\mathrm{H}$ & 2.472804724 & 2.543958097 & -1.472995915 \\
\hline $\mathrm{N}$ & -1.014965235 & -0.839275885 & -1.785913531 & $\mathrm{H}$ & 2.189856506 & 1.771573066 & 2.224 \\
\hline$C$ & -0.339 & -1.531802388 & -2.78101 & $\mathrm{H}$ & -2.682870 & 4.60 & 32 \\
\hline $\mathrm{C}$ & -0.931322513 & 2.103227750 & 2.0930053 & $\mathrm{H}$ & -1.738458312 & 2.793650179 & -0.970 \\
\hline $\mathrm{C}$ & 0.914406062 & -3.300036888 & 0.321299213 & $\mathrm{H}$ & 4.901912963 & -1.459969253 & -2.006897739 \\
\hline $\mathrm{C}$ & 2.923188637 & -0.860332081 & -1.362281195 & $\mathrm{H}$ & -0.994113742 & -2.510614131 & -4.667221221 \\
\hline $\mathrm{C}$ & 1.425739155 & 2.865909695 & -1.333178210 & $\mathrm{H}$ & 5.484636291 & 0.073471159 & -0.052814512 \\
\hline $\mathrm{C}$ & 2.800517041 & 1.236321679 & 1.500882278 & $\mathrm{H}$ & 1.658808225 & -5.223689749 & 1.130347946 \\
\hline $\mathrm{C}$ & -0.352739273 & 1.125230466 & 2.989755041 & $\mathrm{H}$ & -1.844194669 & 3.757511336 & 3.269509933 \\
\hline $\mathrm{N}$ & 1.592371742 & -0.946093368 & -1.592796302 & $\mathrm{H}$ & 1.563793799 & -3.888717627 & 3.512607711 \\
\hline $\mathrm{C}$ & -2.087232300 & 3.721612424 & 1.037068809 & $\mathrm{H}$ & 4.024028731 & -2.756208282 & -3.967937228 \\
\hline $\mathrm{C}$ & -1.609178963 & 2.797659805 & 0.110049530 & $\mathrm{H}$ & 4.897991830 & 1.684554944 & 2.075511500 \\
\hline
\end{tabular}




\begin{tabular}{|c|c|c|c|c|c|c|c|}
\hline $\mathrm{H}$ & 1.551904566 & -2.825441043 & -4.395 & $\mathrm{C}$ & 136407 & 0152117 & -2 \\
\hline & 1.110651560 & -1.830014822 & 5.007554032 & $\mathrm{C}$ & -3.892641361 & 0.755622605 & -1.044954570 \\
\hline & -5.174982307 & -0.954877071 & 2.166686250 & $y$ & 611882653 & -0.592078681 & -2.093704610 \\
\hline & -5.003106113 & -0.453410308 & 407 & $\mathrm{~F}$ & 7.39 & 887 & -5.398978 \\
\hline & -0.555848597 & 9833529 & 4.878148948 & 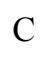 & 0.25 & 73319 & 2.952570329 \\
\hline & -3.453331837 & -1.612703132 & -3.899018795 & $\mathrm{C}$ & 0.488852551 & 2.264444468 & 2.045677796 \\
\hline & -4.467045014 & -2.660233103 & -0.091551902 & $\mathrm{C}$ & 0.163987281 & 1.231438549 & 4.350756463 \\
\hline & -4.374829437 & -3.149889602 & 1.609349288 & $\mathrm{C}$ & 0.002973177 & 0.046326923 & 5.068036730 \\
\hline & 0.452110748 & 0.280960442 & 6.184848147 & $\mathrm{C}$ & 0.558833645 & 3.658763991 & 52572 \\
\hline & -3.16 & 0.82 & 1.3 & C & 00 & 3695 & 5263 \\
\hline & -2.88 & -0.35 & 2.68 & $\mathrm{C}$ & 365 & 377 & 3. \\
\hline & 948323 & -2.744586916 & 1.730216104 & $\mathrm{C}$ & 0.130442262 & 4.495321937 & 4436 \\
\hline & 081081 & -2.772754062 & 083109 & 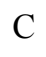 & -1.154587709 & 4.375209879 & 400 \\
\hline & 1.849929300 & 4.657543998 & -2.514069512 & 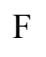 & 2.177311530 & 5.717126869 & 3.382 \\
\hline & 0.188202467 & 4.548424760 & -1.891070850 & $\mathrm{~F}$ & -2.002723140 & 3.426379109 & 3.453531988 \\
\hline & 1.360997547 & 1.136462387 & -3.479963734 & $\mathrm{C}$ & 1.591094660 & -0.061017326 & -4.368849591 \\
\hline & -0.424662491 & 1.192592404 & -3.390541034 & $\mathrm{C}$ & 0.419883253 & 0.243892875 & -5.063504468 \\
\hline & -0.414351042 & 3.540276623 & -3.925005776 & $\mathrm{C}$ & -0.793025263 & 0.384446100 & -4.390744503 \\
\hline \multirow[t]{2}{*}{$\mathrm{H}$} & 1.270213466 & 8450 & -4.4 & 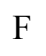 & 3.434450192 & -2.963149944 & -4 \\
\hline & & & & 2 & 108 & -3.1 & -6.5 \\
\hline \multicolumn{2}{|c|}{$\mathrm{Zr}\left({ }^{\mathrm{Me}} \mathrm{PDP}^{\mathrm{C} 6 \mathrm{F5}}\right)_{2}$} & & & $y$ & 3 & -2 & -5 \\
\hline & 0.314416015 & -0.099719593 & 0.004752418 & $\mathrm{C}$ & 4.399416704 & -2.065207048 & -4.489531090 \\
\hline & 6.127127901 & 0.763708756 & -3.017058384 & $\mathrm{C}$ & 6.097751353 & -1.276024406 & 12581 \\
\hline & 0.345256211 & -0.039770178 & -2.323177483 & $\mathrm{C}$ & -4.088311934 & 0.807288015 & -3.587027927 \\
\hline & -1.695235925 & 0.345150245 & -0.760086547 & $\mathrm{C}$ & -4.647185668 & -0.296245621 & -4.251662680 \\
\hline & 2.311703693 & -0.615027408 & -0.738571836 & $\mathrm{C}$ & -5.544605313 & -0.149904556 & -5.314002209 \\
\hline & 0.181256833 & -0.040115074 & 2.322624891 & $\mathrm{C}$ & -4.444157536 & 2.077970489 & -4.064256739 \\
\hline & 0.818117026 & 1.917301223 & 0.741547730 & $\mathrm{C}$ & -5.897870183 & 1.132282496 & -5.743892023 \\
\hline & -0.172682676 & -2.089055068 & 0.786127157 & $\mathrm{~F}$ & -4.341308035 & -1.542581378 & -3.854976123 \\
\hline & 3.456812221 & -0.968055848 & -0.059805767 & $\mathrm{~F}$ & -3.930846813 & 3.173428 & -3.48 \\
\hline & 4.486582904 & -1.161236290 & -0.973050289 & $\mathrm{~F}$ & -6.087938154 & -1.222922385 & -5.906407640 \\
\hline & 1.525791247 & -0.230142620 & -2.976987879 & $\mathrm{~F}$ & -6.774075157 & 1.283822613 & -6.742365662 \\
\hline & 4.704017542 & -1.067299593 & -3.547563458 & $\mathrm{~F}$ & 6.754779902 & -1.377947352 & -7.174742629 \\
\hline Z & -2.887860830 & 0.561942131 & -0.105646013 & $\mathrm{C}$ & -0.566009036 & -4.290065935 & 1.073247955 \\
\hline C & 6.438036177 & -0.278118468 & -5.096838055 & $\mathrm{C}$ & -0.443315271 & -3.271487425 & 0.135093364 \\
\hline $\mathrm{C}$ & 5.757956825 & -0.198866244 & -3.877729753 & $\mathrm{C}$ & -0.137269613 & -2.353149600 & 2.148181012 \\
\hline $\mathrm{C}$ & -1.946021957 & 0.413216492 & -2.126052374 & $\mathrm{C}$ & -0.359788918 & -3.720682021 & 2.360607200 \\
\hline & -0.803999638 & 0.250610890 & -2.993253002 & $\mathrm{C}$ & 0.002676010 & -1.201289255 & 3.010060205 \\
\hline & 3.960050791 & -0.935906396 & -2.274672496 & $\mathrm{C}$ & -0.322274512 & -4.465708972 & 3.638241635 \\
\hline
\end{tabular}




\begin{tabular}{|c|c|c|c|c|c|c|c|}
\hline $\mathrm{C}$ & 1.588566222 & 3.092493967 & -1.357853728 & $\mathrm{H}$ & 2.718534915 & -1.810745826 & 1.789425981 \\
\hline $\mathrm{C}$ & -0.583611943 & -3.349459096 & -1.352411373 & $\mathrm{H}$ & 3.336275077 & -0.148855799 & 1.942085701 \\
\hline $\mathrm{C}$ & 0.943369558 & -5.323750415 & 5.559584791 & $\mathrm{H}$ & 4.465993491 & -1.507716432 & 1.752034331 \\
\hline $\mathrm{C}$ & -1.452221081 & -5.115158516 & 4.161831575 & $\mathrm{H}$ & 1.190205680 & 5.200094780 & 0.681388175 \\
\hline $\mathrm{C}$ & 0.870529186 & -4.596881181 & 4.369118238 & $\mathrm{H}$ & -2.812859297 & -0.409370626 & 1.827258759 \\
\hline $\mathrm{C}$ & -1.409265163 & -5.843435811 & 5.356075693 & $\mathrm{H}$ & -4.041118611 & 0.868611391 & 1.666037287 \\
\hline $\mathrm{F}$ & 1.993153840 & -4.011480975 & 3.918908426 & $\mathrm{H}$ & -2.333084467 & 1.301792609 & 1.850447202 \\
\hline $\mathrm{F}$ & -2.626240051 & -5.025402989 & 3.517111787 & & & & \\
\hline $\mathrm{F}$ & 2.099869329 & -5.433451386 & 6.227257211 & & & & \\
\hline $\mathrm{F}$ & -2.509801055 & -6.431065645 & 5.844910511 & & & & \\
\hline $\mathrm{C}$ & -0.203106958 & -5.951222646 & 6.054181480 & & & & \\
\hline $\mathrm{F}$ & -0.143231068 & -6.647894726 & 7.193971395 & & & & \\
\hline $\mathrm{C}$ & -0.076977500 & -1.181623300 & 4.411063924 & & & & \\
\hline $\mathrm{C}$ & -0.801593843 & 6.250335076 & 5.373947537 & & & & \\
\hline $\mathrm{C}$ & 0.481477906 & 6.403423124 & 4.842189959 & & & & \\
\hline $\mathrm{C}$ & -1.621631190 & 5.224160880 & 4.897401047 & & & & \\
\hline $\mathrm{F}$ & -1.235658622 & 7.077121332 & 6.331804736 & & & & \\
\hline $\mathrm{F}$ & 1.276818352 & 7.381998533 & 5.294269960 & & & & \\
\hline $\mathrm{F}$ & -2.861208179 & 5.070784799 & 5.382062797 & & & & \\
\hline $\mathrm{C}$ & 3.492063828 & -1.113392865 & 1.428712359 & & & & \\
\hline $\mathrm{C}$ & 1.004192223 & 4.157328693 & 0.934437804 & & & & \\
\hline $\mathrm{C}$ & -3.018957635 & 0.578987296 & 1.383386812 & & & & \\
\hline $\mathrm{C}$ & -5.333577022 & 2.253183906 & -5.127586205 & & & & \\
\hline F & -5.662818533 & 3.482414920 & -5.545278862 & & & & \\
\hline $\mathrm{H}$ & 5.504548300 & -1.463767660 & -0.732347151 & & & & \\
\hline $\mathrm{H}$ & -4.941045730 & 0.955048271 & -0.828026859 & & & & \\
\hline $\mathrm{H}$ & 0.237557082 & 2.189948402 & 4.861888042 & & & & \\
\hline $\mathrm{H}$ & -0.066083874 & 0.081261704 & 6.158553967 & & & & \\
\hline $\mathrm{H}$ & 2.538619845 & -0.164540551 & -4.893807789 & & & & \\
\hline $\mathrm{H}$ & 0.456988643 & 0.380571955 & -6.147396583 & & & & \\
\hline $\mathrm{H}$ & -1.710917628 & 0.622933697 & -4.925831641 & & & & \\
\hline $\mathrm{H}$ & -0.783777082 & -5.334968214 & 0.857301365 & & & & \\
\hline $\mathrm{H}$ & 0.745291513 & 2.942367876 & -2.053189719 & & & & \\
\hline $\mathrm{H}$ & 2.332345527 & 2.306958074 & -1.564186286 & & & & \\
\hline $\mathrm{H}$ & 2.049720063 & 4.060576022 & -1.602617209 & & & & \\
\hline $\mathrm{H}$ & -0.958433040 & -4.339003741 & -1.650960330 & & & & \\
\hline $\mathrm{H}$ & 0.377845908 & -3.187045825 & -1.869476411 & & & & \\
\hline $\mathrm{H}$ & -1.295908560 & -2.598532787 & -1.731454303 & & & & \\
\hline $\mathrm{H}$ & -0.223023945 & -2.105310262 & 4.967038964 & & & & \\
\hline
\end{tabular}




\section{D.5. Additional Information for Chapter 5.}
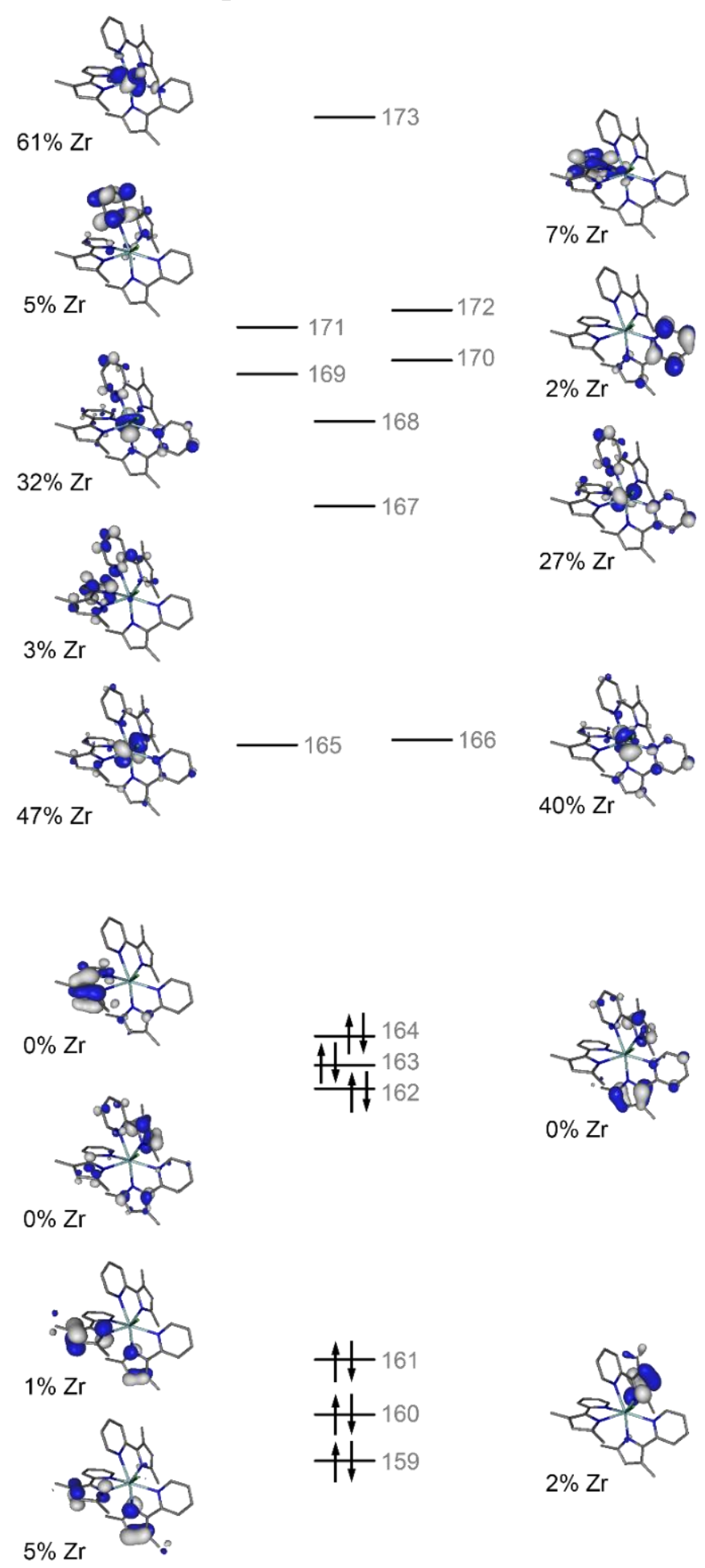

Figure D9. Extended frontier molecular orbital diagram for $\left({ }^{\mathrm{Me}} \mathrm{PMP}{ }^{\mathrm{Me}}\right)_{3} \mathrm{ZrCl}$ showing the donor and acceptor orbitals for TD-DFT excitations computed between 250-1000 nm. The gray numbers to the right correspond to the MO number with 164 being the HOMO and 165 being the LUMO. 
Table D2. Vertical Electronic Excitation Energies and Main Excitations Contributing to the Absorption Bands of ( $\left.{ }^{\mathrm{Me}} \mathrm{PDP}^{\mathrm{Me}}\right)_{3} \mathrm{ZrCl}$ Obtained via TD-DFT Calculations.

\begin{tabular}{|c|c|c|c|c|c|}
\hline Band & $\begin{array}{l}\text { TD-DFT } \\
\text { State }\end{array}$ & $\begin{array}{c}\text { Energy / } \mathrm{cm}^{-1} \\
(\lambda / \mathrm{nm})\end{array}$ & $f_{\text {osc }}$ & $\begin{array}{l}\text { Excitations } \\
\text { (weight) })^{\mathrm{a}, \mathrm{b}}\end{array}$ & $\begin{array}{l}\text { Character } \\
(\% \text { LMCT) }\end{array}$ \\
\hline \multirow{6}{*}{ I } & 1 & $\begin{array}{l}18925.5 \\
(528.4)\end{array}$ & 0.010 & $164 \rightarrow 165(0.93)$ & $\begin{array}{c}{ }^{1} \mathrm{IL} /{ }^{1} \mathrm{LMCT} \\
(47 \%)\end{array}$ \\
\hline & 2 & $\begin{array}{l}19402.5 \\
(515.4)\end{array}$ & 0.015 & $\begin{array}{l}164 \rightarrow 166(0.84) \\
163 \rightarrow 165(0.12)\end{array}$ & $\begin{array}{l}{ }^{1} \mathrm{IL} /{ }^{1} \mathrm{LMCT} \\
(47 \%)\end{array}$ \\
\hline & 3 & $\begin{array}{c}20306.2 \\
(492.5)\end{array}$ & 0.025 & $\begin{array}{l}163 \rightarrow 165(0.75) \\
164 \rightarrow 166(0.10)\end{array}$ & $\begin{array}{c}{ }^{1} \mathrm{IL} /{ }^{1} \mathrm{LMCT} \\
(47 \%)\end{array}$ \\
\hline & 4 & $\begin{array}{r}20330.5 \\
(491.9)\end{array}$ & 0.007 & $\begin{array}{l}163 \rightarrow 166(0.72) \\
162 \rightarrow 165(0.22)\end{array}$ & $\begin{array}{c}{ }^{1} \mathrm{IL} /{ }^{1} \mathrm{LMCT} \\
(40 \%)\end{array}$ \\
\hline & 5 & $\begin{array}{c}20736.0 \\
(482.3)\end{array}$ & 0.014 & $\begin{array}{l}162 \rightarrow 165(0.64) \\
162 \rightarrow 166(0.20) \\
163 \rightarrow 166(0.12)\end{array}$ & $\begin{array}{c}{ }^{1} \mathrm{IL} /{ }^{1} \mathrm{LMCT} \\
(47 \%)\end{array}$ \\
\hline & 6 & $\begin{array}{r}21083.3 \\
(474.3)\end{array}$ & 0.029 & $\begin{array}{l}162 \rightarrow 166(0.67) \\
163 \rightarrow 166(0.10)\end{array}$ & $\begin{array}{c}{ }^{1} \mathrm{IL} /{ }^{1} \mathrm{LMCT} \\
(40 \%)\end{array}$ \\
\hline \multirow{3}{*}{ II } & 7 & $\begin{array}{c}26163.6 \\
(382.2)\end{array}$ & 0.050 & $\begin{array}{l}164 \rightarrow 167(0.61) \\
161 \rightarrow 165(0.31)\end{array}$ & $\begin{array}{c}{ }^{1} \mathrm{IL} /{ }^{1} \mathrm{LMCT} \\
(3 \%)\end{array}$ \\
\hline & 12 & $\begin{array}{c}28114.0 \\
(355.7)\end{array}$ & 0.064 & $\begin{array}{l}160 \rightarrow 165(0.49) \\
161 \rightarrow 165(0.13)\end{array}$ & $\begin{array}{c}{ }^{1} \mathrm{IL} /{ }^{1} \mathrm{LMCT} \\
(47 \%)\end{array}$ \\
\hline & 18 & $\begin{array}{r}29488.9 \\
(339.1)\end{array}$ & 0.052 & $\begin{aligned} 164 & \rightarrow 169(0.27) \\
162 & \rightarrow 168(0.21) \\
159 & \rightarrow 166(0.17)\end{aligned}$ & $\begin{array}{c}{ }^{1} \mathrm{IL} /{ }^{1} \mathrm{LMCT} \\
(32 \%)\end{array}$ \\
\hline \multirow{4}{*}{ III } & 28 & $\begin{array}{c}32724.9 \\
(305.6)\end{array}$ & 0.183 & $\begin{array}{l}164 \rightarrow 172(0.27) \\
162 \rightarrow 172(0.17)\end{array}$ & $\begin{array}{c}{ }^{1} \mathrm{IL} /{ }^{1} \mathrm{LMCT} \\
\quad(7 \%)\end{array}$ \\
\hline & 29 & $\begin{array}{c}33561.4 \\
(298.0)\end{array}$ & 0.330 & $\begin{array}{l}162 \rightarrow 171(0.30) \\
163 \rightarrow 171(0.15)\end{array}$ & $\begin{array}{c}{ }^{1} \mathrm{IL} /{ }^{1} \mathrm{LMCT} \\
(5 \%)\end{array}$ \\
\hline & 31 & $\begin{array}{l}34316.3 \\
(291.4)\end{array}$ & 0.293 & $\begin{array}{l}164 \rightarrow 173(0.16) \\
163 \rightarrow 170(0.15) \\
162 \rightarrow 170(0.11)\end{array}$ & $\begin{array}{c}{ }^{1} \mathrm{IL} /{ }^{1} \mathrm{LMCT} \\
(61 \%)\end{array}$ \\
\hline & 32 & $\begin{array}{l}35160.6 \\
(284.4)\end{array}$ & 0.176 & $164 \rightarrow 173(0.52)$ & $\begin{array}{c}{ }^{1} \mathrm{IL} /{ }^{1} \mathrm{LMCT} \\
(61 \%)\end{array}$ \\
\hline
\end{tabular}

LUMO 165. 

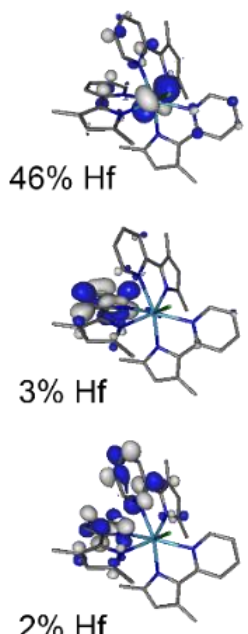

$2 \% \mathrm{Hf}$

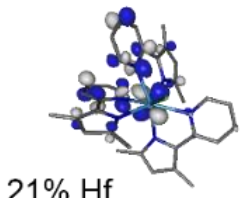

$-18$

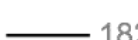

182

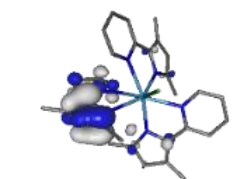

$0 \% \mathrm{Hf}$
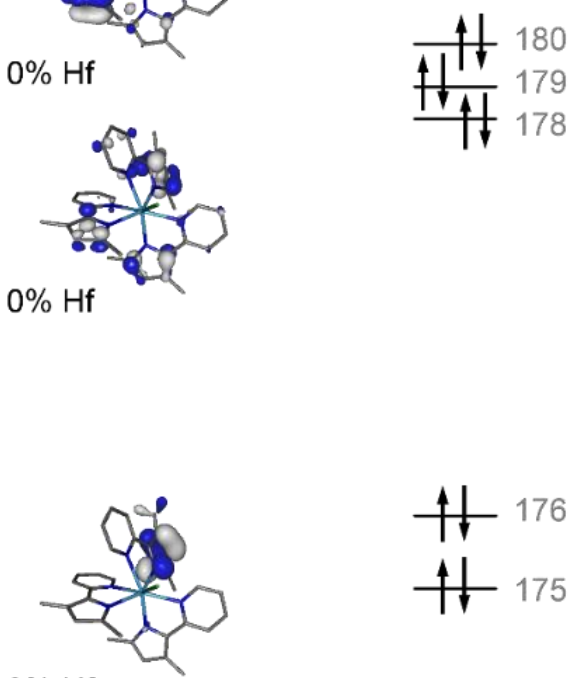

$3 \% \mathrm{Hf}$
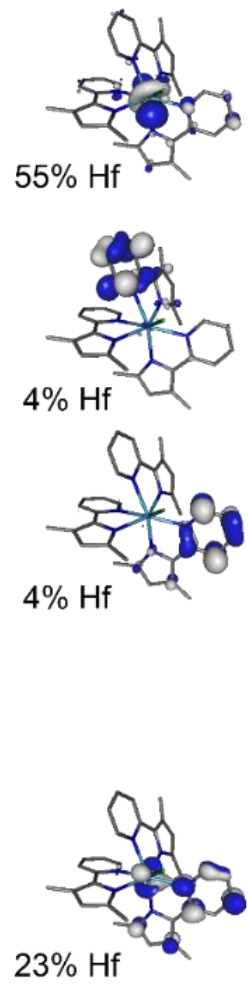

$4 \% \mathrm{Hf}$

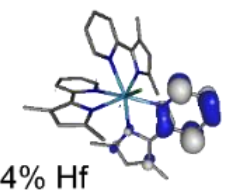

$23 \% \mathrm{H}$
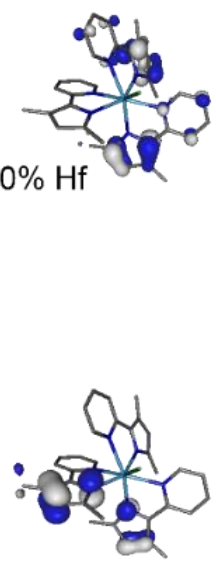

$2 \% \mathrm{Hf}$

Figure D10. Extended frontier molecular orbital diagram for $\left({ }^{\mathrm{Me}} \mathrm{PMP}{ }^{\mathrm{Me}}\right)_{3} \mathrm{HfCl}$ showing the donor and acceptor orbitals for TD-DFT excitations computed between 250-1000 nm. The gray numbers to the right correspond to the MO number with 180 being the HOMO and 181 being the LUMO. 
Table D3. Vertical Electronic Excitation Energies and Main Excitations Contributing to the Absorption Bands of $\left({ }^{\mathrm{Me}} \mathrm{PDP}^{\mathrm{Me}}\right)_{3} \mathrm{HfCl}$ Obtained via TD-DFT Calculations.

\begin{tabular}{|c|c|c|c|c|c|}
\hline Band & $\begin{array}{l}\text { TD- } \\
\text { DFT } \\
\text { State } \\
\end{array}$ & $\begin{array}{c}\text { Energy / } \mathrm{cm}^{-1} \\
(\lambda / \mathrm{nm})\end{array}$ & $f_{\text {osc }}$ & $\begin{array}{l}\text { Excitations } \\
\text { (weight) }^{\mathrm{a}, \mathrm{b}}\end{array}$ & $\begin{array}{l}\text { Character } \\
\text { (\%LMCT) }\end{array}$ \\
\hline \multirow{6}{*}{ I } & 1 & $\begin{array}{l}21867.1 \\
(457.3)\end{array}$ & 0.051 & $180 \rightarrow 181(0.92)$ & $\begin{array}{c}{ }^{1} \mathrm{IL} /{ }^{1} \mathrm{LMCT} \\
(21 \%)\end{array}$ \\
\hline & 2 & $\begin{array}{c}22681.8 \\
(440.9)\end{array}$ & 0.012 & $179 \rightarrow 181(0.86)$ & $\begin{array}{c}{ }^{1} \mathrm{IL} /{ }^{1} \mathrm{LMCT} \\
(21 \%)\end{array}$ \\
\hline & 3 & $\begin{array}{c}22351.4 \\
(447.4)\end{array}$ & 0.018 & $180 \rightarrow 182(0.75)$ & $\begin{array}{c}{ }^{1} \mathrm{IL} /{ }^{1} \mathrm{LMCT} \\
(23 \%)\end{array}$ \\
\hline & 4 & $\begin{array}{c}23486.9 \\
(425.8)\end{array}$ & 0.001 & $\begin{array}{l}178 \rightarrow 181(0.79) \\
179 \rightarrow 182(0.14)\end{array}$ & $\begin{array}{c}{ }^{1} \mathrm{IL} /{ }^{1} \mathrm{LMCT} \\
(21 \%)\end{array}$ \\
\hline & 5 & $\begin{array}{c}23276.9 \\
(429.6)\end{array}$ & 0.017 & $\begin{array}{l}178 \rightarrow 182(0.37) \\
179 \rightarrow 182(0.35) \\
178 \rightarrow 181(0.14)\end{array}$ & $\begin{array}{c}{ }^{1} \mathrm{IL} /{ }^{1} \mathrm{LMCT} \\
(23 \%)\end{array}$ \\
\hline & 6 & $\begin{array}{c}24303.2 \\
(411.5) \\
\end{array}$ & 0.088 & $\begin{array}{l}178 \rightarrow 182(0.53) \\
179 \rightarrow 182(0.33)\end{array}$ & $\begin{array}{c}{ }^{1} \mathrm{IL} /{ }^{1} \mathrm{LMCT} \\
(23 \%) \\
\end{array}$ \\
\hline \multirow{3}{*}{ II } & 9 & $\begin{array}{l}28590.1 \\
(349.8)\end{array}$ & 0.080 & $178 \rightarrow 183(0.73)$ & $\begin{array}{c}{ }^{1} \mathrm{IL} /{ }^{1} \mathrm{LMCT} \\
(2 \%)\end{array}$ \\
\hline & 11 & $\begin{array}{c}29736.6 \\
(336.3)\end{array}$ & 0.108 & $\begin{array}{l}177 \rightarrow 182(0.47) \\
180 \rightarrow 184(0.30)\end{array}$ & $\begin{array}{c}{ }^{1} \mathrm{IL} /{ }^{1} \mathrm{LMCT} \\
(23 \%)\end{array}$ \\
\hline & 14 & $\begin{array}{l}30409.1 \\
(328.8)\end{array}$ & 0.039 & $\begin{array}{l}176 \rightarrow 181(0.42) \\
179 \rightarrow 184(0.12)\end{array}$ & $\begin{array}{c}{ }^{1} \mathrm{IL} /{ }^{1} \mathrm{LMCT} \\
(21 \%)\end{array}$ \\
\hline \multirow{7}{*}{ III } & 26 & $\begin{array}{l}34169.9 \\
(292.7)\end{array}$ & 0.117 & $\begin{array}{l}179 \rightarrow 188(0.44) \\
180 \rightarrow 187(0.12) \\
178 \rightarrow 187(0.20)\end{array}$ & $\begin{array}{c}{ }^{1} \mathrm{IL} /{ }^{1} \mathrm{LMCT} \\
(55 \%)\end{array}$ \\
\hline & 27 & $\begin{array}{l}34106.5 \\
(293.2)\end{array}$ & 0.155 & $\begin{array}{l}177 \rightarrow 183(0.17) \\
179 \rightarrow 188(0.13) \\
180 \rightarrow 187(0.11)\end{array}$ & $\begin{array}{c}{ }^{1} \mathrm{IL} /{ }^{1} \mathrm{LMCT} \\
(46 \%)\end{array}$ \\
\hline & 28 & $\begin{array}{c}34582.1 \\
(289.2)\end{array}$ & 0.124 & $\begin{array}{l}178 \rightarrow 188(0.46) \\
179 \rightarrow 187(0.13)\end{array}$ & $\begin{array}{c}{ }^{1} \mathrm{IL} /{ }^{1} \mathrm{LMCT} \\
(55 \%)\end{array}$ \\
\hline & 29 & $\begin{array}{c}33920.2 \\
(294.8)\end{array}$ & 0.086 & $177 \rightarrow 183(0.74)$ & $\begin{array}{c}{ }^{1} \mathrm{IL} /{ }^{1} \mathrm{LMCT} \\
(2 \%)\end{array}$ \\
\hline & 30 & $\begin{array}{c}34975.8 \\
(285.9)\end{array}$ & 0.154 & $\begin{array}{l}178 \rightarrow 188(0.21) \\
179 \rightarrow 188(0.19) \\
178 \rightarrow 187(0.14) \\
176 \rightarrow 183(0.13)\end{array}$ & $\begin{array}{c}{ }^{1} \mathrm{IL} /{ }^{1} \mathrm{LMCT} \\
(55 \%)\end{array}$ \\
\hline & 31 & $\begin{array}{c}35706.9 \\
(280.1)\end{array}$ & 0.159 & $\begin{array}{l}176 \rightarrow 183(0.51) \\
179 \rightarrow 188(0.11)\end{array}$ & $\begin{array}{c}{ }^{1} \mathrm{IL} /{ }^{1} \mathrm{LMCT} \\
(2 \%)\end{array}$ \\
\hline & 32 & $\begin{array}{l}36145.4 \\
(276.7)\end{array}$ & 0.325 & $\begin{array}{l}176 \rightarrow 183(0.26) \\
178 \rightarrow 188(0.23)\end{array}$ & $\begin{array}{c}{ }^{1} \mathrm{IL} /{ }^{1} \mathrm{LMCT} \\
(2 \%)\end{array}$ \\
\hline
\end{tabular}

a only excitations larger than 0.1 are shown. ${ }^{b}$ HOMO 180, LUMO 181. 


\section{Geometry Optimization of $\left({ }^{\mathrm{Me}} \mathrm{PMP}{ }^{\mathrm{Me}}\right)_{3} \mathrm{ZrCl}$ Isomers}

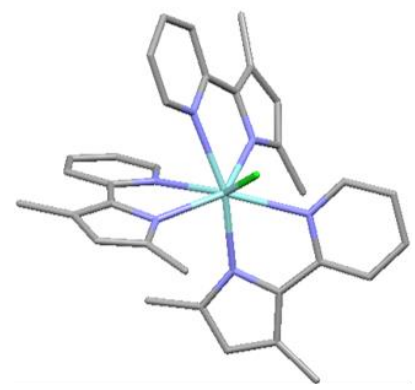

$1 \mathrm{a}$

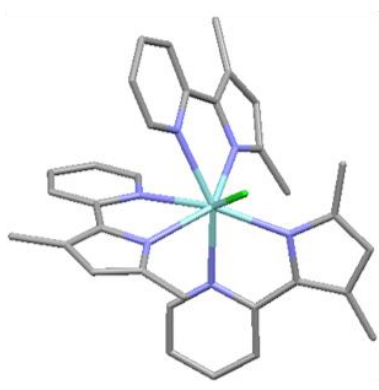

$1 b$

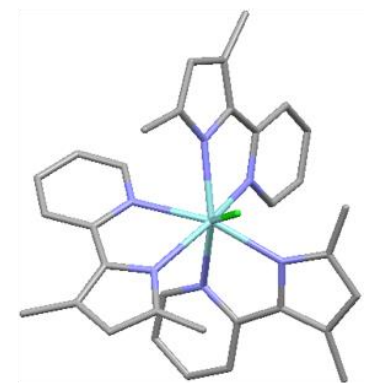

1c

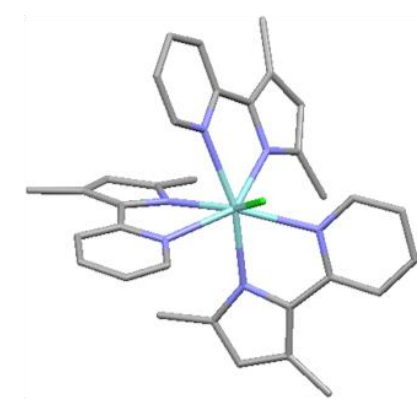

$1 d$

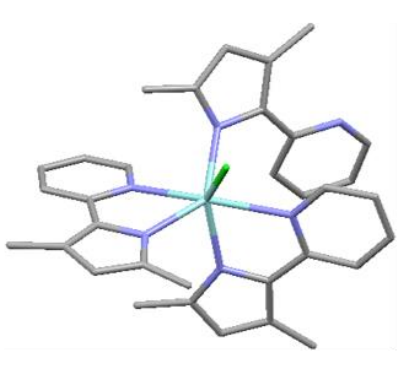

$1 e$

Figure D11. Mercury drawing of DFT optimized geometries for five possible structural isomers.

Table D4. Thermodynamic Parameters from Numerical Frequency Calculations at 298 K.

\begin{tabular}{c|cc}
\hline & Gibbs Free Energy $\left(\mathrm{G}^{\circ}, \mathrm{Eh}\right)$ & Enthalpy $\left(\mathrm{H}^{\circ}, \mathrm{Eh}\right)$ \\
\hline 1a & -5604.926281 & -5604.825218 \\
1b & -5604.926119 & -5604.826923 \\
1c & -5604.921362 & -5604.818987 \\
1d & -5604.917217 & -5604.820064 \\
1e & -5604.889762 & -5604.787071 \\
\hline
\end{tabular}


Optimized Geometries for Compounds Presented at Chapter 5.

\begin{tabular}{|c|c|c|c|}
\hline \\
\hline \multicolumn{4}{|c|}{$\mathrm{Zr} \quad-0.028393936 \quad-0.056887$} \\
\hline $\mathrm{Cl}$ & -0.032534685 & -0.133006506 & 2.47 \\
\hline $\mathrm{N}$ & 1.755589399 & -0.956903646 & -1.089553339 \\
\hline $\mathrm{N}$ & 1.942766740 & 1.095996241 & 0.611712346 \\
\hline $\mathrm{N}$ & -0.838096026 & -2.150707238 & 0.006364393 \\
\hline $\mathrm{N}$ & -1.409927389 & -0.476744030 & 87561 \\
\hline $\mathrm{N}$ & 8837 & 22 & -0 \\
\hline $\mathrm{N}$ & -2.2 & 7 & 8 \\
\hline C & 1.955102242 & -1.9 & 3883 \\
\hline $\mathrm{C}$ & 3.319230168 & -2.237734893 & 96516 \\
\hline $\mathrm{C}$ & 4.022110903 & -1.349874430 & -1.277684251 \\
\hline $\mathrm{C}$ & 3.034705165 & -0.563153710 & -0.659590690 \\
\hline $\mathrm{C}$ & 3.131169547 & 0.54 & 8269 \\
\hline $\mathrm{C}$ & 4.337736048 & 1.109 & 0.73 \\
\hline $\mathrm{C}$ & 4.2933 & 45707 & 1.555613752 \\
\hline C & 3.05 & 2 & 1. \\
\hline $\mathrm{C}$ & 1.9 & 2 & 1. \\
\hline $\mathrm{C}$ & 5.514898295 & -1.30 & 5079 \\
\hline $\mathrm{C}$ & 0.883750659 & -2.690908023 & -2.753814263 \\
\hline $\mathrm{C}$ & -0.632042182 & -3.219990454 & 0.831743488 \\
\hline $\mathrm{C}$ & -1.633631667 & -4.173091614 & 0.613095217 \\
\hline $\mathrm{C}$ & -2.483549465 & -3.695932117 & -0.407396633 \\
\hline $\mathrm{C}$ & -1.948160372 & -2.447510562 & -0.785954170 \\
\hline $\mathrm{C}$ & -2.218427744 & -1.576000048 & -1.894321782 \\
\hline $\mathrm{C}$ & -3.191449780 & -1.827071293 & -2.894340830 \\
\hline $\mathrm{C}$ & -3.285244344 & -0.989402341 & -3.994358738 \\
\hline $\mathrm{C}$ & -2.421826309 & 0.112020002 & -4.09 \\
\hline $\mathrm{C}$ & -1.520290563 & 0.330854331 & -3.062429070 \\
\hline $\mathrm{C}$ & -3.692656244 & -4.413448692 & -0.934284620 \\
\hline $\mathrm{C}$ & 0.536739806 & -3.334195926 & 1.758443196 \\
\hline $\mathrm{C}$ & 0.249029679 & 2.845923595 & -1.662555838 \\
\hline $\mathrm{C}$ & -0.582103857 & 3.897570573 & -2.055040826 \\
\hline $\mathrm{C}$ & -1.842869720 & 3.721236708 & -1.442092482 \\
\hline $\mathrm{C}$ & -1.729834511 & 2.538713588 & -0.689322473 \\
\hline $\mathrm{C}$ & -2.686102863 & 1.820006738 & 0.117655523 \\
\hline
\end{tabular}

$\begin{array}{llll}\text { C } & -3.962130802 & 2.308998315 & 0.485673491\end{array}$

$\begin{array}{llll}\text { C } & -4.791699749 & 1.533773759 & 1.282812997\end{array}$

$\begin{array}{llll}\text { C } & -4.357715731 & 0.272124661 & 1.711081562\end{array}$

$\begin{array}{llll}\text { C } & -3.093533565 & -0.148760356 & 1.319488498\end{array}$

$\begin{array}{llll}\text { C } & -3.022411141 & 4.633156965 & -1.618446664\end{array}$

$\begin{array}{llll}\text { C } & 1.673642657 & 2.646230857 & -2.089276997\end{array}$

H $\quad 3.761469959 \quad-2.992563038 \quad-2.768184662$

H $\quad 5.289979460 \quad 0.667962098 \quad 0.450382560$

$\begin{array}{llll}\mathrm{H} & 5.220331771 & 2.661944593 & 1.934336238\end{array}$

$\mathrm{H} \quad 2.973226004 \quad 3.665119214 \quad 2.539569646$

$\begin{array}{llll}\mathrm{H} & 0.917664503 & 2.552603497 & 1.659995917\end{array}$

H $\quad 5.941748797 \quad-0.342951936 \quad-1.467012974$

H $\quad 5.981770122 \quad-2.091397019 \quad-1.745134132$

$\mathrm{H} \quad 5.842788204 \quad-1.463809805 \quad-0.091835624$

H $\quad 0.184437135 \quad-3.223867473 \quad-2.092634757$

$\mathrm{H} \quad 1.348216463 \quad-3.426300222 \quad-3.427397229$

H $\quad 0.286707922 \quad-2.001230408 \quad-3.371169413$

$\mathrm{H} \quad-1.722682370 \quad-5.128966451 \quad 1.129065337$

$\mathrm{H} \quad-3.841728052 \quad-2.694187981 \quad-2.806565104$

H $\quad-4.021903513 \quad-1.195534701 \quad-4.776208436$

$\mathrm{H} \quad-2.451381703 \quad 0.794931305 \quad-4.946833914$

$\mathrm{H} \quad-0.855141092 \quad 1.194473626 \quad-3.085267369$

$\mathrm{H} \quad-4.593444681 \quad-3.776295540 \quad-0.913426043$

H $\quad-3.908692036 \quad-5.303294408 \quad-0.324311014$

$\mathrm{H} \quad-3.560886855 \quad-4.761428243 \quad-1.974834253$

H $\quad 1.453557962 \quad-2.940114001 \quad 1.290906906$

H $\quad 0.712321714 \quad-4.388068092 \quad 2.020667148$

H $\quad 0.382711450 \quad-2.770940129 \quad 2.692519085$

$\mathrm{H} \quad-0.300104754 \quad 4.716226387 \quad-2.717871641$

H $\quad-4.279683538 \quad 3.296147851 \quad 0.160723104$

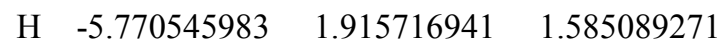

H $\quad-4.977277957 \quad-0.368778659 \quad 2.340327766$

H $\quad-2.692954974 \quad-1.110571756 \quad 1.640849233$

$\mathrm{H} \quad-3.912851120 \quad 4.095490124 \quad-1.987146321$

H $\quad-2.789609649 \quad 5.424008544 \quad-2.346907632$

H $\quad-3.315026349 \quad 5.136241113 \quad-0.679510995$

$\mathrm{H} \quad 2.390359172 \quad 2.955842747 \quad-1.310764918$

H $\quad 1.879859608 \quad 3.261737129 \quad-2.977660892$

H $\quad 1.903371089 \quad 1.599425199 \quad-2.341161085$ 


\section{$\left({ }^{\mathrm{Me}} \mathrm{PMP}{ }^{\mathrm{Me}}\right)_{3} \mathrm{ZrCl}$ (isomer 1b)}

\begin{tabular}{|c|c|c|c|}
\hline & -0.013252933 & -0.123140822 & -0 \\
\hline & 0.000859822 & -0.172768713 & 2.441023878 \\
\hline & 2.081712286 & 0.603452604 & 0.275884609 \\
\hline & 1.512825475 & -1.334087954 & -1.467368145 \\
\hline & -0.867830029 & -2.214775329 & 0.042 \\
\hline & -1.479457489 & -0.559910308 & -1.970728024 \\
\hline & -0.345451885 & 1.920388782 & -0.912053681 \\
\hline & -2.207321013 & 0.641314271 & 0.548171969 \\
\hline & 2.611514428 & 1.605209389 & 91145 \\
\hline & 4.007 & 45 & 57 \\
\hline & $4.370 s$ & 0.508343184 & 61554 \\
\hline & 90773 & -0.063552923 & -0.318350514 \\
\hline & 2.846098954 & -1.091378233 & -1.265546454 \\
\hline & 3.813377973 & -1.829528132 & -1.994004131 \\
\hline & 3.411077008 & -2.776945132 & -2.918670041 \\
\hline & 2.039465746 & -3.008733973 & -3.117093115 \\
\hline & 1.142428216 & -2.271410272 & -2.361064592 \\
\hline & 5.779115702 & 0.136670758 & -0.264478370 \\
\hline & 1.80 & 0005 & 52 \\
\hline & $-0.6^{\circ}$ & -3.2 & 85 \\
\hline & -1.720952085 & -4.181456387 & 85038 \\
\hline & -2.585286269 & -3.709395242 & -0.261575190 \\
\hline & -2.014933007 & -2.496137159 & -0.704484090 \\
\hline & -2.311259154 & -1.635970435 & -1.816108747 \\
\hline & -3.338212591 & -1.872975001 & -2.765633203 \\
\hline & -3.466743057 & -1.042574604 & -3.867777518 \\
\hline & -2.578193254 & 0.031744669 & -4.028652953 \\
\hline & -1.618748910 & 0.235828469 & -3.044862504 \\
\hline & -3.845184393 & -4.392257428 & -0.710721346 \\
\hline & 0.505788458 & -3.381929262 & 1.807867803 \\
\hline & 0.373527117 & 2.711013879 & -1.777604624 \\
\hline & -0.411275951 & 3.798549648 & -2.168941658 \\
\hline & -1.665592216 & 3.697990881 & -1.527092784 \\
\hline & -1.598123608 & 2.520998847 & -0.760300360 \\
\hline & -2.567895981 & 1.867649924 & 0.082047800 \\
\hline & -3.819954051 & 2.415507406 & 0.451532929 \\
\hline & -4.666826629 & 1.696601748 & 1.281208698 \\
\hline & -4.275922799 & 0.431465760 & 1.7416726 \\
\hline
\end{tabular}

$\begin{array}{llll}\text { C } & -3.034174884 & -0.048883609 & 1.349140804\end{array}$

$\begin{array}{llll}\text { C } & -2.797311490 & 4.671284091 & -1.687246407\end{array}$

$\begin{array}{llll}\text { C } & 1.782505239 & 2.448908796 & -2.219926240\end{array}$

$\begin{array}{llll}\mathrm{H} & 4.691122508 & 2.242294889 & 1.473847238\end{array}$

H $\quad 4.869813910 \quad-1.639928427 \quad-1.819761670$

$\mathrm{H} \quad 4.157265508 \quad-3.340586730 \quad-3.484499472$

$\mathrm{H} \quad 1.672073260 \quad-3.748766323 \quad-3.829985509$

H $\quad 0.072353098 \quad-2.438861363 \quad-2.465598167$

$\begin{array}{llll}\mathrm{H} & 6.018576074 & -0.910409717 & -0.009837807\end{array}$

$\mathrm{H} \quad 6.493744303 \quad 0.771991265 \quad 0.278532193$

$\mathrm{H} \quad 5.983238895 \quad 0.267195379 \quad-1.342401649$

H $\quad 1.309446226 \quad 2.127931897 \quad 2.688225993$

$\begin{array}{llll}\mathrm{H} & 1.006385774 & 3.043486911 & 1.203581561\end{array}$

$\mathrm{H} \quad 2.450981681 \quad 3.404221380 \quad 2.187102669$

$\mathrm{H} \quad-1.828251517 \quad-5.113661490 \quad 1.301827728$

H $\quad-4.007214792 \quad-2.720063494 \quad-2.633264882$

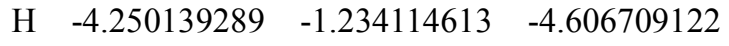

$\mathrm{H} \quad-2.633551943 \quad 0.705541364 \quad-4.885119727$

$\mathrm{H} \quad-0.927467413 \quad 1.076889793 \quad-3.113890605$

$\mathrm{H} \quad-4.721494761 \quad-3.724039940 \quad-0.646445470$

H $\quad-4.055088711 \quad-5.265468015 \quad-0.075218858$

$\mathrm{H} \quad-3.788308554 \quad-4.758401349 \quad-1.751624888$

H $\quad 1.421253803 \quad-2.988655839 \quad 1.337470312$

$\mathrm{H} \quad 0.681647641 \quad-4.437764754 \quad 2.062941790$

$\mathrm{H} \quad 0.366725287 \quad-2.823275757 \quad 2.746984250$

$\mathrm{H} \quad-0.099342477 \quad 4.593971602 \quad-2.846436245$

$\mathrm{H} \quad-4.103415603 \quad 3.403252165 \quad 0.098644626$

$\mathrm{H} \quad-5.626639147 \quad 2.123718162 \quad 1.584020627$

$\mathrm{H} \quad-4.911436985 \quad-0.165688538 \quad 2.397365684$

H $\quad-2.665385982 \quad-1.013960729 \quad 1.696645100$

$\mathrm{H} \quad-3.722416391 \quad 4.180120367 \quad-2.035023118$

$\mathrm{H} \quad-2.536242930 \quad 5.443605127 \quad-2.425836011$

H $\quad-3.042975673 \quad 5.194503184 \quad-0.746072732$

$\mathrm{H} \quad 2.512563699 \quad 2.630648268 \quad-1.414938932$

H $\quad 2.031956554 \quad 3.122146908 \quad-3.053537741$

$\mathrm{H} \quad 1.939412948 \quad 1.416195894 \quad-2.567681656$

$\left({ }^{\mathrm{Me}} \mathrm{PMP}{ }^{\mathrm{Me}}\right)_{3} \mathrm{ZrCl}$ (isomer 1c)

Zr $\quad-0.387570464 \quad 0.029774525 \quad-0.101492708$ 


\begin{tabular}{|c|c|c|c|c|c|c|c|}
\hline 1 & -0.651966972 & 0.06 & 617 & $\mathrm{C}$ & 547 & 9093 & 1.1 \\
\hline $\mathrm{N}$ & 1.745395525 & 0.535105062 & 0.361897995 & $\mathrm{H}$ & 4.447897257 & 1.678426400 & 1.877224523 \\
\hline & 1.123401443 & -0.992232370 & -1.749190710 & $\mathrm{H}$ & 4.283830445 & -2.190249904 & -1.489879990 \\
\hline & -0.715793665 & -2.175555127 & 0.127357064 & $\mathrm{H}$ & 3.563514147 & -3.453719771 & -3.500796741 \\
\hline & -1.968987747 & -0.760911112 & -1.779018478 & $\mathrm{H}$ & 65577 & 896 & 7527 \\
\hline & -2.104893985 & 1.463250265 & -0.033820034 & H & 362 & 73 & 1228 \\
\hline & 0.042820557 & 1.972178142 & -1.529306632 & $\mathrm{H}$ & 5.451326449 & -1.537277456 & 49062682 \\
\hline & 2.343168295 & 1.394791183 & 1.238462189 & $\mathrm{H}$ & 6.121875889 & 0.066955062 & 0.688722887 \\
\hline & 3.718911046 & 1.137661376 & 1.273246328 & $\mathrm{H}$ & 5.649629105 & -0.359441880 & -0.968320279 \\
\hline & 3.998714375 & 0.086144362 & 0.377793339 & $\mathrm{H}$ & 0.861386710 & 2.967380897 & 1.387927841 \\
\hline & 2.753619439 & -0.259922323 & -0.189928743 & $\mathrm{H}$ & 2.327958852 & 3.207895458 & 5535 \\
\hline & 2.40 & -1.124 & -1.2 & & 93 & 2.0 & 826 \\
\hline & 3.289329710 & -2.039761394 & -1.903049170 & $\mathrm{H}$ & -0.279634419 & 703505 & 1.021256802 \\
\hline & 2.881583756 & -2.745209986 & -3.022897243 & $\mathrm{H}$ & -3.701402847 & -3.611149113 & -2.369932371 \\
\hline & 1.593339538 & -2.534791755 & -3.537576355 & $\mathrm{H}$ & -4.735307131 & -2.168584921 & -4.108255801 \\
\hline & 0.758911193 & -1.661627185 & -2.854322859 & $\mathrm{H}$ & -3.954389846 & 0.238993230 & -4.324928583 \\
\hline C & 5.365995740 & -0.466070761 & 0.093696588 & $\mathrm{H}$ & -2.216288296 & 1.054076176 & -2.738775674 \\
\hline$C$ & 1.615133287 & 2.453579768 & 2.006686438 & $\mathrm{H}$ & -3.410078487 & -5.324497094 & -0.855749521 \\
\hline $\mathrm{C}$ & -0.096672812 & -3.120582969 & 0.895614977 & $\mathrm{H}$ & -1.955430681 & -6.324965807 & -0.689737781 \\
\hline C & -0.598113830 & -4.386182865 & 0.568954837 & $\mathrm{H}$ & 498258 & 64202 & -2.17 \\
\hline C & -1.572296310 & -4.232701559 & -0.434801760 & $\mathrm{H}$ & 1.677560597 & -2.082926520 & 1.597114073 \\
\hline C & -1.62 & -2.844805382 & -0.698120668 & $\mathrm{H}$ & 1.478110215 & -3.750284697 & 2.197059931 \\
\hline & -2.340426162 & -2.073635389 & -1.665476133 & $\mathrm{H}$ & 0.480178341 & -2.425707645 & 56405 \\
\hline C & -3.368002378 & -2.584153127 & -2.501201532 & $\mathrm{H}$ & -4.977812173 & 2.847270534 & 0.817200112 \\
\hline $\mathrm{C}$ & -3.947918639 & -1.772890585 & -3.460653061 & $\mathrm{H}$ & -1.180842894 & 5.126578778 & -1.756961858 \\
\hline${ }^{2}$ & -3.523959056 & -0.437957386 & -3.586050881 & $\mathrm{H}$ & 0.867288265 & 5.406258084 & -3.143470473 \\
\hline C & -2.552558962 & 0.017636326 & -2.706631188 & $\mathrm{H}$ & 2.394626760 & 3.415327364 & -3.484058711 \\
\hline${ }^{2}$ & -2.327331474 & -5.362561665 & -1.072501838 & $\mathrm{H}$ & 1.788294672 & 1.267423119 & -2.383091568 \\
\hline 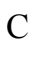 & 0.940196263 & -2.826642635 & 1.934092081 & $\mathrm{H}$ & -2.726641647 & 5.632683984 & 99189 \\
\hline $\mathrm{C}$ & -3.333307605 & 1.382795234 & 0.554477584 & $\mathrm{H}$ & -4.443242093 & 5.201448048 & -0.179440810 \\
\hline & -3.985369173 & 2.616002678 & 0.430198021 & $\mathrm{H}$ & -3.511138852 & 5.113544574 & -1.688665451 \\
\hline$C$ & -3.139210298 & 3.498129655 & -0.270725116 & $\mathrm{H}$ & -3.952836752 & -0.687316719 & 0.456673584 \\
\hline $\mathrm{C}$ & -1.978636569 & 2.746764494 & -0.561979110 & $\mathrm{H}$ & -4.885748498 & 0.326818617 & 1.582665450 \\
\hline C & -0.810194871 & 3.027240432 & -1.343534153 & $\mathrm{H}$ & -3.244194149 & -0.217956973 & 2.010687811 \\
\hline & -0.512287352 & 4.285650305 & -1.928061820 & & & & \\
\hline $\mathrm{C}$ & 0.629490337 & 4.437235585 & -2.696156325 & \multicolumn{4}{|c|}{$\left({ }^{\mathrm{Me}} \mathrm{PMP}^{\mathrm{Me}}\right)_{3} \mathrm{ZrCl}$ (isomer 1d) } \\
\hline C & 1.483602284 & 3.339578583 & -2.889006782 & $\mathrm{Zr}$ & -0.004744099 & -0.081642922 & 0.048337316 \\
\hline & 1.146927792 & 2.140854185 & -2.277832445 & $\mathrm{Cl}$ & 0.091628200 & -0.118091328 & 2.565697101 \\
\hline & -3.464986701 & 4.926702481 & -0.601141324 & $\mathrm{~N}$ & 1.817957675 & -1.021295337 & -0.908320684 \\
\hline
\end{tabular}




\begin{tabular}{|c|c|c|c|}
\hline & 77 & 06 & 0.614656065 \\
\hline 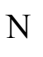 & -1.229134561 & -0.894956891 & -1.714253966 \\
\hline & -0.703320568 & 6 & 7 \\
\hline & -0.51 & 2 & 53 \\
\hline & -2.271141864 & 66 & 6845 \\
\hline & 2.074044792 & -2.089086919 & -1.743749853 \\
\hline & 3.450377427 & -2.272509643 & -1.864480969 \\
\hline & 4.103485680 & -1.291590750 & 59835 \\
\hline & 3.074 & 684 & -0.5 \\
\hline & 3.1 & 0. & 0 \\
\hline & 4.25 & 1.2 & 0. \\
\hline & 19 & 78 & 1 \\
\hline & 2.93 & 2.9 & 1.8 \\
\hline & 1.818515189 & 2.297775474 & 1.356 \\
\hline 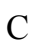 & 5.591433997 & -1.148528920 & -0.966657476 \\
\hline & 1.051140543 & -2.925433391 & -2.444368697 \\
\hline$C$ & -1.590124395 & -0.447976667 & -2.953750130 \\
\hline $\mathrm{C}$ & -2.60 & -1.2 & -3 \\
\hline 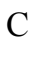 & -2.8 & -2.26 & -2.5 \\
\hline & -2. & -2 & 50 \\
\hline 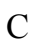 & -1.706949321 & -2.808 & 3011 \\
\hline$C$ & -2.331042380 & -4.038687310 & 407246 \\
\hline$C$ & -1.875394112 & -4.771208970 & 1.117462187 \\
\hline$C$ & -0.786897322 & -4.296264113 & 1.869140601 \\
\hline C & -0.249675827 & -3.067131408 & 1.522479037 \\
\hline C & -3.881282098 & -3.375864468 & -2.752940226 \\
\hline$C$ & -0.970106807 & 0.699133646 & -3.685203669 \\
\hline & 0.157048761 & 2.84479 & -1.567176 \\
\hline & -0.707084866 & 3.879677362 & -1.922848 \\
\hline$C$ & -1.973953261 & 3.621064484 & -1.353317940 \\
\hline$C$ & -1.827017325 & 2.412527009 & -0.64 \\
\hline C & -2.750405427 & 1.659959614 & 0.162297798 \\
\hline C & -4.070123454 & 2.074048005 & 0.465695046 \\
\hline $\mathrm{C}$ & -4.862202665 & 1.300072163 & 1.299491144 \\
\hline $\mathrm{C}$ & -4.344156510 & 0.112584105 & 1.833894945 \\
\hline $\mathrm{C}$ & -3.044829595 & -0.238771257 & 1.4946659 \\
\hline $\mathrm{C}$ & -3.185846682 & 4.489312749 & -1.5337241 \\
\hline & 1.581618650 & 2.709259364 & -2.017504738 \\
\hline & 3.933496481 & -3.042626626 & -2.4659767 \\
\hline
\end{tabular}

\begin{tabular}{llll}
$\mathrm{H}$ & 5.266515393 & 0.861441870 & 0.540400613 \\
$\mathrm{H}$ & 5.100359643 & 2.928310002 & 1.908149861 \\
$\mathrm{H}$ & 2.807910860 & 3.876648470 & 2.430328998 \\
$\mathrm{H}$ & 0.810247592 & 2.656193155 & 1.568183033 \\
$\mathrm{H}$ & 5.952271936 & -0.170404954 & -1.330754497 \\
$\mathrm{H}$ & 6.101287177 & -1.920339170 & -1.561078414 \\
$\mathrm{H}$ & 5.939305202 & -1.256902896 & 0.075198018 \\
$\mathrm{H}$ & 0.421125766 & -3.495885475 & -1.745840697 \\
$\mathrm{H}$ & 1.566465669 & -3.647461481 & -3.095433245 \\
$\mathrm{H}$ & 0.372447183 & -2.321765279 & -3.064682893 \\
$\mathrm{H}$ & -3.075456511 & -1.128620064 & -4.450652841 \\
$\mathrm{H}$ & -3.158014392 & -4.403657093 & -0.568456017 \\
$\mathrm{H}$ & -2.356606268 & -5.717431116 & 1.378861500 \\
$\mathrm{H}$ & -0.376241464 & -4.854725616 & 2.711072511 \\
$\mathrm{H}$ & 0.564547699 & -2.628604594 & 2.098947248 \\
$\mathrm{H}$ & -3.389139415 & -4.361400757 & -2.832884145 \\
$\mathrm{H}$ & -4.436891969 & -3.214248991 & -3.689095582 \\
$\mathrm{H}$ & -4.625847103 & -3.448644947 & -1.942134943 \\
$\mathrm{H}$ & -1.320416406 & 1.672185513 & -3.312690291 \\
$\mathrm{H}$ & -1.243191503 & 0.635907905 & -4.749899337 \\
$\mathrm{H}$ & 0.128116904 & 0.693772806 & -3.615966607 \\
$\mathrm{H}$ & -0.451280596 & 4.731333983 & -2.553649875 \\
$\mathrm{H}$ & -4.452431791 & 3.005350568 & 0.057086323 \\
$\mathrm{H}$ & -5.874647428 & 1.628152605 & 1.550058718 \\
$\mathrm{H}$ & -4.927266734 & -0.523872345 & 2.501151976 \\
$\mathrm{H}$ & -2.586226657 & -1.140043265 & 1.901477886 \\
$\mathrm{H}$ & -4.031817551 & 3.935313664 & -1.975335981 \\
& -2.956462049 & 5.327859651 & -2.207985753 \\
\hline
\end{tabular}

( $\left.{ }^{\mathrm{Me}} \mathrm{PMP}{ }^{\mathrm{Me}}\right)_{3} \mathrm{ZrCl}$ (isomer 1e)

$\begin{array}{llll}\mathrm{Zr} & -0.075424689 & -0.456414636 & -0.723219332 \\ \mathrm{Cl} & -0.985672173 & -1.644996701 & -2.672320098 \\ \mathrm{~N} & 0.064025709 & -0.853970767 & 1.465684657 \\ \mathrm{~N} & -2.251964872 & -0.918358799 & 0.126393748 \\ \mathrm{~N} & 1.689257233 & -1.751869407 & -1.050104194\end{array}$




\begin{tabular}{|c|c|c|c|}
\hline & 747 & 08 & -0 \\
\hline 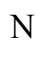 & -0.743678383 & 1.480809224 & -1.522022853 \\
\hline & -3.883420790 & 1096 & 0 \\
\hline & 1 & 76 & 65 \\
\hline & 28 & 77 & 47 \\
\hline & -0.836396069 & -0.984604253 & 3.580000877 \\
\hline & -1.119909898 & -0.959244796 & 2.205668433 \\
\hline 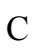 & -2.352906684 & -1.064385649 & 524142 \\
\hline & -3.610234546 & -1.326628220 & 0551 \\
\hline & -4.74 & -1.4 & 349 \\
\hline & -4.6 & 12 & -0 . \\
\hline & -3.3 & 539 & -0 \\
\hline & -1.769133905 & -1.034 & 4.7 \\
\hline & 2.559329119 & -0.882437141 & 2.055636228 \\
\hline & 1.816053012 & -3.106224205 & -1.173762568 \\
\hline & 3.122652928 & -3.413442230 & -1.566614773 \\
\hline & 3.845908704 & -2.206072632 & -1.685124191 \\
\hline & 2.93 & -1.15 & -1 . \\
\hline & 3.074 & 0.209256427 & -1.088593436 \\
\hline & 4.2 & 9 & -1 \\
\hline & 4.32 & 2.26 & -0.8 \\
\hline$C$ & 3.166024260 & 2.883012159 & 31803 \\
\hline $\mathcal{C}$ & 2.000107959 & 2.133542043 & 37880 \\
\hline $\mathcal{C}$ & 5.291979665 & -2.092846043 & -2.075279962 \\
\hline$C$ & 0.698925155 & -4.060113509 & -0.893370700 \\
\hline C & -0.442213500 & 1.729988847 & -2.857667696 \\
\hline$C_{1}$ & -1.498397103 & 2.399076401 & -3.450474300 \\
\hline T & -2.504597434 & 2.613182582 & -2.473 \\
\hline & -2.008837491 & 2.064813448 & -1.283295 \\
\hline$C$ & -2.554928255 & 2.269289569 & 0.057 \\
\hline$C$ & -1.747487047 & $2.285 t$ & 1.2 \\
\hline C & -2.320593465 & 2.551322181 & 2.459422265 \\
\hline C & -3.692089348 & 2.810083696 & 2.532183457 \\
\hline $\mathrm{C}$ & -4.414471151 & 2.783696815 & 1.335242513 \\
\hline$C_{0}$ & -3.795718016 & 3.339881469 & -2.716997979 \\
\hline 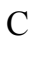 & 0.846338160 & 1.350788694 & -3.526269514 \\
\hline & 1.156621316 & -0.948849512 & 4.591680126 \\
\hline & -3.678818146 & -1.475481587 & 3.1456266 \\
\hline & -5.712833371 & -1.619476001 & 1.73387364 \\
\hline
\end{tabular}

$\begin{array}{llll}\mathrm{H} & -5.487900939 & -1.283957459 & -0.772419127 \\ \mathrm{H} & -3.213973637 & -0.861639202 & -1.703506153 \\ \mathrm{H} & -2.556526714 & -0.264960561 & 4.695170081 \\ \mathrm{H} & -1.209598396 & -0.865527760 & 5.687755698 \\ \mathrm{H} & -2.277350359 & -2.010879334 & 4.853487060 \\ \mathrm{H} & 2.796179960 & -1.603997777 & 1.261625312 \\ \mathrm{H} & 3.127583099 & -1.168815009 & 2.953037869 \\ \mathrm{H} & 2.936180238 & 0.100270397 & 1.729121536 \\ \mathrm{H} & 3.514971175 & -4.415088560 & -1.744472677 \\ \mathrm{H} & 5.170073135 & 0.443535708 & -1.603588253 \\ \mathrm{H} & 5.264330839 & 2.826313591 & -0.900883906 \\ \mathrm{H} & 3.160144264 & 3.922626112 & -0.003473027 \\ \mathrm{H} & 1.060749059 & 2.582934051 & 0.031167772 \\ \mathrm{H} & 5.450848276 & -1.380006655 & -2.901660838 \\ \mathrm{H} & 5.677014187 & -3.067770187 & -2.409884971 \\ \mathrm{H} & 5.929618760 & -1.763081417 & -1.235119974 \\ \mathrm{H} & 0.103871933 & -3.744232113 & -0.019564273 \\ \mathrm{H} & 1.102653174 & -5.061005154 & -0.680020974 \\ \mathrm{H} & 0.004673802 & -4.140982721 & -1.746047752 \\ \mathrm{H} & -1.534920825 & 2.727917324 & -4.489459875 \\ \mathrm{H} & -0.673482781 & 2.112929300 & 1.146979532 \\ \mathrm{H} & -1.696551017 & 2.568414182 & 3.356985492 \\ \mathrm{H} & -4.188437600 & 3.040332365 & 3.477509416 \\ \mathrm{H} & -5.491434751 & 2.995432727 & 1.339221693 \\ \mathrm{H} & -4.654056375 & 2.648728850 & -2.704686717 \\ \mathrm{H} & -3.776530771 & 3.844017378 & -3.696533833 \\ \mathrm{H} & -4.005346733 & 4.089022630 & -1.939467528 \\ \mathrm{H} & 1.703001600 & 1.915034309 & -3.124273972 \\ \mathrm{H} & 0.773263481 & 1.584209924 & -4.598851804 \\ & 1.092634049 & 0.278112115 & -3.453086309\end{array}$

\section{$\left({ }^{\mathrm{Me}} \mathrm{PMP}{ }^{\mathrm{Me}}\right)_{3} \mathrm{HfCl}$}

Hf $\quad-0.062918716 \quad-0.050506913 \quad-0.046873579$

$\begin{array}{llll}\text { Cl } & -0.041442023 & -0.095910370 & 2.415112904\end{array}$

$\begin{array}{llll}\mathrm{N} & 1.698452496 & -0.971389715 & -1.086693214\end{array}$

$\begin{array}{llll}\mathrm{N} & 1.894715978 & 1.118510129 & 0.549616701\end{array}$

$\begin{array}{llll}\mathrm{N} & -0.879832698 & -2.130099549 & 0.062185593\end{array}$

$\begin{array}{llll}\mathrm{N} & -1.415965824 & -0.507395698 & -1.979494325\end{array}$

$\begin{array}{llll}\mathrm{N} & -0.442272983 & 1.992602831 & -0.871604186\end{array}$ 


$\begin{array}{llll}\mathrm{N} & -2.288023979 & 0.626499560 & 0.511815815 \\ \mathrm{C} & 1.901534281 & -2.017818074 & -1.957304640 \\ \mathrm{C} & 3.259219324 & -2.254531392 & -2.100522357 \\ \mathrm{C} & 3.959835962 & -1.336997568 & -1.302521997 \\ \mathrm{C} & 2.979522915 & -0.552966308 & -0.691120647 \\ \mathrm{C} & 3.079124808 & 0.571663370 & 0.181764973 \\ \mathrm{C} & 4.283814903 & 1.143285184 & 0.641192849 \\ \mathrm{C} & 4.247278271 & 2.270063860 & 1.429562323 \\ \mathrm{C} & 3.016783607 & 2.837400513 & 1.771619222 \\ \mathrm{C} & 1.874304827 & 2.217904063 & 1.317077227 \\ \mathrm{C} & 5.451979855 & -1.274067087 & -1.187756059 \\ \mathrm{C} & 0.837803977 & -2.788186955 & -2.663928475 \\ \mathrm{C} & -0.665348836 & -3.202234549 & 0.878754049 \\ \mathrm{C} & -1.609013809 & -4.189640738 & 0.606893431 \\ \mathrm{C} & -2.435350903 & -3.738763904 & -0.431917164 \\ \mathrm{C} & -1.952132296 & -2.464092211 & -0.765180971 \\ \mathrm{H} & -2.229923267 & -1.597781885 & -1.863278185 \\ \mathrm{H} & 2.947476949 & 3.724734424 & 2.384188329 \\ \mathrm{C} & -3.230429566 & -1.832352587 & -2.828127733 \\ \mathrm{C} & -3.345863516 & -1.000099473 & -3.917082608 \\ \mathrm{C} & -2.473974427 & 0.081862687 & -4.049479278 \\ \mathrm{C} & -1.547886128 & 0.292796095 & -3.050234639 \\ \mathrm{C} & -3.553096557 & -4.531114227 & -1.037649284 \\ \mathrm{C} & 0.454025562 & -3.309382311 & 1.860294194 \\ \mathrm{C} & 0.262805122 & 2.833675519 & -1.691779602 \\ \mathrm{C} & -0.514857063 & 3.942839020 & -1.995957015 \\ \mathrm{C} & -1.755351530 & 3.805473777 & -1.351042199 \\ \mathrm{C} & -1.690166503 & 2.583785765 & -0.671746733 \\ \mathrm{C} & -2.663619755 & 1.864809513 & 0.098887297 \\ \mathrm{C} & -3.938745506 & 2.356847542 & 0.435770576 \\ \mathrm{C} & -4.398185236 & 0.307853194 & 1.590227927 \\ \mathrm{H} & -2.600871425 & 1.570728607\end{array}$

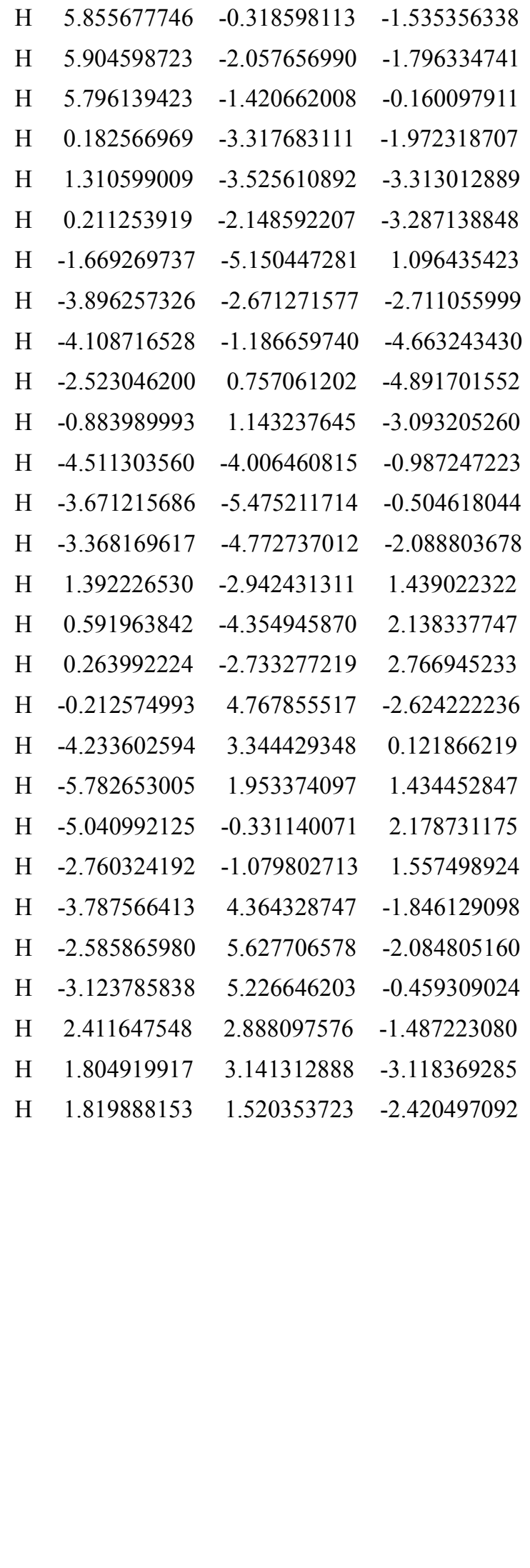

H $\quad 5.855677746 \quad-0.318598113 \quad-1.535356338$

H $\quad 5.904598723 \quad-2.057656990 \quad-1.796334741$

H $\quad 5.796139423 \quad-1.420662008 \quad-0.160097911$

$\mathrm{H} \quad 0.182566969 \quad-3.317683111 \quad-1.972318707$

H $\quad 0.211253919 \quad-2.148592207 \quad-3.287138848$

$\mathrm{H} \quad-1.669269737 \quad-5.150447281 \quad 1.096435423$

$\mathrm{H} \quad-3.896257326 \quad-2.671271577 \quad-2.711055999$

H $\quad-4.108716528 \quad-1.186659740 \quad-4.663243430$

$\begin{array}{llll}H & -2.523046200 & 0.757061202 & -4.891701552\end{array}$

$\mathrm{H} \quad-4.511303560 \quad-4.006460815 \quad-0.987247223$

$\begin{array}{llll}\mathrm{H} & -3.671215686 & -5.475211714 & -0.504618044\end{array}$

$\begin{array}{lllll}\mathrm{H} & -3.368169617 & -4.772737012 & -2.088803678\end{array}$

$\mathrm{H} \quad 0.591963842 \quad-4.354945870 \quad 2.138337747$

$\mathrm{H} \quad 0.263992224 \quad-2.733277219 \quad 2.766945233$

$\begin{array}{lllll}\mathrm{H} & -0.212574993 & 4.767855517 & -2.624222236\end{array}$

$\begin{array}{llll}\mathrm{H} & -4.233602594 & 3.344429348 & 0.121866219\end{array}$

$\begin{array}{llll}\mathrm{H} & -5.782653005 & 1.953374097 & 1.434452847\end{array}$

$\begin{array}{llll}\mathrm{H} & -5.040992125 & -0.331140071 & 2.178731175\end{array}$

$\begin{array}{llll}\mathrm{H} & -2.760324192 & -1.079802713 & 1.557498924\end{array}$

$\mathrm{H} \quad-2.585865980 \quad 5.627706578 \quad-2.084805160$

$\begin{array}{lllll}\mathrm{H} & -3.123785838 & 5.226646203 & -0.459309024\end{array}$

$\begin{array}{llll}\mathrm{H} & 2.411647548 & 2.888097576 & -1.487223080\end{array}$

$\begin{array}{llll}\mathrm{H} & 1.804919917 & 3.141312888 & -3.118369285\end{array}$

H $1.819888153 \quad 1.520353723 \quad-2.420497092$ 


\section{D.6. Additional Information for Chapter 6.}

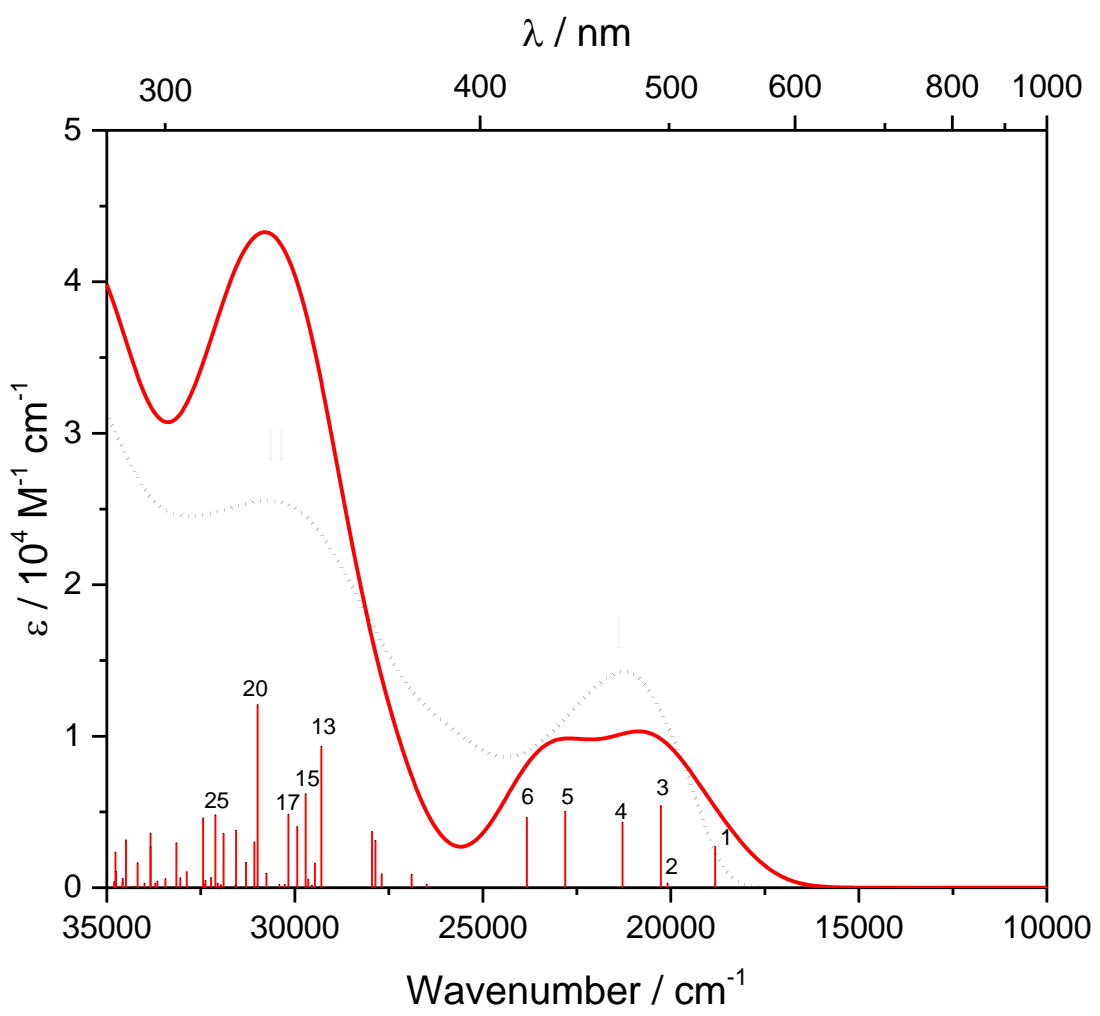

Figure D12. Electronic absorption spectrum of $\operatorname{Zr}(\mathrm{CNN})_{2}$ in benzene obtained via TD-DFT calculations (red line, FWHM of $2500 \mathrm{~cm}-1$ ). The stick plot indicates the positions and relative intensities of individual transitions. Transitions above $25000 \mathrm{~cm}^{-1}$ with calculated oscillator strengths larger than 0.055 are labeled according to their TD-DFT state number. The major contributions to each numbered state are listed in Table S4. The experimental spectrum is shown as a dotted black line for comparison.

Table D4. Vertical Electronic Excitation Energies and Main Excitations Contributing to the Absorption Bands of $\mathrm{Zr}(\mathrm{CNN})_{2}$ obtained via TD-DFT Calculations.

\begin{tabular}{|c|c|c|c|c|c|}
\hline Band & $\begin{array}{l}\text { TD-DFT } \\
\text { State }\end{array}$ & $\begin{array}{c}\text { Energy / cm }{ }^{-1} \\
(\lambda / \mathrm{nm})\end{array}$ & $\mathrm{f}_{\text {osc }}$ & $\begin{array}{l}\text { Excitations } \\
\text { (weight) }{ }^{\mathrm{a}, \mathrm{b}}\end{array}$ & $\begin{array}{l}\text { Character } \\
(\% \text { LMCT) }\end{array}$ \\
\hline \multirow{6}{*}{ I } & 1 & $\begin{array}{c}18820.3 \\
(531.3)\end{array}$ & 0.031 & $181 \rightarrow 182(0.98)$ & $\begin{array}{c}{ }^{1} \mathrm{IL} /{ }^{1} \mathrm{LMCT} \\
(26 \%)\end{array}$ \\
\hline & 2 & $\begin{array}{r}20089.5 \\
(497.8)\end{array}$ & 0.004 & $\begin{array}{l}180 \rightarrow 182(0.80) \\
181 \rightarrow 183(0.19)\end{array}$ & $\begin{array}{c}{ }^{1} \mathrm{IL} /{ }^{1} \mathrm{LMCT} \\
(26 \%)\end{array}$ \\
\hline & 3 & $\begin{array}{l}20268.4 \\
(493.4)\end{array}$ & 0.062 & $\begin{array}{l}181 \rightarrow 183(0.77) \\
180 \rightarrow 182(0.18)\end{array}$ & $\begin{array}{c}{ }^{1} \mathrm{IL} /{ }^{1} \mathrm{LMCT} \\
(20 \%)\end{array}$ \\
\hline & 4 & $\begin{array}{c}21286.9 \\
(469.8)\end{array}$ & 0.050 & $180 \rightarrow 183(0.94)$ & $\begin{array}{c}{ }^{1} \mathrm{IL} /{ }^{1} \mathrm{LMCT} \\
(20 \%)\end{array}$ \\
\hline & 5 & $\begin{array}{l}22811.1 \\
(438.4)\end{array}$ & 0.058 & $181 \rightarrow 184(0.86)$ & $\begin{array}{c}{ }^{1} \mathrm{IL} /{ }^{1} \mathrm{LMCT} \\
(30 \%)\end{array}$ \\
\hline & 6 & 23829.7 & 0.054 & $180 \rightarrow 184(0.86)$ & ${ }^{1} \mathrm{IL} /{ }^{1} \mathrm{LMCT}$ \\
\hline
\end{tabular}




\begin{tabular}{|c|c|c|c|c|c|}
\hline & & (419.6) & & & $(30 \%)$ \\
\hline \multirow{5}{*}{ II } & 13 & $\begin{array}{c}29291.8 \\
(341.4)\end{array}$ & 0.108 & $\begin{array}{l}178 \rightarrow 183(0.45) \\
177 \rightarrow 182(0.25)\end{array}$ & $\begin{array}{c}{ }^{1} \mathrm{IL} /{ }^{1} \mathrm{LMCT} \\
(20 \%)\end{array}$ \\
\hline & 15 & $\begin{array}{c}29715.2 \\
(336.5)\end{array}$ & 0.071 & $\begin{array}{l}180 \rightarrow 186(0.28) \\
177 \rightarrow 183(0.22) \\
177 \rightarrow 182(0.12)\end{array}$ & $\begin{array}{c}{ }^{1} \mathrm{IL} /{ }^{1} \mathrm{LMCT} \\
(14 \%)\end{array}$ \\
\hline & 17 & $\begin{array}{c}30168.1 \\
(331.5)\end{array}$ & 0.056 & $\begin{array}{l}177 \rightarrow 183(0.22) \\
177 \rightarrow 182(0.20) \\
178 \rightarrow 183(0.19)\end{array}$ & $\begin{array}{c}{ }^{1} \mathrm{IL} /{ }^{1} \mathrm{LMCT} \\
(20 \%)\end{array}$ \\
\hline & 20 & $\begin{array}{c}30990.4 \\
(322.7)\end{array}$ & 0.139 & $179 \rightarrow 184(0.65)$ & $\begin{array}{c}{ }^{1} \mathrm{IL} /{ }^{1} \mathrm{LMCT} \\
(30 \%)\end{array}$ \\
\hline & 25 & $\begin{array}{c}32111.8 \\
(311.4)\end{array}$ & 0.055 & $\begin{array}{l}177 \rightarrow 184(0.56) \\
173 \rightarrow 182(0.13) \\
175 \rightarrow 182(0.12)\end{array}$ & $\begin{array}{c}{ }^{1} \mathrm{IL} /{ }^{1} \mathrm{LMCT} \\
(30 \%)\end{array}$ \\
\hline
\end{tabular}
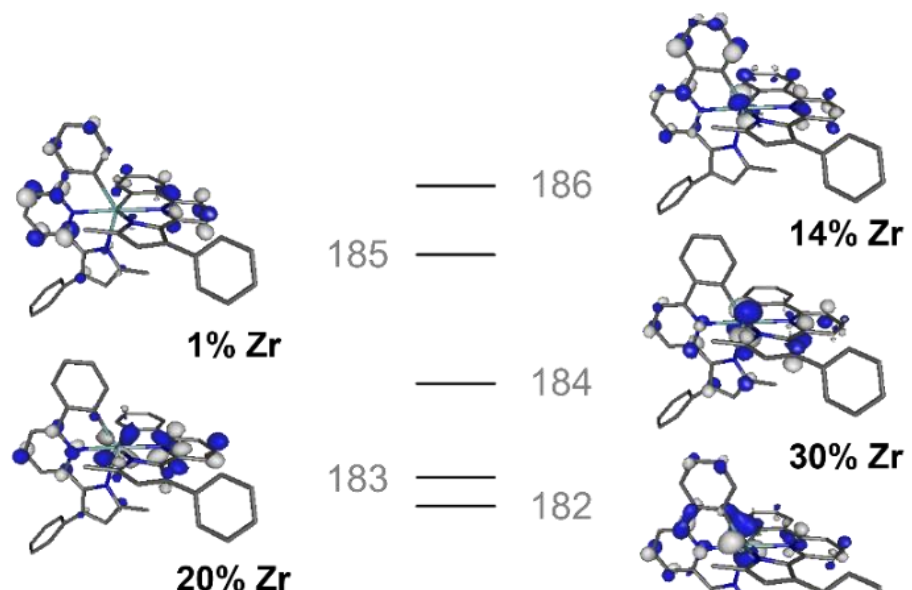

183
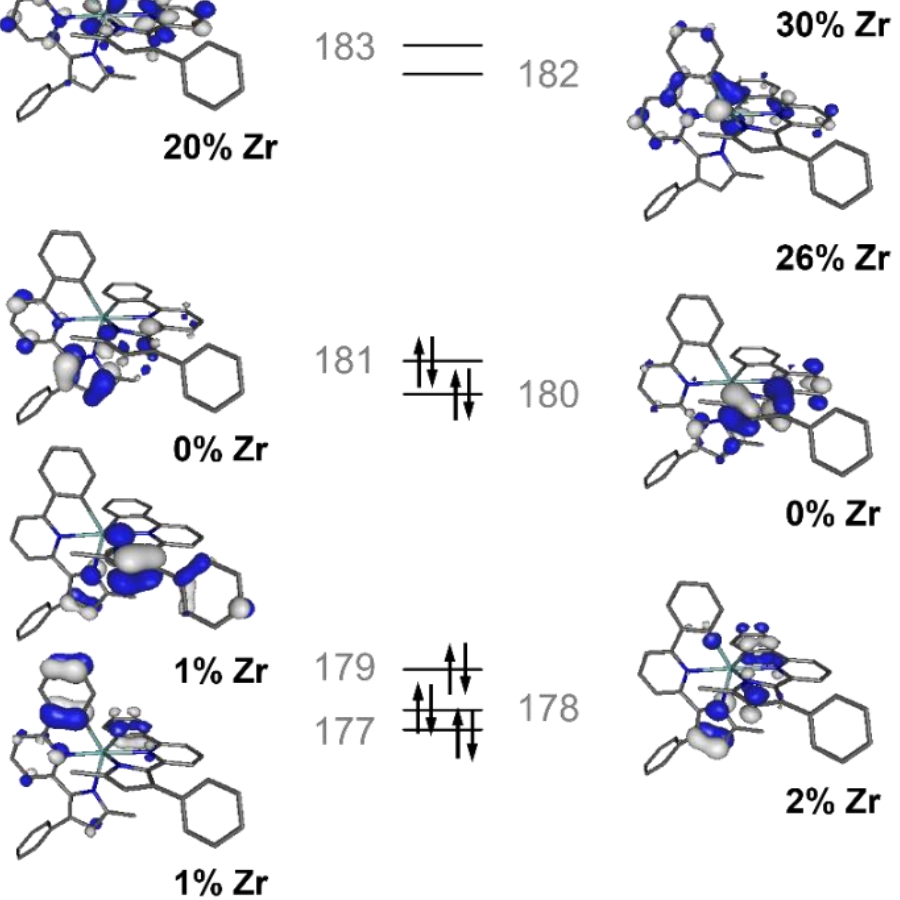

Figure D13. Extended frontier MO diagram for $\mathrm{Zr}\left({ }^{\mathrm{H}} \mathrm{CNN}\right)_{2}$ showing the donor and acceptor orbitals for major TD-DFT excitations computed between $250-1000 \mathrm{~nm}$. The gray numbers to the right correspond to the MO number with 181 being the HOMO and 182 being the LUMO. 
Optimized Geometries for Compounds Presented in Chapter 6.

\begin{tabular}{|c|c|c|c|}
\hline \\
\hline \multicolumn{4}{|c|}{$\mathrm{Zr}\left({ }^{1} \mathrm{CNN}\right)$ 2_Singlet } \\
\hline & -0.116291904 & 0.056605485 & 2.294080633 \\
\hline & -0.070265158 & -0.000430847 & -2.423450484 \\
\hline & 1.812767761 & -0.648340289 & -0.724564833 \\
\hline & -0.719724032 & -2.061059854 & 0.928135189 \\
\hline & 4.008182620 & -1.116560069 & -0.905989315 \\
\hline & 2.92 & 3137 & 68444 \\
\hline & 2.9 & 4951 & 0271 \\
\hline & 4.936634459 & 0.525150379 & 1871 \\
\hline & 3.562737630 & -0.732204382 & -2.188110670 \\
\hline & 2.200410365 & -0.455286348 & -2.047239168 \\
\hline & 4.413419570 & -0.682044998 & -3.400018407 \\
\hline & 5.756518279 & 0.556666147 & -4.996220861 \\
\hline$r$ & 5.56 & -1.829341110 & 6537 \\
\hline & 4.747283857 & -1.859359447 & 2516 \\
\hline & 6.07 & -0. & -5 . \\
\hline & 22186 & 884 & 70 \\
\hline & -0.388075843 & -4.343 & 39765 \\
\hline & -0.866902388 & -4.262138967 & 1.347658299 \\
\hline & 0.641059988 & -5.288038311 & 3.957591090 \\
\hline & -1.283634505 & -3.457019935 & -1.080276898 \\
\hline & -0.953878637 & -3.287924001 & 0.368041879 \\
\hline & -1.225151233 & -4.155453789 & 4.959919563 \\
\hline & -0.588648352 & -3.622786838 & 2.580204236 \\
\hline & -1.167261573 & 0.214956561 & -3.187828979 \\
\hline & 1.161472076 & -0.131900891 & -2.981168500 \\
\hline & 1.322201934 & 0.000875519 & -4.371081972 \\
\hline $\mathrm{C}$ & -1.054959246 & 0.330483213 & -4.566879567 \\
\hline $\mathrm{C}$ & 0.207495991 & 0.227420429 & -5.150516452 \\
\hline $\mathrm{C}$ & -0.191930318 & -1.073718767 & 3.044998989 \\
\hline & 0.040648865 & -1.013291876 & 4.427903382 \\
\hline & 0.137082686 & 1.260968829 & 2.857608419 \\
\hline & 0.340784931 & 1.368460224 & 4.228202645 \\
\hline & 0.302647571 & 0.212909356 & 5.005067884 \\
\hline & 0.842425005 & -6.001450780 & 5.132727932 \\
\hline
\end{tabular}

$\begin{array}{llll}\text { C } & 0.010299307 & -5.795141886 & 6.227015299\end{array}$

$\begin{array}{llll}\text { C } & -1.026781369 & -4.872097477 & 6.134893530\end{array}$

$\begin{array}{llll}\text { C } & -2.322969757 & 0.090649334 & -1.034288865\end{array}$

$\begin{array}{llll}\text { C } & -2.428660748 & 0.279475593 & -2.427221792\end{array}$

$\begin{array}{llll}\text { C } & -3.668541497 & 0.495621837 & -3.034047866\end{array}$

$\begin{array}{llll}\text { C } & -3.504687340 & 0.121438219 & -0.286738083\end{array}$

$\begin{array}{llll}\text { C } & -4.745557712 & 0.330978936 & -0.886466247\end{array}$

$\begin{array}{llll}\text { C } & -4.823253696 & 0.519774096 & -2.262675281\end{array}$

$\begin{array}{llll}\text { C } & 0.009194559 & 3.086590920 & -0.388413899\end{array}$

$\begin{array}{llll}\text { C } & 0.201551723 & 4.411220642 & -0.000909430\end{array}$

C $\quad 0.386027318 \quad 4.719513266 \quad 1.342493546$

$\begin{array}{llll}\text { C } & -0.007614990 & 2.042966544 & 0.543799999\end{array}$

$\begin{array}{llll}\text { C } & 0.175318850 & 2.381499375 & 1.899839556\end{array}$

$\begin{array}{llll}\text { C } & 0.373851153 & 3.707727732 & 2.293601147\end{array}$

H $\quad 5.012979172 \quad-1.410069109 \quad-0.643045865$

H $\quad 2.794981889 \quad-0.494314142 \quad 2.037489840$

H $\quad 3.876159325 \quad-1.843884560 \quad 1.692198603$

H $\quad 2.130079838 \quad-2.086692587 \quad 1.674719604$

H $\quad 4.697132932 \quad 1.442978443 \quad-3.349511605$

H $\quad 6.152721921 \quad 1.501409735 \quad-5.348706594$

$\mathrm{H} \quad 5.820485597 \quad-2.752271859 \quad-5.707165430$

$\mathrm{H} \quad 4.349742283 \quad-2.801115293 \quad-3.718764576$

H $\quad 6.713699354 \quad-0.597198591 \quad-6.537961532$

$\mathrm{H} \quad-1.027467190 \quad-5.320312202 \quad 1.206775683$

H $\quad 1.290976471 \quad-5.453878368 \quad 3.107245228$

$\mathrm{H} \quad-2.126278060 \quad-2.826662837 \quad-1.371938336$

H $\quad-1.551368701 \quad-4.493226244 \quad-1.287680774$

$\mathrm{H} \quad-0.439655616 \quad-3.194642413 \quad-1.726230731$

$\mathrm{H} \quad-2.041728904 \quad-3.446514521 \quad 4.891554065$

H $\quad 2.302037987 \quad-0.096744121 \quad-4.811707427$

$\begin{array}{llll}\mathrm{H} & -1.929562244 & 0.491582567 & -5.178604321\end{array}$

$\mathrm{H} \quad 0.312241246 \quad 0.319233496 \quad-6.225047586$

$\begin{array}{llll}\mathrm{H} & 0.011571480 & -1.912602524 & 5.021812263\end{array}$

$\mathrm{H} \quad 0.540605922 \quad 2.327077183 \quad 4.682145453$

$\begin{array}{llll}\mathrm{H} & 0.483134196 & 0.275656220 & 6.071610047\end{array}$

$\begin{array}{llll}\mathrm{H} & 1.651537877 & -6.719039385 & 5.193678787\end{array}$

H $\quad 0.171538882 \quad-6.347865868 \quad 7.144183033$

$\mathrm{H} \quad-1.686494462 \quad-4.709965378 \quad 6.978893246$

$\begin{array}{llll}\mathrm{H} & -3.747586319 & 0.650249817 & -4.103513962\end{array}$ 


\begin{tabular}{|c|c|c|c|c|c|c|c|}
\hline $\mathrm{H}$ & -3.47253 & -0.031495353 & 0.78 & $\mathrm{C}$ & 0.169848174 & 7487 & 914 \\
\hline $\mathrm{H}$ & -5.647288190 & 0.345870620 & -0.285588209 & $\mathrm{C}$ & 0.568376619 & 1.107115325 & 2.770686999 \\
\hline $\mathrm{H}$ & -5.782779392 & 0.686218748 & -2.736481021 & $\mathrm{C}$ & .745045439 & 1.259793744 & 4.141447251 \\
\hline $\mathrm{H}$ & -0.137685184 & 2.876506859 & -1.443425864 & $\mathrm{C}$ & 0.539332119 & 0.163352923 & 4.974429346 \\
\hline $\mathrm{H}$ & 0.206006810 & 5.201442307 & -0.742813125 & C & 0.178495313 & -5.114816965 & 6.099193451 \\
\hline $\mathrm{H}$ & 0.538087253 & 5.746484140 & 1.651403887 & $\mathrm{C}$ & -1.052885938 & -5.540181135 & 6.584414490 \\
\hline \multirow[t]{2}{*}{$\mathrm{H}$} & 0.516463397 & 3.966225903 & 3.33 & $\mathrm{C}$ & -2.196636754 & -5.329165988 & 5.822889965 \\
\hline & & & & 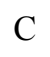 & -2.231716609 & -0.065969549 & -0.839062942 \\
\hline \multicolumn{4}{|c|}{$\left.\mathrm{Zr}\left({ }^{\mathrm{H}} \mathrm{CNN}\right)\right)_{2}$ Triplet } & $\mathrm{C}$ & -2.438077830 & 0.185003028 & -2.213140861 \\
\hline $\mathrm{Zr}$ & -0.088187757 & -0.335651594 & -0.092482421 & $\mathrm{C}$ & 1923 & 0. & -2.71 \\
\hline $\mathrm{N}$ & 599390 & -0.097367434 & 2.25 & $\mathrm{C}$ & 4252 & -0 . & -( \\
\hline $\mathrm{N}$ & -0.083810140 & -0.106664139 & -2.370658358 & $\mathrm{C}$ & -4.628551805 & 6121 & 07014 \\
\hline $\mathrm{N}$ & 1.920084565 & -0.911954467 & -0.970719055 & $\mathrm{C}$ & -4.806457389 & 0.482023111 & -1.851316542 \\
\hline $\mathrm{N}$ & -0.475085447 & -2.256901640 & 0.968827398 & $\mathrm{C}$ & 0.535667906 & 2.861665108 & -0.522364954 \\
\hline $\mathrm{C}$ & 4.117031023 & -1.404304205 & -1.371506126 & $\mathrm{C}$ & 0.835054344 & 4.174670626 & -0.167352616 \\
\hline $\mathrm{C}$ & 3.149 & -1.93 & 0.97 & $\mathrm{C}$ & 082 & 4.493 & 05 \\
\hline $\mathrm{C}$ & 3.078656104 & -1.445219425 & -0.42 & $\mathrm{C}$ & 0.461946835 & 1.835331367 & 0.428 \\
\hline $\mathrm{C}$ & 4.242147495 & 9951 & -4.3 & $\mathrm{C}$ & 802 & 1 & 899 \\
\hline $\mathrm{C}$ & 3.645654324 & -0.80 & -2.5 & $\mathrm{C}$ & 009 & 3.5 & 84 \\
\hline $\mathrm{C}$ & 2.20 & -0.57 & -2.2 & [ & 6558 & 781 & 3502 \\
\hline $\mathrm{C}$ & 4.447960141 & -0.404295762 & -3.677091557 & $\mathrm{H}$ & 3.066705632 & -1.097 & 93909 \\
\hline $\mathrm{C}$ & 5.049649071 & 1.224345983 & -5.379435127 & $\mathrm{H}$ & 4.094171801 & -2.440924101 & 1.155455856 \\
\hline $\mathrm{C}$ & 6.308793547 & -0.813578561 & -5.188857601 & $\mathrm{H}$ & 2.328616353 & -2.617775079 & 1.194970302 \\
\hline $\mathrm{C}$ & 5.509282209 & -1.210149150 & -4.127506836 & $\mathrm{H}$ & 3.458581093 & 1.486304674 & -3.976057095 \\
\hline $\mathrm{C}$ & 6.085137220 & 0.406622521 & -5.822393749 & [ & 4.872866244 & 2.181513769 & -5.853946445 \\
\hline $\mathrm{C}$ & -0.369369044 & -2.369955082 & 2.350049376 & I & 7.105816104 & -1.462823021 & -5.530313256 \\
\hline $\mathrm{C}$ & -0.876850850 & -4.258989417 & 4.087672023 & I & 5.684611399 & -2.167877453 & -3.653882751 \\
\hline $\mathrm{C}$ & -1.185630314 & -4.303675159 & 1.557402681 & I & 6.710136144 & 0.717140778 & -6.650048089 \\
\hline $\mathrm{C}$ & 0.265479027 & -4.480166767 & 4.865900997 & $n$ & -1.565388117 & -5.311331111 & 2883 \\
\hline $\mathrm{C}$ & -1.217503046 & -3.682736923 & -0.956516980 & $\mathrm{H}$ & 1.230594520 & -4.167539129 & 4.486906234 \\
\hline $\mathrm{C}$ & -0.971122021 & -3.439630707 & 0.497163953 & $\mathrm{H}$ & -1.902001900 & -2.939880084 & -1.374125972 \\
\hline $\mathrm{C}$ & -2.107960486 & -4.698911703 & 4.587348926 & $\mathrm{H}$ & -1.662131523 & -4.667467422 & -1.104247635 \\
\hline $\mathrm{C}$ & -0.796899833 & -3.643362150 & 2.747611308 & $\mathrm{H}$ & -0.292261446 & -3.637717224 & -1.537091505 \\
\hline $\mathrm{C}$ & -1.238800573 & 0.126758871 & -3.059013946 & $\mathrm{H}$ & -3.002272363 & -4.532012475 & 3.999669825 \\
\hline $\mathrm{C}$ & 1.110969239 & -0.213872816 & -3.087037750 & $\mathrm{H}$ & 2.064677891 & -0.210469736 & -5.013898445 \\
\hline $\mathrm{C}$ & 1.133659222 & -0.089649149 & -4.481930046 & $\mathrm{H}$ & -2.170630729 & 0.426533397 & -4.961230666 \\
\hline $\mathrm{C}$ & -1.238721670 & 0.257462715 & -4.441987234 & $\mathrm{H}$ & -0.042601362 & 0.236068620 & -6.247825781 \\
\hline $\mathrm{C}$ & -0.041642569 & 0.148451443 & -5.170013723 & П & -0.010407848 & -1.907843316 & 5.084489009 \\
\hline C & 0.019046244 & -1.176046095 & 3.055906893 & $\mathrm{H}$ & 1.025640487 & 2.215487254 & 4.557010442 \\
\hline
\end{tabular}




$\begin{array}{crrr}\mathrm{H} & 0.666223752 & 0.269548587 & 6.045364280 \\ \mathrm{H} & 1.077742633 & -5.289551442 & 6.677634830 \\ \mathrm{H} & -1.119713848 & -6.033861213 & 7.545664871 \\ \mathrm{H} & -3.160914306 & -5.655379896 & 6.193541939 \\ \mathrm{H} & -3.874925278 & 0.663137635 & -3.762374504 \\ \mathrm{H} & -3.243428827 & -0.230237377 & 1.062073764 \\ \mathrm{H} & -5.481027528 & 0.248551400 & 0.176042859 \\ \mathrm{H} & -5.793877496 & 0.695765337 & -2.241847237 \\ \mathrm{H} & 0.349451638 & 2.641692385 & -1.568693401 \\ \mathrm{H} & 0.880690733 & 4.948156148 & -0.925748463 \\ \mathrm{H} & 1.314628128 & 5.511127458 & 1.449301508 \\ \mathrm{H} & 1.189611398 & 3.772027169 & 3.168493684\end{array}$




\begin{tabular}{|c|c|c|c|c|c|c|c|}
\hline \multicolumn{4}{|c|}{ D.7. Additional Information for Chapter 7.} & $\mathrm{C}$ & 57769183 & 42478 & -0.08 \\
\hline \multirow{3}{*}{\multicolumn{4}{|c|}{$\begin{array}{c}\text { Optimized Geometries for Compounds } \\
\text { Presented in Chapter } 7 .\end{array}$}} & $\mathrm{C}$ & 1.750935731 & -4.079999294 & -0.307629488 \\
\hline & & & & $\mathrm{C}$ & 0.628898112 & -3.238890583 & -0.310987635 \\
\hline & & & & $\mathrm{C}$ & -0.344080443 & 3.246906581 & 0.451812228 \\
\hline & $\mathrm{C}$ & -1.668943966 & 2.834067312 & 0.298752604 \\
\hline \multicolumn{4}{|c|}{ Zr(bppda)2_Singlet } & $\mathrm{C}$ & -2.880167244 & 3.545877546 & 0.338244145 \\
\hline 7 & -0.077023375 & 0.091953624 & 0.050652372 & $\mathrm{C}$ & -3.886420258 & 2.608113818 & 0.125054484 \\
\hline & -1.501854001 & -1.048267395 & -1.505918121 & $\mathrm{C}$ & -3.249419395 & 1.368591185 & -0.037030870 \\
\hline & -1.712296535 & -1.341876654 & 1.075535586 & $\mathrm{H}$ & -3.710237725 & -3.088075761 & 1.890976306 \\
\hline & 0.503248778 & 0.656576196 & -2.103475373 & $\mathrm{H}$ & -5.254728011 & -4.234229283 & 0.392189353 \\
\hline & 0.097705146 & 0.194873749 & 2.343260734 & $\mathrm{H}$ & -5.110526803 & -3.883702626 & -2.063738315 \\
\hline & 2.291711307 & 0.360781507 & 0.304217413 & $\mathrm{H}$ & -3.405034496 & -2.395123798 & -2.9 \\
\hline N & 0.617572453 & 2.361961471 & 0.371401648 & $\mathrm{H}$ & -1.750782052 & -1.386741245 & -3.559172730 \\
\hline v & 0.980088229 & -1.953841540 & -0.108746928 & $\mathrm{H}$ & -0.046672808 & 0.071361519 & -5.331488069 \\
\hline $\mathrm{N}$ & -1.912227962 & 1.487831034 & 0.066021732 & $\mathrm{H}$ & 1.929018585 & 1.861720624 & -4.827335087 \\
\hline C & -2.531290846 & -1.897310183 & -1.082270024 & $\mathrm{H}$ & 2.084287898 & 2.066575740 & -2.148779293 \\
\hline $\mathrm{C}$ & -2.631521057 & -2.073896110 & 0.314411847 & $\mathrm{H}$ & -2.383493233 & -2.004713060 & 2.946993900 \\
\hline $\mathrm{C}$ & -3.618581419 & -2.927506580 & 0.825 & $\mathrm{H}$ & -1.066103553 & -0.920733570 & 3270 \\
\hline $\mathrm{C}$ & -4.498634775 & -3.580008109 & -0.022471474 & $\mathrm{H}$ & 0.952807 & 0.879486 & 5.45 \\
\hline $\mathrm{C}$ & -4.415705378 & -3.385871749 & -1.399864540 & $\mathrm{H}$ & 1.620805190 & 3907 & 2.941889193 \\
\hline t & -3.442469269 & -2.549363749 & -1.92 & $\mathrm{H}$ & 1.790087891 & 4.849277642 & 0.688138406 \\
\hline t & -1.214075068 & -0.866963224 & -2.769543179 & $\mathrm{H}$ & 4.187010625 & 5.240694730 & 0.966014672 \\
\hline F & -0.187025735 & 0.012465789 & -3.120258194 & $\mathrm{H}$ & 5.772052183 & 3.326949372 & 0.966956527 \\
\hline$y$ & 0.307470769 & 0.414142936 & -4.371324469 & $\mathrm{H}$ & 4.944620100 & 1.048581920 & 0.669002241 \\
\hline 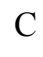 & 1.321202728 & 1.333862552 & -4.109878488 & $\mathrm{H}$ & 4.082784662 & -0.727205427 & 0.371428193 \\
\hline & 1.406675575 & 1.447018626 & -2.714856291 & $\mathrm{H}$ & 3.892804634 & -3.563052506 & -0.028809303 \\
\hline 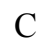 & -1.693607991 & -1.382873081 & 2.383065724 & $\mathrm{H}$ & 1.743885439 & -5.148555108 & -0.453757004 \\
\hline 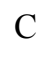 & -0.770462832 & -0.599400736 & 3.078872506 & $\mathrm{H}$ & -0.400841720 & -3.524601414 & -0.454404228 \\
\hline 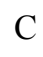 & -0.537567733 & -0.428282081 & 4.452976622 & $\mathrm{H}$ & -0.141116893 & 4.296676393 & 0.647748112 \\
\hline 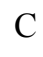 & 0.500257453 & 0.496476684 & 4.556044801 & $\mathrm{H}$ & -2.995223344 & 4.605685598 & 0.506140040 \\
\hline$\tau$ & 0.854914442 & 0.847156269 & 3.246389798 & $\mathrm{H}$ & -4.949049422 & 2.789024320 & 0.087669484 \\
\hline $\mathrm{C}$ & 2.869666815 & 1.619653721 & 0.502780950 & $\mathrm{H}$ & -3.715022879 & 0.414157498 & -0.222063972 \\
\hline C & 1.966847799 & 2.703512924 & 0.523853933 & & & & \\
\hline C & 2.463277028 & 4.003154326 & 0.688512201 & & pda)2_triplet & & \\
\hline 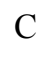 & 3.820864234 & 4.229576821 & 0.842871108 & $\mathrm{Zr}$ & -0.060580470 & 0.076276518 & 0.054273466 \\
\hline 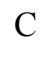 & 4.710425836 & 3.156849338 & 0.839841783 & $\mathrm{~N}$ & -1.486084621 & -1.044819573 & -1.501551026 \\
\hline & 4.237250897 & 1.866043287 & 0.671865314 & $\mathrm{~N}$ & -1.697075323 & -1.340657709 & 1.079137923 \\
\hline & 3.002590107 & -0.736350767 & 0.250422705 & $\mathrm{~N}$ & 0.498920032 & 0.694113512 & -2.111149595 \\
\hline & 2.360291840 & -1.956509402 & 0.032445626 & $\mathrm{~N}$ & 0.086965239 & 0.228111172 & 2.364630631 \\
\hline
\end{tabular}




\begin{tabular}{|c|c|c|c|}
\hline & 36 & 396 & o \\
\hline & 0.619874756 & 2.366638924 & 0.378456019 \\
\hline & 934 & -1.9 & 53 \\
\hline & 9211 & 10 & 1 \\
\hline & 331444 & 845 & 327 \\
\hline & -2.606701800 & -2.082944847 & 0.317643985 \\
\hline & -3.580369844 & -2.954095067 & 0.825635850 \\
\hline $\mathrm{C}$ & -4.449932441 & -3.619217611 & -0.023740750 \\
\hline & -4.369985223 & -3.420719901 & -1.400472177 \\
\hline & -3.40 & -2.5 & -1 \\
\hline & -1.2 & 49 & -2 \\
\hline & -0.1 & 773 & -3 \\
\hline & 437286 & 58 & -4 \\
\hline & 1.292603176 & 9097 & -4.1 \\
\hline & 1.388070829 & 1.488874936 & -2.732769185 \\
\hline$C$ & -1.696352616 & -1.363539583 & 2.389623202 \\
\hline C & -0.787854380 & -0.570044821 & 3.090376367 \\
\hline 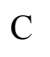 & -0.577672962 & -0.392096932 & 4.470066011 \\
\hline C & 0.4507 & 0.537 & 4.58 \\
\hline T & 0.8 & 12 & 3. \\
\hline & 2.852121866 & 1.565934612 & 0.493163577 \\
\hline & 1.94 & 20 & 0. \\
\hline$C$ & 2.461810507 & 2365 & 0.688846090 \\
\hline$C$ & 3.814149511 & 4.189752343 & 0.835459820 \\
\hline$C$ & 4.708927728 & 3.097884817 & 0.828639840 \\
\hline C & 4.244336421 & 1.821484686 & 0.662984679 \\
\hline C & 3.063012825 & -0.782973535 & 0.242527128 \\
\hline $\mathrm{C}$ & 2.381110825 & -1.961423124 & 0.023952489 \\
\hline$C$ & 2.850415238 & -3.310755085 & -0.110467 \\
\hline & 1.7 & -4.084964 & -0.31 \\
\hline & 0.613539132 & -3.217765423 & -0.3107 \\
\hline$C$ & -0.353141666 & 3.265093023 & 0.449694 \\
\hline$C$ & -1.664110849 & 2.845823965 & 0.299581250 \\
\hline$C$ & -2.886767843 & 3.565472218 & 0.334531158 \\
\hline $\mathrm{C}$ & -3.884183716 & 2.632851043 & 0.132750751 \\
\hline $\mathrm{C}$ & -3.241783813 & 1.380007644 & -0.021093236 \\
\hline${ }_{H}$ & -3.666582751 & -3.122206407 & 1.890648340 \\
\hline & -5.194256454 & -4.287922980 & 0.389333787 \\
\hline & -5.055903079 & -3.929070852 & -2.0657734 \\
\hline
\end{tabular}

$\begin{array}{crrr}\mathrm{H} & -3.371662892 & -2.414974182 & -2.991477685 \\ \mathrm{H} & -1.746167462 & -1.367720148 & -3.557504717 \\ \mathrm{H} & -0.071282693 & 0.094157621 & -5.336221804 \\ \mathrm{H} & 1.890958904 & 1.904100345 & -4.852378518 \\ \mathrm{H} & 2.067093008 & 2.116068418 & -2.176470380 \\ \mathrm{H} & -2.395363711 & -1.977181634 & 2.951425122 \\ \mathrm{H} & -1.114726513 & -0.886981903 & 5.264504732 \\ \mathrm{H} & 0.888878958 & 0.926284839 & 5.491002581 \\ \mathrm{H} & 1.592535097 & 1.583495805 & 2.984581055 \\ \mathrm{H} & 1.797923006 & 4.836680625 & 0.693720171 \\ \mathrm{H} & 4.195774732 & 5.195200019 & 0.957911885 \\ \mathrm{H} & 5.769978422 & 3.273158026 & 0.954704350 \\ \mathrm{H} & 4.945016552 & 1.000624388 & 0.658754519 \\ \mathrm{H} & 4.137072064 & -0.771580247 & 0.357680900 \\ \mathrm{H} & 3.879124145 & -3.629474919 & -0.060111397 \\ \mathrm{H} & 1.692139506 & -5.152976434 & -0.467245435 \\ \mathrm{H} & -0.420223805 & -3.488339562 & -0.447027847 \\ \mathrm{H} & -0.149807244 & 4.315039923 & 0.637141216 \\ \mathrm{H} & -2.998262831 & 4.626706523 & 0.493737902 \\ \mathrm{H} & -4.947708409 & 2.809526174 & 0.096107932 \\ \mathrm{H} & -3.712502531 & 0.425478665 & -0.195722521\end{array}$


D.8. Additional Information for Chapter 8. Optimized Geometries for Compounds Presented in Chapter 8.

\begin{tabular}{llll}
$\mathbf{Z r}\left({ }^{\text {Mes PDPNMe2Ph }} \mathbf{2}\right.$ & \\
$\mathrm{Zr}$ & 0.160095659 & -0.071843281 & 0.074350864 \\
$\mathrm{~N}$ & 0.089837548 & -2.194232180 & 0.745781598 \\
$\mathrm{~N}$ & 0.123121095 & -0.040972488 & 2.319799456 \\
$\mathrm{~N}$ & 0.194588983 & 2.055516639 & 0.732995358 \\
$\mathrm{~N}$ & 2.262436467 & -0.156514872 & -0.678288195 \\
$\mathrm{~N}$ & 0.051493929 & -0.120065538 & -2.172321315 \\
$\mathrm{~N}$ & -2.006787902 & -0.029645149 & -0.486756396 \\
$\mathrm{C}$ & 0.079034367 & -3.443063630 & 0.141410132 \\
$\mathrm{C}$ & 0.339154126 & -4.408232813 & 1.115206759 \\
$\mathrm{C}$ & 0.509129393 & -3.763119107 & 2.369537666 \\
$\mathrm{C}$ & 0.323406446 & -2.393956752 & 2.108959690 \\
$\mathrm{C}$ & 0.192875590 & -1.236093304 & 2.974375558 \\
$\mathrm{C}$ & 0.049271847 & -1.268223803 & 4.370556658 \\
$\mathrm{C}$ & -0.200402331 & -0.071094831 & 5.036416094 \\
$\mathrm{C}$ & -0.270318558 & 1.141667708 & 4.349710798 \\
$\mathrm{C}$ & -0.085779576 & 1.149746115 & 2.960025916 \\
$\mathrm{C}$ & -0.091773294 & 2.311263241 & 2.080304188 \\
$\mathrm{C}$ & -0.398443892 & 3.682456398 & 2.246386242 \\
$\mathrm{C}$ & -0.263013142 & 4.250344436 & 0.949715170 \\
$\mathrm{C}$ & 0.094838957 & 3.257035343 & 0.045797461 \\
$\mathrm{C}$ & 0.879420949 & -4.443308386 & 3.627797317 \\
$\mathrm{C}$ & 0.205487609 & -5.594674091 & 4.072991104 \\
$\mathrm{C}$ & 0.597424365 & -6.282077222 & 5.221541079 \\
$\mathrm{C}$ & 1.701808731 & -5.850881519 & 5.994060111 \\
$\mathrm{C}$ & 2.388754730 & -4.698778482 & 5.540160755 \\
$\mathrm{C}$ & 1.980423116 & -4.018974267 & 4.395034219 \\
$\mathrm{C}$ & -0.953568823 & 4.461316942 & 3.378299934 \\
$\mathrm{C}$ & -2.037261820 & 5.324592192 & 3.123070480 \\
$\mathrm{C}$ & -2.678879582 & 6.045268914 & 4.129749940 \\
$\mathrm{C}$ & -2.260847980 & 5.944742500 & 5.472266352 \\
\hline & -1.128315045 & 5.139466754 & 5.727815504 \\
\hline
\end{tabular}

\begin{tabular}{|c|c|c|c|}
\hline & 0.74 & -4.0 & \\
\hline 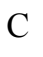 & 0.391499798 & -4.480446415 & -3.531610327 \\
\hline & -0.935687700 & -4.719847935 & -3.900679548 \\
\hline & -1.919100836 & -4.494315613 & -2.933011910 \\
\hline & -1.612656503 & -4.03 & -1.6 \\
\hline & 8404 & 47908 & 67390 \\
\hline & 5387 & 81 & -5 \\
\hline & 055 & -3 & -0 \\
\hline & 0.353949133 & 3.5 & -1 \\
\hline & 1.668479587 & 3.77 & -1. \\
\hline & 1.877321737 & 4.156515966 & 703040 \\
\hline & 0.826105224 & 4.305680125 & 2508 \\
\hline & 0752 & 504 & -3.6 \\
\hline & -0.727984617 & 3.713053419 & -2.3 \\
\hline & 2.86 & 3.6 & -0.5 \\
\hline & 1.0 & 4 & -5 \\
\hline & 864 & 391 & -1 \\
\hline & 3935 & 54 & -0 \\
\hline & 293 & 0.008 & -1.1 \\
\hline & 3.780176286 & 0.0973 & -2.387726312 \\
\hline & 2.417186842 & -0.030928694 & -2.063236876 \\
\hline & 1.219856329 & -0.163932492 & -2.875474225 \\
\hline & 1.180020404 & -0.400360048 & -4.25 \\
\hline $\mathrm{C}$ & -0.059834898 & -0.582580923 & -4.8 \\
\hline C & -1.245031537 & -0.514998899 & -4.1 \\
\hline 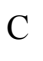 & $-1.1^{\prime}$ & -0. & -2 \\
\hline 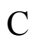 & -2.294152095 & -0.1 & -1.8 \\
\hline $\mathrm{C}$ & -3.684699433 & -0.275944026 & -2.0360 \\
\hline $\mathrm{C}$ & -4.247267722 & -0.198745352 & -0.736661521 \\
\hline $\mathrm{C}$ & -3.219584088 & -0.026515365 & 0.191513095 \\
\hline $\mathrm{C}$ & 4.420837833 & 0.318270382 & -3.701134191 \\
\hline C & 3.941614312 & 1.279453989 & -4.612259891 \\
\hline & 4.541183570 & 1.488652944 & -5.850919205 \\
\hline & 5.688754834 & 0.758754658 & -6.245671 \\
\hline 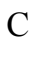 & 6.181429296 & -0.199245207 & -5.32810275 \\
\hline 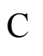 & 5.563942679 & -0.402455217 & -4.093040518 \\
\hline 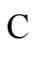 & -4.472202864 & -0.351234157 & -3.286833687 \\
\hline & -5.408812158 & -1.376022575 & -3.508266641 \\
\hline & -6.192477819 & -1.422521801 & -4.661493049 \\
\hline
\end{tabular}




\begin{tabular}{|c|c|c|c|c|c|c|c|}
\hline & -6.08 & -0.428818573 & 026 & $\mathrm{H}$ & 0.0 & 50134 & 5 . \\
\hline & -5.160205111 & 0.619380904 & -5.429322896 & $\mathrm{H}$ & 3.259952820 & -4.325605986 & 6.077538954 \\
\hline & -4.381191517 & 0.646794272 & -4.275678357 & $\mathrm{H}$ & 2.547445855 & -3.143563777 & 9067 \\
\hline & 3.918133837 & -0.406110852 & 342 & $\mathrm{H}$ & 30757 & 258 & 6 \\
\hline & 4.127039960 & 2387 & 475 & $\mathrm{H}$ & 1691 & 2449 & 0202 \\
\hline & 4.637501198 & 0.370549317 & 3.514042930 & $\mathrm{H}$ & -0.718257055 & 5.089435582 & 6.738479181 \\
\hline & 4.980047509 & -0.923603163 & 3.918005494 & $\mathrm{H}$ & 0.413189909 & 3.870630864 & 4.955721747 \\
\hline & 4.792922875 & -1.952609054 & 2.990459690 & $\mathrm{H}$ & 1.189888019 & -4.680640016 & -4.252926996 \\
\hline & 4.274934838 & -1.723415407 & 1.706800397 & $\mathrm{H}$ & -2.965693024 & -4.706011026 & 84618 \\
\hline & 3.872068120 & 2.088952047 & 1.8 & $\mathrm{H}$ & 5450 & -4.127292774 & -2.7 \\
\hline & 5.52 & -1.2 & 42 & $\mathrm{H}$ & 517 & 556368 & -1 \\
\hline & 4.125803201 & -2.90 & 820 & $\mathrm{H}$ & 2.444866085 & -2.820997779 & -1.6 \\
\hline & -3.468455884 & 0.268844922 & 805 & $\mathrm{H}$ & -2.077153117 & -5.9 & -5 \\
\hline & -3.766201942 & 1.601379551 & 2.038497589 & $\mathrm{H}$ & -0.430964790 & -5.615764967 & -5.8 \\
\hline & -4.110409388 & 1.881206833 & 3.368175925 & $\mathrm{H}$ & -1.711817080 & -4.383249998 & -5.898736371 \\
\hline & -4.201369421 & 0.881859955 & 4.341113125 & $\mathrm{H}$ & -3.630315217 & -4.428048048 & -0.990402019 \\
\hline & -3.956864311 & -0.432757720 & 3.933131657 & $\mathrm{H}$ & -3.030843712 & -2.813213186 & -0.566022281 \\
\hline & -3.606767668 & -0.759254809 & 2.61 & $\mathrm{H}$ & 812227 & -4.224082360 & 1267 \\
\hline & -3.756953581 & 2.7 & 1.05 & $\mathrm{H}$ & 74309 & 38 & 0166 \\
\hline & -4.561293612 & 1.2 & 5.769910071 & $\mathrm{H}$ & -1.318959259 & 4.234293701 & -4.314801860 \\
\hline & -3.4 & -2.2 & 5 & $\mathrm{H}$ & 21 & 41 & -1 . \\
\hline $\mathrm{N}$ & -2.907079549 & 6.64 & 6.51 & $\mathrm{H}$ & 6650 & 308 & -0.8 \\
\hline 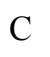 & -3.967170252 & 7.558649835 & 6.135615224 & $\mathrm{H}$ & 2.638982175 & 4.047880971 & 0.040084450 \\
\hline C & -3.210000774 & 5.895233903 & 7.730985000 & $\mathrm{H}$ & 2.095148174 & 5.027969534 & -5.729596584 \\
\hline $\mathrm{N}$ & 2.091815628 & -6.522703302 & 7.155196530 & $\mathrm{H}$ & 0.392141783 & 5.533975684 & -5.855323172 \\
\hline & 3.427179848 & -6.282516697 & 7.678918299 & $\mathrm{H}$ & 0.844457340 & 3.867126869 & -6.241353278 \\
\hline & 1.523587408 & -7.833147744 & 7.423107975 & $\mathrm{H}$ & -2.846289944 & 3.788153353 & -2.724752963 \\
\hline & 6.306105175 & 0.992576523 & -7.476135941 & $\mathrm{H}$ & -2.408923669 & 4.296939812 & -1.081652014 \\
\hline & 7.385751489 & 0.120037662 & -7.900820157 & $\mathrm{H}$ & -2.391125824 & 2.580320410 & -1.501971581 \\
\hline & 5.528939660 & 1.60 & -8.541234 & $H$ & 75 & 3 & -1 \\
\hline $\mathrm{N}$ & -6.838148556 & -0.478371990 & -6.834273862 & $\mathrm{H}$ & 2.102919775 & -0.476429797 & -4.8 \\
\hline$c$ & -7.007090375 & 0.740960855 & -7.606746025 & $\mathrm{H}$ & -0.102338835 & -0.802460596 & -5.9 \\
\hline $\mathrm{C}$ & -7.898928084 & -1.462413228 & -6.930227316 & $\mathrm{H}$ & -2.208830432 & -0.673516373 & -4.616663369 \\
\hline $\mathrm{H}$ & 0.413926624 & -5.480301271 & 0.934777346 & $\mathrm{H}$ & -5.311726198 & -0.200568176 & -0.502863548 \\
\hline$H$ & 0.094138658 & -2.215131819 & 4.904640835 & $\mathrm{H}$ & 3.071491576 & 1.881814750 & -4.341294732 \\
\hline$H$ & -0.360310908 & -0.082107271 & 6.118178902 & $\mathrm{H}$ & 4.115417312 & 2.246678347 & -6.508593288 \\
\hline 11 & -0.484675612 & 2.063126925 & 4.879041212 & $\mathrm{H}$ & 7.051850105 & -0.805780962 & -5.576663144 \\
\hline & -0.400042436 & 5.301807806 & 0.701225716 & $\mathrm{H}$ & 5.970092243 & -1.164499468 & -3.421898822 \\
\hline & -0.653879069 & -5.962903418 & 3.506026210 & $\mathrm{H}$ & -5.529875141 & -2.163097162 & -2.757967997 \\
\hline
\end{tabular}




\begin{tabular}{|c|c|c|c|}
\hline & -6.897758210 & 2744 & -4 \\
\hline & -5.041599343 & 1.425945496 & -6.153038021 \\
\hline & -3.685932565 & 1.477154865 & -4.129069524 \\
\hline & 4.806100450 & 360 & 4 \\
\hline & 5.078228132 & -2.974340534 & 29 \\
\hline & 2.822361209 & 2.261252118 & 1.591877010 \\
\hline & 4.486114497 & 2.389695387 & 1.006565584 \\
\hline & 4.118143227 & 2.760490663 & 2.704271013 \\
\hline & 6.026135928 & -0.321432084 & 5.727 \\
\hline & 6.252166757 & -2.0 & 5.2 \\
\hline & 4.718019746 & 326 & 5. \\
\hline & 7756 & -3.7 & 1 \\
\hline & 4.436902777 & -2.662590897 & -0.2 \\
\hline & 3.076543003 & -3.233130885 & 0.736820770 \\
\hline & -4.331302745 & 2.917097762 & 3.643066073 \\
\hline & -4.065460444 & -1.246161718 & 4.657404898 \\
\hline & -4.288721821 & 3.611216622 & 1.458483329 \\
\hline & -4.230675411 & 2.456722665 & 0.10 \\
\hline & -2.729495998 & 542976 & 0.823064585 \\
\hline & -5.3 & 2.0 & 5. \\
\hline & -3.681689718 & 1.591548503 & 51357 \\
\hline & -4.946716464 & 0.341433784 & 6.312577533 \\
\hline & -4.123511889 & -2.490300824 & 1.429209237 \\
\hline & -3.688280368 & -2.860206635 & 3.112410031 \\
\hline & -2.427890925 & -2.449796824 & 1.928618582 \\
\hline & -3.602485342 & 8.277768763 & 5.387754053 \\
\hline & -4.282545020 & 8.127973787 & 7.022383046 \\
\hline & -4.864517234 & 7.049050791 & 5.723665494 \\
\hline & -4.019505404 & 5.150477798 & 7.578829478 \\
\hline & -3.534011039 & 6.596595863 & 8.51 \\
\hline & -2.326646481 & 5.362788840 & 8.10 \\
\hline & 3.570683215 & -6.880625881 & 8.588671923 \\
\hline & 3.563182106 & -5.226484810 & 7.960303620 \\
\hline & 4.227224831 & -6.548847384 & 6.958635090 \\
\hline & 1.781943227 & -8.584645273 & 6.649150126 \\
\hline & 0.426274892 & -7.780662570 & 7.4928019 \\
\hline & 1.894396267 & -8.196323365 & 8.390780017 \\
\hline & 7.829958843 & 0.524411187 & -8.820572734 \\
\hline & 7.056115261 & -0.920145596 & -8.10358651 \\
\hline
\end{tabular}

$\begin{array}{llll}\mathrm{H} & 8.182040428 & 0.083521820 & -7.141828171 \\ \mathrm{H} & 6.170892295 & 1.739931515 & -9.422002170 \\ \mathrm{H} & 5.160855370 & 2.600337558 & -8.252330534 \\ \mathrm{H} & 4.653283327 & 0.993067935 & -8.840698686 \\ \mathrm{H} & -6.045098829 & 1.107510774 & -7.999738165 \\ \mathrm{H} & -7.468857804 & 1.560717894 & -7.020256927 \\ \mathrm{H} & -7.651100058 & 0.531399239 & -8.470981847 \\ \mathrm{H} & -7.499558704 & -2.477949103 & -6.782733298 \\ \mathrm{H} & -8.336648788 & -1.426391508 & -7.936974168 \\ \mathrm{H} & -8.712699577 & -1.300617570 & -6.193645207\end{array}$

\section{fac-Ti ${ }^{\mathrm{III}}\left({ }^{\mathrm{Me}} \mathrm{PMP}{ }^{\mathrm{Me}}\right)_{3}$}

Ti $\quad 0.004794938 \quad 0.063147100 \quad-0.125939887$

$\begin{array}{llll}\mathrm{N} & -2.088888653 & 0.309164279 & -0.214744882\end{array}$

$\begin{array}{llll}\mathrm{N} & -0.774403234 & -2.026128550 & -0.136191722\end{array}$

$\begin{array}{llll}\text { C } & -2.954674211 & 1.351759769 & -0.259318906\end{array}$

$\begin{array}{lllll}\text { C } & -4.274145508 & 0.872381468 & -0.200414364\end{array}$

$\begin{array}{llll}\text { C } & -4.225448300 & -0.532255541 & -0.123593884\end{array}$

$\begin{array}{llll}\text { C } & -2.846954479 & -0.857764878 & -0.129338903\end{array}$

C $\quad-2.758258073 \quad-3.387363451 \quad-0.107900020$

$\begin{array}{llll}\text { C } & -1.979543595 & -4.531416057 & -0.130798324\end{array}$

$\begin{array}{llll}\text { C } & -0.578087439 & -4.421974607 & -0.171334292\end{array}$

$\begin{array}{llll}\text { C } & -0.034484195 & -3.145107962 & -0.174908030\end{array}$

$\begin{array}{llll}\text { C } & -5.425369175 & -1.433105706 & -0.066104057\end{array}$

$\begin{array}{llll}\text { C } & -2.510504248 & 2.779357130 & -0.354362544\end{array}$

$\begin{array}{llll}\text { C } & -0.668966308 & 0.156745578 & 4.906583699\end{array}$

$\begin{array}{llll}\text { C } & -0.181470103 & 1.238514029 & 4.191303763\end{array}$

C $\quad 0.086269671 \quad 1.107485245 \quad 2.806518100$

$\begin{array}{llll}\mathrm{N} & -0.158200970 & -0.081916984 & 2.174740942\end{array}$

$\begin{array}{llll}\text { C } & -0.630944074 & -1.117539953 & 2.884450058\end{array}$

$\begin{array}{llll}\text { C } & -0.891418685 & -1.061940502 & 4.248230020\end{array}$

$\begin{array}{llll}\text { C } & 1.536208133 & 3.959455898 & 1.018636459\end{array}$

$\begin{array}{llll}\text { C } & 1.187853166 & 3.039713996 & 0.022502195\end{array}$

$\begin{array}{llll}\mathrm{N} & 0.617757220 & 1.940111993 & 0.596517050\end{array}$

$\begin{array}{llll}\text { C } & 0.598931887 & 2.158798349 & 1.971556320\end{array}$

$\begin{array}{llll}\text { C } & 1.167739075 & 3.414944198 & 2.268173468\end{array}$

$\begin{array}{llll}\text { C } & 1.382095047 & 3.189911237 & -1.454220457\end{array}$

$\begin{array}{llll}\text { C } & 1.402905881 & 4.059339557 & 3.605708465\end{array}$

$\begin{array}{llll}\text { C } & -2.144225921 & -2.107456265 & -0.122301351\end{array}$ 


\begin{tabular}{|c|c|c|c|}
\hline & 1.859549479 & -0.114401740 & -3.5 \\
\hline & 1.726566376 & -0.220143606 & -2.549778067 \\
\hline & 0.389245288 & -0.031356725 & -2.181537729 \\
\hline & -0.318108646 & 0.150177890 & -3.336469633 \\
\hline & 0.552442049 & 0.115521013 & 57361 \\
\hline & 3.089161534 & -0.201323301 & 10811 \\
\hline & -1.803180924 & 0.323080554 & -3.3 \\
\hline & 4.885825771 & -0.926958960 & -0.6 \\
\hline & 4.336152926 & -0.951914707 & 0.6 \\
\hline & 2.967212959 & -0.752135618 & 4609 \\
\hline & 2.158466988 & -0.536210722 & -0.240709344 \\
\hline & 2.676016072 & -0.490382954 & -1 \\
\hline & 4.062950268 & -0.702047291 & -1.6 \\
\hline & -5.177798117 & 1.482387653 & -0.2 \\
\hline & -3.84 & -3.4 & -0 \\
\hline & -2.4 & -5.5 & -0.1 \\
\hline & 0.068909365 & -5.2 & -0 \\
\hline & 1.047538905 & 2662 & -0.2 \\
\hline & -6.348318243 & -0.833689040 & -0.051878399 \\
\hline & -5.436279552 & -2.069893124 & 0.836271459 \\
\hline & -5.490510066 & -2.108207768 & -0.938270924 \\
\hline & -3.361241965 & 3.430897303 & -0.603621469 \\
\hline & -1.739685065 & 2.916828050 & -1.129049144 \\
\hline & -2.066881734 & 3.138478928 & 0.58 \\
\hline & -0 & 8 & 9 \\
\hline & -0.021766652 & 2.196131449 & 4.682 \\
\hline & -0.812517281 & -2.035566053 & 2.324918820 \\
\hline & -1.276075037 & -1.939096483 & 4.770524907 \\
\hline & 2.017458426 & 4.923464921 & 0.853143906 \\
\hline & 2.031731023 & 2.405353831 & -1.871239059 \\
\hline & 1.839802084 & 4.164517220 & -1.680454383 \\
\hline & 0.429771854 & 3.124896090 & -2.005696731 \\
\hline & 2.010868890 & 4.969504378 & 3.493059963 \\
\hline & 1.939263082 & 3.391057919 & 4.301357537 \\
\hline & 0.464316829 & 4.359201447 & 4.105549535 \\
\hline & 0.264395303 & 0.244071701 & -5.473623011 \\
\hline & 2.830142140 & -0.011122614 & -5.858977797 \\
\hline & 3.569814073 & -1.194898662 & -4.760868126 \\
\hline & 3.853712885 & 0.541866857 & -4.521218248 \\
\hline
\end{tabular}

$$
\begin{array}{lrrr}
\mathrm{H} & -2.139157241 & 1.259330149 & -2.924398500 \\
\mathrm{H} & -2.335230170 & -0.489998925 & -2.878960231 \\
\mathrm{H} & -2.132716008 & 0.334806323 & -4.445194438 \\
\mathrm{H} & 5.956827431 & -1.087477897 & -0.759922057 \\
\mathrm{H} & 4.949907296 & -1.123747097 & 1.568849133 \\
\mathrm{H} & 2.480838606 & -0.757799664 & 1.785680509 \\
\mathrm{H} & 4.477841047 & -0.675289387 & -2.705220447
\end{array}
$$$$
\text { mer-Ti }{ }^{\mathrm{III}}\left({ }^{\mathrm{Me}} \mathrm{PMP}{ }^{\mathrm{Me}}\right)_{3}
$$$$
\begin{array}{llll}
\text { Ti } & 0.191264919 & 0.159375964 & 0.130970146
\end{array}
$$$$
\begin{array}{llll}
\mathrm{N} & -1.886987114 & 0.280328795 & -0.192869462
\end{array}
$$

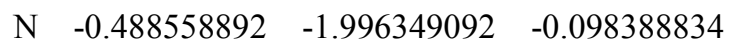$$
\begin{array}{llll}
\text { C } & -2.802216504 & 1.293239527 & -0.233028836
\end{array}
$$$$
\begin{array}{llll}
\text { C } & -4.092863603 & 0.753752895 & -0.265887301
\end{array}
$$$$
\begin{array}{llll}
\text { C } & -3.983145471 & -0.653847663 & -0.244764427
\end{array}
$$$$
\begin{array}{llll}
\text { C } & -2.599485818 & -0.919609197 & -0.206606257
\end{array}
$$$$
\begin{array}{llll}
\text { C } & -2.404820765 & -3.444448730 & -0.254303294
\end{array}
$$$$
\text { C } \quad-1.576289349 \quad-4.556397570 \quad-0.236327696
$$$$
\text { C } \quad-0.186856295 \quad-4.381515081 \quad-0.161307497
$$$$
\begin{array}{lllll}
\text { C } & 0.301928449 & -3.081006750 & -0.097561654
\end{array}
$$$$
\begin{array}{llll}
\text { C } & -5.140791377 & -1.609899575 & -0.254095043
\end{array}
$$$$
\begin{array}{llll}
\text { C } & -2.429061975 & 2.744595162 & -0.239242863
\end{array}
$$$$
\begin{array}{llll}
\text { C } & -0.818475052 & 0.366419559 & 5.005727458
\end{array}
$$$$
\begin{array}{llll}
\text { C } & -0.354620425 & 1.460678316 & 4.295295995
\end{array}
$$$$
\begin{array}{llll}
\text { C } & -0.012604880 & 1.322988803 & 2.926336108
\end{array}
$$$$
\begin{array}{llll}
\mathrm{N} & -0.154600529 & 0.103752818 & 2.318602526
\end{array}
$$$$
\begin{array}{llll}
\text { C } & -0.610266195 & -0.946085754 & 3.020798060
\end{array}
$$$$
\begin{array}{llll}
\text { C } & -0.950281084 & -0.876391465 & 4.364329941
\end{array}
$$$$
\begin{array}{llll}
\text { C } & 1.346381493 & 4.225194980 & 1.150085501
\end{array}
$$$$
\begin{array}{llll}
\text { C } & 1.225406546 & 3.223738901 & 0.179266410
\end{array}
$$$$
\begin{array}{llll}
\mathrm{N} & 0.693990582 & 2.101827555 & 0.739234613
\end{array}
$$$$
\begin{array}{llll}
\text { C } & 0.483427501 & 2.381728314 & 2.091918902
\end{array}
$$$$
\begin{array}{llll}
\text { C } & 0.877329560 & 3.706256582 & 2.376171403
\end{array}
$$$$
\begin{array}{llll}
\text { C } & 1.617789071 & 3.309141474 & -1.262778218
\end{array}
$$$$
\begin{array}{lllll}
\text { C } & 0.864926869 & 4.444231277 & 3.684030271
\end{array}
$$$$
\begin{array}{llll}
\text { C } & -1.845401823 & -2.145268635 & -0.189794622
\end{array}
$$$$
\begin{array}{llll}
\text { C } & 1.059718973 & 0.042157542 & -4.804220451
\end{array}
$$$$
\begin{array}{llll}
\text { C } & 1.980828544 & -0.420485222 & -3.876577349
\end{array}
$$$$
\begin{array}{llll}
\text { C } & 1.690834816 & -0.338289644 & -2.494042956
\end{array}
$$ 


$$
\begin{array}{lrrr}
\mathrm{N} & 0.504484637 & 0.201821073 & -2.082010321 \\
\mathrm{C} & -0.384816914 & 0.629812130 & -2.990924474 \\
\mathrm{C} & -0.157568750 & 0.580208557 & -4.360756299 \\
\mathrm{C} & 4.183598114 & -1.552221741 & -0.088935637 \\
\mathrm{C} & 3.822098357 & -1.418982836 & -1.448634683 \\
\mathrm{C} & 2.570487720 & -0.771497574 & -1.439182556 \\
\mathrm{~N} & 2.171638345 & -0.527966802 & -0.124728461 \\
\mathrm{C} & 3.161952250 & -0.993322591 & 0.688593977 \\
\mathrm{C} & 3.116647634 & -0.872793843 & 2.179914291 \\
\mathrm{C} & 4.635382340 & -1.897900003 & -2.617030121 \\
\mathrm{H} & -5.022098803 & 1.323423201 & -0.298513340 \\
\mathrm{H} & -3.483563205 & -3.566566659 & -0.325949982 \\
\mathrm{H} & -2.010321491 & -5.559091002 & -0.286371967 \\
\mathrm{H} & 0.501472810 & -5.227750989 & -0.152944948 \\
\mathrm{H} & 1.374350686 & -2.883246044 & -0.036137597 \\
\mathrm{H} & -6.091632282 & -1.056075379 & -0.226451718 \\
\mathrm{H} & -5.133056169 & -2.289593500 & 0.616323531 \\
\mathrm{H} & -5.05 \\
\mathrm{H} & -5.160259603 & -2.244905467 & -1.158179475 \\
\mathrm{H} & -3.305883244 & 3.359365883 & -0.491462230 \\
\mathrm{H} & -1.640005737 & 2.965719899 & -0.973619620 \\
\mathrm{H} & -2.042810445 & 3.081156763 & 0.737002676 \\
\mathrm{H} & -1.092507600 & 0.477980071 & 6.058426390 \\
\mathrm{H} & -0.258105031 & 2.429081214 & 4.781220695 \\
\mathrm{H} & -0.707475077 & -1.881862696 & 2.467322498 \\
\mathrm{H} & -1.317330254 & -1.760157472 & 4.887892151 \\
\mathrm{H} & 1.754980748 & 5.223053232 & 0.989073458 \\
\mathrm{H} & 2.278495917 & 2.477010793 & -1.550846614 \\
\mathrm{H} & 2.151082044 & 4.251295888 & -1.458557701 \\
\mathrm{H} & 0.745375094 & 3.271086555 & -1.937379215 \\
\mathrm{H} & 1.331952657 & 5.434231104 & 3.572220085 \\
\mathrm{H} & -0.156777906 & 4.607825108 & 4.070445170 \\
\mathrm{H} & -1.234319982 & 2.619174735 \\
\hline & -1.457589006 & 2.627836741
\end{array}
$$

$$
\begin{array}{llll}
\mathrm{H} & 2.968850541 & 0.172790099 & 2.496306453 \\
\mathrm{H} & 5.513122853 & -2.463050410 & -2.268464577 \\
\mathrm{H} & 5.012162488 & -1.066461452 & -3.239915428 \\
\mathrm{H} & 4.059397856 & -2.564325456 & -3.282975214
\end{array}
$$$$
\text { fac- }\left[\mathrm{Ti}^{\mathrm{IV}}\left({ }^{\mathrm{Me}} \mathbf{P M P}{ }^{\mathrm{Me}}\right)_{3}\right]^{+}
$$$$
\begin{array}{llll}
\mathrm{Ti} & -0.076295526 & 0.108066281 & -0.138192727
\end{array}
$$$$
\begin{array}{llll}
\mathrm{N} & -2.056300004 & 0.286000025 & -0.186263896
\end{array}
$$$$
\begin{array}{llll}
\mathrm{N} & -0.746934468 & -2.015663489 & -0.167143750
\end{array}
$$$$
\begin{array}{lllll}
\text { C } & -2.940129017 & 1.354246060 & -0.157812605
\end{array}
$$$$
\begin{array}{llll}
\text { C } & -4.233525907 & 0.860383792 & -0.117879630
\end{array}
$$$$
\begin{array}{llll}
\text { C } & -4.184816064 & -0.563645038 & -0.114482840
\end{array}
$$$$
\begin{array}{llll}
\text { C } & -2.826826986 & -0.891816336 & -0.157499821
\end{array}
$$$$
\begin{array}{llll}
\text { C } & -2.701620314 & -3.418978240 & -0.217256628
\end{array}
$$$$
\begin{array}{llll}
\text { C } & -1.897668320 & -4.547686330 & -0.257787217
\end{array}
$$$$
\begin{array}{llll}
\text { C } & -0.501040572 & -4.402637513 & -0.270524548
\end{array}
$$$$
\begin{array}{llll}
\text { C } & 0.021683203 & -3.118690766 & -0.227905157
\end{array}
$$$$
\begin{array}{llll}
\text { C } & -5.385049925 & -1.460923103 & -0.073957796
\end{array}
$$$$
\begin{array}{llll}
\text { C } & -2.516511670 & 2.787063725 & -0.189144660
\end{array}
$$$$
\begin{array}{llll}
\text { C } & -0.448432329 & 0.148032777 & 4.848925170
\end{array}
$$$$
\begin{array}{llll}
\text { C } & -0.032606548 & 1.240844114 & 4.105034173
\end{array}
$$$$
\begin{array}{llll}
\text { C } & 0.145273770 & 1.112148642 & 2.708940014
\end{array}
$$$$
\begin{array}{llll}
\mathrm{N} & -0.110486574 & -0.082093625 & 2.094315626
\end{array}
$$$$
\text { C } \quad-0.519337993 \quad-1.133549441 \quad 2.829692804
$$$$
\begin{array}{llll}
\text { C } & -0.690349759 & -1.075404104 & 4.204467461
\end{array}
$$$$
\begin{array}{llll}
\text { C } & 1.405430285 & 3.969346936 & 0.782097758
\end{array}
$$$$
\begin{array}{llll}
\text { C } & 1.044444603 & 3.043963835 & -0.182751712
\end{array}
$$$$
\begin{array}{llll}
\mathrm{N} & 0.526108090 & 1.918630078 & 0.445392113
\end{array}
$$$$
\begin{array}{llll}
\text { C } & 0.578497742 & 2.166354973 & 1.833290804
\end{array}
$$$$
\begin{array}{llll}
\text { C } & 1.119642232 & 3.431616152 & 2.070117616
\end{array}
$$$$
\begin{array}{llll}
\text { C } & 1.173753249 & 3.196040725 & -1.663216191
\end{array}
$$$$
\begin{array}{llll}
\text { C } & 1.399790630 & 4.115365620 & 3.376051849
\end{array}
$$$$
\begin{array}{llll}
\text { C } & -2.109527787 & -2.136684124 & -0.179980667
\end{array}
$$$$
\begin{array}{llll}
\text { C } & 1.889154841 & -0.049966637 & -3.797550092
\end{array}
$$$$
\text { C } \quad 1.724671878 \quad-0.178085762 \quad-2.416014100
$$$$
\begin{array}{llll}
\mathrm{N} & 0.380983137 & 0.070996595 & -2.072822470
\end{array}
$$$$
\begin{array}{llll}
\text { C } & -0.304732782 & 0.305637471 & -3.256856962
\end{array}
$$$$
\begin{array}{lllll}
\text { C } & 0.593780686 & 0.250645701 & -4.308664317
\end{array}
$$$$
\text { C } \quad 3.129862366 \quad-0.179968101 \quad-4.628770096
$$ 


\begin{tabular}{|c|c|c|c|c|c|c|c|}
\hline $\mathrm{C}$ & -1.775926463 & 0.548847822 & -3.347723510 & $\mathrm{H}$ & 22383 & 55084 & -2 \\
\hline$C$ & 4.748940960 & -1.137000666 & -0.375421458 & & & & \\
\hline & 4.133340929 & -1.207795477 & 9647 & & & & \\
\hline & 2.775725113 & -0.937065028 & 0.963377241 & \multicolumn{4}{|c|}{$m e r-\left[\mathrm{Ti}^{\mathrm{IV}}\left({ }^{\mathrm{Me}} \mathbf{P M P} \mathrm{Pe}^{\mathrm{Me}}\right)_{3}\right]^{+}$} \\
\hline & 2.029701598 & -0.618979584 & -0.110542909 & $\mathrm{Ti}$ & 0.222391561 & 0.176430115 & 0.083663608 \\
\hline & 2.614423943 & -0.535283031 & -1.344358032 & $\mathrm{~N}$ & -1.782376363 & 0.389392250 & -0.202438079 \\
\hline & 3.993847791 & -0.801991725 & -1.488488003 & $\mathrm{~N}$ & -0.460768112 & -1.902286471 & -0.039537959 \\
\hline & -5.141304582 & 1.462830388 & -0.098143122 & $\mathrm{C}$ & -2.672903708 & 1.440408238 & -0.279121489 \\
\hline & -3.785560645 & -3.514152022 & -0.220485902 & $\mathrm{C}$ & -3.968282949 & 0.934245278 & -0.323503634 \\
\hline & -2.353779272 & -5.540572347 & -0.28 & $\mathrm{C}$ & -3.907947128 & -0.482242928 & 2921 \\
\hline & 0.165100995 & -5.264872553 & -0.3 & $\mathrm{C}$ & 71 & -0.79430 & 444 \\
\hline & 1.099343389 & -2.949544589 & -0.239202703 & $\mathrm{C}$ & -2.398627351 & -3.320315650 & -0.2 \\
\hline & -6.305590129 & -0.864958313 & 0.001 & $\mathrm{C}$ & -1.588056303 & -4.442072269 & -0 . \\
\hline & -5.363658299 & -2.146903554 & 0.789950159 & $\mathrm{C}$ & -0.193709225 & -4.288706182 & -0.067124110 \\
\hline & -5.469991644 & -2.081900551 & -0.982546879 & $\mathrm{C}$ & 0.319940523 & -3.003571688 & -0.010742642 \\
\hline & -3.395588105 & 3.430298489 & -0.332603374 & $\mathrm{C}$ & -5.098658108 & -1.393489245 & -0.286187329 \\
\hline & -1.811615697 & 2.993712907 & -1.009024226 & $\mathrm{C}$ & -2.271389233 & 2.881027688 & -0.313009576 \\
\hline & -2.017452434 & 3.094108699 & 0.744318444 & $\mathrm{C}$ & -0.726112704 & 0.078950995 & 4.973043495 \\
\hline & -0.597964415 & 0.246667559 & 5.927033664 & $\mathrm{C}$ & -0.392173084 & 1.234129793 & 4.285554620 \\
\hline & 0.1 & 2.20 & 4.58 & $\mathrm{C}$ & -0.059886808 & 1.164375973 & 2.914631035 \\
\hline & -0.71 & -2.0 & 2. & $\mathrm{~N}$ & -0. & -0 & 79 \\
\hline & -1.021905579 & -1.958077924 & 4.752650422 & $\mathrm{C}$ & -0.430104705 & -1.152438363 & 64474 \\
\hline & 1.846422406 & 4.945724403 & 0.584652076 & $\mathrm{C}$ & -0.739876034 & -1.148636674 & 4.292465865 \\
\hline & 1.846844682 & 2.444051057 & -2.100539813 & $\mathrm{C}$ & 1.215472263 & 4.135481627 & 1.180837771 \\
\hline & 1.580926898 & 4.189791657 & -1.897826394 & $\mathrm{C}$ & 1.185448604 & 3.143818059 & 0.211440293 \\
\hline & 0.207949878 & 3.096109663 & -2.182824371 & $\mathrm{~N}$ & 0.642494084 & 1.998656233 & 0.766518866 \\
\hline & 1.985200510 & 5.031542296 & 3.215453735 & $\mathrm{C}$ & 0.361568192 & 2.276904379 & 2.111669591 \\
\hline & 1.972372785 & 3.471954463 & 4.064092285 & $\mathrm{C}$ & 0.699203426 & 3.604694042 & 2.397714010 \\
\hline & 0.472883781 & 4.410104560 & 3.898202133 & $\mathrm{C}$ & 1.656452980 & 3.223056900 & -1.204642758 \\
\hline & 0.344512220 & 0.409620750 & -5.357843644 & $\mathrm{C}$ & 0.604249779 & 4.346688270 & 3.6974 \\
\hline & 2.906213310 & 0.028548483 & -5.684890819 & $\mathrm{C}$ & -1.819808748 & -2.030619819 & -0.158446517 \\
\hline & 3.564060601 & -1.193329641 & -4.576256002 & $\mathrm{C}$ & 0.920875609 & -0.122479260 & -4.802476412 \\
\hline H & 3.913629016 & 0.529650514 & -4.315220002 & $\mathrm{C}$ & 1.872230701 & -0.554197040 & -3.893914366 \\
\hline $\mathrm{H}$ & -2.083037315 & 1.485572833 & -2.857233812 & $\mathrm{C}$ & 1.632685484 & -0.414845476 & -2.508634780 \\
\hline $\mathrm{H}$ & -2.359359667 & -0.260588740 & -2.882597256 & $\mathrm{~N}$ & 0.457099935 & 0.142682714 & -2.069707940 \\
\hline $\mathrm{H}$ & -2.070686441 & 0.614414191 & -4.404246359 & $\mathrm{C}$ & -0.471551938 & 0.539373540 & -2.969320480 \\
\hline $\mathrm{H}$ & 5.815401949 & -1.348917060 & -0.484287326 & $\mathrm{C}$ & -0.281280622 & 0.439852420 & -4.335711880 \\
\hline 11 & 4.693425362 & -1.468635185 & 1.782853911 & $\mathrm{C}$ & 4.190764640 & -1.419210417 & -0.082306785 \\
\hline & 2.248920283 & -0.975073141 & 1.917539046 & $\mathrm{C}$ & 3.806395113 & -1.395124776 & -1.44862104 \\
\hline
\end{tabular}




\begin{tabular}{|c|c|c|c|}
\hline & 532 & 412 & -1. \\
\hline & 2.145927312 & -0.467105783 & -0.163514965 \\
\hline & 3.174691341 & -0.843373682 & 0.675690969 \\
\hline & 3.161069648 & -0.620256427 & 2.152893898 \\
\hline & 4.623770363 & -1.915229214 & 04371 \\
\hline & -4.879098937 & 513 & 0492 \\
\hline & -3.477683053 & -3.424182159 & 8387 \\
\hline & -2.034905478 & -5.438677553 & -0.208961884 \\
\hline & 0.477181213 & -5.147947136 & -0.037305440 \\
\hline & 1.393296039 & -2.825753233 & 0.067606446 \\
\hline & -6.028228371 & -0.806386997 & -0.285683649 \\
\hline & -5.124367397 & -2.051001352 & 0.599665575 \\
\hline & -5.12 & -2 & -1 \\
\hline & -3.1 & 3. & -0 \\
\hline & -1.489514830 & 3.0805 & -1.0 \\
\hline & -1.878198986 & 6487 & 7629 \\
\hline & -0.984970841 & 0.128346724 & 6.033442835 \\
\hline & -0.378978991 & 2.195934950 & 4.794021160 \\
\hline & -0.442222185 & -2.081310922 & 2.375026551 \\
\hline & -0.998059940 & -2.080784384 & 4.796350971 \\
\hline & 1.59 & 26 & 1.0 \\
\hline & 2.359242072 & & \\
\hline & 2.172707506 & 4.177833802 & -1.377357102 \\
\hline & 0.825864362 & 3.158395135 & -1.928613896 \\
\hline & 1.016541104 & 5.360048072 & 3.595921947 \\
\hline & 1.168489644 & 3.843534147 & 4.499689188 \\
\hline & -0.437808718 & 4.447125979 & 4.045828022 \\
\hline & 1.109247058 & -0.222705904 & -5.874645496 \\
\hline & 2.807390707 & -0.990825919 & -4.238402099 \\
\hline & -1.393938638 & 0.942216133 & -2.553438520 \\
\hline & -1.057526375 & 0.785935481 & -5.018750187 \\
\hline & 5.130618620 & -1.806576366 & 0.309968943 \\
\hline & 4.138370001 & -0.886205325 & 2.579570355 \\
\hline & 2.402661354 & -1.231397872 & 2.666461096 \\
\hline & 2.949574962 & 0.431811441 & 2.401679807 \\
\hline & 5.494980572 & -2.474117954 & -2.222507479 \\
\hline & 5.007370496 & -1.098622807 & -3.229386316 \\
\hline & 4.044550201 & -2.592990257 & -3.241740081 \\
\hline
\end{tabular}

\begin{tabular}{|c|c|c|c|}
\hline \multicolumn{4}{|c|}{$\left({ }^{\mathrm{Me}} \mathrm{PMP}{ }^{\mathrm{Me}}\right)_{2} \mathrm{ZrCl}_{2}$} \\
\hline $\mathrm{Zr}$ & -0.115569431 & -0.171135831 & -0.060921777 \\
\hline $\mathrm{Cl}$ & -0.070704576 & 0.450437708 & -2.394732521 \\
\hline $\mathrm{Cl}$ & -0.352890781 & -2.567372072 & -0.160168077 \\
\hline $\mathrm{N}$ & -2.156833016 & 0.552370576 & 0.367 \\
\hline $\mathrm{N}$ & 0.011706008 & -0.287495094 & 52 \\
\hline $\mathrm{N}$ & 0.022325069 & 2.142378067 & 0.52 \\
\hline $\mathrm{N}$ & 2.012098496 & -0.1158 & 21 \\
\hline $\mathrm{C}$ & 1.163227786 & 2.847813780 & 0.612542135 \\
\hline $\mathrm{C}$ & -2.338 & 1.90 & 2946 \\
\hline $\mathrm{C}$ & -4.369336208 & 0.961102106 & 0.547265410 \\
\hline $\mathrm{C}$ & -3.406255547 & -0.017043249 & 0.301388792 \\
\hline $\mathrm{C}$ & -0.017454797 & 4.829557833 & 1.233825961 \\
\hline $\mathrm{C}$ & -3.710739959 & 2.19175 & 0146 \\
\hline $\mathrm{C}$ & -4.3 & 3.5 & 1.03 \\
\hline $\mathrm{C}$ & 1.2 & 4.1 & 0.958 \\
\hline $\mathrm{C}$ & 35606 & 2.7 & 0.7 \\
\hline $\mathrm{C}$ & -1.201056308 & 4.113993537 & 1.149037566 \\
\hline $\mathrm{C}$ & -3.656813130 & -1.460241760 & -0.007771445 \\
\hline $\mathrm{C}$ & -0.933361277 & -0.481902616 & 4.523397182 \\
\hline $\mathrm{C}$ & 2.338007032 & -0.083069599 & 1.891603509 \\
\hline $\mathrm{C}$ & 3.723403342 & 0.094332217 & 2.045622267 \\
\hline $\mathrm{C}$ & 9840 & -0.4 & 3.1 \\
\hline $\mathrm{C}$ & 1. & $-c$ & 4 \\
\hline $\mathrm{C}$ & 0.35 & -0.42181 & 5.080267378 \\
\hline $\mathrm{C}$ & 1.271434495 & -0.222586408 & 2.846013942 \\
\hline $\mathrm{C}$ & 4.242166706 & 0.165785062 & 0.731490479 \\
\hline $\mathrm{C}$ & 3.185695817 & 0.031260683 & -0.168945609 \\
\hline $\mathrm{C}$ & 4.540499819 & 0.191316243 & 3.301380204 \\
\hline $\mathrm{C}$ & 3.274700701 & 0.030490146 & -1.662327430 \\
\hline $\mathrm{H}$ & 2.080153722 & 2.300995957 & 0.392092048 \\
\hline $\mathrm{H}$ & -5.448013838 & 0.800918818 & 0.542783005 \\
\hline $\mathrm{H}$ & -0.037344028 & 5.881515048 & 1.530573539 \\
\hline $\mathrm{H}$ & -4.192396008 & 3.888909844 & 2.049064565 \\
\hline $\mathrm{H}$ & -5.481141379 & 3.400354390 & 0.927780605 \\
\hline $\mathrm{H}$ & -4.067609461 & 4.285588037 & 0.323301366 \\
\hline $\mathrm{H}$ & 2.154735893 & 4.715561499 & 1.020246631 \\
\hline $\mathrm{H}$ & -2.148502129 & 4.593591147 & 1.378575362 \\
\hline $\mathrm{H}$ & -3.359233258 & -1.721516424 & -1.037380321 \\
\hline
\end{tabular}




$\begin{array}{llll}\mathrm{H} & -4.728783825 & -1.680213910 & 0.102550142 \\ \mathrm{H} & -3.099224610 & -2.137701155 & 0.656465729 \\ \mathrm{H} & -1.826409991 & -0.584294226 & 5.140825891 \\ \mathrm{H} & -2.021707001 & -0.446307352 & 2.654133995 \\ \mathrm{H} & 2.455458168 & -0.250746691 & 4.664712285 \\ \mathrm{H} & 0.494345997 & -0.480421045 & 6.163135270 \\ \mathrm{H} & 5.291001319 & 0.291484260 & 0.461298785 \\ \mathrm{H} & 5.585693185 & 0.434968266 & 3.058194711 \\ \mathrm{H} & 4.549470770 & -0.755886571 & 3.869479271 \\ \mathrm{H} & 4.172532314 & 0.976429645 & 3.983605500 \\ \mathrm{H} & 2.825385347 & -0.874482585 & -2.103250211 \\ \mathrm{H} & 4.329719986 & 0.071536738 & -1.969084499 \\ \mathrm{H} & 2.755497166 & 0.889362398 & -2.117197662\end{array}$

\section{$\left({ }^{\mathrm{Me}} \mathrm{PMP}{ }^{\mathrm{Me}}\right)_{2} \mathrm{Zr}\left(\mathrm{NMe}_{2}\right)_{2}$}

Zr $\quad-0.311047793 \quad-0.101791057 \quad-0.270030592$

$\begin{array}{llll}\mathrm{N} & 0.471796682 & -2.020081531 & 0.636620353\end{array}$

$\begin{array}{llll}\mathrm{N} & 2.068780937 & 0.496822450 & -0.170344909\end{array}$

$\begin{array}{llll}\mathrm{N} & 0.021136455 & 0.188223646 & 2.159451594\end{array}$

$\begin{array}{llll}\mathrm{N} & -0.088633225 & 2.153740927 & -0.182072726\end{array}$

$\begin{array}{llll}\text { C } & -0.234662331 & 1.316221313 & 2.837480081\end{array}$

$\begin{array}{llll}\text { C } & 0.820366391 & -2.051622660 & 1.990282818\end{array}$

$\begin{array}{llll}\text { C } & 1.320533616 & -4.059612228 & 1.117947375\end{array}$

$\begin{array}{llll}\text { C } & 0.779510027 & -3.248120680 & 0.117774635\end{array}$

$\begin{array}{llll}\text { C } & 0.668482425 & 0.410187894 & 4.853310113\end{array}$

$\begin{array}{llll}\text { C } & 1.352710073 & -3.316431976 & 2.317882194\end{array}$

$\begin{array}{llll}\text { C } & 1.855600622 & -3.835917312 & 3.635357453\end{array}$

$\begin{array}{llll}\text { C } & 0.055241358 & 1.479683019 & 4.186533355\end{array}$

$\begin{array}{llll}\text { C } & 0.597634833 & -0.873583097 & 2.794769398\end{array}$

C $\quad 0.938635461 \quad-0.763996919 \quad 4.165615637$

$\begin{array}{llll}\text { C } & 0.540203033 & -3.629634029 & -1.310704537\end{array}$

C $\quad 4.413823050 \quad-0.023382355 \quad-0.111924820$

$\begin{array}{llll}\text { C } & 1.190527251 & 2.710877279 & -0.099891747\end{array}$

$\begin{array}{llll}\text { C } & 1.095391595 & 4.115617456 & -0.010340227\end{array}$

$\begin{array}{llll}\text { C } & 3.074545702 & -0.388987029 & -0.177010889\end{array}$

$\begin{array}{llll}\text { C } & 3.681632788 & 2.270417315 & -0.010004196\end{array}$

$\begin{array}{llll}\text { C } & 4.712073923 & 1.343172797 & -0.022521047\end{array}$

$\begin{array}{llll}\text { C } & 2.335991164 & 1.833397615 & -0.091916833\end{array}$

$\begin{array}{llll}\text { C } & -0.285739399 & 4.400765518 & -0.026033026\end{array}$ $\begin{array}{llll}\text { C } & -0.977068237 & 3.190144437 & -0.129725475\end{array}$

$\begin{array}{llll}\text { C } & 2.181575016 & 5.148297958 & 0.082285302\end{array}$

$\begin{array}{llll}\text { C } & -2.462422471 & 3.009181255 & -0.175723546\end{array}$

$\begin{array}{llll}\mathrm{N} & -0.169437280 & -0.291827515 & -2.348893203\end{array}$

$\begin{array}{llll}\mathrm{N} & -2.338593460 & -0.544723369 & -0.032484736\end{array}$

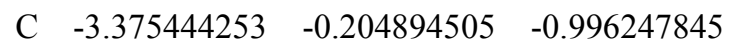

$\begin{array}{llll}\text { C } & -2.911824487 & -1.252049538 & 1.105317888\end{array}$

$\begin{array}{llll}\text { C } & -0.991622194 & -1.173620451 & -3.164207512\end{array}$

$\begin{array}{llll}\text { C } & 0.723020071 & 0.482691133 & -3.201740967\end{array}$

$\begin{array}{llll}\mathrm{H} & -0.683280069 & 2.124018627 & 2.257631365\end{array}$

H $\quad 1.657254719 \quad-5.088636123 \quad 0.989383420$

$\mathrm{H} \quad 0.942230069 \quad 0.497673362 \quad 5.908341379$

$\mathrm{H} \quad 2.692909215 \quad-3.239092773 \quad 4.035214504$

H $\quad 2.221468578 \quad-4.868375578 \quad 3.527002540$

$\mathrm{H} \quad 1.068070646 \quad-3.847450658 \quad 4.409593400$

$\begin{array}{llll}\mathrm{H} & -0.183367822 & 2.417029690 & 4.691530883\end{array}$

H $\quad 1.417518346 \quad-1.597496497 \quad 4.673440512$

H $\quad-0.535060455 \quad-3.736632406 \quad-1.537433362$

H $\quad 1.021482899 \quad-4.594349139 \quad-1.529758310$

$\mathrm{H} \quad 0.943120170 \quad-2.881861460 \quad-2.010095178$

H $\quad 5.193659093 \quad-0.786123357 \quad-0.122644954$

H $\quad 2.778486112 \quad-1.438970118 \quad-0.229494532$

$\begin{array}{llll}\mathrm{H} & 3.906112863 & 3.331403514 & 0.066144253\end{array}$

$\begin{array}{llll}\mathrm{H} & 5.749533845 & 1.684077534 & 0.041518083\end{array}$

$\begin{array}{llll}\mathrm{H} & -0.738381931 & 5.391523898 & 0.027975585\end{array}$

$\begin{array}{llll}\mathrm{H} & 1.743004693 & 6.157819841 & 0.091532214\end{array}$

$\mathrm{H} \quad 2.882329440 \quad 5.102799235 \quad-0.769875808$

$\begin{array}{llll}\mathrm{H} & 2.786740667 & 5.046945745 & 1.000979944\end{array}$

H $\quad-2.824015943 \quad 2.780642957 \quad-1.192960534$

$\begin{array}{llll}\mathrm{H} & -2.965373855 & 3.930455735 & 0.154282384\end{array}$

$\begin{array}{llll}\mathrm{H} & -2.796259626 & 2.187516597 & 0.475540482\end{array}$

$\mathrm{H} \quad-4.168017458 \quad 0.425564327 \quad-0.543437176$

$\mathrm{H} \quad-3.877029356 \quad-1.112258240 \quad-1.393179583$

H $\quad-2.960973218 \quad 0.351082761 \quad-1.850217098$

$\mathrm{H} \quad-3.636890800 \quad-0.620669104 \quad 1.659145124$

$\mathrm{H} \quad-2.132778473 \quad-1.571766226 \quad 1.810434958$

H $\quad-3.458389192 \quad-2.160151529 \quad 0.779110345$

H $\quad-1.650196118-1.797749962 \quad-2.544197109$

H $\quad-0.369191716 \quad-1.857031642 \quad-3.778830339$ 


$$
\begin{array}{cccc}
\mathrm{H} & -1.628671558 & -0.599924188 & -3.870014609 \\
\mathrm{H} & 0.151233114 & 1.085556765 & -3.937309741 \\
\mathrm{H} & 1.405845281 & -0.173947692 & -3.781547346 \\
\mathrm{H} & 1.341460504 & 1.177170345 & -2.617175049
\end{array}
$$

\begin{tabular}{|c|c|c|c|}
\hline$C$ & -3.283438212 & 2.121735883 & 79464 \\
\hline $\mathrm{C}$ & -2.343922361 & 1.118247502 & -3.895941306 \\
\hline $\mathrm{H}$ & 0.345435937 & -2.949142423 & -0.945224483 \\
\hline $\mathrm{H}$ & 3.482429502 & 4.000174381 & -0.042181942 \\
\hline $\mathrm{H}$ & 4.638647837 & -3.341941309 & 183741 \\
\hline 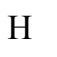 & 5.473550670 & 7 & 0.4 \\
\hline 11 & 5.655683736 & 2.540503755 & -0.028699524 \\
\hline $\mathrm{H}$ & 5.5378 & 1.25 & 8494 \\
\hline $\mathrm{H}$ & 2.344756155 & -4.415173091 & 17712 \\
\hline $\mathrm{H}$ & 4.807439602 & -0.901337028 & 4908 \\
\hline $\mathrm{H}$ & -0.009081485 & 3.903655875 & -1.088120888 \\
\hline $\mathrm{H}$ & 0.955 & 4.806 & 0.109131172 \\
\hline $\mathrm{H}$ & -0.230369138 & 3.579541349 & 0.630676158 \\
\hline $\mathrm{H}$ & 2.216051180 & 1.394279157 & 4.480998782 \\
\hline $\mathrm{H}$ & 312507 & 1.749878621 & 5564 \\
\hline $\mathrm{H}$ & 044268 & 33994 & 8859 \\
\hline H & 1.497616335 & -0.71 & 5.702231860 \\
\hline $\mathrm{H}$ & -3.324285000 & -4.254815749 & 1.176110900 \\
\hline $\mathrm{H}$ & -2.660341265 & -4.617595476 & 3.676556994 \\
\hline $\mathrm{H}$ & -2.202405091 & -3.137615474 & 4.542318827 \\
\hline $\mathrm{H}$ & -0.950792706 & -4.269721302 & 3.987236266 \\
\hline $\mathrm{H}$ & -3.463903102 & -1.483591044 & -1.302461716 \\
\hline $\mathrm{H}$ & -3.647624703 & -3.253137016 & 64617 \\
\hline $\mathrm{H}$ & -2.16 & -2.5 & -1 \\
\hline $\mathrm{H}$ & -3.689089 & 6 & -1.067 \\
\hline $\mathrm{H}$ & -4.503830828 & 3.735203809 & -3.435464210 \\
\hline $\mathrm{H}$ & -3.639668046 & 2.243158973 & -5.218678531 \\
\hline$H$ & -1.954051371 & 0.453378906 & -4.670312617 \\
\hline \multicolumn{4}{|c|}{$\mathbf{N b}^{\mathrm{IV}}\left({ }^{\mathrm{Me}} \mathbf{P D} \mathbf{P}^{\mathrm{Ph}}\right)_{2}$} \\
\hline $\mathrm{Nb}$ & 0.005659039 & -0.003052293 & -0.024054663 \\
\hline $\mathrm{N}$ & -0.037285495 & 0.011126607 & -2.214933178 \\
\hline 10 & -0.040889283 & 0.031135067 & 2.247723295 \\
\hline$T$ & 0.485819492 & 2.010872872 & -0.632266068 \\
\hline N & -2.002295234 & 0.152779682 & 0.617744516 \\
\hline $\mathrm{N}$ & 2.005904154 & -0.256066617 & 0.743751445 \\
\hline $\mathrm{N}$ & 0.080828745 & -2.055057010 & -0.668265236 \\
\hline $\mathrm{C}$ & 0.790624817 & 3.177931961 & 0.024595964 \\
\hline $\mathrm{C}$ & -4.249096591 & 0.134898212 & 0.751359510 \\
\hline
\end{tabular}

\section{( $\left.{ }^{\mathrm{Me}} \mathrm{PMP}{ }^{\mathrm{Me}}\right)_{2} \mathrm{Zr}\left(\mathrm{O}_{2} \mathrm{C}_{6} \mathrm{H}_{4}\right)$}

\begin{tabular}{llll}
$\mathrm{Zr}$ & -0.424534829 & 0.171406145 & -0.200714833 \\
$\mathrm{~N}$ & 1.392082959 & 1.459446455 & -0.341086142 \\
$\mathrm{~N}$ & 0.207568951 & 0.035836003 & 2.126331867 \\
$\mathrm{~N}$ & 1.437718937 & -1.211942460 & -0.685438500 \\
$\mathrm{~N}$ & -1.426980562 & -1.586678515 & 0.716140289 \\
$\mathrm{C}$ & 1.354981757 & -2.533979151 & -0.905961394 \\
$\mathrm{C}$ & 2.635786216 & 0.825987271 & -0.402828304 \\
$\mathrm{C}$ & 3.002260373 & 3.026736997 & -0.146725376 \\
$\mathrm{C}$ & 1.623462257 & 2.798439782 & -0.194665280 \\
$\mathrm{C}$ & 3.731971564 & -2.742818394 & -0.982223422 \\
$\mathrm{C}$ & 3.661656786 & 1.783769839 & -0.275113337 \\
$\mathrm{C}$ & 5.150138831 & 1.592642783 & -0.266594495 \\
$\mathrm{C}$ & 2.467254114 & -3.346669094 & -1.062103272 \\
$\mathrm{C}$ & 2.658522650 & -0.598090017 & -0.615150883 \\
$\mathrm{C}$ & 3.831829674 & -1.378434256 & -0.761824045 \\
$\mathrm{C}$ & 0.529901889 & 3.820411711 & -0.129069821 \\
$\mathrm{C}$ & 1.532946029 & 0.673675408 & 4.029026705 \\
$\mathrm{C}$ & -1.126247912 & -1.939277666 & 2.035208889 \\
$\mathrm{C}$ & -1.862519049 & -3.083654907 & 2.398614347 \\
$\mathrm{C}$ & 1.054888956 & 0.880042301 & 2.742870686 \\
$\mathrm{C}$ & 0.252973109 & -1.370674636 & 4.077496227 \\
$\mathrm{C}$ & 1.123965513 & -0.489560876 & 4.699057465 \\
$\mathrm{C}$ & -0.219251693 & -1.095556651 & 2.770834295 \\
$\mathrm{C}$ & -2.624008532 & -3.422859669 & 1.255602398 \\
$\mathrm{C}$ & -2.343215652 & -2.495077405 & 0.251186754 \\
$\mathrm{C}$ & -1.916233424 & -3.807929831 & 3.713293330 \\
$\mathrm{C}$ & -2.930014658 & -2.432525192 & -1.126228929 \\
$\mathrm{O}$ & -1.848767812 & 1.594829514 & -0.336064207 \\
$\mathrm{O}$ & -0.999198039 & 0.052567216 & -2.149114920 \\
$\mathrm{C}$ & -1.900457622 & 0.974548649 & -2.582229214 \\
$\mathrm{C}$ & -2.384838961 & 1.840439673 & -1.565922834 \\
\hline
\end{tabular}




\begin{tabular}{|c|c|c|c|c|c|c|c|}
\hline$r$ & 3838 & 801330 & -1.6144 & $\mathrm{C}$ & 319 & 53 & 4. \\
\hline$C$ & -3.176512220 & 0.142851844 & -0.121187561 & $\mathrm{C}$ & -0.106105834 & 0.110750103 & 5.010090848 \\
\hline & -4.557765285 & 1.187667407 & 4.263777130 & $\mathrm{C}$ & 6.032286868 & -0.216394981 & 23797 \\
\hline & -3.751924662 & 685409 & 732042 & $\mathrm{C}$ & 0 & 5266 & 790 \\
\hline & -2.357012870 & 0.174488814 & 1.969538986 & $\mathrm{C}$ & -0.284693495 & 67412050 & -4.2856 \\
\hline & -4.624553313 & 0.171976438 & 3.288915057 & $\mathrm{C}$ & 0.036814028 & 127354 & -2.863159477 \\
\hline & -5.424278356 & 1.190663996 & 5.361220111 & $\mathrm{C}$ & -0.120007277 & 1.259840241 & -4.257981661 \\
\hline & -6.469157450 & -0.828590492 & 4.541639905 & $\mathrm{C}$ & -0.270880464 & 0.058702281 & -4.951359309 \\
\hline & -5.606006021 & -0.828881555 & 3.442123041 & $\mathrm{C}$ & -1.855438871 & -5.101080332 & -5.35 \\
\hline & -6.38 & 9437 & 5.50 & $\mathrm{C}$ & 355 & -6 & -5.6 \\
\hline & 4.4 & 75 & 4 & $\mathrm{C}$ & 67 & -6 . & -4 \\
\hline & 5.459753436 & 0.726728157 & 0516 & $\mathrm{C}$ & -0.688149350 & 6.269178727 & -4. \\
\hline & 63321 & -1.209425663 & 136 & $\mathrm{C}$ & 249 & 99 & 1.4 \\
\hline & 3.679366749 & -0.275683951 & 2.301958123 & $\mathrm{H}$ & -5.333382311 & 0.109066374 & 0333 \\
\hline & 4.293206599 & -1.228789626 & 4.562715154 & $\mathrm{H}$ & -3.808413091 & 1.046070402 & -1.944798463 \\
\hline & 3.190636317 & -0.392444836 & 0.074945794 & $\mathrm{H}$ & -3.708632275 & -0.746898017 & -1.982240392 \\
\hline $\mathrm{C}$ & 6.229361709 & 0.748675113 & 4.923562989 & $\mathrm{H}$ & -2.206101164 & 0.237540915 & -2.015299595 \\
\hline & 2.283274435 & -0.193021478 & 2.1 & $\mathrm{H}$ & 372579 & 1.994139122 & 67621 \\
\hline & 4.23532 & -0.38599 & 91234 & $\mathrm{H}$ & 058951 & 30 & 64 \\
\hline & 3.279971479 & -0 & 58749 & $\mathrm{H}$ & -7.220411739 & -1.625349785 & 4.645522789 \\
\hline & 0.31 & 2.3 & -1 . & $\mathrm{H}$ & -5 . & 2 & 97 \\
\hline $\mathrm{C}$ & 0.394760428 & 4.518208362 & -3.41 & $\mathrm{H}$ & -7.05 & 1043 & 557 \\
\hline $\mathrm{C}$ & 1.351939371 & 4.384941094 & -4.439568043 & $\mathrm{H}$ & 5.624117244 & 1.483237364 & 2.974831415 \\
\hline $\mathrm{C}$ & 0.764465407 & 4.235087901 & -0.882597939 & $\mathrm{H}$ & 4.908361241 & -1.978403439 & 6.499579183 \\
\hline $\bar{z}$ & 0.473834165 & 3.709886653 & -2.169865143 & $\mathrm{H}$ & 3.540524467 & -2.020877956 & 4.435962939 \\
\hline & 1.287638690 & 5.176146229 & -5.590547813 & $\mathrm{H}$ & 6.993746100 & 1.527164152 & 5.063817197 \\
\hline & -0.619656565 & 5.482412750 & -3.572448087 & $\mathrm{H}$ & 5.326057287 & -0.448846891 & 0.875212813 \\
\hline & 0.263747734 & 6.118189481 & -5.740496497 & $\mathrm{H}$ & 2.607390072 & 0.162367929 & -1.900261831 \\
\hline$r$ & -0.163139049 & -2.327773443 & -2.016315533 & $\mathrm{H}$ & 2.984201302 & -1.580404931 & -1.683813697 \\
\hline & -0.472207776 & -4.527979705 & -3.421980767 & 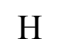 & 4.313977764 & -0.373 & -1.73 \\
\hline & 0.048301224 & -4.290374799 & -0.928211159 & त & 2.158048110 & 3.645318073 & -4.324909528 \\
\hline$c$ & -1.593314955 & -4.292436115 & -4.243842605 & $\mathrm{H}$ & 0.953504911 & 5.261876854 & -0.536233202 \\
\hline$C$ & 0.459401539 & -3.348532911 & 1.455392008 & $\mathrm{H}$ & 2.043211091 & 5.059058093 & -6.381370603 \\
\hline $\mathrm{C}$ & 0.213317280 & -3.253460924 & -0.015336931 & $\mathrm{H}$ & -1.371667835 & 5.624520287 & -2.782331410 \\
\hline $\mathrm{C}$ & 0.369072541 & -5.611665509 & -3.747537811 & $\mathrm{H}$ & 0.211557652 & 6.733590909 & -6.650747809 \\
\hline $\mathrm{C}$ & -0.205918941 & -3.725353013 & -2.208116178 & $\mathrm{H}$ & 0.124970015 & -5.335358945 & -0.593353221 \\
\hline$c$ & 1.130006076 & -0.036998675 & 2.946846472 & $\mathrm{H}$ & -2.266570747 & -3.457211929 & -4.000681622 \\
\hline & -1.241038110 & 0.119025614 & 2.888782022 & $\mathrm{H}$ & -0.188721995 & -2.633379018 & 1.983114335 \\
\hline & -1.301991216 & 0.139386124 & 4.286765429 & $\mathrm{H}$ & 1.512962134 & -3.113139911 & 1.666579556 \\
\hline
\end{tabular}




\begin{tabular}{|c|c|c|c|c|c|c|c|}
\hline $\mathrm{H}$ & 6424 & 69816 & 1761 & $\mathrm{C}$ & 6498 & 3772 & 035 \\
\hline $\mathrm{H}$ & 1.248388937 & -5.831860731 & -3.124387259 & $\mathrm{C}$ & 3.702831710 & -0.304714247 & 2.168868613 \\
\hline $\mathrm{H}$ & -2.277185324 & 0.177192728 & 4.794276289 & $\mathrm{C}$ & 4.380634415 & -1.323026651 & 4349 \\
\hline $\mathrm{H}$ & 2.051974941 & 133 & 4.931659746 & $\mathrm{C}$ & 39915 & 55 & -0.0510 \\
\hline $\mathrm{H}$ & -0.138587993 & 0.149984318 & 6.108910987 & $\mathrm{C}$ & 6.401252170 & 0.583960323 & 4.676191936 \\
\hline $\mathrm{H}$ & 6.630451341 & -0.199213528 & 6.839810439 & $\mathrm{C}$ & 2.310302155 & -0.244523722 & 2.041109322 \\
\hline $\mathrm{H}$ & -0.376281138 & -2.102691979 & -4.857321481 & $\mathrm{C}$ & 4.205627443 & -0.330406209 & 0.829909859 \\
\hline $\mathrm{H}$ & -0.125505190 & 2.214639753 & -4.804175447 & $\mathrm{C}$ & 3.191217613 & -0.404584885 & -1.539826830 \\
\hline $\mathrm{H}$ & -0.380342936 & 0.091770444 & -6.045399799 & $\mathrm{C}$ & 0.210877744 & 2.263737759 & 3512 \\
\hline $\mathrm{H}$ & -2.734230782 & -4.90 & -5.98 & $\mathrm{C}$ & 233 & 300251 & 777831 \\
\hline $\mathrm{H}$ & $-1.20281^{\prime}$ & -6.8 & -6.5 & $\mathrm{C}$ & 771203 & 4.3 & -4 \\
\hline $\mathrm{H}$ & 7055 & -7.26 & -5.094782985 & $\mathrm{C}$ & 0.283823366 & 4.159 & -0.829828839 \\
\hline $\mathrm{H}$ & -1.494862706 & 7.009021663 & -4.83 & $\mathrm{C}$ & 0.272964907 & 850 & 29415 \\
\hline $\mathrm{H}$ & 0.520003918 & 4.025882851 & 1.961608945 & $\mathrm{C}$ & 1.342069917 & 5.156624717 & -5.499 \\
\hline $\mathrm{H}$ & 2.184026098 & 3.445490847 & 1.614811102 & $C$ & -0.616207815 & 5.546538390 & -3.542564397 \\
\hline \multirow[t]{2}{*}{$\mathrm{H}$} & 0.871787066 & 2.264585449 & 1.948433221 & $\mathrm{C}$ & 0.392166713 & 6.172233705 & -5.657552386 \\
\hline & & & & $\mathrm{C}$ & -0.206593868 & -2.349325004 & -2.043758717 \\
\hline \multicolumn{2}{|c|}{$\left[\mathbf{N b}^{\mathrm{V}}\left({ }^{\mathrm{Me}} \mathbf{P D P} \mathbf{P}^{\mathrm{Ph}}\right)_{2}\right]^{+}$} & & & $\mathrm{C}$ & -0.317340142 & -4.585087041 & -3.3 \\
\hline 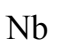 & 0.001661687 & -0.045190251 & 0.000644820 & $C$ & -0.303988631 & -4.244860718 & -0.83 \\
\hline $\mathrm{N}$ & 0.00 & -0.0 & -2.2 & $C$ & -1.298051351 & -4.404471211 & -4.3 \\
\hline$N$ & 0.003 & -0.0 & 2.25 & $\mathrm{C}$ & -0 & 396 & 72 \\
\hline $\mathrm{N}$ & 0.194437467 & 1.914141855 & -0.686430077 & $\mathrm{C}$ & -0.279336840 & -3.182580612 & 0.048189991 \\
\hline $\mathrm{N}$ & -1.955270300 & 0.152918089 & 0.691547236 & $\mathrm{C}$ & 0.613164925 & -5.632400086 & 24703 \\
\hline $\mathrm{N}$ & 1.959849449 & -0.241912792 & 0.687862558 & $\mathrm{C}$ & -0.276557445 & -3.741183053 & -2.172569443 \\
\hline $\mathrm{N}$ & -0.200415053 & -1.999963199 & -0.690396746 & $\mathrm{C}$ & 1.190813573 & -0.128326559 & 2.930370691 \\
\hline $\mathrm{C}$ & 0.257690242 & 3.097749288 & 0.051910983 & $\mathrm{C}$ & -1.181910947 & 0.056671958 & 2.932694305 \\
\hline $\mathrm{C}$ & -4.199878979 & 0.265206480 & 0.836888924 & $\mathrm{C}$ & -1.203815871 & 0.031490749 & 4.332971569 \\
\hline $\mathrm{C}$ & -3.189167732 & 0.301709423 & -1.535390574 & $C$ & 1.215310463 & -0.100137342 & 4.330632792 \\
\hline $\mathrm{C}$ & -3.138725072 & 0.227826170 & -0.045804054 & $\mathrm{C}$ & 0.006431734 & -0.034018232 & 5.0 \\
\hline C & -4.350954741 & 1.290781052 & 4.38062884 & $\mathrm{C}$ & 6.213721826 & -0.391032609 & 5.6 \\
\hline$c$ & -3.694621041 & 0.249141467 & 2.175319774 & C & -0.084404000 & -1.229033543 & -2.931286268 \\
\hline $\mathrm{C}$ & -2.302904021 & 0.172939150 & 2.045281840 & $\mathrm{C}$ & -0.050974942 & -1.251598456 & -4.331313642 \\
\hline $\mathrm{C}$ & -4.538152484 & 0.304408676 & 3.390773831 & 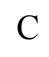 & 0.099586458 & 1.143751056 & -2.929120679 \\
\hline $\mathrm{C}$ & -5.176300369 & 1.339395680 & 5.507443723 & 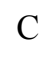 & 0.078128322 & 1.167557400 & -4.329573065 \\
\hline $\mathrm{C}$ & -6.410763354 & -0.572712286 & 4.686160571 & $\mathrm{C}$ & 0.016644481 & -0.041594779 & -5.020734749 \\
\hline $\mathrm{C}$ & -5.592891195 & -0.616715999 & 3.553612572 & $\mathrm{C}$ & -1.331843576 & -5.228379249 & -5.512777184 \\
\hline $\mathrm{C}$ & -6.203000212 & 0.401952858 & 5.668289581 & $\mathrm{C}$ & -0.384808970 & -6.247099600 & -5.668239103 \\
\hline 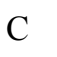 & 4.547764059 & -0.337028148 & 3.384407759 & 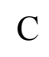 & 0.584202556 & -6.448648044 & -4.679303921 \\
\hline & 5.583318731 & 0.606200339 & 3.543057681 & $\mathrm{C}$ & -0.583711009 & 6.366527714 & -4.673912393 \\
\hline
\end{tabular}




\begin{tabular}{|c|c|c|c|c|c|c|c|}
\hline C & 0.330301568 & 3398 & 1.541417581 & $\mathrm{H}$ & 24049711 & 6441 & 325 \\
\hline $\mathrm{H}$ & -5.249153035 & 0.345751173 & 0.555700457 & $\mathrm{H}$ & 1.191653612 & 2.583717468 & 1.930831447 \\
\hline $\mathrm{H}$ & -2.615765990 & 158908773 & .923450413 & $\mathrm{H}$ & -0.577112379 & 2.749162762 & .021196675 \\
\hline $\mathrm{H}$ & -4.230760519 & 0.425837618 & 2096 & H & 0.4 & 4.192815711 & 8661 \\
\hline $\mathrm{H}$ & -2.794637757 & 409500 & 015298408 & & & & \\
\hline $\mathrm{H}$ & -3.563084754 & 2.037970230 & 4.254716114 & \multicolumn{4}{|c|}{$\mathbf{T a}^{\mathrm{IV}}\left({ }^{\mathrm{Me}} \mathbf{P D P} \mathrm{P}^{\mathrm{Ph}}\right)_{2}$} \\
\hline $\mathrm{H}$ & -5.019595321 & 2.117044599 & 6.260212077 & . & 0.002952840 & 0.100165697 & -0.001127780 \\
\hline $\mathrm{H}$ & -7.215712038 & -1.303148668 & 4.803780113 & $\mathrm{~N}$ & 1.286885292 & 1.652748254 & 0.669149445 \\
\hline $\mathrm{H}$ & -5.762594205 & -1.382412398 & 2.791832883 & $\mathrm{~N}$ & 0.019023586 & 0.011673417 & 2.176919353 \\
\hline & -6.843589959 & 0.435175428 & 6.55 & $\mathrm{~N}$ & 7738 & 612 & 6932 \\
\hline & 5.73 & 1.37 & 2. & $\mathrm{~N}$ & 82 & 574 & 425 \\
\hline & 5.066 & -2.127899667 & 6.260997800 & $\mathrm{~N}$ & 053408 & -0.033305380 & 2394 \\
\hline & 3.607974807 & -2.086487293 & 4.2546 & $\mathrm{~N}$ & 09134 & 233 & 3653 \\
\hline 1 & 7.190502626 & 1.331799408 & 4.791400967 & $\mathrm{C}$ & 2.020680748 & 2.612478045 & 0.010844626 \\
\hline H & 5.255108414 & -0.404057375 & 0.547554954 & $\mathrm{C}$ & 2.795740827 & 3.300860932 & 0.937261100 \\
\hline $\mathrm{H}$ & 2.613089992 & -1.263029560 & -1.917746460 & $\mathrm{C}$ & 2.543266280 & 2.759939847 & 2.227736710 \\
\hline $\mathrm{H}$ & 4.231898720 & -0.537810489 & -1.865272765 & $\mathrm{C}$ & 1.592191044 & 1.742050158 & 2.028132675 \\
\hline$t$ & 2.801365593 & 0.502169096 & -2.029901574 & $\mathrm{C}$ & 0.819544788 & 0.877176758 & 2.880929084 \\
\hline 4 & 2.062086791 & 3.550303368 & -4.25 & $\mathrm{C}$ & 0.783524799 & 0.880 & 103 \\
\hline 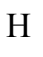 & 0.3 & 8 & -0.5 & $\mathrm{C}$ & 42 & 51 & 10 \\
\hline 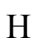 & 2.12 & 15 & -6.2 & $\mathrm{C}$ & 52 & 40 & 02 \\
\hline $\mathrm{H}$ & -1.382898164 & 5.706184785 & -2.77 & $\mathrm{C}$ & -0.817839247 & -0.866 & 68820 \\
\hline П & 0.415974282 & 6.814278030 & -6.541906695 & $\mathrm{C}$ & -1.603437106 & -1.657398657 & 87289 \\
\hline $\mathrm{H}$ & -0.385807884 & -5.293996717 & -0.552008889 & $\mathrm{C}$ & -2.597248631 & -2.635839502 & 2.048506549 \\
\hline $\mathrm{H}$ & -2.052549429 & -3.622871084 & -4.262731811 & $\mathrm{C}$ & -3.097721990 & -2.869510663 & 0.736509615 \\
\hline $\mathrm{H}$ & 0.538098104 & -2.846030839 & 2.027375275 & $\mathrm{C}$ & -2.390428839 & -2.075401097 & -0.152861497 \\
\hline $\mathrm{H}$ & -0.512799041 & -4.269197768 & 1.863363639 & $\mathrm{C}$ & 3.211852113 & 3.213133170 & 3.465795845 \\
\hline $\mathrm{H}$ & -1.225567388 & -2.644871222 & 1.913851868 & $C$ & 3.283885619 & 4.587541183 & 3.769068753 \\
\hline t & 1.374344266 & -5.797599377 & -2.777778343 & $\mathrm{C}$ & 3.950102794 & 5.039601526 & 4.911211097 \\
\hline & -2.153713602 & 080563078 & 4.8613097 & C & 4.564932 & 4.1280 & 70 \\
\hline & 2.166182335 & -0.148114569 & 4.857302873 & $\mathrm{C}$ & 4.512270260 & 2.760562911 & 5.484021971 \\
\hline п & 0.007517436 & -0.033571722 & 6.115115567 & $\mathrm{C}$ & 3.847229940 & 2.309276177 & 4.340894327 \\
\hline $\mathrm{H}$ & 6.854285182 & -0.406717269 & 6.547640020 & C & -3.070125704 & -3.346688653 & 3.255469655 \\
\hline $\mathrm{H}$ & -0.095615863 & -2.201756537 & -4.859605450 & $\mathrm{C}$ & -4.449474467 & -3.436791320 & 3.528723286 \\
\hline $\mathrm{H}$ & 0.126684922 & 2.118234439 & -4.856520178 & $\mathrm{C}$ & -4.918636204 & -4.143130436 & 4.639574902 \\
\hline $\mathrm{H}$ & 0.021373714 & -0.040968278 & -6.113772701 & $\mathrm{C}$ & -4.019464874 & -4.781385970 & 5.500346446 \\
\hline $\mathrm{H}$ & -2.105083309 & -5.076593017 & -6.271124195 & $\mathrm{C}$ & -2.646928046 & -4.711321199 & 5.236480181 \\
\hline$\pi$ & -0.405520747 & -6.885878875 & -6.555001618 & $\mathrm{C}$ & -2.178263445 & -4.005466288 & 4.125273259 \\
\hline & 1.321771675 & -7.247701584 & -4.792655968 & $\mathrm{C}$ & 1.959959458 & 2.818910607 & -1.470105233 \\
\hline
\end{tabular}




\begin{tabular}{|c|c|c|c|}
\hline & 9027 & 1818 & -1 \\
\hline & -2.059799254 & 2.574564272 & -0.064393691 \\
\hline & 97119 & 9989 & 18 \\
\hline & 2206262 & 59538685 & -2 \\
\hline & -1.614308740 & 1.671991893 & 809923 \\
\hline$C$ & -0.826178855 & 0.803584024 & -2.898642020 \\
\hline$C$ & -0.789623258 & 0.779016460 & -4.300277122 \\
\hline & 0.079742787 & -0.105069992 & -4.93 \\
\hline & 0.899701827 & 2333 & -4 \\
\hline & 649 & 2783 & -2.7 \\
\hline & 785 & 108 & -1.8 \\
\hline & 2.650104635 & -2.632356275 & -1 \\
\hline & 3.154701743 & -2.830009641 & -0.678016977 \\
\hline 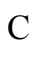 & 2.434104199 & -2.029692026 & 0.194969791 \\
\hline C & -3.256441529 & 3.087736303 & -3.531506384 \\
\hline$C$ & -3.349775161 & 4.454711556 & -3.861429425 \\
\hline$C$ & -4.021542874 & 4.874020397 & -5.012772893 \\
\hline $\mathrm{C}$ & -4.620770857 & 3.936 & -5.8 \\
\hline C & -4.5 & 33 & -5 \\
\hline C & -3.87 & 2.157183888 & -4.3 \\
\hline 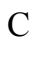 & 3.134688620 & -3.360097703 & -3 \\
\hline 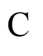 & 2.253941782 & -4.052287744 & -4.041587269 \\
\hline C & 2.734250262 & -4.773063844 & -5.138145315 \\
\hline $\mathrm{C}$ & 4.107673914 & -4.824880946 & -5.401619929 \\
\hline$r$ & 4.996071804 & -4.153287323 & -4.555152289 \\
\hline & 4.515260425 & -3.432047883 & -3.458949134 \\
\hline & -2.003907766 & 2.811201761 & 1.412228540 \\
\hline & 2.599701027 & -1.940935422 & 1.678503892 \\
\hline & 3.458515077 & 4.113260273 & 0.604488405 \\
\hline 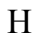 & 1.415958238 & 1.568255017 & 4.8 \\
\hline $\mathrm{H}$ & -0.114572495 & -0.012833127 & 6.039263493 \\
\hline $\mathrm{H}$ & -1.548105753 & -1.591364840 & 4.728189696 \\
\hline $\mathrm{H}$ & -3.915992597 & -3.587758946 & 0.579817211 \\
\hline 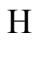 & 2.811191316 & 5.323473664 & 3.102012882 \\
\hline & 3.989876632 & 6.117109208 & 5.128915460 \\
\hline & 5.083882372 & 4.488471683 & 6.676598726 \\
\hline & 4.997268400 & 2.039782700 & 6.158746214 \\
\hline 1 & 3.824396289 & 1.230173020 & 4.128727574 \\
\hline & -5.175208911 & -2.946825316 & 2.862958549 \\
\hline
\end{tabular}

\begin{tabular}{lrrr}
$\mathrm{H}$ & -5.999695850 & -4.196031554 & 4.835818466 \\
$\mathrm{H}$ & -4.393180455 & -5.332456475 & 6.375936508 \\
$\mathrm{H}$ & -1.936026137 & -5.214840359 & 5.908109874 \\
$\mathrm{H}$ & -1.095619540 & -3.968659354 & 3.934151597 \\
$\mathrm{H}$ & 1.473455613 & 3.781329479 & -1.687047494 \\
$\mathrm{H}$ & 1.381709315 & 2.004101376 & -1.930227590 \\
$\mathrm{H}$ & 2.980080385 & 2.823038835 & -1.881610006 \\
$\mathrm{H}$ & -3.111014023 & -1.111190738 & -1.912230445 \\
$\mathrm{H}$ & -3.113760826 & -2.906142279 & -1.977319377 \\
$\mathrm{H}$ & -1.566173761 & -2.004311498 & -2.116922744 \\
$\mathrm{H}$ & -3.522328438 & 4.038618826 & -0.688581022 \\
$\mathrm{H}$ & -1.433490903 & 1.443580960 & -4.895078355 \\
$\mathrm{H}$ & 0.124392173 & -0.134808212 & -6.037991767 \\
$\mathrm{H}$ & 1.584120584 & -1.661447470 & -4.694733827 \\
$\mathrm{H}$ & 3.985139777 & -3.530762243 & -0.506790899 \\
$\mathrm{H}$ & -2.889635731 & 5.210803752 & -3.208286056 \\
$\mathrm{H}$ & -4.078041498 & 5.946347244 & -5.251357884 \\
$\mathrm{H}$ & -5.144141997 & 4.270951056 & -6.768299369 \\
$\mathrm{H}$ & -5.019648766 & 1.834459768 & -6.202971246 \\
$\mathrm{H}$ & -3.836798020 & 1.082889801 & -4.156447226 \\
$\mathrm{H}$ & 1.170915022 & -4.030206920 & -3.850366215 \\
$\mathrm{H}$ & 2.027807806 & -5.301087677 & -5.795511051 \\
$\mathrm{H}$ & 4.480477364 & -5.390356628 & -6.268369455 \\
$\mathrm{H}$ & 6.076954911 & -4.194463389 & -4.755143052 \\
$\mathrm{H}$ & 5.232706785 & -2.915773163 & -2.804173435 \\
$\mathrm{H}$ & -2.489658721 & 3.769264956 & 1.649211675 \\
$\mathrm{H}$ & -0.953982255 & 2.842037914 & 1.738886698 \\
$\mathrm{H}$ & -2.526999553 & 1.996241584 & 1.933970732 \\
& 2.029005165 & -1.081832900 & 2.060929064 \\
& 2.664662027 & -1.810658743 & 1.921168276 \\
\hline
\end{tabular}

$\left[\mathbf{T a}^{\mathrm{V}}\left({ }^{\mathrm{Me}} \mathbf{P D P} \mathbf{P h}^{\mathrm{Ph}}\right)_{2}\right]^{+}$

$\begin{array}{llll}\text { Ta } & 0.003485831 & 0.020901885 & -0.000466663\end{array}$

$\begin{array}{llll}\mathrm{N} & 1.372543522 & 1.437684539 & 0.643616182\end{array}$

$\begin{array}{llll}\mathrm{N} & 0.001591174 & 0.026289511 & 2.211677947\end{array}$

$\begin{array}{llll}\mathrm{N} & -1.387751821 & -1.377470843 & 0.647953782\end{array}$

$\begin{array}{llll}\mathrm{N} & -1.392752335 & 1.397341310 & -0.673574247\end{array}$

$\mathrm{N} \quad 0.006601962 \quad-0.018547404 \quad-2.212288390$ 


\begin{tabular}{|c|c|c|c|}
\hline & 1.42 & -1.3 & -0. \\
\hline & 2.167151450 & 2.318981353 & -0.090468418 \\
\hline & 2.904788349 & 3.082668399 & 0.792064500 \\
\hline & 2.597977305 & 2.677204113 & 39052 \\
\hline & 1.635978521 & 191 & 1.9 \\
\hline & 0 . & 16 & 2 \\
\hline & 0.7 & 92 & 4 \\
\hline & -0.149354696 & 0.178255333 & 4.969653116 \\
\hline & -0.949541358 & -0.736493936 & 4.284653839 \\
\hline & -0.856015267 & -0.803753428 & 73955 \\
\hline & -1.606820043 & -1.643624161 & 2605 \\
\hline & -2.591417708 & 2112 & 0707 \\
\hline & -2.9 & -2 & \\
\hline & -2.2 & -2 & -0 . \\
\hline & 3.233360370 & 3829 & 3.3 \\
\hline & 3.326432510 & 4.635720158 & 6939 \\
\hline & 3.957068074 & 5.186590724 & 4.611721448 \\
\hline & 4.519067176 & 4.353697626 & 5.584576777 \\
\hline & 4.449492759 & 2.964950666 & 5.430795005 \\
\hline & 3.813 & 2.41 & 4.3 \\
\hline & -3.132521431 & -3.273877904 & .353040799 \\
\hline & -4.526055743 & -3.395835583 & 74411 \\
\hline & -5.056736514 & -4.036963121 & 96591 \\
\hline & -4.205964903 & -4.580398521 & 5.611085557 \\
\hline & -2.819582295 & -4.482083283 & 5.448559801 \\
\hline & -2.287248880 & -3.835892710 & 4.330175398 \\
\hline & 2.193882770 & 2.380238836 & -1.582593652 \\
\hline & -2.326284914 & -2.227097240 & -1.570598103 \\
\hline & -2.205407841 & 2.277089776 & 0.042697152 \\
\hline & -2.954657 & 3.010756368 & -0.855353 \\
\hline & -2.636722093 & 2.586847017 & -2.181836 \\
\hline & -1.657463143 & 1.598986866 & -2.031632590 \\
\hline & -0.820531094 & 0.829549248 & -2.905232213 \\
\hline & -0.753999677 & 0.897197902 & -4.301691916 \\
\hline & 0.156994017 & 0.079968663 & -4.972750022 \\
\hline & 0.972246788 & -0.806825292 & -4.269011221 \\
\hline & 0.878958954 & -0.847189860 & -2.872248746 \\
\hline & 1.644018956 & -1.655240175 & -1.969116 \\
\hline & 2.645210356 & -2.625971940 & -2.08605966 \\
\hline
\end{tabular}

\begin{tabular}{|c|c|c|c|}
\hline & 4069 & 591 & -0 \\
\hline & 2.302593825 & -2.148795281 & 0.123505750 \\
\hline & -3.277750041 & 3.116758384 & 71660 \\
\hline & 5777003 & 65 & 95 \\
\hline & -4.031819961 & 5.029542454 & 8667 \\
\hline & -4.574156564 & 4.170090114 & 30186 \\
\hline & -4.479684186 & 2.785133076 & -5.498381234 \\
\hline & -3.838346199 & 2.262764574 & -4.372515472 \\
\hline & 3.195929344 & -3.288589921 & -3.2 \\
\hline & 2.359 & -3.88 & -4 \\
\hline & 2.9 & -4 & -5 \\
\hline & 4.2 & 66187 & -5 \\
\hline & 8342 & 6275 & -4 \\
\hline & 4.591108225 & -3.391500920 & 98317 \\
\hline & -2.237878095 & 2.364374415 & 1.533675455 \\
\hline & 2.375510211 & -2.149307740 & 1.615568919 \\
\hline & 3.633602836 & 3.836901343 & 0.513033850 \\
\hline & 1.374609788 & 1.70 & 4.80 \\
\hline & -0.2 & 254 & 3605 \\
\hline & -1.647075706 & 1391 & 01 \\
\hline & -3.736372839 & -3.692851514 & 550 \\
\hline & 2.886111624 & 5.289944279 & 2.7 \\
\hline & 4.010516299 & 6.268404871 & 4.722906650 \\
\hline & 5.015366168 & 4.783777245 & 6.453218994 \\
\hline & 4.903056253 & 2.310605738 & 6.173762695 \\
\hline & 3.791512045 & 1.331135711 & 4.188622397 \\
\hline & -5.194181481 & -2.969877637 & 2.773490041 \\
\hline & -6.136838475 & -4.112986714 & 4.760537240 \\
\hline & -4.620250015 & -5.084788273 & 6.482850758 \\
\hline & -2.151074764 & -4.921158859 & 6.188004 \\
\hline & -1.207300363 & -3.791892031 & 4.195031 \\
\hline & 2.505084564 & 1.428345001 & -2.030792210 \\
\hline & 2.910186366 & 3.143256431 & -1.901156012 \\
\hline & 1.216930417 & 2.648397198 & -2.004659369 \\
\hline & -2.603441429 & -1.252808263 & -1.993456602 \\
\hline & -3.087024009 & -2.950267065 & -1.880878013 \\
\hline & -1.374104018 & -2.533296527 & -2.022878834 \\
\hline & -3.697742817 & 3.756644692 & -0.591711027 \\
\hline & -1.393527892 & 1.587714427 & -4.8409441 \\
\hline
\end{tabular}




$\begin{array}{lrrr}\text { H } & 0.234289581 & 0.137222354 & -6.057518448 \\ \text { H } & 1.681231593 & -1.447432495 & -4.782307278 \\ \text { H } & 3.809492830 & -3.635279015 & -0.459964459 \\ \text { H } & -2.970746273 & 5.183759065 & -2.841948636 \\ \mathrm{H} & -4.104768042 & 6.108587080 & -4.842422320 \\ \mathrm{H} & -5.074515276 & 4.576610876 & -6.552889678 \\ \mathrm{H} & -4.917782283 & 2.110004236 & -6.232676156 \\ \mathrm{H} & -3.797165450 & 1.184001027 & -4.226796196 \\ \mathrm{H} & 1.278886698 & -3.856540336 & -4.112825528 \\ \mathrm{H} & 2.239507600 & -5.014286947 & -6.081170742 \\ \mathrm{H} & 4.710696727 & -5.144147961 & -6.375225334 \\ \mathrm{H} & 6.212441498 & -4.109653438 & -4.676935896 \\ \mathrm{H} & 5.252720900 & -2.938293953 & -2.714771054 \\ \mathrm{H} & -2.537978295 & 1.415927513 & 1.997407575 \\ \mathrm{H} & -2.965684257 & 3.123231938 & 1.836930053 \\ \mathrm{H} & -1.265820797 & 2.653126592 & 1.953956268 \\ \mathrm{H} & 2.636007232 & -1.161538080 & 2.017143864 \\ \mathrm{H} & 3.148929548 & -2.852320025 & 1.940424863 \\ \mathrm{H} & 1.429174143 & -2.462138004 & 2.075470038\end{array}$




\section{Appendix E}

\section{Permissions}

\section{Part of this dissertation have been published in the following journal articles:}

1) Zhang, Y.; Petersen, J. L.; and Milsmann, C.* A Luminescent Zirconium(IV) Complex as Molecular Photosensitizer for Visible Light Photoredox Catalysis. J. Am. Chem. Soc. 2016, 138, 13115-13118.

2) Zhang, Y.; Lee, T. S.; Petersen, J. L.; and Milsmann, C.* A Zirconium Photosensitizer with a Long-Lived Excited State: Mechanistic Insight into Photoinduced Single-Electron Transfer. J. Am. Chem. Soc. 2018, 140, 5934-5947

3) Zhang, Y.; Petersen, J. L.; and Milsmann, C.* Photochemical C-C Bond Formation in Luminescent Zirconium Complexes with CNN Pincer Ligands. Organometallics 2018, 37, 4488-4499

4) Zhang, Y.; Akhmedov, N. G.; Petersen, J. L.; and Milsmann, C.* Photoluminescence of Seven-Coordinate Zirconium and Hafnium Complexes with 2,2'-Pyridylpyrrolide Ligands. Chem. Eur. J. 2019, 25, 3042-3052 


\section{The permission for reuse:}

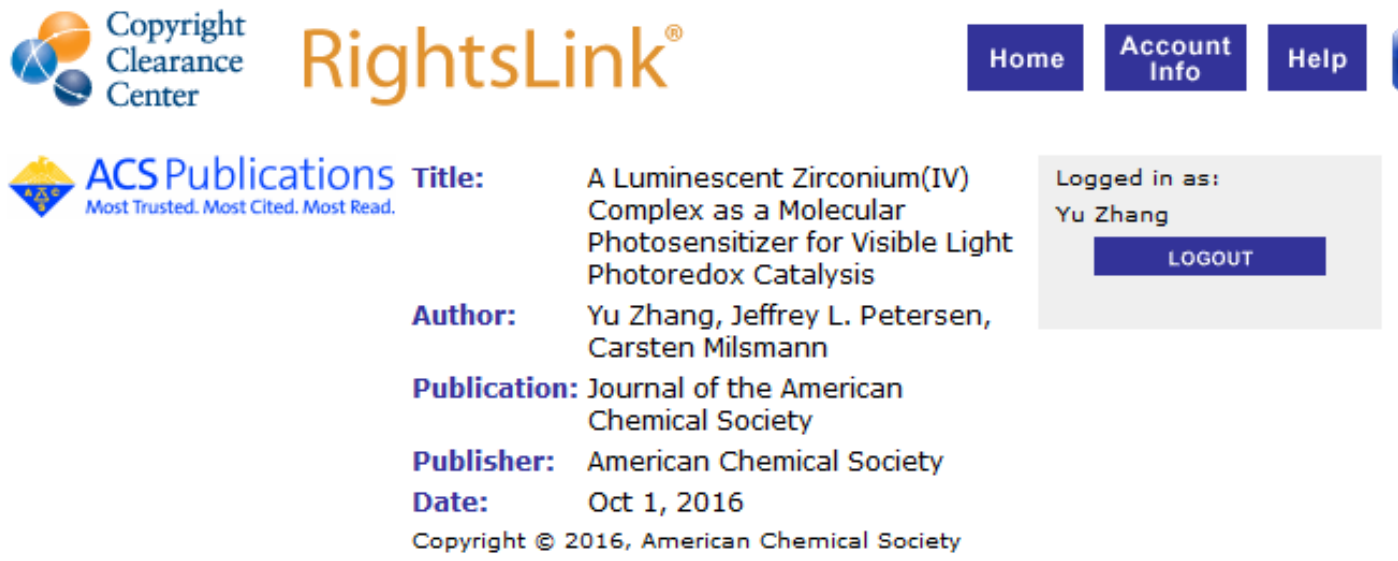

\section{PERMISSION/LICENSE IS GRANTED FOR YOUR ORDER AT NO CHARGE}

This type of permission/license, instead of the standard Terms \& Conditions, is sent to you because no fee is being charged for your order. Please note the following:

- Permission is granted for your request in both print and electronic formats, and translations.

- If figures and/or tables were requested, they may be adapted or used in part.

- Please print this page for your records and send a copy of it to your publisher/graduate school.

- Appropriate credit for the requested material should be given as follows: "Reprinted (adapted) with permission from (COMPLETE REFERENCE CITATION). Copyright (YEAR) American Chemical Society." Insert appropriate information in place of the capitalized words.

- One-time permission is granted only for the use specified in your request. No additional uses are granted (such as derivative works or other editions). For any other uses, please submit a new request.

Copyright (c) 2019 Copyright Clearance Center, Inc. All Rights Reserved. Privacy statement. Terms and Conditions.

Comments? We would like to hear from you. E-mail us at customercare@copyriaht.com 
Copyright

Clearance

Center

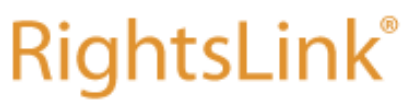

A Zirconium Photosensitizer

with a Long-Lived Excited

State: Mechanistic Insight into

Photoinduced Single-Electron

Transfer

Author: Yu Zhang, Tia S. Lee, Jeffrey L.

Petersen, et al

Publication: Journal of the American

Chemical Society

Publisher: American Chemical Society

Date: $\quad$ May 1, 2018

Copyright (c) 2018, American Chemical Society
ACS Publications Title:

Most Trusted. Most Cited. Most Read.

\section{PERMISSION/LICENSE IS GRANTED FOR YOUR ORDER AT NO CHARGE}

This type of permission/license, instead of the standard Terms \& Conditions, is sent to you because no fee is being charged for your order. Please note the following:

- Permission is granted for your request in both print and electronic formats, and translations.

- If figures and/or tables were requested, they may be adapted or used in part.

- Please print this page for your records and send a copy of it to your publisher/graduate school.

- Appropriate credit for the requested material should be given as follows: "Reprinted (adapted) with permission from (COMPLETE REFERENCE CITATION). Copyright (YEAR) American Chemical Society." Insert appropriate information in place of the capitalized words.

- One-time permission is granted only for the use specified in your request. No additional uses are granted (such as derivative works or other editions). For any other uses, please submit a new request.

\section{BACK}

CLOSE WINDOW

Copyright @ 2019 Copyright Clearance Center, Inc. All Rights Reserved. Privacy statement. Terms and Conditions.

Comments? We would like to hear from you. E-mail us at customercare@copyright.com 


\section{Copyright \\ Clearance \\ Center

ACSPublications Title: Most Trusted. Most Cited. Most Read.
Photochemical C-C Bond Formation in Luminescent Zirconium Complexes with CNN Pincer Ligands

Author: Yu Zhang, Jeffrey L. Petersen, Carsten Milsmann

Publication: Organometallics

Publisher: American Chemical Society

Date: Dec 1, 2018

Copyright (c) 2018, American Chemical Society
Logged in as:

Yu Zhang

\section{PERMISSION/LICENSE IS GRANTED FOR YOUR ORDER AT NO CHARGE}

This type of permission/license, instead of the standard Terms \& Conditions, is sent to you because no fee is being charged for your order. Please note the following:

- Permission is granted for your request in both print and electronic formats, and translations.

- If figures and/or tables were requested, they may be adapted or used in part.

- Please print this page for your records and send a copy of it to your publisher/graduate school.

- Appropriate credit for the requested material should be given as follows: "Reprinted (adapted) with permission from (COMPLETE REFERENCE CITATION). Copyright (YEAR) American Chemical Society." Insert appropriate information in place of the capitalized words.

- One-time permission is granted only for the use specified in your request. No additional uses are granted (such as derivative works or other editions). For any other uses, please submit a new request.

\section{BACK}

Copyright (c) 2019 Copyright Clearance Center, Inc. All Rights Reserved. Privacy statement. Terms and Conditions.

Comments? We would like to hear from you. E-mail us at customercare@copyright.com 


CHEMISTRY

Title:

Photoluminescence of Seven-

Coordinate Zirconium and

Hafnium Complexes with

2,2'-Pyridylpyrrolide Ligands

Logged in as:

Yu Zhang

Account \#:

Author: Carsten Milsmann, Jeffrey L.

Petersen, Novruz G. Akhmedov,

01413012

et al

Publication: Chemistry - A European Journal

Publisher: John Wiley and Sons

Date: $\quad$ Feb 7, 2019

(c) WILEY-VCH Verlag GmbH \& Co. KGaA,

Weinheim

Order Completed

Thank you for your order.

This Agreement between Mr. Yu Zhang ("You") and John Wiley and Sons ("John Wiley and Sons") consists of your license details and the terms and conditions provided by John Wiley and Sons and Copyright Clearance Center.

Your confirmation email will contain your order number for future reference.

\section{printable details}

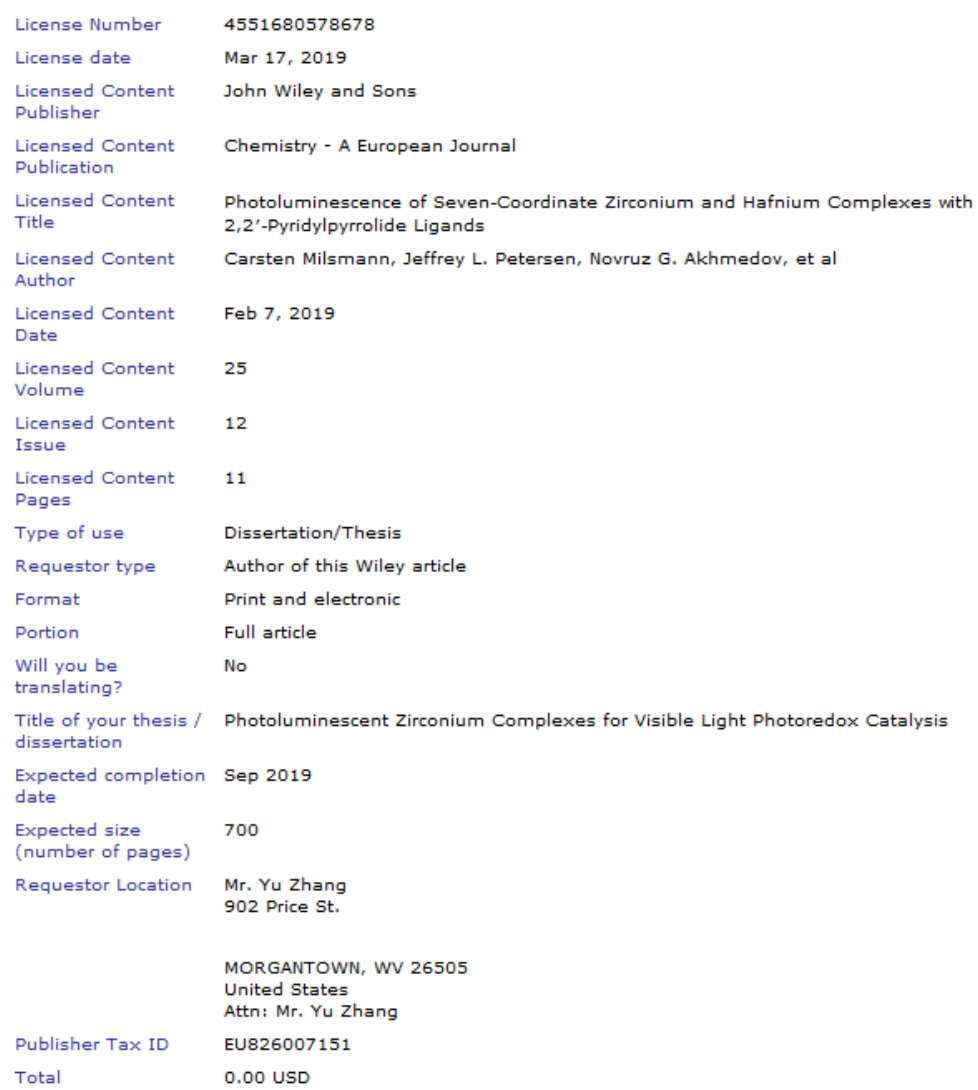

Would you like to purchase the full text of this article? If so, please continue on to the content ordering system located here: Purchase PDF

If you click on the buttons below or close this window, you will not be able to return to the content ordering system.

\section{ORDER MORE CLOSE WINDOW}

Copyright (c) 2019 Copyright Clearance Center, Inc. All Rights Reserved. Privacy statement. Terms and Conditions.

Comments? We would like to hear from you. E-mail us at customercare@copyriaht.com 